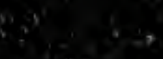


QK314

.K615

1856

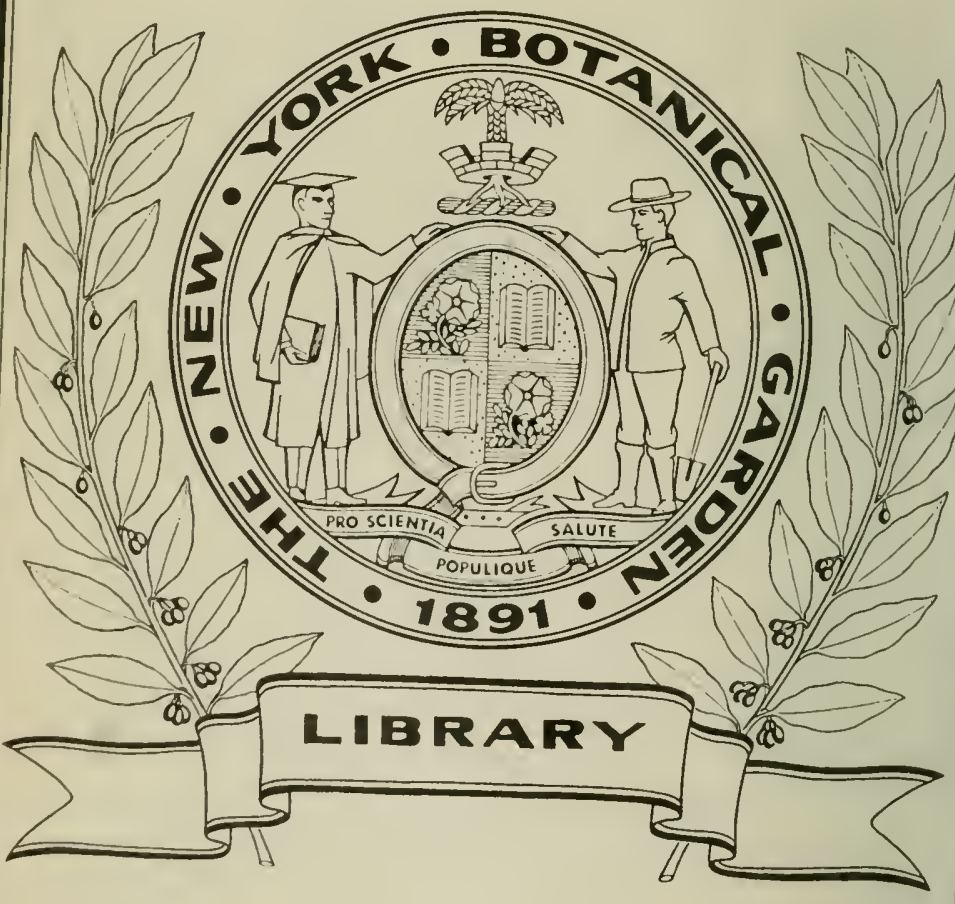






\section{TASCHENBUCH}

DER

\section{DEUTSCHEN UND SCHWEIZER FLORA,}

enthaltend die genauer bekannten Pflanzen,

welche in

\section{Deutschland, der Schweiz, in Preussen und Istrien}

wild wachsen und zum Gebrauche der Menschen in grösserer Menge gebauet werden,

nach dem DeCandollischen Systeme geordnet, mit einer vorangehenden Uebersicht der Gattungen nach den Classen und Ordnungen des Linnéischen Systemes,

bearbeitet von

\section{WILH. DAN. JOS. KOCH,}

weil. königl. bayer. geheim. Hofrathe, Ritter des königl. bayer. Ludwigs-und de.s königl. schwed. Nordsternordens, ordentl. Professor der Medicin und Botanik an der Universität zu Erlangen und Director des bot. Gartens daselbst.

Vierte Auflage.

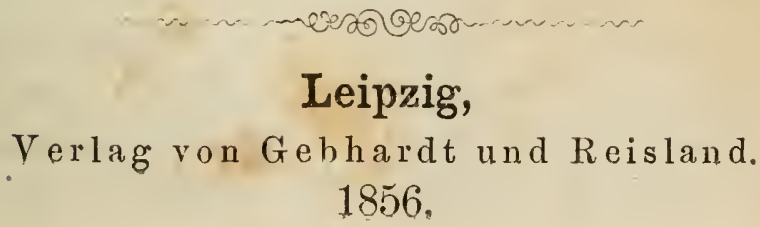





\section{Vorwort}

\section{zur ersten Auflage.}

Das vorliegende Büchlein ist nach seiner nächsten Be. stimmung für botanische Excursionen geschrieben. Deswegen enthält es, um das reiche Material so viel möglich kurz zusammenzufassen, ausser den Diagnosen weiter keine Beobachtungen und Bemerkungen; es enthält ferner die Standörter nur im Allgemeinen, die einzelner Seltenheiten ausgenommen, und von Synonymen nur das Nothwendigste zur Verständlichkeit, und zwar ohne Hinweisung auf Seitenzahl und Abbildungen der Werke dieser angeführten Schriftsteller, wovon auf Excursionen ohnehin kein Gebrauch gemacht werden kann.

Das Büchlein enthält ferner die sämmtlichen Arten meiner Synopsis mit hin und wieder verbesserten Diagnosen. Von Arten, welche die erste Auflage nicht enthält, habe ich nur solche eingeschaltet, welche ich genau untersucht hatte; was ich bis jetzt aus Mangel an Zeit oder wegen unvollständiger Exemplare nicht untersuchen konnte, oder was mir bei meinen Untersuchungen nicht klar wurde, ist weggelassen; ich wollte die vorhandene, nicht geringe Masse des Zweifelhaften und Unklaren nicht in mein Büchlein aufnehmen, 
weil eine solche Aufnahme sich wohl für ein grosses umfassendes Werk schickt, aber hier zu gar Nichts dienen kaun. Nur Einiges habe ich zu weiterer Beobachtung empfohlen.

Die in meiner Synopsis áufgenommenen Namen der Arten habe ich, so viel möglich, beibehalten, weil man nach meinem Buche schon Verzeichnisse zu einem bequemen Gebrauche entworfen hat, und Aenderungen der Namen für solche Einrichtungen manche Unbequemlichkeit herbeiführen. Es ist bei dem vielfachen Wechseln der Namen in unserer Zeit gewiss sehr wünschenswerth, dass in Büchern, wie die meinigen, solche gebraucht werden, die Jeder sogleich versteht. Mit Namen, welche oft gewechselt haben, ist jetzt ohnehin kein Heil mehr; ich weiss aus Erfahrung, welchen Commentar seinen begleitenden Zuhörern man auf Excursionen zu geben hat, wenn man eine Pflanze mit dem Namen benennt, welchen im Jahre vorher eine andere trug. Wenn es mit Dank anerkannt werden muss, dass man die von früheren Schriftstellern aufgestellten Arten aufklärte, so ist doch die praktische Anwendung eines solchen Namens noch manchen Bedenklichkeiten unterworfen, und zwar, weil diese Unänderung oft nur auf einer individuellen Ansicht beruhet und nicht auf einem strengen Beweis, hauptsächlich aber, weil es in das Reich der Unmöglichkeiten gehört, zu bewirken, dass die jetzt lebenden Botaniker ïber einen solchen Namen einig werden, den nach wie vor der eine für die jetzt als die echte angenommene, der andere für die früher so benannte Pflanze gebraucht. Manche Linnéische Namen sind und bleiben für immer praktisch unbrauchbar, allerdings blos deswegen, weil die Botaniker über dieselben nicht 
einig werden, so z. B. der Name Rumex acutus L. Der ehemalige Besitzer des Linnéischen Herbariums, Smith, fand diese Art in dem Rumex conglomeratus Murray; Tausch, ein sehr fleissiger Forscher in den Linnéischen Schriften, findet sie in dem Rumex sylvestris Wallroth, den Fries, dessen Verdienste die ganze Welt anerkennt und ehrt, für den wahren R. obtusifolius hält; Wahlenberg findet dagegen den $R$. acutus in dem R. Hydrolapathrm, und ich selbst habe ihn in dem R. pratensis zu finden geglaubt; und damit sind die Acten bei Weitem noch nicht geschlossen.

Auch die Anordnung der Arten unter die Gattungen habe ich so wenig als möglich abgeändert. Das vorliegende Büchlein hat, wie meine Werke überhaupt, die Bestimmung, die Arten kemnen zu lernen. Wer diese kennt, kann sich unter den vorhandenen eine generische Anordnung nach Belieben wählen. Da solche Anordnungen in unserer Zeit in grosser Fülle in das Leben treten, so lässt sich annelimen, dass nicht alle von gleicher Dauer sein, wenigstens nicht gleichen Beifall finden werden, und da, was heute so heisst, über ein Jahr anders heisst, so wäre für ein Buch, wie das meinige, der Abänderungen kein Ende zu finden. Eine bedauerliche Betrachtung 'drängt sich bei diesem vielfachen Wechsel auf, nämlich, dass dabei gar oft die Erinnerung an die Verdienste der früheren Entdecker und Forscher in den Hintergrund gestellt und vergessen werden. Wenn ein Autor die Unterabtheilungen einer grösseren Gattung zu Gattungen erhebt, so setzt er hinter jede Art der neuen Gattung seinen eigenen Namen, und wenn er auch nicht Eine derselben entdeckt hat. Dass dieses ein Uebelstand ist, wird 
ziemlich allgemein gefühlt, aber wie demselben abzuhelfen sei, hat man noch nicht ermitteln können.

Ich selbst liebe noch immer grössere Gattungen mit Unterabtheilungen von allen Theilen der Pflanze genommen, denn nur in diesen ist eine naturgemässe Zusammenstellung der Arten zu finden, und, wenn die generischen Kennzeichen auf alle Arten passen, und die vorliegende grosse Gattung von ihren Verwandten deutlich scheiden, so ist eine solche auch gut begründet, sie mag auch einen bedeutenden Umfang haben., Wenn man aber in einem Natürlichen Systeme den Scirpus Tabernaemontani von Scirpus lacustris weit entfernt in eine andere Gattung versetzt, sieht, so ist doch in einer solchen Anordnung auch keine Spur einer natürlichen $\mathrm{Zu}$ sammenstellung $\mathrm{zu}$ finden.

Das zu Grunde gelegte System ist, wie in meiner Synopsis, das DeCandollische. Ich habe aber auch hier, wie dort, mit Bedacht eine Uebersicht des Linnéischen vorangeschickt, weil, nach meiner Ansicht und langjährigen Erfahrung, dieses System für die grosse Masse von Freunden der Botanik, welche sich nicht ganz besonders mit dieser Wissenschaft beschäftigen können, das einzig praktische ist. Um Raum zu ersparen, habe ich ausserdem der Gattungskennzeichen weiter nicht erwähnt.

Auf diese Uebersicht des Linnéischen Systemes folgt eine über die wesentlichen Kennzeichen der natürlichen Ordnungen, (Familien), von welchen das Florengebiet Repräsentanten aufzuweisen hat, weil, um Raum zu ersparen, diese Kennzeichen im Büchlein selbst ebenfalls nicht weiter aufgeführt sind. Ich hoffe jedoch, dass diese Darstellung hinreichen wird, die Studirenden an Universitäten und an Forstschulen mit den 
hauptsächlichsten Merkmalen der natürlichen Ordnungen bekannt zu machen. Zur leichteren Uebersicht habe ich deswegen auch die benannten Ordnungen nach gemeinschaftlichen Merkmalen zusammengestellt und nicht in der Reihe folgen lassen, wie sie im DeCandollischen Systeme, welches mit geringen Abänderungen $\mathrm{zu}$ Grunde gelegt ist, aufgestellt sind. Durch den Gebrauch des Büchleins wird man jene DeCandollische Anordnung sich bald eigen machen. Noch bemerke ich, dass ich für diejenigen, welche Zeit und Mittel haben, sich der Botanik in ihrem ganzen Umfange zu widmen und tiefer einzudringen, diese Uebersicht nicht geschrieben habe, für diese bedarf es umfassender Werke; allein es gibt ausser diesen Forschern eine Menge von Freunden der Pfanzen. kunde, welche neben ihren Berufsarbeiten in der Flora ihrc: Gegend sich umsehen, ohne gerade auf das Studium der natürlichen Systeme die erforderliche Zeit verwenden zu könner, und welche doch eine übersichtliche Anschauung der natiillichen Pflanzengruppen ihrer Umgegend zu erlangen wünschen, was nur dadurch geschehen kann, dass sie sich mit den Merkmalen dieser Gruppen bekannt machen; auch diesen wird dio benannte Uebersicht nützlich sein.

Schliesslich muss ich noch bemerken, dass in neuerer Zeit über die Gattung Rubus, die wegen Ueberfüllung mit unhaltbaren Arten auf lange Zeit zur Seite geschoben war, mehrere sehr $\mathrm{zu}$ beachtende Schriften erschienen sind, worunter die neueste von Dr. Godron sich vortheilhaft auszeichnet; allein da dio verschiedenen Verfasser über das, was Art ist, dennoch nicht ganz einig sind und da ich selbst bis jetzt keine Zeit fand, diese Gattung in der freien Natur nach langen Jahren zum zweiten Male und zwar nach auderen Prinzipien zu studiren, 
so habe ich sie in dem vorliegenden Büchlein in dem Gewande, welches sie in meiner Synopsis trägt, aufgeführt; erhält mir jedoch der Himmel Geistesfrische und, wenn auch nur meine bisherige schwankende, Gesundheit, so werde ich, was über diese Gattung in neuerer Zeit vorgetragen wurde, im nächstkommenden Jahre im Felde und Walde studiren und dann die Ergebnisse Meiner Beobachtungen ebenfalls mittheilen. - Und nun noch meinen innigen und herzlichen Dank den Freunden, welche mich so vielfach und so sehr zuvorkommend mit Zusendungen unterstützt haben.

\section{Koch.}




\section{Verzeichniss der Abkürzungen.}

1. Gegenden.
A. $=$ Alpen. VorA. $=$ Voralpen.
C. = Canton, Provinz der Schweiz.
D. = Deutschland.

Geb. = Gebiet; dch d. Geb. = durch das Gebiet, nämlich der Flora dieses Taschenbuches.

Gbg. = Gebirg. Gbge = Gebirge.

g. am Ende des Namens einer Provinz od. Stadt $=$ burg: Salzbg

$=$ Salzburg.

o. = Orte.

Stmk. = Steyermark, Schwz. $=$ Schweiz, und andere werden leicht erkannt werden.

2. Botanische Kunstwörter.

a. Hauptwörter.

B. = Blatt oder Blätter. BzpH. = Blattzipfel. Bścheide = Blattscheide u. s. w.

Bl. = Blume oder Blumenkrone. Blkr. = Blumenkrone.

Blb. = Blumenblatt oder Blumenblätter.

Bth. = Blüthe oder Blüthen. Bthstiel = Blüthenstiel. Bthzeit $=$ Blithenzeit u. s. w.

DeckB. $=$ Deckblatt oder Deckblätter.

Expl. = Exemplar.

Fruchtb. = Fruchtboden.

FruchtK. = Fruchtkelch.

Fruchtkn. od. Fruchtk. = Frucltknoten.

Gf. = Griffel.

HK. = Hauptkelch.

HüllB. = Hüllblatt oder Hüllblätter.

K. = Kelch oder Kelche. KB. = Kelchblatt. Kzähne = Kelchzähne u. s. w.

N. = Narbe.

NebenB. $=$ Nebenblatt.

P. od. Perig. = Perigon.

Pfl. = Pflanze.

R. = Rispe.

S. $=$ Same.

Sch. $=$ Scheide.

St. $=$ Stengel. StB. $=$ Stengelblatt.

Stbf. = Staubfaden. Stbg. = Staubgefäss. Stbk. = Staubkolben oder Staubkölbchen. 
$\mathrm{Tr} .=$ Traube.

Variet. = Varietät. Var. aber bedeutet Variirt.

W. $=$ Wurzel. Wköpfe $=$ Wurzelköpfe. WB. $=$ Wurzelblatt. $\mathrm{Zpfl}=$ Zipfel.

b. Beiwörter und Bestimmungswörter.

bth. am Ende eines Wortes = blüthig; vielbth. $=$ vielblüthig.

dch $=$ durch.

f. am Ende = förmig; herzf. = herzförmig.

gesp. $=$ gespalten.

geth. = getheilt.

b. am Ende = haarig; steifh. = steifhaarig.

1. am Ende $=$ lich; längl. = länglich.

od. $=$ oder.

sp. am Ende = spaltig; fünfsp. = fünfspaltig.

st. am Ende $=$ ständig; randst. = randständig.

th. am Ende = theilig; dreith. = dreitheilig.

trag. = tragend; driisentrag. = drüsentragend.

$\mathrm{v} .=$ von.

vkt. $=$ verkehrt; vktherzf. $=$ verkehrtherzförmig.

zs. = zusammen; zsgefaltet $=$ zusammengefaltet.

$\mathrm{zw}$. = $\mathrm{zwischen}$.

Einige andere Ablï̈rzungen sind leicht verständlich und Abkürzungen von Namen der Schriftsteller, L. $=$ Linné, DC. $=$ De-Candolle, WK. $=$ Waldstein und Kitaibel und ähnliche sind allgemein bekannt. D. fl. bedeutet Mertens und Koch Deutschlands Flora.

Noch bemerke ich über den Gebrauch von dem Worte scaber und Corymbus folgendes. Das Wort scaber, welches eine Oberfläche anzeigt, die sich durch spitze oder stumpfe Knötchen oder kurze steife Härchen rauh anfühlt, wurde bisher mit scharf übersetzt. Scharf aber ist ein geschliffenes Messer und rauh ist ein grobkörniger Sandstein. Das Scharfe verletzt mit der Kante, das Rauhe mit der Oberfläche. Destregen übersetzte ich scaber mit rauh, scabriusculus mit etwas rauh, scaberrimus mit sehr rauh. Scaberrimus und asper sind nicht verschieden und letzteres Wort in der botanischen Terminologie ganz überflïssig. - Für das Wort Corymbus, welches einen flachen Strauss bedeutet, dessen Stiele nicht aus einem Punkte entspringen, und welches mit Doldentraube übersetzt wird, habe ich das Wort Ebenstrauss, ein ebener, flacher Strauss, eingeführt. Der Corymbus hat mit der Dolde gar nichts und der Corymbus compositus auch mit der Traube nichts gemcin, man betrachte den Corymbus compositus der Achillea Millefolium. Das Wort Doldentraube könnte man für denjenigen Blüthenstand gebrauchen, welcher aus einem einfachen Corymbus durch Verlängerung der Achse bei dem Uebergang in Frucht zum Racemus wird, z. B. für den der Cruciferen für die Worte flores racemosocorymbosi. 
Anordnungen der Gattungen der Flora von Deutsch. land und der Schweiz nach dem Linnéischen Sexualsysteme.

\section{CIAASSEN.}

I. EINMAENNIGE, MONANDRIA: 1 freies Stbg. in einer Zwitterbthe.

II. ZWEIMAENNIGE, DIANDRIA : 2 freie Stbg. in einer Zwitterbthe. III. DREIMAENNIGE, TRIANDRIA: 3 freie Stbg. in einer Zwitterbthe.

IV. VIERMAENNIGE, TETRANDRIA : 4 freie, nicht zweimächtige Stbg. in einer $\mathbf{Z}$ witterbthe.

V. FUENFMAENNIGE, PENTANDRIA: 5 freie Stbg. in einer $Z$ witterbthe.

VI. SECHSMAENNIGE, HEXANDRIA : 6 freie, nicht 4 mächtige Stbg. in einer Zwitterbthe.

VII. SIEBENMAENNIGE, HEPTANDRIA: 7 freie Stbg. in einer Zwitterbthe.

VIII. ACHTMAENNIGE, OCTANDRIA : 8 freie Stbg. in einer $Z$ witterbthe.

IX. NEUNMAENNIGE, ENNEANDRIA : 9 freie Stbg. in einer Zwitterbthe.

X. ZEHNMAENNIGE, DECANDRIA: 10 freie Stbg. in einer $Z$ witterbthe.

XI. ZWOELFMAENNIGE, DODECANDRIA: 12, 16, 18 freie Stbg. in einer $Z$ witterbthe.

XII. ZWANZIGMIAENNIGE, ICOSANDRIA: $20 \mathrm{u}$. mehr freie Stbg. auf dem $K$. eingefügt in einer $Z$ witterbthe.

XIII. VIELMAENNIGE, POLYANDRIA : 20 u. mehr freie Stbg. auf dem Fruchtb. eingefügt in einer $\mathbf{Z}$ witterbthe.

XIV. ZWEIMAECHTIGE, DIDYNAMIA : 4 freie zweimächtige Stbg., nämlich 2 gleichf. längere und 2 kürzere, in einer $Z$ witterbthe.

XV. VIERMAECHTIGE, TETRADYNAMIA : 6 freie, 4 mächtige Stbg., nämlich 2 gleichf. kürzer $u$. entfernter, in einer $Z$ witterbthe.

XVI. EINBRUEDERIGE, MONADELPHIA: die Stbf. alle unter sich zsgewachsen in einer $\mathbf{Z}$ witterbthe.

XVII. ZWEIBRUEDERIGE, DIADELPHIA : die Stbf. in 2 gleiche Bündel zsgewachsen, od. 9 zsgewachsene u. ein zehenter freier in einer $\mathbf{Z}$ witterbthe. 
XVIII. VIELRRUEDERIGE, POLYADELPHIA : die Stbf. in 3 oder mehrere Bündel zsgewachsen in einer Zwitterbthe.

XIX. VEREINTKOLBIGE, SYNGENESIA: die Stbk. in eine Walze zsgewachsen in Bthen, welche mit einem gemeinschaftlichen $K$., einem Hauptk., umgeben sind und eine-zsgesetzte Blüthe bilden. XX. WEIBERILAENNIGE, GYNANDRIA: die Stbg. an den Stempel angewachsen in einer Zwitterbthe.

XXI. EINHAEUSIGE, MONOECIA: Bth. eingeschlechtig, männliche und weibliche auf derselben Pflanze.

XXII. ZWEIHAEUSIGE, DIOECIA: Bth. eingeschlechtig, die mänulichen auf einer, und die weiblichen auf einer anderen Pflanze derselben Art.

XXUI. VIELEHIGE, POLYGAMIA : eingeschlechtige Bthen mit Zwitterbthen gemischt.

XXIV. VERBORGENEHIGE, CRYPTOGAMIA: die Stbg. fehlend; (nur bei den Moosen deuten längliche, 1fächerige, mit einer bröckeligen Masse angefüllte Schläuche die männlichen Geschlechtsorgane an. Bei den übrigen kryptogamischen Pflanzen findet man nichts Aehnliches.)

\section{ORDNUNGEN.}

Die ORDNUNGEN der Klassen werden von der ersten bis zur dreizehnten Klasse nach der Anzahl der Fruchtkn., und, wenn ein einzelner Fruchtkn. vorhanden ist, nach der Anzahl der Gf., wenn aber die Gf. fehlen, nach der Anzahl der Narben gebildet. Die Einweibige (Monogynia), hat 1 Fruchtkn., mit 1 Gf. od. 1 Narbe bekrönt; die Zweiweibige (Digynia), hat 2 Fruchtkn., od. 1, mit 2 Gf., od. wenn die Gf. fehlen, mit 2 Narben versehen; die Vielweibige (Polygynia), viele Fruchtkn., od. 1 Fruchtkn. mit vielen Gf. oder Narben. Die Ordnungen der folgenden Klassen werden bei der Aufzählung der Gattungen erklärt od. sie sind an $u$. für sich klar.

\section{GATTUNGEN.}

Die vor den Gattungsnamen stehende Zahl zeigt die Seite des Buches an.

\section{Cl. EINMAENNIGE, MONANDRIA.}

\section{EINWEIBIGE, MONOGYNIA.}

178. HIPPURIS. Perigon aus einem schwachen, den Fruchtkn. krö nenden, Rande bestehend.

236. CENTRANTHUS. Saum des K. zuletzt in einen Pappus sich entwickelnd. Bl. gespornt.

Zu dieser Ordn.: Salicornia. Arten von Corispermum. 


\section{ZWEIWEIBIGE, DIGYNIA.}

Zu dieser Ordn.: Callitriche. Blitum. Festuca Myurus, Pseudomyurus u. sciuroides. Psilurus.

\section{Cl. ZWEIMAENNIGE, DIANDRIA. EINTVEIBIGE, MONOGYNIA.}

A. Bth. unvollst., unterst.

463. RUPPIA. Perig. fehlend. Niisse 4.

417. SALICORNIA. Perig. ungeth., dch eine Ritze geöffnet, in die Aushöhlung einer Spindel eingesenkt.

464. LENNA. P. zsgedrückt, ungeth., od. am Kande fein gekerbt.

$\mathrm{Zu}$ dieser Unterabtheilung: die blumenblattlosen Fraxinus. Mehrere Arten von Scirpus u. Rhynchospora, u. Cladium. - Die $2 m a ̈ n-$ nigen Gräser enthält die Triandria digynia.

B. Bth. vollständig, oberst.

177. CIRCAEA. Blkr. 2blätterig.

C. Bth. vollst., unterst., 1 früchtig, regelmässig.

a. Scheidewand des Fruchtkn. in dem grösseren Durchmesser desselben.

336. JASMINUM. Blkr.Saum 5-8sp.

335. LIGUSTRUM. Blkr.Saum 4sp. Beere.

335. PHILLYREA. Blkr.Saum. 4sp. Steinfrucht mit zerbrechlicher Schale.

335. OLEA. Blkr.Saum 4sp. Steinfucht mit knöcherner Schale.

335. SYRINGA. Blkr.Saum 4sp. Kapselfrucht.

b. Scheidewand des Fruchtkn. in dem kleineren Durchmesser desselben.

336. FRAXINUS. Blkr.Saum 4th., od. die Blkr. fehlend.

D. Bth. vollst., unterst., 1 frïchtig, unregelmässig.

400. PINGUICULA. Fruchtkn. 1 fächerig. K. 5sp.

400. UTRICULARIA. Fruchtkn. 1fächerig. K. 2blätterig.

368. WULFENIA. Fruchtkn. 2fä̈cherig. Stbk. nierenf., in ein Scheibchen aufspringend.

358. GRATIOLA. Fruchtkn. 2fächerig. Stbk. 2ritzig. N. 2plattig.

368. PAEDEROTA. Fruchtkn. 2fächerig. Stbk. 2ritzig. N. ungeth. Kapsel geschnäbelt-zugespitzt.

363. VERONICA. Fruchtkn. 2fächerig. Stbk. 2ritzig. N. ungeth. Kapsel ausgerandet.

E. Bth. vollst., unterst., 4 früchtig.

383. LYCOPUS. Stbk. 2fä̀cherig, 2ritzig. 
384. ROSMARINUS. Stbk. 1fächerig. Stbf. mit einem rückwärtsgerichteten Zahne.

384. SALVLA. Stbk. 1fächerig. Stbf. zahnlos. Connectiv fädlich.

$\mathrm{Zu}$ dieser Classe: Lipidium ruderale. Arten $v$. Corispermum $u$. Blitum.

\section{CI. DREIMAENNIGE, TRIANDRIA. EINWEIBIGE, MONOGYNIA.}

A. Bth. vollst., oberst.

234. VALERIANA. KSaum zuletzt zu einem Pappus entwickelt. Blkr. an der Basis höckerig.

236. VALERIANELLA. KSaum gezähnt, seltener unmerklich.

B. Bth. vollst., unterst.

181. MONTIA. K. 2blätterig. Blk. an einer Seite bis zur Basis gespalten, mit 5lappigem Saume.

C. Bth. unvollst., Perig. blumenkronenartig.

478. IRIS. Perig.Saum 6th., mit abwechselnd zurïckgebogenen $\mathrm{Zpfln}$.

477. TRICHONEMA. Perig.Saum 6th., abstehend, regelmässig. N. mit sehr schmalen zurückgekrïmmten $Z$ pfln.

476. CROCUS. Perig.Saum 6th., glockig, regelmässig. Zpfl. der N. aufwärts verbreitert.

477. GLADIOLUS. Perig.Saum 6th., unregelmässig, fast 2lippig. Stbg. aufstrebend.

D. Bth. unvollst., Perig. kelchartig.

418. POLYCNEMUM. P. 6blätterig, mit 2-3 DeckB. gestiitzt.

E. Bth. unvollst., balgartig.

a. Aehrchen 2reihig.

503. CYPERUS. Bälge zahlreich, die unteren 1-2 kleiner, leer.

504 SCHOENUS. Bälge 6-9, die 2-3 unteren leer.

b. Aehrchen von allen Seiten dachig. Die 3-4 unteren Bälge kleiner u. unfruchtbar.

504. CLADIUM. Nuss bespitzt deh die bleibende, ungegliederte Basis des Gf.

504. RHYNCHOSPORA. Nuss bespitzt dch die bleibende, gegliederte Basis des Gf.

c. Aehrchen von allen Seiten dachig. Die unteren Bälge grösser od. gleichgross, 1-2 derselben unfruchtbar.

505. HELEOCHARIS. Borsten eingeschlossen. Nuss bespitzt dch die bleibende, gegliederte Basis des Gf.

509. FIMBRISTYLIS. Borsten eingeschlossen od. fehlend. Nuss bespitzt. Der Gf. zsgedrückt, oberhalb der Basis gegliedert. 
506. SCIRPUS. Borsten eingeschlossen od. fehlend. Nuss bespitzt dch die bleibende, ungegliederte Basis des Gf.

509. ERIOPHORUM. Borsten hervortretend, viel länger als die Bälge. $\mathrm{Zu}$ dieser Ordn.: einige Gräser. Asperula tinctoria.

\section{ZWEIWEIBIGE, DIGYNIA.}

Bth. balgartig. Gräser.

A. Aehrchen in die Aushöhlungen einer Spindel eingesenkt.

571. PSILURUS. Balg 1klappig, (an der endst. Bth. 2klappig), viel kürzer als die Bthe.

571. LEPTURUS. Balg 1-2klappig, die eingesenkte Bthe bedeckend.

B. Aehrchen alle auf den Zähnen einer Spindel sitzend, keines gestielt.

571. NARDUS. Balg fehlend.

569. LOLIUM. Balg der seitenst. Aehrehen 1klappig, der endst. 2 klappig.

568. HORDEUM. Aehrchen an den Gelenken der Spindel zu 3, 1 bth.

568. ELYMUS. Aehrchen an den Gelenken der Spindel zu 3, 2vielbth.

565. GAUDINIA. Aehrchen einzeln; Bth. auf dem Ruicken begrannt, Granne gekniet.

570. AEGLLOPS. Aehrchen einzeln; Bth. an der Spitze 2-4zähnig; Zähne oft begrannt.

565. TRITICUM. Aehrchen einzeln; Bth. aus der Spitze begrannt od. grannenlos. Klappen eyf. od. ey-lanzettf.

568. SECALE. Aehrchen einzeln; Bth. aus der Spitze begrannt; Klappen pfriemlich.

C. Aehrchen an den Gelenken einer Aehre oder gegliederten Rispe gezweiet, das eine sitzend, das andere gestielt.

531. ERIANTHUS. Aehrchen sämmtlich zwitterig u. alle lineal.

532. ANDROPOGON. Die sitzenden Aehrchen zwitterig, die gestielten männlich, alle lineal.

532. SORGHUM. Die sitzenden Aehrchen zwitterig, ey-od. ey-lanzettf;; an der Spitze 3zähnig; die gestielten männlich.

532. HETEROPOGON. Die unteren sitzenden Aehrchen u. die gestielten sämmtlich männliche; die sitzenden oberen dch Fehlschlagen weibliche.

D. Aehrchen gestielt, länger- od. kürzer-, manchmal aúch sehr kurz-gestielt, 1bth., od. 1 bth. mit einem Ansatze zu einer zweiten oberen od. zu zweien unteren Bth.

a. Aehrchen vom Rücken her zsgedrückt.

332. PANICUM. Balg 3klappig, die untere Klappe kleiner, oft sehr klein; Hülle fehlend. 
533. SETARLA. Balg 3klappig, die untere Klappe kleiner od. sehr klein. Borstenf. Hüllen unter den Aehrchen.

532. TRAGUS. Balg 2klappig, die untere Klappe sehr klein, häutig; die óbere lederig, dornig; Bth. häutig.

541. MILIUM. Balg 2klappig, grösser als die knorpelige, grannenlose Bthe.

541. PIPTATHERUM. Balg 2klappig, grösser als die knorpelige, begrannte Bth.; Granne abfällig.

b. Aehrchen v. der Seite her zsgedrückt; Balg fehlend.

538. LEERSIA. Bälglein die Karyopse einschliessend.

538. COLEANTHUS. Bälglein kürzer als die Karyopse.

c. Aehrchen von der Seite her zsgedrückt; Balg 2klappig;

Bth. an ihrer Basis mit 2 schuppenf. od. spelzigen Ansätzen zu unteren Bthen.

534. PHALARIS. Bth. an der Basis mit 2 grannenlosen Schuppen. 535. ANTHOXANTHUM. Bth. an der Basis mit 2 begrannten Spelzen, die grösser als die Bth. selbst sind.

d. Aehrchen v. der Seite her zsgedrückt od. stielrund; Balg $2 \mathrm{klappig}, 1 \mathrm{bth}$, od. $1 \mathrm{bth}$. mit einem Ansatze zu einer oberen Bthe

$\alpha$. N. fädlich, aus der Spitze des Aehrchens hervorgestreckt.

535. ALOPECURUS. Bälglein 1klappig.

537. CHAMAGROSTIS. Klappen kiellos. Bälglein 2klappig.

536. PHLEUM. Klappen gekielt, fast gleich, länger als das 2klappige Bälglein.

536. CRYPSIS. Klappen gekielt, kürzer als die.Bthe, die untere kürzer; Spelzen fast gleich, die obere ein wenig kürzer.

538. SPARTINA. Klappen gekielt, die untere kürzer als die Bthe; Spelzen ungleich, die obere länger.

$\beta$. N. auf einem verlängerten $\mathrm{Gf}$. aufsitzend, sprengwedelf., unter der Spitze der Bthe hervortretend.

537. CYNODON. Klappen schmal, abstehend. Die obere Spelze lineal., dch eine Furche ausgehöhlt, die untere v. der Seite her zsgedrïckt, im Umrisse eyf., papierartig.

535. IMPERATA. Klappen ein 3spelziges, dünnhäutiges Bälglein einschliessend. Die Gf. v. der Basis bis zur Mitte zsgewachsen.

$\gamma$. N. federig, an der Basis des Aehrchens hervortretend.

Dic Gf. kurz od. fehlend.

540. LAGURUS. Klappen pfriemlich, in eine Granne verschmälert. Die untere Spelze mit 2 endst. und einer rïckenst., geknieten Granne.

538. POLYPOGON. Klappen aus der stumpfen oder etwas ausgerandeten Spitze begranut. Spelzen häutig. 
538. AGROSTIS. Klappen spitz, die untere grösser. Spelzen häutig, kahl od. an d. Basis mit sehr kurzen Haaren umgeben.

539. APERA. Klappen spitz, die untere kleiner. Spelzen häutig, an der Basis kahl, od. mit selı kurzen Haaren umgeben.

540. CALAMAGROSTIS. Klappen spitz, die untere grösser. Spelzen an der Basis mit Haaren umgeben, die länger als der Querdchmesser der Spelze sind.

541. PSAMMA. Klappen spitz, die untere kleiner- Spelzen an der Basis mit Haaren umgeben, die länger als der Querdchmesser der Spelze sind.

542. LASIAGROSTIS. Klappen spitz, die untere grösser. Die untere Spelze auf dem Rücken mit verlängerten Haareu besetzt. Granne bleibend, unter der Spitze eingefügt.

542. STIPA. Klappen spitz od. aus der Spitze begrannt. Spelzen knorpelig, die untere walzlich-zsgerollt; Granne stark, an der Basis gegliedert, bleibend, aus d. Spitze d. Spelze hervorgehend.

541. GASTRIDIUM. Klappen spitz, sehr zsgedrückt, an der Basis fast kugelig-gedunsen. Spelzen häutig.

E. Aehrchen länger- od. kürzer-, manchmal sehr kurz-gestielt, 2-vielbth.; seltener die unteren geschlechtlos od. männlich, die oberste aber oft verkiimmert.

a. N. fädlich, aus der Spitze des Aehrchens lang-hervorgestreckt.

543. SESLERIA. Die untere Spelze ganzrandig u. stachelspitzig od. begrannt, od. an der Spitze 3-5zähnig, die Zähne stachelspitzig od. begrannt.

542. ECHINARLA. Die untere Spelze handf.-5sp.; Zptl. lanzettl.pfriemlich.

b. N. sprengwedelf., unter der Spitze der Bth. hervortretend.

542. ARUNDO. Aehrehen vielbth.; Bth. sämmtl. zwitterig, auf dem Rücken mit verlängerten Haaren besetzt.

542. PHRAGMITES. Aehrchen vielbth.; die untere Bthe männlich od. gesehlechtlos, nackt, die iibrigen $z$ witterig, mit verlängelten, v. der Achse entspringenden Haaren umhüllt.

535. HIEROCHLOA. Aehrchen 3 bth., die 2 unteren Bth. männlich, 3 männig; die obere zwitterig, 2 männig (kahl).

c. N. federig, an der Basis der Bth. hervortretend.

544. LAMARCKIA. Die geschlechtlosen Aehrchen vielbth., mit abgerundet-stumpfen Spelzen; die zwitterigen 1bth., mit einem Ansatze zu einer zweiten Bthe.

545. ARRHENATHERUM. Aehrehen $2 \mathrm{bth}$, die untere Bthe männ. lich, begrannt; die obere zwitterig, grannenlos.

545. HOLCUS. Aehrchen 2 bth., die untere Bthe zwitterig, grannenlos; die obere männlich, begrannt. 
545. CORYNEPHORUS. Aehrchen 2bth.; Bth. zwitterig. Die untere Spelze an der Spitze ganzrandig, an der Basis begrannt; Granne oberwärts keulig, in der Mitte mit einem Ringe umgeben.

544. AIRA. Aehrchen 2bth.; Bth. $z$ witterig. Die untere Spelze an der Spitze abgeschnitten, 4zähnig, an der Basis od. auf dem Rücken begrannt; Granne an der Basis gedrehet, in ein Knie gebogen od. fast gerade.

546. AVENA. Aehrchen 2-vielbth.; Bth. zwitterig. Die untere Spelze an der Spitze 2sp. od. 2grannig, auf dem Rücken mit einer an der Basis gedrehten Granne.

550. DANTHONIA. Aehrchen 2-vielbth.; Bth. zwitterig. Die untere Spelze an der Spitze 2sp., in der Spalte begrannt, mit einer an der Basis flachen und gewundenen Granne.

550. TRIODIA. Aehrchen 2-vielbth.; Bth. zwitterig. Die untere Spelze an der Spitze 3zähnig, der mittlere Zahn stachelspitzf., etwas flach.

550. MELICA. Aelurchen 2-mehrbth.; Bth. grannenlos, die untere od. die 2 unteren zwitterig, vollkommen, die zweite od. dritte unähnlich, unvollkommen u. noch $1-2$ unvollkommene einschliessend.

543. KOELERIA. Aehrchen 2-mehrbth.; Bth. lanzettf., zsgedriicktgekielt. Die untere Spelze an der ungeth. od. 2sp. Spitze stachelspitzig od. begrannt; Granne borstlich, gerade.

556. DACTYLIS. Aehrchen 3-mehrbth.; Bth. eyf., auf dem Rükken zsgedrückt-gekielt, nach der inneren Seite gekrümmt. Die untere Spelze ungleichseitig, an der ungeth. od. 2sp. Spitze stachelspitzig od. begrannt; Granne borstlich, gerade.

551. POA. Achrchen 2-vielbth.; Bth. eyf., od. lanzettf., auf dem Rücken zsgedrüickt-gekielt, grannenlos, mit den Gelenken der Achse abfällig.

551. ERAGRUSTIS. Aehrehen 2-vielbth.; Bth. eyf. od. lanzettf., auf dem Riicken zsgedrückt-gekielt, grannenlos, die obere Spelze so wie die Achse bleibend.

555. GLYCERIA. Aehrchen 2-vielbth.; Bth. länglich, stumpf, auf dem Rücken halbwalzlich, einwärts fast bauchig, grannenlos.

556. MOLINIA. Aehrchen 2-vielbth.; Bth. aus einwärts-bauchiger 13asis kegelf., auf dem Rücken halbwalzlich, grannenlos od. an der Spitze begrannt; Granne gerade.

550. BRIZA. Aehrchen 2-vielbth.; die untere Spelze an der Basis herzf.-geöhrelt.

556. FESTUCA. Aehrchen 2-vielbth.; Bth. lanzettl. od. lanzettl.pfriemlich, auf dem Rücken stielrund, begrannt od. grannenlos. Die obere Spelze am Rande fein gewimpert. Gf. od. N. auf der Spitze des Fruchtkn. eingefügt. Hülle fehlend.

556. CYNOSURUS. Die einzelnen Achrchen an der Basis mit einer, 
aus zahlreichen, 2reihigen Klappen gebildeten Hülle gestïtzt; sonst alles, wie bei Festuca.

562. BRACHYPODIUM. Die obere Spelze am Rande kammf. - horstig; sonst alles, wie bei Festuca.

562. BROMUS. Aehrchen vielbth.; Bth. lanzett.- od. ey-lanzettf., begrannt od. grannenlos. Gf. od. N. oberhalb der Mitte des Fruchtkn. auf dessen vorderer Seite eingefügt.

$\mathrm{Zu}$ dieser Ordn.: Arten v. Corispermum u. Blitum.

\section{DREI- $u$. VIERWEIBIGE.}

182. POLYCARPON. K. 5th., Zpfl. gekielt. Kapsel 3klappig, 1fächerig,-vielsamig.

Zur Trigynia: Holosteum. Polycarpon. Tillaea. Zur Tetragynia: Elatine.

\section{Cl. VIERMAENNIGE, TETRANDRIA. EINWEIBIGE, MONOGYNIA.}

A. Bth. vollständig.

a. Besonderer $\mathbf{K}$. doppelt; der innere zuletzt an die Frucht angewachsen. Blkr. 1blätterig.

238. KNAUTIA. Fruchitb, raulih.

237. DIPSACUS. Fruchtb. spreuig. Der äussere K. vielzähnig. Dit äusseren Hüllblättchen länger, u. länger als die Spreuen.

238. CEPHALARIA. Hülle dichtdachig, die äusseren Blättchen kürzer; sonst alles wie bei Dipsacus.

239. SUCCISA. Fruchtb. spreuig. Der äussere K. 4lappig, Lappen krautig.

239. SCABIOSA. Fruchtb. spreuig. Der äussere K. glockig od. radf., trockenhäutig.

b. K. einfach. Blkr. einblätterig, unterst.

410. GLOBULARIA. Blk1. unregelmässig, 3-5sp.

412. PLANTAGO. Blkr.Saum regelmässig, 4th. Narbe täulich, verlängērt. Kapsel rundum-aufspringend.

402. CENTUNCULUS. Saum der Bl. regelmässig, 4th. Narbe kopfig. Kapsel 1fächerig, rundum-aufspringend.

342. CICENDIA. Saum der Bl. regelmässig, 4th. Narbe kopfig. Kapsel halb-2fächerig, der Länge nach aufspringend.

c. K. einfach, der Saum oft verwischt und unmerkliclı.

Bl. 1 blätterig, oberst.

229. CRUCIANELLA. B1. trichterf., $Z$ pfl. einwärtsgekrümmt u. zsneigend. Saum des K. verwischt.

228. ASPERLLA. Bl. trichter- od, glockenf, Znf, ahatehend. Srum des $K$, verwischt. 
228. SHERARDIA. Bl. trichterf., $Z \mathrm{ppl}$. abstehend. Saum d. K. gezähnt. 230. GALIUM. B1. flach od. radf. Frucht 2 knotig, trocken.

230. RUBIA. BI. flach od. radf. Frucht 2 knotig, saftig.

234. VAILLANTIA. Bl. flach od. radf. Frucht mit 3 Hörnern.

d. Blkr. vielblätterig, unterst.

18. EPIMEDIUM. K. 4blätterig. Blkr. 4blätterig. Nebenkrone 4blätterig.

e. Blkr. vielblätterig, oberst.

225. CORYUS. K. 4sp. Blkr. 4blätterig. Steinfrucht.

177. TRAPA. K. 4sp. Blkr. 4blätterig. Dornige Nuss.

B. Bth. unvollst.

a. Unterst.

483. MAIANTHEMUM. P. blumenkronenartig, 4th., flach oder zurückgebogen.

420. CAMPHOROSMA. P. 4zähnig, die 2 gegenst. Zähne grösser. Stbg. in die Basis des P. eingeftigt.

170. ALCHEMILLA. P. kelchartig, mit 8sp. Saume. Stbg. auf einem den Schlınd verengernden Ringe eingefügt.

170. SANGUISORBA. P. kelchartig, farbig, mit 4sp. Saume. Stbg. auf einem den Schlund verschliessenden Ringe eingefügt.

438. PARIETARIA. P. glockig. Stbg. auf dem Grunde des P. eingefuigt. Bth. vielehig.

431. ELAEAGNUS. P. glockig, an der Basis in eine Röhre zsgezogen. Stbg. dem Saume des P. eingefitgt. Bth. vielehig.

b. Bth. oberst.

176. ISNARDIA. P. oberst., 4sp., bleibend.

Zur Monogynia: Cicendia filiformis und die 4sp. Gentianen. Ar. ten vur Econymus u. Thesium. Cardamine hirsuta.

\section{ZWEIWEIBIGE, DIGYNIA.}

20. HYPECOUM. K. 2blätterig, hinfällig. Blkr. 4blätterig.

76. BUFFONIA. K. 4blätterig, bleibend. Blkr. 4blätterig. Kapsel 2klappig, 2samig.

\section{VIERWEIBIGE, TETRAGYNIA.}

335. IIEX. K. 4 zïhnig. Blkr. 4th. Gf. fehlend. Fruchtkn. 4 füeherig.

92. RADIOLA. K. 4sp., mit 2-3sp. Zpfln. Blkr. 4 blätterig. Fruchtkn. 8 facherig.

183. TILLAEA. K. 3-4th. Blkr. 3-4blätterig. Kapseln 3-4, zweisamig.

183. BULLIARDA. K. 4th. Blkr. 4blätterig. Kapseln 4, vielsamig.

459. POTAMOGETON. P. 4th. Steinfrüchte 4 , sitzend.

Zur Tetragynia: Sagira. Moenchia. Cuscuta. Mehrere Gentianen. 


\section{Cl. FUENFMAENNIGE, PENTANDRIA. EINWEIBIGE, MONOGYNIA.}

I. Bth. vollst., 1blätterig, unterst.

A. Nüsse 4, 1samig, od. 2, jede 2samig.

a. Fruchtkn. 1, mit 4 Näthen, bei der Reife aber in 4 , an der Basis flache, Niisse zerfallend.

344. HELIOTROPIUM. Blkr. trichterf., Schlund offen, Saum faltig.

b. Nüsse 4, mit dem Rücken an den bleibenden Gf. angewachsen.

344. ASPERUGO. Niisse zsgedrückt, mit der schmäleren Seite an den Gf. angewachsen. FruchtK. flach-zsgedriickt.

344. ECHINOSPERMUM. Nüsse 3eckig, an Rde weichstachelig.

344. CYNOGLOSSUM. Niisse platt-gedrückt, weichstachelig.

345. OMPHALODES. Nüsse platt-gedrückt, mit einem häıtigen, an der Spitze zsgezogenen $u$. einwärtsgebogenen Rande umzogen.

c. Nüsse 4, der unterweibigen Scheibe eingefïgt, an der Basis mit einem gedunsenen, gerieften Ringe versehen u. innerhalb des Ringes ausgehöhlt.

345. BORAGO. Blkr. radf.; Deckklappen kurz, ausgerandet.

345. ANCHUSA. Blkr. trichterf.; Röhre gerade; Schlund dch stumpfo Deckklappen verengert.

346. LYCOPSIS. Blkr. trichterf.; Röhre einwärtsgebrochen-gekrümmt; Schlund dch stumpfe Deckklappen verengert.

346. NONNEA. Blkr. trichterf.; Schlund offen, bärtig od. mit kleinen haarigen Deckklappen besetzt.

346. SYMPHYTUM. Blkr. walzlich-glockig; Deckklappen 5, priem. lich, in einen Kegel zsneigend.

d. Niisse 4, der unterweibigen Scheibe eingefügt, an der Basis nicht ausgehöhit.

347. ONOSMA. Blkı. walzlich-glockig. Decklklappen fehlend. Stbl. pfeilf., an der Basis zshängend. Nüsse 4, einsamig.

347. CERINTHE. Blkr. walzlich-glockig. Deckklappen fehlend. Stbk. pfeilf., an der Basis zshängend. Nüisse 2, jede zweisamig.

348. ECHIUM. Blkr. glockig od. allmählig erweitert. Deckklappen fehlend. Stbk. oval, frei.

348. PULMONARIA. Blkr. trichterf., im Schlunde behaart. Deckklappen fehlend. K. $5 \mathrm{sp}$.

349. LITHOSPERMUM. Blkr. trichterf.; Schlund dch 5 behaarte Falten etwas verengert. K. 5zähnig.

349. MYOSOTIS. Blkr.Schlund dch kahle Deckklappen verengert. Niisse unberandet.

350. ERITRICHIUM. Blkr.Schlund dch kahle Deckklappen verengert. Nüsse mit einem hervorspringenden Rande umgeben. 
B. Kapsel 1 fächerig, 1samig.

412. PLUIMBAGO. Blkr. trichterf.

C. Kapsel 1fächerig, mit einem freien mittelpunktst. Samenträger.

a. Blkr.Zpfl. am Ende der Röhre zuriickgeknickt.

409. CYCLAIIEN. Blkr.Röhre glockig; Zpfl. des Saumes zurückgeknickt.

b. Blkr. trichterf. od. tellerf. K. 5sp. od. 5zähnig.

402. ANDROSACE. Blkr. Röhre eyf., an d. Spitze verengert. Stbg. frei. 404. PRIMULA. Blkr.Röhre walzlich od. keulig. Stbg. frei. Eychen sehr viele.

404. ARETIA. Blkr.Röhre keulig. Stbg. frei. Eychen 5.

409. CORTUSA. Blkr.Rölre kurz, walzlich. Stbg. am Grunde deh einen Ring verbunden.

e. Blkr. trichterf. od. tellerf. K. 5th.

401. LYSIMACHIA. Blkr. radf., 5th. Kapsel 5klappig.

402. ANAGALLIS. Blkr. rədf., 5th. Kapsel ringsum aufspringend.

409. HOTTONIA. Blkr. tellerf.; Röhre walzlieh; Saum flach, 5th.

409. SOLDANELLA. Blkr. trichterf.; Röhre kurz; Saum in zahlreiche $Z$ pfl. gespalten.

D. Fruchtkn. 1fächerig; Samenträger 2, wandst.

337. MENYANTHES. Blkr. triehterf. $N$. ungeth.

337. LINNANTHEMUM. Blkr. radf. N. 2 th.

E. Kapsel 2-5fächerig.

342. ERYTHRAEA. Blkr. trichterf. od. tellerf. Stbk. nach dem Verblühen sehraubenf.-gedreht.

343. POLEMONIUM. Blkr. radf. N. 3.

343. CONVOLVULUS. Blkr. trichterf.-glockig, faitig, 5kantig. Fächer des Fruchtkn. 2eyig.

352. DATURA. Blkr. triehterf., faltig, 5kantig. K. abfallig, mit einer bleibenden, ringsum abgesprungenen Basis.

352. NICOTIANA. Blkr. triehterf., faltig, 5kantig. K. bleibend. Fächer des Fruchtkn. vieleyig.

352. HYOSCYAMUS. Blkr. trichterf. Kapsel bauchig, in einen Hals versehmälert, mit einem Deckelchen aufspringend.

352. SCOPOLINA. Blkr. rölrrig-glockig. Kapsel ringsum aufspringend.

353. VERBASCUMI. BIlk. radf. Stbk. auf die verbreiterte Spitze der Stbf. quer aufgewachsen.

333. AZALEA. Blkr. glockig. Stbg. vor einer unterweibigen Scheibe, nicht aber in der Blkr. eingefügt.

F. Frucht aus 2 Balgkapseln bestehend. Fruchtkn. 2 mit einem gemeinschaftl. Gf.

336. VINCA. Blkr. tellerf.; Z pfl. schief-abgeschnitten; Schlund nackt.

337. NERIUM.! BI. trichterf.; $Z$ pfl. schief-abgesehnitten; Schlund init einer zerschlitzten Krone. 


\section{G. Frucht eine Bcere.}

351. LYCIUM. BI. trichterig. Fruchtkelch klein, an der Basis der Frucht anliegend.

352. ATROPA. Blkr. glockig. Frucht auf dem vergrösserten Fruchtkelch sitzend.

352. PHYSALIS. Blkr. radf. Stbk. der Länge nach aufspringend.

351. SOLANUM. Blkr. radf. Stbk. an der Spitze mit 2 Oeffnungen aufspringend.

II. Bth. vollst., 1 blütterig, oberst.

A. Kapselfrucht.

410. SAMOLUS. Stbg. 10, von diesen 5 fruchtbar. Fruchtkn. 1fächerig.

324. LOBELIA. Stbk. verwachsen. Bl. auf einer Seite der Längo nach gespalten.

324. JASIONE. $\mathrm{Zpfl}$. der Bl. lineal., verwachsen, zuletzt v. der Basis an sich lösend. Stbf. pfriemlich; Stbk. zshängend.

324. PHYTEUMA. Zpfl. der Bl. lineal., verwachsen, zuletzt $\nabla$. der Basis an sich lösend. Stbf. an der Basis verbreitert. Stbk. frei.

326. CAMPANULA. BI. 5lappig od. 5 sp., oft glockig; die oberweibige Scheibe Alach. Kapsel kreiself., mit 3-5 Löchern aufspringend.

330. ADENOPHORA. Die oberweibige Scheibe um den Gf. in Ge. stalt eines Röhrchens erhöht; sonst alles, wie bei Campanula.

330. SPECULARIA. Bl. radf. Kapsel lineal.-länglich, prismatisch, mit Seitenritzen aufspringend.

331. WAHLENBERGIA. Bl. glockig od. trichterig. Kapsel an d. Spitze in $3-5$ scheidewandtragende Klappen aufspringend.

330. EDRAJANTHUS. Bl. glockig. Kapsel 2-3fächerig, in dem K. unregelmässig aufspringend.

\section{B. Beerenfrucht.}

227. LONICERA. Bl. unregelmässig. Beere 2-3fächerig.

III. Bth. vollst., vielblätterig, unterst.

a. Bth. unregelmässig.

102. IMPATIENS. K. 3blätterig, das unpaarige Blatt viel grösser, gespornt. Bl. 5 blätterig, die seitenst. Blb. paarweise zsgerrachsen.

57. VIOLA. K. 5blätterig. Bl. 5blätterig.

b. Bth. regelmässig.

98. VITIS. Blb. 5, an der Spitze zshängend u. wie einc Haube an der Basis sich ablösend, dem Fruchtb. eingefügt.

98. AMPELOPSIS. BIb. 5, von der Spitze nach der Basis sich trennend, dem Fruchtb. eingefïgt.

104. EVONYMUS. Blb. 4-5, dem K. eingefïgt. Stbg. 4-5, mit den Blb. abwechselnd, einer drüsigen Scheibe eingesetzt.

105. RHAMNUS. Blb. 4-7, dem K. eingefügt, Stbg. vor die Blb. 
gestellt, oft auch bei dem vielehig-weibl. Geschlechte klein od. ganz fehlend. Steinfrucht mit mehreren knorpeligen Steinen.

105. ZIZYPHUS. Steinfrucht saftig, flügellos; der Stein 2-3fächerig; sonst alles wie bei Rhamnus.

105. PALIURUS. Steinfrucht trocken, mit einem kreisrunden Flügel umzogen; der Stein 2-3fächerig; sonst alles, wie bei Rhamnus.

IV. Bth. vollst., vielblätterig, oberst.

188. RIBES. Blb. u. Stbg. dem KSaume eingefügt. Blb. benagelt. 225. HEDERA. Blb. u. Stbg. vor einer oberweibigen Scheibe eingefügt. Blb. mit breiter Basis sitzend.

V. Bth. unvollst., unterst.

a. Stbg. 5 .

151. CERATONIA. K. 5th. Bl. fehlend. Hülse vielsamig.

410. GLAUX. P. glockig, 5lappig, farbig. Fruchtkn. 5fächerig.

b. Stbg. 10, von diesen 5 unfruchtbar.

182. HERNIARIA. P.5th., mit flach-concaven $\mathrm{Zpfln}$. Hautfrucht ohne Ansatz zu einem Deckelchen.

182. PARONYCHIA. P. 5th., mit flach-concaven $Z$ pfln. Hautfrucht mit einem angewachsenen Deckelchen. $\mathrm{N}$. ungeth.

182. ILLECEBRUM. P. 5th., mit verdickten, v. der Seite her zsgedrückten Zpfln., deren innere Oberfläche schmal ist.

VI. Bth. unvollst., oberst.

429. THESIUM. P. bleibend. Stbg. dem P. eingefigt, von einem Haarbüschel eingeschlossen.

Zur Monogynia: Rubia. Crucianella. Arten v. Gentiana u. Polygonum.

\section{ZWEIWEIBIGE, DIGYNIA.}

I. Bth. unvollständig.

439. ULMUS. P. 4-5zähnig. Fruchtkn. 2fächerig. Nuss dch Fehlschlagen 1fächerig, mit einem Flügel umzogen.

439. CELTIS. P. 5-6th. Steinfriichte mit einem knöchernen, 1samigen Steine.

417. CORISPERMCM. P. fehlend, od. in 2 durchsichtigen Schüppchen vorhanden. Nuss mit einem Flügel umzogen.

120. BETA. P. 5sp., an der Basis in ein, den Fruchtkn. einschliessendes Röhrchen zsgezogen.

416 SALSOLA. P. 5th., zuletzt auf dem Rücken mit einem quergestellten Anhängsel. Keim schraubenf.

118. KOCHIA. P. 5th., zuletzt auf dem Rücken mit einem Flügel od. einer Querfalte bezeichnet. Keim ringf.

416. SCHOBERIA. P. 5th., olıne Anhängsel. Keim schraubenf.

418. CHENOFODIUM. P. 5th., ohne Anbängsel. Keim ringf. S. alle wagerecht. 
419. BLITUM. P. 3-5th., ohne Anhängsel. S. alle aufrecht od. wagerechte darunter gemischt.

II. Bth. vollst., 1blätterig, unterst.

a. Fruchtkn. 2, mit einem einzigen seitcnst. Samenträger.

Eine den zwei Fruchtkn. gemeinschaftliche N.

336. CYNANCHUM. Krone der Stbf. 1blätterig, 5lappig.

336. APOCYNUM. Fünf spitze Zähnchen in der Röhre der Bl.

b. Fruchtkn. 1, mit 2 gegenst. Samenträgern.

337. SWERTIA. Zpfl. der Bl. an der Basis mit 2, am Umfange fransigen Honiggruben versehen.

338. LOMATOGONIUM. Zpfl. der Bl. ohne Honiggrube. Gf. fehlend. N. kurz, auf den Ḱlappenrändern mit Papillen hinabziehend.

338. GENTIANA. Zpfl. der Bl. ohne Honiggruben. Gf. 2 od. 1. mit 2 N.

c. Fruchtkn. 1. Eychen wenige, auf dem Grunde des Fruchtkn. eingeftigt.

343. CUSCUTA. Bl. 4-5sp. Kapsel ringsum aufspringend.

III. Bth. 5blätterig, oberst. (Umbelliferen.)

$\mathfrak{A}$. Bth. in einem Köpfchen od. in einer einfachen Dolde.

198. HYDROCOTYLE. Blb. ungeth., spitz. Frucht v. der Seite her flach-zsgedrückt, beiderseits auf dem Nittelfelde mit 2 bogigen Riefen.

199. ERYNGIUM. Blb. aufrecht, zsneigend, von der Mitte an in ein Läppchen v. d. Länge des Blb. eingeknickt. Friichtchen riefenlos, beschuppt od. höckerig.

199. ASTRANTIA. Früchtchen mit 5 erlabenen, faltig-gezähnten Riefen. Blb. wie bei Eryngium.

199. HACQUETIA. Friichtchen glatt, mit 5 fädlichen, inwendig v. einem Kanale durchbohrten Riefen. Blb. wie bei Eryngium.

\section{$\mathfrak{B}$. Dolde zsgesetzt.}

A. Eyweiss vorne flach od. convex. Hauptriefen 5, fädlich; Nebenriefen fehlend. Frucht v. der Seite her deutlich zsgedrückt.

a. Blb. ganz.

205. BUPLEURUM. Blb. an der Spitze abgeschnitten, eingerollt. 201. HELOSCIADIUM. Blb. in einen Stern ausgebreitet, spitz od. stumpflich, aber mit einem kleinen, geraden oder einwärts gebogenen Spitzchen.

200. APIUM. Blb. in einen Stern ausgebreitet, rundlich, mit einem dicht-eingerollten Spitzchen.

201. TRINIA. Blb. der männl. Bth. lanzettl., einwärtsgebogen. Riefen des Früchtchens v. einem Kanale durchbohrt.

201. PETROSELINUM. Blb. rundlich, einwärtsgekrümmt, ganz, in ein einwärtsgebogenes Läppchen verschmälert. Thälchen 1striemig. 
b. Blb. verkehrtherzf., mit einem kleinen, einwärtsgebogenen Läppchen. KRand unmerklich.

202. AMMI. Blb, unregelmässig.

202. AEGOPODIUM. BIb. regelmässig. Striemen fehlend.

202. SISON. Blb. regelmässig. Striemen keulig.

202. CARUM. Blb. regelmässig. Gf. zuriickgebogen. Frucht länglich, mit 1striemigen Thälchen; Striemen fädlich.

203. BUNIUMI. Blb. regelmässig. Gf. zurïckgebogen. Frucht längl. mit 3striemigen Thälchen. Striemen fädlich.

203. PIMPINELLA. Blb. regelmässig. Gf. haarfein, abstehend. Frucht 2 knotig; Thälchen 3striemig; Striemen fädlich.

c. Blb. verkehrtherzf., mit einem kleinen, einwärtsgebogenen

Läppchen. K. 5zähnig.

aa. Thälchen 1striemig.

200. CICUTA. Eyweiss im Querdurchschnitte kreisrund. Frucht 2knotig.

201. PTYCHOTIS. Eyweiss vorne flach. Läppchen der BIb. v. einer Querfalte ausgehend.

202. FALCARIA. Eyweiss vorne flach; Läppchen aus der Ausrandung der Blb. hervortretend.

bb. Thälchen 3striemig.

204. BERULA. Striemen mit d. rindigen Fruchtgehäuse bedeckt.

204. SIUM. Striemen oberflächlich.

B. Eyweiss vorne flach od. convex. Hauptriefen 5, fädlich od. gefligelt; Nebenriefen fehlend. Frucht auf dem Querdurchschnitte stielrund, od. vom Rücken her zsgedrückt, aber nicht linsenf.-zsgedrückt.

a. Same frei in der Höhle des Fruchtgehäuses.

212. CRITHMUM. Riefen geflügelt, die seitenst. kaum breiter.

213. ARCHANGELICA. Die seitenst. Riefen in einen Flügel v. der doppelten Breite der Rückenriefen verbreitert.

b. Saum nur in den Thälchen an das Fruchtgehäuse angewachsen.

212 OSTERICUM. Riefen holl.

c. Same überall an das Fruchtgehäuse angewachsen. Blh. ganz, spitz od. zugespitzt.

211. MEUMr. Riefen geschärft, gleich.

212. ANGELICA. Die seitenst. Riefen einen Flügel v. der doppelten Breite der rückenst. bildend.

d. Same an das Fruchtgehäuse angewachsen. Blb. aufrecht, von d.

Mitte an in ein Läppchen v. der Länge des Blblattes eingeknickt.

199. SANICULA. Frucht mit hakigen Stacheln dicht-bedeckt. 
e. Same an das Fruchtgehäuse angewachsen. Blb. rundlich, ganz, eingerollt.

208. FOENICULUM. Läppchen fast 4 eckig, gestutzt.

f. Same an das Fruchtgehäuse angewachsen. BIb. rundlich, verkehrteyf. od. verkehrtherzf., mit einem einwärtsgebogenen

Läppchen.

212. GAYA. Riefen gefliigelt.

- aa. Thälchen striemenlos.

bb. Thälchen 1striemig. KRand unmerklich.

212. LEVISTICUM. Die seitenst. Flügel der Frucht noch einmal so breit als die rückenst. Riefen. Blb. rundlich, einwärtsgekrümmt, in ein Läppchen verschmälert.

212. SELINUM. Die seitenst. Flïgel der Frucht noch einmal so breit als die rückenst. Riefen. Blb. verkehrtherzf.

208. AETHUSA. Riefen dick, erhaben, scharf-gekielt, die seitenst. ein wenig breiter.

210. CNIDIUM. Riefen geflügelt, fast häutig, gleich.

cc. Thälchen 1striemig. KRand gezähnt.

207. OENANTHE. Gf. aufrecht. Fruchtträger angewachsen.

209. SESELI. Gf. zurïckgebogen. Fruchtträger frei. KZähne 3eckig. (Thälchen 1-3striemig.)

210. LIBANOTIS. Gf. zurückgebogen. Fruchtträger frei. KZähne pfriemlich, verlängert.

dd. Thälchen 3striemig. (Hierher gehören einige Arten von Seseli.)

212. CONIOSELINUM. Riefen geflügelt, die randst. Flügel noch einmal so breit als die rückenst.

211. ATHAMANTA. Riefen fast gleich. Gf. aufrecht.

211. TROCHISCANTHES. Riefen fast gleich. Gf. zurückgebogen. Blb. lang-benagelt, spatelig, mit einem kurzen, einwärtsgekrümm• ten Läppchen.

211. LIGUSTICUM. Riefen fast gleich. Gf. zurückgebogen. Blb. verkehrtherzf.

211. ISILAUS. Riefen fast gleicl. Gf. zurückgebogen. Blb. mit breiter Basis sitzend.

C. Eyweiss vorne flach od. convex. Hauptriefen fädlich; Nebenriefen fehlend. Frucht vom Rücken her flach- oder linsenf.-zsgedrüickt, mit einem geflügelten spitzen od. verdickten Rande umzogen.

a. Striemen in grosser Menge, das ganze Eyweiss dichtbedeckend.

213. FERULAGO. Die Rückenstriemen von dem Fruchtgehäuse bedeckt. 
b. Striemen oberflächlich, 1-2 in jedem Thälchen.

aa. Riefen sehr fein, die 3 riickenst. gleichweit-abstehend, die seitenst. entfernt, den verbreiterten Rand berührend od. von diesem bedeckt.

217. TORDYLIUM. Blb. verkehrtherzf. Striemen fädlich. Fruchtrand verdickt.

216. HERACLEUM. Blb. verkehrtherzf. Striemen keulig. Fruchtrand abgeflacht.

216. PASTINACA. BIb. eingerollt. Striemen fädlich.

bb. Riefen fädlich, gleichweit-abstehend.

215. ANETHUM. Blb. abgeschnitten, dicht-eingerollt.

215. IMPERATORIA. Blb. verkehrtherzf. KRand unmerklich.

213. PEUCEDANUM. BIb. verkehrtherzf. od. rundlich in ein Läppchen verengert, flach od. etras einwärtsgekrümmt. Die Fugenstriemen oberflächlich.

215. TOMMASINIA. Blb. eingerollt, das Uebrige, wie bei Peucedanum.

215. THYSSELINUM. Die Fugenstriemen vom Fruchtgehäuse bedeckt; sonst alles, wie bei Peucedanum.

D. Eyweiss vorne flach. Frucht vom Rücken her mehr od. weniger zsgedrickt. Hauptriefen 5 ; Nebenriefen 4.

217. SILER. Früchtchen mit erhabenen, fädlichen Riefen; die $4 \mathrm{Ne}$ benriefen weniger hervortretend.

217. LASERPITIUM. Früchtchen mit fädlichen Hauptriefen; die Nebenriefen geflügelt, die Flügel ungeth.

219. DAUCUS. Früchtchen mit fädlichen, borstigen Hauptriefen; Nebenriefen 1reihig-stachelig.

219. ORLAYA. Früchtchen mit fädlichen, borstigen Hauptriefen; Nebenriefen 2-3reihig-stachelig.

E. Fyweiss eingerollt od, vorne mit einer tiefen Furche eingeschnitten.

a. Früchtchen stachelig.

219. CAUCALIS. Friichtchen mit 4 stacheligen Riefen, Stacheln 13reihig.

220. TURGENIA. Früchtchen mit 7 stacheligen Riefen, Stacheln 23reihig.

220. TORILIS. Früchtchen auf dem Rücken dicht-stachelig, mit 3 dazwischen liegenden Reihen von Börstchen.

b. Früchtchen nicht stachelig, aber manchmal mit Börstchen tragenden Knötchen bestreut. Riefen plattgedrückt, stumpf, nicht gekerbt, bisweilen fehlend.

224. ECHINOPHORA. Riefen 5, plattgedriickt, wellig-gerillt. Frucht in dem hohlen Fruchtb. eingeschlossen, nur mit dem Sclınabel hervortretend. 
221. ANTHRISCUS. Früchtchen riefenlos; Sclnabel 5riefig.

221. SCANDIX. Friichtchen mit 5 stumpfen Riefen. Frucht sehr lang-geschnäbelt.

222. CHAEROPHYLLUM. Früchtchen mit 5 stumpfen Riefen. Frucht schnabellos. Gf. fädlich.

222. PHYSOCAULUS. Narbe auf der Spitze der kegelf. Stempelpolster sitzend, Gf. fast gänzl. fehlend, das Uebrige, wie bei Chaerophyllum.

c. Friichtchen nicht stachelig. Riefen spitz oder geflügelt, nicht gekerbt.

224. MALABAILA. Same am Rande eingerollt, frei in der Höhle des Fruchtgehäuses.

224. MYRRHIS. Same eingerollt. Riefen hohl.

223. BIASOLETTLA. Same an das Fruchtgehäuse angewachsen, vorne mit einer tiefen Furche eingesclnitten. Blb. vliteyf.

224. MOLOPOSPERMUM. Same an das Fruchtgehäuse angewachsen, 4seitig, auf der auf der Fuge liegenden Kante dch eine tiefe Furche eingeschnitten. Blb. lanzettl., lang-zugesp.

224. SMYRNIUM. Same an das Fruchtgehäuse angewachsen, eingerollt. Blb. lanzettl., zugespitzt.

d. Früchtchen nicht stachelig; Riefen erhaben, gekerbt.

224. CONIUM. Riefen 5, hervortretend, wellig-gekerbt, inwendig nicht hohl.

224. PLEUROSPERMUM. Riefen 5, hohl.

F. Eyweiss oder Same auf dem Rücken halbkugelig-convex, vorne concav.

225. CORIANDRUM. Frucht kugelig, mit 10 fädlichen Riefen, und eben so vielen dazwischen liegenden schlängelichen.

225. BIFORA. Frucht 2 knotig; Früchtch. kugelig-bauchig, mit eingedrückten, schwachen Rillen. Fuge mit 2 Oeffnungen.

Zur Digynia: Herniaria, Polycnemum. Zizyphus.

\section{DREIWEIBIGE, TRIGYNIA.}

\section{a. Bth. vollst., unterst.}

107. RHUS. K. 5th. Steinfrucht mit einer 1samigen Nuss.

104. STAPHYLEA. K. 5th. Kapseln $2-3$, aufgeblasen, an der Basis zsgewachsen. Samen knöchern.

179. TAMARIX. K. 5th. Gf. abstehend, in die Narben verbreitert. Kapsel 1fächerig. Samen mit einem sitzenden Schopfe.

181. CORRIGIOLA. K. 5th. Narben sitzend. Kapsel 1samig, nicht aufspringend.

181. TELEPHIUM. K. 5th. Gf. fädlich. Kapsel 3klappig, an der Basis 3fächerig. Samen mehrere.

76. DRYPIS. K. röhrig, 5zähnig. Kapsel ringsum aufspringend. 
b. Bth. vollst., oberst.

226. VIBURNUM. Bl. radf. od. röhrig. Beere 1samig.

226. SAMBUCUS. Bl. radf., zuletzt riickwärtsgebogen. Beere 3samig. Zur Triginia: Paliurus.

VIERWEIBIGE, TETRAGYNIA.

63. PARNASSIA. Nebenkrone 5blätterig, drüsig-fransig.

FUENFWEIBIGE, PENTAGYNIA.

162. SIBBALDLA. Fruchtkn. 5, frei. K. 10sp.

183. CRASSULA. Fruchtkn. 5, an d. Basis verwachsen. K. 5sp.

90. LINUM. Fruchtkn. 1, 10 fächerig.

63. DROSERA. Fruchtkn. 1, 1fächerig, mehreyig. K. 5sp.

410. STATICE. Fruchtkn. 1, 1eyig. K. mit einem trockenhäutigen Saüme.

Zur Pentagynia: Arten von Cerastium u. Spergula.

VIERIVEIBIGE, POLYGYNIA.

$\mathrm{Zu}$ dieser Ordnung: Myosurus.

VI. Cl. SECHSMAENNIGE, HEXANDRIA. EINWEIBIGE, MONOGYNLA.

I. Bth. vollst.

18. BERBERIS. K. 6blätterig, unterst.

179. PEPLIS. K. 12zähnig, unterst. Blb. schnell abfallend.

226. LORANTHUS. K.: ein etwas hervortretender oberständiger Rand.

II. Perig. blumenkronenartig, oberst.

480. STERNBERGIA. P. trichterf., mit 6th. Saume. Stbf. in die Spitze der Röhre eingefügt, gerade.

480. AGAVE. P. trichterf., mit 6th. Saume. Stbg. der Röhre des P. eingefügt, vor der Bthzeit einwärtsgekrümmt.

481. LEUCOJUM. P. glockig, bis zur Basis 6 th., mit gleichen Zpfln.

481. GALANTHUS. P. glockig, bis zur Basis 6th., die inneren $\mathrm{Zpfl}$. kürzer, ausgerandet.

480. NARCISSUS. P. tellerf. Stbg. nebst der glockigen Nebenkrone dem Schlunde eingefügt.

III. P. blumenkronenartig, 6zähnig oder 6sp., unterst.

494. HEMEROCALLIS. P. trichterf. Stbg. abwärtsgeneigt.

482. CONVALLARIA. P. glockig oder röhrig, halb-6sp. oder 6zähnig. Becrenfrucht.

495. ENDYMION. P. glockig, 6sp. Kapselfrucht.

495. MUSCARI. P. kugelig od. walzlich, an der Mündung verengert, mit einem schr kurzen, 6zähuigen Saume. 
IV. P. blumenkronenartig, 6blättrig, unterst.

A. Gf. an der Spitze 3sp.

481. ASPARAGUS. $P$. an der Basis in ein mit dem Bthstiele gegliedertes Stielchen zsgezogen.

484. FRITLLLARIA. B. des $P$. an der Basis mit einer Honiggrule versehen.

484. ERYTHRONIUM. Die 3 unteren B. des P. an der Basis 2schwielig.

495. BULBOCODIUM. B. des P. lang-benagelt; Nägel in eine Röhre zsneigend, an der Spitze durch seitenst. Zähne verbunden.

B. Gf. an der Spitze ungeth. oder fehlend. N. stumpf od. 3lappig.

a. Stbk. aufrecht, (mit ihrer Basis auf die Spitze des Stbf. gestellt).

482. STREPTOPUS. Die 3 äusseren B. des P. an der Basis sackartig-concav. Gf. fadenf. Beerenfrucht.

487. GAGEA. B. des P. an der Basis gleich. Gf. fadenf. Kapselfrucht.

483. TULIPA. B. des P. an der Basis gleich. Stbg. auf dem Fruclith. eingefügt. Gf. fehlend.

b. Stbk. aufliegend. B. des P. an der Basis mit einem

Honigbehälter versehen.

484. LILIUM. B. des P. an der Basis mit einer honigtragenden Längenfurche.

484. LLOYDIA. B. des P. an der Basis mit einer honigtragenden Querfalte.

c. Stbk. aufliegend. Honigbehälter fehlend. P. an der Basis in ein mit dem Bthstiel gegliedertes Stielchen zsgezogen.

484. ASPHODELUS. Fruchtkn. mit den an der Basis verbreiterten Stbg. bedeckt.

485. ANTHERICUM. Fruchtkn. nicht bedeckt; .Stbg. pfriemlich.

d. Stbk. aufliegend. Honigbehälter fehlend. P. an der Basis nicht in ein gegliedertes Stielchen zsgezogen.

489. ALLIUM. Dolde vor der Bthzeit mit einer Blumenscheide bedeckt.

495. NARTHECIUM. Blumenscheide fehlend. Stbf. bärtig. Gf. 3seitig.

485. PARADISIA. Bl.Scheide fehlend. Stbf. kahl, auf dem ein wenig erhabenen Fruchtb. eingefügt. Gf. 3seitig.

485. ORNITHOGALUM. Bl.Scheide fehlend. Stbf. dem Fruchtb. vor den PBlättern eingefügt. Gf. 3seitig.

488. SCLLLA. Bl.Scheide fehlend. Stbg. auf der Basis der Blb. eingefügt. Gf. 3seitig. 
V. kelchartig, (durchsichtig od. trockenhäutig). 496. JUNCUS. Gf. mit 3 fädlichen N. Kapsel vielsamig. 501. LUZUI,A. Gf. mit 3 fädlichen N. Kapsel 3samig. 466. ACORUS. Gf. fehlend. N. stumpf, sitzend.

Zur Monogynia: Elaeagnus. Lythrum Hyssopifolia.

\section{ZWEIWEIBIGE, DIGYNIA.}

426. OXYRIA. P. 4blättrig.

Zur Digynia: Celtis.

DREIWEIBIGE, TRIGYNIA.

a. P. 1 blättrig.

495. COLCHICUM. P. trichterf., mit verlängerter Röhre.

b. P. 6blättrig.

496. VERATRUM. Stbk. quer- in ein Schüsselchen aufspringend.

Fruchtkn. 3, in den Gf. verschmälert, an der Basis verwachsen.

496. TOFJELDIA. Stbk. der Länge nach aufspringend. Fruchtkn. 3 , in den Gf. verschmälert, bis zur Mitte verwachsen.

458. SCHEUCHZERIA. Fruchtkn. 3; Gf. fehlend; N. auf der Spitze des Fruchtkn. auswärts schief-aufgewachsen.

458. TRIGLOCHIN. Fruchtkn. 3-6, zuletzt v. der Basis an sich ablösend; Gf. fehlend; N. federig.

422. RUMEX. Fruchtkn. 1 ; Gf. 3 ; N. federig.

Zur Trigynia: Elatine hexandra.

SECHS-VIELWEIBIGE, HEXA-POLYGYNIA.

457. ALISMA. K. 3blätterig. Bl. 3blätterig.

Zur Hexagynia: Triglochin maritima.

VII. Cl. SIEBENMAENNIGE, HEPTANDRIA.

EINWEIBIGE, MONOGYNIA.

401. TRIENTALIS. K. $7 \mathrm{sp}$. Bl. 7 th. Stbg. der Bl. eingefügt.

97. AESCULUS. K. 5zähnig. Blb. 5, ungleich.

\section{Cl. ACHTMAENNIGE, OCTANDRIA. EINWEIBIGE, MONOGYNIA.}

A. Bth. vollständig, 5 blätterig.

97. ACER. K. 5th. Bl. 5blätterig. Frucht 2 flügelig.

B. Bth. vollständig, 4blätterig.

176. OENOTHERA. KSaum 4th. Blb. 4, dem K. eingefügt. S. nackt. 
173. EPILOBIUM. KSaum 4th. Blb. 4, dem K. eingefitigt. S. schopfig.

103. RUTA. K. 4 th., bleibend. Blb. 4, dem Fruchtb. eingefiigt. Honiggruben 8 , in die unterweibige Scheibe eingegraben.

C. Bth. vollständig, 1blätterig, unterst.

337. CHLORA. K. 8sp. Bl. tellerf., 8sp. Stbg. der Röhre der Bl. eingefügt.

335. DIOSPYROS. K. 4sp. Bl. 4sp. Bth. vielehig.

332. CALLUNA. K. 4 blätterig. Saum d. Bl. 4 sp. Scheidewände an das Samensäulchen angewachsen, den Nähten gegenst.

332. ERICA. K. 4blätterig. Saum der BI. 4sp. Scheidewände in der Mitte der Ǩlappen angewachsen.

D. Bth. vollständig, 1blätterig, oberst.

331. VACCINIUM. K. 4zähnig, oberst. Stbg. am Rande der oberweibigen Scheibe eingefügt.

E. Bth. unvollständig, unterst.

428. DAPHNE. P. mit 4sp. Saume, abfällig. Stbg. der Röhre eingefügt. N. 1.

428. PASSERINA. P. mit 4sp. Saume, bleibend, verwelkend. Stbg. der Röhre eingefügt. N. 1.

426. POLYGONUM. P. 3-5th., bleibend. N. 2-3.

Zur Monogynia: Monotropa.

\section{ZWEI-DREIWEIBIGE, DI-TRIGXNIA.}

198. CHRYSOSPLENIUM. P. 4sp., halb-oberst. Stbg. der oberweibigen Scheibe eingefügt. Kapsel vielsamig.

Zur Digyn.: Möhringia. Ulmus effusa. Arten v. Polygonum.

\section{VIERWEIBIGE, TETRAGYNTA.}

482. PARIS. K. 4blätterig. Blb. 4, schmäler als die KB.

226. ADOXA. K. an der endst. Bth. 2sp., an den seitenst. 3sp. Die endst. Bl. 4 sp., die seitenst. $5 \mathrm{sp}$.

89. ELATINE. K. 2-4sp. Bl. 3-4blätterig.

\section{Cl. NEUNMAENNIGE, ENNEANDRIA.}

\section{EINWEIBIGE, MONOGYNIA.}

429. LAURUS. P. 4th. Die seitenst. Bth. 9männig, die endst. 12 männig. Stbk. mit Klappen aufspringend.

\section{SECHSWEIBIGE, HEXAGYNIA.}

458. BUTOMUS. P. blumenkronenartig, 6blätterig. Kapseln 6, unterwärts zsgewachsen. 


\section{Cl. ZEHNMAENNIGE, DECANDRIA.}

\section{EINWEIBIGE, MONOGYNIA.}

\section{A. Bl. 5blätterig, selten 4 blätterig.}

104. DICTAMNUS. K. 5blätterig, abfällig. Fruchtkn. 5lappig, auf einem kurzen Fruchtträger sitzend.

103. TRIBULUS. K. 4-5blätterig, abfällig. Drüsen 2, an der Basis der, mit den Blb: abwechselnden Stbg.

334. MONOTROPA. K. 5blätterig. Blb. glockig-zsgestellt, an der Basis höckerig. Drüsen 5, unterweibig.

334. LEDUM. K. 5zähnig, bleibend. Stbg. am Rande der unterweibigen, gekerbten Scheibe eingefügt.

334. PYROLA. IK. 5 sp., bleibend. Unterweibe Driisen fehlend. Stbk. mit 2 Löchern aufspringend.

151. CERCIS. K. glockig. Bl. schmetterlingsf.

B. Bl. 1 blätterig.

333. RHODODENDRON. K. 5th. Bl. trichter- od. radf. Die Scheidewände aus den einwärtsgebogenen Klappenrändern gebildet.

332. ANDROMEDA. K. 5sp. Bl. glockig, eyf. od. fast kugelig. Die Scheidewände auf der Mitte der Klappen angeheftet.

331. ARBUTUS. Beere 4-5fächerig; Fächer 4-5samig; sonst alles, wie bei Andromeda.

331. ARCTOSTAPHYLOS. Steinfrucht 5steinig; Steine 1samig; sonst alles, wie bei Andromeda.

Zur Monogyn.: Ruta. Crysosplenium. Erodium. Geranium.

\section{ZWEIWEIBIGE, DIGYNIA.}

189. SAXIFRAGA. K. 5zähnig od. 5th. Kapsel 2schnäbelig, mit einem Loche aufspringend.

198. ZAHLBRUCKNERA. Die Blb. von derselben Substanz wie die KB.; das Uebrige wie bei Saxifraga.

65. GYPSOPHILA. K. 5zähnig, an der Basis nackt. Blb. aus dem Nagel allmählig verbreitert. Kapsel 4 klappig. S. nierenf.-kugelig.

66. TUNICA. K. 5zähnig, an der Basis mit Schuppen gestützt. Blb. aus dein Nagel allmählig verbreitert. Kapsel 4klappig. S. schildf.

66. DIANTHUS. K. 5zähnig, an der Basis mit Schuppen gestützt. Blb. plötzlich in den Nagel zsgezogen. Kapsel 4klappig. S. schildf.

70. SAPONARIA. K. 5zähnig, an der Basis nackt. Blb. plötzlich in den Nagel zsgezogen. Kapsel 4klappig. S. nierenf.-kugelig.

182. SCLERANTHUS. K. 5zähnig. Blb. fehlend. Hautfrucht 1samig, in dem Grunde des bleibenden $\mathbf{K}$.

Zur Digyn.: Mochringia. 


\title{
DREIWEIBIGE, TRIGYNIA.
}

\author{
A. K. 1blätterig.
}

70. CUCUBALUS. K. 5zälnnig. Blb. 5. Beere 1 fächerig.

70. SILENE. K. 5zälnig. Blb. 5. Kapsel an d. Basis 3fächerig.

B. K. 5blätterig, selten 4blätterig. Blb. 5, selten 4. Kapsel tief-gespalten od. auch nur an der Spitze gezähnt.

82. CHERLERIA. Blb. ungeth. od. fehlend. Zwei lineal.-verlängerte Drïsen an die Basis der äusseren Stbg. angewachsen sen. Kapsel 3klappig.

79. ALSINE. Blb. ungetl. od. seicht-ausgerandet. Die äusseren Stbg. an der Basis mit 2 kleinen Drüsen gestützt. S. nierenf., flïgellos. Kapsel 3klappig.

78. LEPIGONUMI. Blb. ungeth. Die äusseren Stbg. an d. Basis mit 2 kleinen Driisen gestützt. S. 3eckig od. rundl.-vkteyf., flïgellos od. gefliigelt. Kapsel 3klappig.

79. FACCHINIA. Blb. ungeth. Die äusseren Stbg. an der Basis mit 2 kleinen Drüsen gestïtzt. S. nierenf., mit einem Krauze spreuiger Haare bewimpert. Kiapsel 3klappig.

79. HALIANTHUS. Blb. ungeth. Die äusseren Stbg. an der Basis mit 2 eyf. Driisen gestützt. S. vkteyf, auf dem Riicken aufgetrieben-convex, auf der entgegengesetzten Seite mit einer längl. Grube versehen. Kapsel 3klappig.

82. MOEHRINGIA. Bl. ungeth. od. seicht-ausgerandet. Kapsel 46klappig. S. mit einem Anhängsel.

83. ARENARIA. Blb. ungeth. od. seicht-ausgerandet. Kapsel an der Spitze 6klappig. S. niereuf., ohne Anhängsel.

84. HOLOSTEUM. Blb. gezähnt. Kapsel an der Spitze 6klappig. Samen schildf.

84. STELLARIA. Blb. tief-ausgerandet od. 2th. Kapsel 6klappig.

\section{VIERWEIBIGE, TETRAGYNIA.}

85. MOENCHIA. K. 4blätterig. Blb. 4, ungeth. Kapsel 8klappig. $\mathrm{Zu}$ dieser Ordng.: Arten v. Sagina.

\section{FUENFWEIBIGE, PENTAGYNIA.}

76. SAGINA. K. 4-5blätterig. Blb. 4-5, ungeth. Kapsel 4-5klappig. S. nierenf., flügellos.

78. SPERGULA. K. 5blätterig. Blb. 5, ungeth. Kapsel 5klappig. S. kreisrund, mit einem Flügel umzogen.

86. MALACHIUM. K. 5blätterig. Blb. 5, 2sp. Kapsel 5klappig; Klappen 2sp.

86. CERASTIUM. K. 5blätterig. Blb. 5, ausgerandet od. 2sp. Kapsel an der Spitze 10klappig. 
102. OXALIS. K. 5blätterig. Blb. 5. Stbg. an der Basis zsgewachsen. Kapsel an den Kanten aufspringend.

183. SEDUM. K. 5th. Blb. 5. Fruchtkn. 5, an der Basis zsgewachsen.

188. UMBILICUS. K. 5th. B. 1 blätterig, 5sp. Fruchtkn. 5.

75. LYCHNIS. K. 5zähnig. Blb. 5. Kapsel 1. Narben einwärts mit Papillen besetzt, ausserdem kahl.

76. AGROSTEMMA. K. 5zähnig. Blb. 5. Kapsel 1. Narben einwärts mit Papillen u. überall mit Haaren besetzt.

$\mathrm{Z} u$ dieser Unterabtheilung: Moenchia.

ZEHNWEIBIGE, DECAGYNIA.

416. PHYTOLACCA. P. 5blätterig. Beere oberst.

\section{Cl. ZWOELFMAENNIGE, DODE- CANDRIA.}

\section{EINWEIBIGE, MONOGYNIA.}

432. ASARUM. P. 3sp., oberst.

181. PORTULACA. K. 2sp. Bl. 5blätterig.

179. LYTHRUM. K. röhrig, 8-12zähnig. Bl. 4-6blätterig.

ZWEIWEIBIGE, DIGYNIA.

163. AGRIMONIA. K. unter dem Saume mit zahlreichen, hakigen Dornen.

163. AREMONIA. K. unter dem Saume mit 5 Zälnnchen versehen, die sich bei der Reife verlängern $u$. in gerade, au den Saum angepasste Dornen verwandeln."

\section{DREIWEIBIGE, TRIGYNIA.}

62. RESEDA. Blb. unregelmässig. Kapsel an der Spitze offen.

'ZWOELFWEIBIGE, DODECAGYNIA.

186. SEMPERVIVUM. Blb. 6 od. 12 u. mehrere, mit der Basis der Stbg. in cine 1 blätterige Bl. zsgewachsen.

Zur Dodecandr.: Laurus.

XII. Cl. ZW ANZIGMAENNIGE, ICOSAN DRIA.

EINWEIBIGE, MONOGYNIA.

A. Bth. vollständig, oberst.

188. OPUNTIA. Blb, zahlreich. N. vielsp.

180. PHILADELPHUS. Blb。 4-5. Gf. 4sp. 


\section{XXXVII}

180. MYRTUS. Blb. 5. G. 1; N. einfach. KZpfl. in der Knospenlage dachig.

173. PUNICA. Blb. 5. Gf. 1; N. einfach. KZpfl. in der Knospenlage klappig.

B. Bth. vollständig, unterst.

151. AMYGDALUS. Steinfrucht saftlos, bei der Reife unregelmässigzerreissend.

151. PERSICA. Steinfrucht saftig, nicht aufspringend. Stein mit Furchen unregelmässig-dchzogen u. mit Löchern durchbohrt.

151. PRUNUS. Steinfrucht saftig, nicht aufspringend. Stein glatt od. unregelmässig mit Furchen dchzogen, aber ohne Löcher.

\section{ZWEI-FUENFWEIBIGE, DI-PENTAGYNIA.}

\section{A. Bth. vollständig, oberst.}

171. CRATAEGUS. Steinfrucht $1-5$ steinig, mit einer Scheibe, welche schmäler als die Steinfrucht ist, endigend. Steine in das Fleisch eingesenkt.

171. MESPILUS. Steinfrucht 5steinig, mit einer verbreiterten Scheibe, welche fast die Breite d. Steinfrucht hat, endigend. Steine in das Fleisch eingesenkt.

171. COTONEASTER. Steinfrucht3-5steinig. Steine an den fleischigen K. angewachsen, an der Spitze nackt und frei, unter sich zshängend, aber nicht in das Fleisch eingesenkt.

171. PYRUS. Kernfrucht 2-5fächerig; Fächer mit einer knorpeligen Haut bekleidet, 2samig.

171. CYDONIA. Kernfrucht 2-5fächerig; Fächer mit einer knorligen Haut bekleidet, vielsamig.

172. ARONLA. Die Fächer der Beere durch eine unvollständige Scheidewand $2 \mathrm{sp}$.

172. SORBUS. Die Fächer der Beere ungeth.

B. Bth. vollständig, unterst.

153. SPIRAEA. K. 5sp. Kapseln mehrere, 2-6samig.

C. Bth. unvollständig, unterständig.

170. POTERIUM. KSam 4theilig. Blb. o. Stbg. vor dem Ringe des K. eingesetzt. Fruchtkn. 2-3; der Gf. mit pinself. Narbe.

\section{VIELWEIBIGE, POLYGYNIA.}

A. K. 5-9sp., mit einreihigen $Z \mathrm{pfln}$.

163. ROSA. Nüsse sehr viele, von der KRöhre, welche zuletzt eine falsche Beere darstellt, eingeschlossen.

155. RUBUS. Steinfrüchte sehr viele, auf einem kegelf. Fruchtb. eingefügt, in eine falsche Beere zsgewachsen. 
154. DRYAS. Niisse sehr viele, auf einem halbkugeligen Fruchtb. eingefiigt, in einen bleibenden, federigen Gf. endigend.

B. K. 8-10sp., mit 2reihigen Zpfln., davon die äusseren anhängself.

154. GEUM. Niisse mit bleibenden Gf. begrannt.

156. FRAGARIA. Nüsse grannenlos, auf einem saftigen, meist abfälligen, Fruchtb. eingefügt.

156. COMARUM. Niisse grannenlos, auf einem fleischig-schwammigen, sich vergrössernden Fruchtb. eingefügt.

156. POTENTILLA. Niisse grannenlos, auf einem saftlosen Fruchtb. eingefügt. Blb. 5.

Zur Polygynia: Arten von Spiraea.

\section{Cl. VIELMAENNIGE, POLYANDRIA.} IEINWEIBIGE, MONOGYNIA.

A. Bl. vielblätterig.

20. CHELDONIUM. K. 2blätterig. Eychen an 2 zwischen den Klappen gelegenen Samenträgern angeheftet.

20. GLAUCIUM. K. 2blätterig. Eychen am Rande einer vollst. Scheidewand angeheftet.

19. PAPAVER. K. 2blätterig. Eychen an 4 od. mehrere unvollvollständige Scheidewände angeheftet.

55. CAPPARIS. K. 4blätterig. Stbk. aufliegend, drehbar.

17. ACTAEA. K. 4blätterig. Stbk. an die verbreiterte Spitze der Stbf. angewachsen.

B. B1. 5blätterig.

94. TILIA. KB. in der Knospenlage klappig.

55. CISTUS. Die 3 inneren KB. in der Knospenlage zsgerollt. Kapsel 5-10klappig.

55. HELIANTHEMUM. Die 3 inneren KB. in der Knospenlage zsgerollt. Kapsel 3klappig.

$$
\text { C. Bl. vielblätterig. }
$$

18. NYMPHAEA. Blb. ohne Honigbehälter.

19. NUPHAR. Blb. auf dem Rücken mit einem Honigbehälter.

$$
\text { ZWEI - VIELWEIBIGE, DI - POLYGYNIA. }
$$

A. Fruchtkn. melir - vieleyig. Kapsel einwärts aufspringend.

a. Bth. unregelmässig.

16. DELPHINIUN. K. blumenkronenartig, das obere KB. gespornt. 16. ACONITUM. K. blumenkronenartig, das obere KB. gewölbt. b. Bth. regelmässig, 4 blätterig.

17. CIMICIFUGA. K. nebst der Bl. hinfällig. 
c. Bth. regelmässig, 5-mehrblätterig. K. krautig. Blb. grösser als der K., flach.

17. PAEONLA. Blb. 5 od. mehrere, ohne Honigbehälter. d. Bth. regelmässig, 5-vielblätterig. K. blumenkronenf.

Blb. honigbehälterf. od. fehlend.

15. AQUILEGIA. Blb. trichterf, abwärts-gespornt.

15. NIGELLA. Platte der Blb. 2sp., an der Basis eine mit einer Schuppe bedeckte Honiggrube tragend.

14. TROLLIUS. Platte od. Blb. lineal., an der Basis eine entblösste Honiggrube tragend.

14. HELLEBORUS. Platte der BIb. röhrig. KB. bleibend.

14. ERANTHIS. Platte der Blb. röhrig. KB. abfällig. Fruchtkn. gestielt.

15. ISOPYRUM. Platte der Blb. an der Basis kappenf. KB. abfällig. Fruchtkn. oline Stiel.

14. CALTHA. Blb. fehlend.

B. Fruchtkn. 1 eyig. Früchtchen nussartig, nicht aufspringend.

a. K. in der Knospenlage dachig. Bl. 5-melirblätterig.

7. ADONIS. Blb. olne Honiggrube.

8. RANUNCULUS. Nagel der Blb. kürzer als die Platte, od. sehr kurz, mit einer Honiggrube rersehen. Fruchtkn. 1 fäch.

7. MYOSURUS. Nagel der Blb. fädlich, länger als die Platte, mit einer Honiggrube versehen. Fruchtkn. 1fächerig.

7. CERATOCEPHALUS. Nagel der Blb. mit einer Honiggrube versehen. Früchtch. mit 1 fruchtb. u. 2 unfruchtb. Fächern.

b. K. in der Knospenlage dachig, blumenkronenartig.

Bl. fehlend.

5. ANEMONE. Fruchtb. der Frucht vergrössert, kegel- oder halbkugelf.

2. THALICTRUMI. Fruchtb. der Frucht ein kleines Scheibchen darstellend.

c. K. in der Knospenlage klappig od. am Rande einwärtsgefaltet, blumenkronenartig.

1. CLEMATIS. Blb. fehlend.

2. ATRAGENE. Blb. sehr viele, kleiner als der $\mathrm{K}$.

\section{Cl. ZWEINAENNIGE, DIDYNAMIA. NACKTSAMIGE, GYMNOSPERMIA.}

Eigentlich Vierfrïchtige, nämlich Fruchtkn. 4, 1eyig. Gf. 1, aus der Mitte der Fruchtkn. hervortretend. Nïsse 4, od.

Steinfrüchte 4, in dem Grunde des $\mathbf{K}$.

I. Säckchen der Stbk. mit einer Kilappe aufspringend.

391. GALEOPSIS. Stbg. unter der Oberlippe gleichlaufeud, 
II. Stbk. nierenf., 1fächerig, mit einer halbkreisf. Spalte aufspringend, nach Ausstreuung des Btlistaubes eine kreisrunde, flache Scheibe darstellend.

381. OCYMUM. Obere Lippe der Bl. 4sp., untere ungeth.

381. LAVANDULA. Obere Lippe der Bl. 2sp., untere 3sp.

UI. Säckchen der Stbk. gerade, gleichlaufend od. auseinanderfahrend, jedes mit einer Längenspalte aufspringend od. mit den Spitzen aufeinanderstehend u. mit einer einzigen, den

beiden Säckchen gemeinschaftlichen Längenspalte aufspringend.

A. Röhre der Bl. inwendig, an der Finfügung der Stbg. mit einem unterbrochenen Ringe v. Haaren besetzt. Gf. nebst den Stbg. eingeschlossen.

395. MARRUBIUM. Nüsse an der flachen, 3eckigen Spitze abgeschnitten.

395. SIDERITIS. Nüsse an der Spitze abgerundet.

B. Röhre der Bl. inwendig, unterhalb der Einfügung der Stbg. mit einem ununterbrochenen Ringe v. Haaren besetzt. Der Gf. aus dem Schlund der Bl. hervortretend, auch bei eingeschlossenen Stbg.

a. Stbg. v. einander entfernt, unter der Oberlippe der Bl. bogig-zsneigend.

389. HORMINUM. K. 2lippig.

b. Stbg. genähert, unter der Oberlippe gleichlaufend. K. 2lippig.

397. PRUNELLA. Der fruchttrag. K. zsgedrückt-geschlossen. 398. PRASIUM. Der fruchttrag. K. geöffnet.

c. Stbg. genähert, gleichlaufend. K. 5zähnig. Obere Lippe der, Bl. flach, sehr klein.

398. AJUGA. Obere Lippe der Bl. sehr kurz, 2lappig, untere 3sp., viel grösser.

d. Stbg. genähert, unter der Oberlippe gleichlaufend. K. 5zälnnig. Obere Lippe der Bl. gewölbt od. concav.

390. LAMIUM. Die scitenst. ${ }^{3} \mathrm{Zpfl}$. der unteren Lippe der Bl. sehr klein, zalnnf. od. fehlend.

391. GALEOBDOLON. Zpfl. der unteren Lippe der Bl. alle spitz.

393. STACHYS. Zpfl. der unteren Lippe der Bl. stumpf. Nüsse oberwärts abgerundet. Stbg. nach dem Verblïhen zsgedreht, auswärts gebogen.

396. BALLOTA. Zpfl. der unteren Lippe der Bl. stumpf. Nüsse oberwärts abgerundet. Stbg. nach dem Verblühen gerade. 
396. PHLOMIS. Zpf. der unteren Lippe der Bl. stumpf. Nüisse dch ein flaches, 3eckiges, berandetes Ende abgeschnitten od. an der Spitze gezähnt. Die Stbg. unter der angewachsenen Basis in ein Anhängsel auslaufend.

396. LEONURUS. Zpfl. der unteren Lippe der Bl. stumpf. Nüsse dch ein flaches, 3eckiges, berandetes Ende abgeschnitten., Stbg. an der Basis olne Anhängsel.

C. Röhre der Bl. inwendig nackt, nämlich ohne Haarring.

a. Stbg. genähert, gleichlaufend. Obere Lippe der Bl. fehlend od. eigentlich 2 th., aber die Zpfl. auf den Rand d. Unterlippe vorgeriickt.

398. TEUCRIUM. K. 5zähnig od. lippig.

b. Stbg. genähert, unter der Oberlippe gleichlaufend, diese flach, ausgerandet.

389. NEPETA. Untere Lippe der Bl. sehr concav. Stbk. nicht in ein Kreuz gestellt.

389. GLECHONA. Untere Lippe der Bl. flach. Stbk. in ein'Kreuz gestellt. K. walzlich, 5zähnig.

390. MELITTIS. Untere Lippe der Bl. flach. Stbk. in ein Kreuz gestellt. K. glockig, lappig.

c. Stbg. genähert, unter der Oberlippe gleichlaufend, diese concav od. gerrölbt.

397. SCUTELLARIA. K. 2lippig, Lippen ungeth.

390. DRACOCEPHALUM. K. 2lippig, Lippen gezähnt.

394. BETONICA. K. 5zälnnig. Nüsse an der Spitze zsgedrückt, abgerundet.

396. CHAITURUS. K. 5zähnig. Niisse dch ein flaches, 3eckiges berandetes Ende abgeschnitten.

d. Stbg. von einander entfernt, oberwärts auseinandertretend, aber gerade.

383. PULEGIUM. Säckchen der Stbk. gleichlaufend. BI. trichterf., 4sp., Zpfl. aufrecht-abstehend, der obere ungeth.

381. MENTHA. Säckchen der Stbk. gleichlaufend. Bl. trichterf., 4 sp., Zpfl. aufrecht-abstehend, der obere ausgerandet.

381. ELSHOLTIA. Säckchen der Stbk. auseinanderfahrend. Bl. fast gleich, 4sp., der obere Zpfl. gerade, etwas concav, ausgerandet, die unteren abstehend.

389. HYSSOPUS. Säckchen der Stbk. auseinanderfahrend. Obere Lippe der Bl. flach, 2sp., untere 3sp., der mittlere Zpfl. verkehrtherzf.

e. Stbg. von einander entfernt, unter der Oberlippe bogigzsneigend.

388. MELISSA. K. 2lippig, auf der oberen Seite flach. 
IV. Säckchen der Stbk. an ein 3eckiges Connectiv zu beiden Seiten angewachsen.

386. THYMUS. K. vollkommen-2lippig. Stbg. von einander entfernt, gerade, oberwärts auseinandertretend.

387. CALAMINTHA. K. vollkommen-2lippig. Stbg. v. einander entfernt, oberwärts bogig-zsneigend. Hïlle fehlend.

388. CLINOPODIUM. Hiille aus borstlichen Blättchen zsgesetzt, unter die Bth.Quirle gestellt; sonst alles wie bei Calamintha.

387. MICROMERIA. K. undeutlich-2lippig, 13-15rillig. Stbg. aufstrebend, gewöhnlich paarweise genähert.

386. SATUREJA. K. 5zähnig, 10rillig. Stby. v. einander entfernt, oberwärts hogig-zsneigend.

385. ORIGANUM. K. 5zähnig od. schief-gespalten, 10rillig. Stbg. v. einander entfernt, gerade, oberwärts auseinandertretend.

\section{BEDECKTSAMIGE, ANGIOSPERMIA.}

Eigentlich Einfrüchtige, nämlich nur eine einzelne Frucht auf dem Fruchtb.

I. Säckchen der Stbk, an der Basis mit einem Dörnchen versehen.

A. Fruchtkn. 1fächerig, vieleyig, mit wandst. Samenträgern.

373. LATHRAEA. Bl. nach dem Verblithen mit ihrer Basis abfällig. 368. OROBANCHE. Bl. nach dem Verblühen abfällig, mit Zurücklassung einer ringsum abgesprungenen Basis.

B. Fruchtkn. 2fächerig, 4-vieleyig, bei der Frucht 1-vielsamig.

\section{a. K. 5zähnig.}

374. TOZZIA. K. röhrig. Obere Lippe der Bl. 2sp., untere 3sp., Zpfl. fast gleich.

374. PEDICULARIS. K. oft anfgeblasen. Oberc Lippe der Bl. helmig, zsgedrückt.

b. K. 4zähnig.

378. RHINANTHUS. S. glatt mit einem kreisrunden Flügel umzogen, od. flügellos. K. aufgeblasen. Obere Lippe der Bl. zsgedrückt.

379. BARTSIA. S. auf der einen Seitc 3 flügelig, Flügel in die Quere gestreift.

379. TRIXAGO. S. rippig, Rippen flügellos. Kapsel in einen Schnabel verschmälert.

379. EUPIHASIA. S. rippig, Rippen flïgellos. Kapsel sehr stumpf, ganz od. ausgerandet.

374. MELAMPYRUM. S. glatt, fliigellos. K. röhrig. Obere Lippe der_B1. stumpf-gekiclt, am Rande zurückgeschlagen. 


\section{Stbk. grannenlos.}

A. Fruchtkn. 1fächerig; Samenträger frei, vieleyig.

368. LINDERNIA. Bl. 2lippig. K. 5sp.

368. LMIOSELLA. Bl. fast gleich. K. 5zähnig.

B. Fruchtkn. 2fächerig.

400. ACANTHUS. Bl. 1lippig.

357. SCROPHULARIA. Bl. 2lippig, fast kugelig. Stbk. auf die verbreiterte Spitze der Stbf. quer-aufgewachsen.

360. ANTIRRHINUM. Bl. 2lippig, an der Basis höckerig; Unterlippe mit einem höckerigen Gaumen. Kapsel mit Löchern aufspringend.

360. LINARIA. Bl. 2lippig, an der Basis gespornt; Unterlippe mit einem höckerigen Gaumen. Kapsel mit Klappeu aufspringend.

358. DIGITALIS. Bl. aus kurzer Röhre glockig od. röhrig-glockig; Saum schief, der obere $\mathrm{Zpfl}$. ansgerandet.

363. ANARRHINUM. Röhre der Bl. walzlich; Sanm flach, schief. Scheidewand der Kapsel einfach.

363. ERINUS. Die 2 oberen Zpfl. der trichterf. Bl. schmäler; Röhre an der Spitze schlank. Scheidewand aus den eingebogenen Klappeurändern gebildet.

C. Fruchtkı. 3fächerig.

228. LINNAEA. Bth. oberst.

D. Fruchtkn. 4fächerig; Fächer 1eyig.

400. VERBENA. K. 5sp. Frucht in 4 Nüsse zerfallend.

399. VITEX. K. 5zähnig, Nuss 4samig.

\section{Cl. VIERMAECHTIGE, TETRADYNANIA. SCHOETCHENFRUECHTIGE, SILICULOSA.}

Die Frucht im Verhältniss ihrer Länge breit u. kurz.

1. Das Schötchen gedunsen, hart u. nussartig, nicht aufspringend, manchmal durch Verschwinden der Scheidewaud

1 fächerig.

A. Schötchen aus einem einzigen Gelenke bestehend.

53. NESLIA. Schötchen kugelig, mit einem aufgesetzten Gf., 1fächerig, 1samig.

53. CALEPINA. Schötchen rundlich-cyf., kurzzugespitzt, 1fächerig, 1samig.

52. EUCLIDIUMr. Schötchen rundlich, iv den Gf. zugespitzt, mit 2 nebeneinander stehenden, 1samigen Fächern.

53. BUNIAS. Schötchen eyf. od. länglich, mit 2 übereinandergestellten oder 2 Paar uibereiuandergestellteu 1samigen Fächern.

53. MYAGRUM. Schötchen birnf., 3fächerig, die 2 oberen Fächer ngebeneinander-gestellt, leer. 
B. Schötchen 2gliederig, die Glieder bei der Reife sich quer trennend.

54. RAPISTRUM. Das untere Glied stielchenf., das obere eyf. od. rundlich. Nabelstrang sehr kurz.

54. CRANIBE. Das untere Glied stielchenf., das obere kugelig. Nabelstrang sehr lang.

54. CAKILE. Beide Gelenke des Schötchens 2schneidig, das obere dolchf.

II. Das Schötchen von der Seite zsgedrückt, mit einem hervorragenden od. gefliigelten Kiele der Klappen, oder v. der Seite flach-zsgedriickt.

A. Schötchen nicht aufspringend od. zuletzt in 2, die S. jedoch nicht ausstreuende, Klappen sich trennend.

53. ISATIS. Schötchen flach, 1samig; Scheidewand durchbohrt.

50. BISCUTELLA. Schötchen flach, an der Basis und Spitze ausgerandet, 2schildig, mit einem geflügelten Rande umzogen.

52. SENEBIERA. Schötchen von der Seite zsgedrïclst, od. fast 2 knotig, ohne geflïgelten Rand.

B. Schötchen aufspringend $u$. die S. ausstreuend.

a. Stbg. mit einem Anhängsel od. Flïgel.

49. TEESDALIA. Stbf. an d. Basis mit einem blblattf. Anhängsel. 52. AETHIONEMA. Die längeren Stbf. geflügelt, Flügel an der Spitze oft gezähnt.

b. Stbg. weder mit einem Anhängsel, noch Flïgel versehen.

50. LEPIDIUM. Fächer 1samig. Blb. gleich.

49. IBERIS. Fächer 1samig. Blb. strahlend.

48. THLASPI. Fächer 2-mehrsamig. Klappen, besonders an der Spitze geflügelt.

51. HUTCHINSLA. Fächer 2samig. Klappen flïgellos.

51. CAPSELLA. Fächer vielsamig. Klappen flügellos.

III. Schötchen fast kugelig, mit einer Scheidewand von der Breite des Schötchens selbst, oder das Schötchen vom Rücken her zsgedrïckt und gedunsen, oder vom Rïcken her flach zsgedrückt.

A. Schötchen nicht aufspringend.

43. PELTARIA. Stbf. zahnlos.

43. CLYPEOLA. Stbfäden mit einem Zahne versehen.

B. Schötchen aufspringend. Stbf. mit einem flügelf. Zahne od. an der Basis mit einer schwieligen Hervorragung.

40. ALYSSUM. Fächer 1-4eyig.

43. FARSETIA. Fäeher mit 6 od. mehreren Eychen. Klappen flach od. convex. 
40. VESICARIA. Fächer mit 6 od. mehreren Eychen. Klappen halb-kugelig-gedunsen.
C. Schötchen aufspringend. Stbf. zalnnlos.

47. CAMELINA. Schötchen birnf. Scheidewand nach Abspringen der Klappen des Gf. beraubt.

43. LUNARIA. Schötchen auf einem fädlichen, verlängerten Fruchtträger sitzend, flach-zsgedrückt. Nabelstränge an die Scheidewand angewachsen.

43. PETROCALLIS. Schötchen flach-zsgedrückt od. ein wenig convex. Fruchtträger fehlend. Fächer 2samig. Nabelstränge ganz an die Scheidewand angewachsen.

43. DRABA. Schötchen flach-zsgedrïckt od, ein wenig convex. Fïcher vieleyig. Nabelstränge frei.

43. LOBULARIA. Schötchen flach-zsgedrïickt. Fächer 1 samig.

48. SUBULARIA. Schötchen vom Rücken ein wenig zsgedriickt; Klappen in einen Kiel gefaltet, aber ohne Mittelnerven.

46. COCHLEARIA. Schötchen sehr gedunsen od. fast kugelig. Gf. auf der Scheidewand bleibend.

$\mathrm{Zu}$ den Silic.: Arten von Nasturtium.

\section{SCHOTENFRUECHTIGE, SILIQUOSA.}

Frucht schmal u. im Verhältniss ihrer Breite lang.

I. N. aus 2 aufrechten, aneinanderliegenden Plättchen gebildet.

32. HESPERIS. Plättchen der $\mathbf{N}$. auf dem Rücken nicht verdickt.

23. MATTHIOLA. Plättchen der N. auf dem Rüicken verdickt od. daselbst in ein Horn vorgezogen, od. der Gf. zu beiden Seiten mit einém Horn versehen.
II. N. stumpf od. ausgerandet, od. auch 2lappig, aber mit stumpfen Lappen.

A. Schote nicht aufspringend.

54. RAPHANUS. Schote walzlich od. perlenschnurf, nicht aufspringend, aber bei der Reife manchmal sich quer in Glieder trennend.

B. Schote in 2 Kklappen aufspringend.

a. Klappen nervenlos od. nur an der Basis mit einem schwachen Nerven versehen.

31. DENTARIA. S. in jedem Fache einreihig. KeimB. an Rande beiderseits zsgefaltet.

29. CARDAMINE. S. in jedem Fache 1reihig. KeimB. flach.

23. NASTURTIUM. S. in jedem Fache 2reihig od. unregelmässig gereihet. 
b. Klappen 1-3-5nervig, (bei einigen Arten von Arabis ist nur ein schwacher Nerve, aber es sind selır viele Längsrillchen vorhanden).

aa. Das Würzelchen auf der Seite der KeimB.

25. TURRITIS. S. in jedem der Fächer 2reihig.

23. CHEIRANTHUS. S. in jedem der Fächer 1reihig. N. 2sp., mit zurückgekriimmten Lappen.

25. BARBAREA. S. in jedem Fache einreihig. N. stumpf od. ausgerandet. Schote fast stiehund od. 4seitig.

25. ARABIS. S. in jedem Fache 1reihig. N. stumpf od. ansgerandet. Schote zsgedrüickt.

bb. Das Wüirzelchen auf dem Rücken der flaclien KeimB.

34. BRAYA. S. in jedem Fache 2reihig. Schote stielrund. Ruickennerve der Klappe fein.

37. SYRENIA. S. in jedem Fache 2reihig. Schote 4 seitig, die Kilappen einnervig.

35. ERYSIMUM. S. in jedem Fache einreihig. Schote 4 seitig, die Klappen einnervig.

34. HuGUENINLA. S. in jedem Fache 1reihig. Schote 2schneidig, die Klappen einnervig.

33. SISYMBRIUM. S. in jedem Fache 1reihig. Schote mit convexen, 3nervigen Klappen.

33. MALCOLMUA. S. in jedem Fache 1reihig. Schote stielrund, mit einer kegelf. N. endigend.

cc. Das Würzelchen auf dem Rücken der tief-rinnigen od. rinnig-gefalteten KeimB.

39. DIPLOTAXIS. S. in jedem Fache 2reihig, oval od. längl., ein wenig zsgedrückt.

40. ERUCA. S. in jedem Fache 2reihig, kugelig. Klappen einnervig.

39. ERUCASTRUM. S. in jedem Fache 1reihig, oval od. längl., ein wenig zsgedriickt.

38. BRASSICA. S. in jedem Fache 1reihig, kugelig. Klappen einnervig.

38. SINAPIS. S. in jedem Fache 1reihig, kugelig. Klappen 3od. 5nervig.

\section{Cl. EINBRUEDERIGE, MONADELPHIA. ZEHNMAENNIGE, DECANDRIA.}

180. MYRICAIRLA. Schopf der S. gestielt.

98. GERANIUM. Grannen der Klappen bei der Reife kreisf.-zurückgerollt. 
102. ERODIUM. Grannen der Klappen bei der Reife schraubenf.zsgedreht.

\section{VIELMAENNIGE, POLYANDRIA.}

94. ABUTILON. K. einfach.

94. LAVATERA. Der äussere K. 3sp.

93. ALTHAEA. Der äussere K. 6-9sp.

92. MALVA. Der äussere K. 3blätterig.

94. HIBISCUS. Der äussere K. vielblätterig.

Zur Monadelphia: Radiola. Linum. Arten von Lysimachia. Oxalis. Polygala. Spartium. Sarothamnus. Genista. Cytisus. Ülex. Lupinus. Ononis. Anthyilis. Galega.

\section{Cl. ZWEIBRUEDERIGE, DIADELPHIA.}

\section{SECHSMAENNIGE, HEXANDRIA.}

22. FUMARIA. Stbf. 2, jeder mit 3 Stbk. Fruchtkn. 1eyig.

20. CORYDALIS. Stbf. 2, jeder mit 3 Stbk. Fruchtkn. mehreyig.

ACHTMAENNIGE, OCTANDRIA.

63. POLYGALA. Stbf. 8, an der Basis in einen od. 2 Kürper verwachsen; Stbk. einfächcrig.

\section{ZEHNMAENNIGE, DECANDRIA.}

\section{Stbg. 1 brüderig.}

A. Flügel der Bl. an der Basis oberwärts zierlich runzeliggefaltet. K. deutlich lippig.

107. ULEX. K. bis an die Basis 2th.-lippig.

107. SPARTIUM. K. 1lippig, oberwärts gespalten; Lippe au der Spitze fein-gezähnelt.

107. SAROTHAMNUS. K. 2lippig. Schiffchen stumpf. Gf. kreisf.zs̀gerollt, oberwärts verbreitert, an der inneren Seite flach.

107. GENISTA. K. 2lippig. Schiffchen stumpf. Gf. aufstrebend. N. einwärts abschüssig.

109. CYTISUS. K. 2lippig. Schiffchen stumpf. Gf. aufstrebend. N. auswärts abschiissig.

112. LUPINUS. K. 2lippig. Schiffehen geschnäbelt-zugespitzt.

B. Flügel der Bl. nicht gefaltet. K. 5zähnig od. etwas

2 lippig.

113. ONONIS. K. 5sp., bleibend, der fruchttrag. offen.

114. ANTHYLLIS. K. 5zähnig, verwelkend, der fruchttrag. geschlossen. Stbf. oberwärts verbreitert.

132. GALEGA. K. 5zähnig, verwelkend, der fiuchttrag. offen. Stbf. priemlich. 
II. Stbg. 2brïderig. Hülse nicht in Glieder zerfallend. Gf. kahl.

A. Schiffchen geschnäbelt.

130. LOTUS. Hülse stielrund od. zsgedrückt, mit zsgédreheten Klappen aufspringend.

131. TETRAGONOLOBUS. Hülse 4flïgelig.

140. SECURIGERA. Hülse flach-zsgedriickt, mit verdickten Rändern, nicht aufspringend.

B. Schiffchen ungeschnäbelt, einfach-spitz od. stumpf.

a. Die Säule der Stbg. mehr od. weniger an die Blb. gewachsen.

121. TRIFOLIUM. Bl. verwelkend, bleibend.

b. Säule der Stbg. nicht an die Blb. gewachsen. Schiffchen 2 blätterig.

131. GLYCYRRHIZA. Hülse lederig, zsgedrückt.

c. Säule der Stbg. nicht an die Blb. gewachsen. Schiffch. 1blättr.

aa. Hülse der Länge nach mehr od. weniger 2 fächerig.

134. ASTRAGALUS. Schiffchen stumpf, ohne Stachelspitze.

133. OXYTROPIS. Schiffchen unter der stumpfen Spitze mit einer ' Stachelspitze.

bb. Hülse einfächerig, stark aufgeblasen.

132. PHACA. Hülse vielsamig. Samen rundl.

140. CICER. Hülse 2samig. Samen runzl., spitz. cc. Hülse 1fächerig, nicht aufgeblasen.

130. DORYCNIUM. Fliigel in die Quere wie eine Blase hervorgetrieben.

130. BONJEANIA. Flügel gleichf.-convex, mit einem vorne berandeten Eindruck der Länge nach versehen.

120. MLLILOTUS. Flïgel gleichf.-convex, olne Eindruck. Fruchtkn. gerade. Hiilse kurz, $1-3$ samig.

119. TRIGONELLA. Flügel gleichf.-convex, ohne Eindruck. Fruchtkn. gerade. Hülse lineal., vielsamig.

114. MEDICAGO. Fliigel gleichf-convex, olne Eindruck. Fruchtkn. aufwärtsgekrümmt, an d. Fahne anliegend. Hülse gewunden.

140. ONOBRYCHIS. Hülse knöchern, vkteyf., auf der unteren Naht flügelartig-bekiclt, wehrlos od. kämmig-gezälnnt, 1samig.

III. Stbg. 2brüderig. Hülse nicht in Glieder zerfallend. Gf. behaart.

A. Gf. auf der oberen (inneren) Seite behaart.

145. ERVUM. Ist aus Arten v. Lathyrus $u$. Vicia zsgesetzt.

147. LATHYRUS. Gf. oberseits flach, v. gleicher Breite oder nach 
oben verbreitert, gerade od. mit einwärts-gekrümmter Spitze endigend. Wickelranken meistens vorhanden.

149. OROBUS. Wickelranken an d. Spitze der B. fehlend; sonst alles wie bei Lathyrus.

146. PISUM. Gf. 3kantig und v. der Seite her zsgedrückt, an der Basis oberseits gekielt, unterseits rinnig.

B. Gf. v. der Basis an gewimpert.

132. COLUTEA. Gf. halbstielrund, von der Basis an gewimpert, an der Spitze hakig. $N$. in der Biegung des Hakens.

C. Gf. durchaus flaumig od. unterhalb der Spitze auf der äusseren Seite bärtig.

141. VICIA. Gf. gerade aufstrebend.

150. PHASEOLUS. Gf. nebst den Stbg. u. dem Kiele schraubenf.gedreht.

IV. Hülse quer in Glieder zerfallend.

a. Schiffehen ungeschnäbelt.

140. HEDYSARUM. Stbg. pfriemlich.

139. ORNITHOPUS. Stbg. oberwärts verbreitert.

b. Schiffchen geschnäbelt.

139. HIPPOCREPIS. Hülse an der oberen Naht buchtig-ausgeschnitten u. lappig.

138. SCORPIURUS. Hülse schraubenf-zuriickgerollt, an den Gelenken zsgezogen.

138. CORONILLA. Hülse gerade od. gekrümmt, an den Gelenken zsgezogen.

\section{Cl. VIELBRUEDERIGE, POLYA- DELPHIA.}

95. ANDROSAEMUM. Frucht eine Beere. K. 5th. BIb. 5. 95. HYPERICUM. Frucht eine Kapsel. K. 4-5th. Blb. 4-5.

\section{Cl. VEREINTKOLBIGE, SYNGENESIA. GLEICHFOERMGE VIELEHE, POLYGAMIA AEQUALIS.}

Bth, alle zwitterig.

A. Zungenblüthige. Bth. alle zungenf.

I. Pappus aus federigen Strahlen gebildet.

1. Fruchtb. spreuig.

301. HYPOCHOERIS. Spreuen abfällig. 
2. Fruchtb. nackt u. kahl od. auf dem Rande der Beetchen fransig.

A. HK. einfach; Blättchen gleichlang $u$. gleichgestaltet.

298. UROSPERMUM. Federchen des Pappus frei.

298. TRAGOPOGON. Federchen des Pappus in einander gewebt.

B. HK. dachig od. aussenkelchig.

a. Die Federchen des Pappus verwebt.

299. SCORZONERA. Die an der Basis der Achene befindliche, den Nabel umgebende Schwiele sehr kurz.

300. PODOSPERMUM. Die an der Basis der Achene befindliche, den Nabel umgebende Schwiele verlängert, dicker als die Achene selbst.

b. Die Federchen des Pappus frei.

295. THRINCIA. Pappus der randst. Achenen kronenf.

297. PICRIS. Pappus gleichförmig, federig, hinfällig.

295. LEONTODON. Pappus gleichförmig, federig, bleibend. Achene nach oben allmählig verschmälert.

298. HELMINTHIA. Papp. gleichförmig, bleibend. Achene an der Spitze abgerundet-stumpf, mit einem fädlichen Schnabel.

II. Die Strahlen des Pappus sehr rauh, die äusseren haarfein, die innersten an der Basis verbreitert $u$. daselbst zottig.

301. GALASIA. Achenen schnabellos.

III. Pappus aus haar- od. borstenf. Strahlen gebildet.

A. Fruchtb. spreuig. Spreuen haarf.

306. PTEROTHECA Cass. Die randst. Achenen einwärts 3kielig oder 3 flügelig.

B. Fruchtb. nackt, kahl od. am Rande der Beetchen feinfransig od. deh hervortretende Ränder etwas wabig.

a. Papp. der Achenen am Rande kronenf., der im Mittelfelde spreuig od. borstig.

295. HYOSERIS. Die randst. Achenen u. die innersten des Mittelfeldes ziemlich stielrund; die dazwischen liegenden geflügeltzsgedrückt.

295. HEDYPNOIS. Alle Achenen ziemlich stielrund.

b. Papp. aller Achenen aus Spreuen od. Hachen Haaren gebildet.

294. CICHORIUM. Spreuen des Pappus kurz, lanzettl. od. längl. c. Pappus aller Achenen aus haarf. od. borstl. Strahlen gebildet.

aa. Achenen verschiedengestaltig.

305. ZACYNTHA. Achenen verschieden-gestaltet, die randst. auf 


\section{LI}

dem Rïcken sehr höckerig, von den Blättchen des wulstigen HK. dicht-umschlossen, mit einem seitenst. Pappus.

bb. Achenen gleichgestaltet-geschnäbelt; Schnabel an d. Basis mit Schuppen od. mit einem Ringe umgeben.

302. CHONDRILLA. Bth. 2reihig.

301. WILLEMETIA. Bth. vielreihig. Krönchen an der Basis des Schnabels feingekerbt.

301. TARAXACUM. Bth. vielreihig. Krönchen aus weichstacheligen . Schuppen gebildet.

cc. Achenen gleichgestaltet, geschnäbelt, aber ohne Schuppen od. Ring an der Basis des Schnabels, od. schnabellos.

1. Achenen stark zsgedrückt.

303. LACTUCA. Achenen in einen fädl. Schnabel zugespitzt.

304. MULGEDIUM. Achenen schnabellos od. in einen kurzen Schnabel zugespitzt. Pappus mit einem Krönchen von kurzen Borsten umgeben, steif $u$. zerbrechlich.

305. SONCHUS. Achenen schnabellos. Pappus auswendig ohne Krönchen, weich u. biegsam.

2. Achenen vierkantig.

305. PICRIDIUM. Achenen 4seitig, 4furchig, an den Kanten tiefgekerbt.

3. Achenen ziemlich cylindrisch od. stielrund.

303. PRENANTHES. Achenen schnabellos. Köpfchen $3-5$ bth.

306. CREPIS. Achenen schnabellos od. geschnäbelt. Köpfchen vielbth. Pappus weich, nicht zerbrechlich, Strahlen haarf.

310. SOYERIA. Achenen schnabellos. Köpfchen vielbth. Papp. nicht zerbrechl., Strahlen borstenf., an der Basis dicker.

311. HIERACIUM. Achenen schnabellos. Köpfchen vielbth. Pappus zerbrechl.

IV. Pappus fehlend od. aus einem Krönchen od. aus 2 Borsten gebildet.

a. Fruchtb. spreuig; Achenen v. der Spreue eingehüllt u. an dieselbe gewachsen.

294. SCOLYMUS. Statt des Pappus ein gekerbter Rand oder 2 Borsten.

b. Fruchtb. nackt.

294. RHAGADIOLUS. Der fruchttrag. HK. weit abstehend. Achenen ohne Pappus, die randst. eingerickelt u. bleibend.

294. ARNOSERIS. Der fruchttrag. HK. wulstig kugelig-zsschliessend. Achenen abfällig, 10riefig, mit abwechselnd mehr hervortretenden Riefen. Pappus ein 5kantiges, sehr kurzes Krönchen. 
294. LAPSANA. Der fruchttrag. HK. unverändert, die Blättchen aufrecht. Achenen abfällig, 20riefig, mit schwachem Rande endigend.

294. APOSERIS. Der fruchttrag. HK. unverändert. Achenen abfällig, 5riefig, mit schwachem Rande endigend.

B. Kopfblüthige. Bth. alle röhrig.

I. Fruchtb. nackt.

242. ADENOSTYLES. HK. einfach, mit schwachem Nebenkelch. Schenkel des Gf. fädlich, verlängert.

242. EUPATORIUM. HK. dachig. Schenkel des Gf. fädl. verlängert.

243. LINOSYRIS. HK. dachig. Schenkel des Gf. lanzettl.-verschmälert-spitz.

II. Fruchtb. tief-wabig.

285. ONOPORDUM. Papp. an der Basis in einen Ring verwachsen, abfällig.

III. Fruchtb. spreuig od. spreuig-borstig.

A. Strahlen des Pappus ästig, in einen Ring od. mehrere

büschelweise .zsgewachsen.

285. CARLINA. Strahlen des Pappus ästig; Aeste federig.

286. STAEHELINA. Strahlen des Pappus ästig; Aeste einfach, haarfein, fiederig-gestellt u. v. einander entfernt.

B. Strahlen des Pappus federig od. haarf., in einen Ring verwachsen u. mit diesem abfällig.

282. CARDUUS. Pappus haarig.

275. CIRSIUM. Pappus federig. Blättchen des HK. in einen Dorn od. eine Stachelspitze zugespitzt. Stbf. frei.

282. CYNARA. Pappus federig. Blättchen des HK. ausgerandet, mit einer Stachelspitze od. mit einem Dorne in der Ausrandung. Stbf. frei.

282. SILYBUM. Pappus federig. Stbf. 1briderig.

282. TYRIMNUS. Pappus haarig. Stbf. 1 brüderig.

C. Strahlen des Pappus haarf., an einen auf der Frucht befindl. Knopf angewachsen $u$. mit diesem zuletzt ron der Frucht getrennt.

288. JURINEA. Achene 4 kantig.

D. Strahlen des Pappus federig od. haarf, bleibend, nicht abfällig.

286. SAUSSUREA. Pappus federig.

287. SERRATULA. Pappus haarig, die innerste Reihe der Haare länger. Achene zsgedrïckt.

288. KENTROPHYLLUM. Pappus haarig, die innerste Reihe der Haare sehr kurz, zsneigend. Achene 4kantig. 
E. Pappus aus hinfälligen Börstchen gebildet.

285. LAPPA. Blättchen des HK. mit einer hakenf. Spitze endigend.

F. Pappus fehlend.

288. CARTHAMUS. Achenen ohne Pappus, 4kantig, Fruchtnabel seitenst.

Zur gleichf. Vielehe noch: Arten von Artemisia, Santolina, Helichrysum, Bidens ohne Strahlenbth., Arten v. Centaurea u. Serratula.

\section{UEBERFLUESSIGE VIELEHE, POLYGAMIA SUPERFLUA.}

Die randst. Bth. weiblich, zungenf. od. röhrig; die des Mittelfeldes zwitterig, fruchtbar, immer röhrig.

I. Pappus haarig. Fruchtb. nackt. Die randst. Bth. nicht zungenf., (bei Petasites ein wenig zungenf.).

A. HK. einfach, mit einem schwachen Aussenkelche.

242. HOMOGYNE. Die randst. Bth. weiblich, 1 reihig.

243. PETASITES. Die randst. Bth. weiblich, in den männlichen Köpfchen 1reihig, in den weiblichen mehrreihig.

B. HK. dachig; die äusseren Blättchen allmählig kürzer.

252. FILAGO. Blättchen des HK. krautig oder nur am Rande trockenhäutig.

254. HELICHRYSUM. HK. trockenhäutig. Weibliche Bth. 1reihig, wenige.

253. GNAPHALIUM. HK. trockenhäutig. Weibl. Bth. mehrreihig. Köpfchen bei einigen 2 häusig.

$\mathrm{Zu}$ dieser Unterabtheilung: Arten $v$. Inula, Senecio $u$. Cineraria.

II. Papp. haarig. Fruchtb. nackt. Die randst. Bth. zungenf.

A. HK. dachig; Blättchen vielreihig.

a. Stbk. geschwänzt.

251. PULICARIA. Papp, haarig, die äussere Haarreihe kurz, in ein Krönchen verwachsen.

248. INULA. Papp. haarig, gleichgestaltet.

b. Stbk. ungeschwänzt.

246. ERIGERON. Weibl. Bth. mehrreihig.

244. ASTER. Weibl. Bth. 1reihig. Die Randbtl. verschiedenfarbig, fruchtbar.

247. SOLIDAGO. Weibl. Bth. 1reihig. Die Randbth. gleichfarbig, fruchtbar.

B. HK. gleich, aus 1-3reihigen u. gleichlangen Blättchen gebildet od. die äusseren einen Aussenkelch bildend, 
a. Papp. verschiedengestaltet.

245. STENACTIS. Papp. der randst. Bth. einfach, in kurzen Börstchen bestehend; der des Mittelfeldes doppelt, der äussere aus kurzen Börstchen, der innere aus verlängerten Haaren gebildet.

b. Papp. gleichgestaltet, haarig, an den randst. Achenen manchmal fehlend. Weibl. Bth. 1reibig.

aa. HK. halbkugelig od. ziemlich flach.

245. BELLIDIASTRUM. Schenkel des Gf. verschmälert-spitz.

266. DORONICUM. Schenkel des Gf. kopfig, abgeschnitten. Die randist. Achenen ohne Pappus.

267. ARONICUM. Schenkel des Gf. kopfig, abgeschnitten. Alle Achenen mit Pappus.

bb. HK. walzlich.

269. LIGULARIA. Schenkel des Gf. fädlich, halbstielrund.

268. ARNICA. Schenkel des Gf. oberwärts verdickt, mit einer kegelf. Spitze endigend.

270. SENECIO. Schenkel des Gf. kopfig, abgeschnitten-stumpf. HK. mit einem Aussenkelche.

268. CINERARIA. Schenkel des Gf. kopfig, abgeschnitten-stumpf. HK. einfach. .

c. Papp. gleichgestaltet, haarig. Weibl. Bth. mehrreihig.

243. TUSSILAGO. HK. mit einem schwachen Aussenkelche.

III. Papp. nicht haarig. Fruchtb. nackt.
A. HK. aus 2reihigen, gleichlangen Blättchen gebildet.

245. BELLIS. Pappus fehlend.

B. HK. dachig, vielreihig.

a. Achenen geschnäbelt.

252. CARPESIUM. Randbth. mehrreihig.

b. Achenen schnabellos. Die randst. Bth. fädlich od. fehlend.

259. COTULA. Die Achenen am Rande des Köpfchens blattig-flach.

258. TANACETUM. Achenen kantig-gerillt, die oberweibige Scheibe v. der Breite der Achenen.

255. ARTEMISIA. Achenen verkehrteyf., flügellos, die oberweibige Scheibe klein.

c. Achenen schnabellos. Die randst. Bth. zungenf. od. glockigröhrig $u$. den Bthen des Mittelfeldes gleichgestaltet.

264. MATRICARLA. Achenen flügellos. Fruchtb. kegel-walzenf.

264. CHRYSANTHEMUM. Achenen flügellos. Fruchtkn. convex.

266. PINARDIA. Achenen des Randes 3flügelig; Flügel mit einer Stachelspitze endigend. 
IV. Papp. nicht haarig. Fruchtb. spreuig.

A. HK. 1reihig, einfach.

251. GALINSOGA. Papp. spreuig; Sprenen federig-fransig.

B. HK. vielreihig, dachig. Gf. an der Spitze verdickt, Schenkel kurz, eyf., aufrecht.

293. XERANTHEMUM. Papp. bleibend.

C. HK. vielreihig, dachig. Gf. an der Spitze nicht verdickt, Schenkel fädl.-zuriickgekrümmt.

a. Stbk. ungeschwänzt.

259. SANTOLINA. Bth. alle röhrig, Röhre 2flügelig, an der Basis von einer halbirten Haut ein abwärts gerichtetes Anhängsel.

259. ACHILLEA. Die randst. Bth. zungenf, mit rundlich-eyf. Saume, die des Mittelfeldes mit flach-zsgedrückter, 2flïgeliger Röhre.

262. ANTHEMIS. Die randst. Bth. zungenf., mit längl. Saume; die des Mittelfeldes wie bei Achillea. Achenen flïgellos.

264. ANACYCLUS. Die randst. Bth.zungenf., mit länglichem Saume; die des Mittelfeldes wie bei Achillea. Achenen geflügelt.

b. Stbk. geschwänzt.

248. PALLENIS. Achenen der randst. Bth. flach-zsgedrückt.

248. ASTERISCUS. Die randst. Achenen 3seitig. Die Bl. des Mittelfeldes an der Basis ihrer Röhre verdickt.

248. BUPHTHALMUM. Die randst. Achenen 3seitig. Bl. des Mittelfeldes an der Basis verschmälert.

247. TELEKIA. Alle Achenen stielrund, vielrillig.

FRUCHTLOSE VIELEHE, POLYGAMIA FRUSTRANEA.

Die randst. Bthen weiblich, aber durch Fehlschlagen des Gf. und der N. geschlechtslos, die des Mittelfeldes zwitterig und fruchtbar.

a. Fruchtb. spreuig-borstig.

288. CENTAUREA. Achenen mit einem seitenst. Nabel. Pappus haarig.

293. CRUPINA. Achenen mit einem endst. Nabel. Papp. haarig.

b. Fruchtb. spreuig, jede Bthe mit einem einzelnen Spreublättchen.

252. HELIANTHUS. Pappus aus 2 od. 4 abfälligen Schuppen bestehend.

251. BIDENS. 'Pappus aus 2 od. 4 bleibenden, rïckwärts stacheligen, starren Borsten.

$\mathrm{Zu}$ der fruchtlosen Vielehe: Galatella u. Arten $v$. Anthemis $u$. Anacyclus, auch Explare v. Tyrimnus $u$. Xeranthemum. 
NOTHWENDIGE VIELEHE, POLYGAMIA NECESSARIA

Die randst. Bth. weiblich u. fruchtbar, die des Mittelfeldes zwitterig, aber unfruchtb., u. keine S. tragend.

274. CALENDULA. HK. 2reihig; Blättchen gleichlang. Achenen verschieden gestaltet.

247. MICROPUS. HK. 1reihig, 5-9blättrig; Blättchen die 5-9 fruchtb. Bth. einwickelnd; männl. Bth. 5sp.

247. EVAX. HK. 1-2reihig; weibl. Bth. vielreihig, mit Spreublättchen geschieden; männl. 4sp.

Bei der nothwendigen Vielehe zu erwähnen: Tussilago, Carpesium.

\section{ABGESONDERTE VIELEHE, POLYGAMIA SE-} GREGATA.

Köpfchen 1-mehrblüthig, in einen gemeinschaftl. Kopf zsgestellt.

274. ECHINOPS. Köpfchen 1blüthig, in einen gemeinschaftl. kugeligen Kopf zsgestellt.

\section{Cl. WEIBERMAENNIGE, GYNANDRIA.}

\section{EINMAENNIGE, MONANDRIA.}

I. Stbk. ganz angewachsen.

A. Lippe gespornt.

a. Fruchtkn. gewunden. Fächer des Stbk. gleichlaufend, unterwärts aneinanderliegend.

466. ORCHIS. Fächer der Stbk. an der Basis dch ein 2 fächeriges Beutelchen verbunden. Stiele der Staubmassen auf 2 getrennten Haltern eingesetzt. Lippe abstehend, niclt gewunden.

470. ANACAMIPTIS. Fächer der Stbk. deh ein 1fächeriges Beutelchen verbunden. Stiele der Staubmassen anf einen gemeinschaftlichen Halter eingesetzt. Lippe abstehend, nicht gewunden.

470. HIMANTOGLOSSUM. Stbk. wie bei Anacamptis, aber die Lippe zusammengedrehet.

470. GYMNADENLA. Fächer des Stbk. an der Basis ohne Beutelchen. Lippe abstehend.

b. Fruchtkn. gewunden. Fächer des Stbk. unterwärts dch eine Bucht des ausgeschnittenen Schnäbelchens getrennt.

471. PLATANTHERA. Sporn lang, fädl.

470. PERISTYLUS. Sporn kurz, sackf.

c. Fruchtkn. nicht gewunden.

471. NIGRITELI.A. P. fast glockig, umgestürzt. 


\section{B. Lippe spornlos, 2 gliederig.}

473. SERAPIAS. Lippe 3lappig, der mittlere Lappen gekniet-zuriickgebrochen.

C. Lippe spornlos, ununterbrochen.

471. OPHRYS. P. abstehend. Beutelchen 2, getrennt.

472. CHAMLAEORCHIS. P. helmig. Beutelchen 2, getrennt.

472. ACERAS. P. helmig. Fächer des Stbl. an der Basis dch ein 1 fächeriges Beutelchen verbunden. Halter 1, gemeinschaftlich.

473. HERMINIUM. P. glockig; $Z \mathrm{pfl}$. u. Lippe aufrecht. Kein Beutelchen.

II. Stbk. frei.

A. Lippe gespornt.

473. EPIPOGIUM. Sporn aufgeblasen, aufrecht.

473. LIMODORUM. Sporn pfriemlich, hinabsteigend.

B. Lippe spornlos, 2 gliederig.

473. CEPHALANTHERA. Fruchtkn. stiellos, gewunden.

474. EPIPACTIS. Fruchtkn. gestielt, nicht gewunden.

C. Lippe spornlos, nicht gegliedert.

475. CORALLORRHIZA. Lippe an der Basis mit den seitenst. $Z$ pfln. des P. verbunden $u$. daselbst einen kurzen, angewachsenen Sporn darstellend.

475. STURMIA. P. abstehend. Säule der Stbk. verlängert, halbwalzenf. Stbk. endst., abfällig.

475. MALAXIS. P. ganz absteliend. Säule der Stbg. sebr kurz. Stbk. endst., bleibend. Innere Zpfl. des P. eyf.

476. MICROSTYLIS. P. ganz abstehend. Säule sehr kurz. Stbk. endst. bleibend. Innere $\mathrm{Z}$ pl. des $\mathrm{P}$. borstl.

475. NEOTTIA. P. glockig, fast helmig. Stbk. endst., sitzend, bleibend.

474. LISTERA. P. in einen Helm zsneigend. Befruchtungssäule hinten mit einem eyf. Fortsatze endigend, der den bleibenden Stbk. an der Basis oder Spitze trägt.

475. SPIRANTHES. P. rachig. Lippe eingeschlossen. Stbk. sitzend. 475. GOODYERA. P. rachig. Lippe eingeschlossen. Stbk. gestielt.

\section{ZWEIMAENNIGE, DIANDRIA.}

476. CYPRIPEDIUM. Lippe bauchig-aufgeblasen.

\section{SECHSMLENNIGE, HEXANDRIA.}

431. ARISTOLOCHIA. P. blumenartig, röhrig, an der Spitze in eine $\mathrm{Zunge}$ verbreitert. 


\section{Cl. EINHAEUSIGE, MONOECIA.}

\section{EINMAENNIGE, MONANDRIA.}

432. EUPHORBIA. Eigenhülle glockig, 9-10zähnig; 4-5 Zähne v. einer fleischigen $u$. honigtragenden Scheibe bedeckt.

465. ARUM. Frucht eine Beere. Bl.Scheide kappenf. Kolben an der Spitze nackt.

466. CALLA. Frucht eine Beere. Bl.Scheide flach. Kolben überall v. Bthen bedeckt.

464. ZOSTERA. Früchte nussartig, unter ihrer Spitze an den lineal. Kolben angeheftet. Bl.Scheide in ein B. endigend.

464. NAJAS. Steinfrucht saftlos, 1samig. Bl.Scheide fehlend.

178. CALLITRICHE. Steinfrucht saftlos, in 4 Früchtchen sich trennend.

463. ZANICHELLIA. Früchtchen nussartig, mehrere gestielt.

\section{ZWEIMAENNIGE, DIANDRIA.}

455. PINUS. Frucht ein Zapfen mit holzig-erhärtenden Schuppen.

\section{DREIMAENNIGE, TRIANDRIA.}

465. TYPHA. Männliche und weibl. Aehre walzlich, männliche obenstehend. Fruchtkn. mit Borsten umgeben.

465. SPARGANIUM. Aehren kugelig, die männlichen die oberen. Bth. deh spreuige $u$. mehrblätterige $P$. getrennt.

510. CAREX. Balg 1klappig, einen zweiten inneren mit seinen Rändern zsgewachsenen, ein flaschenf. P. darstellenden, den Fruchtknoten einschliessenden Balg stïtzend. Das $P$. eine falsche Frucht bildend.

510. ELYNA. Aehrchen 2bth., mit einem DeckB. bedeckt; die untere Bth. männl., die obere weiblich. Balg 1klappig. Das flaschenf. P. fehlend.

510. KOBRESIA. Aehrchen mit einem DeckB. bedeckt; die unteren der Aehren weibl., 1balgig, 1bth., mit einem gestielten Ansatze zu einer zweiten Bth., der sich seltener zu eincr männl. Bth. entwickelt; die oberen männl., olıne Balg, aus 3, auf einem Sticlchen sitzenden Stbg. bestehend.

531. ZEA. Weibl. Bth. mit Scheiden eingehïllt. Karyopsen rundlich-nierenf., in dicht genäherten Reihen einer gemeinschaftl. Achse cingefügt.

439. FICUS. Bth. von einem fleischigen, an der Spitze benabelten, inwendig hohlen Fruchtb. eingeschlossen.

\section{VIERMAENNIGE, TETRANDRIA.}

a. Bth. vollst.

412. LITTORELLA. BI.Röhre der männl. Bth. walzlich, mit 4th. Saume. 
432. BUXUS. Männl. Bl. 2-, weibl.3-4blätterig. Kapsel 3schnäbelig.

b. Bth. unvollst. Männl. u. weibl. Bth. mit einem P.

421. EUROTIA. Weibl. P. krugf., an der Spitze 2zähnig.

438. URTICA. Weibl. P. 2th. N. sitzend, kopfig-pinself.

439. MORUS. Weibl. P. 4blätterig. N. 2, fädlich.

c. Bth. unvollst., in Kätzchen. Weibl. od. männl. P. fehlend od. nackter S.

454. CUPRESSUS. Weibch.: Eychen krugf. Männch.: Stbk. 4, 1fächerig an die Kätzchen-Schuppe gewachsen. S. nackt.

453. ALNUS. Männch.: P. 3, 4sp., auf dem Stielchen der Kätzchen-Schuppe sitzend. Weibch.: P. fehIend.

\section{FUENF-VIELMAENNIGE, PENTANDRIA-PO-} LYANDRIA.

a. Bth. vollst., nicht kätzehentragend.

177. MYRIOPHYLLUM. Männch.: Blb. 4, hinfällig. Weibch,: K. oberst., 4zähnig. Blb. sehr klein.

458. SAGITTARIA. K. 3th. BIb. 3. Weibch.: Früchtchen sehr viele, auf einem kugeligen Fruchtb. sitzend.

b. Bth. volist.; die männl. unrollst., in Kätzchen.

439. JUGLANS. Männch.: P. 2-6th. Weibch.: K. oberst., zähnig. Blb. 4, krautig.
c. Bth. unvollst., nicht in Kätzchen.

416. AMARANTHUS. P. 3-5blätterig. Kapsel ringsumaufspringend. 421. ATRIPLEX. Männch.: P. 5blätterig. Weibch.: P. 2sp. od. 2th. Hautfrucht. S. mit einer krustigen Samenhaut.

421. HALIMUS. Männch.: P. 5blätterig. Weibch.: P. 2sp. od. 2th. Hautfrucht. Samenhaut dünnhäutig.

422. THELIGONUM. P. 2sp. Männch.: Stbg. 12. Weibch.: Nuss, lederig.

178. CERATOPHYLLUM. Männch.: P. vielblätterig. Stbk. sitzend. Weibch.: Nuss mit einem Dorn endigend.

324. XANTHIUM. Männch.: Hülle vielblätterig. P. 5zähnig. Weibch.: Hülle 1 blätterig, 2fächerig, 2blüthig. Falsche Frucht aus der erhärteten Hülle gebildet.

d. Bth., unvollst. die männl. in Kätzchen. Stbg. auf einem $P$. eingefügt.

439. FAGUS. Weibl. Hülle 4sp., 2bth., bleibend. Männl. Kätzchen kugelig.

440. CASTANEA. Weibl. Hülle 4sp., 2-3bth., bleibend. Männl. Kätzchen verlängert; Bth. geknäuelt. 
440. QUERCUS. Weibl. Hülle 1bth., ungeth., bei der Reife sich in ein, dle Frucht unterwärts umgebendes Becherchen verwandelnd, bleibend.

e. Bth. unvollst., die männl. od. die männl. u. weibl. in Kätzchen. Die Stbg. auf den Kätzchen-Schuppen eingefügt.

440. CORYLUS. Nuss mit einer 2sp., eingeschnittenen, bleibenden Hiille umgeben.

441. CARPINUS. Nuss mit einer blattigen, halbirten Hülle umgeben, mit dem bleibenden K. gekrönt.

441. OSTRYA. Nuss v. einer krugf., kapselartigen, aufgeblasenen Hülle eingeschlossen.

452. BETULA. Nuss mit einem Flügel umzogen, bei der Reife mit den Kätzchen-Schuppen abfällig. Hülle fehlenđ.

\section{EINBRUEDERIGE, MONADELPHIA.}

431. CYTINUS. Männch.: Die Säule der Stbf. an der Spitze mit 8 angewachsenen Stbk. Weibch.: Fruchtkn. unterst.

\section{VIELBRUEDERIGE, POLYADELPHIA.}

Stbg. 5, davon 4 parweise zsgewachsen, das 5. frei. Stbk. frei od. zsgewachsen.

180. CUCURBITA. Männch.: Stbk. zsgewachsen. Weibch.: Beere berindet. S. mit einem gedunsenen Rande umzogen.

180. CUCUMIS. Männch.: Stbk. zsgewachsen. Weibch.: Beere berindet, vielsamig. S. mit einem spitzen Rande.

180. BRYONLA. Männch.: Stbk. frei. Weibch.: Beere 3-4samig. S. mit einem stumpfen, nicht gedunsenen Rande.

181. ECBALLION. Männch.: Stbk. frei. Weibch.: Beere vielsamig, sich am Bthstiel lostrennend und durch eine grundst. Oeffnung die S. elastisch herauswerfend. S. mit einem stumpfen, nicht gedunsenen Rande.

\section{Cl. ZWEIHAEUSIGE, DIOECIA.}

\section{ZWEIMAENNIGE, DIANDRIA.}

441. SALIX. Kätzchen aus DeckB. gebildet. P. fehlend. Drüsen 1 od. 2, an der Basis der Geschlechtsorgane.

\section{DREIMAENNIGE, TRIANDRIA.}

457. VALLISNERIA. P. oberst., 3th. Gf. o. N. 3, 2sp. Fruchtkn. 1 fächerig, vieleyig. Eychen wandst.

431. OSYRIS. P. obcrst., 3sp. Gf. 1. N. 3sp. Fruchtkn. 1fächerig, 1 eyig.

432. EMIETRUM. K. 3blätterig. Bl. 3blätterig. Weibl. Bth. unterst. 
457. UDORA. K. 3th. Bl. 3blätterig. Weibl. Bth, oberst. Gf, fadenf. N. 3.

\section{VIERMAENNIGE, TETRANDRIA.}

431. HIPPOPHÄ̈. Männch.: P. 2th. Weibch.: P. röhrig, an der Spitze 2sp. N. 1, verlängert.

225. VISCUM. BI. 4th. Männch.: K. fehlend. Stbk. auf die BIb. aufgewachsen. Weibch.: K. in einem oberst. Rande bestehend. Gf. fehlend. N. stumpf, sitzend.

420. SPINACLA. Männch.: P. 4th. Weibch.: P. 2-3sp. Gf. 4.

453. MYRICA. Bth. in Kätzchen. Männch.: Stbg. 4, auf d. Basis der Kätzchenschuppe eingefügt. P. fehlend. Weibclı.: P. aus 4 Schüppchen gebildet.

\section{FUENFMAENNIGE, PENTANDRIA.}

439. CANNABIS. Männch.: P. 5th. Weibch.: P. 1blätterig, auf der einen Seite der Länge nach gespalten.

439. HUMULUS. Männch.: P. 5th. Weibch.: P. schuppenf., innerhalb der Schuppen eines Zapfens.

106. PISTACIA. Männch.: P. 5sp. Weibch.: P. 3-4sp. N. 4. Steinfrucht.

454. JUNIPERUS. MännI. Bth. in Kätzchen. Stbk. an der Basis der Schuppen angewachsen, 1fächerig. Weibl. Bth.: nackte Eychen endst. zu 3. Falsche Beere aus drei fleischigen Schuppen.

453. TAXUS. Männl. Bth. in Kätzchen. Stbk. an schildf. Schuppen unterseits angewachsen, 1fächerig. Weibl. Bth.: nackte Eychen endst., einzeln. Falsche Beere aus dem vergrösserten Bthb.

\section{SECHSMAENNIGE, HEXANDRIA.}

483. SMILAX. P. 6th., unterst.

483. TAMUS. P. 6th., oberst.

\section{ACHTMAENNIGE, OCTANDRIA.}

451. POPULUS. P. ganz, der Kätzchen-Schuppe eingefügt. Fruchtkn. 1.

183. RHODIOLA. K. 4th. Männch.: Bl. 4blätterig. Weibch.: Bì. feblend, od. klein. Fruchtkn. 4.

NEUNMAENNIGE, ENNEANDRIA.

438. MERCURIALIS. P. 3th. Männch.: Stbk. 9-12. Weibch.: Gf. kurz; N. 2, verlängert. 
457. HYDROCHARIS. K. 3th., der des Weibchens oberst. Bl. 3blätterig.

\section{ZWOELFMAENNIGE, DODECANDRIA.}

457. STRATIOTES. K. 3th., der des Weibchens oberst. Bl. 3blätterig. NebenStbg. (unfruchtbare) 20-30; fruchtbare Stbg. bei dem Männchen 12.

\section{EINBRUEDERIGE, MONADELPHIA.}

453. EPHEDRA. Hülle 2sp., aus 2 zsgewachsenen Schuppen gebildet. Männch.: Stbg. an der Basis zsgewachsen, an der Spitze frei. Weibch.: Eychen krugf.

483. RUSCUS. P. bis zur Basis 6th. Stbf. in ein eyf. Röhrchen zsgewachsen, die 3 Stbk. auf ihrer Spitze tragend.

\section{Cl. VIELEHIGE, POLYGAMIA.}

Die Gattungen dieser Classe sind in die vorhergehenden Classen, welche der Zwitterblüthe entsprechen, vertheilt. 


\section{Tabellarische Uebersicht derjenigen Ordnungen des natürlichen Systems, welche zu unserer Flora gehören.}

\section{Cl. RINGFASERIGE PHANEROGAMISCHE GEFAESSPFLANZEN.}

I. Unterabtheilg. BLUETHEN VOLLSTAENDIG, VIELBLAETTERIG, UNTERSTAENDIG.

A. Fruchtkn. melrere, getrennt, jeder einen Gf. tragend; od. mehrere in eine lappige Frucht mehr od. weniger zsgewachsen, u. jeder Lappen einen Gf. tragend; od. ein einzelner Fruchtkn., mit einem einzigen seitenst. Samenträger.

18. B erberideen. KB. $3-6$, aussen oft mit Schuppen gestützt. Blb. unterweibig, den KB. gegenüber, mit einem Anhängsel inwendig an der Basis. Stbg. so viel als BIb. u. diesen gegenüber, Stbk. angewachsen, mit 2 Klappen aufspringend. Frucht beerenoder kapselartig, 1fächerig. Samen 1-3, im Boden des Faches auf einer Seite. Keim gerade in der Achse des Eyweisses.

1. Ranunculaceen. KB. 3-6, regelmässig oder unregelmässig, oft blumenartig. Blb. 4-15 in einer od. mehreren Reihen, bei mehreren Gattungen verkleinert $\mathfrak{u}$. nektarienartig, oder auch fehlend. Stbg. zahlreich. Stbl. angewachsen, Fächer mit Längsritzen aufspringend. Frucht nuss-, beeren- od. kapselartig. Keim klein, im Eyweisse eingeschlossen.

183. Crassulaceen. KB. an der Basis mehr od. weniger verbunden. Bl. regelmässig, 3-20blätterig, mit den Stbg. im Grunde des K. eingefügt, zuweilen 1 blätterig. Stbg. so viel als Blb., od. doppelt so viel. Die Fruchtkn. an der Basis mit einer unterweibigen Schuppe. Balgfrüchte einwärts aufspringend. Keim umgekehrt, in der Achse des Eyweisses. NebenB. fehlend.

153. Rosaceen. $K$. 4-5sp., mit einer die Röhre auskleidenden od. den Schlund umgebenden Scheibe. Blb. 5, kelchst., gleich. Stbg. $12 u$. mehrere, dem Kelche vor den Blb. eingefügt, in 
der Knospenlage einwärts-gekrümmt. Fruchtkn. 1-viele, 1fächerig. Eychen 2 od. mehrere. Keim umgekehrt, gerade. Gf. seitl. B. mit NebenB.

107. Papili o na ceen. K. zähnig od. lippig. Bl. unregelmässig, schmetterlingsf., tief unten im K. eingefügt, 5 blättcrig, die 2 unteren B. meist in eines, das Schiffchen, zsgewachsen. Stbg. 10, eines frei u. 9 zsgewachsen, od. alle zsgewachsen, vor den Blb. eingefügt. Fruchtkn. mit einem seitenst. Samenträger. S. eyweisslos. Keim auf die Ritze der Samenblätter zurückgelegt. B. mit NebenB.

151. Caesalpinieen. K. zähnig od. lippig. Bl. unregelmässig, schmetterlingsf. od. fast rosenartig tief unten im $K$. eingefügt, 5blätterig, Blb. frei. Stbg. frei, bei ausländ. auch zsgewachsen. Fruchtkn. mit einem seitenst. Samenträger. S. eyweisslos. Keim gerade.

B. Fruchtkn. einer, mit wandst., an den Rändern der Klappen gelegenen Samenträgern.

19. P а p a v race en. K. 2blätterig. Bl. 4blätterig, regelmässig od. 2 gegenst. Blb. grösser und seicht-3lappig. Stbg. unterweibig, 4, od. zahlreich, frei. Frucht 1fächerig, od. mit unvollst. Fächern. Samenträger zwischen den Klappen od. auf den Wänden d. Fächer. Keim selır klein, gerade, in der Basis des Eyweisses.

20. Fumariaceen. K. 2blätterig. Bl. 4blätterig, unregelmässig, 2lippig, gespornt. Stbg. unterweibig, 6, in zwei Bündel zsgewachsen. Fruchtkn. 1fäeherig, 1-melreyig. Samenträger zwischen den Klappen. Keim an der Basis des Eyweisses.

22. Cruciferen. K. 4blätterig. Bl. 4blätterig. Stbg. unterweibig, 6, viermächtig, die 4 längeren den Samenträgern, die 2 kürzeren den Klappen gegenüber. Fruchtkn. 2fächerig, 2-mehreyig, mit zwischenklappigen, an der Scheidewand anliegenden Samenträgern. S. eyweisslos. Keim gekrümmt.

55. Ca p parideen. K. 4blätterig. Bl. 4blätterig. Stbg. unterweibig, 6, viermächtig, od. zahlreich. Fruchtkn. 1fächerig. Samenträger 2, seitenst., zwisehenlklappig. S. eyweisslos. Keim gekrümmt.

18. Nympha e a ceen. K. 4-6blätterig. Bl. regelmässig, vielblätterig. Blb. zahlreich, allmählig in die Stbg. übergehend, unterweibig od. auf dem, den Fruchtkn. überziehenden Bthboden eingefügt. Fruchtkn. mehrfäeherig, Fäeher vieleyig, Eychen an den Wänden der Fächer. Keim ausserhalb des Lyweisses im bleibenden Keimsacke eingeschlossen.

62. Res ed a ce en. $K$. bleibend, 4-6th. Bl. unregelmässig. Stbg. 10-24, mit dem Fruchtkn. auf einem nach eiruer Seite in eine drüsige Scheibe verbreiterten Fruchtträger eingefügt. Fruchtkn. 1fächerig, an der Spitze offen, 3-6lappig, Lappen in einen kurzen kegelf. Gf. endigend, Samenträger 3-6, an den Nähten, vieleyig; od. 4-6 getrennte, an der Basis offene, $u$. daselbst 1-2eyige Frichtchen. 
C. Fruchtkn. einer. Samenträger wandst., auf der Mitte der Klappen.

57. Violarieen. K. 5blätterig. Bl. 5blätterig, bci den einheimischen unregelmässig. Sthg. 5 auf einer unterweibigen Scheibe; Stbk. dicht an dem Fruchtkn. anliegend, nach innen sich öffiend; Stbf. über die Stbk. verlängert. Fruchtkn. 1fächerig, dreiklappig, Samenträger in der Mitte der Klappen. Gf. 1, mit schräger Narbe. Keim gerade, aufrecht, in der Achse des Eyweisses.

63. Droseraceen. K. 5blätterig. Bl. 5blätterig, regelmässig. Stbg. 5, od. mehrere, unterweibig. Stbk. endständig. Fruchtkn. 13 fächerig. Samenträger wandst. Gf. melirere, od. mehrere Narben. Keim gerade, aufrecht, in der Achse des Eyweisses.

55. Cistineen. K. 5blätterig, die 3 inneren B. in der Knospenlage zsgedrehet. Blb. 5, hinfällig, in der Knospenlage zsgedrehet, aber in einer den KB. entgegengesetzten Richtung. Stbg. unterweibig, zahlreich. Gf. 1. Narbe einfach. Kapsel 1fächerig, die Klappen in der Mitte samentragend, od. durch halbirte Scheidewände 3-, seltener 6-10fächerig, die Scheidewände auf der Mitte der Klappen, die S. am inneren Rande dieser Scheidewände. Keim im Eyweisse.

179. T a mariscineen. K. 4-5theilig. Blb. 4-5, im Grunde des K. eingefügt, welkend. Stbg. unterweibig, so viel als Blb. od. doppelt so viel, getrennt od. 1 brüderig. Narben 3. Kapsel 1fücherig, 3klappig, vielsamig. S. geschopft, am Grunde od. längs der Mitte der Klappen. Keim gerade, aufrecht, eyweisslos.

D. Fruchtkn. einer, einfächerig od. unterwärts mehrfächerig. Der Samenträger in der Mitte der Frucht, frei od, an die unvollst. $Z_{w i-}$ schenwände angewachsen, aber doch oberwärts frei.

65. Sileneen. K. einblätterig, gezähnt. Blb. so viel als KZähne, mit den Stbg. auf einem mehr od. weniger bemerkl. Fruchtträger unter dem Fruchtkn. eingefügt. Stbg. noch einmal so viel als Blb. Gf. $2-5$, getrennt. Keim um das Eyweiss gekriimmt. B. gegenst., nebenblattlos.

76. Alsineen. K. 4-5blätterig, od. tief 4-5theilig. Blb. so viel als Theile des K. Stbg. 10, od. weniger, auf einem aus Drüsen gebildeten, mellr od. weniger kelchst. und mehr od. weriger deutl. Ringe eingefügt. Fruchtkn. 1fächerig, Samenträger mittelpunktst., frei. Gf. 2-5, getrennt. Keim um das Eyweiss gekrümmt. B. gegenst., nehenblattlos, (nur Spergula u. Lepigonum haben als Aus-
nahme trockenhäutige NebenB.).

181. Paronychieen. K. 5th., seltener 3-4theilig. Blb. so viel als $Z$ pfl. des K., 5, oft klein, u. Trägern ohne Kölbchen ähnlich, dem Kelche eingefügt. Staubg. so viel als $Z$ pfl. des K., mit den Blb. wechselnd, od. weniger, auf einer oft schwachen, unterweibigen Scheibe eingefïgt. Fruchtkn. 1fächerig, Eychen zahlreich, an 


\section{LXVI}

einem freien Mittelsäulchen, od. nur eines, an einer vom Grunde des Fruchtkn. entspringenden Nabelschnur aufgehängt. Gf. 2-3, getrennt od. unterwärts zsgewachsen. Keim an der Seite des Eyweisses. Neben B. trockenhäutig.

181. Portulaceen. K. $2-5$ sp. od. theilig, zuweilen unten an den Fruchtkn. angewachsen. Blb. $3-5-6$, getrennt od. in eine kurze Röhre zsgewachsen. Stbg. unsymmetrisch, so viel als Blb. od. weniger u. den Blb. od. Zpfln. gegenüber, od. zahlreich u. im Grunde des K. Kapsel 1fächerig, 3-vielsamig; die Samenträger mittelpunktst. Gt. 1 od. fehlend. Narben mehrere. Keim um das Eyweiss gekrümmt. NebenB. trockenhäutig od. fehlend.

151. Amygdaleen. K. 5zähnig, inwendig mit einer Honigscheibe überzogen. Blb. 5. Stbg. 20, so wie die $5 \mathrm{Blb}$. dem Rande der Röhre dts $K$. eingefïgt, in der Knospenlage einwärts-gekrümmt. Fruchtkn. 1fächerig, 2eyig. Eychøn hängend. Steinfrucht. Gf. 1. Narbe einfach. Keim gerade, eyweisslos. B. mit Neben B.

106. Terebinthaceen. K. einblätterig, gespalten, die $\mathrm{Zpfl}$. in der Knospenlage dachig. Blb. so viel als Zpfl. des K. Stbg. in bestimmter od. unbestimmter Zahl, vor piner in der Basis des K. befullichen, unterweibigen Scheibe eirgefügt u. frei, od. an der Basis zsyewachsen bei fehlender Scheibe. Der Fruchtkn. 1fächerig, eineyig, oberst. Frucht nicht aufspringend. Keim eyweisslos. Neben B. fehlend.

E. Fruchtkn. einer, mehrfächerig. K. in der Knospenlage klappig.

105. Rhamneen. K. an den Fruchtkn. angewachsen, Saum $4-5$ sp., in der Knospenlage klappig, abfällig. Blb. mit d. Zpfln. des $\mathrm{K}$. wechselnd, im Schlunde eingefügt. Stbg. so viel als Blb., und diese gegenst. Fruchtkn. von einer drüsigen Scheibe umzogen, 2-4fächerig, Fächer eineyig. Gf. 1. Narben 2-4. Keim aufrecht, im Eyweisse. B. mit kleinen NebenB.

179. L y thrari e en. K. bleibend, gezähnt, Zähne in d. Knospenlage klappig od. auseinander-stehend, die Buchten zuweilen in äussere Zähne hervortretend. Blb. am oberen Ende des K., die Stbg. in die Rölure eingesetzt. Fruchtkn. frei, 2-4fächerig, vieleyig. Samenträger mittelpunktst. Gf. 1. Narbe einfach. Kapsel liäutig. S. eyweisslos. Keim gerade. NebenB. fehlend.

94. Tiliaceen. K. 4-5blätterig, in der Knospenlage klappig. Blb. so viel als B. des K., u. mit diesen abwechselnd. Stbg. urterweibig, zahlreich, frei od. vielbrüderig; Stbk. 2fächerig, mit Längsritzen aufspringend. Fruchtkn. 4-10fächerig, Fächer 2-mehreyig. S. mittelpunktst. Keim gerade, in der Achse des Eyweisses. B. mit NebenB.

92. Malvaceen. K. $3-4-5$ sp., Zpfl. in der Knospenlage klappig, oft ein äusserer K., mehrfach geth. od. aus gesonderten B. gebildet. Blb. so viel als ZpH. des inneren K., mit diesen abwechselnd, 
in der Knospenlage schraubenf.-zsgedrehet. Sthf. unterweibig, an die BIb. angeheftet, in eine Röhre zsgewachsen; Stbk. 1 fächerig, mil einer Querritze aufspringend, Fruchtkn. mehr- und vielficherig, bistveilen gelappt; Fächer 1-mehreyig. Samenträger mittelpunktst. Eyweis fehlend od. wenig. Keim mit gefalteten Keimblättern.

F. Fruchtkn. einer, mehrfächerig. K. in der Knnospenlage dachig. Unterweibige Drüsen od. Scheibe fehlend.

98. Geraniaceen. K. 5blätterig, bleibend. Bib. 5. Stbg. unterweibig, noch einmal so viel als Blb., an der Basis meist einbrüderig. Um die Basis der in tinen Schnabel verlängerten Achse 5, gedunsene, 2eyige Fächer; die Gf. an die Achse angelehnt, am Ende des Schnabels in 5 Narben iibergehend. Die Fächer bei der Reife 1samig. Die Klappen mit dem Gf. $v$. der Basis bis zur spitze v. der Achse abspringend, mit zirkelf. od. schraubenf.-zsgerolltem Gf. Eyweiss fehlend. Keim gekrümmt, mit gerollten oder gefalteten Keimblättern.

90. Lineen. K. 4-5blätterig, bleibend. Blb. unterweibig, 4-5, in der Knospenlage zsgerollt. Stbg. $4-5$, mit den Blb. Wechselnd, an der Basis in einen Ring zsgewachsen, mit $4-5$ dazwischengestellten, verkümmerten, zahnf. Stbg. Fruchthn. dch vollstärdige, aus einer doppelten Haut gebildete, und eben so viele unvollst. Scheidewände 810 fächerig; Fächer eineyig; Eychen hängend. Samenträger mittelpunktst. Gf. $4-5$. S. eyweisslos. Keim gerade. NebenB. fehlend.

102. Oxalideen. K. 5th., bleibend. Blb. regelmässig, 5, unterweibig, bisweilen mit der Basis zshängend, in der Knospenlage zsgerollt. Stbg. 10, an der Basis oft 1 brüderig. Gf. 5. Kapsel 5- od. $10 \mathrm{klappig}, 5$ fächerig, Fächer mehreyig. Samenträger mittelpunktst. $S$. mit eirem fleischigen, elastisch-aufspringenden Mantel. Keim im Eyweisse.

102. B als amine en. K. u. Bl. unregelmässig, ahfällig, das untere KB. gespornt. Stbg. 5, unterweibig, oberwärts mehr oder weniger zshängend. Fruchtkn. 5fächerig, vielsamig. Narbe sitzend, Gf. fehlend. Kapsel 5klappig, elastisch aufspringend. Eyweiss fehlend. Keim gerade.

95. Hypericineen. K. 4-5th., bleibend. Bl. regelmässig, Blb. 4, 5, in der Knospenlage zsgerollt. Stbg. vielbrïderig, in $2-3$ Bündel zsgewachsen, unterweibig. Fruchtkn. vieleyig, mehr-fächerig, die Eychen im innern Winkel der Fächer, od. dch verkürzte Scheidewände 1fächerig, die Eychen am Rande der Klappen. Kapsel od. Beere. S. eyweisslos. B. oft durchscheinend punktirt.

89. Elatineen. K. $3-5 \mathrm{sp}$. od. theilig. Blb. eben so viel, unterweibig, Stbg. eben so vicl od. doppelt so viel, unterweibig. Fruchtkn. 3-4-5fächerig, Fächer mehreyig. Gf. so viel als Fächer. Kapsel klappig-aufspringend, die Scheidewände mit der Achse verbunden. S. eyweisslos. NebenB. fehlend. 


\section{LXVIII}

334. Pyrolaceen. K. 5sp., bleibend. Blb. 5, regelmässig. Stbg. frei, unterweibig, 10. Fruchtkn. 4-5fächerig, vieleyig. Gf. 1 . Kapsel mit Ritzen fachspaltig-aufspringend, die Scheidewände mit den Klappen u. der Achse verbunden. S. klein, geflügelt, eiweisshaltig.

432. Empetreen. Bth. eingeschlechtig. K. 3blätterig. Blb. 3, unterweibig, bleibend, aber vertrocknend. Stbg. 3, nach dem Abfalle der Stbk. bleibend. Fruchtkn. 3-6-9fächerig, Fächer 1 eyig. Gf. kurz, od. fehlend. $N$. strallig-gelappt. Steinfrucht mit 3-6-9 Steinen.

G. Fruchtkn. einer, mehrfacherig, auf einer unterweibigen Scheibe sitzend, od. v. unterweibigen Drïsen umgeben. K. in der Knospenlage dachig.

97. A c erineen. K. tief-gespalten, an der Basis mit einer drüsigen Scheibe bedeckt. Blb. 4-5-9, am Rande der Scheibe. Stbg. 8, selten 5-15. Fruchthn. 2-3flügelig, 2-3fächerig, Fächer 2eyig. Gf. 1. N. 2. Frucht in 2-3 geflügelte Nüsse zerfallend. Eyweiss fehlend. Keim gekrümmt. KeimB. zsgerollt. B. gegenst., ohne NebenB.

97. Hippoca stan e n. K. einblätterig, 5zähnig, Bl. unregelmässig, 4blälterig, B. lang-benagelt, unter einer unterweibigen Scheibe. Stbg. 7-8, auf der Scheibe eingefügt, ungleich. Fruchtkn. 3fächerig; Fücher 2eyig; Eychen aufrecht. S. mit einem breiten Nabel, eyweisslos. Keim gekrümmt, KeimB. zsgewachsen, mit einer Spalte an der Basis, aus welcher das Federchen heraustritt. B. gengenst., ohne NebenB.

98. Ampelideen. K. ganz od. am Rande 4-5zähnig. Blb. 45 , vor einer drüsigen Scheibe eingefïgt, in der Knospenlage klappig. Stbg. so viel als Blb. u. vor diese gestellt. Fruchtkn. 2fächerig, Fächer 2 eyig. Gf. 1. Narbe kopfig. Beere.

104. Celastrineen. K. 4-5sp., an seiner Basis mit einer unterveibigen Scheibe ausgekleidet. Blb. 4-5. Stbg. eben so viel, mit dert Bih. abwechselnd $u$. mit diesen am Rande der Scheibe eingefügt. Fruchtkn. 2-4fächerig. Fächer 1-mehreyig. Keim gerade, aufrecht.

103. Zyg ophylle en. K. 4-5th. Blb. eben so viel, mit den $\mathrm{Zpfin}$. des IK. wechselnd. Stbg. unterweibig, doppelt so viel als Blb. Fruclitkı. an d. Basis von Drüsen od. einer buclutigen Scheibe umgeben, 4-5fächerig. Gf. 1. B. gegenst., Neben B. bleibend.

103. Rutaceen. K. 4-5th. Blb. eben so viel, mit den KZipfeln wechselnd, od. doppelt so viel. Stbg. auf einer unterweibigen Scheibe eingefügt. Fruchtkn. 3-5lappig. B. wechselst., dchscheinend-punktirt, olune Neheri $B$.

334. Monotropeen. nend, bleibend. Stbg. noch einmal so viel als Blb., bei der einheimischen Art 5 in die Bucht $\mathrm{v}$. ausgerandeten, unterweibigen Drüsen, $5 \mathrm{zw}$. die Drüsen gestellt. Blattlose, nicht grüne Pfl., statt der $B$. mit schuppen bekleidet. 


\section{Unterabtheilung. BLUETHEN VOLLST., VIEL- BLAETTERIG, OBERSTAENDIG.}

A. Fruchtkn. 1fächerig. Frucht saftig.

188. Cacteen. K. an den Fruchtkn. angewachsen, $Z$ nfl. $z a h l$ reich, an der Spitze frei, mehrreihig, allmählig in eine vielhlätterige, dem Kelche eingefügte $B l$. ütırgeherid. Stbg. zahlreich. Gf. 1. Fruchtkn. 1 fächerig, vieleyig; Samenträger wandst. Beere.

188. Grossularieen. Der oberst. Saum des K. 4-5sp. Blb. 4-5, am Rande des Schlundes eingefïgt. Stbg. 4-5, mit den Blb. abwechselnd. Fruchtlin. 1fächerig, vieleyig. Samenträger 2, wand-u. gegenst. Gf. 2-4sp. Beere.

225. Loranthace en. K. oberst. aus kleinen Zähnen od. bloss aus einem etwas hervortretendem Rande gebildet. Blb. in d. Knospenlage klappig, 4-8th., od. 4-8blätterig. Stbg. so viel als Blh. $u$. diesen gegenst., frei, od. mit dem Stbk. auf die Blb. aufgewachsen. Gf. 1, od. fehlend. Narbe einfach. Becre 1samig.

B. Fruchtkn. einer, 2-4fächerig. Stbg. so viel als Blb., od. doppelt so viel. Frucht bei den einheimischen Arten trocken, vielsamig.

189. Saxifrageen. K. mehr od. weniger an den Fruchtkn. angewachsen, od. auch frei, bleibend. Blb. 4, 5, in der Knospenlage dachig, selten fehlend. Stbg. so viel als Blb., od. noch einmal so viel. Fruchtkn. vieleyig, 2schnäbelig, 2fächerig, die Scheidewände dch die einwärtsgebogenen Klappen gebildet, die Samenträger mittelpunktst., od. einfächerig, die Samenträger am Rande der Klappen. Narben am Ende der Schnäbel des Fruchtkn. schief aufgervachsen. Gf. fehlend. Kapselfrucht am innern Rande der Schnäbel aufspringend.

173. Onagrarieen. K. an den Fruchtkn. angewachsen, oft über denselben verlängert, Saum 4 th., seltener 2 th. Blb. so viel als KZpfl, in dem Schlunde des K. od. auf dem Fruchtkn. eingefügt, mit dem Kzpfln. wechselnd, in der Knospenlage zsgedrehet. Stbg. so viel als Blb., od. doppelt so viel. Gf. fadenf. Fruchtkn. 2-4fächerig. Fächer 1 -vieleyig.

C. Fruchtkn. 2-4fächerig. Stbg. so viel als Blb., od. doppelt so viel. Frucht in $2-4$ einsamige Früchtchen sich trennend.

198. Umbelliferen. Röhre des K. an den Fruchtkn. angewachsen, Saum 5zähnig od. verwischt. Blb. 5, dem K. eingefügt, in der Knospenlage einwärts gerollt, so wie die 5 mit den Blb. abwechselnden, hinfälligen Stbg. Gf. 2, jeder an der Basis in eine oberweibige Scheibe (Stempelpolster), verbreitert, das Ende des Fruchtkn. deckend. Frucht sich von der Basis gegen die Spitze in 2; an einer 2 sp. od. 2th. Achse aufgehängte, Halbfrüchte trennend. S. meist an 
das Fruchtgehäus angewachsen. Keim klein, in der Spitze des grossen Eyweisses.

177. Hal or a g e n. Röhre des K. an den Fruchtkn. angewachsen, Saum 3-4th. Blb. so viel als Zpfl. des K. Stbgef. so viel als Blb., od. doppelt so viele. Fruchtkn. 1-4fächerig, Fächer 1 eyig. Gf. fehlend. Narben so viel als Fächer des Fruchtkn. Frucht bei d. einheimischen Gattung in 4 einsamige Stiicke zerfallend.

D. Fruchtkn. 2-vielfächerig, Fächer mit einem Eychen. Frucht sich nicht trennend. Stbg. so viel als Blb., od. doppelt so viel.

225. Araliaceen. Saum des K. ganz od. gezähnt. Bl. 510 blätterig, vor einer oberweibigen Seheibe eingefügt: Blb. mit breiter Basis sitzend, in der Knospenlage klappig. Stbg. so viel als Blb., mit diesen wechselnd. Fruchtkn. 2-mehrfächerig, Fächer 1eyig. Gf. 1 od. mehrere. Frucht beerenartig.

225. Corneen. Saum des K. gezähnt. Bl. 4blätterig, vor einer oberweibigen Scheibe eingefïgt. Blb. mit breiter Basis sitzend, in der Knospenlage klappig. Stbg. 4, mit den Blb. wechselnd. Gf. 1. Steinfrucht mit 2fächerigem Steine.

E. Fruchtkn. 2-mehrfächerig. Stbg. viermal so viel als Blb., od. mehr.

171. Pom a ce en. Saum des K. 5zähnig, od. 5sp., Zpfl. in der Knospenlage dachig. Blb. 5. Stbg. 20, mit den Blb. dem, den Schlund des K. umgebenden Ringe eingefügt, in der Knospenlage einwärtsgekrümmt. Fruchtkn. 2-5fächerig, Fächer 2-mehreyig, Eychen aufrecht. Gf. so viel als Fächer des Fruchtkn. Frucht fleischig. S. eyweisslos. Kcim gerade, aufrecht. B. mit Neben B.

173. Granateen. Saum des K. 5-7sp., Zpfl. in der Knospenlage klappig. Blb. 5-7. Stbg. 20 u. mehr, mit den Blb. dem Schlunde des K. eingefügt. Fruchtkn. mehrfächerig, Fächer vielcyig. Gf. 1. Beere rindig. S. eyweisslos. Keim gerade, aufrecht. B. nicht punktirt u. ohne Ader am Rande, NebenB. fehlend.

180. Myrtaceen. Saum des K. 4-6sp., Zpfl. in der Knospenlage klappig. Blb. 4-6. Stbg. dem Schlunde des K. eingefügt, zahlreich, od. auch doppelt so viel als Blb., in der Knospenlage einwärtsgekrümmt, frei od. vielbrüderig. Fruchtkn. mehrfächerig. Gf. 1. S. eyweisslos. Keim gerade, aufrecht. NebenB. fehlend. B. drüsig-punktirt, mit einer dem Rande parallel laufenden Ader ausgestattet.

180. Philadelphe en. Saum des K. 4-10th., in der Knospenlage klappig. Blb. so viel als Zipfel des K. Stbg. 20 u. mehr. Kapsel 3-10fächerig, Fächer vielsamig. Samen auf Samenträgern, welche aus dem inneren Winkel der Fächer hervortreten. Die äussere Samenhaut locker, häutig, viel weiter als der Kern. B. gegenst., nicht punktirt, ohne Ader am Rande. NebenB. fehlend. 


\section{Unterabtheilung. BLUETHEN VOLLSTAENDIG, EINBLAETTERIG, OBERSTAENDIG.}

A. Stbg. auf dem Ende des Fruchtkn. vor der Bl. eingefügt.

180. Cucurbitaceen. Bl. regelmässig, an die Basis des $\mathrm{K}$. inwendig angewachsen, mit dem $K$. ahfällig. Stbg. ganz unten in der Bl. eingefiigt, frei oder ein- od. dreibriiderig.' Narben dick, lappig. Beerenfrucht mit mehreren oder vielen Samen.

324. Campanulaceen. $B l$. regelmässig, vor den Kzähnen cingefügt, verwelkend. K. ganz od. zur Hälfte an den Fruchtkn. angewachsen. Stbg. nicht vor der Bl. eingefügt. Stbk. frei od. in eine Röhre zshängend. Kapsel 2-8fächerig; S. an der Mittelsäule angeheftet.

324. Lobeliaceen. Bl. unregelmässig, das übrige wie bei den Campanulaceen.

331. Vaccinieen. Bl. regelmässig, abfällig. Bl. u. Stbg. vor eine oberueibige gekerbte Scheibe eingefïgt. Beerenfrucht.

B. Stbg. in der Röhre der Bl. od. zwischen den Zpfin. des Saumes eingefügt.

242. Compositen. Zpfl. der Bl. in der Knospenlage klappig. Stbk. in eine Röhre zsgewachsen. Fruchtkn. 1fächerig, mit 1 Eychen. Achene ohne Hüllchen. Bthen mit einem HK. umgeben.

324. Ambrosiaceen. Bth. eingeschlechtig. Zpfl. der Bl. in der Knospenlage klappig. Stbk. frei. Fruchlkn. 1fächerig, mit 1 Eychen. Weibl. Bthen blumenblattlos, einzeln od. mehrere in ein eigenes, zuletzt nussartiges und knöchernes Hüllchen eingeschlossen

228. Stellaten. Zpfl. der Bl. in der Knospenlage klappig. Stbg. frei, zwischen den $Z$ pfln. der BI. eingefügt. Fruchtkn. 2fächerig, Fächer mit 1 Eychen. Früchtchen 2, trocken od. beerenartig, zuletzt sich trennend.

226. Ca prifoliace en. Zpfl. der Bl. in der Knospenlage dachig. Stbg. frei, in der Röhre der Bl. eingefiigt. Fruchtkı. 2-5fächerig, Fächer mit 1 oder mehreren Eychen. Frucht beerenartig.

234. Valerianeen. Zpf. der Bl. in der Knospenlage dachig. Stbg. frei in der Röhre der Bl. eingefügt. Fruchtkn. 3fächerig. 2 Fächer leer, zuweilen in eines zsgeflossen od. fehlend, das dritte mit 1 Eychen. Frucht trocken, nicht aufspringend, lederig oder häutig.

237. Dipsaceen. Zpfl. der Bl. in der Knospenlage dachig. Stbg. frei, in der Röhre der Bl. tief unten eingefügt. Fruchtkn. 1fächerig, mit 1 Eychen, in ein Hïllchen, welches einen äusseren $K$. darstellt, eingeschlossen. 


\section{Unterabtheilung. BLUETHEN VOLLSTAENDIG, EINBLAETTERIG, UNTERSTAENDIG.}

A. Fruchtkn. 4 od. 2, auf einer unterweibigen Scheibe sitzend;

Gf. 1, vermittelst der Scheibe mit den Fruchtkn. zshängend.

344. B o ragin e en. Fruchtkn. 4, eineyig, od. 2, zweifächerige; Eächer eineyig, auf einer Drüsenscheibe eingefügt. Stbg. 5. Bl. regelmässig od. ungleich. Keim umgekehrt.

381. L a biaten. Fruchtkn. 4, eineyig, auf einer Drüsenscheibe eingefügt. Stbg. 4, zweimächtig, od. $2 \mathrm{Bl}$. rachenf., seltener fast gleich. Keim aufrecht.

B. Fruchtkn. einer, 1fächerig, 1eyig.

410. Plumbagineen. Stbg. 5, unterweibig, od. auf der Basis der Bl. eingefügt. Bl. 5th. od. tellerf. mit 5sp. Saume. Gf. od. Narben 5.

410. Globularieen. Stbg. 4, ganz oben in der Röhre eingefiigt. Bl. mit 2lippigem Saume, untere Lippe 3sp. Gf. 1. Narbe iinfach.

C. Fruchtkn. einer, 1 fächerig, mehrsamig; Samenträger mittelpunktst., frei.

412. Plantagineen. Bl. regelmässig, trockenhäutig; Saum 4sp. Stbg. 4, der Bl. eingefügt, mit den Zpfln. wechselnd, in der Knospe einwärts-geknickt. Narbe lang, fädl. Samenträger frei, 2-4flïgelig.

401. Primulaceen. Bl. regelmässig, 5- selten 4sp. Stbg. so viel als Zpfl., vor diese gestellt. Sameriträger frei, walzl.

400. Le ntibularieen. B. unregelmässig, 2lippig. Stbg. 2. Samenträger frei, walzl.

D. Fruchtkn. einer, 1 fächerig, mit wandst.-, od. 2 fächerig, mit mittelpunkst. Samenträgern. Stbf. 2, od. 4 zweimächtige. Bl. unregelmässig od. ungleich.

368. Orobancheen. Bl. rachenf, verwelkend, aber mit bleibender, ringsum abgesprungener Basis. Stbg. 4, zweimächtig. Frucittkn. einer, 1 fächerig, mit 2 od. 4 wandst. Samenträgern. S. viele, sehr klein. Blattlose Pf., auf Wurzeln schmarotzend; B. auf farblose od. wenigstens nicht grüne Schuppen zurückgeführt.

374. Rhinanth a ceen. Bl. rachenf, abfällig. Stbg. 4, zweimächtig. Stbk. an der Basis mit 2 Stachelspitzen. Fruclitkn. einer. Kapsel 2 fächerig.

358. Antirrhin e en. Bl. unregelmässig, zweilippig od. ungleich. Stbg. 2, od. 4 zwcimächtige, zuweilen mit dem Ansatze eines fünften. Stbk. an der Basis nicht stachslspitzig. Kapsel 2fächerig, mit Klappen od. Löchern aufspringend. S. eyweisshaltig. 
400. A canth a ceen. Bl. unregelmässig, 1lippig, od. ungleich. Stbg. 2, od. 4 zweimächtige. Kapsel 2fächerig; Mittelsäule sich spaltend, die Hälften an die Klappen angewachsen od. sich auch von diesen lösend. Nabelstränge starr, pfriemlich, aufstrebend, (sogenannte Fortsätze). Samen eyweissios.

399. Verben a ceen. Bl. ungleich. Stbg. 2, od. 4 zweimächtige. Steinfmucht $2-4$ fächerig, oft in $2-4$ Früchtchen zerfallend; Fächer einsamig.

F. Fruchtkn. einer, 2fächerig. Stbg. 8. Bl. unregelmässig.

63. Polygal een. Bl. unregelmässig, die äusseren KB. flügelartig. Stbg. 8, in eine oft geschlitzte Röhre zsgewachsen, an der Basis stets einbriiderig $u$. mit der $\mathrm{Bl}$. verwachsen.

F. Fruchtkn. einer, 2fächerig. Stbg. 2. Bl. regelmässig.

336. J a smineen. Bl. regelmässig, 5-8lappig. Stbg. 2, der Röhre der Bl. eingefügt. Fruchtkn. 2fächerig, Fächer 1eyig, Eychen aufrecht.

335. Oleaceen. Bl. regelmässig, 4sp., die Stbg. der Röhre der Bl. eingefügt, od. 4blätterig u. die Blb. je 2 durch das Staubgefäss vereinigt, od. K. u. Bl. gänzl. fehlend. Fruchtkn. 2fächerig, 2eyig, Eychen nebeneinander-hängend.

G. Fruchtkn. einer, 2-vielfächerig, mit mittelpunktst. Samenträgern, od. zwei cinfächerige, deren jeder mit einem Gf. und einem Samenträger an der innern Naht versehen ist. Stbg. 4, nicht zweimächtig, oder 5 u. mehrere.

335. Aquifoliaceen. Bl. regelmässig, 4-5th., in der Knospenlage dachig, Stbg. so viel als $\mathrm{Zpfl}$. der Bl., mit diesen wechselnd. Fruchtkn. 2-6fächerig; Fächer 1eyig, Eychen hängend. Unterweibige Scheibe fehlend. Steinfrucht $2-6$ steinig.

335. Ebenaceen. Bl. regelmässig, 3-6lappig, in der Knospenlage dachig. Stbg. so viel als $\mathrm{ZpH}$. der Bl., mit diesen wechselnd, od. 2 - od. 4mal so viel. Stbf. einfach od. 2sp. Fruchtkn. mehrfächerig; Fächer 1-2eyig, Eychen hängend. Unterweibige Scheibe fehlend. Frucht beerenartig.

343. Convolvula ceen. Bl. regelmässig, 5lappig, oft gefaltet. Stbg. 5. Fruchtkn. auf einer unterweibigen Scheibe. Kapsel 2-3-4fäch€rig, die Ränder der Klappen an Kanten oder Flügel des Mittelsäulchens anliegend, welche die Scheidewände bilden, zuweilen einfächerig. S. 1 od. 2 nebeneinander an der Basis des Mittelsäulchiens.

343. Polemoniaceen. Bl. regelmässig, 5lappig, in der Knospenlage klappig. Stbg. 5, in der Mitte der Röhre der Bl. eingefügt. Fruchtkn. 3fächerig. Kapsel 3klappig, fächer-od. scheidewandtrennend sich öfnend. Die Klappen von der Scheidewand sich lösend. 
353. Verbasceen. Bl. ungleich od. unregelmässig, in der Knospenlage dachig. Stbg. 5, oder 4 mit einem unvollständigen oberen Stbk. auf die verbreiterte Spitze der Stbf. quer-od. schiefaufgewachsen. Kapsel 2fächerig, vielsamig.

351. Solaneen. Bl. regelmässig od. ungleich, abfällig, in der Knospenlage gefaltet, 5-od. 4sp. Stbg. so viel als Zpfl. d. Bl. Frucht eine 2-4fächerige, vielsamige Kapsel. Die Scheidewände mit den Rändern der Klappen verbunden, od. eine vielsamige Beere.

337. Gentianeen. Bl. regelmässig, in der Knospenlage dachig und spiralig gedrehet, verwelkend, 4-10sp. od. 4-10lappig. Stbg. so viel als $Z$ pfl. der Bl. Gf. 1. Narben 1-2. Frucht 1-2fächerig, vielsamig; S. bei d. 1fächerigen an die einwärts-gebogenen Ränder der Frucht, bei der 2fächerigen an die mittelpunktst. Samenträger angeheftet.

336. A pосуneen. Bl. regelmässig, in der Knospenlage schiefgedrehet, abfällig, 5sp. Stbg. 5, frei. Stbk. mit 2 Längsritzen aufspringend, den pulverigen BIstaub unmittelbar an die Narbe abgebend. Fruchtkn. u. Gf. einer, mit einer Narbe, od. Fruchtkn. u. Gf. 2, mit einer einzigen, beiden Gf. gemeinschaftl. Narbe.

336. Asclepiadeen. Bl. regelmässig, 5sp., in der Knospenlage dachig, abfällig. Stbg. im Grunde der Bl. eingefügt. Stbf. oft einbrüderig; Stbk. 2- od. 4fächerig. Blumenstaub in wachsartige Massen zsgedrängt, welche an die 5 Drüsen der grossen 5kantigen Narbe angeheftet sind. Fruchtkn. 2. Gf. 2. Narbe eine, beiden Gf. gémeinschaftlich.

331. Ericineen. Bl. regelmässig, od. etwas unregelmässig, $4-5 \mathrm{sp}$, in der Knospenlage dachig. Stbg. vor einer unterweibigen, gekerbten Scheibe od. vor den Drüsen auf dem Fruchtb. eingefügt, u. frei, od. an der Basis der Blb. ein wenig anhängend, so viel als Zpfl. der Bl., od. doppelt so viel. Fächer der Kapsel so viel als Zpfl. der Bl.

\section{Unterabtheilung. BLUETHEN UNVOLLSTAENDIG, PERIGON EINFACH OD. FEHLEND.}

A. Bth. oberst., nicht in Kätzchen.

431. Cytineen. Bth. cinhäusig od. zwitter. Saum des P. 34-6lappig, der weibl. od. Zwitter-Bthe oberst. Stbg. in eine Walze zsgevvachsen. Fruchtkn. 1fücherig, mit w̦andst., häutigen, vielsamigen Samenträgern. Beere. Braune od. farbenlose Pf.; die B. auf Schuppen zurückgeführt.

431. Aristolochieen. P. regelmässig, 3sp., od. unregelmässig mit schiefem Saume. Stbg. auf dem Fruchthn. cingefügt, od. Stbk. olhne Stbf., an den sehr kurzen Gif. urter der grossen Narbe angewachsen. Fruchtkn. mchrfächerig, vielsamig. 
178. Hippurideen. P. an den Fruchtkn. angewachsen, Saum als ein sehr schwacher, zweilappiger Rand hervortretend. Stbg. 1, frei, dem Rande des $P$. an der Basis des vorderen Lappens eingefügt. Fruchtkn. 1fächerig, 1eyig, Gf. fädl.

429. S antál a ceen. P. 3-5sp., inwendig farbig, in der Knospenlage klappig. Stbg. 3-4-5, frei, an der Basis der Zpfl. eingefügt, den $Z_{p} f i n$. gegerist. Fruchtkn. 1fächerig, mit mittelpunkst. Samenträger, 2-4eyig, Eychen hangend. Gf. 1.

B. Bth. unterst., nicht in Kätzchen. Frucht in mehrere Früchtchen zerfallend. od. in solche elastisch aufspringend.

178. Callitrichineen. Bth. meist eingeschlechtig, mit 2 DeckB. gestützt. K. u. Bl. fehlend. Gf. 2 ungeth., Narbe klein. Fruchtkn. 4fächerig, 4samig, zuletzt in 4 Früchtchen zerfallend.

432. Euphorbiaceen. Bth. eingeschlechtig, 1-2häusig. P. gesp. od. fehlend. Bl. bei unseren Arten stets fehlend. Gf. od. Narben getheilt. Frucht aus 3, seltener 2, od. mehreren, ron der mittelpunktst. Achse abspringenden Früchtchen bestehend.

C. Bth. unterst., nicht in Kätzchen (bei Morus in Kätzchen).

Frucht nicht aufspringend $u$. nicht in Früchtchen zerfallend.

B. mit Nebenblättern.

422. Polyg o neen. Neben B. in eine, den Stengel cinschliessende Scheide zsgewachsen. P. getheilt, in d. Knospenlage dachig. Fruchtkn. einer, eineyig. Gf. od. Narben mehrere. Nussfiucht.

170. Sanguisorbeen. NebenB. an den Bstiel angenoachsen, P. mit 3-4sp. Saume, Zpfl. in der Knospenlage klappig, zuweilen durch äussere, kleinere in doppelter Zahl vorhanden; Röhre mit einem Ringe geschlossen. Stbg. vor dem Ringe eingefiigt. Fruchtkn. 1-4. Gf. 1, seitl. Eychen 1. Frucht in dem oft erhärteten P. eingeschlossen.

438. Urticeen. NebenB. frei, abfällig od. hleibend. P. gesp. od. ganz. Fruchtkn. 1fächerig, 1eyig, od. 2fächerig, mit 1eyigen Fächern. Gf. 1 od. 2. Nuss- od. Steinfrucht; zuweilen eine falsche Frucht, durch fleischig gewordene u. zsgewachsene Perigone od. dch einen fleischigen, gemeinschaftl. Fruchtb. gebildet.

D. Bth. unterst., nicht in Kätzchen. Frucht nicht aufspringend u. nicht in Früchtchen zerfallend. B. ohne NebenB.

429. L a urineen. P. 4-6sp. Stbg. den Perigonzpfln. eingefügt. Stbk. 2-4fäch., mit 2-4 Klappen aufspringend. Fruchtkn. 1 fächerig, mit einem hangenden Eychen. Gf. 1. Narbe 1. Frucht beeren- od. steinfruchtartig. Keim gestürzt, KeimB. gross, planconvex, Federchen deutl., Würzelchen zw. den KeimB. versteckt.

428. Thymela e e n. P. röhrig, Saum 4-5sp. Stbg. 2, 4, 8, der Röhre od. dem Schlunde eingefügt, Stbk. mit Längsritzen auf- 
springend. Fruchtkn. 1fächerig, 1eyig, mit einem einzigen hängenden Eychen. Gf. 1. Narbe 1. Keim gestürzt, KeimB. planconvex, Federchen undeutl. Wahre Frucht.

431. Ela eagneen. P. 2 - od. 4sp. Stbg. dem Schlunde des P. eingefügt. Fruchtkn. 1fächerig, 1 eyig, Eychen aufstrebend. $G f$. 1. Narhe 1. Keim gerade, aufrecht. Falsche Beere od. Steinfrucht, aus der fleischig gewordenen Röhre des P. gebildet.

182. Scleranthe en. Röhre des $\boldsymbol{P}$. glockig, zuletzt erhärtend u. die Schlauchfrucht einschliessend, Schlund mit einem Ringe geschlossen; Saum 4-5sp. Stbg. doppelt so viel als $\mathrm{Zpfl}$. des Saumes, vor dem Ringe eingefügt. Fruchtkn. 1 fächerig, 2eyig, Eychen an einem v. der Basis der Frucht aufsteigenden Nabelstrang hängend, eines oft fehlschlagend. Gf. 2. P. bleibend, mit der Frucht abfällig. Keim um das Eyweiss gekrümmt.

416. Chenopodeen. P. getheilt. Stbg. an der Basis des P. eingefiigt, v. gleicher $Z a h l$ der $Z p f l$. $u$. diesen gegenüber, od. weniger an der Zahl. Fruchtkn. 1fächerig, 1eyig, Eychen auf d. Grunde des Fruchtkn. sitzend. Gf. 2-1 sp. od. 2-4 Narhen. Frucht trocken, nicht aufspringend, zuweilen in dem fleischig gewordenen Kelch eingeschlossen u. dadurch eine falsche Frucht darstellend. Keim ringf. od. hufeisenartig-zsgelegt, od. schraubenf., zur Seite des Eyweisses od. ohne solches.

416. Phytolacceen. P. getheilt. Stbg. in der Basis des P. eingefügt, v. gleicher Zahl der Zpfl. u. mit diesen abwechselnd, oder mehr an der Zahl. Fruchtkn. mehrfächerig, Fächer 1eyig, Eychen aufrecht. Gf. so viel als Fächer. Keim um das Eyweiss gekrümmt.

416. A maranthaceen. $P$. meist rauschend, 3-5hlätterig. Stbg. unterweibig, bei dor männl. Bthe in der Mitte der Bthe, 3-5, frei od. an der Basis in eine Kuppel od. weiter hinauf in eine Röhre zsgewachsen, zuweilen abwechselnd unfruchtbare Zähne darstellend. Fruchtkn. 1fächerig, 1-mehrsamig. Gf. 1. Narbe 1 od. mehrere. Schlauchfrucht. Keim um das Eyweiss gekrümmt od. ringf.

178. Ceratophylleen. Wasserpflanze mit 2-3gabelig-getheilten $B$. Bthe 1häusig. Hülle vielblätterig. Männl. Bth.: Antheren mehrere in der Mitte der Hïlle sitzend, dicht zsgestellt. Weibl. Bth. in der Hülle einzeln, frei. Gf. 1. Narbe einfach. Nuss eyweisslos. Keim aufrecht. KeimB. 4.

\section{E. Die männl. Bthen immer in Kätzchen.}

439. Jugl an decn. Bth. einhäusig. Männl. in Kätzchen. P. 2-6th. Stbg. mehrere. Weibl. Bth. eirzeln od. 2-3, am Ende der Aestchen, ohne Hülle. K. oberst., abfällig. Blb. 4, krautig, bei ausländischen fehlend. Fruchtkn. 1fächerig, 1eyig, Eychen aufrecht. Steinfrucht fleischig, Nussschale 2-4klappig. S. eyweisslos. KeimB, runzelig, 2 sp. NebenB. fehlend. 
439. Cupuliferen. Bth. einhäusig. Männl. in Kätzchen aus Deckb. (Schuppen) zsgesetzt. P. fehlend od. 4-5sp. Stbg. dem P. od. den DeckB. eingefügt. Weibl. Bthen eirıeln, od. gehäuft, od. ährig. P. oberständig, Saum gezälnnelt, oft verschwindend. Fruchıkı. 2-6fächerig, Fächer 1-2eyig, Eychen hängend. Narben 2-6. Hülle marnichfaltig, nach der Bthezeit vergrössert, das Fruchtgehäus bedeckend. Nuss beinhart od. lederig, 1-3samig. Keim eyweisslos, gestürzt.

452. B etul ineen. Bth. einhäusig, in Kätzchen, diese aus schup. penf. DeckB. zsgesetzt. Männl. Bthen: Perigone 3, auf dem DeckB., jedes mit 2-4 Stbg. Weibl. Bthen: P. fehlend. Fruchtkn. unter jeder Schuppe 2-3, frei, 2fächerig, Fächer 1eyig, Eychen hängend. Narben 2. Nüsse meist geflügelt. S. eyweisslos. Keim gestürzt.

441. Salicineen. Bth. 2häusig, in Kätzchen, diese aus DeckB. (Schuppen) zsgesetzt. Anstatt des P. eine (manchmal doppelte) Drüse od. ein fleischiger Becher an d. Basis der Geschlechtsorgane. Männl. Bth.: Stbg. 2-24. Weibl. Bth.: Fruchtkn. hirter jeder Schuppe 1, frei, 1 fächerig, vieleyig, Eychen hängend. Samenträger wandst., Gf. 1, Narben 2, oft gespalten. Kapsel 2klappig. S. schopfig, eyweisslos. Keim gerade, aufrecht.

453. Myriceen. Bth. 1-od. 2häusig, in Kätzchen, diese aus DeckB. (Schuppen) zsgesetzt. Männl. Bth.: zwei kleinere Schuppen an der Seite des DeckB. Stbg. 2 od. mehrere. Weibl. Bth.: zwei bis sechs unterweibige Schuppen. Fruchtkn. hinter jeder Schuppe 1, 1fächerig, 1eyig, Eychen aufrecht. Gf. sehr kurz. Narben lang. Frucht durch die vergrösserten u. angewachsenen Schuppen steinfruchtartig. Keim gestürzt.

453. C on if eren. Bth. 1- od. 2häusig, in Kätzchen od. am Ende der Zweige einzeln od. zu 2 od. 3. Die veibl. in eiren Zapfen, od. in eine falsche Beere übergehend. Männl. Bth.: Stbg. 1, od. mehrere, mit den Stbf. zsgewachsene; od. viele, der Länge nach an eine Achse gestellt, die Stbf. in Schuppen (in ein schuppenf. od. schildf. Konnectiv) verbreitert, auf der unteren Fläche die Stbk. tragend, u. zwar 2 nebeneinanderliegende, od. mehrere rundum gestellte od. am unteren Rande angeheftete. Weibl. Bth.: Nackte Eychen auf einem schuppenartigen, flachausgebreiteten, mit einem DeckB. gestützten Fruchtblatte, od. ohne Fruchtblatt im Winkel von verschieden gebaueten DeckB. Same eyweisshaltig. Keim mit 2 od. mehreren quirlig-gestellten KeimB.

\section{Classe. ZERSTREUTFASERIGE PHANERO- GAMISCHE GEFAESSPFLANZEN.}

A. Fruchtkn. mehrere, getrennt, od. an d. Basis zsgewachsen od. völlig zsgewachsen und erst bei der Reife oberwärts auseinander- 
tretend od. v. der mittelpunktst. Achse sich trennend; jeder griffeltragend od. mit einer sitzenden N. endigend. P. unterst.

457. Alism aceen. K. 3blätterig, krautig. Bl. 3blälterig, regelmässig, unterst. Stbg. unterweibig, frei, 6 od. zahlreich. Fruchtkn. 3-6, od. viele, jeder mit einem Gf., 1-2eyig, Eychen an der inneren Naht. Narbe einfach. Früchte trocken, nicht aufspringend.

458. Butomeen. Bthe 6blätterig (bei ausländischen 3 grüne KelchB. u. 3 gefärbte Blb.), regelmässig, unterst. Stbg. unterweibig, frei, 9 od. mehr. Fruchtkn. 6, od. mehrere an der Basis zsgewachsen, jeder mit einer Narbe, vieleyig, die Eychen die ganze Wanä inwendig bekleidend.

458. Juncagineen. P. Cblätterig, kelchartig, od. etwas gefärbt. Stbg. 6, unterweibig. Fruchtkn. 3-6, jeder mit einem freien Gf. od. einer schief-aufgewachsenen Narbe, 1-2eyig, an d. Basis zshängend od. zu einer ganzen, trockenen Frucht zsgewachsen, bei der Reife aber in 3-6 Früchtchen sich ablösend.

495. Colchicaceen. P. 6sp. od. 6blätterig. Stbg. 6, auf der Basis des P., od. im Schlunde der Röhre des 6sp. P. eingefügt. Fruchtkn. oberst., od. nur an der untersten Basis an das P. angewachsen, einer mit 1 Gf., od. 3, jeder mit 1 Gf. od. mit 1 Narbe. Kapsel einwärts aufspringend. Samenträger an der inneren Naht.

459. P otameen. P. 4th. od. fehlend. Stbg. 1, 2, 4. Fruchtkn. 4, od. mehrere, getrennt, 1eyig, mit 1 Gf. od. mit 1 sitzenden N. Früchtchen nuss- od. steinfruchtartig. S. eyweisslos. Keim gekrümmt od. eingerollt.

B. Fruchtkn. einer, unterst.

466. Or chideen. P. oberst., 6th., unregelmässig, meist rachenf., der dritte innere $\mathrm{ZpH}$. eine Lippe darstellend. Fruchtkn. 1fächerig, vieleyig, mit wạndst. Samenträgern. Stbf. 3, mit dem $G f$. in eine Säule zsgewachsen, davon 1-2 mit Antheren versehcn, 2 od. 1 ohne Antheren. Narbe über einer klebrigen Vertiefung als Spitze od. Platte vortretend.

457. Hy drocharideen. K. 3blätterig, krautig. Bl. 3blätterig, regelmässig. Stbg. frei, 3 od. mehrere. Fruchtkn. 1-mehrfächerig, vieleyig. Gf. $2-6$, meist 2 sp. Frucht fleischig, nicht aufspringend. $\mathrm{S}$. eyweisslos.

476. Irideen. P. 6th., blumenartig. Stbg. 3, an der Basis der äusseren $Z \mathrm{pfl}$. des P., od. auf dem Fruchtkn. eingefügt. Stbk. auswärts aufspringend. Fruchtkn. 3fächerig, vieleyig. Kapsel 3klappig, Klappen die Scheidewand tragend.

483. D i o s c o r e e n. P. Csp., krautartig, od. etwas blumenartig. Stbg. 6, auf der Basis der Zpt. eingesetzt. Stbk. einwärts aufspringend. Fruchtkn. 3fächerig, 1-vicleyig. Frucht eine geflügelte Kapsel, od. eine Becre. Bth. klein, zweihäusig, in Trauben od. Rispen. 
480. Amaryllideen. P. 6blätterig od. 6sp., blumenartig. Stbg. 6, auf dem Fruchtkn. od. dem P. eingefügt. Stbk. einwärts aufspringend. Fruchtkn. 3fächerig, 1-vieleyig. Frucht eine Kapsel od. Beere. Schönblüthige Gewächse, Bth. vor dem Aufblühen in Bthschtiden eingeschlossen.

\section{Fruchtkn. einer, oberst.}

483. Liliaceen. P. 6blätterig od. 6sp., blumenartig. Stbg. 6, auf dem Bthboden od. dem P. eingefügt. Fruchtkn. 3fächerig, Fächer 2-vielsamig. Gf. 1. Kapselfrucht. Keim im fleischigen Eyweisse. 481. Asparageen. P. 4-6-Ssp., hlumenartig. Stbg. 4-68, auf dem Bthboden od. dem P. eingefügt. Fruchtkn. 2-3-4fächerig, Fächer 1-mehreyig. Gf. 1 od. mehrere. Beerenfrucht. Keim im fleischigen Eyweiss.

496. Juncaceen. $P$. 6blättrig, die Blätter einem Grashalge ähnelrı, u. venigstens am Rande trockenhäutig. Stbg. 6, seltener 3, an der Basis der Blätter des P. eingefügt. Fruchtkn. 1-3fächerig, 1- od. vieleyig. Gf. 1. Narben 3. Kapselfrucht. Keim im Lyweisse.

465. Aroide en. Bth. eirgeschlechtig $u$. nackt, od. zwitterig u. mit einem aus schupperif. Blättern gebildeten $P$. versehen, auf einem Kolben zsgestellt, den Kolben ganz od. einen Theil desselben dicht bedeckend. Kolben oft in eine Bthscheide eingeschlossen. Frucht nicht aufspringend, trocken od. beerenartig. S. 1, od. mehrere. Kieim im Eyweisse.

465. Ty phace en. Bth. einhäusig, in walzl.od. kugeligen Kolben od. Aehren dicht-zsgedrängt, die oberen Aehren männl., die untern weibl. $P$. aus 3 u. mehreren Schuppen od. Borsten. Stbg. 3, jedes mit 1 Stbk. od. 3 Stbk. auf der Spitze eines Stbf. Fruchtkn. 1eyig. Frucht trocken, nicht aufspringend. Keim im Eyweisse.

464. Najadeen. Bth. eingescllechtig, zerstreut. $P$. fehlend, od. durch Häute, welche den Stbk. einschlossen, angedeutet. Stbg. 1-3. Stbf. fellend. Stbk. sitzend. Fruchtkn. 1 fächerig, 1eyig. Frucht nuss- od. steinfruchtartig. S. eyweisslos. Unter dem Wasser lebende Kräuter.

464. Lemnaceen. Bth. einzeln, am Rande eines blattlosen, aber blattartig schwimmenden St., der aus 2 od. mehreren solchen blattartigen zsgesetzt ist. Perigon nngeth. Stbg. 2. Fruchtkn. 2-6eyig. S. eyweisslos.

503. Cyperaceen. Balgbthen, zwitterig oder eingeschlechtig. Bälge dachig sich deckend und Aehrchen bildend. Der Balg 1klappig (das äussere DeckB.) od. 2klappig, die innere Klappe bei Carex zu einem krugf. Schlauche mit ihren Rändern zsgewachsen. Perigon durch Borsten angedeutet, oft fehlend, Stbg. 1-3. Stbk. aufrecht. Gf. 1. Narben 2-3. Nuss 1samig. Keim in der Basis des Eyweisses eingeschlossen. Bscheiden ganz. 


\section{$\operatorname{LXXX}$}

531. Gramineen. Balgbthen, zwitterig od. eingeschlechtig, Bälge dachig sich deckend u. Aehrchen bildend. Unterste 2 Bälge, (die untersten 2 DeckB.) leer, Klappen genannt, bilden den Balg, Kelchbalg bei Linné; zuweilen fehlt die eine, selten fehlen die beiden Klappen. Die 2 folgenden die Geschlechtsorgane einschliessenden, die Spelzen, bilden das Bälglein, die Blüthe, Blumenbalg bei Linné, davon die untere 1 kielig, die obere 2 kielig. Perigon dch $2-3$ kleine Schuppen, Deckspelzen, angedeutet. Stbg. 1-3 oder mehrere. Stbk. drehbar. Gf. 2 , od. 1 mit 2 Narben. Karyopse. Keim ausserhalb d. Eyweisses. Bscheiden aufgespalter, selten ganz. 


\section{Gefässpflanzen.}

Pflanzen aus Zellgewebe und Gefässen gebauet.

\section{Classe. Phanerogamische EX0GENEN, DIC0- TYLEDONEN.}

Gefässbündel im Stengel in einen Kreis gestellt, und $z u$ einem Holzringe zslaufend, wodurch Rinde und Mark geschieden wird. Bei strauch- und baumartigen Pflauzen der Stamm aus mehreren concentrischen, von der Rinde umzogenen Holzlagen gebildet. Keim mit zwei oder mehreren gegenst. Keimblättern versehen.

I. Unterklasse. THALAMIFLOREN (Fruchtbodenblüthige).

Blb. mehrere, getrennt und nebst den Stbg. auf dem Fruchtboden, und nicht auf dem K. eingefügt.

I. Ordng. RANUNCULACEEN. Juss.

I. Gruppe. CLEMATIDEEN DC. Knospenlage des K. klappig od. einwärts - gefaltet. Friichtchen nicht aufspringend, 1samig.

1. CLÉMATIS Linn. Waldrebe.

I. Rotte. Flammula DC. Hülle fehlend. Schweife d. Früchtch. lang, bärtig.

1. C. integrifolia L. St. aufrecht; B. eyf.-lanzettl., od eyf., spitz, ganzrandig, kahl, auf d. Adern unterseits flaumb.; Bth. überhängend; KB. längl., spitz. 24. Feuchte Wiesen; Unterbaiern, Oestr.,j Litt. Jun. Jul. Bth. violett. 
2. C. recta L. St. aufrecht; B. gefiedert, Blättch. eyf., zugespitzt; $K B$. längl., stumpf, kahl, am Rande auswendig flaumh. 2 . Wiesen, unbeb. O.; sehr zerstr. dch d. Geb. Jun. Jul. Bth. weiss.

3. C. Flammula L. St. kletternd; B. doppelt-gefiedert, Blättch. eyf., längl. od. lineal., ganzrandig, ungeth. od. 2-3sp.; KB. längl., stumpf, unterseits am Rande filzig. Ђ. Felsige O., Gebiisch; Littor., Istr. Jun. Jul. Bth. weiss. Var.: $\beta$. maritima, Blättch. lineal. C. maritima Lam. u. $\gamma$. rotundifolia, Blättch. rundlich. C. fragrans Ten.

4. C. Vitalb a L. St. kletternd; B. gefiedert, Blättch. eyf., zuge†-spitzt, ganzrandig, grob-gesägt, od. etwas gelappt, an d. Basis meist herzf.; KB. längl., auf beider Seiten filzig. Ђ. Zäune, Gebüsch. Jun. Jul. Bth. weiss.

II. Rotte. Viticell a DC. Hülle fehlend. Schweife d. Früchtch. kurz, bartlos.

5. C. Viticella L. St. kletternd; B. gefiedert, Fieder 3zählig od. 5zählig-fiederig, Blättch. eyf., ganzrandig, ungeth., od. 2-3lappig; KB. 3eckig-vkteyf., stumpf mit einem abwärts gebogenen Spitzchen; Gf. kahl. Ђ. Gebüsch, Zäune; Litt., Istr. Mai, Aug. Bth. sattviolett od. roth.

\section{ATRAGÉNE L. Alpenrebe.}

1. A. alpina L. B. doppelt-3zählig, Blättchen gesägt, ungeth.; Blb. spatelig, stumpf. Ђ. Felsige O. d. Wäld. d. VorA. u. A. Jul. Aug. A. austriaca Scop. Bth. violett u. selten weiss.

II. Gruppe. ANEMONEEN DC. Knospenlage des K. u. d. Bl. dachig. Blb. flach ohne Schuppe od. Honiggribchen, od. auch fehlend. Früchtchen nicht aufspringend, 1samig.

\section{THALÍCTRUM L. Wiesenraute.}

I. Rotte. Tripterium DC. Früchtchen glatt, nicht gerieft, 3 kantig, Kanten geflügelt, mit einem Stielchen üb. d. Fruchtboden emporgehoben.

1. Th. aquilegifolium L. Verästelung d. Bstieles mit Nebenblättchen; R. fast ebensträussig; Früchte 3kantig-gefiügelt, glatt. 4. Wiesen, Wälder, Ebenen, Gebirg. u. VorA. Mai, Jun. Bth. grünl. od. weiss. Stbf. lila, $\beta$. St. violett, bereift, Bth. auswendig violett: Th. atropurpureum Jacq.

II. Rotte. Euthalictrum DC. Früchtch. längsfurchig.

§. 1. Früchtchen in ein kurzes Stielchen verschmälert, an $d$. Spitze mit d. Narbe hakig gebogen. Bth. grünlicl.

2. Th. alpinum L. St. ganz einfach, fast nackt; $\boldsymbol{T} r$. endst., einfach; fruchttrag. Bthstielch. zurückgekrümmt. 24. Höchste A.; Tyrol, Kärnth., Unterengadin. Jun. Jul. 
§. 2. Friichtch. sitzend, an der Spitze gerade.

a. R. dem Umfange nach pyramidenf. od. eyf.; Bth. zerstreut, od. an d. Spitze d. Aestchen doldig, aber nicht dicht büschelig. Bth. grünl. od. gelbl., äinsserl. oft röthl. überlaufen.

1. Die Bstiele dreizählig zsgesetzt.

3. Th. fo etidum L. St. schwach-gerieft, nebst den B. v. $a b$ stehenden, einfachen $u$. drüsentrag. Haaren flaumh.; die besondern Bstiele schwach-kantig; Oehrchen der Bsch. kurz, ganzrandig; Blättch. rundl., od. vkteyf., 3zähnig od. 3sp. u. gezähnt; R. abstehend, locker; Bth. u. Stbg. iiberhangend; Narben längl.-eyf., franziggezähnelt, mit hinterwärts aneinander geschlagenen Seiten. 24. Felsen d. A. 11. VorA.; Wallis, Graubind., Tyrol, Stmk., Böhm. St. Ivan. Jul. Aug. - Var. $\beta$. glabrum, kalll. Th. alpestre Gaud. ?

4. Th. sylvaticum Koch. St. an d. Gelenken gerade, schwachbereift, d. Glieder zuweilen schlängelich; besond. Bstiele zsgedrücktstielrund, schwach-kantig; Blättch. rundl., 3zähnig od. 3sp. u. 5zähnig, unterseits graugrün, kahl; Oehrchen'd. Bsch. kurz, abgerundet, zuriickgerollt-abstehend; Nebenblättch. keine; Aeste abstestehend; Bth. zerstreut, fast doldig, nébst d. Stbg. niederhängend. 4. Dammerde d. Wäld.; Rheinpf., Odergeb. Jul. Ang. Th. minus $\delta$. strict. K. syn. ed. 1. p. 4. W. weit kriechend.

5. Th. minus L. St. gerieft, etwas bereift, an den Gelenken eingeknikt- hin u. her gebogen; besondere Bstiele durch hervortretende Linien kantig; Blättch. rundl. od. keilf.-vkteyf., 3zähnig od. 3sp. u. 5zälnig, unterseits graugrïn, kahl od. drüsig-flaumig; Oehrchen d. Bsch. kurz, abgeruridet, etwas abstehend; Nebenblättch. keine; mittlere Aeste der R. fast wagerecht spreitzend; Bth. zerstreut, fast doldig u. nebst $d$. Stbg. niederhängend. 2. Wiesen, Hügel. Mai, Jun. Varirt $\alpha$. virens, St. glänzend. - $\beta$. roridum, St. bereift. - $\gamma$. glaudulosum, St. Bstiele u. Bsch. mit sehr kurz gestellten Drïsen.

6. Th. maju s Jacquin. St. gerieft, nicht bereift, fast schnurgerade; besondere Bstiele durch hervortretende Linien kantig, die untersten sehr weit abstehend; Brättch. rundl. od. keilf.-vkteyf., 3zähnig od. 3sp. u. 5zähnig, unterseits bleicher, etwas graugriun, kahl; Oehrchen d. Bsch. kurz, abgerundet, etwas abstehend; Nebenblättchen keine; Aeste der R. aufrecht-abstehend; Bth. zerstreut, fast doldig u. nebst d. Stbg. niederhängend. 4. Wiesen, Ackerränder; zerstr. deh. d. G. Mai, Jun. T. minus $\varepsilon$. dumosum K. syn. ed. 1. p. 4. Wohl nur Variet, von T. minus.

7. Th. Jacquinianum Koch. St. gerieft, ganz kahl, glänzend, unbereift; besondere Bstiele durch hervortretende Linien kantig; Blättch. rundl.-vkteyf., 3sp., 5-9zähnig, grün, unterseits bleicher; Oehrchen der Bsch. verbreitert, abgerundet, wagerecht-abstehend, zu- 
letzt zurückgerollt; erste Verzweigung $d$. Bstieles oft mit Nebenblättch.; Aeste der R. etwas abstehend u. nebst d. besondern Bstielen etwas schlänglich; Bth. zerstreut u. nebst d. Stbg. niederhängend. 2. Hügel, Wiesen; östl. u. südl. Geb. Jun. Jul. Th. minus Jacq. a. t. 419. Th. collinum Koch. syn. ed. 1. p. 4. Varirt $\beta$. B. unterseits schwach graugrün $u$. manchmal fein drüsig: Th. nutans Schleich.

8. Th. elatum Jacq. St. gefurcht, bereift; Blättch. rundl. od. vkteyf., bis 7zälınig, graugrün u. matt; Oehrchen der Bsch. kurz, abgerundet, etwas abstehend; Verzweigung d. Bstieles olne Nebenblättch.; R. ausgebreitet, Aeste abstehend, steif; Bth. fast doldig u. quirlig; Bthstielch., Bth. 'u. Stbg. gerade-hervorgestreckt; W. faserig. 4. Hügel; Fiume. Jun. Jul.

2. Die Bstielé fiederig, zsgesetzt.

9. Th. simplex L. St. gefurcht; Blättch. längl.-keilf., 3sp. u. ungeth., längl., matt; Ochrch. $d$. obern Bsch. eyf.-längl. zugespitzt; $R$. längl.-pyramidenf., Aeste traubig; Bth. zerstreut, nickend; $W$. kriechend. 2. Berge, Wiesen; Holst., Harz, Wallis. Jun. Jul.

10. Th. galioides Nestler. St. gefurcht; Blättch. spiegelnd, lineal., ungeth., die endst. oft-3sp.; Oehrchen d. obern Bsch. eyf.längl., zugespitzt, gezähnelt; $R$. längl.-pyramidenf., Aeste traubig; $B t h$. zerstreut, nickend; $W$. kriechend. 2. Wiesen u. Haiden; südl. u. südwestl. Geb. Jul. Wahrscheinl. Variet. v. Th. simplex. Var.: mit u. ohne Stipellen.

b. Rispe fast ebensträussig. Bth. an d. Spitze d. Aeste u. Aestchen gedrängt, Früchte daselbst in dichten Büscheln. Bth. gelb.

1. Bstiele dreizählig-zsgesetzt.

11. Th. angustifolium Jacq. St. gefurcht; Blättch. längl.keilf., od. lineal., ungeth. u. 3sp., glänzend, unterseits bleicher, u. feinflaumig; Oehrchen d. obern Bsch. eyf., zugespitzt; Verästelung d. Bstieles ohne Nebenblïttch.; $R$. fast ebensträussig, Bth. an d. Spitze d. Aestchen gehäuft $u$. nebst d. Stbg. aufrecht; W. faserig. 4. Feuchte Wiesen; siidl. u. östl. Geb. Jun. Jul.

2. Bstiele fiederig - zsgesetzt.

12. Th. flavum I. St. gefurcht; Blättch. vkteyf.-keilf., ganz od. 3sp., unterseits bleicher, die der obern B. lincal; Oehrchen der Bsch. längl.-eyf., länger als $d$. Breite $d$. Sch.; d. untern Verästelungen d. Bsticles mit Nebenblättch.; R. fast ebensträussig, Bth. an d. Spitze d. Aestchen gehäuft u. nebst d. Stbg. aufrecht; W. kriechend. 24. Feuchte Wiesen. Jun. Jul. Th. nigricans Jacq.

13. Th. rufinerve Lej. u. Curtois. St. gefurcht, glänzend; Blättch. unterseits meergrün, die d. untern B. vkteyf., 3sp., die d. obern längl.-lineal., ungeth., 3zähnig; Oehrchen d. ubern Bsch. eyf., zugespitzt, gezähuclt; Verïstelungen d. Bstieles ohne Nebenblättch.; 
Aeste d. R. gleichhoch u. glcichlaufend-aufrecht. Bth. an d. Spitze d. Aestchen gehäuft $u$. nebst d. Stbg. aufrecht; W. faserig. 2 . Blisten, Geb. d. Fl. v. Spaa. Jun. Jul.

14. Th. exaltatum Gaud. St. gefurcht, glänzend; Blättch. unterseits i. d. Sch. mit sitzenden sehr kleinen Drüsen bestreut, ganz od. keilig u.2-od. 3sp., Oehrchen d. Sch. kurz, rundl., schmäler als d. Durchmesser der Sch., d. obersten spitz, Nebenblättch. oft fehlend, Aeste d. ebensträussigen R. abstehenrl, Bth. an d. Spitze d. Aestchen gehäuft $u$. nebst d. Stbg. aufrecht; W. kriechend. 2. Flussufer; siidl. Schwz. Jun. Jul.

\section{ANEMÓNE L. Windröschen.}

I. Rotte. Hepatica. B. d. Hülle 3zählig, sitzend, ungetheilt, klciner als die Bth., derselben sehr genähert, einen K. darstellend.

1. A. Hepatica L. B. 3lappig-ganzrandig. 2. Haine. März, Apr. Hepatica triloba DC. Bth. blan, selten roth od. weiss.

II. Rotte. Pulsatilla. HiillB. 3zählig, sitzend, gefingertvielth., an d. Basis scheidig. Früchtch. lang, bärtig geschwänzt.

2. A. vernalis L. HiillB. sitzend, gefingert-vielth.; WB. gefiedert, Blättch. eyf., 3sp., Zpfl. ganz, 2-3zähvig, Zähne od. Läppchen eyf., Früchtch. u. der vielmal längere Schweif rauhh. 24. A. $u$. auch Wälder u. Haiden niedriger Gegend.; zerstr. dch. d. Geb. Apr. Mai. Bth. weiss, auswendig violett.

3. A. Halleri Allion. HüllB. sitzend, fingerig-vielth.; WB. zottig, gefiedert, 2 paarig, Fieder fiedersp., Zpfl. lineal-lanzettl., ganz od. 2-3zähnig; Bth. aufrecht; Friichtch. u. der vielmal längere Schweif rauhh. 24. A., auch niedrigere O.; Schwz., Stmk., Oestr., Böhn. Jul. Ang. A. Halleri n. Hackelii K. syn. ed. 1. Bth. hellviolett; an A. Hackelii Tausch. Runkelviolett.

4. A. Pulsatilla L. HüllB. sitzend, fingerig-vielsp.; WB. 3fach-

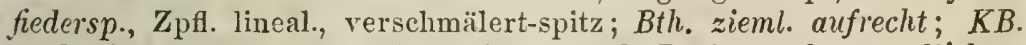
noch einmal so lang als die Stbg., an d. Basis glockig, endlich v. d. Mitte an zurückgebogen-abstehend; Früchtch. u. ihr vielmal längerer Schweif ranhh. 2. Sonnige Hügel u. Berge. Apr. Mai. Bth. sattviolett, dann bleicher.

5. A. m on ta 11 a Hoppe. HiillB. sitzend, fingerig-vielth.; WB. 3fachfiedersp., Zpfl.lineal., spitz; Bth. iiberhangend; KB. gerade, mit d. Spitze auswärts gebngen, noch einmal so lang als d. Stbgf.; anfangs glockig gestcllt, zulctzt abstehend; Friichtch. u. ihr vielmal hingerer Schweif rauhh. 24. Sonnige Hïgel; Litt., siidl. Tyr., Chur, Wallis. Apr. Mai. Bth. schwarzviolett.

6. A. pratensis L. HiillB. sitzend, fingerig-viclth.; WB. 3fachfiedersp., Zpfl. lineal., Bth. nicderhängend; KB. immer glockig-zsschliessend, oberwärts zurückgerollt; Stbgf. fast so lang, als d. 
glockige Theil d. Bthe., Früchtch. u. ilır vielmal längerer Schweif rauhh. 24. Sandhügel, Haiden; v. d. Thüringer Walde bis an d. Ostsee, Schles., Böhm., Mähr. Apr. Mai. Bth. schwarzviolett.

7. A. patens L. HüllB. sitzend, fingerig-vielth.; WB. 3zählig, Blättch. meist 3th., Zpfl. längl., an der Spitze eingeschnitten, 23zähnig od. vielsp. mit lineal. Zipfelchen; Bth. ziemlich aufrecht; KB. abstehend-glockig, an d. Spitze aufrecht. 24. Sonnige Hügel, Haiden; Preussen bis Frankf. a. d. O., Schles., Lausitz, Böhm., Geg. v. München. Apr. Mai. Bth. blauviolett.

II. Rotte. Anemonanthea DC. HüllB. sitzend, ganz, od. fingerig-eingeschnitten, v. d. Bth. entfernt. Frucht nicht geschwänzt.

8. A. hortensis L. HüllB. sitzend, längl., ungeth., od. an d. Spitze 3sp.; WB. 5theilig, Zpfl. 3sp., gezähnt u. eingeschnitten, an d. Basis keilf., die seitenst. zsfliessend; Bth. einzeln; KB. meist zu 12, lanzettl.; Früchtch. wollig, fast so lang, als d. Gf. 24. Gebüsch; Waadt, Wallis, Istr. Febr. März. Bth. rosenroth.

9. A. narcissiflora L. HülB. sitzend, eingeschnitten; WB. 5th.; $\mathrm{Zpfl}$. am Rande übereinand. gelegt, 3sp. u. eingeschnitten mit lineal. Zipfelchen; Bth doldig; KB. meist zu 5, elliptisch; Früchtch. kahl. 2. Wiesen d. A. VorA. u. Sudet. Mai. Jul. Bth. weiss. Var.: St. $1 \mathrm{bth}$.

IV. Rotte. Preonanthus DC. HüllB. 3zählig, auf einem kurzen, erweiterten Bstiele sitzend, von d. Gestalt d. WB.; Früchtch. geschwänzt.

10. A. alpina L. WB. 3zählig, doppelt zsgesetzt, Zpfl. eingeschnitten; Hüllb. 3zählig, kurzgestielt, v. Gestalt der WB.; Bth. einzeln; KB. meist zu 6; Früchtch. u. der vielmal längere Schweif rauhh. 4. A., VorA., Sudeten, Voges., Brocken. Mai-Jul. Bth. weiss, od. gelb, letztere ist: A sulphurea L. A. apiifolia Wulf. - Eine kleinere Variet. ist: Pulsatilla alba Rchb., eine grössere mit längern BZipfeln: A. myrrhidifolia Vill., Puls. Burseriana Rchb.

V. Rotte. An emone. HüllB. 3zählig, gestielt, v. d. Gestalt der WB. Früchtchen nicht geschwänzt. Die wurzelst.B. fehlen oft.

11. A. baldensis L. HüllB. den WB. gleichgestaltet, kurzgestielt; WB. 2-3zählig, Blättch. 3th., Zpfl. 3zähnig; Bth. einzeln; KB. meist zu 9, elliptisch-längl., unterseits zottig. Früchtch. wollig, fast so lang als d. kahle $G f$. 24. Höchste A. Jul. Aug. A. fragifera Wulf. Bth. weiss.

12. A. sylvestris L. HüllB. den WB. gleichgestaltet, gestielt; WB. 5th., Zpfl. fast rautenf., 3sp., ungleich-gesägt; Btl. einzeln; KB. meist zu 5, eyf., unterseits zottig; Früchtch. filzig, Gf. kahl, sehr kurz. 2. Sonnige Hügel. Mai. Jun. Bth. weiss. 
$3 / 14.5 \cdot 13.6$

At. onlfurca, Pratyel

sta.s. 13.14.

$\#$

$$
\text { Stansute: Bei Schkeury,.... }
$$

n: hil ranunculoid: = nem mara, kunge sin intermeria, $2 r_{2}, d x$.

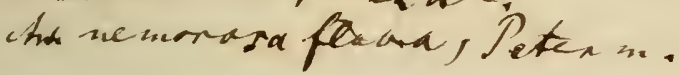



13. A. nemor os a L. HüllB. 3zählig, gestielt, Bstiel fast so lang als das B.; Blättch. eingeschnitten-gesägt, das mittlere 3sp., an der Basis keilig, die seitenst. 2sp., an der Basis schief-eyf., Bth. einzeln; $K B$. meist zu 6, längl., stumpf, auf beiden Seiten kahl; Früchtch. flaumh., so lang als der Gif. 2. Wälder, Waldwiesen. März. Apr. Bth. weiss.

14. A. ran unculvides I. HüllB. 3zählig, gestiell; Bstiel vielmal kürzer als das B.; Blättch. eingeschnitten-gesägt, das mittlere 3sp., an der Basis keilf., die seitenst. 2sp., an der Basis etwas schief; Bth. meist zu 2; KB. oval, seicht ansgerandet, unterseits flaumh.; Früchtch. flaumh., fast so lang als der Gf. 21. Wälder, Waldwiesen. Mai. Bth. gelb.

15. A. trifolia L. HüllB. 3zählig, gestielt; Blättch. breit-lanzettl,, zugespitzt, ungeth., gesägt, an der Basis ganzrandig; Bth. einzeln; KB. meist zu 6, oval-längl, auf beiden Seiten kahl. 24. Wälder d. A. u. VorA.; siudl. Tyrol, Krain u. Kärnth. Apr. Bth. weiss.

5. ADONIS Linn. Adonis.

1. A. a utumnalis L. K. kahl, abstehend, v. den halbkugeligzsschliessenden Blb. entfernt; Früchtch. zahnlos, in den geraden Schnabel auslaufend. $\odot$. Aecker; Wallis, Istr. Mai-Herbst. Blb. blutroth, an der Basis schwarz.

2. A. aestivalis L. K. kahl, an die ausgebreiteten Blb. angedriickt; Früchtch. mit 2 Zähnen am obern Rande u. einem spitzen Zahn an der Basis, Schnabel aufstrebend, gleichfarbig. ○. Aecker. Jun. Jul. A. miniata Jacq. Blb. mennigroth, einfarbig od. an der Basis schwarz. Var. Blb. strohgelb: A. citrina Hoffm., A. flava DC.

3. A. flammea Jacq. K. rauhh., an die ausgebreiteten Blb. angedriickt; Früchtch. an ihrem obern Rande vor dem aufstrebenden, an der Spitze brandigen Schnabel mit einem abgerundeten Zahne. $\odot$. Aecker; siidl. u. mittler. Geb. Blb. klatschroth, einfarbig od. an der Basis schwarz. Var. Blb. strohgelb.

4. A. vernalis L. K. flaumh.; Friichtch. fast kugelig-vkteyf., runzelig, flaumh., vor der Spitze geschnäbelt; fruchttrag. Bthstiele aufrecht; die wurzelst. B. schuppenf., die stengelst. sitzend, Bzipfel schmal-lineal. 24. Somnige, nukultiv. O.; südl. u. östl. G., zerstr. dch. das mittl. Apr. Blb. hellgelb.

III. Gruppe. RANUNCULEFN DC. Ǩnospenlage des K. u. der Bl. dachig; Blb. an der Basis mit einer Schuppe, od. honiggrubigen Oeffnung versehen.

6. MYOSÚRUS L. Mäuseschwanz.

1. M. minimus L. (. Aecker. Mai. Jun. Blb. weisslich.

7. CERATOCÉPHALUS Moench. Hornköpfehen.

1. C. falcatus Pers. Früchtch. auf d. Rücken zw. den Höckern 
rinnig mit einem gebogenen Schnabel. $\odot$. Aecker; Wien, Ulm, zw. d. Donau u. Ilm. März. Ranunculus falcatus L. Bl. gelb.

2. C. orthoceras DeCand. Früchtch. auf dem Rücken hahnenkammf., Kamm fast 4eckig, Schnabel fast gerade. ( ). Trockne Hügel; Prag, Wien. März. Apr. Blb. gelb.

\section{RANUNCULUS L. Hahnenfuss.}

I. Rotte. Batrachi um DC. Blb. weiss, mit einem hellgelb. Nagel. Honiggrübchen umbedeckt $u$. auch nicht mit einem hervortretenden Rande versehen. Früchtch. quer-gestreift-runzelig, oberwärts und unterwärts schwach bekielt.

1. R. hederaceus L. B. sämmtl. gleichf., nierenf., stumpf. 5lappig; Früchtch. etwas gedunsen, quer-runzelig, kahl, an dem Ende kurz bespitzt, auf dem kahlen Fruchtboden sitzend. 24. Quellen u. Bäche; westl. u. nördl. Geb. Mai-Jul.

2. R. aquatilis L. Die untergetauchten B. borstl.-vielsp., gegestielt, $Z_{Y}$ fl. nach allen Seiten abstehend; die schwimmenden nierenf., lappig od. gespalten; Blb. vkteyf.; Stbg. $20 u$. mehr, länger als d. Köpfch. der Fruchtkn.; Früichtch. etwas gedunsen, quer-runzlich, steifh. od. kahl, an dem Ende kurz bespitzt; Fruchtboden beháart, fast kugelig. 2. Stehende Wasser und Bäche. Mai-Aug. R. heterophyllus Wigg. Var. $\alpha$. peltatus: schwimmende B. herzf.-rundl., bis über d. Mitte 3sp., seitenst. Lappen 2lappig, od. 5lappig, der mittlere Lappen mit 3, die seitlichen mit 2 Kerben. R. peltatus Schrank. $\beta$. truncatus: dieselbe Var., aber d. B. an d. Basis gestutzt, nicht herzf. - $\gamma$. quinquelobus: schwimmende B. 5lappig, Lapp. nicht gekerbt. - $\delta$. tripartitus: schwimmende B. 3th., Bzipfel 3eckig-vkteyf., oft gestielt, 2-3sp. u. gekerbt. $-\varepsilon$. Petiveri: schwimmende B. 3 th., d. mittlere Bzipfel 3kerbig, d. seitenst. 2lappig, Lappen 2kerbig; Früchtch. meist kahl. R. tripartitus Nolt. R. tripartitus $\beta$. obtusiflorus DC. R. Petiveri Koch. bei Sturm. R. pantothrix Brot. - ל. succulentus: B. sämmtl. vielsp.; Zipfelchen fadenf. dicker, saftig; entsteht ausserhalb d. Wassers.

3. R. paucistamineus Tausch. B. sämmtl. untergctaucht, borstl.-vielsp., gestielt, Zpfl. nach allen Seiten abstehend; Blb. vkteyf., Stbg. meist 12, länger als das Köpfchen der Fruchtkn.; Früchtch. etwas gedunsen, quer-runzelig, meist ein wenig steifh., an d. Ende kurz bespitzt, Fruchtboden behaart, fast kugelig. 24. Stehende Wasser u. Bäche; Rheinpfalz bei Kaiserslautern; Böhm. bei Lissa. Jun. Jul. Auf der Grenze des Gebiets kommt vor:

R. Baudotii Godron. Die untergetauchten B. borstl.-vielsp., gesticlt, Zpfl. nach allen Seiten abstehend; die schwimmenden dreith. u. gespalten; Blb. vkteyf; Stbg. länger als das Köpfchen der Fruchtkn.; Früchtch. ctwas gedunsen, quer-runzelig, kahl ungefähr 100, Fruchthod. 
behaart, ey-kegelf. 7. Stehende Wasser bei Saarburg auf d. Grenze d. Gebietes, vielleicht auch diesseits. Jun. Jul.

4. R. divaricatus Schrank. B. sämmtl. untergetaucht, borstl.vielsp., Zpfl. in eine kreisrunde Fläche auscinander treterd; Blb. 5, vkteyf.; Stbg. länger als das Köpfchen der Fruchtkn.; Früchtch. etwas gedunsen, quer-runzelig, unberandet, steifh., an dem Encle kurzbespitzt. 2. Stehende Wasser. Jun.-Aug. R. circinatus Sibth. R. rigidus Hoffm.

5. R. fluit a n s Lamarck. B. sämmtl. untergctaucht, borstl.vielsp., Zpfl. verlängert, gleichlaufend, gerade hervorgestreckt; St. stielrund; Blb. 9-12, längl.-keilig; Stbg. kürzer als das Köpfchen der Fruchtkn.; Friichtch. etwas gedunsen, quer-lunzelig, nuberandet, kahl, an dem Ende bespitzt. 24. Flüsse, stehende Wasser. Jun.-Aug. R. peucedanoides Desf.

II. Rotte. Hecatonia. Honiggribehen am Rande nackt, od. am Rande in eine Röhre od. oberwärts in eine oft 2 sp. Schuppe vorgezogen; Röhre od. Schuppe häutig, u. nicht dicklich u. fleischig. Früchtchen an d. Seiten glatt, od. daselbst mit unregelmässig ineinander laufenden Adern.

a. B. äderig; Blb. weiss, od. rosenroth angelaufen.

6. R. $\mathrm{ruta}$ folius L. WB. doppelt-gefiedert, Fiederchen 3 th.vielsp., Läppchen lineal.; St. 1-3l,th.; K. kahl; Blb. vkteyf., ganzrandig, od. ungleich-gekerbt; Friichtch. schräg-eyf., netzig-runzelig, unberandet, Schnabel kurz, gebogen. 2. Höchste A.; Wallis, Graubünd., Tyr., Salzb., Kärnth. Jul. Aug.

7. R. an emonoides Zahlbruckner. WB. 2-3zältlig, Blättch. 3th.vielsp., Läppchen lineal.; St. 1-2blättrig; K. kahl; Blh. lineal.längl., an der Spitze stumpf-ungleich-gekerbt; Früchtch.... 2. NaNelwälder d. VorA.; Oberstmk., Schneeberg in Unteröstr. März. Apr.

8. R. glacialis L. WB. 3zählig; Blättch. gestielt, 3th.-vielsp. mit lanzettl. stumpflichen Läppchen; St. $1-3 \mathrm{bth}$; $K$. sehr rauhh.; Blb. vkteyf., seicht ausgerandet; Frïchtch. schräg-eyf., kahl, unberandet, Schnabel gerade. 21. Höchste A. Jul. Aug.

9. R. S e guieri Vill. WB. u. stengelst. B. handf.-vielsp., im Umriss herzf.-rundl., Läppchen zugespitzl; St. 1-3btl.; K. kahl; Blb. vkteyf., abgerundet; Früchtch. schräg-eyf., convex, unberandet, netzigrunzlig, Schnabel dïnnn, hackig. 24. Höchste A.; Tyrol, Krain. Jun. Jul.

10. R. alpestris L. WB. herzf.-rundl., 3-u. 5sp., Zpfl. vkteyf., vorne eingeschnitten-gekerbt; St. 1 bth., meist 1 blätterig; das stengelst. B. 3sp. mit lineal. od. ungeth. Zpfin.; Bthstiel gefurcht; K. kahl; Blb. vkteyf. od. 3lappig, Friichtch. vkteyf., konvex, glatt, unberandet, Schnabel gerade, an d. Spitze hakig. 24. A. u. VorA. Jun. Jul.

11. R. Traunfellneri Hoppe. WB. 3 th., im Umriss nierenf., der 
mittl. Zpfl. 3sp., die seitlichen tief-2sp., Zpfleh. wiederum 2sp., Läppchen lanzettl.; St. 1bth., meist 1blättrig; das StB. lineal., ungeth.; K. kahl; Bthstiel gefurcht; Blb. vktherzf. od. 3lappig; Friichtchen..... 24. A. v. Tyr., Kärnth., Krain. Jun. Jul.

12. R. crenatus W. K. WB. rundl. u. nierenf., ganz od. vorn 3lappig, gekerbt, die hintern Kerben abneltmend; St. meist 1 bth $u$. meist 1 blättrig; das StB. lineal., ungeth.; Bthstiel gefurcht; K. kahl; Blb. vkteyf., geschweift-gekerbt; Friichtch. konvex, glatt, unberandet, Sehnabel mit breiter Spitze, etwas hakig. 2. GranitA. in Stmk. Jul. Aug.

13. R. a conitifolius L. W.- und StB. handf.-3-7th., Zpfl. 3sp., zugespitzt, eingeschnitten-gesägt ; St. vielbth.; Frïchtch. vkteyf., höckerig-konvex, äderig-runzelig, unberandet, Schnabel dünn, hakig. 2. Gebirgswälder; mittl. u. südl. Geb., u. in den A. Mai-Aug. Var.: Auf den A. kleiner, St. 3-5bth. R. aconitifolius L.; auf niedrigern Bergen $\beta$. höher, St. vielbth., Bzpfl. länger-zugespitzt: $R$. platanifolius $\mathrm{L}$.

b. B. nervig; Blb. weiss, od. rosenroth angelaufen.

14. R. parnassifoli us L. WB. herzf.-eyf., nervig, ganzrandig, Nerven der obern Fläche nebst d. St. u. Bthstielen wollig; Früchtchen... 4. Höchste A., Schwz., A. v. Aelen, Wallis, Graubünd.; Tyrol, Kirsehbaumer A. Jun. Jul.

15. R. pyrenaeus L. B. lanzettl., nervig, ganzrandig; St. 13bth.; Bthstiele an d. Spitze wollig ; Früchtch. vkteyf., konvex, glatt, unberandet, Schnabel dünn, hakig; Wurzelfasern stielrund, gegen d. Spitze verschmälert. 24. Feuchte O. der A.; Schwz., Tyr. u. Kärnth. Jun. Jul. Bth. weiss; B. meist lineal-lanzettl. Varirt: $\beta$. bupleurifolius DC., B. lanzettl., St. 1 bth. $-\gamma$. plantagineus DC., B. breitlanzettf.; St. mehrbth.; R. plantagineus All., nicht Pers.

e. B. nervig; Blb. gelb.

16. R. gramineus. L. B. linéal.-lanzettl., nervig, ganzrandig, nebst d. St. $u$. Bthstielen ganz kahl; St. 1- u. mehrbth.; Friichtch. sehräg-vkteyf., zsgedriickt, runzelig, u. etwas gestreift, bekielt, kurzbespitzt; WFasern gegen d. Spitze verdickt, etwas keulenf. 24. Sonnige Hügel im wärmern Wallis. Mai. Jun. Bth. sattgelb.

III. Rotte. Ranuneulus. Bth. hell- od. goldgelb. Das Honiggriibchen mit einer fleischigen aufwärts gerichteten Schuppe bedeckt. Bth. gelb.

§. 1. B. ungeth.; W. faserig.

17. R. Flammula L. B. elliptiseh, lanzettl. od. lineal-; St. aufrecht, aufstrebend od. mit geraden Gliedern niedergestreckt $u$. oft wurzelnd, vielbth.; Früehtch. vlsteyf., glatt, schwach-berandet, mit 
einem kurzen stumpfen Spitzchen endigenâ. 2. Feuchte Wiesen, Gräben, Pfützen. Jun.-Herbst.

18. R. reptans L. B. lineal. od. lineal.-lanzettl.; St. fädl., an d. Gelenken wurzelnd, die Glieder mit aufwärts gerichtetem Bogen gekrümmt; die untere Bscheide an d. Gelenken meist blattlos; Früchtch. vkteyf., glatt, schwach-berandet, mit einem geraden am Ende zurückgekrümmten Spitzchen. 2. Auf feuchtem Sande; Ufer der Seen in d. Schwz. Jun.-Herbst.

19. R. ophioglossifolius Vill. B. längl.-elliptisch, die untern herz-eyf., St. aufrecht, vielbth., Friichtch. schräg-eyf., berandet, kurzgeschnäbelt, auf beiden Seiten knötig-rauh. $\odot$. Siimpfe; Littorale, bei Aquileja, auf Veglia. Mai. Jun. R. fistulosus Brign. R. cochlearifolius Hornem.

20. R. Lingua L. B. verlängert-lanzettl., zugespizt; St. steifaufrecht, vielbth., an d. Basis quirlig-bewurzelt, ausläufer-treibend; Frïchtch. zsgedrückt, berandet, glatt, schnabel breit, kurz-schwertf. 4. Stehende Wasser, Ufer. Jul. Aug.

§. 2. B. ungeth. od. etwas lappip; W. vielknollig, nämlich aus verdickten Fasern zsgesetzt.

21. R. Ficaria L. St. beblättert; B. rundl.-herzf., die untern, geschweift, die obern eckig; K. meist 3blättr. 2. Wiesen, Zäune, Wälder. Apr. Mai. Ficaria ranunculoịdes Roth.

22. R. Thora L. var. $\alpha$. Das untere stengelst. B. sitzend od. kurzgestielt, mundl.-nierenf., gekerbt, das folgende vkteyf., vorne eingeschnitten, das blüthenst. lanzettl.; St. 1- od. 3bth. 2. Gebirgswäld., VorA. u. A.; Jura, Tyrol, Unterstmk., Krain. Mai. Jun. R. scutatus WK.

23. R. hybridus Biria. Das untere stengelst. B. sitzend od. kurzgestielt, quer-breiter, etwas nierenf., vorne fast gestutzt, eingeschnitten-lappig, der mittl. Lappen eyf.-zugespitzt; die blüthenst. lanzettl.; St. 1-3bth. 2. A. v. Tyr. bis Oestr. Mai. Jun. R. Thora Jaeq. R. Thora. $\beta$. L. Woll Variet. v. R. Thora.

§. 3. B. getheilt od. zsgesetzt; W. vielknollig.

24. R. illyricus L. B. nebst dem St. seidig-wollig; WB. 3zäl1lig, Blättch. lineal.-lanzettl., ungeth. od. 2-3th.; Bthstiele rund; K. zurückgeschlagen. 2. Felder, unkultiv. O.; östl. Geb. Mai. Jun.

§. 4. B. zsgesetzt od. tief-gelappt u. gespalten; W. faserig (bei dem R. bulbosus ist d. Basis des St. knollenartig verdickt); Früchtch. glatt.

* Bthstiel stielrund, u. nicht gefurcht.

25. R. auricomus K. WB. herzf.-kreisrund od. nierenf., gekerbt, ungeth. 3- od. vielsp.; Bstiele an d. Basis scheidig; StB. fingerig-geth., Zpfl. lineal. od. lanzettl., spreitzend; St. vielbth.; Bthstiele rund; Früchtch. bauchig, schmal-berandet, sammeth., Schnabel fast v. d. Basis an hakig. 24. Haine, Waldwiesen, Zäune. Apr.Mai. 
26. R. cassubicus I. Wurzelst. Scheiden häutig, blattlos; das WB. einzeln, herzf.-kreisrund od. nierenf., ungetheilt, gekerbt, seltner etwas gelappt od. 3sp.; Bstiel mit blattlosen Scheiden an d. Basis umgeben; die stengelst. gefingert, Z Zpfl. längl.-lanzettl., spreitzend; St. vielbth.; Bthstiele rund; Früchtch. bauchig, schmal-berandet, sammeth., Schnabel ziemlich gerade, an d. Spitze hakig. 4. Schattige Wälder; Schles. Mai. Selten mehrere WB.

27. R. montanus Willd. WB. handf.-getheilt, Zpfl. vkteyf., 3sp., stumpfl.-gezähnt; das untere stengelst. 5 th., Zpfl. längl.-lineal., handf.spreitzend, das obere 3sp.; St. 1-mehrbth.; Bthstiele rund; Friichtch. berandet auf beiden Seiten konvex, Schnabel etwas gekrümmt, vielmal kürzer als das Früchtch. Fruchtboden borstig. 24. A. u. VorA. u. niedrigere $O$. an Fusse d. A. bis in d. Ebenen. Jun. Jul. $\beta$. major: WB. mit mehreren Läppchen eingeschnitten; die mittlern $Z$ pfl. des untern stengelst. länger, an d. Spitze 3- u. mehrzähnig; R. pyrenaeus Gouan. R. Gouani Willd. - R. carinthiacus Hopp. ist weiter zu beobachten; die Blättchen spitzel', d. Lappen entfernter, schmäler.

28. R. Villarsii DeCand. WB. handf.-geth., Zpfl. vkteyf., 3sp. spitz-gezähnt, das stengelst. einzeln od. mehrere, fingerig-getheilt; Zpfl. lineal., St. 1-mehrbth.; Bthstiele rund, Fruchtboden borstig; Früchtch. linsenf.-zsgedriickt, berandet, Schnabel hakig. 24. VorA. u. A.; siidl. Schwz., Krain, Karstgbg. Mai. Jun. R. Hornschuchii Hopp.

29. R. acris L. WB. handf.-geth., Zpfl. fast rautenf., eingeschnitten-spitz-gezähnt; StB. gleichgestaltet, die obern 3th. mit lineal. Zpfln.; Bstiele flaumig, Haare anliegend od. aufrecht; St. vielbth.; Bthstiele rund; Friichtch. linsenf.-zsgedriickt, berandet, Schnabel etwas gekrïmmt, vielmal kürzer, als das Früchtch.; Fruchtboden kahl. 2. Wiesen d. Ebenen, Gbge. u. A. Mai-Jul.

30. R. lanuginosus L. WB. handf.-geth., Zpfl. breit-vkteyf., 3sp.-eingeschnitten, spitz-gezähnt; StB. gleichgestaltet, die obern 3th., mit längl.-langzettl. Zpfln.; Bstiele rauhh., Haare weit abstehend; St. vielbth.; Bthstiele rund; Früchtch. linsenf.-zsgedriickt, berandet, Schnabel an d. Basis breit, an d. Spitze eingerollt, fast halb so lang, als das Früchtch.; Fruchthoden kahl. 2. Wälder d. Gebge. Mai-Jul.

31. R. velutinus Tenor. WB. handf.-geth., Zpfl. breit-vkteyf. 3sp., eingeschnitten-gezähnt; die stengelst. obern 3th., Zpfl. lineal.; Bstiele rauhh., Haare weit abstehend; St. vielbth.; Bthstiele rund, K. zurückgeschlagen; Früchtch. linsenf.-zsgedrückt, berandet, glatt, Schnabel gerade, viel kürzer als das Früchtch.; Fruchtboden etwas haarig. 24. Siidl. Istrien u. dabei liegende Inseln. Mai. Jun. ** 13thstiel gefurcht.

32. R. polyan themos I. WB. handf.-geth., Zpfl. 3sp. od. 3th., eingeschnitten, Abschnittchen fast lineal.; Bthstiele gefurcht; Früchtch. 
linsenf.-zsgedrückt, berandet, Schnabel hakig; Fruchtboden borstig. 4. Waldwies. u. Wälder. Mai-Jul.

33. R. nemorosus DC. WB. handf.-gcth., Zpfl. vkteyf., 3sp., gezähnt; Bthstiele gefurcht; Frïchtch. linsenf.-zsgedriickt, berandet, Schnabel an d. Spitze eingerollt; Fruchtboden borstig. 2. Gebirgswälder, VorA. u. A. Mai. Jun. Der R. aureus Schleich. besteht in kleinen Exempl.

34. R. repens. L. WB. 3zählig u. doppelt-3zählig, Blättch. 3sp., eingeschnitten-gezähnt; Bthstiele gefurcht; K. abstehend; Friichtch. linsenf.-zsgedriickt, berandet, fein-eingestochen-punktirt; Ausläufer kriechend. 4. Wiesen, Aecker, Wälder. Mai-Jul.

35. R. bulbosus L. WB. $3 \approx$ ählig und doppelt-3zählig, Blättch. 3sp., eingeschnitten-gezähnt; Bthstiele gefurcht; $K$. zurückgeschlagen; Früchtch. linsenf.-zsgedriekt, berandet, glatt; St. an d. Basis knollenf. 24. Felder, unkultiv. O. Mai-Jul.

§. 5. B. zsgesetzt, od. tief-gelappt; W. fascrig; Früchtch. runzlig, od. mit Knötchen od. Dornen besetzt.

36. R. Philonotis Ehrhart. WB. 3zählig od. doppelt-3zählig, Blättch. 3sp., eingeschnitten-gezähnt; Bthstiele gefurcht; $K$. zurückgeschlagen; Frïchtch. linsenf.-zsgedriickt, berandet, auf den ganzen Mittelfeldern od. mur vor dem Rande mit einer Reihe Knötchen besetzt. $\odot$. Kultiv. O., an Sümpf. Mai-Ang. R. hirsutus Curt. R. sardous Crtz.

37. R. sceleratus L. Die unteri B. handf-getheilt, eingeschnitten-gekerbt, die obern 3 sp., Zpfl. lineal.; K. zurückgeschlagen; das Fruchtköpfchen längl-ährenf.; Früchtch. unbekielt, am Rande mit einer eingegrabencu Linie umzogen, in d. Mitte auf beiden Seiten fein-runzelig. $\odot$. Feuchte 0 . Jun.-Herbst.

38. R. arvensis L. WB. ganz od. 3sp., gezähnt, StB. 3zählig; Blättch. gestielt, 3 -vielsp., Zpfl. keilf., vorne gezähnt, die obern lineal.; Früchtch. flach-zsgedrückt, geschnäbelt, dornig, knötig, od. $n \epsilon t z i g$, mit einem hervorspringenden auf beiden Seiten dornigen od. gezälmnten in d. Mitte bekielten Rande. $\odot$. Aecker, kultiv. O. MaiJul. Var. $\alpha$. mit dornigen Friichtch. u. $\beta$. tuberculatus: Früchtch. auf beiden Seiten mit stumpfen Knötchen u. am Rande mit stumpfen Zähnen besetzt: R. tuberculatus DeCand. $\gamma$. inermis: Früchtch. auf beiden Seiten mit hervorspringenden, ineinanderfliessenden Adern besetzt $u$. ganz wehrlos; Rand ohne Zähne. Bisher an einem einzigen $O$. in d. Nähe v. Bonn.

39. R. muricatus L. Die untern B. rundl. od. nierenf., 3lappig, ungleich-grob-gekerbt, die obern $3 \mathrm{sp}$. an d. Basis keilig; Bthstiele den Blättern gegenst.; $K$. abstehend; Früchtch. geschnäbelt, flach, knötig od. dornig, mit einem glatten, geschärften Rande umzogen. $\bigcirc$. Niedrig gelegene O.; Fiume, südl. Tyrol. Mai-Jul.

40. R. parviflorus L. B. herzf.-rundl., 3sp., lappig-gekerbt, die 
obern 5lappig, die obersten längl., ungeth. od. 3lappig; Bthstiele d. Blättern gegenst.; $K$. zurückgeschlagen, Früchtch. geschnäbelt, linsenf.-zsgedrückt, knötig od. dornig mit einem glatten, geschärften Rande umzogen. (0. Unkultiv., etwas feuchte O. u. Weinberge; Monfalcone, Istr. Mai-Jul.

NII. Gruppe. HELLEBOREEN. DeC. Knospenlape des K. u. d. Bl. dachig. Stbk. auswärts aufspringend. Früchtch. kapselig.

9. CALTHA L. Dotterblume.

1. C. palustris L. St. aufstrebend; B. herzf.-kreisrund, kleingekerbt. 2. Wiesen, Ufer, Gräben. Apr.-Jun.

10. TRÓLLIUS. L. Trollblume.

1. T. europaeus L. Die $10-15 \mathrm{~KB}$. fast in eine Kugel zsschliessend; Blb. so lang, als die Stbg. od. ein wenig kürzer; B. 5th., Zpfl. rautenf., 3sp., eingeschnitten u. gesägt. 2. Feuchte Wiesen; Gbge. u. VorA. Mai-Jul. Bth. gelb.

\section{ERÁNTHIS Salisbury. Winterling.}

1. E. hyemalis Salisbury. KB. 5-8, längl. 2. Schattige Haine d. Ebenen u. VorA.; sehr zerstreut deh. d. Geb. Febr. März. Bth. gelb.

\section{HELLÉBORUS L. Niesswurz.}

1. H. niger L. WB. fussf.; Schaft mit $2-\mathbf{3}$ Deckblättern, 1-2bth.; DeckB. oval. 24. Schattige Wälder d. Gbge u. VorA.: südl. u. östl. Geb. Decemb.-Febr. Btl. weiss.

2. H. viridis L. St. nackt, an d. Verästelungen beblättert; B. fussf., Blättch. der WB. zurückgekrïmmt, rinnig-gebogen, verlängertlanzettl., spitz, ungleich-tief-gesägt, kahl od. etwas flaumh., unterseits runzelig-geädert, Adern hervorspringend, Narben aufrecht. 4. Wälder; südl. Geb., im mittl. hin u. wieder. März. Apr. Bth. grün.

3. H. odorus W. K. St. nackt, an d. Verästelungen beblättert; B. fussf., Blättch. der WB. flach, breit-lanzettl., zugespitzt, klein-, fast gleich-gesägt, kahl od. unterseits kurzh., runzelig-äderig, Adern vorspringend; Narben wagrecht-zurückgekrïmmt. 24. Gebirgige Wälder; südl. Geb. März. Apr. Bth. grün. Var. $\beta$. atromibens, Bth. aussen mit einem violetten Anstriche: H. atrorubens WK., dieser inStmk.

4. H. dumetorum W. K. St. nackt, an den Verästelungen beblättert; B. fussf., Blättch. der WB. lanzettl., klein-, ziemlich gleichgesägt, kahl, die Hauptaderı unterseits etwas hervorspringend, die Nebenadern eingesenkt. 24. Hecken; Krain, Stmk. März. Apr. Bth. grün.

5. I. foetidus L. St. vielbth., bebiättert; die untern B. fussf. mit 7 u. 9 Blättch., die obern 3sp., kleiner als der verbreiterte Bstiel; DeckB. d. Aeste u. Bthstiele oval. 4. Steinige O.; südl. u. westl. Geb. März. Apr. Bth. grüu. 


\section{ISÓPYRUM L. Muschelblümchen.}

1. I. thalictroides L. W. kriechend, Fasern büschelig; Blb. stumpf. 24. Wälder; Genf, Littor. u. östl. Geb. bis Schles. u. Preuss. März-Mai. Bth. weiss.

14. NIGELLA L. Schwarzkümmel.

1. N. arvensis L. Stbk. begrannt, Granne halb so lang, als das Stbk.; Kapseln glatt, auf d. Riicken 3nervig, von d. Basis bis zur Mitte zsgewachsen; Bthhülle fehlend; S. 3kantig, feinkörnigrauhlich. $\odot$. Kultiv. O. Jul.-Sept. KB. weiss, vorne bläulich, unterseits griingestreift u. netzig.

2. N. damascena L. Stbk. grannenlos; Kapseln glatt, von d. Basis bis zur Spitze verwachsen; Bth. behüllt; S. 3kantig, quer-runzelig. $\odot$. Kultiv. O.; Istr., Fiume. Mai-Jul. KB. hellblau, an d. Spitze u. an d. Adern unterseits grün.

3. N. sativa L. Stbk. gramnenlos; Kaps. drüsig-rauh, auf d. Riicken 1nervig, von d. Basis bis zur Spitze verwachsen; Bthhiille fehlend; S. 3kantig, quer-runzelig. ○. Bei Erfurt gebaut, u. daselbst hin u. wieder unter d. Saat. Jun. Jul. KB. weisslich.

\section{AQUILÉGIA L. Akelei.}

1. A. vulgaris L. Sporne an d. Spitze hakig, Platte sehr stumpf, ausgerandet; Stbg. ein wenig länger als d. Platte; KB. längl.eyf.; B. doppelt-3zählig, Blättch. 3lappig, gekerbt, Kerben eyf., abgerundet. 24. Wälder. Jun. Jul. Bth. blau. Var. kleiner, St. meist 1bth., Blättch. viel kleiner: A. viscosa Gouan.

2. A. Ha enkeana Koch. Sporne an der Spitze hakig, länger als die gestutzt-stumpfe Platte; Stbg. etwas länger, als d. Platte; KB. längl.-eyf.; B. doppelt-3zählig, Blättch. bis üher d. Mitte 3sp., eingeschnitten-gekerbt, Kerben eyf., od. längl., stumpf. 24. Ortenburger A. bei Spital in Oberkärnthen, u. längs d. Savestrom bei Laibuch. Jun. Jul. Aquilegia alpina Haenke. A. Sternbergii Rchb. K. syn. ed. 1. Vielleicht Var. v. d. A. vulgaris mit tiefer-eingeschnittenen B. Bth. blau.

3. A. atrata Koch. Spnrne an d. Spitze hakig, länger, als die sehr stumpfe, mit einer kleinen vorspringenden Spitze versehene Platte; Stbg. $11 \frac{2}{2}$ mal länger als d. Platte; KB. längl.-eyf.; B. doppelt3zählig; Blättch. halb-3sp., gekerbt, Kerben eyf., stumpf. 24. A. u. VorA. Jun. Jul. Bth. violettbraun.

4. A. alpina L. Sporne ziemlich gerade od. gebogen, (nicht hakig) so lang, als d. gestutzte Platte od. etwas länger; Stbg. kürzer, als d. Platte; KB. breit-eyf.; B. doppelt-3zählig, Blättch. tief3sp., eingeschnitten od. gekerbt, Kerbeu längl., stumpf. 2. A. d. Schw. Jul Aug. Bth. freudigblau. A. montana Sternb.

5. A. pyrenaica DeCand. Sporne an d. Spitze gerade; Platte 
abgerundet, so lang als der Sporn u. die Stbg., od. ein wenig länger; KB. längl.-eyf.; B. 1 fach-od. doppelt-3zählig, wenig-kerbig, Kerben abgerundet. 2. Steinige O.; Krain, Kärnth., siidl. Tyrol; südl. Schwz. Jun. Jul. A. alpina Lam. Sternb. A. viscosa Treviran. Bth. blau, fast um d. Hälfte kleiner, als bei A. vulgaris.

\section{DELPHINIUM L. Rittersporn.}

1. D. Consolida L. Bl. 1blättrig; St. einfach-ästig; Tr. armbth.; Bthstielch. viel länger als das DeckB.; Kapsel kahl. $\odot$. Kult. O. Jun.-Aug. azurblau.

2. D. paniculatum Host. Bl. 1blättrig; St. sehr ästig, rispig; Tr. armbth.; Bthstielchen viel länger als das DeckB.; Kapsel kahl. $\odot$. Aecker auf d. Insel Osero. Ganz ähnlich ist D. divaricatum Ledeb., nur sind die Früchtchen angedrückt-flaumig; Variet.?

3. D. elatum L. Bl. 4blättrig, Saum d. untern Blb. 2sp., bärtig; B. handf.-5sp., Zp甘l. 3sp., eingeschnitten-gesägt, Bstiele ar der Basis nicht scheidig; Bthstielch. oberwärts mit 2 lineal. Deckblättchen. 24. Grasige O., an Bächen; Gbge. v. Stmk., Mähr., im Riesengbg., Aelener Berge d. Schwz. Jun. Jul. D. intermedium Ait. D. Clusianum Host. D. alpinum W. K. D. montanum DC. K. azurblau; Blb. russfarben.

4. D. hybridum Willd. Bl. 4blättrig, Saum d. untern Blb. 2sp., bärtig; B. 3zählig-vielth., Zpfl. lineal.; Bstiele unterwärts scheidigverbreitert; Bthstielch. in d. Mitte mit 2 lineal. Deckblättch. 4. Karstgbg. im Litt. Jun. Jul. D. fissum WK. Bth. blau.

5. D. Staphysagria L. Bl. 4blättrig, Blb. an d. Basis zsgewachsen, bartlos; B. handf.-5sp., Zpfl. ganz od. 3sp.; Bthstielch. an d. Basis mit 3 Deckblättern. $\odot$. Am Meere in Istrien. Jun. Jul. K. blau; Blb. weissl.

\section{ACONÍTUM L. Eisenhut.}

1. A. Anthora L. Honigbehälter auf einem gebogenen Nagel wagerecht-nickend, Sporn kreisf.-zurückgerollt, an der obern Seite seiner Basis rechtwinkelig einwärtsgebrochen. 2. Steinige 0 . der A.; Jura, Graubünden, Krain, Oestr. Ang. Sept. Bth. gelb.

2. A. Napellus L. Honigbchälter auf einem gebogenen Nagel wagerecht-rickend, Sporn etwas zurückgekrümmt; Bth. traubig; die jüngern Früchtch. spreitzend; S. scharf-3kantig, auf d. Rücken stumpf-faltig-runzelig. 24. Feuchte O., A. u. VorA., Berggegend. in Böhm., Schles., Vogelbg. Jun.-Aug. Bth, violett, selten bläulich od. weiss. $\alpha_{*}$ A. tauricum Wulf.: ganz kahl, Traube gedrungen. $\beta$. A. angustifolium Bernh.: kahl, Bzipfel sehr schmal. - $\gamma_{.} \boldsymbol{A}$. pyramidale Mill.: flaumh., Bthstiele aufstrebend. A. Nappellus Jacq. fl. austr. - $\delta$. A. neomontanum Wulf, : flaumh., höher, spätblühend, Bthstiele steifabstehend. 
3. A. Stocrkeanum Rchb. Honigbehälter auf einem oberwärts gebogenen Nagel schief-geneigt, Sporn hakig; die jüngern Früchtch. einwärts gekrümmt, zsschliessend; S. scharf-3kantig, auf d. Rïcken geschärft-runzelig-faltig. 2. Gebirgswälder; sehr zerstreut dch. d. Geb. Juu. - Aug. A. intermedium DC. A. neomontanum Willd. A. Napellus Stoerk. Bth. violett od. weiss, od. violett u. weiss-bunt.

4. A. variegatum I. Honigbehälter auf einem geraden Nagel aufrecht od. schief-geneigt, Sporn hakig; Tr. "an d. Basis ästig, endlich rispig; jüngere Früchtch. parallel; S. scharf-3kantig, quergefaltet, Rückenfalten geflïgelt, häutig, wellig, 24. A. u. höhere Gbge.; siidl. u. mittl. Geb. Jul. Aug. Bth. violett, blau, weiss u. blaubunt; A. Cammarum Jacq.

5. A. paniculatum Lam. Honigbehälter auf einem gekrümmten Nagel nickend, Sporn zurückgekriimmt; Bth. traubig, endlich sperrig-rispig; jiingere Frïchteh. spreitzend; S. scharf-3kantig, quergefaltet, Rückenfulten geflügelt, häutig, wellig. 4. Feuchte O. d. A. Jul. Aug. Bth. violett, R. immer flaumh., Haare gerade, wagerechtabstehend. A. cernum Wulf. A. flexicaule Hoppe u. Hornsch.

6. A. Lycoctonum L. Die Honigbehälter aufrecht, Sporn fädlich, zirkelf.-zsgerollt; S. iiberall faltig-runzelig, stumpf-3kantig mit scharfem Kiele; B. handf. 24. Gebirgswälder u. VorA. Jun. Jul. Bth. schwefelgelb, weisslich, roth (bei Ungarisch. Expl.) bläulich u. violett.

5. Gruppe. UNEIGENTLICHE RANUNCULACEEN DC. Stbk. einwärts aufspringend. Knospenlape dachig. Früchtch. mehrsamig.

18. ACTAÉA L. Christophskraut.

1. A. spicata L. Beeren rundl.oval; Blb. so lang, als d. Stbg.; Tr. eyf.; B. 3zählig-doppelt-gefiedert, Blättch. eyf. odl. längl., eingeschnitten-gesägt. 24. Schattige Wälder. Mai. Jun. Bth. weiss.

\section{CIMICÍFUGA L. Wanzenkraut.}

1. C. foetida L. Fruchtkn. meist zu 4, flaumh., sehr kurzgestielt; B. 3zählig-doppelt-gefiedert, Blättch. eyf.-längl., ungleich-doppelt-gesägt. 24. Haine; Mähren bei dem $O$. Sloun, Weichselufer bei Graudenz. Jul. Aug. Actaea cimicifuga L. DC. Bth. grünlich.

20. PAEONIA L. Päonie.

1. P. corallina Retz. St. ganz einfach, 1 bth.; Friichtch. meist 5, wagerecht-abstehend; B. doppelt-3zählig, unterseits weissliclı-lauchgrün, Blättch. elliptisch-längl. od. elliptisch, ganz, das endst. an d. Basis keilig; WFasern rübenf., gegliedert-ästig, sitzend od. kurzgestielt. 24. Wälder; auf d. Müllersberge am Kugelbache bei Reichenhall. Apr. Mai. Bl. purpuru. 
2. P. peregrina Mill. St. ganz einfach, 1 bth.; Friiehteh. 2 od. 3 von d. Basis an fast wagereelit-abstehend; B. doppelt-3zählig, unten weisslich-lanehgriin, Blättch. 2-3sp., Fetzen ganz, 2- od. 3sp.; WFasern zu länglichen Knollen verdickt, meist lang-gestielt. 4. Steinige O.; südl. Schwz., südl. Tyrol, Krain, Litt. Mai. Jun. P. off. u. peregrina M. et. K. D. Fl. u. Gaud. P. rosea Host. P. bannatica Roch. P. humilis Retz. Bl. purp. - Die P. offieinalis L. u. der Gärten ist nach d. Beobaehtung v. Dr. Faeehini Abkömmling der wilden $\mathbf{P}$. peregrina Mill.

\section{Ordng. BERBERIDEEN. Vent.}

\section{BÉRBERIS L. Sauerdorn.}

1. B. vulgaris L. Dornen 3th.; B. büsehelig, vkteyf, gewimpert-gesägt; Tr. vielbth., niederhängend; Blb. ganz od. seichtausgerandet. $\hbar$. Gebiiseh $u$. gebirgige, waldige O. Mai. Jun. Bth. hellgelb.

2. EPIMEDIUM L. Sockenblume.

1. E. a lpiu um L. WB. fehlend, das stengelst. doppelt-3zählig. 4. Schattige O.; Krain, südl. Tyrol, auch bei Danzig. Apr. Mai. Bth. blutroth, Honigbehälter liellgelb.

\section{Ordng. NYMPHAEACEEN. DC.}

\section{NYMPHAEA L. Smith. Seerose.}

1. N. alba L. B. rundl., tief.-herzf., ganzrandig, Lappen $d . B a-$ sis wegen der geradelinigter Bucht schief-eyf.; Fruchtkn. bis gegen d. Spitze mit. Stbg. besetzt; Narbe 12-20strahlig. 4. Stehende u. langsam fliessende Wasser. Jun.-Aug. Narben gelb; Blb. sehneeweiss. Var. mit um d. Hälfte kleinern Bth.: N. alba $\beta$. minor DC.

2. N. biradiata Sommeramer. B. rundl., tief-herzf, etwas gesehweift, Lappen der Basis fast gleichzeitig-eyförmig, wegen der, mit gekrïmmten Rändern, auswärts offenen Bucht; Fruehtku. bis gegen d. Spitze mit Stbg. bedeckt; Narbe 5-10strahlig. 2. Triebener See in Oberstmk., Zellersee im Salzb. Jul. Ang. IBlb. sehneeweiss, Narben in d. Mitte mit einem kreisrunden, gezähnten, blutrothen, getroeknet violetten, mit 3 Zälınen in die einzelnen gelben Strahlen auslaufenden Flecken.

3. N. c andida Presl. B. rundl., tief-herzf., etwas gesehweift, Lappen der Basis fast gleiehzeitig-eyf., wegen der, mit gekrümmteı Rändern, auswärts offenen Bucht; Fruchtkr. entblösst, glatt, nur an d. Basis mit Sthg. besetzt; Narbe 8strahlig. 24. Steliende Wasser; Böhmen. Jul. Aug. Bl. weiss; Fruehtkn. ey-kegelf., glatt, nur am untersten Drittheil seiner Höhe mit Blb. u. den hier entspringenden Stbg. bedeckt (nach Presl). 
2. NÚPHAR Smith. Teichrose.

1. N. lute um Smith. K. 5blättrig; Narbe flach, tief-genabelt, ganzrandig, kaum randsehweifig, 10-20strahlig, Strahlen vor d. Rande versehwindend; Stbk. längl.-lineal.; B. oval, auf 1/3 herzf.eingeschnitten, Lappen genähert. 24. Stehende $u$. Iangsam fliessende Wasser. Jun.-Aug. Bth. gelb, wie bei allen. Variirt: Bth. um d. Hälfte kleiner, ibrigens nicht verschierlen; u. B.- и. Bthstiele seidigflaumh. Nymphaea Iutea L.

2. N. pumilum Smith. Engl. Fl. K. 5blättrig; Narbe sternf.spitz-gezähnt od. eingeschnitten, meist 10strahlig, zuletzt halbkugelig mit an den Rand anslaufenden Strahlen; Sthk. fast 4eckig, um d. Hälfte länger, als breit; B. fast oval, tief.-herzf., Lappen meist anseinandertretend. 2. Stehende Wasser; zerstr. deh. d. Geb. Jul. Aug. Nymphaea pumila Hofm. Bth. gelb.

3. N. Spennerianum Gaud. K. Sblätrig; Narbe sternf.-spitzgezähnt od. eingeschnitten, meist 10strahlig, zuletzt halbkugelig, Strahlen an den Rand auslaufend; Stbk. lineal.-länglich, fast $4 \mathrm{mal}$ länger, als breit; B. fast oval, tief-herzf., Lappen meist auseinandertretend. 24. Im Feldsee d. Schwarzwaldes, Spitzingsee in Oberbaiern. Jun.-Aug. N. minima Spemn. bot. Ztg. Bth. gelb.

\section{Ordng. PAPAVERACEEN. DC.}

\section{PAPÁVER L. Mohn.}

1. P. alpinum L. Stbf. pfrieml.; Kapsel rkteyf., steifh.; Sehaft 1lth.; B. fast doppelt-gefiedert. 2. Höchste A. Jul. Aug. Kommt vor: $\alpha$. albiflorum: Blb. weiss, an d. Basis sehwefelgelb. P. alpinum Jaeq., P. Burseri Cranz. - $\beta$. flaviflorum: Blb. citrongelb, an d. Basis sehwefelgelb odl. blassgrün. P. pyrenaicum $\alpha$. luteun DC. $\gamma$. aurantiacum: die Blb. in Leben orangenfarben. P. aurantiacum Lois. - $\delta$. puniceun: die Blb. hochroth. P. pyrenaicum $\beta$. puniceum DC.

2. P. Argemone L. Stbf. oberwärts verbreitert; Kapsel verlängert-keulenf., v. zerstrenten, aufrechten Borsten steifh. St. beblättert, mehrbth. $\odot$. Aecker. Mai-Juli. Bl. hochroth. Var. selten mit kahler Kapsel.

3. P. hybridum L. Stbf. oberwärls verbreitert; Kapsel rundl., von weit abstchenden, gebogenen Borsten steifh.; St. beblättert, mehrbth. $\odot$. Aeeker; sehr zerstreut deh. d. Geb. Mai-Jul. Bl. hochroth.

4. P. Rhoeas L. Stbf. pfrieml.; Kapsel kurz-vkteyf., an d. Basis abgerundet, kahl; Läppch. der Narbe mit ihrem Rande sich deckend; St. steifh., mehrbth.; B. gefiedert, u. doppelt-gefiedert, Zpfl. längl.-lanzettl., eingesehnitten-gezähnt. $\odot$. Kultiv. O., Sandfelder. Mai-Jul. Bl. hochroth. Var. $\beta$. Haare der Bthstiele angedriickt: $\mathrm{P}$. Rhoeas $\beta$. strigosum v. Bönningh. 
5. P. dubium L. Stbf. pfrieml.; Kapsel keulenf., gegen d. Basis allmählig verschmälert, kahl; Kerben $d$. Narbe getrennt; St. steifh., mehrbth.; B. doppelt-fiedersp., Zpfl. lineal., entfernt-gezähnt. ○. Iinltivirte O. Mai-Jul. Bl. hochroth, selten weiss. Var. kahl: P. laevigatum MB.

6. P. somniferum L. Stbf. oberwärts verbreitert; Kapsel fast kugelig, kahl; B. längl., ungleich-gezähnt, die obern ganz, mit herzf. Basis stengelumfassend, die unteren buchtig, an d. Basis verschmälert. $\odot$. Gebautet. Jul. Aug. Bl. weiss od. violett.

2. GLAUCIUMI Tournef. Hornmohn.

1. G. luteum Scop. Die oberen B. mit tief-herzf. Basis stengelumfassend, lappig-fiedersp., im Umriss rundlich-herzf.; Schoten knötig-rauh. $\odot$. Unkultiv. O., Fluss - u. Meeresufer; sehr zerstreut dch. d. G. Jun. Jul. Chelidonium Glancium L. Bth. citrongelb od. rothgelb.

2. G. corniculatum Curtis. Die obern B. mit abgeschnittener Basis sitzend, fiedersp., im Umriss längl.-eyf.; Schoten borstig-steifh. ○. Aecker; Oestr., Böhm., Thiiring., Rheinpfalz. Juu. Jul. G. phocniceum Gärtn. Chelidonium corniculatum L. Blb. roth, an d. Basis mit einem schwarzen Flecken. Var. d. schwarze Flecken von einem weissen Saum umzogen: G. tricolor Bernh.

3. CHELIDONIUM L. Schöllkraut.

1. Ch. majus L. Bthstiele doldig; K. fast kahl; Stlf. oberwärts breiter. 2. Schattige felsige 0 ., auf Schutt, an Mauern u. Wegen. Mai-Aug. Blb. gelb. Var. $\beta$. laciriatum: die Blättch. od. die Bfieder länger gestielt, bis iiber $d$. Mitte fiedersp., Zpfl. längl., eingeschnittengekerbt; das endst. Blättch. 5-7th.; Blb. oft eingeschnitten-gekerbt; an d. Bädern v. Baden-Baden u. bei Carlsruhe, bei Eisleben, Frankf. a. d. O. C. laciniatum Mill. C. quercifolium Willemet.

4. HYPÉCOUM L. Lappenblume.

1. II. pendulum L. Die 2 äusseren Blb. elliptisch-länglich, ganz, die innern halbdreisp., mittlerer Lappen rundl., gestielt, länger als die seitenst. $\odot$. Aecker; $z w$. Gönuheim u. Ellẹstadt, Rheinpfalz. Jun. Jul. Blb. gelb.

\section{Ordng. FUMARLACEEN. DC.}

\section{CORÝdALIS DeC. Hohlwurz.}

1. C. cava Schweigg. u. Koert. W. knollig, auf allen Seiten mit WFasern besetzt, holl, zuletzt vielstengelig; St. 2blättrig, ohne S'chuppe über d. Basis; B. doppelt-3zählig, eingeschnitten; fruchttrag. Tr. aufrecht; DeckB. ganz; Bthstielchen dreimal kürzer als 
die Kapsel. 2. Haine, Gebüsch d. Wiesen. Apr. Mai. Fumaria eava Mill. F. bulbosa $\alpha$. L. Coryd. tuberosa DC. Bth. truibpurpurn od. weiss.

2. C. solida Smith. W. knollig, nicht ausgehöhlt, am untersten Ende mit Fasern besetzt; B. doppelt-3zählig, eingeschnitten; der untere Bstiel blattlos, schuppenf., DeckB. firgerig-geth.; Fruchttraube verlängert, aufrecht, Früchte entfernt; Bthstielch. so ling als d. Kapsel. 24. Haine, Gebüsch. Apr. Fumaria solida Ehrh. F. bulbosa $\boldsymbol{\gamma}$. L. F. Halleri Willd. Coryd. digitata Pers. C. bulbosa DC. Btlı. trïbpurp.

3. C. fa b a cea Pers. W. knollig, nicht hohl, an untersten Ende mit Fasern besetzt; B. doppelt-3zählig, eingeschnitten; der untere Bstiel blattlos, schuppenf.; DeckB. ganz; Fruchttraube gedrungen, überhangend; Bthstielch. 3mal kürzer als d. Kapsel. 21. Haine, Gebiisch; nördl. u. mittl. Geb., im südl. in d. A.-Apr. Mai. Fumaria fabacea Retz. F. intermedia Ehrh. F. bulbosa f. L. Der Buckel in der Mitte des untern Blb. stark hervortretend, fast einen rechten Winkel bildend. Bth. triibpurp.

4. C. pumila Host. W. knollig, nicht hohl, an untern Eude mit Fasern besetzt; B. doppelt-3zählig, eingeschnitten; der untere Bstiel blattlos, schuppenf.; DeckB. fingerig-geth.; Fruchttraube gedrungen, überhangend; Bthstielchen dremal kürzer als die Kapsel. 24. Mit d. vorhergehenden hin und wieder. Bliihet früher. Der Buckel am untern Blb. viel schwächer. C. Lobelii T'ausch. Bth. trübpurp.

5. C. lutea DC. W. ästig-faserig; B. dreizählig-dreifach-fiederig, in das Lauchgriine spielend, Blättch. ganz u. 3sp., die endst. breitvkteyf.; Bstiele oberseits flach, unberandet; DeckB. längl., haarspitzig, gezähnelt; Schoten längl., meist so lang als das Bthstielchen; S. glänzend, sehr fein-körnig-runzelig, mit abstehendem, körnig-lappigem, gezähneltem Anhängsel. 24. Felsenspalten, Mauern; siidl. Tyr., C. Tessin; am Sclılosse Idstein in Nassau; bei Linz am Rheine. Jul._Sept. C. capnoides f. lutea DC. Fumaria lutea L. Bl. citrongelb, an der Spitze sattgelb.

6. C. ochroleuca Koch. W. ästig-faserig; B. 3zählig-dreifachfiederig, in das Lauchgriine spielend, Blättcl. ganz u. $3 \mathrm{sp}$., die endst. vkteyf., keilig; Bstiele oberseits flach $u$. zu beiden Seiten mit einem hervortretenden Rande versehen; DeckB. länglich, haarspitzig, gezälmelt; Schoten lineal-länglich, länger als das Bthstielchen; S. fast glanzlos, körnig-rauh, mit angedrïcktem, fast ganzrandigem Anhängsel. 4. An felsigen O.; 'Triest, Istr., siidl. Tyrol. Jul.—Sept. C. capnoides $\alpha$. DC. Fumaria capnoides Scop. Bl. weissgelblich, an der Spitze gelb.

7. C. acaulis Pers. W. ästig-faserig; B. 3zählig-doppelt-fiederig od. fiederig, weisslich-graugriin; Blättch. ganz od. 3sp. u. 5sp., das endst. breit-rkteyf.; Bstiele oberseits flach, unberandet; DeckB. längl.; haarspitzig, gezähnelt; Schoten längl., 2-3ınal kürzer als 
das Bthstielchen; S. fast glanzlos, körnig-rauh, mit angedrücktem, fast ganzrandigem Anhängsel. 2. Felsen u. Mauerritzen; siidl. Istrien. Mfai-Jul. Fumaria acaulis Wulf. Bl. schneeweiss, mit einem griinen Kiele an der Spitze der Blb.

8. C. capnoi des L. W. ästig-faserig; B. 3zählig, Blättch. 3th. od. 3sp. u. eingeschnitten; unterstes DeckB. von der Gestalt eines StB., länger als das Bthstielchen; Sporn fast von der Länge der Bl.; Samen sehr glatt, glänzend. $\odot$. Steinige, fette $O$. im obern Teferecken im Pusterthal an der obern Gränze der Cerealien $u$. weiter hinauf. Jun. Jul. Bl. gelblichweiss.

9. C. claviculata DC. W. einfach; B. doppelt-gefiedert, Blättch. ganz, die d. Fieder 3- od. 5zählig-fussf.-gestellt; Bstiele in Wickelranken endigend; DeckB. längl., zugespitzt, gezähnelt, länger als das Bthstielchen. $\odot$. Wälder; von Westph. bis Holst. Jun.Sept. Bth. klein, weisslich.

2. FUMARIA L. Erdrauch.

1. F. capreolata L. KB. halb so lang als die Bl.; Schötchen rundl., sehr stumpf; die fruchttrag. Tr. locker; Bzpfl. längl. u. vkteyf. $\odot$. Zäune u. Schutt; sehr zerstreut dch. d. Geb. Jun.Sept. Bl. weiss oder gelblichweiss, auf dem Rücken manchmal purpurn, an der Spitze schwarzpurpurn.

2. F. Petteri Reichenbach. KB. 3 mal kürzer als die $B l$, breiter als das Bthstielchen; Schötch. eyf., stumpfl.; die fruchttrag. Tr. locker; Bzpfl. längl. u. längl.-vkteyf. $\odot$. Auf Mauern bei Hamburg. Jun. - Sept. Bth. der F. off., Schötchen eyf., nicht quer-breiter, stumpf, nicht ausgerandet, Ansehen d. F. capreolata.

3. F. officinalis L. KB. 3mal kürzer als die Bl., breiter als das Bthstielchen; Schötch. rundl., quer-breiter, vorne gestutzt, etwas ausgerandet; die fruchttrag. Tr. locker; Bzpfl. längl. u. lineal. $\odot$. Kultiv. O., Sandfelder. Mai - Sept. 131. purpurn, an der Spitze schwarzpurpurn, wie bei allen. Var.: Bth. halb so gross, Kraut gesättigter-meergrün.

4. F. Vaillantii Lois. KB. schmäler als das Bthstielchen, vielmal kürzer als die $B l$.; Schötchen kreisrund, abgerundet-stumpif; die fruchttrag. Tr. locker; Bzpfl. lineal. $\odot$. Kultivirte O. Jun.Sept. Bl. purpurn.

5. F. parviflor a Lam. KB. 6mal kürzer als die $B l$, so breit als diese; Schötch. eyf.-rundl., vorne spitzl.; die fruchttrag. Tr. locker; Bzpfl. lineal. $\odot$. Kultiv. O.; Rheingegend, Schwz, Istr. Jun. -Sept. Bl. weiss. F. tenuifolia Fl. d. Wett.

\section{Ordng. CRUCIFEREN Juss.}

I. Unterordng. SILIQUOSEN. SCHOTENFRÜCHTIGE. Schote lineal., od. lineal-lanzettl., 2klappig, aufspringend. 
I. Gruppe. ARABIDEEN. Die KeimB. aneinanderliegend; das Würzelchen seitlich auf der Spalte der KeimB.

\section{MATTHÍlola Brown. Mathiole.}

1. M. varia DC. St. aufrecht; 13. lineal., stumpf, ganzrandig, nach der Basis schmäler; Bth. fast sticllos; Blb. vkteyf. 27. Felsige O.; Oberwallis, siddl. Tyr. am Gardasce. Mai. Jun. Bbl. schön purp. Cheiranthus varius Sibth.

2. M. s in u a ta Rob. Brown. St. aufrecht, die Aeste abstehend; B. lanzettl., stumpf, filzig, die unteru buchtig- od. geschweift-gezähnt; Bthstielchen fast so lang als der $K$.; Platte der Blb. vktherzf. $\odot$. Iitt., Felsen unter d. Schlosse Duino. Apr. Mai. Bhl. purp.

2. CHEIRANTHUS DC. L. Lack.

1. Cl. Cheiri L. B. lanzettl., spitz, ganzrandig, von einfachen zerstreuten Haaren angedriickt-haarig, die untern beiderseits 1-2zähnig, Zähne spitz; Schoten zsgedriickt. 24. Mauern u. Kirchen längs $d$. Rheins von Basel bis Wesel, alyer nicht viel weiter als eine Stunde landeinwärts, auch bei Aachen, siidl. Schwz., Burg Duino im Litt. Mai. Jun. Bth. sattgelb. Ch. Cheiri L. die kultivirte Pflanze; die wilde Clı. fruticulosus L. Mant. mach Smith.

3. NASTURTIUM Brown. Brumenkresse.

1. N. officinale R. Brown. Schoten lineal., fast so lang als das Bthstielchen; B. gefiedert, die obern 3-7paarig, die untern 3zählig, die Blättch. geschweift, die seitenst. elliptisch, das endst. eyf., an der Basis fast herzf. 24. Quellen, Bäche, Teiche. Jun.-Sept. Sisymbrium Nasturtium L. Blb. weiss. Var. ansser dem Wasser an feuchten $O$., sehr klein, Blättch. kurzgestielt: N. microphyllum Rchb. In tiefem Wasser, die Blättch. aus einer herzf. Basis lanzettl. zugespitzt. N. siifolium Rehb.

2. N. a ustria cum Crantz. Schötch. kugelig, kaum so lang als der Gf., vielmal kürzer als das Bthstielchen; B. lanzettf.-spatelig, gezühnelt od. gesägt, mit tief-herzf.-geöhrelter Basis sitzend, die untern in den Bstiel verschmälert, zuweilen eingeschnitten; St. aufrecht; Blb. länger als der K. 2. Feuchte Wiesen, Ufer; östl. Gel. Jun. Jul. Myagrum austriacum Jacq. Blb. gelb. B. kahl, var. unterseits auf den Adern von feinen Spitzchen etwas rauh.

3. N. amphibium R. Brown. Schötch. elliptisch od. fast kugelig, 2-3mal kürzer als das Bthstielchen; B. längl. od. lanzettl., nach der Basis verschmälcrt, gesägt od. gezähnelt, an der Basis mit od. ohne Oehrchen, die untern kämmig- od. leyerf.-eingeschnitten; St. an der Basis wurzelnd, ausläufertreibend u. im Wasser aufgeblasen-röhrig; Blb. länger als der K. 24. Stehende Wasser, Ufer. Mai-Jul. Sisymbrium amphibium L. Blb. gelb. Var. $\alpha$. riparium 
Tausch.: St. aufrecht härter, weniger röhrig, B. ungetheilt, od. die untersten kämmig- od. leyerf.-eingeschnitten. - $\beta$. aquaticum: Stengel mit der Basis kriechend, ausläufertreibend, weit-röhrig, sehr dünnwandig, dic B. lanzettl., die untersten fiederspaltig od. leyerf. $\because$ submersum: St. zum Theil selıwimmend, die untergetauchten B. kämmig-fiederspaltig, Fetzen haarfein, die ober dem Wasser kämmigeingeschnitten it. ungetheilt. $N$. aquaticum variifolium DC. K. syn.

4. N. a r m or a i o ides Tausch. Schötch. elliptisch, kaum noch einmal so lang als das Bthstielchen; B. uriterseits v. feinen Spitzchen etwas rauh, vkteyf.-spatelig, unglcich-eingeschnitten-gezähnt, mit tiefherzf.-geöhreltel Basis sitzend, dic untersten in den Bstiel verschmälert; St. aufrecht; Blb. länger als đer K. 2. Wiesen, feuchte $O$. an d. Moldau u. Elbe in Böhm. Jun. Jul. Blb. gelb. Scheint eine Variet. des N. terrestre nit unterseits etwas rauhen B.

5. N. terrestre Tausch. Schötch. elliptisch, 2-3mal kürzer als das Bthstielchen; B. kahl, vkteyf., eingeschnitten-gezähnt od. leyerf.-fiedersp. u. gezähnt, an Iler Basis deutl.- od. schwach-geöhrelt; St. aufrecht; Blb. länger als der K. 2. Wiesen, feuchte O.; Böhm. Jun. Jul. Blb. gelb.

6. N. a n ceps Reichenb. nach schwed. Exempl. Schötch. lineal. od. längl.-lineal., ungefähr hulb so lang als das Bthsticlchen; B. leyerf.fiedersp. u. gezähnt, die obern vkteyf., eingeschnitten-gezähnt od. fiedersp., mit gezähnten Fiedern; St. aufrecht; Blb. länger als der K. 24. Feuchte, O., Schles., Böhm. Sachs. Jun. Jul. Blb. gelb. N. harbareoides Tausch. Sisymbrium anceps Wahlenb.

7. N. s ylvestre R. Brown. Schötch. lineal, so lang od. etwas länger od kürzer als das Bthstielchen; B. sämmtl. tief-fiedersp. od. gefiedert, Fieder längl.-lanzettl., gezälnnt od. wieder fiedersp., dic der obern B. oft lineal.; St. sehr ästig, ausgebreitet; Blb. länger als der K. 4 . Feuchte Triften, Gräben. Jun. Jul. Sisymbrium silvestre L. Bth. gelb.

8. N. palustre DC. Schoten längl., gedunsen, ungefähr so lang als das Bthstielch.; die untern B. leyerf., dic obern tief-fiedersp., Zpfl. längl., gezähnt; Blb. so lang als der $K$. $\odot$. Feuchte 0 . Jun.-Sept. N. terrestre Brown. Sisymbrium palustre Leyss. Bth. unanselnnlich, Blb. gelb.

9. . . lippicense DC. Schoten lineal., ungefähr so lang als das Bthstielchen.; die ersten uruelst. B. langgestielt, oval, einfach od. am Bstiele geöhrelt, die untern stengelst. leyerf., die oberen tieffiedersp., Zpfl. lineal., ganzrandig. 24. Steinige, sonnige 0.; südl. Krain, Littorale. Mai. Jun. Blb. gelb. Sisymbrium lippicense Wulf.

10. N. pyrenaicum Brown. Schötch. eyf. od. längl., 3mal kürzer als das Bthstielch.; die ersten wurzelst. B. langgestielt, oval, einfach, od. am Bstiel geöhrelt, dic untern stengelst. leyerf., die obern tief-fiedersp., Zpfl. lineal., ganzrandig od. gezähnt. 4 . A. u. VorA. u. Gluge.; Schwz, Elsass, Oberbad. Mai. Jun. Sisymbrium pyrenaicum L. Blb. gelb. 


\section{BARBARÉA R. Brown. Barharee.}

1. B. vulg a $r$ is R. Brown. Die untern B. leyerf., der Endlappen sehr gross, rundl. od. eyf., an der Basis etwas herzf., dic Seitenlappen 4paarig, "das oberste Paar von der Breite des Qucrdurclmessers des Endlappens, die obern B. ungeth., vkteyf., gezähnt; die Tr. während des Aufblïhens gedrungen, die jüngern Schoten schrägaufrecht. (.) Feuchte O. Apr.-Jun. Erysimum Barbarea L. Blb. noch 1 mal so lang als der $\boldsymbol{K}$., gelb, wie bei allen folgenden. Var. Blätt. entfernt-bewimpert. B. hirsuta Weihe.

2. B. a r c n a t a Rchb. Die untern B. leyorf., der Endlappen sehr gross, rundl. od. eyf., an der Basis etwas herzf., die Scitenlappen 4 paarig, das oberste Paar von der Breite des Querdurchmessers des Endlappens, die oberen B. ungeth., vkteyf., gezähnt; die Tr. wällrend des Aufblïhens locker; die jüngeren Schoten auf dem fast horizontalen Bthstielchen aufstrebend, nach allen Seiten abstehend, doch bei der Reife ziemlich gerade. $\odot$. Feuclite 0. ; zerstr. deh. das Geb. Apr.-Jun. B. tamrica DC.

3. B. strict a Andrzejows. Die unteru B. leyerf., der Endlappen sehr gross, längl.-eyf., Seitenlappen 2-3paarig, sehr klein, die mittleren B. an der Basis leyerf.-eingeschnitten, die obersten ungeth., vkteyf., geschweift-gezähnt; Blb. längl.-keilf., um 1/3 länger als der K. $\odot$. Feuchte O.; nördl. u. mittel. Geb. Apr. Mai.

4. B. praecox Brown. Die untern B. gefiedert, 5-8paarig, mit allmählig aufwärts grössern Paaren, das letzte von der Breite des rundlichen, fast herzf. Endlappens, die obern B. tief-fiedersp. mit lineal., ganzrandigen Fiedern, u. einer linial. -länglichen Endfieder. ๑. Feuchte O., Ufer; Unterelsass, Nahethal, Rheinthal v. Coblenz bis Aachen, Frankf. a. d. O., Unterrhein. Apr. Mai.

5. TÚRRITIS. L. Thurmkraut.

1. T. glabra L. WB. schrotsägef. od. gezähnt od. ganzrandig, von 3gabligen Haaren rauh, die stengelst. kahl, mit herzpfeilf. Basis stengelumfassend; Schoten steif-aufrecht, 6mal länger als das Bthstielchen. $\odot$. Raine, steinige O. Jun. Jul. Blb. gelblich-weiss.

\section{6. ÁRABIS L. Gänsekraut.}

I. Rotte Al o m a ti u m DC. Samen flügellos, od. mit einem sehmälern gegen d. Spitze manehmal verbreiterten Flügel umzogen.

§. 1 Die stengelst. B. an d. Basis herzf.-stengelumfassend.

1. A. brassicaeformis Wallroth. B. kahl, ganzrandig, die wurzelst. längl. od. rundl., in den Bstiel zugeschweift, die stengelst. längl.-lanzettl. mit tief-herz-pfeilf. Basis stengelumfassend; Sehoten auf einem abstehenden Bthstielehen ziemlich aufreeht, Klappen etwas convex, mit einem starken Nerven bezeichnet; S. flügellos. 2. Stei- 
nige Gcbirge; nittleres Ceb., sodann Voges., C. Waadt, Stmk. Jun. Blb. weiss.

2. A. alpina L. B. von ästigen Härchen rauh, etwas ins Graue fallend, die untern längl.-vkteyf., in den Bstiel verschmälert, die obern eyf., mit tief-herzf. Basis stengelumfassend; St. etwas zottig; Schoten abstehend, flach, etwas holperig, am Rande ein wenig verdickt, Klappen fast nervenlos; S. mit einem häutigen, schmalen Rande umzogen; Stämmchen verlängert, niedergestreckt. 24. A. u. VorA., u. Sehles., Harz, Franken, Mai-Aug. Blb. weiss. Var. StB. stärker gezähnt: A. crispata Willd.

3. A. verna Brown. B. n. St. von ästigen Härchen steifh.; B. gezähnt-gesägt, d. wurzelst. vlsteyf., in d. Bstiel verschmälert, die stengelst. eyf., sitzend, mit etwas herzf. Basis umfassend; Tr. meist 6bliithig; Bthstielchen kürzer als der $K$.; Sehoten auf verdickten Bthstielchen kurz absteheud, lineal., längs-netzig-äderig mit einem schwachen Nerven; S. flïgellos. $\odot$. Felder, steinige Hïgel; Pola in Istr. Apr. Mai. Hesperis verna L. Blb. sehön violett.

4. A. a uriculat a Lam. B. u. St. von ästigen Härchen rauh; WB. längl. in den Bstiel verschmälert, die stengelst. eyf.-längl., gezähnt, mit tief-herz-pfeilf. Basis sitzend; Tr. zuletzt verlängert, schlängelig; Sehoten ziemlich entfernt, abstehend, zsgedriickt, fast 3nervig, kaum breiter als das Bthstielchen; S. mit einer gesättigteren Linie cingefast, flügellos; Stämmchen fehlend. $\odot$. Troekne, steinige O.; zerstr. dch. das Geb. Apr. Mai. Blb. weiss.

5. A. Saxatilis Allioni. B. u. St. von ästigen Härchen rauh, fast zottig; WB. längl. in deu Bstiel verschmälert, die stengelst. eyf. od. längl., schwaeh-gezähnt, mit tief-herz-pfeilf. Basis sitzend; 'Tr. armbliithig, fast steif; Schoten etwas entfernt, abstehend, zsgedriielit, fast 3nervig, 3mal breiter als das Bthstielchen; S. schmal-gefliigelt; Stämmchen fehlend. $\odot$. A. des siidl. Tyrols, der siidl. u. westl. Schwz. Jul. Blb. weiss.

6. A. Gerardi Besser. St. von ästigen, angedrückten Haaren raulı; 13. längl., gezähnelt, mit ästigen IIärchen bestrent, die wurzelst. in den Bstiel verschmälert, die stengelst. von der Basis bis zur Mitte an den St. angedrückt, mit tief-herz-pfeilf. Basis sitzend, die Ochrchen abwärts an dem St. anliegend; Schoten aufrecht, schmal-lineal., zssgedriickt, zierlicl-holperig, fast nervenlos; S. schmal-geflügelt, netzigpunktirt. $\odot$. Wiesen n. unkultiv. O.; sehr zerstrent deh. das Geb. Mai Jun. Turritis nemoreusis Wolf. Blb. weiss.

7. A. sagittata DC. St. unterwärts rauhh. von einfachen $u$. isstigen, abstehenden od. hinabgebogenen Haaren, oberwärts ziemlieh kahl; 3. längl., gezähnelt, mit ästigen Härchen bestreut, die wurzelst. in den Bstiel verschmälert, die stengelst. aufrecht-abstehend, mit tiefherz-pfeilf. Basis sitzend; Oelirchen abstehend; Schoten aufrecht, schmal-lineal., zsgedrückt, der Mittelnerv fein, zulctzt fast verschwin- 
dend; S. schmal-geflügelt, fein purktirt. ๑. Steinige Hïgcl n. felsige Gbge; sehr zerstreut dch. d. Geb. Mai Jun. longisiliqua Wallr. Blb. weiss.

8. A. hirsuta Scop. St. unterwärts von abstehenden Haaren rauhh.; B. längl., gezähnelt, mit ästigen Härchen bestreut, die wurzelst. in den Bstiel verschmälert, dic stengelst. aufrecht, etwas abstchend, mit gestutzt-geöhrter od. herzf. Basis sitzend, die Ochrchen vom St. abstehend; Schoten aufrecht, schmal-lineal., zsgedrückt, längsäderig, mit einem etwas hervortretenden Nerven; S. niclit punktirt, an der Spitze etwas gefliigelt. (-). u. 2. Wiesen, Hügel. Mai. Jun. Blb. weiss. Turritis hirsuta L. An kleinen Ex. sind die StB. an der Basis nur gestutzt, aber nicht herzf. Var. $\beta$. glaberima: ganz kahl, od. nur mit kurzen Haaren an dem Rande der B. Kessel im Gesenke der Sudeten, anderwärts schr selten.

§. 2. Die stengelst. B. sitzend, manchmal halbstengel-umfassend. aber an der Basis nicht herzf.

9. A. ciliata R. Brown. St. kalıl od. unterwärts vou abstehenden Haaren rauhh.; B. längl., gezähnelt, odl. ganzrandig, nit ästigen Härchen bewimpert od. bestreut, die wurzelst. in den Bstiel velschmälert, die stengelst. aufrecht, etwas abstehend, sitzend, an der Basis abgerurdet; Schoten ziemlich abstehend, schmal-lineal., zsgedriickt, längsärlerig mit einem etwas hervortretenden Nerven; S. von einer gesättigteren Linie umzogen, flügcllos, unpunktirt. ... A. u. VorA. Jun. Jul. Blb. weiss. Var. $\alpha$. glabrata: St. kalıl, B. kahl, nur am Rande mit einfachen od. ästigen Haaren besetzt. A. ciliata Brown. Turritis ciliata Schleich. T. rupestris Hoppe. 'T. alpina L. $-\beta$. hirsuta: St. rauhh.; B. von ästigen Härchen kurzh.-rauh. Turritis alpestris Schleich.

10. A. murali s Bertoloni. St. unterwärts von abstchenden Haaren rauhh.; B. von ästigen Härchen rauhh. n. in das Grauc fallend, die wurzelst. längl., vkteyf., etwas spatelf., stumpf-gez:̈̈hnt, in den Bstiel verschmälert, die stengelst. längl., aufrecht, sitzend; Schoten an die Spindel angedrückt, lineal., zsgedrüickt, längsgeärlert, mit cinem schwachen Nerven; S. mit einem häutigen Flügel umzogen. 2!. Manern, Felsen; Vevay in C. Waart, Branson im C. Wallis, Carouge im C. Genf, bei Cardin in sïdl. Tyrol. Mai. Blb. weiss. A. incana Willd., nicht Roth.

11. A. stricta Huds. St. kahl, an der Basis steifh.; B. glänzend, mit einfachen od. gabligen Borsten bewimpert od. bestreut, die wurzelst. längl.-vkteyf., stumpf- fast buchtig-gezälınt, in den Bstiel verschmälert, die stengelst. längl., etwas abstehend, sitzend; Tr.56bth.; Schoten auf einem etwas kurzen, absteheuden Bthstielchen, ziemlich aufrecht, lineal., zsgedriickt, längsïderig, mit einem hervortretenden Nerven; S. scharf-beraudet, an der Spitze geflügelt. 2. Kalk- 
felsen; im C. Genf. Mai. A. hirta Lam. Turritis Raji Vill. Bth. auswendig $u$. vor der Entfaltung strohgelb, getrocknet gelblich.

12. A. serpyllifolia Vill. St. schlängelig $u$. nebst den $B$. von ästigen Härchen rauhh. $u$. grau; B. längl.-eyf., ganzrandig od. etwas gezähnt, die wurzelst. in den Bstiel verschmälert, dic stengelst. etwas abstehend, sitzend; Schoten auf einem kurzen, abstehenden Bthstielchen aufrecht, schmal-lineal., zsgedrückt längsäderig, mit einen etwas hervortretenden Nerven; S. mit einer dunkler gefärbter Linie umzogen, flügellos. (-. A. u. VorA.; C. Waadt, Aelener Gbge. Jun. Jul. Blb. weiss.

13. A. procurrens W. K. B. in ein Stachelspitzchen kurz-zugeschweift, ganzrandig, kahl, am Rande von 2 th., angedrückten Haaren rauh, die wurzelst. vkteyf. in den Bstiel verschmälert, die stengelst. längl., sitzend; Schoten abstehend, lineal., mit einem hervortretenden Nerven; Gf. so lang als der halbe Querdurchmesser der Schote; Stämmchen ausläuferartig, kriechend. 2. A. in Krain. Apr. Mai. Blb. weiss. A. praecox Willd.

14. A. vochinensis Spreng. B. stumpf, kurz-bespitzt, ganzrandig, kahl, am Rande von 2th., angedrückten Haaren rauh, die wurzelst. in den Bstiel verschmälert, die stengelst. längl., sitzend; Schoten abstehend, lineal., mit einem hervortretenden Nerven bezeichnet; Gf. so lang als die Breite der Schote, Stämmchen ausläuferartig, kriechend. 2. Alpentriften; Krain, Oberkärnth. Jul. Blb. weiss.

15. A. petraea Lamarck. St. kahl; WB. gestielt, längl.-vkteyf., ganzrandig, od. hinten gezähnt, mit meistens 3 Zähnen od. Läppchen auf jeder Seite, od. leyerf, kahl od. von 2-3gabligen Haaren rauhh., die stengelst. längl.-linial., nach der Basis verschmälert, ganzrandig, sitzend, kahl; Schoten abstehend, schmal-lineal., fast flach, mit einem sehr feinen Längsnerven. 24. Felsen; Stmk., Oestr., Böhm., Weltenburg in Baiern, Franken, Thïring. Apr. Mai. Blb. weiss, selten bleichrosenroth. Cardamine petraea L. Arabis hispida L. fil. Sm. A. Crantziana Ehrl. Var. $\alpha$ glabrata: B. kahl, od. sparsamer mit Haaren bestreut. - $\beta$. hirta: B. mit kïrzeren, 2-3gabeligen Haaren dichter bedeckt.

16. A. arenos a Scopoli. St. von einfachen Haaren rauhh.; B. mit ästigen Härchen bestreut, die wurzelst. gestielt, leyerf.-schrotsägerıartig, mit 6-9 Läppchen auf jeder Seite, die stengelst. nach der Basis verschmälert, kurz-gestielt, die obern ganzrandig; Schoten abstehend, lineal., fast flach, mit einem sehr feinen Längsnerven. $\odot$. Sandfelder, steinige O. der Gb́ge. u. A. Jun. Jul. Sisymbrium arenosum L. Blb. lila, seltner weiss.

17. A. Halleri L. B. ganzrandig od. etwas gezähnt, gestielt, die murzelst. herzf.-rundl., od. eyf., auf einem nackten od. mit Anhängseln versehenen Bstiele, die untern stengelst. eyf., die obern lanzettl. 
4. Grasige, schattige O. der A. u. VorA.; sodann Gbge u. niedrige O. in Schles., Sachs., Thüring. Jun. Jul. Blb. weiss, selten rosenroth. Var.: 1) A. Halleri DC.: Endlappen der B. eyf.; 2) A. stolonifera DC. Hornem.: Eudlappen der B. herzf.; 3) A. ovirensis Wulf.: WB. kreisrund, ohne Anhängsel am Bstiel; 4) Cardamine diversifolia Sternb.: WB. längl.-eyf.; 5) A. tenella Host.: kleiner, mit ästigen Härchen bestreut.

II. Rotte. L o maspora DC. Die S. mit einem breiten häutigen Flügel umzogen.

18. A. Turrita L. B. mit ästigen Härchen bestreut, gezähnt, die wurzelst. elliptisch, in den Bstiel verschmälert, die stengelst. längl., mit tief-herzf. Basis stengelumfassend; Bthstielchen ungefähr so lang als der K.; Schoten auf einem aufiechten Bthstielchen abwärts-gekrümmt, flach, in der Mitte holperig, am Rande verdickt; S. mit einem häutıgen breiten Flügel umzogen. $\odot$. Felsen, steinige, waldige O.; zerstrent in sïdlichen Geb. Mai Jun. Blb. weiss od. gelblichweiss.

19. A. pumila Jacq. B. ganzrandig od. etwas gezähnelt, glänzend, nebst dem 2-3blättrigen St. von ästigen und einfachen Härclıen zerstreut-haarig, die wurzelst. in eine Rosette ausgebreitet, vkteyf., in den Bstiel verschmälert, die stengelst. eyf.-längl., sitzend; Schoten aufrecht, Hlach, in der Mitte holperig, am Rande etwas verdickt; S. mit einem breiten häutigen Flügel umzogen. 2. Felsen u. Kíes d. A. u. VorA. Jun. Jul. Blb. weiss. A. scabra All. Var. fast kahl, die WB. am Rande nur gewimpert, u. $\beta$. lax $\alpha$, Tr. locker, nickend, anch oft noch mit den reifen Schoten nickend: A. ciliaris Willd.

20. A. bellidifolia Jacq. B. ganzrandig od. etwas gezahnt, glänzend, kahl, die wurzelst. in eine Rosette ausgebreitet, vkteyf., in den Bstiel rerschmälert, die stengelst. eyf. od. längl., halbstengelumfassend; St. reichblätterig, kahl; Schoten aufrecht, flach, in der Mitte holperig, am Rande etwas verdickt; $S$. mit einem breiten häutigen Flügel umzogen. 4. Fenchte Triften der A. u. VorA. Jun. Jul. Blb. weiss.

21. A. caerulea Haenke. B. glänzend, kahl, mit einfachen Haaren bewimpert, die wurzelst. aufrecht, vkteyf., in den langen Bstiel verschmälert, vorne 3- od. 5zähnig, die stengelst. längl., sitzend; St. von einfachen Haaren flaumig, 2-3blättrig; Schoten aufrecht, flach, in der Mitte holperig, am Rande etwas verdickt; S. mit einem breiten häutigen Flügel umzogen. 24. Höchste A. Jul. Aug. Blb. blassblatt.

\section{CARDAMÍNE L. Schámkraut.}

I. Rotte. Cardamine. Stränge dünne u. schmal.

1. C. as arifolia L. B. kahl, gestielt, herzf.-kreisrund, geschweift- 
gezähnt; St. aufstrebend, beblättert. 24. An Quellen u. Bächen; Alpe la Bergamasia iiber Darzo im südl. Tyrol, Col de Morbegno in Unterveltlin. Jun.-Aug. Blb. weiss.

2. C. alpin a Willd. WB. ungeth., rauten-eyf., abgerundet-stumpf, olne Spitzchen, langgestielt, die stengelst. ganz od. fast 3lappig, od. an der Basis mit einem Oehrchen, kurz-gestielt. 24. Höchste A. Jul. Aug. Blb. weiss.

3. C. resedifoli a L. Die ersten WB. eyf., stumpf, langgestielt, die folgenden 3th., od. nebst den StB. gefiedert-2-3paarig, die Blättchen längl.-keilf., stumpf, ganzrandig, das ungepaarte grösser; fruchttrag. Tr. kurz, gedrungen; Schoten u. Bthstielchen aufrecht. 4. A. u. VorA., Sudet. Jul. Aug. Blb. weiss. Var. selten: alle B. ungetheilt.

4. C. parviflori L. B. sämmtl. gefiedert, fast gleichf, vielpaarig; Blättchen ganzrandig, nach der Basis verschmälert, sitzend, an den untern B. längl., an den obern lineal., das Endblättchen beinahe gleichgross; Frucht'Tr. verlängert; Schoten auf den sehr weit abstehenden Bthstielchen aufrecht. $\odot$. Feuchte O. u. Teichränder; Mähr., Schles., Odergebiet bis Frankf. an d. O., Holst. Jun. Jul. Blb. weiss.

5. C. impatiens L. B. sämmtl. gefiedert, vielpaarig, Blättchen der untern B. eyf., 3-5sp., gestielt, die der obern längl.-lanzettl., an dem hintern Rande gezähnt, sitzend, das Endblättchen grösser; Bstiele der stengelst. B. pfeilf.-geöhrelt. $\odot$. Fenchte 0 ., Ufer; zerstreut dch. d. Geb. Mai-Jul. Bth. sehr klein, meist ohne Blb.

6. C. sylv a ti ca Link. B. sämmtl. gefiedert, Blättchen der untern B. mundl.-eyf., geschweift od. gezähnt, gestielt, das endständige grösser, die der obern B. längl. od. lineal.; Bstiele ohne Oehrchen; Blb. noch I mal so lang als der $K$., längl.-vkteyf., in den Nagel allmählig verschmälert; Schoten auf dem etwas abstehenden Bthstielchen ziemlich aufreclıt; Gf. so lang als die Breite der Schote; St. kantig. $\odot$. Waldige O. Apr.-Jun. Bl. sehr klein, weiss.

7. C. hirsuta L. B. sämmtl. gefiedert; Blättchen der untern B. rundl.-eyf., geschweift od. gezähnt, gestielt, das Endblättchen grösser, die der obern längl. od. lineal.; Bstiele ohne Oehrchen; Blb. noch 1 mal so lang als der $K$., längl.-vkteyf., in den Nagel almählig yerschmälert; Schoten u. Bthstielchen aufrecht; Gf. kürzer als die Breite der Schote; St. kantig. $\odot$. Unbebante O. u. Weinberge. Apr.-Jun. C. multicaulis Hopp. Blb. weiss.

8. C. pratensis L. B. sämmtl. gefiedert, Blättchen der wurzelst. rundl.-eyf., geschweift od. gezähnt, gestielt, das Endblättchen grösser, fast nierenf., die der stengelst. lineal., ganzrandig; Bstiele ohne Oehrchen; Blb. 3mal so lang als der $K$., vkteyf.; Stbg. um die Hälfte kürzer als die 131.; St. stielrund, oberwärts schwach-gerillt. 24. Wiesen u. grasige, waldige O. Apr. Mai. Blb. lila, selten weiss. Stbk. 
gelb. Var. $\beta$. dentata: St. höher, Blättchen der untern StB. eckiggezähnt. C. sylvatica Bess. C. dentata Schult.

9. C. amara L. B. sämmtl. gefiedert, Blättchen der untern B. rundl.-eyf., der obern längl., alle eckig-gezähnt, das Endblättchen grösser; Blb. 3mal so lang als eler K., vkteyf.; Stbg. fast so lang als die Bl.; St. kantig-gefurcht. 24. Quellen, Grïben, fenclite, waldige $O$. Apr. Mai. Blb. weiss. Stbk. violett. Gf. lang, dünn. St. unterwärts mit zerstreuten Haaren besetzt.' Var. $\beta$. hirta: St. steifh.; Bthstielchen kahl. C. amara $\beta$. hirta W. et Grab. $-\gamma$. subalpina: St. u. Bthstielchen kurzh.; B. aus 15,17 w. die obern aus 13 Blättchen zsgesetzt. C. amara $\gamma$. umbrosa IVimm. u. Grab. C. Opicii Presl. VorA. u. Sudeten.

II. Rotte. Chelidonia. Nabelstränge melr oder weniger verbreitert.

10. C. maritima Portenschl. B. 3zählig od. gefiedert; Blättchen gleichf., gestielt, eyf., 3sp. od. fiederig-5sp., an der Basis verschmïlert, Lappen stuynpf, kurzgespitzt; Sclioten lanzettl.-lineal.; Gf. lineal., zsgedriickt; St. ansgebreitet, sehr ïstig. ๑. Meeresrand der Insel Osero. Mai. Jun. PIb. weiss. - C. graeca L. hat einen breit-geHligelten Gf.

11. C. thalictroides All. B. 3zählig od. gefiedert, Blättchen gleichf., gestielt, eyf., 3sp., Lappen stumpf, kurz-zugespitzt; Schoten lineal., auf den abstehenden Bthstielchen aufrecht; St. ästig, schwach. $\odot$. Fenchte, waldige O.; Gipfel des M. Maggiore in Istr. 11. Ber'g Osero. Mai. C. Plumieri Vill. Blb. weiss.

12. C. trifolia L. B. 3zählig, Blättchen kurzgestielt, rautenf.rundl., geschweift-gekerbt; St. einblättrig od. nackt; Ausläufer kriechend. 24. Feuchte Wälder; Gbge u. VorA. v. Tyrol bis Oestr., sodamn Böhm., Schles. Mai. Jun. Blb. weiss.

8. DENTARIA L. Zahnwurz.

1. D. en ne aphyll o s L. St. 3blitttrig; B. quirlig-gestellt, 3zählig, Blättchen ungleich-gesägt; Stbg. so lang als die Bl. \&. Laubwälder, VorA. u. Waldregion der A.; Salzburg, Oestr, Mähr., Oberlausitz, Böhm., Schles., Sächs. Gbge n. Fichtelgebirg. Apr. Mai. Blb. gelblichwieiss.

2. D. glandulosa W. K. St. 3blättrig; B. quirlig-gestellt, 3zählig, Blättchen ungleich-gesägt, zugespitzt mit tinem spitzen Ende; Stlog. halh so lang als die Bl. 24. Gebirgswälder; Schles. Lei Huldheim, Schillersdorf. Apr. Mai. Blb. purpurn.

3. D. trifolia W. u. K. St. 2-5blättrig; B. werhselst., gestielt, 3zählig, Blättchen entfernt-stumpf-gesägt, zugespitzt, die Spitze selbst stumpf. 2. Schattige 0 ; in 'Tenfelsgraben bei Cilli in Unterstmk. Apr. Mai. Blb. weiss. 
4. D. digit at a Lamarck. St. 3-4blättrig; B. wechselst., gestielt, 5zählig, die obern 3zählig, Blättchen ungleich-gesägt, zugespitzt mit einem feinen sehr spitzen Ende, die äusseren kleiner. 4. Wälder der Gbge u. VorA.; Krain, Tyrol, Stmk., Salzbg., baier. A. Mai-Jul. D. pentaphyllos Scop. L. sp. pl. var. $\beta$. u. $\gamma$. Blb. rosenroth.

5. D. polyphylla W. K. St. 2-4blättrig; B. abwechselnd od. quirlig-gestellt, gestielt, alle gefiedert, Blättchen lanzettl., lang-zugespitzt, gesägt. 2. Fette, schattige Wälder; Schwz. in d. Clus u. bei Valzaina über Marschlins. Apr. Blb. gelblichweiss.

6. D. pinnat a Lamck. St. 3-5blättrig; B. wechselst., gestielt, sämmtl. gefiedert, Blättchen lanzettl., spitz, gesägt. 24. Wälder der Gbge u. VorA.; Schwz., Elsass bei Rappoltsw. u. Barr, Oberbad. bei Freibg. u. Candern, Stmk. bei Cilli, südl. Tyrol. Apr. Mai. Blb. purpurn.

7. D. bulbi fer a L. St. vielblättrig; B. wechselst., die untern gefiedert, die obern ungeth.; Blattwinkel zwiebeltragend. 4. Wälder der A. u. VorA., übrigens zerstreut deh. das Geb. Apr. Mai. Blb. hellroth od. weissl.

II. Gruppe. SIS YMBRIEEN. KeimB. aufeinanderliegend, flach, das Würzelchen auf dem Rücken des einen Keimblattes.

9. HÉsPERIS L. Nachtviole.

1. H. matronalis L. Bthstielchen so lang u. länger als der K.; Blb. vkteyf., sehr stumpf, meist mit einem Spitzchen, Schoten an den abstehenden Bthstielchen aufrecht, kahl, ziemlich stielrund, holperig; B. ey-lanzettl., zugespitzt, gezähnt, die untersten zuweilen leyerf.; St. aufrecht, kahl od. von ästigen Haaren flaumig. ๑. 2. Wiesen, Gebiisch, kultiv. Land; zerstr. dch. das Geb. Mai. Jun. H. matronalis $u$. inodora L. Blb. lila od. weiss.

2. H. runcinata W. K. Bthstielchen so lang als der K. od. länger; Blb. vkteyf., sehr stumpf, mit einem Spitzchen; Schoten auf den abstehenden Bthstielchen aufrecht od. hinabgebogen, kahl, ziemlich stielrund, holperig; B. ey-lanzettf.-zugespitzt, gezähnt, die untersten leyerf.; St. aufrecht, von einfachen u. drüsigen Haaren flaumig. $\odot$. Wälder bei Wien. Mai. Jun. H. bituminosa Savi. Blb. lila.

3. H. tristis L. Bthstielchen so lang als der K. u. länger; $B l b$. lineal.-lanzettl., stumpf; Schoten mit dem Bthstielchen weit-abstehend, kahl, zsgedrückt, in der Mitte holperig; Klappen nur halb so breit als die Scheidewand; B. ey-lanzettf., zugespitzk, ganzrandig oder schwach-gezähnelt. $\odot$. Unbebauete 0 ., Ackerränder; Unteröstr. Mai. Blb. schmutzig-grün, mit einem violetten Adernetze.

4. II. la ciniat a Allioni. Bthstielchen kürzer als der K.; Blb. längl.-vkteyf.; Schoten drüsig-flaumh.; B. gezähnt; die untern an der Basis buclitig-fiedersp. ○. Felsige 0.; Insel Veglia. Apr. Mai. Blb. gelbl. od. röthl. 
10. MALCOLMLA R. Brown. Malkolmie.

1. M. maritima Brown. St. aufrecht, ästig; B. elliptisch, stumpf, ganz, an der Basis verschmälert, mit angedrückten, 2-4th. Härchen bedeckt; Bthstielchen meist kürzer als der K.; Schoten flaumhaarig, an dem Ende lang-zugespitzt. $\odot$. Ufer des Meeres; Fiume. März. Apr. Cheiranthus maritimus L. Blb. purp.

11. SISYMBRIUM L. Rauke.

I. Rotte. Vela rum DC. Schoten gegen dio Spitzo rerschrax. lert, pfriemenf. Blb. gelb.

1. S. officinale Scop. B. schrotgägenartig-fiederth., Zpfl. 2-3paarig, längl., gezähnt, der endständige sehr gross, spontonf.; Schoten mit den Bthstielchen an die Spindel angedrücht, lineal.-pfrieml., fiaumh. $\odot$. Wege, Schutt, Felder. Jun.--Aug. Erysimum officinale L. Var. selten mit abstehenden Schoten.

II. Rotte. Irio DC. Schoten stielrund. S. längl. od. fast eyf. Blb. gelb.

2. S. a ustri a c u m. Jacq. B. schrotsägenf.-fiederth., vielparig, u. nebst dem St. kahl, od. ein wenig borstig, $Z$ pfl. aus einer breitern Basis 3eckig-spitz od. lanzettl. - verschmälert, der endständ. grösser, an den obern B. verlängert; $K$. etwas abstehend; Schoten genähert, auf dem aufstrebenden od. gewundenen Bthstielchen etwas abstehend od. abwärts-geneigt, die jïngern kürzer als der konveze Strauss. - . Steinige O.; zerstreut dch das Geb. Mai. Jun. S. eckartsbergense Willd. S. multisiliquosum Hoffm. Schoten kahl. Var.: $\beta$. contortum: Schoten zerstreut-borstig. S. contortum Willd. S. taraxacifolium DC. $-\gamma$. acutangulum: Schoten um die Hälfte kürzer, auf bogigen Stielchen an die Spindel gelehnt. S. acutangulum DC. S. pyrenaicum Vill. Sinapis pyrenaica L.

3. S. Lo eselii L. B. schrotsägenf.-fiederth., die untern nebst dem St. steifh., Zpfl. gezähnt, an der Basis ohne Oehrchen, an den untern B. längl., die endst. zsfliesend, an den obern lanzettl., der endst. sehr gross, spontonf.; K. abstehend; Schoten aufstrebend, etwa. gekrümmt, noch 1 mal so lang als das abstehende Bthstielchen, die jüngern kürzer als der konvexe Strauss. ๑. Schutt, Mauern; zerstreut dch das Geb. Jun. Jul. Leptocarpaea Loeseli DC.

4. S. Irio L. B. schrotsägenf.-fiederth.; Zpfl. gezähnt, ohn॰ Oehrchen, die der untern B. längl., der endst. eckig, an den obern lanzettl., der endst. verlängert-spontonf.; K. etwas abstehend; Schoten $4 \mathrm{mal}$ so lang als das Bthstielchen, abstehend, die jüngern über den flachen Strauss hinausragend. $\odot$. Wege, Ackerränder, Felder; Unteröstr., Subl in Thüringen, Wallis. Mai. Jun. Bthstielchen schlank.

5. S. C ol u m n a e L. B. schrotsägenf.-fiederth.; Zpfl. gezähnt, an der Basis geöhrelt, mit aufgerichteten Oehrchen, an den untern 
B. eyf.-längl., der endst. eckig, an den obern lanzettl., der endst. verlängert-spontonf.; $K$. aufrecht, geschlossen; Schoten vielmal länger als das Bthstielchen, abstehend. $\odot$ Wege, Schutt, unbebaute O.; Stmk., Oestr., Mähr., Bölım. Jun. Jul. Bthstielchen dick. Var. $\beta$. hebecarpa: Schoten flaumig.

6. S. panno nicum Jacq. Die untern B. schrotsägenf-fiederth., $\mathrm{Zpfl}$. gezähnt, an der Basis geölurelt, mit aufstrebenden Oehrchen, die obern gefiedert, Fieder schmal-lineal., der endst. gleichf.; $K$. weit abstehend, Bthstielchen $u$. Schoten abstehend, fast gleich-dick. $\odot$. Wege, Brachäcker, Ackerränder; zerstreut deh das Geb. Mai. Jun. Bth. gelblich-weiss.

7. S. Sophia I. B. dreifach gefiedert, Fieckerchen an den untern B. schmal-lanzettl., an den obern lineal.; Bthstielchen noch $1 \mathrm{mal}$ so lang als der K.; Blb. so lang als der K. u. kürzer. $\odot$. Sandfelder, Aecker, Wege. Mai-Oct.

III. Rotte. Norta DeC. Schoten stielrund. S. lineal., verlängert. Blb. gelb.

8. S. strictissimum L. B. längl.-lanzettl., ungeth., zugespitzt, gezähnt, flaumig $v$. einfachen Haaren; K. zuletzt wagerecht-al,stehend;

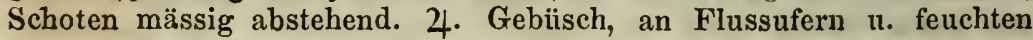
O.; zerstreut dch. das Geb. Jun. Jul.

IV. Rotte. Alliaria DC. Schoten stielrund. S. längl., längsgestreift. Blb. weiss.

9. S. Alliaria Scop. B. ungeth., die untern nierenf., grob-geschweift-gekerbt, die obern herz-eyf., spitz-gezähnt; Schoten abstehend, vielmal länger als das Bthstielchen. ๑. Gebuisch, Wege, Waldsäume. Apr. Mai. Erysimum Alliaria L.

V. Rotte. Arabidopsis DC. Schoten lineal. S. nicht gestreift. Blb. weiss.

10. S. Thalia num Gaud. B. längl.-lanzettl., ungeth., stumpfl., entfernt-gezähnelt, v. 2-3gabligen Haaren flaumh., die wurzelst. in den Bstiel verschmälert; K. aufrecht; Schoten auf dem abstehenden Bthstielchen aufstrebend. $\odot$. Felder, gebautes Land. Apr. Mai, u. wiederum im Herbst. Arabis Thaliana L.

12. HUGUENINIA Reichenb. Hugueninie.

1. H. tanacetifolia Rchb. B. gefiedert, Fieder lanzettl., eingeschnitten-gesägt, die äussersten zsfliessend; Schoten auf dem aufrechten Bthstielchen aufstrebend. 24. Walliser A. Jul. Sisymbrium tanacetifolium L. Blb. gelb.

13. BRAYA Sternberg u. Hoppe. Braye.

1. B. a $l$ p in a Sternb. u. Hoppe. B. lineal.-lanzettl., ungeth., ganz- 
randig od. entfernt-wenig-gezähnt, die wurzelst. lang-gestielt; die fruchttrag. Traube eyf., zsgedrängt. 24. Höchste A.; Gamsgrube u. Leiter bei Heiligenblut, Südwestseite des Solsteines bei Innsbruck. Jul. Blb. weiss, getrocknet violett.

2. B. pinnatifida. (Sisymbrium DC.) Die stengelst. B. buchtig-fiєdersp., Zpfl. längl.-lineal., ganzrandig, der endst. grösser, die untern B. fast leyerf., die wurzclst. vkteyf., gezähnt; $\mathrm{Tr}_{\mathrm{r}}$. verlängert, ohne DeckB.; Schoten auf den abstehenden Bthstielchen aufstrebend. 4. Höchste Granit A. d. Schwz.; Fouly, St. Bernhard u. a. Jul. Aug. Blb. weiss.

3. B. s upina (Sisymbrium L.) B. buchtig-fiedersp., Zpfl. längl.lineal., etwas gezähnt, der endst. grösser; Tr. verlängert, mit blattigen Deckblättern; Schoten mit den kurzen Bthstielchen etwas abstehend, kurzhaarig-flaumig. (- Kiesige feuchte O.; am See v. Joux im Jura, Lauterthal des untern Elsasses. Jul. Aug. Blb. weiss.

\section{ERÝSIMUM L. Hederich.}

1. Rotte. Erysimastrum DC. Blb. hell- od. goldgelb. Die stengelst. B. sitzend, längl. od. lineal., an der Basis nicht herzf.

1. E. cheiranthoides L. B. längl.-lanzettl., nach beiden Enden verschmälert, geschweift-gezähnelt od. gezähnt, mit gleichf. $3 s p$. Haaren bestreut $u$. etwas rauh; Bthstielchen 2-od. $3 \mathrm{mal}$ so lang als der K. u. fast halb so lang als die Schote; Schoten 4kantig, v. der Seite etwas zsgedrückt, mit entfernten Härchen bestreut, fast kahl. ○. Aecker, Felder. Jun.-Herbst. Var. $\beta$. dentatum: B. fast buchtig-gezähnt. E. micranthum Buek.

2. E. virg a tu m Roth. B. ganzrandig, mit gleichf. 3sp. Haaren bestreut $u$. etwas rauh, die untern längl.-lineal., stumpf, in den Bstiel verschmälert, die obern lineal.-lanzettl., spitz; Bthstielchen meist so lang als der K.; Schoten aufrecht, 4kantig, v. der Seite etwas zsgedrückt, flaumh.-rauh; Platte der Blb. keilig-vkteyf. $\odot$. Unkultiv. O.; zerstreut dch. das Geb. Jun. Jul. Var.: Gf. kurz: E. durum Presl.; Schoten sehr lang: E. longisiliquosum Schleich.; Schoten um die Hälfte kürzer: E. virgatum Schleich.

3. E. strictum Fl. der Wetterau. B. längl.-lanzettl., geschweiftgezähnelt, mit gleichf. 3sp. Haaren bestreut $u$. etwas rauh, die untern stumpf, kurz-stachelspitzig, in den Bstiel verschmälert, die obern sitzend, kurz-zugespitzt; Bthstielchen meist so lang als der K.; Schoten 4kantig, v. der Seite etwas zsgedrückt, flaumh.-rauh, gleichfarbig; Platte der Blb. keilig-vkteyf. @. Mauern, unkult. O., Ufer; zerstreut dch das Geb. Jun. JuI. E. hieracifolium L. A. suec., nicht der Linneischen Sammlung. E. hieracif. Ehrh. E. virgatum DC.

4. E. o d or a t u m Ehrh. B. längl-lanzettl., geschweift-gezähnt, mit gleichf. 3sp. Haaren bestrcut $u$. etwas rauh, die untern stumpf, 
kurz-stachelspitzig, in den Bstiel verschmälert, die obern sitzend, zugespitzt; Bthstielchen halb so lang als der K. ; Schoten 4kantig, v. der Seite etwas zsgedrückt, grau, mit kahleren, grünen Kanten; Platte der Blb. rundl. $\odot$. Kalkgbge.; Donauthal v. Pappenheim an, wahrscheinl. bis Wien, Mähr., Böhm., Thüring., Fränk. Gbge., Krain. Jun. Jul. E. hieracifolium Jacq. E. strictum DC. E. cheiriflorum Wallr. Cheiranthus erysimoides L. Var. $\beta$.: B. tiefbuchtig. E. carniolicum Dolliner. Bth. mit Honiggeruch.

5. E. repandum L. B. lanzettl.-zugespitzt, etwas buchtig-od. geschweift-gezähnt, od. ganzrandig, an der Spitze zuriickgebogen, v. einfachen u. 3sp. Haaren etwas rauh; Bthstielchen halb so lang als der K.; Schoten stumpf-4kantig, fast stielnind, kaum dicker als das verdickte, wagerecht-abstehende Bthstielchen, oberwärts in die gestutzte Narbe verschmälert. $\odot$. Felder; Unteröstr., Stmk., Böhm., Thüring., Göttingen, Würzbg. Jun. Juli.

6. E. crepidifolium Reichenbach. B. lanzettl., buchtig- od. geschweift-gezähnt od. ganzrandig, an der Spitze zuriickgebogen, v. einfachen od. 3sp. Haaren etwas rauh, die untern stumpf, kurzstachelspitzig, in den Bstiel verschmälert, die obern spitz, sitzend; Bthstielchen um das 2-od. 3 fache kürzer als der K.; Schoten stumpf4 kantig, vom Rücken ein wenig zsgedrückt, gleichfarbig, mit dem Gf. u. der kopfigen Narbe bekrönt. $\odot$. Felsen, Mauern ; Stmk., Böhm., Thür., Baireuth, Ansbach auf d. Hesselberg, Rheinpf. Mai Jun. E. hieracifolium des Linn. Herb. u. DC. Bth. hellschwefelgelb, geruchlos. Schoten gleichfarbig.

7. E. can escens Roth. B. lineal.-lanzettl., ganzrandig od. entfernt-gezähnelt, an der Spitze zurückgebogen, v. fast lauter einfachen Haaren etwas rauh, die untern kurz-stachelspitzig, in den Bstiel verschmälert, die obern lineal., spitz; sterile Aestchen in den Blattwinkeln; Bthstielchen so lang als der Kelch; Schoten abstehend, rechtwinckeligvierkantig, grau, mit kahleren, grünen Kanten. $\odot$. Sonnige, unbebaute O.; Mähr., Unteröstr., Wallis. Jun. Jul. E. diffusum Ehrh. Cheiranthus alpinus Jacq. K. an der Basis nicht höckerig. Blb. hellschwefelgelb.

8. E. rh a eticum DC. B. lineal.-lanzettl., spitz, ganzrandig, od. entfernt-gezähnelt, v. einfachen Haaren etwas rauh, die untern in den Bstiel verschmälert; sterile Aestchen in den Blattwinkeln; Bthstielchen um das 2-od. 3fache kürzer als der $K$.; Schoten rechtwinkeligvierkautig, einfarbig grüı-grau; Narbe ausgerandet. 2. Steinige Berge; südl. Tyr., Veltlin, Tessin. Mai.Jun. K. an der Basis mit 2 Höckern.

9. E. Cheiranthus Pers. B. lincal.-lanzettl., ganzrandig, od. entfernt-gezähnt, $v$. einfachen Haaren etwas rauh, die untern in den Bstiel verschmälert; die Blattwinkel nackt; Bthstielchen um das 2- 
od. 3fache kürzer als der K.; Schoten 4kantig, einfarbig, faumh. od. grau; Gf. so lang als die Breite der Schote; Narbe ausgerandet. 4. Gebirge, VorA. bis zu den höchsten A.; Litt., Krain, Kärnth., Stmk., Unteröstr., südl. Tyrol. Mai. Jun. E. lanceolatum R. Brown. E. murale DC. Cheiranthus erysimoides Jacq. W. vielköpfig, mit sterilen WKöpfen neben den blïhenden. Bth. mit Honiggeruch.

10. E. helve ti c u m DC. B. lineal.-lanzettl., ganzrandig, od. eutfernt-gezälnt, etwas rauh $v$. einfachen Haaren, die untern in den Bstiel verschmälert; die Blattwinkel nackt; Bthstielchen um das 2 . od. 3 fache kürzer als der $K$.: Schoten rechtwinkelig-4kantig, cinfarbig, flaumh. od. grau; Gf. 2-3mal so lang als die Breite der Schote; Narbe ausgerandet. 24. Gbge., VorA. u. A.; Jura, Wallis, Tyr., Stmk. Mai. Juni. Cheiranthus pallens Hall. fil. Ganz ähnlich dem vorhergeh. $u$. nur deh den langen Gf. verschieden; ob Variet.?

11. E. ochroleucum DC. B. lineal.-lanzettl., od. lanzettl., ganzrandig od. entfernt-gezähnt, etwas raulı v. einfachen Haaren, die untern in den Bstiel verschmälert; die Blattwinkel nackt; Bthstielchen um das 2-od. 3fache kürzer als der $K$; Schoten zsgedrückt$4 k a n t i g$, einfarhig, angedriickt-flaumh. od. grau; Gf. 3mal so lang als die Breite der Schote; Narbe knotig-2lappig. 24. Steinige 0.; Jura in der Schwz. Jun.-Aug. Die WKöpfe zuletzt zu Stämmchen verlängert. Blb. erst lielleitrongelb, dann strohgelb.

12. E. suffrutic os um Spreng. B. längl.-lanzettl., kurz-stachelspitzig, etwas rauh $v$. fast lauter einfachen Haaren; Bthstielchen so lang als der K., die fruchttrag. vielmal kürzer als die Schote; Schoten 4 kantig, v. der Seite etwas zsgedrückt; filzig-grau, mit grünen Kanten, die Klappen auf der inneren Seite filzig. -.. Wegränder, zw. Verviers u. Limburg. Mai. Jun. E. murale Desf. Cheiranthus helveticus Jacq. Ch. fruticulosus L. nach Gay. Bth. dottergelb.

II. Rotte. Coringia DC. Die stengelst. B. an der Basis tiefherzf., stengelumfassend. Bth. weiss od, gelblich. (Erysimum austriacum gelört wegen der 3nervigen Klappen der Schoten eigentlich zur Gattung Sisymbrium.)

13. E. orientale R. Brown. Die stengelst. B. herzf., stengelumfassend, Schoten abstehend, Klappen 1nervig. $\odot$. Aecker, Lettenu. Kalkboden. Mai-Aug. E. perfoliatum Crantz. DC. Brassica orientalis L. Bth. weiss od. gelblich-weiss.

14. $\mathrm{E}$ a ustria c um Baumg. Die stengelgelst. B. herzf., stengelumfassend; Schoten aufrecht, Klappen 3nervig. $\odot$. u. $\odot$. Aecker; Unteröstr. Mai. Jun. Brassica austriaca Jacq. Bth. hell-gelb.

15. SYRÉNIA Andrzejowski. Fadengriffel.

1. S. angustifolia Rchb. Schoten viel länger als der Gf.; Bth. 
fast sitzend; B. lineal., ganzrandig. $\odot$. Sandige 0. ; Unteröstr., nach Host. Jun.-Aug. Erysimum angustifolium Ehrh. Bth. citrongelb.

III. Gruppe BRASSICEEN. KeimB. aufeinanderliegend, um das Würzelchen rinnig-gefaltet od. herumgerollt.

16. BRÁSSICA L. Kohl.

1. B. olera cea L. B. meergrün, die untern leyerf., gestielt, die obern längl., sitzend; $T r$. schon vor dem Aufblühen verlängert $u$. locker ; K. aufrecht, geschlossen; Stbg. sämmtlich aufrecht. $\odot$. Wird in vielen Variet. gebaut. Mai. Jun. Blb. gelblichweiss, seltner weiss. B. ganz kahl.

2. B. R a pa L. Die ersten B. grasgrün, die folgenden meergrün, die untern leyerf., die obern eyf., zugespitzt, mit tief-herzf. Basis stengelumfassend; $T r$. während des Aufblühens flach, die geöffneten Bth. höher als die gedrängten Bthknöpfe; K. zulezt wagerecht abstehend; die kürzern Stbg. abstehend-aufstrebend. ๑. u. ๑. Aecker, u. in Variet. angebauet. Die wilde Pfl., Variet. $\alpha$. campestris, ist einjährig, überwintert auch aus spät aufgelaufenem Samen, erstere blühet Jul. Aug., letztere Apr. Mai. Stellenweise dch das Geb. u. daselbst häufig, in andern Provinzen gar nicht. W. dünn, Brassic. campestris L. Al. suec. - Die kultivirte Pfl. mit dünner W., Varietät $\beta$. oleifera wird gebauet als jährige u. blïhet Jul. Aug.: B. Rapa oleifera annua, Sommerrübenreps; od. als zweijährige u. blühet Apr. Mai: B. Rapa oleifera biennis, Winterrübenreps. Die zweijährige mit dicker, fleischiger W. bildet $\gamma$. die Varietät esculenta, die weisse Rïbe, die Brassica Rapa L.

3. B. Napus L. B. meergrün, die untern leyerf., die obern längl., hinten etwas schmäler, aber mit verbreiterter, herzf. Basis halbstengelumfassend; $\boldsymbol{T} r$. locker, schon während des Aufblühens verlängert; K. zuletzt halboffen; die kürzern Stbg. abstehend, auf-

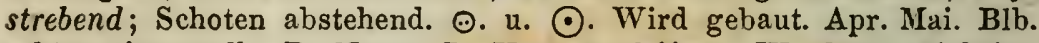
schön citrongelb. B. Napus L. Var. $\alpha$. oleifera: W. dünn, 2jährig: Winterkohlreps. Apr. Mai. - $\beta$. arnua: W. dünn, jährig: Sommerkohlreps. Diese im Jul. Aug. - $\gamma$. esculenta: W. fleischig, dick, essbar: Erdkohlrabe, Dorschen. Mai.

4. B. nigra Koch. B. sämmtl. gestielt, die untern leyerf., gezähnt, der Endzipfel sehr gross, gelappt, die obern lanzettl., ganzrandig; K. wagerecht-abstehend; Schoten an die Spindel angedrückt. $\odot$. Gebüsch, Kies der Flüsse, auch bebaute 0 .; Ufer des Neckars v. Tübingen bis Heidelberg, am Main v. Würzbg. bis Mainz, Moselufer, südl. Tyrol, auserdem hin u. wieder. Jun. Jul. Blb. gelb. Sinapis nigra $L$.

\section{SINÁPIS Linn. Senf.}

1. S. a rvensis L. Schoten walzlich, holperig, Klappen 3nervig, 
Nerven hervortretend, Schnabel so lang als die Schote od. kürzer, 2schneidig; K. wagerecht-abstehend; B. eyf., ungleich-gezähnt, die untern an der Basis geöhrelt, od. etwas leyerf. $\odot$. Kultiv. O.'Jun. $J u l$. Blb. gelb. Var. Schote kahl u. $\beta$. rückwärts steifhaarig: S. orientalis Murray u. auch Linn.

2. S. al b a L. Schoten walzlich, holperig, Klappen 5nervig, Nerven hervortretend, Schnabel so lang als die Schote, od. kürzer, zsgedriickt; K. wagerecht-abstehend; $\mathbf{B}$. gefiedert, Fieder grob-ungleichgezähnt, etwas gelappt, die oberen 3 zsfliessend. $\odot$. Unter der Saat; zerstreut dch das sïdl. Geb. Jun. Jul. Blb. gelb.

3. S. Cheiranthu s Koclı. Schoten walzlich, etwas holperig, Klappen 3nervig, Nerven hervortretend; K. aufrecht, geschlossen; B. sämmtl. tief-fiedersp. od. gefiedert, Fieder längl., ungleich-gezähnt, die der obern B. lineal., ganzrandig. $\odot$. Sand- u. Kiesfelder u. steinige, schroffe Bergabhänge; Rhein-, Nahe- u. Moselgegend. Jun.Aug. Brassica Cheiranthus Vill.-B. cheiranthiflora N. v. Esenb. ist die im ersten Jahre blühende Pfl. Blb. schwefelgelb.

18. ERUCASTRUMI Schimper 11. Spenner. Rempe.

1. E. o btus angulum Reichenb. B. tief-fiedersp., Zpfl. längl., ungleich-eckig-gezähnt, an der Basis dch eine gerundete Bucht gesondert.; Tr. ohne Deck-B.; KB. wagerecht-abstehend; die längern Stbg. oberwärts ron dem Stempel abgebogen; Schoten abstehend 7. Sonnige O., Mauern, Schutt; Wallis, Genf, Rheinthal der Schwz, am Bodensee, Oberbaden, Elsass, südl. Tyrol. Jun. Jul. Blb. hellcitrongelb. Sisymbrium obtusangulum Schleich. S. Erucastrum Vill.

2. E. P olli chi i Schimp. u. Spenn. B. tief-fiedersp., Zpfl. längl., ungleich-stumpf-gezähnt, an der Basis deh eine gerundete Bucht gesondert; $T r$. unteruärts mit DeckB.; KB. aufrecht abstehend; längere Stbg. an den Stempel angepresst; Schoten abstehend. $\odot$. u. $\odot$. Aecker, Brachfelder, Schutt; Rhein- u. Moselthal, Halle, Unteröstr. - April-Octob. Sisymbr. Erucastrum Poll. Blb. gelblich-weiss.

3. E. in ca n u Koch. B. leyerf, kurzh., die obern lineal.-lanzettl.; Schoten an die Spindel angedrückt, holperig. -.. Steinige Hügel u. Schutt; bei Basel 11. Miihlhausen, Neuenbg. in Oberbaden. Mtai-Jul. Blb. hellgelb. Sinapis incana L.

\section{DiPLOTÁXIS DC. Doppelsame.}

1. D. tenu ifolia DC. St. ästig, blättrig, an der Basis halbstrauchig; B. völlig kahl, buchtig-gezähnt, ungeth., od. einfach- u. doppel-fiedersp., Zpfl. lineal., entfernt-gezähnt; Bthstiєlchen noch 1mal so lang als die Bth.; Blb. rundl.-vkteyf., in den kurzen Nagel zsgezogen. 4. Unkult. O.; zerstr. dch das südl. u. mittlere Geb. 
Jun.-Herbst. Blb. citrongelb, abgeblüht lederbraun, wie bei den folgenden. Sisymbrium tenuifolium L.

2. D. muralis DC. St. krautig, nur án der Basis beblättert; B. zerstreut-behaart, buchtig-gezähnt u. fiedersp., $\mathbf{Z}$ pfl. eyf., od. längl., gezähnt, der endst. vkteyf., eckig-gezähnt; Bthstielchen so lang als die Bth.; Blb. rundl.-vkteyf., in den kurzen Nagel zsgezogen. $\odot$. Aecker a. bebsute O.; sehr zerstreut deh das Geb. Mai-Oct. Sisymbrium murale $\mathrm{L}$.

3. D. vimin e a DC. St. krautig, nur an der untersten Basis beblättert; B. buchtig-leyerf., Zpfl. eyf., geschweift-gezähnt, der endst. oval; Bthstielchen kürzer als die ehen geöffnete Bth.; Blb. längl.vkteyf., keilig, allmälig in den Nagel versshmälert. $\odot$. Aecker, Weinberge; um Werthheim in Franken u. um Hochheim bei Mainz. Jun. Jul. Sisymbr. vimineum L.

20. ERÚCA DC. Runke.

1. E. sativa Lam. B. leyerf.-fiederth., Zpfl. gezähnt, spitz; St. rauhh.; Bthstielchen kürzer als der abfällige K. $\odot$. Wege, Schutt; Wallis, in südl. Gegenden auch angebaut. Mai. Jun. Blb. milchweiss od. gelblichweiss, mit violetten Adern. Brassica Eruca L.

II. Unterordng. LATISEPI'EN. BREITWANDIGE. Schötchen 2klappig, aufspringend, (gedunsen, längl., oval, od. kugelig, od. vom Rücken her zsgedrückt, od. vom Rücken her flach); Scheidewand so breit als der grössere Querdurchmesser des Schötchens, od. an sehr gedunsenen nur ein wenig schmäler.

IV. Gruppe. ALYSSINEEN. KeimB. aneinanderliegend. Würzelchen seitlich auf der Spalte des KeimB.

21. VESICARIA Lam. Blasenschötchen.

1. V. utric u lata Lam. Schötchen kahl; B. längl., ganzrandig; kahl, die untern bewimpert, fast spatelf. 4 . od. $\hbar$. Felsige 0 . am Fusse der A.; C. Wallis, häufig an dem Giesbache Trient, 'wo er in die Rhone fällt, Godesberger Ruine bei Bonn. Apr.-Jun. Blb. gelb. Alyssum utriculatum $\mathbf{L}$.

2. V. s in u a t a Poiret. Schötchen kahl; B. weich-filzig, die der Stämmchen längl.-lanzettl., nach der Basis verschmälert, buchtig gezähnt, od. fast ganzrandig. 24. od. Ђ. Felsen, steinige 0.; Monfalcone, Fiume, Osero, Cherso. Mai. Jun. Blb. gelb. Alyssum sinuatum $\mathbf{L}$.

\section{ALÝSSUM L. Steinkraut.}

I. Rotte. Aurinia Meyer. Stbf. an der Basis inwendig mit 
einem stumpfen Zähnchen. Fächer der Schötchen 2- u. mehreyig. Blb. gelb.

1. A. petra eum Arduino. St. krautig, anfrecht, ïstig; Trauben rispig, die fruchttrag. verlängert; Platte der Blb. halb $2 s p$., mit spitzer Bucht; Stbf. an der Basis inwendig mit einem stumpfen Zähnchen; Schötçhen kahl, breit-elliptisch, in der Mitte aufgeblasen, am Rande plattgedrückt, Fächer 2eyig; die wurzelst. B. längl.-vkteyf., in den Bstiel verschmälert, die stengelst. lanzettl., sitzend. $\odot$. Sonnige, steinige O.; Krain, Stmk. Mai. Jun. A. edentulum W. K. A. gemonense L. mant.

2. A. medium Host. Stämmchen strauchig; die jälırigen St. einfach od. ästig; die fruchttrag. Tr. verlängert; Blb. seicht-ausgerandet; Stbf. an der Basis inwendig mit einem stumpfen Zähnchen; Schötchen kahl, oval, od. rundl., in der Mitte aufgeblasen, am Rande plattgedrückt, Fächer 4eyig; B. der Stämmchen längl. in den Bstiel verschmälert, sehr weich-filzig. 4. †. Kalkgebge; Oberkärnthen, Krain, Osero. Mai. Jun. A. gemonense Koch. syn. ed. 1.

3. A. saxatile L. Stämmchen strauchig; die jährigen St. an der Spitze traubig-ästig; die $T r$ r rispig, auch die fruchttrag. noch kurz; Blb. breit-ausgerandet; Stbf. an der Basis inwendig mit einem stumpfen Zähnchen; Schötchen kahl, oval od. vkteyf., flach, in der Mitte kouvex, Fächer 2eyig; B. der Stämmchen längl., in den Bstiel verschmälert, sehr weichfilzig. 2. Ђ. Kalkgbge; Unteröstr., Mähr., Böhm., Schles., Sachs., Franken bei Muggendorf. Apr. Mai.

II. Rotte. Odont arrhena Meyer. Längere Stbf. v. der Basis bis über die Mitte mit einem geflïgelten Rande, die küirzern an der Basiṣ mit flügelf. Anhängsel. Fächer der Schötchen 1eyig. Nabelstrang frei. Bl. gelb.

4. A. al pestre L. St. krautig, aufstrebend, an der Basis etwas strauchig, an der Spitze traubig-ästig; Tr. flachrispig; Blb. gestutzt; die längern Stbf. geflügelt, die kürzern an der Basis mit flügeligem Anhängsel; Schötchen v. sehr dicht-gestellten, angedrückten Sternhärchen grau; S. oval, auf der einen Seite sehr schmal geflügelt; B. grau, vkteyf. od. längl., nach der Basis verschmälert. 2. VorA. u. A.; Wallis. Jul. Ang. Var. $\alpha$. St. $2-3$ Zoll lang; B. kürzer, vkteyf. $-\beta$. majus: St. $5-6$ Zoll lang; B. schmäler im Verhältniss ihrer Länge: A. alpestre $\beta$. D. fl., A. tortuosum WK. DC., A. serpyllifolium MB. - $\beta$. elatius: St. $6-9$ Zoll lang; B. spatelig: A. alpestre $\beta$. argenteum Gaud. Wallis u. Schaufelsen bei Stetten am kalten Markt im Bad. Zeyher.

5. A. argenteum Vitman. St. krautig, aufstrebend, an der Basis etwas strauchig, an der Spitze traubig-ästig; Tr. in einem flachen Strausse; Blb. gestutzt; die längern Stbg. geflïgelt, die kürzern an der Basis mit geflügeltem Anhängsel; Schötchen rundl, od. 
oval, v. zerstreuten Sternbärchen etwas rauh; S. kreisrund, mit einem breiten Flügel umzogen; B. vkteyf. od. lanzettl., unterseits grau. 2. Sonnige Berge; Verviers im Gebiete der Fl. v. Spaa. Mai. Jun. A. murale W. K.

III. Rotte. Alyssum Meyer. Längere Stbf. geflügelt od. zahnlos; kürzere mit flügelf. Anhängsel, od. doch Zähnchen gestützt. Fächer der Schötchen 2 eyig; Nabelstränge mit ihrer Basis an die Scheidewand angewachsen.

6. A. montannm L. St. krautig, niedergestreckt od. aufstrebend, zuletzt an der Basis etwas strauchig; $\boldsymbol{T r}$. endst., einzeln, fruchttrag. verlängert; Blb. stumpf., od. gestutzt; die längern Stbf. geflügelt, die kürzern an der Basis mit geflügeltem Anhängsel; Schötchen oval od. rundl. v. dichtgestellten angedrückten Sternhärchen grau; B. grau, lanzettl., die untern vkteyf. 4. Felsenspalten, sonnige, gebirgige $O$., Sandfelder; zerstreut deh das Geb. Mai. Jun. Var.: untere B. vkteyf. A. arenarium Gmel. Blb. gelb.

7. A. Wulfeni a n u Bernhardi. St. krautig, niedergestreckt od. aufstrebend, zuletzt an der Basis etwas strauchig; T'r. endst., einzeln; Blb. ganz, od. gestutzt; die längern Stbf. geflügelt, die kürzern an der Basis mit geflügeltem Anhängsel; Schötchen oval, mit Sternhärchen bestreut, zuletzt kahl; B. lanzettl. od. vkteyf., mit Sternhärchen bestreut. 24. Alpen; Kärnthen, Krain. Jul. Aug. Var.: B. breiter u. schmäler. A. alpestre Wulf. Blb. gelb.

8. A. caly cinum L. St. aufstrebend, krautig; Tr. endst.; $K$. bleibend; Stbf. sämmtl. zahnlos, die kïrzern auf beiden Seiten mit einem borstlichen Zahne gestiitzt; Schötchen kreisrund, v. sehr kurzen angedrückten Sternhärchen grau; B. grau, lanzettl., an der Basis verschmälert, die untersten vkteyf. $\odot$ Felder, sonnige Hïgel. Mai. Jun. Blb. gelbl., zuletrt weiss, wie bei den beiden folgenden.

9. A. c a m pestre L. St. aufstrebend, krautig; Tr. endst.; K. abfällig; die längern Stbf. schmal-geflügelt, die kürzern an der Basis mit geflügeltem Anhängsel; Schötchen kreisrund, v. sternhaarigem od. einfachem etwas abstehendem Flaume kurzh.; B. grau, lanzettl., nach der Basis verschmälert, die untern vkteyf. $\odot$. Felder; Gebiet der Fl. v. Spaa. Var. $\alpha$. hirtum: Haare der Schötchen alle sternf. u. kurz. A. campestre Auctor. - $\beta$. micropetalum Fisch.: Haare der Schötchen alle sternf., kürzere u. längere gemischt. $-\gamma$. hirsutum MB.: Haare der Schötchen gemischt, kiirzere sternf. u. längere einfache.

10. A. m in i $\mathrm{m} \mathrm{u} \mathrm{m}$ Willı. St. aufstrebend, krautig; Tr. endst.; K. abfällig; die längern Stbf. zahnlos, die kürzern geflügelt, u. auf beiden Seiten mit einer kleinen Borste gestützt; Schötchen kreisrund, ganz kahl od. am Rande bewimpert; B. grau, lanzettl., die untersten vkteyf. $\odot$. Sandplätze, unkultiv. Hïgel; Unteröst. Jun. Jul. 


\section{LOBULARIA Desvaux. Lobularie.}

1. L. maritima.Desv. 24. Meeresufer bei Fiume, Bartling; Triest, Küitzing. Jun. Aug. Clypeola maritima L. Alyss. maritimum Lam. Blb. weiss.

24. FARSETIA Brown. Farsetie.

1. F. incana R. Brown. St. krantig, aufrecht, od. aufstrebend; Blb. 2sp.; die längern Stbg. an der Basis geflïgelt, die kürzern gezähnt; Schötchen elliptisch, convex-zsgedrückt, flaumh.; B. lanzettl., die untern in den Bstiel verschmälert. $\odot$. Unkult. O., Wege; zerstr. dch. das Geb. Jun.-Oct. Berteroa incana DC. Alyssum incanum L. Blb. weiss.

2. F. cly peata R. Brown. St. krautig, aufrecht, od. aufstrebend.; Blb. abgerundet-stumpf, ungetheilt; die längern Stbg. bis zur Mitte geflügelt, die kiirzern zahnlos; Schötchen elliptisch, flach, filzig; B. lanzettl., die untern in den Bstiel verschmälert. $\odot$. Auf einem trock. nen Orte Alle Laste bei Trient. Mai. Jun. Alyssum clypeatum L.

25. LUNARIA L. Mondviole.

1. I. rediviva L. Schötchen elliptisch-lanzettl., an beiden "Enden spitz; S. nierenf, noch $1 \mathrm{mal}$ so breit als lang. 2. VorA. u. Gbge; zerstr. dch. das Geb. Mai. Jun. Blb. lila.

2. L. biennis Moench. Schötchen breit-oval, an beiden Enden stumpf; S. herzf.-rundl., so breit als lang. $\odot$ Wälder, buschige, felsige O.; Fl. von Spaa, Oberbad., Nahegeb.; ob wirklich einheimisch? Apr. Mai. L. annua L. Blb. violett.

26. CLYPÉOLA L. Schildkraut.

1. C. Jonthlaspi L. St. liegend od. aufstrebend. (-) Meerufer; Litt., Fiume, Sitten in Wallis. Apr. Mai. Blb. sehr klein, gelb, zuletzt weiss. Var.: Schötchen ain Rande kurzh.-bewimpert, u. am Rande ganz kahl; letztere: C. Gaudini Trachsel.

27. PELTARIA L. Scheibenkraut.

1. P. alliacea L. Die stengelst. B. mit tief herzf. Basis stengelumfassend; Schötchen flach, netzig-geädert. 2. Felsige Ufer der Waldbäche; Stmk., Unteröstr., Istr. Mai-Jul. Blb. weiss.

28. PETROCÁLLIS R. Brown. Steinschmückel.

1. P. pyrenaica Brown. 4. Felsige Gipfel der, höchsten A. Jun. Jul. Draba pyrenaica L. Blb. hellpurp.

29. DRABA L. Hungerblümchen.

1. Rotte. Aizopsis DC. W. stark, vielköpfig. Stämmchen viele, unterwärts mit den vertrockneten $B$. der vorigen Jahre be- 
deckt, an der Spitze mit einer Blätter-Rosette bekränzt. B. starr, mit starren Borsten kammf.-gewimpert. Blb. gelb.

1. D. äzoides L. St. blattlos, kahl, B. starr, lineal., spitzl., kahl, mit steifen Borsten kammf.-gewimpert; Stbg. so lang als die Bl.; Gf. fast so lang als der Querdurchmesser des Schötchens. 4. Felsige 0 , niedrigere Gbge, VorA. u. A. März-Mai, in den A. später. Blb. gelb, fast goldgelb. Var.: Schötchen kahl od. borstigrauh, od. nur am Rand borstig-bewimpert, lanzettl., elliptisch, od. fast rundl. $\alpha$. alpina: kleiner, Schötchen 2-3 Linien lang; Bthstielchen so lang als das Schötchen. Höchste A. - $\beta$. affinis: grösser, Bth. noch 1mal so gross; Schötchen bis zu 6 Linien lang; Bthtielchen länger, doch nicht länger als das Schötchen. D. affinis Host. VorA. - $\gamma$. montana: grösser u. kleiner; Bthstielchen 2- od. $3 \mathrm{mal}$ so lang als das Schötchen. D. elongata Host., wegen der längern Bthstielchen so benannt; niedrigere Gloge.

2. D. Z a hlbruckneri Host. St. blattlos, kahl; B. starr, lineal., spitzl., kahl, mit steifen Borsten kammf.-bewimpert; Stbg. so lang als die Bl.; Gf. kürzer als der Querdurchmesser des Schötchens. 4. Höchste GranitA. Jun. Jul. Bthstielchen kürzer als das Schötchen, der Gf. kurz. Scheint eine Variet. der D. aïzoides, deh den höchsten Standort erzeugt.

3. D. S a u teri Hoppe. St. blattlos, kahl; B. starr, lanzettl., nach der Basis verschmälert, kahl, mit steifen Borsten bevimpert; Stbg. halb so lang als die Bl.; Gf. kürzer als der Querdurchmesser des Schötchens. 4. Höchste KalkA.; Salzbg., Tyrol, Stmk. Jun. Jul. Var.: Schaft flaumh.: D. Spitzelii Hopp.

II. Rotte. Le u codraba DC. W. stark, vielköpfig. Stämmchen viele, unterwärts mit den vertrockneten $B$. der vorigen Jahre bedeckt, an der Spitze mit einer Blätter-Rosette bekrönt. B. weicher, sehr oft mit Sternhärchen besetzt. Blb. weiss.

4. D. tomentos a Wahlenb. St. meist 2 blättrig, u. nebst den Bthstielchen $v$. Sternhärchen flaumig; B. der Stämmchen elliptisch, nach der Basis verschmälert, v. Sternhärchen filzig, hinten v. einfachen Haaren wimperig; Schötchen oval od. längl., mit einfachen Haaren bewimpert; Gf. selır kurz. 24. Höchste A.

5. D. stellata Jacq. St. meist 2 blättrig, oberwärts nebst den Bthstielchen kahl; B. der Stämmchen lanzettl. od. elliptisch, nach der Basis verschmälert, v. Sternhärchen etwas grau, hinten mit einfachen Haaren bewimpert; Schötchen oval, kahl; Gf. fast so lang als der Querdurchmesser des Schötchens. 4. Nackte Felsen der KalkA.; Oestr., Stmk. Jun. Jul. D. hirta Jacq. fl. austr.

6. D. frigida Sauter. St. meist 2 blättrig u. nebst den Bthstielchen mit ästigen Härchen locker bestreut; B. der Stämmchen lanzettl. od. elliptisch, nach der Basis verschmälert, v. Sternhärchen 
etwas filzig, hinten mit einfachen Haaren bewimpert; Schötchen längl., kahl; Gf. kurz od. fast felllend. 2. Felsen der hohen A. Jul. Var.: Schötchen gewimpert od. flauml.

7. D. Traunsteineri Hoppe. St. meist 2blättrig, oben nebst den Bthstielchen kahll; B. der Stämmchen lanzettl., nach der Basis verschmälert, v. Slernhärchen filzig, hinten v. einfachen Haaren bewimpert; Schötchen nach beiden Enden gleichf.-verschmälert; $G f$. noch einmal so lang als hreit. 2. A. v. Tyrol. Jul. Aug.

8. D. Joh ann is Host. St. meist 2blättrig, oberwärts nebst den Bthstielchen kahl; B. der Stämmcheu lanzettl., nach der Basis verschmälert, mit Sternhärchen bestreut, hinten mit einfachen Haaren bewimpert; Schötchen lanzettl., an beiden Enden gleichf.-verschmälert, kahl; Gf. sehr kurz, fast fellend. 24. Höchste GranitA.; Schwz., Tyrol, Salzbg., Kärnth. Jul. Aug. D. hirta Gaud. u. D. nivalis Gaud. Grössere: D. Johannis Hoppe; kleinere: D. carinthiaca Hoppe. Var. $\beta$. glabrata, kahl: die B. bloss bewimpert: D. Hoppeana Rudolphi D. Hoppii Trachsel.

9. D. W a hlenbergi Hartmann. St. blattlos od. 1-2blättrig nebst den Bthstielchen kahl; B. der Stämmchen lanzettl., nach der Basis verschmälert, ganz kahl, od. mit längern einfachen od. gabcligen Haaren bewimpert $u$. ausserdem kahl od. noch mit sternf. Flaume bestreut; Schötchen längl.-lanzettl. od. lanzettl., nach beiden Enden fast gleichf.-verschmälert, kahl, Gf. sehr kurz, fast fehlend. 2. Steinige O. der höchst. A. Jul. Aug. Var. $\alpha$. homotricha: B. mit eir. fachen Borstchen fast kammf.-bewimpert, übrigens kahl od. mit eirfachen Haaren bestreut. D. fladnizensis Wulf. D. sclerophylla Gaud. - $\beta$. heterotricha: B. mit einfachen od. gabeligen Borstchen bewimpert, die äussern meist kahl, die innern mit kurzem sternf. Flaume bestreut. D. lapponica Willd. - $\gamma$. glabrata: B. überall kahl. D. laevigata Hopp.

10. D. cili a ta Scopoli. St. 2-3blättrig; B. etwas lederig, kahl, am Rande knorpelig-gezähnelt, $u$. horstig-gewimpert, die der Rosetten vkteyf., kurz-zugespitzt, die am Schafte längl.; Schötchen lineal., nebst den Bthstielchen u. dem St. ganz kahl. 24. Felsen; Nord- u. Ostseite des Nanas, Einsattelung d. M. Magg. in Krain. Mai. Jun.

III. Rotte. Holarges DC. W. 1fach, jährig, od. 2jährig, odl. wenigstens nicht v. langer Dauer. Die unfruchtbaren Blätterbiischel fehlen, od. sind in geringer Zahl vorhanden. St. beblättert, an stärkern Exempl. ästig. Blb. weiss.

11. D. mu ralis L. St. einfach od. ästig, beblättert; StB. eyf., stengelumfassend; Bthstielchen wagerecht abstehend, noch einmal so lang als das kahle Schötchen; W. einfach. $\odot$. Steinige beschattete O.; Rheingeb., Thüring., Schles., Böhm., Mähr. Mai. Jun. Bth. weiss. 12. D. incana L. St. viclblättrig, an der Spitze ästig od. ein- 
fach; W. nichtblühende Rosetten trag.; B. ganzrandig od. gezähnt, die wurzelst. dicht-rosettig, lanzettl., die obern stengelst. eyf.; Schötchen länger als das Bthstielchen, kahl od. flaumig. $\odot$. Steinige O.; Schweiz am Ganterich bei Rüggisberg; Albula in Graubünd., Fassa in Tyrol. Mai. Jun. Bth. weiss. Var. a. legitima: Schötchen kahl. D. contorta Ehrh. - $\beta$. hebecarpa: Schötchen flaumig. D. confisa Ehrh.

13. D. Thomasi i Koch. St. vielblättrig, v. der Basis an ästig od. einfach; nichtblühende Rosetten fehlend; B. ganzrandig od. gezähnt, die wurzelst. rosettig, lanzettl., die obern stengelst. längl.lanzettl.; Schötchen länger als das Bthstielchen, flaumh. $\odot$. Steinige O.; Schleherugbg. des suidl. Tyrols, Wormser Joch, St. Nicolai, Saasthal u. Gemmi in der Schwz. Mai. Jun. D. confusa Koch. synop. ed. 1. D. stylaris Gay. Bth. weiss. Der Gf. zuweilen ziemlich lang, zuweilen fast fehlend.

IV. Rotte. Erophila DC. W. einfach, jährig. WB. rosettig. Schäfte nackt. Blb. weiss, halbzweispaltig.

14. D. ve rna L. Schäfte blattlos, nach oben nebst den Bthstielchen kahl; WB. lanzettl., spitz, nach der Basis verschmälert; Schötchen lanzettl., längl. od. rundl., kürzer als das Bthstielchen; Gf. sehr kurz; Platte der Blb. halbzweisp. $\odot$. Kultiv. u. unkultiv. O. März. Apr. Erophila vulgaris DC. Var.: $\beta$. Schötchen rundl. D. spathulata Lang. D. praecox Stev. - $\gamma_{\text {.: }}$ Schötchen lanzettl. Erophila americana DC.

30. COCHLEARIA L. Löffelkraut.

a. Schötchen mit einem Mittelnerven auf den Klappen. S. feinknötig-rauh. Stbf. nicht winkelig-gebrochen.

1. C. officinalis L. WB. gestielt, breit-eyf., dch einen seichten Ausschnitt etwas herzf., die stengelst. eyf., gezähnt, die obern mit tief-herzf. Basis umfassend. $\odot$. Meeresufer u. Salzquellen. Mai. Jun. Blb. weiss, wie bei den folgenden.

2. C. p y ren a ic a DC. WB. gestielt, fast alle nierenf. u. querbreiter, dch eine tiefe Buclit herzf., die stengelst. wenigè, gezähnt, das oberste sitzend. $\odot$. Grïne Au bei Mariazell $u$. auf $d$. Zinken bei Seckau in Stmk. Jul. C. groenlandica Host.

3. C. danica L. B. sämmtl. gestielt, die wurzelst. herzf., die stengelst. 3- od. 5lappig, die obern ey-spiesf., in den kurzen Bstiel zugeschweift. $\odot$. Seestrand; Holstein u. Oldenburg. Mai. Jun.

4. C. anglica L. WB. gestielt, eyf.-längl., oder eyf., an der Basis abgerundet, od. in den Bstiel vorgezogen, die stengelst. längl., gezihnt od. ganzrandig, die obern mit tief-herzf. Basis stengelumfassend. $\odot$. Seestrand; Bremen, Holstein, Mecklenbg. Mai. Jun. 
b. Schötchen mit einem Nerven an der Basis der Klappen. S. glatt. Die längern Stbf. in der Mitte rechtwinkelig-gebrochen. Kernera.

5. C. saxatil is Lamck. WB. in den Bstiel verschmälert, längl., stumpf, ganzrandig od. gezähnelt, etwas rauh v. angedrückten Härchen; StB. lineal.-längl., ganzrandig; Tr. deckblattlos; längere Stbf. in der Mitte gebrochen. 24. Steinige O. der VorA. 11. A., mit den Flüssen in die Ebenen hinab. Jun.-Aug. Myagrum saxatile L. Kernera saxatilis Rchb. K. syn. ed. 1. Var. $\beta$.: StB. an der Basis mit Oehrchen. Cochlearia auriculata Lam.

c. Schötchen ohne Nerven auf den Klappen; S. fein-knötig[ rauh. Staubf. gleichf. aufstrebend. Tr. mit DeckB. Rhizobotry a Tausch.

6. C. brevicaulis Facchini in briefl. Mittheilungen. B. in den Bstiel verschmälert, längl., stumpf, ganzrandig od. beiderseits 1-2zähnig, etwas rauh v. angedrückten Härchen; Tr. deckblättrig; Stbf. nicht winkelig-gebrochen. 4. Steinige O.; A. Neva seconda in Primiero u. A. Camerloi in Fassa, im südl. Tyrol. Jul. Aug. Rlizobotrya alpina Tausch.

d. Schötchen ohne Nerven auf den Klappen; S. glatt. Stbf. nicht winkelig-gebrochen. Tr. deckblattlos.

7. C. Armor a ci a L. WB. längl., herzf., od. eyf.-längl., gekerbt, die untern stengelst. kämmig-fiedersp., die obern eyf.-lanzettl., gekerbt-gesägt, die obersten lineal., fast ganz. 4. Ufer, feuchte Zäune; vielleicht an den meisten $O$. blos verwildert. Jun. Jul. C. rusticana Lamck. Armoracia rusticana Fl. d. Wett. K. syn. ed. 1.

V. Gruppe. CAMELINEEN. Die KeimB. aufeinander liegend, das Würzelchen auf dem Rücken des einen KeimB.

\section{CAMELÍNA Crantz. DC. Leindotter.}

1. C. Sativa Crantz. Schötchen biruf; die mittleren StB. längl.lanzettl., ganzrandig od. gezähnelt, an der Basis pfeilf. $\odot$. Felder, Aecker, sandige O. Jun. Jul. Blb. gelbl. Myagrum sativum L. Var. a. pilosa DC.; behaart. C. silvestris Fries. Diese Variet. ist, wenn die Schötchen um die Hälfte kleiner sind: C. microcarpa Andrz. bei Rchb. C. sylvestris Wallr. - $\beta$. subglabra: fast kahl. C. sativa $\beta$. glabrata DC.

2. C. dentata Pers. Schötchen birnf.; die mittlern StB. lineal.längl., buchtig-gezähnt od. fiedersp.; hinten verschmälert, aber an der pfeilf. Basis wiederum verbreitert. ○. Aecker unter d. Lein. Jun. Jul. Blb, gelbl. 
VI. Gruppe. SUBULARIEEN. KeimB. in der Mitte zurlickgeschlagen.

\section{SUBULARIA L. Pfriemenkresse.}

1. S. a quatica L. 24. Fischteiche unter dem Wasser u. nach vermindertem Wasser am Rande derselben; Wittenberg, Braunschw., Holstein, Bischoffsweyer bei Erlangen. Jun. Jul. Unter dem Wasser heimlich mit' geschlossenen Bth. blühend; ausser dem Wasser die kleinen weissen Bth. entfaltend.

III. Unterordng. ANGUSTISEPT'EN. SCHMALWANDIGE. Schötchen 2klappig, aufspringeud, v. d. Seite zsgedrückt, Klappen kahnf., auf dem Rücken gekielt od. gefligelt. Scheidewand schmal, lineal. od. lanzettf., an beiden Enden verschmälert.

VII. Gruppe. THLASPIDEEN. Die KeimB. aneinanderliegend, das Würzelchen auf der Spalte der KeimB.

33. THLASPI L. Täschelkraut.

1. Th. arvense L. Fruchttrag. Tr. verlängert; StB. längl., mit pfeilf. Basis sitzend; Fächer des Fruchtkn. vieleyig; St. oberwärts ästig; S. bogig-runzelig. $\odot$. Kultiv. O., Schutt. Mai-Herbst. Blb. weiss.

2. Th. alli a ce u m L. Fruchttrag. Tr. verlängert; StB. längl., mit pfeilf. Basis sitzend; Fächer des Fruchtkn. vieleyig; St. oberwärts ästig; S. grübig-netzig. $\odot$. Aecker; Berchtesgaden, Aachen, Holstein. Mai. Jun. Blb. weiss.

3. Th. perfoliatum L. Fruchttrag. Tr. verlängert; StB. herzf, sitzend; Fächer des Fruchtkn. 4eyig; St. ästig; S. glatt. $\odot$. Aecker, Kalk- u. Lehmbod. Apr. Mai. Blb. weiss.

4. Th. alpestre L. Fruchttrag. Tr. verlängert; StB. ey-herzf., sitzend; W. vielköpfig; Stämmchen kurz, rasenartig zsgedrängt; St. einfach; Fruchtkn. 8-16eyig; Schötchen 3eckig-vkt-herzf., nach der Basis verschmälert; Flügel der Klappen vorne so breit als die Höhle des Faches; Gf. so lang als die Bucht der Ausrandung; S. glatt. 4. Gebirgige, steinige, buschige O.; zerstreut dch. das Geb. Apr. Mai. Blb. weiss. Stbk, zuerst gelb, bald purpurn, zuletzt schwarz. Stbg. meist so lang als die Blb., seltner ein wenig kürzer. Var. Stbk. bleibend gelb.

5. Th. praecox Wulfen. Fruchttrag. Tr. verlängert; StB. längl.herzf., sitzend; $W$. vielköpfig; Stämmchen kurz, rasenartig-zsgedrängt.; St. einfach; Fruchtkn. 8-10eyig; Schötchen vktherzf., nach der Basis verschmälert, der Flügel der Klappen vorne so breit als die Höhle des Faches; Gf. hervorgestreckt, über die Lappen des Schötchens hinausragerid; S. glatt. 2. Hügel und gebirgige 0 .; Litt. März. Apr. Blb. weiss.

6. Th. montanum L. Fruchttrag. Tr. verlängert; StB. herzf., 
sitzend; W. vielköpfig; Stämmchen verlängert, ausläuferartig; St. einfach; Fruchtkn. 4eyig; Schötchen rundl.-vktherzf., an der Basis abgerundet; S. glatt. 24. Gebirgige, fclsige, buschige O.; zerstr. dch das Geb. Apr. Mai. Blb. Weiss.

7. Th. al pin u m Jacq. Fruchttrag. Tr. verlängert; StB. herzf., sitzend; W. vielköpfig; Stämmchen verlängert, ausläuferartig; St. einfach; Fruchtkn. 8-16eyig; Schötchen längl.-vktherzf., nach der Basis verschmälert, der Flügel der Klappen halb so breit als die Höhle des Faches; S. glatt. 2. Weiden der A.; Wallis, südl. Tyrol, Kärnth., Stmk., Oestr. Apr.-Jul. Th. sylvium Gaud. Blb. weiss.

8. Th. rotundifolium Gaud. Fruchttrag. T'r. doldenf., verkürat; die obern StB. sitzend, an der Basis mit umfassenden Oehrchen; W. vielköpfig; St. einfach; Fruchtkn. 4-8eyig; Schötchen längl.-vkteyf., sehr stumpf oder seicht ausgerandet, der Randflïgel schmal. 24. Höchst. A.; Schwz. bis Kärnth. Jul. Aug. Iberis rotundifolia L. Blb. hellviolett, selt. weiss. Var. $\beta$. corymbosum: Oelıchen der B. spitz, Bl. satter violett. Hutchinsia corymbosa Gay. A. im Wallis.

9. Th. cepeaefolium Koch. Fruchttrag. T'r. doldenf.s verkürzt; die obern StB. sitzend, an der Basis ohne Oehrehen; W. vielköpfig; St. einfach; Fruchtkn. 8-12eyig; Schötchen längl.-vkteyf., gestutzt, seicht ausgerandet, der Randflügel schmal. 24. Felsen; Kärnth. im Rabelthal an den Galmeigruben unter der Vitriolwand, Zermatten im Wallis. Mai. Iberis cepeaefolia. Wulf. Bl. hellviolett.

34. TEESDALIA R. Brown. Teesdalie.

1. T. nudicaulis R. Brown. Blb. ungleich. $\odot$. Aecker, unkultiv. O., Sandboden. Apr. Mai, die NebenSt. bis in den Sommer. Teesdalia Iberis DC. Iberis nudicaulis L. Blb. weiss.

35. IBERIS L. Bauernsenf.

1. I. saxatilis L. Strauchig; B. zerstreut, lineal., ganzrandig, nach der Basis schmäler, etwas fleischig, spitz od. stachelspitzig, die untern stumpf; die fruchttrag. Sträusse fast traubig; Schötchen oval, gestutzt-ausgerandet, Lappen stumpf. 5 . Felsige 0 .; Jura, nur im C. Solothurn. Jun. Blb. weiss.

2. I. u mbellata L. Krautig; B. lanzettl., zugespitzt, ganzrandig, die untern schwach-gezähnt; Fruchttrauben eyf.; die Schötchen mit den aufrechten Bthstielchen dichtaufeinanderliegend, 2sp. Lappen eyf., in d. pfriemliche Spitze zugeschweift, so lang als das Fach, hervorgestreckt. $\odot$. Unkultiv., felsige O.; Littor. Jun. Bl. fleischfarbig.

3. I. intermedia Guersent. Krautig; $B$. des ersten Jahres lanzettl., beiderseits 1-2zähnig, des zweiten Jahres lineal.-lanzettl., spitz; ganzrandig; Fruchttrauben längl.; Schötchen mit dem Bth- 
stiele abstehend, ausgerandet-2lappig, Lappen zugespitzt, viel kürzer als das Fach, hervorgestreckt. $\odot$. Gebirgige 0 .; Boppard am Rheine, östr. Littor. Jun. Jul. Bl. weiss od. röthlich.

4. I. a mara L. Krautig; B. längl., stumpf, in den Bstiel keiligverschmälert, vorne beiderseits 2-3zähnig, Zähne eyf., stumpf; Schötchen traubig, fast kreisrund, mit einer Kerbe ausgerandet, Lappen 3eckig, spitz, hervorgestreckt. $\odot$. Aecker, Brachfelder; zerstr. dch. das Greb. Jum.-Oct. Bl. weiss. Var.: $\beta$. kleiner, Blb. in das Violette spielend. I. ruficaulis Lej.

5. I. pinnata L. Krautig; StB. lineal., vorne auf beiden Seiten 2-3zähnig, Zähne lang, lineal., stumpf; Schötchen doldig-gehäuft, oval, vorne mit einer breiten Bucht gestutzt, Lappen 3eckig, spitz, spreitzend. $\odot$. Felsige O.; Triest u. Wien. Jun. Jul. Blb. weiss.

\section{BISCUTELLA L. Brillenschote.}

1. B. hispida DC. K. 2spornig, Sporne walzlich; Schötchen an der Basis u. Spitze ausgerandet; St. steifh. $\odot$. Sonnige O.; Insel Veglia. Jun. Jul. Bl. gelb.

2. B. la evigata L. K. an der Basis spornlos; Schötchen an der Basis u. Spitze ausgerandet; WB. längl., in d. Bstiel verschmälert, gezähnt u. ganzrandig; StB. längl., mit abgerundeter, halbstengelumfassender Basis sitzend, die obern lineal. 24. VorA. u. A., auch niedrigere Berge u. Ebenen; zerstr. dch das Geb. Jul. Aug. Bl. gelb. - $\beta$. glabra: B. kahl. B. laevigata $\beta$. glabra Gaud., u. B. lucida DC., wenn die B. glänzend sind. - $\gamma$ scabra: Friichte von feinen Knötchen rauh. B. saxatilis Schleich. DC. - $\delta$. macrocarpa: Früchte noch $1 \mathrm{mal}$ so gross, glatt od. rauh. - $-\varepsilon$. hispidissima, d. steifhaarige: B. von stärkeren Borstchen steifh. B. ambigua DC.

VIII. Gruppe. LEPIDINEEN. Die KeimB. aufeinander liegend, Würzelchen auf dem Rïcken des einen KeimB.

\section{LEPIDIUM L. Kresse.}

1. L. Draba L. Schötchen herzf., flügellos, dch die aufgedunsenen Klappen fast 2knötig; Gf. so lang als die Scheidewand; B. längl., geschweift-gezähnt, die wurzelst. in den Bstiel verschmälert, die stengelst. mit pfeilf. Basis stengelumfassend. 24. Weiden, Wege; zerstreut dch das Geb. Mai. Jun. Cochlearia Draba L. Blb. weiss, wie aller Arten.

2. L. s ativum L. Schötchen rundl.-oval, geflügelt, stumpf, ausgerandet, an die Spindel angedrückt; die untern B. gestielt, unregelmässig-eingeschnitten, gelappt, gefiedert od. doppeltgefiedert, die obern sitzend, lineal., ungeth. $\odot$. Kultivirt u. zufällig auf Schutt. Jun. Jul. Var. $\beta$. crispum: B. am Rande kraus. L. sativum $\beta$. crispum L. $\gamma$. latifolium: Lappen der B. breiter, od. die untern B. ganz. L. sativum latifolium DC. 
3. L. campestre R. Brown. Schötchen blatterig-punktirt, eyf., v. der Mitte an breit-geflügelt, am Ende abgerundet u. ausgerandet; B. grau-flaumig, die wurzelst. längl., in den Bstiel verschmälert, an der Basis buchtig-gezähnt, die stengelst. gezähnelt, an der Basis pfeilf., stengelumfassend. $\odot$. Brachfelder, kultiv. O. Jun. Jul. Thlaspi campestre L.

4. L. perfoliatum L. Schötchen rundl-elliptisch, an der Spitze schmal-geflügelt, ausgerandet; die untern B. gestielt, gefiedert, Fieder vielsp., die obern sitzend, ungeth., tief-herzf., stengehumfassend. $\odot$. Wiesen, Wegränder; Unteröstr. Mai. Jun.

5. L. ruderale L. Schötchen abstehend, rundl.oval, stumpf, an der Spitze schmal-geflïgelt, ausgerandet; die untern $B$. gestielt, gefiedert $u$. doppelt-gefiedert, die obern sitzend, lineal., ungeth.; Bth. 2 männig, blumenblattlos. $\odot$. Wege, Manern; zerstrent dch das Geb. Jun.-Aug.

6. L. graminifolium L. Schötchen eyf., spitz, mit dem kurzen Gf. bekrönt; WB. längl. od. spatelig, in den Bstiel rersehmälert, gesägt, od. an der Basis fiedersp., die obern stengelst. lineal., ungeth. $\odot$. Unkultiv. O., an Mauern, Wegen; Rheinlande, Litt., südl. Tyr., Wallis. Jun.-Oct.

7. L. la tif o lium L. Schötch. rundl., seicht-ausgerandet, flaumh.; B. ungeth., gekerbt-gesägt, die wurzelst. eyf., stumpf, langgestielt, die obern aus eyf. Basis lanzettl. 4. Seestrand $u$. salzhaltige 0. ; zerstreut im Geb. Jun. Jnl.

\section{HUTCHINSIA R. Brown. Hutchinsie.}

1. H. alpin a R. Brown. B. gefiedert; St. einfach, nackt; Fruchttraube lang, locker; Blb. noch $1 \mathrm{mal}$ so lang als der K.; Schötchen längl., an beiden Enden spitz, mit dem kurzen Gf. endigend. 4. Kiesige O. der KalkA. Apr.-Ang. L. alpinum L. Blb. weiss, wie aller Arten.

2. H. brevicaulis Hoppe. B. gefiedert; St. einfach, nackt; Fruchttraube gedrungen, doldentraubig; Blb. noch $1 \mathrm{mal}$ so lang als der K.; Schötchen längl.-vkteyf., stumpf, Narbe sitzend. 4. Kiesige O. der höheren GranitA.; Kärnth., Salzb., Tyrol. Jul. Aug.

3. H. petraea R. Brown. B. gefiedert; St. ästig, beblättert; Blb. wenig länger als der K.; Schötchen elliptisch, stumpf. $\odot$. Felsen und trockne, sonnige $\mathrm{O}$; selı zerstreut deh das Geb. Apr. Mai. Lepidium petraeum I.

\section{CAPSÉLLA Medikus DC. Hirtentäschel.}

1. C. Bursa pastoris Mönch. B. schrotsägef., fiedersp., Zpfl. eyf.-3eckig, spitz, etwas gezähnt, die obern stengelst. ungeth.; Schötchen 3eckig-vkther $\approx f$. $\odot$. Felder, kultiv. O. Blühet fast das ganze Jahr. Blb. weiss, wie der folg. Thlaspi Bursa pastoris L. Kommt 
vor: B. ganz, od. buchtig-gezähnt, od. fiedersp., od. fiedersp. mit vorne eingeschnittenen $\mathrm{Zpfln}$., u. Bth. blumenblattlos, 10männig.

2. C. procumbens Fries. B. tief-fiedersp., Zpfl. ganzrandig, lauzettl. od. elliptisch, der endst. grösser, die obern stengelst. B. od. alle B. ganz; Tr. verlängert, reichblïthig; Schötchen oval, längl., stumpf od. etwas gestutzt. $\odot$. Nasse, salzhaltige Triften; Thüring., Cant. Freiburg. Mai. Lepidium procumbens L.

3. C. pauciflora Koch. B. ganzrandig, längl., in den Bstiel verschmälert, die untern 3sp.- etwas leyerf., die obersten lanzettl.; T'r. 3-4blüthig, fast doldig; Schötchen rundl., stumpf od. etwas gestutzt. $\odot$. VorA. u. u. A.; südl. Tyrol auf dem Udai u. Bondon am Idro-See. Jun. Jul.

\section{AETHIONÉMA R. Brown. Steintäschel.}

1. A. saxatile R. Brown. B. lineal.-längl., sehr kurzgestielt, die untersten oval; die fruchttrag. Tr. verlängert; Bthstielchen so lang als die Schötchen. 24. Kiesige u. steinige O. der KalkA. bis in die Ebenen hinab. Mai. Jun. Thlaspi saxatile L. Blb. roth.

IX. Gruppe. BRACHYCARPEEN. KeimB. in der Mitte zurückgeschlagen.

\section{ISENEBIÉRA Pers. Senebiere.}

1. S. Coronopus Poiret. B. tief-fiedersp., Zpfl. ganz od. vorne eingeschnitten; Bthstielchen kiirzer als die Bth.; Schötchen fast nierenf., zsgedrüickt, mit dem pyramidenf. Gf. gekrönt, netzig-runzelig, am Rande fast strahlig-gestreift $u$. gezähnt. $\odot$. Triften, Gräben, Wege; zerstreut dch das Geb. Jul. Aug. Cochlearia Coronopus L. Blb. weiss.

2. S. didyma Persoon. B. tief-fiedersp., Zpfl. ganz, od. vorne eingeschnitten; Bthstielchen länger als die Bth.; Schötchen $2 \mathrm{knötig,}$ zsgedrückt, an der Basis u. Spitze ausgerandet, netzig-runzelig; Gf. fehlend. $\odot$. Ufer u. kultiv. O.; um Hamburg u. Altona, Bern in der Schwz. Jul.Aug. S. pinnatifida. DC. Lepidium didymum L. Blb. weisśs.

IV. Unterordng. NUCAMENTACEEN. DC. NUSSARTIGE. Schötchen nicht aufspringend, durch Schwinden der Scheidewand manchmal 1 fächerig.

X. Gruppe. EUCLIDIEEN. Die KeimB. aneinander liegend, Würzelchen auf der Spalte der KeimB.

42. EUCLIDIUM·R. Brown. Schnabelschötchen.

1. E. syriacum R. Brown. Schötchen kurzh.-rauh; Gf. kegelf.; StB. gestielt, lanzettl. $\odot$. Wege u. Ackerränder; un Wien. Mai. Anastatica syriaca L. Blb, weiss. 
XI. Gruppe. ISATIDEEN. Die KeimB. aufeinander liegend, flach, Würzelchen auf dem Rïcken des einen KeimB.

\section{ISÁTIS L. Waid.}

1. I. tinctoria L. Schötchen längl., sehr stumpf, od. ausgerandet, nach der Basis verschmälert. .. Sonnige Higel, felsige $\mathbf{A b}$ hänge, Mauern; sehr zerstreut deh das Geb. Mai. Jun. Blb. gelb. a. vulgaris: Schötchen lineal.-keilig, gestutzt od. ausgerandet. P. campestris: Schötchen lineal.-keilig, an der Spitze abgerundet: I. campestris Stev. - $\gamma$. praecox: Schötchen oval od. vkteyf.: I. praecox Kit. Die Isatis Villarsii Gaud. ist für die Schwz. zweifelhaft.

\section{MYÁGRUM L. Hohldotter.}

1. M. perfoliatum L. -). Unter der Saat; Litt., Wallis, im Würtemb. an mehreren O., ausserdem sehr zerstr. dch das Geb. u. sehr selten. Mai. Jun. Blb. gelbl.

\section{NESLIA Desvaux. Neslie.}

1. N. paniculata Desv. $\odot$. Aecker, Brachfelder. Jun. Jul. Bl. gelb. Myagrum paniculatum L.

XII. Gruppe. ZILLEEN. KeimBI. aufeinander liegend, um das Würzelchen rinnig-gefaltet.

\section{CALEPINA. Desvaux. Calepine.}

1. C. Corvini Desv. $\odot$. Brachäcker u. Felder; zw. Mayen, Coblenz u. Andernach, Branson in der Schwz., Fiume. Mai. Jun. Bl. weiss.

XIII. Gruppe. BUNIADEEN. KeimB, anfeinander liegend, zirkelf.-eingerollt.

\section{BUNIAS L. Zackenschote.}

1. B. Erucago L. Schötchen $4 \mathrm{kantig,} \mathrm{Kanten} \mathrm{gefiügelt,} \mathrm{gezähnt.}$ $\odot$. Unter der Saat; C. Waadt u. Wallis, Litt., Oestr., Salzbg. Jun. Jul. Blb. gelb. - Var. $\beta$. integrifolia: B. ganz. B. aspera Retz.

2. B. orientalis L. Schötchen schräg-eyf., flügellos. $\odot$. Trockne Bergwiesen, grasige O.; Luibeck, Warnemilnde, Danzig u. Limburg. Jun. Jul. Laelia orientalis Desv. Bl. gelb.

V. Unterordng. LOMENTACFEN DC., GLIEDERHÜLSIGE.

Schoten od. Schötchen quer in 1samige Glieder sich trennend.

XNN. Gruppe. CAKILINEEN. Die KeimB. aneinander liegend, Würzelchen auf der Spalte der KeimB. 
48. CÁKILE Tournef. DC. Meersenf.

1. C. maritima Scop. Das obere Glied des Schötchens schwertf. ○. Am Seestrande. Jul.-Oct. Bunias Cakile L. Bl. hell-violett. Var.: $\beta$. ganzblätterig; B. längl., an der Basis verschmälert, unregelmässig-stumpf-gezähnt. C. aegyptiaca Willd. C. latifolia Poir.

XV. Gruppe. RAPHANEEN. Die KeimB. um das Würzelchen rinnig gefaltet.

\section{RAPÍSTRUM Boerhave. DC. Repsdotter.}

1. R. perenne All. Gf. kurz-kegelf., kürzer als das obere Glied des Schötchens; B. fiedersp., Zpfl. längl., winkelig-gezähnt. 24. Aecker, Wege; Stmk., Oestr., Mähr., Böhm., Sachs., Thïring. bis Barby. Jun. Jul. Myagrum perenne L. Bl. gelb.

2. R. rugosum All. Gf. fädlich, so lang od. länger als das obere Glied des Schötchens; B. leyerf., kurz-gezähnt, der Endzpfl. sehr gross, eyf. $\odot$. Aecker, Brachfelder; siidl. Schwz., Rheinfläche v. Basel bis Mainz u. Bingen, südl. Tyrol, Littor. Jun. Jul. Myagrum rugosum L. Bl. gelb. Var. Schötchen rauhh.: R. hirsutum Host; Schötchen rauh: R. scabrum Host; Schötchen kahl: R. glarum Host.

\section{CRAMBBE L. Meerkohl.}

1. C. maritima L. Die längern Stbf. an der Spitze gabelig; Schötchen griffellos; B. rundl., buchtig, wellig, gezähnt, hechtblau u. nebst dem St. kahl. 24. Am Seestrande; Holst., Mecklenb. Mai. Jun. Bl. weiss.

2. C. Tataria Jacq. Die längern Stbf. an der Spitze gabelig; Schötchen griffellos; die jüngern B. steifh., die ältern nebst dem St. fast kahl, WB. doppeltzsgesetzt, Fiederchen längl., gezähnt od. eingeschnitten. 24. Kultiv. O., Wiesen; Mähren. Apr. Mai. Bl. weiss.

\section{RÁPHANUS L. Rettig.}

1. R. sativus L. Schoten stielrund, zugespitzt, kaum länger als das Bthstielchen. (-). In vielen Variet. gebaut. Mai. Jun. Blb. schwach-violett, Adern gesättigter.

2. R. Raphanistrum L. Schoten perlschnurf., bei der Reife gerieft, länger als der Gf.; B. einfach-leyerf. $\odot$. Kultiv. O. Jun. Jul. Kommt vor: 1) Blb. weiss, mit violetten Adern, Raphauistrum arvense Reichenb., mit folgender; 2) Blb. gelblich-weiss, violett-aderig; Blb. schwefelgelb, mit gelben, u. nicht violetten Adern, Raphanistr. segetum Rchb. 


\section{Ordng. CAPPARIDEEN. Juss.}

\section{CÁPPARIS L. Kapperustrauch.}

1. C. spinosa L. Bthstiele einzeln, 1 bth.; B. rundl., stumpf od. ausgerandet; NebenB. dornig, gebogen. b. Felsenspalten u. Mauern; um Duino, Rovigno in Istrien, am Comersee, bei Botzen kultiv. Jun. Jul. Blb. weiss od. sehr schwach-rosenroth. Var.: $\beta$. St. unbewehrt. C. rupestris Sibtl. u. Sm. $-\gamma$. B. eyf., spitz. C. ovata Desfont. C. Fontanesii DC.

\section{Ordng. CISTINEEN. Dunal.}

1. CISTUS L. Cistrose.

1. C. monspeliensis L. B. lineal--lanzettl., sitzend, 3nervig, netzig-runzelig, auf beiden Seiten klebrig-flaumig; Tr. einseitswendig; Narben fast sitzend. Ђ. Steinige, sonnige O.; Istrien. Mai. Jun. B1. weiss.

2. C. salvifolius L. B. an der Basis abgerundet, eyf., stumpf, kurzh.-rauh, unterseits etwas filzig; Bthstiele einzeln, 1-2bth., od. an der Spitze der Aestchen fast doldig; Narben fast sitzend. $\hbar$. Steinige O.; Litt. Mai. Jun. Bl. weiss.

3. C. creticus L. B. in den Bstiel verschmälert, eyf., stumpf, filzig-kurzh., wellig, aderig-runzelig; Bthstiele so lang als der zottige K., die endst. einzeln od. fast doldig; $G f$. so lang als die Stbg. $\hbar$. Gebirgige O.; Osero u. Cherso. Jun. Jul. C. villosus Wulf. Bl. purpurn.

2. HELIANTHEMUM Tournef. DC. Somnenröschen.

1. H. guttatum Miller. Krautig; B. gegenst., lanzettl., kurzl., 3nervig, die untern vkteyf., nebenblattlos, die obcrn wechselst., nebenblätterig; Tr. deckblattlos; $K$. auf dem fruchttrag., weit abstehenden Bthstielchen gerade hervorgestreckt; Narben fast sitzend. $\odot$. Sandige O., somnige Hügel; Insel Norderney, Teucherl bei Wittenberg, Lausitz. Jun.-Aug. Var.: Blb. citrongelb, mit einem blutrothen Flecken an der Basis od. ungefleckt; ausserdem $\beta .:$ Blb. gezähnt, mit dem Flecken: Cistus serratus Cav. $-\gamma$. : Blb. gezähnt, ungefleckt: Cistus serratus Desf. C. plantagineus Willd.

2. H. F u m an a Mill. Nebenblattlos, halbstrauchig, niederliegend; Aeste aufstrebend; B. zerstreut, lineal., fein-stachelspitzig, etwas rauh, schwach-wimperig; Bthstiele seitenst., einzelı, die fruchttrag. zuriickgekrümmt; Gf. 3 mal so lang als der Fruchtkn. ち. Somige Hügel, kiesige O.; Rheinfläche v. Schwetzingen u. Dürkheim bis Mainz, Thüring., Oestr., Krain, siidl. Tyrol u. siidl. Schwz. 11. Graubünd. Jun. Jul. Blb. goldgelb. Kommt in einer grösseren r. kleineren Variet. vor. 
3. H. o ela ndi cum Wahlenb. Nebenblattlos, halbstrauchig, niederliegend; Aeste aufstrebend; $B$. gegenst. lineal.-längl. od. oval, mit biischeligen Haaren am Rande od. auf beiden Seiten bestreut od. unterseits filzig; Tr. deckblätt.; Gf. so lang als d. Fruchtkn.; K. auf $d$. fruchttrag. weit abstehenden Bthstielchen aufstrebend. $b$. VorA. u. A.; dch die g. AK. u. steinige Hiigel im südl. Tyr., Oestr., Thüring., Frank. Mai-Aug. Blb. gelb. Var.: Bth. grösser u. um die Hälfte kleiner; $u$. iiberdies: $\alpha$. glabrum: B. kalıl, am Rande u. an der Mittelrippe unterseits sparsam büschelig-haarig, Haare angedrückt; Bstiele gewimpert; St. oberwärts nebst den Bthstielchen etwas flaumh. H. oelandicum b. Wahlenb. - $\beta$. hirtum: B. auf beiden Seiten büschelig-haarig, St. oberwärts nebst den Bthstielchen grau. Helianth. alpestre DC. H. oelandicum $\beta$. ciliatum Wahlenb. $-\gamma$. tomentosum: B. unterseits grau od. schneeweiss-filzig; übrigens nicht haarig, od. zugleich auch kurzh. Cistus canus Jacq. C. vinealis Willd. C. anglicus L. Helianth. oclandicum $\gamma$. canescens Wahlenb.

4. H. sali cifolium Persoon. Mit Nebenblättern, krautig, etwas ausgebreitet; B. gegenst., elliptisch, kurzh.; Tr. mit Deckblättern; $K$. auf den fruchttrag., weit abstehenden Bthstielchen aufstrebend; Gf. kürzer als der Fruchtkn. $\odot$. Sonnige O.; Istrien, Wallis bei Branson. Apr. Mai. Cistus salicifolius L. Blb. gelb. Var. $\alpha_{.}:$Blb. gefleckt, S. röthl. Cistus sanguineus Host. $-\beta .:$ Blb. nicht gefleckt. Cistus salicifolius Host.

5. H. vulgare Gärtner. Mit Nebenblättern, halbstrauchig, aufstrebend; B. oval od. lineal.-längl., wimperig, kurzh. od. unterseits filzig, am Rande etwas umgerollt; Tr. mit Deckblättern; die fruchttrag. Bthstielchen gewunden-herabgebogen; Gf. 2- od. 3mal so lang als der Fruchtkn.; die innern KB. stumpf, mit einem aufgesetzten Spitzchen. Ђ. Haiden, trockene Wiesen, Waldsäume; Ebenen, Berge, bis auf die A. Jun.-Aug. Blb. citrongelb, der Var. $\varepsilon$. weiss. Cistus Helianthemum L. St. meist mit angedrücktem Flaum bedeckt, seltener v. abstehenden Haaren rauhh. Var. «. tomentosum: B. unterseits grau- od. weiss-filzig, oben mit einfachen od. sternf. Härchen bestreut. Helianthemum vulgare DC. Gaud. - $\beta$. hirsutum: B. unterseits wegen entferntgestellter Haare grïn, iibrigens wie bei der Variet. $\alpha$. H. obscurum Pers. H. vulgare $\beta$. obscurum Wahlenb. $\gamma$. glabrum: B. kahl, nur am Rande u. der Mittelrippe unterseits gewimpert, freudig-griin. Cistus serpyllifolius Crantz, u. C. helianthemoides $\mathrm{Cr}$. Auf den höchsten A., wie $\delta$. grandiflorum: der vorgehenden ähnlich, aber grösser; B. grasgrün, mit büscheligen, abstehenden Haaren bestreut; Bth. gross, manchmal 1 Zoll breit, an der Spitze des St. einzeln, od. 3, 5 an den kurzen Tr. Cistus grandiflorus Scop. Diese Variet. mit unterseits weiss-filzigen B.: Cistus tomentosus Scop. Smith. $-\varepsilon$, albiflorum: Bth. weiss. Cistus apen- 
ninus L. Südl. Schw. u. Ockelheimer Spitze bei Mainz. - $\zeta$. leptopetalum: Blb. lanzettl., Monstrosität; H. surreijanum Mill.

6. H. polifolium. (Cistus L.) Mit Nebenblättern, halbstrauchig, niedergestreckt od. aufstrebend; B. lineal.-längl., oben etwas grau, unterseits filzig, am Rande zuriickgerollt; Tr. mit DeckB.; die fruchttrag. Bthstielchen gewunden-herabgebogen; Gf. 2- od. 3mal so lang als der Fruchtkn.; die innern KB. sehr stumpf. $\hbar$. Sonnige Kalkhügel; Locarno im C. Tessin, zw. Mainz u. Bingen auf der Ockelheimer Spitze, Würzbg., Botzen. Jun.-Aug. H. appenninum Gaud. BI. weiss, Näigel blassgelb. B. oben nicht kurzh.; K. v. Sternhärchen sparsamer bestreut od. dichtbedeckt, nicht kurzh; Bthknöpfe stumpf, nicht in ein Spitzchen endigend. Var. $\alpha$. oblongifolium: B. längl. od. längl.-lineal., weniger zurückgerollt. Cistus polifolius L. - $\beta$. angustifolium: B. lineal., sehr zurückgerollt, unterseits gleichsam 2furchig. Cistus pilosus L. var. $\alpha$. C. linearis Lej. $-y$. roseum: Bth. rosentoth. C. mutabilis. Jacq.

\section{JX. Ordng. VIOLARIEEN. DC.}

\section{VÍOLA L. Veilchen.}

I. Rotte. Nomimium Gingins. Die 2 mittlern Blb. seitlich abstehend, sehr oft gegen die Basis hin bärtig; das unpaarige immer bartlos. Gf. gerade, od. wenig geneigt, an der Basis verschmälert. Die spätern Bth. blumenblattlos.

§. 1. Narbe in ein schiefes Scheibchen ausgebreitet, od. an der Spitze schief-gestutzt. Die fiuchttrag. Bthstiele aufrecht, an der Spitze hakig. B. nach dem Verbliihen viel grösser.

1. V. pinnata L. Stengellos; B. im Umriss rundl., vielth., Zpfl. 2-3zähnig. 2. Triften der A. Jun. Jul. Bth. blassviolett.

2. V. palustris L. Stengellos; B. sämmtl. nieren-herzf., kahl; KB. stumpf; NebenB. eyf., zugespitzt, kurz-fransig-gezähnelt od. ganzrandig, frei; fruchttragende Bthstiele aufrecht mit hängender Kapsel. 4. Im Sumpfinoose torfiger Wiesen; auf Ebenen u. bis in die höchsten A. Mai. Jun. Blb. blass-lila, das unpaarige mit violetten Adern.

3. V. epipsila Ledebour. Stengellos; B. kahl, das untere fast nierenf., das zweite ey-herzf.; KB. stumpf; NebenB. eyf., zugespitzt, kurz-fransig-gezahnelt od. ganzrandig, frei; fruchttragende Bthstiele aufrecht mit hängender Kapsel. 4. Sumpfwiesen u. nasse Waldstellen; Salzb., Krain. Mai. Jun. Blb. blau, nicht aderig.

4. V. uliginos a Schrader. Stergellos; B. herzf., kahl; Bstiel geflügelt; NebenB. lanzettl., drüsig-gezähnelt, bis über die Mitte an den Bstiel angewachsen; fruchttragende Bstiele aufrecht mit hängender Kapsel. 2. Schwammige Siimpfe; bei Laibach in Krain, Oppeln 
in Schlesien, Wiehe in Thüringen. März. Apr. V. nitens Host. Blb. sattviolett.

§. 2. Narbe in ein herabgebogenes Schnäbelchen verschmälert. Fruchttragende Bthistiele auf die Erde niedergestreckt. B. nach dem Verbliihen viel grösser.

5. V. hirta L. Stengellos; Ausläufer fehlend, die seitenst. Stäınmchen zuletzt in kurze Ausläufer verwandelt; B. eyf. od. längl.eyf., die inneren späteren tiff-herzf.; untere NebenB. eyf., obere lanzettl., alle spitz od. an der Spitze selbst stumpf, ncbst den Fransen am Rande kahl, die Fransen kürzer als der Querdurchmesser des NebenB.; KB. stumpf; fruchttragende Bthstiele niederliegend; Kapsel flaumig. 24. Trockne Wiesen, Haiden, Hecken. Apr. Mai. Bl. heller od. satter blauviolett, geruchlos.

6. V. c ollin a Besser. Stengellos; Ausläufer fehlend od. die seitenständigen Stämmchen zuletzt in kurze Ausläufer verwandelt; $B$. breit-eyf., tief-herzf.; NebenB. lanzettl., verschmälert-haarspitzig, fransig, am Rande nebst den Frarsen fein-rauh.; die mittleren Fransen v. der Länge des Querdurchmessers des NebenB.; KB. stumpf; fruchttragende Bthstiele niederliegend; Kapsel flaumig. 4. Haine, Hecken; Schwz., u. wahrscheinl. längs der g. AK., Regensb. Apr. Mai. Bl. bleichblau, wohlriechend.

7. V. sciaphila Koch. Stengellos; Ausläufer fehlend; B. breiteyf., dch einen breiten offnen Ausschnitt herzförmig; NebenB. spitz, fransig, u. nebst den Fransen am Rande kahl, die inneren an der Spitze feinwimperig, Fransen kürzer als der Querdurchmesser des NebenB.; KB. stumpf; fruchttragende Bthstiele niederlicgend; Kapsel kahl. 2. Schattige O. der Berge u. VorA.; Schwz., Tyr. Apr. Mai. Blb. violett, am Schlunde weiss, Bl. wohlricchend.

8. V. ambigu a W. K. Stengellos; Ausläufer fehlend; B. dch einen breiten, offenen Ausschnitt herzf., die äusseren eyf., die innern längl.-eyf.; NebenB. lanzettl., verschmälert-haarspitzig, fransig, am Rande kahl od. an der Spitze fein-wimperig, Fransen ungleich, die längeren von der Länge des Querdurchmessers des NebenB. KB. stumpf; fruchttragende Bthstiele niederliegend; Kapsel flaumh. 4. Triften; Wallis. Apr. Mai. V. campestris MB. Blb. violett.

9. V. odorata L. Stengellos; Ausläufer verlängert; $B$. breiteyf., tief-herzf., der Sommerausläufer nieren-herzf.; NebenB. ey-lanzettf., spitz, am Rande nebst den Fransen kahl, an der Spitze feinwimperig; Fransen viel kürzer als der Querdurchmesser des NebenB.; KB. stumpf; fruchttragende Bthstiele niederliegend; Kapsel flaumh. 4. Am Rande von Hainen u. Hecken; März. Apr. Bth. sattviolett, rlas unpaarige Blb. an der Basis hellviolett mit sattvioletten in das violette Mittelfeld auslaufenden Adern. Var. Steveni: das unpaarige 
Blb. von der Basis bis zur Mitte weiss mit dunkelvioletten Adern; V. odorata var. $\beta$. Steveni Bess., bis jetzt noch nicht in D.; ferner, Blb. weissl.-lila od. weiss: V. alba der Autor., nicht Besser. Davon untersch. sich V. alba Besser. dch fast dreieckig-herzf., auffallend zugespitzte, mit einer tiefen, jedoch breiten Bucht an der Basis ausgeschnittene B., dch dreieckige B. der Sommerausläufer, welche schon im ersten Jahre blühen; diese auf Kalkbergen in Lothringen.

10. V. s u av is MB. Stengellos; Ausläufer verlängert; B. breit-eyf., tief-herzf., an den Sommerausläufern nieven-herzf.; NebenB. lanzettl.zugespitzt, an der Spitze nebst den Fransen flaumig-wimperig, Fransen verlängert, v. der Länge des halben Querdurchmessers des NebenB.; KB. stumpf; fruchttr. Bthstiele niederliegend; Kapseln flaumh. 2. An dem abhängigen Ufer der Oder bei Frankf. a. d. O. März. Apr. Blb. blan-violett, die beiden obern v. der Basis auf ein Drittel weiss, die drei unteren $\mathbf{v}$. der Basis bis zur Mitte weiss, das unterste mit sattvioletten Adern.

§. 3. Narbe in ein herabgebogenes Schuäbelchen verschmälert. Fruchttrag. Bthstiele unverändert; Kapsel nickend. Die Sommerpflanze der des Friihlings meist unähnlich; diese einfach, Bth. langgestielt, mit Blumenblättern, die NebenB. grösser; die Sommerpflanze ästig, Bth. blumenblattlos, B. an den Aesten kurzgestielt, NebenB. klein.

11. V. are naria DC. St. niederliegend, aufstrebend, von selir kurzem Flaum etwas graugrün od. kahl; B. herzf. stumpf, klein-gekerbt, die unteren nieren-herzf.; Neben B. eyf.-längl., gefranst-gesägt, mehrmal kürzer als der Bstiel; KB. längl.-lanzettl., spitz; Kapsel eyf., meist stumpf. 24. Sandfelder, trockne Nadelwälder u. gebirgige O.; zerstr. deh das Geb. Mai. Jun. V. Allionii Pio. V. glauca MB. V. livida Kit. Blb. bleichviolett od. weiss.

12. V. silvestris Lam. St. riederliegend $u$. aufstrehend, kahl od. etwas flaumh.; B. deutl. herzf. u. eyf., oder fast nierenf., kurzzugespitzt, die unteren stumpf; Bstiele flügellos; die mittlerer stengelst. Neben B. lanzettl., nach vorne verschmälert, gefranst-gesägt, mehrmals kürzer als der Bstiel; KB. lanzettl.-zugespitzt; Kapsel spitz. 2. Wälder, Gebüsch 11. Zäune. Apr. Mai. Bth. blässer-blau, mehr od. weniger in das Violette spielend. Sporn oft violett. Var. $\beta .:$ Bth. grösser, blässer, Sporn oft weisslich. V. Riviniana Rchb.

13. V. canina I. St. niederliegerd $u$. aufstreberd, kahl od. etwas flaumh.; B. aus einer herzf. Basis längl.-eyf., spitzl. (nicht zugespitzt), die unteren stumpf; Bstiele flïgellos, die mittleren stengelst. Neben B. längl.-lanzettl., gefranst-gesägt, mehrmals kürzer als der Bstiel; KB. eyf.-lanzettl., verschmälert-spitz; Kapsel gestutzt-stumpf, bespitzt; Sporn meist doppelt so lang als die Anhängsel des K. 24. Haiden, trockne O., Walđränder. Mai. Jun. Eine grössere Modif.: 
V. canina lucorum Rchb.; eine kleinere: V. ericetorum Schrad.; eine aufrechte mit schmäleren $u$. längeren $B$. v. feuchten Sandfeldern: V. canina Ruppii M. et K. V. Ruppii All. nach Bertolon. - Bth. satter-violett. Sporn gelblich-weiss.

14. V. Schultzii Billot. St. aufrecht kahl; B. herz-eyf., vorne etwas zugespitzt-verschmälert; Bstiel oberwärts gefügelt; die stengelst. NebenB. längl.-lanzettl., blattig, tief-gezähnt, die mittleren halb so lang als der Bstiel, die oberen so lang als derselbe; KB. spitz, der Sporn doppelt u. dreimal so lang als die Anhängsel des $K$., zugespitzt, an der Spitze aufwärts-gekrümmt, zweispitzig. 24. Torfwiesen, doch nicht im Sumpf; Elsas bei Hagenau, Hafling im südl. Tyrol, Krain bei Laibach. Apr. Mai. V. Ruppii Rchb. fl. g. exs. n. 1770. Bth. vor dem Aufbl. gelblich, dann schneeweiss; Sporn erst grïl., dann gelbl.

15. V. stagnina Kitaibel. St. aufrecht, kahl; B. aus einer herzf. Basis längl.-lanzettl.; Bstiel oberwärts etwas geflügelt; die mittleren stengelst. Neben B. lanzettl., zugespitzt, fransig-gesägt, um die Hälfte kürzer als der Bstiel, die oberen so lang als derselbe; KB. spitz; Sporn meist so lang als die Anhängsel der KB. 2. Auf nassen O., an Bächen. Mai. Jun. V. lactea Rchb. V. persicifolia Schweigg. et Körte. Modification mit grösseren NebenB. V. Billotii Schultz. Blb. weiss, od. lila. - V. lactea Smith. ist Synon. mit V. lancifolia Thore.

16. V. stricta Hornem. Die St. aufrecht, kahl; B. herz-eyf., vorne etwas zugespitzt-verschmälert; Bstiel oberwärts geflügelt; die stengelst. NebenB. längl.-lanzettl., blattig, fransig-gezähnt, die mittleren um die Hälfte kürzer als der Bstiel, die oberen so lang als derselbe; KB. spitz; Sporn etwas länger als die Anhängsel der KB., stumpf. 2. Haine; Magdeburg, Pormm., Schles., Etschland in Tyr. Mai. Jun. V. nemoralis Kuitz. V. Ruppii Koch. syn. ed. 1. Blb. gross, hellblau. Dch die B. nähert sich diese Pfl. mehr der V. canina, dch die blattigen NebenB. aber mehr der V. stagnina.

17. V. pratensis Mertens u. Koch. St. aufreht u. nebst den B. ganz kahl; B. aus einer eyf. Basis lanzettl., in den gefligelten Bstiel zugeschweift, od. an der Basis keilig; die mittleren stengelst. Neben B. blattig, längl.-lanzettl., eingeschnitten-gezähnt, länger als der Bstiel; KB. spitz; Sporn so lang als die Anhängsel des K. 2. Wiesen; Rheinfäche, Thüring., Sachs., Böhmen. Mai. Jun. V. lactea K. u. Ziz., Fries. BIb. blau. Var. selten weiss.

18. V. el a t i o r Fries. St. aufrecht, oberwärts nebst den B. flaumh.; B. aus einer seicht-herzf. Basis lanzettl.; Bstiel geflügelt; die mittleren stengelst. Neben B. blattig, längl.-lanzettl., eingeschnitten-gezähnt, länger als der Bstiel; KB. spitz; Sporn so lang als die Anhängsel des K. od. cin wenig länger. 2. Haine; zerstr. dch das Geb. MaiJul. V. persicifolia M. et K. Blb. blau. 
19. V. mirabilis L. St. aufrecht, einzeilig-behaart, die Bstiele am Kiele haarig; B. breit-herzf., kurz-zugespitzt, klein-gekerbt, die unteren fast nierenf.; NebenB. längl.-lanzettl., zugespitzt, die oberen mit kurzen Borstchen gewimpert, übrigens ganzrandig od. etwas gezähnelt; die wurzelst. Bth. mit Blb. versehen, die stengelst. blumenblattlos. 2. Gebirgswälder; zerstr. deh das Geb. Apr. Mai. Blb. bleich-röthlich od. lila.

II. Rotte. Dischidium Ging. Die 4 obern Blb. anfwärtsgerichtet, u. aufwärts dachig. Gf. an der Basis herabgekriimmt, u. dann in einem Winkel gebogen sich erhebend, oberwïrts keulig verdickt; Narbe flach, fast 2lappig.

20. V. bifl or a L. St. sehwach, meist 2blättrig, 2blüthig; B. nierenf., sehr stumpf, gekerbt; die NebenB. eyf., ganzrandig; KB. spitz. 2. Nasse waldige 0 . der A. u. VorA., Vogesen, Sudeten. Mai-Aug. Blb. citrongelb, braun-gestreift, das untere bis iiber die Mitte dottergelb.

IU. Rotte. Melani um DC. Die 4 obern Blb. aufwärts gerichtet und aufwärts dachig. Gf. aufstrebend, oberwärts keulig; N. gross, krugf., auf beiden Seiten mit einem Haarbiisehel u. unterwärts mit einem Lippchen versehen.

21. V. tric ol or L. B. gekerbt, die untern ey-herzf.; NebenB. leyerf.-fiedersp., der mittlere Z $p f$. gekerbt; Sporn fast noch $1 \mathrm{mal}$ so lang als die Anhängsel des K.; W. einfach; St. aufstrebend, ästig. $\odot$. Aecker, auch unfruchtb. Felder; die Variet. $\beta$. überall, die Variet. $\alpha$. nicht aller $O$. Mai-Oet. Var.: $\alpha$. mulgaris: Bl. grösser als der K., zuweilen auch kleiner, aber violett u. blau, weiss u. gelb variirend, die gelbe Farbe nur auf der Basis des unpaarigen Blb. $\boldsymbol{\beta}$. arvensis, V. arvensis Murray u. der Aut.: Bl. so lang als der K. od. kiirzer, weiss, die obern Blb. hell-violett. $-\gamma$. saxatilis: Bl. wie bei der Variet. $\alpha$, aber ganz gelb: V. saxatilis Sehm. A. u. Sudeten. Gelbe u. violett-bunte Bth. nieht selten an demselben Expl. $-\delta$. bannatica: mehrere der untern B. an der Basis herzf., Blkr. wie bei der Var. $\alpha$ : V. bannatica Kit. - An Seestrande ist die Pfl. fleischig: Variet. syrtica Flörke; an sandigen, unfruchtb. O. klein u. einfach u. der mittlere Zpfl. der NebenB. bei den meisten B. dem B. selbst ähnl.: V. Kitaibeliana R. u. S.

22. V. rothomagensis Desf. B. gekerbt, die untern ey-herzf.; Neben B. fiedersp., der mittlere Zpfl. breiter, ganzrardig; Sporn fast noch $1 \mathrm{mal}$ so lang als die Anhängsel des K.; W. einfach; St. gestreckt, sehr ästig. $\odot$. Kultiv. O.; im Gebiete der Fl. v. Spaa. MaiOct. Ueberall v. steifen, abstehenden Haaren kurzh.

23. V. I utea Smith. B. gekerbt, die untern ey-herzf., die obern lanzettl.; Neben B. fingerig-vielth., Zpfl. lineal., der mittlere breiter; Sporn so lang als die Anhängsel des K. od. ein wenig länger; 
Stämmchen kriechend, fädl.; St. einfach. 24. VorA. u. A.; mittlere Schwz., Voges., Sudet.; die Variet. $\gamma$. auf niedrigern O. im Geb. der Fl. v. Spaa. Mai. Jun. Blb. gelb, od. die obern violett, od. alle violett. - Var. $\alpha$. grandiflor : niedriger, Bth. gross, Blb. länger-benagelt, sehr gestutzt, das unpaarige bisweilen tief-ausgeschnitten: V. grandiflora Vill., nicht Linné. - $\beta$. sudetica : höher, Bth. gross, Blb. oft geschweift-gekerbt: V. sudetica Willd. - $\gamma$. multicaulis: Bth. nicht grösser als bei der gewöhnl. V. tricolor.

24. V. het erophylla Bertolon. B. gekerbt, die unteren eyf. od. längl., die oberen lanzettl.-lineal.; NebenB. fingerig-vielth., $\mathbf{Z p f l}$. lineal., der mittlere nur ein wenig breiter; Sporn länger als die Anhängsel des K., halb so lang als die Bl.; Stämmchen kriechend, fädl.; St. einfach. 24. Felsenspalten; südwestl. Gebirge Tyrols, auf Tremali Val die Ledro, Tombéa Valle di Vestino, u. herabgeschwemmt unter die Pfarre Turano, Dr. Facchini. Jul. Aug. Bl. violett. Var. $\alpha$. Bertolonii: obere B. lineal., sehr schmal, aber doch noch nach der Basis verschmälert. V. Bertolonii Pio. - $\beta$. declinata: obere B. lanzettl.-gekerbt. V. declinata W. K. V. gracilis Sm.

25. V. calcarata I. B. gekerbt, eyf,, od. die oberen längl. od. lanzettl.; NebenB. ganz od. 3sp.-gezälnnt, u. fast fiedersp.; Sporn so lang als die Blb.; Stämmchen kriechend, fädl.; St. ganz einfach. 4. Triften der A.; Schwz. an vielen O., Jura, Wormser Joch, Linkerskopf in den baier. A. Jul. Aug. Var.: der St. länger u. sehr kurz, Bth. grösser u. kleiner; violett u. $\beta$. flava, gelb; V. Zoysii Wulf. Diese auf den Krain. A.

26. V. cenisia L. B. ganzrandig, die unteren eyf., die oberen öfters längl.; die oberen NebenB. spatelf., an der Basis ganz od. daselbst auf beiden Seiten 1-2zälnnig, od. 2-4th. mit spatelf. Zipfeln; Sporn so lang als die KB.; Stämmchen kricchend, fädl. 24. Steinige O. der höheren A.; Wallis, südwestl. Schwz. Jul. Aug. Blb. sattviolett. Die Variet. mit geth. NebenB. u. länglicheren obern B.: V. valderia All.

27. V. Com olli a Massara. B. ganzrandig, ein wenig geschweift, rundl. u. oval; die oberen NebenB. spatelf. ungeth.; Sporn ein wenig länger als die Anhängsel der $K B$.; Stämmchen fädl., kriechend. 4. Gbge; Veltlin. Jul. Aug. Blb. sattviolett.

28. V. alpin a Jacq. B. gekerbt, rundl.-eyf., alle vurzelst.; NebenB. längl., bis über ihre Mitte an den Bstiel gewachsen, an der Spitze 2sp.; Stämmchen sehr kurz; St. fehlend. 24. Höchste A.; Stmk., Oestr. Jul. Aug. Bth. satt-blau.

\section{Ordng. RESEDACEEN. DC.}

1. RESEDA L. Reseda.

1. R. Phyteuma L. B. stumpf, die mittleren stengelst. vorne 
3sp.; Bthstielchen so lang als der K.; K. 6th., Zpfl. längl., bei der Frucht vergrössert; Kapsel lüngl.-keulig; stumpf-kantig; St. ausgebreitet. $\odot$. Brachäcker, Weinberge; Unteröstr., Littor., bei Genf. Jun.-Aug. Blb. weisslich.

2. R. lutea L. B. im Umrisse 3eckig, die mittlern stengelst. doppelt-fiedersp., die oberen 3sp.; Bthstielchen so lang als der K.; K. 6th., Zpfl. lineal.; St. ausgebreitet. $\odot$. Steinige Hügel, Wege, kultiv. O.; zerstr. deh das Geb. Jul. Aug. Blb. gelbl.

3. R. I u teola L. B. verlängert-lanzettl., kahl, an der Basis 1zähnig; K. 4th.; St. aufrecht. $\odot$. Felder, Wege. Jul. Aug. Blb. gelb.

\section{Ordng. DROSERACEEN. DC.}

\section{DRÓSERA L. Sonnenthau.}

1. D. rotundifolia L. B. kreisrund; Schaft aufrecht, 3mal so lang als die B. 24. Sümpfe u. Moore mit Sphagnum angefuillt. Jul. Aug. Blb. weiss wie der folg.

2. D. I ongifolia L. Hayn. B. lineal.-keulig; Schaft aufrecht, noch 1 mal so lang als die B. 24. Torfmoore; zerstrent deh das Geb. Jul. Aug. 'D. anglica Huds. - Var. $\beta$. ohovata: B. rkteyf.-keulig, od. vkteyf. D. obovata M. et $K$.

3. D. intermedia Hayne. B. vkteyf.-keulig; Schaft an der Basis bogig od. niederliegend, aufstrebend; wenig länger als die B. 4 . Tiefe Sümpfe; zerstr. dch das Geb. Jul. Aug. D. longifolia Sm.

\section{PARNÁSSIA L. Parnassie.}

1. P. palustris L. Nebenkronblätter mit 9-13 Borsten; Blb. kurz-benagelt; WB. herzf., das stengelst. stengelumfassend. 24. Wiesen, feuchte O. der Ebenen u. Gbge u. bis auf die A. Jul. Aug. Blb. weiss mit wässerigen Adern, Nebenkronblätter gelb-grünlich.

\section{Ordng. POLYGALEEN. Juss.}

\section{POLÝGALA L. Kreuzblume.}

1. P. major Jacq. Bl. mit vielsp. Anhängsel; die endst. Tr. vielbth.; die Flügel elliptisch, 3nervig, die Nerven an der Spitze mit einer schiefen Ader ineinanderfliessend, die Seitennerven auswendig aderig, die Adern ästig, netzig-verbunden; Stiel des Fruchtkn. während des Aufblühens 3-od. 4mal so lang als der Fruchtkn. 4. Trockne Wiesen u. unkultiv. Hügel; Unteröst. u. Mähr. Mai. Jun. Bth. $1 / 2$ " lang, rosenroth. Var. $\alpha$. vulgaris: DeckB. kuirzer als die nicht geöffnete Bthe. $\beta$. comosa: DeckB. länger als die nicht geöffneten Bth., einen Schopf bildend. 
2. P. nicaeensis Risso. Bl. mit vielsp. Anhängsel; die endst. Tr. vielbth.; die Fliigel rundl.-eyförmig, 3nervig, die Nerven an der Spitze mit einer schiefen Ader ineinanderfliessend, die Seitennerven auswendig aderig, die Adern ästig, netzig verbunden; der Stiel des Fruchtkn. während des Aufbliihens so lang als der Fruchtkn.; die seitenst. DeckB. so lang als das Bthstielchen; die B. lanzettl., die untersten elliptisch, kürzer 24. Unkultiv. Hügel; Litt. Mai. Jun. Bth. blau od. rosenroth.

3. P. v ulg aris L. Blkr. mit vielsp. Anhängsel; die endst. Tr. vielbth.; die Flügel elliptisch od. eyf., 3nervig, die Nerven an der Spitze mit einer schiefen Ader verbunden, die Seitennerven auswendig aderig, die Ādern ästig, netzig-verbunden, der Stiel des Fruchtkn. während des Aufblühens ungefähr von der Länge des Fruchtkn.; die seitenst. DeckB. halb so lang als das Bthstielchen; B. lanzettl., die untersten elliptisch, kürzer. 24. Trockne Wiesen, unkultiv. O. der Ebenen, Berge u. VorA. Mai. Jun. Bth. blau, rosenroth u. weiss; die Breite der Flïgel sehr veränderlich. Var. $\beta$. P. oxyptera Rchb.: mit schmälern Flügeln als die Kapsel. P. multicaulis Tausch. $-\gamma$. alpestris: niedriger u. mit kurzen dichten Tr. Sudeten, Salzb. A.

4. P. c om os a Schk. Blkr. mit vielsp. Anhängsel; die endst. Tr. vielbth.; die Flügel elliptisch, 3nervig, Nerven an der Spitze dch eine schiefe Ader ineinanderfiessend, die Seitennerven auswendig aderig, die Adern ästig, netzig-verbunden; Stiel des Fruchtkn. während des Aufbliihens so lang als der Fruchtkn.; dic seitenst. DeckB. so lang als das Bthstielchen; B. lineal.-lanzettl., die untersten elliptisch, kürzer. 4. Mit d. vorhergehenden. Mai. Jun. Bth. meist rosenroth, seltener blau od. weiss.

5. P. depressa Wenderoth. BI. mit vielsp. Anhängsel; Tr. meist 5bth., zuletzt seitenst.; die Fliigel elliptisch, 3nervig, die Nerven an der Spitze dch eine schiefe Ader ineinanderfliessend, die Seitennerven auswendig aderig, die Adern ästig, netzig-verbunden; die seitenst. DeckB. halb so lang als das Bthstielchen; B. lanzettl., die unteren elliptisch, die mittleren fast gegenst. 2. Torfhaltige Wiesen; zerstr. dch. das Geb. Mai. Jun. bis Herbst. P. serpyllacea Weihe. Bth. blau od. weiss.

6. P. c a lcarea F. W. Schultz. Bth. mit vielsp. Anhängsel; die endst. Tr. vielbth.; Fliigel eyf., 3nervig, der mittlere Nerve fast $v$. der Mitte an aderig-ästig, dic Seitennerven auswendig aderig, die Adern ästig, vielfach netzig verbunden; Stämmchen sehr verlängert; $B$. derselben vkteyf., stumpf, die obersten davon sehr gross, die an den im Sommer getriebenen Stengeln befindlichen lanzettl.-lineal. 4. Trockne kalkhaltige Hügel $u$. Berge; bei $Z_{w}$ eibrücken in $d$. Rheinpfalz. Apr.-Jun. Bth. blat, selt. weiss.

7. P. amara L. Bth. mit vielsp. Anhängsel; die endst. Tr. vielbtl.; die Flügel längl.-vkteyf., 3nervig, die Nerven an der Spitze 
kaum ineinanderfliessend, die Seitennerven auswendig aderig, die Adern spärlich ästig, wicht netzig verbunden; Stämmchen mässig verlängert; $B$. derseltien r.kteyf., stumpf, die obersten davon rosettig, sehr gross, die an den im Sommer getriebenen Stengeln befindlichen längl.-keilig. 2. Auf feuchten torfhaltigen Wiesen der Ebenen, Berge u. A. Jun.-Aug. Bth. blau. Die W. der jüngern Pflanze schwach, fädlich, der alten dicker, bolzig, gewunden, Var. $\alpha$. genuina: Bth. grösser, die Flügel oft länger als die Kapsel, die WB. sehr gross, in eine Rosette zsgedrängt. P. amara Jacq. - $\beta$. amblyptera: Bth. u. B. wie bei der Variet. $\alpha$, aber die Fligel breiter, fast so breit als die Kapsel. - $\gamma$. alpestris: niedriger, die B., auch die oberen, elliptisch. Die WB. fehlen oft, doch nicht immer: P. alpestris Rehb. - $\delta$. austriaca: Bth. kleiner, die Fliigel oft kïrzel als die Kapsel. Bth. weisslich od. bläulich, seltener satt-blau. Kommt sehr bitter u. fast geschmacklos vor. Var.: wie alle mit mehr zugerundeter Kapsel: P. austriaea Rchb., u. mit melı keilf.: P. uliginosa Rehb.

8. P. Chaina ebuxus L. Kamm der Bl. 4lappig; Bthstiele blattwinkel- u. endst., meist 2bth.; die St. strauchig, ästig, aufstrebend; B. lanzettl. od. elliptisch, stachelspitzig, die untern kleiner, vkteyf. ち. Haiden, Wälder; VorA. u. A., übrigens zerstreut im sïdl. u. mittlern Geb. Apr.-Jun. Bth. gelb, selten purpurn.

XIII. Ordng. SILENEEN. DC. Caryophyllearum gen. Juss.

1. GYPSÓPHUA L. Gypskraut.

1. G. repens L. St. aus niedergestreckter Basis aufrecht, nberwärts locker-ebensträussig $u$. nebst den Aesten kahl; der K. kreiself.glockig, halb-5sp., Zpt. eyf.-längl., stumpf, gerade; Stbg. u. Gf. kiilzer als die Blb.; B. lineal., nach beiden Enden versehmälert. 24. Kiesige Abhänge der A., mit den Flïssen in die Ebenen, vereinzelt am Harze. Jun.-Aug. Blb. weiss od. röthl.

2. G. fastigiat a L. St. aus einer aufstrebenden Basis aufrecht, an dem Gipfel gedrungen-ebensträussig, oberwärts nebst den Aesten sclumierig-flaumig; der K. glockig, halb-5sp., Zpfl. eyf., abgerundetstumpf, gerade; Gf. u. die Stbg. länger als die Blb.; B. lineal., nach beiden Enden verschmälert. 2. Gebirgige O., Sandfelder; Mähr., Böhm., Schles., Lausitz, Sachs., Thüring. bis nach Hannover, vereinzelt bei Berlin, Mainz, Unadlingen, Oberbad. u. in Graubünd. Jun.Aug. G. arenaria WK. Blb. weiss od. röthl.

3. G. panieulata L. St. v. der Basis an sehr ästig, rispig; unterwärts kurzh.; Rispe weitläuftig, locker, kahl; der K. beckenf.glockig, tief-5sp., Zpfl. rundl.-eyf., sehr stumpf, gerade, mit vor der Spitze verschwindendem Rückenstreifen; B. lanzettl., sehr spitz, meist 
3nervig. 4. Sandige, steinige Hügel; Mähren am Czeizer See, Wagram u. Tuirkenschanze bei Wien. Jul. Blb. weiss.

- 4. G. a cutifolia Fischer. St. v. der Basis an sehr ästig, rispig, kahl; Rispe locker, weitläuftig, Aestchen nebst den Bthstielchen schmierig-flaumig; der $K$. glockig, halb-5sp., $Z$ p $f$. längl., zugespitzt, an der Spitze zurückgekrümmt; Stbg. u. Gf. kürzer als die Blb.; B. lanzettl., sehr spitz, meist 3nervig. 24. Sandfelder; in den an Ungarn grenzenden Gegenden v. Unteröstr. Jul. Aug. Blb. weiss od. röthl.

5. G. murali is L. St. aufrecht, fast gabelsp., ästig-rispig, an der Basis etwas rauh; die Bth. zerstreut; der K. kreiself., 5zähnig, Zähne abgerundet-stumpf; die Blb. gekerbt od. ausgerandet; B. lineal., nach beiden Enden verschmälert. $\odot$. Aecker, Feld. Jul. Aug. Blb. hellpurpuru, Adern satter. G. serotina Hayne ist nicht verschieden.

2. TUNICA Scopoli mit Abänderung. Felsnelke.

1. T. saxifraga Scop. St. nach allen Seiten hingebreitet, oberwärts ästig; der $\mathbf{K}$. glockig, stumpf.-5zähnig; B. lineal., spitz, am Rande rauh, an der Basis häutig-berandet, an deu St. angedrückt. 4. Steinige Hügel, Kiesfelder, Wege ; südl. Gøbiet, sodaun Regensb., Böhm., Jena. Jul. Aug. Gypsophila saxifraga L. Blb. bleich-purp., Adern dunkler.

\section{DIÁNTHUS L. Nelke.}

1. Rotte. Armeriastrum Ser. Bth. köpfig od. etwas gehäuft. Blb. gezähnt od. fast ganzrandig. Bl. fleischfarbig od. purpurn.

1. D. prolifer L. Bth. gehäuft-köpfig; die 6 Hüllschuppen durchscheinend-häutig, rauschend, elliptisch, die 3 äusseren um die Hälfte kürzer, stachelspitzig, die innersten sehr stumpf, länger als der K.; Kelchschuppen den Hüllschuppen gleichgestaltet, den K. einwickelnd; St. kahl; S. glatt. $\odot$. Sandfelder, sonnige Hügel. Jul. Aug. D. diminutus $\mathrm{L}$. ist dieselbe $\mathbf{P f l}$.

2. D. velutinus Gussone. Bth. gehäuft-köpfig; die 6 Hüllschuppen durchscheinend-häutig, rauschend, elliptisch, die 2 äusseren um die Hälfte kürzer, stachelspitzig, die inmersten sehr stumpf, länger als der K.; die Kelchschuppen den Hüllschuppen gleichgestaltet, den K. einwickelnd; die mittleren Glieder des St. zottig; die S. kurzstachelig. ○. Unfruchtbare, sonnige Hügel; bei Triest, F. Mayer; Fiume, Noë. Jul. Aug.

3. D Armeria L. Bth. gebüschelt; die Kelchschuppen u. DeckB. lanzettl.-pfriemlich, krautig, ungefähr lo lang als die Röhre, rauhh.; B. lineal., nach vorne verschmälert, an der Spitze stumpflich u. nebst dem St. flaumh. ๑. Waldige O., Zäune. Jul. Aug. 
4. D. barbatus L. Bth. biischelig-gehäuft; die Kelchschuppen krautig, eyf., begraunt; Granne pfriemlich, so lang als die Röhre; die äusseren DeckB. lineal.-lanzettl., sєhr spitz, zurückgebogen-abstehend; B. kurzgestielt, lanzettl. 24. Bergwiesen, ATriften; Veltlin, Kärnth., Krain, Stınk. Jul. Aug.

5. D. Carthusianorum L. Bth. in eine cndst., meist 6blïthiges Köpfchen gehäuft; Kelchschuppen lederig, braun, rauschend, vkteyf., sehr stumpf, begraunt, Granne pfriemlich, länger als die halbe Röhre; Hïllschuppen fast eben so gestaltet; Platte der Blb. so lang als ihr Nagel; B. sämmtl. lineal.; die Scheide länger als die 4fache Breite des B. 24. Trockne Wiesen, bis in die A. Jul. Aug.

6. D. atrorubens All. Bth. in ein Endst., 12-30blüthiges Köpfchen dicht-zsgeballt; Kelchschuppen lederig, braun, rauschend, vkteyf., sehr stumpf, begrannt, Granne pfriemlich, länger als die halbe Röhre; Hüllschuppen fast eben so gestaltet; Platte der Blb. halb so lang als ihr Nagel; B. sämmtl. lineal.; die Scheide länger als die 4 fache Breite des B. 21. Triften der niedrigen Gebirge n. A.; Wallis u. Uri, südl. Tyr., Littor. Jun. Jul. D. vaginatus Vill.

7. D. liburnicus Bartling. Bth. in ein endst., meist 6blüthiges Köpfchen gehäuft; Kelchschuppen lederig, bleichgrün, geglättet, längl., in eine krautige lanzettl.-pfriemliche Spitze, ungefähr v. der Länge der Röhre endigend; Hüllschuppen fast eben so gestaltet; B. sämmtl. lineal.-lanzettl., od. lineal.; die Scheide länger als die doppelte Breite des B. 24. Felsige Hügel; Litt. Jul. Von Expl. des D. Seguierii mit dicht-gehäuften Bth. deh den 4 kantigen St. und die längeren Bscheiden verschieden.

8. D. S eguierii Villars. St. oberwärts 2 sp.; Bth. gezweiet od. büschelig-gehäuft od. rispig; Kelchschuppen eyf., begrannt, Granne krantig, so lang als die Röhre od. 2- od. 3mal kürzer; DeckB. lanzettl.; B. lineal.-lanzettl., verschmälert-zugespitzt, meist 5nervig; die Scheide ungefähr so lang als die Breite des B.; Blb. vkteyf., gezähnt. 24. Grasige buschige O.; Wallis, Tessin, Südtyrol, Stmk., Mähr., Böhm., bei München, Regensb., Dresd., Medebach in Westph. Jul. Aug. D. asper IVild. En. $\alpha$. asper: Kelchschuppen etwas abstehend. D. Seguierii Wulf. D. asper Rchb. D. scaber Schleich. $\beta$. sylvaticus: Kelchschuppen aufrecht od. angedrückt. D. sylvaticus Hoppe. D. Seguierii Rchb. - $\gamma$. collinus: die Bth. in ein dichteres Büschel gedrängt. D. collinus WK. $-\delta$. controversus: Blb. bis über den dritten Theil eingeschnitten-gezähnt, Zähne lanzettl.-pfrieml. D. Stembergii Schleich., nicht Hoppe. D. controversus Gaud.

II. Rotte. Caryophyllum Ser. Die Bth. einzeln od. rispig. §. 1. Blb. gezähnt od. fast ganzrandig.

9. D. neglectus Lois. St. 1bth.; Kelchschuppen eyf, mit einer pfrieml., straffen Granne, so lang als die Röhre od. länger; B. lineal., 
starr, v. der Mitte an verschmälert-spitz, am Rande rauh, unterseits 3nervig; Blb. gekerbt. 24. Höchste A. der Schwz, sehr selten; Umbrail in Graubünd., Glarner A. gegen Graubünd. zu, A. la Denna im Val di Non siidl. Tyr. Jul. D. glacialis DC. prodr. Gaud. D. tener Balb. Blb. purp.

10. D. alpinus L. St. 1bth.; Kelchsehuppen lanzettl., begrannt, Granne lineal.-pfrieml., krautig, ungefähr so lang als die Röhre; $B$. lanzettl.-lineal., stumpf, nach der Basis verschmälert, 1nervig; $B l b$. gekerbt, noch $1 \mathrm{mal}$ so lang als der K. 24. A. u. VorA.; Unteröstr. u. Stmk. Jun.-Aıg. Bl. oben fleischfarbig, mit einem purpurn- u. weiss-gefleckten Ringe, unterseits grünlich-weiss. St. 2-3 Z $\mathrm{oll}$ hoch.

11. D. glacialis Hänke. St. 1bth.; Kelehschuppen lanzettl., begrannt, Granne lineal.-pfrieml., krautig, länger als die Röhre; $\boldsymbol{B}$. lineal., stumpf, 1nervig, nach der Basis versehmälert; Blb. gekerbt, anderthalbmal so lang als der $K$. 24. Höchste GranitA. Jul. Aug. St. dicht-rasig, 2-3" hoch, od. fast fehlend. Blb. einfarbig, kürzer als am vorigen.

12. D. deltoides L. Bth. einzeln; Kelchschuppen meist zu 2, elliptisch, begrannt, mit der pfriemlichen Granne un die Hlälfte kürzer als der K.; B. lineal.-lanzettl., die unteren stumpf, nach der Basis versehmälert, St. flaumig-rauh; Blb. vkteyf., gezähnt. 2. Wiesen u. trockene Triften, Waldränder; südl. der A. sehr selten. Jun.Sept. Bl. rosenroth, mit purpurnem Ring. Var. $\beta$. glaucus: B. meergrün, Bl. hell-rosenroth od. weiss, mit purpurnem Ringe. D. glaucus $\mathrm{L}$.

13. D. ciliatus Gussone. St. aufreeht, 3-vielbth.; Bth. wechselst., die oberen genähert, sehr kurz-gestielt, an d. Spindel angedrückt, die unteren gestielt, entfernt, etwas traubig-gestellt; Schuppen des $K$. längl.eyf., zugespitzt-verschmälert, fast dornig-stachelspitzig, am Rande durchscheinend-trockenhäutig, $2 \mathrm{mal}$ kürzer als die Röhre des K.; B. lineàl., spitz, rinnig, an Rande fast wimperig-rauh; Blb. etwas spitz, lanzettl.-längl. od. elliptisch, ganzrandig od. schwachgezähnt. 24. Felsen am Meere; Torre d'Orlando bei Pola in Istr., Veglia bei Besea nuova. D. littoralis Host. D. racemosus Visian. Bl. fleisehroth.

14. D. sylvestris Wulfen. St. 1-3bth.; Bth. einzeln; Kelchschuppen angedruiekt, breit-єyf., abgestutzt-stumpf, kurz-begrannt, 4 mal kürzer als die Rölıre; B. gras- od. bläul.-grün, lineal., spitz, am Rande rauh; Blb. vkteyf., gekerbt, bartlos; Stämmchen sehr kurz. 4. Felsige, troekne O. der A., in die südlichen Gegenden hinabsteigend. Jul. Aug. D. Caryophyllus $\varepsilon$. inodorus L. D. virgineus Iost. Bth. geruchlos. Var.: B. gras- u. meergriin, K., wie bei anderen, kürzer u. länger, breiter u. schmäler; Blb. hell-fleischfurbig od. sattrosenroth, gekerbt od. fast ganzrandig; u. $\alpha$. elatior: St. höher, 2-, 3- u. inchrbth.: D. virgineus Jacq. Fl. austr. - $\beta$. humilior: niedriger, 
einbth. D. sylvestris Wulf. bei Jacq. ic. rar. Auf höheren A. manchnal fast stengellos; diese $\gamma$. subacaulis, hat das Ansehen des D. glacialis; dazu D. frigidus Koch. bot. Ztg. 1824.

15. D. Caryophyllus I. Bth. einzeln; Kelchschuppen angedriickt, fast rautenf., mit einem Spitzchen, 4mal kürzer als die Röhre; B. lineal., spitz, meergriin, am Rande glatt, an der Basis etwas rauh; Blb. vkteyf., gekerbt, bartlos; Stämmichen verlängert, niederliegend, selır ästig. 24. Ueberall der Zierde wegen kultivirt, 11. hie u. da auf Mauern gleichsam wild. Jul. Ang. 131. sehr wohlriechend, die Farbe ins Unendliche rariirend.

16. D. caesius Smith. St. meist 1bth.; Kelchschuppen angedrückt, eyf., stumpf, kurzgespitzt od. begrannt, 4mal kiirzer als die Röhre; B. lineal., stumpfl., meergriin, am Rande rauh; Blb. vkteyf., gekerbt, bärtig; die Stämmchen niederliegend, wurzelnd, sehr ästig, dicht-rasig. 24. Felsen u. steinige Gebirge, zerstreut dch das Geb. Mai. Jun. D. virgineus $\beta$. L. BI. fleischfarb.

§. 2. Die Blb. tief fingerig- od. fiedersp.-eingeschnitten.

17. D. p l umarius L. St. 2-5bth.; Bth. einzeln; Kelchschuppen rundl.-eyf., kurz-stachelspitzig, 4mal kürzer als die Röhre; B. lineal.pfrieml., meergrün, am Rande rauln; Blb. bis zur Mitte fingerigvielsp., mit einem ganzen, vkteyf. Mittelfєlde; Stämmchen niederliegend, wurzelnd, sehr ästig, dicht-rasig. 24. Felsige O.; Stmk., Unteröstr., Mähr. Jul. Aug. später als D. caesins. Blb. rosenroth od. weiss, zuweilen ohne Bart: D. hortensis Schrad.

18. D. arenarius L. St. meist 1bth.; Kelehschuppen eyf., stumpf, kurz-bespitzt, 4mal kürzer als die Röhre; B. lineal.-pfrieml., rrasgriin, am Rande rauh; Blb. fiedersp.-vielth., mit einem ganzen, länglichen Mittelfelde; Stämmchen niederliegend, wurzelnd, sehr ästig, dicht-rasig. 24. Sandfelder; v. Königsberg deh Prenss., Pomm., bis Frankf. an d. O.; Grüneberg in Schles. u. östl. Grenze v. d. Unterlansitz. Jnl.-Sept. Platte d. Blb. weiss, an der Basis mit einem grünen Flecken, u. mit weissl. od. purpurnen Haaren bestreut.

19. D. superbus L. St. meist einzeln, 2-mehrlstl.; Bth. zerstreut; Kelchschuppen eyf., zugespitzt-begrannt, 3mal kirzer als die Röhre; B. grasgriin, lineal.-lanzettl., zugespitzt, die unteren stumpt.; Blb. fiedersp.-vielth., mit eincm ganzen, länglichen Mittelfelde. $\odot$. 4. Feuchte, sumpfige Wies.; zerstr. deh das Geb. Jul. Aug. Bl. hellrosenroth od. lila, an der Basis oft grün u. mit purpurnen Haaren gebärtet.

20. D. monspessulanus L. Bth. gezweiet od. fast gehäuft; Kelchschuppen eyf., begrannt, mit krautiger, pfriemlicher Granne, halb so lang als die Röhre; $B$. lineal., verschmälert-zulaufend $u$. sehr spitz; Blb. bis zur Mitte fingerig-vielth., mit einem ganzen 
vkteyförmigen Mittelfelde; W. mehrstengelig; St. aus liegender Basis aufstrebend. 24. Felsige, waldige $O$. der Gbge u. A.; Stmk., Littor., Krain, Kärnth., siidl. Tyı•ol, Tessin, Jura. Jul. Aug. Blb. fleischfarbig od. weiss. D. monspeliacus L. im syst. nat. D. erubescens Trev. Blb. bärtig. Var. $\beta$. plumosus: Blb. bartlos. D. plumosus Sprengl. D. Waldsteinii Sternb. $-\gamma$. alpicola: St. niedrig, $1 \mathrm{bth}$, deh den Standort auf den höheren A. D. alpestris Sternb.

\section{SAPONÁRIA L. Seifenkraut.}

1. S. Vaccaria L. Bth. locker-ebensträussig; $K$. geflügeltkantig; Blb. klein-gekerbt, nackt; St. aufrecht, ganz kahl; B. lanzettl., an der Basis zsgewachsen. - . Kultiv. O. Jun. Jul. Bl. fleischfarben.

2. S. officinalis L. Bth. büschelig - ebensträussig; K. walzl., kahl; Blb. gestutzt, bekrönt; St. aufrecht; B. längl.-elliptisch. 24. Kies der Bäche, Zäune, Gebüsch. Jul. Aug. Bl. hell-fleischfarbig.

3. S. o cymoides L. Kurzh.; Bth. ebensträussig-rispig; $K$. walzl., zottig; Blb. stumpf, od. seicht-ausgerandet, bekrönt; St. niedergestreckt; B. lanzettl. od. elliptisch, die unteren in d. Bstiel verschmälert, vkteyf. 2. Sandige Hïgel u. VorA.; Kärnth., Tyr., Mittenwalde in OBaiern, südöstl. Schwz. Apr.-Aug. Bl. rosenroth.

4. S. lutea L. Bth. ebensträussig-köpfig; $K$. fast walzl., rauhh.; Blb. stumpf, bekrönt; St. aufrecht; $B$. lineal., die wurzelst. ganz kahl. 24. Höchste A.; sïdl. Schwz. auf der mittäglichen Seite des Matterhorn, am Fusse desselben über dem Thale Tornanche $u$. etwas uiber den Alpenhütten, am Breuil, häufig. Jul. Aug. Blb. schwefelgelb; Nägel u. Stbg. schwarz-violett.

\section{CUCÚBALUS L. Gärtner. Taubenkropf.}

1. C. bacciferus L. 2. Wälder der Ebenen, etwas feuchte O., Ufer unter den Weiden; zerstr. deh das Geb. Jul. Aug.

6. SILENE L. Leimkraut.

I. Rotte. Viscago. Bthstand traubig od. ährenf.; Bth. abwechselnd in einseitswendige od. zweizeilige, meist gezweiete $\mathrm{Tr}$. Qd. Aehren geordnet, mit einer einzelnen Bth. in d. Gabelspalte.

1. S. gallica L. Tr. endst., meist gepaart, klebrig-flaumig; Bth. wechselst.; K. röhrig, rauhh., der fruchttrag. eyf., mit dem Bthstielchen abstehend od. zurückgeschlagen, Zähne des K. lanzettl.-pfrieml.; $B l b$. vkteyf., ungeth., ganzrandig, gezähnelt od. ausgerandet; B. längl., die unteren vkteyf. $\odot$. Unter der Saat; zerstr. deh das Geb. Jun. Jul. Blb. fleischfarbig od. weisslich. Fruchtträger viel kürzer als die Kapsel. Var. $\beta$. quinquevulnera: Blb. im Mittelfelde blutroth, 
am Rande röthlichweiss, od. weisslich. S. quinquevulnera L. Blb. oft, wie bei der Art iberhaupt, ganzrandig, klcin-gekerbt u. vktherzf. - $\gamma$. anglica: der St. ästiger, ausgebreiteter. S. anglica L.

2. S. ve spertin a Retzius. 'Tr. endst, meist gepaart, gewöhnlich 5bth.; Bth. wechselst.; $K$. röhrig u. etwas kenlig, 10 streifig, aderlos, angedrückt-flaumig, während der Bthezeit auf dem aufrechten Bthstielchen nickend, die fruchttrag. keulenf., aufrecht, Zähne des K. eyf., spitzl.; Blb. bis ïber die Mitte 2sp., spitz-bekränzt; B. vkteyf. od. lanzettl., nach der Basis verschmälcrt. $\odot$. Sandiger Meeresstrand bei Triest. Mai. Jun. S. bipartita Desf. Blb. Heischroth; Fruchtträger so lang als die Kapsel.

3. S. di ch ot o ma Ehrhart. Tr. endst., gepaart, vielbth.; Bth. wechselst.; $K$. röhrig, etwas bauchig, 10streifig, aderlos, rauhl.., während der Bthezeit nebst den sehr kurzen Bthstielchen nickend, die fruchttrag. eyf.-längl., aufrecht, Zähne des K. eyf., spitz; Blb. bis ïber die Mitte 2sp., gestutzt-bekränzt; B. elliptisch-lanzettl., zugespitzt, die untersten spatelig. $\odot$. Aecker, Wege; zwischen Wien u. der ungarischen Grenze. Mai. Jun. Blb. weiss. Fruchtträger kurz, 3 mal kürzer als die Kapsel.

II. Rotte. Otites. Bthstand rispig od. traulig-rispig. Bth. in einer pyramidalischen, breitern ocl. schmälern R., die Aeste gegenst., gabelsp., mit einem Bthstiel in der Gabelspalte, seltener wiederholtgabelsp. Die R. wird zu einer quirligen Tr., wenn die Aeste sich verkürzen od. ganz fehlen; u. zu eincr einfachen Tr., wenn sich die erste Bthe der Aeste allein entfaltet.

4. S. viscosa Persoon. Klebrig-zottig; die T'r. quirlig; Bthstiele gegenst., $1-3 b t h . ; \mathrm{K}$. walzl., in der Mitte ein wenig bauchig, Zähne stumpf; Blb. 2sp., nackt; B. wellig. $\odot$. Wege, sandige Triften; Böhm., Mähr., Ins. Rügen. Jun. Jul. Cucubalus viscosus L. Bl. weiss.

5. S. italica Persoon. Flaumig; die $R$. aufrecht, locker, $d$. Aeste gegenst., 3 gabelig-verzweigt, klebrig-beringelt, 3 -vielbth.; Bth. gerade-vorgestreckt; K. keulig, Zähne stumpf; Blb. 2sp. nackt; $B$. an der Basis gewimpert, die unteren spatelig-lanzettl., in den Bstiel hinablaufend. 24. Steinige, sonnige Hiigel; Littor., Siiltyrol, Tessin. Jun. Jul. Cucubalus italicus L. Bl. oben weiss, unterseits mit hellvioletten, blaugrauen od. grasgrinen Adern. Var. Bth. kleiner, Fruchtträger nicht ganz so lang als die Kapsel: S. viscosa Schleich.! S. insubrica Gaud.; u. mit dichter-flaumigen fast grauen B.: S. pilosa Spreng. Cucub. mollissimus WK., nicht L.

6. S. ncmoralis WK. Flaumig; $R$. aufrecht, beinahe gehäuft, die Aesté gegenst., 3gabelig-verzweigt, klebrig-beringelt, 3-vielbth.; Bth. geradehervorgestreckt; K. keulig, Zähne stumpf;? Blb. 2sp., nackt; B. an der Basis bärtig-gewimpert, die unteren rundl.-elliptisch, 
in den Bstiel hinablaufend. 2. Waldige O.; Schles., Böhm., Mähr., Sachs., Stmk., Krain u. Littor. Jun. Jul. Fruchtträger auffallend länger als d. Kapsel. Bl. wie an S. italica.

7. S. nut an s I. Flaumig, oberw. driisig-klebrig; $\boldsymbol{R}$. einerseitswendig, während des Aufblühenseinuärts-geknickt-überhängend, Aeste gegenst., 3 gabelig-verzweigt, 3-7bth.; K. röhrig, etwas keulig, Zähre spitz; Blb. 2sp., bekränzt, die unteren B. lanzettl.-elliptisch, in den Bstiel hinablaufend. 2. Unkultiv. O., felsige Gebirgsabhänge, trockene Wies. Jun. Jul. Bl. weiss, unterseits manchmal mit bleigrauen od. grünen Streifen. Fruchtiräger kaum den dritten Theil so lang als die Kapsel. Var.: Blb. unterseits olivengrün: S. livida Willd. K. syn. ed. 1., Litt., Stmk., Krain, Kärnth., Südtyr. - $\beta$. infracta: kahl, B. nur an der Basis gerrimpert: S. infracta WK. Rosstrapp am Harz.

8. S. chloranth a Ehrlhart. Kahl; Tr. einseitswendig, Aeste gegєnst., 1-3hth.; Bth. während des Aufblühens überhangend; $K$. röhrig, etwas keulig, Zälne stumpf; Blb. 2sp., bekränzt; die untern B. lineal. -lanzettl., in den Bstiel verschmälert; St. fast nackt. 7 . Sandige, grasige Hügel, Nadelwälder; Schles., Lausitz, Brandenbg., Vorpommern. Jul. Aug. Cucubalus chloranthus Willd. Blb. gelblichgrün. Fruchtträger 4mal kürzer als die Kapsel.

9. S. tat a ric a Persoon. Ir. einseitswendig, aufrecht, Aeste gegenst., 1-3bth.; Bth. während des Aufblühens auf aufiechtem Bthstielchen nickend; K. röhrig, etwas keulig, Zähne spitz; Blb. 2sp., nackt; B. lineal.-lanzettl., an der I3asis verschmälert; St. dch die genäherten Gelenke dicht-beblättert. 24. Sandige O.; Neumark, in sehr grosser Menge längs am Ufer der Oder u. der Warthe: Jul. Aug. Cucubalus tataricus L. Kapsel $4 \mathrm{mal}$ so lang als der Fruchtträger. Bl. weiss.

10. S. Otites Smith. Aeste der R. gegenst., quirlig-traubig, Quirle reichbth.; Bth. geradehervorgestreckt; K. röhrig-glockig, nebst der R. kahl, Zähne stumpf; Blb. lineal., ungeth., nackt; B. vkteylanzettf. 24. Unkultiv. Hügel, Sandfelder; zerstr. deh das Geb. MaiJul. Cucubalus Otites L. Bth. klein. Blb. griinlich; die Pflanze vielehig-zweihäusig. Fruchtträger kaum vorhanden.

III. Rotte. Atocion. Bthstand ebensträussig od. ebensträussig-rispig; der St. gabelsp., mit einzelnen, deckblattlosen Bthstielen in der Gabelspalte, u. mit 2 deckblättrigen am Ende der Aeste. Die R. erscheint ebensträussig, wenn sich die Aeste u. Aestchen verlängern; sie wird $\%$ einem flachen Büschel dch sehr abgekürzte Aeste u. Aestchen; der St. wird 3bth., wenn er sich nur 1 mal theilt. Von den 3 Bthstielen dieses 3blüthigen St. ist der mittlere nackt, die seitenst. mit 2 Deckbl. versehen; wenn einer von diesen 3 Bthstielchen fehlt, so ist der eine von den beiden vorhandenen 
kïrzer $u$. nackt, der andere länger $n$. hat 2 Deckbl., u. wenn die 2 seitenst. Bthstiele verschwinden, entsteht ein 1 blüthiger St.

§. 1. K. aufgeblasen, nervig-vielstreifig, (20-30streifig) u. netzig-aderig.

11. S. infl at a Smith. R. endst., gabelsp.; 13th. gabel- u. endst.; K. eyf., aufgeblasen, vielstreifig, netzig-aderig, kahl, Zähne eyf. spitz; Platten der Blb. 2th., an der Basis 2höckerig; B. elliptisch od. lanzettl., zugespitzt. 2. Unkultiv. O. Jul. Aug. Cucubalus Behen L. Blb. weiss, zuletzt schief-gestellt, fast unregelmässig; die Pflanze vielehig-2häusig. Fruchtträger kurz, halh so lang als die Kapsel. Var.: B. kahl, kahl und gewimpert, kurzh. u. rallhl.; auf den A. mit grösseren Bth. u. reichblüthigem St.: C. Antelopum Vest. - $\beta$. angustifolia: B. lineal. od. lineal.-lanzettl., manchmal kaum 1/2 Linio breit. S. inflata $\beta$. M. et K. Steinige O. zw. Imsbach u. den alten Kobaltgruben am Donnersberge in der Rheinpfalz; Salzburg bei Lofer. - $\gamma$. alpina : B. längl. od. ellipt., St. niedergelegt, $1-3 \mathrm{bth}$. S. maritima Host., nicht Wlthering u. Smith. Cucubalus alpinus Lam. A. v. Oestr.

12. S. Pumilio Wulfen. Bth. endst., einzeln; $K$. aufgeb:asen, längl.-glockig, vielstreifig, netzaderig, rauhh., Zähnc eyf., stumpf; Platten der Blb. ungeth., randschweifig, borstl.-bekränzt; B. lineal., stumpfl, nach der Basis verschmälert. 24. Felsige, ctwas feuchte 0 . der GranitA.; Tyrol, Salzbg., Kärnth., Stmk. Jun. Jul. Cucubalus Pumilio L. Blb. rosenroth. Bth. v. den grössten der Gattung. Pfl. $1-2 "$ hoch.

§. 2. K. eyf., nach der Basis nicht verschmälert, nervig-vielstreifig (30streifig), Streifen dicht-genähert, nicht netzig.

13. S. conica L. St. grau-flaumig, oberwärts gabelsp.; Bth. gabel- u. endst.; $K$. 30streifig, an der Basis benabelt, Zähne pfrieml., sehr spitz; Blb. vlktherzf, bekränzt; Kapsel längl.-eyf.; B. lineal.lanzettl. $\odot$. Sandige O.; Rheinlande v. der Schwz. bis Westphal., Littor. Jun. Jul. Blb. rosenroth. Fruchtträger, wie bei der folgend., sehr kurz.

14. S. conoidea L. St. driisig-flaumig, oberwärts gabelsp.; Bth. gabel - $u$. endst.; $K$. 30streifig, an der Basis benabelt, Zähne pfrieml., sehr spitz; Blb. ganz, kleingekerbt; Kapsel platt-kugelig; lang-geschnäbelt; B. längl.-lanzettl. $\odot$. Accker bei Luxembg. Jun. Jul. Blb. rosenroth.

§. 3. K. länglich od. länglich-keulig, 10nervig.

15. S. noctifíora L. St. oberwörts gabelsp., nebst den Bthstielen u. K. klebrig-zottig; Bth. gabel-u. endst.; K. etwas bauchigröhrig, 10streifig, aderig, die fruchttrag. elliptisch, Zälıne pfrieml.fädl.; Blb. tief-2sp., bekränzt; B. längl., spitz, die obersten aus lan- 
zettl. Basis schmal-zulaufend, die untersten vkteyf. $\odot$. Aecker. Jul. -Septbr. Blb. bleich-fleischroth. Fruchtträger $8 \mathrm{mal}$ kiirzer als die eyf. Kapsel.

16. S. vallesia L. St. rasig, niederliegend, $1-3 b t h$; B. $u$. $K$. drüsig-rauh; Bth. endst.; K. röhrig, 10streifig, oberwärts aderig, der fruchttrag. keulig, Zähne längl.; Blb. 2sp., bekränzt; B. lanzettl., spitz, die stengelst. sitzend, die wurzelst. in den Bstiel verschmälert. 2. Hohe A. in d. Schwz, a. d. grossen St. Bernhard, unter d. Matterhorn bei Breuil, zw. Courmageur u. Allée-Blanche. Jul. Blb. oben schwach-rosenroth, unten blutroth. Fruchtträger so lang als die eyf.-längl. Kapsel, oder länger.

17. S. A rmeria L. Völlig kahl; die oheren Glieder des St. klebrig-beringelt; die R. endst., büschelig-gedrungen, reichbth.; K. röhrig-keulig, 10streifig, Zähne eyf., stumpf; Blb. ungeth., ausgeran. det, spitz-bekränzt; B. eyf. $\odot$. Felsige O., zw. Gebüsch, auch sandige O.; südl. Schw., südl. Tyr., Kärnth., Littor., Rheinpfalz zw. Pirmasenz u. Annweiler, Nahe- u. Rheingbge zw. Creuznach u. Coblenz, Gbge der Bode am Harz, Höxter in Westph. Jul. Aug. Blb. rosenroth. Fruchtträger so lang als die längl. Kapsel, od. länger.

18. S. lin i c ol a Gmelin. St. oberwärts gabelsp., ebensträussigrispig, nebst den Bthstielen $u$. $K$. v. sehr kurzem Flaume etwas rauh; Bth. gabel- u. endst.; K. röhrig, 10streifig, die fruchttrag. eyf.-keulig, $\mathrm{zw}$. den Streifen aderig, Zähne des K. eyf., stumpf; Blb. ungeth., ausgerandet, bekränzt; B. lineal.-lanzettl., die untersten vkteyf. 4 . Aecker unter d. Lein; in Würtemberg u. nördl. bis Werthheim u. Wassertrüdingen, östl. bis München. Jun. Jul. Blb. blassfleischroth. Fruchtträger halb so lang als die eyf. Kapsel.

19. S. annulata Thore. St. oberwärts gabelsp., ebensträussigrispig, nebst den Bthstielen u. $K$. kahl; Bth. gabel- u. endst.; K. keulig-röhrig, 10streifig, die fruchttrag. eyf.-keulig zwischen den Streifen aderlos; Zähne des K. eyf., spitz; Blb. 2sp., bekränzt; B. lineal.lanzettl., die unteren vkteyf.-lanzettl., od. vkteyf. $\odot$. Getreidefelder; Unterstmk., neue Aufschüttung bei Triest. Blb. purp. Fruchtträger 4-5mal kürzer als die eyf. Kapsel. S. rubella Wulf., nicht Linn.

20. S. s edoides Jacq. St. gabelsp., nebst den Bthstielen $u$. $K$. drüsig-kurzh.; Bth. gabel- u. endst.; K. röhrig, 10streifig, die fruchttrag. längl.-keulig, Zähne eyf., stumpf; Blb. ungeth., ausgerandet, bekränzt; B. stumpf, die untersten vkteyf., in den Bsticl versclimälert, die obern längl. u. lanzettl., sitzend. $\odot$. Sonnige, felsige 0 . der Insel Oscro. Jun. Jul. Blb. rosenroth. Die Bthstiele nach dem Verblühen abstchend, mit cinem schräg-aufrechten K. Fruchtträger 4mal kürzer, als die längl. Kapsel.

21. S. saxifraga I. St. rasig, v. sehr kurzem Flaume etwas rauh; Bthsticle endst., einzeln od. gepaart; $K$. keulig, 10streifig, aderlos, kahl, Zähne eyf., stumpf; Blb.tief-2sp., bekränzt; B. lineal., 
nach der Basis verschmälert. 4. Gehirgige O. der VorA. u. A.; südl. Schwz., südl. Tyr., Kärnth., Krain, Stmk., Jun. - Aug. Blb. oberseits weiss, unterseits röthl. od. gelbl.-griin. Fruchtträger so lang als die oval-längl. Kapsel.

§. 4. K. kreiself.-glockig, kurz. S. am Rande kammf.-gewimpert.

22. S. quadrifid a L. St. rasig, gabelsp., die oberen Glieder u. d. Bthstiele klebrig-beringelt; Bth. gabel- u. endst., od. an dem 1 bliithigen St. einzeln; K. kreiself., 10streifig, Zälnne desselben eyf., stumpf; Blb. vkteyf., 4zähnig, bekränzt; Kapsel oval, ungefähr so lang als der K.; S. kammf.-gewimpert; B. liveal., die untersten spatelig. 2. Felsige, etwas feuchte O. der A. Jun. Jul. Blb. milchweiss. Var. $\beta$. pusilla: auf höheren A. kleiner: S. pusilla WK. $\gamma$. pudibunda: an nassen $O$. der GranitA. grösser, Blb. ein wenig breiter, mit den Rändern zsstossend, manchmal rosenroth: S. pudibunda Hoffmannsegg.

23. S. al pestris Jacq. St. rasig, gabelsp., die oberen Gelenke u. Bthstiele klebrig-beringelt; Bth. gabel- u. endst.; K. kreiself., 10streifig, Zähne eyf., stumpf; Blb. vkteyf., 4zähnig, bekränzt; Kapsel längl., noch $1 \mathrm{mal}$ so lang, als der K.; S. kammf.-gewimpert; B. lanzettl. 4. Waldränder u. nasse $O$. der VorA.; Unteröstr., Kärnth., Krain, Tyrol. Jul. Aug. B. lanzettl., gegen 3 Linien breit, Bth. 56 Linien breit. Blb. weiss.

Kamm.

§. 5. K. glockig od. kreiself.-glockig, kurz. S. am Rande ohne

24. S. rupestris L. St. gabelsp., völlig kahl; Bth. gabel-u. endst.; $K$. kreiself., 10riefig, Zälnne eyf., stumpf; Blb. vktherzf., bekränzt; $B$. eyf., spitz, sitzend, die unteren lanzettl., an der Basis verschmälert. 24. Trockne, felsige 0 . der A. u. VorA. u. Voges. Jul. Aug. Blb. weiss od. rosenroth.

25. S. acaulis L. St. einen sehr gedrungenen Rasen bildend, nebst den Bthstielen $u$. K. kahl; Bth. endst., einzeln; $K$. glockig, 10 riefig, aderlos, Zähne eyf., stumpf od. ausgerandet; Blb. vkteyf., seicht-ausgerandet, bekränzt; B. lineal.-pfrieml. 24. Felsige, befeuchtete O. der A. Jun.-Aug. Blb. satt-rosenroth; Kapsel längl., noch $1 \mathrm{mal}$ so lang als der $K$. - Var. $\beta$. exscapa: Bth. blass-rosenroth, Kapsel oval, nur wenig länger als der K. S. exscapa All.

7. LYCHNIS DC. Lichtnelke.

1. L. V is ca ria L. Blb. ungeth., bekränzt; St. kahl, oberwärts unter den Gelenken klebrig; B. lanzettl., kahl, an der Basis gewimpert; Bth. traubig-1ispig, fast quirlig. 4. Trockene Hügel, buschige Bergabhänge. Mai. Jun. Blb. freudig-purpurn.

2. L. alpina L. Blb. halb-2sp., nackt; St. kahl, nicht klebrig; 
B. lanzettl., kahl, an der Basis gewimpert; Bth. dichtdoldig-köpfig. 4. Höchste GranitA.; Wallis. Graubünd., Tyrol, Kärnth. Jul. Aug. Bl. purp.

3. L. Flos cuculi L. Blb. bis über die Mitte $4 s p$., Z $\mathrm{Z}$ fl. lineal., handf.-auseinanderstehend; StB. lineal.-lanzettl. 2. Wiesen, waldige, feuchte O. Mai-Jul. Blb. fleischroth.

4. L. co ro n a ri a Lamarck. Blb. ungeth., bekränzt; B. nébst dem St. dichtfilzig; Bthstiele mehrfach länger als der $K$. $\odot$. Gebirgige, waldige O.; siidl. Schwz, siidl. Tyrol, in mittl. Geb. sehr zerstr. Jun. Jul. Agrostemma coronaria L. Blb. purp.

5. L. Flos Jovis Lamarck. Blb. beinahe halb-2sp., bekränzt; St. $u$. die B. wollig-filzig; Bthstiele kürzer als der K. 2. Bergwiesen, Gebirgsal)hänge; Wallis, Graubünd., südl. Tyrol, Jun. Jul. Agrostemma Flos Jovis L. Blb. fleischroth.

6. L. vespertina Sibthorp. Blb. halb-2sp., bekränzt; St. unterwärts zottig; die obern B. ey-lanzettf., verschmälert-zugespitzt u. nebst den Bthstielen $u$. K. drüsig-kurzh.; Kapsel ey-kegelf., mit vorgestreckten Zähnen; Bth. 2häusig. $\odot$. Var. mit gefiillten Bth. u. ist sodann mehrjährig. Unkultiv. O., trockene Wiesen, Raine. Jun.Ang. L. dioica $\beta$. L. Blb. weiss, selten röthlich, am Abend offen u. angenehm riechend.

7. L. diurna Sibthorp. Blb. halb-2sp., bekränzt; St. nebst den $B .$, Bthstielen $u . K$. zottig, mit einfachen Haaren; die oberen B. eyf., plötzlich-zugespitzt; Kapsel rundl.-eyf., mit zurückgerollten Zähnen; Bth. 2häusig. 2. Feuchte Wiesen u. Wälder, Ufer. Mai. Jun. L. dioica $\alpha$. L. Bth. geruchlos, am Tage offen, schön-purpurn, sehr selten weiss.

\section{Agrostemina L. Rälen.}

1. A. Githago L. Blb. gestutzt; Kzpfl. länger als die Röhre des $K$. $u$. die $B l b$. $\odot$. Unter der Saat. Jun. Jul. Githago segetum Desf. Bth. purpurn, sehr selten weiss.

9. DRYPIS L. Kronenkraut.

1. D. spinosa L. 24. Steinige Orte im wärmeren Krain, Meeresufer im Littor. Jun. Jul. Bl. röthl.

\section{Ordng. ALSINEEN. DC.}

1. BUFFONIA I. Buffonic.

1. B. tenuifolia I. Nerven des K. gerade, gleichlaufend; Knötchen der S. warzenf., stumpf. 24. Nach DC.; (jährig nach Gaud.) Kiesige O.; im unteren Wallis. Jul. 13lb. weiss, kürzer als der K.

2. SAGÍNA L. Mastkraut. 


\section{a. Bthentheile vierzählig. Sagina-Arten bei Linn.}

1. S. ciliat a Fries. St. ausgebreitet; $B$. lineal., begrannt, an der Basis gewimpert; Bthentheile 4zählig; die abgeb!ühten Bthstiele an ler Spitze hakig, die fruchttrag. aufrecht; die 2 äusseren $K B$. zugespitzt-stacilelspitzig. $\odot$. Aecker u. Brachfelder, selten, u. sehr zerstr. dch das mittl. u. nördl. Geb. Jun. Jul. Blb. sehr klein, weiss wie bei den folgend. - Var. $\beta .:$ B. an der Basis mit sehr wenigen Wimpern: S. depressa Schultz.

2. S. proeumbens I. St. niederliegend, an der Basis wurzelnd; Aeste aufstrebend; $B$. lineal., stachelspitzig, ganz kahl; Bththeile 4zählig; die abgeblïhten Bthstiele an der Spitze hakig, die fruehttrag. aufrecht; KB. stumpf, grannenlos. $\odot$. Aecker, Triften, grasige, etwas feuchte 0 . Mai-Herbst. Blb. stumpf, 3-od. 4mal kiirzer als der K.

3. S. bry oi des Frölich. St. kriechend; B. lineal., stachelspitzig, schwach-gezähnelt, fein-gewimpert; Bthentheile 4zählig; Bthstiele aufstrebend, die abgeblühten an der Spitze hakig, die fruchttrag. aufrecht; $K B$. stumpf, gramienlos. $\odot$. VorA.; nördl. Tyrol im Thale Syn bei Steeg, siill. Tyrol an mehreren O., sodann Oberharz. Jul. Aug. KB. stumpf. Blb. eyf., spitz, um die Hälfte kïrzer u. schmäler als der K., v. Frölich.

4. S. apetala I. St. autrecht, voul der Basis an ästig, die seitenst. Aeste aufstrebend; $B$. lineal., begrannt, an der Basis gewimpert; Btheile 4zählig; die abgeblïhtenBthstiele immer aufrecht, kaum einwärts-geneigt; KB. stumpf, die 2 äusseren sehr kurz stachelspitzig; Stachelspitzen einwärts-gekriinmt. $\odot$. Aecker, Triften; zerstr. deh das Geb. Mai. Jun. Blb. lanzettl., selır klein, vielmal kürzer als der $\mathbf{K}$.

5. S. stricta Fries. St. v. der Basis an ästig u. nebst den Aesten aufrecht; $B$. lineal., kurz-bespitzt, kahl; Bthentheile 4zählig; die abgeblühten Bstiele immer aufrecht; KB. stumpf. $\odot$. Am Seestrande. Mai-Aug. S. maritima Don. Blb. fehlend.

b. Bthentheile fünfzählig. Arten v. Spergula bei Linn.

6. S. s axatilis Wimmer. B. lineal., kurz-stachelspitzig, nebst dem St. थ. Bstielen kahl; Bthentheile 5zählig; die abgebliihten Bthstiele nickend, die fruchttrag. aufrecht; Blb. kürzer als de: K.; St. niederliegend, anfstrebend. 2. Fclsige, moosige u. entblüsste $\mathrm{O}$. der A. u. VorA.; Feldberg in Bad., Gesenke der Sudeten. Jun. Jul. Spergula saginoides L. K. syn. ed. 1.

7. S. subulata Wimmer. B. lineal., zugespitzt, lang-begrannt, am Rande, nebst dem oberen Theile des St. u. den Bthstie'en etwas behaart; Bthentheile 5zählig; die abgebliihten Bthstiele ziemlich nickend, die fruchttrag. aufrecht; Blb. so láng als der $K$.; St. nie- 
derliegend, aufstrebend. 24. Sandfelder; sehr zerstr. deh das Geb. Jul. Aug. Spergula subulata Swartz.

8. S. gl abra Koch. B. lineal.-fädl., kurz-stachelspitzig; Bthentheile 5zählig; Bth. vor dem Aufblühen überhangend, die fruchttrag. aufrecht; Blb. noch einmal so lang als der $K$.; St. niedergestreckt, kriecherid. 4. Triften der A.; in dem Thale $\mathbf{z w}$. Terragnolo u. Colsando östl. v. Rovoredo. Jul. Aug. Spergula glabra Willd. Var. behaart.

9. S. no dosa E. Meyer. B. lineal.-fädl., knrz-stachelspitzig, die oberen in dem Winkel v. kurzen B. büschelig; Bthentheile 5zählig; Bth. immer aufrecht; Blb. noch einmal so lang als der $K$.; St. ausgebreitet od. aufstrebend. 4. Feuchte Triften u. Haiden; zerstreut deh das Geb. Jul. Aug. Spergula nodosa L. Var. kahl u. behaart, wie S. glabra.

\section{SPERGULA L. Spark.}

1. S. arvensis L. B. lineal.-pfrieml., gebüschelt-quirlig, unbegrannt, oberseits convex, unterseits mit einer Furche durchzogen; Bthstiele nach dem Verblühen herabgeschlagen; S. kugelig-linsenf., von feinen Körnchen etwas rauh. od. von kurzen Härchen feinwarzig, mit einem schmalen, glatten Flügelrande umzogen. $\odot$. Aecker u. Felder. Jun. Jul. B. mit NebenB. u. Blb. weiss, wie an folgengender. Var. $\alpha$. sativa: S. sammetschwarz, kahl, von sehr feinen Punkten rauh: S. sativa v. Bönningh. $-\beta$. vulgaris: S. mit weisslichen, zuletzt bräunlichen Wärzchen besetzt: $\mathrm{S}$. vulgaris v. Bönningh. $-\gamma$. maxima: S. 3mal so gross, übrigens denen der Variet. $\beta$. ähnlich; die Pflanze höher: S. maxima Weihe. Diese Variet. im nördl. D.

2. S. pentandra L. B. lineal.-pfrieml., gebüschelt-quirlig, grannenlos, fast stielrund, unterseits glatt, (nicht mit einer Furche dchzogen); Bthstiele nach dem Verblühen zurückgeschlagen; S. flachusgedrückt, glatt, mit einem verbreiterten strahlig-gerieften Flügelrande umzogen, vor dem Rande mit feinen Blätterchen besetzt. $\odot$. Felder, sandige Haiden; zerstr. dch das Geb. Apr. Mai.

\section{LEPÍGONUMI Wahlberg. Schuppenmiere.}

1. L. segetale Koch. B. fädl., stachelspitzig; St. aufrecht, sehr ästig; Aeste an der Spitze eingeknickt-überhangend; Bthstiele gabelst., nach dem Verblühen herabgeschlagen; KB. weiss, rauschend, mit einem krautigen Rückennerven; Blb. kürzer als der K. ○. Unter der Saat; Luxembg., Westphal., Hannover, Hessen, Linz am Rheine, Lausitz. Jun. Jul. Alsine segetalis L. K. syn. ed. 1. Blb. weiss.

2. I. rubrum Wahlberg. B. lineal.-fädl., stachelspitzig, etwas fleischig, auf bciden Seiten flach; St. gestreckt u. aufstrebend, ästig; 
Aeste traubig; Bthstiele nach dem Verblühen herabgeschlagen; $K B$. lanzettl., stumpf, nervenlos, am Rande häutig; S. keilig, beinahe 3eckig, fein-runzelig; flügellos. $\odot$. Sandige $\mathrm{O}$. Mai-Septbr. Arenaria rubra var. $\alpha$. campestris L. Alsine rubra Wahlenb. K. syn. ed. 1. Blb. rosellroth.

3. L. m e dium Wahlberg. B. lineal.-fädl., fast grannenlos, fleischig, ober- u. unterseits convex; die St. gestreckt u. aufstrebend, ästig; Aeste traubig; Bthstiele nach dem Verblïhen herabgeschlagen; $K B$. lanzettl., stumpf, nervenlos, am Rande häutig; s. rkteyf., zsgedrückt, schwach-runzelig, alle flügellos od. sehr wenige mit einem Flügel umzogen. $\odot$. Meeresufer u. salzhaltige O. Mai-Sept. Alsine marina $\alpha$. K. syn. ed. 1. Arenaria marina Roth. A. rubra $\beta$. marina L. Blb. rosenroth.

4. L. margin a tum Koch. B. lineal.-fädl., fast grannenlos, fleischig, halbwalzenf.; St. gestreckt u. aufstrebend, ästig, Aeste traubig; Bthstiele nach dem Verblühen hinabgeschlagen; $K B$. lanzettl., stumpf, nervenlos, am Rande häutig; S. rundl.-vkteyf., zsgedriickt, schwachrunzelig, alle mit einem Flügel umzogen. $\odot$. Am Seestrande mit der vorhergehenden, aber viel seltener. Aug. L. marinum Wahlberg. Arenaria marginata DC. Alsine media L. Blb. weiss od, rosenroth.

5. HALIANTHUS Fries. Salzmiere.

1. H. peploides Fries. B. sitzend, eyf., spitz, kahl, 1nervig, fleischig; St. gabelsp., niederliegend; Bth. einzeln, gabel- u. blattwinkelst.; KB. eyf., stumpf, 1 nervig; Blb. vkteyf., länger als der K. 4. Am Seestrande. Jun. Jul. Arenaria peploides L. Honkenya peploides Ehrh. Alsine peploides Wahlenb. K. syn. ed. 1. Blb. weiss.

\section{FACCHINIA Reichenb. Facchinie.}

†. FACCHINIA Reichenb. B. aus einer abgerundeten Basis lanzettl., spitz, flach, unterseits mehrmervig, kurz-gewimpert; Stämmchen rasig, gestreckt; St. aufstrebend; Bthstiele endst., 1-3bth.; KB. lanzettl., spitz, meist 5nervig, ohngefähr so lang als die Blb. 4. Felsensp. der höchsten A.; Krain, sïdl. Tyrol, Veltlin. Jul. Aug. Blb. weiss. Alsine lanceolata M. et K., K. syn. ed. 1. Var. $\alpha$. laxa: lockerer; Glieder des St. fast so lang als die B.; B. abstehend, in den Winkeln der unteren, Büschel v. kleineren B.; Bthstiele länger, zuweilen fast 1 Zoll lang. Arenaria lanceolata All. - $\beta$. condensata: gedrungener; Glieder des St. sehr kurz, v. der zsgewachsenen Basis der B. bedekt, die oberen nur ein wenig länger; die B. oft dichtdachig. Arenaria cherlerioides Vill. A. lanceolata $\beta$. cherlerioides DC.

\section{ALSÍNE Wahlenberg. Miere.}

§. 1. B. elliptisch, oval od. längl.

1. A, aretioides Mert. u. K. B. dachig sich deckend, oval- 
längl., stumpf, kurz-stachelspitzig, oberseits tief-concav, unterseits convex, 3nervig, ganz kahl; Stämmchen gedrungen-rasig; Bth. einzeln, endst., sitzend, 4blätterig, 8männig. 4. Felsenspalten der höchsten A.; Tyr., Salzb., Oberstmk., Kärnth. Jun. Jul. Arenaria aretioides Portenschl. Siebera cherlerioides Hoppe. Blb. weiss, wie bei den folgenden.

§. 2. B. schmal, lineal. od. pfrieml., 1nervig od. nervenlos, auch im getrockneten Zustande.

2. A. stricta Wahlenb. B. fädl., halbstielrund, nervenlos; Stämmchen gestreckt, rasig; die blühenden St. aufrecht, oberwärts nackt; Bthstiele endst., meist zu 3, sehr lang; KB. ey-lanzettf., spitzl., nervenlos, im trockenen Zustande 3nervig; Blb. längl.-oval, an der Basis verschmälert, ungefähr so lang als der K. 2. Torfhaltige 0 .; Oberbaiern, Jura. Jun. - Aug. Spergula stricta Swartz. Arenaria uliginosa Schleich.

3. A. biflora Wahlenb. B. schmal-lineal., stumpf, 1nervig, unterseits etwas convex; Stämmchen gestreckt, rasig; St. 1-2bth.; $K R$. lineal., an der Spitze kappenf., sehr stumpf, 3nervig; Blb. längl.keilf., so wie die Kapsel anderthalbmal so lang als der K. 24. Höchste A. der Schwz., an Felsenabhängen; Panerosaz u. Fouly, auf dem Crespeina der Seiseralpe in Tyrol. Jul. Aug. Stellaria biflora L.

4. A.laricifolia Wahlenb. B. lineal.-pfrieml., nervenlos; Stämmchen rasig; die blüthentrag. St. aufstrebend, 1 -vielbth.; $K B$. lineal.längl., abgerundet-stumpf, 3nervig; Blb. keilig, noch 1mal so lang als der K. 2. Höhere A. Jul. Aug. Arenaria laricifolia L. A. rostrata Kit. Rochel. A. macrocarpa Hornem. Var. Bthstiele u. St. oberwärts mit driisenlosen Haaren besetzt; u. $\beta$. glandulosa: mit drüsigen Haaren daselbst bedeckt. A. laricifolia $\beta$. DC. A. liniflora $\mathrm{L}$.

§. 3. B. schmal-lanzettl., lineal. od. pfrieml., 3nervig, wenigstens im getrockneten Zustande.

5. A. a ustriaca Mert. u. Koch. B. schmal-lineal., 3nervig, aderlos; Stämmchen niedergestreckt, sehr ästig; St. aufrecht, 2 bth., oberwärts nackt; Bthstiele endst., gepaart, sehr lang; KB. lanzettl., spitz, 3nervig, am Rande häutig, kiirzer als die Kapsel; Blb. längl., an der Spitze gezähnelt od. gestutzt, an der Basis keilig, beinalie noch 1mal so lang als der K. 4. Höhere A.; Krain, sïdl. Tyrol, Kärnth., Stmk., Oestr. Jul. Aug.

6. A. Villarsii Mert. u. Koch. B. schmal-lineal., 3nervig, entfernt-äderig; Stämmchen gestreckt, sehr ästig; St. aufrecht, 3-7bth.; Bthstiele flaumig; KB. lanzettl., spitz, 3nervig, am Rande häutig, länger als die Kapsel; Blb. längl., stumpf od. geslutzt, an der Basis keilig, beinahe noch $1 \mathrm{mal}$ so lang als der $K$. 24. Höhere A.; 
Wallis, Kärnth. Jul. Aug. Arenaria Villarsii Balb. $\beta$. villosula: ganz mit abstehenden, etwas klebrigen Haaren bestreut. A. Villarsii $\beta$. Gaud.

7. A. verna Bartling. B. lineal.-pfrieml., 3ncrvig; Stämmchen rasig; die blühenden St. aufstrebend od. aufrecht, 1 -vielbth.; $K B$. ey-lanzettf., spitz, 3nervig, am Rande häutig; $B l b$. länger als der $K$, eyf., kurz-benagelt, an der Basis beinahe her $z$. 24. Steinige 0 . der A. u. VorA., u. ausserdem sehr zerstr. deh das Geb. Jun.-Aug. Arenaria verna L. - $\beta$. alpina: St. niedriger, armbth., Bth. grösser. Arenaria liniflora Jacq. A. Gerardi Willd.

8. A. rubella Wahlenberg. B. lanzettl.-lineal., 3nervig, stumpfl., unbegrant; St. dicht-rasig, aufrecht u. aufstrebend, 1-2bth.; KB. eyf., spitz, 3nervig, am Rande häutig; Blb. eyf., an der Basis abgerundet, kurz-benagelt, so lang od. ein wenig länger als der $K .24$. Höchste A. im Allgau. Jul. Aug. A. sedoides Fröl. K. syn. ed. 1. Sagina decandra Reichenb. Blb. röthlich od. weiss. Der vorhergeh. ähnlich, aber die B. lanzettl., in der Mitte bemerklich breiter. Kapsel über die Hälfte 3 sp., selten 4- od. $5 \mathrm{sp}$.

9. A. recurva Wahlenberg. B. lineal.-pfrieml., 3nervig; Stämmchen rasig; die blïhenden St. aufstrebend, 1-vielbth.; KB. evf.lanzettl., am Rande häutig, die äussern 5-7nervig; Blb. ungefälır so lang als der $K$., oval, ncch der Basis schmäler. 24. Sonnige 0. der höchsten A.; Schwz., Tyrol, Käruth. Jul. Aug.

10. A. setacea Mert. u. Koch. B. pfrieml.-borstl., 3nervig; Stämmchen rasig; die blühenden St. aufstrebend, oberwärts rispig; Bthstiele sämmtl. länger als der $\mathbf{K} . ; K B$. eyf., spitz, kreideweiss, fast knorpelig, mit krautigem, 1nervigem Rückenstreifen; Blb. oval, wenig länger als der K. 2. Felsige O.; Böhmen, Mähren, Oestr., Gegend v. Regensbg: Jul. Aug. Arenaria setacea Thuill. A. heteromalla Pers.

11. A. rostrata Koch. B. pfrieml.-borstl., 3nervig; Stämmchen rasig; die blühenden St. aufstrebend; Aeste büschelig-ebensträussig; Bthstielchen so lang od. kuirzer als der K., das unterste länger; $K B$. lanzettl., sehr spitz, weiss, mit krautigem, 1nervigem Rückenstreifen; Blb. längl., ungefähr so lang als der $K$. 24. Felsenspalten der A.; Wallis, Graubünd. Jul. Aug. Arenaria rostrata Pers. A. fastigiata Smith. A. mucronata DC. Alsine mucronata Gouan.

12. A. Jacquini Koch. B. prieml.-borstl., an der Basis 3nervig; St. aus einer aufstrebenden Basis aufiecht, schnurgerade, oberwärts ästig; Bth. büschelig-ebensträussig; Bthstielchen küizer als das DeckB.; KB. ungleich, lanzettl.-pfrieml., sehr spitz, weiss-knorpelig, mit krautigem, 1nervigem Rückenstreifen; Blb. 3mal kürzer als der $K$. $\odot$. Trockne Hügel, sandige Felder; südl. Geb., Rheinlande. Jul. Aug. Arenaria fasciculata Jacq. - $\beta$. pubescens: flaumig; 
Bthstiele, Bthstielchen u. K. mit driisentrag., abstehenden Haaren bestreut.

13. A. ten u ifolia Wahlenb. B. pfrieml., 3nervig; St. gabelsp.; Bth. büschelig; Bthstielchen mehrmal länger als der $K$.; $K B$. lanzettl.-pfrieml., 3nervig, am Rande häutig; Blb. oval, an der Basis schmäler, kürzer als der $K$. $\odot$. Aecker, Felder, gebirgige O.; zerstr. deh das Geb. Jun.-Aug. Arenaria tenuifolia L. $\beta$. viscosa: klebrig; oberwärts mit drüsentrag., abstehenden Haaren besetzt; Alsine viscosa Schreb. Von A. verna u. den Verwandten deh den Mangel nicht blühender Stengel sogleich zu unterscheiden.

8. CHERLÉRIA L. Cherlerie.

1. Ch. sedoi des L. 2. Felsen der höhern A. Jul. Aug. Gewöhnl. ohne Blb., var. abel öfter mit kleinen grünl. Blb., selteuer mit schneeweissen v. der Länge des $K$. u. kommt nach v. Salis mit längeren $\mathfrak{u}$. kürzeren Gf. vielehig-2häusig vor.

9. MOEHRINGIA L. Möhringie.

1. M. muscosa L. B. fädl., spitz, halbstielrund, nervenlos, kahl, grasgrün; die St. rasig, gestreckt; Bthstiele endst., 2-5bth.; KB. ey-lanzettf., spitz, 1nervig; Bth. 8männig, 4blätterig; Blb. länger als der K. 24. Etwas feuchte, schattige Felsen der VorA. u. Mähr. u. Schles. Gbg. Jun.-Aug.

2. M. P o n a e Fenzl. B. lineal., stumpf, kurz-stachelspitzig, nervenlos, fleischig, kahl, meergrün, alle stielrund od. die oberen auf der Oberseite flach; St. rasig, gestreckt; Bthstiele endst., meist 2bth.; KB. ey-lanzettf., stumpf, 3nervige, Bth. 10männig, 5blätterig; Blb. länger als der K. 2. Steile Felsen; Südtyrol, Stmk. Jun.-Aug. Arenaria bavarica L. B. 3mal so dick als bei der vorhergeh., St. sehr zerbrechlich. Var. $\alpha$. : B. alle stielrund. - $\beta .:$ B., wenigstens die oberen, oberseits flach.

3. M. polygonoides Mert. u. Koch. B. lineal.-fädl., nach der Basis verschmälert, etwas fleischig, nervenlos; die St. rasig, gestreckt; Bthstiele seitenst., 1-mehrbth.; KB. ey-lanzettf., stumpf, im getrockneten Zustande 3nervig; Blb. länger als der K. 24. Felsige, steinige $O$. der höheren A. Jun. Jul. Arenaria polygonoides Wulfen. A. obtusa All.

4. M. villos a Fenzl. B. lanzettl.-lineal., spitz, nacl der Basis verschmälert, nervenlos, die untersten viel kleiner, elliptisch, in den Bstiel zsgezogen; Bstiel kürzer als das B., nebst dem St. überall flaumig; St. rasig, aufstrebend; Bthstiele endst., 1-3bth.; Bthstielchen naclı dem Verblühen zurückgeschlagen; KB. lanzettl., spitz, nervenlos; Blb. länger als der K. 24. Gebirgige O. u. A.; in Oberkrain am Poresenberg iiber Zurz. Aug. Arenaria villosa Wulf. Ueberall flaunig. Var. $\beta$, glabra: ganz kalıl. 
5. M. diversifolia Dolliner. B. lineal.-lanzettl., spitz, in einen Bstiel verschmälert, die untersten eyf., spitz, gestielt, der Bstiel 3-4mal länger als das B.; Bthstiele endst., 1-3bth., nach dem Verblïhen gerade-vorgestreckt; KB. eyf., 1nervig, die äusseren spitz, die inneren stumpf; Blb. so lang als der K. 4 ? Beschattete Felsen; Unterkrain u. Stmk. Mai. Jun.

6. M. trinervia Clairville. B. eyf., spitz, 3-5nervig, die unteren gestielt, Bstiel so lang als das B.; St. ästig; KB. spitz, 3nervig, Nerven genähert, der mittlere stärker u. bekielt; Blb. kürzer als der K. $\odot$. Gebüsch u. etwas feuchte Wälder. Mai. Jun. Arenaria trinervia $\mathbf{L}$.

\section{ARENARIA L. Sandkraut.}

1. A. Marschlinsi Koch. B. eyf., zugespitzt, sitzend, d. untersten in einen kurzen Bstiel zsgezogen; St. aufsteigend, gabeligrispig; Bth. gabel- u. blattwinkelst.; $K B$. ey-lanzettf., haarspitzigverschmälert, 3nervig, anderthalb mal so lang als $d$. Blb., der häutige Rand der inneren um die Hälfte schmäler als der krautige Theil des KB.; Blb. eyf. $\odot$. Höchste A. der Schwz. u. Tyrol. Jul. Aug. A. serpyllifolia $\beta$. alpina Gaud. Blb. weiss.

2. A. serpyllifolia L. B. eyf., zugespitzt, sitzend; St. aufstrebend, gabelsp., rispig; Bth. zerstreut, einzeln in den Gabeln $u$. Blattwinkeln; $K B$. lanzettl., zugespitzt, 3nervig, anderthalb mal so lang als die Blb., der trockenhäutige Rand der inneren so breit als der krautige Theil; Blb. oval, nach der Basis verschmälert. $\odot$. Felder u. Gbge bis in die A. hinauf. Jul. Aug. Blb. weiss, wie bei den folgenden.Var.: $\beta$. glutinosa: kleiner, aufrecht od. aufstrebend, oberwärts mit driisentrag. Haaren bedeckt. A. viscida Lois. - $\gamma$. tenuior: St. u. Bthstiele halb so dick, K., Blb. u. Kapsel um die Hälfte kleiner, übrigens die Pflanze kahl od. drüisig-haarig.

3. A. ciliata L. B. ey-od. lanzettf., spitzl., in den kurzen Bstiel herablaufend, an der Basis borstig-gewimpert; St. rasig, aufstrebend; Bth. endst., einzeln od. mehrere, fast rispig; KB. im trockenen Zustande nervig; Blb. länger als der $K$., eyf., kurz-benagelt. 4. Felsige, kiesige O. der A. Jul. Aug. Var. $\alpha_{.}$: B. meist breiter, im trockenen Zustande mehr nervig-aderig, die St. an der Spitze 3 -7bth. A. ciliata Wulf. - $\beta$. frigida: B. meist schmäler, im trockenen Zustande weniger nervig, die St. 1-2bth. A. multicaulis L. Wulf.

4. A. biflora L. B. rundl., stumpf, kurzgestielt, an der Basis borstig-gewimpert; Stämmchen gestreckt, ausläuferartig; die blüthentrag. Aestchen seitenst., sehr kurz, dicht beblättert, an der Spitze 1-2bth.; KB. schwach-1nervig; Blb. länger als der K., oval, nach der Basis verschmälert. 24. Felsige feuchte 0 , u. an Bächen der höheren A. Jul. Aug. 
5. A. grandiflor a Allioni. B. lanzettl.-pfrieml., begrannt, am Rande verdickt, unterseits 1nervig, mit starkem Nerven; Stämmchen rasig; St. aufstrebend, 1-3bth.; KB. ey-lanzettf., zugespitzt, begrannt, 1nervig; Blb. längl.-vkteyf., noch $1 \mathrm{mal}$ so lang als der K. 4. Felsige, gebirgige Wiesen; westl. Schwz. auf dem Chasseron, Saleve u. Suchet, Mähren auf den Polauer Bergen, Krain hinter Görz, Wien. Mai-Jul.

\section{HOLÓSTEUM L. Spurre.}

1. H. umbellatum L. Bth. doldig. $\odot$. Felder u. bebauete $O$. März-Mai. Bl. weiss, seltener rosenroth.

12. STELLARIA L. Sternmiere.

a. Der K. an der Basis abgeruudet.

1. S. viscida M. v. Bieberst. St. stielrund, gerillt, oberwärts gabelig-rispig, vielbth.; Bthstielchen, $K$. u. Blätterrand klebrig-flaumig; B. lineal., die unteren gestielt, fast spatelig; Blb. länger als der K. - . Trockne Triften; Mähr., Schles., Oberbad., Fiume. Mai. Jun. Cerastium anomalum WK. Blb. weiss, wie bei den folgenden.

2. S. cerastoides L. St. stielrund, gestreckt, an der Spitze aufstrebend, mit einer herabzielenden Haarlinie besetzt, 3-vielbth.; Bthstiele flaumig, nach dem Verblühen herabgeschlagen; B. sitzend, längl.-lanzettl., spitzl., kahl, die unteren stumpf, an der Basis verschmälert, die obersten beinahe eyf., spitz; Blb. länger als der K. 4. Feuchte O. u. an den Bächen der höheren A. Jul. Aug.

3. S. nemorum L. St. aufstrebend, oberwärts zottig; B. gestielt, herzf., zugespitzt, die an den Aesten sitzend; R. gabelsp.; KB. lanzettl.; Blb. tief-2sp., noch $1 \mathrm{mal}$ so lang als der K.; Kapsel längl., länger als der K. 2. Feuchte Haine, an Bächen gebirgiger Gegenden, VorA. Mai-Jul.

4. S. media Vill. St. aufstrebend, gabelsp., einzeilig-behaart; B. eyf., kurz-zugespitzt, gestielt, die oberen sitzend; Bth. gabel- u. endst.; Blb. so lang als der K. od. kürzer, 2 th.; Kapsel längl., länger als der K. $\odot$. Kultiv. O., an Wegen, Gräben. Blühet fast das ganze Jahr. Alsine media L. Var. auf fettem, feuchtem Boden: $\boldsymbol{\beta}$. Inajor: grösser, Bth. 10männig. S. neglecta Weihe. S. umbrosa Opitz.

5. S. bulbosa Wulfen. St. aufrecht, einfach, od. 1- bis $2 \mathrm{mal}$ gabelsp., meist 3bth.; B. elliptisch, spitz, in einen kurzen Bsticl verschmälert; Bthstiele nach dem Verblühen bogig-zurückgekrümmt; Wurzelstock wagerecht, fädlich, mit Rübchen besetzt. 24. Schattige Haine, am Fusse bejahrter Eichen; Krain, Stmk. Apr. Mai.

6. S. Holoste a L. St. aufstrebend, 4kantig; B. sitzend, lanzettl., lang-zugespitzt, am Rande $u$. auf dem Kiele rauh; Ebenstrauss gabelig; DeckB. krautig; KB. nervenlos; Blb. halb-2sp., noch $1 \mathrm{mal}$ 
*o lang als der K.; Kapsel kugelig, so lang als der K. 24. Grasige O., Wälder, Zäune, Gebiisch. Apr. Mai.

7. S. gl a u c a Withering. St. aufrecht, schwach, 4eckig, u. ncbst den sitzenden, lineal.-lanzettl., spitzen B. ganz kahl; Ebenstrauss gabelig; DeckB. trockenhäutig, am Rande kahl; KB. 3nervig; Blb. 2th., länger als der K.; Kiapsel längl.-eyf., so lang als der K. 4. Feuchte Wiesen, Sünıfe, Ufer. Jun. Jul. S. graminea $\beta$. L. S. palustris Retz.

8. S. gramin a L. St. ausgebreitet, 4eckig, kahl; B. sitzendlanzettl., spitz, kahl, an der Basis wimperig; Ebenstrauss gabelig; DeckB. trockenhäutig, am Rande gewimpert; KB. 3nervig; Blb. 2th., so lang als der K.; Kapsel längl., länger als der K. 4. Wiesen, Haiden, Felder. Mai-Jul. Var. mit un tie Hälfte kleineren Bth.

9. S. Frie s ean a Seringe. St. ausgebreitet, 4eckig, oberwärts rauh; B. sitzend, lanzettl.-lineal, spitz, nach der Basis verschmälert, am Rande u. auf der, Mittclrippe rauh; R. gabelig, fast ebensträussig; DeckB. trockenhäutig; KB. nervenlos, getrocknet an der Basis 3nervig, der Mittelnerve auslaufend; Blb. 2th., so lang als der K.; Kapsel eyf.-längl., länger als der K. 2. Grasige O.; Gesenke der Sudeten, Lauenburg, Ostpreussen, südl. Tyrol. Jul.--Septbr. S. longifolia Fries.

b. Der K. an der Basis kurz-trichterf. L'Arbrea St. Hil.

10. S. uliginos a Murray. St. ausgebreitet, 4eckig, kahl; $B$. sitzend, längl.-lanzettl., kahl, an der Basis gewimpert; R. gabelig; DeckB. trockenhäutig, am Rande kahl; KB. 3nervig; Blb. 2th., kưrzer als der K.; Kapsel eyf., ungefähr so lang als der K. $\odot$. Sumpfige Wiesen, Ufer. Jun. Jul. S. graminea $\gamma$. I. S. Alsine Reichard. S. aquatica Poll. Var. grösser u. kleiner u. mit gesättigter-grünen B. u. ohne Blb., Varietas apetala.

11. S. crasifolia Ehrh. St. ausgchreitet od. aufrecht, 4eckig, kahl, zuletzt obelwärts rispig; B. sitzend, längl.-lanzettl., ganz kahl; Bthstiele einzeln, gabelst.; die Deck $B$. krautig; KB. nervenlos, getrocknet an der Basis 3nervig; Blb. 2th. u. nebst der Kapsel länger als der K. 24? Auf feuchten Wiesen, auf torfhaltigem Boden, v. Westph. deh das nördl. Geb. Jul. Aug.

\section{MOENCHIA Ehrh. Mönchie.}

1. M. ere cta Fl. d. Wett. St. meist 2bth.; Blb. um ein Drittel kürzer als der K.; Gf. zurückgekrïmmt, während des Blühens um die Hälfte kiirzer als der Fruchtkn.; Bth. 5männig. ○. Auf Triften u. Haiden; zerstr. deh das Geb. Apr. Mai. Sagina erecta L. Blb. weiss, wie bei der folgenden.

2. M. mantic a Bartling. St. gabelig, 3-vielbth.; Blb. doppelt so lang als der $K$.; Gf. gerade, während des Blühens doppelt 
so lang als der Fruchtkn.; Bth. 8-10männig, ○. Auf Grasplätzen; Krain, siidl. Tyr., Veltlin u. C. Tessin. Mai. Jun. Cerastium manticum L. Malachium manticum Rchb. K. syn. ed. 1.

14. MÁLACHIUM Fries. Weichlzraut.

1. M. aquaticum Fries. St. gestreckt u. kletternd, an der Basis wurzelnd; $B$. herz- $\epsilon y f$., zugespitzt, sitzend, die der nichtblühenden St. gestielt; Bstiel ungefähr so lang als das B.; R. gabelig, spreitzend, drüsig-haarig; DeckB. krautig; Blb. 2th. 2. Feuchtes Gebüsch, Ufer, Gräben. Juu.-Aug. Cerastium aquaticum. L. Blb. weiss.

\section{CERASTIUMI L. Hornkraut.}

1. Rotte. Orthodon Ser. Kapsel an der Spitze mehr od. weniger aufwärts-gekriimmt, Zähne gerade, am Rande zurückgerollt.

§. 1. W. einfach, jährig, od. 2jährig; die St. aufrecht od. aufstrebend, seltener an der Basis wurzelnd; perennirende Stämmchen fehlend.

a. Blb. so lang als der K., od. kürzer als derselbe.

1. C. glomeratum Thuillier. St. aufrecht od. aufstrebend; B. rundl. od. oval, die unteren in den Bstiel verschmälert; Aeste der R. geknäueIt; DeckB. sämmtl. krautig u. nebst dem $K$. an der Spitze bärtig; die fruchttrag. Bthstielchen so lang als der $K . u$. kürzer; Blb. ungefähr so lang als der K. $\odot$. Kultiv. etwas feuchte O., Ufer, Gräben. Mai-Aug. C. ovale Pers. C. vulgatum des Linn. Herbar. u. Sm. Var. $\alpha$. glandulosum: drüsenhaarig - $\beta$. eglandulosum: Haare drüsenlos. $-\gamma$. apetalum: ohne Blb. Bl. weiss, wie an den folgenden.

2. C. brachypetalum Desportes. St. aufrecht od. aufstrebend; B. längl. u. oval, die unteren in den Bstiel verschmälert; die oberen Aestchen der R. gehäuft; DeckB. sämmtl. krautig u. nebst dem K. an der Spitze bärtig; dic fruchttrag. Bthstielchen 2- od. 3 mal so lang als der $K$.; Blb. ungefähr so lang als der K., od. kürzer. ○. Trockene Hügel, gebirgige, unkultiv. O. Mai. Jun. C. strigosum Fries. Var. mit u. ohne Drüsenhaare.

3. C. semidecandrum L. St. aufrecht od. aufstrebend; B. längl. u. oval, die unteren in den Bstiel verschmälert; die oberen Aestchen der R. gehäuft; die DeckB. sämmtl. nebst den $K B$. halbtrockenhäutig, an der Spitze kahl, ausgebissen-gezähnelt; die fruchttrag. Bthstielchen 2- od. 3mal länger als der K., hinabgeschlagen; Blb. fast so lang als der K., od. kürzer. $\odot$. Brachäcker, Haiden, sonnige Hügel. März-Mai. Var. mit u. ohne Drïsenhaare, u. $\beta$. ma- 
cilentum, ganz kahl: C. macilentum Aspegren; bei Giistrow im Mecklenb.

4. C. glutinos u m Fries. St. aufrecht od. aufstrebend; B. längl. u. oval, die unteren in den Bstiel verschmälert; die oberen Aestchen der R. gehäuft; die unteren DeckB. krautig; die oheren nebst den K. am Rande trockenhäutig, an der Spitzekahl, mit einem krautigen, beinahe auslaufenden Streifen; die fruchttrag. Bthstielehen 2- od. 3mal länger als der K., wagerecht abstehend; Blb. ungefähr so lang als der K. (.) Brachäcker, trockene Weiden. Apr. Mai. C. pumilum M. et K. D. Flor., C. Grenieri Sehultz. exs., C. alsinoides Grenier. monogr. Var. $\alpha$. lactius: heller griin, die DeckB., anch die untersten, an der Spitze schmal-häutig-berandet: C. pumilum $\alpha$. K. syn. ed. 1., C. Grenieri $\beta$. pallens Schultz. exs., C. alsinoides Sehultz. Jahrb. d. pharm. d. Pfalz, ob Loiseleur's - $\beta$. obscurum: dunkler griin, die unteren DeckB. krautig, die oberen an der Spitze sehr schmal-häutig-berandet: C. pumilun $\beta$. K. syn. ed. 1., C. obscurum Chaubart, C. Lensii var. obseurum Schultz. Jahrb., C. Grenieri var. obscurum Schultz. exs.

5. C. triviale Link. St. aufstrebend, die seitenst. an der Basis wurzelnd; B. längl. od. cyf., die untersten in den Bstiel verschmälert; die oberen Aeste der R. gehäuft; DeckB. nebst den $K$. am Rande trockenhäutig, an der Spitze lahl; die fruchttrag. Bthstielchen 2- od. 3mal so lang als der K.; Blb. ungefähr so lang als der K. ๑. u. $\odot$. Kultiv. O., Wiesen, Ufer. Mai-Herbst. C. viscosum Sm. C. vulgatum Wahlenb. Var. mit u. ohne Driisenhaare, u. $\beta$. holosteoides: fist kahl: C. holosteoides Fries. Auf den A. mit breiteren B., Varietas alpina. Diese Variet. untersch. sich v. C. alpinum: die R. vielbth., die oberen Aestchen gehäuft; die Haare straffer, kiirzer; die St. höher, die unfruchtbaren Rosetten fehlend u. die Blb. so lang als der K.

b. Blb. noch $1 \mathrm{mal}$ so lang als der K.

6. C. campanulatum Viv. St. aufrecht od. aufstrebend, nicht wurzelnd; $B$. längl., die untersten in den Bstiel verschmälert, fast spatelig; die R. reichbth., zuletzt zerstreutbth.; dic unteren DeckB. krautig, die oberen schmal-trockenhäutig-berandet; die fruchttrag. Bthstielchen 2 mal länger als der K.; Blb. noch einmal so lang als der K. ๑. u. ... Aecker, Hügel; Wallis, nach Schleich. und Rchb. Apr. Mai. C. praecox Tenor.

7. C. sylvaticum W. K. St. aufstrebend, die seitenst. an der Basis wurzelnd; die untersten B. eyf., spitz, in einen Bstiel plötzlich zsgezogen, die mittleren längl., die oberen lanzettl., verschmälertzugespitzt; die R. reichbth., zuletzt zerstreutbth.; die unteren DeckB. krautig, die oberen schmal-trockenhäutig-berandet; die fruchttrag. Bthstielchen verlängert; Blb. noch 1 mal so lang als der $K$. $\odot$. 
Feuchte Wälder; Mauerbach bei Wien, Marburg in Stmk., oberes Isonzothal, Triest, Valsugana in Suidtyr. Jun.-Aug. C. repens des Linn. Herbar. nach Gusson.

§. 2. Die W. vielköpfig; Stämmchen, obgleich schlank, doch perennirend $u$. jährlich blüthentragende u. nichtblühende St. treibend.

8. C. la tifolium L. Stämmchen rasiz, gestreckt; St. aufstrebend, die nicht blühenden dicht-rasig, die bliithentrag. ziemlich aufrecht, 1-3bth.; B. elliptisch od. lanzettl.; DeckB. krautig; Bthstielchen nach dem Verblühen eingeknickt; Blb. fast noch 1 mal so lang als der K. 24. Höhere A. Jul. Aug. Die nicht blühenden Stämmchen so lang als die blühenden, nicht rosettig; Haare des St. u. der B. dicklich, deutlich gegliedert, drüsentragend, mit wenigen längeren, 1 fachen untermischt. Var. der St. kurz, B. elliptisch-längl.: C. glaciale Gaud.; der St. kurz, B. lanzettl.: C. pedunculatum Gaud.

9. C. alpinum L. Stämmchen kriechend, die nicht blühenden St. rosettig, die blïhenden aufstrebend, 1-5bth.; B. elliptisch od. lanzettl.; DeckB. krautig, an der Spitze schmal-trockenhäutig; Bthstiele nach dem Verblühen schief-abstehend; Blb. fast noch $1 \mathrm{mal}$ so lang als der K. 24. Zerstreut dch d. A. u. Babia Gora in Schles., Dachauer Moos in Oberbaiern. Mai-Aug. Untersch. v. C. arvense dch die rosettigen nicht blühenden Stämmchen, den armblüthigen St., die nach dem Verblühen eingeknickten Bthstiele, den an die Blbkr. angedrückten K. u. die längeren Haare; v. C. latifolium dch die rosettigen Stämmchen, die längeren Haare $u$. die oberen, häutig-berandeten DeckB. Var. $\beta$. glanduliferum: St. oberwärts nebst d. Bthstielen mit drüsentrag. Haaren bedeckt. $-\gamma$. lanatum: mit wolligen Haaren dicht bedeckt $u$. v. weitem grau. C. lanatum Lam. C. alpinum Wulf. Diese Variet. kommt vor $\delta$. glutinosum: der St. oberwärts nebst den Bthstielen v. drüsentrag. Haaren sehr klebrig. C. Soleirolii Sering. In Schweden kommt es fast ganz kahl vor: Variet. glabrata, C. glabratum Hartm.

10. C. ovatum Hoppe. Stämmchen gestreckt, am Grunde wurzelnd; St. rasig, die blühenden aufstrebend, 6-9bth.; die untern B. lanzettl., die obern aus eyf. Basis verschmälert-spitz; DeckB. mit trockenhäutigem, breitem, kahlem, an der Basis etwas wimperigem Rande; Bthstiele kurzh.-flaumig, nach dem Verblühen schief-abstehend; Blb. noch $1 \mathrm{mal}$ so lang als der K. 24. Bachlsies der höheren A.; Krain, Kärnth., Stmk. Jun.-Aug. C. carinthiacum Vest.

11. C. arvense L. Stämmchen gestreckt, an der Basis wurzelnd; St. aufstrebend, die nicht blühenden dicht-rasig, die blühenden aufrecht, 7-15bth.; B. lineal.-Ianzettl. od. lineal.; DeckB. breittrockerhäutig-berandet; Bthstiele kurzh.-flaumig, nach dem Verblühen aufrecht, mit nickendem $K$.; Blb. noch 1 mal so lang als der K. 24. Felder, sonnige Hügel, Wege bis in die höchsten A. hinauf. 
Apr. Mai, in den A. später. Var. $\beta$. strictum: St. u. B. kahl, letztere an der Basis gewimpert: C. strictum Haencke. $-\gamma$. suffruticosum: B. aufrecht, steifer; DeckB. mit einem trockenhäutigen, breiteren Rande umzogen, $u$. nur an der Basis gewimpert, od. am Rande fast ganz kahl: C. suffruticosum L. Dieses im südl. Tyrol.

12. C. tomentosum L. Stämmchen gestreckt, an der Basis wurzelnd; St. aufstrebend $u$. nebst den $B$. filzig, die nicht blïhenden dicht-rasig, die blühenden aufrecht, $7-15$ bth.; B. lineal.-lanzettl. od. lineal.; DeckB. breit-trockenhäutig-berandet; Bthstiele wollig-filzig, nach dem Verbliilien aufrecht, mit nickendem K.; Blb. noch 1 mal so lang als der K.; Kapselzähne vor-restreckt, am Rande zurückgebogen. 7. Sonnige O., Mauern; Lüttich, Waadt u. Wallis, ob verwildert? Mai. Jun. C. repens Koch syn. ed. 1.

II. Rotte. Strephod on Ser. bei DC. Kapsel gerade, mit zirkelf.-zurückgerollten Zähnen.

13. C. grandiflorum W. K. Stämmchen gestreckt, an der Basis wurzelnd; St. aufstrebend, knotig-gegliedert, die nicht blühenden dicht-rasig, die blühenden aufrecht, 7-15bth.; B. schmil-lineal., etwas fleischig, unterseits convex, getrocknet am Rande zurückgeschlagen; Zähne der geraden Kapsel zirkelf.-zurïckgerollt. 24. Auf dem hohen Schwab unfern Mariazell in Oberstmk., nach Mïller. Jun. Jul.

\section{Ordng. ELATINEEN. Cambessedes.}

\section{ELATÍNE L. Tännel.}

1. E. Hydropiper L. (mit Ausschluss des Syn. Vaillants u. der Variet. $\beta$.) B. gegenst., kürzer als der Bstiel; Bth. sitzend, od. sehr kurz-gestielt; Bl. 4blätlerig, 8männig; S. halbzirkelf.-gekrümmt. $\odot$. Ueberschwemmte, feuchte O., Ufer. Jun.-Aug. BIb. rosenroth od. weiss, wie bei den beiden folgend. E. Schkuhriana Drev. u. Hayn. Bth. völlig sitzend.

2. E. tria ndra Schk. B. gegenst., länger als der Bstiel; Bth. sitzend; Bl. 3blälterig, 3männig; S. seicht-gekrümmt. (- Am Rande der Sümpfe u. Fischteiche; Lausitz, Stmk., Wittenberg, Carlsruhe u. Regensbg. Jun.-Aug. K. 2sp.

3. E. hexandra DC. B. gegenst., länger als der Bstiel; Bth. gestielt; Bthstiel so lang als die Frucht od. länger; Bl. 3blättrig, 6 männig; S. seicht - gekrümmt. $\odot$. An ähnlichen $O$. hin u. wieder. Jun.-Aug. E. tripetala Sm. E. Hydropiper L. var. $\beta$. K. 3sp. E. major A. Braun, im Geb. noch nicht beobachtet, untersch. sicl deh 8männige, gestielte Bth., 4 blätterige Bl., Bthstiele von der dreifachen Länge der Frucht u. deh B. u. S. der E. hexandra: E. Hydropiper DC.

4. E. Alsinastrum L. B. quirlig. $\odot$ ?. In Seen, Fischteichen, Sümpfen; zerstr. dch das Geb. Jul. Aug. Blb. weiss. 


\section{Ordng. LINEEN. DC.}

1. LINUM L. Flachs.

§. 1. KB. am Rande drüsig-gewimpert.

a. Blb. gelb.

1. L. galli cum L. KB. lanzettl., drüsig-gewimpert, in eine am Rande etwas rauhe Spitze zugespitzt-verschmälert, anderthalb mal so lang als die Kapsel; Aestchen der R. ganz kahl; B. lineal.-lanzettl., am Randle etwas rauh; die fruchttrag. Bthstiele so lang als der K. u. länger. $\odot$. Brachäcker u. unkultiv. O.; Triest, Fiume. Jun. Jul. L. aureum WK.

2. L. corymbulosum Rehb. KB. lanzettl., drüsig-gewimpert, in eine am Rande rauhe Spitze zugespitzt-verschmälert, noch $1 \mathrm{mal}$ so lang als die Kapsel; die blattwinkelst. Aestchen an der Basis einwärts flaumig; B. lineal.-lanzettl., am Rande rauh; die fruchttrag. Bthstielchen so lang als der $\mathbf{K}$. u. länger. $\odot$. Trockene Hügel; Triest, Fiume. Jun. Jul. L. aureum DC.

3. L. strictum L. KB. lanzettl., drüsig-gewimpert, in eine an Rande rauhe Spitze zugespitzt-verschmälert, noch $1 \mathrm{mal}$ so lang als die Kapsel; B. lineal.-lanzettl., am Rande sehr rauh; die fruchttrag. Bthstielchen viel kürzer als der $K$. $\odot$. Küste des Meeres in Istrien. Jun. Jul.

4. L. nodiflor um L. KB. verlängert-lineal., an der Spitze kurzzugespitzt, begrannt, am Rande feingesägt-rauh, drüsenlos, 2-3mal länger als die Kapsel; B. am Rande sehr rauh, die unteren vkteylanzettf., sehr stumpf, die oberen lanzettl., spitz; fruchttragende Bthstiele viel kürzer als der $K$. $\odot$. Brachäelrer, Weinberge; auf dem Strammare bei Triest, Istrien, Cherso. Jun. Jul. L. liburnicum Scop.

5. L. m a ritim u m L. KB. eyf., kurz-zugespitzt, drisig-gewimpert, v. der Länge der Kapsel; B. kahl, 3nervig, die unteren gegenst., elliptisch, die oberen wechselst., lanzettl.; die fruchtrag. Bthstiele mehrmals länger als der K. 24. Kïste des Meeres bei Triest 11. Monfalcone. Aug. Sept.

6. L. fl a v u m L. $K B$. lanzettl., zugespitzt, drüsig-gewimpert, länger als die Kapsel; B. kahl, 3nervig, am Rande glatt, an der Basis bëiderseits v. einer Drüse gestützt, die oberen lanzettl., spitz, die unteren vktey-lanzettf., kurz-zugespitzt; St. obervärts scharfkantig. 2. Bergwiesen, trockene Hügel, Krain, Stmk., Oestr., Mähren, Böhm., bei Ulm, Jul. Aug.

b. Blb. blau, rosenroth od. weisslieh.

7. I. hirsutum L. KB. lanzettl., zugespitzt, länger als die Kapsel ; B. ey-lanzettf., oder lanzettf., 5nervig u. nebst den K. zot- 
tig ; K. u. DeckB. drïsig-gewimpert; St. filzig-zottig. 24. Wiesen, unkultiv. Hügel ; Unteröstr., Mähr. Juı. Jul. Blb. lila, an der Basis weisslich.

8. L. viscosum L. ǨB. lanzettl., zugespitzt, länger als die Kapsel; B. lanzettl., 3-5nervig, zottig; die oberen DeckB. u. K. drüsig-gewimpert, fast kahl; St. von weit abstelienden Haaren zottig. 4. Wiesen, Haiden; Oberbayern, Salzbg., Südtyrol, Kärnth., Krain bis nach Oestr. Jun. Jul. Blb. hellrosenroth, an der Basis mit violetten Adern.

9. L. tenuifolium L. KB. elliptisch, an der Spitze pfriemlich, drüsig-gewimpert, wenig länger als die Kapsel; B. lineal., zugespitzt, am Rande wimperig-raul u. nebst dem St. kahl. 24. Hïgel, trockene, steinige 0 .; zerstr. dch die Schwz. u. das mittlere u. südI. Geb. Jun. Jul. Blb. hell-röthl.-lila.

§. 2. KB. am Rande driisenlos.

10. L. narbonense L. KB. lanzettl., zugespitzt, drüsenlos, noch 1 mal so lang als die Kapsel; B. lineal.,lanzettl., kahl, am Rande etwas rauh; St. zahlreich. 24. Bergwiesen, grasige O.; Krain, Littor. Jun. Jul. Blb. himmelblau.

11. L. angustifolium Hudson. KB. eyf., zugespitzt, drüsenlos, fast so lang als die Kapsel, die inneren schwach-wimperig; B. lineal.-lanzettl., kahl; St. zahlreich, ausgebreitet. 24. Steinige Hiigel; südl. Krain, Littor., Istrieı. Jun. Jul. L. tenuifolium L. Spec.

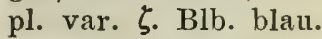

12. L. usitatissimum L. KB. eyf., zugespitzt, klein-gewimpert, drüsenlos, fast so lang als die Kapsel; B. lanzettl., kahl; der St. einzeln, aufrecht. $\odot$. Kultiv. u. unter der Saat hie u. da gleichsam wild. Jul. Aug. Blb. blau.

13. L. perenne L. KB. eyf., am Rande drüsenlos u. kahl, kürzer als die Kapsel, die inneren selhr stumpf; Blb. breit-vkteyf., mit dem ganzen Seitenrande sich deckend, der Nagel längl--3eckig; Kapsel rundl.-eyf.; die hlüthen- $u$. fruchttrag. Bthstiele steif-aufrecht; B. lineal.-lanzettl., kahl; St. zahlreich. 24. Sonnige Hïgel, sandige Wälder; Rheinfläche zw. Benzheim Il. Darmstadt, Franlfurt am M. hinter dem Schwengelsbrunnen am Wege, der nach der kleinen Sau* stiege führt, links im Walde. Jun. Jul. L. anstriacum Pollich. Blb. hell-blau. St. 2-3' hoch. Das Glied des Bthstieles unter dem K. ungefähr noch einmal so lang als scine Breite am Gelenke. Bth. mit starkem Honiggeruch.

14. L. a lpin um Jacq. KB. eyf., am Rande drüsenlos und kahl, um die Hälfte kürzer als die Kapsel, die inneren sehr stumpf; $B l b$. vkteyf., v. der Mitte an auseinandertretend, der Nagel längl.-3eckig; Kapsel oval; die blüthen- u. fruchttrag. Bthstiele steif-aufrecht; $\mathbf{B}$. lineal.-lanzettl., kahl; St. zahlreich. 4. Triften der A. u. VorA. Var. 
及. Triften u. Wiesen niederer Gegenden, bei München, Regensbg. westl. Schwz. Jun. Jul. Var. St. 3-6" lang, oft gestreckt, u. $\beta$. St. $1^{\prime}$ hoch od. etwas höher, aufstrebend od. aufrecht: L. montanum Schleich. L laeve Scop. - Blb. satter-blau. Glied des Bthstieles unter dem K. ungefähr 4 mal so lang als seine Breite am Gelenke. Bth. nicht riechend.

15. L. austriacum L. KB. eyf., am Rande drüsenlos $u$. kahl, kürzer als die Kapsel, die inneren sehr stumpf; Blb. rundl. vkteyf., mit dem ganzen Seitenrande sich deckend; der Nagel 3eckig, so breit als lang; Kapsel kugelig, die abgeblüheten Bthstiele bogenf. nach einer Seite hinabhängend; B. lineal.-lanzettl., kahl; St. zahlreich. 4. Unkultiv. O.; Littor., Oestr., Mähr., Böhm. Jun. Jul. Blb. azurblau.

16. L. catharticum L. KB. elliptisch, zugespitzt, drüsig-gewimpert, ungefähr so lang als die Kapsel; $B$. kahl, am Rande etwas rauh, die unteren vkteyf., die oberen lanzettl., sämmtl. gegenst. $\odot$. Wiesen u. Triften. Jul. Aug. Bth. weiss.

2. RADÍOLA Gmel. Zwergflachs.

1. R. linoides Gmel. (- Sandige feuchte O. Jul. Aug. R. millegrana Sm. Linum Radiola L. Blb. weiss.

\section{Ordng. MALVACEEN. Brown.}

\section{MALVA L. Malve.}

1. M. Alcea L. St. aufrecht; die wurzelst. $B$. herzf.-rundl., gelappt, dic stengelst. handf.-5th., Zpfl. fast rautenf., 3sp., eingeschnitten-gezähnt od. fiedersp.; Bthstielchen nebst den $\mathbf{K}$. filzig-rauhh., Haare büschelig; Klappen kahl, fein-quer-runzelig, auf dem Rücken gekielt, am Rande abgerundet. 2. Sonnige Hügel, unkultiv. O.; zerstr. dch das Geb. Jul. Aug. Bl. rosenroth; Kraut geruchlos. Var. $\beta$. multidentata: Bzpfl. häufiger gezähnt: M. italica Pollini, M. decumbens Host. - $\gamma \cdot$ fastigiata: B. weniger eingeschnitten, die oberen stengelst. 3 sp., die mittleren 5sp., Zpfl. längl., ungleich-gezähnt: M. fastigiata Cav., M. Morenii Pollin.

2. M. moschata L. St. aufrecht; die wurzelst. B. herzf.-rundl., gelappt, die stengelst. 5th., Zpfl. fiedersp., eingeschnitten od. doppelt fiedersp.; Bthstielchen nebst den K. rauhh., Haare meist einfach; Klappen dicht-rauhh., glatt, am Rande abgerundet. 2. Unkultiv. Hügel, stcinige O.; zerstr. dch das Geb. Jul.-Herbst. Blb. rosenroth. Das Kraut welk nach Moschus riechend.

3. M. sylvestris L. Der St. aufrecht od. aufstrebend; Bstiele nebst den Bthsticlen rauhh.; B.5-7lappig; Bthstiele gehäuft, nach dem Verblühen aufrecht; Blb. viel länger als der $K$., tief-ausgerandet, 
am Nagel dicht-gebartet; die äusseren KB. ellipt.-längl.; Klappen berandet, grubig-runzelig. ๑. Zäune, Sclutthaufen. Jul. Aug. Blb. rosenroth mit Purpurstreifen. - Malva mauritiana L., hie u. da auf Schutthaufen, hat gesättigtere, fast blutrothe, breitere, weniger tiefausgerandete Blb., nur auf der oberen Fläche flaumige Bstiele 1. kahle Bthstiele, kaum v. der Länge der entfalteten Bth.

4. M. ni ca eensis Allioni. St. niederliegend, aufstrebend; B. herzf.-rundl., 5-7lappig; Bthstiele gehäuft, nach dem Verblühen aufrecht; $\boldsymbol{B} l b$. noch einmal so lang als der $K$., tief-ausgerandet, am Nagel schwach-gebartet; die äusseren KB. eyf.; Klappen berandet, grubig-runzelig. $\odot$. Wege, Schutt; Istrien. Jul. Aug. Blb. bleichrosenroth.

5. M. vulgar is Fries. St. gestreckt, aufstrebend; B. herzf.rundl., 5-7lappig; Bthstiele gehäuft, nach dem Verblühen abwärtsgeneigt, mit aufrechtem K.; Blb. 2-oder 3 mal so lang als d. K., tief-ausgerandet; die äussern KB. lineal.-lanzettl.; Klappen am Rande abgerundet, glatt od. schwach-runzelig. $\odot$. Kultiv. O., Wege, Schutt. Jun.-Herbst. Bl. hell-rosenroth. M. rotundifolia der meisten Deutschen r. Franzosen. M. neglecta Wallr. Blb. hellrosenroth.

6. M. borealis Wallmann. St. gestreckt, aufstrebend; B. herzf.rundl., 5-7lappig; Bthstiele gehäuft, nach dem Verblühen abwärtsgentigt, mit aufrechtem K.; Blb. so lang als der K., schwach-ausgerandet; d. äusseren KB. lineal.-lanzettl.; Klappen berandet, grubigrurzelig. ○. Kultiv. O., Wege, Schutt; nördl. Geb., sodann Schles., Thüring. Jun.-Herbst. M. rotundifolia L., nach Fries. Bl. hellrosenroth.

\section{ALTHÁEA L. Eibisch.}

1. A. officinalis L. B. auf beiden Seiten weich-filzig, ungleich-gekerbt, herz- od. eyf., die unteren 5lappig, die oberen 3lappig; Bthstiele blattwinkelst., reichbtl., viel kürzer als das B. 4 . Feuchte Wiesen, salzhaltige O., Seestrand. Jul. Aug. Bth. röthlichweiss.

2. A. cannabina L. B. filzig-rauh, ungleich-gesägt-gezähnt, die unteren handf., die oberen fingerig, die obersten 3 zählig; Bthstiele länger als das B., 1-2luth.; die inneren Zpfl. des K. eyf., zugespitzt. 4. Gräben, Wiesen; Unteröstr., Littor. Jul. Aug. Blb. rosenrotl, mit einem purpurnen Nagel.

3. A. hirsuta L. B. gekerbt, von wagerecht-abstehenden Haaren steifh., die unteren nierenf., 5lappig, die mittleren handf., die oberen tief-3sp.; Bthstiele 1 bth., länger als das B.; Zpfl. des K. verlängertlanzettl. $\odot$. Aecker, Weinberge; sehr zerstr. im südl. u. mittl. Geb. Jul. Aug. Blb. rosenroth.

4. A. pallida W. K. St. U. B. rauhh., die Haare büschelig; 
B. gekerbt, die unteren herzf.-rundl., 5lappig, die oberen 3lappig; Bthstiele einbth., einzeln od. mehrere, blattwinkelst., die oberen kürzer als der $K$., in einer lockeren Aehre; der äussere K. ungefähr so lang als der innere; Blb. ausgerandet-2lappig, länger als breit. $\odot$. Unkultiv. O., Wiesen; Gegend v. Wien. Jul. Aug. Blb. lila, an der Basis schwefelgelb, v. einander abstehend und tief-ausgerandet; an A. rosea sind sie breiter, weniger ausgerandet $u$. berühren sich mit den Rändern.

\section{LAVATÉRA L. Lavatére.}

1. L. thu ringi a c a L. St. krautig, filzig; B. dünn-filzig, die unteren eckig-gelappt, die oberen 3lappig, der mittlere Lappen länger ; Bthstiele einzeln, länger als der Bstiel; Blb. 2lappig. 2. Unkultiv. O., Weinberge; Littor., Unteröstr., Böhm., Schles., Sachs., Höxter auf der Grenze v. Westph., Thïring. Jul. Aug. Blb. blass-rosenroth.

\section{HIBISCUS L. Ibisch.}

1. H. Trionum L. B. gezähnt, die unteren fast ungeth., die oberen 3th., Zpfl. lanzettl., der mittlere sehr lang; K. aufgeblasen, läutig, nervig-aderig. $\odot$. Kultiv. O. u. an Wegen; südl. Tyrol, Stmk., Unteröstr., Littor. Jul. Aug. Blb. sclıwefelgelb, an der Basis dunkelblutroth.

\section{ABUTILON Gärtner. Abutilon.}

1. A. Avicennae Gärtner. B. rundl.-herzf., zugespitzt, gekerbt, filzig; Bthstiele kürzer als der Bstiel ; Früchtchen ungefähr 15, abgestutzt-2schnäbelig, rauhh. $\odot$. Feuchte O.; Veglia. Jul. Aug. Sida Abutilon L.

\section{Ordng. TILIACEEN. Juss.}

\section{TILIA L. Linde.}

1. T. gran difolia Ehrh. B. schief-rundl.-herzf, zugespitzt, unterseits kurzh., u. in den Achseln der Adern gebartet; Ebensträusse 2-3bth.; NebenkronB. fehlend; Lappen der Narbe aufrecht; Kapsel 5rippig. ち. Laubwälder bis in die VorA. Ende Jun. u. Anfang Jul. T. platyphyllos Scop. T. europaea $\beta, \delta, \varepsilon$, L. Bl. weiss, wie an folgender.

2. T. parvifoli a Ehrh. B. schief-rundl.-herzf., zugespitzt, auf beiden Seiten kahl, unterseits meergrün $u$. in den Achseln der Adern gebartet; Ebensträusse 5-7bth.; NebenkronB. fehlend; Lappen der Narbe zuletzt wagerecht-auseinanderfahrend; Kapsel undeutlich 4- 
5kantig. Ђ. Laubwälder, nicht bis in die VorA. hinauf. Jul., 14 Tage später als die vorhergehende. T. ulmifolia Scop. T. microphylla Willd. T. cordata Mill. T. europaea $\gamma$. L. T. vulgaris Hayn. Var. Btl. 7-11 im Strausse, etwas kleiner, B. kleiner, Bthstiele u. Bstiele roth iiberlaufen. T. parvifolia Hayn.

\section{Ordng. HYPERICINEEN. DC.}

\section{ANDROSAEMUM All. Grundheil.}

1. A. officinale All. 24. Feuchte O.; im C. Tessin, Sitten in Wallis. Jun. Jul. Hypericum Androsaemum L. Bl. gelb.

\section{HYPÉRICUM L. Hartheu.}

I. Rotte. Perforaria DC. Stbf. an der Basis in 3 Biindel verwachsen; Bündel vielmännig.

a. KB. ganzrandig, am Rande weder fransig, noch drüsig-gewimpert.

1. H. perforatum L. St. aufrecht, 2schneidig; B. oval-längl., durchscheinend-punktirt; Bth. ebensträussig; KB. lanzettl., sehr spitz, ganzrandig, noch einmal so lang als der Fruchtkn.; Stbgf. 50-60. 4. Trockene Wiesen, unkultiv. O. Jul. Aug. Bl. gelb, wie bei den folgenden. Var. $\beta$. latifolium: B. bei $1^{\prime \prime}$ Länge $1 / 2^{\prime \prime}$ breit, K. breiter lanzettl.: H. commutatum Nolt., H. medium Peterm.

2. H. veronense Schrank. St. aufrecht od. aufstrebend, zweischneidig; B. lineal.-längl., durchscheinend-punktirt; Bth. rispig, R. eyf.; KB. lanzettl., spitz, ganzrandig, so lang als der Fruchtkn.; Stbgf. 50-60. 4. Trockene, sonnige 0.; Istr., siidl. Tyrol, Waadt. Jul. Aug.

3. H. h umifusum L. St. gestreckt, fast 2schneidig, fädl., B. oval-längl., durchscheinend-punktirt; $K B$. längl., stumpf, stachelspitzig; ganzrandig, noch einmal so lang als d. Fruchtkn.; Stbgf. 15-20. 4. Haiden, Triften. Jun.-Herbst. Auf Aeckern oft niedriger, ziemlich aufrecht, armbth., 2jährig, u. die Bth. lie u. da 4blätterig: $H$. humifusum $\beta$. Liottardi Vill.

4. H. quadrangulum L. St. aufrecht, 4 kantig; B. oval, zerstreut-durchscheinend-punktirt od. unpunktirt; $K B$. elliptisch, stumpf, ganzrandig, ungefähr so lang als der Fruchtkn. 24. Waldtriften, Wiesen, Ufer. Jul. Aug. H. delphinense Vill. H. dubium Leers.

5. H. tetra pterum Fries. St. aufrecht, 4 kantig, Kanten etwas geflügelt; B. oval, dicht-durchscheinend-punktirt; $K B$. lanzettl., zugespitzt, ganzrandig. 2. Feuchte Wieseu, Gräben. Jul. Aug. H. quadrangulare Smith u. fast aller Aut.

b. KB. am Rande drüsig-kleingesägt, od. gefranst. 
6. H. barb a tum Jacquin. Der St. aufrecht, stielrund; B. längl.lanzettl., nach vorne versclimälert, unterseits graugrün u. am Rande etwas entfernt- $u$. oft auf dem Mittelfelde zerstreut-kohlschwarz-punktirt, durchscheinende Punkte keine od. wenige; DeckB. schmal-lanzettl., nebst den KB. borstl.-gefranst, die Fransen 2- u. mehrmal länger als der Querdurchmesser des DeckB., an der Spitze schwachkeulig; die S. der Länge nach wellig-gestreift. 2. Waldwiesen, Mauerbach bei Wien, Marburg in Stmk. Mai Jun.

1: 7. H. Richeri Villars. St. aufrecht, oberwärts zweischneidig; B. eyf., unterseits netzig-aderig, am Rande dicht- u. klein-kohlschwarzpunktirt, auf dem Mittelfelde ohne durchscheinende Punkte; DeckB. eyf., nebst den KB. dicht-ungleich-borstl.-fransig, die Fransen an der Spitze schwach-keulig, die längeren so lang als der Querdurchmesser $\operatorname{der}$ DeckB.; die $S$. der Länge nach wellig-gestreift. 24. Hohe A.; Jura, Schneeberg in Krain. Jul. Aug. H. fimbriatum Lam.

8. H. elegans Stephan. St. aufrecht, fast 2schneidig; B. aús herzf. Basis lanzettl.- od. eyf., am Rande kohlschwarz-, auf dem Mittelfelde durchscheinend-punktirt; $K B$. lanzettl., spitz, gefranst, Fransen kürzer als der Querdurchmesser der KB., "an der Spitze fein-drüsig; S. feinpunktirt. 24. Gebirgige, sonnige O., Weinberge; bei Halle, Erfurt, Hildesheim, in Böhm., Mähr. Jun. Jul. H. Kohlianum Sprengel.

9. H. pulchrum L. St. aufrecht, stielrund, kahl; B. herz-eyf., sitzend, kahl, unterseits graugrün, durchscheinend-punktirt; KB. vktєyf., sehr stumpf, drüsig-gewimpert, die Drüsen sehr kurzgestielt; $S$. sehr fein-punktirt. 2. Gebirgswälder, Haiden; zerstr. dch das Geb. Jul.-Sept.

10. H. mont a num L. St. aufrecht, stielrund, kahl; B. herz-eyf., sitzend, die oberen durchscheinend-punktirt, unterseits etwas rauh; KB. lanzettl., spitz, drüsig-gewimpert, die Drüsen kugelig, gestielt; S. feinpunktirt. 24. Wälder, Gebüsch. Jun.-Aug. Var. $\beta$. scabrum: B. unterseits rauh.

11. H. hirsutum L. St. aufrecht, stielrund; $B$. eyf. od. längl., kurzgestielt, durchscheinend-punktirt $u$. nebst dem St. rauhh.; KB. lanzettl., drüsig-gewimpert, die Drïsen sehr kurzgestielt; S. sammetig. 4. Wälder, Gebüsch. Jun.-Aug.

12. H. Coris L. St. halbstrauchig; B. zu 3 od. 4, lineal., stumpf, durchscheinend punktirt, am Rande zurückgerollt; KB. drüsig-gewimpert. Ђ. Felsige O.; ober Cei gegen das Joch la Breca, Rovoredo gegenüber $u$. auf dem Berge Wiggis im C. Glarus. Jul. Aug.

II. Rotte. Elodes. Stb. bis zur Mitte in 3 Bündel verwachsen; Bündel 5männig. Unterweibige Schuppen zwischen den Bündeln. 
13. H. elodes I. Die St. niederliegend u. aufstrebend, an d. Basis wurzelnd; $B$. rundl.-eyf., sitzend, durehscheinend-punktirt $u$. nebst dem St. rauhh.; KB. eyf., driisig-gewimpert, die Driisen gestielt; die R. armbth., zuletzt seiten- od. blattwinkelst.; S. der Länge nach gefurcht. 2. Sumpfige, torfhaltige O.; Markwald $z w$. Messel u. Roth bei Frankf. a. MI., v. Bomn bis Westphalen u. Hannover. Aug. Sept. Elodes palustris Spach.

\section{Ordng. ACERINEEN. DC.}

\section{ACER L. Ahorn.}

1. A. Ps e u doplát an us L. B. handf.-5lappig, unterseits matt u. meergrün, Lappen zugespitzt, ungleich-gekerbt-gesägt; $T$ r. hangend, verlängert, an der Basis zsgesetzt; die Fruehtkn. zottig; Flïgel etwas abstehend; das Stbg. der männI. Bth. noch $1 \mathrm{mal}$ so lang als die BI. 5. Gebirgswälder bis anf die VorA. Mai. Jun. Bth. grüin; Früchte zuletzt kahl.

2. A. opulifolium Vill. B. handf.-5lappig, unterseits matt u. meergrün, Lappen stumpf, gekerbt-gezähnt; Ebensträusse bald überhangend; Fruehtkn. ziemlich kahl, Flïgel etwas abstehend; Stbg: der männl. Bth. noch $1 \mathrm{mal}$ so lang als die Bl. ち. Wälder am Fusse der A.; Wallis, Waadt. März. Apr. A. Opalus Ait. A. Opulus DC. Bth. gelbgrün. Die jüngeren B. unterseits flaumig od. filzig, die äIteren kahl. Var. auch die älteren B. unters. filzig: A. obtusatum Kit. A. neapolitanum Ten.

3. A. platanoides L. B. handf.-5lappig, buchtig-3-5zähnig; Zähne verschmälert-haarspitzig; Ebensträusse aufrecht, an der Basis nebst den jüngeren B. zerstreut-driisig; Fruehtkn. kahl; Flügel weitauseinanderfahrend; Stbg. der männl. Bth. von der Iänge des $\mathrm{K}$. ち. Wälder der njedrigen Gbge. Apr. Mai. Bth. gelbgrün.

4. A. campestre L. B. handf.-5lappig, Zpfl. ganzrandig, längl., der mittlere stumpf-3lappig; Ebensträusse aufreeht; KB. nebst deu Blb. lineal., zottig; Stbg. der männl. Bth. so lang als die Bl.; die Flügel wagerecht-auseinanderfahrend. ち. Gebüsch, Wälder. Mai. Bth. dunkelgriin.

5. A. monspessulanum I. B. hardf.-3lappig, Lappen stumpf, ganzrandig od. etwas gesehweift; Ebensträusse hangend; KB. nebst den Blb. vkteyf., kahl; Stog. der mänul. Bth. noch 1 mal so lang als die Bl.; die Flügel vorwärtsgerichtet, etwas abstehend. 5 . Gebirgige, felsige $\mathrm{O}$; ; am Mittelrheine, Mosel- $\mathrm{u}$. Nahe-Gbge, Donnersberg in der Rheinpfalz, Litt. Apr. Bth. gelbgrün.

\section{Ordng. HIPPOCASTANEEN. DC.}

1. AESCULUS L. mit Ausschluss v. Arten, Rosskastanie. 
1. A. Hippocastanum L. Kapseln igelstachelig; Bth, 5blättrig. ђ. Ueberall kultivirt, aus Asien stammend. Mai.

\section{Ordng. AMPELIDEEN. Humb. Bonpl. u. Kunth.}

\section{AMPELOPSIS Michaux. Zaunrebe.}

1. A. hederacea Mich. B. 3-5zählig, kahl, Blättchen gestielt, eyf. od. längl., zugespitzt, stachelspitzig-gesägt. †. Unter Gebüsch; südl. Tyrol, verwildert, wie Vitis vinifera, aber' seltener, Facchini. Jul. Aug. Bl. grünl. Hedera quinquefolia L.

2. VITIS L. Weinstock.

1. V. vinifera L. B. herzf.-rundl., 5lappig, grobgezälnt. ち. In wärmeren Gegenden kultiv., u. in den Wäldern an der Donau u. dem Rheine hie u. da einheimisch geworden. Jun. Bl. grünlich. Die verwilderte: V. sylvestris Gmel.

\section{Ordng. GERANIACEEN. DC.}

1. GERANIUM L. mit Ausschluss v. Arten. Storchschnabel.

I. Rotte. B atrachium. Die Wurzel ein abgebissenes, schiefes od. wagerechtes, mit langen Fasern in der Erde befestigtes, vielköpfiges Rhizom; Köpfe mit den Ueberbleibseln der Bstiele u. NebenB. der vorigen Jahre bedeckt.

a. Klappen querrunzelig od. querfaltig.

1. G. macrorrhizum I. Bthstiele 2bth.; Bthstielchen nach dem Verblühen aufrecht; Blb. spatelig, benagelt, Nagel so lang als der K.; Stbg. abwärtsgeneigt; Klappen kahl, querrunzelig; B. handf.7 sp., eingeschnitten-gezälnt; St. aufrecht, gabelsp. 24. Felsige $O$. der VorA. u. A.; Krain, Oberkärnth., Siidtyr., Feldberg in Oberbad. Aṕr.-Jun. Bl. blutroth od. satt-rosenroth.

2. G. pha eum L. Bthstiele 2bth.; Bl. flach, etwas zurückgebogen; Blb. rundl.-vkteyf., ungleicli-gekerbt, kurz-benagelt, an der Basis bärtig, ein wenig länger als der stachelspitzige K.; Stbg. bis $z$ ur Mitte steifh.-gewimpert; Klappen haarig, vorne quer-faltig; B. handf.-7sp., eingeschnitten-gezähnt. 2. Wälder der VorA. u. Gbge.; südl. Geb. u. zerstr. im mittl. Mai. Jun. Bl. schwarz-violett. Var. $\beta$. lividum: Blb. schmutzig-lila, oft mit einem schmutzig-gelbvioletten Flecken an der Basis: G. lividum L'Herit., letzteres in der Schwz.

b. Klappen glatt, weder runzelig, noch faltig, übrigens kahl od. haarig. 
3. G. nodosum L. Bthstiele-2bth.; Bthstielchen nach dem Verblühen aufrecht; Blb. vktherzf., noch $1 \mathrm{mal}$ so lang als der langbegrannte K.; Klappen glatt, flaumig; die wurzelst. B. handf.-5sp., die stengelst. 3sp., Zpfl. eyf., zugespitzt, gesägt. 2. Rauhe waldige 0.; Krain, Littor., südl. Tyrol, Veltlin, C. Tessin, Dessenberg bei Bern. Jun. Jul. Blb. hellrosenroth.

4. G. sylvaticum L. Bthstiele 2bth.; Bthstielchen nach dem Verblïhen aufrecht; Blb. vkteyf., noch 1 mal so lang als der begrannte $K$.; Klapjen glatt $u$. nebst dem Schnabel haarig, Haare weit ahstehend, drïsentrag.; S. sehr fein-punktirt; B. handf.-7sp., eingeschnitten-gezälnt; St. aufrecht, oberwärts driisig-haarig. 24. Wälder, waldige Bergwiesen; zerstr. deh das Geb. Jun. Jul. Blb. purpur-violett, über dem Nagel bärtig.

5. G. pratense L. Bthstiele 2bth.; Bthstielchen nach dem Vejblühen mit dem nach der Erde gerichteten $K$. zurückgeschlagen; Blb. vkteyf., noch $1 \mathrm{mal}$ so lang als der langbegrannte K.; Klappen glatt u. nebst dem Schnabel haarig, Haare weit abstehend, drïsentrag.; S. sehr fein-punktirt; B. handf.-7th., eingeschnitten; St. aufrecht, oberwärts drïsig-haarig. 2. Wiesen, Ufer, fenchtes Gebüsch ; zerstr. deh das Geb. Jul. Aug. Blb. blau, iiber dem Nagel kahl u. nur am Rande wimperig.

6. G. a conitifolium L'Herit. Bthstiel 2btlr.; Bthstielchen nach dem Verblühen aufrecht; Blb. vkteyf., noch 1 mal so lang als der begrannte K.; Klappen glatt, $u$. nebst dem Schnabel angedrücktflaumh., Haare sehr kurz, driisenlos; S. sehr fein-punktirt; B. handf.7 th., eingeschnitten-gezähnt; St. aufrecht, oberwärts flaumh., Haare drüsenlos. 24. Walliser A. u. selten im Oberimnthal bei Mauritius. Jun.-Aug. Blb. weiss mit purpurn. Adern.

7. G. palustre L. Bthstiele 2bth.; Bthsticlchen nach dem Verblühen abwärtsgeneigt, mit aufgerichtetem $K$.; Blb. vkteyf., noch 1mal so lang als der begrannte K.; Klappen glatt, mit abstehenden, driisenlosen Haaren bestreut; S. sehr fein-punktirt; B. handf.-5sp., eingeschnitten-gezähnt; St. ausgebreitet, oberwärts nebst den Bthstielen rauhh., Haare drüsenlos, rückwärtsgekehrt. 24. Sumpfige Wiesen, Wiesengebiisch; zerstreut dch das Geb. Jul. Aug. Blb. purpurn.

8. G. sanguineum L. Bthstiele 1-2bth., nach dem Verblühen etwas abwärts geneigt; Blb. vkteyf., ausgerandet, noch 1 mal so lang als der begrannte $K . ;$ Klappen glatt, oberwärts haarig, Haare zerstreut, borstl.; S. sehr fein-punktirt; B. im Umriss nierenf., 7th., Zpfl. 3-vielsp., Zpflchen lineal.; St. ausgebreitet $u$. nebst den Bthstielchen rauhh., Haare wagerecht abstehend, drüsenlos. 24. Sonnige, steinige O.; zerstr. deh das Geb. Jun.-Herbst. Bl. purpurn.

II. Rotte. B atrachioides. Die W. spindelf., hinbastei,gend 
im Alter vielköpfig, Köpfe v. den Rüekbleibseln der Bstiele u. NebenB. der vorhergegangenen Jahre bedeckt.

9. G. argente u m L. Grau-seidenhaarig, stengellos, od. stengeltreibend; Bthsticle 2hth.; Blb. vkteyf., seieht-ausgerandet, länger als der stachelspitzige K.; Klappen glatt, seidenhaarig; B. 5-7th., Zpf. tief-3sp., Zpflehen lineal. 2. Höhere A.; Krain u. 'Tyr. Jul. Aug. Blb. fleischroth.

10. G. sibiricum L. Bthstiele einbth., nach dem Verblühen $a b$ wärtsgeneigt; Blb. vkteyf., schwach-ausgerandet, so lang als der begrannte K.; Klappen glatt, flaumig; S. sehr schwach-punktirt; $\boldsymbol{B}$. handf., 5th., Zpfl. rautenf.-längl., spitz, grob-eingeschnitten-gesägt; St. ausgebreitet, nebst den Bthstielen rauhl., die Haare wagereehtod. abwärts gerichtet. 2. Unkultiv. O. bei Bruchsal in Baden. Jul. Aug. Blb. weiss od. blassröthl., mit purp. Adern.

11. G. pyrenaicum L. Bthstiele 2bth.; Bthstielchen nach dem Verblühen abwärtsgeneigt; Blb. vktherzf., 2sp., noch 1mal so lang als der stáchelspitzige $K$, oberhalb des Nagels beiderseits dicht-bärtig; Klappen glatt, angedrïckt-flaumh.; S. glatt; B. im Umriss nierenf., 7-9sp., $Z \mathrm{pH}$. der unteren vorne eingesehnitten, stumpf-gelierbt; St. aufrecht, nebst den B. flaumig u. etwas zottig. 24. Waldwiesen, Wälder; zerstr. dch. das Geb. Jul.-Herbst. Bl. purpurn-violett.

III. Rotte. Col umbinum. W. jährig, spindelf., aber schlank, hinabsteigend, meist vielstengelig, ohne Sehuppen auf der Krone.

§. 1. Klappen glatt, aber dabei oft haarig; S. glatt.

12. G. pusillum L. Bthstiele 2bth.; Bthstielehen nach dem Verblühen abwärtsgeneigt; Blb. längl.-vktherzf., so lang als der kurzbegrarnte $K$. od. ein wenig länger; Nägel fein-gewimpert; Klappen glatt, angedrïckt-flaumig. $\odot$. Sehutt, Wege, Zäune. Jul.-Herbst. G. rotundifolium Pollich. Fries. G. malvaefolium. Seop. Blb. bläulich.

13. G. bohemicum L. Bthstiele 2btl.; Bthstielchen nach dem Verblühen aufrecht, etwas abstehend; Blb. vktherzf., an der Basis $u$. am vorderen Rande gewimpert; Klappen glatt, haarig, Haare abstehend, druisentrag.; B. handf.-5sp., $Z$ pfl. spitz, eingesehnitten-gezähnt; St. ausgebreitet, nebst den Bthstielen drïsig-haarig u. zottig. ○. Wälder. Haiden; Carlsbad in Böhmen, zw. Museau u. Niesky in der Lausitz, Walliser A. auf dem Herbignon u. Fouly, Graubiinden bei Chur. Jun. Jul. Blb. blau, mit 5 violetten Adern.

§. 2. Klappen glatt, aber oft haarig; S. wabenartig-punktirt.

14. G. dissectum L. Bthstiele 2bth.; Bthstielehen nach dem Verblühen abwärtsgeneigt; Blb. vktherzf., so lang als der begrannte K.; Klappen glatt, nebst dem Schnabel haxrig, Haare abstehend, 
driisentrag.; S. wabenartig-punktirt; B. 5-7th., Zpfl. der unteren vielsp., der oberen 3 sp., Zpflchen lineal., St. ausgebreitet, kurzh. ○. Kultiv. O., Hecken, Raine. Mai-Jul. Blb. purpurn.

15. G. columbinum L. Bthstiele 2bth.; Bthstielchen nach rem Verblühen abwärtsgeneigt; Blb. vktherzf., so lang als der lang-begrannte K., Klappen kahl; S. wabenartig-punktirt; B. 5-7th., Zpfl. der unteren vielsp., der oberen 3 sp., Zpflchen lineal.; St. ausgebreitet, nebst den Bthstielen flaumh., Haare abwärts angedriickt. $\odot$. Aecker, Gebüsch, steinige O. Jun. Jul. Blb. rosenroth.

16. G. rotund ifolium L. Bthstiele 2bth.; Bthstielchen nach dem Verblühen abwärtsgeneigt; $B l b$. längl.-keilig, ungeth., ein wenig länger als der kurzhegrannte K.; Klappen glatt, flaumh., Haare abstehend; S. wabenartig-punktirt; B. im Umrisse nierenf., die unteren 7 sp., vorne stumpf-eingeschnitten-gekerbt; St. ausgebreitet, weichflaumig. $\odot$. Weinberge, Aecker u. steinige, buschige O.; zerstr. dch das Geb. Jun.-Herbst. G. visciduhm Fries. G. malvaceum Wahlenb. Blb. fleischroth.

§. 3. Klappen runzelig:

17. G. molle L. Bthstiele 2bth.; Bthstielchen nach dem Verbliihen abwärtsgeneigt; Blb. vktherzf., länger als der kurz-stachelspitzige $K$., an der Basis fein-gewimpert; Klappen querrunzelig, kahl; S. glatt; B. 7-9sp., im Umriss nicrenf., Zpfl. der unteren vorne eingeschnitten, stumpf-gekerbt; St. ausgebreitet, weich-flaumig u. zottig. $\odot$. Wege, Ackerränder. Mai-Aug. Blb. purpurn.

18. G. 1 u ci d u m L. Bthstiele 2bth.; Bthstielchen nach d. Verbliihen abwärtsgeneigt; Blb. vkteyf., ungeth., länger als der querrunzelige, pyramidenf. $K$; Klappen netzig-runzelig 11 . klein-gekerbt-gestreift, oberwärts flaumig; S. glatt; B. in Umrisse nierenf., $5-7$ sp., eingeschnitten-stumpf-gekerbt; St. aufrecht. $\odot$. Felsige, schattige Wälder der Gbge u. VorA.: zerstr. rlch das Geb. Mai-Aug. Blb. purpurn.

19. G. divaricatum Elurh. Bthstiele 2bth.; Bthstielchen nach dem Verblïhen abwärtsgeneigt;i Blb. vktherzf., so lang als der begraunte K.; Klappen querrunzelig, kurzh.; S. glatt; B. handf. - 5sp., Z/pfl. rautenf, groh-eingeschnitten-gezähnt, die obersten 3sp., der eine Seitenlappen länger. $\odot$. Weinberge, gebirg. O.; Bischwitz in Schles., Frankf. a. d. O., Schwarzenberg in Erzgeb., AThäler des Wallis. Jul. Aug. Blb. hell-rosenroth, dunkler geädert.

20. G. robertianum L. Bthstiele 2bth.: Bthstielchen nach dem Verblühen etwas abwärts geneigt; Blb. vkteyf,, ungeth., länger als der begrannte K.; Klappen netzig-runzelig; S. glatt; B. 3- od. 5zählig, Blättchen gestielt, 3sp., fiedersp.-cingeschnitten; St. aufrecht. $\odot$. Schattige Wälder, feuchte Zäune. Jul.-Herbst. Blb. rosenroth, mit 3 weisslichen Streifen. 
2. ERODIUM L'Heritier. DC. Reiherschnabel.

1. E. cicutarium L'Heritier. Bthstiele vielbth.; Blb. ungleich; B. gefiedert, Blättchen fast bis zum Mittelnerven fiedersp., Zpfl. gezähnt; Stbg. kahl, die fruchtbaren an der Basis mundl.-verbreitert. $\odot$. Aecker, kultiv. O., Sandfelder. Apr.-Herbst. Geranium cicutarium L. Blb. purp. Var. $\alpha$. immaculatum: Btlı. ungefleckt. $-\beta$. maculatum: die 2 grössern Blb. an der Basis mit einem gelbl., braunpunktirten Flecken.

2. E. moschatum L'Heritier. Bthstiele vielbth.; Blb. ungleich; B. gefiedert, Blättchen ungleich-doppelt gesägt, fast klein gelappt; Stbg. kahl, die fruchtbaren an der Basis verbreitert, 2zähnig. $\odot$. Aecker, Wege; sehr zerstr. dch das Geb. u. selten. Mai-Jul. Geranium moschatum L. Blb. purp.

3. E. ciconium Willd. Bthstiele 3-5bth.; B. im Unrisse eyf., herablaufend-gefiedert, Fieder fiedersp., nebst der Spindel gezähnt; die fruchtbaren Stbg. v. der Basis bis zur Mitte lanzettl. $u$. gewimpert, oberhalb der Mitte fädl., kahl. $\odot$. Unkult. O., Grasplätze; Littor., Istrien. Mai-Jul. Geranium ciconium L. Blb. hellblau, mit 3 dunkleren Adern.

4. E. malacoides Willd. Bthstiele vielbtl., nebst den B. u. Bstielen drïsig-flaumig; B. herzf., stumpf, gezähnt, flaumig; Stbg. kahl, sämmtl. lanzettl. $\odot$. Schutt, Wege, Manern; Littor., Istrien, Cherso, Veglia. Jun. Jul. Geranium malacoides L. Bl. rosenroth.

\section{Ordng. BALSAMINEEN. A. Richard.}

\section{IMPATIENS L. Springkraut.}

1. I. noli tangere L. Bthsticle 3 -thth., kiirzer als das B., unter diesem verborgen $u$. abstehend; Bth. hangend, Sporn an der Spitze zurïckgebogen; B. eyf., grobgezähnt; die Gelenke des St. geschwollen. $\odot$. Haine, feuchtes, beschattetes Gebüsch. Jul. Aug. Bth. citrongelb, mit blutrothen Punkten am Schlunde u. untersten KB.

\section{Ordng. OXALIDEEN. DC.}

\section{1. ÓXALIS L. Sauerklee.}

1. O. A cetosella L. Stengellos; Wurzelstock kriechend, gezähnt; B. 3zählig, Blättchen vktherzf., flaumig; Schaft länger als die B., über der Mitte mit 2 DeckB.; I3lb. längl.-vkteyf., seicht-ausgerandet. 24. Haine und feuchtes Gebïsch. Apr. Mai. Blb. weiss od. rosenroth, mit purp. Adern u. einem gelben Flecken an der Basis, fast $4 \mathrm{mal}$ so ang als der K.; die inneren Stbg. noch $1 \mathrm{mal}$ so lang 
als der K. Var. $\beta$. parviflora: Blkr. wur noch 1 mal so lang als der K., Stbg. 5, so lang als der K., 5 fust verschwunden: O. parviflora $\mathrm{Lcj}$.

2. O. stricta L. St. einzeln, aufrecht, zerstreut-flaumig; B. 3zählig, nebenblattlos, Blättchen vktherzf.; Bthstiele 2-5bth., ohngefälır so lang als das B.; die fruchttrag. Bthstielchen aufrecht-abstehend; Wurzelläufer etwas fleischig. (-) die Wurzellänfe ○. Jun.Oct. Blb. gelb.

3. O. corniculata L. St. ausgebreitet, flaumig, an der Basis wurzelnd; B. 3zählig, Blättclien vktherz., NebenB. längl., au den Bstiel argewachsen; Bthstiele 2-5btl., kiirzer als das B.; rlie fu'uchttrag. Bthstielchen zurückgeschlagen; W. ästig-faserig; Ausläufer fehlend. - Kultiv. O.; Unterrhein, Westphal., Niedersachsen bis Holst. n. Hannov., bei Leipzig, Carlsrulıe, sürl. Schwz., südl. Tyrol, Littor. Jun._Oct. Blb. gell.

\section{Ordng. ZYGOPHYLLEEN. Brown.}

\section{TRÍBULUS L. Burzeldorn.}

1. T. terrestris L. B. 6parig, Blättchen fast gleich; Bthstiele kiirzer als der Bstiel; Frïchtchen 2-4doruig. - . Wege, Weinberge, kultiv. O.; Fiume, Istrien. Jun.-Herbst. Blb. gelb.

\section{Ordng. RUTACEEN. Juss.}

1. Unterordnung. Wahre $R U T A C E E N$. Die Innenhaut der Kapsel trennt sich nicht vom Fleische.

\section{RUTA L. Raute.}

1. R. graveolens L. var. \%. Lappen der Kapsel stumpf; Blb. gezähnelt od. ganzrandig, plötzl., in den Nagel zsgezogen; B. beinahe 3fach-gefiedert, gestielt, im Umrisse fast 3cckig, Fieder nach der Spitze des B. an Grösse abnehmend; Blättchen oval-längl., die endst. vkteyf. 24. Steinige Hügel; sïdl. Tyrol, im Werrathale an Badensteine in Hessen, Kaiserstuhl in Oberbad., transalpinische Schwz. Jun. Jul. Blb. gelb, wie an den folgend.

2. R. divaricata Tenore. Lappen der Kapsel stumpf; Blb. gezähnelt od. ganzrandig, plötzl. in den Nagel zsgezogen; B. beinahe 3 fach-gefiedert, gestielt, im Umrisse fast 3eckig, Fieder nach der Spitze des B. an Grösse abnehmend; Blättchen längl.-lineal. od. lineal., die endst. der unteren B.verlängert-vkteyf. 2 . Steinige, sonnige Hügel u. Wiesen; Littor. Jun. Jul. R. crithmifolia Moricand. Expl. mit schmäleren Blättchen: R. divaricata DC.; Expl. mit breiteren Blättchen: R. graveolens $\alpha$. L. 
3. R. bracteosa DC. Lappen der Kapsel zugespitzt; Blb. fransig, plötzl. in den Bstiel zsgezogen; Bthstielchen ganz kahl; B. fast sitzend, beinahe 3fach-gefiedert, Fieder nach der Basis $u$. der Spitze an Grösse abnehmend, die untersten fast Nebenblätter darstellend, Blättchen lineal.-längl. 24. Felsige, sonnige 0 .; Rovigno in Istr., Fiume, Osero, Veglia. Jun. Jul.

4. R. p atavina L. Lappen der Kapsel stumpf; Blb. ganzrandig, kurzbenagelt; die Bthstielchen u. K. zottig; B. sitzend, 3zählig, Blättchen lineal. od. lanzettl., nach der Basis verschmälert, die untersten einfach. 24. Steinige O.; Istrien. Jun.

II. Unterordng. DIOSMEEN. A. Juss. Fächerhaut der Kapsel elastisch abspringend.

\section{DICTÁMnUS L. Diptam.}

1. D. Fraxinella Pers. 7. Gebirgige Wälder u. Bergwiesen; zerstr. deh das Geb. Mai. Jun. D. albus L. Blb. rosenroth, mit purp. Adern, seltener weiss: D. albus Link. Var. $\beta$. Blättchen der B. viermal kleiner, Bth. kleiner, Blb. breit-elliptisch: I. obtusiflorus Koch syn. ed. 1. - Fruchtträger länger od. um die Hälfte kürzer: letzterer D. sessilis Wallroth.

\section{Unterclasse. CALYCIFLOREN (Kelchblüthige.)}

KB. sind mehr od. weniger unter sich verwachsen, $\mathbf{u}$. Blb. u. Stbg. einer, auf die Basis des K. aufgewachsenen, Scheibe eingefügt; od. der, an den Fruchtkn. angewachsene K. trägt die Blb. u. Stbg. od. die 1blätterige Bl.

\section{Ordng. CELASTRINEEN. R. Brown.}

\section{STAPHYLÉA L. Pimpernuss.}

1. S. pinnata L. B. gefiedert, Blättchen 5-7, längl.-lanzettl., ganz kahl, gesägt; Bth. traubig; Kapseln häutig, aufgeblasen. b. Gebirgswälder; v. Oberbad. längs der A. bis Oestr., Krain, Tyrol, im nördl. Geb. hin u. wieder verwildert. Mai. Jun. Blb. weisslich.

\section{EVÓNYMUS L. Spindelbaum.}

1. E. e uropae us L. Blb. längl.; Aeste 4eckig, glatt; B. elliptisch-lanzettl., klcin-gesägt, kall1; Kapseln meist 4lappig, stumpfkantig, glatt, flügellos; der Mantel den ganzen S. einhiüllend. $\hbar$. Wälder, Gebüsch. Mai. Jun. Blb. hellgrün.

2. E. verrucosus Scop. Blb. rundl.; Aeste stielrund, warzig, elliptisch, klein-gesägt, kalıl; Kapsel meist 4lappig, stumpfkantig, 
glatt, flügellos; Mantel den halben S. bedeckend. b. Gebirgswälder; von Triest dch Krain, Stmk., Oestr., Mähr., Böhm., Schles. nach Preussen. Mai. Jun. Blb. grïn, mit feinen blutrothen Punkten.

3. E. latifolius Scop. Blb. rundl.; Aeste stielrund, etwas zsgedrückt, glatt; Blb. längl.-elliptisch, klein-gesägt, kahl; Kapseln meist 5lappig, geflügelt-kantig. $\hbar$. GebirgswäIder; anf beiden Seiten der A., v. der Schwz. bis Oestr. Mai. Jun. Blb. griinl.

\section{Ordng. RHAMNEEN. R. Brown.}

\section{ZÍZYPHUS Tournef. Judendorn.}

1. Z. vulg aris Lam. B. eyf., ausgerandet, gezähnelt, nebst den Aestchen kahl; Stacheln gezweiet, der eine zurïckgebogen, od. fehlend; Steinfrüichte eyf.-längl. †. Aus Syrien stammend; im siidl. Tyrol, östr. Littor. kultivirt, u. daselbst verwildert. Jun. - Aug. Rhamnus Zizyphus L. Blb. grünl.

\section{PALIÚRUS Tournef. Stechdorn.}

1. P. aculeatus Lam. Aestehen flaumig; B. eyf., kurz-zugespitzt, 3nervig; Flïgel der Frucht klein-gekerbt. b). Unkultiv., felsige O.; Tessin, südl. Tyrol, Krain, Littor. Jun.-Aug. P. australis Gärtn. Rhamuus Paliurus L. Blb. griinl.

\section{RHAMNUS L. Wegdorn.}

I. Rotte. Cervispina Dill. DC. Aeste gegenst.; ein Dorn an dem diesjährigen Aestchen endst., später gabelst. B. gegenst. Blb. griinl. od. grünl.-gelb.

1. Rh. cathartica L. Dornen end- u. gabelst.; B. rundl-oval, klein-gesägt, an der Basis fast herzf., Bstiel 2-od. 3mal so lang als die Neben B.; Steinfrucht auf der bleibenden, zienulich convexen Basis des K. sitzend; Ritze der S. geschlossen, an der Basis u. Spitze knorpelig-berandet. ђ. Wälder, Gebüsch. Mai. Jun. Die Ritze in den Samen bei dieser Art $u$. den folgenden bemerkt man erst nach Wegnahme der den S. umgebenden Schale.

2. Rh. tinctoria W. K. Dornen end- u. gabelst.; B. elliptisch, klein-gesägt, Bstiel v. der Länge der NebenB.; Steinfrucht auf der bleibenden, halbkugeligen, kantigen Basis des $K$. sitzend; die Ritze der S. klaffend, überall knorpelig-berandet. b. Steinige O.; Unteröstr. Mai. Rinde der Aeste gelbgrau.

3. Rh. infectoria L. Dornen end- u. gabelst.; B. elliptiseh od. rundl., klein-gesägt, Bstiel meist v. der Länge der NebenB.; Steinfrüchte auf cier bleibenden, ganz flachen Basis des K. sitzend; Ritze der S. geschlossen, an der Basis u. Spitze knorpelig-berandet. Ђ. Felsige O.; Istricu, Fiume. Mai. Rinde der Aeste dunkelbraungrau. 
4. Rh. saxatilis I. Dornen end- u. gabelst.; B. elliptisch od. lanzettl., kleingesảgt, Bstiel v. der Länge der NebenB.; St.einfrüchte auf der bleibenden, flachen, ziemlich convexen Basis des $K$. sitzend; Ritze der $\boldsymbol{S}$. klaffend, iiberall knorpelig-berandet. $\hbar$. Felsige, sonnige O.; Oberschwaben, Oberbayern, u. suidlicher v. der Schwz. bis Oestr. Mai. Jun.

II. Rotte. Rhamnus. Aeste wechselst. B. abfällig. Gf. 23 spaltig.

5. Rh. alpina L. Wehrlos; Bth. 2häusig, 4männig; B. elliptisch, zugespitzt, an der Basis stumpf od. fast herzf., kleingesägt, am Mittelnerven beiderseits 12 gerade-laufende, schiefe Adern; Gf. $3 s p . ;$ St. ausgebreitet od. aufrecht. b. VorA.; Sehwz., Tyrol, Kärnth. Mai. Jun. Blb. grünl., oberwärts braun.

6. Rh. pumila L. Wehrlos; Bth. 2häusig, 4männig; B. elliptisch od. rundl., klein-gesägt, am Mittelnerven beiderseits 6 , etwas bogige, schiefe Adern; Gf. 3sp.; St. nebst den Aesten gestreckt. b. Felsen der A. Apr.-Jun. Blb. weisslich.

III. Rotte. Alaternus DC. Aeste wechselst. B. mehrjährig. Gf. 2-3sp.

7. Rl. Alaternus L. Wehrlos; $B$. eyf., elliptisch od. lanzettl., entfernt-gezähnelt-gesägt, ganz kahl, lederig, mehrjährig; Tr. blattwinkelst., kurz; Bth. 2häusig. ђ. Felsige 0.; Istrien. März. Apr. Variet. mit lanzettl. B.: Rh. Clusii Willd. Blb. grïngelb.

IV. Rotte. Frangula DC. prodr. Aeste wechselst. B. abfällig. Gf. ungeth. Narbe köpfig. K. an der inneren Oberfläche nebst den Blb. weiss.

8. Rh. rupestris Scop. Wehrlos; B. oval od. rundl., stumpf, an der Basis abgerundet od. fast herzf., gekerbt-gesägt, Sägezähne knorpelig-berandet; Bth. zwitterig, 5männig; Narbe ungeth.; St. aufstrebend. b. Felsige O.; Krain. Littor. Jun. Jul. R. pumilus Wulf. R. Wulfenii bot. 'Ztg.

9. Rh. Frangula L. Wehrlos; B. elliptisch, zngespitzt, ganzraredig; Bth. zwitterig, 5 männig; Bthstiele $\mathbf{u}$. K. kahl od. angedriicktflaumig; Narbe ungeth.; St. aufrecht. $\hbar$. Wälder, Gebiisch. Mai. Jun.

\section{Ordng. TEREBINTHACEEN. DC.}

\section{PISTÁCIA L. Pistazie.}

1. P. Terebinthus L. B. unpaarig-gefiedert, Blättchen meist zu 7, eyf.-längl. od. lanzettl., spitz, stachelspitzig. $\hbar$. Unkultiv., steinige O.; Littor., südl. Tyrol. Apr. Mai. Bth. grünl.

2. P. Lentiscus L. B. algebrochen-gefiedert, Blättchen zu 8 , 


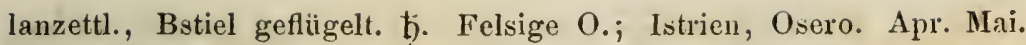
Bth. grïnl.

2. RHUS L. Sumach.

1. Rh. Cotinus L. B. vkteyf. b. Gebirgige, felsige O.; siidl. Schwz., siidl. Tyrol, Krain, Unterstmk., Littor., Oestr. Mai. Bth. grïnl.

2. Rh. Toxicodendron L. B. 3zählig, Blättehen winkeliggezähnt. Ђ. Bei Jungbunzlan in Böhmen wild geworden, Sekera.

\section{Ordng. PAPILIONACEEN. L.}

I. Gruppe. LOTEEN DC. Hülse 1fäeherig, od. mit Einwärtsbiegung einer der Nähte 2fücherig. KeimB. ziemlich flach, iiber die Erde hervortretend.

I. Untergruppe. Genistekn. Stbg. 1briiderig. Fliigel der BI. am oberen Rande zierlich-faltig-runzelig.

1. ULEX L. Hecksame.

1. U. e uropaeus L. B. lineal., in eine stechende Stachelspitze zugespitzt, die bliithenst. so lang als der Bthsticl; die unter dem K. befindlichen Deckblättehen viel breiter als der Bthstiel. b. Felder, sandige Haiden; Holst., Mecklenb., Bremen u. Verden, Hannov., Lausitz, Sachsen, Elsass, Zweibriicken in der Rheinpf. Mai. Jun. Blb. gelb.

2. SPARTIUM L. Pfriemen.

1. S. junceum L. ち. Steinige, gebirgige O.; Jittor., Stmk. Mai. Juı.

\section{SAROTHÁMNUS Wimmer. Besenstrauch.}

1. S. vulgaris Wimm. Fl. v. Schles. b. Wälder, sandige Haiden. Mai. Jun. S. scoparius Koch. syu. ed. 1. Spartium seoparium L. Bl. gelbl.

4. GENÍSTA L. Ginster.

I. Rotte. Corothamnus. Die Oberlippe des K. kurz-2zähnig. Die Bth. an dem St. u. den Aesten seitenst., einzeln, gepaart od. zu mehreren, mit einem Blätterbiischel aus derselben Knospe hervorbrechend. - Die Bth. bei allen Arten gelb.

1. G. diffus a Willd. St. wehrlos u. nebst den längl.-lanzettl. B. kahl, diese am Rande etwas bewimpert; Bthstiele seitenst., einzeln $u$. mehrere v. einem Blätterbiischel umgeben, 3mal so lang als

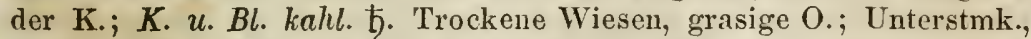
Krain, Littor. Mai. Jun. Spartium decumbens Jacq. Genista humifusa Wulf., nicht L. 
2. G. Halleri Reynier. St. wehrlos; B. längl.-lanzettl., unterseits u. am Rande, nebst den Aesten, Bthstielen $u$. K. rauhh., Haare ahstehend; Bthstiele seitenst., einzeln u. mehrere v. einem Blätterbüschel umgeben, 3mal so lang als der K.; Bl. kahl. h. Gebirgige, felsige O.; westl. Schwz. Mai. Jun. G. prostrata Lam.

3. G. procumbens W. K. St. wehrlos; $B$. längl.-lanzettl., unterseits u. am Rande, nebst den Aesten u. K. angedrückt-haarig; Bthstiele seitenst., einzeln $u$. mehrere v. einem Blätterbüschel umgeben, 3mal so lang als der K.; Bl. kahl. ち. Felsige O.; Mähr., Unteröstr., Waadt. Mai. Jun. Die Arten dieser Rotte sind nur dch den Ueberzug verschieden $\mathfrak{u}$. wohl Varietäten einer Species.

II. Rotte. Wahre Genisten. Die obere Kelchlippe bis auf die Basis 2theilig.

a. Die Bth. an dem St. u. den Aesten seitenst., einzeln, gepaart od. zu mehreren, mit einem Blätterbüschel aus derselben Knospe hervortretend.

4. G. pilosa L. St. liegend od. aufstrebend; B. längl.-lanzettl., unterseits, nebst den Aesten, Bthstielen u. K., angeảrückt-haarig; Bthstiele seitenst., einzeln $u$. mehrere $\mathrm{v}$. einem Blätterbüschel umgeben, so lang als der K.; Fahne u' Schiffchen seidenhaarig. $\hbar$. Gebirgige, waldige Haiden; zerstr. dch d. Geb. Mai. Jun.

b. Bth. traubig. St. wehrlos.

5. G. s erice a Wulfen. St. wehrlos; B. lanzettl., unterseits nebst den Aestclien angedruickt-liaarig; NebenB. felılend; $\boldsymbol{T r}$. endst., armbth.; Bthstielchen u. K. zottig; Falne u. Schiffchen seidenhaarig. ち. Gebirgige, steinige O.; Littor. Jun. Jul.

6. G. s carios a Viviani. St. wehrlos u. nebst den lanzettl. B. kahl; Aeste gefligelt-3kantig; NebenB. bleiljend, pfrieml., endl. dornig; Bth. traubig; Bl. ganz kahl. h. Felsige, gebirgige O.; Unterstmk., Krain. Jun. G. januensis Bertolon. G. triquetra W. K. G. triangularis Willd.

7. G. tinctoria L. Stämme kurz, nielerliegend, Aeste aufrecht, tief-, fast kantig-gffurcht, wehrlos, kahl, oberwärts flaumig; B. lanzettl. od. elliptisch, am Rande flaumig; NebenB. pfrieml., sehr klein; Bth. traubig, Bl. $u$. Hülsen kahl; Schiffehen v. der Länge der Fahue. b. Trockene Wiesen, Triften, waldige O. Jun. Jul.

8. G. elatior Koch. Stämme aufrecht, oberwärts ästig, Aeste stielrurd, gleichf-gerieft, an dem oberen Ende etwas kantig, wehrlos, kahl, oberwärts flaumig; $B$. lanzettl. od. elliptisch, am Rande flaumig; Neben13. pfrieml., sehr kIein; 13th. traubig; Bl. u. Hülsen kahl; Schiffchen v. der Lä̈nge der Falıne. h. Trockene Wiesen; südl. Tyrol. Jun. Jul. G. virgata Willd. G. sibirica Rchb. G. mantica Pollin.? 
9. G. ovata W.K. St. wehrlos, stielrund, erlöht-gestreift u. nebst den B. rauhh., Haare abstehend; B. lanzettl., elliptisch od. eyf.; NebenB. pfrieml., sehr klein; Bth. traubig; Bl. kahl; Schiffchen v. der Länge der Fahne; Hülsen dicht-rauhh. ந. Trockene Hügel; Waadt, Tessin, Stmk. Jun. Jul. Die G. nervata Kit. ist eine Form mit längeren u. nicht so dichten Haaren am St. u. den $B$.

c. Bth. tranbig, Trauben an der Spitze. des St. mehrere. Aestchen beblättert, die St. blattlos, clornig.

10. G. germanica L. St. dornig, unterwärts blattlos, oberwärts ästig; Aestchen beblättert, rauhh., die bliithentrag. wehrlos; B. lanzettl. od. elliptisch; Bth. traubig; DeckB. pfrieml., halb so lang als das Bthstielehen. t). Waidige O. Mai. Jun. Var. selten wehrlos.

11. G. anglica L. St. dornig, nnterwärts blattlos, oberwärts ästig; Aestchen beblättert, kahl, die blïthentrag. wehrlos; B. lanzettl. od. elliptisch; Bth. traubig; DeckB. blattig, länger als die Bthstielchen. $\hbar$. Fenchte, torfhaltige Haiden; v. den Niederlanden deh das nördl. Geb. bis Mecklenbg., Schlesien, Lausitz. Mai. Jun.

d. Die St. mit einer einzelnen Bthtranbe endigend, v. der Basis an beblättert.

12. G. sylvestris Scopoli. St. rasig, einfach, v. der Basis, an beblättert, mit einer einzelnen Bthtraube endigend, gerillt, angedrüclt-haarig, Dornen zsgesetzt, aufrecht-abstehend, biegsam, feirtgerieft; B. lanzettl., die der Dornen sehr schmal, nebst dem K. u. Schiffchen flaumig. h. Felsige, somige O.; Krain, südl. Stmk., Littor. Mai. Jun.

13. G. arcuata Koch. St. rasig, einfach, v. der Basis an beblättert, mit einer einzelnen Bthtraube endigend, kantig-gerieft, oberwärts, so wie die Spindel seidenhaarig-grau, Dornen zsgesetzt, abstehend, bogig, etwas biegsam, 4kantig; B. lineal., die der Dornen sehr schmal, nebst dem K., der Fahne u. dem Schiffchen seidenhaarig; Zähne des K. so lang als die Röhre desselben. $\hbar$. Steinige O. bei Triest. Mai. Jun.

14. G. dalmatica Bartling. St. rasig, einfach, v. der Basis an beblättert, mit einer einzehnen Bthtraube endigend, kantig-gerillt, rauhh., Haare abstehend, Dorner zsgesetzt, abstehend, gerade, steif, 4 kantig; B. lineal.-lanzettl., die der Dornen sehr schmal; K. etwas rauhh.; Spitze der Fahne u. Schiffehen flaumig; DeckB. lineal.; Zähne des K. noch einmal so lang als die Röhre desselben. t). Felsige, trockene O.; Cherso, Osero. Jun. Jul. Nach Tommas. sind $\mathrm{n}$. 13 u. 14. Variet. v. G. sylvestris.

\section{CÝTISUS L. Bohnenbaum.}

I. Rotte. Untere Kelchlippe kurz-3zähnig. Bth. in blattlosen Trauben. Bl. gelb. 
a. Bth. in einer nackten Traube.

1. C. Laburnum L. Tr. seitenst., reichbth., hängend, angedrückt-haarig; Blättchen elliptisch, oberseits kahl; Hülsen seidenh., obere Naht mit einer rechtwinkeligen Kante bekielt. $\hbar$. Wälder, Berge u. VorA.; Krain, Oestr., suidl. Stmk., südl. Tyrol, Tessin, Genf. Apr. Mai.

2. C. alpinus Mill. I'r. seitenst., reichbth., hängend, kahl; Blïttchen elliptisch, am Rande nebst den Tr. etwas flauml., Haare abstehend; Hülsen kahl, an der oberen Naht geflügelt-bekielt. $\hbar$. Wälder, Gbge. u. VorA.; stidl. Sehwz., Tyrol u. Krain. Mai. Jun.

3. C. W eldeni Visiani. Tr. endst., eyf., aufrecht; Bthstielchen u. K. flaumig; $K$. röhrig-glockig, obere Lippe bis anf die Basis 2sp., Zpfl. eyf., stumpf; Bl. kahl, Schiffchen flaumig; Blättchen vkteyf., so wie die Hülsen kahl. h. Waldgegenden $\mathrm{zw}$. Duino u. Monfalcone. Mai.

4. C. nigricans L. Tr. endst., reichbth., verlängert, aufrecht; Bthstielchen $\mathrm{n}$. K. angedriickt-flaumig; $K$. kurzglockig, obere Lippe klein-2zähnig, Zälnne spitz; Bl. kalıl; Blättchen vkteyf. od. längl., unterseits, so wic die Hülsen angedrückt-behaart. $\downarrow$. Haiden, steinige, waldige O.; südl. u. östl. Geb. bis Schles. u. Sachs. Jun. Jul.

5. C. sessilifolius L. Trr. endst., 4-8bth.; Bthstielchen u. K. kahl; K. kurzglockig, obere Lippe ungetheilt; B. kahl, Blättchen vkteyf., die der oberen B. fast rautenf., so wie die Hülsen kahl. $\mathbf{b}$. Wälder, Haiden; siidl. Tyr., Oberbad. zw. Coustanz u. Rudolfszell, Villeneuve am Genfersee. Mai. Jun.

II. Rotte. Untere Kelchlippe kurz-3zähnig. K. kurzglockig. Bth. in seitenst. beblätterten Büscheln. B1. gelb.

6. C. glabrescens Sartorelli. Bth. seitenst., gebüschelt; Bthstielchen 4mal länger als der K. od. noch länger; K. kurzglockig, an der Basis mit einem linealen DeckB. gestïtzt; St. ausgebreitet, wehrlos; 13. unten, so wie die Bstiele u. Bthstiele angedrïckt-behaart. $\hbar$. Sonnige Berge; auf dem Gipfel des Calbege im Cant. Tessin. Mai. Jun.

III. Rotte. K. vor dem Anfbliihen schlauchf., kurzlippig, nach d. Entwickelung der Bthe rundum abspringend. Calycotome Link.

7. C. spinosus Lam. Bth. seitenst., gebüschelt; Bthstiele unter dem K. mit 3lappigem DeckB.; St. gerillt, Aeste zu Dornen erhärtend, pfrieml.; $K$. ringsum abspringend, so wie die untere Seite der B. angedrückt-behaart. b. Ins. Osero. Mai. Jun. Spartium spinosum L. Hülsen kahl. - Var: Hülsen rauhh. Spartium lanigerum Desf.

IV. Rotte. Untere Kelchlippe kurz-3zähnig. K. längl., röhrig. Bth. in endst. mit B. ungebenen Köpfchen, od. in seitenst. Bïscheln $u$. beblätterte Tr. darstellend. 
8. C. austriacus L. Bth. endst., doldig-köpfig; die äusseren Bthstiele mit Deckblättchen; Aeste aufrecht u. nebst den K. rauhh.; K. längl.; B. grau v. angedrïckten Haaren. b. Waldige, rauhe 0 .; Oestr., Böhmen. Jul. Aug. Fahne auf dem Rïcken angedriickthaarig. Bl. gelb.

9. C. capitatus Jacq. Bth. endst., duldig-küpfig, zahlreich; die äusseren Bthstiele mit Deckblättchen; Aeste steif, aufrecht-abstehend, gleichhoch; Aestchen nebst den 1. u. K. rauhl., Haare abstehend; K. längl. Ђ. Sonnige O., Wälder; r. Schles. .l. B̈̈hm. bis Oestr. u. im südl. Geb. Jun. Bl. gelb.

10. C. supinus L. (var. $\alpha$, nach dem Synon. aus Clus.) Bth. endst., zu 2- u. 4doldig; Bthstiele nit Deckblättchen; St. sehr ästig u. nebst den Aesten gestreckt, Aestelien aufstrebend u. nelst den B. locker-behaart, Haare abstehend; K. längl., fast kahl. t). Haiden, Waldränder; Gegend v. Wien. Mai. Bl. gelb.

11. C. prostratus Scop. Bth. an der jährigen Aestchen seitenst., zu 2 od. 3, Bthstielchen ohne Deckblättchen, um die Hälfte kürzer als der Kelch, an den heurigen Aestchen endst., doldig, später die äusseren Bthstiele derselben unter dem Kelche mit Deckblättchen; St. nebst den Aesten liegend; Aestehen aufstrebend, nebst den B. u. K. rauhh., Haare abstehend; K. längl. †. Gebirgige, steinige O.; Krain, siidl. Tyrol. Dic seitenst. Bth. erscheinen im Mai, die endst. nach 4 Wochen im Jun. C. biflorens Host. Bl. gelb. $\beta$. ciliatus: Fruchtkn. u. Hülsen kahl, nur am Rande rauhh.: C. ciliatus Wahlenb.

12. C. hirsutus L. Bth. sämmtl. seitenst., zu 2 od. 3 , ziemlich kurz-gestielt; Bthstielchen ohne Deckblättchen; St. aufrecht u. aufstrebend; Aestchen nehst den B. u. K. rauhh., Haare abstehend; K. längl. †. Gebirgige, felsige O.; Krain, Littor., Böhm. Mai. Jun. C. falcatus WV. K. Bl. gelb. Var. $\beta$. ciliatus: Fruchtkn. u. Hülsen kahl, am Rande wimperig-rauhh.

13. C. ratisbonensis Schäffer. Bth. meist gezweiet, kurzgestielt, sämmtl. seitenst.; St. nebst den Aesten gestreckt; Aestchen aufstrebend, nebst den $B . u$. $K$. seidenh., Haare angedrückt; $\mathbf{K}$. längl. ち. Grasige Hügel, Bergwiesen; v. Augsbg. u. Regensbg. dch Bayern nach Oestr., Böhm., Mähr., Schles. Apr. Mai. C. supinus Jacq. C. supinus $\beta$. L. C. biflorus L'Herit. K. syn. ed. 1. Bl. gelb. - Var. $\beta$. minor: mit kleineren, kiirzer gestielten Bth. u. mit B., die während der Bthezeit um die Hälfte kïrzer als die Bth. sind: C. supinus $\beta$. Wahlenb. C. biflorus W. K.

14. C. purpureus Scop. Bth. meist gezweiet, seitenst.; Bthstielchen kürzer als der längl. K.; St. aufstrebend, Aestchen nebst den B. u. K. kahl od. zerstreut-haarig, Rand des K. nebst den Nägeln der Blb. gewimpert; Hülsen kahl. †. Gebirgige O.; Krain, Littor., Kärnth., suidl. Tyrol. Apr.-Jun. Bl. purpurn, S. schwarz. 
15. C. spinescens Sieber. Bth. seitenst, einzeln; St. sehr iistig; Aeste pfrieml., zu Dornen erhärtend; Aestchen nebst den B., K. u. Hülsen silberweiss-seidenh.; K. länglich. ち. Gebirgige felsige O.; Cherso. Mai. Jun. C. argyreius Rchb. C. ramosissimus Tenore. Bl. gelb.

V. Rotte. Untere Kelchlippe dreizähnig. NebenB. fehlend. B. gegenst. Bthstiele bleibend.

16. C. radiatus Koch. Angedrïckt behaart; Köpfchen endst., gesticlt, meist 4bth.; Deckblättchen eyf.; Fahne schwach behaart, tief-ausgerandet, Schiffchen dicht-seidig; Flïgel kiirzer als das Schiffchen; B. gegenst., kurzgestielt; Blättchen lineal. $\hbar$. Gbge u. VorA.; Krain, Stmk., Suidtyr., Wallis. Mai. Jun. Spartium radiatum L. Bl. gelb.

17. C. holopetalus Fleischmanu. Angedrüickt-behaart; Köpfchen endst., gestielt, meist $4 \mathrm{bth}$; Deckblättchen lineal.-pfrieml.; Fahne abgerundet-stumpf, so wie das Schiffchen dicht-seidig; Fliigel so lang als das Schiffchen; B. gegenst., kurzgestielt; Blättchen lineal. Ђ. Gbge u. VorA.; Zhaun im Innerkrain. Mai. Jun. Genista holopetala Rehb. Flor. germ. exsicc. n. 2066.

VI. Rotte. Salzwedelia Fl. d. Wett. Untere Kelchlippe bis zur Mitte 3sp. NebenB. fehlenrl. B. wechselst., nit den Bstielen abfällig.

18. C. s a gitt alis Koch. Die St. geflügelt-2schneidig, gegliedert; $T$ Tr. endst., fast köpfig; B. einfach. $\hbar$. Waldige O., trockene Wiesen; in mittleren u. siidl. Geb. Mai. Jun. Genista sagittalis L. Bl. gelb.

VII. Rotte. Lotoides DC. Untere Kelchlippe bis zur Mitte 3sp. NebenB. krautig.

19. C. arge nteus L. Seidenartig; Köpfchon gestielt, meist $3 b$ th., endlich seitenst.; B. 3zählig, wechselst. 24. Steinige, gebirgige 0. ; sïdl. Tyrol, Krain, Littor. Apr. Mai. Bl. gelb.

\section{LUPÍNUS $\mathrm{I}$. Lupine.}

1. L. hirsutus L. St. krautig, nebst den Bstielen raulh., Haare lang, weit abstehend; Bth. wechselst. od. halbquirlig; DeckB. lineal.; K. mit Deckblättehen, obere Lippe des K. 2 th., die untere halb-3sp.; Blättchen längl.- od. vkteyf.-keulig, beiderseits rauhh. $\odot$. Unter der Saat; Istrien. Mai. Jun. Bl. blau.

2. I. a $11 \mathrm{~g}$ u s tif o liu s L. St. angedrückt-belıaart; Bth. wechselst.; DeckB. eyf.; K. mit Deckblättchen, obere Lippe des K. 2th., die untere fasst $3 \mathrm{sp}$.; Blätchen lineal., unterseits angedrückt-haarig; K. länger als die halbe Bl. $\odot$. Unter der Saat; C. Waadt. Mai. Jun. Bl. blau. Var.: mit kleineren, rundlicheren Samen: L. linifolius Roth. 
II. Untergiuppe. Axthyllmens. Stbg. 1brüderig. Die Flügel der Bl. nicht runzelig-gefaltet.

7. ONÓNIS L. Hauhechel.

I. Rotte. Hülse nebst dem Bthstiele aufrecht, eyf.

1. O. spinosa L. St. aufrecht $u$. aufstrebend, 1reihig-zottig u. zerstreut-drüisig; Aeste unterbrochen-traubig, dornig, Dornen meist zu 2; Bth. blattwinkelst., einzeln; Bthstiele kïrzer als der K.; Blättchen oval-längl. u. nebst den NebenB. gezähnelt, ziemlich kahl; Hülsen eyf., aufrecht, v. der Länge des $K$. u. länger; S. knötigrauh. 2. Triften, unfruchtbare Felder, Wege. Jun. Jul. Bl. rosenroth.

2. O. repens L. St. liegend, an der Basis vurzelnd, zottig; Aeste aufstrebend, locker-traubig, an der Spitze dornig; Bth. blattwinkelst., einzeln; Bthstiele kürzer als der K.; Blättch. oval u. nebst den NebenB. gezähnelt, drüsig-haarig; Hülsen aufrecht, eyf., kürzer als der K.; S. knötig-rauh. 24. Aecker, Triften, trockene Wiesen. Jun. Jul. O. procurrens Wallroth. Var. unbewehrt:p. O. mitis Gmel. Bl. rosenroth.

3. O. hircina Jacq. St. aufrecht u. aufstrebend, wehrlos, zottig; Bth. blattwinkelst., gezweiet, an der Spitze der Aeste dicht-ährig; Bthstiele küirzer als der K.; Blättchen oval u. nebst den NebenB. gezähnelt, drüsig-haarig; Hülsen aufrecht, eyf., kürzer als der $K$., S. knötig-rauh. 2. Wiesen; sehr zerstr. deh das Geb. Jun. Jul. O. arvensis L. syst. nat. O. altissima Lam. Bl. rosenroth.

4. O. Columna All. St. aufstrebend, flaumig; Bth. blattwinkelst., sitzend; Bl. kürzer als der K.; Blättchen vkteyf., gezähnelt, drüsig-haarig; Neben B. lanzettl., zugespitzt, scharf-gezähnelt; Hiilsen aufrecht, eyf., beinahe so lang als der zottige K. 24. Bergabhänge, sonnige O.; Oestr., stidl. Tyrol, Tessin, Wallis. Mai. Jun. Bl. gelb.

II. Rotte. Hülse auf einem aufrechten od. abstehenden Bthstiel hängend, lineal., gedunsen.

5. O. Natrix Lam. Driisig-zottig; St. aufstrebend; Bthstiele 1bth., begrannt, in eine Traube zsgestellt, länger als das B.; Bl. länger als der K.; Blättchen längl., gezähnelt; NebenB. zugespitzt, ganzrandig; Hülsen lineal., gedunsen, hängend. 4. Sonnige O., Wege, bis in die A.; Krain, südl. Tyrol, Wallis. Jun. Jul. Bl. gelb, auswendig mit blutrothen Streifen.

6. O. rotund if olia L. Driisig-zottig; St. aufrecht $u$. aufstrebend; Bthstiele blattwinkelst., begrannt, 2-3bth., zuletzt länger als das B.; Blättchen fastkreisf., gezähnt; Hülsen lineal.-längl., gedunsen, hängend. 4. Auf den VorA.; Tyrol, Graubünd., Wallis. Mai. Jun. Bl. rosenroth. 
7. O. reclinat a I. St. aufstrebend, zottig; Bthstiele 1bth., grannenlos, kürzer als das B., so lang als die nickende Bth.; Bl. kürzer als der K.; B. keilig, od. rundl.-vkteyf., drüsig-haarig, an der Spitze nebst den NebenB. gezälnnelt; Hülsen hängend, lineal., gedunsen, stielrund, ein wenig länger als der K. $\odot$. Sonnige 0 .; Istrien. Mai. Jun. O. mollis Lagase. O. pilosa Bartl. O. Cherleri Koch. syn. ed. 1. Bl. rosenroth.

\section{ANTHÝLLIS L. Wundklee.}

1. A. Vuln e rari a L. Krautig; B. gefiedert, Blättehen ungleich; Köpfchen behïllt, Hülle fingerig-getheilt; $K$. bauchig, mit schiefer Mündung, Kzähne viel kürzer als die Röhre, die oberen eyf.; Fahne halb so lang als ihr Nagel. 24. Trockene Wiesen, berasete Hïgel bis in die höchsten A. Mai. Jun. Variet. sind: a. vulgaris: Bl. gelb, St. nackt od. 1-2blätt. Die Pfl. v. den A., die Varietas alpestris Hegetschw. ist nicht verschieden. - $\beta$. maritima: Bl. gelb, St. höher, oft ästig, dichter behaart: A. maritima Schweigg. - $\gamma$. rubriflora: die Fahne, der Rand, die Flügel und das Schiffchen blutroth: A. Dillenii Schult., im südl. Geb. u. in der Rheinpfalz. - $\delta$. polyphylla: ganz ähnlich der rubriflora, aber die Bl. gelbl.-weiss, der obere Theil des Schiffchens blutroth.

2. A. montana L. Krautig; B. gefiedert, Blättchen gleich; Köpfchen behïllt, Hïlle fingerig-getheilt; K. röhrig, die Zähne lineal.pfrieml., gleichlang, so lang als die KRöhre; Fahne noch einmal so lang als ihr Nagel. 24. Gebirgige, felsige, berasete 0. ; Oestr., Stmk., Krain, suidl. Tyrol, siidwestl. Schwz. Mai. Jun. Bl. bleichpurp.

III. Untergruppe. Trifolienn. Stbg. 2brüderig. B. 3zählig. Hülse 1fächerig.

\section{MEDICAGO L. Schneekenklee.}

I. Rotte. Falcago Rchb. Hülsen zsgedrückt, sichelf. od. schneckenf.-gewunden, im Mittelpunkte offen.

1. M. s a ti v L L. Tr. reichbth., längl.; Hülsen wehrlos, schneckenf.gewunden, meist mit 3 Windungen, schwach-netzig-aderig, angedrücktflaumig; Bthstielchen kürzer als der K., nach dem Verblülıen aufrecht; die NebenB. ey-lanzettf., pfrieml.-zugespitzt, die unteren gezälınt; Blättchen ausgerandet, stachel-spitzig, an der Spitze gezähnt, die der unteren 13. längl.-vkteyf., die der oberen lineal.-keilig. 4. Wiesen. Jul.-Herbst. Bth. violett od. bläulich. Val. \&. versicolor: Bth. anfangs hellgelb, dann grün, zuletzt hellviolett. M. media Pers.

2. MI. fal c a ta L. Tr. reichbth., kurz, oft fast köpfig; Hülsen wehrlos, sichelf. od. einmal zsgedreht, netzig-adrig, flaumig od. abstehendod. auch drüsig-behaart; Bthenstielchen kürzer als der K., nach dem Verblïlien aufrecht; NebenB. ey-lanzettf., pfrieml.-zugespitzt, 
die unteren gezähnt; Blättchen stachelspitzig, nach der Spitze gezähnt, die der unteren B. längl.-, die der oberen lineal.-keilig. 24. Trockene Wiesen, sonnige Hügel, Wege. Jun.-Herbst. Var. Bl. gelblichweiss, gelb od. safrangelb, u. $\beta$. versicolor: BI. anfangs gelb, dann grasgrün, zuletzt violett. - $\gamma$. major: St. verlängert, liegend, mit grösseren, mehr gezähnten NebenB. u. grösseren Bth.: M. procumbens Besser. M. intermedia Schult. - Die Haare d. Hülse meist angedrückt, zuweilen abstehend $u$. einfach, od. letztere drüsentragend: diese, $\delta$. glandulosa, ist M. glomerata Balb.; in Littorale.

3. M. prostrata Jacq. Tr. 5-10bth., abgekürzt; Hülsen wehrlos, dreimal gewunden, schwach-aderig, etwas flaumig od. kahl; Bthstielchen noch $1 \mathrm{mal}$ so lang als der $\mathbf{K}$., nach dem Verblühen zurückgeschlagen; NebenB. ey-lanzettf., pfrieml.-zugespitzt, gezähnt; Blättchen ausgerandet, stachelspitzig, die der unteren B. keilig, an der Spitze etwas gezähnt, die der oberen lineal.-keilig, ganzrandig. 2 . Somnige O., Wege; Triest, Fiume--Jun.-Aug. Bl. gelb.

4. M. marina L. Bthstiele 5-10bth., ungefähr so lang als das B.; Hülsen schneckenf., wollig-filzig, rundl., in der Mitte offen, Windungen meist 3, auf der Oberfläche netzig-aderig, am Rande stumpf, unbewehrt od.entfernt-dornentrag., Dornen kurz, kegelf.-pfrieml.; NebenB. eyf., stumpf-gezälnnt; Blättchen vkteyf., gezähnelt, nebst den Bstielen u. den St. dicht-wollig-filzig. 24. Sandige O. am Mecre bei Monfalcone. Mai. Jun. Bl. gelb.

II. Rotte. Hymenocarpos DC. Hülsen nierenf., blattig-flach, im Mittelpunkte nicht geschlossen, ganzrandig, od. am Rande gezähnelt-dörnig.

5. M. radiata L. Bthsiele meist 2bth., ungefähr so lang als das B.; Hülsen nierenf., flach-zsgedrückt, strahlig-aderíg, kahl, der vordere Rand dörnig, der hintere frarsig-zerfetzt; dic S. querrunzelig; NebenB. an der Basis gezähnt; Blättchen ranten-eyf. $\odot$. Felder, Aecker; Istrien. Jul. Ang. Bl. gelb.

III. Rotte. Spirocarpus DC. Hülsen schneckenf.-gewunden, mit einer u. mehreren Windungen, im Mittelpunkte geschlossen. Blb. an allen gelb.

\section{§. 1. Hülsen wehrlos.}

6. M. lupulina L. Aehren reichbth., gedrungen; Bthsiele ungefähr so lang als das B.; Hülsen wehrlos, nierenf., gedunsen, an der Spitze gewunden, der Länge nach bogig-aderig, kahl od. angedriickt-flaumig od. zerstreut-drüsig-haarig, mit gegliederten, abstehenden Haaren; NebenB. eyf., fast ganzrandig; Blättchen vkteyf., seichtausgerandet, vorne gezähnelt. $\odot$. Wiesen, kultiv. O. Mai-Herbst. Bl. gelb. Var. $\alpha$. vulgaris : Hülsen kahl od. angedrückt-flaumig. $\beta$. Willdenowiana: Hülsen drüisg-haarig, Haare abstehend, gegliedert: 
M. Willdenowii Bönningh. Eine monströse Pfl. mit langen Bthstielchen ist M. corymbifera Schmidt.

7. M. scutell ata Allioni. Bthstiele $1-3 b t h$, kürzer als das B.; Hülsen welırlos, schneckenf., unterwärts convex, oberwärts flach, die Windungen meist zu 6, beckenf., concentrisch-zsgerollt, schiefnetzig-aderig, ganzrandig; NebenB. eyf., gezälınt; Blättchen elliptisch, geschärft-gezähnelt, unterseits nebst dem St. drüsig-haarig, die untern vkteyf. $\odot$. Hïgel, Enltiv. O.; Fiume. Mai. Jun. M. polymorpha $\beta$. L.

8. M. orbicularis Allioni. Bthstiele $1-3 b$ th., kiurzer als das B.; Hülsen welırlos, schneckenf., kreisrund, linsenf.-plattg€drückt, beiderseits etwas convex, die Windungen meist zu 6, etwas häutig, ganzrandig, mit dem einwärts-gebogenen Rande dicht aufiegend, queraderig, die Adern nach dem Rande dicker; NebenB. tief-borstl.fiedersp.; Blättchen geschärft-kleingesägt u. nebst dem St. kahl, die oberen vkteyf., die unteren vktherzf. $\odot$. Kultiv. O., Wege; Littor.; südl. Tyrol. Mai. Jun. M. polymorpha $\alpha$. L.

9. M. ma rginata Willd. Blhstiele $1-3 b t h$., kürzer als das B.; Hülsen wehrlos, schneckenf., kieisrund, plattgedriickt, beiderseits flach, die Windungen meist zu 6, etwas häutig, ganzrandig, am Rande von einander abstehend, queraderig, Adern nach dem Kande dicker; NebenB. tiefborstl.-fiedersp.; Blättchen geschärft-kleingesägt u. nebst dem St. kahl, die der unteren vktherzf. $\odot$. Kultiv. O., Wege; Fiume. Mai. Jun.

10. M. tuberculata Willd. Bthstiele $1-2 b$ th., so lang od. kürzer als das B.; Hülsen schneckenf., fast walzlich., aderlos, kahl, die Windungen zu 3 u.5, dick, dicht aufeinanderliegend, auf der Mitte des Randes bekielt, zu beiden Seiten des Kieles mit Knötchen, die Kuötchen an der jungen Hülse kurze Dornen, an der reifen stumpfe Zitzen darstellend; NebenB. eyf., borstl.-gezähnt; Blättchen vkteyf., gezähnt; Bthstiele u. St. oberwärts flaumig. $\odot$. Unter der Saat bei Rovigno in Istr. Mai. Jun.

§. 2. Hülsen dornig, Dornen an der Basis fast stielrund u. nicht mit einer merklichen Furche bezeichnet, auf den Rand der Windungen selbst anfgesetzt; die Windungen meist dicht aufein'anderliegend.

11. M. tribuloides Lam. Bthstiele 1-2bth., kürzer als das B.; Fahne fast noch einmal so lang als das Schiffchen; Hülsen dornig, schneckenf., walzl., fast aderlos, zerstreut-haarig, Windungen meist 5, dick, dicht aufliegend, in der Mitte des selır stumpfen, dornentrag. Randes bekielt, Dornen aus cy-kegelf. Basis stielrund-pfrieml., 2zeilig-abstehend u. zurückgebingen od. angedrückt; NebenB. eyf., borstl.-gezähnt; Blättchen vkteyf., gezähnelt; Bthstiele nebst dem St. oberwärts flaumh., IIaare etwas abstehend. $\odot$. Meeresufer u. kultiv. O.; Istr., Fiume. Mai. Jun. $\alpha$. geruina: Dornen stark, 2zeilig-auf- 
u. abwärtsgekrümmt, Huilsen grösser. $-\beta$. Hornemanniana: dieselbe, aber die Hülsen halb so gross. M. pubescens Hornem. M. Hornemanniana DC. $-\gamma$ rigidula: Friichte $v$. Aler Grösse der Variet. $\alpha$. die Dornen dick, gerade, zwar abstehend, aber doch wenig auseinanderfahrend, u. nicht bogig-zuriickgekrümmt: M. rigidula Willd. $-\delta$.truncatula: Dornen an der Basis dick, 2zeilig-auf- u. abwärts an die Hülse dicht angedrückt. Diese ist M. truneatula Gärtn. Mr. tentaculata Willd.

12. M. littoralis Rohde. Bthstiele $1-4$ bth., begrannt, ungefählr so lang als das B.; Fahne so lang als das Schiffchen; Hïlsen dornig, schneckenf., walzl., an der Basis u. Spitze spärlich-aderig, kahl, Windungen meist zu 5, dicklich, dicht aufliegend, der Rand abgerundet-stumpf, dornentrag., in rler Mitte bekielt, die Dornen entfernt, aus stielrunder Basis pfrieml., abstehend od. zurückgehngen; NebenB. eyf., borstlich-gezähnt; Blättchen 3eckig-vktherzf., an der Spitze gezähnelt, nebst den Bthstielen u. dem St. flaumh., Haare etwas abstehend. $\odot$. Saudige $\mathrm{O}$. am Meere; Litt. Mai. Jun.

13. M. Gerardi W. K. Bthstiele 2-3bth., ohngefähr so lang als das B.; Hülsen dornig, schneckenf., eyf.-walzl., filzig-flaumig, aderlos, Windungen meist zu 6, dick aufliegend, mit abgerundetem, stumpfem, kiellosem, domentrag. Rande, Dornen ziemlich entfernt, aus stielrunder, beiderseits mit einer schwachen Furche bezeichneter Basis kegelf.-pfriemlich., abstehend, an der Spitze etwas hakig; NebenB. eyf., borstl-gezähnt; Blättchen vktherzf., vorne gezähnelt, nebst dem Bthstielchen u. dem St. flaumh., Haare ziemlich abstehend. $\odot$. Aecker, kultiv. O.; Littor., siidl. Tyro]. M[ai. Jun. MI. rigidula Lam. M. polym. ı. regidula L. - Var. $\beta$. cylindrica: Hiilsen fast um die Halfte kleiner, aber länger. Mr. villosa $\beta$. DC.

§. 3. Hülsen dornig, Dornen an der Basis zsgedriickt u. beiderseits mit einer deutlichen Furche dehzogen, daher gleichsam 2schenkelig, Windungen meist locker aufliegend od. abstehend.

a. Die Oberfläche der Windungen glatt od. wenigstens nach dem Rande glatt; der hintere Schenkel dex Dornen aus dem Rande selbst entspringend.

14. M. disciformis DC. Bthstiele 1-2bth., länger als das B.; Hülsen schneckenf., platt-walzlich, kahl, Windungen zu 5, aufliegend, glatt, am Rande stumpf, die oberste wehrlos, die ührigen 2ztilig-dornentrag., Dornen pfrieml., geradehervorgestreckt, etwas bogig, an der Spitze nicht hakig, auf heiden Seiten durch eine Furche ausgehöhlt; NebenB. eyf., kurz-gezähnelt; Blättchen vkteyf., spitzgezähnelt, nebst den Bthstielen u. dem St. zottig-flaumig, Haare einfach, mit eingemischten drüsentrag. am oberen Theile des Stengels. ○. Kultiv. O.; Osero. Mai. Jun.

b. Die Oberfläche der Windungen aderig; der hintere Schenkel der Dornen aus dem Rande selbst entspringend. 
15. M. maculata Willd. Bthstiele 1-2bth., 2- od. 3mal kürzer als das B.; Hiilsen dornig, schneckenf., platt-rundl., kahl, Windungen zu 5, ziemlich locker aufliegend, schief-aderig, der Rand breit, 4kielig, 2zeilig-dornentrag., Dornen pfrieml., bogig-zurückgekrümmt, an der Spitze nicht hakig, auf beiden Seiten dch eine Furche ausgehöhlt; NebenB. eyf., eingeschnitten-gezähnt, Zähne lanzettl.-pfrieml.; Blättchen breit-vkteyf., kurz-gezähnelt, die unteren vktherzf.; St. u. Bstiele nebst den Bthstielen zerstreut-haarig, Haare gegliedert. $\odot$. Kultiv. O.; Istr., Strasbg. im Elsass, Spaa. Mai. Jun. M. polymorpha $\eta$. arabica L.

c. Die Oberfläche der Windungen glatt, od. mit einfachen, bogigen Adern belegt; der hintere Schenkel der Dornen aus einer erhöhten, mit dem Rande gleichlaufenden u. vom Rande entfernten Linie entspringend.

16. M. minima Lam. Bthstiele 1-2bth., länger od. kürzer als das B.; Hülsen dornig, schneckenf., fast kugelig, spärlich-haarig, Windungen zu 5, locker aufliegend, aderlos, der Rand schmal, stumpf, 2zeilig-dornentrag., Dornen abstehend, pfrieml., gerade, an der Spitze hakig, auf beiden Seiten dch eine Furche ausgehöhlt; Neben B. eyf., kurz-gezähnelt, die oberen fast ganzrandig; Blättchen vorne gezähnelt, nebst den Bstielen, Bthstielen u. dem St. flaumh. $\odot$. Sonnige trockene O. Mai. Jun. M. polymorpha $\mu$. minima L. - Var. $\beta$. mollissima : St. u. B. grau-zottig, Haare einfach. M. mollissima Spreng. M. graeca Hornem. - $\gamma$. viscida: St. u. B. klebrig-flaumh., Haare drüsentrag.

d. Oberfläche der Windungen netzig-aderig; der hintere Schenkel der Dornen aus einer erhöhten, mit dem Rande gleichlaufenden $u$. v. Rande entfernten Linie entspringend.

17. M. a piculata Willd. Bthstiele reichbth., kürzer als das B.; Hülsen schneckenf., kahl, Windungen zu 2 od. 3, am Rande v. einander abstehend, auf der Oberfäche quer-grubig-aderig, der Rand stumpf, 2zeilig-dornentrag., Dornen auseinanderfahrend, sehr kurz, kürzer als der halbe Querdchmesser der Hülse, ziemlich gerade, auf beiden Seiten eingedriickt; NebenB. fiedersp.-gezähnt, Zähne borstl.; Blättchen stumpf-gezähnelt, nebst den Bthstielen u. dem St. kahl, vkteyf., die astst. vktherzf. $\odot$. Unter der Saat; Elsass, Hess., Thür., Spaa, Istr. Mai. Jun. Var. $\beta$. confinis Koch : die Dörnchen zu Knötchen verkürzt, welche nicht länger als breit sind.

18. M. denticulat a Willd. Bthstiele reichbth., ohngefähr so lang als das B.; Hülsen schneckenf., kahl, Windungen zu 2 od. 3, am Rande v. einander abstehend, auf der Oberfäche quer-grubigaderig, d. Rand stumpf, 2zeilig-dornentrag., Dornen auseinanderfahrend, pfrieml., an der Spitze hakig, halb so lang als der Dchmesser der Hülse, auf beiden Seiten eingedrückt; NebenB. fiedersp.-gezähnt, 
Zähne borstl.; Blättchen stumpf-gezähnelt, nebst den Bthstielen u. dem St. kahl, vkteyf., d. astst. vktherzf. $\odot$. Unter der Saat; Rheinfäche v. der Schwz. bis nach den Niederlanden, 'Thuïring., Litt. Mai. Jun. Var. $\beta$. lappacea: Früchte noch cinmal so gross. M.lappacea DC.

19. M. Terebell u m Willd. Bthstiele 2-5bth., kiirzer als das B.; Hülsen schneckenf., walzl., kalıl, Windungen zu 5, v. einander abstehend, auf der Oberfiäche schief-grubig-aderig, $d$. Rand stumpf, 2zeilig-dornentrag., Dorren kurz, sehr spreitzend, fast angedrückt, an der Basis beiderseits eingedriickt; NebenB. fiedersp.-gezähnt, Zähne borstl.; Blättchen vkteyf.-gestutzt, die astst. vktherzförmig. ( Kultiv. O.; Flor. v. Spaa, dch fremde Wolle eingefiihrt. Mai. Jun.

e. Die Oberfläche der Windungen in der Mitte netzig-aderig; aus diesem Netze zieht eine schiefe, dickere Ader in den hinteren Schenkel der Dornen.

20. M. carstiensis Jacq. Bthstiele reichbtl., ungefähr so lang als das B.; Hülsen schneckenf., eyf.-walzl., kahI, Windungen meist zu 5, am Rande abstehend, strahlig-aderig, in der Mitte netzig, der Rand seicht-rinnig, 2zeilig-dornentrag., Dornen borstl. - pfrieml., auseinanderfahrend, gerade; NebenB. spitz-gezähnt; Blättchen vkteyf., gestutzt. 24. Rauhe, schattige O.; Krain, Kärnth., Littor., Unterstmk. Mai. Jun.

\section{TRIGONELLA L. Hornklee.}

1. T. Foenum graecum L. Bth. einzeln od. gezweiet, fast sitzend; Hülsen lineal., etwas sichelf., längsaderig-gestreift, dch den verlängerten Gf. geschnäbelt, kahl, meist 20eyig; Blättchen längl.keilig, vorne gezähnelt; St. spärlich-ästig u. nebst den Aesten aufrecht. $\odot$. Bei Mühlheim im Oberbad. unter dem Getreide, dch Anbau verwildert, um Erfurt eben so, daselbst in Grossen kultiv. Jun. Jul. Bl. weiss.

2. T. gladiata Stev. Bth. Einzeln, fast sitzend; Hülsen lineal., sichelf., längsaderig - gestreift, mit dem verlängerten $\mathrm{Gf}$. geschnäbelt, flaumig, meist 10eyig; Blättchen vkteyf., geschärft-kleingesägt; St. aufrecht, an der Basis ästig, Aeste gestreckt. $\odot$. Sonnige steinige O.; Insel Veglia. Jun. Jul. T. prostrata DC. T. Foenum graecum $\beta$. L. B1. weiss.

3. T. monspeliaca I. Bth. 6 od. mehrere, doldig-gehäuft u. nebst den Dolden sitzend, der gemeinschaftliche Bthstiel sehr kurz, stachelspitzig; Hülsen abwärtsgeneigt, lineal., gebogen, schief-aderig, flaumig; Blättchen rauten-vkteyf., spitz-gezähnelt; St. liegend. $\odot$. Sonnige O., Wege; Böhm. bei Leitmeritz, Mähren auf den schwarzen Feldern, Oestr. zw. Himberg u. Moosbrunn, in Istrien, Wallis bei Sitten u. Fouly. Jun. Jul. Bl. gelb.

4. T. corniculata L. T'r. gestielt, Bthstiel länger als das B., 
stachelspitzig; Hülsen abwärtsgeneigt, lineal., gebogen, queraderig, kahl; die unteren NebenB. gezähnt; Blättchen vkteyf., stachelspitziggezähnelt; St. aufrecht. $\odot$. Kultiv. O., Wege; um Fiume. Jun. JuI. Bl. gelb.

\section{MELILÓTUS Tournef. Lam. Honigklee.}

1 M. dentata Pers. Tr. gedrungen, zuletzt verlängert; Bthstielchen halb so lang als der K.; Flügel kürzer als die Fahne, länger als das Schiffchen; Hülsen eyf., spitzl., netzig-runzelig, an der oheren Naht zsgedrückt, kahl; Neben B. aus verbreiterter, cingeschnitten-gezälınter Basis pfrieml.; Blättch. längl.-lanzettl., stumpf, geschärft-ungleich-fast dörnig-gesägt. $\odot$. Wiesen; zertr. dch das Geb. Jul. - Sept. Trif. dentatum WK. T. Kochianum Hayn. Bl. gelb. Hülsen schwarz.

2. M. marcrorrhiza-Pers. Tr. ziemlich locker, zuletzt verlängert; Bthstielchen halb so lang als der K.; Flügel u. das Schiffchen so lang als die Fahne; Hülsen eyf., kurzzugespitzt, netzigrunzelig, an der oberen Naht zsgtdrückt, flaumig; NebenB. pfrieml.borstl., ganzrandig; Blättchen geschärft-gesägt, etwas gestutzt, die der unteren B. vkteyf., der oberen längl.-lineal. $\odot$. Wiesen, Ufer. Jul.-Septbr. M. officinalis Willd. K. syn. ed. 1. Var. B. schwachgezähnt: Trifol. palustre WK. Bl. gelb. Hülsen schwarz.

3. M. alba Desrousseaux. Tr. locker, zuletzt verlängert; Bthstielchen halb so lang als der K.; Flügel ungefähr so lang als das Schiffchen, kürzer als die Fahne; Hülsen eyf., stumpf, stachelspitzig, netzig-runzelig, an der oberen Naht stumpf-gekielt, kahl; NebenB. pfrieml.-borstl., ganzrandig, Blättchen gesägt, stumpf, die der unteren B. vkteyf., der oberen längl.-lanzettl. $\odot$. Wege, unkultiv. O. Jul. Septbr. M. vulgaris Willd. Bl. weiss. Hiils. schwarzbraun.

4. M. officinalis Desrousseaux. Tr. locker, verlängert; Bthstielchen kiirzer als der K.; Flügel ungefähr so lang als die Fahne, länger als das Schiffchen; Hülsen eyf., stumpf, stachelspitzig, quernunzelig-faltig, etroas netzig, an der oberen Naht stumpf-gekielt, kahl; NebenB. pfrieml.-borstl., ganzrandig; Blättchen gesägt, stumpf, die -der unteren B. vkteyf, der oberen lanzettf. ๑. Wege, Aecker. Jul.-Sept. M. Petitpierreana K. syn. ed. 1. M. arvenis Wallr. Bl. gelb, selten weiss. Hüls. hellbraun.

5. M. parviflora Desf. $T r$. gedrurgen, zuletzt verlängert; Bthstielchen halb so lang als der K.; Fliigel v. der Länge des Schiffchens, kürzer als die Fahne; Hülsen fast kugelig, sehr stumpf, netzig-runzelig; NebenB. an der Basis schwach-gezähnelt; Blättchen etwas gestutzt, vorne gezähnt, die der unteren B. vkteyf., der oberen längl.-keilig. $\odot$. Kultiv. O., Wege; Littor. Jun. Jul. Trif. MeI. indica $\delta$. L. Blb. gelb. 
6. M. gracilis DC. Tr. locker; Bthstielchen halb so lang als der K.; Flügel u. Schiffchen so lang als die Fahne; Hülse kugelig, zugespitzt-geschnäbelt, grubig-runzelig; NebenB. aus breiterer Basis pfrieml.; Blättchen vorne gezähnelt, längl--vkteyf., die oberen keilig. $\odot$. Kultiv. O.; Insel Sansego, Tommas. Mai. Jun.

7. M. sulcata Desf. Tr. zuletzt verlängert, locker; Bthstielchen halb so lang als der K.; Fahne so lang als das Schiffchen, länger als die Fliigel; Hülsen rundl., sehr stumpf, gleichlaufendbogig-gerieft, untere NebenB. an der Basis gezähnt; Blättchen gestutzt, geschärft-gezähnt, an den unteren B. vkteyf., an den oberen längl.-keilig. ○. Kultiv. O.; Triest. Jun. Jul. M. mauritanica Willd. Trif. Mel. indica $\gamma$. L. Bl. gelb.

8. M. ca erulea Lam. Bliithen u. fruchttrag. Tr. gedrungen, rundl. u. oval; Flügel länger als das Schiffchen, kürzer als die Fahne; Hülsen längl.-eyf., geschnäbelt, der Lärge nach aderig-gestreift; NebenB. eyf.-pfrieml., die der unteren B. an der Basis verbreitert; Blättchen längl.-lanzettl., geschürft-gesägt. $\odot$. Wiesen; Krrain in der Wochein. Jun. Jul. Trif. Mel. caerulea,L. Trigonella caerulea DC. Bl. blau.

12. TRIFOLIUM L. Klec.

1. Rotte. Lagopus. Bth. sitzend, in eine rundl. od. längl. Aehre zsgestellt. Der Schlund des K. innen mit einer erhöhten, schwieligen u. oft behaarten Linie od. mit einem Ringe v. Haaren besetzt.

1. T. pallidum W. K. Aehren rundl., einzeln, an der Basis behïllt; K. 10nervig, flaumig, ein werig länger als die lialbe Bl., Zähne fädl., gewimpert, dic des fruchttrag. $K$. aufrecht, die 4 oberen anderthalbmal so lang als ihre Röhre, Schlund deh einen schwieligen Ring zsgeschnïrt; Neber B. eyf., abgebrochen-begranrt; Blättchen eyf., etwas gestutzt, klein-gesägt, nebst den Bstielen u. dem St. zottig, Haare abstehend. -). Wiesen, Wege; Osero, neue Aufschïttung bei Triest. Mai. Jun. Bl. weiss od. rosenroth angeflogen.

2. T. pratense L. Aetren kugelig, zuletzt eyf., meist gezweiet, an der Basis behüllt; $K$. 10nervig, flaumig, kürzer als die Hälfte der $B l$., Zähne fädl., gewimpert, die des fruchttrag. $K$. aufrecht, die 4 oberen so lang als ihre Röhre, Schlund deh einen schwieligen Ring zsgeschnürt; NebcnB. ('yf., abgebrochen-begrannt; Blättchen oval, fast ganzrandig, flaumig, Haare auliegend; St. aufstrebend. $\odot$. Auf Wiesen. Mai-Sept. Bl. purpurn. Var. $\beta$. sativum: deh Kultur vergrössert. - $\gamma$. nivale: niedriger, Köpfchen dicker, Bl. schmutzigweiss od. gelbl.-weiss, seltener in das Röthliche spielend. Höchste A. Dazu: T. pratense alpinum Hoppe. T. nivale Sieb.

3. T. me dium L. Aeliren kugelig, einzeln, an der Basis nackt; K. 10nervig, kahl, kürzer als die Hälfte der Bl., Zähne fädl., ge- 
wimpert, die des fruchttrag. $K$. aufrecht, die oberen 4 ungefähr so lang als ihre Röhre, Schlund dch einen schwieligen Ring zsgeschnürt; der freie T'heil der NebenB. lanzettl., verschmälert-spitz; Blättchen elliptisch, sehr fein-gezähnelt; St. ästig, aufstrebend. 4 . Gebirgswiesen, berasete, bergige 'O., Wälder. Jun. Jul. T. flexuosum Jacq. Bl. purpurn.

4. T. alpestre L. Aehren kugelig, gezweiet, an der Basis behüllt; K. 20nervig, zottig, Zähne fädl., gewimpert, die des fruchttrag. K. aufrecht, die 4 oberen ungefähr so lang als ihre Röhre od. kürzer, der unterste die Basis der Flïgel erreichend, Schlund dch einen schwieligen Ring zsgesclnürt; der freie Theil der NebenB. lanzettl.-pfrieml.; Blättchen längl.-lanzettl., sehr fein-gezähnelt; St. aufrecht, ganz einfach, flaumig. 24. Gebirgige, buschige O., bis in die VorA. hinauf. Jun.-Aug. Bl. purpurn. Var.: Bl. weiss, Schiffchen rosenroth: T. alpestre $\beta$. bicolor Rchb.

5. T. $\mathrm{r} u \mathrm{bens}$ L. Aehren längl.-walzl., meist gezweiet, an der Basis oft behüllt; K. 20nervig, kahl, Zähne pfrieml., gewimpert, die 4 oberen 2- nd. 3mal kürzer als ihre Röhre, der unterste die Basis der Flügel erreiclıend; Schlund deh einen schwieligen Ring zsgeschnürt; der freic Theil der NebenB. lanzettl., zugespitzt, entferntkleingesägt; Blättchen längl.-lanzettl., dörnig-gesägt $u$. nebst dem aufrechten St. ganz kahl. 2. Gebirgige, felsige, waldige 0.; zerstr. dch das Geb. Jun. Jul. Bl. purpurn.

6. T. noricum Wulf. Aehre kugelig, einzeln, nickend, an der Basis behüllt; K. 10nervig, rauhh., kürzer als die Hälfte der Bl., Zähne fast gleich, lineal.-pfrieml., ungefähr so lang als ihre Röhre, Schlund dch einen scliwieligen Ring zsgeschnürt; der freie Theil der NebenB. 3eckig-eyf., zugespitzt, kürzer als der angewachsene Theil, NebenB., Bstielc, B. u. der einfache, aufrechte St. zottig, Haare abstehend; Blättchen längl.-lanzettl., ganzrandig. 2. Höchste A.; Stmk., OKärnth., Krain, Südtyr. Jul. Bl. weiss.

7. 'T. p a nn on icum Jacquin. Aehre längl.-oval, einzeln, gestielt, an der Basis nackt; K.10nervig, zottig, Zähne lanzettf.-pfrieml., so lang als dic KRöhre, rer untere doppelt länger, 1/3 der Flïgel erreichend, an der Frucht aufrecht; Schlund deh einen schwieligen Ring zsgesehniirt; der freio Theil der NebenB. lanzettf.-pfrieml., in der Mitte des St. so lang als die Bstiele; Blättchen längl.-lanzettl., ganzrandig, behaart, stumpf, an den unterel B. ausgerandet; St. steif-aufrecht, nebst den NebenB. u. Bstielen rauhh. 2. Wiesen; Gerjansberg in Unterkrain. JuI. Aug. Bl. gelblich-weiss.

8. T. ochroleucum L. Aehren kugelig, zuletzt oval, oft behüllt; $K$. 10nervig, v. abstehenden Haaren rauhh., die Zähre lanzettl.-pfrieml., 3nervig, der untere so lang als die KRöhre, die 4 oberen halb so lang; der FruchtK. längl., die Zühne hervorgestreckt, der untere hinabgebogen, Schlund dch einen schwieligen Ring ver- 
engert; Bl. noch einmal so lang als der K.; der freie Theil der NebenB. lanzettl.-pfrieml., zugespitzt; Blättchen ellipt.-längl., ganzrandig, behaart, an den unteren B. ausgerandet; St. aus einer aufstrebenden Basis aufrecht, rauhh., oberwärts fast blattlos. 2. Wiesen, Wälder. Jun. Jul. B. gelbl.-weiss.

9. T. alexandrinum L. Aehren zuletzt längl., oval, gestielt, oft behiullt; $K$. 10nervig, v. weichen, aufrechten Haaren flaumig, die Zähne lanzettl.-pfrieml.; FruchtK. glockig, häutig, die Zähne hervorgestreckt, etwas sichelf., der untere nach oben aufstrebend, etwas länger, Schlund mit einem vorspringenden, behaarten Ring versehen; Fahne noch einmal so lang als das Schiffchen; der freie Theil der NebenB. lanzettl.-pfrieml.; Blättchen längl.-lanzettl., schwach-gezäl1nelt; der St. aufrecht, ästig. $\odot$. Wiesen u. Brachäcker, zw. dem Hügel Pantaleone u. Zaule bei Triest. Jun. Jul. Bl. weiss.

10. T. maritim um Hudson. Aehren zuletzt oval, an der Basis nackt; K. 10nervig, Röhre des FruchtK. kahl, vktkegelf., unter den Zähnen schwielig-aufgetrieben, Zähne lanzettl., schwach-3nervig, behaart, halb-abstehend, der untere etwas länger, hinabgebogen, an den untersten Bth. verlängert, Schlund v. einem schwieligen, kurzflaumigen Ringe verengt; Fahne anderthalbmal so lang als das Schiffchen; der freie Theil der NebenB. lanzettl.-pfrieml.; Blättchen längl.od. lanzettf.-keilig, fast ganzrandig; St. ästig. $\odot$. Feuchte Wiesen; Rovigno in Istr. Jun. Jul. Bl. weiss od. blassröthl.

11. T. stellatum L. Aehren kugelig, zuletzt eyf., einzeln, an der Basis nackt; K. 10streifig, borstig-rauhh., der FruchtK. v. einem schwieligen Ringe $u$. filzigen Haaren geschlossen, Zähne aus einer eyf. Basis verschmälert, sehr spitz, gleich, länger als die Bl., die des fruchttrag. $K$. sternf.-abstehend, 3nervig, netzig-aderig; der freie Theil der NebenB. häutig, eyf., spitzl., gezähnelt; Blättchen vktherzf., vorne gezähnelt u. nebst dem St. zottig; St. aufstrebend. $\odot$. Trockene Wiesen u. Brachäcker; Littor., Istr. Jun. Jul. Bl. röthl.-weiss.

12. T. incarnatum L. Aehren eyf., zulctzt walzl., einzelu, an der Basis nackt; K. 10nervig, rauhh., Zähne fast gleich, lanzettl.pfrieml., sehr spitz, ein wenig länger als ihre Rölıre, kürzer als die $B l$., die des fruchttrag. K. abstehend, meist 3nervig, Schlund offen, am Rande behaart; der freie Theil der NebenB. eyf., stumpf od. spitzl., gezähnelt; Blättchen vkteyf., gestutzt n. nebst dem St. zottig; St. aufrecht. $\odot$. Wiesen, Wege; Littor., siidl. Schwz. Jun. Jul. Bl. satt-purpurn, seltener fleischroth od. weiss; letzterer ist T. Molinieri Balb.

13. T. angustifolium L. Aehren walzl., zuletzt verlängert, einzeln, an der Basis nackt; K. 10streifig, borstig-rauhh., der fruchttrag. dch einen schwieligen Ring geschlossen, Zähne pfrieml., sehr spitz, der unterste länger als die Bl., die übrigen ein wenig kürzer, die des fruchttrag. $K$. abstehend, nervig; der freie Theil der NebenB. 
lanzettl.-pfrieml.; Blättchen lineal u. nebst dem st. zottig; St. aufrecht. $\odot$. Unkult. O.; Littor. Jun. Jul. Bl. hellrosenroth.

14. T. la p p с е и L. Aehren kugelig, einzeln, an der Basis nackt; $K$. 20nervig, kahl, Zähre so lang als die Bl. od. ein wenig kürzer, borstig-haarig, endlich an der Basis 3eckig-verbreitert, netzigaderig, der unterste ein wenig länger, Schlund des fruchttrag. K. mit einem Ringe zsneigender Haare geschlossen; der freie Theil der NebenB. eyf., lanzettl.-pfrieml.-zugespitzt; Blättchen vkteyf., schwach-gezähnelt; St. ästig, ausgebreitet. $\odot$. Sonnige, buschige 0 .; Fiume, Istr. Mai. Jun. Bl. röthl.-weiss.

15. T. Cherleri L. Aehren kugelig, einzeln, an der Basis behüllt; $K$. 20nervig, rauhh., Zälıne fast gleich, fädl., seltr rauhh., so lang als die Bl. $u$. länger, die des fruchttrag. K. aufrecht, Schlund v. dichten Haaren geschlossen; der freie Theil der NebenB. eyf., zugespitzt, nebst den B. u. St. zottig; Blättchen vktherzf., vorne schwach-kleingesägt; St. aufstrebend. $\odot$. Trockene Hïgel, Wege; Osero, wärmeres Istr. Mai. Jun. Bl. weissl., zuletzt röthl.

16. T. arvense L. Aehren einzeln, sehr zottig, zuletzt walzl., an der Basis nackt; $K$. 10nervig, Zähne pfrieml.-borstl., länger als die Bl., etwas abstehend, nerverlos, Schlund schwach-haarig, mit der verwelkenden Bl. geschlossen; der freie Theil der oberen NebenB. eyf., zugespitzt; St. ästig, ausgebreitet u. nebst den B. zottig; Blättchen lineal.-längl., selıwach-gezähnelt. $\odot$. Aecker u. unkult. O. Jul. -Septbr. Bl. weissl., sodann röthl. Var. $\beta$. strictius: St. schlanker, untere NebenB. schmäler, der freie Theil länger, KZälme 1/3 länger. T. Brittingeri Weitenweb.

17. T. Bocconii Savi. Aehren eyf., zuletzt längl.-walzenf., end- $u$. seitenst., behüllt; K. flaumig, Zälhne lanzettl.-pfrieml., stachelspitzig, an die Bl. angedrückt, gerade, Röhre des FruchtK. nicht bauchig, Schlund v. der vertrockneten Bl. n. einem Haarringe geschlossen; der freie Theil der NebenB. lanzettl.-pfrieml., allmählig verschmälert; Blättchen vorne gezähnelt, längl.-kcilf., an den untersten B. vktherzf., die Aederchen derselben gleichdick, gegen den Rand hin ziemlich gerade. $\odot$. Zw. Gebüsch; Ins. Brioni bei Istrien. Jun. Jul. Bl. rosenroth.

18. T. striatum I. Aehren eyf., zuletzt fast walzl., an der Basis bchiillt, endst. $u$. an der Spitze von kurzen Aestchen seiterst.; K. rauhh., Zä̈hue lanzettl.-pfrieml., stachelspitzig, abstehend, gerade, Röltre des fruchttrag. K. bauchig-angeschwollen, Schlund dch einen knorpeligen Ring zsgeschnürt; der freie Theil der NebenB. eyf., haarspitzig; Blättchen vorue kleingesägt, an den unteren B. vkteyf. od. vktherzf., an den oberen längl--keilig; Aedcrchen derselben gleichdick, am Rande ziemlich gerade. $\odot$. Unkultiv., sonnige 0. ; sehr zerstr. deh das Geb. Jun. Jul. Bl. rosenroth.

19. T. scabrum L. Aehren eyf., seiten- u. endst., einzeln, an 
der Basis behüllt; K. länger als die Bl., flaumig, der fruchttrag. walzl., Zähne lanzettl., starr, zuletzt bogig-abstehelud, 1nervig, Nerve verdickt, Schlund zsgeschnürt; der freie Theil der NebenB. eyf., haarspitzig; Blättchen längl.-keilig u. vkteyf., kleingesägt, Aederchen derselben an dem Rande verdickt, bogig. $\odot$. An grasicichen, trockenen O.; sehr zerstr. deh das Geb. Mai. Jun. Bl. rosenroth.

20. T. sax a til e Allioni. Aehren rundl., einzeln, end- $u$. seitenst., an der Basis behüllt; $K$. 10nervig, sehr rauhh., der fruchttrag. eyf., Schlund v. Haaren geschlossen, Zähne aufrecht, pfrieml., ungefäh: so lang als die Bl.; der freie Theil der NebenB. eyf., zugespitzt; Blättchen fast adertos, tief-ausgerandet, vorne stumpf-gezälnelt, dis der unteren B. vkteyt., die der oberen lüngl.-keilig. 24. Ǩiesige $O$. der höchsten Walliser A. Jul. Aug. Bl. weissl.

II. Rotte. Trichocephalnm. Fruchtbare Bth. in dem Köpfchen wenige, fast sitzend, nach dem Verbliihen zurïckgebogen; K. am Schlunde inwendig kalıl u. offen; die untruchtbaren später heranwachsenden Bth. kugelig-zsgehäuft, die fruchttragenden K. bedeckend.

21. T. subterraneum L. Fruchtbare Bth. 3-5, doldig, aufrecht, nach dem Verblühen zurïckgebogen; K. kahl, Zähne fädl., kürzer als die Bl., fast gleich, rauhh.; die unfruchtharen Bth. später, zuletzt ein kugeliges Köpfchen bildend, die fruchtbaren bedeckend; NebenB. eyf., zugespitzt; St. gestreckt, ausläuferartig u. nebst den B. rauhh.; Blättehen vktherzf. ○. Grasige O.; Triest, Istrien, Osero. Apr. Mai. Bl. weiss, Fahne rosenroth.

III. Rotte. Fragifera. Bth. in einem Köpfehen od. einer rundlichen Aehre, sitzend. Schlund des K. inwendig kahl u. offen; Riicken des K. mit den 2 oberen Zähnen nach dem Verblühen sehr vergrössert, aufgeblasen, häutig, mit einem Adernetze geziert.

22. T. fragiferum L. Köpfehen zuletzt kugelig; Bthstiele blattwinkelst., länger als das B.; Hülle vielth., so lang als der $K$.; die fruchttrag. $K$. auf dem Rücken kugelig-aufgeblasen, netzig, haarig, die 2 oberen Zähne gerade hervorgestreckt; St. kriechend. 24. Etwas feuchte Triften; zerstr. deh das Gebiet. Jun.-Herbst. Bl. fleischroth.

23. T. resupinatum L. Köpfehen behüllt, zuletzt kugelig; Hülle 10-12lappig, sehr kurz, r. der Länge der Bthstielchen; Bthstiele blattwinkelst., so lang als das B. od. ein wenig lïnger; die fruchttrag. $K$. auf dem Rücken kugelig-aufgeblasen, netzig, haarig, dic 2 oberen Zähme gerade hervorgestreckt; der St. liegend od. aufstrebend. $\odot$. Grasige O., Seestrand; Istrien, Osero. Jun. Jul. Bl. rosenroth, umgekehrt.

24. T. to m ent os um L. Köpfchen behïllt, zulctzt kugelig; Hïlle 10-12lappig, sehr kurz, so lang als die Bthstielchen; Bthstiele blatt- 
winkelst., kürzer als das B.; die fruchttrag. $K$. auf dem Rücken kugelig-aufgeblasen, netzig, filiz-haarig, die 2 oberen Zähne kurz, fast ganz mit Filz verdecht; St. gestreckt. $\odot$. Grasige 0.; Istrien. Mai. Jun. Bl. rosenroth.

IV. Rotte. Vesicastrum DC. zum Theil. Bth. in rundl. od. ovaleu Aehren, sitzend. Schlund des K. inwendig nackt; d. Röhre nach dem Verblühen gleichf. bauchig-aufgeblasen, zwischen den 2 oberen Zähnen gespalten; Zälhne gleich. Blkr. bleibend, rauschend.

25. T. multistriatum Koch. Aehren oval, an der Basis nackt; K. 24riervig, deckblätterig, kahl, die fruchttrag. eyf., etwas aufgeblasen, Zähne aus einer 3eckigen Basis borstl., von der halben Länge der Bl., Schlund nackt; DeckB. eyf., so lang als die KRöhre; Blb. zugespitzt, vielnervig, schon zur Bthezeit rauschend; der freie Theil der NebenB. lanzettf., pfrieml.; Blättchen vkteyf. od. längl., geschärftgesägt, aderig-gerieft, die Adern etwas verdickt. $\odot$. An 0 . nahe am Meere; auf der neuen Anschüttung bei Triest. Aug. Bl. weiss, nach dem Verblïhen braun.

V. Rotte. Lupinaster DC. Bth. in einem Köpfchen, läuger od. kürser gestielt. Schlund des K. inwendig nackt. Der unterste KZahn merklich länger als die iibrigen. Blkr. nach der Bthezeit rauschend. Hülse mehreyig.

26. T. alpin $u \mathrm{~m}$ L. Stengellos; Bthstiele wurzelst.; Bth. gestielt, locker-doldig, nach dem Verblühen abwärtsgebogen; K. kürzer als die Bl., kahl, im Schlunde nackt, Zähne lanzettl.-pfrieml., der unterste länger; der freie Theil der NebenB. lanzettf.-pfrieml.-zugespitzt, nebst den B. u. Bthstielen kahl; Blättchen lineal-lanzettl., schwachkleingesägt. 2. Höhere A.; des südl. Tyrols u. der Schwz. Jun.Aug. Bl. sehr gross, purpurn, selten weiss.

VI. Rotte. Trifoliastrum DC. Bth. länger- od. kürzer-gestielt. Schlund des K. inwendig nackt, Zähne gleich, od. die 2 oberen länger. Blkr. nach der Bthezeit bleibend, rauschend.

27. T. monta num L. Aehren rundl, zuletzt oval, an der Basis nackt; Bthstielchen selır kurz, 2-od. 3mal kürzer als die Röhre des $K$., nach dem Verblühen herabgebogen; K. halb so lang als die Bl., etwas zottig, im Sclllunde nackt, Zähne fast gleich, lanzettf.-pfrieml., gerade; der freie Theil der NebenB. eyf., zugespitzt; Blättchen elliptisch, geschärft-kleingesägt, unterseits nebst dem St. haarig, am Rande dicht-äderig, Aederchen verdickt; die St. aufrecht od. aufstrebend. 2. Wiesen, vorzüglich der Berge. Mai-Jul. Bl. weiss.

28. T. glomeratum L. Kahl; Aehren end- u. seitenst., sitzend, zuletzt kugelig; Bthstielchen schr kurz, kiirzer als das sehr kurze 
DeckB.; K. kahl, im Scblunde nackt, Zähne gleich, eyf.-zugespitzt, an der Basis herzf., flach-abstehend, etwas zurückgckrümmt; NebenB. rauschend, der freie Theil dersclben eyf., lang-zugespitzt; Blättchen vkteyf., geschärft-gezähnelt; St. ausgebreitet. $\odot$. Insel Brioni bei Istr. Jun. Jul. Bl. rosenroth.

29. T. parviflorum Elurh. Aelıren rundl.; Bthstielchen sehr kurz, viel kürzer als die Röhre des $K$.; nach dem Verblühen herabgebogen; $K$. ein wenig länger als die Bl., etwas haarig, im Schlunde nackt, der fruchttrag. auf der unteren Seite bis an die Basis gespalten, Zähne des $\mathbf{K}$. lanzettl., aufwärts-gebogen, die 2 oberen länger; NebenB. rauschend, der freic Theil eyf., lıarspitzig; Blättchen vkteyf., geschärtt-gesägt, Adern etwas verdickt; die St. ausgebreitet. $\odot$. Hiigel, sonnige O.; bei Kröllwiť, Fl. v. Halle, bei Prag, Bölım., neue Aufschiittung bei Triest. Juı. B1. weissl.

30. T. suff o c at um L. Aehren blattwinkelst., sitzend, genähert, rundl. u. nebst dem St. an die Erde angedrückt; Bth. sitzend, aufrecht; K. 2 mal so lang als die Bl., kalll, im Sclilunde nackt, der fruchttrag. eyf., Zähne lanzettl., sichelf, abwärts-gekriimmt, die 2 oberen länger ; NebenB. eyf., haarspitzig, die Aehre umhiillend; Blättchen vktherzf., vorne geschärft-kleingesägt; St. gestreckt, sehr kurz. ○. Sonnige O.; sïdl. Istrien. Apr. Mai. Bl. weiss.

31. T. repens L. IKöpfchen rundl.; Bthstiele blattwinkelst., länger als das B.; Bthstielchen nach dem Verblühen herabgebogen, die inneren so lang als die Rölı̀e des K.; K. kahl, im Schlunde nackt, halb so lang als die Bl., Zälıne lanzettl., die 2 oberen länger; Rand der Hülsen gleich; St. gestreckt, wurzelnd; NebenB. rauschend, abgebrochen-haarspitzig; Blättchen rkteyf., klein-gesägt. 24. Wiesen, Triften, kultiv. O. Mai-Herbst. Bl. weiss, die juingeren oft in das Fleischrothe spielend. Kleinere Variet? T. prostratum Biasol.

32. T. pallescens Schreb. Köpfchen rundl.; Bthstiele blattwinkelst., -länger als das B.; Bthstielchen nach dem Verblühen herabgebogen, die inneren so lang als die Röhre des K.; K. kahl, im Schlunde nackt, 3mal kürzer als die Bl., Zälne ey-lanzettf., die 2 oberen länger; St. rasig, liegend, aufstrebend; der freie Theil der NebenB. ey-lanzettf., allnählig gespitzt; Blättchen vkteyf., kleingesägt, u. nebst dem St. kahl. 24. Triften der A. Jul.-Sept. Bl. gelblich-weiss. Var. kleiner mit weissen Bl.: T. glarcosum Schleich.

33. T. caespitosum Reynier. Köpfehen rundl.; Bthstiele blattwinkelst., länger als das B.; Bthstielchen viel kürzer als der $K$., so lang als die Deckblättchen, nach dem Verblühen nicht herabgebogen; K. kahl, im Schlunde nackt, länger als die halbe Bl., Zähne lanzettl., zugespitzt, die 2 oberen ein wenig länger; St. rasig, aufstrebend; NebenB. ey-lanzettf., zugespitzt; Blättchen vkteyf., kleingesägt u. nebst dem St. kahl. 24. Triften u. kiesige O. der A. u. VorA.; Tyrol, Schwz. Jul. Aug. Bl. weiss. 
34. T. nigrescens Viviani. Köpfchen rundl.; Bthstiele blattwinkelst., länger als das B.; Bthstielchen nach dem Verbliihen herabgebogen, die inneren so lang als die Röhre des K.; K. kahl, im Schlunde nackt, halb so lang als die Bl.; Zähne ey-lanzettf., die 2 oberen länger; Hülsen am unteren Rande deutlich-gekerbt; St. aufstrebend; die oberen NebenB. etwas gestutzt, abgebrochen-haarspitzig; Blättchen rkteyf., v. der Mitte bis zur Basis ganzrandig, vorne kleingesägt. $\odot$. Wiesen; Istr. Mai. Jun. T. hybridum Savi. Bl. weiss.

35. T. hybridum L. Köpfchen rundl., gedrungen; Bthstiele blattwinkelst., zuletzt noch $1 \mathrm{mal}$ so lang als das B.; Bthstielchen nach dem Verblühen herabgebogen, die inneren 2- od. 3 mal so lang als die Röhtre des $K$.; K. liahl, im Schlunde nackt, halb so lang als die Bl., Zähne pfrieml., die 2 oberen länger; St. aufrecht od. aufstrebend, ganz kahl, rölhig, leicht zusammenzudrücken; NebenB. eyf., in eine sehr feine Spitze verschmälert; Blättchen rautenf.-elliptisch, stumpf, klein-gesägt, mit ungefähr 20 Adern beiderstits am Rande. 24. Feuchte Wiesen. Mai-Herbst. Die unteren Blättchen vkteyf. Bl. weiss, dann schön-rosenroth u. bald hinabgebogen.

36. T. elegans Savi. Köpfehen rundl., gedrungen; Bthstiele blattwinkelst., 2 mal so lang als das B.; Bthistielchen nach dem Verblühen herabgebogen, die inneren 3 mal so lang als die Röhre des $K$.; K. kahl, im Schlunde nackt, halb so lang als die Bl., Zähne pfrieml., die 2 oberen länger; die St. in einen Kreis niedergestreckt, an der Spitze aufstrebend, oberhalb flaumig, fest $u$. hart; NebenB. ey-lanzettf., in eine sehr feine Spitze verschmälert; Blättchen vkteyf., geschärft-kleingesägt, mit ungefähr 40 Adern beiderseits am Rande. 4. Kalkhügel u. Berge; Zweibriieken in der Rheinpf., Litt., Oestr. Jun. Jul. Bl. röthl. u. zwar schon vom Anfange der Bthezeit.

VII. Rotte. Chronosemium DC. Bth. länger- od, kürzer-gestielt. Schlund des $K$. inwendig nackt, die 2 oberen KZähne bemerklich kïrzer. Bl. nach dem Verbliihen bleibend, rauschend. Hülse 2eyig.

a. Fahne v. der Basis an eyf.-gewölbt, gefurcht; Fliigel gerade hervorgestreckt. Hülse halb so lang als die Fahne.

37. T. spadiceum L. Köpfchen endst, einzeln u. gezweiet, gestielt, gedrungen, zuletzt walzl.; Bthstielchen nach dem Verblühen herabgebogen; K. kahl, im Schlunde nackt, Zälne haarig, die oberen 2 kürzer; Fahne v. der Basis an gevölbt, gefurcht, Flügel geradevorgestreckt; Gf. $4 \mathrm{mal}$ kürzer als die Hülse; NebenB. sämmtl. längl.lanzettl. $\odot$. Nasse, torfhaltige Wiesen; sehr zerstreut im Geb., auch in den A. Jul. Aug. Bl. goldgelb, aber bald satt-kastanienbraun.

38. T. ba dium Schreber. Köpfchen endst., einzeln od. gezweiet, gedrungen, kugelig, zuletzt, wegen der hinabgebogenen unteren Bth- 
stielchen, oval-rundl.; K. kahl, im Schlunde nackt, die 2 oberen Zälne kürzer; Fahne v. der Basis an gewölbt, gefurcht, Flügel geradevorgestreckt; Gf. 4 mal kürzer als d. Hülse; NebenB. längl.-lanzettl., die oberen beinahe eyf. $\odot$. Feuchte ATriften; Stmk., Kärnth., Salzbg., Tyr., Schwz. Jul. Aug. Bl. zuerst goldgelb, hernach hellbraun.

b. Fahne hinten zsgedrückt, vorne löffelf.-erweitert, gefurcht; Flïgel auseinandertretend. Hülse halb so lang als die Fahne.

39. T. agrarium L. Köpfchen seitenst., gestielt, gedrungen, rundl. u. oval; Bth. zuletzt herabgebogen; K. kahl, im Schlunde nackt, die 2 oberen Zälnne kürzer; Fahme löffelf., gcfurcht, Flügel ueitauseinandertretend; $G f$. ungefähr so lang als die Hülse; NebenB. längl.-lanzettl., an der Basis nicht breiter. 2. Bergwiesen, Waldränder. Jun. Jul. T. aureum Pollich. Bth. goldgelb.

40. T. procumbens L. Köpfchen seitenst., gestielt, rundl. u. oval, meist $40 \mathrm{bth}$; Bth. zuletzt herabgebogen; K. kahl, am Schlunde nackt, Zähne an der Spitze etwas haarig, die 2 oberen kürzer; Fahne löffelf., gefurcht, Flügel weitauseinandertretend; Gf. $4 \mathrm{mal}$ kürzer als die Hülse; Neben B. eyf. $\odot$. Aecker, Wiesen, Raine. Mai-Herbst. T. agrarium Pollich. Var. a. majus: der Hauptstengel aufrecht; Aeste abstehend; Köpfchen grösser. T. campestre Schreb. - $\beta$. minus: Köpfchen kleiner; Bl. hellergelb; St. meist liegend: T. procumbens Schreb.

41. T. paten s Schreb. Köpfchen seitenst, gestielt, locker, während der Bthezeit halbkugelig; Bth. zuletzt herabgebogen; K. kahl, im Schlunde nackt, Zähne an der Spitze etwas haarig, die 2 oberen kuirzer; Fahne löffelf., gefurcht, Flügel weitauseinandertretend; Gf. v. der Länge der Hülse; NebenB. eyf., an der Basis deutlich-herzf. ○. Grasige O.; Unterstmk., Krain, Litt., südl. Schwz. Jun.-Aug. Bl. goldgelb. Mittleres Blättchen bald kurz-, bald lang-gestielt.

c. Fahne fast glatt, kaum bemerklich gefurcht, zsgefaltet. Hülse nur ein wenig kürzer als die Fahne.

42. T. filiforme L. Köpfchen seitenst., gestielt, locker, meist 10bth.; Btl. zuletzt herabgebogen; K. kahl, in Schlunde nackt, Zähne an der Spitze etwas haarig, die 2 oberen kürzer; Fahne zsgefaltet, fast glatt, Flügel geradehervorgestreckt, Gf. 4mal kürzer als die Hülse; Neben B. eyf. - . Wiesen, Aecker. Mai-Herbst. Bl. gelb. T. minus Smith.

43. T. micranthum Vivian. Köpfchen seitenst., gestielt, locker, $2-6$ bth.; Bth. zuletzt entfernt, hinabgebogen; K. kahl, im Schlunde nackt, Zähne an der Spitze ein wenig behaart, die 2 oberen kürzer; Faline zsgefaltet, glatt, Flïgel geralevorgestreckt; Gf. 4mal kiirzer 
als die Hülse; NebenB. längl., an der Basis nicht breiter. $\odot$. Wiesen; Pola in Istr. Mai. Jun. T. filiforme Smith. Bl. gelb.

\section{DORYCNIUM Tournef. Backenklee.}

1. D. suffruticosum Vill. Blättchen lineal.-keilig, fast seidenh.-zottig, Haare anliegend; Köpfchen meist 12bth.; Hiilsen kugelig. 24. Triften, steinige O.; zerstr. im südl. Geb. Mai. Jun. Btl. weiss, Fahue auswendig an der Basis rosenroth, Schiffchen an der Spitze schwarz-violett wie bei der folgend.

2. D. her ba ce un Vill. Blättchen längl.-keilig, zerstreut-haarig, Haare abstehend; Köpfchen meist 20bth.; Hülsen kugelig. 2. Sonnige Bergtriften; zerstr. im siidl. Geb. Jul. Aug. Bth. kleiner als bei D. suffruticosum.

\section{BONJEANLA Reichenb. Bonjeanie.}

1. B. hixs uta Rchb. Hülsen längl., gedunsen. 2. Felsige unkultiv. O.; Istr., Fiume, siidl. Tyrol. Mai. Jun. Lotus hirsutus L. Dorycnium hirsutum DC. Bl. röthl., Schiffchen an der Spitze schwarzviolett; die ganze Pflanze filzig rauhh. Var. $\beta$. incana: Haare melı anliegend; dicht-filzig. Lotus tomentosus Rhode. L. sericeus DC.

\section{LOTUS L. Schotenklee.}

1. L. edulis L. St. ausgebreitet od. aufstrebend, rauhh. v. abstehenden Haaren; Bth. einzeln od. gezweiet; Bthstiele noch einmal so lang als das B.; Kelchzähne lanzettl., rauhh., 3mal länger als die Röhre; Hülsen längl., gedunsen, gebogen, 2-3mal länger als der K. ○. Unkultiv. O. der Insel Sansego. Mai. Jun.

2. L. ornithopodioides L. Flaumig; St. ausgebreitet; Blättchen rauten-vkteyf.; Köpfchen gestielt, 3-5bth.; DeckB. noch $1 \mathrm{mal}$ so lang als der K.; Hülsen lineal., gekriimmt, zsgedrückt, holperig, fast gliederhülsig, kahl. $\odot$. Grasige, unkultiv. O.; suidl. Istr., Osero. Apr.-Jun. Blb. gelb, wie an den folgend.

3. I. cytisoides L. Ausgebreitet, grau, Haare angedrückt; Köpfchen meist 5bth.; Blättchen vliteyf.; Bthstiele noch 1 mal so lang als das B.; Zähne des $K$. längl.-lanzcttl., spitz, die 2 scitenst. kürzer; Hülsen sticlrund, lincal., gerade od. etwas gekrïmmt. 4. Unkultiv. O. am Meere; Ist., Osero. Mai. Jun.

4. L. corniculatus L. Liegend, kahl od. rauhl., Haare abstehend; Bthstielc 4-5mal längcr als das B.; Köpfchen mcist 5bth., lang-gestielt; Zähne des $K$. aus 3eckiger Basis pfrieml., fast gleich, so lang als die Röhre, vor dem Aufblühen zsschliessend; Flïgel lanzettl.-vkteyf.; Schiffchen fast rauterf., reshtwinkelig-aufstrebend; Hülsen lineal., stielrund, gerade. 24. Unkultiv. O., Triften, Wiesen. Mai-Herbst. L. arvensis Schk. Bth. gelb, auswendig oft blutroth, selten ganz blutroth. Var. a. vulgaris: kahl od. zerstreut-haarig. 
- $\beta$. ciliatus: eben so, Blättch. nebst den K. mit langen Haaren bewimpert. - $\gamma$. hirsutus: ganz rauhh.: L. villosus Thuill.

5. L. tenuifolius Reichenb. Liegend, kahl, od. etwas behaart v. abstehenden Haaren; Bthstiele 4-5mal länger als d. B.; Köpfchen meist 5bth.; KZähne aus einer 3eckigen Basis pfrieml., vor dem Aufblühen zsneigend; Flügel längl.vkteyf.; Schiffchen etwas rautenf., rechtwinkelig-aufsteigend; Hülsen lineal., stielrund, gerade. 4. Wiesen, besonders an salzhaltigen O. Mai-Herbst. L. corniculatus $\gamma$. tenuifolius L. L. tenuis Kit. Flügel bemerklich schmäler als an L. corniculatus. Bl. gelb.

6. L. uliginosus Schkuhr. Ziemlich aufrecht, kahl od. etwas haarig, Faare abstehend; Köpfchen meist 12bth., lang-gestielt; Zähne des K. aus 3eckiger Basis pfrieml., fast gleich, halb so lang als die Bl., vor dem Aufblühen zurüskgebogen; Schiffchen aus einer eyf. Basis allmählig in einen Schnabel verschmälert; Hülsen lineal., stielrund, gerade. 2. Gräben, sumpfige Wiesen. Jun. Jul. L. major Sm. K. syn. ed. 1 .

7. L. angustis simus L. Liegend od. aufstrebend, rauhl. v. abstehenden Haaren; Bth. einzeln od. gezweiet; Bthstiele 2 mal so lang als das B.; KZähne wimperig, aus einer breiteren Basis fädl.; KRöhre nach der Basis kreiself.-verschmälert, etwas kürzer als die Zähne; Hülsen gerade, sehr schlank, 5-6mal länger als der K. $\odot$. Wiesen am Meere; südl. Istr. Jun. Jul.

\section{TETRAGONÓLOBUS Scopoli. Spargelerbse.}

1. T. purpureus Moench. Bth. einzeln od. gezweiet; Bthstiel v. der Länge des B.; Flügel der Hülsen wellig, v. der Breite der Hülse. $\odot$. Zum ökonom. Gebranche kultiv. Jul. Aug. Lotus tetragonolobus L. Bl. purpurbraun.

2. T. siliquos us Roth. Bth. einzeln; Bthstiele 2- od. 3mal so lang als das B.; Flügel der Hülsen gerade, 4mal schmäler als die Hülse. 2. Feuchte Wiesen u. Triften; zerstr. dch das Geb. Mai. Jun. Lot. siliquosus L. Bl. gelb. Var. $\beta$. maritimus: kahler, B. fast fleischig: Lotus maritimus L. An feuchten, salzhaltigen $O$.

IV. Untergruppe. Garegeen. Stbg. 2briiderig. B. umpaariggefiedert. Hülse 1 fächerig, ohne eingedrückte Nalit.

\section{GLYCYRRHÍZA L. Süssholz.}

1. G. glabra I. Bättchen eyf, etwas gestutzt, unterseits klebrig; NebenB. fehlend; Aehren gestielt, kürzer als das B.; Bth. von einander stehend; Huilsen kahl, 3-4samig. 24. Wird im Grossen bei Bamberg kultivirt, u. kommt daselbst verwildert vor. Jun. Bl. violett. 
18. GALÉGA L. Geisraute.

1. G. officinalis L. Blättchen lanzettl., stachelspitzig, kahl; NebenB. breit-lanzettl.; Tr. länger als das B. 2. Sumpfige Wiesen, Ufer; westl. u. südl. Geb. Jul. Aug. Bl. lila.

\section{COLÚTEA L. Blasenstrauch.}

1. C. arborescens L. Blättchen elliptisch, gestutzt; Höcker der Fahne ảbgekürzt; Hülsen geschlossen. $\hbar$. Hügel u. Berge unter Gebïsch; zerstr. in südl. Geb. Mai. Jun. Bl. gelb.

2. C. cruenta Ait. Blättchen vkteyf., gestutzt, bläulich-grïin; Höcker der Fahne stumpf, sehr klein; Hülsen an der Spitze klaffend. †. Hügel, Weinberge; Flor. v. Halle, ursprüngl. angepflanzt und jetzt verwildert. Mai. Jun. Bl. pomeranzenfarben.

V. Untergruppe. AstragaleEn DC. Stbg. 2brüderig. B. unpaarig-gefiedert. Hülse deh die untere, (nicht samentrag.) einwärtsgebogene Naht 2fächerig od. halb-2fächerig od. an der oberen Naht eingedrückt.

20. PHÁCA L. Berglinse.

I. Rotte. Cenantrum. Hülsen vollkommen 1fächerig, nämlich ohne Scheidewand, sowohl auf der unteren als oberen Naht.

1. $\mathrm{Ph}$. frigida I. St. aufrecht, sehr einfach; NebenB. oval, blattig; B. 4-5paarig, Blättchen eyf.-längl.; Schiffchen etwas kürzer als die Fahne; Hülsen längl., kurzhaarig-flaumig, Fruchtträger länger als der K. 24. Triften der höheren A, Jul. Aug. Bl. gelblichweiss.

2. Ph. alpin a Jacq. St. aufrecht, ästig; Neben B. lineal.-lanzettl.; B. 9-12paarig, Blättchen oval-längl.; Seliffchen fast so lang als die Fahne; Hülsen halbeyf., die jüngeren kurzh., die älteren ziemlich kahl, Fruchtträger länger als der K. 24. Felsige O. der A.; südl. Schwz., Salzb., Tyrol, Kärnthen. Jul. Aug. Bl. gelb.

II. Rotte. Hemiphragminm. Hülse auf der unteren, nicht samentrag. Naht inwendig mit einem schmalen, der Länge nach durchziehenden Flïgel versehen, welcher eine unvollkommene Scheidewand darstellt. Diese Abtheilung gehört zur Gattung Astragalus u. nicht zu Phaca.

3. Ph. a ustralis L. St. ausgebreitet; NebenB. eyf.; 13. meist spaarig, Blättchen lüngl.-lanzettl. u. oval; Flügel ausgerandet od. 2sp.; Schiffchen viel kürzer als die Fahne; Hülsen elliptisch-längl., kahl; Fruchtträger länger als der K. 24. Höhere A.; Schwz., Tyr., Salzb., Kärnth. Jul. Aug. Bl. weiss od. gelbl.-weiss, Schiffchen violett. Var. fast kahl: Ph. glabra DĆ. 
21. OXÝTROPIS DC. Spitzkiel.

I. Rotte. Die obere u. untere Nalıt der Hiilse inwendig in einen Flügel verbreitert; beide sich beriilırende Fligel scheinbar eine vollständige Scheidewand bildend.

1. O. If alleri Bunge. Stengellos, zottig-seidenl.; Bthstiele aufrecht, länger als das B., u. nebst den $K$. rauhh.-wollig; Aelnen kopfig, eyf.; DeckB. ungefähr so lang als der K.; Hïlsen aufrecht, in dem $K$. sitzend, eyf., aufgeblasen, zugespitzt, 2fächerig. 24. Kiesige O. $\operatorname{der}$ A. u. VorA.; Wallis, Tyr., Salzb., Kärnth. Jul. Aug. O. uralensis DC. K. syn. ed. 1. Astragalus uralensis Jacq. B1. violett. Var. wollig-zottig: A. velutinus Sieb.

II. Rotte. Die obere Naht der Hülse inwendig in einen Fliigel verbreitert, die untere flügellos.

a. Stengellose; die NebenB. an den Bstiel angewachsen.

2. O. campestris DC. Stengellos, zerstreut-liaarig od. etwas zottig; B. meist 12paarig, Blättchen Ianzettl., spitz; Bthstiele niederliegend, länger als das B. u. nebst dem K. haarig, Haare aufrecht, beinahe angedrückt; Aehren kopfig, eyf.; DeckB. so lang als der K. od. kürzer; Hülsen aufrecht, in dem $K$. sitzend, eyf., aufgeblasen, zugespitzt, halb-2fächerig. 2. Kiesige O. der VorA. u. A.; Schwz., Tyr., Salzbg., Kärnth., Stmk. Jul. Aug. Astragalus campestris Is. Bl. gelblichweiss od. hellgelblich, mit dunkelviolettem Flecken vor der Spitze des Schiffchens. Var.: $\beta$. sordida: BI. schmutzig-gelbl., Falne bis zur Mitte mit einem grïnen u. violetten Anstriche, Schiffchen beiderseits mit einem schwarz-violetten Flecken: O. sordida Gaud. Astragalus sordidus Willd. A. uralensis L. suec., nicht I. spec. A. tyrolensis Sieb. - $\gamma$. caerulea: Blkr. blau, Fahne in der Mitte mit einem grünlichgelben, blaugestreiften Flecken; Fuscherthal der Salzb. A.

3. O. foetida DC. Stengellos, etwas haarig $u$. dch sitzende Drüsen klebrig; B. meist 20paarig, Blättchen lineal.-lanzettl.; Bthstiele so lang als das B., oberwärts dicht-haarig; Achren kopfig, armbth.; DeckB. kürzer als der K.; Hülsen aufrecht, in dem $K$. sitzend, längl., aufgeblasen, halb-2fächerig. 24. Höchste Walliser A. Jul. Aug. Astragalus foetidus Vill. A. Halleri All. Bl. gelbl.

b. Stengeltreibende; die NebenB. auf den BKissen eingesctzt, nicht an den Bstiel gewachsen.

4. O. pilosa DC. Stengelig, aufrecht, zottig; Blättchen der unteren B. längl., der oberen lanzettl.; Bthstiele blattwinkelst., länger als das B.; Aehren eyf.längl.; Hülsen aufrecht, lineal., 2fächerig, 
zottig. 2. Sandige u. felsige O.; v. der Schwz. dch Tyr. bis Oestr. u. noch zerstreut deh das Geb. Jun. Jul. Astragalus pilosus L. Bl. gelb.

III. Rotte. Beide Nähte der Hülse inwendig flïgellos.

5. O. lapponica Gaud. Kurzstengelig, aufstrebend, haarig; Blättchen fast lanzettl., spitz; Bthstiele zuletzt noch 1 mal so lang als das B.; Tr. abgekürzt, 6-12bth.; Fahne anderthalbmal so lang als das Schiffchen; Hülsen hängend, lineal.-walzl., Fruchtträger halb so lang als die Röhre des K. 24. Walliser A. Jul. Phaca lapponica Wahlenb. helv. B. hellröthl., getrocknet blau.

6. O. montana DC. Meist stengellos, haarig od. ziemlich kahl; Blättchen eyf. od. längl., spitz; Bthstiele v. der Länge der B.; Tr. abgekürzt, 6-12bth.; Fahne anderthalbmal so lang als das Schiffchen; Hülsen anfrecht, oval-längl., Fruchtträger so lang als die Röhre des K. 2. Triften der-A. Jul. Aug. Astragalus montanus L. Bl. rosenroth, getrocknet bläulich.

7. O. cyanea Bieberst. Meist stengellos, grauhaarig; Blättchen eyf. od. längl., spitz; Bthstiele v. der Länge der B.; Tr. abgekürzt, 6-12bth.; Fahne 2 mal länger als das Schiffchen; Hülsen aufrecht, längl., Fruchtträger halb so lang als die Röhre des $K$. 24. Triften der A.; im Nikolaithale über dem Dorfe Zermatten. Jul. Aug. BI. rosenroth, getrocknet bläulich.

8. O. triflora Hoppe. Stengellos, etwas haarig; Blättchen eyf. od. längl., spitz; Bthstiele v. der Länge der B.; Tr. 3bth.; Falne 2 mal länger als das Schiffchen; Hïlsen aufrecht, längl., Fruchtträger halb so lang als die Rölnre des K. 2. Kiesige, felsige O. der A.; Tauern u. Fleiss bei Heiligenblut, Krainer A. Jul. Aug. Bl. wie bei voriger.

\section{ASTRÁGALUS L. Tragant.}

I. Rotte. Glycyrrhizi. NebenB. nur mit der Basis an dem Bstiel hängend od. ganz frei.

a. Bth. roth od. violett. Die NebenB. unter sich zsgewachsen, u. so ein einzelnes, dem B. gegenst. NebenB. darstellend.

1. A. le ontinus Wulfen. Hingebreitet, behaart, die Haare angedrückt; die NebenB. zsgewachsen, blattgegenst.; B. 6-9paarig; Blättchen längl.-eyf., stumpf od. schwach-ausgerandet; Aehren kopfig, eyf. od. längl., während der Bthezeit nickend; Bthstiele länger als das B.; Fahne eyf., ausgerandet, anderthalbmal so lang als die Flïgel; Hülsen aufrecht, oval-längl., in dem $K$. sitzend, rauhh. 4 . Felsige O. der A.; Krain, Stmk., Tyr., Wallis. Jul. Aug. B. hellblau.

2. A. purpureus Lamarck. Liegend, aufstrebend, behaart; NebenB. zsgewachsen, dem B. gegenst.; B. 10-12parig; Blättchen 
ey-lanzettf., an der Spitze 2zähnig-ausgerandet, Zühne spitzl.; Aehren köpfig; Bthstiele länger als das B.; Fahue eyf., tief-ausgerandet, $1 \frac{1}{2}$ mal so lang als die Fligel; Fruchtkn. in K. kurz-gestielt, der Stiel v. der Länge des sechsten Theiles des Fruchtlin.; Hälsen aufrecht, rundl.-eyf., an der Basis herzf., raulhh. 2. Felsige O. des Schlehern u. bei Predazzo im siidI. Tyr. Jul. Aug. Bl. violettroth. A. bidentatus Sauter.

3. A. hypoglottis L. Hingebreitet, behtart, die Haare anliegend: die oberen NebenB. zsgewachsen, blattgegenst.; B. 8-10paarig; Blättchen lanzettl., die der unteren B. eyf., ausgerandet; Aelnen kopfig, eyf.; Bthstiele länger als das B.; Falme eyf., tiefausgerandet, andertbalhmal so lang als die Fliigel; Fruchtkn. $u$. Hülse im Kelche gestielt, der Stiel halb so lang als der Fruchthn.; Hïlsen aufrecht, rundl.-eyf., rauhh. 2. Triften, trockene Wiesen; zerstreut dec das mittlere Geb. Mai. Jun. A. microphyllus Willd. BI. violett.

4. A. $\mathrm{Onobrychis} \mathrm{L}$. Hingebreitet, behaart, Haare anliegend: die oberen NebenB. zsgewachsen, blattgegenst.; B. 8-12paarig; Blättchen lanzettl., die der untersten B. eyf., ausgerandet; Aehren kopfig, längl.-eyf.; Bthstiele länger als das B.; Falme lineal.-längl., gestutzt, 3inal so lang als die Flïgel; Fruchtkn. u. Hülse sitzend; Hülsen aufrecht, eyf., zugespitzt, rauhh. 24. Wiesen, Triften, Gbge., VorA. u. A.; südl. Schwz., Tyr., Krain, Unteröstr., Mähr. Jun. Jul. Bl. bläulichpurpurn.

5. A. alpinus L. Niederliegend, etwas flaumh.; NebenB. eyf., die oberen schmal-vereinigt; B. 8-10paarig; Blättchen längl--lanzettl., od. oval; Tr. ungeführ 10hth.; Bthstiele ungefülur so lang als das B.; Flügel kürzer als das Schiffchen; Schiffehen fast so lang als die Fahne; Hülsen hängend, längl., rauhl., der Stiel v. der Länge des K. 2. Triften der A.; Schw., Tyr., Kärnthen, Salzbg. Jul. Aug. Phaca astragalina DC. K. syn. ed. 1. Fahne bläul., mit dunkleren Adern; Flïgel weiss; Schiffchen rorne schön weiss.

6. A. orob oides Hornemann. Aufstrebend, etwas flaumh.; Ne. benB. eyf., die oberen schmal vereinigt; B. 6paarig; Blättchen längl.lanzettl., odl. oval; Tr. vielbth.; Btlisticle lëinger als das B.; Flügel länger als das Schiffchen, kiirzer als rlie Falne; Fruchtkn. im $K$. gestielt, der Stiel v. der Länge des sechsten Theiles des Fruchtkn.; Hülsen hängend, eyf., rauhl. 24. Grasige O. der A.; am Rothkogel in Stmk. JuI. Aug. Bl. blau.

7. A. arenarius L. Hingebreitet, v. angedrickten Haaren grau; die oberen NebenB. zsgewachsen, blattgegenst.; B. 3-4paarig; Blättchen lineal., stumpf; Tr. 4-8bth.; Bthstiele ein wenig kürzer als das B.; Hülsen aufrecht, lineal.-längl., grau-haarig, Fruchtträger so lang als die Röhre des $K$. 24. Felder, sandige Fichten- 
wälder; Böhm., Schles., Lausitz, Thüringen, Brandenbg., Pommern, Mecklenbg., Preussen, vereinzelt bei Nïrnberg. Jun. Jul. B. fleischroth.

b. Bth. roth od. violett. NebenB. frei, doch die untersten bei A. anstriacus, sulcatus u. sesameus, wenigstens an den nicht blühenden Stengeln, zu einem zsgewachsen.

8. A. a ustriacus Jacq. en. Ausgebreitet, kahl; NebenB. eyf., frei; B. 7-10paarig; Blättchen lineal., ausgerandet, die der untersten B. vkteyf.; Tr. gestielt, länger als das B., locker; DeckB. kürzer als das Bthstielchen; Flügel 2sp.; Hülsen hängend, lineal., beinahe 3eckig, flaumig, in dem K. sitzend. 24. Hügel, Felder, Wiesen; Krain, Unteröstr., Mähr., Böhm. Jul. Aug. Bl. bläulich, Schiffchen strohgelb, an der Spitze mit einem violetten Flecken.

9. A. sulcatus L. Aufrecht, kahl; NebenB. ans verbreiterter Basis lanzettl.; B. 7-10paarig; Blättchen lineal.-lanzettl.; Tr. gestielt, länger als das B., locker; DeekB. länger als die Bthstielchen; Flügel ganz; Hülsen aufrecht, lineal., beinahe $3 \mathrm{kantig,} \mathrm{in} \mathrm{dem} \mathbf{K}$. kurz-gestielt, ziemlich kahl. 24. Grasige, feuchte O., Sümpfe; Unteröstr. Jun. Jul. Bl. hellviolett, mit dunkleren Linien.

10. A. a r g en te u s Visiani. Ausgebreitet, weisslich-grau, mit angedrückten, im Mittelpunkte angehefteter Haaren; St. einfach; NebenB. eyf., frei; B. 5-7paarig; Blättchen lineal. u. lanzettl., die der unteren B. oft oval; $\boldsymbol{T r}$. gestielt, länger als das B., locker; DeckB. länger als das sehr kurze Bthstielchen; Haare des $K$. angedriickt; Hülsen noch $1 \mathrm{mal}$ so lang als der $K$., lineal., gerade, beinahe $3 \mathrm{kan-}$ tig, grau. 2. Sonnige felsige O.; Cherso, Osero, Veglia. Mai. Bl. blau.

11. A. vesicarius L. Ausgebreitet, grau, mit angedrückten, im Mittelpunkte angehefteten Haaren; NebenB. Ianzettl.-pfrieml., frei; B. 5-7paarig; Blättchen längl. od. elliptisch; Aehren fast kopfig; Bthstiele länger als das B.; $K$. v. schwarzem, angedriicktem Flaume u. weissen, etwas abstehenden Haaren rauhl., die fruchttrag. aufgeblasen; Hülsen längl., ein wenig länger als der $K$., rauhh., in dem $K$. sitzend, halb-2fächerig. 24. Steinige O.; Krain, südl. Tyr., Graubünd. Mai. Jun. Bl. violett, od. weiss, od. gelbl.-weiss.

12. A. sesameus L. Ausgebreitet, zottig; NebenB. aus eyf. Basis lanzettl.; B. 9-10paarig; Blättchen elliptisch-längl.; Köpfchen blattwinkelst., sitzend od. kurz-gestielt; Hülsen sternf.-kopfig, lanzettl., auf dem Rücken mit einer Furche ausgehöhlt. $\odot$. Dürre O.; im südl. Istrien. Mai. Jun. Bl. bläulich.

c. Bth. gelblieh-weiss. NebenB. in ein einziges blattgegenst. zsgewachsen.

13. A. Cicer L. Ausgebreitet, haarig, Haare anliegend; die oberen NebenB. zsgewachsen, blattgegenst.; B. 8-12paarig; Blättchen längl.-lanzettl. od. oval; Aehren kopfig, eyf.; Bthstiele länger od. kürzer als das B.; Fahne eyf., ausgerandet, anderthalbmal länger 
als die Flügel; Stiel des Fruchtkn. 6mal kürzer als dieser; Hülsen aufrecht, mindl., aufgeblasen, in dem $K$. beinahe sitzend, rauhh. 4. Wiesen, Triften; zerstr. deh das Geb. Jun. Jul. A. microphyllus der Aut., nicht Willd.

d. Bth. gelblich-weiss od. gelb. NebenB. frei.

14. A. hamosus L. Liegend, flaumig, Haare angedriickt; B. meist 12paarig; Blättchen keilig, ausgerandet, oben kahl; Aehren meist 6bth., locker; Bthstiele so lang als das B. u. kürzer; Hülsen stielrund, abstehend, in einen Haken gekrümmt, an dex Spitze pfrieml., auf dem Rücken mit einer Furche dehzogen, die jüngeren flaumig. ๑. Unkult. O.; Istrien, Veglia. Mai. Jın. Bl. weissl.

15. A. glycyphyllos L. Liegend, fast kahl; die NebenB. oval, stachelspitzig od. zugespitzt; B. 5-6paarig; Blättchen eyf.; Bthstiele kürzer als das B.; Achren eyf.-längl.; Hülsen lineal., fast 3 kantig, an der unteren Naht tief-eingedriickt, gebogen, kahl, aufrecht, zuletzt zsschliessend. 2. Waldige O., Bergwiesen. Jun. Jul. Bl. gelblichweiss, zuletzt russfarben.

16. A. depressus L. Liegend od. fast stengellos; NebenB. eyf., häutig, 3mal so breit als der St., lang-gewimpert; B. 9-11paarig; Blättchen rundl.-vkteyf., sehr stumpf od. ausgerandet, oberseits kahl, unterseits angedriickt-flaumig, etwas grau; Bthstiele kürzer als das B.; Hülsen lineal., fast stielhund, gerade, abstehert od. etwas herabgebogen, endlich kahl. 24. Steinige, sonnige O. der A.; südl. Schwz., südl. Tyrol. Mai. Jun. Bl. gelblichweiss, Schiffehen an der Spitze mit einem violetten Flecken.

17. A. a s per Jacq. Aufrecht, steif, flaumh.-rauh, Haare angedrückt, in der Mitte angeheftet; NebenB. lanzettl.; B. 12-15paarig, Blättchen lanzettl. u. lineal.; Aehren verlängrert, gedrungen; Bth. aufrecht; Bthstiele 2-3mal länger als das B.; Hülsen lïngl.-lineal., flaumig, an die Spindel angedrïickt. 2. Wiesen, grasige 0. ; Unteröst. Mai. Jun. BI. hellgelb.

II. Rotte. Tragacanthae. Die NebenB. fast bis $z u$ ihrer Mitte an den Bstiel angewachsen. Bstiele bleibend, Dornen darstellend.

18. A. aristatus L'Heritied. Zottig; Bsticle bleibend, an der Spitze dornig; B. 6-10paarig; Blättchen längl., stachelspitzig; Bthstiele blattwinkelst., viel kürzer als das B., 5-8bth.; Zähne des K. borstl.-pfrieml., so lang als das Schiffehen; Hülsen kürzer als der K., eyf., zottig, 1fächerig. $\hbar$. Steinige 0 . der A.; im C. Waadt u. Wallis. Mai. Jun.

III. Rotte. Podochreati. Die NebenB. fast bis zu ihrer Mitte an den Bstiel angewachsen. Bstiele nicht dornig u. nicht bleibend. 
19. A. exscapus L. Stengellos, sehr zottig; NebenB. an den Bstiel angewachsen; B. 12-20paarig, Blättchen eyf.; Bth. auf der Wurzel gelıäuft; der gemeinschaftliche Bthstiel sehr kurz; Bthstielchen ungefähr so lang als die Röhre des K.; Zähne des K. pfriemI.; Bl. kahl; Hülsen eyf., zugespitzt-stachelspitzig, zottig. 4. Wiesen u. Sandwälder der niedrigeren O. u. VorA.; Wallis, Tyr., Mähr., Böhm., Thüring. Mai. Jun. Bl. schwefelgelb.

20. A. mouspessulanus L. Fast stengellos, grau-flaumig, od. beinahe kahl; NebenB. an den Bstiel angewachsen; B. 12-20paarig; Blättchen ey-od. lanzettf.; Bthstiele länger als das B.; Zähne des K. lineal.; Hülsen lineal., fast stielrund, gebogen, mit der Spitze aufioärts gerichtet, 12-20eyig, ausgewachsen ziemlich kahl. 2. Grasige O. der Berge; siidl. Tyr., Granbünd., siidl. Schwz. Apr. Mai. Bl. purpurn.

21. A. Wulf eni Koch. Fast stengellos, grau-flaumig, od. beinahe kahl; Neben B. an den Bstiel angewachsen; B. 12-20paarig; Blättchen ey- od. lanzettf.; Bthstiele fast so lang als das B.; Zähne des K. lineal.; Hülsen lineal.-längl., oberwärts gebogen, mit abwärts gerichteter Spitze 24-30eyig, etwas grau v. angedrückten Haaren. 4. Steinige O. u. Triften; Litt., Istr. Mai. A. incanus Wulf. A. incurvus Rehb. Bl. purpurn.

II. Gruppe. HED YSAREEN DC. Hülse in Fächer od. Glieder quer abgetheilt $\mathbf{u}$. oft in Glieder zerfallend.

I. Untergruppe. Cononilleen DC. Bth. doldig.

23. SCORPIÚRUS $\mathrm{L}$. Skorpionskraut.

1. S. subvillosa L. Die inneren Rippen der kahlen Hïlse glatt, die äusseren $6-8$ steife, etwas gedrungen-gestellte, zum Theil an der Spitze hakige Dornen tragend. $\odot$. Wege, Ackerränder; Istrien, Veglia. Mai. Jun. Bl. gelb.

\section{CORONILLA L. Kronwicke.}

1. C. Emerus L. Stranchig, aufrecht; NebenB. frei, lanzettl.; Blättehen 7-9, vkteyf.; Bthstiele meist 3bth.; Nägel der Blb. 3mal so lang als der $K$.; Hiilsen ziemlich stielrund. $\hbar$. Gebuisch der Gbge. u. VorA.; Schwz., Oberelsass, Oberbad., Vorarlberg, Tyrol, bis Oestr. u. Krain. Mai. Jun. Bl. gelb.

2. C. vaginalis Lam. Halbstrauchig, gestreckt; NebenB. in ein einziges blattgegenst., eyf., zsgewachsen, v. der Grösse der Blättchen; 13. 3-4paarig, Blättchen vliteyf., das unterste Paar v. der Basis des Bstieles entfernt; Dolden 6-10bth.; Bthstielchen so lang als die liöhre des K.; die unteren Zähne des K. sehr klein, wenig bemerklich; IIülsen 4flügelig. 2. Berg- u. Alpentriften; v. der Schwz. bis Oestr., Böhınen, Thüringen. Mai--Jul. C. minima Jacq. Bl. gelb. 
3. C. minima L. Halbstrauchig, ausgebreitet; NebenB. klein, in ein einziges blattgegenst. zsgewachsen; B. 3-4paarig, Blättch. längl.-keilig od. vkteyf., das unterste Paar die Basis des Bstieles einnehmend; Dolden 5-8bth.; Bthstielchen so lang als die Röhre des $K$. od. etwas länger; llie unteren Zähne des K. dreieckig, den vierten Theil der Röhre lang; Hülsen $4 \mathrm{kantig.} \mathrm{h.} \mathrm{Sonnige} \mathrm{Hügel;}$ bei Varona u. Siders im Wallis. JuI. Ang. 13l. gelb. Die Variet. mit vkteyf. Blättchen: C. minima DC. Die Variet. $\beta$. lotoides Koch, mit längl.-keilf. Blättchen: C. coronata DC.

4. C. montana Scopoli. Krautig, aufrecht; Neben B. klein, d. unteren in ein einziges blattgegenst. ausgerandetes zsgewachsen, die oberen getrennt; B. meist 5paarig, Blättehen oval u. vkteyf., das unterste Paar die Basis des Bstieles einnehmend; Dolden 15-30bth.; Bthstielchen 3mal so lang als die Röhre des $K$.; Hülsen zsgedrückt4 kantig, gerade. 24. Kalkgebirge; sehr zerstr. deh das mittlere $u$. südl. Geb. Jun. C. coronata L. spec. Bl. gelb.

5. C. scorpioides Koch. Krautig; NebenB. klein, in ein einziges blattgegenst. zsgewachsen; B. 3zählig, sitzend, das unpaarige sehr gross; Hülsen gebogen, 4kantig, gestreift. $\odot$. Weinberge, Aecker; Littor. Mai. Jun. Ornithopus scorpioides L. Bl. gelb.

6. C. cretica L. Krautig, aufstrebend; Neben B. lanzettl, frei; B. 6-8paarig, Blättchen längl.-vkteyf., gestutzt; Btlıstiele kürzer als das B.; Dolden 3-6bth.; Bthstielchen so lang als der $K$.; Hülsen 4kantig. ○. Grasige O., Wege; Istrien, Osero, Fiume. Mai. Jun. Bl. weisslich, Fahne mit purp. Streifen, Schiffehen schwarz-purpurn.

7. C. varia L. Krautig, liegend; Neben B. lanzettl., frei; B. meist 10paarig, Blättchen längl.-vliteyf., stumpf; Bthstiele länger als das B.; Dolden meist 20bth.; Bthstielchen 3mal so lang als die Röhre des $K$.; Hülsen 4kantig. 24. Sonnige Hügel, Felder, trockene Wiesen; zerstr. deh das Geb. Jun. Jul. Fahne rosemroth, Flügel u. Schiffehen weiss, dieses an der Spitze schwarz-purpurn.

\section{ORNÍTHOPUS L. Vogelfuss.}

1. O. perpusillus L. Bthstiele länger als das B.; Zähne des K. eyf., 3mal kürzer als die Röhre; Schnabel der Hülse so lang als ein Glied derselben. - . Sandfelder; zerstr. deh das Geb. Mai. Jun. Fahne weisslich, rosenroth-gestreift; Fliigel hell-rosenroth od. weisslich; Schiffelen gelblich. Ornithopus intermedius Roth, wuchernde Expl.

\section{HIPPOCRÉPIS L. Hufeisenklee.}

1. H. comosa L. St. krautig, ausgebreitet; Bthstiele länger als das B., an der Spitze doldentrag:; Hülsen etwas gebogen, Glieder gekrümmt, rauh, Gelenke eingedriickt, kahl. 24. Sonnige, gebirgige O.; zerstr. deh das Geb. u. bis in die höchsten A. Mai-Jul. Bl. gelb. 
2. H. unisiliqu os a L. Bth. blattwinkelst., einzeln, sehr kurzgestielt; Hülsen auf dem mittleren Theile der Glieder weichstacheligrauh. $\odot$. Sonnige, steinige O.; Istrien. Mai. Jun. Bl. gelb.

\section{SECURÍGERA DC. Beilwicke.}

1. S. Coronilla DC. $\odot$. Aecker; Istrien, Fiume, Veglia. MIai. Jun. Coronilla Securidaca L.' Bl. zu 3-6doldig, gelb.

II. Untergruppe. Euhedysareen DC. Bth. traubig.

28. HED YSARUM L. Sïssklee.

1. H. obscurum L. St. aufrecht; B. 5-9paarig; Blättchen eyf.-längl. od. elliptisch; NebenB. in ein einziges blattgegenst., 2sp. zsgewachsen; DeckB. länger als die Bthstielchen; Hülsen hängend. 4. Nasse Triften der A. u. Sudet., Mähr. Gbge. Jul. Aug. H. alpinum Jacq. Bl. purpurn.

\section{ONÓBRYCHIS Tournef. Esparsette.}

1. O. sativa Lam. St. aufstrebend; Flügel kürzer als der K.; Schiffchen länger als die Fahne od. ein wenig kürzer als diese; Hülsen ain vorderen Rande gekielt, auf dem Mittelfelde erhaben-netzig, am Rande it. auf dem Mittelfelde dornig-gezähnt, Zähne halb so lang als die Breite des Kieles, die mittleren Maschen des Netzes grösser. 4. Hügel, Bergwiesen, Kalkboden; mittleres u. südl. Geb. Mai-Jul. Hedysarum Onobrychis L. Bl. rosenroth. F. montana: die St. melır ausgebreitet, Blättchen kiirzer, breiter. O. montana DC. Alpenwiesen, auch auf den Kalkhïgeln der Rheinfläche.

2. O. arenaria DC. St. aufstrebend; Flügel kürzer als der K.; Schiffchen länger als die Fahne od. ein wenig kürzer als diese; Hiilsen am vorderen Rande gekielt, auf dem Mittelfelde erhaben-netzig, an Rande u. anf dem Mittelfelde dornig-gezähnt, die mittleren Zähne des Randes pfrieml., so lang als die Breite des Kieles, die mittleren Maschen des Netzes grösser. 24. Kalkberge; Litt., südl. Schwz. Mai.-Jul. O. supina Gaud. Hedysarum arenarium Kit. Bl. rosenroth.

III. Gruppe. VICIEEN Bronn. Hülse 1fächerig od. dch weiche, aus lockerem, schäumigem Zellgewebe gebildete Querwände in unvollst. Fächer getheilt. KeimB. dick, nicht über die Erde hervortretend. B., mit Ausnahme von Cicer, abgebrochen-gefiedert.

\section{CÍCER I. Kicher.}

1. C. a rietinum I. B. sämmtl. nnpaarig-gefiedert; Blättchen oval. $\odot$. Wird in südlicheren Provinzen kultiv. u. kommt daselbst unter der Saat vor. Jun. Jul. 
31. VÍCIA L. Wicke.

I. Rotte. Der Gf. rundum gleichf.-behaart. Den Gattungsmerkmalen nach $v$. Ervum nicht verschieden.

1. V. pisiformis L. Die Tr. reichbth., kürzer als das B.; B. meist 5paarig, Blättchen eyf., stumpf, aderig, die untersten an dem St. anstehond, die halbpfeilf., gezähnten NebenB. verbergend; Gf.v. der Mitte an gleichf.-behaart. 4. Haine, Bergwälder, in die VorA. hinauf. Mai. Jun. Bl. gelblich-weiss.

2. V. sylvatic a L. Tr. reichbth., länger als das B.; 13. meist 8paarig, Blättchen eyf., stumpf, aderig; Neben B. halbmondf., eingeschnitten-vielzähnig, Zähne borstl.-haarspitzig; G'f. $v$. der Mitıe an gleichf-behaart; Hülsen lineal.-längl. 2. Bergwälder; zerstreut deh das Geb. Jul. Aug. Bl. weisslich, Fahne mit bläulichen Adern schönbemalt.

3. V, e assubica L. Tr. reichbth., kürzer als das B.; Btlistielchen so lang als die Röhre des K.; B. vielpaarig, mit einer 3sp., zsgerollten Wickelranke endigend; Blättchen eyf.-längl. od. lanzettl., stumpf, aderig; NebenB. halbspiessf., ganzrandig; $G f$. oberwärts überall flaumig; Hiilsen fast rautenf.; W. kriechend. 24. Gebirgswälder; zerstreut dch das Gebiet. Jun. Jul. V. multiflora Pollicl. Bl. violett.

4. V. Orobus DC. Tr. reichbth., zuletzt länger als das B.; B. vielpaarig, mit einer einfachen, stachelspitzf. Ranke endigend, Blättchen eyf.-längl. od. lanzettl., stumpf, aderig; NebenB. halbspiessf., an der Basis etwas gezähnt; Gf. oberwärts überall flaumig; Hülsen lineal.-längl.; W. vielköpfig. 24. Wiesen u. Gebüsclı am F'usse des Winterberges bei Orb im Spessart. Mai. Jun. Orobus sylvaticus L. Bl. weiss, Falne mit violetten Adern.

II. Rotte. Vicien. Gf. an der unteren Seite gegen die Spitze hin bärtig $u$. ausserdem kahl, od. zugleich oberwärts iiberall zottig.

§. 1. Bthstiele verlängert, reichbtlı, länger od. anch küirzer als das stützende $B$.

5. V. dum e torum L. Tr. meist 5bth., ungefähr so lang als das B.; B. meist 5paarig, Blättchen eyf., stumpf, aderig, die unter'sten vom St. entfernt; NebenB. halbmondf., eingeschnitten-vielzähnig, Zähne haarspitzig; Gf. mundum behaart, hinten aber mit längeren Haaren gebärtet. 4. Haine der Berge u. VorA.; zerstr. dch das Geb. Jul. Aug. Bth. roth-violett, mit dunkleren Adern.

6. V. Cracea L. Tr. reichbth., gedrungen, so lang als das B. u. länger; B. meist 10paarig, Blättchen längl. od. lanzettl., nervigaderig, angedrückt-flaumig; NebenB. halbspiessf., ganzrandig; Platte der Fahne v. d. Länge des Nagels; die oberen Zähne des K. aus breiter Basis plötzlich pfrieml., sehr kurz; Hülsen lineal.-längl., der 
Stiel derselben kürzer als der K. 2. Wiesen, Ufer, Jun.-Aug. Bl. violett. Der Stiel der Hülse nicht so lang als die untere Seite der Kelchröhre.

7. V. Gerardi DC. Tr. reichbth., gedrungen, so lang als das B. od. kürzer; obere B. meist 15paarig, Blätlchen längl. od. lanzettl., nervig-aderig, abstehend-behaart; NebenB. halbspiessf., ganzrandig; Platte der Fahne v. d. Länge des Nagels; obere Zälne des K. aus breiter Basis plötzlich pfrieml., sehr kurz; Hülsen lineal.-längl., Stiel derselben länger als die Röhre des $K$. 24. Zwischen Gebüseh u. in Hainen; Triest, Wallis. Jun. Jul. V. Craeea $\beta$. K. syn. ed. 1. V. galloprovineialis Poir. Bl. violett.

8. V. tenuifolia Roth. Tr. reichbth., gedrungen, länger als das B.; B. meist 10paarig, Blättchen lanzettl., nervig-aderig, unterseits abstehend-haarig; NebenB. halbspiessf., ganzrandig; Platte der Fahne noch $1 \mathrm{mal}$ so lang als ihr Nagel; die oberen Zähne des $\mathrm{K}$. aus breiter Basis plötzlich pfrieml., sehr kurz; Hülsen lineal.-längl., Stiel derselben kürzer als die Kelchröhre. 2. Wiesen, Waldtriften; zerstrent deh das Geb. Jun.-Aug. Bl. violett, die Flügel meist bleicher.

9. V. villo s a Roth. Tr. reichbth., gedrungen, v. der Länge des B. u. länger; Bthstielehen so lang als die halbe Röhre des K.; B. meist 8paarig, Blättchen lanzettl., nervig-aderig, abstehend-flaumig od. zottig; NebenB. halbspiessf., ganzrandig; Platte der Fahne halb so lang als illr Nagel; Hülsen elliptiseh, fast rautenf.; Nabel $8 \mathrm{mal}$ kürzer als der Umriss des S. $\odot$. Unter der Saat; nördl. Geb. u. ansserdem sehr zerstreut. Mai-Jul. V. polyphylla WK., nicht Desf. Bl. dunkler - od. heller-violett, Flügel weisslich od. blässer. Var. $\beta$. glabrescens: St. fast kahl; Blättehen weniger haarig, Haare meln angedrüekt. V. polyphylla Koch bot. Ztg., nieht Desf.; V. varia Host. Vorzügl. in Franken $\mathfrak{u}$. Baiern.

10. V. onobrychioides L. Tr. 6-12bth., länger als das B.; Bth. entferrt, wagerecht-abstehend; Bthstielchen $1 / 3$ so lang als die Röhre des K.; B. 6-8paarig, Blättelien lanzettl. od. lineal., nervig, unterseits flaumig; NebenB. halbspiessf., etwas gezähnt; Hülsen lineallängl.; Nabel 1/3 des S. umgebend. 4. od. ๑. Unter der Saat; Wallis, Istrien. Mai-Jul. Bl. violett.

§. 2. Bthstiele 1-2bth., od. 4-6bth. u. kurz-traubig; Bthstiele od. Tr. kürzer als die I3th., an V. bithyniea zuweilen etwas länger.

11. V. F ab a L. Tr. hlattwinkelst., 2-4bth., sehr kurz; B. mit einer Stachelspitze endigend, d. oberen 2-3paarig; Blättchen elliptiseh, stumpf; Fahne kahl; Zähne des K. ungleieh, die 3 unteren lanzettl., die 2 oberen kürzer, zsneigend; Hülsen fast stielrund, lederig, flaumig. $\odot$. Wird in mehreren Variet. gebauet. Jun. Jul. Bl. weiss, mit schwarzem Fleeke auf den Flügeln. 
12. V. narbonensis L. Tr. blattwinkelst., 2-4bth., sehr kurz; die oberen B. 2-3paarig, Blättchen oval, stumpf, gezähnt od. ganzrandig; Fahne kahl; Zähne des $K$. ey-lanzettf., ungleich, die oberen halb so lang; Hülsen zsgedrückt, kahl od. haarig mit an der Basis zwiebeligen Haaren, am Rande weichstacheligg-gewimpert. $\odot$. Kultiv. O.; Littor. Mai. Jun. $\alpha$. integrifolia: Blïttchen ganzrandig od. vorne schwach-gesägt. - $\beta$. serratifolia: Blättchen fast v. der Basis an gesägt. V. serratifolia Jacq. Bl. grall-riolett.

13. V. bithynica L. Bthstielchen blattwinkelst., 1-2bih., hall so lang als das $B$. od. länger; $B$. mit einer. Wickelranke endigend, die oberen 2 paarig, Blättchen elliptisch u. lanzettl., an beiden Enden spitz; Fahne kahl; Zälne des K. lanzettf.-pfricml., fast gleich, geractehervorgestreckt, so lang als ihre Röhre; Hülscn lineal.-längl., zottig. ○. Grasige, unkultiv. O., Ackerränder; Triest, Fiume. Mai. Jun. Bl. purpurn.

14. V. oroboides. Wulf. Tr. 3-6bth., sehr kurz; B. mit einer Stachelspitze erdigend, 2paarig, Blättchen eyf., zugespitzt; Fahne kahl; Zähne des K. lanzettl.-pfrieml., abstehend-zurtickgekrümmt; Hülsen lineal., kahl. 24. Wälder der Berge u. VorA.; Stmk., Krain u. Kärnthen. Jun. Jul. Orobus Clusii Spr. Bl. bleicligelb.

15. V. sepi itm L. Tr. blattwinkelst., meist 5bth., sehr kurz; B. mit einer Wickelranke endigend, nneist 3parig, Blättchen oval od. längl., stumpf; Fahne kahl; Zälne des K. aus breiterer Basis pfrieml., ungleich, die 2 oberen zsneigend; Hiilsen lineal.-längl., kahl. 24 . Haine, Gebiisch, Zäune. Apr.-Jun. Bl, hell- u. etwas schmutzigviolett, Fahne mit dunkleren Adern, selten gelbl.-weiss od. weiss. Var. $\alpha$. vulgaris: Blättchen eyf., die der untersten B. rundl. - $\beta$. montana: Blättchen eyf.-längl. od. ey-lanzettf. V. montana Fröl.

16. V. panno nic a Jacq. Tr. blattwinkelst., 3-4bth., sehr kurz; B. 5-8paarig, Blättchen längl. u. vkteyf., stumpf od. gestutzt; Fahne haarig; Zähne des K. pfrieml.-borstl., nngefähr so lang als ihre Röhre; Hïlsen hinabgeschlagen, längl., rauhh., Haare einfach. $\odot$. Aecker; Stmk., Mähr., Oestr., Istrien. Mai-Jul. Bth. weissl. Fahne auf dem Rücken bräunl., vorne braungestreift. Var. $\beta$. purpurascens: Bth. purpurn. V. purpurascens DC:

17. V. hy brida L. Bth. blattwinkelst., einzeln, kurz-gestielt; B. mit einer Wickelranke endigend, 5-7paarig, Blättchen längl. od. vkteyf., gestutzt; Fahne haarig; Zähne des K. pfrienl., mingleich; geradehervorgestreckt; Hülsen hinabgeschlagen, elliptisch-längl., rauhl., Haare auf einem feinen Knötchen sitzend. ○. Kultiv. O., Grasplätze; Triest, Fiume, sïdl. Schwz. Mai. Jun. Bl. gelblichweiss. Var. Blättchen kurz, vktherzf., u. $\beta$. angustifolia, Blättchen längl., kaum gestutzt.

18. V. lutea L. Bth. blattwinkelst, einzeln u. gezweiet, kurzgestielt; B. 5-8parig, Blättcheu lineal. u. längl., stumpf; Fahre 
kahl; Zähne des K. lanzettl., zugespitzt, ungleich, die 2 oberen um die Hälfte kïrzer, zsneigend, der unterste länger als die Röhre; Hülsen hinabgeschlagen, elliptisch-längl., rauhh., Haare auf einem starken Knötchen sitzєnd. $\odot$. Unter der Saat; südl. Schwz. selten, auf der Rheinfläche zerstreut v. Strassbg. bis Neuwied. Jun. Jul. Bl. hellgelb. Var. mit rosenrothen B1., u. $\beta$. hirta, St. dicker, aufrechter; die ganze Pflanze mehr steifh., Bth. manchmal, nicht immer, bleicher: V. hirta Balb.

19. V. grandiflora Scop. Bth. blattwinkelst, einzeln u. gezweiet, kurzgestielt; B. 4-7paarig, Blättchen vkteyf. od. längl.-lineal., gestutzt; Fahne kahl, noch 1 mal so lang als die Flïgel; Zähne des $K$. lanzettf.-pfrieml., halb so lang als ilıre Röhre, fast gleich, geradehervorgestreckt; Hülsen wagerecht-abstehend, lineal.-längl., flaumig, od. kahl. $\odot$. Aecker, Grasplätze; Litt., Istr., Fiume. Mai. Jun. Bl. hellgelb, Fahne auf dem Rüicken nach der Basis olivenbraun. Var. $\alpha$. Scopoliana: Blättchen kurz, vktherzf. $-\beta$. Kitaibeliana: Blättchen, mit Ausnahme der untersten B., längl.-keilig. V. sordida WK. $-\gamma$. Biehersteiniana: Blättchen der oberen B. lineal. V. Biebersteinii Bess. V. sordida M. Bieberst.

20. V. sativa L. Bth. blattwinkelst., meist gezweiet, kurzgestielt; B. meist 7paarig, Blättchen vkteyf. orl. längl.-vkteyf., sämmtl. ausgerandet-gestutzt; Fahne kahl; Zähne des K. lanzettl.-pfrieml., ungefähr so lang als iłrre Röhre, geradehervorgestreckt; Hülsen aufrecht, längl., flaumig; S. kugelig; etwas zsgedrückt. ○. Aecker; in den siidlicheren Gegenden, u. iberall kultiv. Jun. Fahne blau, Fliigel purpurn.

21. V. angustifolia Roth. Bth. blattwinkelst., meist gezweiet, kurz-gestielt; B. meist 5paarig, Blättchen der unteren B. vkteyf., ausgerandet-gestutzt od. abgeschnitten; Fahne kahl; Zähne des $K$. lanzettf.-pfrieml., ungefähr so lang als ihre Rölre, geradehervorgestreckt; Hülsen abstehend, lineal., bei der Reife kahl; S. kugelig. ○. Aecker. Mai-Jul. Bth. purpurn. Die reifen Hïlsen schwarz. Var. $\alpha$. segetalis: Blättchen der oberen B. lanzettl.-lineal. V. sativa ק. Ser. bei DC. V. segetalis Thuill. V. angustifolia Forster. $-\beta$. Bobartii: Blättchen der oberen B. lineal. V. Bobartii Forst. V. angustifolia Smith., Roth. Spielt mit lichtbraunen, braungefleckten u. schwarzen S.

22. V. cordata Wulfen. Bth. blattwinkelst,, meist gezweiet, kurz-gestielt; B. meist 7 paarig, Blättchen der unteren B. vktherzf., die der oberen lineal.-keilig, 2lappig-ausgerandet; Fahne kahl; Zähne des K. lanzettf.-pfrieml., geradehervorgestreckt; Hülsen lineal. $\odot$. Unter der Saat; Littor., Krain. Mai. Jun. BI. purp.

23. V. peregrina L. Bth. blattwinkelst., einzeln, kurz-gestielt; B. 4-7paarig, Blättchen lineal., gestutzt; Fahne kahl; Zähne des $K$. lanzettl., zugespitzt, fast gleich, die 4 oberen aufwärts gekrümmt; 
Hülsen herabgeschlagen, längl., flaumig. $\odot$. Kultiv. O.; Unterstmk., Istr., Fiume. Mai. Jun. Fahne trübviolett, Flügel u. Schiffchen weissl. od. lila. Nabel oval, halb so lang als bei $V$. angustifolia.

24. V. I a th y r o ides L. Bth. blattwinkelst., einzeln, fast sitzend; B. 2-3paarig, mit einer Stachelspitze, die oberen mit einer Wickelranke endigend, Blättchen vkteyf., gestutzt; Zähne des K. pfrieml., gerade, fast gleich; Hülsen lineal., kahl; S. cubisch, körnig-rauh. $\odot$. 'Triften, Hügel, mit niedrigem Grase bedeckte, trockene Wiesen; zerstr. deh das Geb. Apr. Mai. Bth. klein; Bl. hellviolett.

32. ERVUM L. Linse.

I. Rotte. Gf. oberwärts iiberall gleichf,-behaart. Hierher gelört die erste Rotte der Gattung Vicia.

1. E. hirsutum L. Bthstiele 2-6bth., ungefähr so lang als das $B$.; die oberen $B$. mit einer Wickelranke endigend, meist 6paarig, Blättchen lineal., stumpf od. gestutzt; die unteren NebenB. lanzettl., halbspiessf., Zähne des K. so lang als ihre Röhre; Hülsen längl., 2samig, flaumig. $\odot$. Aecker, Gärten, sandige Ufer. Jun. Jul. Vicia hirsuta K. syn. ed. 1. Bl. bläul.-weiss.

2. E. tetraspermum L. Bthstiele 1bth., grannenlos, ungefähr so lang als das B.; die oberen B. mit einer Wickelranke endigend, 3-4paarig, Blättchen lineal., stumpf; NebenB. halbspiessf.; Zähne des K. kürzer als ihre Röhre; Hülsen lineal., 4samig, kahl. $\odot$. Kultiv. O., Sandfelder. Jun. Jul. Vicia tetrasperma Mönch. K. syn. ed. 1. Fahne lila, blau-gestreift, Flügel u. Schiffchen weissl.

3. E. gracile DC. Bthstiele 1-4bth., begrannt, zuletzt noch 1 mal so lang als das B.; die oberen B. 3-4paarig, Blättchen lineal., spitz; NebenB. halbspiessf.; Zähne des K. kürzer als ihre Röhre; Hülsen lincal., 6samig, kahl. $\odot$. Kultiv. O.; Rheinfläche, zerstreut v. Basel bis Westphal., Thüring., Istr. Jun. Jul. Vicia gracilis Lois. K. syn. ed. 1. Bl. fast noch $1 \mathrm{mal}$ so gross als bei der vorhergehenden, Nabel des S. aber um die Hälfte kürzer u. oval.

4. E. monanthos $\mathrm{L}$. Bthstiele 1 bth., ungefähr so lang als das B.; B. meist 7paarig, Blättchen lineal., stumpf od. gestutzt; Nehen B. ungleichförmig, das eine lineal., ganz, sitzend, das andere halbínondf., borstl.-gezähnt, gestielt; Zähne des K. länger als ihre Röhre; Hülsen breit-längl., meist 3samig. $\odot$. Aecker, kultiv. O.; am mittleren Rheine auf dem Meienfelde bei Andernach u. um Coblenz häufig, ausserdem hin u. wieder, wo die Pflanze kultivirt wird. Jun. Jul. Vicia monantha K. syn. ed. 1. V. multifida Wallr. Fahne lila, mit violetten Adern.

5. E. Ervilia L. Bthstiele 2bth., kiirzer als das B.; B. meist 10paarig, mit einer Stachelspitze endigend, Blättchen längl., gestutzt; NebenB. gleich, halbspiessf., gezähnt; Zähne des K. pfrieml., länger als ihre Röhre; Hülsen lineal.-längl., buchtig-holperig, fast perlschnurf. 
○. Aecker unter der Saat; Istr., Oberbad., Glahn- u. Nahethal der Pfalz, Schwz. Jun. Jul. Vicia Ervilia Willd., K. syn. ed. 1. Bl. weissl., Fahne violett-gestreift; S. eckig-kugelig.

II. Rotte. Gf. auf seiner oberen Fläche eben u. gegen die Spitze hin der Länge nach behaart, auf der unteren Seite kahl. Arten von Lathyrus.

6. E. Lens L. Bthstiele 1-2bth., ungefähr so lang, als das B., begrannt; die oberen $B$. mit einer Wickelranke endigend, meist 6paarig; NebenB. lanzettl., ganzrandig; K. so lang als die Bl.; Hülsen fast. rautenf., 2 samig, kahl. (-) Kultiv, u. hie u. da gleichsam wild. Jun. Jul. Fahne weiss, mit lilafarb. Adern.

7. E. nigricans M. B. Bthstiele 1-2bth., länger als das B., begrannt; $B$. mit einer Stachelspitze endigend, die oberen 3 paarig; Neben B. halbspiessf., gezähnelt; K. so lang als die BI.; Hülsen fast rautenf., 2samig, kahl. $\odot$. Unkultiv. O.; Istrien, Montfaleone. Apr. Mai. Bl. bläulichweiss.

8. E. Lenticula Schreb. Bthstiele 1bth., länger als das B., grannenlos; B. mit einer Stachelspitze endigend, die oberen 3paarig; NebenB. halbspiessf., ganzrandig; K. kürzer als die Bl.; Hülsen fast rautenf., 2samig, flaumig. $\odot$. Steinige, unkultiv. O.; Kärnthen, Fiume. Jun. Jul. Bl. bläulich-treiss.

\section{PISUM L. Erbse.}

1. P. elatius MBieberst. NebenB. eyf., halhherzf., an der Basis ungleich-gezähnt, 2-3mal kürzer als die Bthstiele; B. 3paarig, Blättchen elliptisch od. längl.; Bthstiele $1-2 b$ th. $\odot$ ? Lebende Zäune in Istrien. Jun? P. elatum DC. prodr.

2. P. arvense L. NebenB. ey-halbherzf., an der Basis ungleichgezähnt, so lang als der 1 bth. Bthstiel od. bis an die untere Bthe der $2 b t h$. Bthstiele reichend; B. 2-3paarig, Blättchen eyf., kleingekerbt; Bthstiele meist 2bth.; S. kantig-eingedrückt. $\odot$. Kultiv. Mai-Jul. Pisum arvense Schübl. u. Mart. Deutsch: Zuckererbse. Fahue hellviolett, Fligel purpurn. S. grau-griin, braun-punktirt.

3. P. sativum L. NebenB. ey-halbherzf., an der Basis ungleichgezähnt, so lang als der 1 btll. Bthstiel od. bis an die untere Bthe der 2 btl. Bthstiele reichend, gezähnt; B. 3paarig, Blättchen eyf., ganzrandig, am Rande wellig; Bthstiele 2-vielbth.; S. kugelig. $\odot$. Kultiv. Mai-Jul. Deutsch: Brecherbse. Bth. immer weiss. S. nicht eingedrückt, gleichfarbig, hellgefärbt.

4. P. unaritimum L. Neben B. spiessf., mit spitzen Oehrehen; B. Apaarig, Blättchen elliptiseh, ganzrandig; Bthstiele reichbth.; St. kantig. 24. Am Meere; Mecklenbg., Pomm., Preuss., Istrien. Jun.Aug. Fahne purpurn, mit dunkleren Adern; Flügel bläul.-rosenfarben. 


\section{LÁTHYRUS L. Platterbse.}

I. Rotte. Nissolia. Die Blätter fehlend; Bstiel wickelrankenf. od. blattförmig.

1. L. Aphaca L. Bthstiele 1bth.; Bstiele fädl., blattlos, mit einer Wickelranke endigend; Neben B. sehr gross, vkteyf., an der Basis geöhrelt-pfeilf. $\odot$. Aecker der Ebenen; zerstr. dch das mittl. u. siidl. Geb. Jun. Jul. Bl. gelb. S. glatt.

2. L. Nissolia L. Bthstiele 1-2bth.; Bstiele lanzettl., blattf., oline Wickelranke; NebenB. pfrieml., an der Basis halbspiessf. $\odot$. Aecker; zerstr. im westl. Geb., sodam Schles., Krain. Mai-Jul. Bl. purpurn. S. knötig-rauh.

II. Rotte. Clymen um DC. Die unteren Bstiele blattlos, die oberen blättertragend.

3. L. Ochrus DC. Bthstiele 1bth.; Bstiele breit-geflügelt, die unteren hinablaufend, lanzettl. od. elliptisch, blattlos, die oberen blättertrag.; B. 1-2paarig; Hülsen breit-längl., zsgedrüickt, netzigaderig, kahl, 4-8samig, am oberen Rande 2flïgelig, Flügel häutig; S. kugelig u. etwas kantig, glatt. $\odot$. Unter dem Getreide; Istr. Mai. Jun. Pisum Ochrus L. Bl. gelblichweiss.

4. L. purpureus Desfontaines. Bthstiele 1-3bth.; Bstiele breitgeflügelt, die unteren hinablaufend, lanzettl., zugespitzt, blattlos, die oberen blättertrag.; B. 1-3paarig; Hülsen längl.-lineal., am oberen Rarde stumpf-2kielig; S. etwas zsgedriiclit, oft an beiden Enden abgestutzt, glatt. $\odot$. Kultiv. Land; Insel Unie bei Istr. Mai. Jun. L. auriculatus Bertol. L. spurius Willd. Fahne purp., Flügel bläul., Schiffehen weissilich.

III. Rotte. Eulathyrus DC. Alle Bstiele blättertragend.

§. 1. B. 1-2paarig; Bthstiele 1-2bth.; W. jährig.

a. S. glatt.

5. L. inconspicuus L. Bthstiele 1bth., kürzer als der Bstiel, an der Basis gegliedert, grannenlos, mit kleinen Deckblättchen; $\mathbf{B}$. 1paarig; der Fruchtkn. seidenh.-zottig; Hülsen verlängert, lineal., 8-10samig, gedunsen, flaumig, gestreift-aderig; S. oval, beiderseits abgeschnitten-stumpf, glatt, Nabel rundl. $\odot$. Meeresstrand; Istrien. Jun. Jul. Bl. bläulich.

6. L. stans Visiani. Bthstiel 1bth., kürzer als der Bstiel, an der Basis gegliedert, grannenlos, mit einem kleinen Deckblättchen; B. 1paarig; Fruchtkn. kahl, fein drïsig-punktirt; Hülsen lang-lineal., 8-10samig, gedunseu, kahl, gestreift-aderig; S. kugelig, glatt, Nabel rundl. $\odot$. Unter der Saat; Fiume. Jun. Jul. B1. lila.

7. L. sphaericus Retz. Bthstiele 1bth., kürzer als der Bstiel, an der Basis gegliedert u. begrannt; B. 1paarig; der Fruchtkn. kahl; 
Hülsen verlängert, lineal., 8-10samig, gedunsen, kahl, nervig, gestreift-aderig, Adern hervor'springend; S. kugelig, glatt, Nabel längl.oval. - . Auf Aeckern n. an grasreichen O.; Wallis, suidl. Tyrol, Triest, Istrien. Mai. Jun. L. coccinens All. L. axillaris Lam. Bl. ziegelroth, Falıne purp.-geadert, Schiffchen weissl.

8. L. Cicera L. Bthstiele 16th., kürzer als das B., oberwärts gegliedert, mit kleinen Deckblättchen; Bstiele schmal-geflügelt, lineal., alle blättertrag.; B. 1paarig; Hülsen (reife) längl., zsgedrückt, netzigaderig, kahl, meist 4samig, der obere Rand gerade, schmal-2flügelig; S. kantig, glatt. $\odot$. Aecker, kultiv. O.; Schwz am Genfersee, Littor., Istrien, Fiume. Apr.-Jun. Bl. roth. S. röthlich, ungefleckt.

9. L. sativus Is. Bthstiele 1bth., kürzer als das B., oberwärts gegliedert, mit kleinen Deckblättchen; Bstiele schmal-gefliigelt, lineal., alle blättertrag.; B. 1 paarig; Hü!sen elliptisch-längl., flach-zsgedrückt, netzig-aderig, kahl, meist 4samig, der obere Rand gekrümmt, 2flügelig; S. kantig, glatt. $\odot$. Aecker; siidl. Geb., auch hin u. wieder im Grossen gebanet. Mai. Jun. Bl. blau, rosenroth u. weiss. Zpfl. des K. abstehend, bei L. Cicera aufrecht. S. ledergelb, braun-gefleckt.

b. S. knötig-rauh.

10. L. setifolius L. Bthstiele 1bth., kürzer als das B., oberwärts gegliedert, mit kleinen Deckblättchen; B. 1paarig; Hülsen längl., flachzsgedrückt, netzig-aderig, kahl, 2-3samig; S. kugelig, knötig-rauh. ○. Weinberge, steinige O.; Istrien, Fiume. Apr.-Jun. Bl. purpurn.

11. L. annu s L. Bthstiele 1bth., kürzer als das B., an den Bthstielchen mit Deckblättchen; B. 1paarig; Hülsen lineal. -längl., zsgedrückt, netzig-aderig, kahl, 6samig; S. kugelig, knötig-rauh. $\odot$. Kultiv. O.; Osero. Mai-Jun. Bl. gelb. St. geflügelt.

12. L. angulatus L. Bthstiele 1bth., länger als das B., an der Spitze gegliedert u. begrannt; B. 1paarig; Hülsen schmal-lineal., glatt, aderlos, kahl, meist 10samig; S. cubisch, knötig-rauh. $\odot$. Weinberge, Aecker; Wallis, Littor. Bl. purpurn.

13. L. hirsutus L. Bthstiele 2bth., länger als das B.; B. 1paarig; Hülsen lineal-längl., rauhh., Haare an der Basis zwiebelig; S. kugelig, knötig-rauh. $\odot$. Aecker; sehr zerstr. dch das siidl. u. mittl. Geb. Bl. violettroth, damn blau.

§. 2. B. 1-mehrpaarig. Bthstiele reichbth. W. perennirend.

a. St. kantig, flügellos.

14. L. tuberosus L. Bthstiele reichbth., länger als das B.; B. 1 paarig; Hülsen lineal.-längl., kahl, netzig-aderig; S. schwachknötig; die oberen Zähne des K. kurz-3eckig; St. kantig, flügellos. 4. Aecker. Jul. Aug. Bl. purpurn.

15. L. pratensis L. Bthstiele reichbth., länger als das B.; B. 
1paarig; Oehrehen deı NebenB. lanzettl., pfeilf.-zuriiekgekrimmt; Hiilsen lineal.-längl., sehief-aderig, Adern hervorspringend; S. kugelig, glatt; Zähne desK. kürzer als der Fruchthn. sämmtl. lanzettf.-pfrieml.; St. kantig, flügellos. 2. Wiesen, Zäune, Ufer. Jın. Jul. Bl. gelb. Var. grauzottig.

16. L. s e piu m Seop. Bthstiele reiehbth., länger als das B.; B.1paarig; Oehrchen der NebenB. eyf., spiessförmig, fast reeht-winkeligabstehend; Hülsen....; Zähne des K. sämmtl. lanzettl.-pfrieml., der untere so lang als der Fruchtkn.; St. kantig, flügellos. 24. Hecken bei Görz. Mai. Jun. L. Hallersteinii Baumgart. Bl. gelb.

b. St. augenfällig geflïgelt.

17. L. sylvestris-L. Bthsticle reichbtlı., länger als das B.; B. 1paarig; Hülsen längl.-lineal., kahl; S. knötig-runzelig, Nabel die Hälfte des S. umgebend; St. breit-geflïgelt, Flügel noch einmal so breit als die der Bstiele. 24. Waldige, buschige, gebirgige O. Jul. Aug. Fahne auf dem Rüicken röthl.-grün, inwendig an der Basis purpurn, iibrigens fleisehroth mit dunkleren Adern, Fligel vorne u. das Schiffchen an der Spitze purpurn.

18. L. platyphyllos Retzius. Bthstiele reichbth., länger als das B.; B. cinpaarig; Hülsen längl.-lineal.; S. schwach-knötig; Nabel die Hälfte des S. umgebend; St. breit-geflügelt; Flügel der Bstiele fast eben so breit. 2. Gebüseh, waldige O.; zerstr. im nördl. u. mittleren Geb. Jul. Aug. Fahne inwendig rosenroth, Fliigel vorne violett.

19. L. heterophyllus L. Bthstiele reichbth., länger als das B.; die oberen B. 2-3páarig; Hülsen längl.-lineal., kahl.; S. knötig, Knötchen rundl.; Nabel kaum 1/3 des S. umgebend; St. breit-gefligelt; die Flügel der Bstiele fast eben so breit. 24. Gebiisch, waldige 0 ; zerstr. deh das Geb. Jul. Aug. B1. purp.

20. L. latifolius L. Bthstiele reichbth., länger als das B.; $R$. 1 paarig; Hülsen längl.-lineal., kahl; S. knötig, Knötchen längl., ineinanderfiessend; Nabel kaum 1/3 des S. umgebend; St. breit-gefligelt; die Flügel der Bstiele fast eben so breit. 2. Gebiisch, Hecken; Istr., Fiume, ïbrigens hin u. wieder verwildert. Jul. Aug. Bth. schön rosemroth. B. $1 \frac{1}{2} "$ breit, od. Var. $P$. angustatus, schmäler u. nur $1 \frac{1}{2}$ “' breit, letzterer: L. ensifolius Badarro.

21. L. palustris L. Bthstiele reichbth., länger als das B.; $B$. 2-3paarig; Oehrehen der NebenB. lanzettl., zugespitzt; Hülsen lineal.längl., gerade, kahl; S. glatt, Nabel den vierten Theil des S. umgebend; St. geflügelt; Bstiele flügellos, schmalberandet. 24. Sumpfige Wiesen; zerstr. deh das Geb. Jul. Aug. BI. blau.

35. ÓROBUS L. Walderbse. Ist generisch v. Lathyrus nicht versehieden.

1. O. vernus L. 'St. kantig; B. 2-3paarig, Blättchen eyf., 
längl.-eyf., lanzettl., od. lineal., lang-zugespitzt, gewimpert, unterseits glänzend; Bthstiele blattwinkelst., gerade, meist 4 bth., ungefähr so lang als die B.; Hülsen kahl. 24. Wälder bis in die A. hinauf. Apr. Mai. Bl. purpurn, sodann lasurblau-schimmernd, zuletzt ins Grüne iibergehend. S. glatt, NabeI $1 / 3$ des S. umgebend. Var. $\beta$. flaccidus: Blättchen lanzettl., $2-3^{\prime \prime}$ lang, $5-6^{\prime \prime \prime}$ breit. O. flaccidus Radius. - $\gamma$. gracilis: Blättchen lineal., $1 / 2-1^{\prime \prime \prime}$ breit, $2-3^{\prime \prime}$ lang. O. gracilis Gaud.

2. O. variegatus Tenore. St. kantig; ${ }^{\prime} .2-3$ paarig, Blättchen breit-eyf., zugespitzt, an der Basis schiff-abgerundet, gewimpert, unterseits glänzend; Bthstiele blattwinkelst., einwärtsgekrümmt, reichbth., ungefähr so lang als das B.; die jüngeren Hülsen fcin-drüsig-rauh. 24. Bergwälder; Triest, Görz, Krain, siidl. Tyrol. Jun. Jul. Bl. purpurn, mit satteren Linien auf der Fahne.

3. O. tuberosus L. St. geflügelt; B. 2-3paarig, Blättchen lanzettf.-längl. od. lineal., unterseits meergrün, glanzlos; Gf. lineal.; Wurzelstock kriechend, an den Gliedern knollig. 24. Wälder. Apr. Mai. Bl. hellpurp. Var. $\beta$. tenuifolius: Blättchen lineal. od. auch sehr schmal-lineal., nur $1 / 2$ Linie breit. O. linifolius Reichard. O. tenuifolius Roth.

4. O. albus L. St. kantig, einfach, oberwärts schmal-geflügelt; B. 2-3paarig, Blättchen lineal.-lanzettl. u. lineal., kahl; NebenB. an die Basis der unteren Blättchen reichend u. kürzer; Gf. lincal.; W. büschelig, Fasern keulig. 24. Bergwiesen, steinige 0.; Böhm., Mähr., Oestr., Littor., Hirschaner Berge in Würtemb. Mai. Jun. O. pannonicus Jacq. Bl. weiss od. gelbl.-weiss, Fahne auf dem Rücken oft rosenroth iiberlaufen. Var. $\beta$. versicolor: Fahne purpurn, Fliigel u. Schiffchen gelb. O. versicolor Gmel. K. syn. ed. 1.

5. O. Iuteus L. St. kantig, meist 1 fach; B. meist 4paarig, Blättchen elliptisch, ziemlich spitz, unterseits ineergrün, glanzlos; Gf. lineal., an der Spitze bärtig; Wurzelstock wagerecht, Fasern fädl., die heurigen einfach, d. älteren feinzaserig; Nabel 1/4 des S. umgebend. 24. Wälder höherer Gbge u. A.; Schwz., Tyrol, Salzb., Krain, Stmk. Mai. Jun. O. montanus Scop. O. laevigatus WK. Bl. anfänglich gelblich-weiss, sodann gelbbraun.

6. O. niger L. St. kantig, ästig; B. meist 6paarig, Blättchen eyf.-längl., stumpf, unterseits meergrün, glanzlos; Gf. lineal., v. der Mitte bis zur Spitze bärtig; W. ästig. 24. Wälder. Jun. Jul. Bl. purpurn.

IV. Gruppe. PHASEOLEEN Bronn. Hülse 1 fächerig. B. 3zählig; die Blättchen mit Nebenblättchen. KeimB. dick. Erste Blätter gegenständig.

36. PHASÉOLUS I. Bohne.

1. Ph. multiflorus Willd. Blättehen eyf., zugespitzt; Tr. ge- 
stielt, länger als das B.; Bthstielchen gezweiet; Hülsen hängend, etwas sichelf. $\odot$. Kultivirt. Jul. Ang. Bl. weiss. Var. mit hochrothen Bl.: $\mathrm{Ph}$. vulgaris $\rho$. coccineus $\mathrm{L}$. Ph. coccineus Lam.

2. Ph. vulgaris L. Blättchen eyf., zugespitzt; ' $T$ 'r. gestielt, kürzer als das B.; Bthstielchen gezweiet; Hülsen hängend, ziemlich gerade. $\odot$. Kultiv. Var. in Gestalt u. Farbe des S. u. mit schlingendem hohem St.: Ph. vulgaris $\alpha$. L.; u. mit niedrigem, kaum schlingendem St.: Ph. nanus L. Jul. Aug. BI. weiss od. röthl.

\section{Ordng. CAESALPINIEEN. R. Brown.}

1. CERATÓNIA L. Johannisbrod.

1. C. Siliqua L. Wehrlos; Blättchen oval, stumpf, flach. $\hbar$. Unkultiv. O.; Istr., Osero. Sept. Oct.

2. CERCIS L. Judasbaum.

1. C. Siliquastrum L. B. sehr stumpf, ganz kahl. h. Steinige O.; südl. Tyrol. Apr. Mai. Bl. rosenroth.

\section{Ordng. AMYGDALEEN. Juss.}

\section{AMÝGDALUS L. Mandelbaum.}

1. A. communi s L. B. lanzettl., driisig-gesägt; Bstiel oberwärts drüsig, so lang als der Querdurchmesser des B. od. länger; Röhre des K. glockig; Nussschale mit Löchelchen durchstochen. Ђ. In wärmeren Gegenden kultiv.; auf Felsen bei Fiume u. im Wallis verwildert. Febr.-Apr. Blb. hellrosenroth, od. weiss.

2. A. nana L. B. lanzettl., in den kurzen Bstiel verschmälert, driisenlos-gesägt, an der Basis ganzrandig, gänzlich kahl; Röhre des K. walzl.; Nussschale fast glatt, olnne Löchelchen. Ђ. Steinige O.; Wien, an der Donau hinauf gegen Bayern. Apr. Bl. hellrosenroth.

2. PÉRSICA Tournef. Pfirsichbaum.

1. P. vulgaris Mill. Ђ. In wärmeren Gegenden kultiv. u. auf Felsen bei Fiume verwildert. März, Apr. Amygdalus Persica L. Blb. hellrosenroth. Untersch. sich v. A. communis dch spitz u. oft doppeltgesägte B. u. den kurzen, nicht den halben Querdurchmesser eines B. erreichenden Bstiel.

3. PRUNUS L. Pflaume (u. Kirsche).

I. Rotte. Armeniaca, Aprikose. Tournef. Steinfrucht sammetartig. 
1. P. Armeniaca L. Bth. seitenst., einzeln $u$. gezweiet, kurzgestielt; Bthstielchen eingeschlossen; B. eyf., etwas herzf., zugespitzt,

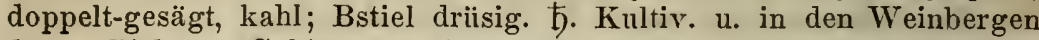
des südlichsten Gebiets verwildert, März. Apr. Deutsch: Aprikosenbaum. Blb. weiss.

II. Rotte. Pruni gen uinae, eigentliche Pflaumen. Steinfrucht kahl, mit einem bläulichen od. weisslichen, leicht wegzuwischenden Reife.

2. P. spinosa L. Bthknospen 1bth., einzeln, gezweiet od. zu dreien; Bthstiele kahl; Aestchen flaumig; B. elliptisch od. breit-lanzettl. ; Früchte kugelig, aufrecht. ち. Hecken, Zäune, Wälder, steinige O. Apr. Mai. Schlehendorn. Blb. weiss. Mit gleichzeitigen Bth.: P. spinosa $\beta$. coretanea W. u. G. P. fruticans Weihe.

3. P. insititia L. Bthknospen meist 2bth.; Bthstiele sehr feinflaumig; Aestchen sammetig; B. elliptisch; Frïchte kugelig, hängend. Ђ. Gebauet $\mathfrak{u}$. in Zäunen u. Obstgärten verwildert. Apr. Mai. Haferschlehe, Spilling. Blb. rundlich, schneeweiss.

4. P. d o mestica L. Bthknospen meist 2bth.; Bthstiele flaumig Aestchen kahl; B. elliptisch; Früchte längl. ち. Kultiv. u. hie u. da verwildert. Apr. Mai, später als die vorherg. Zwetsche. Blb. längl.eyf., weiss, ins Grïnliche spielend.

5. P. cerasifera Ehrh. Bthknospen 1bth.; Bthstiele nebst den Aestchen kahl; B. elliptisch; Früchte kugelig, hängend. \$. Unter dem Namen Kirschpflaume kultiv. Apr. Mai. Früchte roth, saftig. B1. weiss.

III. Rotte. Cerasi, Kirschen. Steinfrucht kahl, ohne Reif. Die Bth. zu 2 od. doldig, aus einer Knospe. Blb. weiss.

6. P. avium L. Dolden sitzend; Schuppen der Bthknospen blattlos; $B$. elliptisch, zugespitzt, etwas runzelig, unterseits flaumig; Bstiel 2 drüsig; W. nicht ausläufertreibend. 占. Wälder. Apr. Mai.

7. P. Cerasus L. Dolden sitzend; die inneren Schuppen der Bthknospen blättertrag.; $B$. flach, kahl, glänzend, etwas lederig, elliptisch, sämmtl. zugespitzt; Bstiel drüsenlos; Blb. rund; W. ausläufertreibend. Ђ. Aus dem Oriente, nun iiberall kultiv., in Zäunen u. Obstgärten verwildert. Apr. Mai.

8. P. Ch am a e e r a s u Jacq. Dolden sitzend; die inneren Schuppen der Bthknospen blättertrag.; B. flach, kahl, glänzered, etwas lederig, die oberen längl. od. lanzettl., zugespitzt, die der seitenst. Knospen vkteyf., abgerundet-stumpf; Bstiel drisenlos; Blb. längl.vkteyf. od. vkteyf.; W. ausläufertreibend. Ђ. Bergabhänge, Raine, Wege; Unteröstr., Böhmen, um Halle, Rheinpfalz. Apr. Mai.

IV. Rotte. Padi, Traubenkirschen. Steinfrucht kahl, ohne Reif. Bth. traubig, nach den B. erscheinend. Blb. weiss. 
1/2. Hopulifölia, L. B.einung og. hery-eimus, mehrod.

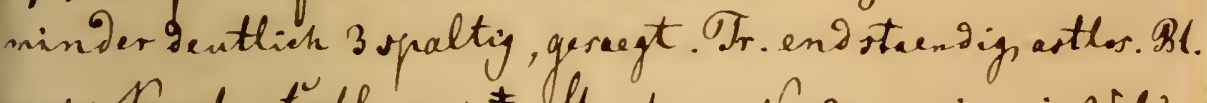
weios. Kaprel anfgeblasen. 5 lftant ang Noxgamerice, in Walde - Preitenfeld 6. Leipgig andeptlangte vex wildast. Mai, Luni.

$\#$ 


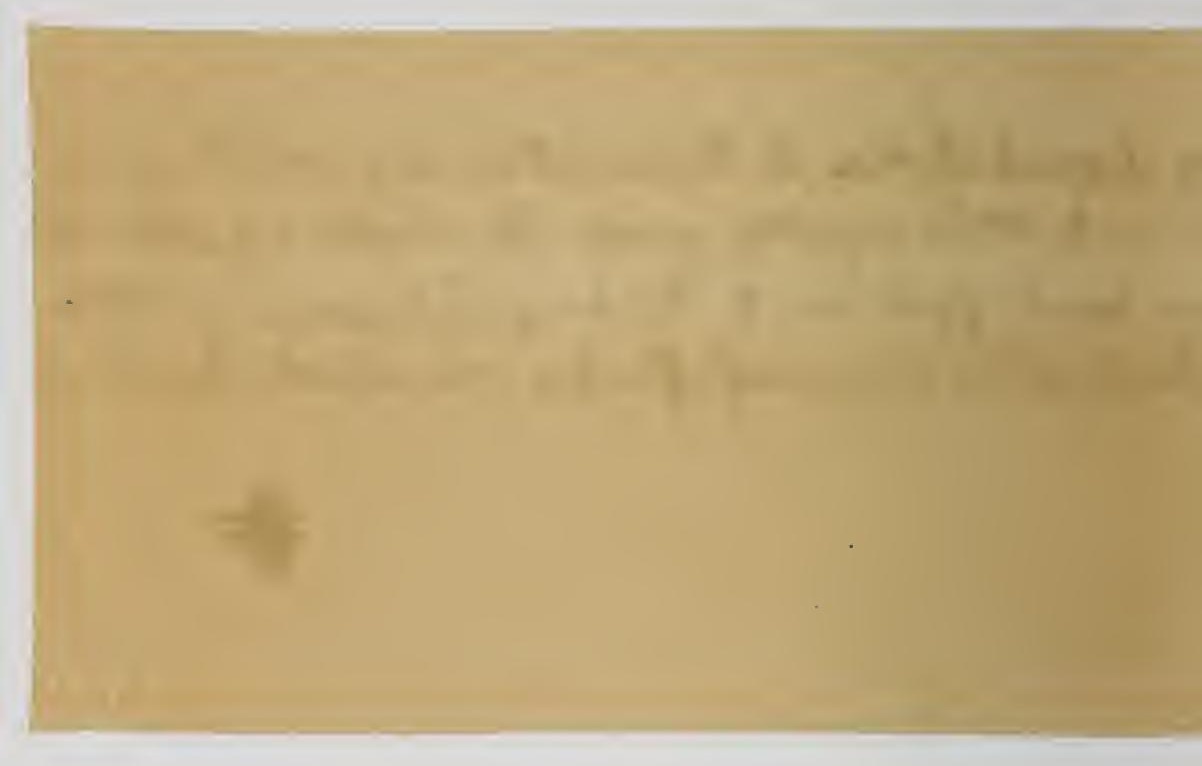


9. P. Padus L. $T r$. üherhangend; B. abfällig, elliptisch, fast doppelt-gesägt, etwas runzclig; Bstiel 2driisig. 1). Feuchte Haine, Ufer, Gebüsch. Mai.

10. P. MI a haleb L. Ehensträusse gestielt, convex, einfach; B.

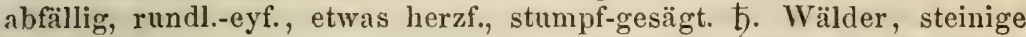
O., in die VorA. hinauf; suidl. Scliwz., Suidtyr., Krain, Litt., Regensb., Rhein-, Nahe- u. Mosel-Gbge. Mai. Jun.

\section{Ordng. ROSACEEN. Juss.}

1. Gruppe. SPIRAEACEEN DC. Fritchtchen 2-4eyig, bei der Reife kapselig, einwärts aufspringend.

1. SPIRÁEA L. Spierstaude. lend.

I. Rotte. Chamaedryon Ser. Bth. zwitterig. NebenB. feh-

1. S. S ali cifolia L. B. längl.-lanzettl., ungleich- fast doppeltgesägt, kahl; Tr. gedrungen-rispig. $\hbar$. Haine, Ufer; Kärnth., Krain, Stmk., Böhm. Jul. Aug. Blb. rosenroth.

2. S. ulmifolia Scop. B. eyf., spitz, ungleich- fast doppeltgesägt, an d. Basis abgerundet, ganzrandig, beiderseits kahl, die jüngeren am Rande u. unterseits flaumig; Aestchen kantig-gestreift; Ebensträusse endst., fast halbkugelig, eiufach; Stbg. länger als die Blb. ち. Felsige O.; Krain, Görz. Mai. Jun. S. chamaedryfolia Jacq. BI. weiss.

3. S. chamaedryfolia L. B. vkteyf. od. längl., stumpf, vorne mit wenig Kerben, an der Basis in den kurzen Bstiel verschmälert, am Rande flaumig-wimperig, die unteren ganzrandig; Aestchen stielmund, glatt; Ebensträusse endst., fast halbkugelig, einfach; Stbg. so lang als die Blb. ち. Berge; Krain. Mai. Jun. Bl. Wéiss.

4. S. d ecu mbens Koch. B. vkteyf. od. längl., stumpf, ungleich- fast doppelt-gesägt, an der Basis ganzrandig, in den Bstiel verschmälert, ganz kahl; Aestchen stielrund, glatt; Ebensträusse endst., zsgesetzt; Stbg. so lang als die Blb. b. Karnische A. zw. Resciuto u. Ponteba auf der Grenze, aber ausser dem Geb. Mai. Jun Bl. weiss. lend.

II. Rotte. Aruncus Ser. Bth. vielehig-2häusig. NebenB. feh-

5. S. Aruncus L. B. mehrfachzsgesetzt; Aehren rispig; Bth. 2häusig. 4. Feuchte Haine, Bäche u. Quellen, in die VorA. hinauf; zerstr. deh das Geb. Jun. Jul. BI. weiss.

III. Rotte. Ulmaria Cambass. Bth. zwitterig. NebenB. an den Bstiel angewachsen. 
6. S. Ulmaria L. B. unterbrochen-gefiedert, Blättchen eyf., ungeth., das endst. grösser, handf.-3-5sp.; Ebensträusse rispig, sprossend; Kapseln kahl, zsgewunden. 24. Feuchte Wiesen, Gräben, Weidengebïsch. Jun. Jul. Bl. weiss. Var. $\alpha$. denudata: B. unterseits kahl. S. denudata Hayn. - $\beta$. disculor: B. unterseits aschgrau- od. reiss-filzig. S. glanca Schultz.

7. S. Filipendula I. B. unterbrochen-gefiedert, Blättchen längl., fiedersp.-cingeschnitten, Lappen gesägt; Ebensträusse rispig, sprossend; Kapseln flaumig, gleichlaufend an einander-angedrückt. 2 . Viesen; zerstr. deh das Geb. Jun. Jul. Bl. weiss, selten röthlich.

II. Gruppe. DRYADEEN. Früchtchen 2 od. mehrere, 1eyig, nuss- od. steinfruchtartig, nicht aufspringend, auf einem trockenen od. fleischigen Fruchtb. sitzend. Der fruchttrag. K. krautig, od. verhärtet.

2. DRYAS L. Dryade.

1. D. octopetala L. B. gekerbt-gesägt, stumpf. Ђ. Triften der A., mit den Flüssen in die Thäler hinab. Jul. Aug. Bl. weiss.

\section{GEUM L. Geum.}

I. Rotte. Caryophyllata. Der St. mehrbth. Gf. in der Mitte hakig-gegliedert, das obere Glied abfällig.

1. G. urbanum L. Früchtchen behaart, Granne derselben 2gliederig, das untere Glied kahl, 4mal so lang als das obere, letzteres an seiner Basis flaumig; Bth. aufrecht; der fruchttrag. $K$. zurückgeschlagen; Blb. vkteyf.; Fruchtträger fehlend. 24. Haine, feuchtes Gebüisch. Jun. Jul. Bl. gelb.

2. G. intermedi um Ehrl. Früchtchen behaart, ihre Granne 2gliederig, das untere Glied kahl, 4mal so lang als.das obere, letzteres behaart, an der Spitze kabl; Bth. nickend od. aufrecht; der fruchttrag. K. abstehend. 4. Haine, feuchtes Gebiisch; nördl. Geb., Rothenbuch in OBayern u. St. Gallen in der Schwz. Mai. Jun. BI. gelb. Var.: Bl. rothgelb: G. rubifolium Lej., u. ausserdem mit um die Hälfte kleineren $\mathrm{B}$ th.

3. G. rivale I. Friichtchen behaart, ihre Granne 2gliederig, das untere Glierl an der Basis behaart, das obere fast gleichlang mit dem unteren, bis unter die Spitze behaart; Bth. nickend; Blb. so lang als die aufrechten $K B$., breit-r)kteyf., ausgerandet, lang-benagelt; Fruchtträger fast $v$. der Länge des $K_{\text {. }}$; die wurzelst. B. leyerf.-gefiedert, die stengelst. 3zählig. 2. Feuchte Wiesen, Bäche, in die A. hinauf; zerstr. deh das Geb. Mai. Jun. Bl. feuerfarben, selten hellgelb od. weiss.

4. G. inclinatum Schleich. Frïchtchen behaart, ihre Granne 
2 gliederig, Glieder zottig, das untere 2mal so lang als das obere; Bth. nickend; Blb. mundl., schr kurz benage't, so lang als dic anfrechten KB.; Fruchtb. auch bei der Fruchtreife fast sitzend; die wurzelst. B. leyerf.-gefiedert, die stengelst. 3zählig. 2. Fenchte Wiesen; höchste Abhänge der Sudeten, A. der Schwz. Jun. Jul. Bl. gelb. G. sudeticum Tausch. G. pyrenaicum K. syn. ed. 1. Das G. pyrenaic. Willd. ist zweideutig geworden.

III. Rotte. Oreoge um Ser. Siversia Willd. Der St. 1 bth. Gf. nicht gegliedert.

5. G. reptans L. Friichtchen nebst den ununterbrochenen (nicht gegliederten) Grannen zottig; St. 1bth.; Ausläufer niedergestreckt; B. unterbrochen-gefiedert, oberwärts breiter, Blättchen cingeschnitten-gesägt, mit spitzen Sägezähnen, meist 3sp., das endst. 3-5sp. 24. Höchste A.; Schwz., Tyrol, Salzb., Kärnth., Stmk. Jul. Aug. Bl. gelb.

6. G. montanum L. Früclitchen nebst den ununterbrochenen (nicht gegliederten) Grannen zottig; St. 1bth.; Ausläufer fellend; B. leyerf.-unterbrochen-gefiedert, Blättchen ungleich-gekerbt, das endst. sehr gross, fast herzf., stumpf-lappig. 2. Triften der A., VorA. u. höheren Sudet. Jun.-Aug. Bl. gelb.

\section{RUBUS L. Brombeerstrauch.}

1. R. Id a e u s L. St. aufrecht, ästig, strauchig; $B$. gefiedert, die oberen 3zählig; Blb. vkteyf.-keilig, aufrecht; K. abstehend. ち. Wälder, Hecken. Mai. Jun. I3I. weiss, Friichte roth, seltener gelblichweiss.

2. R. fruticosus L. St. bogig-zurïckgekriimmt od. gestreckt, ästig, strauchig; B. 5- u. $3 z a ̈ h l i g ; B l b$. oval u. nebst dem K. $a b$ stehend; Frïchte glänzend; K. bei der Frucht oft zurïckgebogen. Ђ. Wälder, Hecken, Aecker. Jul. Aug. Man untersch. 1. R. fruticosus : B. unterseits weiss-filzig; 2. R. corylifolius Smith: B. unterseits grïn, haarig; 3. R. tomentosus Borkh: B. beiderscits filzig; 4. R. amvenus Portenschl.: B. unterseits filzig, der St. v. sehr dünnem, angedrïcktem Filz weisslich-grau; 5. R. hybridus Vill. (R. glandulosus Bellard.): St. oberwärts nebst der Rispe mit zahlreichen, drüsentrag. Borsten besetzt, $u$. noch viele andere näher $z u$ bestätigende Arten. Bl. weiss od. rosenroth. Friichte schwarz, glänzend.

3. R. ca esius L. St. bogig-zuriickgekrïmmt od. gestreckt, ästig, strauchig; B. 5- u. 3zählig; Blb. oval u. nebst dem K. abstehend; Früchte glanzlos, blau-bereift; $K$. auf der Frucht aufliegend. $\hbar$. Hecken, Aecker. Jul. Aug. I)ie unteren B. seltener 5zählig-gefiedert. Bl. weiss, Friichte blau-bereift, glanzlos.

4. R. saxatilis L. Fruchttrag. St. aufrecht, ganz einfach, krau- 
tig, die unfruchtbaren gestreckt, ausläuferartig; B. 3zählig; Ebenstrauss endst., 3-6bth. \%. Wälder, Haine bis in die A. hinauf; zerstr. deh das Geb. Jun. Jul. Blb. weisslich, Früchte roth. Schale der Steinfriichtchen frisch glatt, getrocknet grubig-runzelig, wie bei den vorhergehenden.

5. R. Chamaemorus L. St. aufrecht, ganz einfach, 1bth.; B. einfach, herz-nierenf., 5lappig; Bth. 2häusig. 4. Sumpfige O.; Riesengeb., Halbinsel Dars in Pomm., Königsberg in Preuss. Mai. Jun. Blb. weiss. Früchte roth, zuletzt rothgelb.

5. FRAGARIA L. Erdbeere.

1. F. vesca I. K. bei der Frucht weit abstehend od. zurückgekriimmt; Stbgf. kaum so lang als das Köpfchen der Ovarien; Haare der Bstiele u. Stengel wagerecht-abstehend, der seitenst. od. aller Bthenstiele aufrecht od. angedruickt. 24. Wälder, Hecken, unkultiv. O. Mai. Jun. Bl. weiss, wie bei den folgenden.

2. F. elatior Ehrh. $K$. bei der Frucht weit abstehend od. zurückgekriimmt; Stbgf. der fruchtbringenden Pflanze so lang als das Köpfchen der Ovarien, der nicht fruchtbringenden noch einmal so lang als diese; Haare der B., St. u. sämmtlichen Bthenstielchen wagerecht-abstehend. 24. Wälder; zerstr. dch das Geb. Mai. Jun.

3. F. Hagenbachiana Lang. $K$. an die Frucht angedrückt; Stbgf. so lang als das Köpfchen der Ovarien; Haare d. Bthenstiele 1. des St. wagerecht-abstehend, der seitenst. od. aller Bthstiele aufrecht od. angedrückt; Blättchen lang-gestielt, das mittlere Bstielchen den vierten Theil so lang als das Blättchen. 24. Steinige Hügel bei Zunzingen im Breisgau, Gegend v. Mühllheim. Mai. Jun. F. Majaufea Seringe?

4. F. collin a Ehrh. $K$. an die" Frucht angedrückt; Stbgf. der nicht fruchtbringenden Pfanze noch einmal so lang als das Köpfchen der-Ovarien; Haare der Bstiele u. Stengel wagerecht-abstehend, der seitenst. od. aller Bthstiele aufrecht od. angedriickt. 24. Gebirgige O., unkultiv. Hügel. Mai. Jun.

\section{CÓMARUM L. Siebenfingerkraut.}

1. C. palustre L. 2. Sumpfige, torfhaltige O., Gràben. Jun. Jul. K. inwendig dunkelrothbraun. Blb. klein, nebst den Stbgf. u. Gf. dunkelbraun-purpurn.

7. POTENTílla L. Fingerkraut.

I. Rotte. Potentillae g enuinae. Früchtehen kahl.

8. 1. A cephala e. W. einfach, jährig od. 2 jährig, treibt einen einzigen St. od. einen $v$. der Basis in mehrere getheilten, aber 
6. OR. og oratus, L. It. aufrecht, tachellos, davisig be

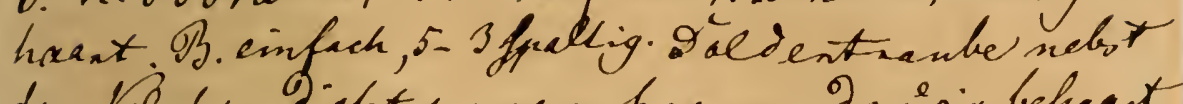

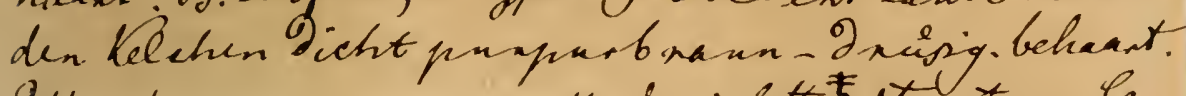

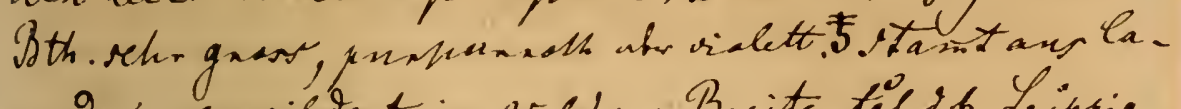
naga; venwiltest in walse v. Breitenfeler b. Leifgig. Auni-Augast. Ofreichte... 

keine bloss blättertragenden, erst im folgenden Jahre einen blühenden St. hervortreibende Wurzelköpfe. Bl. gelb.

1. P. supin a L. St. gabelsp.; B. gefiedert, Blättchen längl.-eingeschnitten-gesägt, die oberen herablaufend; Bth. einzeln; Bthstiele nach dem Verblülten zurückgekrümmt. $\odot$. Aecker, sandige, etwas feuchte O., Wege ; zerstr. deh das Geb. Jun.-Oct.

2. P. norvegica L. St. gabelsp., reichbth., nebst den B. rauhh., Haare abstelıend, an der Basis zwiebelig; B. 3zählig, Blättchen längl.-vkteyf. od. lanzettl., grobgesägt, die wurzelst. 2 paarig-gefiedert; die unteren Bth. gabelst., die oberen zuletzt fast traubig; Nüsschen kahl, schwach-runzelig. $\odot$ u. $\odot$. Sandige, feuchte 0 .; sehr zerstr. deh das Geb. Jun. Jul.

§. 2. Multicipites. W. perennirend, holzig, vielköpfig, treibt blühende St. u. zugleich Blätterbüschel, nämlich nicht blïhende -Wurzelköpfe, welche in den folgenden Jahren erst blïhende St. exzeugen.

* B. gefiedert; Bl. weiss.

3. P. rupestris L. St. aufrecht, oberwärts gabelsp.; die unteren B. gefiedert, die oberen 3zählig; Blättchen eyf.-rundl., ungleicheingeschnitten-gesägt, flaumig; NebenB. ganz; Blb. vkt-eyf., länger als der K. 2. Felsenspalten, steinige $O$. bis in die VorA. hinauf; im mittleren u. südl. Geb. Mai-Jul.

** B. gefiedert; Bl. gelb.

4. P. multifid a L. St. aufstrebend; B. gefiedert, wenig-paarig, Blättchen tief-fiedersp., Zpfl. lincal., unterseits filzig. 4. Um die Gletscher; Walliser A. Jul. Aug.

5. P. an serina L. St. rankenartig, kriechend; B. unterbrochengefiedert, vielpaarig, Blättchen längl., geschärft-gesägt; Bthstiele einzeln; die stengelst. NebenB. scheidig, vielsp. 4. Triften, Wege, sandige Ufer. Mai-Jul.

*** B. gefingert; Bl. gelb.

6. P. recta L. St. aufrecht, nebst den B. rauhh., u. zugleich etwas rauh, längere u. auf Knötchen sitzende Haare mit kurzen drüsentrag. gemischt; B. 5- u. 7zählig, Blättchen längl., nach der Basis keilig-verschmälert, grob-eingeschnitten-gesägt; Nüsschen erhabenrunzelig, mit einem flügelf., bleicheren Kiele umgeben. 2. Waldige, steinige $\mathrm{O}$, , sonnige Hügel; sehr zerstr. dch das Geb. Jun. Jul. Bl. schwefelgelb. Var. $\beta$. obscura: Bl. citrongelb, oft etwas kleiner. P. obscura Willd. - $\gamma$. laciniosa: B. tief-eingeschnitten-gesägt, die Zähne oft wieder gesägt; Bl. schwefelgelb, auch citrongelb. P. laciniosa Lehm. Es gibt Varietates laciniosas fast von allen Arten.

7. P. hirta L. St. aufrecht, od. aus liegender Basis aufstrebend, rauhh., u. zugleich etwas rauh, längere auf einem Knötchen 
sitzende Haare mit kürzeren, drüsenlosen gemischt; B. 5- u. 7zählig, Blättchen eingeschnitten-gesägt, die der WB. vkteyf.-keilig, v. der breiteren, stumpfen Spitze allmählig nach der Basis verschmälert, die der StB. lineal.-keilig; Nüsschen erhaben-runzelig, mit einem fïgelf., bleicheren Kiele umgeben. '2. Grasige O.; Littor. Jul. Aug. Blättchen beiderseits mit 2-3 Zälnnen. Var. $\beta$. angustifolia: Blättchen schmäler; NebenB. 2sp. P. angustifolia DC. $-\gamma \cdot$ pedata: St. roth, höher; Blättchen fast bis zur Basis gesägt, beiderseits mit $6-8$ Zähnen. P. pedata Willd.

8. P. pilos a Willd. St. aufrecht, rauhh. v. verlängerten, auf einem Knötchen sitzenden Haaren $u$. zugleich etwas filzig v. kurzen Haaren; B. 5zählig, Blättchen lanzettl.-längl., v. der Mitte nach der Basis ver'schmälert, grob-gesägt, mit verlängerten Haaren beiderseits bestreut u. damit bewimpert, an den unteren B. vkteyf.-längl.; Früchtchen runzelig, mit einem sehr schmalen, geschärften Kiele umgeben. 4. Sonnige Hügel bei Arnstadt in Thüring.; bei Colmar, bei Flottbeck, unweit Hamburg. Mai. Jun.

9. P. inclinata Vill. St. aufrecht, od. aus niederliegender $B a-$ sis aufstrebend, weich-zottig $u$. zugleich filzig, an der Spitze ebensträussig; B. 5zählig, Blättchen längl.-lanzettl., nach der Basis verschmälert, eingeschnitten-gesägt, unterseits dünn-graufilzig, mit abstehenden Haaren bestreut $\mathfrak{u}$. gewimpert; Nüsschen runzelig, mit einem fädl., schwachen Kiele umgeben. 24. Sonnige Hügel; sehr zerstr. dch das Geb. Mai-Jul. P. adscendens Willd.

10. P. argentea L. St. aufstrebend, filzig, an der Spitze ebensträussig; B. 5zählig, Blättchen aus einer ganzrandigen, verschmälerten Basis vkteyf., tief-eingeschnitten-gesägt, od. fiedcrsp.zerfetzt, ain Rande umgerollt, unterseits woiss-filzig; Bthstiele auch nach dem Verblühen gerade; Nüsschen runzelig, unberandet. 24. Sonnige, unkultiv. O. Jun. Jul. Var.: B. oberseits grasgrün u. oft glänzend $u$. unterseits weissfilzig, od. auch oberseits, jedoch mit dünnerem Filze überzogen; u. $\beta$. impolita: Blättch. nach vorne weniger verbreitert, weiter nach d. Basis gezähnt, unterseits graufilzig; P. impolita Wahlenbg. Flor. carpat. Vielleicht eigene Art.

11. P. collina Wibel. Die St. niedergelegt od. aufstrebend, v. der Mitte an rispig, zottig-filzig; B. 5zählig, Blättchen vkteyf.-keilig, flach, unterseits auf den Adern zottig u. ausserdem daselbst dünngrau-filzig, eingeschnitten-gesägt; Bthstiele nach dem Verblühen zurückgekrümmt; Nüsschen runzelig, unberandet. 2. Sandige O., Raine; Frankf. a. d. O., Schles., Böhm., Werthheim, unterste Moselgbg. Mai, früher als P. argentea. P. Wiemanniana Günth. P. Guintheri Pohl. P. Lindackeri Tausch. P. sordida Fries. - P. collina Lehm. mit stumpfen Zähnen der B. halte ich für Abänderung.

12. P. patula W.K. St. aus aufstrebender Basis aufreeht od. niederliegend, nebst den Bstielen rauhh., Haare etwas angedrückt; 
B. 5- u. 7zählig, Blättchen lineal.-keilig, eingeschnitten-gesägt, unterseits gleichfarbig, auf dem Mittelnerven rauhh., Sägezähne der stengelst. auf jeder Seite 2 od. 3 ; Nüsschen runzelig. 24. Sonnige Hügel; Czeiz in Mähren, u. Leobschütz in Schlesien. Mai. Die inne-

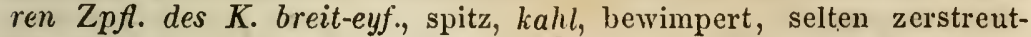
behaart.

13. P. heptaphylla Miller, Bernhardi select. sem. hort. Exfurt. 1833. St. nach allen Seiten niedergelegt $u$. aufstrebend, $v$. der Mitte an gabelsp.-rispig, rauhh., Haare abstehend, drüsenlos auf einem Knötchen sitzend; $\mathbf{R}$. ebensträussig, locker, beblättert; WB. rasig, 7zählig, Blättchen längl.-keilig, sämmtl. gleichfarbig, unterseits rauhh., eingeschnitten-gezähnt, Zähne beiderseits 5-10, abstehend, der letzte kleiner; Nüsschen runzelig. 24. Felsige, kiesige O.; C. Waadt, Wallis u. Tessin. Mai. Jun. P. intermedia K. syn. ed. 1. Die P. intermedia L., Fries. Herbar. normale fasc. 7. n. 51. ist eine andere Pflanze.

14. P. thuringiaca Bernhardi. St. nach allen Seiten abstehend $u$. aufstrebend, $v$. der Mitte an gabclsp.-rispig, rauhh., Haare abstehend, drüsenlos, auf einem Knötchen sitzend; R. locker, beblättert; B. unter'seits rauhl., gleichfarbig, die wurzelst. rasig, 7zählig, gesägt, Sägezähne geradehervorgestreckt, eyf., beiderseits 9-12, die oberen B. lineal.-lanzettl., entfernt-gesägt, Sägezähne etwas angedrückt; Nüsschen runzelig. 21. Waldige, steinige 0 .; Thüringer Wald am südl. Abhang, Unterwallis, Unterengadin. Mai. Jun. P. parviflora Gaud.

15. P. reptans L. St. rankenf., gestreckt, einfach, an den Grelenken wurzelnd; $B$. 5zählig, mit einigen eingemischten 3zähligen, Blättchen längl.-vkteyf., fast v. cler Basis an gesägt, kahl, od. unterterseits angedrückt-behaart, Sägezähne eyf., stumpfl.; Bth. einzeln, Bththeile 5zählig; Früchtchen körnig-rauh. 24. Feuchte Triften, Wege, Gräben. Jul. Ang. Var. $\beta$. die kahle: B. viel kleiner, 3-4"“ lang, die oberen ganz kahl, fast 3eckig-vkteyf., vorne gesägt; Oberöstr. u. Oberbad.

16. P. mixta Nolte. St. rankenf., gestreckt, oberwärts ästig; B. 5zählig, mit eingemischten 3zähligen, Blättchen längl.-vkteyf., v. der Spitze an bis über die Mitte gesägt, unterseits angedrückt-behaart, Sägezähne eyf., stumpfl.; Bth. einzeln, Bththeile meist 4zählig, Früchtchen ..... 2. Triften; Holstein. Jul. Aug. Verschied. v. P. reptans deh meist 4zählige Bththeile u. ästige St.

17. P. procumbens Sibthorp. St. rankenf., gestreckt, oberwärts ästig, die fruchttrag. an den Gelenken wurzelnd; $\boldsymbol{B}$. gestielt, 3zählig, od. die untersten 5zällig, Blättchen vkteyf., eingeschnittengesägt, unter der Mitte keilf. u. ganzrandig, Sägezähne abstehend, ey-lanzettf., spitz; NebenB. ganz od. 2-3zähnig; Bththeile meist 4zählig; Früchtchen fein-runzelig. 24. Schattige Wälder; nördl. Ge- 
biet bis zum Thüringer Wald, Böhm., Schwz. bei Bern. Jun. Jul. P. nemoralis Nestl. Tormentilla reptans L. K. syn. ed. 1. Die St. treiben gegen Herbst an den Gelenken Wurzelfasern u. ein Büschel B., u. theilen sich hierauf in viele Stöcke, was bei P. Tormentilla niemals geschieht.

18. P. Tormentilla Sibthorp. St. niedergelegt od. aufrecht, oberwärts ästig, nicht wurzelnd; B. 3zählig, sitzend od. kurz-gestielt, die wurzelst. 3- od. 5zählig, Blättchen längl.-lanzettf., eingeschnittengesägt, an der Basis ganzrandig, an den unteren B. vkteyf., Sägezähne etwas abstehend, ey-lanzettf., spitz; NebenB. 3-vielsp.; Bththeile meist 4zählig; Früchtch. schwach-runzelig. 24. Wälder, Haiden, Triften. Jun. Jul. Tormentilla erecta L. T. officinalis Sm.

19. P. a urea L. Stämmchen niedergestreckt, auch wurzelnd; St. aus gebogener Basis aufrecht u. nebst den Bstielen behaart, Haare aufrecht, etwas angedrïckt; WB. 5zählig, Blättchen längl.; kahl, am Rande $u$. auf den Adern unterseits silberglänzend-seidenh., an der Spitze spitz-gesägt, Sägezähne auf jeder Seite meist 3, der letzte kleiner; Nüsschen schwach-runzelig, kahl. 2. Grasige 0 . der A. u. VorA. u. Schles. u. Mähr. Gbge, Feldberg in Bad. Jul. Aug. P. Halleri Sering.

20. P. salisburgensis Haenke. Stämmchen niedergestreckt, zuweilen wurzelnd; St. aus aufstrebender Basis aufrecht, flaumig; WB. 5zählig, Blättchen vkteyf., kahl, am Rande u. auf den Adern unterseits abstehend-haarig, vorme eingeschnitten-gesägt, Zähne hervorgestreckt, auf jeder Seite meist 3 , der letzte fast gleich; $\mathrm{Ne}$ ben B. sämmtl. eyf.; Niisschen schwach-runzelig. \%. Höhere A. u. Iloheneck der Vogesen u. Babia Gora der Sudet. Jul. Aug. P. alpestris Haller. fil. P. aurea Sm.

21. P. ambigua Gaud. St. aufstrebend u. nebst den Bstielen flaumig; die wurzel- u. unteren stengelst. B. 5zählig, Blättchen vkteyf., oberstits zerstreut-, unterseits auf den Adern dichter- fast seidenartig-behaart, von vorne bis über die Mitte fast fingerf-eingeschnitter, Zähne lineal., beiderseits meist zu 3, der letzte fast gleich; NebenB. sämmtl. eyf.; Niisschen ..... 2. A. v. Wallis; bisher blos über Zermatten am Matterhorn. Jul. P. geranioides Schleicher.

22. P. verna L. Stämmchen gestreckt, oft wurzelnd; St. aufstrebend u. nebst den Bstielen v. aufrechten, etwas abstehenden Haaren rauhh.; die unteren B. 5- u. 7zählig, Blättchen längl.-vkteyf. od. vkteyf., gestutzt, kahl, $u$. am Rande od. unterseits od. oberu. unterseits haarig, tief-gesägt, Sägezähne meist 4 auf jeder Seite, der Endzahn kürzer; die untersten NebenB. schmal-lineal.; Nüsschen schwach-runzelig. 2. Sonnige, trockene O., Waldränder. Apr. Mai. Var.: B. beiderseits nur 2zähnig: P. pusilla Host., diese auf den A.

23. P. cinerea Chaix bei Villars. Stämmchen gestreckt, oft wurzelnd; St. aufstrebend, nebst den Bstielen u. B. grau-filzig u. 
behaart mit aufrechten, etwas abstehenden Haaren; die unteren $\mathbf{B}$. 5zälllig, Blättchen längl.-vkteyf. od. vkteyf., gestutzt, tief-gesägt, Sägezähne auf jeder Seite meist 4, der Endzahn kürzer; die untersten NebenB. schmal-lineal.; Niisschen schwach-runzelig. 24. Sandige, trockene u. felsige O.; zerstr. deh das Geb. Apr. Mai. P. incana Moench. Var. $\beta$. trifoliata: B. 3zählig, selten 4-5zählig: P. subacaulis Wulf.

24. P. op aca L. Stämmchen gestreckt, oft wurzelnd; St. aufstrebend $u$. nebst den Bstielen rauhh., Haare verlängert, wagerechtabstehend; B. 5- u. 7zählig, Blättchen längl-keilig, tief-gesägt, gestutzt, der Endzahn kürzer; Nüsschen runzelig. 24. Steinige, buschige u. waldige $\mathrm{O}$.; zerstr. deh das Geb. Mai. Jun.

25. P. grandiflora L. St. aus aufstrebender Basis aufrecht, nebst den Blattstielen v. kurzen, wagerecht-abstehenden Haaren zottig; B. 3zählig, Blättchen vkteyf., tief-gesägt, oberseits flaumig, unterseits zottig; Nüsschen kahl. 4. A. u. VorA.; Schwz. u. Tyr.

26. P. nivea L. St. aufrecht, armbth.; WB. 3zählig, Blättchen längl., eingeschnitten-gesägt, oberseits kahl od. rauhh., unterseits schneewciss - filzig, glanzlos, an Rande flach; Nüsschen kahl. 2. Höchste A. der Schwz. u. Tyrol, Stmk. Jul. Aug.

27. P. minima Haller fil. St. aufstrebend, flaumig, meist 1bth.; B. 3zählig, Blättchen vkteyf., abgerundet-stumpf, kaum gestutzt, kahl, am Rande u. unterseits auf den Adern behaart, mit etwas abstehellden Haaren, vorne eingeschnitten-gesägt, Zähne auf jeder Seite meist 4, der endst. fast gleich. 2. Triften u. felsige O. der A. Jul. Aug.

28. P. frigida Villars. Ueberall sehr zottig; St. aufstrebend, meist 1bth.; B. 3zählig, Blättchen vkteyf., stumpf-gezähnt, Zähne am Rande sich deckend; Nüsschen etwas runzelig, unbehaart. 4. Höchste A.; Wallis, C. Glarus, Oberengadin, Stmk. Jul. Aug.

II. Rotte. Fragariastrum DC. Nüsschen auf der ganzen Oberfäche od. wenigstens am Nabel mit Haaren besetzt.

a. Bl. weiss.

29. P. a l b a L. Stämmchen kriechend; St. schwach, aufstrebend, meist 3bth.; WB. 5zählig, Blättchen längl.-lanzettl., nach der Basis verschmälert, oberseits kahl, unterseits $u$. am Rande seidenh., vorne gesägt, Sägezähne spitz, zsneigend, der endst. schmäler; Stbf. nebst den Nüsschen kahl, letztere am Nabel behaart. 4 . Wälder; zerstr.
dch das Geb. Mai. Jun.

30. P. splendens Ramond. Stämmchen niedergestreckt, auch Wurzelnd; St. schwach, niederliegend od. aufstrebend, 2-4bth.; WB. 3-4-5zählig, Blättchen vkteyf.-längl. od. vkteyf., oberseits ziemlich kahl, unterseits $u$. am Rande scidenh.-zottig, vorne gesägt, die 
oberen Sägezähne zsneigend, der endst. schmäler; Stbf. u. Fruichtchen kahl, diese am Nabel behaart. 2. Wälder in Thüring. MaiOct. P. hybrida Wallr., K. syn. ed. 1.

31. P. Fragariastrum Elurh. Stämmchen niederliegend, oft wurzelnd; St. schwach, niederliegend, meist 2bth.; WB. 3zählig; Blättchen rundl.-eyf., gestutzt, oberseits ziemlich kahl, unterseits zottig, die jüngeren seidenh., das mittlere vorne, die seitenst. an der äusseren Seite fast v. der Basis an gesägt; das stengelst. B. 3zählig; Niisschen an dem Nabel behaart. 24. Buschige Hügel, Waldränder; zerstr. dch das Geb. Apr. Mai. P. Fragaria Sm. Fragaria sterilis L.

32. P. micranth a Ramond. Stämmchen kurz, nicht kriechend; St. schwach, niederliegend, meist 2bth.; WB. 3zählig, Blättchen oval, etwas gestutzt, oberseits ziemlich kahl, unterseits zottig, die jüngeren seidenh., das mittlere vorne, die seitenst. an der äusseren Seite fast v. der Basis an gesägt, das stengelst. B. einfach; Nüsschen an dem Nabel behaart. 24. Gebirgige, steinige, buschige 0 .; Unterstmk., sïdl. Tyrol, sïdl. Schwz., Nahethal. Apr. Mai.

33. P. petiolulat a Gaud. W. vielköpfig; St. ziemlich aufrecht, reichbth.; WB. 5- n. 3zählig, Blättclien kurz-gestielt, vkteyf.-längl., an der Basis keilig, nach vorne zu spitz-gesägt, ziemlich kahl, am Rande gewimpert; Stl.f. rauhh.; Nïsschen überall zottig. 24. Felsenspalten; Saleve in der Schwz. Jul. Aug. Vielleicht Abart der folgenden.

34. P. c a ul es cens L. W. vielköpfig; St. aufstrebend, reichbth.; WB. 5zählig, Blättchen fast sitzend, längl,-lanzettl., an der Basis keilig, nach vorne hin spitz-gesägt, etwas zottig, am Rande fast seidenh.-gewimpert; Stbf. rauhh.; Nüsschen iiberall zottig. 24. Felsenspalten der VorA. Jul. Aug.

35. P. Clusiana Jacq. W. vielköpfig; St. aufstrebend, meist 3bth.; WB. 5zählig, Blättchen längl.-lanzettl., an der Basis keilig, oberseits ziemlich kahl, unterseits zottig, am Rande fast seidenh.gewimpert, an der Spitze 3zähnig, Zähne geradevorgestreckt; Stbf. kahl; Niisschen ïberall zottig. 2. Felsenspalten der liöchsten A.; Tyrol bis Oestr. Jul. Aug. Stbf. oft purpurn.

b. Bl. rosenroth.

36. P. nitida L. St. meist einbth.; B. 3zählig, Blättchen elliptisch, auf beiden Seiten seidig-filzig, an der Spitze 3zähnig, Zühne geradehervorgestreckt; Stbf. kahl; Früchtch. iiberall behaart. 7. Felsenspalten der böchsten A.; Krain, Kärnth., Tyr., Stmk. Jul. Aug.

9. SIBBALDIA L. Sibbaldie.

1. S. procumbens L. B. 3zählig, Blättehen oberseits fast kalıl, unterseits behaart; Bth. ebensträussig; Blb. lanzettl. 2. Felsige $\mathrm{O}$. der A.; Iolreneck in den Voges. Bl. gelb. 


\section{AGRIMÓNIA I. Odermennig.}

1. A. Eupatoria L. Die entwickelten Aehren verlängert, ruthenf.; Fruchtkelche entfernt-gestellt, vktkegelf., bis zur Basis tiefgefurcht; die äusseren Dornen weit abstehend; B. unterbrochen-gefiedert, Blättchen längl.-lanzettl., gesägt, unterseits grau-kurzh., die dazwischen gestellten kleineren eyf., gezähnt, das unpaarige gestielt. 4. Trockene Wiesen, unkultiv, buschige Hügel bis in die VorA. Jun.-Aug. Bl. gelb, wie der folgenden.

2. A. odorata Aiton. Die entwickelten Aelren verlängert, ruthenf.; Fruchtkelche entfernt-gestellt, halbkugelig-glockig, bis zur Mitte seicht-gefurcht; die äusseren Dornen zurückgeschlagen; $\mathbf{B}$. unterbrochen-gefiedert, Blättchen längl--lanzettl., gesägt, unterseits kurzh. u. mit kleinen Driisen bestreut, die dazwischen gestellten kleineren eyf., gezähnt, das unpaarige gestielt. 24. Grasige O.; Oberbaden, bei Ems, Bonn, Hamburg. Jun.-Aug. A. procera Wallr.

11. AREMÓNLA Necker. Aremonia.

1. A. Agrimonio ides Neck. 24. Gebirgige, waldige O.; Unterkrain, südl. Tyrol. Mai. Jun. Agrimonia Agrimonioides L. Bl. gelb.

III. Gruppe. ROSEEN. DC. Früchtchen mehrere, 1eyig, nussartig, nicht aufspringend, v. der fleischigen u., bei der Reife, saftigen Röhre des K. eingesclılossen.

\section{ROSA L. Rose.}

I. Rotte. Pimpinellif oliae. Dic Fruchtkn. im Mittelpunkte des K. kurzgestielt, mit cinem Stiele nicht v. der halben Länge des Fruchtkn., od. fast sitzend. Bth. einzeln, deckblattlos, od. mit einem einzigen DeckB. gestiitzt, das aus einem, auf ein NebenB. zuriickgeführten B. entstanden. Die NebenB. fast gleichgestaltet. Die jungen Stämme sehr stachelig.

1. R. Iutea Miller. Die Stacheln der diesjährigen Wurzeltriebe gerade, gedrungen, ungleich, die grösseren pfrieml., die kleineren borstl., an den Zweigen zerstreut, stärker, etwas gekrïmmt; Blättchen 5-9, rundl. od. elliptisch, gleichfarbig, doppelt-gesägt; NebenB. säınmtl. gleichgestaltet, flach, am Rande umgebogen, lineal.-keilig, die Oehrehen lanzettl., zugespitzt, auseinanderfahrend; $Z$ pfl. des $\mathbf{K}$. mit Anhängseln, kürzer als die Bl.; Früchte aufrecht platt-kugelig, mit den bleibenden, weit abstehenden od. zurückgebogenen K. bekrönt. Ђ. Hin u. wieder verwildert in Zäunen. Jun. Jul. R. eglanteria L., mit Ausschluss der Synonyme. Blb. schön dottergelb, die Stbk. an der Basis spiessf., Früchte gelb-scharlachroth. Var. $\beta$. punicea: Blb. scharlachroth. R. pmicea Mill. R. bicolor Jacq.

2. R. pimpinellifolia DC. Die Stacheln ungleich, pfrieml. $u$. borstl., gerade, an den jülrigen Wrurzeltrieben gedrungen, an den 
Aesten zerstreut; Blättchen 5-9, rundl. od. oval, einfach-od. doppeltgesägt, Sägezähne etwas abstehend; NebenB. lineal.-keilig, Oehrchen lanzettl., zugespitzt, etwas spreitzend, die der bliihenden Aestchen breiter; Zpfl. des K. ganz, halb so lang als die Bl., lineal.-zugespitzt; Bthstiele 1bth., die fruchttrag. gerade; Früchte platt-kugelig, lederig, mit dem bleibenden, zsschliessenden $K$. bekrönt. 5. Unkultiv. O.; zerstr. deh das Geb. Jun. Jul. Frucht schwarz od. schwarzblutroth. Var. $\alpha$ : Bl. weiss, Bthstiele kahl. R. pimpinellifolia L. - $\beta$. spinosissima: dieselbe, mit steifh. Bthstielen. R. spinosissima L. - $\gamma \cdot$ myriacantha: dieselbe, die B. unterseits drüsig. R. myriacantha DC. - $\delta$. leiostyla: dieselbe, die Gf. verlängert, nur an der Basis zottig. R. microcarpa Bess. - $-\varepsilon$. mitissima: ohne Stacheln. R. mitissima Gmel. - ל. rosea: Blb. heller od. dunkler rosenroth. R. pimpinellifolia Willd.; Bth. rosenroth-gestreift: R. spinosissima $\beta$. eiphiana Sm. - $\eta$. affinis: Blb. rosenroth, der St. wehrlos. R. aftinis Sternb.

3. R. gentilis Sternb. Die Stacheln pfrieml. u. borstl., gerade, die der jährigen Stämme gedrungen, an den Aesten zerstrent; Blättchen $9-11$, rundl. u. oval, gesägt, Sägezähne etwas abstehend; $\mathrm{Ne}$ ben B. lineal.-keilig, ausgebreitet, Oehrchen ey-lanzettf., spitz an den bliuhenden Aestchen eyf.; Zpfl. des $K$. ganz, halb so lang als die Bl., mit einer lanzettl. Spitze; Bthstiele mit einem DeckB. gestuitzt, 1 bth., die fruchttrag nickend; Früchte rundl.eyf. od. elliptisch, mit dem bleibenden, zsschliessenden $K$. gekrönt, lederig. $\hbar$. Steinige 0 .; Istr., bei Triest. Mai. Jun. Blättchen kahl, Bthstiele u. Rölıre des K. driisig-steifh. Blb. rosemroth, Frucht hochrotl.

4. R. rever'sa IV.K. Die Stacheln pfrieml. u. borstl., gerade, die der jährigen Stämme gedrungen, an den Aesten zerstreut; Blättchen 5-8, eyf., gesägt; Neben B. an den blühenden Aestchen verbreitert, an der Basis keilig, rinnig-zsgefaltet, Oehrchen eyf., spitz; Zpfl. des $K$. ganz, kürzer als die Bl., mit einer lanzettl. Spitze; Bthstiele mit einem DeckB. gestützt, 1 bth., die fruchttrag. abuärtsgebogen; Früchte eyf., mit dem bleibenden, zsschliessenden $K$. gekrönt, lederig: $\hbar$. Gebirgige, felsige 0 .; auf dem Slavnik im Littor., Donatiberg in UStmk. Mai. Bl. blassröthl. Untersch. sich beim ersten Blick v. R. pimpinellifolia deh die längl., hängenden, v. R. gentilis deh die schwarzen Früchte.

5. R. alpina L. Die erwachsenen Stämme meist wehrlos, die jährigen gedrungen-stachelig, Stacheln borstl., gerade, driisenlos; Blättchen $7-11$, längl.-elliptisch, doppelt- od. einfach-gesägt; $\mathrm{Ne}$ benB. an den bliihenden Aestehen verbreitert u. an der Basis keilig, die ülrrigen lineal. $u$. an der Spitze breiter, die freien Enden eyf.-zugespitzt, auseinanderfahrend; $Z p f$. des $K$. ganz, mit einer lanzettl. Spitze, länger als die Bl.; die fruchttrag. Bthstiele zurückgekrümmt; Früchte hängend, elliptisch od. längl., mit dem bleiben- 
den zsschliessenden $K$. gekröut. 5 . Felsige O. der A. u. VorA., Voges., Sudet. u. des Feldberges in Oberbal. Jun. Jul. Blb. satt-rosenroth. Var. $\beta$. pyrenaica: Bthstiele u. Rölıre des K., od. nur die Bthstiele drïsig-steifh.: R. pyrenaica Gouan.; dieselbe, mit zugleich tief-doppelt-gesägten B.: R. monspeliaca Gouan.

6. R. lucida Ehrhart. Die Stacheln der diesjährigen Stämme gerade, gedrungen, ungleich, die grösseren pfrieml., die kleineren horstl., drïsenlos, an der Basis der NebenB. zu zweien, gerade, an der erwachsenen Pflanze oft fehlend; Blättchen 7-9, längl.-1anzettl., einfach-gesägt, oberseits sehr kahl u. spiegelnd; NebenB. fast gleichgestaltet, fast gleichbreit, flach, die Oehrchen eyf., mit ilı'en Spitzen zsneigend; Zpfl. des K. so lang als die Bl., Anhängsel meist fehlend, die Spitze derselben am Ende lanzettl.; die fruchttrag. Bthstiele gerade; Früchte plattkugelig, frühreif.; der $K$. abfällig. 方. Am Meeresufer bei Rostock $u$. an der Elbe bei Hamburg. Jun. JuI. Blb. rosenroth.

II. Rotte. Cinnamomeae. Die Fruchtkn. im Mittelpunkte des K. kurz-gestielt, Stiel halb so lang als der Fruchtkn. Bth. an der Spitze der Aestchen 3-5 u. mehrere, ebensträussig, sämmtl. mit einem DeckB. gestützt. Die NebenB. an den blühenden Aestchen deutlich breiter.

7. R. cinnamomea L. Die Stacheln der diesjährigen Stämme gerade, gedrungen, ungleich, die grösseren pfrieml., die kleineren borstl., drïsenlos, die der Z Zweige zu zweien an die Basis der $\mathrm{Ne}$ benB. gestellt, stärker, gekrïmmt; Blättchen 5 od. 7, oval-längl., einfach-gesägt, unterseits aschgrau, flaumig; NebenB. der nicht blïherden Aestchen vineal-längl., mit röhrig-zsschliesserden Rändern, die der blühenden oberwärts verbreitert, Oehrchen eyf., zugespitzt, abstehend; Zpfl. des K. so lang als die Bl., ganz, mit einer lanzettl. Spitze; die fruchttrag. Bthstiele gerade; Früchte kugelig, mit dem bleibenden, zsschliessenden $K$. gekrönt, frïhreif, markig. b. Hecken, unkultiv., waldige Hïgel; südl. Gebiet bis an die Donau, im nördI. selten. Mai. Jun. Blb. rosenroth. Die gefüllte Var., $R$. foecundissima Münchh., hin $u$. wieder verwildert. Die NebenB. der nicht blühenden Aestchen sind fast in ein Röhrchen zsgerollt u. umfassen mit ihrer Basis mehr als das halbe Aestchen. Die NebenB. der R. turbinata umfassen auf dieselbe Weise das Aestchen, sind aber flach ausgebreitet u. vorne selır verbreitert.

8. R. turbinata Ait. Die Stacheln der jährigen Stämme gedrungen,-ungleich, die grösseren aus verbreiterter Basis pfrieml., fast sichelf., die kleineren borstl., mit driisentrag. Borsten untermischt, sämmtl. im Alter verschwindend; Zweige wehrlos; Blättchen eyf., grob-gesägt; Ncben B. der blüthenst. B. elliptisch-verbreitert, die iibrigen längl., zieml. flach, Oehrchen eyf., zugesptzt, geradehervorge- 
streckt; Zpfl. des K. so lang als die $\mathrm{Bl}$., Anhängsel wenige od. fehlend; die fruchttrag. Bthstiele gerade; Früclıte elliptisch od. längl., mit dem sehr abstehenden $K$. gekrönt. $\hbar$. Hecken; auf dem Kahlenberge bei Wien. Jun. Blb. rosenroth. KelchR. eyf. od. rundl., in einen Hals zsgezogen; aber die gefüllte Abart hat eine becherf. KelchR. wie die gefüllten Abarten anderer Arten, u. kommt verwildert vor. Dazu gehört $R$. francofurtana Münchhausen.

9. R. rubrifolia Vill. Hechtblau' angelaufen; die Stacheln der Stämme ungleich, die grösseren etwas sichelf., an der Basis zsgedrückt, die kleineren schlank; Blättchen 5-7, elliptisch, einfachgeschärft-gesägt, unterseits kahl, die oberen Sägezähne zsneigend; Neben B. flach, die der blïthenst. B. elliptisch-verbreitert, die iibrigen längl., an der Basis keilig, Oehrchen eyf., zugespitzt, auseinanderfahrend; Zpfl. des $K$. garz od. mit schmalen Anhängseln, mit einer lanzettl. Spitze, länger als die Bl., nach dem Verblühen zsschliessend, v. der reifen Frucht abfallend; die fruchttrag. Bthstiele gerade; Früchte kugelig, frühreif, markig. $)$. Felsige O. der VorA. u. niederiger Berge des südl. Geb. Jum. Blb. rosenroth.

10. R. glandulos a Bellardi. Die Stacheln an den Stämmen in geringer Anzahl, etwas sichelf., an der Basis zsgedrückt, an den Aestchen schlanker, meist parweise unter die NebenB. gestellt; Blättchen 7, rundl., doppelt-geschärft-gesägt, unterseits kahl, die oberen Sägezähne zsneigend; NebenB. der blüthenst. B. clliptisch-verbreitert, die übrigen längl., an der Basis keilig, Oelurchen eyf., zugespitzt, auseinanderfahrend; $Z_{p} f$. des $K$. fiedersp., mit einer lanzettl. Spitze (länger als die Blkr.?); die fruchttrag. Bthstiele aufrecht; Früchte fast kugelig. ђ. Berge u. YorA.; Stmk., südl. Tyrol, Oberelsass, Schwz. Jun. Blb. rosenroth. R. Reynieri Hall. fil. R. glabrata Vest. - Verschied. v. R. rubrifolia del kleinere, rundl. Blättchen u. steifh. Bthstlele u. K.; von R. spinulifolia clch kleinere, rundl., unterseits kahle Blättchen u. ziemlich sichelf. Stacheln.

11. R. spinulifolia Dematra. Stacheln der Stämme aus einer verbreiterten Basis plötzlich verschmälert, pfriemlich, gerade an den Aestchen wenige schlanke; Blättchen zu 7, elliptisch, doppelt-geschärft-gesägt, unterseits drüsig, die Drüsen dicklich-beinahe dorniggestielt, die oberen Sägezähne zsschliessend; Nebenl3. der blüthenst. B. elliptisch-verbreitert, die übrigen an der Basis keilf, dic Oehrchen eyf., spreitzend; Zpfl. des $K$. fiedersp., mit einer larızettl. Spitze, lïnger als die Bl.; fruchttrag. Bthstiele aufrecht; Früchte rundl. od. elliptisch. Ђ. Hecken der Schwz. selten; Freiburg, Wallis. Jun. Jul. Die B. der R. rubiginosa mit deutlicher gestielten Drüsen, der Kelch der 1 . rubrifolia. Bl. rosenroth.

III. Rotte. Caninae. Die Fruchtku. im Mittelpunkte des K. lang-gestielt, Stiel, so lang als der Fruchtkn. Bth. an der Spitze 
der Aestchen $3-5$, u. mehrere, ebensträussig, sänmtl. mit eincm DeckB. gestützt. Die NebenB. wie bei der vorhergehenden Rotte, die an den oberen B. der blïhenden Aestchen verbreitert. Dic grösseren Stacheln derb.

12. R. canina L. Die Stacheln derb, sichelf., an der Basis verbreitert, zsgedrückt, ziemlich gleich, an d. Stämmen zerstreut, an den Zweigen meist paarweise unter die NebenB. gestellt; Blättchen 5-7, elliptisch od. eyf., geschärft-gesägt, die oberen Sägezähne zsneigend; NebenB. der bliithenst. B. elliptisch, verbreitert, die übrigen längl., ziemlich flach, Oehrchen eyf., zugespitzt, geradehervorgestreckt; $Z_{p f l}$. des $K$. fiedersp., fast v. der Länge der Bl., zurückgeschlagen, v. der reifenden Frucht abfallend; dic fruchttrag. Bthstiele gerade; Früchte elliptisch od. rundl., knorpelig; Niisschen in der Frucht gestielt. $\hbar$. Hecken, Zäune, waldige O. Jun. Blb. rosenroth od. weiss. Var. $\mathrm{B}$. grasgriin, spiegelnd: $\mathrm{R}$. canina nitida Fries., R. nitens Merat.; B. meergrün, glanzlos, v. einem bläulichen, abwischbaren Reife angehaucht; R. canina opaca Fries., u. B. einfachu. doppelt-gesägt, u.: $\alpha$.canina vulgaris: Bstiele, Blättchen, Bthstiele u. Röhre des K. kahl, Bstiele öfters mit entfernten Drüsen bestreut u. manchmal an der Basis etwas behaart. - $\beta$. canina dumetorum: Bstiele überall behaart; Blättchen unterseits auf den Hauptadern od. auf der ganzen Blattfläche od. auch auf der oberen Fläche mit Haaren bedeckt, Bthstiele nicht borstig-steifh. Hieher: R. dumetorum Thuill. R. collina DC., nicht Jacq. R. corymbifera Borkh. $-\gamma \cdot c a-$ nina collina: Bthstiele druisig-steifh.; B. kahl od. behaart, Röhre des K. kahl od. drüsig-steifh., Bstiele entfernter oder dichter mit Driisen bestreut, u. zugleich haarig od. unbehaart: R. colina Jacq., B. behaart, einfach-gesägt; dieselbe, die Blättchen doppelt-gesägt, unterseits kahl: R. psilophylla Rau.; die Blättchen 3fach-gesägt, kahl: R. trachyphylla Rau.; die Blättchen 3fach-gesägt, unterseits mit Haareı bestreut: R. flexuosa Rau. Die schönste Form der R. canina collina ist die kultivirte $u$. gefüllte $R$. alba $\mathbf{L}$. mit weissen $u$. hellrosenrothen BI. - $\delta$. canina sepium: Bstiele u. Blättchen unterseits od. auch beiderseits mit klebrigen Driisen bestreut; Bthstiele u. Röhre des K. kahl. Grössere Form dieser Variet. $\delta$. mit oft nach der Basis verschmälerten Blättchen: R. glutinosa Schultz., nicht Sm. R. Ǩluckii Bess. - Eine kleinere Form kleinblätterig u. oft kleinblumig: R. sepium Thuill. R. myrtifolia Hall.

13. R. rubiginosa L. Die Stacheln derb, sichelf., an der Basis verbreitert, zsgedrückt, an den Stämmen zerstreut, ungleich, die kleineren garader $u$. schlanker, auf den Zweigen meist unter die NebenB. gestellt; Blättchen 5-7, elliptisch, spitz-doppelt-gesägt, Sägezähne etwas abstehend; NebenB. der bliithenst. B. elliptisch, verbreitert, die iibrigen längl., zieml. flach, Oehrchen eyf., zugespitzt, ge- 
radehervorgestreckt; $Z p f$. des $K$. ficdersp., fast v. der Länge der Bl., zurückgeschlagen, v. der reifenden Frucht abfallend; die fruchttrag. Bthstiele gerade; Frïchte rundl., knorpelig. ち. Gebiisch, Wälder. Jun. R. eglanteria Mill. Blb. rosenroth.

14. R. to mentos a Smith. Die Stacheln derb, gerade, an der Basis zsgedrückt, auf den Stämmen zerstreut, ungleich, die kleineren schlanker, auf den Zweigen etwas sichelf., unter die NebenB. gestellt; Blättchen elliptisch od. eyf., graugrün, spitz-doppelt-gesägt, Sägezähne etwas abstehend; NebenB. der blüthenst. B. elliptisch, verbreitert, die übrigen längl., ziemI. flach, Oehrchen eyf., zugespitzt, geradehervorgestreckt; $\mathrm{ZpH}$. des $\mathrm{K}$. fiedersp.; so lang als die Bl., meist bleibend; Früchte rundl., knorpelig; Blb. am Rande kahl. ち. Hecken, Wälder. Jun. Blb. lieblich rosenroth. Die langen, meist wagerechtabstehenden, schlankeren, fast geraden Stacheln, u. die aschgraue, weder abwischbare, noch v. Haaren herriihrende Farbe der B. bilden den characteristischen Unterschied dieser Ar Var. 1.: B. zottig, drüsenlos, sehr weich anzufühlen; 2.: B. zottig, driisig, ziemlich rauh anzufühlen, u. 3.: B. ziemlich kahl. Ansserdem sind die Früchte kugelig, R. mollissima Willd., od. eyf., R. hispida Borkh., R. villosa Poll.

15. R. po mifer a Herrmann. Die Stacheln derb, aus verbreiterter, zsgedrückter Basis pfrieml., gerade, an den jährigen Stämmen zerstreut, ungleich, die kleineren borstl., an den Zweigen wenige, etwas gekrümmte; Blättchen 5-7, längl-lanzettl., grau-grün, doppelt-gcsägt, Sägezähne etwas abstehend; NebenB. der blüthenst. B. elliptisch-verbreitert, die übrigen längl., zieml. flach, Oehrchen eyf., geradehervorg'streckt; $\mathrm{Zpfl}$. des $\mathrm{K}$. fiedersp., so lang als die drüsiggewimperte Bl.; Früchte kugelig, frühreif, nickend, mit dem bleibenden, zsschliessenden $K$. gekrönt. $\hbar$. Gbge u. VorA.; Wallis, Kärnth., Stmk., Oberelsass, Lahn- u. Aarthal bei Coblenz. Jun. R. villosa Wulf., DC. Bl. rosenroth.

16. R. ciliato-petala Besser. Stacheln derb, aus verbreiterter, zsgedrückter Basis pfrieml., gerade, an den jährigen Stämmen...., an den Zweigen wenige, etwas gekrümmte; Blättchen 5-7, ‘yf., graugrün, doppelt-gesägt, Sägezähne etwas abstehend; NebenB. der blïthenst. B. elliptisch-verbreitert, die übrigen längl., Oehrchen eyf., geradehervorgestreckt; $\mathrm{Zpfl}$. des $\mathrm{K}$. fiedersp., so lang als die drüsiggewimperte 13l.; Früchte fast kugelig, frühreif;, aufrecht, mit dem bleiberiden, zsschliessenden $K$. gekrönt. ち. A. v. Tyrol; Karstgebirg in Krain. Jun. Jul. R. resinosa Sternb. Blb. rosenroth.

17. R. systyla Bastard. Dic Stacheln derb, sichelf., an der Basis zsgedrückt, ziemlich gleich, an dem Stamme zerstreut, an den Zweigen öfters an die Basis der NebenB. gestellt; Stamm aufrecht; Blättchen 5-7, elliptisch, geschärft-gesägt, die oberen Sägezähne zsneigend; NebenB. längl., Oehrehen eyf., zugespitzt, geradehervorgestreckt, 
die der blüthenst. B. breiter; Z $Z$ pfl. des $K$. fiedersp., fast so lang als die Bl.; Gf. kahl, zsgewachsen. ち. YorA.; Stmk., Sauter ; Oberelsass, Kirschleger; Schwz., Thomas. Jun. Blb. rosenroth od. weiss.

IV. Rotte. Rosae nobiles. Fruchtkn. sämmtl. völlig stiellos. NebenB. gleichgestaltet, an den blühenden Aestchen 'kaum breiter; daher die aus verkleinerten, blattlosen NebenB. gebildeten DeckB. schmäler.

18. R. arvensis Hudson. Die Stacheln zerstreut, derb, sichelf., an der Basis zsgedruickt; Aeste verlängert, peitschenf., niederliegend; Blättchen 5-7, rundl.-elliptisch, gekerbt-gesägt, verschiedenfarbig, unterseits glanzlos, abfällig; NebenB. sämmtl. gleichgestaltet, längl.lineal., flach, Oehrchen eyf., zugespitzt, geradehervorgestreckt; Zpfl. des K. schwach-fiedersp., die Spitze derselben kürzer als die Blïthenknospe, v. der reifenden Frucht abfallend; $G f$. zsgewachsen, so lang als die Stbg.; Friichte aufrecht, elliptisch od. fast kugelig. 方. Haine, Hecken, bis in die VorA.; zerstr. deh das Geb. Jun. R. sylvestris Herrm. Blb. weiss.

19. R. sempervirens L. Die Stacheln zerstreut, derb, sichelf., an der Basis zsgedriickt; Aeste verlängert, peitschenf., niederliegend; Blättchen 5-7, rundl.-elliptisch, fast angedriickt-gesägt, gleichfarbig; beiderseits spiegelnd, immergrïn;. NebenB. sämmtl. gleichgestaltet, längl.-lineal., flach, Oehrchen lanzettl., zugespitzt, geradehervorgestreckt; Zpfl. des K. ganz or. schwach-fiedersp., v. der reifenden Frucht abfallend; Gf. zsgewachsen, fast $v$. der Länge der Stbg.; Friichte anfrecht, rundl. b. Steinige O. im Litt. Jun. Blb. weiss.

20. R. gallica L., Lindl. Die Stacheln der jährigen Stämme gedrungen, ungleich, die grösseren ans verbreiterter, zsgedrückter Basis pfrieml., etwas sichelf,, die kleincren borstl., die eingemischten drüsentrag. Borsten zahlreich; Blättchen elliptisch orl. rundl., etwas starr, lederig, einfach-gesägt; Neben B. lineal.-längl., flach, Oehrchen ey-lanzettf., spitz, auseinanderfahrerd, an den bitithenst. B. gleichgestaltet; Zpfl. des K. fiedersp., liïzer als die Bl., zurückgebogen, endl. abfällig; Nüsschen sämmtl. stiellos; Friichte aufrecht, kugelig, knorpelig. Ђ. Haine, Waldränder, Aecker; zerstr. dch das Gebiet. Jun. Blb. satt-purp., bei Varict. bleicher. R. austriaca Jacq. Var. $\beta_{\text {.: }}$ die Gf. verlängert, v. der Länge der Stbg., kahl. R. hybrida K. u.

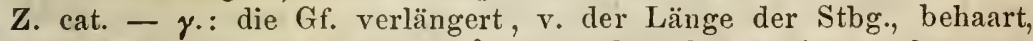
frei. R. hybrida Schleich. - $\delta$.: dieselbe, Gf. in eine verlängerte, behaarte Säule zsgewachsen. R. Axmanni Gmel.

R. centifolia kommt im Geb. nicht wild vor, auch nicht verwildert. 


\section{Ordng. SANGUISORBEEN. Lindl.}

\section{ALCHEMILLA L. Frauenmantel.}

1. A.v ulgaris L. WB. nierenf., bis zum dritten Theile 7-9lappig, Lappen halbkreisrund, ringsum-gesägt. 24. Wiesen, Triften, in die A. hinauf. Mai-Jul. Bth. gelblichgrün, wie bei den folgenden. B. subsericea: B. etwas rauhh., schwach-seidig-glänzend. A. inontana Willd. sp. A. vulgaris $\gamma$. hybrida Willd. en.

2. A. pubescens MBieberst. WB. nierenf., bis zum dritten Theile 7-9lappig, Lappen kurz-vkteyf., abgeschnitten, vorne spitzgesägt, am Grunde ganzrandig. 24. Triften der höchsten A. Jun. Jul.

3. A. fiss a Schummel. WB. nierenf., bis zur Mitte 7-9sp.; Lappen vkteyf., vorne eingeschnitten-gezähnt, am Grurde ganzrandig. 2. Feuchte Triften der A. u. Sudet. Jun. Jul.

4. A. al pin a L. WB. fingerig-5-7th., Zpfl. lanzettl.-keilig, stumpf, an der Spitze angedrüickt-gesägt, unterseits seidenh. 24. Felsige u. kiesige $\mathrm{O}$. der A. u. Voges. Jun.-Aug.

5. A. pentaphyllea L. WB. bis zur Basis 5th., die 3 mittleren $Z$ pfl. vkteyf.-keilig, vorne eingeschnitten-4-6zähnig, die seitenst. 2 sp., 1 -mehrzälnig, $Z$ ähne geradehervorgestreckt. 24. Nasse 0 . der höehsten A. der Schwz. u. der A. östl. vom Orteles in Tyrol. Jul. Aug.

6. A. arvensis Scop. B. handf.-3sp., an der Basis keilig, Zpfl. vorne eingeschnitten-3-5zähnig. $\odot$. Aecker. Mai-Herbst. A. Aphanes Leers. Aphanes arvensis $\mathrm{L}$.

\section{SANGUISORBA L. Wiesenknopf.}

1. S. officinalis L. Aehren eyf. -längl.; Stbg. 4, ungefährv. der Länge des $K$.; Blättchen herzf.-längl. 24. Wiesen. Jun.-Aug. Bth. purpurbraun. Var.: besondere Bstielehen mit Nebenblättehen. S. auriculata Seop.

2. S. dodecandra Morett. Aehren walzl., verlängert; Stbg. $6-12$, viel länger als die Zpft. des $K$.; Blättchen herzf.-längl. 24 . Im Thale Ambria in Veltlin. Jul. Aug. Bth. grünl.-gelb od. röthl.

3. POTERIUM L. Becherblume.

1. P. S anguisorba I. Krautig; St. kantig; die fruchttrag. $K$. knöchern-erhärtet, netzig-runzelig, 4kantig, Kanten stumpf. 2. Wiesen u. Triften. Jun. Jul. Bth. grïn, wie an folgend. Var.: kahl, unterwärts kurzh.: P. guestphalieum Bönningh.; u. mit graugriuen B.: P. glauceseens Rchb.

2. P. poly gamum W. K. Krautig; St. kantig; die fruchttrag. $K$. knöchern-erhärtet, grubig-runzelig, 4 kantig, Kanten geflügelt, Runzeln erhaben, gezähnt. 4. Gebirgige O.; Stmk., Kärnth., Krain, Istr. Jun. Jul. 
XXXVI. Ordng. POMACEEN. Lindl.

\section{CRATAEGUS L. Weissiorn.}

1. C. Oxyacantha L. B. vkteyf., 3-5lappig, eingesclmitten u. gesägt, an der Basis keilig, nebst den Aestehen u. Bthstielen kahl; Zpfl. des K. aus eyf. Basis zugespitzt, drïsenlos; Früchte oval, 1-3steinig. ち. Hecken, WäIder. Mai. Jun. Blb. weiss, wie bei den folgenden.

2. C. monogyn a Jacq. B. vkteyf., tief-3-5sp., eingeschuitten u. gesägt, an der Basis keilig; Aestchen kalu, Bthstiele zottig; Zpfl. des K. lanzettl., zugespitzt, drüsenlos; Früchte fâst liugelig, 1steinig. ђ. Hecken $u$. Wälder. Hliihet 14 Tage später als C. Oxyacantha.

3. C. Azarolus L. B. vkeyf., 3-5 sp., an der Basis keilig, Z $\mathrm{Z} f$ fl. ganz od. 1-2zähnig; die jüngeren Aestchen filzig; Bthstiele nebst den K. krauszottig; Z pfl. des K. 3eckig, spitz, driisenlos. ந. Unter Gebüsch; Krrain, Litt., im südl. Tyrol nur angepflanzt. Mai.

\section{COTONEASTER Medikus, Lindl. Steinmispel.}

1. C. vulgaris Lindl. B. rundl.-eyf., an der Basis abgerundet, spitz od. ausgerandet; K. kahl, am Rande rebst den Bthstielen elwas flaumig. ち. Steinige O., Felsen, bis in die VorA.; zerstr. im südl. u. mittleren Geb. Apr. Mai. Blb. rosenroth. Friichte mit 3 Steinen.

2. C. to mentosa Lindl. B. oval, abgerundet-stumpf; K. nebst den Bthstielen filzig. Ђ. Abhänge n. felsige O. der vorA. u. A.; Oestr., Salzbg., Tyrol, Schwz. Mai. Blb. rosenroth. Früchte hochroth, 4-5steinig.

3. MÉSPILUS L., mit Ausschluss von Arten. Mispel.

1. M. germanica L. B. lanzettl., ungeth., nuterseits filzig; Bth. einzeln. 5. Gebirgige $O$. unter Gebüsch, Zäune; im südl. Geb. u. daselbst hin u. wieder bloss angepflanzt, u. diesseits der A. wohl bloss verwildert. Mai. Blb. weiss.

4. CYDONIA Tournef. Quitte.

1. C. vulgaris Persoon. B. eyf., an der Basis stumpf, ganzrandig, unterseits nebst den K. filzig. $\hbar$. Felsige O.; Ufer der Donau in Oestr., Littor., Fiume, südI. Schwz., im iibrigen Geb. nur verwildert u. kultiv. Mai. Pyrus Cydonia L. Blb. hellrosenroth.

\section{PYRUS L. Birn, Birn- u. Apfelbaum.}

I. Rottte. Pyri genuinae. Birnen. Gf. frei. Frucht rundl. od. kreiself., an der Basis nicht benabelt. Bth. weiss.

1. P. communis L. B. eyf., ungefähr so lang als der Bstiel, kleingesägt, im Alter nebst den Zweigen u. Knospen kahl; Ebensträusse einfach; Gf. frei. 方. Wälder, Hecken. Apr. Mai. Blb. weiss. 
$\alpha$. glabra: Ueberzug der B. dünn, spinnwebig, bald nach ihrer Entwickelung verschwindend. $-\beta$. tomentosa: Filz der $B$. dicht, fast bis in den Herbst bleibend. P. Pollveria Lej., nicht L. P. communis dasyphylla Tsch.

2. P. a mygdal if orm is Villars. B. längl.-lanzettl., elliptisch od. vkteyf., kurz-zugespitzt, an der Spitze schwach-kleingesägt, unterseits filzig, 3- od. 4mal so lang als der Bstiel; Ebensträusse einfach. 万. Sonnige, trockene O.; Istrien. Apr. Mai. Blb. weiss. Var. $\beta$. nivalis: vergrössert deh Kultur: P. nivalis Jacq., diese Variet. wächst nicht in den A., sondern ist kultiv. u. wird nach Host deh Pfropfen fortgepflanzt.

II. Rotte. Malus. Apfel. Gf. "an der Basis zsgewachsen. Frucht an der Insertion des Bthsticles benabelt.

3. P. Malus L. 'B. eyf., stumpf-gesägt, kurz-zugespitzt, kahl, od. unterseits filzig; Bstiele halb so lang als das B.; Ebensträusse einfach; Gf. an d. Basis zsgewachsen. $\hbar$. Wälder, Hecken. Mai. Blb. auswendig rosenroth, inwendig bleicher. Var.: Gf. kahl od. an der Basis wollig, u. B. u. Fruchtkn. kahl: P. acerba Merat., u. B. unten u. Fruchtkn. wollig: P. Malus DC., beide nur dch den Ueberzug versch.

6. ARÓNIA Persoon, mit Auschl. v. Arten. Felsenmispel.

1. A. rotundifolia Pers. B. oval, stumpf, unterseits filzig, in Alter kahl; Blb. lanzettl. - keilig. ந. Bergabhänge, Felsenspalten; auf beiden Seiten der AK. dch das Gebirge auf beiden Seiten des Rheines bis nach Coblenz, Thüringen. Apr. Mai. Mespilus Amelanchier L. Blb. weiss.

7. SORBUS L. Eberesche.

* Blb. abstehend, weiss.

1. S. domestica L. Die jüngeren B. zottig, die älteren kahl, gefiedert; Blättchen spitz-gesägt; Knospen kahl, klebrig; Früclite birnf. ち. Gebirgige O.; Oestr., Krain, Litt., Jura, Nahegebirg, Thüring. Mai. Jun. Blb. weiss, wie bei den folgenden.

2. S. a u cuparia J. Die jüngeren $B$. zottig, die älteren kahl, gefiedert; Blättchen spitz-gesägt; Knospєn filzig; Friichte kugelig. $\hbar$. Wülder. Mai. Jun.

3. S. hybrida L. B. unterseits filzig, längl., an der Spitze doppelt-gesägt, an der Basis gefiedert, od. tief-fiedersp., Z $Z_{1}$ H. lanzettl.längl., ganzrandig, an der Spitze gesägt. Ђ. Gebirgswälder, Felsenwände; südl. Abhänge Thüringens, auf dem Singer- u. WillingerBerge im Schwarzb.-Rudolst., hei Coburg, Creux du Van im Jura. Mai.

4. S. s can dica Fries. B. längl-oval, eingeschnitten-lappig, ungleich-gesïgt, unterseits filzig, die Lappen parallel, vorne abgerundet 
u. dch den mittleren Zahn stachelspitzig, die grösseren an der Basis ganzrandig. †. Wälder bei Redlau, 2 Meilen v. Danzig. Mai. Crataegus Aria $\beta$. scandica L. Pyrus intermedia Ehrh. Beeren nach Tausch, längl. u. scharlachroth.

5. S. A ria Crantz. B. eyf.-längl. od. eyf., doppelt-gesägt, od. am Rande klein-gelappt, unterseits filzig, Sägezähne u. Läppchen $v$. der Mitte des B. nach der Basis abnehmend; Blb. abstehend. t). Bergwälder bis in die A. Mai. Crataegus Aria $\alpha$. L. spec. Beeren roth od. gelblich.

6. S. I a tifolia Persoon. B. breit-eyf., unterseits filzig, am Rande lappig, Lappen 3eckig-eyf., zugespitzt, gesägt, die urtersten 3 grösser, etwas abstehend. Ђ. Laubwälder; Nendinger Höhe bei Ludwigsthal in Würtemb., Willinger Berge im Schwarzb.-Rudolst. Mai. Crataegus latifolia Lam. C. dentata Thuill. Beeren roth.

7. S. torminalis Crantz. B. eyf., lappig, im Alter kahl, Lappen zugespitzt, ungleich-gesägt, die unteren grösser, abstehend. †. Bergwälder. Mai. Crataegus torminalis L. Beeren oval, lederbraun.

* Blb. aufrecht, rosenroth.

8. S. Chama emespilus Crantz. B. elliptisch od. lanzettl., doppelt-gesägt, kahl od. unterseits filzig; Blb. aufrecht. h. Felsige Alhänge der A., Voges. u. Sudet. Jun. Jul. Var.: B. unterseits filzig. Pyrus sudetica Tausch.

\section{Ordng. GRANATEEN. DC.}

1. PÚNICA L. Grauate.

1. P. Granatum L. B. lanzettl.; St. baumartig. 5. Im Littor. u. siidl. Tyrol kultiv. u. daselbst verwildert. Jun. Jul. Bl. scharlachroth.

\section{Ordng. ONAGRARIEN. Juss.}

I. Gruppe. ONAGREEN. DC. Röhre des K. länger als der Fruchtkn., der freie Theil mit dem Saume abfällig.

1. EPILOBIUM L. Weidenröschen. :

I. Rotte. Chamaenerion Tausch. B. zerstreut. Blb. ausgebreitet. Stbg. aus einer zsschliessenden Basis zurückgebogen, abwärtsgeneigt. Gf. zuletzt hakig-zurückgekrïmmt. Bl. schön purpurn.

1. E. angustifolium L. B. zerstreut, lanzettl., ganzraudig od. schwach-drüsig-gezähnelt, aderig; Blb. benagelt, vkteyf.; Gf. zuletzt abwärtsgebogen. 24. Wälder, besonders Schläge, in die VorA. hinauf. Jul. Aug. 
2. E. Dodonaei Vill. B. zerstreut, lineal., wach beiden Enden verschmälert, ganzrandig od. schwach-gezälnnelt, aderlos; Blb. sitzend, elliptisch-längl., nach der Basis verschmälert; $G f$. an der Basis flaumig, so lang als die Stbg., zuletzt zuriickgekrümmt. 24. Kiesige $O$. der A.; besonders auf den siidl. Abhängen, bis in die Thäler hinab, Sudet. Jul. Aug. E. rosmarinifolium Haenke. E. angnstissimum Ait.

3. E. Fle is cheri Hochstetter. B. zerstreut, lineal., od. lineal.lanzettl., nach beiden Enden verschmälert, ganzrandig od. schwachgezähnelt, aderlos; Blb. sitzend, elliptisch-längl., nach der Basis verschmälert; $G f$. bis über die Mitle flaumig; halb so lang als die Stbg., zuletzt zuriickgekrümmt. 2. Thäler der höheren A.; Suldenthal am Fusse des Orteles in 'Tyrol, Schwz.? Jul. Aug. E. denticulatum Wender., nicht Ruiz u. Pav.

II. Rotte. Lysim a chion Tausch. Die unteren B. gegenst., die oberen wechselst. Blb. trichterf.-gestellt. Stbg. aufrecht. Alle haben eine gross - $u$. kleinblumige Form.

§. 1. Bthen u. Spitze des St. zu jeder Zeit aufrecht.

a. Der St. nicht mit erlabenen Linien belegt $u$. nicht zweizeilig behıart.

4. E. hi r su tum L. B. gegenst., stengelumfassend, mit blattiger Basis etwas herablaufend, lanzettl.- längl., haarspitzig, gezähneltkleingesägt, Sägezähne einwärtsgebogen, die oberen B. wechselst.; St. stielrund, sehr ästig, von einfachen längeren $u$. driisigen kürzeren Haaren zottig; Narben abstehend; W. ausläufertreibend. 2. Sumpfige, waldige O., Ufer. Jun. Jul. Blb. ansehul., purpurn.

5. E. parviflorum Schreber. B. sitzend, lanzettl., spitz, gezälınelt, die unteren gegenst., kurzgestielt; St. stielrund, meist einfach, v. einfachen Haaren zottig od. flaumig; Narben abstehend; Ausläufer fehlend. 2. Sumpfige O., Ufer, Weidengebiisch. Jun. Jul. E. hirsutum $\beta$. L. E. pubescens Roth. Blb. hellviolett od. weisslich. Var. fast kahl: E. rivulare Wallenb.

b. Der St. mit 2 oder 4 erhabenen Linien belegt.

6. E. virgat um Fries. B. lanzettl, aus einer abgerundeten Basis allmählig vérschmälert, entfernt-gezähnelt, fast sitzend, die oberen kurzgestielt, die unteren gegenst.; St. etwas flaumig, mit 2 od. 4 crhabenen, herablaufenden Linien; Narben in eine Keule zsgewachsen od. etwas, abstehend. 2. Gräben, feuchte Wiesen u. Wälder; Lauenburg, Hamburg, Neumarek. Jul. Aug. Bl. hellrosenroth.

7. E. t etragonum L. B. lanzettl., v. der Basis bis zur Spitze allmählig verschmälert, gezähnelt-gesägt, die mittleren mit blattiger Basis herablaufend-angewachsen, die unteren etwas gestielt; St. sehr ästig, fast kahl, mit 2 oder 4 erhabenen, herablaufenden Linien; Nar- 
ben in cine Keule zsgewachsen. 2. Sumpfige O., Bäche, Gräben. Jun. Jul. Chamaenerion obscurum Schreb. Blb. rosenroth.

§. 2. Die Bth. mit der Spitze des St. vor dem Aufblühen nickend od. überhangend, während des Aufblühens sich allmählig aufrichtend. behaart.

a. Der St. nicht mit erhabenen Linien belegt u. nicht zweizeilig-

8. E. montanum L. B. eyf. od. eyf.längl., ungleich-gezähntgesägt, am Rande u. auf den Adern flanmig, die unteren gegenst., gestielt; St. stielrund, flaumig; Narben abstehend; Ausläufer fellend. 4. Wälder, Gebüsch. Jun. u. Aug. Var. $\alpha$. verticillatum: B. zu 3 quirlig; St. stielrund, nicht kantig, wie an E. trigonum. - $\beta$. lanceolatum: B. eyf.-längl., stumpfer, länger-gestielt. E. nitidum Host. - $\gamma$. collinum Gmel.: klein, B. 4mal kleiner. E. collinum Gmel. fl. bad.

9. E. hypericifolium Tausch. B. eyf., zugespitzt, ganzrandig, auf den Adern u. am Rande flaumig, die unteren gegenst., gestielt; St. stielrund, flaumig; Narben abstehend; Ausläufer fehlend. 24. Waldige, gebirgige O.; Böhm. Jun. Jul. Blb. zuerst weiss, dann hellrosenroth.

10. E. palustre I. B. lanzttl., nach der Spitze allmählig verschmälert, ganzrandig od. gezähnelt, mit keilf. Basis sitzend, die unteren gegenst.; St. stielrund, etwas flaumig; Narben in eine Keule zsgewachsen; Ausläufer fädlich. 24.'Torf haltige sumpfige Wiesen, Gräben. Jul. Aug. Blb. bleichroth od. weiss. Flaum des St. kraus u. angedrückt, seltener $\beta$. pilosum: die Haare wagerecht-abstehend: E. simplex Tratt. $-\gamma$. Schmidtianum: B. breiter, deutlicher gezähnelt. E. Schmidtianum Rostkov.

b. Der St. mit zwei erhabenen, behaarten Linien belegt, od. zweizeilig-behaart.

11. E. roseum Schreb. B. ziemlich lang gestielt, längl., an den beiden Enden spitz, dicht-ungleich-gezähnelt-gesägt, am Rande u. auf den Adern flaumig, die unteren gegenst.; St. sehr ästig, reichbth., mit 2 od. 4 erhabenen, herablaufenden Linien, oberwärts flaumig; Narben in eine Keule zsgewachsen, od. zuletzt etwas abstehend. 4. Gräben, sumpfige O. Jul. Aug. Blb. rosenroth.

12. E. trigon um Schrank. B. gegenst., zu 3 od. 4 quirlig, sitzend, fast stengelumfassend, längl.-eyf., zugespitzt, ungleich-gezähnelt-gesägt, kahl, auf den Adern u. am Rande flaumig, die oberen wechselst.; St. meist einfach, oberwärts nebst den 2-3-4 erhabenen, herablaufenden Linien flaumig; Narben in eine Keule zsgewachsen. 4. Feuchte Triften der A. u. VorA., sodann Vogesen, Feldberg in 
Oberbad. u. Mähr. u. Schles. Gbge. Jul. Aug. E. alpestre Rchb., nicht Schmidt. Blb. rosenroth.

13. E. or ig a n if ol i um Lam. B. gegenst., etwas gestielt, eyf., zugespitzt, geschweift- u. etwas entfernt-gezähnelt, kahl, die untersten stumpf, die oberen wechselst.; St. einfach, armbth., mit 2 erhabenen, flaumigen Linien; Narben in eine Kenle zsgewachsen. 24. Bäche u. Quellen der A. u. höheren Gbge.: Voges., Feldberg in Baden, Schles. ı. Mähr. Gbg. Jul. Aug. E. alsinefolium Vill. E. alpestre Schmidt. Blb. rosenroth.

14. E. alp inum L. B. gegenst., etwas gestielt, längl. od. längl.lanzettl., stumpf, ganzrandig od. sclwwach gezähnelt, an der Basis verschmälert, die oberen lanzettl., wechselst., die der nicht bliihenden Rosetten vkteyf.; St. einfach, armbtl., mit 2 erhabenen, flaumigen Linien; Narben in eine lieule zsgewachsen. 24. Nasse O. der A., sodann Mähr. u. Schles. Gbge., Brocken, Feldberg in Baden. Jul. Aug. Blb. bleichrosenroth. St., auch an der kultiv. Pflanze nur 36" hoch, Kapseln kahl. Var. $\beta$. : Kapseln flaumhaarig: E. nutans Schmidt, nicht Hornem.

\section{OEONTHÉRA L. Nacktkerze.}

1. OE. biennis L. Die B. gezähnelt, etwas geschweift, flaumig, die wurzelst. des ersten Jahres elliptisch-od. längl.vkteyf., stumpf mit einem Spitzcher, in den Bstiel hinablaufend, die unteren stengelst. elliptisch od. breit-lanzettl.; St. flaumig u. mit längeren auf einem Knötchen sitzenden Haaren bestreut. $\odot$. Ufer u. Kies der Fliisse, sandige O. Jun.-Aug. Blb. gelb, bis $10^{\prime \prime \prime}$ lang. Var.: B. an der Basis gezähnt, wie folgende, u. $\beta$. parviflora (aber nicht Oe. parviflora L.) Bl. nur halb so gross.

2. OE. muricata L. Die B. gezühnelt, etwas geschweift, flaumig, die wurzelst. des ersten Jahres verlängert-lanzettl., zugespitzt, in den Bstiel hinablaufend, die stengelst. lanzettl.; St. flaumig u. mit längeren auf einem Knötchen sitzenden Haaren bestreut. $\odot$. Ufer; an Treisam bei Freiburg im Breisgau, an Bächen bei Colmar u. Mühlheim im Elsass, an der Elbe in Mecklenb. u. Holstein. Jun.Aug. Blb. gelb.

II. Gruppe. JUSSIEEN. DC. Röhre des K. nicht iiber den liruchtkn. hervortretend, Saum 4-6sp., bleibend, Frucht kapselig, aufspringend.

\section{ISNARDIA I. Isnardie.}

1. I. palustris L. St. an der Basis wurzelnd, kahl; B. gegenst., eyf., sjitz, in den Bstiel verschmälert; Bth. blattwinkelst., einzeln, sitzend, blumenblattlos. 2. Gräben u. langsam fliessende 
Wasser; suidlichstes Geb., sodann v. Genf zerstr. dch das westl. Geb. bis Holst. Jul. Aug. Blïhet nur ausser d. Wasser. Bth. grün.

III. Gruppe. CIRCAEEEN. DC. Röhre des K. nicht über den Fruchtkn. hervortretend, Saum 2-4sp., abfällig.

4. CIRCAEA L. Hexenkiaut.

1. C. I utetiana L. B. eyf., etwas herzf., geschweift-gezähnelt; Deckblättchen fehlend. 2. Schattige u. feuchte Haine. Jul. Aug. Bl. weiss.

2. C. interme dia Ehrh. B. eyförmig, an der Basis herzf., geschweift-gezähnt; Deckblättchen borstl.; Frïchte fast kugelig-vkteyf. 4. Feuchte, schattige Haine, an Gebirgsbächen. Jul. Aug. Bl. weiss od. röthl.

3. C. alpina L. B. breit-eyf., tief-herzf., geschweift-gezähnt; Deckblättchen borstl.; Früchte längl.-keulig. 24. Schattige Bergwälder, in die VorA. hinauf. Jun. Jul. Bl. weiss od. röthlich.

IV. Gruppe. HYDROCARYEN. Link. Röhre des K. angewachsen, Saum bleibend. Frucht umssartig, knöchern.

5. TRAPA L. Wassernuss.

1. T. natans L. Friichte 4dornig, Dornen an der Spitze rückwärts-rauh. $\odot$. Seen, stehende u. langsam fliessende Wasser; zerstr. deh das Geb. Jun. Jul. Blb. weiss.

\section{Ordng. HALORAGEEN. R. Brown.}

\section{MYRIOPHÝLLUM L. Tausendblatt.}

1. M. verticillatum L. B. quirlf, fiederth., Zptl. borstl.; Bth. quirlig, Quirl blattwinkelst. od. ährenf.; DeckB. sämmtl. kammf.fiedersp. 4. Gräben u. stehende Wasser. Jul. Aug. Var. $\alpha$. pirnnatifidum: DeckB, vielmal grösser als die Bth., Fiedex ziemlich entfernt. M. verticillatum $\alpha$. pinnatifidum Wallr. $-\beta$. intermedium: DeckB. $3 \mathrm{mal}$ so lang als die Bth., Fieder genähert. M. verticillatum $\beta$. pinnatum Wallr. - $\gamma$. pectinatum: die DeckB. ungefähr so lang als die Bth., Fieder fast sich berïhrend. M. verticillatum $\gamma$. Wallr. M. pectinatum DC.

2. M. spicatum L. B. quirlig, fiederth.; Zpfl. borstl.; Bth. quirlig, Quirl ährenf., die jungen Aehren aufrecht; die unteren DeckB. eingeschnitten, so lang als der Quirl od. ein wenig länger, die übrigen sämmtl. ganz, kürzer als der Quirl. 24. Gräben, Teiche, Flüsse. Jul. Aug.

3. M. alterniflorum DC. B. quirlig, fiederth., Zpfl, haar-fein; die'männl. Bth. wechselst., ährig, Aehren vor dem Aufblühen überhängend; weibl. Bth. wenige, blattwinkelst., an der Basis der männl. 
Aehre quirlig. 2. Teiche, stehende Wasser, Rheinpfalz zw. Kaiserslautern u. Schopp, Zweibrücken, Westph., Oldenb., Braunschwg. Jul. Aug.

\section{Ordng. HIPPURIDEEN. Link.}

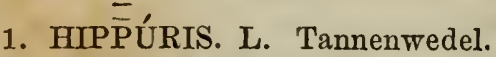

1. H. vulgaris L. B. lineal., quirlig, Quirl mehrblätterig. 4. Stehende Wasser, Bäche; zerstr. deh das Geb. u. bis in die A. Jul. Aug. Bth. grün. In Bächen fluthend sind die B. verlängert, durehscheinend. Var. weiter: $\beta$. maritima: B. 4 od. 6, fast lanzettl. H. vulgaris $\beta$. maritima Wahlenb. H. maritima Hellen. H. tetraphylla L.

\section{Ordng. CALLITRICHINEEN. Link.}

\section{CALLÍTRICHE L. Wasserstern.}

1. C. stagnalis Scop. B. sämmtl. vkteyf.; DeckB. sichelf. an der Spitze zsneigend; Gf. bleibend, zuletzt zurïckgekrümmt; Kanten der Frucht flügelig-gekielt. 24. Stehende u. fliessende Wasser. MaiOctbr.

2. C. platycarpa Kützing. Die unteren B. der Aeste lineal., die oberen vkteyf.; DeckB. sichelf., an der Spitze ziemlich gerade u. sich kreuzend; Gf. zuletzt zurückgekrümmt; Kanten der Frucht flügeliggekielt. 24. Stehende u. fliessende Wasser; zerstr. dch das Geb. Mai-Oct.

3. C. vernalis Kützing. Die unteren B. der Aeste lineal., die oberen vkteyf.; DeckB. etwas gebogen; $G f$. aufrecht, bald verschwindend; Kanten der Frucht spitz-gekielt. 24. Fliessende u. stehende Wasser. Mai-Oct.

4. C. hamulata Kützing. Die unteren B. der Aeste lineal., die oberen vkteyf.; DeckB. kreis-sichelf., an der Spitze hakig; die Kanten der Frucht flügelig-gekielt. 24. Wohnort u. Bthzeit wie die vorhergeh.

5. C. a u tu mnal is L. B. sämmtl. lineal., an der Basis breiter, nach der Spitze schmäler; Kanten der Frucht flügelig-gekielt. 4. Langsam fliessende u. stehende Wasser; Mecklenb. Jul.-Oct.

\section{XLU. Ordng. CERATOPHYLLEEN. Gray.}

\section{CeratophÝllum. L.}

1. C. submersum L. B. 3 mal gabelsp. in 5-8borstl. Zpfl. getheilt; Früchte oval, flügellos, an der Basis nackt, an der Spitze mit einem Dorne, der mehrmal kürzer ist als die Frucht. 2. Seen, Weiher, Gräben; zerstr. dch das Geb. B. freudig-grïn mit haarfeinen Zpflu. Jul. Aug. 
2. C. d emersum L. B. gabelsp. in 2-4 lineal.-fädl. Zpfl. getheilt; Früchte oval, flügellos, 3dornig, 2 Dornen an der Basis zurückgekrümmt, der endst. so lang als die'Frucht od. länger. 2. Stehende u. langsam fliessende Wasser. Jul. Aug. B. dunkelgrün.

3. C. platy a canthum Chamisso. B. gabelsp. in 2-4lineal.-

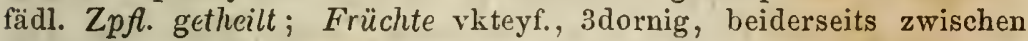
den Dornen gefiügelt, Fliigel etwas gezälnnt; Dornen der Basis flach, der endst. länger als die Frucht. 24. Stehende u. langsam fliessende Wasser; bei Berlin. Jul. Aug. Variet. der vorhergeh., nach Wimmer.

\section{Ordng. LYTHRARIEEN. Juss.}

1. LYTHRUM L. Weiderich.

1. L. Salic aria L. B. herz-lanzettf., die unteren gegenst. od. quirlig; Bth. 12männig, quirlig-ährig; K. an der Basis ohne Deckblättchen, die inneren Zähne pfrieml., noch 1mal so lang als die äusseren. 24. Feuchte O., Ufer, Gräben. Jul.-Sept. Var. lang- u. kurzgriffelig. Blb. purp., wic bei folgend.

2. L. virgatum L. B. lanzettl., die unteren gegenst., an der Basis abgerundet, die oberen nach beiden Enden verschmälert; Bth. 12 männig, die unteren quirlig, die oberen wechselst.; $K$. an der $B a$ sis olıne Deckblältchen, Zähne gleichlang, abwechselnd pfrieml. $\mathbf{4}$. An feuchten O.; Gräben; Oestr., Bölım., Stmk. Jun. Jul.

3. L. Hys s o p if o lia L. B. lineal. od. längl.; Bth. 6männig, einzeln, blattwinkelst.; $K$. an der Basis mit 2 sehr kurzen, pfrieml. Deckblättchen, Zähne pfrieml., abwechselnd länger. $\odot$. Feuchte Triften u. Aecker. Jul.-Sept.

2. PEPLIS L. Afterquendel.

1. P. Portula L. B. gegenst., vkteyf., gestielt; Bth. blatt-winkelst., einzeln, fast sitzend. $\odot$. Feuchte O., Triften, Aecker, Gräben. Jul.-Sept.

\section{Ordng. TAMARISCINEEN. Desv.}

\section{TAMARIX L. Tamarisken.}

1. T. gallic a L. Kahl, meergriin; B. eyf., zugespitzt; Aehren seitenst.; DeckB. zugeschweift-haarspitzig. $\hbar$. Meeresufer, Monfalcone. Jul. Blb. rosenroth, wie folg.

2. T. africana Poir. Kahl, etwas meergrün; B. eyf., zugespitzt, an der Spitze selbst stumpf; Aehren seitenst.; DeckB. aus eyf. Basis längl. od. lanzettl., stumpf. $\hbar$. Feuchte 0 . am Meere; Osero. Jul. Aehren noch 1 unal so dick als bei der vorhergehenden. 
2. MYRICÁRIA Desv. Myrikarie.

1. M. germanica Desv. Strauchig, kahl; B. lineal.-lanzettl., sitzend; Aehren endst., einzeln; DeckB. länger als die Bthstielchen; Kapseln āufrecht, etwas abstehend. Ђ. Im Kiese der Bäche u. Flüsse der A. bis in die Ebenen u. in Oberschles., Mähr., Harz. Mai. Jun. Tamarix germanica L. Blb. rosenroth.

\section{Ordng. PHILADELPHEEN. Don.}

1. PHILADELPHUS L. Pfeiffenstrauch.

1. Ph. cor on arius L. B. elliptisch, zugespitzt, gesägt-gezähnelt, oberseits kahl, unterseits kurzh.; Bth. traubig; Zpfl. des K.

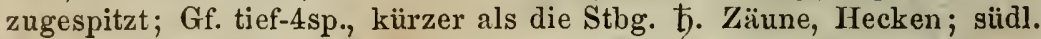
Tyrol, ausserdem hie u. da verwildert. Mai. Jun. Blb. weiss.

\section{Ordng. MYRTACEEN. R. Brown.}

\section{MYRTUS L. Myrte.}

1. M. communis L. Bthstiele einzeln, 1 bth., ein wenig kürzer als das B.; die 2 Deckblättchen lineal., abfällig, unter die Bth. gestellt; K. 5sp.; B. ey- od. lanzettf., zugespitzt; Beeren eyf. $\hbar$. Sonnige felsige O.; Littor. Jul. Aug. Blb. weiss.

\section{Ordng. CUCURBITACEEN. Juss.}

\section{CUCÚRBITA L. Kürbis.}

1. C. Pepo L. St. steifh., kletternd; Wickelranken ästig; B. herzf., 5lappig, rauh; Früchte rundl. od. oval, glatt. $\odot$. In wärmeren Provinzen zum ökonom. Gebrauch kultiv. Jun.-Aug. Bl. gelb.

2. CÚCUMis L. Gurke.

1. C. sativus L. St. steifh., kletternd; Wickelranken einfach; B. herzf., 5eckig, Ecken spitz; Friichte längl., knotig. $\odot$. Ueberall zum ökonom. Gebrauch kultiv. Mai-Aug. Bl. gelb.

2. C. Melo L. St. steifh., kletternd; Wickelranken einfach; $B$. berzf., 5eckig, gezähnelt, Ecken rund; Früchte kugelig od. oval, glatt, knotig od. netzig. $\odot$. In den südl. Prov. im Freien kultiv., in den übrigen im Nistbeete. Bl. gelb.

3. BRYONLA L. Zaunrübe.

1. B. a Ib a L. B. herzf., 5lappig, gezähnt, schwielig-rauh; Bth. traubig-ebensträussig, 1 häusig; $K$. des Weibchens so lang als die Bl.; Narben kahl. 24. Zäune u. Gebüsch, zerstr. dch das Geb. Jun. Jul. Beeren schwarz.

2. B. di o i ca Jacq. B. herzf., 5lappig, gezälnt, schwielig-rauh; Bth, traubig-ebensträussig, 2häussig; $K$. des Weibchens halb so lang 
als die Bl.; Narben rauhh. 2. Zäune u. Gehiiseh; zerstr. deh das Geb. Jun. Jul. Beeren roth.

4. ECBÁLLION Richard. Esclsgurkc.

1. E. Elaterium Rich. Wickelranken fehlend; Friichte steifh. ○. Wege u. Zäune; Littor. Jul.-Herbst. Momordica Elaterium L. Bl. grünl.-weiss.

\section{Ordng. PORTULACEEN. Juss.}

1. PORTUlá́CA L. Portulak.

1. P. oleracea L. St. nebst den Aesten gestreckt; B. längl.keilig, fleischig; Bth. gabelst., einzeln, zu 2 od. 3, sitzend; Zpfl. des K. stumpf-gekielt. $\odot$. Kultiv. O., Wege. Jun.-Sept. BI. gelb.

2. P. S ativa Haw. St. aufrecht; Aeste ausgebreitet, aufstrebend; B. vkteyf.; Bth. gabelst., einzeln u. mehrere, sitzend; $\mathrm{Zpfl}$. des $K$. auf dem Rücken geflügelt-zsgedrückt. $\odot$. Zum ökonom. Gebrauch kultiv. Jun.-Sept. P. oleracea $\beta$. L. Bl. gelb.

2. MÓNTLA L. Montie.

1. M. minor Gmelin. Samen knotig-rauh, fast glanzlos. $\odot$. Feuchte Aecker $u$. feuchte Sandplätze. Mai. Jun. M. fontana $\alpha$. minor K. synops ed. 1. M. arvensis Wallr. Bl. weiss.

2. M. rivularis Gmel. Samen sehr fein knotig-punktirt, glänzend. 24. In kaltem Quellwasser. Mai-Herbst. M. fontana $\beta$. major K. synops. ed. 1. Bl. weiss.

\section{Ordng. PARONYCHIEEN. St. Hil.}

I. Gruppe. TELEPHIEEN. DC., Bartling. B. wechsel-, seltener gegenst. Blb. v. der Grösse der KB.

1. TELÉPHIUN L. Telephie.

1. T. Imperati L. B. wechselst.; Bth. traubig-ebensträussig, etwas gedrungen. 24. Felsige, sonnige O.; Siidtyrol im Vinschgau, Wallis bei Sitten u. Gonthey. Jul. Bl. weiss.

2. CORRIGÍOLA L. Hirschsprung.

1. C. littoralis L. Ebensträusse beblättert; Bth. gestielt; StB. lineal.-keilig. $\odot$. Kies der Flüsse, sandige, fenchte Wege; zerstr. deh das Geb. Jul. Aug. Bl. weiss.

II. Gruppe. ILLECEBREEN. DC., Bartling. B. gegenst. Blb. feblend od. sehr klein, pfrieml., Trägern ohne Kölbchen ähnelnd, einem nebenweibigen Ringe eingefiigt. Stbg. 5, selten 3 od. 1. Frucht 1 samig. 


\section{HERNIÁRIA L. Bruchkrant.}

1. H. gl a bra L. St. niedergestreckt; B. elliptisch od. längl., nach der Basis verschmälert, kahl; Knäuelchen blattwinkelst., meist 10bth.; K. kahl. 24. Sandige, kiesige Felder, Triften, Haiden. Jul.Oct. Bth. grünl., wie an den folgenden. Var.: die Pfl. mit einem sehr kurzen Flaume bedeckt.

2. H. hirsuta L. St. niedergestreckt, nebst den B. u. K. kurzh.; B. elliptisch od. längl., nach der Basis verschmälert; Knäuelchen blattwinkelst., meist $10 \mathrm{bth}$; Kelchzpfl. v. einer längeren Borste stachelspitzig. 2. Sandfelder; zerstr. dch das Geb. Jul.-Oct.

3. H. incan a Lam. St. niedergestreckt, nebst den B. u. K. kurzh.; B. längl. u. lanzettl., nach der Basis verschmälert; Knäuelchen blattwinkelst., meist 3 bth., locker; Haare der Kelchzpf. gleich. 4. Sonnige, trockene O.; Fiume, Istrien. Mai. Jun.

4. H. al pin a Vill. St. niedergestreckt; $B$. vkteyf. od. längl., gewimpert; Knäuelchen blattwinkelst., 1-armbth., an der Spitze der Aestchen gehäuft; K. kurzh., Haare gleich, 2. Felsen der höchsten Walliser A. Jul. Aug.

4. ILLÉCEBRUM L. Knorpelblume.

1. I. verticillatum L. 24. Fenchte, sandige O., Torfbrüche an Gräben; 'nördl. Geb. u. zerstr. deh das mittl. u. süidl. Jul. Aug. Bth. schneeweiss.

5. PARONÝCHIA Tournef. DC. Paronychie.

1. P. c a pitat a Lam. Die St. niederliegend od. aufstrebend; B. lanzettl. od. elliptisch, ziemlich stumpf, gewimpert; DeckB. breiteyf., kurz-stachelspitzig, silberweiss-trockenhäutig, in endst. Köpfchen gedrängt, die Bth. bergend; $\mathrm{Zpfl}$. des K. grannenlos. 2. Sonnige, trockene O.; Fiume, Osero, Veglia. Mai. P. serpyllifolia D. fl. Illecebrum capitatum I. Bth. gritinl. Var. $\beta$. serpyllifolia: B. breiter, eyf. od. vkteyf. P. serpyllifolia DC.

III. Gruppe. POLYCARPEEN. DC. B. gegenst. Blb. 5, od. fehlend. Kapsel 1fächerig, vielsamig.

6. POLYCARPON L. Nagelkraut.

1. P. tetraphyllum L. fil. Dreimännig; Blb. ausgerandet; B. am St. zu 4, an den Aesten gegenst. $\odot$. Sandige O.; Baden zw. Mannheim u. Carlsruhe, Littor., Schles., Veltlin. Aug. Sept. Bth. grünl.

\section{Ordng. SCLERANTHEEN. Link.}

\section{SCLERÁNTHUS L, Knauel.}

1. S. annu u L. Bth. meist 10männig; Kelchzpfl. eyf., ziem- 
lich spitz, sehr schmal häutig-berandet, so lang als "Nie Röhre, die fruchttrag. etwas abstehend. $\odot$. Felder, kultiv. 0 . Jun.-Oct. Bth. grünl., Z $Z$ pfl. sehr schmal weissl.-berandet.

2. S. perennis L. Bth. 10männig; Kelchzpfl. längl., abgerundet-stumpf, mit einem breiten häutigen Rande umgeben, die fruchttrag. geschlossen. 24. Sandfelder, trockene Triften, gebirgige, felsige O. Mai-Oet. Bth. grün, Zpfl. breit weiss-beraudet.

\section{Ordng. CRASSULACEEN. DC.}

\section{TILLAEA L. Tilläe.}

1. T. muscosa L. St. an der Basis niederliegend, Aeste aufstrebend; Bth. blattwinkelst., sitzend, 3sp. (- Feuchte Saudfelder; Westphalen bei Coesfeld hinter der Klinke, bei Haltern u. Marienbaum zw. Xanten u. Cleve. Mai. Jun. Blb. röthl. od. weissl.

\section{BULLIÁRDA DC. Bulliarde.}

1. B. a qu atic a DC. B. lineal.; Bth. sehr kurzgestielt od. sitzend. $\odot$. Stehende Wässer u. Ufer: Trebon in Böhm., Wittenberg, Berlin, Osnabrïck u. Burgsteinf. in Westpl. Aug. Sept. Tillaea aquatica L. im Wasser aufrecht, an Ufern liegend, letztere: Tillaea prostrata Schk. Blb. weiss. - Die Bulliarda Vaillantii mit Bthstielen, die länger als das B. sind, hat sich in neverer Zeit nicht wieder gefunden.

\section{RHODÍOLA L. Rosenwurz.}

1. Rh. rosea L. 2. Felsige O. der A., Voges. u. Sudet. Jul. Aug. Blb. röthl. od. gelbl.

\section{CRÁSSULA L. Dickblatt.}

1. C. rubens L. St. aufrecht, oberwärts 3 sp., trugdoldig od. ästig, Aeste aufstrebend; B. zerstreut, abstehend, halbwalzl., kahl, stumpf; Bth. einzeln, einseitswendig, sitzend; Aeste nebst dem $K$. drüsig-behaart. $\odot$. Weinberge, Aecker, siid-westl. Schwz., u. bei Basel u. gegenüber in Oberbaden, sodann um Trier. Mai. Jun. Blb. weiss mit rothem Kiele.

2. C. Magnolii DC. St. aufrecht, oberwärts 2-3sp., trugdoldig, armbth., nebst den Aesten, B. u. $K$. kahl; B. eyf., stumpf, dachig; Bth. einzeln, einseitswendig, sitzend. $\odot$. Sonnige Hiigel; Istrien. Apr. Pfl. um die Hälfte kleiner als die vorhergeh. Blb. hell-fleischroth, Kiel purpurn.

5. SEDUM L. Fetthenne.

I. Rotte. Telephium. W. stark, ästig, vielköpfig, mehrstengelig, ohne kriechende Stämmchen. (Die W. treibt im Herbste 
neue Knospen od. Schösslinge, die im künftigen Jahr hervorsprossen, während die jährigen St. absterben.)

1. S. maximum Sut. B. flach, längl. od. eyf., stumpf, 'ungleich-gezähnt-gesägt, meist gegenst., od. 3quirlig, die unteren mit breiter Basis sitzend, die oberen an der Basis kurz-herzf., etwas stengelumfassend; Trugdolden endst., gedrungen; Blb. abstehend, gerade, an der Spitze rinnig-eingedrückt, mit einem kleinen, zsgedrückten Hörnchen endigend; die inneren Stbgf. tief auf die Basis der Blb. eingefïgt. 24. Wälder, Raine, Felsen. Fängt im halben Aug. zu blïhen an. S. Telephium $\delta$. et. $\varepsilon$. L. S. latifolium Bertol. Blb. grüngelblich-weiss.

2. S. purpurascèns Koch. B. flach, vkteyf., längl. od. lanzettl., ungleich-gezähnt-gesägt od. fast ganzrandig, die obcren mit abgerundeter Basis sitzend, die unteren kurz-gestielt, oft gegenst. od. 3quirlig; Trugdolden endst., gedrungen; Blb. über der Mitte zurïckgekrümmt-abstehend, an der Spitze flach, ein wenig rinnig, schwach behörnelt; die inneren Stbgf. ein 6tel über die Basis der Blb. eingefügt. 2. Wälder, Raine, unkultiv. O.; westl. Gebiet bis Regensb. Fängt gegen Ende Juli zu blühen an. S. Telephium Smith in Engl. f. K. syn. ed. 1. S. Teleph. $\beta$. purpureum L. Telephium purpurascens Fuchs. Blb. purp.

3. S. Fabaria Koch. B. fach, längl.-lanzettl. od. lanzettl., gezähnt-gesägt, mit der ganzrandigen, keiligen Basis in den kurzen Bstiel verschmälert, zerstreut od. wechselst.; Trugdolden endst., gedrungen; Blb. abstehend, an der Spitze flach, etwas rinnig, schwachbehörnelt; die inneren Stbgf. ein Drittel über die Basis der Blb. eingefügt. 2. Auf dem Gipfel der Babia Gora in Schles., auf der hohen Acht in der Eifel. Blïhet in Gärten einen ganzen Monat früher als S. purpurascens u. $1 \frac{1}{2}$ Monat friiher als S. maximum. Bl. purpurn.

4. S. Anacampseros L. B. Alach, vkteyf., ganzrandig, sehr stumpf, kahl; St. niederliegend; Ebensträusse endst., gedrungen. 4. Felsen der A. des südl. Tyrols, südwestl. Schwz. Jul. Bl. purpurn.

II. Rotte. Cepa e a. W. diinn. Der St. einzeln, einfach, od. v. der Basis an in Aeste od. Nebenstengel getheilt; die kriechenden Stämmchen fehlend.

${ }^{*}$ B. flach.

5. S. stellatum L. B. flach, rundl., eckig-gekerbt, in den Bstiel verschmälert, gegen- od. wecliselst., kahl; Trugdolde meist 2sp., armbth.; Bth. blattwinkelst., stiellos; Blb. lanzettl., spitz. $\odot$. Gebirgige, felsige O., Mauern; siidl. Schwz. Jun. Jul. Blb. weiss od. hell-rosenroth.

6. S. Cepaea L. B. flach, ganzrandig, stumpf, die unteren gestielt, vkteyf., gegenst., 3- auch 4 st., die oberen lineal.-keilig; die 
$R$. längl.; BIb. lanzettl., in eine sehr feine Haarspitze ausgehend. ○. Felsige, schattige O.; siid-westl. Schwz., sïdl. Tyrol. Jun. Jul. Bl. rosenroth.

**B. halbstielrund od. sticlrund.

7. S. hispanicum L. B. beinahe stielrund, lineal., stumpf od. ziemlich spitz, abstehend, mit gleicher Basis aufsitzend; Trugdolde fast kahl; Bth. 12männig, 6blättrig; Blb. lanzettl., haarspitzig, 4mal so lang als der $\mathbf{K}$; kriechende Stämmchen fehlend. (-). In Gebiisch u. an felsigen O. der Alpenthäler. Jul. S. Guettardi Gmel. S. glaucum WK. S. sexfidum MB. Blb. weiss, Mittelnerv roth.

8. S. villos um L. B. lineal., stumpf, beinahe stielrund, oberseits ziemlich flach, aufrecht, mit gleicher Basis aufsitzend u. nebst der $R$. drüsig-flaumig; R. etwas traubig; Blb. eyf., spitz, noch $1 \mathrm{mal}$ so lang als der K.; kriechende Stämmchen fehlend. $\odot$. Feuchte, torfhaltige Wiesen bis in die A. Jul. Aug. Blb. rosenroth, mit purpurnem Rückenstreifen.

9. S. a trat u m L. B. stielrund-keulig, mit gleicher Basis sitzend; Ebensträusse endst., einfach, gedrungen, kahl, nach dem Verblïhen gleich-hoch; Bth. gestielt; Blb. ey-lanzettf., ziemlich stumpf mit einem kurzen Spitzchen, noch $1 \mathrm{mal}$ so lang als der K.; kriechende Stämmchen fehlend. $\odot$. Felsige, sonnige O. der A. Jul. Aug. Blb. weiss od. grüngelbl., Mittelnerv grün.

10. S. a nnu um L. B. lineal., stumpf, stielrund, oberseits ziemlich flach, mit gleicher Basis sitzend; Trugdolden kahl; St. v. der Basis an ästig; Aeste meist 2sp., zuletzt verlängert, schlängelich; Bth. 1seitig, fast sitzend; Blb. lanzettl., spitz, fast noch 1 mal so lang als der K.; kriechende Stämmchen fehlend. $\odot$. Felsen der A. u. VorA.; Voges., Belchen im Breisgau, Sandhiigel in Holst. Jun.Aug. S. saxatile Wigg. Bl. gelb.

III. Rotte. Seda genuina. Die W. treibt einen Rasen v. kriechenden Stämmchen u. aufstrebenden Stengeln. Die bliihenden St. treten $\mathrm{zw}$. den beblätterten hervor. (Die beblätterten, nicht blühenden Aeste dauern über der Erde fort, die blïhenden St. aber sterben jährlich ab.)

* Bth. weiss od. rosenroth.

11. S. a lbum L. B. längl.-lineal. n. lineal., stumpf, beinahe walzl., oberwärts etwas flach, abstehend, mit gleicher Basis sitzend; $\boldsymbol{R}$. fast;gleich-hoch, kahl; Blb. lanzettl., stumpflich, 3mal so lang als der K.; Stämmchen kriechend; die nicht blïhenden St. zerstreutu. abstehend-beblättert. 2. Felsen, Mauern, steinige O. Jul. Aug. Blb. weiss od. hell-rosenroth.

12. S. dasyphyllum L. B. fleischig, kurz-elliptisch, auf dem Rücken buckelig, mit gleicher Basis sitzend, die meisten gegenst.; R. drüsig-flaumig; Blb. eyf., stumptich, noch $1 \mathrm{mal}$ so lang als der 
K.; Stämmchen kriechend, die nichtblühenden Aeste dieht-beblättert. 2. Felsen der Alpenthäler u. Voges. Jun. Jul. Blb. weiss mit rothem Kiiele.

** Blb. gelb.

13. S. a ere L. B. fleischig, eyf., spitzl., auf dem Rücken buckelig, mit stumpfer Basis sitzend; Trugdolde kahl; Blb. lanzettl., spitz, noch 1mal so lang als der K:; Stämmchen kriechend; die nichtblïhenden St. 6zeilig-beblättert. 24. Sandfelder, Haiden, Mauern, Bergabhänge. Jun. Jul.

14. S. sexangulare L. B. stielrund, lineal, stumpf, mit $a b$ uärts bespitzter Basis sitzend; T'rugdolde kahl; Blb. lanzettl., spitz, noch $1 \mathrm{mal}$ so lang als der K.; Stämmchen kriechend; die niehtbliihenden St. 6zeilig-beblättert. 24. Mit dem vorhergeh., doch weniger häufig u. 14 Tage später bliihend.

15. S. repens Schleich. B. lineal., stielrund, beiderseits etwas flach, mit gleicher Basis sitzend; Trugdolde 2-5bth., kahl; Blb. eyf.-längl., stumpf, anderthalbmal so lang als der K.; Stämmchen kriechend; die niehtblühenden St. zerstreut-u. dichtbeblättert. 4 . Felsen der A., Sudeten u. Vogesen. Jul. Aug. S. rubens Haenk.

16. S. anopetal nm DC. B. lineal.-pfrieml., fleischig, spitz, stachelspitzig, oberseits etwas flach, an der Basis vorgezogen, etwas gespornt, die der niehtblühenden Aeste dachig; Trugdolde kahl; Kelchzpfl. zugespitzt; $B l b$. fast noch 1 mal so lang als der K., lanzettl., zugespitzt, aufrecht; Stämmchen kriechend. 24. Sonnige Kalkfelsen; Triest, Schwz. Jul. Aug.

17. S. reflexum L. B. lineal.-pfrieml., spitz, kurz-stachelspitzig, fleischig, beirlerseits convex, an der Basis vorgezogen, etwas gespornt, an den nichtblühenden Aesten dachig, abstehend u. zurïckgekrïmmt; Trugdolde kahI; Kelchzpfl. spitz; Blb. noch $1 \mathrm{mal}$ so lang als der K., lanzettl., abstehend; Stämmchen kriechend. 2. Sandfelder, felsige O. Jul. Aug. Var.: B. entfernter, abstehend od. zuriickgekrïmmt, od. dieht-daelig, dünner od. noch 1 mal so dick; u. P. viride: B. freudig-grïn. S. reflexum L. S. erassicaule Link. Diese Var. wächst auf höheren, besonders Porphyr-Gbgen. $-\gamma$. glaucum: B. bläulichgrïn, meergriîn od. hechtgrau. S. rupestre L.

18. S. elegans Lej. B. lanzettl-lineal., spitz, kurz-stıchelspitzig, fleischig, beiderseits etwas flach, an der Basis vorgezogen, etwas gespornt, die der nichtblïlıenden Aeste dicht-dachig; TrugIolde kahl; Kelchzpfl. abgerundet-stumpf; Blb. längl., noch $1 \mathrm{mal}$ so lang als der K., abstehend; Stämmchen kriechend. 4. Fclsen u. Manern bei Mastricht. Jul. Aug. S. rupestre Sm.

6. SEMPERVIVUM L. Hauswurz.

I. Rotte. Sempervivum genuinum. Blb. u. Kelchzpfl. sternf.-ausgebreitet. 
1. S. tectorum L. B. der Rosetten längl.-vkteyf., plötzl. in eine Stachelspitze zugespitzt, grasgrïn, kahl, am Rande überall gewimpert; Blb. sternf.-ausgebreitet, lanzettl., zugespitzt, noch $1 \mathrm{mal}$ so lang“als der K.; unterwcibige Schup; sen sehr kurz, convex, drüsenf. 4. Felsen $\operatorname{der}$ A. u. VorA.; häufig kultiv, auf Maueru, Dächern. Jul. Ang. Die kultiv. Pfl. hat immer zum Theil monströs veränderte Stbgf. Bl. purp.

2. S. Wulfeni Hoppe. B. der Rosetten längl.-vkteyf., plötzl. in eine Stachelspitze zugespitzt, meergriin, kahl, gewimpert, Rand $d$. Spitze im Alter kabl werdend; Blb. sternf--ausgebreitét, lineal., an der Spitze pfrieml., 3mal so lang als der K.; unterweihige Schuppen aufrecht, plättchenf., fast 4eckig. 2. Felsen der höchsten A.; Tyrol, Kärnth., Stmk. Jul. Aug. S. globiferum Wulf. BIb. schwefelgelb.

3. S. Funkii Braun. B. der Rosetten längl., kurz-zugespitzt, beiderseits drüsig-flaumig u. v. längeren, starken Haaren gewimpert; Blh. sternf.-ausgebreitet, lanzettl., zugespitzt, fast $3 \mathrm{mal}$ so lang als der K.; Stbf. stielrund; Fruchtkn. breit eyf., fast rautenf.; unterweibige Schuppen aufrecht, plättchenf., fast 4 eckig. 24. A. v. Tyrol, Kärnthen, Salzbg. Jul. Aug. Blb. rosenroth.

4. S. montanum L. B. der Rosetten längl.-keilig, kurz-zugespitzt, beiderseits drüsig-flaumig u. v. etwas längeren Haaren undeutl.-gewimpert, die stengelst. längl., aufrecht, vorne ein wenig breiter; Blb. sternf.-ausgebreitet, lanzettf.-pfrieml., sehr spitz, fast $4 \mathrm{mal}$ so lang als der K.; Stbf. stielrund; Fruchtkn. schief-längl.; unterweibige Schuppen aufrecht, plättchenf., fast 4eckig. 24. Auf deu A. u. der Babia Gora in Schles. Jul. Aug. Blb. rosenroth.

5. S. Braunii Funk. B. der Rosetten längl.-keilig, spitz, beiderseits drüsig-flaumig u. v. etwas längeren Haaren undeutl.-gewimpert, dic oberen stengelst. aus breiterer, eyf. Basis lanzettl., abstehend; Blb. sternf.-ausgebreitet, lineal.-lanzettl., ver-schmälert-zugespitzt, fast $3 \mathrm{mal}$ so lang als der K.; Stbf. unterwärts zsgedrückt; Fruchtkn. schief-längl.; unterweibige Schuppen aufrecht, plättchenf., fast 4eckig. 7. Felsen der höchsten A.; am Grossglockner. Jul. Aug. Blb. gelblich-weiss.

6. S. arachnoide $u \mathrm{~m}$ L. B. der Rosetten vkteyf. od.' längl., kurz-spitz, drïsig-kurzh., borstig-gewimpert, an der Spitze büschelig-gebärtet, mit strahlig-auseinandertretenden, spinnwebartigen, die Spitzen der B. verbindenden Haaren; Blb. längl.-lanzettl., zugespitzt, 3 mal so lang als der K. 24. Felsen der A. u. südl. bis in die niedr. Gegend.; Schwz., Tyrol, Salzbg., Kärnth., Stmk. Jul. Aug. Blb. rosenroth.

II. Rotte. Jovibarba. Blb. u. Kelchzpfl. aufrecht, glockig, erstere an der Spitze zuriickgekriimmt.

7. S. hirtum L. B. der Rosetten längl.-lanzettl., spitz, v, der 
Mitte nach der Spitze verschmälert, kahl, am Rande gewimpert, die stengelst. herz-eyf., zugespitzt $u$. nebst den K. am Rande wimperig u. ober- u. unterseits kurzh.; Bth. glockig; der K. kürzer als die halbe Bl. 2. Felsen der A. 11. höheren Gbge.; Steyerm., Oestr., Schles. u. Mähr. Gbge. Jul. Aug. Bl. gelblichweiss.

8. S. s o bolifer um Sims. B. der Rosetten vkteyf.- od. längl.keilig, spitz, die stengelst. längl., zugespitzt, die obersten eyf., alle nebst dem $K$. ober- $u$. unterseits kahl, am Rande gewimpert; Bth. glockig; K. um die Hälfte kürzer als die Bl. 24. Felsen der A. u. Polauer Berge in Mähr., u. angepflanzt auf Mauern u. Däeheru. Jul. Aug. Bl. gelblichweiss.

9. S. a renarium Koch. B. der Rosetten lanzettl., v. der Mitte nach der Spitze allmählig schmäler, spitz, die unteren stengelst. aus breiterer, etwas herzf. Basis eyf.-längl., die oberen 3eckig-eyf., alle nebst den $K$. am Rande bewimpert, ober- $u_{0}^{-}$unterseits kahl; Bth. glockig; $K$. ein Drittel so lang als die Bl. 2. Auf griesiger Erde der Wälder u. auf Felsen in Tyr. bei Antholz im Brunnecker Thale u. im Pusterthal. Jul. Aug. Bl. gelblichweiss.

7. UMBILICUS DC. Nabelkraut.

1. U. pendulinus DC. Untere B. schildf., kreisrund, concav; Bth. traubig, hängend; Bthstielchen so lang als das ganzrandige NebenB. 24. Felsen bei Belgirate am langen See im C. Tessin; an den Manern des Klosters der Stadt Veglia. Jun. Jul. Cotyledon Umbilicus $\beta$. L. sp. Bl. grïnlichweiss.

\section{Ordng. CACTEEN. DC.}

1. OPUNTIA Tournef. Feigendistel.

1. O. vulgaris Mill. Ausgebreitet-niederliegend, kriechend; Glieder vkteyf.; Stacheln gleichgross, sehr kurz, haarf., sehr zahlreich. b. Sonnige Felsen; sïdl. 'Tyr., südl. Schwz., aus Amerika, nun einheimisch. Jul. Cactus Opuntia L. Blb. schwefelgelb.

\section{Ordng. GROSSULARIEEN. DC.}

1. RIBES I. Johannis- u. Stachel-Beere.

I. Rotte. Grossularia. Stachelbeere. Bthstiele 1-3bth.

1. R. Grossularia L. Bthstiele $1-3$ bth., mit $2-3$ DeckB.; K. glockig, Zpfl. längl., zurückgebogen; Blb. vkteyf.; Stacheln 3theilig. Ђ. Unkultiv. felsige O., Mauern. Apr. Mai. Blb. weiss. Beeren grünlichweiss, seltener roth. Var. ausserdem: $\alpha$. glanduloso-setosum : Fruchtkn. u. Beeren mit drüsentrag. Borsten. R. Grossularia L. B. pubescens: Fruchtkn. mit kurzen, weichen, drüsenlosen Haaren, die Beeren zulctzt kahl: R. Uva crispa L.; überall gemein. $-\gamma$. 
glabrum: Fruchtkn., B., Bstiele, Bthstiele, DeckB. u. K. kahl; Rand der B., Bstiele, DeckB. u. KelchzpH. gewimpert: R. reclinatum L. Diese kultivirt.

II. Rotte. Ribesia. Johannisbeere. Bth. traubig, Tr. reichblüthig.

2. R. alpinum L. Tr. drïsig-behaart, aufrecht; K. kahl, flach, ZpH. eyf.; Blb. spatelig; DeckB. lanzettl., länger als das Bthstielchen. $\hbar$. Gebirgige, felsige $O$, in die VorA. hinauf. Mai. Jun. Bth. gelblich-grün, die weibl. satter-griin.

3. R. nigr u m L. Tr. flaumig, hangend; K. flammig, drüsigpunktirt, glockig, Zpfl. des Saums längl., zurïckgekrimmt; Blb. längl.; DeckB. pfrieml., kiirzer als das Bthstielchen; $B$. fast 5lappig, unterseits drüsig-punktirt. 方. Feuchte, waldige O., an Sümpten, Bä̈chen; nördl. Geb., im mittl. u. südl. selten. Apr. Mai. Bth. grün, Blb. inwendig roth.

4. R. rubrum L. Tr. fast kahl, nickend, nach dem Verblühen hangend; $K$. kahl, beckenf., am Rande kahl, Zpfl. nebst den Blb. spatelig; DeckB. eyf., kürzer als das Bthstielchen; B. fast 5lappig. Ђ. Wälder an etwas feuchten $O$., Wiesenränder; nördl. Geb., mittl. u. südl. selten, in den VorA. Apr. Mai. BI. einfarbig grïn-gelblicl. Var. $\beta$. sylvestre: Grund des K. bräunlich od. mit braunen Punkten bestreut; Blb. kürzer; Gf. kürzer; Stbf. nicht so lang als die Stbk. breit sind.

5. R. petraeum Wulfen. Tr. etwas zottig, zuerst aufrecht u. nickend, nach dem Verblühen hängend; $K$. kahl, glockig, $Z p f$. spatelig, gewimpert, aufrecht-abstehend; BIb. spatelig; DeckB. eyf., kürzer als das Bthstielchen; B. fast 5lappig. $\hbar$. Felsige, feuchte O. der VorA., der Sudet. u. Voges. Apr.-Jun. Bl. röthl.

\section{SAXIFRAGEEN. Vent.}

\section{SAXÍFRAGA L. Steinbrech.}

I. Rotte. Aizooni a Tausch. Stämmchen dauernd, beblättert. B. am Rande mit einer Längslinie v. eingedrückten Punkten $b \epsilon-$ zeichnet, die mit einem weissen, kalkartigen, später ausfallenden Schülferchen bedeckt sind.

1. S. Cotyledon L. B. der Rosetten zungig, längs des gesägten Randes vielpunktig, Punkte mit einer kalkigen, grübigen Schülfer gedeckt, Sägezähne an der Spitze knorpelig, vorwärts-zugespitzt; R. pyramidal.; Aeste v. der Mitte an 5-15bth.; Blb. keilig. 4. A. der Schwz., Wallis, Tessin, Veltlin, Graubiind. Jul. Aug. S. pyramidalis Lap. Blb. weiss, od. am Nagel purpurn.

2. S. Aizóon Jacq. B. der Rosetten zungig, längs des gesägten Randes vielpunktig, Punkte mit einer kalkigen, griibigen Schül- 
fer gedeckt, Sägezähne an der Spitze knorpelig, vorwärts-zugespitzt; St. oberwärts traubig; Aeste nackt, 1bth. od. an der Spitze 2bth.; Blb. rundl. 2. Felsen d. A. u. VorA., auch niedrigerer Berge; zerstr. dch das Geb. Jul. Aug. Blb. weiss od. grünlich-weiss, rothpunktirt. Var.: Blb. einfarbig: S. intacta Willd.; B. längl.-lineal.: S. recta Lap.; B. vkteyf.: Variet. brevifolia Strnbg.

3. S. elatior M. u. K. B. der Rosetten zungig, längs des gekerbten Randes vielpunktig, Punkte dch ein kalkiges, grïbiges Schülferchen gedeckt, Kerben knorpelig, abgeschnitten, die der stengelst. B. abgeschnitten u. gezähnelt; der St. oberwärts traubig-rispig; Aeste verlängert, nackt, an der Spitze ebenstränssig, 6-12bth.; Blb. vkteyf. 2. Felsen; sürll. Schwz., südöstl. Tyr., Krain, Stmk. Jul. Aug. S. longifolia Host, nicht Lap. Blb. weiss, rothpunktirt.

4. S. crustata Vest. B. der Rosetten lineal., stumpf, ganzrandig, am Rande vielpunktig, Punkte mit einem kalkigen, grübigen Schülferchen gedeckt; St. oberwärts traubig, Aeste nackt, 1bth., od. der St. fast rispig, Aeste an der Spitze 3-6bth.; R. aufrecht; $B l b$. stumpf, vjkteyf. od. keilig. 2. Höchste A. v. Tyrol, Kärnth., Krain, Stmk. Jul. Aug. Blb. weiss.

5. S. mutata L. B. der Rosetten zungig, mit cinem knorpeligen, hinten dicht gefranseten, vorne ganzrandigen od. undeutlich-kleingesägten Rande, vielpunktig; St. traubig-rispig; Blb. lineal.-lanzettl., spitz. $\odot$. Felsige O. die A. begleitender Gbge; nördl. Schwz., Vorarlberg, Bayern, Salzbg., Kärntlı., Stmk., Tyr. Jun. Jul. Blb. schmäler als die Kelchzpfl, pomeranzengelb.

6. S. Burseriana L. B. der Stämmchen gedrungen-gehäuft, pfrieml., zugespitzt, starr-stachelspitzig, 3kantig, geschärft-knorpeligl,erandet, oberseits 7 punktig, an d. Basis kurz-gewimpert, d. jüngeren kalkig-bekrustet; St. meist 1bth.; Blb. abstehend, rundl., klein-gekerbt, vielnervig, Nerven gerade. 24. Kalkfelsen; Tyrol, Salzbg., Kärnth., Krain, Stmk. Jun. Jul. Blb. weiss.

7. S. V andelli Sternb. B. der Stämmchen dicht-dachig, aufrecht, ey-lanzettf., spitz, starr-stachelspitzig, 3kantig, kmorpeligberandet, oberseits 5punktig, an der Basis gefranset, die jüngeren dünn-kalkig-bekrustet; St. armbth., dicht-drüsig-zottig; K. aufrecht; Blb. noch $1 \mathrm{mal}$ so lang als der K., glockig-gestellt, oval, 5nervig, Nerven gerade. 4. Felsen der A.; Schwz., Unterengadin, Wormser Joch, Tyr., Kankofel. Jun.-Aug. Blb. weiss.

8. S. di apensoides Bellard. B. der Stämmchen dicht-dachig, aufrecht od. an der Spitze etwas zurückgekrümmt, lineal.-längl., stumpf, auf dem Rücken convex, stumpf-gekielt, oberseits 7 punktig, an der Basis etwas gewimpert, die jüngeren kalkig-bekrustet; St. 2-5bth., dicht-klebrig-behaart; Blb. vkteyf., nach der Basis verschmälert, ganzrandig; vielnervig, Nerven gerade. 24. A. der Schwz.; 
Bagnesthal am St. Bernhard, u. Schweizer Seite des M. Rosa. Jun. Jul. Bl. weiss.

9. S. squarrosa Sieber. B. der Stämmchen dachig, aufrecht, an der Spitze bogig-abstehend, lineal.-lauzettl., stumpf, schwach-stachelspitzig, sehr schmal-knorpelig-berandet, auf dem Rücken convex, stumpf-gekielt, oberseits 7 punktig, an der Basis gefranset, die jiingeren kalkig-bekrustet; St. 1-6bth., zerstreut-drüsig-haarig; Blb. rundl.-vkteyf., 5nervig, Nerven gerade. 2. Felsen der A.; Stmk. auf dem Reducha, Krain, Wocheiner u. Steiner A., Tyrol, Duron in Fassa, Schlehern, Orteles. Jul. Aug. Bth. weiss oul. gelblich-weiss.

10. S. caesia L. B. der Stämmehen gedrungen-gehäuft, $v$. der Basis an bogig-zurückgekrümmt, lineal.- längl., spitzl., oberscits 7punktig, auf dem Riicken convex, stumpf-gekielt, v. der Basis bis zur Mitte gefranset, die jüngeren kalkig-bekrustet; St. 2-6bth., kahl od. zerstreut-drüsig-haarig; Blb. vkteyf., 3-5nervig, Seiternerven bogig. 4. Felsen der VorA. u. A., mit den Fliissen in die Thäler linab. Jun. Jul. Bl. weiss.

11. S. patens Gaud. B. der Stämmchen dachig, weit-abstehend, an der Spitze etwas zurückgekrümmt, lineal.-längl., spitz, oberseits 7 punktig, auf dem Rücken convex, stumpf-gekielt, v. d. Basis bis zur Mitte gefranset, die jüngeren diinn-kalkig-bekrustet; $s t .2-6 b$ th., zerstreut-drüsig-haarig. Blb. längl. - vkteyf., 3nervig, Seitennerven bogig. 2. Felsen der A.; Fouly in der Schwz., bei Mittenwalde in Tyrol. Jun. Jul. B. 2- u. $4 \mathrm{mal}$ so gross als bei S. caesia; Blb. längl., gelbl.-weiss, nicht milchweiss.

II. Rotte. Porphyrion Tausch. Stämmchen dauernd, beblättert. B. gegenst., an der dickeren, gestutzten Spitze mit 1-3 eingedrückten Punkten.

12. S. retusa Gounan. Stämmchen liegend, sehr ästig; Aeste dicht-rasig; $B$. gegenst., vierzeilig-dachig, v. der Mitte an abstehend od. zurückgebogen, längl.-lanzettf., dreiseitig-kielig, mit einer flachen, 3eckigen, 3punktigen Spitze gestutzt; Kzpfl. am Rande kahl; Bth. endst., einzeln, od. zu 3 u. 4. 24. Felsen; Sirbitzkogel u. Hochgolling, Judenbg. A., Schweizer Seite des M. Rosa. Jul. Aug. Blb. rosenroth.

13. S. oppositifolia L. Stämmchen niedergestreckt, sehr ästig; Aeste aufrecht, gedrungen-rasig; $B$. gegenst., 4reihig-dachig, längl., stumpf, an der Spitze verdickt, 1punktig, unterseits dch einen Kiel 3 kantig u. nebst den Kelchzpfln. drüsenlos-gewimpert; Bth. endst., fast sitzend, einzeln. 2. Felsen der A. u. höheren Sudet. Mai. Jun.- Bl. rosenroth, zuletzt blau.

14. S. $\mathrm{R} u \mathrm{dol}$ phian a Hornsch. Stämmchen niedergestreckt, sehr ästig; Aeste aufrecht, gedrungen-rasig; $B$. gegenst., 4reihig-dachig, vkteyf., stumpf, an der Spitze etwas verdickt, 1punktig, auf dem 
Rücken flach, schwach-gekielt, d. oberen nebst den Kelchzpfin. drüsiggewimpert; Bth. endst., einzeln. 2. Höchste A. Jun. Jul. Varietät der S. oppositifolia?

15. S. biflor a All. Stämmchen niedergestreckt, sehr ästig; Aeste aufstrebend; $B$. gegenst., ziemlich entfernt, vkteyf. od. spatelig, an der Spitze etwas verdickt, 1punktig, auf dem Rücken flach, schwachgekielt, die oberen nebst der Kelchzpfln. drüsig-gewimpert; Bth. endst., $z u$ 2- u. 3kopfig; Blb. abstehend, lanzettl., ungefähr so lang als die Stbgf. 24. Felsen der A. Jul. Aug. Bl. rosenroth oder weiss.

16. S. Ko c hii Hornung. Stänmchen niedergestreckt, ästig; Aeste aufstrebend; $B$. gegenst., locker-dachig, vkteyf. od. spatelig, an der Spitze etwas rerdickt, 1punktig, auf dem Riicken flach, schwach-gekielt, die oberen nebst den Kelchzpfin. drüsig-gewimpert; Bth. endst., $z u$ 2- $u$. 3kopfig; Blb. längl., einander berührend, 2- od. 3mal so lang als die Stbgf. 24. Felsen der A.; an den Gletschern v. Oberwallis, in der Zwing im Salzb. Jul. Aug. Grossbliithige Variet. v. S. biflora?

III. Rotte. Trachyphyllum Gaud. Stämmchen dauernd, beblättert. B. wechselst., am Rande, wenigstens nach der Basis, mit nicht gegliederten Wimpern besetzt, vor der Spitze mit einem Knötchen bezeichnet. K. aufrecht od. abstehend.

17. S. a spera L. B. lanzettl.-lineal., dornig-begrannt $u$. dorniggewimpert, an der Spitze oberseits 1punktig, die stengelst. entfernt, abstehend; Stämmchen niedergestreckt, knospentrag.; Knospen halb so lang als das stützende B.; St. mehrbth.; K. unterst., abstehend, Zpfl. kurz-stachelspitzig. 24. Felsige, feuchte O. der A. Jul. Aug. Bth. weisslich-gelblich.

18. S. bryoides L. B. lanzettl--lineal., dornig-begrannt $u$. dornig-gewimpert, an der Spitze oberseits 1punktig, die stengelst. etwas genähert, aufrecht, an den St. beinalie angedrückt; Stämmchen niedergestreckt; Knäuel der B. dicht-zusammengedrängt, so lang als das sie stützende $B$.; St. 1 bth.; $K$. unterst., abstehend, Zpfl. etwas stachelspitzig. 24. Felsige u. kiesige O. der A., u. kleine Schneegrube der Sudeten. Jul. Aug. 131. hellgelblich.

19. S. ten ell a Wulfen. Stämmchen niedergestreckt od. aufrecht; B. lineal.-pfrieml., haarspitzig-begrannt, borstig-wimperig od. kahl, an der Spitze oberseits 1punktig; $K$. oberst., $Z p f$. begrannt. 4 . Felsige O. der A.; Kärntlı., Krain, Stmk., Oberöstr. Jul. Aug. Bth. weisslich.

20. S. a izoides L. Stämmchen nebst den St. aufstrebend, beblättert; B. lineal., stachelspitzig, am Rande borstig-wimperig od. kahl., unterseits flach, oberseits ziemlich convex, vor der Spitze 1punktig; K. halbunterst., Zpfl. alstehend, grannenlos. 4. Nasse O., Rand der 
Bäche in den A. u. VorA. u. Schwarzwald. Jul. Ang. B. citrongelb, mit safraugelben Punkten. Var.: 13. wimperlos: S. autumnalis L.; Blb. safrangelb: S. autummalis Sturm; Blb. dunkel-safranfarben: S. atrorubens Bertol.

IV. Rotte. Hirculus Tausch. Stämmchen dauernd, der St. jährig, beblättert. B. flach. $K$. zurückgeschlagen. Blb. an der Basis schwielig. Stbf. pfriemlich.

21. S. Hirculus L. Stämmchen niedergestreckt, fädl.; St. aufrecht, beblättert; $\boldsymbol{B}$. lanzettl., flach, ganzrandig, die untersten in den gewimperten Bstiel verschmälert; K. unterst., zuriickgeschlagen; Blb. vielnervig, an der Basis 2schwielig. 24. Fenchte Haiden u. torfhaitige Wiesen; nördl. Geb., sodam Oberbayern, Oberschwaben, Jura. Jul. Aug. Bl. gelb, an der Basis safrangelb-punktirt.

V. Rotte. Ar abida Tausch. Stämmchen dauernd, beblättert; die St. jährig, blattlos, (Schäfte). K. zurückgeschlagen, frei, Stbf. pfrieml. Blb. schwielenlos. Blattwimpern nicht gegliedert.

22. S. stellaris L. Stämmchen rosettig od. zerstrent-beblättert; B. vkteyf.-keilig, fast sitzend, an der Spitze gezälnnt-gesägt; Schaft an der Spitze ebensträussig; $K$. unterst., zurückgeschlagen; Blb. abstehend, lanzettl., sämmtl. gleichförmig in einen Nagel zsgezogen; Stbf. pfrieml. 24. Bewässerte O. der A. u. VorA. Voges. u. Schwarzwald. Jul. Aug. Blb. schneeweiss, mit 2 citrongelben Punkten.

23. S. Clusii Gouan. Stämmchen rosettig od. zerstreut-beblättert; B. längl.-keilig, gestielt, v. der Mitte an gezähnt; Schaft an der Spitze ebensträussig; $K$. unterst., zurückgeschlagen; Blb. wagerechtabstehend, ungleich, 3 ey-lanzettf., abgebrochen-benagelt, 2 lanzettl., in den Nagel verschmälert; Stbf. pfrieml. 24. Nasse O. der AThäler; Tyrol. Jul. Aug. S. leucanthemifolia Lap. Blb. schneeweiss, 3 breiter, an der Basis mit 2 citrongelben Flecken, 2 einfarbig.

VI. Rotte. Hydatica Tausch. Stämmchen dauernd, beblättert; die St. jährig, blattlos, (Schäfte). K. zurückgeschlagen, frei. Stbf. aufwärts breiter. Blattwimpern, wenn sie vorhanden, gegliedert, an der Basis des B. aber gliederlos.

24. S. cuneifolia L. Stämmehen rosettig; B. rundl.-vkteyf. od. spatelig, sehr stumpf, geschweift-gekerbt, ganz kahl, am Rande knorpelig; Bstiel flach, keilig, kahl; St. blattlos, rispig; $K$. unterst., zurückgeschlagen; Stbf. oberwärts breiter. 2. Schattige Felsen der A.; südl. Schwz., Tyrol, Kärnth., Krain. Jun. Jul. Blb. milchweiss, mit 2 zsgeflossenen, gelben Flecken. Var. $\beta .:$ Platte der B. dreieckig-keilf., vorne gerade abgeschnitten, auf beiden Seiten nur mit 2-3 Zähnen, auf der Oberseite etwas lauchgrün. S. apennina Bert. fil. S. cuneifolia $\beta$. Bertol. fl. ital. Wohl eigene Art, aber in Piemont, noch nicht im Geb. 
25. S. umbrosa L. Stämmchen an der Spitze beblättert; B. vkteyf., etwas gestutzt, gekerbt, kahl, am Rande knorpelig; Bstiel verbreitert, flach, lineal., an Rande zottig-wimperig; St. blattlos, rispig; K. unterständig, zurïckgeschlagen; die Stbf. oberwärts breiter. 4. Feuchte, schattige O.; Mähren hinter Goldenstein im Gesenke, u. bei Oslowan im Mittelgebirge. Jul.

VU. Rotte. Dactyloides Tausch. Stämmchen dauernd, beblättert. B. weder am Rande, noch an der Spitze eingedrücktpunktirt, die unteren zwar abgestorben, aber übrigens nicht verändert. Die St. jährig, beblättert od. blattos. K. an den Fruchtkn. angewachsen, aufrecht od. abstehend. Blattuimpern sämmtlich geglicdert.

26. S. muscoides Wulfen. Stämmchen rasig, an d. Spitze dichtrosettig; B. olhe Furchen (im trockenen Zustande etwas nervig), lineal., ganz od. lineal.-keilig, 3sp., Zpfl. gerade-hervorgestreckt, lineal., $\mathrm{u}$. so wie die ungetheilten B. an der Spitze abgerundet-stumpf, grannenlos, an d. jungen Trieben sämmtl. ungeth.; St. meist 1blättrig, an d. Spitze gewölnnl. 3-5bth.; Blb. abstehend, oval-längl., stumpf, sitzend, länger als der $K$. 24. Felsige $O$. der A. u. hohen Sudet. Jun. Jul. Blb. grünl. - od. gelbl.-weiss. $\alpha$. compacta: Rasen klein, sehr gedrungen, B. dicht-dachig, Rosetten nicht ausgebreitet, St. meist 1bth., oft kaum $1 / 2$ Zoll lang. S. acaulis Gaud. - $\beta$. intermedia: Rasen gedrungen, aber die oberen B. in Rosetten ausgebreitet, St. 2-3 Zoll hoch, mehrbth. - $\gamma$. laxa: Rasen locker, B. entfernt, gegen die Spitze der Aeste rosettig, daher die Stämmchen oft gleichsam quirlig. - $\delta$. integrifolia: B. sämmtlich ungetheilt, manclumal mit dem Ansatze eines zweiten Lappens ausgerandet. S. pygmaea Haworth. - $\varepsilon$. moschata: iiberall reichlich mit driisig-klebrigen Haaren bedeckt. S. moschata Wulf. - $\zeta$. atropurpurea: Bth. gesättigt-dunkelpurp., übrigens kahl od. drüsig-behaart. S. atropurpurea Sternb. - $\eta$. crocea: Blb. schön safranfarben. S. crocea Gaud. Monte Rosa gegen das Zermattthal.

27. S. exarata Vill. Stämmchen rasig, an der Spitze dicht-rosettig; B. mit einer 3fachen Furche durchzogen, (getrocknet vorspringend-nervis), 3-5sp., die an den Rosetten keilig u. sitzend, od. handf. $u$. gestielt, an den jungen Tricben gestielt, $3 \mathrm{sp}$. mit einem lineal., flachen Bstiele, Zpfl. lineal. od. längl., abgerwndet-stumpf, graunenlos; St. meist 1blättrig, an der Spitze gewöhuliclı ein-mehrbth.; Blb. abstchend, oval od. längl., stumpf, noch $1 \mathrm{mal}$ so lang als der K., sitzend. 24. Felsen der A.; Schwz., Tyr. 11. walurscheinl. noch auf anderen A., aber mit S. muscoides verwechselt. Jun. Jul. Blb. weiss od. gelbl., nicht grïngelb. Var.: $\alpha$. compacta: u. zwar 1. B. sümmtl. breit-keilig, mit breiter Basis sitzend, in den Rosetten $3^{\prime \prime \prime}$ lang. $11 / 2 "$ breit, mehrere mit 5 Zälmen versehen, an kleinen Expl. 
oft so breit als lang, an den Stämmchen schmäler, aber nicht länger; unter dieser Form kommt niemals S. muscoides vor. 2. B. sämmtl. wie an den Stämmehen der ersten For'm u. dadurch der S. muscoides sehr ähnl. S. exarata DC. S. caespitosa Gaud. S. intricata Lap. - $\beta$. laxa: B. der Rosetten wie bei der Variet. $\alpha$, an den Stämmchen aber 1/2"lang, auf einem sclumalen Bstiele sitzend, Saum handf., 3-5sp., Zpfl. schmal, lineal.; lierher S. nervosa Lapeyr.

28. S. caespitos a L. Stämmchen rasig, an der Spitze rosettig, die seitenst. liegend; $B$. gestielt, mit einem flachen, glatten od. schwach1 furchigen Bstiele, an den Rosetten handf. 5-9sp., Zpfl. elliptisclı od. lanzettl., stumpf, gramnenlos, od. kurz-stachelspitzig, an den jungen Trieben u. St. handf.-3sp.; St. armblïtterig, oberwärts 3-9bth.; Blb. abstehend, oral od. längl., stumpf, noch $1 \mathrm{mal}$ so lang als der K., sitzend. 2. Felsenspalten u. steinige O.; Böhm., Mähr., Schles., Harz, Hessen, Westph., Franken, Voges. Mai. Jun. S. decipiens Ehrh. Var.: $\alpha$. compacta: B. gedrungen-dachig, St. nur 1-2" hoch. S. groenlandica L., nicht Lap. - $\beta$. laxa: B. lockergestellt: S. Sternbergii Willd., B. gewimpert; S. villosa Willd. dieselbe, die B. zottig. - Blb. weiss oder gelblich.

29. S. sponhemica Gmelin. Stämmchen rasig, an der Spitze rosettig, die seitenst. niederliegend; $B$. gestielt, mit einem flachen, glatten od. schwach-1 furchigen Bstiele, an den Rosetten handf.-5-9sp., Zpfl. lanzettl. zugespitzt, stachelspitzig, die an den Stämmchen u. St. handf.-3sp.; St. oberwärts 3-9bth.; Blb. oval od. längl., stumpf, sitzend, noch 1 mal so lang als der K. 24. Felsen der niedrigeren Gebg.; Rheinpfalz, Glalın-, Nahe- u. Moselgbg., Fl. v. Spaa, bei Runkel im Lahnthal. Mai. Jun. Wohl nur Variet. v. S. caespitosa. Blb. weiss od. gelblich.

30. S. hypnoides L. Stämmchen rasig, an der Spitze rosettig, die an der Seite kriechend; $B$. gestielt, mit einem (bei der lebenden Pflanze) unterseits anfgeblasen-halbstielrunden Bstiele, an den Roseiten handf.-5sp., Zpfl. elliptisch od. lamzettl., zugespitzt, haarspitzig-begrannt, an den jüngeren Aesten 1 . Stämmen meist ungeth., an den Knospen oft häutig-berandet; St. armblätterig, an der Spitze 2-9bth.; Blb. abstehend, oval od. lanzettl., stumpf, noch $1 \mathrm{mal}$ so lang als der K. 24. Felsenspalten; Luxemburg bei Dickrick u. Viandem. Jun. S. aggregata Lej. Blb. weiss.

31. S. stenopetala Gaud. Stämmchen zerstreut-beblättert $u$. rosettig; B .keilig; 3-5sp., od. ganz, Zpfl. ey-lanzettf., stumpf, grannenlos; St. blüthenstielf., blattlos, 1bth.; Blb. lineal., zugespitzt, 3 mal schmäler als die Kelchzpfl. 24. Höchste A. Jul. Aug. S. aphylla Sternbg. Blb. citrongelb.

32. S. sedoides L. Stämmchen zerstreut-blätterig u. rosettig; B. lanzettl., spitz, stachelspitzig, ungeth., an der Basis in den verbreiterten Bstiel verschmälert, getrocknet 3nervig; St. 1-3bth.; Blb. 
eyf., spitz, kürzer $u$. schmäler od. ungefähr so lang als der $K$. $\mathcal{\Psi}$. Felsen der A.; v. Tyr. u. Salzbg. bis Oestr. Jul. Aug. Bl. citrongelb, einfarbig od. an der Spitze dunkelpurpurn. St. blattlos. Var. f.: St. beblättert. S. Hohenwarti Strnbg. K. syn. ed. 1.

33. S. planifolia Lapeyr. Stämmchen dicht beblättert; B. dachig, lanzetll., abgerundet-stumpf, grannenlos, nach der Basis schmäler, sämmtl. ungeth., die abgestorbenen 3nervig, an der Spitze grau gefärbt; St. mehrblätterig, 1-5bth.; Blb. vkteyf., an der Basis abgerundet, noch $1 \mathrm{mal}$ so lang $u$. noch $1 \mathrm{mal}$ so breit als die $K z p f$., dreifältig-nervig. 2. Felsen d. höchsten A.; Schwz., Salzbg., Tyrol. Jul.-Aug. Bth. weiss, getrocknet gelblich; die abgestorbenen B. an der Spitze grau.

34. S. Fachinii Koch. Stämmchen dicht-beblättert; B. dachig, lineal. od. lanzettl., abgerundet-stumpf, grannenlos, nach der Basis schmäler, sämmtl. ungeth., die abgestorbenen 3-5nervig, zuletzt weissl.; St. mehrhlätterig, 1-3bth.; Blb. vkteyf. - keilig od. längl. $u$. nach der Basis verschmälert, ganz od. ausgerandet, einnervig, ein wenig länger als der K:, so breit als die Kzpfl. 24. Südöstl. Tyrol, auf d. höchsten Kamm der Seiseralpe, auf der Plattkofel der Seiseralpe gegenüber, auf $d$. Rosengarten $\mathfrak{u}$. d. Alpe Contria in Fassa. Jul. Aug. Farbe der Blb. veränderl., vom Schwarzpurp. bis zum Bleichgelbl.

35. S. S eguieri Spreng. WB. rasig-gehäuft, gestielt, spateliglanzettl., in einen Bștiel verschmälert, stumpf, ganzrandig od. 2kerbig, getrocknet 5-7nervig; St. nackt od. einblätterig, meist 1bth.; Blb. längl.-lineal., stumpf, so lang u. breit als die Kzpfl., schwach-dreifältig-nervig. 2. Höchste A.; Schwz., Tyr. Jul. Aug. Blb. gelb.

36. S. andros a c a L. WB. rasig-gehäuft, gestielt, spatelig-lanzettl. od. vkteyf., in den Bstiel verschmälert, an der Spitze 3zähnig od. ganzrandig, getrocknet 5-11nervig; St. nackt od. 1blättrig, meist $2 b t h . ; B l b$. vkteyf., ausgerandet, noch 1 mat so breit $u$. lang als die Kelchzpfl. 2. Felsige, feuchte O. der A. Jul. Aug. Blb. weiss.

VIII. Rotte. Nephrophyllum Gaud. Stämmchen ober der Erde felulend. St. beblättert. Zwei DeckB. an der Basis der Bthstiele, das eine kleiner. K. halbangewachsen mit aufiechten od. etwas abstehenden Zpfln., od. frei u. abstehend.

37. S. a dscenden s L. Fries novit. St. einzeln, aufrecht, starr, beblättert; Aeste an der Spitze 3bth.; Bthstielchen mit 2 DeckB., die fruchttrag. traubig, v. der Länge der Frucht; B. keilig, vorne 3-5. zähnig, Zühne gerade hervorgestreckt, die stengelst. abweclıselnd, die wurzelst. gehäuft, die uranfänglichen spatelig, ganz; W. einfach. $\odot$. Steinige O. der A. Jun.-Aug. S. controversa Sternb. Koch. syn. ed. 1.

38. S. tridactylites L. St, einzeln, aufreclit, einfach od, ästig, 
beblättert; Bthstiele 1bth., mit 2 DeckB., vielmal länger als die Frucht; $W B$. vkteyf.-spatelig, ungeth., 3lappig od. 3sp., langgestielt, mit flachem Bstiel, die stengelst. ahwechselnd, handf.-3sp.; W. einfach. $\odot$. Trockene, sonnige O., Manern. $\Lambda_{1}$ r. Mai. Blb. weiss.

39. S. petra e a I. St. einzeln, niederliegend, locker-ästig-rispig, beblättcrt; Bthstiele 11,th., mit 2 DeckB., vielmal tänger als die Frucht; $B$. handf.-3sp., geschlitzt-gezähnt, die unteren beinahe nierenf., die obersten an der Basis keilig, gaiz u. 3sp., Iappen zugespitzt, Bstiel der unteren verlängert, halbstielrund, rinnig; Blb. vkteyf., noch 1mal so lang als der K.; W. einfach. (-). Felsige O.; Krain, südl. Tyrol. Jun. S. Ponae Sternbg. Blb. weiss.

40. S. granulata I. St. aufrecht, oberwärts ästig-ebensträussig, armblätterig; WB. nierenf., lappig-gekerbt, gestielt; Bstiel rinnig;; StB. keilig, 3-5sp.; K. halb-oberst.; Blb. längl.-vkteyf., noch $1 \mathrm{mal}$ so lang als der K.; W. körnig. 2. Wiesen, sonnige Hügel. Mai. Jun. Blb. weiss.

41. S. bulbifera L. St. aufrecht, ganz einfach, reichblätterig, an der Spitze trugdoldig; Trugdolde 3sp., 3-7bth.; WB. nierenf., lappig-gekerbt, gestielt, die oberen StB. sitzend, längl., an der Basis eingeschnitten, die obersten lineal., ganz, in den Winkeln zwiebeltragend; $K$. halboberst.; Blb. längl.-vkteyf., noch 1 mal so lang als der K.; W. körnig. 2. Grasige Hügel, trockene Triften; Unteröstr., Mähr̉en, Wallis. Mai. Jun. Blb. weiss.

42. S. cernua L. St. aufrecht, einfach od. etwas ästig, an der Spitze 1bth.; WB. nierenf., handf.-5-7lappig, getheilt, die oberen StB. sitzend, an der Basis eingeschnitten, die obersten lanzettl., ganz, in den Winkeln zuiebeltragend; $K$. frei; Blb. längl., gestutzt. 2 . Bewässerte Felsen der A.; Berner A. bei Sanen, Wallis über Lenz и. Bellalui, Eisenhut in Stmk., Möllthaler A. u. Grossfragant in Kärnth. Jul. Aug. BJb. weiss, die völlig aufgebliiheten aufrecht.

43. S. rotundifolia L. St. aufrecht, rispig, reichbth.; WR. herzf.-nierenf., ungleich-grobgesägt, langgestielt; StB. eingeschnittengezähnt; $K$. frei, abstehend; Blb. lanzettl., noch 1 mal so lang als der K. 2. Feuchte O. der A. u. VorA. Jun.-Aug. Blb. sternf.-abstehend, weiss, hinten gelb-, vorne rothpunktirt. Var. $\beta$. : B. stumpfgekerbt. S. repanda Sternbg.

44. S. a rachnoide a Sterub. St. niederliegend, beblättert; $B$. rundl.-vkteyf., in den Bstiel verschmälert, vorne sehr stumpf, 3-5. lappig; Lappen sehr kurz, stumpf; Btlı. zuletzt locker-traubig, sehr lang-gestielt (halb unterst.?); Blb. eyf., länger als der K. 24. Felsige, schattige $O$. im Valle d'Ampola siidl. Tyrol. Jul. Aug. Blb. hellcitrongelb.

IX. Rotte. Micr anthes Tausch. Stämmcher über der Erde fehlend. Der St. blattlos, (Schaft). K. halbangewachsen. 
45. S. nivali s L. Sämmtl. B. wurzelst., vkteyf. od. spatelig, in d. Bstiel verschmälert, ungleich-gezälınt-gekerbt; Schaft blattlos, kopfig od. etwas ebensträussig, 5-8bth.; K. halboberst., aufrecht; Blb. längl., stumpf, kurz-benagelt, länger als der K. 2. Felsen der kleinen Schneegrube der Sudeten. Jul. Blb. weiss.

46. S. hieracifolia W. K. Sümmtl. B. wurzelst., eyf.-längl. od. längl., entfernt-geschweift-gezähnt, in den Bstiel verschmälert, kahl, am Rande u. am Kiele unterseits zottig; Schaft traubig; Tr. an der Basis etwas zsgesetzt; K. halboberst., zuletzt zuriickgebogen; Blb. eyf., spitz, so lang als der $K$. 24. Torfhaltiger Boden; Stmk. in den Judenburger A., Lantseher A., Wand iiber den Putzenthaler Seen, an dem Reichart. Jul. Aug. Blb. bleichgrïn, Rand röthl.

2. ZAHLBRUCKNERA Reichenb. Zahlbrucknere.

1. Z. paradoxa Reichenb. St. niederliegend, entfernt-beblättert; untere B. lang-gestielt, herz-nierenf., 5-7lappig, oberste B. 3lappig; Bth. zuletzt sehr lang-gestielt, einzeln; Blb. schmal-lanzettl., spitz, schmäler u. kürzer als die Kzpfl. 2. wahrscheinlicher. @. Feuchte Felsen u. an Bächen; Kärnthen im oberen Lavanthale zw. Wolfsberg u. Wiesenau, Stmk. im Lassnitzthal bei Deutschlandsberg. JuI. Aug. Saxifraga paradoxa Sternbg. Blb. grïnlich.

3. CHRYSOSPLÉNIUM L. Milzkraut.

1. Ch. al ternifolium I. B. wechselst., nierenf, tief-gekerbt, Kerben ausgerandet. 2†. Nasse, sehattige O., neben Quellen u. Bächen. März. Apr. Bth. u. DeckB. gelb, wie an folgend.

2. Ch. oppositifolium L. B. gegenst., halbkreisrund, geschweift-gekerbt, an der Basis abgeschnitten. 2. Feuchte, schattige Felsen, an Bäehen u. Quellen; zerstreut dch das Gebiet. Mai. Jun.

LV. Ordng. UMBELLIFEREN. Juss.

I. Unterordng. ORTHOS PERMEEN. Geradesamige. Eyweiss auf der Fugenseite flach od. schwach concav od. convex; aber weder mit den Rändern eingekrümmt, noch sackartig-hohl.

I. Gruppe. HYDROCOTYLEEN. Spreng. Fruclit v. der Seite zsgezogen od. flach-zsgedrückt. Dolde unvollkommen.

1. HYDROCótYLE L. Wasscrnabel.

1. H. vulgaris I. B. schildf., kreisrund, doppelt-gekerbt, 9nervig; Bstiele an der Spitze behaart; Dolden kopfig, meist 5bth.; Frueht an der Basis etwas ausgerandet. 24. Sumpfige O., Ufer der Seen u. Teiche. Jul. $\Lambda$ n. Plb. weiss od. röthl. Var. $\beta$.: Blattkerben sehr stumpf. H. Schkuhriana Relıb. 
II. Gruppe. SANICULEEN. Koch. Frucht auf dem Querdurchschnitte fast stielrund. Dolden büschelig od. kopfig, cinfach od. etwas u. zwar unregelmässig-zsgesetzt, od. kopfige Döldchen.

2. SANÍCULA L. Sanikel.

1. S. e uropa e a L. Wris. handf.-geth., Zpfl. 3 sp., ungleich-eingeschnitten-gesägt; die zwitterigen Bth. sitzend, die männlichen sehr kurz-gestielt. 2. Schattige, etwas feuchte Wälder. Mai. Jun. Blb. weiss.

3. HACQUÉTIA Neck. Hacquetie.

1. H. Epipaetis DC. 2f. Wälder der VorA. u. Gbge.; Kärnth., Krrain, Mähr., Stmk., südöstl. Sudet., Schwz., am grossen Bernh. Apr. Mai. Astrantia Epipactis Scop. Dondia Epipactis Spreng. Blb.gelb.

\section{ASTRÁNTIA L. Astrantie.}

1. A. minor L. WB. gefingert; Blättchen 7-9, lanzettl., spitz, ungleich-spitz-eingeschnitten-gesägt; Hüllblättchen ganzrandig; Kelchzähne längl.-eyf., sehr kurz-stachelspitzig; Zähne der Riefen spitz. 7. Höhere A.; sïdl. Schwz., sïdl. Tyrol. Jul. Aug. Bl. nebst den HüllB. weiss.

2. A. gracil is Bartling. WB. 3th., $/ 4 \mathrm{pf}$. ungleich-gesägt, der mittlere keilf.-längl., die scitenst. 2sp., der äussere halbeyf.; Hüllblättchen ganzrandig; Kzähne eyf., stumpf, stachelspitzig; Zähne der Riefen kegelf.-pfrieml., spitz. 4. A. v. Krrain. Jul. Aug. Bl. u. HüllB. weiss.

3. A. carniolica Wulf. WB. haudf.-5th., Zpfl. längl.-vkteyf., spitz, fast 3sp., ungleich-spitz-eingeschnitten-gesägt; Hüllblättchen ganzrandig; Kelchzähne eyf., stumpf, kurz-stachelspitzig; Zähne der Riefer stumpf. 2. A. r. Thäler der VorA.; Krrain, Stmk., bayer. A. Jul. Aug. Bl. u. HiillB. weiss.

4. A. major L. WB. handf.-5th., $Z_{p}$ fl. längl--vkteyf., spitz, fast 3 sp., ungleich - spitz - cingeschnitten - gesägt; Hüllblättchen ganzrandig od. an cler Spitze beiderseits 1-2zälnig; Kelchzähne ey-lanzettf., in eine Stachelspitze zugespitzt; Zähne der Riefen stumpf. 2. VorA. u. Berge, auch Niedermingen im siidl. u. zerstr. im mittl. Geb. Jul. Aung. Var.: Bthstielchen, K. u. oft die Huille weiss od. rosenroth, u. $\alpha$. vulgaris: Hïlle $\mathrm{r}$. der Länge der Dolde. - $\beta$. involucrata: Hïlle 11/2mal so lang als die Dolde: A. carinthiaca Hopp.

\section{ERÍNGIUM L. Mannstreu.}

1. E. campestre L. B. 3zählig-doppeltfiedersp., netzig-aderig, dornig-gezälnt, die wurzelst. gestielt, die slengelst. geöhrelt-umfassend, Oehrchen geschlitzt-gezähnt; St. rispig, ausgesperrt; Hiillehen länger als die rundl. Köpfchen; Spreublättchen ganz; K. länger als 
die Bl. 4. Unkultiv. O., an Wegen; zerstr. dch das Geb. Jul. Aug. Bth. hellbläulich-griin.

2. E. a methystinum L. B. doppelt-fiedersp., nervig-aderig, dornig - gezälmt, die wurzelst. gestielt, die stengelst. mit scheidiger, ganzrandiger Basis umfassend; St. an der Spitze ebensträussig; Hüllchen länger als die rundl. Köpfchen; Spreublättchen ganz; Bl. länger als der K. 2. Sonnige, trockene O.; südl. Tyrol u. Ḱrain, Fiume. Jul. Aug. Bth. stahlblau, wie der ganze Ebenstrauss.'

3. E. maritimum L. B. dornig-gezähnt u. gelappt, weissl--meergrün, die wurzelst. ungeth., gestielt, herz-nierenf., die oberen stengelumfassend, fast handf.-lappig; Hüllblättchen eyf., gezähnt-dornig, fast 3lappig, länger als das rundl. Köpfchen; Spreublättchen mit 3 Haarspitzen. (-). Sandige O. am Meere. Jun.-Aug. Bth. amethystblau od. weissl.

4. E. alpinum L. WB. ungeth., gestielt, tief-herzf., spitz, gesägt-gezähnt, die oberen sitzend, handf.-3-5sp., gewimpert-gesägt; Hüllblättchen vielsp.-fiedersp., borstig-gezähnt, ein wenig länger als das längl. Kïpfchen; St. 1-3köpfig. 24. Triften der A.; westl. u. südl. Schwz., Oberkärnth. in der Wochein. Jul. Aug. Hülle bläulich. Bl. weiss.

5. E. planum L. WB. ungeth., gestielt, oval-herzf., stumpf, gekerbt-gesägt, die mittleren stengelst. sitzend, ungeth., die oberen 5 th., dornig-gesägt; Hüllblättchen lineal.-lanzettl., entfernt-dornig-gezähnt, so lang als das eyf. Köpfchen od. ein wenig länger; St. an der Spitze ebensträussig. 2. Trockene, sandige O., Felder, Wiesen; Oestr., Mähren, Böhmen, Schlesien, Frankf. a. d. O., Preussen bei Königsberg. Jun. Jul. Bth. u. oft der ganze Ebenstrauss amethystfarb.

III. Gruppe. AMMINEEN. Koch. Frucht v. der Seite deutlich-zsgedrückt. Früchtchen mit 5 Riefen; die Riefen sämmtlich gleich. Eyweis auf der Fugenseite ziemlich flach od. convex, od. völlig stielrund. Dolden vollkommen.

6. CICÚTA L. Wasserschierling.

1. C. virosa L. Wurzelfasern fädl.; B. 3fach-gefiedert, Blättchen lineal.-lanzettl., spitz, gesägt. 24. Gräben, Teiche, moosige Sümpfe. Jul. Aug. Blb. weiss. Var. $\beta$. tenuifolia: niedrig, manchmal nur 1 Fuss hoch; W. u. St. dünn; Blattzpfl. lineal., spärl.-gesägt od. ganzrandig; Dolden 5-8strahlig. C. angustifolia Kit. C. tenuifolia Fröl.

\section{7. ÁPIUM L. Selleric.}

1. A. grave ol ens I. Kall ; B. gefiedert; die obcren 3zählig, Blättchen keilig, an der Spitze eingeschnitten u. gezähnt. $\odot$. Sumpfige $O$. u. Gräben am Mecre u. an salzhaltigen O. Jul.-Sept. Blb. klein, weiss. Eine Variet. mit dicker W. iiberall kultiv. 


\section{PETROSElínum Hoflin. Petersilie.}

1. P. sativum IIoffm. St. aufrecht, kantig; $B$. glänzend, die unteren 3 fach-gefiedert, Blättchen eyf-keilig, 3sp. u. gezähnt; die oberen 3zählig, Blättchen lanzettl., ganz u. 3sp. ๑. Ueberall kultiv. Jun. Jul. Apium Petroselinum L. Blb. griin-gelblich. Var. P. crispum DC.: die untersten B. grösser, breiter u. kraus. Apium crispium Mill.

2. P. s e g etu $\mathrm{m}$ Koch. St. aufrecht, stielrund, fast nackt; B. gefiedert, Blättchen der untersten fast sitzend, fiedersp.-eingeschnitten, gezähnt-gesägt, die der stengelst. lineal., ganz u. 3sp., die der obersten fehlschlagend; Hülle 2-3blätterig; Strahlen der Dolde u. d. Döldcheı schr ungleich. $\odot$. Feuchte Brachäeker; im Thale Erguel der Schwz. Jul. Aug. Sison segetum L. Blb. weiss od. röthl.

\section{TRINIA Hoffm. Trinie.}

1. T. vulgaris DC. Kabl; Hüllchen felllend od. 1blätterig; Riefen der Früichte stumpf. (.). Auf Kialkboden an unkultiv. O.; südwestl. Schwz. u. deh das Rheinthal bis Bingen, Mainthal bei Würzb.; Sïdtyrol, Krain, Oestr., Mähr. Apr. Mai. T. Henningii M. et K. Pimpinella glauca L. P. pumila Jacף. Bl. weiss. Var. mit verlängerten Bzptln.: T. Henningii Hoffin.

2. 'T. Kitaibelii MB. Kahl; Hüllchen 4-5blätterig; Riefen d. Früchte stumpf. $\odot$. Trockene Grasplätze zw. Göding u. Mutenitz im siidl. Mähren, Reisseck. Jun. Seseli pumilum L. Bl. weiss.

\section{HELOSCIÁDIUM Koch. Sumpfschirm.}

1. H. nod if lor u m Koch. B. gefiedert, Fieder ey-lanzettf., gleichf.stumpflich-gesägt; Dolden den B. gegenst., gestielt, länger als der Bstiel od. anch sitzend; St. an der Basis liegend u. wurzelud. 4. Quellen, Gräben, Bäche, Teiche; westl. Schwz. u. Rheinfläche bis nach den Niederlanden, u. westl. bis Frankreich. Jul. Aug. Sium nodiflorum L. Bl. grünl.

2. H. re pen $\mathrm{s}$ Koch. B. gefiedert, Fieder rundl.-eyf., ungleich-gezähnt-gesägt od. gelap;t; Dolden den B. gegenst., kürzer als der Bthstiel; St. niedergestreckt, wurzelnd. 24. Sumpfige 0 .; sehr zerstr. dch das Geb. Jul.-Sept. Sium repens L. Bl. weiss.

3. H. in und at um Koch. Die aufgetauchten $B$. gefiedert, Fieder keilf., an der Spitze 3sp., die untergetauchten in haardünne Fetzen vielfach-gespalten; Dolden den B. gegenst., 2strahlig; St. an der Basis kriechend. 2. Sümpfe, Gräben; Westphalen, Hannover, Bremen, Oldenbg., Holstein. Jun. Jul. Sison inundatum L. Bl. weiss.

11. PTYCHÓTIS Koch. Faltenohr.

1. P. beterophyll a Kocl. St. aufrecht, sehr ästig; WB. ge- 
fiedert, Blä tur r rund., eingeschnitten-gelappt u. gesägt; StB. vielsp., Zp1. line!1. - fïdl.; Frucht längl.; Hülblättchen sämmtl. horstl. ๑. Sonnige, felsige Hiigel; im südl. Tyrol weit verbreitet, am Genfersee. Jul. Aug. Carum Bunius L. Meum heterophyllum Moench. 131. weiss.

2. P. a in $\mathrm{moides} \mathrm{Koch.} \mathrm{St.} \mathrm{aufrecht,} \mathrm{ästig;} \mathrm{B.} \mathrm{gefiedert-vielsp.,}$ Zpfl. lineal.-fädl., die der wurzelst. 13. lineal.-keilig, an der Spitze 2-3sp.; Frucht eyf.; 2 Hüllblättchen spatelig $u$. haarspitzig, 3 derselben-lineal.-fprieml. $\odot$. Aecker, Weinberge; Istrien. Mai. P. verticillata DC. Seseli ammoides Gouan. Bl. weiss.

\section{FALCARIA Host., nicht Cav. Sicheldolde.}

1. F. Rivini Host. WB. einfach u. 3zählig; StB. 3zählig, das mittlere Blättchen 3sp., die seitenst. auswärts 2- u. 3sp., Zpft. lineal.-lanzettl., gleichf.-genähert-gesägt, Sägezähne dornig-stachelspitzig. $\odot$. Aecker, Wegeränder, auf Kalk- u. Lettenboden; zerstr. deh das Geb. Jul. Aug. Sium Falearia L. Bl. weiss.

2. F. latifoli a Koch. B. 3zählig, die seitenst. Blättchen ungeth. u. 2sp., das endst. 3sp. od. 3th., Zpfl. der untersten B. ungleich-tiefgesägt, $\epsilon y f$., an der Basis keilig, die der ïbrigen längl.-keilig, eingeschnitten-gezälnnt, die seitenst. an der inneren Scite, das endst. beiderscits, v. der Basis bis über dic Mitte hinaus ganzrandig. $\odot$. VorA.; in Krain, auf dem Berge Zhann. Jun. Jul. Bl. weiss. Hladnikia pastinacifolia Rchb.

13. SISON I. Sison.

1. S. Amomum I. $\odot$. Feuchte O.; um Genf, u. nach Scop. in Krain. Jul. Aug. Bl. weiss.

\section{AMMI I. Ammi.}

1. A. majus L. Die unteren 13. einfach- u. doppeltgefiedert, Blättchen lanzettl., geschärft-knorpelig-stachelspitzig-gesägt, die oberen doppeltzsgesetzt, $Z_{\mathrm{p}}$ fl. lineal.-lanzettl., an der Spitze gesägt; St. stumpfkantig. $\odot$. Aecker; Littor., Fiume, un Wien. Jul. Aug. 13lb. weiss. Hiillblättelıen $3 \mathrm{sp}$.

\section{AEGOPODIUMI. Geissfuss.}

1. AE. Podagraria L. 2. An Hecken, Zäunen, sclattigen O., in die VorA. hinauf. Mai-Jul. BI. weiss.

\section{CARUM L. Kümmel.}

I. Rotte. Carvi DC. Carum L. Hülle fehlend; Hüllchen fehlend oder armblätterig. BI. weiss. W. spindelig-ästig.

1. C. Carvi I. B. doppelt gefiedert, Blättchen fiedersp.-viclsp., die untersten Paare an den gemeinschaftlichen Bstiel kreuzweise gestellt ; beide Hïllen felilend; St. kantig; W. spindelig. $\odot$. Wiesen, Triften. Apr. Mai. 
II. Rotte. Bulbocastanum Adans., DC. Allgemeine u. besondere Hïlle mehrblätterig. 13l. weiss. W. knollig, rund od. gebüschelt.

2. C. Bulbocastanum Koch. B. fast 3fach-gefiedert, Zpfl. lineal., spitz; Dolden 12-24strahlig; beide Hüllen reichblätterig, Blättchen lanzettl., zugespitzt; Bthsticlchen nach dem Verblühen nufrecht; Friichte aneinanderliegend, längl., an der Spitze verschmälert; St. sticlrund; W. fast kugelig. 2. Aecker; westl. Geb., siidl. Schwz., Kr:iu. Jun. Jul. Bunium Bulboeastanum L. Gf. herabgebogen, noch $1 \mathrm{mal}$ so lang als das Stempelpolster.

3. C. divaricat u $\mathrm{m}$ Koch. B. fast 3facl-gefiedert, etwas fleischig, Zpfl. lineal., spitz; Dolden 6-12strahlig; Hülle armblätterig, abfällig; Hüllchen 3-6blätterig, Blättchen ey-lanzettf., zugespitzt; Bthstielchen nach dem Verblühen spreitzend, die äusseren wagerecht; Frïchte v. einander abstelıend, lineal., an d. Spitze etwas verdickt; der St. stielrund; W. fast kugelig. 24. Aecker in Istrien, nach Biasol., doch noch näher zu ermitteln. Jun.? Bunium divaricatum Cesati, nicht Bertolon. Stempelpolster v. der Breite der Frucht, Gf. auf demselben liegend.

4. C. verticillatum Koch. B. gefiedert, Blättchen vielth., $Z \mathrm{pfl}$. fädl., quirlig-gestellt; W. gebüschelt, Fasern fleischig, verlängertkeulig. 24. Trockene, humusreiche Wiesen um Heinsherg, Regierungsbez. Aachen, Thieme, Pharmac. Jul. Aug. Sison verticillatum L.

\section{BÚNIUM Linn. Erelknoten.}

1. B. moutanum Kóoch. Die unteren B. 3fach-gefiedert, die Z Zpfl. lineal., 1nervig, kurz-stachelspitzig; Dolden 5-10strahlig; beide Hiillen 5-6blätterig, Blättchen der Hiillchen lanzettl., schmal-häutig-berandet, meist $v$. der Länge der Bthstielchen; die fruchttrag. Bthstielchen aufrecht-abstehend, die äusseren v. der Länge der Frucht; Gf. zuriickgebogen; Wurzel fast kugelig. 2. Unter der Saat; Monte Maggiore in Istrien. Nai. Jun. B. divaricatum Bertol. Bl. weiss.

\section{PIMPINELLA L. Biebernell.}

I. Rotte. Tragoselinum Tournef. Frïchte kahl; W. dauernd. Bl. weiss, als Varict. rosenroth.

1. P. magna L. B. gefiedert, Blättchen spitz, gezähnt, ungeth. od. lappig od. geschlitzt; St. beblättert, kantig-gefurcht; Gf. länger als der Fruchtkn.; Friichte längl.-eyf., kahl. 24. Wiesen, Mai. Jun. Var. $\beta$. rosea: Blb. rosenroth; auf höheren Gbgen u. VorA. P. rubra Hoppe. - $\gamma$. laciniata: Blättchen handf.-fiedersp., Zpfl. lanzettl., eingeschnitten-gesägt. P. orientalis Gouan. P. media Hoffm. - $\delta$. dissecta: Blättchen handf.-doppelt-fiedersp. P. dissecta Retz.

2. P. Saxifraga L. B. gefiedert; Blättchen eyf., stumpf, ge- 
zähnt, lappig od. gesehlitzt, etwas glänzend; St. stielrund, zart-gerillt, obervärts fast blattlos, kahl od. flaumig, die Bthstiele kahl; Gf. während der Bthezeit kïrzer als der Fruchtkn.; Früchte eyf., kahl. 24. Triften, unkultiv., sonnige, waldige O., in die A. hinauf. Var. $\alpha$. integrifolia: Blättchen eyf., an den StB. oft zerschnitten. $\boldsymbol{\beta}$. dissectifolia: Blättchen der sämmtl. B. zerschnitten. P. hircina Leers. - $\gamma$. poteriifolia: kleiner, Blättchen rundl.-eyf., gekerbt; diese an den sterilsten $O$. Die Var. $\alpha$. bis $\gamma$. bald kahl, bald flaumig. $\delta$. alpestris: kleiner, Blättchen im Umriss rundl., fast handf.-eingeschnitten, Zpfl. lanzettl., zugespitzt. P. alpina Host. In den VorA., seltener auch in den niedrigeren Gbgen.

3. P. nigra Willd. B. gcfiedert, Blättchen eyf., stumpf, lappig 11. gezähnt, glanzlos; St. stielrund, zart-gerillt, oberwärts fast blattlos, u. nebst den B., Aesten u. Bthsticlen dicht-flaumig, Gf. während der Bthezeit kürzer als der Fruchtkn.; Frïchte eyf., kahl. 24. Trockene Hügel u. unkultiv. O., bisher mit Sicherheit bloss im nördl. Geb. Unterschieden v. P. Saxifraga dch stärkeren St., u. die Eigenschaft der W., bei Beriihrung mit der atmosphärischen Luft, wenn sie durchschnitten wird, nach kurzer Zeit eine blaue Färbung anzunehmen, was besonders an den äusseren Lagen derselben bemerklich ist.

II. Rotte. Tragium. Früchte flaumig od. rauh.; W. mehrjährig od. zweijährig. Bl. weiss.

4. P. peregrina L. B. gefiedert, Blättchen der wurzelst. eyod. herzf., gezähnt, der stengelst. eingeschnitten od. gelappt; Früchte rauhh. v. geraden, abstehenden Haaren. -). Unbebauete Hügel um Fiume. Jun. Jul.

III. Rotte. Anis um Adans. Friichte flaumig. Jährige Arten. Bl. weiss.

5. P. Anisum L. Die unterst. B. herzf.-rundl., eingeschuittengesägt, die mittleren gefiedert, Blättchen keilig, lappig od. gezähnt, die obersten 3̈sp. u. ungeth.; Früchte eyf., angedriickt-flaumig. $\odot$. In Gärten u. auch im Grossen in Thüringen u. im Elsass gebauet. Jul. Aug.

\section{BÉRULA Koch. Berle.}

1. B. angustifolia Koch. B. gefiedert, Blättchen eingesehnittengesïgt; Dolden gestielt, den B. gegenst.; Hülle meist fiedersp. 4. Gräben, Bäche, Teiche. Jul. Aug. Sium angustifolium L. Bl. weiss.

20. SIUMI L. Wassermerk.

I. Rotte. Sia genuina. Schenkel des Fruchthalters an die Friichtehen angewachsen.

1. S. latifolium L. W. faserig, ausläufertreibend; $B$. gefiedert, Blättchen lanzettl., an der Basis ungleich, gleichf.-geschärft-gesägt, 
die der untergetauchten B. doppeltfiedersp. od. vielsp.; Hülle vielblätterig; Schenkel des Fruchthalters an das Früchtchen angewachsen. 2. Stehende u. langsam fliessende Wasser; zerstr. dch das Geb. Jul. Aug. Bl. weiss.

II. Rotte. S is arum. Fruchthalter 2 th., frei.

2. S. Sisarum L. W. knollig-büschelig; die unteren B. gefiedert, Blättchen längl., ungleich-spitz-gesägt, das endst. eyf., an der Basis etwas herzf., die oberen B. 3zählig, Blättchen lanzettl.; Hülle 5blätterig; Fruchthalter frei. 24. Zum Hausgebranch kultiv. Jul. Ang. Bl. weiss.

21. BUPLEURUM L. Hasenohr.

a. B. nicht durchwachsen; Früchte körnig-rauh. B1. gelb.

1. B. tenuissimu in L. St. aufrecht, ästig; B. lineal.-lanzettl., zugespitzt; die endst. Dolden 3 strahlig, die seitenst. unvollständig; Hüllblättchen lineal.-lanzettl., zur Bthezeit länger als das 3-5bliithige Döldchen; Früchtchen 5riefig, zwischen den Riefen körnigweichstachelig, die Riefen körnig-gekräuselt. $\odot$. Salzhaltige O.; zerstr. deh das Geb. Jul. Aug.

2. B. semicompositum L. St. aufrecht, ästig; B. lanzettl., die unteren stumpf, stachelspitzig, in den Bstiel verschmälert, die oberen haarspitzig; die endst. Dolden 3-5strahlig, die seitenst. unvollständig; Hiillblättchen lanzettl., länger als die Döldehen; Früchte körnig, Riefen verwischt. $\odot$. Unkultiv. O.; Istrien. Jul. Aug.

b. B. nicht durchwachsen; Thälchen der Frucht nicht körnig. W. jährig. Bl. gelb.

3. B. a ffine Sadler. St. rispig; Aeste ruthenf., etwas abstehend, v. der Basis an mit Aestchen besetzt, Aestchen kurz, aufrecht, fast angedrückt; B. schmal-lineal.-lanzettl., zugespitzt, 3-5nervig, die unteren nach der Basis verschmälert; die endst. Dolden meist 5strahlig, die seitenst. meist 2strahlig; Hüllblättchen lanzettl., zugespitzt, länger als die Döldchen; Bthstielchen halh so lang als die Frucht; Frïchte oval, Riefen fädl., geschärft, Thälchen mit einem vortretenden Striemen dchzogen. $\odot$. Unbebauete O., Ackerränder bei Wien. Jul. Aug.

4. B. Gerardi Jacq. St. rispig, Aeste ziemlich abstehend, an der Spitze doldentragend; B. schmal-lineal.-lanzettl., zugespitzt, 35nervig, die unteren nach der Basis verschmälert; Dolden meist 5strahlig; Hüllblättchen lanzettf.-pfrieml., spitz, länger als die Döldchen; Bthstielchen so lang als die lineal.-längl. Frucht; Riefen fädl., Thälchen concav, striemenlos. $\odot$. Weinberge, steinige O.; Oestr. Jul. Aug.

5. B. ju nceum L. St. rispig; B. schmal-lineal.-lanzettl., zugespitzt, 7 nervig, mit gleicher Basis den St. umfassend, die unteren 
nach der Basis verschmälert; Dolden 2-3strahlig; Hüllblättchen lanzettl.-lineal., spitz, kürzer als das fruchttrag. Döldchen; Bthstielchen halb so lang als die Frucht; Riefen geschärft, Thälchen concav, striemenlos. (. Steinige, unkultiv. O.; Littor. Jul. Aug.

6. B. a rist a tum Bartling. St. ästig; B. lineal.-lanzettl., zugespitzt, 3nervig, die unteren nach der Basis verschmälert; Hüllblättchen länger als die Döldchen, elliptisch od. lanzettl., begrannt-haarspitzig, mit einem durchscheinenden Rande umgeben, 3nervig, Nerven allerig-ästig; Bthstielchen halb so lang als der Fruchtkn., gleichlang, das mittlere kürzer. $\odot$. Somnige, steinige Hüigel; süid. Tyrol, Stmk., südl. lirain, Litt. Jul. Aug.

c. B. nicht dehwachsen; Thälehen der Frueht nicht körnig. W. mehrjährig. Bl. gelb.

7. B. faleatum L. St. ästig; B. 5-7nervig, zw. den Nerven aderig, die unteren elliptisch $c d$. längl., in den Bstiel verschmälert, die wheren lanzettl., an beiden Enden spitz, sitzend; Hüllchen lanzettl., haarspitzig; Bthstielshen ungefähr v. der Länge der Frucht; Riefen schmal-geflügelt, Thälchen flach, 3striemig. 4 . Sonnige, -unkultiv. 0. Jul.-Oet.

8. B. exaltatum MBieberst. Beschreibg. der Länder am Casp. Meere. St. loeker-rispig; WB. lanzettf.-lineal., in den Bstiel verschmälert, die oberen lineal., nach der Basis sehmäler, alle spitz, 5nervig, zw. den Nerven aderig; Dolden 5-10strahlig; Hüllblättchen lanzettl., zugespitzt, $u$. wie die Frïchte $v$. der Länge der Bthstielchen; Riefen schmal-gefliigelt, Thälchen flach, 3striemig. 2. Auf den Slavnik u. anderen Bergen im Litt. Jul. Aug. B. baldense Willd., MIB. taur.-cane., M. et Kr.

9. B. ranun euloides L. St. einfach od. ästig; B. nervig, die wurzelst. lineal.-lanzettl. od. lineal., zugespitzt, nach der Basis rerschmälert, die stengelst. aus herz-od. cyf.-stengelumfassender Basis verschmälert-spitz; Hülle meist 3blätterig; Hüllblättchen elliptisch, zugespitzt, länger als die Döldchen; Riefen geflïgelt, Thälehen 1striemig. 24. Triften der A.; Schwz., Tyrol, Algau, Salzbg., Krain. Jul. Aug. Var.: niedrig, einfach u. höher, ästig; B. breiter u. schmäler, u. sehr selumal.

10. B. gram in if oli um Vahl. St. einfach, nackt, oberwärts 1blätterig; WB. lineal., zugespitzt, nervig, das stengelst. lanzettl.; Hïlle meist 5blätterig; Hülblättchen elliptisch, zugespitzt, länger als die Döldchen, frei; Riefen .... 4. Felsenspalten, steinige O. der A. u. löheren Gbge.; Krain, OKärnth., Stmk., südl. Tyrol, Tessin. Jul. Aug. B. petracum Wulf.

11. B. stellatum L. St. einfach, nackt, oberwärts 1blätterig; W]3. lineal.-lanzettl., nach der Basis verschmälert, netzig-aderig; Hüllblätlchen vkteyf., kurz-zugespitzt, v. der Basis bis zur Mitle 
zsgewachsen, länger als die Döldehen; Riefen häutig-gefliigelt, Thälehen 1 striemig. 24. Felsige O. der A.; Scliwz., 'Tyr. lírain. Jul. Aug.

12. B. long ifolinm L. St. einfach, oberwärts etwas ästig; B. eyf. od. eyf.-längl., die unteren in den Bsticl verschmälert, die oberen sitzend, mit tief-herzf. Basis stengelumfassend; Hüllchen elliptisch, liurz-zugespitzt, so lang als dic Döldehen; liefen fädl., geschärft, Thälchen 3striemig. 24. Waldige, gebirgige $O$. u. VorA.; zerstr. deh das Geb. Jul. Aug.

d. B. durchwachsen. Bl. gelb.

13. B. protractum Link. u. Hoffmgg. St. v. Iler Basis an ästig; B. eyf., durchwachsen, die unteren eyf.-längl., stengelumtissend, die untersten nach der Basis verschmälert; Iliillchen eyf., zugespitzt; Riefen fädl., Thälchen bekörnt, striemenlos. ( ). Unter der Saat; Littor. Jun. Jul. B. subovatum Link. Hüllchen immer abstehend.

14. B. rotundifolium L. St. oberwärts ästig; B. eyf., durchwachsen, die unteren mach der Basis verschmälert, stengelumfassend; Hüllchen eyf., zugespitzt; Riefen fädl.; Thälchen gerillt, striemenlos. $\odot$. Unter der Saat, Letten- u. Kalkboden. Jun. Jul. Hüllblättchen nach dem Verblühen aufrecht-zsneigend.

IV. Gruppe. SESELINEEN. Koch. Frucht auf dem Querdurchschnitt stielrund od. ziemlich stielmund. Früchtchen mit 5 Riefen; die seitenst. Riefen gleiehbreit od. ein wenig breiter. Eyweiss auf der Fugenseite flach od. fast stielrund. Dolde vollkommen.

22. OENANTHE L. Rebendolde.

I. Rotte. Oenantha e verae. W. büschelig, mit mehr od. weniger knollig-verdickten Fasern. Bl. weiss.

1. OE. fistulosa L. W. büsclıelig, Fasern rübenf, längl. od. fädl.; St. ausläufertreibend; StB. geficlert, kürzer als der rölırige Bsticl, Blättchen lineal., einfach u. 3sp.; WB. 2-3fach-gefiedert; Hauptdolde 2-3strahlig, fruchtbar, die iibrigen 3-7strahlig, fehlschlagend; Früehte kreiself., Riefen zsgewachsen, die Thälehen verdeckend. 24. Sumpfige O.; zerstr. deh das Geb. Jun. Jul. Var.: WB. 3fach-gefiedert: Oe. Tabernaemontani Gmel.

2. OE. Lachenalii Gmel. W. buischelig, Fasern fleischig, fädl. od. verlängert-keulig; WB. doppeltgefiedert, Blättchen eyf. od. keilig, eingeschnitten-stumpf-gekerbt; die unteren StB. doppelt-, die oberen einfach-gefiedert, Zpfl. lineal., spitz; Frïchte längl., nach der Basis verschmälert, unter dem $K$. zsgezogen; Blb. strahlend, rundl.vktherzf., bis zur Mitte gespalten. 24. Sumpfige Wiesen, feuehte Triften; bei Monfaleone, westl. Schwz., Rheinflïche v. Basel bis Mainz, nördl. Geb. Jun. Jul. Oe. gymnorrhiza Brign.

3. OE. pe ucedan if o li a Pollich. W. büsehelig, Fasern rübenf., oval od. längl., sitzend; WB. doppeltgefiedert; die oberen StB. ge- 
fiedert, Zpfl. aller B. lineal., die der wurzelst. kürzer; Früchte längl., nach der Basis verschmälert, unter dem $K$. zsgezogen; Blb. strahlend; vktherzf., an der Basis keilig, 1/3 gespalten. 24. Fruchtbare Wiesen; zerstr. in der Schwz., den Rheingegenden, in Hess., Thüring., Würtemb. Jun. Jul. Untersch. v. der vorhergeh. deh die strahlenden, noch 1mal so grossen, in einen längeren Nagel verschmälerten, nư $1 / 3$ ihrer Länge gespalt. Blb.

4. OE. silaifoli a Bieberst. W. büschelig, Fasern längl. od. verlängert-keulig; B. 3fach- u. doppelt-gefiedert, $\mathrm{Z}_{\mathrm{p}}$ fl. fast gleichf., die der unteren lanzettl., die der oberen lineal.; Früchte valzl., an der Basis mit einer Schwiele umgeben. 24. Feuchte, sumpfige 0.; Krain, Istr. Jun. Jul. Oe. prolifera Host., nicht L. Dch die um die Hälfte kürzeren Zpfl. der oberen B. v. Oe. Lachenalii sogleich zu unterscheiden.

5. OE. pimpinelloides I. W. büschelig, Fasern fädl., an ihrem Ende in cine fast kugelige od. eyf. Knolle verdickt; B. doppeltgefiedert, Blättchen der unteren eyf., an der Basis keilig, fiedersp.eingeschnitten, Zpfl. spitz, die der ersten WB. eyf., eingeschnittenstumpf-gekerbt, die der oberen StB. lineal., ungeth.; Früchte walzl., an der Basis mit einer Schwiele umgeben. 2. Nasse Wiesen; Litt., Unteröstr. Jun. Jul. Var.: WKnollen kugelig od. längl. an langen Fäden: Oe. chaerophylloides Pourr. $-\beta$.: WKnollen ey-riibenf., kürzer gestielt. Oe. virgata Poir.

II. Rotte. Phellandrium. W. spindelig, faserig. Bl. weiss.

6. OE. Phellandrium Lam. W. spirdelig, Fasern fädl.; an der Basis des St. quirlig; St. sehr ästig, Aeste ausgesperrt; B. doppelt- u. 3fach-geficdert, Blättchen spreitzend, eyf., fiedersp.-eingeschnitten, die untergetauchten vielsp., Zpfl. haardünn; Dolden den B. gegenst.; Früchte eyf.-längl. 24? Gräben u. Bäche. Jul. Aug. Phellandrium aquaticum $\mathbf{L}$.

\section{AETHÚSA L. Gleisse.}

1. AE. Cynapium L. Hüllchen 3blätterig, länger als die Döldchen; die äusseren fruchttrag. Bthstielchen noch 1mal so lang als die Frucht; Striemen der Fuge an der Basis etwas auseinanderstehend. ○. Kultivirte O., Schutt. Jun. - Herbst. Var.: auf Aeckern $1-3^{\prime \prime}$ hoch: Ae. Cynap. $\beta$. agrestis Wallr.; dieselbe mit stumpfen Bzpfln.: Ae. segetalis v. Bönning. Bl. weiss.

2. AE. cynapioides MBieb. Hüllchen 3blätterig, so lang als die Döldchen; die äusseren fruchttrag. Bthstielchen v. der Länge der Frucht; Striemen der Fuge sich an der Basis berührend. $\odot$. Wege, Wälder; Unteröstr., Böhmen. Jun.-Aug. Bl. weiss.

24. FOÉNíCULUM Hoffim. Fenchel.

1. F. officinale All. St. an der Basis stielrund; Zpfl, der B. 
lineal.-pfrieml., verlängert; Dolden 13-20strahlig; Hülle fehlend. $\odot$. Felsen u. steinige Hiigel; Unterstmk., Littor., siidl. Schwz., Oberelsass. Jul. Aug. Auethum Focniculum L. Bl. gelb.

\section{SÉSELI L. Sesel.}

1. S. Hippomarathrum L. St. oberwärts ästig; B. 3fachgefiedert, im Umrisse längl.-eyf., $\mathrm{Z}_{\mathrm{p}} \mathrm{f}$. lineal.; Dolden 9-12strahlig, Strahlen kantig, einwärts nebst den jïngeren Frïchten flaumig; Hüllchen zsgewachsen-1blätterig, beckenf., gezälınt. 24. Steinige O. u. Felsenspalten; sehr zerstr. dch das südl. 11. mittl. Geb. Jul. Aug. Bl. weiss, wie aller folgenden.

2. S. Gou ni Koch. St. v. der Basis an ästig, gesperrt; WB. 3mal-3zählig-zsgesetzt u. doppelt-zsgesetzt, im Umriss 3eckig, Blättchen schmal u. fast 3eckig-lineal., mit stielrundem Bstiel; Dolden 3-6strahlig, Strahlen fast stielrund, kahl; Hiillblättchen pfrieml., sehr schmal-häutig-berandet, zur Bthezeit so lang als das Bthstielchen; die jüngeren Früchte runzelig-flaumig, die älteren kahl, Thälchen 3rillig, 3striemig. (-). Kalkberge v. Görz bis Fiume, südl. Tyrol. Aug. Sept. S. elatum Gouan.

3. S. glaucum Jacq. St. ästig; WB. 3zëhlig-3fachgefiedert, im Umrisse 3eckig; Blättchen lanzettl.-lineal. u. lineal.; Bstiel stielrund od. v. der Seite zsgedrücht; Dolden 10-15strahlig, Strahlere fast stielrund, kahl; Hüllblättchen pfrieml., sehr schmal-häutig-berandet, zur Bthezeit halb so lang als das Bthstielchen; die juingeren Friichte runzelig, kurz-kreisel-eyf., bei d. Reife kahl od. fein-flaumig, Thälchen 1rillig, 1striєmig. $\odot$. Grasige Hügel n. waldige Gbge; südl. Tyrol, Kärnth., Strok., Oest., Böhm., Mähr. Jul. Aug.

4. S. varium Trevir. St. ästig; WB. 3zählig-3fachgefiedert, im Umrisse 3eckig, Zpfl. lineal.; Bstiel oberseits rinnig; Dolden 15-25strahlig; Strahlen fast stielrund u. nebst dem längl. Fruchtkn. kahl; Hïllblättchen lanzettl.-zugespitzt, häutig-berandet, zur Bthezeit halb so lang als das Bthstielchen; die reifen Friichte lineal.-längl., Thälchen 1rillig, 1striemig. ๑. Trockene, steinige O.; Stmk., südl. Tyrol, Unteröstr., Mähren. Jul. Aug. Strahlen der Dolde noch $1 \mathrm{mal}$ so lang als bei $\mathrm{S}$. glaucum.

5. S. montanum L. St. einfach-ästig; die W.- u. unteren StB. 3 fachgefiedert, im Umrisse längl.-eyf., $\mathrm{Zp}$ fl. lineal.; Bstiel oberseits rinnig; Dolden 6-12strahlig;, Strahlen fast gleich, kantig, einuärts, nebst den jüngeren Friichten flaumig; Hüllblättchen lanzettl., sehr schmal-häutig-berandet, so lang als das Bthstielchen od. Döldchen. 4. Kalkgbge'sehr zerstrent; Stmk., Jura, Basel, Ober- u. Niederclsass, Istr. Jul. Aug.

6. S. tortuosum L. St. ästig, spreitzend; die W.- u. unteren StB. 3zählig-3fachgefiedert, im Umrisse 3eckig, Zpfl. lineal.; Bstiel oberscits rimig; Dolden 6-10strahlig; Strahlen scharfkantig, 
anef der inneren Seite flaumig; Mïlle 1-3blättenig; Hüllblättchen lanzettl., zugespitzt, breit-häutig-berandet, zur Bthezeit so lang als das Döldchen; Friichte flaumig-rauh. 2. Sonnige felsige 0.; zw. Triest u. Fiume, siidl. Istr., südl. Tyr. Jul. Ang.

7. S. coloratum Ehrh. St. einfach-ästig; die W.- u. unteren StB. dreifachgefiedert, im Umrisse längl.-eyf., Z Zpfl. lineal.; Bstiel oberseits rinnig; Hauptdolde 20-30strahlig, Strahlen kantig, fast gleich, auf der inneren Seite flaumig; jiingere Frïchte flaumig; Hülle fehlend; Hüllchen lanzettl., zugespitzt, breit-häutig-berandet, länger als das Döldchen. $\odot$. Grasige Ilïgel, Bergwälder, zerstr. dclı das Geb. Jul. Aug. S. annumu L.

\section{LIBANÓTIS Crantz. Heilwurz.}

1. L. montan Allioni. B. doppelt-dreifachgefiedert, Blättchen fiedersp. - eingeschnitten, Zpfl. lanzettl., stachelspitzig, die untersten Paare der Blättchen an der Mittelrippe kreuzst.; allgemeinc Hülle reichblätterig; St. Kantig-gefurcht; Früchte kurzh. $\odot$. Gelirgige, waldige O., bis in die A.; zerstr. deh das Geb. Jul. Aug. Athamanta Libanotis L. Bl. weiss. Var.: Blättchen sehr zerschnitten: Crithmum pyrenaicum L. $-\beta$. minor: St. 1' hoch, flaumig: Athamanta pubescens Retz.

2. L. a thamantoides DC. B. dreifach-gefiedert, Blättchen fiedersp.-eingeschnitten, Zpfl. lanzettl., stachelspitzig, die untersten Paare der Blättchen an der Mittelrippe kreuzst.; allgemeine Hülle reichblätterig; St. kantig-gefurcht; Frïchte kahl. ๑. Gebirge u. VorA.; Krain. Jul. Aug. Seseli Libanotis $\beta$. M. u. K. Bl. weiss. Var.: Hüllblättchen eingeschnitten: Ammi daucifolium Scop. - Athamanta sibirica wächst nicht bei Danzig nach Dr. Klinsmann.

\section{CNIDIUM Cusson. Brenndolde.}

1. C. Monnieri Cusson. St. ästig, kantig; B. doppeltgefiedert, Blättchen fiederth., Zpfl. lineal.-Ianzettl. od. lineal., liurz-bespitzt; Scheiden locker; Hüllblättchen borst.l., borstig-rauh, so lang u. länger als das Döldchen. $\odot$. Gebiisclı; bei Görz u. im wärmeren Tŕrin, nach Wulf., seitdem nicht wieder gefunden. Jul. Aug. Selinum Monnieri L. Bl. weiss, wie der folgenden.

2. C. apioides Spreng. St. ästig, gerillt; B. 3facligefiedert, Blättchen fiederth., Zpfl. lineal.-lanzettl., stachelspitzig; Scheiden locker; Hüllblättchen borstl., kahl, so lang als das Bthstielchen. 2. Gebirgige, felsige O.; Krain, Littor., Veltlin, Tessin. Jul. Aug. Ligusticum apioirles Jam. Laserpitium silaifolium Jacq.

3. C. venosum Koclı. St. gerillt, einfach od. oberwärts mit

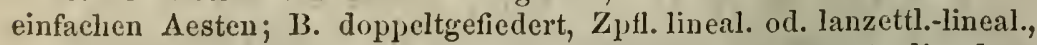
kurz-bespitzt, ungeth. od. 2- u. 3sp.; Scheiden verlängert, die obern straff-anliegend; Hüllblättchen pfrieml., kahl, so lang als das Döld- 
chen. 4 nach' Fries. Wiesen u. fenchte Wälder; nördl. Geb., Rheinfläche bei Speyer, Jura. Jul. Aug. Seseli venosum Hoffm. Selinum

28. TROCHISCANTHES Koch. Rädchenblïthe.

1. T. nodiflorus Koch. 24. Waldige, steinige 0 .; unteres Wallis, zw. St. Morizen u. Martinach, im südl. Tyrol in Villarsa oder Camposilvano. Jun.-Aug. Ligusticum nodiflorum Vill. Bl. weiss.

29. ATHAMANTA Koch. Augenwurz.

1. A. cretensis L. St. etwas ästig, stielrund, gerillt; B. 3fachgefiedert, Zpfl. lineal., zugespitzt, 2-3sp.; Dolde 6-9strahlig; Hüllblättchen längl.-lanzettl., haarspitzig, häutig, mit einem krautigen Rückenstreifen; Früchte längl-lanzettl., in einen Hals verschmälert, kurzh. v. weitabstehenden Haaren. 24. Felsige u. kiesige O. der VorA. u. A. Jul. Aug. B. u. Bl. unterseits kurzh. Var. $\beta$. : B. fast kahl. A. mutellinoides Lam. A. rupestris Vill., nicht Scop. Bl. weiss.

2. A. Matthioli Wulf. St. ästig, stielrund, gerillt; B. gefiedertvielfachzsgesetzt, $\mathrm{Zpfl}$. fädl., spreitzend; Dolde 15-25strahlig; Hüllblättchen längl.-lanzettl., haarspitzig, häutig, mit einem krautigen Rückenstreifen; Früchte längl.-lanzettl., in einen Hals verschmälert, sammetartig von kurzen, aufrecht-abstehenden Haaren. $\odot$. Steinige O.; Stmk., suidl. Tyr., Krain, Littor. Jul. Aug. Libanotis rupestris Scop. B. kahl; Blb. unterseits in der Mitte spärlich behaart, weiss.

\section{LIGÚSTICUM L. Liebstock.}

1. L. ferulaceum All. St. ästig, gerillt; B. vielfachzsgesetzt, Zpfl. lineal., zugespitzt-stachelspitzig; Hüllblättchen an der Spitze fiedersp. $\odot$. Sonnige O. der A.; Thoiry u. Saleve in der Schwz.
Jun. Jul. Bl. weiss.

2. L. Seguieri Koch. St. stielrund, gerillt, ästig; B. vielfachzsgesetzt, $\mathrm{Z}$ ph. lineal., zugespitzt-stachelspitzig, am Rande kahl; Hülle fehlend od. 1-3blätterig, Blättchen ungeth. 24. Gebirgige 0 . u. VorA.; Krain, siidl. Tyrol. C. Tessin. Jul. Aug. Selinum Se-
guieri. L. fil. Bl. weiss.

\section{SILAUS Bess. Silan.}

1. S. pratensis Bess. St. kantig; WB. 3- u. 4fachgefiedert, die seitenst. Abschnitte ganz od. 2th., die endst. 3th., Zpfl. lineal., stachelspitzig; Hülle 1-2blätterig. 24. Fruchtbare Wiesen. Jun.Aug. Peucedanum Silaus L. Bl. bleichgelb.

32. MEUM. Tournef. Bärenwurzel. 1. MT. a th a m a n ti c m Jacq. B. doppeltgefiedert, Fiederchen
fiederth.-vielsp., Zpfl. fast quirlig, haardünn, spitz. 24. Triften der 
A., VorA. u. zerstr. deh das Geb. auf höheren Gbgen. Jul. Aug. Athamanta Meum L. Bl. weiss.

2. M. Mutellin a Gärtn. B. doppeltgefiedert, Fiederchen fiederth., $\mathrm{Z} p f$. lineal.-lanzettl. u. lineal., zugespitzt-stachelspitzig, ungeth. u. 2-3sp. 4. Triften der A., VorA. u. Vogesen, Schles. u. Mähr. Gbge, u. im Schwarzwald. Jul. Aug. Phellandrium Mutellina L. Bl. weiss od. röthl.

33. GAYA Gaud. Gaye.

1. G. simplex Gaud. Hüllblättchen 7-10, meist 3sp: 2. Triften der höheren A.; Schwz., Tyrol, Salzbg., Kärnth., Stmk. Jul.Aug. Laserpitium simplex All. Bl. weiss.

34. CRITHMUM L. Bazille.

1. C. maritimum L. 2. Steinige O. am Meere bei Triest. Jul. Aug.

35. CONIOSELÍNUM Fischer. Schierlingssilge.

1. C. Fischeri Wimm. et Grab. 24. Grasige, schattige, etwas feuchte O.; auf dem Nesselurlich u. dem kleinen Keilig im Gesenke der Sudet., Windisch-Landsberg in Unterstmk. Jul. Aug. C. tataricum Fisch. Bl. weiss.

V. Gruppe. ANGELICEEN. Koch. Frucht auf beiden Seiten zweiflügelig, die Flügel nicht aufeinanderliegend. Jedes Früchtchen mit 5 geflügelten Riefen od. 3 fädlichen Riickenriefen. Eyweiss auf der Fugenseite ziemlich flach. Dolde vollkommen.

36. LEVÍSTICUM Koch. Liebstöckel.

1. L. officinale Koch. 2. Häufig in den Gärten der Landbewohner kultivirt. Jul. Aug. Ligusticum Levisticum L. Bl. gell.

37. SELÍNUM L. Silge.

1. S. Carvifolia L. St. gefurcht-kantig; Strahlen der Dolde kahl. 2. Feuchte Wälder, Waldwiesen. Jul. Aug. Bl. weiss.

38. OSTÉRICUM Hoffm. Mutterwurzel. ?

1. O. palustre Bess. 4. Feuchte Wiesen; Thüringeu bei Erfurt, Arnstadt u. Halle. Jul. Aug. O. pratense Hoffm. Imperatoria palustris Bess. Bl. weiss.

39. ANGELICA L. Angelik.

1. A. sylvestris I. B. 3fachgefiedert, Blätchen ey - od. lanzettf.', geschärft-gesägt, nicht herablaufend, das endst. ganz od. 3sp., die seitenst. fast sitzend, an der Basis ungleich u. manchmal 2sp. 4 . Wiesen, feuchte Wälder. Jul. Aug. Bl. weiss.

2. A. In ontan a Schleich. B. 3fachgefiedert, Blättchen längl. od. 
lanzettl., geschärft-gesägt, die obcrsten an der Basis herahlaufend, das endst. ganz od. 3 sp., die seitenst. fast sitzend, an der Basis ungleich u. manchmal 2sp. 24. Wiesen u. feuchte O. der VorA. Jul. Ang. B]. weiss.

3. A. pyrenae a Spreng. WB. doppeltgefiedert, Fiederchen fiederth., $Z_{p} f$. lineal.-lanzettl. od. lineal., ganzu. 2-3sp.; Strahlen der Dolde 3-7, ungleich; St. meist blattlos, einfach, gefurcht. 2. Triften der höchsten Vogesen. Jul. Aug. Seseli pyrenaeum L. Bl. weiss.

\section{ARCHANGÉLICA Hofim. Engelwurzel.}

1. A. officinalis Hoffm. St. kahl, stielrund, gerillt; B. doppeltgefiedert, Blättchen ey-od. fast herzf., ungleich-gesägt, das endst. 3-, die seitenst. meist 2lappig; die oberen Bstiele sackartig-aufgeblasen; Dolden mehlig-flaumig; Hüllchen ganz kahl. $\odot$. Hecken u. sumpfige O.; nördl. Geb. u. Sudet., Böhm., Kärnth., Görz, Veltlin, Jura. Jul. Aug. Bl. griinlich.

VI. Gruppe. PEUCEDANEEN. DC. Frucht v. Rücken flachod. linsenf.-zsgedrückt, mit einem verbreiterten, geflügelten, abgeflachten, od. convexen u. verdickten Rande umgeben. Friichtchen mit 5 Hanptriefen; d. seitenst. Riefen dem verbreiterten Rande anliegend od. in denselben verschmelzend; Nebenriefen fehlend. Frucht beiderseits 1 flügelig. Eyweiss vorne flach. Dolde vollkommen.

41. FERULÁGO Koch. Birkwurzel.

1. F. galbanifera Koch. St. gerillt, etwas kantig; B. vielfachzsgesetzt, im Umrisse eyf., Zpfl. lineal., haarspitzig, an den Hauptrippen kreuzst. ; Blättchen d. Hiulle u. Hüllchen lineal.-längl., zugespitzt; Gf. der Frncht bogig-zuriickgelegt, ein wenig länger als der Rand des Stempelpolsters. 4. Unfruchtbare Wiesen, felsige 0 .; Krain, Littor., siidl. Tyrol. Jun. Jul. Fertlago nodifora M. u. K. Ferula Ferulago I. F. nodiflora Jacq. Bl. gelb.

42. PEUCÉDANUM L., Koch. Haarstrang.

I. Rotte. Yeucedana legitima. Rand der Früchtchen weniger verbreitert. Die allgemeine Hülle fehlend od. armblätterig.

1. P. officinale L. St. stielrund, gerillt; $B$. $5 \mathrm{mal} 3 \mathrm{fach}-z s-$ gesetzt, Blättchen lineal., an der Basis 11. Spitze verschmälert, ungeth., die endst. 3zählig; allgemeine Hiille meist 3blätterig, abfällig; Bthstielchen 2-od. 3mal so lang als die Frucht; Strahlen rer Dolle kahl. 24. Fruchtbare Wiesen; sehr zerstr. deh das Geb. Jul. Aug. Bl. gelb.

2. P. parisiense DC. St. stielrund, gerillt; B. 3-od. 4 mal 3 fachgesetzt, Blättchen lineal-lanzettl., an der Basis u. Spitze verschmälert, ungeth., die endst. 3zählig; allgemeine Hiille armblätterig, abfällig; Bthstielchen so lang als die Frucht; Strahlen der Dolde 
anf der inneren Seite flaumig-rauh. 24. Wiesen; um Triest, auf dem Monte Magg. Jul. Aug. Bl. weiss.

3. P. Chabraei Reichenb. St. gefureht, aufrecht; $B$. beiderseits glänzend, gefiedert, Fieder aller B. sitzend, vielsp., od. die der obersten B. ungeth., Zpfl. lineal., spitz, an der Basis kreuzst.; Strahlen der Dolde auf der iuneren Seite kurzh.; Hüllchen meist 1blätterig; Thälchen 3striemig. 24. Fruchtbare Wiesen; im Rhein-, Blies-, Saar-, Mosel-, u. Donauthale u. ausserdem sehr zerstr. dch das Geb. Jul. Aug. Selinum Chabraei Jacq. S. podolicum Bess. BI. gelblichweiss od. grünlich.

4. P. Schottii Bess. St. stielrund, gerillt, aufrecht od. schiefaufstrebend; $B$. etwas meergrün, glanzlos, gefiedert, Fieder sitzend, an den unteren B. od. an allen vielsp., Zpfl. lineal., zugespitzt, an der Basis kreuzst.; Strahlen der Dolde kahl; Hüllchen armblätterig od. fehlend; Thälchen 1striemig. 24. Krain, Litt. Jul. Aug. Bl. weiss. Var. $\beta$. petraeum Noë: Fieder der StengelB. ungetheilt, lanzettl.-lineal., verschmälert- sehr spitz, der WB. 3-vielsp., Zpfl. li. neal., spitz, Hüllchen oft 5blätterig: P. petraeum K. syn. ed. 1 .

II. Rotte. Cervaria DC. Rand der Frucht weniger verbreitert. Allgemeine Hülle reichblätterig.

5. P. Cervaria Lap. St. stielrund, gerillt; B. 3fachgefiedert; Blättchen mcergrün, eyf., fast dornig-gesägt, die unteren an der hinteren Seite d. Basis gelappt, die oberen zsfliessend; allgemeine Hülle reichblätterig, zurückgebogen; Striemen der Berfihrungsfäche gleichlaufend. 4 Unkultiv. Hügel, Wiesen, Wälder; zerstr. dch das Geb. Jul. Aug. Athamanta Cervaria L. BI. weiss.

6. P. Ore oselin um Mönch. St. stielrund, gerillt; B. 3fachgefiedert; Verästelungen des Bstieles zurïckgeschlagen-spreitzend; Blättchen glänzend, eyf., eingeschnitten- od. fast fiedersp.-gezähnt, Zähne kurz-zugespitzt-stachelspitzig; allgemeine Hülle reichblätterig, zuriickgebogen; Striemen der Berührungsfäche bogig, an dem Rande anliegend. 24. Trockene Wiesen, Wälder. Jul. Aug. Athamanta Oreoselinum L. Bl. weiss.

7. P. alsaticum L. St. kantig-gefurcht, fast rispig; Aeste ruthenf.; B. 3fachgefiedert, Blättchen eyf., fiedersp., Zpfl. lineal.-lanzettl., stachclspitzig, am Ranide rauh; allgemeine Hülle 5-8blätterig, abstehend; Strahlen der Dolde kahl; Gf. der Frucht zurückgebogen, ein wenig länger als das Stempelpolster. 24. Hügel, steinige, trockene O.; zerstreut dch das südl. u. mittl. Geb. Jul. Aug. Bl. gelb.

8. P. venetum Koch. St. kantig-gefurcht, fast rispig; Aeste ruthenf.; B. 3 fachgefiedert, Blättchen eyf., fiedersp., Zpfl. lineal.-lanzettl., stachelspitzig, am Rande rauh; allgemeine Hülle 5-8blätterig, abstehend; Strahlen der Dolde auf der inneren Seite flaumig-rauh; Gf. der Frucht zurückgebogen, länger als der dritte Theil der Frucht. 
4. Steinige 0.; siidl. Sehwz., siidl. Tyr., Littor. Jul. Aug. Selinum venetum Spreng. Bl. weiss, grösser als bei den rorhergeh.

III. Rotte. Selinoides DC. Rand der Friichtehen breit, fast durchscheinend. Allgemeine Hiille reichblätterig.

9. P. a ustriacum Koch. St. gefurcht, etwas ästig; B. 3zählig3 fachgefiedert, Blättchen eyf., fiedersp., Zpfl. lanzettl.-lineal., zugespitzt, am Rande kahl; allgemeine Hiille reichblätterig, zuletzt zuriickgebogen; Stralılen der Dolde einwärts flaumig-raul,; Blb. breitvktherzf., benagelt. 2. Felsige $\mathrm{O}$., unter Gesträuch; C. Waadt, Wallis, Graubiind., Krain, Kärnth., Böhm. Jul. Aug. Selinum austriaeum Jacq. Bl. weiss. Var. mit schmäleren Bzpflı. : Selinum nigricans Gaud. S. montanum Schleich.

10. P. rablense Koch. St. gefureht, etwas ästig; B. 3zählig3fachgefiedert, vielsp., Zpfl. schmal-lineal., zugespitzt, am Rande kahl; allgemeine Hïlle reichblätterig, znletzt zurïckgebogen; Strallen der Dolde auf der inneren Seite flaumig-rauh; Blb. breit-vktherzf., benagelt. 24. Steinige O. der VorA.; Krain, Kärnth., südl. Tyrol, siidl. Schwz. Jul. Aug. Bl. weiss.

43. TOMLASINIA Bertolon. Tommasinie.

1. T. verticillaris Bertolon. St. stielrund, fein-gerillt, bereift; B. 3fachgefiedert, Blättchen eyf., spitz-gesägt, die seitenst. oft 2lappig, die endst. 3sp.; Scheiden gross, aufgeblasen; Hïlle fehlend. 2 . VorA.; Wallis, Tessin, Graubünd., Stmk., Litt. Jul. Aug. Angelica verticillaris L. Penced. vert. Koch. Bl. grün-gelbl.

\section{THYSSELINUM Hoffm. Olsenick.}

1. Th. palustre Hoffm. St. gefurcht; allgemeine Hïlle reichblätterig, zuriickgeschlagen; B. 3fachgefiedert, Blättchen tief-fiedersp., Zpfl. lineal.-lanzettl., zugespitzt, am Rande etwas rauh; Hüllblättchen frei. $\odot$. Sümpfe, Teiche. Jul. Ang. Bl. weiss.

45. IMPERATORIA. I. Meisterwurzel.

1. I. Ostruthium L. B. doppelt-3zällig, Blättchen breit-eyf., doppelt-gesägt, die seitenst. 2sp., die endst. 3sp.; Scheiden erweitert. 4. Gebirgswiesen; VorA., Sudet., Erzgeb., Thiiringer Wald, Pommern. Jun. Jul. Bl. weiss.

2. I. angustifolia Bellard. WWB. 3zählig, u. doppelt-3zählig, Blättchen geschärft-ungleich-gesägt, 3sp. ı. 2 sp., an der Basis verschmälert, $Z_{p f l}$. längl., vorne eingeschnitten, zugespitzt; Scheiden erweitert. 2. Schweizer A., Schleicher; ,hat aber d. speciellen Standort nicht angegeben" Gaud. Jun. Jul. Bl. weiss.

\section{ANETHUM L., Hoffm. Dill.}

1. A. graveolens L. Blattzpfl. lineal.-fädl., verlängert; Frucht 
elliptisch, v. einem verbreiterten, flachen Rande umgeben. $\odot$ Unter der Saat; Littor., Istrien, wird uiberall kultiv. Jul. Ang. Bl. gelb.

\section{PASTINÁCA L. Pastinak.}

1. P. sativa L. St. kantig-gefurcht; B. gefiedert, oherseits glänzend, unterseits flaumig, Blättchen eyf.längl. od. längl., stumpf, gekerbt-gesägt, dic seitenst. an der Basis gelappt u. 3zühlig, das endst. 3lappig, Sägezähne sehr kurz-stachelspitrig; Hiillen fehlend; Kelchzähne verwischt; Früchte oval, Fuge 2striemig. @. Wiesen, unkultiv. O., wird auch angebaut. Jul. Aug. Bl. gelb, wie der folgenden.

2. P. op a ca Bernh. St. kantig-gefurcht; B. gefiedert, glanzlos, beiderseits flaumig, Blättchen eyf., an der Basis etwas herzf., stumpf, gekerbt-gesägt, die seitenst. an der Basis gelappt u. 3zählig, das endst. 3lappig; Hüllen fehlend; Kelchzähne verwischt; Frïchte oval, Fuge 2striemig. $\odot$. Triften; Fiume. Jul. Aug.

3. P. Fleisch manni Hladnik. St. kantig-gefurcht; B. doppeltgefiedert, Fiederchen gegenst., entfernt, elliptisch-lanzettl., fiedersp.gezähnt; Hüllen fehlend; Kelchzähne verwischt; Friichte oval, Fuge 2striemig. $\odot$. Steinige O.; Schlossberg bei Laibach. Jul. Aug.

\section{HERACLÉUM L. Heilkraut.}

1. H. Sphondylium L. B. rauhh., gefiedert od. tief-fiedersp., Fieder lappig od. handf.-getheilt; Dolden strahlend; Fruchthn. dichtfaumig; Friichte oval, stumpf, ausgerandet, zuletzt kahl, Fuge 2striemig. (.) Wiesen, waldige $\mathrm{O}$. bis in die A. linauf. Jun.-Herbst. Blb. weiss, od. weiss mit 2 griinen Flecken an der Basis, od. hellgrün od. rosenroth. Var. Bzpfl. verlängert: H. elegans Jacq.

2. H. sibiricum L. B. rauhh., gefiedert od. tief-fiedersp., Fieder gelappt od. handf.-geth., gesägt, nebst den Fruchtkn. kahl; Blb. fast gleich; Früchte rundl.-oval, an der Spitze tiefausgerandet, kahl, Fnge 2striemig. (.). Triften der A. u. VorA. u. d. Sudeten. Jun.-Herbst. Blb. grün od. gelblich, gleich od. nur wenig ungleich. Var. $\beta$.: mit schmäleren Bzpfln: H. angustifolium Jacq., u. mit ganz schmalen: $H$. angustifolium $\mathrm{L}$.

3. H. asperum MB. B. einfach, fast handf-lappig, unterseits kurzh.-grau od. kahl u. auf den Adern kurzh., Zpfl. zugespitzt od. feinspitzig, ungleich-gesägt-gezälnt, die stengelst. B. manchrnal $3 z a ̈ h-$ lig; Dolden strahlend; Fruchtkn. kurzh.-rauh; Frichte oval, ausgerandet, zuletzt kalıl. $\odot$. Wälder der VorA.; Jura, Tyr., Bayern, Salzb., Stmk. Jul. Aug. H. Panaces Bertolon. H. montanum Schl. Var.: B. unterseits dünn-weiss-filzig: H. pyrenaicum Lam. Bl. weiss. - Das H. Panaces L. hat warzig-rauhe Friichte, Fries nov. mant. 3.p. 21. 4. H. al pinum I. B. einfach, herzf.rundl., fast hardf.-lappig, am Rande u. unterseits auf den Adern flaunig, zuletzt kahl werdend, Lappen gekerbt, abgerundet, mit einer Vorspitze od. stumpf; Früchte 
vkteyf.-kreisrund, Striemen auf der Berührungsfiäche sehr kurz od. fehlend. 4. Gebirgswälder u. VorA.; Jura u. Wallis. Jul Aug. Bl. weiss.

5. H. a ustriacum L. B. gefiedert u. 3zählig, Blättchen sitzend, gesägt, die seitenst. ganz, die der WB. eyf., stumpf, die der StB. lanzettl., zugespitzt, an der Basis etwas lappig, das endst. 3sp.; Fruchtkn. flaumig; Friichte oval, kahl, Striemen der Berïhrungsfläche fehlend od. sehr kurz. 24. Wiesen der A. u. VorA.; nördl. Tyrol bis Oestr. Jul. Ang. Var. $\beta$. siifolium: Blattspitze weniger vorgezogen: Tordylium siifolium Scop. Bl. weiss od, rosenroth.

49. TORDYIIUN L. Zirmet.

1. T. maximum L. Steifh., am St. v. riickwärtsgekehrten Haaren; B. gefiedert, Blättchen stumpf-gekerbt, die der unteren B. eyf., die der oberen lanzettl., das endst. verlängert; Hüllblättchen lineal., kürzer als die Dolde; Früchtchen auf dern Mittelfelde borstig-steifh., 4 striemig. $\odot$. Unkultiv. O., Hecken; sehr zerstr. deh das Geb. Jul. Aug. Fuge 2striemig. B1. weiss.

2. T. ap ulum L. St. ästig, beblättert, unterwärts zottig; B. gefiedert, Blättchen eingesehnitten-gekerbt; Strahlen der Dolde vielmal länger als die allgemeine Hülle; Früchte auf dem Mittelfelde rauh, vielstriemig. $\odot$. Somnige O.; Istrien. Apr. Maai. Fuge vielstriemig. Bl. weiss.

VII. Gruppe. SILERINEEN. Koch. Frucht v. Rücken her linsenf.-zsgedriickt. Frïchtchen mit 5 Hauptriefen, die seitenst. Riefen randend; Nebenriefen 4, weniger hervortretend. Eyweiss vorne ziemlich flach.

50. SILER Scop. Rosskïmmel.

1. S. tril o bu m Scop. 2. Gebirgswälder; Oestr., Stmk., Hanuov., Harz, Hess. Jul. Ang. Laserpitium aquilegifolium Jaeq. Bl. weiss.

VIII. Gruppe. THAPSIEEN. Koeh. Friichtchen mit 5, fädl., manchmal steifhaarigen Hauptriefen; d. seitenst. Rief. auf d. Beriihrungsfläche liegend; Nebenriefen 4, die imeren fädl., die äusseren geflitgelt, od. sämmtl. geflitgelt, Fliigel wehrlos. Daher die Frucht entweder 8- od. beiderseits 2 fliigelig. Eiweiss vorne platt.

\section{LASERPITIUN I. Laserkrant.}

1. L. la tifolium L. W. - u. untere StB. 3zählig-doppelt-geficdert, Blättchen eyf., gesägt, an der Basis herzf., sämmtl. ungeth. od. die endst. der WB. 3sp.; Strahlen der Dolde auf der inneren Seite rauh; St. stielrund, fein-gerillt, kahl. 24. Gebirge u. VorA.; zerstr. deh das Geb. Jul. Aug. Bl. weiss. Var. Fruelitfiigel flach od. wellig-kraus, Blättchen tiefer- od. seichter-herzf., u.: $\alpha$. glabrum: B. kabl. L. glabrum Crantz. DC. - $\beta$. asperum: B. unterseits nebst den Bstielen kurzh.-rauh. L. asperum Crantz, DC. 
2. L. alpinum W. K. W.- u. untere StB. 3zählig-doppelt-gefiedert u. doppelt-3zäIligr, Blättchen $€ y f$., ungleich-gesägt, ganzod.2-3sp., die seitenst. meist $2 \mathrm{sp}$., die endst. 3 sp.; Dolde gleichhoch, Strahlen kahl; Blb. breit-vktherzf., an der Basis in einen kurzen Nagel zsgezogen; St. stielrund, gerillt, kahl. 24. Wälder u. Gesträuch; Unterkrain zw. Kletsch u. Altlag, u. an dem Fahrwege, der v. Gottschee ii]er Seisenburg nacl Sittich u. Weichselburg führt, Wulfen. Jul. Ang. L. aquilegifolium DC. prodr. Bl. weiss. Eine für das Geb. noch zweifelhafte Pfl.

3. L. margin a tum W. K. W.- u. untere StB. 3zählig-dopjeltgefiedert u. doppelt-3zählig, Blättchen ey- od. herzf., ungleich-gesägt, ganz od. 2-3sp.; Dolde ausgesperrt, Strahlen auf der innern Seite kurzh.-rauh; Blb. rundl.-vktherzf.; Hauptriefen der Frucht kurzsteifh.; St. stielrund, gerillt, kahl. 2. Gebirge O., unter Gestränch; Krain, Litt. Jul. Aug. Blb. gelblich, roth-berandet.

4. L. Ga u dini Moretti. W.- u. untere StB. 3zählig-doppelt-gefiedert od. doppelt-3zählig, Blättchen ey- od. herzf., ungleich-gekerbtgesägt, ganz od. 2-3sp.; Dolde ausgesperrt, Strahlen ungleich, kahl; Blb. rundl.-vktherzf.; Hauptriefen der Frucht kahl; St. stielrund, gerillt, kahl. 2. Gbge u. VorA.; Tessin, Graubünd., südl. Tyr. Jul. Aug. L. luteolum Gaud. Blb. gelbl, roth-berandet.

5. L. Siler I. B. ganz kahl, die W.- u. unteren StB. 3fach-gefiedert, Blättchen lanzettl. ganzrandig, ungeth. od. 3lappig, Hauptadern schief; Früchte lineal.-längl., Gf. zurückgekrümmt, an die Frucht angedrückt; St. sticlrund, gerillt. 4. Gbge u. VorA., u. auf der Alp in Würtemb. Jul. Aug. Blb. weiss.

6. I. peuced anoides I. B. ganz kahl, die W.- u. unteren StB. 3zählig-doppelt- u. 3fachgefiedert, Blättchen lineal.-lanzettl. u. lineal., ganzrandig, ungeth., Hauptadern mit dem Rande gleichlanfend; Frichte oval, Gf. aufrecht, etwas spreitzend; St. sticlrund, gerillt. 4. Gbge u. VorA.; Krain, Stmk., Tyr., Tessin. Jun. Jul. Blb. weiss.

7. L. hirsutum Lam. B. kurzh., mehrfachzsgesetzt; Fiederchen im Umriss eyf., fiedersp.-vielsp., Läppchen lineal.; Frïchte oval, kahl, Stempelpolster kegelf., Gf. auseinanderfahrend; St. stielrund, gerillt kahl. 2. Thäler der A.; siidl. Schwz., südl. Tyr. Jul. Ang. L. Halleri All. Var.: fast kahll. Blb. weiss.

8. L. pruthenicum L. B. an dem Rande u. den Bstielen rauhh., doppeltgefiedert, Blättchen fiedersp., Zpfl. lanzettl.; Frïchte oval; Hauptriefen steifh., Stempelpolster niedergedriickt, mit einem erhabenen, welligen Ranle umzogen; St. kantig-gefurcht, unterwärts steifh., Haare rïckwärtsgekehrt. F. Fenchte Wälder, Waldwiesen; zerstr. deh das Geb. Jul. Aug. 131. weiss, getrocknet oft gelb.

9. L. nitidun Zantedi. B. doppeltgefiedert, Blättch€n, längl., fiedersp-gelappt, geschärft-gesägt, unterseits v. zerstreuten Borstehen steifhaarig; Frïchte kahl; Blättchen der vielblätterigen allg. Hülle 
an der Spitze eingeschnitten od. 3sp. 24. Felsige Gbge.; siidl. Tyr., Tessin. Jul. Aug. L. hirtellum Gaud. B1. weisslich.

10. L. Archangelica Wulf. 13. unterseits nebst den Bstielen rauhh., 3zählig-3faclıgefiedert, Blättchen eyf., ungleich-gesägt, die cndst. 3sp., mit keiliger Basis herablaufend, die seitenst. fast 2sp.; die obersten Scheiden sackartig - aufgeblasen; Frïchte kahl; St. gefurcht, rauhh. 2. Wälder der VorB.; Krain, Sudet. Jul. Aug. Bl. weiss.

IX. Gruppe. DAUCINEEN. Koch. Friichtchen mit 5, fädlichen, (borstigen) Hauptriefen, d. seitenst. Riefen auf d. Berïhrungsfläche liegend; Nebenriefen 4, mehr hervorspringend, stachelig; Stacheln frei od. in einen Flügel verwachsen. Eyweiss flach od. fast halbstielrund, vorne ziemlich platt.

52. ORLÁYA Hoffm. Breitsame.

1. O. grandiflor a Hoffm. St. aufrecht; Blb. strahlend, vielmal länger als der Fruchtkn.; Nebenriefen der Frïchtchen gleich, Stacheln an der Spitze pfrieml., hakig. ○. Aecker; zerstr. dch das siidl. u. mittl. Geb. Jul. Aug. Cancalis grandiflora L. Bl. weiss.

2. O. platycarpos Koch. St. ausgebreitet, Aeste spreitzend; Blb. strahlend, so lang als der Fruchtkn.; die äusseren Nebenriefen der Frïchtehen doppelt-breiter, Stacheln an der Spitze pfrieml., hakig. ○. Unter der Saat; Istrien. Juı. Jul. Caucalis platycarpos L. BI. weiss.

53. DAUCUS L. Mohrribe.

1. D. Carota L. St. steifl.; B. 2-3fachgefiedert, glanzlos, Fiederchen fiedersp., Zpfl. lanzettl., haarspitzig; Hiillblättchen 3sp. u. fiedersp., fast so lang als das Döldchen; Stacheln so lang als der Querdurchmesser der längl. - ovalen Frucht. (.) Wiesen u. unkultiv. O.; wird zum Hausgebrauch kultiv. Jun.-Herbst. Bl. weiss.

II. Unterordng. C AMP YLOSPER MIE N. Koch. Eyweiss am Rande einwärtsgekriimmt, od. gänzlich eingerollt, od. an der inneren Seite rinnig $v$. einer Längsfurche.

X. Gruppe. CAUCALINEEN. Früchtchen mit 5, fädlichen, borstigen od. stacheligen IIauptriefen; d. 3 mittleren Riefen auf dem Ruicken, die 2 seitenst. anf der Beriihrungsfäche liegend; Nebenriefen 4, mehr licrvorspringend, stachelig, od. dch die das ganze Thälchen bedeckenden Stacheln verwischt. Eyweiss einwärtsgerollt, od. am Rande einwïrtsgebogen.

54. CÁUCALIS Hoffm. Haftdolde.

1. C. da ucoides L. B. 2-3fachgefictert, Fiederchen fiedersp', 
Zipfelchen lineal., spitz; Hülle fehlend od. 1blätterig; Stacheln der Ncbenriefen 1reikiz, kahl, aus einer kegelf. Basis pfrieml., an der Spitze hakig, so lang od. länger als der Querdurchmesser der Früchtchen. - Unter der Saat. Jun. Jul. Bl. weiss, wie der folgend.

2. C. muricata Bischoff. B. 2-3fachgefiedert, Fiederchen ficdersp., Zipfelchen lineal., spitz; Huille fehlend od. 1blätterig; Stacheln der Nebenriefen 1reihig, kahl, viel kürzer als der Querdurchmesser der Frïchtchen, aus einer fast walzlichen Basis haarspitzig, die Haarspitze aufwärts-gebogen. $\odot$. Unter der Saat bei Nenndorf unweit Wien.

3. C. leptophylla I. B. 2-3fach-gefiedert, Zipfelchen lineal., spitz; Hiille fehlend; Stacheln der Nebenriefen 3reihig, rauh, an der Spitze widerhakig. $\odot$. Unter der Saat; Istrien, Wallis, Basel, Lüttich, Luxemburg, Eljeshausen bei Göttingen. Jun. Jul.

55. TURGENIA Hofim. Turgenie.

1. T. latifoli a Hoffm. B. gefiedert, Fieder lauzettl., eingeschnitten-gesägt; Dolde 2-3strahlig; Stachelchen der Riefen auf der Berührungsfiäche so lang als der Querdurchmesser der Fuge u. kürzer. ○. Unter der Saat; zerstr. dch das Gebiet. Jul. Aug. Caucalis latifolia L. syst. nat. Bl. weiss od. purpurn.

56. TÓRILIS. Adanson. Hoffm. Borstdolde.

1. T. Anthriscus Gmelin fl. bitd. Aeste abstehend; B. doppeltgefiedert, Blättchen eingeschnitten-gesägt; Dolden lang-gestielt; allgemeine Hülle reichblätterig; Stacheln einwärtsgekrümmt, an der Spitze einfach, spitz, nicht widerhrkig. (-). Wälder, Zäune, Hecken. Jun. Jul. Tordylium Anthrisens L. Bl. weiss, wie der folgend.

2. T. n e glecta R. u. S. Aeste, abstehend; B. doppelt-gefiedert, Blättchen eingeschnitten-gesägt; Dolden lang-gestielt; Hiulle 1blätterig od. fehlend; Stacheln widerhakig; Blb. strahlend, noch 1 mal so lang als der Fruchtkn.; Gf. viel länger als das Stempelpolster. $\odot$. Aecker, Waldränder in Unteröstr. Jul. Aug. Scandix infesta Jacq. Von der folgenden deh convexere Döldchen, noch einmal so grosse Bth. u. lange Gf. verschieden.

3. T. helvetica Gmel. Aeste auseinanderfahrend; die untersten B. doppelt-gefiedert, die oberen gefiedert u. 3zählig, Blättchen eingeschnitten-gesägt, das endst. der oberen B. oft verlängert; Dolden lang-gestielt; Hülle 1 blätterig od. fehlend; Stacheln viderhakig; Blb. so lang als der Fruchtku.; Gf. kaum noch einmal so lang als das Stempelpolster. ๑. Aecker; südl. u. mittl. Geb. Jul. Aug. Caucalis helvetiea Jacq. Scandix infesta L. Bl. weiss. Var. 2-3' hoch.

4. 'T. heterophylla Guss. Aeste aufrecht, etwas abstelend; die untersten J3. doppelt-gefiedert, die oberen 3zählig, Blättchen eingeschnitten-gesägt, das endst. der oberen $B$. oft verlängert $u$. entfernt- 
gesägt; Dolden lang-gestielt; Hülle 1blätterig od. fehlend; Stacheln widerhakig; Blb. so lang als der Fruchtkn. $\odot$. Accker, Hecken; Istr. Apr.-Jun.

5. T. nodos a Gärtn. Aeste ansgebreitet; B. doppelt-gefiedert, Blättchen fiedersp.-eingeschnitten; Dolden geknäuelt, sitzend, blattgegenst.; die äusseren Früchte stachelig, widerhakig, die imncren körnig-rauh. $\odot$. Aecker; Istr., Litt., siidl. Tyrol, Varel in Oldenbg. Apr. Mai. Tordylium nodosum L.

XI. Gruppe. SCANDICINEEN. Koch. Frucht lïngl., v. der Seite her merklich-zsgedrückt od. zsgezogen, öfters geschnäbelt. Früchtchen mit 5, durchziehenden, od. nur an der Spitze bemerklichen, gleichen Hauptriefen; Nebenriefen fehlend. Eyweiss vorne mit einer tiefen Furche ausgehöhlt od. am Rande einwärțsgerollt.

57. SCANDIX L. Nadelkerbel.

1. S. Pecten veneris $L$. Hüllblättchen an der Spitze 2-3sp., od. ganz; Schnabel der Frucht rom Rücken her zsgedrückt, 2reihigsteifh. $\odot$. Unter der Saat. Mai. Jun. Bl. weiss.

2. S. a ustralis L. Hüllblättchen meist 2zähnig; Schnabel der Frucht v. der Seite her zsgedriickt, überall steifh.; die äusseren Blb. ein wenig länger; St. kahl. $\odot$. Unter der Saat; Osero, Lossino. Mai. Jun. Blb. weiss.

\section{ANTHRÍSCUS Hoffm. Klettenkerbel.}

1. A. sylvestris Hoffm. St. unterwärts rauhh., oberwärts kahl; B. kahl od. unterseits anf den Hauptnerven borstl.-haarig, doppeltgefiedert, Fiederchen fiedersp., die unteren Zpfl. eingeschnitten; Früchte längl., glatt ot. zerstreut-knotig, Knötchon grannenlos, Furchen des Schnabels $1 / 5$ so lang als die Frucht; Hüllchen 5blätterig, ziemlich lang-gewimpert; Gf. länger als das Stempelpolster.P24. Wiesen, Hecken, Ufer, bis in die A. hinauf. Mai. Jun. Bl. weiss, wie der folgend. Var. $\alpha$. tuberculata: Frucht mit kleinen haarlosen Knötchen unregelmässig bestreut. - $\beta$. alpestris': B. weniger eingeschnitten. A. alpestris Wimm. A. torquata DC.? - $\gamma$.torquata: B. in lineal., entfernte Zpfl. fiedertheilig-zerschnitten. A. torquata Thomas. Chaerophyllum alpinum Vill.

2. A. nemorosa M. Bieberst. St. unterwärts raul., oberwärts kahl; B. kahl, unterseits auf den Nerven borstig-haarig, doppeltgefiedert, Fiederchen fiedersp., die unteren Zpfl. eingeschnitten; Früchte längl., knötig, Knötchen dch ein Börstchen weichstachelig; Furchen des Schnabels ungefähr 1/5 so lang als die Frucht; Hüllchen 5blätterig, ziemlich lang-gewimpert; Gf. länger als das Stempelpolster. 4. Schattige O. bei Frankf. an d. O. Mai. Jun. Chaerophyllum nemorosum MB. 
3. A. fumarioides Spreng. St. nebst den B. v. sehr kurzem Flaum fast sammetartig; B. 2-3fachgefiedert, Fiederchen fiedersp.eingeschnitten; Früchte lineal.-längl., knotig, Knötchen dch ein Borstchen weichstachelig, Furchen des Schnabels ungefähr 1/5 so lang als die Frucht; Hüllchen 5blätterig, am Rande selrr kurz-flaumig. 4. Höhcre Berge im Karstgebirge; Nanas, Plania, M. Magg. Mai. Jun. Scandix fumarioides W. K. Var. $\beta$. Hladnikiana: mit breiteren u. kiirzeren Blättchen. Chaerophyllum Hladnikianum Reichenb.

4. A. trichosperma Schultes. St. oberhalb der Gelenke flaumig; B. 3fachgefiedert, kahl, unterseits auf den Nerven zertreut-haarig, Blättchen fiedersp.; Früchte lineal., borstl.-weichstachelig, Furchen des Schnabels ungefähr. 1/2 so lang als die Frucht; Hïllchen halbirt, 3-4blütterig; Gf. lünger als das Stempelpolster. $\odot$. Zäune; Böhmen. Mai.

5. A. Cercfolium Hoffm. St. oberhalb der Gelenke flaumig; B. 3 fachgeficdert, kahl, unterseits auf den Nerven zerstreut-haarig, Blättchen tiedersp.; Frïchte lineal., glatt, Furchen des Schnabels ungefähr $1 / 2$ so lang als die Frucht; Hiillchen halbirt, 2-3blätterig; Gf. länger als das Stempelpolster. $\odot$. Hecken, Weinberge; südl. Geb., im nördlicheren verwildert. Mai. Jun. Scandix Cerefolium L.

6. A. vulgaris Pers. St. kahl; B. 3fachgefiedert, kahl, unterseits auf den Nerven zerstreut-haarig, Blättchen fiedersp.; Früchte eyf., stachelig, Stacheln pfrieml., eimwärts-gekrümmt, Furchen des Schnabels ungefähr 1/3 so lang als die Frucht; Hüllchen halbirt, $2-$ 3blätterig; Gf. sehr kurz; Narben fast sitzend. $\odot$. Unkultiv. O. um Dörfer, an Wegen. Mai. Jun. Scandix Anthriseus L. Torilis Anthriscus Gärtn.

\section{PHYSOCAUIUS Tausch. Blasenstengel.}

1. Ph. n edosus Tausch. St. unter den Gelenken aufgeblasen; B. 3zählig -doppeltgefiedert, Fiederchen eyf., fiedersp.-eingeschnitten u. gezïhnt; Friichte steifh.; Stempelpolster kegelf.; Gf. fast fehlend; Narben fast sitzerid. $\odot$. In Gebüsch bei Fiume. Mai. Jun. Seandix nodosa L. Biasolettia nodosa Bertolon. Chaerophyllum nodosum Lam. K. syn. ed. 1. Bl. weiss.

\section{CHALROPHÝLLUM I. Kälberkropf.}

1. Ch. te mulum L. St. unter den Gclenken aufgeblasen, an der Basis steifl., oberwärts kurzh.; B. doppeltgefiedert, Blättchen eyf.lïngl., lappig-fiedersp., Lappen stumpf, kurz-stachelspitzig, etwas gekerbt; Blättehen der Hiillchen ey-lanzettf., haarspitzig, gewimpert; Blb. kahl; Gf. zurïckgekrümmt, so lang als das Stempelpolster. (-). Unkultiv. u. waldige O., Hecken. Jun. Jul. Bl. weiss.

2. Ch. bulbosum L. St. unter den Gelenken aufgeblasen, an der Jasis steifh., oberwärts kahl; B. mehrfachzsgesetzt, Blättchen 
tief-fiedersp., Zpfl. lineal.-lanzettl.-spitz, die der oberen B.lineal., sehr schmal; Blättchen der Hüllchen lanzettl., lıarspitzig, kahl; Gf. zu, rückgebogen, ungefähx so lang als das Stempelpolster. $\odot$. Hecken, Wege, Ufer. Jun. Jul. Bl. weiss.

3. Ch. a ure um L. St. unter den Gelenken etwas angeschwollen; B. 3fachgefiedert, Blättchen aus eyf. Basis lanzettl., zugespitzt, eingeschnitten u. gesägt, an der Basis fiedersp., an der tang-vorgezogenen Spitze einfach-gesägt; Blättchen d. Hüllchen breit-lanzettl:, haarspitzig, gewimpert; Blb. kahl; Gf. zuletzt zurüickgebogen, läuger als das convex-kegelf. Stempelpolster. 24. Unkultiv. O., zwischen Gebüsch, bis in die VorA.; zerstr. deh das Geb. Jun. Jul. Bl. weiss. St. u. B. von kurzen Härehen flaumig, St. an der Basis steifh. ß.: B. kahl, am Rande u. unten mit kurzen Haaren betreut. Ch. maculatum Willd. $-\gamma_{.}$: ganz kahl. Ch. monogonum Kit.

4. Ch. elegan s Gaud. St. unter den Gelenken fast gleichdick; B. doppeltgefiedert, Fieder fiedersp., Zpfl. lanzettl., eingeschnitten-gesägt, die unteren fiedersp.; Blättchen der Hüllchen verlängert, lanzettl.lineal., zugespitzt, durchaus häutig u. nebst den Blb. gewimpert; die Gf. aufrecht- etwas abstehend, melırmals länger als das Stempelpolster; Fruchthalter bis auf die Basis getheilt. 24. An Giesbächen am Fusse des St. Beruhard im Wallis. Jul. Aug. B1. weiss.

5. Cl. Villarsii Koch. St. unter den Geleuken fast gleichdick; B. doppeltgefiedert, Fieder fiedersp., Zpfl. lanzettl., eingeschnitten-gesägt, die unteren fiedersp.; Blättchen der Hüllchen lanzettl., zugespitzt, krautig, am Rande häutig $u$. nebst den Blb. gewimpert; Gf. aufrecht, mehrmals länger als das Stempelpolster; Fruchthalter bis auf die Basis getheilt. 24. Wiesen u. Wälder der A.; Schwz., Tyrol, bayer. A., Stmk. Jun. Jul.: Ch. hirsutum Vill. Bl. weiss.

6. Ch. hirsutum L. St. unter den Gelenken fast gleichdick; B. doppelt-3zählig, Blättchen 2-3sp. od. fiedersp., eingeschnittengesägt; Blättchen der Hïllchen breit-lanzettl., zugespitzt, krautig, am Rande nebst den Blb. gewimpert; Gf. aufrecht, mehrmals länger als das Stempelpolster; Fruchthalter an der Spitze 2sp. 24. Nasse Wiesen, feuchte Wälder; zerstr. dch das Geb. u. bis in die A. hinauf. Jul. Aug. Ch. Cicutaria Vill. 13l. weiss od. roseurotl.

7. Ch. aromaticum L. St. unter den Gelenken angeschwollen; B. 3fach-3zählig od. 3fach-3zählig-doppeltgefiedert, Blättchen ungeth., eyf.-längl., zugespitzt, gesägt; Blättchen der Hüllchen breitlanzettl., pfrieml.-zugespitzt, gewimpert; Gf. spreitzend, länger als das kegelf. Stempelpolster. 24. Haine, Waldwiesen; Oestr., Mähr., Böhm., Sehles., Neumark, Sachsen. Jul. Aug. Bl. weiss.

\section{BIASOLETTIA Koch. Biasolettie.}

1. B. tuberosa K. 24. Monte Maggiore in Istrien, nach Biasoletto, doch neuerdings nicht wiedergefunden, weswegen der Stand- 
ort etwas zweifelhaft. Jul. Aug. Myrrhis eynapioides Guss. Bunium eynapioides Bertolon. Wr. knollig, wie bei Carum Bulbocastanum. Früchte reinschwarz. Ansehen eines Anthriscus. St. 1' hoch, mit 23 Dolden. Hüllehen abstehend, lanzettf., am Rande glatt. Bl. weiss.

62. MYRRHIS Seop. Sïssdolde.

1. M. odorata Scop. B. fein-zottig v. kurzen Haaren; Hüllchen lanzettl., zugespitzt. 24. Thäler der A., Triften der VorA. u. Gbge.; zerstr. deh das Geb. Jun. Jul. Scandix odorata L. Bl. weiss.

63. MOLOPOSPÉRMUM Koch. Striemensame.

1. M. cicutarium DC. 24. Steinige, gebirgige 0 ., in die A. hinauf; Wallis, Tessin, Veltlin, südl. Tyrol, Krain, Görz. Jul. Aug. Ligustieum peloponnesiacum L. Bl. weiss.

XII. Gruppe. SMYRNEEN. Koch. Frucht gedunsen, v. der Seite her oft zsgedriickt od. zsgezogen. Friichtchen mit 5 Riefen, d. seitenst. Rief. randend od. vor dem Rande gelegen, d. Riefen lisweilen fast verwischt. Eyweiss einwärtsgerollt od. auf der inneren Seite gefureht, $u$. deshalb auf dem Querdchschnitt halbmondf. od. zsgefaltet.

\section{ECHINÓPHORA L. Stacheldolde.}

1. E. spinos a L. B. gefiedert, Blättchen fiedersp., die der oberen B. einfach u. 3 sp., $Z$ pfl. lineal., starr, fast $3 \mathrm{kantig}$, in einen Dorn zugespitzt. 4. Am Meere bei Aquileja. Jun. Jul. Blb. weiss.

65. CONIUM L. Schierling.

1. C. in a culatum L. Hüllblättchen lanzettl., kürzer als das Döldehen. -.. Schutt, Hecken, Wege. Jul. Ang. Bl. weiss.

66. PLEUROSPERMUM Hoffm. Rippensame.

1. P. austriacum Hoffm. Riefen der Frïchtehen stumpf, gekielt; Kiel etwas gekerbt. 24. A., VorA. u. höhere Gbge der Sudet., Mähr. Gbg.; Thüring. Wald u. Hessen. Jul. Aug. Bl. weiss.

67. MALABAILA 'Tausch. Malabaile.

1. M. Hacqueti i Tausch. 24. Höhere Gbge in Krrain, Alpe Campogrosso in Vallorsa, stidl. Tyr. Jun. Jul. Athamanta Golaka Hacquet. Ligustieum carniolieum Host. Hladnikia golacensis K. syn. ed. 1. Bl. weiss.

68. SMYRNIUM I. Sinyrnium.

1. S. perfoliatum Mill. St. oberwärts kantig-geflügelt; StB. stengelumfassend, herı-eyf., gekerlt. $\odot$. Wälder, Waldwiesen; Littor, Apr. Mai. S. Dioscoridis Spreng. Bl. gelb. . 
III. Unterordng. COELOSPERMEN. Koch. Eyweiss halbkugelig- od. sackartig-concav.

XIII. Gruppe. CORIANDREEN. Koch. Frueht kugelig, od. deh 2 fast kngelige Früchtehen 2 knotig. Früchtehen mit 5, niedergedrückten $u$. geschlängelten od. eine verwischte Furche darstellenden Hauptriefen; die seitenst. Riefen vor dem Nebenrand liegend; Nebenriefen 4, mehr hervorspringend; sämmtl. flïgellos.

69. BIFÓRA Hoffm. Bifore.

1. B. radians MBieberst. Dolden 5strahlig; dic äusseren Bth. strahlend; Gf. ungefähr halb so lang als das Frïchtehen; Friichtchen sehr stumpf. $\odot$. Aecker; südl. Geb. über den A. Jun. Jul. Blb. weiss.

70. CORIANDRUM L. Koriander.

1. C. sativum L. $\odot$. Unter der Saat; in den südlich. über den A. gelegenen Gegenden, ausserdem lin u. wieder verwildert. Jun. Jul. Blb. weiss.

\section{Ordng. ARALIACEEN. Juss.}

\section{HÉDERA L. Ephen.}

1. H. Helix L. St. mit wurzelf. Fasern kletternd; B. lederig; kahl, glänzend, winkelig-5lappig, die obersten u. die der blühenden Aestchen ganz, eyf., zugespitzt; Dolden einfach, flaumig. ち. Wälder, Felsen u. Manern. Oct., Fruchtreife im folgenden Friilıling. Blb. grün.

\section{Ordng. CORNEEN. DC.}

1. CORNUS L. Hornstranch.

1. C. s anguinea L. Aeste aufrecht; B. eyf., gleichfarbig; Trugdolden flach; Hülle fehlend; Haare der Aeste 1 . Bthstiele angedrückt. ち. Waldige O., Hecken. Mai. Jun. Bl. weiss.

2. C. mas L. Aeste kahl, die jüngeren angedrückt-haarig; B. eyf., zugespitzt; die vor den Blättern blühenden Dolden ungefähr so lang als die Hülle. ち. Trockene Hügel, gebirgige $0 . ;$ zerstr. im südl. u. mittl. Geb. Apr. Mai. Bl. gelb.

3. C. suecic a L. St. krautig; B. sämmtl. gegenst., sitzend, eyf., 5-7nervig; Dolde gestielt, halb so lang als die Hülle. 2. Torfhaltige, schattige O.; Ostfriesland, Oldenbg., Holst. Jun. Jul. Blb. purpurn.

\section{Ordng. LORANTHACEEN. Don.}

1. VISCUM L. Mistel.

1. V. album L. St. gabelsp.; sehr ästig, Aeste stielrund; $B$. 
lanzettl., stumpf, nervenlos; Bth. endst., sitzend, meist 5zählig, geknäuelt. Ђ. Sclınarotzend auf Aesten verschiedener Bäume. März Apr. Bl. gelb. Beeren weiss.

2. V. Oxycedri DC. Blattlos; St. sehr ästig, gegliedert, Aestchen etwas zsgedrückt; Scheidchen beckenf.; männl. Bth. an den Gelenken zu 1-3, sitzend, die weibl. an der Spitze der Aestchen zu 3, kurzgestielt. Ђ. Schmarotzend auf den Aesten v. Juniperus Oxycedrus; Insel Cherso u. andere benachbarte Inselı. Blühet.... Habitus einer Salicornia. Frucht längl., bläulich.

2. LORANTHUS I. Riemenblume.

1. L. e uro pa e us Jacq. Kahl, sehr ästig, Aeste stielrund; B. gegenst., gestielt, oval-längl., stumpf, an der Basis etwas verschmälert, spärlich-aderig; Aehren endst., locker, einfach; Bth. dch Fehlschlagen 2häusig, 6blätterig. ち. Auf den Aesten der Eichen u. Linden schmarotzend; Litt., Krain, Stmk., Unteröstr. u. Mähren. Apr. Mai. Bl. gelblich-grün; Beeren hellgelb.

\section{Ordng. CAPRIFOLIACEEN. Juss.}

I. Gruppe. SAMBUCEEN. H. B. u. K. Blkr. radf. Gf. od. Narben 2-5.

\section{ADÓXA L. Bisamkraut.}

1. A. Moschatellina L. 24. Haine, feuchte Hecken der Ebenen u. Gbge u. bis auf die A. März. Apr. Bl. grün.

\section{SAMBÚCUS L. Hollunder.}

1. S. Ebul us L. St. krautig, kleinwarzig; NebenB. blattig, eyf., gesägt; Hauptäste des Ebenstrausses 3zählig. 24. Waldränder, Hecken. Jul. Aug. Bl. weiss, auswendig röthl.; Beeren schwarz.

2. S. nigra L. St. strauchig, fast baumig; NebenB. warzenf. od. fehlend; Hauptäste der Trugdolde 5zähligg. 24. Wälder. Jun. Jul. Bl. weiss, Beeren schwarz, Mark d. Aeste schmeeweiss. Tar. mit grïnen u. weissen Früchten u. doppeltgefiederten Bl., letztere: S. laciniata Mill., diese bei Wandsbeck Fl. v. Hambg.

3. S. racemosa L. St. strauchig; R. eyf. ち. Wälder. Apr. Mai. Bl. weiss, Beeren roth, Mark der älteren Aeste rothgelb. Var. $\beta$. laciniata: B. doppelt-gefiedert, Fiederchen gesägt u. eingeschnitten. In der Rheinpfalz entdeckt, nun in botan. Gärten verbreitet.

3. VIBURNUM L. Schneeball.

1. V. Tinus L. B. eyf.-längl., ganzrandig, immergriinend, unterseits in den Winkeln der Adern gebartet. $\hbar$. Unkultiv. O.; Istrien, Litt. zw. 'Triest u. Duino. Mär\%. Apr. Bl. weiss, wie der folgend. 
2. V. Lantana L. B. eyf., gezähnelt-gesägt, an der Basis etwas herzf., unterseits runzelig-alerig u. nebst den $\Lambda$ estchen v. einem sternf. Flaum kleiig-filzig, oberseits v. sternf., zerstreuten Härchen flaumig; Ebenstrauss endst., gestielt. h. Waldige, gebirge O., auf Letten- u. Kalkboden. Mai.

3. V. Opulus L. B. 3- od. 5lappig, Lappen zugespitzt, gezähnt; Bstiele drüisig, kahl ; Ebensträusse endst., gestielt; dio äussern Bth. strahlend, geschlechtslos. 5). Feuchte Hecken, Ufer. Mai. Jun. Eine Variet. mit kugeligen Trugdolden u. lauter grossen, geschlechtslosen Bth., V. Opulus $\beta$. roseum L., wird in den Gärten kultivirt.

II. Gruppe. LONICEREEN. Brown. Blkr. röhrig od. glockig, oft unregelmässig. Gf. fädlich.

\section{LONICÉRA L. Lonicere.}

I. Rotte. Caprifolinm DC. Bth. kopfig-quirlig. Beeren mit dem bleibenden $K$. gekrünt. St. siclı schlingend.

1. L. Caprifolium DC. Bth. quirlig und kopfig, das eridst. Köpfchen sitzend; B. abfällig, die oberen zsgewachsen, etwas dchwachsen; Gf. kahl;" Aeste-sich schlingend. †. Waldige O. unt. Gestrïuch; Oestr., Krrain, südl. Tyrol, südl. Schwz; im übrigen Geb. hin u. wieder verwildert. Mai. Jun. Bl. purpurn, inwendig weiss, dann gelb; od. weissl., dam gelbl.; letztere: L. pallida Host.

2. L. implexa Ait. Bth. quirlig u. kopfig, das endst. Köpfehen sitzend; B. immergriin, die oberen zsgewachsen, etwas dchwachsen; Gf. rauhh.; Aeste sich schlingend. ந). Unkultiv. O. unt, Gebüsch in Istr. Mai. Jun. Yar.: die unteren B. breiter, an der Basis herzf.: L. balearica Vivian. Bl. ein wenig kleiner, sonst wie an L. Caprifolium.

3. L. etrusca Savi. Bth. kopfig, Köpfchen gestielt; B. abfällig; die obersten zsgewachsen u. völlig dchwachsen; Gf. kahl; Aeste sich schlingend. Ђ. Unt. Gesträuch, an Zäunen; Littor., Wallis. Jul. Aug. B. unterseits meist rauhl. Bl. wie an L. Caprifol.

4. L. Periel ymenum L. Bth. kopfig, Köpfehen gestielt; B. ab-

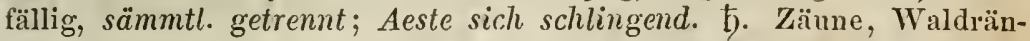
der. Jun.-Aug. Bl. gelblich-weiss, oft auswendig röthlich, zuletzt schmutzig-gelb. Var. nit unterseits rauhh. B.: L. etrusea Lej.; u. mit lappigen B.: L. Periclymennm quercifol. Ait.

II. Rotte. Xylosteum DC. Bth. gezweiet. Saum des K. abfällig, die Beere nicht bekrönend. Die St. aufrecht.

5. L. Xylosteum L. Bthstiele 2bth., zottig, ungefähr so lang als die Bth.; Fruchtkn. an der Basis zsgewachsen; B. oval, flaumig. ち. Hecken, Wälder. Mai. Jun. Bl. flaumig, blassgelb. Beeren roth. 6. L. nigra L. Bthstiele 2bth., kahl, mehrmals länger als die 
Bth.; Fruchtkn. an der Basis zsgewachsen; B. längl.-elliptisch, die jüngeren etwas flaumig, die älteren ganz kahl. b. Steinige O. der A. u. VorA. u. Sudeten. Apr. Mai. Bl. auswendig purp. od. weisslich. Beeren schwarz.

7. L. ca erulea L. Bthstiele 2bth., kürzer als die Bth.; Fruchtkn. in einen einzigen, kugeligen, 2bthigen zsgevachsen; B. längl. - elliptisch, stumpf od. ziemlich spitz. Ђ. Steinige O. der A. u. VorA. u. auf dem Ried bei Memmingen. Bl. gelbl.-weiss, Beeren schwarz, blaubereift.

8. L. alpigen a L. Bthstiele 2bth., melırmals länger als die Bth.; Fruchtkn. fast bis an die Spitze zsgewachsen; B. elliptisch, lang-zugespitzt. Ђ. A. u. VorA., mit den Flüssen in die Ebenen hinab. Mai. Jun. Bl. gelbl.-grïn, mit röthl. Anfluge.

5. LINNÁEA Gronov. Limnäa.

1. L. bore al is L. 24. Nadelwälder, im Noose kriechend; nördl. Geb., u. Lausitz, Schles., Böhm., Mähr., sodann in d. A. v. Salzbg, Tyr., Graubïnd., Wallis. Mai-Jul. Bl. weiss, inwendig mit blutrothen Streifen.

\section{Ordng. STELLATEN. L.}

1. SHERARDIA L. Sherardie.

1. S. arvensis L. $\odot$. Aecker u. andere kult. O. Jun.-Oct. Bl. lila.

\section{ASPÉRULA L. Waldmeister.}

1. A. arvensis L. B. unterseits rauh, die unteren vkteyf., 4 st., die übrigen stengelst. lineal.-lanzettl., stumpf, 6-od. 8st.; Bth. endst., gebüschelt, kürzer als die borstig-gewimperte Hülle; Früchte kahl. ○. Aecker, Kalk- u. Lehmboden; zerstreut im südl. u. mittleren Geb. Mai. Jun. Bl. blan.

2. A. t a urina L. B. 4st., elliptisch, zugespitzt, 3nervig; Ebensträusse gebüschelt, gestielt; Röhre der Bl. weit länger als der Saum; Früchte kahl, punktirt-rauh. 24. Gebirgswälder am Fusse der A., zerstreut im sïdl. Geb. Mai. Jun. Bl. weiss.

3. A. longifl or a W. K. B. 4st., lineal., kahl, die oberen ungleich; W. spindelf., reichstengelig; St. aufrecht od. ausgebreitet; Ebensträusse endst.; DeckB. lanzettl.-pfrieml., haarspitzig; Blkr. kahl, Röhre viel länger als der Saum; Frïchte körnig-rauh. 24. Haine der VorA., zerstreut im südl. Geb. Jul. Aug. B. auswendig trïbpurpurn, inwendig gelblich. Var.: Bl. auswendig gelbl.: A. aristata L. fil.?

4. A. c anescens Visiani. Kurzh. od. kahl; B. lineal., stachelspitzig, 4st., ungleich; St. aufstrebend; Ebensträusschen seitenst., fast 
sitzend od. kurz-gestielt u. endst.; DeckB. lanzettl.-pfrieml., stachelspitzig; Bl. kurzh. od. raul, Röhre viel länger als der Saum; Friichte schwach-körnig od. kurzh. 2. Steinige O. der Insel Losino. Sept. Kommt vor: $\alpha$. die ganze Pfl. mit den Fruchtkn. u. Bl. kurzh.; $\beta$. die Pfl. von unten bis zur Mitte kurzh.; $\gamma$. die ganze Pfl. kahl, die Bl. von Piinktchen raul.

5. A. tinctoria L. B. lineal., kahl, am Rande etwas rauh, die unteren 6st., die oberen 5st., ungleich; W. kriechend; St. aufrecht, einzeln; Ebensträusse endst.; DeckB. oval, spitz, grannenlos; Bl. kahl, Röhre so lang als der Saum; Früchte glatt. 2. Haiden u. gebirgige $O$. unt. Gesträuch. Jun. Jul. 131. weiss.

6. A. cynanchica I. B. 4st., lineal., kalll, am Rande etwas rauh, die oberen ungleich; W. spindelf., reichstengelig; St. ausgebreitet, aufstrebend, sehr ästig; Ebensträusse endst.; DeckB. lanzettl., stachelspitzig; Bl. rauh, Röhre so lang als der Saum; Früchte körnig-rauh. 24. Sonnige O., Haiden; zerstr. deh das Geb. Jun. Jul. Bl. fleischroth, inwendig weiss. Var. die unteren B. 6st.; St. höher 11. schlaffer: A. montana Kit.

7. A. o dorata L. B. lanzettl., kahl, am Rande und Kiel rauh, die unteren 6st., die oberen 8st.; Ehensträusse gestielt; Früchte steifh., Borsten hakig. 24. Schattige Wälder. Mai. Jul. Bl. weiss.

8. A. Ap arine Schott. B. meist 8st., am Rande $u$. Kiel, so vie der St. rückwärts kleinstachelig-rauh; Bth. rispig; Früichte körnig. 2. Feuchtes Gebiisch, Bachufer; Schles., Mähr. Jul. Aug. A. Aparine MB. Bl. weiss. Var. Röhre halb so lang als die Bl.: A. rivalis Sibth.

9. A. galio ides MBieberst. B. starr, lineal., stachelspitzig, am Rande umgerollt und rauh, die stengelst. meist 8st.; St. aufrecht od. aufstrebend, stielrund, schwach-kantig, kahl od. an der Basis flaumig, oberwärts-rispig-ebensträussig; Saum der Bl. länger als die Röhre; Frïchte glatt. 24. Unkultiv. sonnige O.; zerstr. deh das südl. ı. mittl. Geb. Jun. Jul. Galium glaucum L. G. campanulatum Vill. Bl. weiss. Var. mit längerer or. kürzerer Röhre der Bl.

3. CRUCIANELLA L. Kreuzblatt.

1. C, angustifolia L. B. 6st., lincal.-lanzettl.; Aehren verlängert, 4zeilig dachig, 4eckig; die äusseren DeckB. an der Basis zsgewachsen, spitz-gekielt, mit einer fligeligen Kante herablaufend, am Rande kahl. $\odot$. Sandige 0 .; im wärmeren Istr. Jun. Jul. Bl. gelb.

2. C. $\mathrm{m} o 11 \mathrm{ug}$ inoides MBieberst. B. 6-12st., lineal. - lanzettl., rauh; Köpfchen blattwinkelst. u. endst., gestielt, fast rispig; DeckB. eylanzettf., zugespitzt, am Rande zottig; Bth. mit der Fiinfzahl. 24. Gebirgige, steinige O.; am Kahlenberge bei Laibach. Jul. Aug. Bl. grïnlich-weiss. 


\section{RUBIA L. Roethe.}

1. R. tinctorum L. St. jährig; B. 4- od. 6st., etwas gestielt, lanzettl., (getrocknet) netzig-adtrig, am Rande rückwärts-stacheligrauh; Bthstiele blattwinkelst., 3gabelig; Zpfl. der Bl. in ein Anhängsel zugespitzt. 24. Aus dem Orient, u. wo sie gebautet wird, auf Aeckern u. an Zäunen, verwildert. Jun. Jul. Bl. gelbl.

2. R. pere grina L. B. und St. dauernd; B. 4-orl. 6st., sitzend, lanzettl. od. elliptisch, aderlos, am Rande rïckwärts-stachelig-rauh; Bthstiele blattwinkelst., 3gabelig; $Z$ pfl. der BI. dch ein Anhängsel haarspitzig. 2. Hecken u. steinige O.; Litt. Mai. Jun. Bl. gelblich.

\section{GÁLIUM L. Labkraut.}

I. Rotte. Cruciata Tournef. Arten von Valantia bei L. Bthstand blattwinkelst. Bth. vielehig. Die endst. Bthe an den Verästelungen zwitterig, fruchtbar; die seitenständigen männl., unfruchtbar. Bthstiele nach der Bthzeit bogig-zuriickgekrümmt, die Frucht unter den, nun ebenso zurïckgeschlagenen B. bergend.

1. G. Cruciat a Scop. B. 4st., elliptisch-längl. od. eyf., 3nervig; Bthstiele seitenst., ästig, deckblätterig, steifh. od. kahl, bei der Fruchtreife abwärts-gekrümmt; Frïchte glatt; St. rauhh. 2. Waldwiesen, Zäune, Hecken. Apr. Mai. G. cruciatum Sm. Valantia Cruciata L. Bl. gelb. Bthstiele rauhh.: V. chersonensis Willd. Var. Bthstiele kahl: V. Cruciata Willd.

2. G. vernum Scop. B. 4st., oval od. länglich, 3nervig; Bthstiele seitenst., ästig, deckblattlos, kahl, bei der Fruchtreife abwärts gekrümmt; Friichte glatt; St. kahl od. unterwärts kurzh. 2. Schattige Wälder, feuchte Wiesen; südl. Geb. u. westl. v. Oestr. bis Schles. Mai. Jun. Valantia glabra L. Blb. gelb, seltener weissl. Var.: Bth. um die Hälfte kleiner $u$. Bthstiele nur halb so lang als das B.

3. G. pedemontanum All. B. 4st., elliptisch-längl., 3nervig; Bthstiele seitenst., einfach od. 2sp., deckblattlos, zottig, bei der Fruchtreife abwärts-gekrümmt; Friichte glatt, kahl; St. rückwärtsstachelig, ausserdem kahl od. zottig. $\odot$. Sandige O.; Wallis, Veltlin, siidl. Tyrol, Littor., bei Wien. Mai. Jun. Bl. gelblich. Die Var. ohne Zotten am St.: G. retrorsum DC.

II. Rotte. Vaillantioides. Arten v. Vaillantia bei L. Bthstand blattwinkelst. Bth. vielchig. Die endst. Bthe an den Verästelungen zwitterig, fruchtbar; die seitenständigen männl., unfruchtbar. B. nicht abwärts-gekriimmt.

4. G. s a c charatum All. B. meist 6st., lineal.-lanzettl., stachelspitzig, 1nervig, am Rande aufioärts-stachelig-rauh; St. schlapp, niederliegend, riickwärts-stachelig-rauh; Bthstiele seitenst., 3bth., nach dem. Verhlühen zurückgebogen; Bthstielchen kürzer als die dicht- 
warzige Frucht. $\odot$. Accker; im Braunschweig., bei Halle, Merseburg, Basel, im Bad. Jun. Jul. Bth. weissl. G. verrucosum Smith. Valantia Aparine $\mathrm{L}$.

III. Rotte. A parine. Bthstand blattwinkelst., od. zuletzt rispig. Bth. zwitterig. Dic St. v. abwïrts-gekrümmten, zicmlich breiten Stacheln rauh, u. mit diesen sich den Kleidern u. sogar den Händen der Menschen anhängend.

5. G. tric or ne Withering. B. meist 8st., lineal.-lanzettl., stachelspitzig, 1nervig, ain Rande rückwärts stachelig-rauh; St. schlapp, gestreckt, riickwärts - stachelig-raul ; Bthstiele seitenst., meist 3bth.; Bthstielchen nach dem Verblühen zurückgekrümmt, lünger als die warzig - körnige Frucht. $\odot$. Aecker, Kalk- u. Lehmboden. Jul.Herbst. Bl. weisslich.

6. G. trifi d u m L. B. 4st., lincal.-längl., vorne breiter, sehr stumpf, grannenlos, 1nervig, am Rande rückwärts-stachelig-rauh; St. schlapp, fädlich, 4eckig, rïckwärts-stachelig-rauh; Bthstiele seitenst., 1-3bth., nach dem Verblühen zurückgekrümmt; Friichte glatt. 2 . Schlammige, torfhaltige O.; am Bürgersee im Secthale bei Judenburg in Oberstmk. Jul. Aug. Bl. weiss.

7. G. A parine L. B. 6- u. 8st., lineal.-lanzettl., stachelspitzig, 1nervig, am Rande $u$. an dem Kiele rückwärts-stachelig-rauh; St. schlapp, 4eckig, riickwärts - stachelig-rauh; Bthstiele blattwinkelst., zuletzt fast rispig; Bthstielchen nach dem Verblühen gerade; Frïchte steifh. od. glatt; Bl. schmäler als die cntwickelte Frucht. $\odot$. Aecker, Gärten, Zäune. Jun.-Herbst. Bl. weiss od. griinl. Var. im Schatten der Wälder u. in den A. mit vkteylanzettf. B. u. schwachem niederliegenden St.: G. tenerum Schleich., und $\beta$. Friichte halb so gross: G. Vaillantii DC. G. infestum W.K. $-\gamma$. Friichte glatt. G. spurium $\mathbf{L}$.

8. G. uliginosum L. B. meist 6st., lineal.-lanzettl., stachelspitzig, 1nervig, an dem Rande u. Kiele rückwärts-stachelig-rauh; St. schlapp, 4eckig, riickwïrts-stachelig-raul ; Bthstiele blattwinkelst., zuletzt fast rispig; Bthstielchen nach dem Verblühen gerade; Früchte knotig-rauh; Bl. breiter als die entwickelte Frucht. 24. Moosige, torfhaltige Wiescn, an Gräben u. Teichen. Mai-Jul. BI. weiss.

9. G. parisiense I. B. meist 6st., lineal.-lanzettl., stachelspitzig, 1nervig, am Rande aufwärts stachelig-rauh; St. schlapp, sehr ästig, rückwärts stachelig-rauh; Bthstiele blattwinkelst., zuletzt fast rispig, gerade; Früichte körnig-raul, oder steifh.; Bl. schmäler als die entwickelte Frucht. $\odot$. Aecker; sïdl. u. westl. Schwz, Litt., Istr., Rhein- u. Moselthal, Sachs., Thüring. Jun.-Aug. Bl. grüngelbl., auswendig röthlich. Var. $\alpha$ : Frïchte borstig-steifl. G. parisiense I. G. litigiosun DC. - $\beta$.: Früchte körnig-rauh. G. anglicum Huds. 
10. G. palustre L. B. 4st., seltener 6st., lineal.-längl., vorne breiter, stumpf, grannenlos, 1nervig, am Rande rïckwärts-rauh; St. schlapp, ausgebreitet, 4eckig, rïckwärts-rauh; $R$. ausgebreitet; Bthstielchen nach dem Verblühien gerade, wagerecht-abstehend; Friichte glatt. 2. Gräben, Ufer. Mai-Jul. Bl. weiss.

IV. Rotte. Platygalium DC. Bthstand endst., rispig. Bth. zwitterig. Bthstiele nach dem Verblühen gerade. B. 3nervig.

11. G. rotundifolium L. B. 4st., oval, 3nervig; kurz-stachelspitzig, am Rande borstl.-rauh; St. schlapp, 4eckig, kahl od. kurzh.; $\boldsymbol{R}$. endst., gestielt, auseinander-fahrend, armblïthig; Frïchte borstigsteifh. 24. Haine u. schattige Wälder; selı zerstr. deh das mittlere n. südl. Geb., bis in die VorA. hinauf. Jul."Aug. Bl. weiss.

12. G. boreale L. B. 4st., lanzettl., 3nervig, grannenlos, am Rande rauh; St. aufrecht, steif, 4eckig, kahl od. flaumig, oberwärts rispig; Bthstielchen nach dem Verbliihen aufrecht-abstehend; Friichte filzig-steifh. od. kahl. 24. Haiden, Wälder, Waldwiesen. Jul. Aug. Bl. weiss. Früchte mit kurzen, aufrechten, an der Spitze hakigen Borsten. Var. $\beta$. intermedium: Früchte mit sehr kurzen, angedrückten Börstchen bestreut. - $\gamma$. hyssopifolizm: Früchte ganz kahl: G. hyssopifolium Hoffm.

13. G. $\mathrm{r}$ ubioides L. B. 4st., oval od. längl.-lanzettl., 3nervig, grannenlos, am Rande rauh; St. ausgebreitet, aufstrebend, kahl, oberwärts rispig; $\mathrm{R}$. verbreitert; Bthstielchen nach dem Verblühen aufrecht-abstehend; Frïchte kahl od. etwas flaumig. 24. Ufer, Wiesen; Krain. Mai. Jun. Bl. weiss.

V. Rotte. Eugalium DC. Bthstand endst., rispig od. quirlig. Bth. zwitterig. Bthstielchen nach dem Verblühen gerade. B. 1nervig. Der St. kahl od. rauhh., aber ohne rüekwärts-gekrümmte Stachelchen.

14. G. verum L. B. lineal., stachelspitzig, unterseits fast sammetig-faumig, die stengelst. 8- oder 12st.; St. aufrecht oder aufstrebend, steif, stielrund, 4rippig, flaumig-rauh; Aeste der R. abstehend, dichtbliuthig; Bthstiele nach dem Verblïhen fast wagerechtabstehend; Zpfl. der Bl. stumpflich, sehr kurz-bespitzt; Frichte glatt. 2. Wiesen, Triften, Waldränder. Jun.-Herbst. Bl. gelb. Var. B. oberseits rauh: G. verosimile R. u. S., und Bl. weissl.gelb: G. ochroleueum Wolf, nicht Kit.

15. G. purpureum L. B. lineal., sehr schmal, stachelspitzig, die stengelst. 8- od. 10st.; St. aufrecht, steif, rispig, selı ästig, stielrund, 4rippig, flaumig; Bthstielchen haarfein, nickend, fast traubig; Z/pfl. der Bl. kurz-bespitzt; Früchte glatt. 24. Steinige, unkultiv. O.; C. Tessin, südl. Tyrol, Litt. Jul. Aug. Bl. klein, blutroth.

16. G. sylvaticu m L. B. längl.-lanzettl., stumpf, stachelspitzig, am Rande rauh, die stengelst. 8st.; St. aufrecht, stielrund, stumpf- 
4rippig, kahl od. kurzh.; R. weitschweifig; Bthstielchen haarfein, vor der Bthezeit nickend, wach dem Verbliihen anfrecht-abstehend; Zpfl. der Bl. kurz-bespitzt; Frïchte kahl, etwas runzelig. 24. Wälder. Jun. Jul. Bl. weiss.

17. G. aristatum L. B. lanzettl., nach beiden Enden verschmälert, spitz, stachelspitzig, am Rande raul od. glatt, die stengelst. 8st.; St. aufrecht, 4 eckig; $R$. weitschweifig; Bthstielchen haarfein, vor u. nach der Bthezeit aufrecht, etwas abstehend; Zpft. der Bl. haarspitzig; Friichte glatt. 24. Gebirgige O. inter Gesträuch; Kärntlı., Stmk., siidl. Tyr., stidl. Schwz. Jul. Ang. Bl. weiss. Var.: B. am Rande kahl: G. linifolium Lmk.

18. G. insubrieum Gaud. B. vkteyf., abgebrochen-bespitztstachelspitzig, glanzlos, die stengelst. 6st., die an den Aesten 4st.; St. gestreckt, sehr ästig, 4eckig, kahl; Aeste armbth., mit einer einmal 3 gabeligen Dolde endigend; die abgeblihten Bthstielchen abstehend; Zpfl. der Bl. haarspitzig. 24. Felsige O.; C. Tessin. Jun.Aug. Bl. weiss.

19. G. Mollugo-I. B. lanzettl. od. vkteyf.lanzettl., stachelspitzig, unterseits glanzlos, die stengelst. meist 8st.; St. gestreckt od. aufrecht, 4 eckig, kahl od. kurzh.; Aeste der ausgesperrten $\boldsymbol{R}$. reichbth., die unteren wagerecht-abstehend; die abgehlühten Bthstielchen spreitzend; $\mathrm{Z}_{p} f$. der Bl. haarspitzig; Friichte kahl, etwas runzelig. 24. Wiesen, Wegeränder, Wälder. Mai-Aug. Bl. weiss od. gelbl.-weiss.

20. G. I и ci dum All. B. lineal., stachelspitzig, steif, spiegelnd, unterseits mit einem starken Nerven versehen, die stengelst. meist 8st.; St. aufrecht, 4eckig, kahl od. kurzh.; die unteren Aeste der längl. R. wagerecht-abstehend; die abgeblühten Bthstielchen spreitzend; Zpfl. der Bl. harrspitzig; Frichte kahl, etwas runzelig. 24. Felsige, unkultiv O.; südl. Schwz., sïdl. Tyr., Litt., Stmk., Unteröstr. MaiJul. Bl. weiss. Var.: $\beta$. B. weissl.-bereift: G. cinereum All.

21. G. г и bг и L. B. lineal.-lanzettl. od. lanzettl., stachelspitzig, 1 nervig, die stengelst. 6- od. 8st.; St. schlapp, gestreckt, 4eckig, kahl od. kurzh.; R. ausgebreitet, spreitzend; Bthsticlchen laarfein, gerade; Zpfl. der Bl. begrannt-haarspitzig; Früchte körnig. 24. Bergwiesen; südl. Tyr., Graubünd., Tessin. Jun. Jul. Bl. blutrotl, dann gelbl. Var.: Bl. weissl.: G. obliquum Vill.

22. G. saxatile L. B. meist 6st., stachelspitzig, 1nervig, die unteren vkteyf., die oberen umgekehrt-lanzettl.; St. 4 eckig, kahl, gestreckt, die blïthentrag. aufstrebend; Bth. ebenstränșsig-rispig; Bthstielchen aufrecht-abstehend; Zpfl. der Bl. spitz; Frïchte dicht-körnig-rauch. 24. Feuchte steinige Triften u. Felsen; im mittl. u. westl. Geb., u. torfhalt. Haiden des nördl. Jul. Aug. Bl. weiss. G. hercynicum Weig.

23. G. sylvestre Pollich. B. lineal. - lanzettl., vorne breiter, 
zugespitzt, stachelspitzig, 1nervig, die stengelst. meist 8st., die unteren vktey-lanzettf.; St. aus aufstrebender Basis aufrecht od. licgend, 4eckig, kahl od. kurzh.; Bth. ebenstränssig-rispig; Bthstielchen aufrecht-abstehend; Zpfl. der Bl. spitz; Früchte unmerklichkörnig. 2. Haiden, Waldränder, bis in die A. hinauf. Jun. Jul. Bl. weiss. Auf den A. niedrig, 2-3" hoch, R. kurz, 1-2mal gabelig, kaum länger als d. stiitzenden B.: G. supinum Lam.

24. G. pumilum Lam. B. lineal., v. der Mitte an pfrieml.verschmälert, bcgrannt, am Rande $u$. an d. Basis etwas verdickt, unterseits neben den starken Nerven 2furchig, die stengelst. 6- od. 8st.; die St. selır ästig, liegend, aufstrebend, 4eckig; Aeste ebensträussig-rispig u. nebst den Bthstielchen steif, diese aufrecht-abstehend; Zpfl. der Bl. spitz; Früchte fein-körnig. 24. Sonnige Hiigel; bei Wien die grössere Variet., die kleinere in Stmk. auf der Krebenzer A. bei St. Lamprecht u. im siidl. Tyr. Jun. Jul. Bl. weiss. Var.: dichtrasig: G. hypnoides Vill.; rauhh.: G. pusillum L.; grösser, 3-4" hoch: G. austriacum Jacq.

25. G. helvetic um Weigel. B. 6- od. 8st., fast nervenlos, flach, etwas fleischig, grannenlos od. kurz-stachelspitzig, die oberen lanzettl., spitz, die unteren od. alle vkteyf. od. spatelig, stumpf; St. sehr ästig, liegend, aufstrebend, Aeckig, kahl; Bthstiele doldig, endu. blattwinkelst., 1-3bth., ein wenig länger als die B.; Zpfl. der Bl. spitz; Früchte glatt. 24. Kiesige O. der A.; Schwz., Tyr., Salzb., Bayern, mit den Flïssen hinabsteigend. Jul. Aug. Bl. gelbl.-Treiss. G. baldense Spreng. G. rupicola Bertol.

\section{VAILLANTIA DC., Arten v. Valantia L. Vaillantie.}

1. V. muralis L. St. nebst den B. u. K. kahl. ○. Sonnige O., Mauern; Istr. Mai. Bl. griingelbl.

\section{Ordng. VALERIANEEN. DC.}

\section{VALERLANA L. Baldrian.}

a. Bth. gleichförmig.

1. V. exaltata Mikan. B. sämmtl. géfiedert, 7-10paarig, Blättchen lanzettl., gezähnt-gesägt; St. gefurcht; $W$. vielstengelig, Ausläufer fehlend. 24. Feuchte Wälder. Jul. Ang. Bl. fleischroth. V. officinalis $\alpha$. altissima K. syn. ed. 1. V. altissima Hornem. V. multiceps Wallr. Blühet 4 Wochen später als $V$. officinalis.

2. V. of ficinalis I. B. sämmtl. gefledert, 7-10paarig, Blättchen lanzettl., gezähnt-gesägt orl. ganzrandig; St. gefurcht; W. einstengelig, mit Ausläufern. 24. Wälder, feuchte O., Ufer, Hccken. Jun. Jul. 131. fleischıroth. Var. $\alpha$. major: St. höher, B. sämmtl. gezähnt. V. off. var. f. media K. syn. ed. 1. V. procurrens Wallr. 
- $\beta$. minor: B. ganzrandig od. dic unteren wenig-gesägt. V. angustifolia Tausch.

3. V. sambueifolia Mikan. B. sämmtl. gefiedert, 4-5paarig, Blättchen lanzettl. od. längl., gezähnt-gesägt; St. gefurcht; W. einstengelig, mit Ausläufern. 24. Feuchte Haine, Ufer; Schles., Böhm., Mähr., Oestr., Stmk., Hamburg. Jun. Jul. Bl. fleisehrotl.

4. V.Phu $\mathrm{C}$. WB. längl.-lanzettl., in den Bstiel versehmälert, ungeth. od. eingeschuitten, StB. gefiedert, 3-4paarig; Blättchen ganzrandig; St. stielrund; W. ohne Ansläufer. 24. Haine; zw. Verviers u. Limburg. Mai. Jun. Bl. weiss od. lıell-fleischroth.

b. Bth. ungleichf, auf einem Stocke derselben Art grösser, die Staubgef. länger als die BI., auf dem auderen kleiner, an manchen Arten um die Hälfte kleiner, die Staubgf. in der Bl. eingeschlossen.

5. V. dioica L. Die untersten WB. rundl.-eyf. od. elliptisch, die der nichtblühenden WKöpfe lang-gestielt, eyf., spitzl.; die unteren StB. leyerf.-fiederth., die oberen meist 3paarig, $Z$ pfl. lineal.; Ebensträusse endst.; Friichte kahl; W. ausläufertreibend. 2. Nasse Wiesen, bis in die VorA. Mai. Jun. Var. selten mit lauter ganzen StB. Bl. fleischroth.

6. V. tuberosa L. WB. elliptisch-längl., gesticlt; die unteren StB: leyerf.-ficderth., die oberen 3-4paarig, Kptl. lineal.; Ebensträusse endst.; Friichte beiderseits mit 2 seidenh.-flaunigen Linien; W. knollig. 2. Sonnige Hïgel, Bergwiesen; jenseits der A. in lirain u. im Littor. Mai. Bl. fleischrotl.

7. V. tripteris L. B. gezähnt, die untersten rundl., kürzergestielt, die der nichtblühenden WKöpfe herzf., lang-gestielt, die stengelst. 3zählig; Ebensträusse endst.; W. vielköpfig. 2. A., VorA. u. höhere Gbge, zerstr. deh das siidl. u. westl. Geb. Mai-Aug. Bl. weiss od. fleischroth. Var.: die StB. ungeth. V. intermedia Vahl.

8. V. montana L. B. etwas gezälnut od. ganzrandig, die untersten rundl., kürzer gestielt, die der nichtblühenden WKöpfe eyf., lang-gestielt, die stengelst. eyf., zugespitzt, die obersten lanzettl.; Ebenstrauss endst., zsgesetzt; W. vielköpfig. 24. A., VorA. n. höhere Gbge; zerstr. deh das siidl. u. westl. Geb. Mai-Aug. Bl. fleischroth.

9. V. supina L. B. gestielt, spatelig, ganzrandig od. etwas gezähnelt, gewimpert, das obere Paar lanzettl., sitzend; Ebenstrauss endst., kopfig; W. vielköpfig. 2. Feuchte O. der A.; Käruth., Tyr., Stmk., Fraelen u. Bernina in der Schwz. Jul. Aug. Bl. fleischroth.

10. V. saliunca All. B. ganzrandig, völlig kahl, vkteyf. od. längl., in den Bstiel verschmälert, die stengelst. sehr wenige, lineal.; Ebenstrauss endst., kopfig; W. vielköpfig. 24. Höhere A.; Fouly im Wallis, Mortrys im C. Freibg. Jul. Aug. Bl. fleischroth.

11. V. saxatilis L. B. ganzrandig od. etwas gezähnt, 3-5nervig, gewimpert, die wurzelst. längl.-spatelig, lang-gestielt, die 
stengelst. lanzettl.-lineal.; Ebensträusschen armbth., zuletzt locker, fast traubig-rispig; W. faserig-schopfig. 2. A. u. VorA. Jun. Jul. B1. weiss.

12. V. elongata L. B. eyf., völlig kahl, die wurzelst. gestielt, etwas gezähnt, die stengelst. sitzend, eingeschnitten-gezähnt; Ebensträusschen armbth., rispig-traubig; W. nicht schopfig. 24. Feuchte, felsige O. der A.; v. Tyr. bis Oestr. Jun. Jul. Bl. schmutziggelblich.

13. V. celtica L. B. ganzrandig, völlig kahl, die wuzelst. längl.lanzettl., in den Bstiel verschmälert, die stengelst. meist nur zwei, lineal.; Ebensträusschen quirlig-ährig; W. schuppig-schopfig. 2 . Höchste GranitA. Jul. Aug. Bl. trüb-gelbl., auswendig roth.

2. CENTRANTHUS DC. Spornblume.

1. C. angu stifo lius DC. B. lineal.-lanzettl. od. lineal, ganzrandig; Sporn viel kürzer als die Röhre, ungefähr so lang als der Fruchtkn. 24. Steinige O. am Creux du Van im Jura. Jul. Aug. Valeriana rubra $\beta$. L. Bl. purpurn.

2. C. ruber DC. B. ey- od. lanzettf., die obersten etwas gezähnt; Sporn viel kürzer als die Röhre, noch 1 mal so lang als der Fruchtkn. 4. Steinige 0.; südI. Schwz., südl. Tyr., Litt. Jul. Aug. Bl. purpurn.

3. VALERIANEILA Pollich. Feldsalat.

I. Rotte. Saum des K. aus kurzen, getrennten, wenig bemerklichen Zähnen gebildet.

1. V. olitoria Mönch. Früchte eyf.-rundl., zsgedrückt, beiderseits zicmlich platt, auf dem Rande mit einer Furche durchzogen, an den Seiten 2rippig, die eine Rippe sehr dünn; Saum des K. unmerklich-3zähnig. - - Gärten, Felder. Apr. Mai.- Valeriana Locusta olitoria L. Var. $\beta$. lasiocarpa: Friichte flanmig. Bl. weiss, in das Bläuliche od. Röthliclıe spielend, wie bei allen Arten.

2. V. carinat a Lois. Früchte längl., fast 4 seitig, auf der hinteren Fläche tief-rinnig, auf der vorderen ziemlich platt, in einen beiderseits hervorspringenden Rand verbreitert, in der Mitte und auf den Scitenflächen fein-1rippig; K. unmerklich-1zähnig. ○. Kultiv. O., besonders Weinberge; zerstr. dch d. Geb. Apr. Mai.

II. Rotte. Saum des K. aus sticlrunden, pfriemliehen, zuriekgekrümmten Zälınen gebildet.

3. V. e ch in at a DC. Früchte längl., fast 3seitig, 3furclig; Kelch aus 3; kegelf.-pfrieml., steifen, zurückgekrümmten Zähnen. ○. Kultiv. u. unkultiv. O.; Littor. u. wärmeres Krain. Apr. Mai. Valeriana echinata $\mathbf{L}$.

III. Rotte. Saum des K. krautig, schief-abgesehnitten, fast glockig, gezähnt, der hintere Zahn grösser.! 
4. V. eriocarpa Desv. Friichte eyf., linten convex, fein-3rippig, vorne ziemlich platt, mit einem ovalen, zwischen den erhabenen Ränderñ eingedrïckten Beete; Saum des K. v. der Breite der Frucht, glockig, schief-abgeschnitten, netzig-aderig, gezähnelt; Aestchen der Ebensträusschen dicht-gehäuft. $\odot$. Kultiv. O.; im Elsass, bei Zweibrücken, Trier u. Coblenz, Istr. Apr. Mai. Frucht behaart, od. $\beta$. lejocarpa: Frïchte kahl.

5. V. Moris oni i DC. Friichte ey.-kegelf., hinten convex, fein 3rippig, vorne ziemlich platt, mit einem länglichen, zwischen den erhabenen Rändern eingedrückten Beete; Saum des $K$. halb so breit als die Frucht, schief-abgeschnitten, spitz, gezähnelt; Aestchen der Ebensträusschen spreitzend. $\odot$. Aecker. Jul. Aug. Frïchte kahl: V. Morisonii $\beta$. lejocarpa DC: ; od. behaart: V. Morisonii $\alpha$. DC., V. mixta Dufresne, V. dentata Pollich, Fries.

6. V. Auricula DC. Früchte fast kugelig-eyf., fein-5rippig, vorne 1 furchig; Saum des K. ein Drittel so breit als die Frucht, in einen hinteren, längl., stumpfen Zahn schief-abgeschnitten, gezähnelt, die vorderen Zähnchen sehr klein. $\odot$. Aecker. Jul. Aug. Var.: Früchte kahl, od. $\beta$. lasiocarpa: beliaart, u. $\gamma$. dentata: vordere Zähnchen des K. etwas bemerklicher: V. dentata DC. Fedia tridentata Rchb.

IV. Rotte. Saum des K. becherf., glockig od. kugelig, läutig, aderig-netzig, in 6-12 an der Spitze borstliche Zähne sich endigend.

7. V. corouat a DC. fl. fr., nicht des Prodr. Friichte eyf., zottig; vorne 1 furchig; Saum des K. läutig, netzig-aderig, breiter als die Frucht, becherf., inwendig ganz kahl, bis iiber die Mitte 6sp., Zpfl. eyf., begrannt, an der Spitze hakig. $\odot$. Kínltiv. O.; südl. Tyr., Littor., Lïttich, Stettin, Göttingen. Mai-Jul. V. hamata Bast., DC. prodr. Fedia coronata Vahl. Die V. discoidea Lois., V. coronata DC. prodr., hat einen grösseren, inwend. rauhb. $K$.

8. V. vesicaria Moench. Frïchte fast kreiself., zottig; Saum des $K$. kugelig-aufgeblasen, häutig, netzig-aderig, an der Spitze 6zähnig, Zähne begrannt, gerade, wagerecht-einwärts-gerichtet. $\odot$. Kultv. O., um Lüttich. Mai-Jul. Valeriana Locusta $\beta$. vesicaria L.

\section{Ordng. DIPSACEEN. DC.}

\section{DÍPSACUS L. Karden.}

1. D. sylvestris Mill. B. sitzend, gekerbt-gesägt, am Rande kahl od. zerstreut-stachelig, die untersten an der Basis verschmälert, die stengelst. breit-zsgewachsen, ganz od. die mittleren fiedersp.; Hüllblättchen lineal.-pfrieml., bogig-aufstrebend; Spreublättchen biegsam, längl.-vkteyf., begrannt-haarspitzig, gerade, länger als die Bth. 
$\odot$. Felder, Wegeränder, Gräben. Jul. Aug. Bl. lila, selten weiss. Var. $\beta$. pinnatifidus: mittlere StB. fiedersp.

2. D. laciniatus L. B. sitzend, borstig-gewimpert, die untersten ganz, an der Basis verschmälert $u$. lappig-gekerbt, die übrigen fiedersp., die mittleren an der Basis breit-verwachsen; Hiillblättchen lanzettl.-pfrieml., steif, bogig-aufstrebend; Spreublättchen biegsam, längl., begrannt-haarspitzig, gerade, länger als die Bth. $\odot$. Feuchte Triften, Gräben; sehr zerstreut deh d. Geb. Jul. Aug. Bl. weissl.

3. D. Fullo n um Mill. L. B. sitzend, eingeschnitten-gekerbt, d. stengelst. breit-verwachsen, ungeth.; Hüllblättehen wagerecht-abstehend, an der Spitze etwas abwärts-gebogen; Spreublättchen steif, länglich, begrannt-haarspitzig, zurückgekrümmt, so lang als die Blkr. $\odot$. Kultiv. Jul. Aug. Bl. lila.

4. D. pilos us L. B. gestielt, an der Spitze des Bstieles geöhrelt; Hüllblättchen abwärts gerichtet, ungefähr v. der Länge der Bth.; Spreublïttchen vkteyf., begrannt-haarspitzig, borstig-gewimpert, gerade. $\odot$. Selattige Ufer, Haine; zerstreut deh das Geb. Jul. Aug. Bl. weiss.

2. CEPHALARIA Schrad. Cephalarie.

1. C. alp in a Schrad. B. gefiedert, flaumig; Fieder lanzettl, herablaufend, gesägt; Hüll- u. Spreublättchen ey-lanzettf., zugespitzt; Zähne des äusseren K. 8, pfrieml., fast gleich; Bl. gleich. 24. A. der südwestl. Schwz. Jun. Jul. Scabiosa alpina L. B1. gelblich.

2. C. transsylvanica Schrad. St. unterwärts nebst den B. zerstreut-behaart; B. gefiedert; Fieder etwas herablaufend, an den unteren B. längl., gesägt, die endst. sehr gross, an den StB. lineal.lanzettl.; Hüll- u. Spreublättchen ey-lanzettf., begrannt-haarspitzig; Zähne des äusseren K. 8, pfrieml., fast gleich; Bl. strahlend. 24. Weinberge, Ackerränder; Istr. Jul. Aug. Scabiosa transsylvanica L. Bl. lila od. weiss.

3. C. le u canth a Schrad. B. gefiedert; Fieder gezähnt od. fiedersp.; Hüllblättchen eyf., die äusseren abgerundet-stumpf, die inneren nebst den Spreublättchen spitz; äusserer K. mit einem trockenhäutigen, vielzähnigen Saume gekrönt. 2. Steinige O.; Krain, Litt. Jul. Aug. Bl. weiss. Scabiosa leucantha L.

\section{KNAUTIA Coult. Knautie.}

1. K. hybrida Coult. Dic unteren B. längl., an der Basis versclimälert, gekerbt-gesägt, ganz od. leyerf., d. oberen lanzettl.; der innere $K$. 4mal kürzer als die Frucht, meist 16zähnig. $\odot$. Hügel, Weinberge; Istrien, Osero. Jun. Jul. Scabiosa hybrida All. Bl. bläulich. Die Form mit ganzen B.: Seabiosa integrifolia I.

2. K. $10 n g$ ifolia Koch. B. verlängert-lanzettl., ganzrandig od. unmerklich-gezïhnelt, zugespitzt, ungeth.; St. v. kurzen Haaren sam- 
metig od. au der Basis kahl, nach der Spitze v. kurzen, drïsentrag. Haaren etwas klebrig, u. v. längeren steiflı.; der innere K. halb so lang als die Frucht, meist 8zähnig. 4. Triften d. A. Jun. Jul. Seabiosa longifolia W. K. Bl. lila.

3. K. sylvatica Dub. B. elliptisch-lanzetll, gekerbt, ganz od. an der Basis eingeschnitten; St. ziemlich kahl, an der Basis v. zwiebeligen Haaren steifh., oberwärts v. sehr kurzen, drüsenlosen Haaren flaumig $u$. v. längeren steifh.; der innere K. halb so lang als die Frucht, meist 8zähnig. 4. Gebirgswälder. Jun. Jul. Scabiosa sylvatica L. Bl. bläulich-roth. Exempl. mit breiteren B.: Scab. dipsacifolia Host.

4. K. arvenis Coult. StB. fiedersp., Zpfl. entfernt, lanzettl., ganzrandig, der endst. Lappen grösser, zugespitzt, etwas gesägt; St. $v$. sehr kurzen, drüscnlosen Haaren graulich u. v. längeren steifh.; der innere K. halb so lang als die Frucht, meist 8zälnnig. 4. Felder, Wiesen. Jul. Aug. Scabiosa arvensis L. Bl. bläulich-roth. Var. $\beta$. campestris: Köpfchen nicht strahlig. Scab. campestris Bess. - $\gamma$. rigidiuscula: ganz kahl, glänzend od. B. am Rande u. auf der Mittelrippe unten bewimpert, od. St. oberwärts flaumig u. steifl. Scabiosa Fleischmami Reichenb. - $\delta$. glandulifera: diesclbe, aber die StB. u. alle B. fiedersp., St. oberwärts flaumig u. mit Drüsenhärchen u. längeren einfachen besetzt. Scabiosa trivialis Reichenb. fl. exs. $\gamma$. u. $\delta$, ; in Krain.

\section{SUCCISA M. u. K. Abbisskraut.}

1. S. pratensis Moench. Köpfchen halbkugelig, die fruclittrag. kugelig; der äussere K. rauhh., Saum 4sp., Zpfl. eyf., spitz, stachelspitzig, der innere K. 5borstig; W. abgebissen. 24. Wiesen, Wälder. Aug. Sept. Scabiosa succisa L. Bl. blau.

2. S. a ustralis Reichenb. Die fruchttrag. Köpfchen längl.-eyf.; der äussere K. kahl, Saum 4lappig, Lappen kurz, stumpf, der innere K. ohne Borsten; W. kriechend. 24. Sumpfige O.; Monfalcone u. Aquileja, Kärnth., Stmk., Oberöstr. Aug. Scabiosa repens Brign. Bl. hellblau. Var. mit Borstchen am inneren $\mathbf{K}$.

\section{SCABIOSA. Röm. u. Schult. Scabiose.}

I. Rotte. Sclerostemma D. fl. Frucht mit 8 tiefen, spitzeingeschnittenen, auslaufenden Furchen, welche ebensoviele starke Riefen abtrennen. Krone des äusseren K. v. einfachen Nerven strahlig, am Rande schwach- $u$. klein-gekerbt.

1. S. gramuntia L. B. an den nichtbliihenden Wköpfehen längl., stumpf, an der Basis verschmälert, gestielt, gekerbt, ganz od. leyerf., die stengelst. bis auf die Mittelrippe doppelt- u. 3fach-fiedersp., Zpfl. der oberen B. lineal.; Frucht 8furchig, mit durchlaufenden Furchen; Borsten des inneren K. ungefälır so lang als die Krone des äusseren 
od. beinahe noch einmal so lang oder fehlend. 24. Grasige 0 .; südl. Tyr., Littor. Jun. Jul. Bl. blau. Var. u. agrestis: oberseits ziemlich kahl, od. weniger flaumig: S. agrestis WK., u. wenn die Borsten am inneren Kelche fehlen: S. lejocephala M. et K. - $\boldsymbol{\beta}$. mollis: untere B. dicht weich-flaumig: S. mollis Willd. $-\gamma$. tomentosa: überall dicht filzig: S. mollissima DC.

2. S. ochroleuca L. B. an den vichtblühenden Wköpfen längl., stumpf, an der Basis verschmälert, gestielt, gekerbt, ganz od. leyerf., die untersten stengelst. leyerf., dic iibrigen bis auf die Mittelrippe fiedersp., Fieder lineal., an den unteren B. fiedersp.-gesägt, an den obersten ganzrandig; Friichte 8furchig mit durehlaufenden Furchen; Borsten des inneren K. an d. Basis zsgedriickt, hervenlos, 3- od. 4 mal länger als die Krone des äusseren, hellbraun. -) u. 24. Gbge, unkultiv. O., zerstr. deh d. Geb. Jul. Aug. Bl. gelbl.-weiss, selten röthl. Wohl Variet. der folgenden Art.

3. S. columbaria L. B. an den nichtbliihenden Wköpfen längl. stumpf, an der Basis verschmälert, gestielt, gekerbt, ganz od. leyerf. die untersten stengelst. leyerf., die übrigen bis auf die Mittelrippe fiedersp., Fieder lineal., an den unteren B. fiedersp.-gesägt, an den obersten ganzrandig; Früchte 8furchig, Furchen durchlaufend; Borsten des inneren K. an der Basis zsgedrückt, nervenlos, 3- od. 4mal länger als $d$. Krone des äusseren K., braunschwarz. $\odot$ u. Z. Felder, trockene Hügel. Jun.-Herbst. Bl. blau.

4. S. lu ei d a Vill. B. an den nichtbliihenden Wköpfchen längl., an der Basis verschmälert, gestielt, gekerbt, ganz od. leyerf., die unteren stengelst. ganz od. an d.Basis.fiedersp., die oberen fiedersp., Zpfl.lanzettl.lineal., eingeschnitten-gesägt od.ganzrandig; Frucht 8furchig, mit durchlanfenden Furchen; Borsten des imneren K. an der Basis zsgedrückt, einwärts 1nervig-gekielt, 3-od. 4nial länger als die Krone des äusseren K. ๑. Triften der A., VorA., u. Schles., Mähr., Böhm. Gbge u. Voges. Jul. Aug. Bl. röthl.-lila. S. stricta WK. S. norica Vest.

5. S. Hladnikiana Host. B. der nichtblühenden Wköpfe u. die untersten des St. lïngl., an der Basis verschmälert, gestielt, gekerbt, die stengelst. leyerf., der endst. Lappen sehr gross, eyf., spitz, gesägt, die obersten fiedersp., $\mathrm{Z}_{\mathrm{p}}$ fl. lanzettl., eingeschnitten-gesägt, die endst. zsfliessend; Frucht 8furehig, mit dchlaufenden Furchen; Borsten des inneren K. 3- od. 4mal länger als die Krone des äusseren. 2. Gebirgige O.; in Krain, Istr. Aug. Sept." Bl. blau. Untere B. zur Bthezeit abgestorben, Gelenke entfernt.

6. S. s u aveolens Desf. B. der vichtblühenden Wköpfe u. die untersten stengelst. längl. od. lanzettl., ungeth., ganzrandig, die übrigen fiederth., 'Lpfl. lineal., ganzrandig; Frucht 8furchig, mit durehlaufenden Furchen; Krone des äusseren $K$. ungespalten, klein-gekerbt, Borsten ungeführ doppelt so lang als die Krone. 2. Hügel, Haiden; 
zerstr. deh das Geb. Jul.-Sept. S. canescens WK. BI. blau. Borsten strohfarben.

7. S. silenifolia WK. B. der nichtblühenden Wköpfe u. die unteren stengelst. vkteyf.-keilig, ungethcilt, ganzrandig, obere fiederth., Zpfl. lineal., ganzrandig, iler endst. sehr gross; Frucht 8furchig, Furchen auslaufend; Krone des äusseren $K$. bis zur Mitte 4lappig, Lappen zugespitzt, gekerbt; Borsten etwas länger als die Krone. 2. Felsige O.; bei Gottschee in Krain. Jul. Bl. hell-lila.

8. S. vestina Facchini. B. der nichtblühenden Whöpfe spatelkeilf., ungetheilt, ganzrandig, die stengelst. fiederth., alle Zpfl. lineal., ganzrandig; Frucht 8furchig, Furchen auslanfend; Krone des äusseren $K$. ungespalten, gekerbt, Borsten 4 mal so lang als die Krone. 4. Waldige 0 . in Thale Vestino u. in den Bergen v. Giudicarie: Bondon und Brixen, Facchini. Jul. Aug. Bl. blau. Borsten u. auch oft die Krone des K. schwarz-purp.

II. Rotte. Asterocephalus Coult. Trochocephalus D. ff. Frucht v. der Basis bis z. Mitte stielrund, glatt orl. schwach-rippig, dicht-zottig, oberhalb der Mitte in 8 säulenf. Zähne gespalten, die dch eben so viele Gruben getrennt und dch häutige, einwärtsgefaltete Anhängsel verbunden sind u. einen glockigen od. radf., häutigen, v. einfachen Nerven strahligen Saum tragen.

9. S. ucranica L. WB. lineal.-längl., gezähnt, die unteren stengelst. fiedertl., Zpfl. entfernt, lineal., ganzrandig, die oberen stengelst. lineal., fast ganz; Bl. strahlend; Früchte v. der Mitte bis z. Spitze grubig, an der Basis zottig, obervärts laahl; Borsten des inneren K. noch einmal so lang als die spitz-gezälnte Krone. $\odot$. Sandige 0 .; am Ufer des Meeres bei Monfalcone und Sagrado. Jul. Aug. Bl. weissl. od. bläulich.

10. S. graminifolia I. B. lineal. oder lanzettl.-lineal., ganzrandig, silber-seiterh.; Bl. strahlend; Friichte v. der Basis bis zur Spitze zottig; Borsten des inneren K. ein wenig länger als die gekerbte Krone. 2. Steinige unkultiv. O.; Krain, Görz, südI. Tyrol, Tessin. Jul. Aug. Bl. blau.

III. Rotte. Callistemma D. fl. Frucht wie bei der vorhergeh. Rotte, aber an der Basis von angedrückten Haaren flaumig, nicht zottig; Borsten des inneren K. 10, kämmig-wimperig.

11. S. multisieta Vis. Unterste B. vkteyf. od. leyerf, etwas gesägt, obere fiederth., ganzrandig; BI. strahlend; Früchte v. der Mitte grubig, an der Basis angedriiclit-flaumig, Borsten des inneren $K$. lineal.-pfrieml., zsgedrückt, kämmig-wimperig, noch einmal so lang als die spitz-gezähnte Krone. $\odot$. Grasige $O$. in südl. Istr. Mai Jul. Pterocephalus palaestinus $\gamma$. dalmaticus DC. Bl. weisslich, am Rande blau. 


\section{Ordng. COMPOSITEN. Compositae Adans.}

1. Unterordng. CORYMBIFEREN Vaill. Bth. alle röhrig, od. die des Randes zungenf. Gf. an der Spitze nicht verdickt und daselbst nicht bekränzt.

I. Unterabtheilung. Eupatoriaceen Lessing. Gf. der Zwitterbth. walzlich, zweisp., die Schenkel lang, fast stielrund oder etwas keulig, oberseits auswendig v. feinen Papillen flaumig; an den männl. Bth. ganz od. kurz zweisp., Schenkel keulig. Stbk. ohne Anhängsel.

1. Gruppe. EUPATORIEEN. Bth. alle zwitterig.

\section{EUPATORIUM L. Wasserdost.}

1. E. c annabinum L. B. gestielt, 3- oder 5th., Zpfl. lanzettl., gesägt, der mittlere länger. 2. Waldige, nasse 0 ., Bäche, Gräben. Jul. Aug. Bth. hell-purpurn.

\section{ADENÓSTYLES Cassin. Drüsengriffel.}

1. A. albifrons Reichb. B. nieren-herzf., grob-ungleich-doppelt-gezälınt, unterseits ctwas filzig; Köpfchen 3-6bth. 24. A., VorA. u. Sudet., Schwarzw., Voges. Jul. Aug. A. Petasites Bl. et Fing., DC. pr. Cacalia alpina $\alpha$. L. sp. C. albifrons L. fil. Bl. purpurn wie die folgenden. Var. wie die folg. mit Oehrehen an der Basis der Bstiele.

2. A. alpin a Bl. u. Fing. B. nierenf-herzf., fast gleich-gezähntgekerbt, unterseits auf den Adern flaumig; Köpfchen 3-6btl. 24. Triften der A. Jul. Aug. A. glabia DC. pr. Cacalia alpina $\beta$. L. sp.

3. A. hybrida DC. B. nieren-herzf., ungleich-fast-doppelt-gezähnt-gesägt, oben ziemlich kahl, unten filzig; Ebenstrauss etwas locker; HK. schwach-wollig-flaumig; Köpfehen 12-18bth. 2. A.; Wallis, Graubiind. Aug. Cacalia tomentosa $\beta$. hylurida Villars.

4. A. l c u c phyll a Reichb. B. nicren-herzf., fast gleich-gezähnt, beiderseits filzig; Ebenstrauss rundl., gedrungen; HK. wollig; Köpfchen 12-20bth. 2. Höchste Wallisèr A.; im Nicolaithale uiber Zermatten. Ang. A. candidissima Cass. Cacalia leucophylla Willd. C. tomentosa Vill.

\section{Gruppe. T'USSILAGINEEN Cassin. Bth. vielehig.}

\section{HOMOGYNE Cassin. Homogyne.}

1. H. sylvestris Cassin. $B$. herz-nierenf., gelappt, die mittleren Lappen 3zähnig. 2. Wälder d. VorA.; Kärnth., Krain, Stmk. Mai. Jun. Tussilago sylvestris Scop. Bl. purp.

2. IT. a $1 \mathrm{p}$ in a Cassin. B. herz-nierenf., gezälnt-gekerbt, unterseits auf den Nerven Alaumig. 24. Feuchte Triften der A., TorA. 
u. Gbge in Oberbaden, Mähr., Schles. Mai-Jun. Tussilago alpina L. Bl. purp.

3. H. discolor Cassin. B. herz-nierenf, geschweift-gekerbt, unterseits dicht-filzig. 2. Höchste A.; v. Tyrol bis Oestr. Mai-Jul. Tussilago discolor Jacq. T. alpina $\beta$. L. BI. purp.

4. TUSSILÁGO L. Huflattig.

1. T. Farfara L. 2. Fenchte O., Lelım- u. Kalkboden. März. Apr. Bl. gelb.

5. PETASITES Gärtn. Pestilenzwurz.

1. P. officinalis Mönch. 1797. B. herzf., ungleich-gezähnt, unterseits wollig-grau, die Lappen der Basis abgerundet; Strauss längl.; weibl. Btlı. fädl.; Narhen der Zwitterbth. kurz, eyf. 2. Ufer, feuchte O. März. Apr. Petasites vulgaris Desf. 1798., DC. pr. Bl. trübpurp. Zwitter; Strauss eyf.: Tussilago Petasites I. Weib; Strauss längl., Köpfchen halb so gross: Tussilago hybrida L.

2. P. alb us Gärtn. B. rundl.-herzf., winkelig, stachel-spitziggezähnt, unterseits wollig-filzig; Strauss eyf., od. gleich-hoch; weibl. Bth. fädl.; Narben der Zwitterbth. verlängert, lineal.-lanzettl., zugespitzt. 2. Feuchte O., Ufer, A. u. VorA., höhere Gbge. Mai. BI. gelbl.-weiss. Zwitter; Strauss eyf.: Tussilago alba L. Weib; Strauss längl.-eyf.: Tussilago ramosa Hoppe.

3. P. niveus Baumg. B. eyf.- od. fast 3eckig-herzf., ungleichstachelspitzig-gezähnt, unterseits schneeweiss-filzig, Lappen der Basis auseinanderfahrend, ganz od. fast 2lappig; Strauss eyf.; weibl. Bth. fädl.; Narben der Zwitterbth. verlängert, linealisch-lanzettl., zugespitzt. 2. Bäche der VorA. u. A. Apr. Mai. Tussilago nivea Vill. act. paris., T. frigida Vill. dauph. Weib: T. paradoxa Retz. Bl. weissl. od. röthl.

4. P. s p u ri us Reichenb. B. fast 3eckig-lıerzf., ungleich-gezähnelt, unterseits schneeweiss-filzig, Lappen der Basis vorne verbreitert-einwärtsgekrümmt, und 2-3lappig; Strauss fast ebensträussig; weibl. Bth. oberwärts breiter, fast zungenf.; Narben d. Zwitterbth. kurz, eyf. 24. Flussufer im nördl. Geb. Apr. Bl. weiss od. röthl. P. tomentosus DC. Tussilago spuria Retz. T. tomentosa Ehrh.

II. Unterabtheilung. Asterondeen. Gf. der Zwitterbth. walzl., zweisp., Schenkel lineal., auswendig fast flach, und oberwärts gleichu. kurz-flaumig.

III. Gruppe. ASTERINEEN. Stbk. an der Basis olme Anhängsel.

6. LINÓSYRIS DC. Linosyre.

1. L. vulgax is Cassin. B. lineal., kalıl; HK. locker. 24. Son- 
nige, felsige O.; zerstr. deh das Geb. Jul. Aug. Chrysocoma Linosyris L. K. syn. ed. 1. Bl. gelb.

7. ASTER L. Aster.

1. A. alpinus L. B. 3nervig, flaumig, ganzrandig, die stengelst. lanzettI., die wurzelst. längl., in den Bstiel verschmälert, die ersten spatelig; Blättchen des HK. lanzettl., locker; St. 1 köpfig. 24. Felsige O., Triften der A. u. VorA. u. Feldberg in Breisgau, Mährische Karpath., Sudet., Unterharz. Jul.-Sept. Strahl blau, Mittelfeld gelb, Köpfchẹn ansehnlich. Stärker behaarte Expl. bilden den A. hirsutus Host.

2. A. Amellus L. B. 3nervig, flaumig-rauh, die oberen längl.lanzettl., etwas gesägt od. ganzrandig, die unteren elliptisch, in den Bstiel verschmälert; Ebenstrauss einfach, abstehend; Blättchen des HK. abgerundet-stumpf, etwas abstehend. 24. Gebirgige, sonnige O.; zerstr. dch das siidl. u. mittl. Geb. Aug.-Oct. Strahl blau. Stärker behaart ist A. Amellus $\gamma$. hispidus Wallr. DC. pr.

3. A. Tripoli um L. B. ziemlich fleischig, kahl, lineal.-lanzettl., ganzrandig od. schwach-kleingesägt; St. an der Spitze od. v. der Basis ästig; Aeste ebensträussig; die inneren Blättchen des angedrïckt-dachigen $H K$. länger, stumpf. $\odot$. Meeresstrand u. salzhaltige O. Aug. Sept. Tripolinm vulgare Nees, DC. Aster pannonicus Jacq. Strahl blau. B. zuweilen schwach bewimpert.

4. A. brumalis Nees. B. umfassend, lanzettl., zugespitzt, am Rande rauh, die äusseren in der Mitte entfernt-geschärft-gesïgt; der St. traubig-pyramidal, die Aeste meist einköpfig; HK. locker, die Blättchen fast gleichlang, die unteren von der basis an abstehend. 4. Aus Nordamerika abstammend, an Flussufern hin u. wieder verwildert. Oct. Nov. A. Novi-Belgii Willd. Köpfchen ansehnlich, Strahl blau. Var. Aeste mehrköpfig, d. Köpfchen traubig.

5. A. Novi-Belgi i L. B. etwas umfassend, lanzettl.-spitz, oberseits am Rande hin rauh, die unteren in der Mitte entfernt-angedrückt-kleingesägt, die oberen der Bthstiele in die Blättchen des HK. übergehend; der St. ebensträussig, der Ebenstrauss zsgesetzt od. mehrfachzsgesetzt; HK. locker, Blättchen fast gleichlang, die äusseren fast v. der Basis an abstehend. 2. Aus Nordamerika, jetzt hin u. wieder an Ufern verwildert. Sept. Oct. A. serotinus Willd. Strahl lieblich röthlich-violett.

6. A. s a lignus Willd. Stengelst. B. sitzend, lanzettl., oberseits am Rande hin rauh, ganzrandig od. in der Mitte etwas gesägt, die Sägezähre wenige, abstehend, B. der Bthstiele wenige, linealisch, aufrecht; St. rispig, die Aeste an der Spitze und die Aestchen ebensträussig; $H K$. argedrückt-dachig, die Blättchen nur mit der äussersten Spitze etwas abstehend. 24. An Uferu; Elbe, Werra, Donau. Jul. Aug. Köpfchen $1^{\prime \prime}$ im Durclimesser. Strahl weiss, zuletzt lila. A. salicifolius Scholler. 
7. A. I e $\mathrm{u}_{\mathrm{c}} \mathrm{n}$ the mus Desfont. Stengelst. B. sitzend, lang, lanzettl.-lineal., verselmälert-zugespitzt, oberseits im Unfange rauh, ganzrandig od. in der Mitte etwas gesägt, Sägezähne beiderseits 13, klein, entfernt; B. der 13thstiele lineal., abstehend; St. rispig, Aeste tranbig, Aestchen $1 \mathrm{köpfig}$, die oberen an den $\Lambda$ esten 2-4köpfig; $H K$. angedrückt-dachig, die Blättchen nur mit der äussersten Spitze etwas abstehend. 2. Ans Nordamerika, jetzt an Ufern verwildert; Spree bei Berlin. Ang. Sept. A. dractinenloides IV. Strahl weiss, am Abbliihen an der Spitze bleich-röthl. Köpfehen 10" im Durchinesser.

8. A. parviflorus Nees. Stengelst. B. sitzend, lanzettl., zugespitzt, entfernt-kleingesägt, oberseits im Umfange rauh, an den Aesten lineal.-lanzettl., an den Bthsticlen viel kürzer, längl.-lanzettl., v. der Mitte gegen die Basis verschmälert; der St. rispig, $\Lambda$ ste 11 . Aestchen traubig; $H K$. angedrücht-dachig, die Blättchen $n u r$ mit der äussersten Spitze etwas austehend. 21. Aus Nordamerika, jetzt an Ufern verwildert; Main, Rhein, Elbe hin u. wieder. A. lanceolatus Lejeune bei Reichb. Fl. exsicc. Strahl weiss, am Abbliihen an der Spitze röthl.

8. GALATELLA Cass. Galatelle.

1. G. c a na Nees. B. lanzettl., stachelspitzig, ganzrandig, 3nervig, punktirt, beiderseits nebst dem St. gran-flaumig; St. oberwärts ebensträussig-rispig. 24. In einem sumpfigen Wäldchen bei Mönitz in Mähren. Aug. Sept. Aster canus WK. Strahl lila.

9. BELLIDIASTRUM Cass. Bellidiastrum.

1. B. Michelii Cass. 2. Kiesige u. fenchte O. der A., VorA., mit den Fliissen hinab, auf der Wiirtemb. Alp und dem Feldberge in Oberbad. Jun. Jul. Doronicum Bellidiastrum L. Strahl weiss od. röthl.

10. BELLIS L. Gänseblïmchen.

1. B. perennis L. Blättchen des HK. sehr stunf; B. vkteyf.spatelig, gekerbt, meist 3nervig; WV. kriechend. 2. Wiesen u. Triften. Blühet fast das ganze Jahr hindnrch. Man findet nicht selten einen beblätterten, aber liegenden St. Strahl weiss.

2. B. annua L. Blättchen des HK. stumpf; B. vkteyf.-spatelig, gekerbt, aderig; W. nicht auslïufertreibend. $\odot$. Wiesen in Istrien. Apr.-Jun. Der St. oft selır kurz, wie bei der vorhergehenden. Strahl weiss.

11. STENACTIS Cassin. Stenaktis.

1. S. bellidiflora Alex. Braun. St. am Ende ebensträussig; untere B. vkteyf., grob-gesägt, die oberen lanzettl., entfernt-gesägt, od. ganzrandig; HK. raulh. 24. Wälder, Zäune; zerstr. deh das 
Geb. Jul. Aug. S. annua Cass., K. syn. ed. 1. Pulicaria bellidiflora Vallr. Aster annuus L. Strahl weiss.

\section{ERÍGERON L. Berufkraut.}

1. E. can adensis L. St. steif, rispig; $R$. längl., reich mit Köpfchen besetzt; Aeste $u$. Aestchen traubig; B. kurzh., lineal., lanzettl., beiderseits verschmälert, borstig-gewimpert, die untersten entfernt-gesägt. $\odot$. Kultiv. O. u. Kies der Flüsse. Jul. Aug. Strahl weissl., klein.

2. E. a cris L. St. traubig, zuletzt fast ebensträussig; Aeste 13köpfig; B. 'entfernt, abstehend, lineal.-lanzettl., rauhh., die unteren in den Bstiel verschmälert; Strahl aufrecht, so lang als die Bthen des Mittelfeldes od. ein wenig länger; die immeren weibl., fädlichen Bth. zahlreich. (-) u. 2. Sonnige, unkult. O., Haiden. Jul. Aug. Strahl hellpurpurn od. weiss. B. wellig od. flach, untere zuweilen gesägt. Var.: Pappus röthl., Strahl etwas länger als das Mittelfeld: E. serotinus Weihe, bliihet aber nicht später.

3. L. dröbachensis Miller Fl. dan. St. traubig, zuletzt fast ebensträussig, Aeste 1-3köpfig; $B$. entfernt, abstehend, lineal., lanzettl., kahl, am Rande gewimpert, Wimpern aufwärts-gekrïmmt, die unteren B. in den Bstiel verscbmälert; Strahl aufrecht, so lang als die Bth. des Mittelfeldes od. ein wenig länger; die inneren weibl., fädl. Bth. zahlreich. $\odot$ u. 24. Kies der Bäche in den A. u. am Rheine bis Carlsruhe. Jul. Aug. E. angulosus Gaud. K. syn. ed. 1. E. elongatus Ledeb. Fl. altaic. Strahl purp. Ist vielleicht Variet. v. E. acris.

4. E. Villarsii Bellard. St. 2-3köpfig od. fast rispig; Aeste nebst den B. u. dem HK. drüsig-flaumig; B. längl.-lanzettl., die unteren in den Bstiel verschmälert; Strahl abstehend; die inneren weibl, röhrig-fädl. Bth. zahlreich. 24. Thäler der A.; Schwz. auf der Stockhornkette u. den Wallisser A., südl. Tyr., Kärnth. auf der Pasterze. Jul. Aug. Strahl purpurn. E. atticum Vill. E. rupestris Hopp.

5. E. a l pinus L. St. 1-armköpfig; B. lanzettl., rauhh., die unteren in den Bstiel verschmälert, etwas spatelig; Strahl abstehend, noch einmal so lang als die Bth. des Mittelfeldes; HK. rauhh.; die inneren weibl., röhrig-fädl. Bth. zahlreich. 24. Kiesige O. der A. Jul. Aug. Strahl purpurn, selten weiss. - E. grandiflorus Hoppe, mit doppelt grösseren Köpfchen, Variet.?

6. E. g labratus Hopp. u. Hornsch. St. 1-armköpfig; B. lanzettl., kahl, kurzh.-gewimpert od. raulh., die unteren in den Bstiel verschmälert, etwas spatelig; Strahl abstehend, noch einmal so lang als die Bth. des Mittelfeldes; HK. flaumig-kurzh.; weibl. Bth. sämmtl.

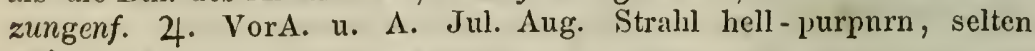
weiss. 
7. E. un iflorus L. St. 1köpfig; B. lanzettl., rauhl., die unteren in den Bsticl versehmälert, etwas spatelig, kahl werdend; Strahl abstehend, noch eimmal so lang als die 13th. des Mittelfeldes; $H K$. dicht-wollig-rauhh.; weibl. Bth. sämmtl. zungenf. 2. Grasige O. der A. Jul. Aug. Strahl weiss od. hellpurpurn.

\section{SOLIDÁGO I. Goldruthe.}

1. S. Virga a urea L. St. anfrecht, an der Spitze rispig-traubig, od. 1fach-traubig; Tr. aufrecht; B. ey- u. lanzettf., zugespitzt, in den gefligelten Bstiel herablaufend, ziemlich harrig, die unteren gesägt. 24. Wälder, buschige O. Jul. Aug. BI. gelb. Var. $\alpha$. vulgaris: höher; die unteren B. gesägt, elliptisch, die oberen lanzettl., ganzrandig; Aeste nebst den Bthstielehen flaumig; steht gleichsam zw. den 2 folg. Variet. in der Mitte. - $\beta$. angustifolia: höher; $B$. sämmtl. lanzettl., undeutlicher gesägt od. ganzrandig; scheint Var. $\beta$. ericetorum DC. prodr. - $\gamma$. latifolia: die StB. stämmtl. eyf.; Bthstielehen an der Spitze mit häutigen Deckblättchen; südl. Schwz., sïdl. Tyrol, Triest. - $\delta$. alpestris : niedrig; $B$. lanzettl. od. elliptisch-lanzettf., fast kahl, dic unteren Tr. oft kürzer als das sie stützende B.; Köpfchen grösser. S. alpestris WK. Höhere Gbge u. A. - $\varepsilon$. cambrica: St. niedriger, manchmal 3--4 Zoll hoch, u. sodann mit einer einfachen Tr. endigend; Köpfchen noch einmal so gross; B. längl.lanzettl., beiderseits haarig; Aeste nebst den Bthstielchen kurzh.-flaumig: S. Virgaurea $\gamma$. pumila Gaud., $\gamma$. cambrica Sm. S. cambrica Huds. Schwz., siidl. Tyrol.

IV. Gruppe. TARCHONANTHEEN. Less. Stbk. mit Anhängsel. Pappus mit getrennten Strahlen od. fehlend. Bth. des Randes weibl., des Mittelfeldes männl. od. steril.

\section{MÍCROPUS L. Falzblume.}

1. M. erectus L. B. weehselst., lanzettl.; Bth. wollig; HK. wehrlos. $\odot$. Unkultiv. Felder; Littor., Istr. Jun. Jul. Bl. gelbl.-weiss.

15. EVAX Gärtner. Evax.

1. E. pyg in a a Pers. BthB. vkteyf., stumpf. $\odot$. Sonnige, felsige $\mathrm{O}$. am Meere der Insel Cherso. Jun. Jul. Bl. schmutzig-weiss. Filago pygmaea L.

V. Gruppe. BUPHTHALMEEN. Stbk. mit Anhängsel. Pappus kronenf.

16. TELEKIA Baumg. Telekie.

1. T. speciosa Baumg. B. gestielt, herzf., doppelt-gesägt, die obersten sitzend, an der Basis abgerundet od. herzf.-stengelumfassend. 7. Gebirgige 0 ; Marslavadiza bei Fiume, im Rauschengrund bei 
Oberleitensdorf in Böhmen. Aug. T. cordifolia DC. pr. Buphthalmum speciosum Schreb. B. cordifolium W. K. Bl. gelb.

17. BUPHTHALMUM L. Rindsange.

1. B. s peciosissimum Arduin. B. spitz-gezähnt, netzig-aderig, kahl, gewimpert, herzf.-stengelumfassend, die oberen eyf., zugespitzt, die unteren längl.-eyf., nach der Basis verschmälert; Blättchen des HK. lineal.-lanzettl., verschmälert-spitz, die äusseren länger als das Mittelfeld; Achenen an der Spitze flaumig. 2. Kalkfelsen zw. der Grenze v. Bondon u. Giudicari u. Valle di Vestino südl. Tyrol. Jun. Jul. Telekia speciosissima DC. pr. Bl. gelb, wie der folgenden.

2. B. salicifolium L. B. längl. u. lanzettl., etwas gezähnelt, flaumig, die unteren stumpf, in den Bstiel verschmälert, die oberen sitzend, verschmälert-spitz; Blättchen des HK. lanzettl., haarspitzig, so lang als die Bth. des Mittelfeldes; Achenen kahl. 2. Gebirgige O., auf Kalk im sïdl. u. im östl.-mittleren Geb. Jul. Aug. Var. ß angustifolium: die unteren B. lanzettl., die oberen lang-verschmälertspitz. B. grandiflorum L.

18. ASTERISCUS Tournef. Sternange.

1. A. a,qu a ticus Lessing. B. längl.-lanzettl., stumpf; Köpfchen gabelst., sitzend, u. endst.; Blättchen des $H K$. viel länger als der Strahl, stumpf, wehrlos; Achenen seidenh. $\odot$. Brachäcker; Littor. Istrien. Jul. Aug. Buphthalmum aquaticum L. Bl. gelb.

19. PALLÉnis Cass. Pallenis.

1. P. spinosa Cass. $\odot$. Brachfelder; bei Fiume, auf Cherso. Jun.-Ang. Buphthalmum spinosum L. Aehnlich dem Buphthalmum aquaticum, aber höher, wollig-zottig; Blättchen des HK. mit einem Dorne endigend. Bl. gelb.

VI. Gruppe. INULEEN. Cassin. Staubk. mit Anhängsel. Pappus mit getrennten Strahlen. Bth. des Randes weibl., des Mittelfeldes zwitterig.

\section{0. ÍNULA. ¿Alant.}

I. Rotte. Corvisaria Merat. Die inneren Blättchen des HK. an der Spitze verbreitert, spatelig. Bl. gelb.

1. I. Helenium L. B. ungleich-gezähnt-gesägt, unterseits fil$z i g$, die wurzelst. gestielt, elliptisch-längl., die stengelst. herz-eyf., zugespitzt, stengelumfassend; die äusseren Blättchen des HK. eyf., die inneren lineal.-spatelig; Achenen kahl. 2. Feuchte Wiesen, Gräben; nördl. Geb. u. Schles., Mähr. Jul. Aug.

II. Rotte. Enula Dub. Die inneren Blättchen des HK. am Ende zugespitzt. Bl. gelb. 
a. Achenen kahl.

2. I. german ica L. B. längl.-lanzettl. od. längl., spitzl., entfernt-gezähnelt, aderig, unterseits wollig-haarig, am Rande rauh, die stengelst. an der Basis herzf.; Ebenstrauss zsgesetzt, geknäuelt-vielköpfig; Blättchen des fast walzl. HK. aut d. Rüeken wollig-flaumig; Zungenbth. kaum länger als die des Mittelfeldes; Achenen kahl. 24. Steinige Hügel; Oestr., Böhm., Mähr., Thuiring., Frank., Mittelrhein. Jul. Aug.

3. I. media MBBiebst. B. lanzettl., spitz, entfernt-gezähnelt, aderig, unterseits etwas haarig, am Rande gewimpert-rauh, die stengelst. an der Basis herzf.; Ebcnstrauss fast einfach, gedrungen, vielköpfig; Blättchen des etwas bauchigen HK. ziemlich kahl, gewimpert; Zungenbth. ungefähr noeh eimmal so lang als die des Mittelfeldes; Achenen kahl. 24. Bergwiesen; Rheinpfalz bei Laubenheim u. zw. Kreuznach u. Bingen, bei Halle in Thüring. Jul. Aug.

4. I. hybrida Baumgart. B. schmal-lanzettl., spitz, entfernt-unmerklich-gezähnelt od. ganzrandig, nervig-aderig, kahl, am Rande rauh u. etwas wollig, die stengelst. sitzend; Ebenstrauss meist 5köpfig, gedrungen; die äusseren Blättehen des HK. auf dem Rüeken u. dem Rande etwas zottig; Achenen kahl. 2. Auf dem Kahlenberge bei Wien. Jul. Aug.

5. I. en sifolia L. B. lanzettl.-lineal., spitz, entfernt-unmerklichgezähnelt u. ganzrandig, nervig, kahl, am Rande rauh u. fast wollig, die stengelst. sitzend; St. 1-mehrköpfig; Köpfehen einzeln, endst.; HK. v. 3-6 lanzettl., nervigen B. v. der Länge des HK. selbst umgeben; Achenen kahl. 24. Steinige O.; südl. Tyr., Littor., Krain, Unteröstr., Mähren. Jul. Aug.

6. I. salicina L. B. lanzettl., zugespitzt, eutfernt-unmerkliehgezähnelt od. ganzrandig, aderig, kahl, am Rande rauh, die oberen herzf.-stengelumfassend; St. 1-melurköpfig, fast ebensträussig; Blättehen des HK. kahl, gewimpert; Achenen kahl. 2. Feuchte Wiesen, Gräben. Jul. Aug. Var. Stengel u. Bl. kurzhaarig.

7. I. squarrosa L. B. oral od. lanzettl., gezälnelt, aderig, kahl, am Rande gewimpert-rauh, mit abgerundeter Basis sitzend; St. 1-mehrköpfig, fast ebensträussig; Blättehen des HK. kahl, gewimpert, die äusseren allmählig kïrzer; Achenen kahl. 24. Hügel, Berge unter Gesträuch; Tessin, Littor., Krain,. Unteröstr. Jul. Aug. I. Bubonium Jaeq. - Form mit eylanzettl. B. ist I. germaniea Vill., Lam. u. DC. fl. franç.; Form mit gedrungenem Ebenstrauss am Ende des St.: I. spiraeifolia L. u. DC.

8. I. birta L. B. oval, längl. od. lanzettl., ganzrandig od. etwas gezähnelt, aderig u. nebst dem St. v. an der Basis zwiebeligen Haaren rauhh; St. köpfig; Blättchen des $H K$. lanzettl., verschälert, steifh., sämmtl. länger als die Bth. des Miltelfeldes; Achenen kahl. 2. Son- 
nige, steinige Hügcl; sehr zerstr. dch das Geb. Mai. Jun. I. montana Pollich.

9. I. Vaillantii Vill. B. elliptisch-lanzettl, zugespitzt, ganzrandig od. etwas gezälnnelt, unterseits nebst den $H K$. filzig, die wurzelst. gestielt, die stengelst. an der Basis verschmälcrt, etwas gestielt; Achenen kahl. 24. Feuchte O., Flussufer; südwestl. Schwz. Aug. Sept. I. cinerea Lam.

b. Achenen rauhh. od. flaunig.

10. I. Con y z a DC. B. elliptisch od. elliptisch-lanzettl., spitzl., oberseits flaunig, unterseits wie der St. dünn-filzig, die unteren gestielt; St. oberwärts rispig-ästig; Aeste ebensträussig, reichköpfig; Blättchen des ITK. abstehend-zuriickgebogen; Bth. des Randes 3sp., kaum zungenf., $v$. der Länge des $H K$. $\odot$. Unkult. u. waldige $\mathrm{O}$. Jul. Aug. Conyza squarrosa L. K. syn. ed. 1.

11. I. s u a ve ole n s Jacq. B. elliptisch-lanzettl., spitz, unlerseits filzig, auf dem Mittelnerven, dem Rande, so wie der St. zottigwollig, die unteren gestielt, entfernt gezähnelt, die oberen nach der Basis verschmälert, ganzrandig; der St. an der Spitze ebensträussig, Aeste 1-3köpfig; Blättchen des HK. abstehend-zurïckgebogen; Bth. des Randes zungenf., lïnger als der HK.; Actienen kurzh. 24. Feuchte O.; beilonfaleone, neuerdings nicht wiedergefunden. Jul. Aug.

12. I. Oeulus Christi L. B. längl., stumpfl., ganzrandig od. etwas gezähnelt, nebst dem St. filzig, wollig, die unteren in den Bstiel verschmälert, die oberen mit herzf. Basis stengelumfassend; Blättchen des $H K$. lanzettl., die äusseren allmählig kürzer, zottig; St. 2-5köpfig; Achenen kurzh. 24. Sonnige, unkultiv. O.; Unteröstr. ı. Mähr. Jun. Jul.

13. I. britannie a L. B. lanzettl., ganzrandig od. gezähnelt, unterseits nebst dem St. zottig-wollig, die unteren in den Bstiel verschmälert, die oberen mit herzf. Basis stengelumfassend, oft an der Basis rleutlicher gezähnt; Blättchen des $H K$. lineal.-lanzettl., verschmälert, die äusseren so lang als die inneren $u$. das Miltelfeld od. länger; St. 2-vielköpfig; Achenen kurzh. 24. Feuehte Triften, Gräben; zerstr. dch das Geb. Jul. Aug. Var.: etwas kahler: I. Oetteliana Rchb.; u. ohne Strahl.

14. I. montana L. B. lanzettl, ganzrandig u. etwas gezälınelt, nebst dem St. zottig-wollig, etwas seidenh., die unteren gestielt, an der Basis verschmälert, die oberen sitzend; St. 1 köpfig; die äusseren Blättehen des HK. an der Spitze filzig-kurzh., allmählig kürzer; Achenen kurzh. 4. Gebirgige O.; siidl. Sehwz. Jul. Aug.

15. I. erith mo ides I. B. lineal., fleischig, die stengelst. stumpf, 3zackig, die astst. ganzrandig. 4. Am Meere bei Triest u. Aquileja. Jul. Aug. I. crithmifolia Willd. 
16. I. graveolen s Desf. Flaunig, klebrig; St. fast v. der Basis an sehr ästig; Aeste ruthenf., traubig, aufrecht- etwas abstehend; B. fast lineal., ganzrandig. $\odot$. Fenchte Aecker in Istrien. Aug. Sept. Erigeron graveolens L. Solidago graveolens Lam. K. syıı. ed. 1.

21. PULICARIA Gärtn. Flohkraut.

1. P. vulgaris Gärtn. B. längl-lanzettl., wellig, mit abgerundeter Basis sitzend, fast stengelumfassend, die jïngeren nelsst dem St. zottig; St. rispig-ebensträussig; Köpfehen seiten- u. endst. Strahl sehr kurz. $\odot$. Feuchte, unkultiv. O. Jul. Ang. Inula pulicaria L. BI. gelb, wie der folgenden.

2. P. dysenterica Gärtn. B. längl., mit breiterer, tief-herzf. Basis stengelumfassend, schwach gezähnelt, unterseits gran-filzig; Köpfchen an den St. u. Aesten ebensträussig; Strahl viel länger als die Bth. des Mittelfeldes. 24. Feuchte Wiesen, Gräben; zerstr. deh das Geb. Jul. Aug. Inula dysenterica L.

3. F. viscos a Cassini. B. lanzettl., gesägt, nebst dem St. flaumig u. klebrig; Trr. endst., pyramidenf., an der Basis etwas zsgesetzt. 2. Steinige O.; Triest, Fiume. Jul. Ang. Erigeron viscosum L. Inula viscosa Ait., DC.

III. Unterabtheilung. Senecromideen. Iess. Gf. der Zwitter walzl., Schenkel lineal., an der Spitze pinselig u. gestutzt, od. über dem Pinsel mit einem kurzen Kegel od. einem verlängerten, schmalen, rauhh. Anhängsel versehen.

VII. Gruppe. HELENIEEN. Cassin. Stbk. ohne Anhängsel. Pappus aus mebreren Spreublättchen bestehend.

\section{GALINSóGA Ruiz et Pavon. Galinsoge.}

1. G. parviflor a Cavanilles. Ziemlich kahl; Fruchtb. kegelf.; Pappus aus 8-16 Sprenblättchen. $\odot$. Aus Peru stammend, nun an vielen Orten ein lästiges Unkraut. Jul. Ang. Wiborgia Acmella Roth. K. syn. ed. 1. Strahl weiss.

VIII. Gruppe. HELIANTHEEN. Lessing. Stbk. ohne Anhängsel, schwärzlich. Pappus fehlend od. begrannt, od. kronenf.

23. BDENS L. Zweizahn.

1. B. tripartita L. Köpfchen scheibenbth.; die äusseren Blättchen des HK. länger als die Köpfchen; B. 3th. od. fiederig-fünfsp., Zpfl. lanzettl., gesägt; Achenen vkteyf., am Rande riickwärts stachelig, so lang als die äusseren Blättchen des HK. $\odot$. Sumpfige O., Gräben. Jul._Oct. Var. selten mit stralıligen Köpfehen. Bl. gelb, wie der folgenden.

2. B. cernua L. Köpfchen scheibenbth. od. strahlig, nickend; die äusseren Blättclıen des HK. länger als d.Köpfchen; B. lanzettl., 
gesägt, an der Basis etwas zsgewachsen; Achenen vkteyf.-keilig, am Rande rückwärts-stachelig, ungefähr so lang als die inneren Blättchen des HK. ๑. Sumpfige O., Gräben. Aug.-Oct. Kleine 2-3" hohe Expl.: B. minima L. Var. $\beta$. radiata: mit strahligen Köpfchen. Coreopsis Bidens L.

3. B. bipinnata L. Köpfehen etwas strahlig; die äusseren Blättchen des HK. v. der Länge der inneren; $B$. doppelt-gefiedert; Blättchen eingeschnitten; Achenen lineal., nach der Spitze verschmälert, am Raude glatt, noch einmal so lang als der $H K$. $\odot$. Ackerränder, Felder, im sïdlichsten Tyrol eine Landplage nach Facchini, bei Botzen selten. Jun.-Herbst.

\section{HELIANTHUS L. Sonnenblume.}

1. H. aunuus L. B. sämmtl. herzf., 3nervig, gesägt; Bthstiele verdickt; Köpfcheu nickend. ○. Aus Peru; als Oelgewächs kultiv. Jul.-Herbst. Bl. gelb.

2. H. $t u$ beros us L. B. 3fachnervig, gesägt, rauh, die untereu herz-eyf., die oberen längl.-eyf. od. lanzettl., zugespitzt, wechselst. 7. Aus Brasilien, zum ökonom. Gebrauche kultiv. Oct. Nov. Bl. gelb.

IX. Gruppe. GNAPHALIEEN. Stbk. mit Anhängsel.

\section{CARPESIUM L. Kragenblume.}

1. C. c ernuum L. Köpfchen einzeln, endst., überhängend. $\odot$. Feuchte O. u. Haine; Oestr., Krain, südl. Tyr., siidl. Schwz. Jul. Aug. Bl. gelb.

2. C. abrotanoides L. Köpfehen blattwinkelst., fast traubig, einseitswendig. $\odot$. Wälder um Aquileja u. Monfalcone. Jul. Aug. Bl. gelb.

\section{FILÁGO L., Fries. Fadenkraut.}

1. F. germanica L. Filzig-wollig; St. gabelsp.; B. lanzettl.; Köpfchen geknäuelt, Knäuelchen gabel- u. endst.; Blättchen des $H K$. haarspitzig, Haarspitze kahl. ○. Aecker, Felder. Jul. Aug. Bl. gelblich-weiss, wie der folgend. Var. mit gelb-graulichem Blattfilze u. oft röthlichen Haarspitzen des HK. u.: $\beta$. pyramidata, mit weissem Blattfilze u. meist bleichgelben Haarspitzen des HK.: Filago pyramidata Gaud. u. der deutsch. Aut., nicht L., F. germanica $\beta$. pyramidata DC. pr.

2. F. arvensis L. Dicht-wollig; St. rispig; Aeste aufrecht, beinalie einfach, fast ährig; Knäuelchen seiten- u. endst.; 13. lanzettl.; Blättchen des HK. stumpflich, wollig, an cler Spitze zuletzt kahl. ○. Felder, Haiden. Jul. Aug. F. arvensis DC. pr. F. arvensis u. montana L. fl. suec. et herbar. F. montana Wahlenb.

3. F. minima Fries. Filzig, etwas wollig; der St. ästig; Aeste gabelsp.; Kinäuclcheu gabcl-, seiten- u. endst., länger als die B.; B. 
lineal.-lanzettl., aufrecht und angedrüickt; Blättchen des HK. ziemlich stumpf, an der Spitze kahl. - . Accker, Sandfelder. Jul. Ang. F. arvensis Wahlenb. F. montana L., nach den Synon., DC. u. den meisten Autoren.

4. F. gallica L. Filzig, fast seidenh.; St. ästig; Aeste gabelsp.; Knäuelchen gabel-, seiten- u. endst.; $B$. lineal.-pfrieml., länger als die Knäuelchen; Blättchen des HK. stumpflich, an der Spitze kahl. $\odot$. Aecker; Wallis, Basel, Elsass, Rheinpfalz, Halle, Böhm. Jul. Aug.

\section{GNAPHALIUM L. Ruhrkraut.}

I. Rotte. Gnaphalion. Köpfehen 1häusig. Bth. des Randes weiblich, die des Mittelfeldes zwitterig. Pappus aller Bth. fädlich, od. an der Spitze nur wenig verdickt.

1. G. sylvaticum L. St. einfach, ruthenf, ährig; WB. lanzettl.; StB. allmählig kleiner, die oberen lineal., sämmtl. spitz, nach der Basis verschmälert, unterseits weissfilzig, oberseits zuletzt kahl werdend; die äussersten Blättchen des HK. 3 mal kürzer als das Köpfchen. 2. Haiden, lichte, waldige O. Jul. Aug. G. rectum Smith. G. sylvaticum $\alpha$. Wahlb. Bl. gelbl.-weiss.

2. G. n orvegicum Gunner. St. einfach, aufrecht, ährig; $B$. lanzettl., oberseils dünn-, unterseits dicht-filzig, in einen kurzen Bstiel allmählig verschmälert, dreinervig, die mittleren stengelst. zugespitztstachelspitzig, von der Länge der unteren u. länger; die äussersten Blättchen des HK. 3 mal kürzer als das Köpfchen. 24. A., VorA. u. Schles. u. Mähr. Gbge u. Voges. Jul. Aug. G. sylvaticum Sm. G. sylvaticum $\beta$. fuscatum Wahlenb., DC. prodr.

3. G. Hoppe an um Koch. St. einfach, aufrecht, an der Spitze ährig; B. lanzettl., an der Basis undeutlich 3nervig; auf heiden Seiten dicht-filzig, die mittleren stengelst. spitz, in einen Bstiel fast v. der Länge des $\mathrm{B}$. verschmälert, so lang als die unteren od. län$g \in r$; die äussersten Blättchen der HK. 3mal kürzer als das Köpfchen. 2. A., VorA. u. höhere Mähr. u. Schles. Gebge u. Erzgebg. Jul. Aug. G. supinum Hoppe bei Sturn D. Fl. H. 38. Bei den anderen Autoren Variet. v. norvegicum.

4. G. supinum L. St. einfach, fast fädl.; Stämmchen kricchend, dicht-rasig; B. sämmtl. schmal-lanzettl. od. lineal., wolligfilzig; Köpfchen kurz-ährig, od. fast traubig od. cinzeln an der Spitze des St.; die äussersten Blättchen des HK. länger als die Hälfle des Köpfchens. 24. Felsige, befeuchtete O. der A. u. Sudet. Jul. Aug. G. pusillum Haenke. Bl. gelbl.-weiss. Var. $\alpha_{.}$: Köpfechen an der Spitze des St. sitzend, kurz- u. dicht-ährig. G. supinum Willd. Pers. G. supinum $\alpha$. Wahlenb. - $\beta$.: Köpfchen gestielt, fast traubig. G. fuscum Scop. Willd. G. pusillum $\gamma$. fuscum Pers. $\gamma$. : die St. 1köpfig. G. pusillum Willd. G. supinum $\beta$. pusillum Pers. 5. G. uliginosum L. St. v. der Basis an ästig, ausgebreitet; 
B. lanzettl.-lineal., nach dex Basis verschmälert, graulich; Köpfchen knäuelig-gchäuft, beblättert. $\odot$. Feuchte O., Gräben. Bl. gelb-weiss, Achenen glatt. Var. $\beta$. pilulare: Achenen kurz-weich-stachelig. G. pilulare Wahlenb. Dieses in der Gegend v. Stettin. $-\gamma$. glabrum: die ganze Pfl. kahl, die Achenen glatt. G. nudum Hoffm. Dieses in Westphal., Hamnov., Oldenbg.

6. G. luteo-album L. St. einfach od. an der Spitze ästigebensträussig; Köpfchen geknäuelt, blattlos; B. lanzettl., beiderseits wollig-flaumig, halbstengelumfassend, die unteren vorne breiter, stumpf, die oberen nach der Spitze verschmälert. $\odot$. Felder, Haiden. Jul. Aug. HK. gelbl.-silberfarben. Bl. triib-röthl.

II. Rotte. Le o nto podium. Köpfchen 1häusig. Bth. des Randes weiblich, mit fädlichem Pappus; die des Mittelfeldes zwitterig, mit an der Spitze verdicktem Pappus.

7. G. L e on to podium Scop. St. ganz einfach; Köpfehen endst., ebensträussig-gehäuft; Ebenstrauss strahlig durch dichtwollige B., welche länger als das Köpfchen sind. 2. Sonnige Triften der A. Jul. Aug. Filago Leontopodium L. Leontopodium alpinum Cass., DC. Bl. grün-gelbl.

III. Rotte. Antennaria Gärtı. Köpfchen 2häusig; die zwitterigen mit einem an der Spitze verdickten Pappus.

8. G. dioi um L. Ausläufer gestreckt, wurzelnd; St. ganz einfach; WB. vkteyf.-spatelig, oberseits kahl, unterseits schneeweissfilzig; StB. sämmtl. fast gleich, lineal.-lanzettl., an den St. angedrückt; Ebenstrauss endst., gedrungen; Blättchen des weibl. HK. gefärbt, stumpf, die der innersten Reihe spitz. 24. Haiden, lichte WaldO. Mai. Jun. Antemnaria dioica DC. pr., Gärtn. HK. rosenroth od. sclneeweiss. Bl. weiss od. purp.

9. G. carpathicum Wahlenb. Ausläufer fehlend; W. mehrköpfig, mit aufrechten Köpfen; St. ganz einfach; B. lanzettl., an der Basis verschmälert, beiderseits wollig, 3nervig, spitz, die ersten wurzelst. stumpf, die stengelst. allmählig an Grösse abnehmend; Ebenstrauss endst., gedrungen; Blättchen des IIK. brandig-trockenhäutig, die inneren zugespitzt. 24. Feuchte, felsige Abhänge der höchsten A. Jul. Aug. G. alpinum Willd. Antennaria carpathica Bl. et Fing., DC. pr. HK. olivenbraun. Bl. weiss.

Gnaphalium margaritaceum wächst nicht im Geb. u. kommt auch nirgends verwildert vor.

\section{HELICHRÝSUM Gärtn. Sonnengold.}

1. H. arenarium DC. Krautig; B. filzig, die wurzelst. vkteyf.lanzettl., die stengelst. lineal.-lanzettl., die unteren stumpf, d. oberen spitzl.; Ebenstranss zsgesetzt. 24. Sandige Haiden, trockene Triften. Jul. Aug. Gnaphalium arenarium L. IIK. schön-citrongelb; variirt 
nait an den Spitzen rothen Blättchen der Hȟ.: G. arenarium $\beta$. aurantiacum Pers., u. selten mit blassgelben Köpfehen.

2. H. angustifolium DC. Halbstrauchig; B. lineal., grau; Ebenstrauss zsgesetzt; Köpfehen ey-kreiself.; Blättehen des HK. stumpf. ந. Sonnige Hügel; Istr., Fiune. Jul. Aug. HK. bleichgelb.

X. Gruppe. ANTHEMIDEEN. Stbk. ohne Anhängsel, gelb. Pappus fehlend od. kronenf.

\section{ARTEMISIA. L. Beyfuss.}

I. Rotte. Absinthium Tournef. Randbth. weiblich. Fruchtb. zottig. - Die meisten Arten der Gatt. variiren mit um dic Hälfte kleineren Köpfchen. Bl. gelbl., od. gelbl. u. röthlich angelat:fen.

1. A. Absinth i um L. St. aufrecht, rispig; B. grau, die wurzelst.- 3 fach-, die stengelst. doppelt-fiedersp. u. einfachfiedersp., Zpflchen lanzettl., stumpf, die blïthenst. B. ungeth.; Bstiele öhrchenlos; Föpfehen fast kugelig, nickend; Blättchen des HK. grau, die inneren sehr stumpf, am Rande trockenläutig, die äusseren lineal., nur an der Spitze trockenhäutig, so lang als die inneren; Fruchtb. rauhh. 4. Gebirgige, felsige O.; Wallis, Graubünd., Moselthal. JuI. Aug.

2. A. e amplorata Vill. Die nicht blïhenden St. liegend, die blüthentrag. aufstrebend, oberwärts traubig-rispig; $R$. schmal, ruthenf.; B. filzig-grau, od. etwas grau od. kahl, im Umrisse rundl.eyf., doppelt-gefiedert, mit schmal-lineal. Z $\mathrm{p} f \mathrm{fn}$., sämmtl. gestielt, an der Basis des Bstieles geöhrelt, die oberen einfach-gefiedert, die bliithenst. ganz; Köpfchen fast kugelig, nickend; Blättchen des HK. grau, die inneren sehr stumpf, am Rande trockenhäutig, die äusseren lineal, krautig; Fruchtb. v. gekräuselten Haaren etwas zottig. 4. Felsige, unkultiv. O., auf Kalk; Elsass, südl. Tyrol, Litt. Sept. Oct. Var. $\alpha$. saxatilis: B. grau, Köpfehen weissfilzig. A. saxatilis Willd. $-\beta$. Biasolettiana: B. u. Köpfehen weissfilzig. A. Biasolettiana.Vis.

3. A. rupestris L. Die nichtbliihenden St. liegend, die blüthentrag. aufstrebend, einfach-traubig od. oberwärts ästig-rispig; $\mathbf{R}$. schmal, ruthenf.; B. kahl, doppelt-gefiedert, mit lineal.-lanzettl. Zpflchen, die unteren gestielt, mit fiedersp.-gezähntem Bstiele, die stengelst. sitzend, die oberen $u$. blüthenst. sämmitl. einfach, kammf.-fiedersp.; Köpfchen fast kugelig, nickend, die inneren Blättchen des HK. eyf., am Rande lıäutig, angedrückt, die äusseren abstehend, lineal., ganz od. eingeschnitten u. krautig; Fruchtb. zottig. 2. Unkultiv. O., Triften; Stassfurth, Bernbg., Borksleben in Thüring. Sept.

4. A. I an at a Willd. sp. (1809.) Die nichtblühenden St. rasig, die blüthentrag. aufstrebend, ganz cinfach; B. grau-seidenh., die unteren gestielt, 3th.-vielsp., mit lineal.-lanzettl. Zpflehen, d. oberen u. blüthenst. sitzend, fiedersp.; Köpfchen fast kugelig, traubig, sämmtlich gestielt $u$. nickend, meist $24 b t h$. ; Blättchen des HK. filzig, 
am Rande trockenhäutig, eyf. 24. A. des südl. Tyrols. Jul. Aug. A. pedemontana Balb. in Lois. not. (1810.) K. syn. ed. 1.

5. A. glacialis L. Die nichtblïhenden St. rasig, die blüthentrag. aufstrebend, ganz einfach; $B$. grau-seidenh., die unteren gestielt, 3th.-vielsp., mit lineal.-lanzettl. Zptlchen, d. oberen $u$. blüthenst. fast fingerig-fiedersp., an der Basis des Bstieles oft geöhrelt; Köpfchen rundlich, aufrecht, etwas geknäuelt-ährig, 30-40bth.; Blättchen des HK. filzig, am Rande trockenhäutig, die äusseren eyf.; Fruchtb. rauhh. 24. Höchste A.; Wallis u. Innthal der Schwz. Jul.Aug.

6. A. $\mathrm{m}$ ut telli na Vill. Die nichtblïhenden St. rasig, die blïthentrag. aufstrebend, ganz einfach; B. grau-seidenh., gestielt, die unteren 3th.-vielsp., mit lineal.-lanzettl. Zpflchen, die oberen $u$. blüthenst. fast fingerig-fiedersp., an der Basis des Bstiels oft geöhrelt; Köpfchen rundl.-kreiself., aufrecht, traubig-älurig, meist 15bth.; Blättchen des HK. filzig, längl., am Rande trockenhäutig; Fruchtb. zottig. 24. Sounige Felsen der höheren A. Jul. Aug. A. glacialis Wulf.

II. Rotte. Abrotanum Tournef. Randbth. weibl. Fruchtb. nackt. Bl. gelbl., od. gelb u. röthl. ïberlaufen.

*B. vielsp., an der Basis des Bstieles nicht geöhrelt.

7. A. spicata Wulf. Die nichtbliihenden St. rasig, die blüthentrag. aufstrebend, ganz einfach; B. grau-seidenh., gestielt, die unteren fingerig-vielsp., mit lineal.-lanzettl. Zpflchen, die stengelst. im Umrisse längl., fiedersp., an der Basis öhrchenlos, die obersten $u$. blüthenst. ganz od. an der Spitze 3zähnig; Köpfehen fast kugelig, aufrecht, traubig-ährig; Blättchen des HK. filzig, am Rande trockenhäutig; Fruchtb. kaht. 2. Felsen der A. Jul. Aug.

8. A. la ciniat a Willd. Die nichtblühenden St. rasig, die blüthentrag. aufstrebend, ganz einfach, mit einer einfachen Tr. endigend, od. ästig, die Aeste traubig, aufrecht; $B$. zuletzt kahl, doppelt-fiedersp., Fiederchen gezährt, Zähne u. Zpflchen lanzettl, in eine kurze Stachelspitze z"gespitzt, alle B. gestielt, Bstiel an der Basis öhrchenlos, die blïthenst. oberen I3. ganz; Köpfchen fast kugelig, nickend, meist 20bth.; Blättchen des HK. sämmtl. eyf., stumpf, am Rande trockenhäutig, die äusseren kürzer; Fruchtb. nackt. 24. Triften; Stassfurth, Bernbg., Borksleben in Thüring. Jul. Aug. A. Mertensiana Wallroth.

9. A. tan acetifolia Allioni. Die niclitbliihenden St. rasig, die blüthentrag. aufstrebend, ganz einfach, mit einer einfachen od. an der Basis zsgesetzten 'Tr. endigend; $B$. kahl od. behaart, doppelt-fiedersp., Fïederchen gezähnt, Zähne u. Zpflchen lanzettl., in eine kurze Stachelspitze zugespitzt, alle gestielt, Bstiel an der Basis öhrchenlos, die blüthenst. oberen ganz; Köpfehen kugelig, nickend, meist 40bth.; Blättchen des IHK. eyf., stumpf, am Rande brandig-trockenhäutig, 
die äusseren kürzer; Fruchtb. nackt. 2. Auf der Spitze der A. Morosch bei Flitsch in Krain. Jul. Aug.

10. A. Abrotanum I. St. strauchig, aufreclit, rispig; $B$. unterseits flaumig, sämmtl. gestielt, an der Basis des Bstieles öhrchenlos, die unteren doppelt-gefiedert, mit sehr schmal-lineal. $\mathrm{Z} p f(n$., die oberen u. blüthenst. 3sp. od. ganz, verlängert-lineal., Köpfchen graulich, fast kugelig, nickend; die inneren Blättchen des HK. vkteyf., am Rande trockenhäutig, die äusseren lanzettl., spitz, fast krautig. 4. Häufig in Gärten kultiv.; zweifelhaft bei Sitten im Wallis $u$. bei Triest. Jul. Aug.

** B. vielsp., an der Basis des Bstiels geöhrelt.

11. A. p ontica L. W. kriechend; St. aufrecht, oberwärts rispig, fast ruthenf.; $B$. unterseits filzig, oberseits kahl od. grau, doppeltgefiedert, mit lineal., genäherten, ganzen od. etwas gezähnten $\mathrm{Zpfl-}$ chen, die unteren stengelst. am Bstiele geöhrelt, die oberen sitzend, die blüthenst. ganz; Köpfchen grau, etwas kugelig, nickend; Blättchen des HK. vkteyf., sehr stum If, am Rande trockenhäutig, die äusseren krautig, kiirzer, lanzettl.; Fruchtb. kahl. 24. Sonnige, unkultiv. O.; zerstr. dch das siidl. u. mittl. Geb. Jul. Aug.

12. A. a ustri a ca Jacq. W. kriechend; St. aufrecht, oberwärts rispig; $B$. grau-filzig, im Umriss rundl., doppelt-gefiedert-vielsp., mit lineal. Zpflchen, die stengelst. fast fingerig-geth., am Bstiel geöhrelt, die oberen sitzend, die obersten blïthenst. ganz; Köpfchen rauhh.filzig, rundl.-eyf.; Blättchen des HK. längl., stumpf, am Rande trockenhäutig, die äusseren kürzer, die äussersten lineal., krautig. 24. Sonnige Hügel; Unteröstr. JuI.-Sept.

13. A. campestris L. Die nichtblühenden St. rasig, die blüthentrag. aufstrebend, rispig; $B$. seidenh.-grau od. kahl, im Umrisse rundl.-eyf., doppelt-3fachgefiedert, mit lineal., stachelspitzigen $\mathrm{Zpf-}$ chen, die unteren stengelst. am Bstiel geöhrelt od. fitdersp.-gezähnt, die obersten sitzend, einfach-fiedersp., die oberen bliithenst. ungeth.; Köpfchen eyf., kahl, aufrecht od. nickend; Blättclien des HK. eyf., am Rande trockenhäutig, die äusseren kürzer, die inneren eyf.-längl. 4. Felder, unkultiv. O. Jul. Ang. Var. $\beta$. sericea: Flaum der B. bleibend. $-\gamma$ robustior: in allen Theilen grösser, kahl; in den VorA. - $\delta$. alpina DC. : niedrig, 3-6" hoch, St. einfach od. kaum etwas rispig; letztere auf höheren $A$.

14. A. nan a Gaudin. Die nichtblühenden St. rasig, die bthtrag. aufstrebend, rispig-traubig; B. seidenh.-grau, im Umrisse rundl.-eyf., doppelt-gefiedert, mit lineal., stachelspitzigen $\mathrm{Zpflchen,} \mathrm{die} \mathrm{unteren}$ stengelst. am Bstiel geöhrelt od. fiedersp.-gezähnt, die oberen sitzend, einfach-fiedersp., die obersten bthständigen ungeth.; Köpfchen kugelig, kahl, anfrecht od. nickend; Blättchen des HK. sämmtl. eyf., am Rande trockenhäutig, die äusseren kiirzer. 2. Kies der Giesbäche 
am obersten Ende des Saasthales am See Mat-Mar im Wallis. Jul. Aug. A. helvetica Schleich. Var. mit halb so grossen Köpfchen.

15. A. scoparia W.K. St. einzeln, aufrecht, nebst den B. $v$. etwas absteluenden Haaren rauhh. od. kahl, rispig; $\mathbf{R}$. sehr ästig, abstehend; B. im Uinrisse eyf., doppelt-3fachfiedersp., Zpflchen der untersten lineal.-lanzettl., der übrigen sehr schmal-lineal., die unteren stengelst. B. am Bstiel geöhrelt od. fiedersp.-gezähnt, die oberen sitzend, einfach-fiedersp., die obersten blüthenst. ungeth.; Köpfchen rundl.-eyf., kahl, nickend; Blättchen des HK. eyf., am Rande trockenhäutig, die äusseren kürzer. ○. Sandige O., Hügel; Stmk., Unteröstr., Mähr., Böhm. Aug. Sept.

16. A. vulgaris L. St. aufrecht, rispig; $B$. unterseits weissfilzig, fiedersp., Fieder lanzettl., zugespitzt, eingeschnitten-gesägt u. gauz, die stengelst. B. an der Basis geöhrelt, die obersten lineal.lanzettl., zugespitzt; Köpfchen eyf. od. längl., nickend od. aufrecht, fast sitzend, filzig. 24. Unkultiv. Hügel, Wege, Ufer. Aug. Sept.

*** B. ungeth.

17. A. Dracunculus L. St. krautig, aufrecht; B. grün, kahl, lanzettl.-lineal., ungeth., die wurzelst. an der Spitze 3sp.; Köpfchen rispig, fast kugelig, nickend; Blättchen des HK. breit-elliptisch, die inneren am Rande trockenhäutig. 24. Zum Küchengebrauche kultiv. Aug. Sept.

III. Rotte. Seriphida Bess. Bth. sämmtl. zwitterig. Bl. gelbl., od. gelbl. u. rồthl. überlaufen.

18. A. maxitima L. Die nichtblühenden St. rasig, die blüthentrag. aufstrebend od. aufrecht; $B$. schneeweiss-filzig, od. dch den sich verlierenden Filz fast kahl, im Umrisse eyf., 2-3fach-gefiedert, mit lineal., stumpfen Zpflchen, die unteren stengelst. B. am Bstiel geöhrelt, die oberen sitzend, die obersten blüthenst. ungeth.; Köpfchen längl., filzig; Blättchen des HK. längl.-lineal., die inneren trockenhäutig, die äusseren kürzer, krautig; Bth. sämmtl. zwitterig. 4 . Wiesen u. Sandplätze am Meere $u$. an Salinen. Sept. Oct. Var. $\alpha$. maritima: Köpfchen aufrecht, aber die Aeste u. Aestchen an der Spitze nickend. A. maritima Willd. - $\beta$. gallica: Köpfchen aufrecht, Aeste steif, nicht nickend. A. gallica Willd. - $\gamma$. salina: Köpfchen hängend. A. salina Willd. - $\delta$. valesiaca: iiberall mit schneeweissem Filze überzogeu, Köpfehen u. Aeste aufrecht. A. valesiaca All.

19. A. cacrulescens L. St. strauchig; B. grau, lanzettl., ungeth., die der nichtblühenden St. eingeschnitten .u. fiedersp.; Köpfchen längl.; Bth. sämmtl. zwitterig. 2. Sumpfige O.; Littor. Aug. Sept.

30. TANACÉTUM L. Rainfarn.

1. T. vulgar c L. B. doppelt-fiedersp., Zpfl, gesägt. 4. Unkultiv. Iügel, Wege, Ufer. Jul, Aug. Bl. gelb. 
2. T. Balsamita L. B. eyf., ungeth., gesägt, die unteren gestielt, die oberen sitzend, an der Basis geöhrelt; Köpfchen ebensträussig. 2. Unkultiv. O.; Tessin, in Gärten kultiv. Aug. Sept. Btl. sämmtl. zwitterig. Bl. gelb.

31. CÓTULA L. Laugenblume.

1. C. coronopifolia L. B. lanzettl.-lineal., stengelumfassend, fiedersp.-gezähnt; St. liegend, Aeste 1köpfig. $\odot$. Gräben u. Wege; längs der Seeküste v. Ostfriesland bis Holstein. Jul. Aug. Bl. gelb.

32. SANTOLÍNA L. Heiligenpflanze.

1. S. Chamae-Cyparis is L. Bthstiele 1köpfig; B. grau, 4reihig-gezähnt, Zähne stumpf; Aeste filzig; HK. Alaumig. Ђ. Sonnige $0 . ;$ im Wallis, in der Koschnitza u. bei Breschia in Unterstmk. Jul. Aug. Bl. gelb.

33. ACHILLÉA L. Schaafgarbe.

I. Rotte. Ptarmica Tournef., DC. Strahl meist 10bth., Zungenbth. v. der Länge des HK.

1. A. Ptarmica L. B. kahl, lanzettl.-lineal., verschmälert-spitz, aus beiderseits eingeschnitten-gezähnter Basis bis zur Mitte klein- $u$. dicht-, über der Mitte tiefer-u. entfernter-gesägt, Sägezähne stachelspitzig, klein-gesägt, ziemlich-angedrïckt; Ebenstrauss zsgesetzt; Zungenbth. v. der Länge des HK. b. Gräben, Ufer, am Gebüsch feuchter O. Jul. Aug. Ptarmica vulgaris DC. Strahl u.' Mittelfeld weiss, wie an allen folgenden der Rotte.

2. A. alpina L. B. kall od. spärlich behaart, larzettl.-lineal., verschmälert-spitz, fiedersp.-gesägt, Sägezähne lanzettl., stachelspitzig, etwas abstehend, so lang als der Querdchmesser der Bfläche; Ebenstrauss zsgesetzt; Zungenbth. v. der Länge des HK. 24. A. der Schwz.; auf dem Gotthard gegen Airolo zu. Jul. Aug. Ptarmica alpina DC.

3. A. Clavennae L. Die W.- u. die unteren StB. im Umrisso längl.-keilig, in den Bstiel verschmälert, einfach-fiedersp., mit längl., stumpfer, ganzrandigen, od. 2-3zährigen Läppchcn, die oberen stengelst. B. sitzend; St. ganz einfach, oberwärts nackt; Ebenstrauss zsgesetzt; Zungenbth. v. der Länge des HK. 2. Hohe A. Jul. Aug. Ptarmica Clavemnae DC. Ueberall seidiggrau. Var. $\beta$. glabrata Hopp.: ganz kahl.

4. A. valesiaca Suter. B. kahl od. etwas haarig, im Umrisse elliptisch, einfach-fiedersp., Fieder längl-lanzettl., spitz, auf der vorderen Seite 1-3-, auf der hinteren 3-6zähnig, Zähne lanzettl., in ein Stachelspitzchen zugespitzt; Ebenstrauss zsgesetzt; Zungenbth. v. der Länge des HK. 24. Rhonegletscher in der Schwz. Jul. Aug. A. helvetica Schleich. Ptarmica valesiaca DC.

5. A. Thomasiana Hall. fil. B. fianml., im Umrisse elliptisch, 
einfach-fiedersp., Fieder fast keilf., an der Spitze eingeschnitten-3-4zähnig, Zähne lanzettl., in ein Stachelspitzchen verschmälert; WB. doppelt-fiedersp., Fieder 3-vielsp.; Ebenstrauss zsgesetzt; Zungenbth. v. der Länge des HK. 24. Bavonaz im C. Waadt; Rhonegletscher im Wallis. Jul. Aug. A. montana Schleich. Ptarmica Thomasiana DC.

6. A. macrophylla L. B. zieml. kahl, die stengelst. im Umrisse breit-eyf., einfach-gefiedert, Fieder zieml. breit-lanzettl., zugespitzt, eingeschnitten-doppelt-gesägt, Sägezähne zahlreich, die obere Fieder an der Basis zsfliessend, herablaufend; Ebenstrauss zsgesetzt; Zungenbth. v. der Länge des HK. 2. Wälder der VorA. u. A.; Schwz., Tyrol, auf der MödlesA. im Algau. Jul. Aug. Ptarmica macrophylla DC.

7. A. moschata Wulfen. B. kahl od. etwas behaart, im Umrisse längl., kammf.-gefiedert, Fieder lanzettl.-lineal., kurzstachelspitzig, ungeth. od. 1zährig, od. an den unteren B. auf der hinteren Seite 2-3zähnig; Ebenstrauss einfach; Zungenbth. v. der Länge des HK. 2. Feuchte O. der höchsten A.; Schwz., Tyrol, Stmk. Jul. Aug. A. impunctata Vest. Ptarmica moschata DC.

8. A. hybxida Gaudin. B. zottig-wollig, im Umrisse längl., kammf.-gefiedert, Fieder lanzettl.-lineal., kurz-stachelspitzig, ungeth. od. 1zähnig, od. an den unteren B. fiedersp.-3-5zähnig; Ebenstrauss einfach; Zungenbth. v. der Länge des HK. 24. Höchste A. im Wallis. Jul. Aug. A. moschata $\beta$. hybrida Gaud. Ptarmica moschata $\gamma$. hybrida DC. Die Achillea intermedia Schleich., von Thomas erhalten, ist nicht verschieden.

9. A. nana L. B. sehr wollig-zottig, im Umrisse schmal-lanzettl., gefiedert, Fieder der StB. an der Basis mit einem Läppchen versehen $u$. dadurch $2 s p$., Zpfl. lineal.-lanzettl., spitz, der zweite kleiner, die der WB. fiedersp.-4-6zähnig od. 2th., der vordere Zpfl. 3sp., der hintere 2sp.; Ebenstrauss einfach, fast kugelig; Zungenbth. v. der Länge des HK. 24. Felsige O. der höchsten A.; Schwz., TYrol. Jul. Aug. Ptarmica nana DC.

10. A. a trata L. B. etuas haarig, im Umrisse längl., gefiedert, Fieder 2-3sp. od. fiederig-5sp., Z $\mathrm{p} f$. lineal., spitz, stachelspitzig; Ebenstrauss 3-9köpfig; Zungenbth. v. der Länge des HK. 4. Feuchte O. der A. Jul. Aug. Ptarmica atrata DC. var. $\boldsymbol{u}$. u. $\beta .-$ Anthemis corymbosa Haenke.

11. A. Clusiana Tausch. B. etwas haarig, im Umrisse längl., dop̀pelt-gefiedert, Fiederchen 2-3sp., od. fiederig-5sp., Zpfl. schmallineal., spitz, stachelspitzig; Ebenstrauss 3-9köpfig; Zungenbth. v. der Länge des $H K$. 2. Feuchte 0 . der A. Jul. Aug. Ptarmica atrata $\gamma$. DC.

II. Rotte. Millefolium Tournef. Strahl 5bth.; Zungenbth. halb so lang als der HK. 
Strahl gelb.

12. A. tomentosa L. B. selur zottig, im Umrisse lanzettl.lineal., gefiedert, Fieder der W.- u. unteren StB. fingerig, 3th., Zpfl. lineal., stachelspitzig, der mittlere $3 \mathrm{sp}$., die seitenst. $2 s p$. od. auch 3sp., Fieder der oberen B. 2- u. 3sp., die der obersten ungeth., dichtkammf-genähert; Ehenstrauss doppelt-zsgesetzt; Zungenbth. halb so lang als der HK. 24. Steinige Hügel, Flusskies, sandige O.; Wallis, siidl. Tyrol. Mai. Jun.

* Strahl weiss, purpurn od. schmutzig- u. hell-gelblichweiss, Mittelfeld weiss.

13. A. Mill efol ium L. B. wollig-zottig od. fast kahl, die stengelst. im Umrisse lanzettl. od. fast lineal., doppelt-fiedersp., Fiederchen 2-3sp. od. gefiedert-5sp., Läppchen lineal. u. eyf., zugespitzt, stachelspitzig, Spindel urgezähnt, od. an der Spitze des B. etwas gezähnt, Zähne ganz; Ebenstrauss doppelt-zsgesetzt; Zungenbth. halb so lang als der HK. 2. Unkultiv. O., trockene Wiesen. Jun.-Oct. Var.: $\beta$. crustata: B. schmal; Läppchen kurz, an der Spitze verdickt u. knorpelig. A. Millefolium $\beta$. crustata Roch. A. scabra Host. $\gamma$. lanata: der St., die B. u. der Ebenstrauss wollig-zottig; übrigens

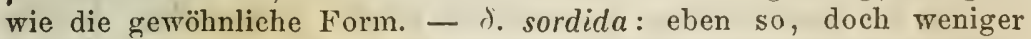
wollig; Zungenbth. schmutzig-weiss. A. polyphylla Schleich. $-\varepsilon$. alpestris: Blättchen des HK. mit einem breiten, schwarz-braunen Rande umgeben. - $\zeta$. setacea: Bzpfl. seln schmal; Zungenbth. oberseits gelblich-weiss, unterseits weiss; Köpfehen meist halb so gross; Kraut wollig-rauhh. A. setacea WK. A. odorata Schleich.

14. A. l an at a Sprengel. . wollig-zottig od. zieml. kahl, die stenzelst. im Umrisse längl., od. lanzettl., doppelt-fiedersp., Fiederchen gezähnt-gesägt, Zähne zugespitzt, stachelspitzig, Spindel geflügelt, die der unteren $B$. unter den Fiedern gezähnt; Ebenstrauss doppelt-zsgesetzt; Zungenbth. halb so lang als der IIK. 2. Bergwiesen; Krain, Fiume, Tessin. Jul. Aug. Wohl Abart der A. tanacetifolia.

15. A. tanacetifolia All. B. wollig-zottig od. fast kahl, die stengelst. im Umrisse lärgl. doppelt-fiedersp., Spindel geflügølt, gezähnt, Spindelzähne, Fieder u. Fiederchen gezähnt-gesägt, Zähne zugespitzt, stachelspitzig; Ebenstrauss doppelt-zsgesetzt; Zungenbth. halb so lang als der. HK. 21. Gebirge, A.; siidl. Sehwz., Graubünd,; Krain, Stuk. Jul. Aug. Var. $\alpha$ dentifera: Bspindel sehr breit, an den mittleren StB. fast 2 Linien breit, der ganzen Länge nach vielzähnig; Bzpfl. v. der Breite der Spindel, ebenso vielzähnig. A. dentifera DC. A. magna L. All. A. distans Willd. Bth. weiss, selten rosenroth. - $\boldsymbol{\beta}$. purpurea: Bspindel breit, unterhalb der Basis der Fieder beiderseits mit 2 , wiederum 2- u. mehrzähnigen Zähnen versehen, iibrigens ganzrandig. A. tanacetifolia All., DC. A. magna Roch. Bth, 
purpurn, selten weiss. - $\gamma$. stricta: ebenso, aber die Spindel kaum 1 Linie breit; B. u. deren $\mathbf{Z}$ pfl. schmäler, daher v. Habitus der A. Millefolium. A. stricta Schleich. - $\delta$. angustifolia: Spindel u. Bzpfl. so schmal, dass die Pflanze den Habitus der A. setacea erhält. Bth. gelblichweiss. - Von allen Variet. der A. Millefolium dch die vielzähnige Spindel u. die gezähnten Zähne derselben verschieden.

16. A. nobilis L. B. wollig-flaumig od. fast kahl, die stengelst. im Umrisse oval, doppelt-fiedersp.; Fiederchen fiederspaltig-gezähnt, die grösseren 5-7zähnig, Zähne kurz, stachelspitzig; Spindel schmal, v. der Spitze bis zur Mitte des B. gezähnt, Zähne lineal, ganzrandig od. gezähnt; Ebenstrauss doppeIt-zsgesetzt; Zungenbth. halb so lang als der HK. 2. Unkultiv. O.; zerstr. deh das südl. u. mittlere Geb. Jul. Aug. Bl. weiss od. gelbl.-weiss.

17. A. odorata L. B. wollig-flaumig, im Umrisse längl.oval, doppelt-fiedersp., Fiederchen lineal., ganzrandig od. $1 \mathrm{zähnig,} \mathrm{nebst}$ den Zähnen spitz, stachelspitzig, Spindel nicht gezähnt; Ebenstrauss doppelt-zsgesetzt; Zungenbth. halb so lang als d. HK. 2. Gebirgige, kalkhalt. O.; Litt. Jul. Aug. Bl. weiss od. gelbl-weiss.

\section{ANTHEMIS L. Anthemis.}

§. 1. Spreublättchen lanzettl. od. längl., ganzrandig, in eine starre Stachelspitze zsgezogen.

* Fruchtb. convex od. fast halbkugelig. Achenen 4eckig-zsgedrückt, 2schneidig, mit einem geschärften Rande bekrönt.

1. A. tin ct or ia L. B. flaumig, doppelt-fiedersp., Spindel gezähnt, Fiederchen kammf.-gestellt, gesägt, Sägezähne stachelspitzig; Fruchtb. fast halhkugelig; Spreublättchen lanzettl. in eine starre Stachelspitze zugespitzt; Achenen 4eckig-zsgedruickt, schmal-geflügelt, beiderseits 5streifig, mit einem geschärften Rande endigend; Zungenbth. kaum halh so lang als der Querdurchmesser des Mittelfeldes. 24., auf Aeckern mit Winterfrïchten. ๑. Sonnige, trockene O. Jul. Aug. Bl. gelb, od. des Strahles bleichgelb, od. selten weiss.

2. A. Triumfetti Allioni. B. flaumig, doppelt-fiedersp., Spindel gezähnt, Fiederchen kammf.-gestellt, etwas gesägt, Sägezähne stachelspitzig; Fruchtb. fast halbkugelig; Spreublättchen lanzettl., in eine starre Stachelspitze zugespitzt; Achenen 4eckig-zsgedrückt, schmalgeflügelt, beiderseits 5streifig, mit einem geschärften Rande endigend; Zungenbth. so lang als der Querdchmesser des Mittelfeldes. 2. Berge; suidl. Schwz., Littor. Jul. Aug. A. rigescens Willd., A. rigescens DC. pr. u. A. austriaca $\beta$. Triumfetti DC. pr. sind nach Expl. v. den Standorten nicht verschieden. Strahl weiss, Mittelfeld gelb, wie an folgenden.

3. A. a u stri a ca Jacq. B. wollig-flaumig, doppelt-fieclersp., Spindel gezähnt, Fiederchen kammf.-gestellt, fast gleich, ganzrandig, stachelspitzig; Fruchtb. halbkugelig; Spreublättchen längl., in eine 
starre Stachelspitze zugespitzt; Achenen 4eckig-zsgedriickt, schmalgeflizgelt, beiderseits 3 streifig, mit einem geschärften Rande endigend. $\odot$. Aecker, kultiv. O.; Unteröstr., Istr., Regensburg. Jul. Aug.

4. A. altissima L. B. ziemlich kahl, doppelt-fiedersp., Spindel etwas gezähnt, Fiederchen gezähnt u. nebst den Zähnen stachelspitzig; Fruchtb. halbkugelig; Spreublättchen vkteyf., plötzl. in eine starre Stachelspitze, $v$. der Länge des Spreublättchens $u$. länger als die Bth. zsgezogen; Achenen 4eckig-zsgedriickt, sehmal-geflïgelt, beiderseits 10rillig, mit einem geschärften Rande endigend. $\odot$. Aecker; Istr. Jul. Aug.

5. A. Cota L. u. Viviani, nach einem Exemplare v. Viviani in der k. Samml. zu Berlin. B. doppelt-fiedersp., Spindel etwas gezähnt, Fiederchen $3 \mathrm{sp}$. od. gefiedert-5sp., Läppchen kurz-stachelspitzig; Fruchtb. halbkugelig; Spreublättchen längl., an d. Spitze in eine steife Stachelspitze, nicht v. der Länge der Bth. zugespitat; Achenen 4 eckig-zsgedriickt, flügellos, beiderseits 5rillig, mit einem geschärften Rande endigend. $\odot$. Weinberge, kultiv. O.; Istr., Fiume. Jun. Jul. A. Cota Vivian. A. brachycentros Gay.

**Der fruchttrag. Fruchtb. verlängert, walzlich od. kegelf. Achenen stumpf-4kantig; Rillen gleich.

6. A. arvensis L. B. wollig-flaumig, doppelt-fiedersp., Fiederchen lineal.-lanzettl., ungeth. od. 2-3fach-gezähnt, spitz, stachelspitzig; Fruchtb. verlängert-kegelf.; Spreublättchen lanzettl., in eine starre Stachelspitze zugespitzt; Achenen stumpf-4kantig, gleich-gefurcht, die äusseren mit einem gedunsenen, faltig-runzeligen Ringe, die inneren mit einem spitzen Rande endigend. $\odot$. Sandplätze, kultiv. 0. Jun.-Herbst. A. arvensis Wallr., die Pflanze mit jüngeren Achenen; A. agrestis Wallr., die Pflanze mit ausgebildeten Achenen.

§. 2. Spreublättchen lineal.-borstlich, spitz.

7. A. Cotula L. B. zieml. kahl, doppelt-fiedersp., Fiederchen lineal., ungeth. od. 2-3zähnig, kurz-stachelspitzig; Fruchtb. verlängertkegelf.; Spreublättchen lineal.-borstl.; Achenen beinahe stielrund, knotig-gerieft, mit einem klein-gekerbten, ein etwas convexes Mittelfeld umgebenden Rande endigend. $\odot$. An kultiv. O. Jun.-Herbst. Maruta Cotula DC.

§. 3. Spreublättchen gegen die Spitze häutig u. rauschend, stumpf od. zerfetzt-gezähnt $\mathfrak{u}$. manchmal deh einen mehr hervorspringenden Zahn stachelspitzig.

* Bth. des Mittelfeldes gelb.

8. A. nobilis L. B. flaumig od. fast kahl, gefiedert, Fieder vielsp., Zpfl. lineal., kurz-stachelspitzig; Fruchtb. verlängert-kegelf.; Spreublättchen längl., grannenlos, am Rande u. an der Spitze trockenhäutig; Achenen fast $3 \mathrm{kantig,} \mathrm{glatt,} \mathrm{mit} \mathrm{einem} \mathrm{schwach-angedeuteten}$ 
Rande endigend; St. ästig, vielköpfig. 24. Kiesige Triften; Schwz., Westphal. Jul. Aug.

9. A. montana L. B. kall, gefiedert, die unteren stengelst. 3-6paarig, Fieder einfach, 2-3sp. u. gefiedert $-5 \mathrm{sp}$., Zpfl. lineal.lanzettl., ziemlich spitz, wehrlos; Fruchtb. halbkugelig; Spreublättchen lineal.-längl., an der Spitze brandfleckig u. zerfetzt-gezähnt u. oft deh einen grösseren Zahn stachelspitzig, so lang als die Bth. des Mittelfeldes; St. ganz einfach, 1köpfig. 2. A. v. Stmk. Aug. Sept. A. montana u. A. Kitaibelli DC. A. Kitaibelli Spreng. A. mont., A. saxatilis u. A. carpatica Willd. A. styriaca Vest. - Bisher nur die kahle od. flaumige Varietät, nicht die seidenhaarige.

** Bth. des Mittelfeldes weiss.

10. A. alpina L. B. wollig-flaumig od. kahl, gefredert, die unteren stengelst. 10-12paarig, Fieder einfach od. 2-3sp., Zpfl. lineal.verschmälert-spitz, stachclspitzig; Fruchtb. halbkugelig; Spreublättchen lineal.-längl., stumpf, an der Spitze zerfetzt-gezähnt u. brandfleckig, bis zur Hälfte des Saumes der Bth. des Mittelfeldes reichend; die St. einfach, 1-mehrköpfig. 24. Höchste A. v. Tyrol u. Stmk. Ptarmica oxyloba DC. pr. Unterscheidet sich v. Achillea atrata deh lineal.-längl. Strahlenbthen, die noch einmal so lang sind als breit, (an A. atrata sind sie rundl.-vkteyf.,) u. deh fast immer 1köpfige St.

\section{ANACYCLUS L. Kreisblume.}

1. A. officinalis Hayn. St. aufrecht od. aufstrebend, meist 1köpfig; Spreublättchen vkteyf., nach der Basis verschmälert; Flïgel der Achenen knorpelig, glanzlos; Bth. des Mittelfeldes gleichf.-5zähnig. $\odot$. In Thüringen im Grossen kultiv. Mai. Jun. A. pulcher DC. pr. Strahl weiss, unterseits purp. gestreift.

36. MATRICARIA. L. Kamille.

1. M. Ch amomilla L. Achenen mit hervortretendem, stumpfem Rande endigend. $\odot$. Aecker, kultiv. O. Mai-Jul. Strahl weiss.

37. CHRYSÁNTHEMUM L. Wucherblume.

a. Strahl weiss.

1. Ch. Leueanthemum L. Die unteren B. lang-gestielt, vkteyf.-spatelig, gekerbt, die oberen sitzend, lineal.-längl., gesägt, Sägezähne der Basis schmäler u. spitzer; Achenen sämmtlich ohne Krönchen. 2. Wiesen, waldige 0 . Jun. Jul. Leucanthemum vulgare DC. pr. Var. selten olne Strahl, n. $\beta$. atratum: niedriger, nur fingerlang od. Spanne hoch u. kahl; Blättchen des HK. breit-schwarzbraun-berandet: Ch. atratum Gaud., Thomas. - Das Leucanth. atratum DC. hat ein häutiges Krönchen auf den Achenen des Strahles, u. ist verschieden. 
2. Ch. montanum L. Die unteren B. längl., in den Bstiel verschmälert od. vkteyf., gekerbt, die darauf folgenden sitzend, lanzettl. u. lineal., gesägt, Sägezähne der Basis schmäler u. spitzer; Achenen, des Randes mit einem häutigen, halbirten, gezähnten Krönchen, $v$. der halben Länge der Röltre, dic des Mittelfeldes ohne Krönchen. 2. Triften der A., u. siidl. auf niedrigeren Gbgen bis zum Adriat. Meere. Jun. Jul. Var.: adustum: die untersten B. vkteyf., in den Bstiel plötzlich zsgezogen, grob-gekerbt, die stengelst. lanzettl., entfernt-gesägt; Bth. gross, Blättchen des HK. mit einen breiten, schwarzbraunen Rande umgeben; Triften der A. Leucanthemum atratum DC.? - $\boldsymbol{\beta}$. heteropluyllum: höher, die untersten B. längl., in den Bstiel allmählich verschmälert, die oberen lanzettl., fast gleichf.-gesägt; Blättchen des HK. vor dem breit-trockenhäutigen Rande mit einer schmalen, bräunlichen Linie bezeichnet. Cl. atratum $\alpha$. Linn., nach den Syn. Leucanthemum heterophyllum DC. Südl. Abhänge der A. - $\gamma$. saxicola: St. niedriger, WB. vkteyf, od. längl. od. lanzettl., spärlich-gezähnt, StB. lineal--lanzettl., entfernt-gesägt, oft fast ganzrandig. Niedrige Gegenden am siidl. Fusse der A. Ch. montanum L. Leucanthemum montanum DC. Dieses scheint in südlicheren Gegenden in Chrys. graminifolium L. iiberzugehen.

3. Ch. coronopifolium Vill. Die untersten B. vkteyf.-keilig, eingeschnitten-5-7zähnig, die stengelst. lanzettl. u. lineal., eingeschnitten-gesägt, Zähne lauzettl.-pfrieml.; Achenen sämmtl. häutigbekrönt, Krörchen der randständigen schief-abgeschnitten, gezühnt, ungefähr so lang als die Röhre der Bl. 24. Felsige O. der A., mit den Flüssen in die Nebenthïler hinab. Jul. Aug. Ch. Halleri Sut. Ch. atratum L., nach der Diagnose. Pyrethrum Halleri Willd., DC.

4. Ch. cer at op hylloides All. Die W.- u. StB. fiedersp., Zpfl. lanzettl.-lineal., verlängert, ingeth. u. 2sp., entfernt, Spindel lineal. od. keilf.-verbreitert; Achenen sämmtl. häutig-bekrönt, Krone der randständigeu schief-abgeschnitten, ungefähr so lang als die Röhre der Bl. 2. Felsige $O$.; auf dem Linkerskopf in clen bayer. A. Jul. Aug. Pyrethr. ceratophylloides Tenor., DC. pr. Variet. v. C. coronopif.?

5. Ch. al pin um L. WB. u. die d. nichtblühenden St. kammf.fiedersp., im Umrisse rundl.-eyf., mit dicht-genäherten, ganzrandigen Fiedern, die der blüthentrag. St. lineal., ganzrandig; Achenen sämmtı. häutig-bekrönt, Krone d. randständigen gleichf.-glockig, gekerbt; Blättchen des HK. längl.-eyf., stumpf. 24. Felsige $O$. der höheren A.; Schwz., Tyrol, Stmk., Kärnth. Jul. Aug. Pyrethrum alpinum Willd., DC. Var. $\beta$.minimum: halb so gross, B. u. St. etwas filzig-rauhh.; Bzpfl. fast elliptisch. Ch. alpinum $\beta$. minimum Gaud. Ch. minimum Vill. Walliser A. Pyrethr. alpinum $\beta$. pubescens DC. pr.

6. Ch. Parthenium Pers. B. flaumig, gefiedert, Fieder elliptisch-längl., stumpf, fiedersp., die obersten zsfliessend, Zpfl. twwas gezähnt, sehr kurz-bespitzt; St. ästig; Köpfehen ebensträussig; Ache- 
nen mit einem geschärften, sehr kurzen Rande endigend. 2. Waldige felsige O., Schutt, scheint verwildert. Jun. Jul. Matricaria Parthenium L. Pyrethr. Parthenium Sm., DC. pr.

7. Ch. corymbos um L. B. gefiedert, flaumh., Fieder der unteren fiedersp., Fiederch. geschärft-gesägt, Sägezähne stachelspitzig; Köpfchen ebensträussig; Zungenbth. lineal.-längl.; Achenen sämmtl. häutig-bekrönt, Krone der randständigen ungefähr so lang als die Röhre. 24. Waldige, gebirgige $O$. Jun. Jul. Pyrethr. corymbosum Willd., DC.

8. Ch. macrophyllum Waldst. u. Kit. B. kurzh., gefiedert, die Fieder in eine breitgeflügelte Spindel hinablaufend, breit-lanzettl., grob-eingeschnitten-gezähnt, die Zähne fast doppelt-gesägt, die hintere Fieder der unteren B. getrennt; Köpfchen ebensträussig; Zungenhth. rundl.-vkteyf,, v. der halben Länge der Hülle; Achenen sämmtl. häutig-bekrönt, Krone der randst. vielmal länger als die Röhre. 24. Im Görjanz-Walde des Uskoken-Gbgs in Krain. Jun. Jul. Pyrethrum macrophyllum Willd., DC.

9. Ch. in od orum L. B. 2-3fach-fiedersp., Zpfl. lineal.-fädl.; Strahl abstehend; Fruchtb. halbkugelig. $\odot$. Kultiv. O., Wegränder. Jul._Oct. Var. am Meeresufer u. an salzhaltigen O. $\beta$. maritimum: Bzpfl. dicker, Achenen etwas grösser. Chrys. inodorum $\beta$. maritimum L. Chrys. inodorum $\beta$. salinum Wallr. - Davon ist Matricaria maritima L., Pyrethrum marit. Sm., Chrysanthemum maritimum Fries. herbar. norm. fasc. 7. verschieden.

b. Strahl gelb.

10. Ch. se getum L. B. kahl, gezährt, vorne verbrcitert 3sp.eingeschnitten, die oberen mit herzf. Basis stengelumfassend. Achenen mit einem verwischten Rande endigend. $\odot$. Aecker; zerstr. dch das Geb. Jul. Aug.

38. PINARDIA Cassin. Pinardie.

1. P. c oronaria Lessing. B. vorne breiter, doppelt-fiedersp. u. nebst dem St. kahl. $\odot$. Südl. A. der Schwz. sehr selten; auf dem Berge la Combaz im unteren Wallis u. auf dem Fräla im Veltlin. Jul. Aug. Bl. gelb.

XI. Gruppe. SENECIONEEN. Pappus behaart; sonst alles wie bei den Anthemideen.

39. DORÓNICUMI L. Gemswurz.

1. D. Pardalianches L. var. $\beta$. B. eyf., gezähnelt, die wurzelst. lang-gestielt, tief-herzf., die mittleren stengelst. geöhrelt-gestielt, die oberen sitzend, stengelumfassend; Fruchtb. zottig; unterirdische Ausläufer verlängert, dünn, an der Spitze zuletzt verdickt, blättertragend $u$. wiederum ausläufertreibend. 24. Gebirgswälder; sehr zerstr. 
dch das Geb. Mai. Jun. D. Matthioli Tausch. Bl. gelb, wie an den folgend.

2. D. s corpioides Willd. B. eyf,, gezähnelt, die wurzelst. langgestielt, an der Basis abgerundet od. abgeschnilten od. undeutlichherzf., in den Bstiel ein wenig hervorgezogen, die mittleren stengelst. geöhrelt-gestielt, die oberen sitzend, stengelumfassend; Fruchtb. zerstreut-behaart; Rhizom kurz, wagerecht; Ausläufer fehlend. 2. Auf dem Saleve bei Genf. Mai. Var. mit flammigen u. kahlen Fruchtkn. der Randbth.

3. D. cordifolinm Sternberg. B. fast kahl, die wurzelst. langgestielt, grob-gezähnt, rundl.-eyf., tief-herzf., Bucht abgerundet, offen, die stengelst. mit tief-herzf. Basis stengelumfassend; Rhizum schief, abgebissen; WKöpfe aufstrebend. 24. Felsige O. der A.; Tyrol bis Oestr. Jun.-Aug. D. caucasicum DC. pr. wegen der kahlen Randachenen. K. syn. ed. 1. Arnica cordata Wulf.

4. D. a ustriac un Jacq. Die WB. fehlerd, die untersten 1-2 StB. viel klciner als die übrigen, die folgenden zalltreich, genähert, herzf., zugespitzt, gezähnelt, geöhrelt-gestielt, die oberen längl., stengelumfassend, die obersten lanzettl.; Rhizom abgebissen; Ausläufer fehlend. 2. A.; Tyr. bis Oestr. Jun.-Aug.

\section{ARÓNICUM Necker. Schwindelkrant.}

1. A. Clu sii Koch. B. krautartig-weich, eyf., od. längl., entfernt-gezähnt od. ganzrandig, die unteren gestielt, die stengelst. halbstengelumfassend; Haare der Bthstiele sämmtl. spitz, gegliedert mit entfernt-gestellten Gelenken; St. röhrig; W. wagerecht. 24. Feuchte O. der A., zerstr. deh die AK. Jul. Aug. A. Doronicum DC. prodr. Arnica Doronicum Jacq. A. Clusii All. Doronicum Clusii Tausch. Bl. gelb, wie der folgend. „Der St. weniger starr, vielmehr leicht $\mathrm{zu}$ biegen, röhrig, die StB. nicht starr $u$. fest, vielmehr weich $u$. biegsam" Wulfen. Die Pfl. behaarter als A. glaciale; „die Strahlenbth. schliessen des Nachts oberwärts zusammen" Hoppe.

2. A. glaci a le Reichenb. B. starr, dicklich, eyf. od. längl., gezähnt od. ganzrandig, die unteren gestielt, die stengelst. halbstengelumfassend; Haare der Bthstiele sämmtl. spitz, gegliedert mit entferntgestellten Gelenken; St. starr, gefüllt, nur unter dem Köpfchen leer; W. schief hinabsteigend. 2. Feuchte $O$. der höchsten A. in der Nähe der Gletscher, zerstr. dch die AK. Jul. Aug. A. Clusii $\delta$. glaciale K. syn. ed. 1. A. scorpioides $\gamma$. glaciale DC. pr. Arnica glacialis Wulf. St. starr, B. dicklich, fast zerbrechlich. Die Strahlenbth. bleiben des Nachts ausgebreitet, Hoppe.

3. A. scorpioides Koch. B. gezähnt, die unteren breit-eyf., an der Basis stumpf, abgeschnitten od. fast herzf., die stengelst. eyf. od. längl., die oberen stengelumfassend; Haare der Bthstiele stumpf, gegliedert mit dicht-genäherten Gelenken. 24. Kiesige, felsige O. der 
A. Jul. Aug. Arnica scorpioides L. StB. sitzend, halbumfassend, die unteren gestielt, der Bstiel nicht geöhrelt: A. scorpioides Rchb., A. scorpioides $\beta$. DC. pr., od. an der Basis geöhrelt: A. latifolium Rchb., A. scorpioides $\alpha$. DC.

\section{ARNÍCA L. Wolverley.}

1. A. montana I. WB. längl.-vkteyf., fast ganzrandig, 5nervig; St. wenigköpfig; Bthstiele u. HK. zottig od. drüsig-flaumig. 4. Waldwiesen, gebirgige feuchte $\mathrm{O}$, in die A. hinauf. Jun. Jul. Bl. gelb.

\section{CINERARIA L. Aschenpflanze.}

1. C. crisp a Jacq. Ebenstrauss endst., einfach; B. glatt, etwas spinnwebig-wollig, gezälnt, die $W .-u$. unteren $S t B$. eyf., herzf., die folgenden in den breit-geflügelten, mehr od. weniger gezähnten Bstiel zsgezogen, die oberen lanzettl. od. lineal., fast ganzrandig; Fruchtkn. kahl; Pappus so lang od. kürzer als die Röhre. 2. VorA. u. Schles. u. Mähr. Gbge., Erzgbge. Mai. Jun. Bl. hell-, dotter- od. safrangelb. Var. $\alpha$. genuina: stengelst. Bstiele breit-geflügelt $u$. sowie die B. selbst gezähnt-gekräuselt. Senecio crispatus DC. - $\beta$. rivularis: Bstiele gezähnt od. ganzrandig, nicht gekräuselt; Blättchen des HK. gleichfarbig-griin. C. rivularis W. K. Senecio rivularis DC. - $\gamma$. sudetica: Bstiele gezähnt od. ganzrandig, nicht gekräuselt; Blättchen des HK. entweder ganz od. nur an d. Spitze purpurn. Senecio sudeticus DC. $-\delta$. crocea: HK. purpurn, Bl. safrangelb: C. crocea Tratt. Pappus kürzer als die Röhre: Senecio croceus DC.

2. C. pratensis Hopp. Ebenstrauss endst., einfach; $B$. etwas spinnwebig-wollig, die urteren ausgeschweift-gezälınelt, längl., an der Basis in den Bstiel verschmälert, die folgenden lanzettl., an der Basis verschmälert, die oberen sitzend, lanzettl. u. lineal.; Fruchtkn. kahl; Pappus während der Bthzeit ohngefähr so lang als die Röhre. 4. Feuchte Wiesen; bei Salzbg. Mai. Jun. Senecio pratensis DC. Bl. gelb. Var. $\beta$. discoidea: Strahl fehlend. C. pratensis eapitata Hopp. et. Hornsch., nicht Wahlenb.

3. C. long if olia Jacq. Ebenstrauss endst., einfach; $B$. kurzh.rauh, mehr od. weniger wollig, die wurzclst. eyf. $u$. längl., gekerbtgezähnt od. ganzrandig, die folgenden verlängert-lanzettl., an der Basis verschmälert; die oberen sitzend, lanzettl. u. lineal.; Fruchtkn. flaumig; Pappus während der Bthezeit so lang als die Röhr€ der Bl. od. kürzer. 24. Alpenwiesen; Oestr., Kärnth., Stmk., Tyrol. Mai. Jun. Senecio brachychactus DC. Bl. gelb. Var. $\beta$. discuidea: Strahl fehlend.

4. C. alpestris Hoppe. Ebenstrauss endst., einfach: B. kurzh.rauh $u$. mehr od. weniger wollig, die unteren eyf. od. fast herzf., gekerbt-gezühnt, die folgenden längl.-eyf., in den breit-geflügellen, keiligen Bstiel zsgezogen, dis obcren sitzend, lanzettl. u. lineal.; Fruchtkn. kahl od. schwach-flaumig; Pappus während der Bthezeit, 
so lang als die Röhre, od. kürzer. 2. VorA.; Oestr., Stmk., Tyr., Kärnth., Krain. Mai-Jul. Bl. gelb. Var.: Mit gegliederten Haaren spärlicher bestreut, od. dch solche dicht kurzh.-rauh u. zugleich mehr od. weniger mit Wollhaaren bedeckt. a. legitima: Fruchtkn. etwas flaumig. C. alpestris Koch. - $\beta$. Clusiana: Fruchtkn. kahl, B. dicht wollh. C. Clusiana Host. Senecio alpestris DC. $-\gamma$. ovirensis: Fruchtkn. kahl, B. dicht wollig, die unteren StB. weniger spatelig. C. ovirensis Koch. C. crassifolia Kit. Senecio ovirensis DC.

5. C. s pathul a folia Gmel. Ebenstrauss endst., einfach; $B$. mit gegliederten, kurzen Haaren spärl. bestreut u. zugleich oberseits spinnwebig-flockig, unterscits weiss-uollig, die untersten eyf., an der Basis fast abgeschnitten, gekerbt od. gezähnelt, die folgenden eyf.längl., in den breit-geflügelten, keiliger Bstiel zsgezogen, die oberen sitzend, lanzettl.-lineal.; HK. wollig; Fruchtkn. dicht-u. kurz-steifh.; Pappus während der Bthezeit ungefähr so lang als die Bl. 2. Steinige, waldige 0 .; zerstreut deh das siidl. u. mittlere Geb. Mai. Senecio spathulaefolius DC. Bl. gelb. Var. $\beta$. discoidea: Köpfchen ohne Strahl. Eine Form mit fast kahlen u. mehr spateligen B.: C. tenuifolia Gaud.

6. C. campestris Retz. Ebenstrauss endst., einfach; $B$. fast glatt, spinnwebig-wollig, die wurzelst. eyf. od. rundl., in den kurzen Bstiel zsgezugen, ganzrandig od. etwas gekerbt, die unteren stengelst. längl., nach der Basis verschmälert, die obersten lanzettl.; HK. fast kahl, an der Basis wollig, an der Spitze meist ungefleckt; Fruchtkn. dicht- u. kurzh. - steifh.; Pappus während der Bthezeit ungefähr so lang als die $B l$. 24. Sonnige Hiigel, trockne Wiesen; zerstreut im siidöstl. u. mittl. Geb. Jun. Jul. Senecio campestris DC. Bl. hellgelb.

7. C. a urantiaca Hoppe. Ebenstrauss endst., einfach; $B$. fast glatt, spärl.-wollig, die uurzelst. eyf., in den kurzen Bstiel zsgezogen, ganzrandig, od. etwas gekerbt, die untersten stengelst. lanzettl., nach der Basis verschmälert, die oberen lineal.; St. oberwärts wegen der entfernten $B$. fast nackt; $H K$. gefärbt; Fruchtkn. dicht- u. kurzsteifh.; Pappus während der Bthezeit so lang als die Bl. 2. A. u. VorA.; Kärnth., Stmk., Böhm. Mai-Jul. Senecio aurantiacns DC. Bl. rothpomeranzenf. Var. $\beta$. lanata: dicht-wollig. C. capitata K. syn. - $\gamma$. discoidea: Strahl fehlend. C. capitata Wahlenb.

8. C. palustris L. Zottig; St. oberwärts ästig; Aeste ebensträussig; B. lanzttl., halbstengelumfassend, die unteren buchtig-gezähnt. $\odot$. Sumpfige O.; nördlich Geb. bis Schles. Jun. Jul. Senecio palustris DC. Bl. hellgelb.

43. LIGULARIA Cass. Ligularie.

1. L. sibirica Cass. B. fast pfeil-herzf., gezähnt; Traube endst., einfach. 2. Sumpfige Wiesen; Habichtstein, Münchengrätz in Böhm. Jun. Jul. Cineraria sibirica L. Bl. gelb. 


\section{SENECIO L. Kreuzwurz.}

§. 1. Bth. sämmtl. röhrig, od. die randst. zurückgerollte Zungenbth. Bl. gelb.

1. S. vulgaris L. B. kahl od. spinnwebig-wollig, fiedersp., die unteren in den Bstiel verschmälert, die oberen mit geöhrelter Basis stengelumfassend; Fieder entfernt, längl.-stumpf, an der Spindel $u$. den Oehrchen spitz-ungleich-gezähnt; Schuppen des Aussenkelches meist 10, angedrückt, viel kürzer als der HK., lang-schwarz-gespitzt; die randst. Zungenbth. fehlend; Achenen flaumig. ○. Kultiv. O., Sandplätze. Blühet fast das ganze, Jahr hindch. Var. seltener: $\beta$. radiatus: Köpfchen strahlend: S. denticulatus Mïller. fl. dan. nach Nolte; nördl. Hannov. u. Holst.

2. S. viscosus L. B. tief-fiedersp., nebst den Bthstielen u. den HK. drüsig-haarig, klebrig; Fieder längl., ungleich-gezähnt u. fast fiedersp., nach der Basis allmählig an Grösse abnehmend; AussenK. locker, halb so lang als der HK.; Zungenbth. zurückgerollt; Achenen kahl. - $\odot$. Waldige O., Sandplätze. Jun.-Oct.

3. S. sylvaticus L. B. spinnwebig-flaumig, tief-fiedersp.; Fieder fast lineal., gezähnt u. fast fiedersp., die dazwischen-geschobenen kleiner; Ebenstrauss weitschweifig, gleichhoch; HK. kahl od. flaumig; AussenK. sehr kurz, angedrïckt, meist ungefleckt; Zungenbth. zurückgerollt; Achenen grau-flaumig. $\odot$. Sandige Wälder. Jul. Aug.

§. 2. Bth. des Randes abstehende Zungenbth. B. eingeschnitten, fiedersp. od. herzf. $u$. an der Basis etwas leierf. Bl. gelb.

4. S. vernalis W. K. St. wollig; B. beiderseits $v$. abstehenden Haaren zottig, längl., fiedersp.-buchtig, die unteren gestielt, die übrigen mit geöhrelter, gezähnter Basis stengelumfassend; Fieder eyf., stumpf, nebst der Spindel u. dem Rande kraus u. gezähnt; Ebenstrauss locker; AussenK. 6-12blätterig, 4mal kürzer als der HK. u. nebst den Deckblättern an der Spitze lang-schwarz-zugespitzt; Strahl abstehend; Achenen grau-flaumig; Pappus bleibend. ○. Wälder u. kultiv. O.; Schles. Apr.

5. A. nebrodensis L. B. kahl od. etwas wollig, die unteren längl.-vkteyf., leierf., gestielt, die stengelst. mit gezähnten Oehrchen stengelumfassend, die mittleren fiedersp.; Fieder längl., stumpf u. nebst der Spindel gezähnt, die vorderen zsfliessend; Ebenstrauss locker; Aussenk. 6-12blätterig, 4mal kürzer als der HK. u. nebst den Deckblättern an der Spitze lang-schwarz-gespitzt; Strahl abstehend; Achenen grau-flaumig; Pappus hinfällig. ○. A. u. VorA.; v. Veltlin bis Unteröst. u. Istrien. Mai. Jun. S. rupestris u. S. montanus Willd. - Der S. rupestris WK. hat nach der Beschreibung perennirende W., unsere Pflauze ist annua. Var. ohne Strahl.

C. S. squ a I idus L. B. kahl od. zottig-wollig, fiederth., die un- 
teren gestielt, die mittleren mit vielth. Oehrchen stengelumfassend; Fieder lineal. $u$. nebst Spindel fast ficdersp.-gezähnt, sämmtlich entferntstehend; Ebensträusse zerstreut, armblïthig; AussenK. meist 1 blätterig u. nebst d. Deckblättern an d. Spitze brandfleckig; Strahl abstehend; Achenen grau-flaumig. $\odot$. Accker, Weinberge; Litt. Host. Jun. Jul. S. chrysanthemifolius Poir., DC. prodr.

7. S. abrota nifolius L. B. kahl, die unteren doppeltgefiedert; Fieder schmal, lineal., ganzrandig, seltener 1zähnig, die der Basis kleiner; Bstiel öhrchenlos, fiedersp.-gezähnt, Zähne lineal.-pfrieml.; Spindel ganzrandig; Ebenstrauss 3-6köpfig; Aussenk. halb so lang als der HK.; Strahl abstehend; Achenen kahl; Pappus bleibend. 24. A. u. VorA. Jul. Aug.

8. S. erucaefolius L. B. fiederth., die unteren gestielt, die iibrigen sitzend; Fieder lineal., gezälnt $u$. fiedersp., die der Basis kleiner, ganzrandig, öhrchenf.; Spindel ganzrandig; Ebenstrauss vielköpfig, gedrängt; AussenK. mehrblättrig, angedrückt, halb so lang als der HK.; Strahl abstehend; Achenen haarig-rauh, sämmtl. mit gleichf. Pappus; W. kriechend. 24. Unkult. O., Lehm- und Kalkboden. Jul. Aug. S. tenuifolius Jacq. u. Smith.

9. S. Jacobaea L. Die W.- u. unteren StB. gestielt, längl.vkteyf., an der Basis verschmälert, leyerf., die übrigen stengelst. mit vielth. Oelurchen stengelumfassend, ficderth.; Fieder gezälnt od. fast fiedersp., vorne 2sp., Zpfl. auseinanderfahrend; Spindel ganzrandig; Aeste des Ebenstrausses aufrecht; AussenK. meist 2blättrig, sehr kurz, angedrückt; Strahl abstehend; Achenen des Mittelfeldes haariggrau, die des Randes kahl, diese mit wenig-behaartem, hinfälligem Pappus; W. abgebissen, faserig. $\odot$. Wiesen, unkultiv. O. Jul. Aug. Var. $\beta$. discoideus: Strahl fehlend.

10. S. aquaticus Huds. Die W.- u. unteren StB. gestielt, längl.-eyf., an der Basis verschmälert, ungeth. u. fast leyerf., die iibrigen stengelst. mit getheilten Oehrchen halbstengelumfassend, an der Basis eingeschnitten od. leyerf., die seitenst. Fieder längl. od. lineal., schief aus der Mittelrippe ausgehend, die endst., eyf.-längl., gezähnt od. fast lappig, die oberen B. fiedersp. od. ungeth., gezähnt; Ebenstrauss aufrecht-abstehend, locker; AussenK. meist 2blättrig, angedrückt, sehr kurz; Strahl abstehend; Achenen des Mittelfeldes schwach-flaumig, die des Randes kahl, diese mit wenig behaartem, hinfälligem Pappus. $\odot$. Feuchte Wiesen; zerstr. dch das Geb. Jul. Aug. Köpfchen grösser als an S. Jacobaca. S. barbareaefolius Rchb. eine grössere Form.

11. S. erraticus Bertolon. B. leyerf., die unteren gestielt, die iibrigen mit getheilten Oehrchen halbstengelumfassend; Fieder gezähnt, meist zu 5, die seitenst.-weit abstehend, vkteyf.-längl., die endst. der WB. sehr gross, herz-eyf., die der oberen keilig; Ebenstrauss spreitzend, locker; AussenK. meist 2blättrig, angedrückt, sehr kurz; 
Strahl abstehend; Acheren des Mittelfeldes kahl od. schwach-flaumig, die des Randes kahl, diese mit wenig-behaartem, hinfälligem Pappus. $\odot$. Feuchte Wiesen, Ufer; zerstr. im südl. u. östl. Geb. Jul. Aug. S. barbareaefolius Irrock. nach Buch u. Wimmer.

12. S. l yratifolius Reichenb. $B$. unterseits dünn-spinnwebigfilzig, leyerf., mit vielth. Ochrchen halbstengelumfassend, die Seitenlappen längl., gezälınt-gesägt, der endst. sehr gross, geschärft-doppeltgesägt od. an der Basis fast fiedersp.-eingeschnitten, der der StB. eyf., der obersten längl.; Strahl abstehend; Achenen flaumig. 4. Thäler der A. Jul. Aug. S. alpinus L. fil. Cineraria alpina $\beta$. alata $\mathrm{L}$.

13. S. cordatus Koch. B. unterseits dünn-spinnwebig-filzig, gestielt, herzf., eyf., anderthalbmal so lang, als breit, ungleich-gezähnt, Bstiel mit Anhängsel od. nackt; die obersten B. lanzettl., Bstiel schmal, ganzrandig, an der Basis etwas geöhrelt, Oehrchen kurz, kaum halbstengelumfassend; Strahl abstehend; Achenen kahl. 4. A. u. YorA. Jul. Aug. S. alpinus $\beta$. cordifolius DC. prodr., aber nicht S. alpinus Scopoli.

14. S. subalpinus Koch. B. kahl, unterseits auf den Aderu kurzh., herzf., so breit als lang, gezähnt, gestielt; Bstiel nackt od. der der oberen B. mit Anhängsel, die obersten B. lanzettl., eingeschnitten-gezähnt, od. ungeth., Bstiel derselben breit-geflügelt, an der Basis geölirelt, stengelumfassend; Strahl abstehend; Achenen kahl. 24. A. u. VorA. und Schles. Gbg. Jul. Aug. S. alpimus $\beta$. auriculatus Rehb., DC., nicht Scopoli's S. alpinus.

15. S. carniolicus Willd. B. v. angedrücktem, fast seidenh. Filze grau, fast kahl werdend, die W.- u. unteren StB. lang-gestielt, eingeschnitten-gekerbt od. fiedersp., Fieder stumpf, ganzrandig u. gekerbt; die obcren B. kurzgestielt, öhrchenlos, Fieder lineal., spitz; Strahl abstehend; Achenen kahl. 24. Hohe A. Jul. Aug. Nach v. Salis M. Variet. des Folg.

16. S. incanus L. B. v. wolligem Filze schneeweiss, die wurzelu. unteren stengelst. eyf., fiedersp., Fieder stumpf, eingeschnitten 23 fach gekerbt; die oljeren B. kurzgestielt, öhrchenlos, Fieder lineal., spitz; Elenstrauss diclit; Strahl abstehend; Achenen kahl. 4. Kiesige O. der höchsten A.; Tyrol u. Schwz. Jul. Ang.

17. S. un if 1 or us All. B. schneeweiss-filzig, die wurzel- u. unteren stengelst. eyf., eingeschnitten-gekerbt, die oberen lineal., ganzrandig; St. $1 k o ̈ p f i g ;$ Achenen flaumig. 2. Höchste A. im Wallis. Jul. Aug. Nach Allioni u. Lagger, Variet. v. S. incanus.

§. 1. Strahlen des Randes abstehend; B. gesägt od. ganzrandig, (weder eingeschnitten, noch zertheilt).

18. S. C a caliaster Lam. B. elliptisch-lanzettl., zugespitzt, ungleich-gezähnt-gesägt, Spitzchen der Sägezähne gerade; die unteren 
B. kurz-herablaufend, die oberen sitzend; Deckblätter lineal.; Ebensträusse vielköpfig; Strahl fehlend. 24. Gbge u. VorA.; im ganzen Südtyrol nicht selten. Jul. Aug. Cacalia saracenica L. Bl. gelbl.-weiss. Der St. an der lebenden Pfl. 1nnter Blattbasis mit 3 starken Riefen, welche 2 tiefe Rinnen $\mathrm{zw}$. sich lassen, was bei der getrockneten Pflanze nicht melır so deutlich ist. An S. nemorensis sind diese Riefen nur schwach angedeutet. Kommt sehr selten mit einem Strahle vor, nach Dr. Facchini.

19. S. nemorensis Linn. B. lanzettl, elliptisch od eyf., kahl od. unterwärts flaumig, ungleich-gezähnt-gesägt, mit geraden Spitzchen der Zähne, die unteren in einen geflügelten Bstiel zsgezogen, die oberen sitzend, od. alle gestielt; Ebenstrauss vielköpfig; DeckB. lineal., od. lanzettl.-lineal.; Aussen K. 3-5blätterig; so lang als der HK.; Strahl 5-8bth.; Achenen kahl. 2. Wälder der niedrigeren 11. höheren Berge. Jul. Aug. Var. $\alpha$. genuinus: Köpfehen breiter, 5-6strahlig. S. nemorensis Willd. S. frondosus Tausch. $-\beta$. odoratus: dieselbe Pflanze mit stärkerem Geruch der Köpfchen. S. Jacquinianus Reichenb. S. nemorensis Jacq. - $\gamma$ octoglossus: dieselbe Pflanze mit 7-8strahligen Köpfchen. S. octoglossus DC. S. nemorensis L. nach der Diagnose. - $\alpha . \beta . \gamma$. zusammen: S. fontanus Wallr. -

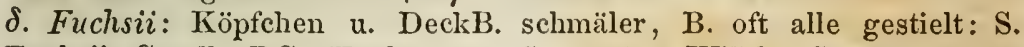
Fuchsii Gmell. DC. Koch syn., S. ovatus Willd., S. saracenicus Wallr., u. schmalblätterig: S. salicifolius Wallr.

20. S. saracenicus L. B. ziemlich kahl, längl.-lanzettl., sehr spitz, an der Basis keilig, die untersten in den geflügelten Bstiel verschmälert, die übrigen nit breiter Basis sitzend, sämmtl. ungleichgezähnelt-gesägt, Spitzchen der Sägezähne vorwärts-gekrümmt; Ebenstrauss vielköpfig; Deckblätter lanzettl.-lineal.; AussenK. 5blätterig, ungefähr so lang als der HK.; Strahl 7-8bthg.; Achenen kahl. 4 . Feuchte Hecken, Weidengebïsch, Flussufer. Jul. Aug. Bl. gelb. Linne sagt (Sp. pl. p. 1222) "unterscheidet sich deh weit kriechende W." S. fluviatilis Wallr.

21. S. Doria L. B. ganz kahl, ins Meergrüne ziehend, kleingesägt od. fast ganzrandig, längl., die untersten in den Bstiel verschmälert, die mittleren sitzend, fast herablaufend, die obersten sehr verkleinert, eyf., verschmälert-zugespitzt; Ebenstrauss vielköpfig; Deckblätter aus eyf., fast herzf. Basis lineal.-pfrieml.; AussenK. sehr kurz; Strahl 5bth.; Achenen flaumig. 24. Wiesen, Triften; Unteröstr. Jul. Aug. Bl. gelb.

22. S. palud os us L. B. sitzend, verlängert-lanzettl., verschmälert-spitz, geschärft-gesägt, kahl od. unterseits filzig; Ebenstraúss vielköpfig; Strahl meist 13bth.; AussenK. meist 10blätterig, halb so lang als der HK.; Achenen schwach-flaumig od. kahl. 24. Sumpfige Wiesen, Gräben; zerstreut dch das Geb. Jul. Aug. Bl. gelb. Var. 
$\beta$. glabratus: B. beiderseits kahl. S. bohemicus Tausch. Dieser in Böhm. und Stmk. $-\gamma$. tomentosus: Blätter unterseits dicht- u. weissfilzig. S. Sadleri Lang.

23. S. Doronicum L. B. lederartig, kurzhaarig-rauh, etwas wollig od. fast kahl, die unteren längl.-lanzettf., gezähnt od. kleingezähnelt, gestielt, die untersten öfters eyf., die oberen lanzettf., stiellos; St. 1-3köpfig; HK. ziemlich kahl, od. etwas wollig; AussenK. vielblätterig, so lang als der $H K$.; Strahl reichbth. 2. A. u. VorA. Jul. Aug. Bl. gold- od. pomeranzengelb.

24. S. I a natus Scopoli. 1772. B. krautartig-weich, wollig od. ziemlich kahl, die unteren spatelig-eyf., gezähnelt, gestielt, die oberen lanzettf., stiellos; St. $1 \mathrm{köpfig;} \mathrm{HK.} \mathrm{dicht-wollig;} \mathrm{AussenK.} \mathrm{vielblät-}$ terig, so lang als der $H K$.; Strahl reichbth. 24. Niedrigere Berge; Litt. Mai-Jun. Bl. hellgelb. S. arachnoideus Sieb. 1812., DC. 1837. S. Scopolii Hopp. et Hornsch.

II. Unterordng. $C Y N A R E E N$. Lessing. Gf. der Zwitterbth. oben in einen Knoten verdickt, am Knoten oft kurzh.

XII. Gruppe. CALENDULACEEN. Cass. Bth. des Strahles weibl., fruchtbar, des Mittelfeldes zwitterig od. männl., 5sp., fehlschlagend. Fruehtb. nackt.

45. CALÉNDULA L. Ringelblume.

1. C. arvensis L. Achenen am Rande ganz, auf dem Rücken weichstachelig, die 3-5äussersten lineal., geschnäbelt, Schnabel aufrecht, wenige eyf., nachenf., die inneren lineal., in einen Ring zsgekrümmt; B. längl.-lanzettl., etwas gezähnelt, die unteren an der Basis verschmälert, kurz-gestielt, die oberen mit. abgerundeter Basis halbstengelumfassend; St. ausgebreitet. $\odot$. Kultiv. O., Weinberge; zerstreut v. Basel dch EIsass bis Coblenz, Mosel-, Neckar- u. Mainthal, Thüring., Sachs., Böhm. Jul.-Oct. Bl. gelb.

XII. Gruppe. ECHINOPSIDEEN. Cass. Einblüthige Hauptkelche ein kugeliges Köpfchen bildend.

\section{ECHINOPS L. Kugeldistel.}

1. E. spliaerocephalus L. B. oberseits v. etwas klebrigen Haaren flaumig, unterseits wollig-filzig u. grau, Zpfl. längl.-eyf., buchtig, dornig-gezähnt; HK. an der Basis borstig, Borsten länger als die halbe Länge dessclben, die äusseren Blättchen desselhen drüsig-haarig; Strahlen des Pappus nur an der Basis zsgewachsen. 24. Weinberge, steinige $\mathrm{O}$; ; sehr zerstreut deh das Geb. Jul. Aug. B1. weiss.

2. E. cxaltatus Schrad. B. oberseits mit doruigen Borstchen locker bestreut, unterseits wollig-filzig u. grau, tief-fiedersp., Zpfl. 
längl., fiedersp.-buchtig, dornig-gezähnt; IIK. an der Basis borstig, Borsten fast dreimal kürzer als derselbe, Blättchen auf dem Rücken kahl; Strahlen des Pappus bis an die Spitze zsgewachsen. 24. Waldige O.; Litt. in dem waldigen Thale v. Suschiza unweit des Dorfes Nacle, Tommas. Jul. Aug. Bl. weiss.

3. E. Ritro L. B. oberseits kall od. etwas spinnwebig-wollig, unterscits schneeweiss-filzig, doppelt-fiedersp., dornig-gezähnt; HK. an der Basis borstig, Borsten fast 3mal kürzer als derselbe, Blättchen desselben auf dem Rücken kahl. 24. Somnige Hügel; Littor. Jul. Aug. Bth. amethystfarben, Bthstiele filzig, nicht borstig.

XIV. Gruppe. CARDUINEEN. Cass. HK. reichbth. Bth. zwitterig. Pappus abfällig, haarig od. federig, (nicht aber ästig).

47. CIRSIUM Tournef. Kratzdistel.

I. Rotte. Epitrachys DC. B. oberseits dornig-kurzh. Bth. purpurn.

1. C. lanceolatum Scop. B. herablaufend, oberseits dornigsteifh., unterseits etwas spinnuebig-wollig, tief-fiedersp., Fieder 2sp., $\mathbf{Z p f l}$. lanzettl., ganzrandig, der vordere an der Basis gelappt, Zpf. u. Lappen mit einem derben Dorn endigend; Köpfchen einzeln, evf., spinnwebig-wollig; Blättchen des HK. lanzettl., mit der pfriemlichen, in einen Dorn endigenden Spitze abstehend. (.) Wege, Triften, Schutt. Jun.-Sept. Carduus lanceolatus L.

2. C. nemorale Rehb. B. herablaufend, oberseils dornig-steifh., unterseits'-ueiss-wollig, fiedersp., Fieder 2sp., Zpfl. lanzettl., ganzrandig, der vordere an der Basis dch ein Läppchen vergrössert, $Z$ pfl. u. Lappen mit einem Dorn endigend; Köpfchen einzeln, rundl., spinnwebig-wollig; Blättchen des HK. lanzettl., mit der pfriemlichen, in einen Dorn endigenden Spitze abstehend. $\odot$. Wald $\mathrm{r}$. Lindenthal bei Leipzig. Jul. Aug. C. lanigerum Nägeli.

3. C. eriophorum Scop. B. stengelumfassend, nicht herablaufend, oberseits dornig-steifh., unterseits filzig, tief-fiedersp., Fieder 2th., Zpfl. lanzettl., ganzrandig, der vordere an der Basis gelappt, Zpf. u. Lappen mit einem Dorn endigend; Köpfehen einzeln, kugelig, spinnwebig-wollig; Blättchen des HK. lanzettl., mit der lineal., vor dem Dorne verbreiterten Spitze abstehend. (-) Gebirgige O., VorA. u. A.; siidl. u. mittleres Geb. Jul. Aug. Carduus eriophorus L.

II. Rotte. Chamaeleon B. oberseits nicht dornig-kurzh. Blättchen des HK. mit einem einfachen Dorn od. fast wehrlos. Bth. zwitterig.

§. 1. B. völlig od. doch etwas herablaufend.

4. C. palustre Scop. B. gänzl.- herablaufend, zertreut-haarig, tief-fiedersp., Fieder 2sp., Zpfl. lanzettl., ganzrandig, der vorlere an der 
Basis gelappt, Zpfl. u. Lappen mit einem Dorne endigend; Aeste an der Spitze viєlköpfig;, Köpfchen traubig-geknäuelt; Blättchen des HK. dornig-stachelspitzig. (-). Nasse Wiesen, sumpfige O. Jul. Aug. Carduus palnstris I. Bl. purpurn. Ausgelaufene Aeste nach der Heuernte sind obcrwärts fast nackt u. haben nur halbherablaufende B. : C. Chailleti Gaud., nicht K. syn. ed. 1. Var. mit rispigen Köpfehen.

5. C. canum M. Bieberst. B. zerstreut-haarig, unterseits oft etwas spinnwebig-wollig, verlängert-lanzettl., dornig-gewimpert, entfernt-geschweift-gezähnt od. buchtig-fiedersp., Fieder 3eckig-lanzettl., spitz, oft 2lappig; die unteren stengelst. B. herablaufend; der St. ganz einfach, 1köpfig od. oberwärts ästig, Aeste verlängert u.1köpfig, fast nackt; HK. deckblattlos; $W$. büschelig, Fasern verdickt, spindelf. 4. Feuchte Wiesen; Böhm., Mähr., Schles., Sachs. Jul. Aug. Carduus canus L. B. purpurn.

6. C. pannonicum Gaud. B. zerstreut-haarig u. unterseits oft spinnwebig-wollig, längl.-lanzettl., ungeth., ganzrandig od. gezähnelt, ungleich-dornig-gewimpert, die wurzelst. in den Bstiel verschmälert, die mittleren stengelst. hinten verschmälert, an der Basis selbst etwas verbreilert, halbstengelumfassend, kurz-herablaufend; der St. v. der Mitte an nackt, mit wenigen schuppenf. DeckB. bestreut, 1-3köpfig; Bthstiele verlängert; $H K$. deckblatilos; Rhizom schief, Fasern fädl. Ђ. Gebirgige 0.; siidl. Tyrol, Kärnth., Krain, Litt. Jun. Jul. Carduus pannonicus L. fil. C. serratuloides Jacq., nicht L. Bl. purpurn.

7. C. Freyerianum Koch. B. kahl od. zerstreut-behaart, lanzettl., fiedersp.-buchtig, Fieder eyf., 2-3sp., Lappen kurz, dornigwimperig u. mit einem stärkeren Dorn endigend; die mittleren stengelst. B. kurz herablanfend; St. einköpfig, v. der Mitte an nackt, od. 2köpfig mit verlängerten Bthstielen; $H K$. deckblattlos; Blättchen des HK. angedruickt. 24. Unkultiv. O., Gottschee in Unterkrain. Die Köpfchen wie an C. tuberosum, die B. fast wie C. acaule, aber lauchgrïn. St. oberwärts mit einigen sehr kleinen $B$. besctzt.

8. C. carniolieum Scop. B. kurzl., die unteren gestielt, an der Basis abgerundet, eyf., ungeth. od. fiedersp., Zpfl. längl., gezähnt u. nebst den Bstielen ungleich-dornig-gewimpert, d. oberen B. mit herzf. Basis stengelumfassend, kurz-herablaufend; St. oberwärts nebst den Bstielen u. DeckB. rostfarbig-zoltig; Köpfchen endst., 3-4 gehäuft, an der Basis mit DeckB., diese lineal. u. nebst den äusseren Blättchen des HK. am Rande dornig. 2. A.; Krain, Kärnth., Oberöstr. Jul. Aug. C. rufescens Ramond. Bl. gelbl.-weiss.

§. 2. B. nicht heralslaufend.

9. C. pa uciflor um Sprengel. B. oberseits zerstreut-haarig, unterseits spinmwebig-wollig, eyf., am Rande gelappt u. gezähnt, ungleichdornig-gewimpert, die wurzelst. gestielt, an der Basis abgerundet, die unteren stengelst. mit dem geflügelten, gezähnten, an der Basis 
geöhrelten Bstiel stengelumfassend, die oberen mit herzf. Basis sitzend; Köpfchen endst., 2-4, gehäuft, nit d. Spitze d. Bthsticle nickend, mit cinem lanzettl.-gezähnten DeckB. gestïtzt; Blättchen des HK. lanzettl., spitz, kurz-staehelspitzig, fast wehrlos. 24. A.; Stmk. Jul. Aug. Cnicus pauciflorus WK. 131. purpurn.

10. C. Erisithales Scop. B. zerstreut-flaumig, ungleieh-dorniggewimpert, stengelumfassend, tief-fiedersp., die unteren stengelst. in den geflïgelten, gezähnten, an der Basis verbreiterten Bstiel zsgezogen; Fieder längl. od. lanzettl. zugespitzt, gezähnt; Köpfchen auf dem nickenden Bthstiele einzeln od. etwoss gehäuft; Blättchen des HK. dornig-stachelspitzig, von der Mitte an wagerecht-ahstehend od. zurückgekrümmt; der St. oljerwärts fast nackt. 24. A., VorA. u. angrenzende Gbge. Jul. Aug. C. glutinosum Lam., DC. Cnicus Erisithales L. Bl. gelbl.-weiss, sehr selt. roth. Var. grösser, mehrköpfiger, mit weuiger klebrigen Blättchen des HK. C. ochrolencum Nägeli (nicht Allion., dessen Pflanze einen ununterbrochen beblätterten St. u. an dem Ende nur ein wenig zurïkkgebogene Blättchen des HK. hat).

11. C. ochroleucum All. B. zerstreut-flaumig; ungleich-dornig-gewimpert, stengelumfassend, tiff-fiedersp., die unteren stengelst. in den gefiïgelten, gezähnten, an der Basis verbreiterten Bstiel zsgezogen; Fieder längl. od. lanzettl. zugespitzt, gezähnt; Köpfchen auf dem aufrechten Bthstiele fast ebensträussig; DeckB. lanzettl.; Blättchen des $H K$. dornig-stachelförmig, von der Mitte an wagerechtabstehend od. zurückgekrïmmt; der St. bis an die Spitze beblättert. 24. A. u. VorA.; Schwz.? Jul. Aug. Bl. gelbl.-weiss. Die kultiv. Pfl. hat klebrige HK., wie sie Allioni beschreibt.

12. C. heterophyll um Allion. B. oberseits kahl, unterseits schneeweiss-filzig, ungleich-dornig-gewimpert, stengelumfassend, lanzettl. od. elliptiseh-lanzettl., zugespitzt, die wurzel- n. unteren stengelst. gesägt, letztere in den breitgeflitgelter, an der' Basis geöhreltverbreiterten Bstiel zsgezogen, die oberen ganzrandig, sämmtl. ungeth. od. die mittleren vorne eingeschnitten, $\mathrm{Zpfl}$. lanzettl., voruärts gerichtet; St. reichblätterig, 1-3köpfig; Köpfehen endst., einzeln, deckblattlos; Blättchen des HK. angedriiekt. 24. Feuchte Wiesen; A., VorA. u. Gbge ron Mälır., Schles. u. Böhm. Jun. Jul. Bl. purpurn. Carduus heterophyllus L. Var.: alle B. ungeth.; Card. helenioides All., nicht L.

13. C. rivula re Link. enum 2. p. 301. B. zerstrent-flaumig, ungleich - dornig-gewimpert, stengelumfassend, fiedersp., die unteren stengelst. in den geflügelten, gezähnten, an der Basis verbreiterten Bstiel zsgezogen; Fieder lanzettl., zugespitzt, spärl.-gezähnt; St. oberwärts fast naekt; Köpfchen endst., 2-1, meist gehäuft, DeckB. lineal., ganzrandig; Blättchen des $H K$. angedrückt, stachelspitzig. 4. Feuchte Wiesen; A., TorA. u. Ebenen längs der A. u. Gbge v. 
Mähr., Schles., Böhm., in Ostpreussen. Jun. Jul. Cirs. tricephalotes Lam., DC. Carduus rivularis Jacq. Cnicus rivularis u. Cn. salisburgensis Willd. Bl. purpurn.

14. C. oleraceum Scop. B. kahl od. zerstreut-flaumig, ungleich-dornig-gewimpert, stengelumfassend, die unteren fiedersp., Fieder lanzettl., zugespitzt, gezähnt; die oberen stengelst. B. stengelumfassend, ungeth., gezähnt; Köpfchen endst., gehäuft, deckblätterig; die äusseren DeckB. eyf., verbleicht; Blättchen des HK. in ein Dörnchen endigend, an d. Spitze abstehend. 24. Feuclıte Wiesen, Gräben. Jul. Aug. Bl. gelblichweiss. Cnicus oleraceus I.

15. C. spino sisimum Scop. B. kahl, unterseits auf den Nerven etwas zottig, längl. od. lanzettl., die untersten an der Basis verschmälert, die stengelst. stengelumfassend, sämmtlich fiedersp.-gelappt, Lappen eyf., 3sp., Zpfl. spreitzend, dornig-gewimpert u. mit einem verlängerten starken Dorn endigend; St. v. der Basis bis zur Spitze dicht-beblättert, an der Spitze zottig; Köpfchen endst., gehäuft, deckblätterig; DeckB. verbleicht, geschlitzt-fiedersp., dornig; Blättchen des $H K$. mit einem Dorn v. der Länge des $H K$. selbst endigend. 24. Nasse O. der A. Jul. Ang. Bl. gelbl.-weiss.

16. C. a ca ule All. B. kahl, lanzettl.; buchtig-fiedersp.; Fieder eyf., eckig, fast 3sp., Lappen kurz-dornig-gewimpert u. mit einem stärkeren Dorn endigend; das Köpfchen einzeln od. zu $2-3$ auf der Wurzel sitzend, seltener cin ganz einfacher, 1-3köpfiger, von der Basis bis zur Spitze beblätterter St.; Blättchen des HK. angedrückt, kurz-stachelspitzig, die äusseren eyf., 1nervig; Wfasern fädl. 4. Wiesen, Triften. Jul. Aug. Carduus acaulis L. Bl. purpurn.

17. C. bulbos um DC. B. oberseits zerstreut-haarig, unterseits etwas spirnwebig-wollig, dornig-gewimpert, tief-fiedersp., die unteren gezähnt; Fieder gezähnt-kleingelappt u. 2-3sp., Zpfl. lanzettl.; St. $v$. der Mitte an blattlos, 1-3köpfig; Bthstiele verlängert; Blättchen des HK. angedrïckt, klein-stachelspitzig; Wfasern verdickt, an d. Basis u. Spitze verschmälert. 2. Wiesen; westl. Schwz. u. dch Elsass u. Baden bis Mainz, im Maingebiete; Thüring., Harz. Jul. Aug. Bl. purpurn. C. tuberosum All. Carduus tuberosus Pollich. u.' der Autor. C. tuberosus var. $\beta$. L.

18. C. anglicum DC. B. oberseits zerstreut-haarig, unterseits spinnwebig-wollig, längl.-lanzettl., spitz, ungleich-dornig-gewimpert, gezähnt od. fast buchtig, Lappen 2-3sp.; die WB. gestielt, stengelst., wenige, über der stengelumfassenden Basis zsgezogen; St. 1 köpfig, oberwärts blattlos; HK. deckblattlos, ziemlich wollig, Blättchen angedrückt, stachelspitzig. 24. Feuchte Wiesen; Stockach u. Zizenhausen in Oberbaden, Obersteyerm. Jun. Carduus anglicus Lam. C. pratensis Huds. Bl. purpurn.

III. Rotte. Breea Less. B. oberseits nicht dornig-kurzh. Blättchen des HK, mit einem einfachen Dorn. Köpfehen zweihäusig. 
16.

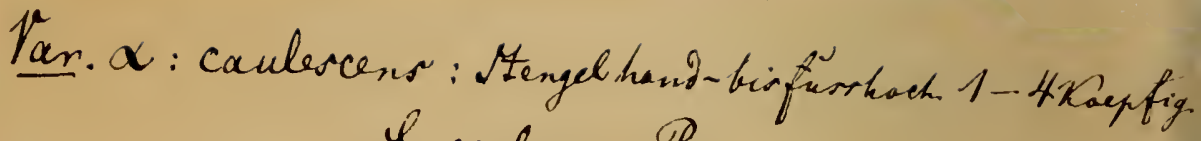
Q. caulercens, Pear.

\# 
19. C. arvense Scop. B. etwas herablaufend, längl.-lanzettl., dornig - gewimpert, ungeth. od. fiedersp.-buchtig, an der Spitze am Ende der Lappen mit einem stärkeren Dorn versehen; Köpfchen rispig-ebensträussig, eyf.; Blättchen des $H K$. angedrïlckt, stachelspitzig, fast wehrlos; W. kriechend. 21. Aecker, kultiv. O. Jul. Aug. Serratula arvensis L. Bth. purpurn, B. unterseits kahl. Var. $\alpha$. horridum: B. sämmtl. wellig, fiedersp., sehr dornig. - $\beta$. mite: StB. buchtig, AstB. ungeth. od. gezähnt, weicher-dornig. - $\gamma$ integrifolium: B. sämmtl. flach, ganzrandig od. etwas gezähnt: Cirsium-setosum MBieb.; dieselbe, die B. nur etwas lappig: Serratula complicata Schweigg. - $\delta$. vestitum: B. unterseits schnecweiss-filzig.

IV. Rotte. Pi cnomon Cass. B. oberseits nicht dornig-kurzh. Blättchen des HK. mit einem gefiederten Dorn.

20. C. A carna DC. fl. fr. B. herablaufend, lanzettl., wollig-grau, gezähnt, dornig; Köpfchen gehäuft, deckblätterig; die inneren Blättchen des HK. mit einem gefiederten Dorn endigend. 24. Felsige, unkultiv. O., Istrien. Jul. Aug. Cnicus Arcana L. Picnomon Arcana Cass. Bl. purpurn.

V. Rotte. Wirkliche od. muthmassliche Bastarde, itber wclche jedoch zum Theil nocl weitere Beobachtungen anzustellen sind, da die Hybridität derselben bis jetzt noch blos auf Vermuthung beruhet:

21. C. pannonico-palustre. (C. Chailleti Koch, syn. ed. 1., nicht Gaud.) B. unterseits spinnwebig - zottig, zuletzt kahl, lanzettl., stumpf-buchtig-gezähnt, dornig-gewimpert, Zähne mit einem ziemlich derben Dorn endigenrl, d. unteren B. gänzl.-herablaufend; St. oberwärts wegen der entfernten, verkleinerten u. wenig herablaufenden oberen B. fast nackt; Ebenstrauss endst., vielköpfig, geknäuelt; Blättchen des HK. an der Spitze dornig. (-). Sumpfige Wiesen; $z w$. Bruck u. Batrandorf unweit Wien. Aug. Bl. purpuru.

22. C. subalpinum Gand. B. zerstrent-haarig, die unteren halbherablaufend, tief-fiedersp.; Fieder lanzettl., spitz, vorne deh einen Zahn vergrössert, ungleich-dolnig-gewimpert, rechtwinkelig-abstehend; St. oberwärts wegen d. entfernten, verkleinerten u. wenig herablaufenden oberen B. fast nackt; Köpfchen 3-4, endst., dicht zsgestellt; DeckB. lineal., kürzer, als das Köpfchen. 2. Nasse Wiesen; Schwz., Oberbayern, Stmk. Jul. Aug. Bl. purpurn. Cnicus palustririvularis Schied. Von C. rivulare versch. dch kleinere Köpfchen $u$. herablaufende $\mathbf{B}$.

23. C. I a c te um Schleich. B. zerstreut-haarig, die unteren halbherablaufend, buchtig-fiedersp. od. fiedersp., Fieder $\epsilon y f$., gezähnt, ungeth. u. 2sp., dornig-gewimpert, Lappen und Zähne mit einem stärkeren Dorn endigend; St. oberuärts wegen der verkleinerten u. wenig 
herablaufenden B. fast nackt; Köpfchen meist zu 6, endst., fast traubig; DeckB. lineal., kürzer als das Köpfchen. 2. Alpenwiesen der Schwz. Jul. Aug. Köpfchen ein wenig kleiner, als bei C. rivulare. Bl. weiss.

24. C. hybridum Koch. B. zerstreut-haarig, die unteren halbherablaufend, tief-fiedersp., d. oberen weniger-herablaufend, ungeth., fast buchtig-gelappt, Fieder gezähnt, fast 2lappig, ungleich-dorniggewimpert, Lappen und Zähne mit einem stärkeren Dorn endigend; St. bis zur Spitze gleich-beblättert; Köpfchen endst., dichtstehend; DeckB. lanzettl., länger als das Köpfchen. ๑. Nasse Wiesen. Jul. Aug. Bl. gelbl. - weiss, schwach-röthl. Gf. violett. Cnicus palustrioleraceus Schied.

25. C. tat aricum Wimm. u. Grab. B. kahl od. unterseits zerstreut-wollig, längl.-lanzettl., dornig-gewimpert, gezähnt, ungeth. od. die wurzelst. buchtig-fiedersp., die stengelst. stengelumfassend, kurzherablaufend; St. ganz einfach, 1 köpfig od. oberwärts ästig, Aeste verlängert $u$. 1köpfig; die HK. an der Basis mit 1-3lineal., am Rande dornigen DeckB.; Rhizom schief, Fasern fädl. 24. Feuchte Wiesen; Oestr., Böhm., Mähr., Schles. Jul. Aug. Cnicus tataricus Bess. Bl. gelbl.-weiss.

26. C. flavescens Koch. (C. spinosissimo-Erisithales.) B. mit zerstreuten Härchen besetzt u. unterseits auf der, Mittelrippe zottig, ungleich-dornig-gewimpert, stengelumfassend, tief-fiederspaltig, die unteren stengelst. in den geflügelten, gezähnten, an der Basis verbreiterten Bstiel zsgezogen, Fieder eyf. od. lanzettl., zugespitzt; Köpfchen auf dem nickenden Bthstiel zu mehreren gehäuft; DeckB. lineal., ungleich-dornig-bewimpert, kürzer als das Köpfchen; Blättchen des HK. in einen Dorn endigend, die inneren stachelspitzig, an der Spitze abstehend od. zurïckgebogen; der St. bis an die Spitze beblättert. 2. Alpenwiesen des Monte di Pozza in Fassa, südl. Tyrol, Dr. Facchini. Jul. Aug. Bl. gelb. Von C. Erisithales versch. dch die DeckB., den bis zur Spitze beblätterten St., u. breitere, genäherte Bzpfl.; v. C. spinosissimum dch breitere tief-fiedersp. B., nickenden Btlıstiel, lineal. DeckB., welche kürzer als das Köpfchen sind, u. schwächere Dornen der Köpfchen.

27. C. praemors um Michl. (C. oleraceo-rivulare DC. pr.) B. zerstreut-flaumig od. kahl, unterseits bleicher od. in das Lauchgrüne ziehend, ungleich-dornig-gewimpert, stengelumfassend, fiedersp., die unteren stengelst. in den gefligelten, gezähnten, an der Basis verbreiterten Bstiel zsgezogen, Fieder lanzettl., zugespitzt, spärlich gezähnt; Köpfchen endst., 2-4, meist gehäuft; DeckB. lanzettl., gezähnt, dornig; Blättchen des HK. nach oben verschmälert, angedrückt od. an der Spitze etwas abstehend, kurz-dornig-stachelspitzig. 2. Feuchte Wiesen; Oberbaiern, Schwz. Jul. Aug. C. erucagineum Gaud. Cnicus oleraceo-rivularis Schiede. Eine Form mit unterseits 
schwach-lauchgrïnen B.: Cirsium semipectinatum K. syn. ed. 1. Cnicus semipectinatus Schleich. nach Ex. vom Autor. Bl. gelbl.-weiss.

28. C. ambigum All. (C. lueterophyllo-rivulare.) B. oberseits kahl, unterseits weisslich-filzig, ungleich-dornig-gewimpert, stengelumfassend, fiedersp., mit hervorgezogener, gezähnter Spitze, die unteren stengelst. in den geflïgelten, gezälnten, an der Basis verbreiterten Bstiel zsgezogen; Fieder lanzettl., zugespitzt, ungetl. u. 2sp., mit einem kurzen Dörnchen endigend; Blättchen des HK. an der Spitze abstehend; Köpfchen endst., 2-5, gehäuft, an der Basis deckblattlos. 24. A. v. Wallis, nach Nägeli, jedoch wahrscheinl. bloss in Piemont. Jul. Aug. Bl. purp. Carduus autareticus Vill. nach DC.

29. C. Cervini Thom. (C. spinosis s imo-heterophyllum? Nägeli.) B. unterseits fein-spinnwebig-filzig, längl. od. lanzettl., die untersten in den Bstiel verschmälert, die stengelst. mit herzf. Basis stengelumfassend, sämmtl. fiedersp.-gelappt, Lappen 2-3sp., Zpfl. lanzettl., dornig-gewimpert u. mit einem verlängerten, schlanken Dorn endigend; St. bis zur Spitze beblättert; Köpfchen endst., 2 u. mehrere, gehäuft, an der Basis $u$. den Bthsticlen deckblätterig; DeckB. lineal.-lanzettl.; Blättchen des HK. in einen Dorn verschmälert, an der Spitze etwas abstehend. 24. Walliser A.; auf dem Matterhorn (Cervin), Graubündner A. bei Hinterrhein u. bei St. Bernardino. Jul. Aug. Bl. röthl. od. weissl., nicht purp., wie Allioni's Name andeutet. C. controversum DC. pr. C. purpureum All. Carduus auta? reticus Vill. nach der Abbildung. DeckB. so lang od. länger als das Köpfchen. Kommt vor: die Köpfchen gestielt, traubig-gestellt, die DeckB. nur halb so lang als das Köpfch.: C. Hallerianum Gaud.; u. DeckB. ebenso, aber die Bzpfl. nicht zweispaltig: C. erucagineum DC. mit Ausschl. v. Expl. u. der Var. $\beta$. nach Nägeli.

30. C. Kocheanum Löhr. (C. palustri-bulbosum Nägeli.) B. zerstreut-behaart, dornig-wimperig, tief fiedersp., Fieder zähnig-lappig od. 2 sp., mit lanzettl. Zpfln., Zpfl. u. Läppchen mit einem stärkeren Dorn endigend, die stengelst. halb herablaufend; St. oberwärts blattlos, 3-8köpfig; Bthstiele nackt; HK. deckblattlos; Fasern der WV. fädl. 24. Wiesen bei Prüm in der Eifel, bei Deidesheim in der Rheinpfalz. Bl. purpurn. Cnicus palustri-tuberosus Schiede.

31. C. Z izianum Koch. (Cacauli-bulbosum.) B. unterseits auf den Nerven flaumig, lanzettl., buchtig-fiedersp.; Fieder eyf., 3sp., Lappen längl., dornig gewimpert u. mit einem stärkeren Dorn endigend; St. einköpfig, v. der Mitte an blattlos, od. $2 \mathrm{köpfig;} \mathrm{Bthstiele}$ verlängert, nackt; Blättchen des IHK. angedriickt, stachelspitzig, die äusseren (getrocknet) an der Spitze 3streifig; Wfasern etwas verdickt. 24. Bergwiesen, um Mainz. Jul. Aug. Cnicus acauli-tuberosus Schied. Bl. purp. Macht sich kenntlich deh die starken Dornen des 
C. acaule $u$. deh den $\mathbf{v}$. der Mitte an nackten St. $\mathbf{u}$. die Köpfehen des C. tuberosum. C. medium All., Nägeli.

32. C. d ecoloratum Koch. (C. acauli-oleraceum.) B. zerstreut-flaumig, ungleich-dornig-gewimpert, die wurzel- u. stengelst. buehtig-fiedersp.; Fiєder eyf., spärlich-gezähnt, fast 2lappig; St. meist $3 k o ̈ p f i g$; Aeste verlängert, beblättert, mit ungeth., gezähnten B.; Köpfchen einzeln, deckblätterig; DeckB. lineal., ungefähr so lang als das Ǩ̈öpfchen. 2. Bergwiesen; Frankf. a. M. Götting., Halle. Jul. Aug. Bth. gelbl.-weiss. C. rigens Wallr., DC. Cnicus acauli-oleraceus Schiede.

33. C. L a chenalii Koch. (C. I ance ol ata-oleraceu m.) B. unterseits auf den Adern etwas zottig, ungleich-dornig-gewimpert, tief-fiedersp., mit gezähnten u. 2-3sp.'Fiedern, u. lanzettl., spreitzenden Zipfeln derselben; die oberen B. sitzend, etwas stengelumfassend u. fast ungeth.; St. bis zur Spitze beblättert; Köpfchen einzeln od. etwas gehäuft, gestielt, deckblätterig, 2-3 DeckB. lineal., ungefähr so lang als die Köpfchen; Blättchen des HK. dornig-stachelspitzig. 4. Feuchte Wiesen; Schwz, Elsass, Rheinpfalz, Franken, Thüring., Pomm. Jul. Aug. Bl. gelbl.-weiss. C. pallens DC. Cnicus Lachenalii Gmel. C. rigens Ait. C. tuberoso-oleraceus Schiede, vermuthlich. Ist Bastard v. C. lanceolatum u. C. oleraceum.

\section{CÝNARA L. Artischocke.}

1. C. Scolymus L. B. etwas dornig, fiedersp. od. ungeth.; Blättchen des HK. eyf. 2. Zum Küchengebrauch kultiv. Aug. Bl.purp.

2. C. Cardunculus L. B. dornig, sämmtl. fiedersp.; Blättchen des HK. eyf. 2. Zum Küchengebrauch kultiv. Aug. BI. purp.

49. SÍLYBUM Gärtn. Mariendistel.

1. S. marian um Gärtn. $\odot$. Gebirgstriften; Litt., übrigens hin u. wieder verwildert. Jul. Aug. Bl. purpurn.

50. TYRIMNUS. Cassini.

1. T. le uc.ograp h us Cass. (.) Unkultiv. u. kultiv. O. bei Lossia auf Osero. Mai. Jun. Carduus leucographus L. St. u. Aeste spinnwebig-wollig; Acste lang u. nackt, einköpfig, B. herablaufend, oberseits spärlich, unterseits dichter spinnwebig-wollig, fiedersp. od. buchtig u. dornig gezähnt, weiss gefleckt.

51. CARDUUS I. Distel.

I. Rotte. Homalolepidoti. Blättchen des HK. angedrückt or. zurückgekrümmt, aber nicht hinabgeknickt.

1. C. pycnocephalus Jacq. B. herablaufend, oberseits etwas zottig, unr unterseits mollig-filzig, buehtig u. fiedersp., Lappen eyf., eckig; gezähnt, dornig; Köpfchen an dem St. und den Aesten endst", 
längl., zu 2 od. mehreren zsgestellt, die seitenst. sitzend; Blättchen des HK. aus breit-lanzettl. Basis zugespitzt, in einen Dorn verschmälert, an der Spitze etwas abstehend. $\odot$. u. $\odot$. Unkultiv. O.; Litt., auf Ballasterde bei Swinemïinde. Jul. Aug. C. tenuifiorus $\gamma$. et $\delta$. DC. pr.

2. C. tenu iflorus Curt. B. herablaufend, oberseits dünu-, unterseits weisslich-wollig, buchtig und fiedersp., Lappen cyf., cckig, gezähnt, dornig; Köpfchen gehäuft, zahlreich, sitzend, fast valzi.; Blättchen des HK. lanzettl., zugespitzt, in einen Dorn verschmälert, etwas abstehend. $\odot$ ? Thäler der A.; im oberen Wallis. C. tenuiflorus $\alpha$. DC. pr. C. microcephalus Gaud. Bl. purp.

3. C. a canthoides L. B. herablaufend, kahl od. unterseits auf den Adern zottig, tief fiedersp., Fieder eyf., fast handf.-3sp., u. gezähnt, dornig-gewimpert, Lappen u. Zähne mit einem starken Dorn endigend; Köpfchen meist einzeln, rundl.; Bthstiele kurz, gekräuselt, dornig. (-). Unkultiv O., Wege. Jul. Aug. C. polyacanthos Schreb. Var. Bthstiele 1-2" lang u. uackt od. auf der einen Seite nackt: C. alpestris Schleich., C. acuminatus Gaud.

4. C. multiflorus Gaud. B. herablantend, zerstreut-haarig, unterseits auf den Adern zottig od. spinnuebig-ucollig, tieffiedersp., Fieder eyf., fast handf.-3sp., u. gezähnt, gewimpert-dornig, Lappen u. Zälnne mit einem stärkeren Dorn endigend; Köpfchen eyf., 3-5, gehäuft; Bthstiele kurz, gekräuselt, dornig. (-). Unkult. O., Wege; Thäler des Jura, bei Trier. Jul. Aug. C. polyanthemus Schleich. K. syn. ed. 1. C. crispus $\beta$. DC. prodr. Bl. purp.

5. C. crispus L. B. herablaufend, oberseits zerstreut-haarig, unterseits wollig-filzig u. auf den Adern etwas zottig, längl., buchtigfiedersp.; Fieder eyf., 3lappig u. gezähnt, der mittlere Lappen grösser, Lappen u. Zähne dornig-gewimpert $u$. mit einem stïrkeren Dorn endigend; Köpfchen rundlich, gehäuft u. cinzeln; Bthstiele kurz, dornig od. an der äussersten Spitze nackt. ๑. Unkultiv. O., Wege. Jul. Aug. Bl. purp.

6. C. P ersonata Jacqu. B. herablaufend, oberseits zerstreuthaarig, unterseits spinnwebig-wollig, ungleich-llonig-gewimpert, die oberen ungeth., ey- u. lanzettf., gesägt-gezähnt, die unteren im $\mathrm{Cm}$ risse breit-eyf., bis zur Mittelrippe fiedersp.; Fieder längl., spitz, lappig u. gezähnt, die oberen zsfliessend; Köpfchen rundlich, gehäuft; Aeste u. Bstiele sehr schmal-geflïgelt od. an der äussersten Spitze nackt. 2. A., VorA. u. Voges., Schwarzw., schwäb. Alp., Gbge v. Böhm., Mrähr., Schles. Jul. Ang. Arctium Personata L. B. purp.

7. C. collinus W. K. B. herablaufend, beiderseits od. unterseits wollig-filzig, od. fast kahl, tief-fiedersp.; Fieder eyf., 3sp. u. gelappt, Lappen dornig-gewimpert u. mit einem stärkeren Dorn endigend; Aeste ruthenf., oberwärts in einem nackten Bthstiel verlaufend, die gekräuselten Flïgel aufwärts allmählig abnehmend u. verschwindend; 
Köpfchen meist einzeln; Blättchen des $H K$. lineal-lanzettl., angedrückt od. abstehend. $\odot$. Sonnige, unkult. O.; Triest, Fiume, Unterkrain. Jul. Aug. Bl. purp. Die Variet. mit anliegenden Blättchen des HK.: C. candicans W. K.

8. C. ham u losus Ehrliart. B. herablaufend, oberseits zerstrenthaarig, unterseits spinnwebig-wollig od. ziemlich kahl, tief-fiedersp., Fïed. eyf.-3sp. u. lappig, Lappen dornig-gewimpert u. mit einem stärkeren Dorn endigend; Aeste ruthenf., oberwärts in den nackten Bthstiel verlaufend, die gekräuselten Flügel aufwärts allmählig abnehmend u. verschwindend; Köpfehen einzeln; Blättchen des $H K$. aus lanzettl. Basis lineal., dic inneren zurückgekrümmt. $\odot$. Trockene, unkultiv. O., Wege; Oestr. Jul. Aug. Bl. purp.

9. C. a retio ides Willd. B. herablaufend, unterseits spinnwebigflaumig, zuletzt kahl, tief-fiedersp., der endst. Isappen verlängert; Fieder lanzettl., ungleich-dornig-gewimpert, an der vorderen Seite 2-3lappig; Bthstiele nackt, meist 1köpfig; Blättchen des HK. lineal., dornig-stachelspitzig, v. der Mitte an abstehend. A. u. VorA.; Krain, Kärnth., sïdl. Tyrol, Schwz. Jul. Aug. Cirsium aretioides Scop. Arctium carduelis L. Carduus centauroides Hopp. Bl. purp. Var. Fieder eyf., 2sp.; C. alpestris WK. K. syn. ed. 1. (nicht C. defloratus $\beta$. alpestris DC.)

10. C. deflorat u s L. B. halbherablaufend, kahl od. unterseits auf den Adern haarig, lanzettl., etwas meergrün od. fast gleichfarbig, dornig-gewimpert, gezähnt-gesägt od. gesägt-kleinlappig, die untersten $u$. oberen halbherablaufend, Läppchen 2 sp., Bthstiele verlängert, nackt; Blättchen des HK. lineal., dornig-stachelspitzig, v. der Mitte an abstehend. 2. Felsige O., A., VorA. u. Gbge; zerstr. im siidl. u. mittl. Géb. Jul. Aug. Bl. purpurn. Kommt vor grasgrün, u. mehr od. weniger graugrün, u. 1. B. grob-gezähnt u. dabei wimperig-dornig. C. summanus Pollin. C. crassifolius Willd. C. Argemone Schleich. 2. B. grob-gezähnt, die Zähne od. Läppchen 2sp. C. transalpinus Sut. nach Hegetschw. C. crassifolius K. syn. ed. 1. 3. B. tiefer buchtig. C. cirsioides Vill. 4. Dieselbe Form, aber die Dornen der B. stark. C. defloratus $\delta$. rhaticus DC. C. carlinaefolius K. syn. ed. 1. Gaud., nicht Lamck. 5. Diese Form mit schmaJen B. C. leptophyllus Gaud. 6. B. halb-fiedersp. C. defloratus $\beta$. alpestris DC., nicht $C$. alpestris Kit.

II. Rotte. Clastolepidoti. Blättchen des HK. oberhalb der eyf. Basis etwas verengert u. mit einer Querfalte heralogeknickt.

11. C. nutans L. B. herablaufend, oberseits ziemlich kahl, unterseits auf den Adern zottig, tief-fiedersp.; Fieder eyf., fast handf.3sp. u. gezähnt, dornig-gewimpert, Iappen u. Zähne nit cinem starken Dorne endigend; Köpfchen rundl., einzeln, nickend; die mittleren Blättchen des $H K$, oberhalb d. cyf. Basis verengert, oberhalb der 
Verengerung lanzettl., in einen starken Dorn zugespitzt, zuriickgeknickt-abstehend. $\odot$. Trockene Triften, Wege. Jul. Aug. Bl. purp.

12. C. platylepis Sauter. B. herablaufend, oberseits ziemlich kahl, unterseits auf den Adern zottig, tief-fiedersp.; Fieler eyf., fast handf.-3sp. ll. gezähnt, dornig-gewimpert, Lappen u. Zähne mit einem stärkeren Dorne endigend; Köpfchen rundlich, aufrecht, einzeln u. gezweiet, das eine sitzend, wagerecht; die mittleren Blättchen des $H K$. oberhalb der eyf. Basis etwas verengert, oberhalb der Verengerung lanzettl., in einen Dorn zugespitzt. $\odot$. Aecker u. Wiesen der Alpenthäler; bei Kitzbichel und Lofer in Tyrol. Im Garten. Mai. Jun. Bl. purp.

52. ONOPORDUM L. Eselsdistel.

1. O. A c an thi um L. B. elliptisch-längl., buchtig, spinnwebigwollig; Blättchen des $H K$. aus eyf. Basis lincal.-pfrieml, die unteren weit abstehend. (-). Unkultiv. O., Wege. Jul. Aug. Bl. purpurn.

2. O. illy ri cum I. B. lanzettl., fiedersp., spinuwebig-wollig; Blättchen des $H K$. єy-lanzettf., die unteren bogig-herabgekrümmi. Unkultiv. O.; Istrien, Fiume. Jul. Aug. Bl. purp. O. elongatum Lam., DC. pr.

\section{LAPPA Tournef., Lam. Klette.}

1. L. major Gärtn. HK. ziemlich kahl, Blättchen sämmtl. pfrieml. u. hakig, die inncren gleichfarbig; Köpfchen fast ebensträussig. $\odot$. Schutt, Wege. Jul. Aug. Aretium Lappa L. Diese u. die folgenden mitbegriffen. Bl. aller purp.

2. L. minor DC. HK. etwas spinnwebig-zottig, Blältchen sämmtl. pfrieml. u. hakig, die inneren etwas gefärbt; Köpfehen traubig. $\odot$. Schutt, Wege. Aug. Sept.

3. L. t o m ent os a Lam. HK. spinnwebig-wollig, die inneren Blättchen lanzettl., stumpf, mit einem aufgesetzten, geraden Stachelspitzchen, gefärbt, fast strahlend; Köpfchen beinahe ebensträussig. $\odot$. Schutt, Wege. Jul. Aug. Aretium Bardana Willd.

XV. Gruppe. CARLINEEN. Cass. HK. reichbth. Bth. zwitterig. Pappus 1reihig, ästig, abfällig.

54. CARLÍNA L. Eberwurz.

1. C. a canlis L. Stengellos od. stengélig sich erhehend; St. $1 \mathrm{köpfig}$; B. kahl od. unterseits etwas spinnwebig-wollig, tief-fiedersp., Fieder eckig-gelappt, gezähnt; d. strahlenden Blättchen des HK. v. der Basis bis über die Mitte lineal., an der Spitze lanzettl.; die längeren Fasern -der Spreublättchen stumpf-keulig. ๑. Steinige O., Haiden. Jul. Aug. C. subacanlis DC. Strahl des HK. weiss.

2. C. simplex W. K. St. 1köpfig; B. kahl od. unterseits etwas spinnwebig-wollig, tief-fiedersp., Fieder eckig-gelappt, gezähnt; die 
strahlenden Blättchen des $H K$. lanzettl., unterhalb der Mitte versehmälert; die längeren Fasern der Spreublättchen an der Spitze stumpf-keulig. $\odot$. Gloge; Oberkrain. Jul. Aug. C. aggregata Willd. Strahl des HK. weiss.

3. C. a eanthifolia All. Stengellos; B. unterseits grau-wollig, die änsseren fiedersp., eckig-gezähnt, die innersten ungeth., gezähnt; die längeren-Fasern der Spreublättchen fädl., spitz, unter der Spitze ein wenig dicker. $\odot$. Trockene Berge im mittleren Istrien. Jul. Aug. C. aeanthifolia $\alpha$. DC. pr. Strahl des HK. weiss.

4. C. I an at a L. St. meist 3köpfig; B. lanzettl., ungleich-gezähnt, filzig-wollig; Blättchen des HK. fast doppeltfiedersp.-dornig, die inneren lanzettl., in einen Dorn verschnälert, die strahlenden lineal.lanzettl., an der Basis versehmälert, kahl. $\odot$. Trockene O.; Istrien, Finme. Jul. Aug. Strabl des HK. purpurn.

5. C. corymbos a L. St. fast ebensträussig; B. längl.-lanzettl., buchtig, gezähnt; Blältchen des $H K$. fast doppeltfiedersp-dornig, die inneren längl., stumpf, stachelspitzig, die strahlenden lanzettl., an der Basis versehmälert, kahl. ๑. Unkultiv. O.; Litt. Jul. Aug. Stràhl des HK. gelb.

6. C. vulgaris L. St. 2-mehrköpfig, fast ebenุsträussig; B. längl.-lanzettl., buchtig, gezïhnt; die äusseren Blättchen des $H K$. doppeltfiedersp.-dornig, die inneren lanzettl., verschmälert-stachelspitzig, die strallenden lineal.-lanzettl., an der Basis ein wenig breiter, bis zur Mitte gewimpert; DeckB. kürzer als das Köpfchen. $\odot$. Unkultiv. O. Jul. Aug. Strahl des HK. strohgelb.

7. C. nebrodensis Gusson. St. 1-3köpfig; B. lanzettl., entfernt-gezähnt, die unteren verlängert-lanzettl., die äusseren Blättchen des HK. doppeltfiedersp.-dornig, dic inneren lanzettl., versehmälertstachelspitzig, $d$. strahlenden lineal.-lanzettl., an d. Basis ein wenig breiter, bis zur Mitte gewimpert; die DeckB. länger als d. Köpfchen. $\odot$. A. u. höhere Gbge; Kitzbichel in Tyrol, Hohneck der Vogesen. Jul. Aug. Strahl des HK. weiss. C. longifolia Rclıb.

\section{STAEHELÍNA-L. Staeheline.}

1. S. dubia I. B. lineal., entfernt-gezähnelt, oberseits grau, unterseits filzig; Blättchen des HK. lanzettl.; Pappus weit länger als der HK. Ђ. Unkultiv. O.; Cherso, Osero. Jun. Jul. Bl. purp.

XVI. Gruppe. SERRATULEEN. Cass. HK. reiehbth. Bth. zwitterig. Pappus mehrreihig, federig od. haarig, bleibend, die innerste Reihe länger als dic iibrigen.

56. SAUSSÚREA DC. Saussurie.

1. S. alpina DC. B. unterseits spinnwebig - filzig, oberseits zuletzt kahl, die wurzelst. ey-lanzetlf., an der Basis abgerundet, gestielt, die stengelst. lanzettl., die oberen sitzend; Köufchen ebensträussig- 
gehäuft. 4. Hohe A. Jul. Aug. Serratula alpina $\alpha$. $\beta$. L. Bl. violett roth, wie die folgenden.

2. S. discolor DC. B. unterseits schneeweiss-filzig, oberseits zuletzt kahl, die wurzel- 11. unteren stengelst. ey-lanzettf., an der Basis herzf., gestielt, die obersteu sitzend, lanzettl.; Köpfehen ebensträussig-gehäuft. 24. Hohe A.; südl. Schwz., südl. Tyr., Krain, Oestr., Istr.' Jul. Aug. Serratula alpina $\gamma$. L.

3. S. py gma ea Spreng. B. lineal.-lanzettl. od. lineal., oberseits zerstreut-, unterseits dicht-raulıh., ganzrandig od. gezälnuelt; dic äusseren Blättchen des HK. an der Spitze etwas abstehend; der St. 1köpfig. 24. Felsige O. der KalkA.; Oestr., Stmk., Krain. Jul. Aug. Serratula pygmaea Jacq.

\section{SERRÁTULA L. Scharte.}

a. Blättchen des HK. ohne Anhängsel.

1. S. tinctoria L. B. etwas raul, geschärft-gesägt, eyf., ungeth. od. leyerf. od. fiedersp.; Köpfchen ebensträussig; HK. längl. 2. Wälder, feuchte Waldwiesen. Jul. Aug. Bl. purp.

2. S. ra di a ta MBieb. B. flaumig-rauh, kammf.-fiedersp., Zpfl. lanzettl., spitz, ganzrandig od. etwas gesägt; St. einfach od. ästig; Aeste 1köpfig; HK. fast kugelig, Blättchen stachelspitzig-dornig. 4. Bergwiesen; Burkersdorf bei Wien, Krinikberg im Litt., Koinizzaberg in Istr. Jun. Jul. Carduus radiatus WK. Bl. hellpurpurn.

3. S. heterophylla Desf. B. v. sehr kurzen Härchen etwas rauh, die wurzel- $u$. unteren stengelst. eyf., grobgezähnt od. an der Basis eingeschnitten, die oberen längl., fiederspaltig-gezähnt, die obersten lineal., ganzrandig; St. einfach, einköpfig; HK. fast kugelig, Blättchen stachelspitzig. 24. Steinige O. u. Bergwiesen; Laxenburg u. Münkendorf bei Wien, Slavnik, Koinizza u. benachbarte Gbge im Litt. Jun. Jul. Carduus lycopifolius Vill. C. nitidus WK. Bl. purp.

4. S. nudicaulis DC. fl. fr. Die unteren B. elliptisch-längl. od. längl., stumpf; in den Bstiel herablaufend, ungeth., die oberen schmal-lanzettl., eingeschnitten-wenigzähnig od. ungeth., sitzend; st. 1 köpfig, oberseits nackt; HK. eyf., die äusseren Blättchen dornighaarspitzig, die inneren an der Spitze verbreitert, trockenhäutig. 4. A.; Saleve im Jura. Jun. Jul. Centaurea nudicaulis L. Bl. purp.

b. Blättchen des HK. mit Anhängseln.

5. S. Rhaponticum DC. B. gestielt, eyf.-längl., gezähnelt, unterseits wollig-filzig, die wurzelst. fast herzf., die oberen lanzettl.; St. 1köpfig; Blättchen des HK. an der Spitze in ein breit-eyf., trockenhäutiges, wehrloses Anhängsel verbreitert. 24. A.; südl. Schwz., siidl. Tyr., Krain. Jul. Aug. Centaurea Rliapontica L. Rhaponticum scariosum DC. Bl. purp. 
58. JURINEA Cassin. Jurinie.

1. J. mollis Rchb. B. unterseits filzig, fiedersp., Fieder lineal., ganzrandig; St. oberwärts nackt, meist 1köpfig; $H K$. fast kugelig, Blättchen lanzettf.-pfrieml., spinnuebig-wollig; Achenen in Plättchen gefaltet. 24. Unkultiv. O.; Litt., Kirain, Stmk., Oestr., Mähr. Mai. Jun. Carduus mollis L. Bl. purp.

2. J. Pollichii Koch. B. unterseits filzig, fiedersp., Fieder lineal., ganzrandig; St. 1-armköpfig; Köpfchen endst., einzeln, fast kugclig; Blättchen des $H K$. lanzettf.-pfrieml., filzig-grau, Achenen glatt, schwach-gribig. 2. Sandfelder, trockene Hiigel; Mittelrhein, sodann bei Würzbg., in Thüring., Böhm., Mecklenbg. Jul. Aug. S. cyanoides $\beta$. DC. Carduus mollis Pollich. Bl. purp.

XVII. Gruppe. CENTAURIEEN. Lessing. HK. reichbth. Bth. zwitterig od. die randst. geschlechtslos. Pappus mehrreihig, federig od. haarig, bleibend, die vorletzte Reihe der Strahlen desselben länger als die ïbrigen, od. kein Pappus.

\section{CÁRTHAMUS L. Farbendistel.}

1. C. tinctorius L. B. ungeth., gezähnt-gesägt u. nebst dem St. kahl, Sägezähue dornig. $\odot$. Aus Aegypten; wird zum Farbengebrauch kultiv. Jul. Aug. Bth. anfangs hellgelb, zuletzt safranfarben.

60. KENTROPHYLLUM Neck., DC. Spornblatt.

1. K. lanatum DC. Die unteren B. fiedersp., gezähnt, die obersten stengelumfassend, fiedersp.-zähnig; St. nebst dem HK. wollig; die randst. Btll. ohne Pappus. ( . Gebirgige O.; siidl. Tyr., Krain, Fiume. Jul. Aug. Bl. citrongelb. Carthamus lanatus L.

\section{CENTAUREA L. Flockenblume.}

I. Rotte. Jacea Juss. Blättchen des HK. mit einem trockenhäutigen Anhängsel endigend, dieses ungeth. od. an den mittleren u. äusseren Blättchen fransig-geth., d. letzte Franse borstl., nicht dicker als die übrigen $u$. nicht starrer. Bth. aller unserer Arten fleischroth od. purpurn.

1. C. splendens L. Die Anhängsel der Blättchen des HK. durchscheinend, eyf., ungeth., aufgeblasen-concav; Pappus ungefähr. so lang als die Achene; $B$. rauh, die unteren doppelt-fiedersp., die oberen einfach-fiedersp.; Fieder aller lineal., stachelspitzig. 24. Gebirgige O.; Litt., südl. Schwz. Jul. Aug. Bl. purp.

2. C. amara L. Die Anhängsel den ganzen HK. bedeckend, trockenläutig, concav, eyf., ungeth. od. zerrissen; Pappus fehlend; $B$. nebst dem St. flockig, fast filzig, die untersten ungeth. od. fiedersp., d. stengelst. lanzettl.-lineal., ganzrandig. 24. Trockene, unkultiv. O.; sïdl. Schwz., Litt. Aug. B1. purp. Varictät v. C. Jacea? Die vou Bertoloni beschricbene scheint verschieden. 
3. C. Jacea L. Die Anhängsel den ganzen HK. bedeckend, trockenhäutig, concav, eyf., ungeth., zerrissen od. die unteren kammf.gefranst; Pappus fehlend; B. lanzettl., ungeth., od. die unteren entfernt-buchtig od. fiedersp. 24. Trockene Wiesen, unkultiv. Orte. Jun. -Herbst. Bl. purp. Var. $\alpha$. genuina: Anhängsel sämmtl. ungeth. od. nur zerrissen-gesp. - $\beta$. pratensis: die unteren od. die unteren $u$. mittleren Anhängsel kammf. - gefranst. C. pratensis Thuill. $-\gamma \cdot d e$ cipiens: die äusseren Anhängsel kammf.-gefranst u. zurückgekrümmt. C. decipiens Thuill. - $\delta$. capitata: randst. Bth. nicht grösser, die Anhängsel ungeth. od. die unteren kammf.-gefranst.

4. C. nigrescens Willd. Die Anhängsel des HK. eyf., aufrecht od. an der Spitze zuriickgekrümmt, kammf.-gefranst, die mittleren $u$. oberen od. alle $v$. einander entfernt, die Fransen ungefähr v. der Breite ihres Mittelfeldes, die der inneren Blättchen rundl., zerrissengezähnt; Pappus fehlend; B. längl. od. eyf., gezähnelt, ungeth. od. die unteren leyerf.-buchtig. 24. Wiesen der A. u. Gbge ; Krain, Stmk., Litt., südl. Tyr., sïdl. Schwz. Jul. Aug. Bl. purp. Anhängsel schwarz, seltener heller-braun. Kommt vor: $\alpha$. transalpina: Anhängsel der unteren Blättchen des HK. klein, dreieckig, v. einander entfernt, die mittleren angedrückt. C. transalpina Schleich., DC. $-\beta$. vochirensis: Anhängsel der unteren u. mittleren Blättchen ey-lanzettf., an der Spitze zurückgekrümmt, übrigens wie Variet. $\alpha$. C. vochinensis Bernhardi. C. salicifolia DC. pr.? - $\gamma$. Candollii: Anhängsel der unteren Blättchen grösser, mit den Rändern sich deckend, mittlere entfernt, übrigens wie Variet. $\alpha$. C. nigrescens DC. pr.

5. C. austriaca Willd. Die Anhängsel des HK. aus lanzettl. Basis lang-pfrieml., zurückgekrümmt, gefiedert-gefranst, die untersten Fransen genähert, die oberen entfernt, sämmtl. borstl., die Anhängsel der 3 inneren Reihen rundl., zerrissen-gezähnt, über die äusseren hinausragend; Pappus $3 \mathrm{mal}$ kürzer als die Achene; Köpfchen eyf.; B. längl.-elliptisch u. lanzettl., gesägt-gezähnt; St. aufrecht, ästig. 4 . Wiesen u. steinige 0 .; Königsberg u. Danzig in Preussen, Schles., Unteröstr., südl. Tyr., Graubünd. Jul. Aug. C. austriaca Willd. Herbar. Bl. purp. Var. $\alpha$. genuina: Anhängsel lang, das ganze Köpfchen, mit Ausnahme der innersten Blättchen, locker bedeckend, $u$. überall schwarz, nur an d. obersten Spitze u. die Fransen an der obersten Spitze braun. - $\beta$. fusca: Anhängsel u. deren Fransen v. der Mitte an braun. C. austriaca $\gamma$. ambigua DC. pr., nach dem Standorte v. Salis. - $\gamma$. pallida: Anhängsel hellbräunl.-gelb, nur an d. Basis schwarz. C. cirrhata Reichenb. - $\delta$. capitata: Köpfchen nicht strahlend, Anhängsel wie bei $\alpha$. $-\varepsilon$. salicifolia: Anhängsel viel kürzer. C. salicifolia MB. nach Besser, (nicht DC.) Von C. nigrescens dch den Pappus verschieden.

6. C. phrygia L. Die Anhängsel des HK. aus lanzettl. Basis lang-pfrieml., zurückgekrümmt, fiederig-gefranst, die untersten Fran- 
sen genähert, die oberen entfernt, sämmtl. verlängert-borstl., die Anhängsel der innersten Reihe rundl., zerrissen-gezähnt, v. den Fransen der folgenden Reihe bedeckt; Pappus 3mal kürzer als die Achene; Köpfchen r'undl.; B. längl.-elliptisch u. eyf., ungeth., gezähnelt; St. aufrecht, ästig. 24. VorA. u. Gbge; zerstr. dch das südl. u. mittlere Geb. Jul. Aug. Bl. purp. C. austriaca DC. pr. Var. $\beta$. pallida: Anhängsel hellbräunl.-gelb, nur an der Basis schwarz. $-\gamma$. capitata: randst. Bth. nicht grösser. C. flosculosa Balb.

7. C. nervos a Willd. Herb. Die Anhängsel des HK. aus lanzettl. Basis lang-pfrieml., zurück-gekrümmt, gefiedert-fransig, d. untersten Fransen genähert, die oberen entfernt, sämmtl. verlängertborstl., die Anhängsel der innersten Reihe rundl., zerrissen-gezähnt, v. den Fransen der folg. Reihe bedeckt; Pappus ungefähr so lang als die Achene; St. einfach, 1 köpfig; Köpfehen rundl.; B. lanzettl., ungeth., gezähnelt, die oberen an der Basis tiefer-gezühnt u. fast abgeschnitten. 24. Triften der A.; Schwz., südl. Tyrol, Krain. Jul. Aug. C. phrygia DC. pr. Kleine Expl.: C. ambigua Thom. Bl. purp. Var. $\beta$. capitata: Köpfchen ohne Strahl.

8. C. nigra L. Die Anhängsel des HK. aufrecht, lanzettl., ge * fiedert-frarsig, Fransen borstl., noch einmal so lang als die Breite ihres Mittelfeldes, sämmtl. geriähert u. d. HK. verdeckend; die inneren Anhängsel rundl., zerrissen-gezähnt; Pappus 3mal kürzer als die Achene; $B$. lanzettl., zieml. rauhh., die unteren gezähnt od. fast buchtig. 2. Gebirgige O.; zerstr. im südl. u. mittl. Geb., selten im nördl. Jul. Aug. Var. $\beta$. pallens: mit hellbräunl.-gelben Fransen der Anhängsel. Bl. purp.

II. Rotte. Cyanus L. Das Anhängsel od. der Rand der Spitze จ. den Blättchen des HK. trockenhäutig, fransig-gespalten; die Endfranse breiter $u$. stärker, (obgleich sie nicht selten kürzer ist als die uibrigen), oft dornig od. auch starr-dornig. Die Länge der dornigen Spitze ist sehr veränderlich $u$. zwar bei einer $u$. derselben Art.

9. C. montana L. Blättchen des HK. geschwärzt-berandet, gesägt-fransig, Fransen ungefähr so breit als der Rand; $B$. herablaufend, längl.-lanzettf., ungeth., ganzrandig od. gezähnelt. 2. Wälder der Gbge u. VorA.; zerstr. deh das siidl. u. mittl. Geb. Jul. Aug. C. mollis WK. Randbth. kornblau, des Mittelfeldes röthl.-violett.

10. C. axillaris Willd. Blättchen des HK. geschwärzt-berandet, gesägt-fransig, Fransen fast knorpelig $u$. beinahe noch einmal so lang als der geschvärzte $R$ and; $B$. herablaufend, verlängert-lanzettl., ungeth. od. buchtig. 2. Gebirgige O.; Schwz, Krain, Littor. Jul. Aug. Bth. wie die der vorhergeh. Art, aber auch oft die des Raudes röthl.violett. Var.: Rand der Blättchen des HK. hell-bräunlich mit weissen Fransen od. schwarz mit an der Basis braunen u. an der Spitze 
weissen Fransen; ferner: $\alpha$. stricta: höher, B. ungeth., die oberen am St. mit breitem Flügel herablaufend. C. stricta WK. - $\beta$. carniolica: höher, B. buchtig-gezähnt. Zähne od. Winkel beiderseits 2. C. carniolica Host. C. Triumfetti All. - $\gamma$. seusana: niedrig, B. sehr schmal-herablaufend, lineal., ungefähr $2^{\prime \prime \prime}$ breit, die unteren entferntgezähnt. C. seusana Vill. C. variegata Lam.

11. C. Cyanus L. Blättchen des $H K$. geschwärzt-berandet, gesägt-fransig; B. lineal.-lanzettl., die untersten ar der Basis gezähnt, die wurzelst. vktey-lanzettf., ungeth. u. 3sp.; Pappus ungefähr so lang als die Achene. $\odot$. Unter der Saat. Jun. Jul. Randst. Bth. blau, die des Mittelfeldes violett.

12. C. Kotschyana Heuffel. Die Anhängsel des mundl. $H K$. geschwärzt, 3eckig, spitz, flach, gefianst, breiter als die nervenlosen Blättchen $u$. diese verdeckend, Fransen schlängelich; Pappus ungefähr so lang als die Achene; B. etwas wollig, glatt od. etwas rauh, fiedersp. od. leyerf.-fiedersp., Zpfl. lanzettl., ganzrandig od. gezähnt. 4. An Abhängen des Ortscher in Oestreich, Dolliner. Jul. Aug. Bl. sattviolettroth.

13. C. S ca bios a L. Die Anhängsel des rundl. HK. geschiwärzt, 3eckig, spitz, flach, gefranst, schmäler als die nervenlosen Rlättchen $u$. diese nicht verdeckend; Fransen schlängelich, die endständige kurz od. in einen Dorn vorgezogen; Pappus ungefähr so lang als die Achene; $B$. etwas wollig u. ausserdem rauh od. kall, fiedersp. $u$. doppeltfiedersp.; Zpfl. lanzettl., ganzrandig od. gezähnt, mit einem schwieligen Punkte endigend. 2. Trockene unkultiv. O. Jul. Aug. Bl. violett. Var.: mit breiteren od. schmäleren Bzpfln. u. mit ungetheilten B., u. $\alpha$. vulgaris: B. am Rande rauh u. auf der Oberfläche kurzh., seltener filzig; HK. mehr oder weniger wollig. $-\beta$. coriacea: B. Kahl, am Rande rauh; HK. fast kahl. C. coriacea WK. - $\gamma$. badensis: B. am Rande u. auf den Flächen kahl. C. badensis Tratt. - $\delta$. spinulosa: die endst. Franse der Blättchen des HK. in einen längl., stärkeren Dorn verwandelt. C. spinulosa Rochel., (nicht DC. prodr., das Ex. v. Rochel selbst hat einen Pappus wie die Hauptart, die Pfl. v. DC. hat keinen Fappus). C. Stoebe Willd. Herbar.

14. C. sordida Willd. Die Anhängsel des rundl.-eyf. HK. geschwärzt, 3eckig, spitz, flach, gefranst, die Blättchen nicht verdeckend, diese nervenlos; Fransen schlängelig, die endständige kurz od. "in einen Dorn vorgezogen; Pappus ungefähr so lang als die Achene; B. etwas wollig, am Rande rauh od. kahl, die wurzelst. doppelt-gefiedert, d. oberen stengelst. fiedersp.; Zpfl. lineal., spitz, in eine feine, knorpelige Stachelspitze endigend. 2. Trockne Wiesen; Litt., Krain. Jun. Jul. Bl. bald trübgelb, bald triibpurpurn. Var. $\alpha$. lutescens : Anhängsel kaum dornig, Bl. zugleich trübgelb. C. pubescens Willd. - 
B. purpurascens: Endfranse der Anhängsel mit einem stärkeren Dorn, Bl. trübpurpurn. C. sordida Willd. C. Grafiana DC.

15. C. rupestris L. Die Anhängsel des HK. längl.-eyf., kurz, bräunl., flach, fransig, Fransen schlängelich, die endständige kurzod. lang-dornig; Pappus kürzer als die Achene; $B$. kahl, am Rande rauh od. unterseits flockig-wollig, die wurzelst. doppeltgefiedert, $d$. oberen stengelst. fiedersp., Zpfl. lineal., spitz-stachelspitzig. 24. Sonnige, felsige O.; Litt., Fiume. Jun. Jul. Bl. citron-od. goldgelb. Var. $\alpha$. subinermis: Dorn der Blättchen des HK. kurz. C. rupestris L. C. adonidifolia Rchb. - $\beta$. armata: Dorn der mittleren Blättchen stark, fast länger als der halbe HK. C. rupestris Rchb.

16. C. maculosa Lamarck., DC. prodr. Anhängsel des rundl.eyf. HK. mit eirem 3eckigen, geschwärzten, beiderseits etwas hinabziehenden Flecken bezeichnet, die 5nervigen Blättchen nicht verdeckend, gefranst, Fransen fast knorpelig, schlängelich, die endst. oft ein Dörnchen bildend; Pappus halb so lang als die Achene; die B. rauh, etwas wollig, die wurzelst. meist doppelt-gefiedert, die stengelst. einfach-gefiedert, mit lineal. $\mathrm{Zpfln}$., die astst. oft ungeth. od. lineal.; St. aufrecht, oberwärts rispig $u$. fast ehensträussig. 24. Unkult., soneige O.; sehr zerstr. deh das Geb. Jul. Ang. C. paniculata Jacq. austr. t. 320. u. der Deutsch. Antoren. Bl. hellviolett.

17. C. paniculat a Lamarck., DC. prodr. Anhängsel des eyf.längl. $H K$. ledergelb, die 5nervigen Blättchen nicht verdeckend, gefranst, Fransen fast knorpelig, schlängelich, die endst. dicker, ein starres etwas abstehendes Dörnchen darstellend; Pappus ungefähr $1 / 3$ so lang als die Achene; die B. rauh, filzig, die wurzelst. meist doppelt-gefiedert, die stengelst. einfach-gefiedert, mit lineal. Zpfln., die astst. meist einfach $u$. lineal.; St. aufrecht, oberwärts rispig, mit locker zerstreuten Köpfchen. ๑. Unkultiv. O., Wege im Wallis, Gaud. Jul. Aug. Bl. nach Gaud. rosenroth. Linné scheint unter C. paniculata 2 od. mehr Arten zn vereinigen.

18. C. cristata Bartl. Die Anhängsel des HK. breit-eyf., gefranst, die äusseren Blättchen verdeckend, Fransen knorpelig, schlängelich, die endständige in einen Dorn vorgezogen od. fast gleich; Pappus fehlend; $B$. rauh, die uurzelst. fast $3 f a c h$ gefiedert, die stengelst. gefiedert, Fieder nebst den obersten B. lineal.; St. sehr ästig, spreitzend. $\odot$. Steinige, sonnige O.; Litt., Fiume. Jul. Aug. C. acutiloba DC. prodr. Bl. fleischroth.

19. C. Karschtiana Scop. Die Anhängsel des eyf. HK. fast 3eckig, spitz, gefranst, die Blättchen nicht verdeckend, diese 5nervig; Fransen lnorpelig, etwas bogig, d. endständige in einen Dorn hervorgezogen, Pappus so lang als der Fruchtkn.; B. kahl, am Rande rauh, dic wurzelst. fast doppelt-gefiedert, die stengelst. gefiedert, Fieder nebst den obersten B. lanzettl., vorne breiter; St. v. der Basis an sehr ästig, rasig. $\odot$. Bei Obschina u. hin $u$. wieder auf dem 
Karscht, Felsen an der Burg Duino, bei Smergo Ins. Cherso. Jul. Aug. Bl. hellviolett.

III. Rotte. Calcitrapa. Blättchen des HK. am Rande nicht gefranst, aber an d. Spitze in einen handf. od. gefiederten Dorn endigend.

20. C. solstitialis L. Blättchen des wolligen HK. handf.dornig, der mittlere Dorn stark, länger als das Köpfchen; endst. Köpfchen einzeln; B. graulich, lineal.-lanzettl., herablaufend, ganzrandig, die wurzelst. leyerf. ๑. Aecker, Wege; Littor., übrigens sehr zerstreut deh das Gebiet. Jul. Aug. B1. citrongelb.

21. C. Calcitrapa L. Blättchen des ganz kahlen HK. fast handf-dornig, der mittlere Dorn stark, länger als das Köpfchen; die seitenst. Köpfchen einzeln, fast sitzend; Pappus fehlend; B. tief-fiedersp., mit lineal., gezähnten Fiedern, die unteren gestielt, die oberen sitzend, die obersten ungeth.; St. sehr ästig, behaart. (-) Unkultiv. O., Wege; zerstreut dch das Geb. Jul. Aug. Bl. purpurn.

62. CRUPINA Pers. Crupine.

1. C. vulgaris Pers. Blättchen des HK. lanzettl., zugespitzt; B. gefiedert, rauh, Fieder lineal., spitz, stachelspitzig-kleingesägt. $\odot$. Unkultiv. O.; Istr. Jul. Aug. Bl. fleischroth.

XVIII. Gruppe. XERANTHEMEEN. Less. HK. reichblüthig. Die randst. Bth. weiblich; d. des Mittelfeldes zwitterig, fruchtbar.

63. XERANTHEMUM L. Spreublume.

1. X. annu um L. HK. halbkugelig, Blättchen ganz kahl, stachelspitzig, die äusseren eyf., die inneren lanzettl., noch einmal so lang als das Mittelfeld. $\odot$. Sonnige, unkultiv. O.; Litt., Oestr., Mähr., Böhm. Jun. Jul. X. annuum var. $\alpha$. L. sp. X. radiatum Lam. Strahl rosenroth, wie an folgend.

2. X. in a pertu in Willdenow. HK. fast walzl., Blättchen ganz kahl, stachelspitzig, die äusseren eyf., die inneren lanzettl., 11/2 mal so lang als die Bth. des Mittelfeldes. $\odot$. Trockne, unfruchtb. O.; Wallis. Mai. Jun. X. annuum $\beta$. inapertum L. X. erectum Presl., DC.pr.

3. X. cylindra c e u m Smith. HK. walzl., die äusseren Blättchen eyf., grannenlos, in der Mitte filzig, am Rande breit-kahl, die inneren lanzettl., $1 \frac{1}{2}$ mal so lang als die Bth. des Mittelfeldes. $\odot$. Sonnige O.; Pola in Istrien. Mai. Jun. X. inapertum DC. fl. fr.

III. Unterordng. CICHORACEEN. Juss. Semiflosculae L. Der Gf. nicht gegliedert. Bth. sämmtl. zungenf. u. zwitterig. Die Schenkel des Gf. fädl., zurückgerollt, kurz-flaumig.

XIX. Gruppe. SCOL YMEEN. Less. Achene v. einem Spreublättchen ringsum eingeschlossen $u$. an dasselbe angewachsen. 


\section{SCÓLYMUS L. Golddistel.}

1. S. hispanicus L. B. mit einem abwärts verschmälerten Flügel herablaufend; St. etwas ästig; Köpfchen blattwinkelst., einzeln od. 2-4 zsgestellt; Blättchen des HK. sämmtl. zugespitzt; Pappus 2borstig. $\odot$. Felsige O., Wege; Litt., Fiume. Jul. Aug. Bl. gelb. S. maculatus Scop.

XX. Gruppe. LAMPSANEEN. Less. Pappus fehlend, od. an dessen Stelle ein hervorspringender Rand.

65. LÁ̂́̄ SANA L. Rainkohl.

1. L. communis L. B. gezähnt, die unteren leyerf.; St. ästig, rispig. $\odot$. Kultiv. u. waldige O. Jul. Aug. Bl. gelb.

66. APOSERIS Neck. Drahtstengel.

1. A. foetida DC. St. blattlos, 1köpfig; B. schrotsägef--fiedersp., Lappen fast rautenf., der endst. 3eckig, fast 3lappig. 4. Haine der VorA. u. angrenzenden Ebenen. Jul. Aug. Hyoseris foetida L. Bl. gelb.

\section{ARNÓSERIS Gärtn. Lämmersalat.}

1. A. pusilla Gärtn. St. blattlos, 1-3köpfig; Bthsiele oberwärts keulig-verdickt, röhrig; B. vkteyf. -längl., gezähnt. $\odot$. Sandäcker. Jul. Aug. A. minima K. syn. ed. 1. Hyoseris minima L. Bl. gelb.

\section{RHAGADÍOLUS Tournef. Sichelsalat.}

1. Rh. stellatus Gärtn. HK. mit einem kleinen NebenK., die äusseren Achenen sternf. - ausgebreitet. $\odot$. Wege, grasige Plätze; Istrien, Fiume. Apr. Mai. Lapsana stellata L. Bl. gelb. Var.: B. ganz od. leyerf.; Achenen gegen die Spitze borstig u. $\beta$. edulis: Achenen glatt: Rh. edulis Gärtn. Lapps. Rhagadiolus L.

XXI. Gruppe. CICHORIEEN. Pappus kronenf, aus kurzen, stumpfen, starken Haaren.

69. CICHORIUM L. Cichorie.

1. C. Intybus $\mathrm{I}$. Köpfchen gezweiet od. mehrere zsgestellt, sitzend u. gestielt; die blüthenst. B. aus breiterer, fast stengelumfassender Basis lanzettl.; Pappus vielmal kürzer als d. Achene. 4. Unkultiv. O, trockene Triften. Jul. Aug. Bl. blau.

2. C. Endivia L. Köpfehen gezweiet od. mehrere zsgestellt, sitzend u. gestielt; die blüthenst. B. breit-eyf., mit herzf. Basis stengelumfassend; Pappus 4mal kürzer als die Achenc. $\odot$. Aus Indien, iiberall kultiv. Jul. Aug. Bl. blau. 
XXII. Gruppe. HYOSERIDEEN. Less. Pappus kronenf. od. spreuig. Spreuen oft in ein Haar verlaufend, aber nicht federig u. nicht v. der Basis an haarf.

70. HYÓSERIS L. Schweinsalat.

1. H. scabra L. St. blattlos, oberwiirts keulig-verdickt; B. schrotsägef.-fiedersp., Lappen eyf., gezähnt; W. einfach. $\odot$. Kult. O., Wege; bei Fiume. Mai. Jun. Bl. gelb. H. microcephala Cass. DC.

71. HEDÝPNOIS Tournef. Röhrleinkraut.

1. H. cretica Willd. St. ausgebreitet; die WB. buchtig-gezähnt; Bthstiele keulig-verdickt; Blättchen des HK. auf dem Rücken nach der Spitze steifh. $\odot$. Unkultiv. O.; bei Volosca in Istrien. Mai. Jun. BI. gelb.

XXIII. Gruppe. LEONTODONTEEN. C. H. Schultz. Pappus aller Achenen federig, mit freien Haaren der Strahlen; od. der Pappus der randst. Achenen kronenf. Fruchtb. kahl od. fein-faserig, Fäserchen bleibend. (Fruchtb. nackt.)

72. THRINCIA Roth. Hundslattich.

1. Th. hirta Roth. W. an der Basis dch starke, fädliche Fasern vergrössert, zuletzt abgebissen; Achenen an der Spitze in einen Schnabel verschmälert. 2. Sandige, etwas feuchte Triften; zerstreut dch das Geb. Jul. Aug. Th. hirta, Th. hispida u. Th. Leysseri DC. BI. gelb. - Die Th. hispida Roth., Th. maroccana Pers. DC., wächst nicht in der Schwz.

2. Th. tuberos a DC. W. abgebissen, büschelig, Fasern rübenf.; Achenen v. der Mitte an in einen Schnabel verschmälert. 24. Wiesen; Istrien $u$. auf den benachbarten Inseln. Mai. Jun. Leontodon tuberosum L. Bl. gelb.

73. LEONTODON L. Löwenzahn.

I. Rotte. Oporina Don. W. abgebissen. Strahlen des Pappus fast gleich, sämmtl. federig, an der breiteren Basis aber blos kleingesägt. Die Köpfchen vor dem Aufblühen anfrecht.

1. L. a utumnalis L. W. abgebissen, iiberall faserig; St. 1mehrköpfig, blattlos; Bthstiele allmählig verdickt, oberwärts schuppig, vor dem Aufblühen aufrecht; B. fiedersp.-gezähnt; Riefen der Achenen fein-runzelig; sämmtliche Strahlen des Pappus federig $u$. gleichgestaltet, an der lanzettl. Basis klein-gesägt. 24. Wiesen, bis in die A. hinauf. Jul.-Herbst. Apargia antumnalis Willd. Oporina autumnalis Don. DC. Bl. gelb. Var. $\beta$. pratensis: HK. nebst den Bthstielen oberwärts dicht-braun-behaart; Apargia pratensis Link., u. wenn der St. einköpfig: Apargia Taraxaci Sm.

II. Rotte. Dens Leonis. W. abgebissen. Die Strahlen des 
Pappus ungleich, die inneren federig, an d. breiteren Basis kleingesägt, die äussereh kurz u. blos rauh.

2. L. Taraxaci Lois. W. abgebissen, v. der Basis an mit starken Fasern besetzt; St. 1köpfig, blattlos, mit 1-2 Schuppen versehen, oberwärts allmählig verdickt $u$. nebst dem HK. von schwarzen Haaren sehr rauhh.; B. lanzettl., in den Bstiel verschmälert, fast ganzrandig, gezähnt od. fiedersp., kahl od. mit einfachen Haaren bestreut; die inneren Strahlen des schneeweissen Pappus federig, an der lineal. Basis klein-gesägt, die äusseren sehr kurz 1. bloss rauh. 4. Triften der höchsten A.; Schwz., Tyrol, Salzb., Kärnth. Jul. Aug. Apargia Taraxaci Willd. DC. Bl. gelb.

3. L. pyrenaicus Gouan. W. abgebissen, v. der Basis an mit starken Fasern besetzt; St. 1köpfig, blattlos, schuppig, oberwärts allmählig verdickt, vor dem Aufblühen überhangerd; B. vktey-lanzettf., ausgeschweift-gezähnelt od. gezähnt, kahl od. mit einfachen Haaren bestreut; die inneren Strahlen des Pappus federig, an der lineal. Basis kleingesägt, die äusseren rauh, sehr kurz. 24. Triften der A., höhere Berge des Schwarzw., Vogesen. Jul. Aug. L. squamosum Lam. DC. Apargia alpina Willd. Bl. gelb. Var. $\beta$. aurantiacus: Bth. in das Safrangelbe spielend, iibrigens der gewöhnl. Form ähnlich. L. croceum Haenk. Apargia aurantiaca Kit. - $\gamma$. pinnatifidus: die B., wenigstens die inneren, fiedersp. Apargia crocea Willd.

4. L. hastilis L. W. abgebissen, an der Basis mit starken Fasern besetzt; St. 1köpfig, blattlos od. mit 1-2 Schuppen besetzt, an der Spitze dicker; B. längl.-lanzettl., in den Bstiel verschmälert, gezähnt od. fiedersp., kahl od. kurzh., Haare 2-3gabelig; die inneren Strahlen des Pappus federig, an der breiteren Basis klein-gesägt, die äusseren kurz, rauh. 4. Wiesen, Triften, bis auf die A. Jun.-Oct. Bl. gelb. Var. $\alpha$. vulgaris: B. od. auch der St. u. HK. kurzb. - $\beta$. glabratus: B., St. u. HK. kahl, od. spärlich mit Haaren bestreut. L. hastile L. L. danubiale Jacq. Dieselbe Var. B. glänzend: Apargia dubia Hoppe. - $\gamma$. hyoseroides: B. bis zur Mittelrippe fiederth., Fieder lineal. -

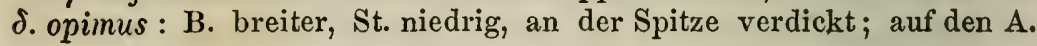

III. Rotte. A pargi a C. H. Schultz. W. senkrecht-hinabsteigend, spindelf., einfach, etwas ästig, mit haarfeinen Fäserchen bestreut. Die Köpfchen vor dem Aufblühen nickend. Strahlen des Pappus sämmtl. federig, od. die äusseren kürzeren rauh, die inneren aber an der Basis klein-gesägt.

5. L. tenu ifloru s DC. W. senkrecht, einfach; St. 1 köpfig, nackt od. mit 1-2 Schuppen besetzt, unter dem Köpfehen dicker; B. lanzettl. - lineal. od. lanzettl., in den Bstiel verschmälert, geschweift-gezähnelt, kurzh., Haare 2-3gabelig; die äusseren Strahlen des Pappus kürzer, rauh, die inneren federig, ungefähr so lang als die Achene. 4. Cant. Tessin auf dem Salvadore und Calbege. Jun. 
Apargia tenuiflora Gaud. Bl. gelb. Haare der B., wie an L. hispidus, W. wie an L. incanus.

6. I. incanus Schrank. W. senkrecht, einfach, etwas ästig; St. $1 \mathrm{köpfig}$, nackt od. mit 1-2 Schuppen besetzt, unter dem Köpfehen dicker; $B$. längl.-lanzettl., in den'Bstiel verschmälert, ganzrandig od. entfernt-gezähnelt, v. sehr kurzen, 3-4 gabeligen Haaren grau-, fast filzig-kurzh.; Pappus ein wenig länger als die Achene, Strahlen des Pappus sämmtlich federig, die inneren an der breiteren Basis kleingesägt. 24. Felsenspalten, steinige $\mathrm{O}$. der A. u. Mähr. Gbg., u. auf Jurakalk in Schwab. u. Frank. Jul. Ang. Hieracium incanum L. Bl. gelb.

7. L. B erinii Roth Manuale. W. senkrecht, einfach, etwas ästig; St. 1-3köpfig; an der Basis ästig; Aeste v. einem B. gestützt; Bthstiele an der Spitze mit 1-2 Schuppen besetzt, unter den Köpfchen dicker; $B$. längl.-lanzettl., in den Bstiel verschmälert, entferntgezähnelt, nebst dem St. grau u. etwas rauh v. fast mehligem, 34 gabeligem Flaume; Strahlen des Pappus sämmtl. federig, die inneren an der breiteren Basis klein-gesägt. 24. Kies des Isonzo, vom Flitschthale bis zum Ausflusse. Jul. Aug. Apargia Berinii Bartl. A. canescens Sieb. BI. gelb.

IV. Rotte. Asterothrix Cass. W. wie bei der vorhergehenden Rotte. Die unaufgeblüheten Köpfchen nickend. Strahlen des Pappus sämmtl. v. der Basis an federig, die äusseren kürzer.

8. L. crispus Villars. W. senkrecht, einfach, etwas ästig; St. 1 köpfig, nackt, od. mit 1-2 Schuppen besetzt, unter dem Köpfchen kaum dicker; $B$. tief-fiedertheilig v. starren, 3 gabeligen Haaren steif $h$.; Achenen kurz-geschnäbelt, gleichf. - feinknotig-rauh, kürzer als der Pappus. 24. Felsige $O$. im oberen Wallis über Zermatten $u$. an den Füneln. Jul. Aug. Bl. gelb.

9. L. saxatilis Reichenb. W. senkrecht, einfach, etwas ästig; St. 1köpfig, nackt od. mit 1-2 Schuppen, unter dem Köpfchen dicker; $B$. lanzettl., in den Bstiel verschmälert, buchtig od. fiedersp.gezähnt, v. starren, 3gabeligen Haaren steifh.; Achenen, fast noch einmal so lang als der Pappus, v. der Mitte an in einen fast kurzh.rauhen Schnabel verschmälert; Strahlen des Pappus sämmtl. v. der Basis an federig, die äusseren kürzer; Röhre der Bth. fast so lang als das Zünglein. 24. Felsige, sonnige O.; Litt. Jun. Jul, Apargia saxatilis Tenor. A. tergestina Hopp. Bl. gelb.

74. PICRIS L. Bitterkraut.

1. P. hieracioides L. Steifh.; B. längl. -lanzettl., gezähnt od. etwas buchtig, die mittleren stengelst. mit abgeschnittener od. spiessf. Basis etwas stengelumfassend; Köpfchen an dem St. und den Aesten endst., ebensträussig; die äusseren.Blättchen des $H K$. abstehend, auf 
dem Rücken steifh., am Rande kahl; Zïnglein fast noch einmal so lang als seine Röhre; Achene unter dem Pappus eingeschnürt, fast schnabellos, fein-quer-runzelig. $\odot$. Unkultiv. O. Jul. Aug. Bl. gelb. Var.: B. ganzrandig: P. ruderalis Schm.; Köpfchen ebensträussig: P. umbellata N. ab E. - $\beta$. crepoides: obere B. längl.-eyf., langzugespitzt, Köpfchen ansehnlicher, Achenen fast noch einmal so gross. P. crepoides Saut. Bergwieseu; Tyrol; Stmk., Hoheneck der Vogesen.

2. P. h is p idissima Bartl. Sehr steifh.; B. lanzettl., buchtig-gezähnt, d. stengelst. mit herzf. Basis etwas stengelumfassend, die obersten ganz; Köpfchen an dem St. u. d. Aesten endst., ebensträussig; die äusseren Blättchen des $H K$. abstehend, borstig-gewimpert; Achenen an der Spitze kurz-zugespitzt, quer-, fast schuppig-runzelig. $\odot$. Sandige Ufer der Insel Veglia. Jun. Jul. Crepis hispidissima Bartl. in Bartl. und Wendl. Beitr. 2. p. 125. 1824. Picris laciniata Visian. Bl. gelb.

\section{HELMINTHIA Juss. Wurmsalat.}

1. H. echioides Gärtu. Die äusseren Blättchen des HK. eyherzf., zugespitzt. $\odot$. Aecker, Schutt; Warnemünde, Börnecke in Braunschweig, Frankf. a. M., wohl mit fremder Erde od. fremdem Getraide eingefihrt. Jul. Aug. Picris echioides L. Bl. gelb.

76. UROSPERMUM Juss. Schwanzsame.

1. U. Dalech a mpii Desf. $H K$. weich -flaumig; Schnabel der Achene v. der Basis bis zur Spitze allmählig verschmälert. 24. Sonnige $u$. steinige $O$.; Istrien, Cherso, Osero. Mai Jun. Tragopogon Dalechampii L. Bl. schwefelgelb.

2. U. pi croides Desf. HK. borstig-steifh.; Schnabel der Achene oberhalb der eyf. Basis plötzl. in einen fadenf. Stiel zsgezogen. $\odot$. Weinberge, kultiv. O.; Insel Osero. Mai. Jun. Tragopogon picroides L. Bl. hellgelb.

XXIV. Gruppe. SCORZONEREEN. C. H. Schultz. Pappus aller Achenen federig, Federchen der Strahlen verstrickt; od. der Pappus der randst. Achenen spreuig, Spreublättchen einfach; od. aller Achenen einfach, die Strahlen klein-gesägt-rauh $u$. an der Basis inwendig-zottig, Zotten verstrickt. Fruchtb. nackt.

77. TRAGOPÓGON L. Bocksbart.

1. T. porrifolius L. Bthstiele aufwärts allmählig verdickt, keulig; HK. 8blätterig, länger als die Blüthen; Köpfchen oberivärts ganz flach; die randst. Aestchen fein-schuppig-knotig, ungefähr so lang als der fadenf. Schnabel. (-) Wiesen; Litt., in Gärten kultiv. Jun. Jul. Bl. purpur-blau. 
2. T. major Jacq. Bthstiele aufwärts allmählig verdickt, keulig; HK. meist 12blätterig, länger als dic Blithen; Köpfchen oberseits concav; die randst. Achenen schuppig-weichstachelig, scharfkantig, ungefähr so lang als der fadenf. Schnabel. $\odot$. Hügel, trockene Wiesen; zerstr. deh das Geb. Jun. Jul. Bl. hellgelb.

3. T. pratensis L. Bthstiele gleich, unter dem Köpfchen ein wenig verdickt; HK. 8blätterig, Blättchen oberhalb der Basis quereingedriickt; Bth. so lang als der HK. od. kürzer; die randst. Achenen so lang als der fadenf. Schnabel, knotig-rauh. $\odot$. Wiesen, Triften. Mai-Jul. Bl. gelb.

4. T. orientalis L. Bthsticle gleich, unter dem Köpfchen ein wenig verdickt; HK. 8blätterig, Blättchen oberhalb der Basis quereingedrückt; Bth. meist länger als der HK.; die randst. Achenen fast noch einmal so lang als der fadenf. Schnabel, schuppig-weichstachelig. $\odot$. Wiesen; zerstr. deh das Geb. Mai-Jul. Bl. gelb. T. undulatum var. $\beta$. orientale DC. nach den Citaten, aber T. undulatus Jacq. hat auf den Achenen einen Schnabel, der vielmal kürzer als die Achene ist.

5. T. floccosus W. K. Bthstiele gleich, unter dem Köpfchen ein wenig verdickt; HK. 8blätterig, kïrzer als die Blüthen; die randst. Achenen an der Basis fast glatt, oberwärts am Pappus ziemlich fein-schuppig-weichstachelig, in einen sehr kurzen Schnabel verschmälert. $\odot$. Grasplätze am Meere, Swinemünde in Pommern, Kurisch Haff in Ostpreussen. Jun. Jul. Bl. hellgelb.

6. T. crocifolius L. Bthstiele gleich, unter dem Köpfchen ein wenig verdickt; $H K$. 5 blätterig, länger als die Blüthen; die randst. Achenen v. der Basis an schuppig-weichstachelig, scharflkantig, ungefähr so lang als der Schnabel. $\odot$. Triften der A.; auf dem grossen Bernhard. Jul. Aug. Bl. dunkelviolett, an der Spitze gelb.

\section{SCORZONÉRA L. Schwarzwurz.}

1. S. a u stria ca Willd. Die wurzelst. B. längl., lanzettl. od. lineal., die stengelst. 2-3, schuppenf.; St. kahl, meist 1köpfig; Blättchen des $H K$. zugespitzt, an der Spitze selbst stumpf, die äusseren eyf.; Schopf der W. fädig. 24. Gebirgige O.; südl. Gebiet u. Gbge in Mähr. Apr. Mai. S. humilis Jacq. DC. Bl. gelb.

2. S. humilis L. WB. länglich, lanzettl. od. lineal.-lanzettl., die 2-3stengelst. lineal.; der St. wollig, 1-3köpfig; HK. halb so lang als die Bth., die äusseren Blättchen ey-lanzettf., zugespitzt, an der Spitze selbst stumpf; Achenen gerieft, glatt; Wurzelschopf schuppig. 24. Feuchte Wiesen; zerstr. deh das Geb. Mai. Jun. S. plantaginea Schleich., DC. Bl. gelb.

3. S. parvifl or a Jacq. WB. lanzettl. od. lineal.-lanzettl.; spitz, die stengelst. wenige, fast lineal.; St. 1-3köpfig, kahl; HK. so lang als die Bth., die äusseren Blättchen ey-, die inneren lanzettf.; Ache- 
nen'gestreift, glatt; Wurzelkrone nackt od. etwas schuppig. (-) Feuchte Wiesen; Unteröstr., Mähr., Böhm. Mai-Jul. Bl. gelb.

4. S. a ri stat a Ramond. B. lineal.-lanzettl. od. lineal.; St. nackt, 1 köpfig; die äusseren Blättchen des $H K$. ey-lanzettf., an der verlängerten Spitze pfrieml., oft so lang als die inneren; Achenen in die Quere faltig-knotig; Wurzelkrone nackt od. etwas schuppig. 24? Triften der A.; Krain, Kärnth., Tyrol. Jul. S. grandiflora Lapp. K. syn. ed. 1. S. alpina Hopp. Bl. gelb.

5. S. his panica L. B. längl. od. lanzettl., zugespitzt; St. beblättert, 1-mehrköpfig, etwas wollig; HK. halb so lang als die Bth., kahl, die äusseren Blättchen 3eckig-eyf., die inneren ey-lanzettf., sämmtl. spitz; die randst. Achenen fein-weichstachelig; Wurzelschopf schuppig. ๑. Wiesen, Grasplätze; zerstr. dch das Geb. Jun. Jul. Bl. gelb. Var. $\beta$. B. verlüngert-lanzettf.: S. glastifolia Willd.

6. S. purpur e a L. B. lineal. od. lineal.-lanzettl.; St. beblättert, 1 köpfig od. an der Spitze ästig u. 2-4köpfig; die äusseren Blättchen des HK. ey-lanzettf.; Achenen gerieft mit glatten Riefen; Wurzelschopf fädig. 24. Unkult. Kalkhiigel; zerstr. dch das Geb. Mai. Jin. Bl. rosenroth.

7. S. rosea WK. B. lineal. od. lineal.-lanzettl.; St. beblättert, 1 köpfig od. an der Basis mit einem oder dem anderen Aste versehen; die äusseren Blättchen des $H K$. ey-lanzettf.; Achenen gerieft, mit oberwärts fein gezähnelt-rauhen Riefen. 2. Gbgswiesen; Wocheiner A. Jul. Bl, rosenroth.

\section{PODOSPERMUM DC. Stielsame.}

1. P. Jacquinian um Koch. W. dauernd, vielköpfig, mit blühenden St. $u$. nichtblühenden Wköpfen versehen; St. aufrecht, ästig; obcrwärts gefurcht; B. fiedersp., Z $\mathrm{p}$ f. lineal., zugespitzt, der endst. lanzettl., verlängert; die randst. Bth. noch einmal so larg als der $H K$. 24. Unkultiv., trockene O., Raine; Unteröstr., Mähren. Jun. Aug. P. octangulare DC. Scorzonera laciniata Jacq. Bl. gelb.

2. P. laciniatum DC. W. 2jährig, einfach, die nichthlühenden Whöpfe fehlend; St. aufrecht, ästig; Aeste (bei der lebenden Pflanze) stielrund; B. ficdersp., Zpfl. lineal., zugespitzt, der endst. lanzettl., verlängert; die randst. Bth. so lang als d. HK. od. nur tin wenig länger. $\odot$. Sonnige IIügel, Aecker; zerstr. dch das Geb. Mai-Jul. Scorzonera laciniata L. S. octangularis Willd. Var.: St. u. B. etwas rauh v. aufgestreuten Knötchen: S. muricata Balb. Bl. gelb.

3. P. calcitrap ifolium DC. W. 2jährig, vielstengelig, der mittlere St. aufrecht, die seitenst. liegend u. aufstrebend; Aeste (an der lebenden Pflanze) stielrund, die nichtblühenden WKöpfe fehlend; 13. fiedersp., Zpfl. elliptisch-lanzettl., der endst. grösser; die randst. Bth. ein wenig länger als der HK. $\odot$. Kalkhügel; Oberelsass. Mai. Jun. Bl. gelb. 
80. GALÁSIA Cass. Galasic.

1. G. villo s a Cass. 24. Steinige O.; Krain, Litt. Mai. Jun. Bl. gelb. Scorzonera villosa Scop. S. angustifolia Host. WK.

XXV. Gruppe. HYPOCHOERIDEEN. Lessing. Pappus federig. Fruchtbod. spreuig, mit abfälliger Spreu.

81. HYPOCHOERIS L. Ferkelkraut.

I. Rotte. Hypochoeris genuina. Aeussere Strahlen des Pappus kürzer, rauh, die inneren federig.

1. H. gl a bra L. St. ästig, kahl, blattlos; Blüth. so lang als der $H K$.; die mittelst. Achener lang-geschnäbelt, die randst. schnabellos, od. alle geschnäbelt. $\odot$. Kultiv. O., Sandboden. Jul. Aug. Bl. gelb wie an d. folgend. Die Var. mit lauter geschnäbelten Achenen: H. Balbisii Koch syn. ed. 1, nicht Lois.

2. H. radicat a L. St. ästig, kahl, blattlos; Bth. länger als der $H K$.; Achenen sämmtl. lang-geschnäbelt. 24. Wicsen, unkult. O. Jul. Aug.

II. Rotte. Achyrophorus. Strahlen des Pappus alle federig.

3. H. ma culata L. St. 1-3köp.ig, meist 1blätterig, steifh.; Bthstiele fast gleichdick; Blättchen des $H K$. am Rande ganz, die mittleren an der Spitze filzig-berandet. 2. Waldtriften, Haiden; zerstr. dch das Geb. Jul. Aug.

4. H. helvetica Jacq. St. 1köpfig, steifh., oberwärts allmählig verdickt, fast keulig, an der Basis beblättert; die äusseren u. mittleren Blättchen des $H K$. am Rande zerrisser-fransig. 24. A., VorA. u. Gbge in Mähr., Böhm., Schles., Feldberg in Bad. Jul. Aug. H. uniflora Vill., K. syn. ed. 1.

XXVI. Gruppe. CHONDRILLEEN. Pappus haarig, die Strahlen fein, an der Basis nicht breiter. Fruchtb. nackt. Achene geschnäbelt; Schnabel an der Basis mit einem hervorragenden Krönchen od. mit schuppenf. Weichstacheln umgeben.

\section{WILLEMÉTIA Necker. Willemetie.}

1. W. a pargioides Cass. 24. Wiesen, Wälder; A. u. VorA., bis in die angrenzenden Ebenen hinab. Jul. Aug. Crepis apargioides W. Hieracium stipitatum Jacq. B1. gelb.

83. TARAXACUMI Juss. Pfaffenröhrlein.

1. T. officinale Wig. Achenen lineal.-vkteyf., gerieft, an der Spitze schuppig-weichstachelig, Riefen der äusseren Achenen v. der Basis an knotig-runzelig, die der inneren glatt; der ungefärbte Theil des Schnabels länger als die Achene mit dem gefärbton Theile vom Schnabel; B. längl.- od. lineal.-lanzettl., fiedersp.-schrotsägef. od. ungeth., gezähnt od. ganzrandig. 2. Feuchte u. trockene Wiesen, Trif- 
ten, kultiv. u. unkultiv. O. überall. Mai-Herbst. Bl. gelb, wie an den folgenden. St. oft wollig, besonders an d. Spitze. Achenen gewöhnlich hell-olivengrün, aber auch dunkelgriin, grasgrün $u$. roth. Var. weiter: $\alpha$. genuinum: Blättchen des HK. sämmtlich lineal., die äusseren abwärtsgebogen. T. Dens leonis Desf. u. DC. Leontodon Taraxacum d. meist. Aut. Bl. meist goldgelb. - $\beta$. glaucescens: Blättchen des HK. sämmtl. lineal., od. die äusseren lanzettl., diese wagerecht-abstehend; das Kraut oft etwas meergrün. Innere Blättchen des HK. vor der Spitze mit einer Schwiele od. kurzem Horn. T. officinale b. corniculatum Koch u. Ziz. L. glaucescens M. Bieb. L. corniculatus Kit. BI. oft hell- od. schwefelgelb. $-\gamma$. alpinum: äussere Blättchen des HK. eyf., abstehend, innere vor der Spitze nicht behörnelt. L. alpinus Hopp. L. caucasicus Stev., MB. L. nigricans Kit. - $\delta$. taraxaccides: äussere Blättchen des HK. eyf. zugespitzt, angedrückt, die inneren an der Spitze behörnelt. L. taraxacoides Hoppe. L. laevigatus Willd, nicht DC. - $\varepsilon$. lividum: die äusseren Blättchen des HK. eyf., zugespitzt, angedrückt, die inneren an der Spitze nicht behörnelt. T. palustre DC. Leontodon salinum Pollich. L. lividus WK. - ל. leptocephalum: dem vorhergehenden sehr ähnlich, Köpfchen schmäler, äussere Blättchen lanzettl., an der Spitze zottig-bärtig. Leontodon leptocephalus Rchb. Moenitzer See in Mähren.

2. T. tenu if olium Hoppe. Achenen lineal.vkteyf., gerieft, an der Spitze schuppig-weichstachelig, Riefen der äusseren Achenen von der Basis an schwach-knotig, die inneren glatt; der ungefärbte Theil d. Schnabels die Länge d. Achene mit dem gefärbten Theile v. Schnabel nicht erreichend; B. lineal.-lanzettf. od. lineal., in einen Bstiel verschmälert, ganzrandig, od. entfernt-gezähnelt. 24. Feuchte Plätze an den Salinen v. Zaule bei Triest. Apr. Mai. Leontodon tenuifolium Hopp. bei Sturm.

3. T. serotinum Poir. Achenen längl.-lineal., beiderseits verschmälert, gerillt, an der Spitze fein-knotig, Riefen der äusseren v. der Basis an runzelig, die der inneren glatt; der ungefärbte Theil des Schnabels kürzer als die Achene mit dem gefärbten Theile $v$. Schnabel; B. längl., im Frühlinge ungeth., die späteren gezähnt od. schrotsägef. 24. Polauer Berge u. um Czeitsch in Mähren. Jul.Sept. Leontodon serotinum WK.

84. CHONDRILLA L. Knorpelsalat.

1. Ch. juncea L. WB. schrotsägef., die oberen stengelst. B. lineal.-lanzettl. $u$. lineal.; Aeste ruthenf.; die seitenst. Köpfchen einzeln, gezweiet orl. gedreiet; Achene mit 5 lanzettl. Zähnên endigend. ๑. Aecker, kiesige O., sonnige Hügel. Jul. Aug. BI. gelb, wie an d. Folgenden. Var. $\beta$. spinulosa: St. unterwärts u. Rand der B. dornig-steifhaarig. Ch. acanthophylla der Autoren. $-\gamma$. latifolia: die 
oberen stengelst. B. lanzettl. od. elliptisch-lanzettl. Ch. latifolia MBB., K. syn. ed. 1. Taurische Expl. stimmen genau mit den Deutschen überein.

2. Ch. prenanthoides Vill. WB. lanzettl., nach der Basis verschmälert, entfernt-gezähnt; St. fast nackt, gabelspaltig-ästig, die endst. Köpfchen gleichhoch; Achene mit einem kurzen, kleingekerbten Krönchen endigend. 2. Kiesige O., Flussufer; südl. Geb. Jul. Aug. Prenanthes chondrilloides L.

XXVII. Gruppe. LACTUCEEN. Pappus haarig; Strahlen haarfein, an der Basis nicht breiter. Fruchtb. nackt. Achene flachzsgedrückt, schnabellos od. mit einem, an der Basis nicht gekrönten, Schnabel endigend.

85. PRENANTHES L. Hasenlattich.

1. P. purpurea L. B. mit herzf. Basis stengelumfassend, kahl, unterseits meergrün, die unteren eyf. od. längl., in den geflügelten Bstiel zsgezogen, gezähnt, die oberen lanzettl., zugespitzt, ganzrandig; Köpfchen rispig. S. Gebirgswälder, mittleres u. südl. Geb. Jul. Aug. Bl. purpurn. Var. tenuifolia: B. lanzettf.-lineal. P. tenuifolia L.

86. LACTÚCA L. Salat.

I. Rotte. Lactuca e genuinae. Achene beiderseits mit mehreren erhabenen Riefen. Bth. gelb.

1. L. sativa L. B. am Kiel stachelig od. glatt, mit herzpfeilf. Basis stengelumfassend, gezähnelt, ungeth. od. schrotsägef.-fiedersp.; $\boldsymbol{R}$. verbreitert, ebensträussig, flach; Achenen beiderseits 5riefig, Schnabel weiss, so lang als die Achene od. länger. $\odot$. Kultiv, u. auf Auswurf der Gärten. Jun.-Aug.

2. L. viros a L. B. am Kiele stachelig, oval-längl., stumpf, pfeilf., stachelspitzig-gezähnelt, ungeth. od. buchtig, die oberen zugespitzt; Rispe abstehend; Achenen beiderseits 5riefig, ziemlich breitberandet, an der Spitze kahl; Schnabel weiss, so lang als die Achene. $\odot$. Gebirgige, felsige O., zerstr. dch das Geb. Jun.-Aug. Achenen schwarz.

3. L. Scariola L. B. am Fiele stachelig, oval-längl., spitz, pfeilf., stachelspitzig-gezähnelt, fiedersp.-schrotsägef., seltener ungeth.; R. pyramidenf.; Aeste traubig; Achenen beiderseits 5riefig, schmalberandet, an der Spitze borstl.-flaumig; Schnabel weiss, so lang als die Achene. $\odot$. Unkult. O. Jul. Aug. Achenen bräunl.-grau.

4. L. saligna L. B. unterseits am Kiele stachelig od. glatt, lineal., zugespitzt, ganzrandig, die untersten schrotsägef.-fiedersp.; Aeste ruthenf., traubig-ährig; Achenen beiderseits 5riefig; Sclinabel weiss, noch $1 \mathrm{mal}$ so lang als die Achene. $\odot$. Aecker, Raine; zerstr. deh das Geb. Jul. Aug. 
5. L. viminea C. H. Schultz. B. herablaufend, die unteren tief-fiedersp., Zpfl. lineal., etwas gezähnt od. ganzrandig, die obersten B. lineal., ungetheilt. $\odot$. Steinige O.; Oestr., Mähr., Böhm., Sachs., Wallis. Jul. Aug. Phoenixopus vimineus Rchb. K. syn. ed. 1. Prenanthes viminea $\mathrm{L}$.

6. L. $\mathrm{muralis}$ Fresenius. B. gestielt, leyerf.-fiedersp., Zpfl. eyf., winkelig, gezähnt; Köpfchen rispig. $\odot$. Wälder, Schutt. Jul. Aug. Prenanthes muralis L.

7. L. stricta WK. $B$. unterseits glatt, die wurzelst. u. unteren stengelst. schrotsäge-leyerf., gezähnt, die oberen schrotsägef.fiedèrsp., an der Basis pfeilf.; R. ebensträussig; Achenen beiderseits 5riefig; Schnabel halb so lang als die Achene, kohlschwarz. $\odot$. Waldungen; Mähr., Böhm., Sachs., Thïring., am Unterharz. Jul. Aug. L. quercina L. flor. suec., wach der Beschreibung. K. syn. ed. 1.

8. L. sagittata WK. B. unterseits glatt, die wurzelst. u. der Bstiel verschmälert, buchtig-gezähnt, die stengelst. pfeilf., ungeth., gezähnelt, die unteren längl., nach d. Basis verschmälert, d. oberen lanzettl., zugespitzt; Rispe ebensträussig; Achenen beiderseits 5riefig; Schnabel halb so lang als die Achene, kohlschwarz. $\odot$. Wälder, um Kanzian im Litt., sodann bei Brïnn in Mähr. Jul. Aug. Vielleicht ganzblätterige Form v. L. stricta, erhält sich aber auch bei der Aussaat in bot. Gärten.

II. Rotte. Cyanoseris. Achene auf der Mitte mit einer

Riefe. Bth. blau.

9. L. perennis L. B. kahl, fiedersp., Zpfl. lineal.-lanzettl., auf der vorderen Seite gezähnt; Ebenstrauss locker, endst., Achenen beiderseits 1riefig, ungefähr so lang als der weisse Schnabel. 24. Steinige O., Felsenspalten; zerstr. deh das Geb. Mai. Jun.

87. MULGÉDIUM Cassin. Milchlattich.

1. Mr. alp inum Cassin. Tr. einfach u. zsgesetzt, drüsig-behaart; 13. gezähnt, leyerf., der endst. Lappen sehr gross, spiessf.-3eckig, lang-zugespitzt, die stengelst. B. mit geflügeltem, an der Basis herzf. Bstiele stengelumfassend; Achenen längl.-lineal., vielriefig, an der Spitze ein wenig verschmälert. 24. Schattige O. d. A., VorA. u. hoher Gbge; Vogesen, Schwarzwald, Mähr., Böhm., Schles., Erzgebirg, Schmon in der Fl. v. Halle, Hurz. Jul. Aug. Sonchus alpinus L. K. syn. ed. 1. Bl. blau.

2. M. Plumieri DC. Köpfchen ebensträussig; Bthstiele u. HK. ganz kahl; B. schrotsägef-fiedersp., gezälnt, die stengelst. mit tiefherzf. Basis stengelumfassend, die oberen lanzettl. zugespitzt, ungeth.; Achenen elliptisch, $v$. der Mitte an bis zur Spitze verschmälert, beiderseits 5riefig. 2. Schattige O. der VorA.; westl. Schwz.; Hohneck u. Ballons der Voges. Jul. Aug. B1. blau. Sonchus Plumieri L., K. syn. ed. 1 . 


\section{SONCHUS L. Gänsedistel.}

1. S. oleraceus L., mit Ausschl. der Variet. $\gamma$. u. $\delta$. St. ästig, Aeste doldig-ebensträussig; HK. kahl; B. längl., schrotsägef.-fiedersp. od. ungeth., die stengelst. an der Basis herzf., mit zugespitzten Oehrchen; Achenen quer-runzelig, beiderseits auf dem Mittelfelde 3riefig. - Kultiv. O. Jun.-Oct. S. laevis Vill. S. ciliatus Lmk., DC. Bl. gelb, wie an den folgenden. Var.: B. ganz od. schrotsägef,, od. tieffiedersp., der Endzpfl. gross, dreieckig, u. $\beta$. lacerus: B. tief-fiedersp., der Endzpfl. auch fiedersp. od. die Z $\mathrm{pfl}$. fast gleich: S. lacerus Willd.

2. S. a sper Vill. St. ästig; Aeste doldig-ebensträussig; HK. kahl; B. oval-längl., ungeth. od. etwas schrotsägef., die stengelst. an der Basis herzf., mit abgerundeten Oehrchen; Achenen glatt, berandet, beiderseits auf dem Mittelfelde 3riefig; W. spindelf. $\odot$. Kultiv 0. Jun.-Oct. S. fallax Wallr., DC.

3. S. maritimus L. St. einfach, an der Spitze 1-wenigköpfig, nebst den $H K$. u. den Bthstielen ganz kahl; B. verlängertlanzettl., ungeth. od. fast buchtig, die stengelst. an der Basis herzf.; Achenen gerieft, Riefen quer-runzelig; $W$. kriechend. 2. Feuchte 0 . am Adriat. Meere. Jul. Aug.

4. S. arvensis L. St. einfach, an der Spitze ebensträussig; $H K$. nebst den Bthstielen drüsig-behaart; B. lanzettl., schrotsägef., die stengelst. an der Basis herzf., die obersten ungeth.; Achenen riefig, Riefen quer-runzelig; W. kriechend. 24. Aecker. Jul. Aug.

5. S. palustris L. St. einfach, an der Spitze ebensträussig, nebst den $H K$. u. den Bthstielen drüsig-behaart; B. schrotsägef.fiedersp., Zpfl. sämmtl. lanzettl., zugespitzt, die StB. an der Basis pfeilf., die oberen ungeth.; Achenen gerieft, Riefen quer-runzelig; W. ohne Ausläufer, 24. Sumpfige Wiesen, Ufer; zerstr. dch das Geb. Jul. Aug.

XXVII. Gruppe. CREPIDEEN. Pappus haarig, die Strahlen haarfein od. pfrieml.-borstl., aber an der Basis nicht spreuig-verbreitert. Achene stielrund, od. kantig, od. etwas zsgedruickt, an der Spitze geschnäbelt, od. schnabellos u. an d. Spitze zsgezogen, od. daselbst von gleicher Breite.

\section{PICRIDIUM Desf. Picridie.}

1. P. v ulgar e Desf. Untere B. buchtig-fiedersp., gezähnelt, die oberen stengelumfassend, längl., fast ganzrandig; Bthstiele an der Spitze dicker; Blättchen des HK. angedriickt. $\odot$. Kultiv. O., Wege; Pola in Istrien u. bei Fiume. Apr. Mai. Scorzonera picroides L. Bl. gelb.

\section{ZACÝNTHA Tournef. Warzenkohl.}

1. Z. verrucosa Gärtn. ○. Felder, unkultiv. O.; Littor. Mai. Jun. Lapsana Zacintha L. Bl. gelb. 


\section{PTEROTHÉCA Cassin. Pterotheke.}

1. P. nemausensis Cassin. ○. Unkultiv. O.; Fiume. Mai. Jun. Bl. gelb. Tar.: randst. Achenen mit $3-5$ häutigen Flügeln : Lagoseris nemausensis K. sya. ed. 1. ; u. $\beta$. : randst. Achenen mit 4 stumpfern Kielen: Lagoseris bifida K. syn. ed. 1., Trichocrepis bifida Vis.

\section{CREPIS L. Pippau.}

I. Rotte. Achenen des Mittelfeldes od. alle lang-geschnäbelt. Barkhausia Moench., DC.

1. C. foetida L. St. aufrecht, beblättert, ästig, nebst den B. rauhh.; B. schrotsägef.-fiedersp., die obersten lanzettl., an d. Basis tief-eingeschnitten; Bthstiele v. dem Aufblühen nickend; Schräbel der randst. Achenen kürzer als der $H K$., die innersten länger als derselbe; $H K$. überall grau u. zuttig, mit einfachen u. drüsentrag. Haaren; Blättchen des AussenK. lanzettl., spitz. (.) Unkult. O.; zerstr. dch das Geb. Jun.-Aug. Barkhausia foetida DC. pr., K. syn. ed. 1. Bl. gelb.

2. C. rhoeadifolia M. Bieberst. Suppl. St. aufrecht, beblättert, ästig, nebst den B. borstig-steifh.; B. schrotsägef.-fiedersp., die obersteu lanzettl., an der Basis tief-eingeschnitten; Bthstiele vor dem Aufblühen rickerul; Schnabel aller Achenen kürzcr als der HK.; der ganze $H K$. v. starren Borsten steifl. u. etwas grau; Blättchen des AussenK. lanzettl., spitz. $\odot$. Sonnige O.; Brünn in Mähr. Jun. Jul. Bl. gelb. Barkhausia rhoeadifolia DC. pr., K. syn. ed. 1.

3. C. rubra L. St. aufrecht u. aufstrebend, einfach od. unterwärts ästig, nackt, an der Basis beblättert; B. schrotsägef.-fiedersp., die oberen lanzettl., an der Basis gezühnt; Bthstiele vor dem Aufblühen nickend; die randst. Acheren so lang als der fruchttrag. $H K$., die innersten länger als derselbe; die inneren Blättchen des HK. steifh., die des AussenK. kahl, ey-lanzettf. $\odot$. Unkultiv. O., Wege; Osero. Jun. Jul. C. incarnata Vis. Barkhausia rubra DC. pr., K. syn. ed. 1. Bl. rosenroth.

4. C. tar axacifolia Thuillier. 'St. aufrecht, beblättert, an der Spitze ebensträussig; B. schrotsägef.-gezähnt od. schrotsägef.-fiedersp.; Bthstiele vor dem Aufbliihen aufrecht; $H K$. grau u. oft steifh., nach dem Verblühen v. der halben Länge des Pappus; Blätchen des AussenK. ty-lanzettf., nach der Spitze verschmïlert, kahl, am Rande häutig; Deck $B$. lineal., krautig, schmal-häutig-berandet. $\odot$. Trockene Wiesen, kiesige O.; westl. Schwz., Elsass, Baden, Würtemb., Oberbayern. Mai-Jul. Bl. gelb. Barkhausia taraxacifolia DC. pr., K. syn. ed. 1. Crepis taurinensis Willd. Var. $\beta$. pratcox: die oberen B. an der Basis verbreitert-geölurelt. Crepis praecox Balb. $-\gamma \cdot$ intybacer: die oberen B. an der Basis geöhrelt; HK. kahl. Barkhausia intybacea DC. H. fr. 
5. C. vesicaria L. St. aufrecht, ästig, ebensträussig, spärlich beblättert; B. schrotsägef.-gezähnt od. schrotsägef.-fiedersp.; Bthstiele vor dem Aufbliihen aufrecht; HK. grau u. oft steifh., nach dem Verblühen v. der halben Länge des Pappus; Blättchen des AussenK. oval, concav, häutig, kahl; DeckB. längl., stumpf, häutig, mit cinem schmalen, krautigen Rückenstreifen. (.). Triften, Wege; Veglia u. Osero. Mai. Barkhausia vesicaria DC., K. syn. ed. 1. et B. scariosa DC. Bl. gelb. Var.: Aussenkelch merklich kürzer als der HK.: C. vesicaria Willd., u. fast so lang als der HK.: C. scariosa Willd.

6. C. setos a Haller fil. St. aufrecht, beblättert, ästig, Aeste ebensträussig; B. schrotsägef.-gezähnt od. leyer-schrotsägef., die oberen pfeilf., ganz od. an der Basis eingeschnitten-gezähnt; Bthstiele vor dem Aufblühen aufiecht; HK. nach dem Verblïhen $\%$. der Länge des AussenK., lanzettl., spitz, nebst den DeckB. am Rande, den inneren Blättchen auf dem Riicken $u$. d. Bthstielen fast dornig-steifh., Borsten starr, einfach. - - Aecker, Weinberge; zerstr. im siidl.u. mittl. Geb. Jul. Aug. Crepis hispida WK. Barkhausia setosa DC. pr., K..syn. ed. 1. Var. mit kahlen Bthstielen.

II. Rotte. Achenen an der Spitze etwas schmäler, walzlich od. in einen kurzen Schnabel ausgehend. Achencn 10-13riefig. Pappus schneeweiss, weich.

1. St. blattlos, an der Spitze vielköpfig. Kööpfehen klein; AussenK. kurz, angedrückt.

7. C. praemorsa Tausch. St. blattlos, traubig, Tr. an der Ba-sis zsgesetzt; d. unteren Bthstiele 2-3köpfig, d. oberen 1köpfig; $\boldsymbol{B}$. oval-längl., an der Basis verschmälert, gezähnelt, flaumig. 2. Gebirgige, steinige $O$.; siidl. u. mittl. Geb. Mai. Jun. Hieracium praemorsum L. Bl. gelb.

8. C. incarnat a Tausch. St. blattlos, ebensträussig; B. vkteyf.längl., an der Basis verschmälert, gezähnelt. 2. VorA. u. Gbge, südl. Tyrol, Krain, Kärnth.? Mai. Jun. Hieracium incarnatum Wulf. Bl. fleischroth, röthl. od. weiss, u. $\beta$. lutea Koch syn.: Bl. gelb. C. Froelichiana DC. prodr. Hieracium parviflorum Schleich. Die rothe Farbe der Bl. geht deh das Weisse in das Gelbe über nach Facchini.

2. St. blattlos od. an der Basis mit einem od. dem anderen B., an der Spitze 1köpfig od. mit wenigen 1köpfigen Aesten.

9. C. bulbosa Tausch. Schaft 1köpfig; blattlos od. an der Basis 1blätterig, an der Spitze nebst der Basis des HK. kurzh.; B. längl.-lanzettl., etwas gezähnt, kahl; Wfasern knollentragend. 4. Triften, sandige O.; Istrien. Apr. Mai. Leontodon bulbosum L. Aetheorrhiza bulbosa Cass., DC. Bl. gelb.

10. C. a urea Cassin. St. $1 \mathrm{köpfig,} \mathrm{blattlos} \mathrm{od.} \mathrm{an} \mathrm{der} \mathrm{Basis} \mathrm{we-}$ nigblätterig u. etwas ästig, oberwärts nebst dem HK. schwarz-rauhh.; 
B. längl., gezähnt od. schrotsägef., kahl; Wfasern stielrund. 2. A. u. VorA. Jul. Aug. Leontodon aureum L. Bl. pomeranzengelb.

11. C. a lpestris Tausch. St. $1 \mathrm{köpfig}$, blattlos od. an der Basis wenigblätterig, etwas ästig, an der Spitze filzig; HK. grau od. kurzh.; B. lanzettl., gezähnt od. schrotsägef. 2. A., VorA. u. Jurakalk in Würtemb., bei Regensb. u. Eichstädt. Jul. Aug. Hieracium alpestre Jacq. Bl. gelb.

12. C. $\mathrm{ju}$ b at a Koch. St. $1 \mathrm{köpfig,} \mathrm{1-2blätterig,} \mathrm{oberuärts} \mathrm{nebst}$ dem Köpfchen dicht rauhh., die Haare abstebend, etwas schlängelich, drüsenlos, gelbliclı; Blättchen des HK. lanzettl., dachig; WB. längl.-lanzettl., stumpf, nach der Basis verschmälert, ganzrandig, od. ein wenig gezähnt, kahl, das stengelst. rauh. 24. Im Thale Bagne im Wallis Em. Thomas. C. chrysantha Fröl.

3. St. beblättert, an der Spitze ebensträussig. Grösse der Köpfchen bei verschiedenen Arten verschieden. Bth. aller citrongelb od. goldgelb.

13. C. chondrilloides Jacq. St. armköpfig, grau u. drüsigbehaart, unterwärts beblättert; Köpfchen fast ebensträussig; $B$. gefiedert, Fieder büschelig-geth., Zpfl. lineal., sehr schmal; HK. filzig; Achenen 10riefig. 2. Sonnige, felsige O.; Litt., Krain. Jun. Jul. C. foeniculacea Fröl., DC. pr. Andryala chondrilloides Scop.

14. C. biennis L. St. beblättert, an der Spitze ebensträussig; B. gezähnt od. schrotsägef.-fiedersp., die stengelst. sitzend, fast stengelumfassend, flach, an der Basis geöhrelt-gezähnt, die obersten ganzrandig; Blättchen des $H K$. sämmtl. längl.-lineal., zieml. stumpf, grauflaumig, die äusseren etwas abstehend, die inneren auf dem Rücken steifh. od. kahl, auf der inneren Oberfläche fast seidig-haarig; Achenen an der Spitze schmäler, 13riefig. $\odot$. Wiesen. Mai. Jun.

15. C. nicaeensis Balb. St. beblättert, an der Spitze cbensträussig; B. gezähnt od. schrotsägef., die stengelst. sitzend, fast stengelumfassend, flach, an der Basis pfeilf., mit zugespitzten, abwärts gerichteten Oehrchen, die obersten ganzrandig; Blättchen des $H K$. lanzettl., nach vorne verschmälert, grau-flaumig, die äusseren etwas abstehend, die inneren auf dem Riicken steifh., auf der inneren Oberfäche kahl; Achenen an der Spitze verschmälert, 10riefig. $\odot$ Trockene Wiesen; Wien, Bern, Knielingen bei Cẩlsruhe, um Mannheim. Mai. Jun. C. scabra DC., nicht Willd. C. agrestis Fries. herb. norm. F. 3.

16. C. tectorum L. St. beblättert, ebensträussig; die wurzelst. B. lanzettl., gezïlnnt od. schrotsägef.-fiedersp., die stengelst. lineal., sitzend, pfeilf., am Rande zurückgerollt; Blättchen des HK. lanzettl., nach vorne verschmälert $\mathfrak{u}$. nebst den Bthstielen grau-flaumig, die äusseren lineal., etwas abstehend, die inneren auf der inneren Oberfläche angedrückt-behaart; Achenen 10riefig, an der Spitze ver- 
schmälert-zsgezogen, fast geschnäbclt, Schnabel rauh. $\odot$. Aecker. Mai. Jun.

17. C. cernua Tenore. St. aufrecht, v. der Basis an ästig, beblättert; Aestchen 2-3köpfig, vor der Bthzeit überhangend; die unteren B. gezähnt od. schrotsägef., die oberen pfeilf., oft an der Basis kammf.-fiedersp.; HK. nach dem Verllühen ungefähr so lang als der hinfällige Pappus; Blättchen schwach-graulich, die des AussenK. lanzettl., angedrückt $u$. rehst den DeckB. am Rande kahl; Schnabel der Achene $3 \mathrm{mal}$ kürzer als die Achene. $\odot$. Unkultiv. O., Wege, Triften; Littoral. Jun.-Aug. Barkhausia cernua Rchb., K. syn. ed. 1. Crepis polymorpha DC. zum Theil.

18. C. virens Vill. St. beblättert, ästig, ebensträussig; die wurzelst. B. lanzettl., gezähnt od. schrotsägef.-fiedersp., die oberen stengelst. lineal., flach, an der Basis pfeilf.; die äusseren Blättchen des HK. lineal., angedrückt, auf der inneren Oberfläche kahl; Acheren lineal.-längl., 10riefig, an der Spitze cin wenig schmäler, Riefen glatt; Fruchtb. kahl. ○. Aecker, Triften, Wege. Jun.-Herbst. C. polymorpha DC. zum Theil. Var. Köpfehen noch eiumal so gross: C. agrestis WK.

19. C. pulchra L. St. an der Spitze rispig; die wurzelst. B. schrotsägef., die stengelst. lanzettl., an der Basis abgeschnitten, hinten gezähnt; $R$. gleich-hoch, nackt; HK. ganz kahll; Blättchen des AussenK. sehr kurz, eyf., angedrückt; Achenen lineal., schwach 10riefig, an der Spitze wenig verschmälert, kahl, die randst. rauh. (.) Hügel, Weinberge; westl. Geb. v. Basel bis Bingen, u. Oestr. u. Litt. Jun. Jul.

III. Rotte. Achenen 10-13riefig. Pappus zerbrechlich, in das Gelbliche spielend. Bl. gelb.

20. C. J a cqu ini Tausch. St. an der Spitze 1-5köpfig; B. lanzettl., kahl, gestielt, die äusseren wurzelst. ungeth., die stengelst. schrotsägef., lang-zugespitzt, Zpfl. der oberen lineal.; HK. nebst den Bthstielen locker-filzig $u$. oft schwarz-rauhh.; Achenen meist 12riefig. 2. Felsige O. der A.; v. der östl. Schwz. bis Oestr. Jul. Aug. Hieracium chondrilloides $\mathrm{L}$.

21. C. paludosa Moench. St. aufrecht, ästig, ebensträussig; B. kahl, die unteren längl., spitz, schrotsägef.-gezähnt, an der Basis verschmälert, die oberen ey-lanzettf., an der Basis herzf., stengelumfassend, gezähnt, an der Spitze ganzrandig, lang-zugespitzt, sehr spitz; Blättchen des $H K$. lanzettl., verschmälert-spitz, drüsig-behaart, die äusseren $3 \mathrm{mal}$ lzürzer; Achenen 10riefig. 24. Nasse Wiesen u. Waldplätze. Jun. Jul. Hieracium paludosum L.

IV. Rotte. Achenen 20riefig. Pappus schneeweiss. Bl. gelb.

22. C. succis a e fol ia Tausch. St. an der Spitze ebensträussig; Bthstiele ästig; B. längl., schwach-gezähnt, kahl od. mit einfachen 
Haaren bestreut, die wurzelst. an der Basis verschmälert, gestielt, stumpf, die stengelst. stengelumfassend, das unterste über der Basis zsgezogen; Bthstiele nebst dem HK. drüsig-behaart; Blättchen des HK. lanzettl., verschmälert-spitz, die äusseren halb so lang, angedrückt. 4. Feuchte Wiesen, VorA. u. Gbge in Würtemb., Oberbad. u. bis Oestr., u. Mähr., Böhm. u. Schles. Jul. Aug. Hieracium succisaefolium All. H. molle Jacq. H. integrifolium Hopp.

23. C. p y g ma ea L. St. wenigköpfig, liegend, an der Basis ästig; B. gestielt, eyf. od. etwas herzf., gezähnelt; Bstiel leyerf.-gezähnt; Achenen 20riefig. 24. Höchste A.; Aelen, Wallis, Graubünd. Jul. Aug. Hieracium prunellaefolium Gouan.

24. C. blattarioides Vill. St. 1-6köpfig; Köpfchen fast ebensträussig; B. längl., gezähnt, die wurzelst. an der Basis verschmälert, die stengelst. stengelumfassend, ar der Basis pfeil-od. spiessf.; Blättchen des $H K$. längl.-lanzettl., stumpf, die äusseren etwas ab. stehend, so lang als die inneren, sämmtl. rauhh., Haare borstig, einfach; Achenen 20riefig. 24. A., VorA. u. Ballon der Voges. Jul. Aug. C. austriaca Jacq., Hieracium blattarioides L. sp., H. pyrenaicum L. syst. nat.

25. C. grandifl or a Tausch. St. einfach, 3-5köpfig; B. drüsigflaumig, gezähnt, die wurzelst. längl.-lanzettl., in einen breiten Bstiel verschmälert, die stengelst. pfeilf.-stengelumfassend, lanzettl., fast ganzrandig; $H K$. nebst den Bthstielen v. Iängeren einfachen u. kürzeren drüsentrag. Haaren rauhh., dessen Blättchen längl. - lanzettl., die inneren stumpf, die äusseren halb so lang, ziemlich locker, spitz, sämmtl. rauhh. 2. Triften der A. Jul. Aug. Hieracium grandiflorum All.

V. Rotte. Achenen 30riefig. Pappus schmutzig-weiss, zerbrechlich.

26. C. sibirica L. St. rauhh., an der Spitze ebensträussig; $\boldsymbol{B}$. runzelig, elliptisch-längl., gezähnt, die unteren stengelst. in den tiefgezähnten, stengelumfassenden Bstiel verschmälert, die oberen lanzettl., fast ganzrandig; HK. v. einfachen Haaren rauhh., die äusseren Blättchen kürzer, locker; Achenen meist 30riefig. 24. Gesenke der Sudet. Jul. Aug.

93. SOYÉRIA Monnier. Soyerie.

1. S. montana Monn. St. 1köpfig, an der Basis beblättert, an der Spitze verdickt; $B$. elliptisch-lüngl., gezähnt, die stengelst. halbstengelumfassend; HK. sehr rauhh. 24. Wiesen der A. u. VorA. Jun. Jul. Hieracium montanum. Jacq. Crepis montana Tausch., DC. Bl. gelb.

2. S. h yoscri difolia Koch. St. 1köpfig, blattreich; B. sämmtl. gestielt, schrotsägef., das oberste lineal., ganzrandig; HK. schwarz-behaart u. schr rauhh. 4. Höchste A.; Schwz., Vorarlberg, Oberstrak. Jul. Aug. Hicracium hyoseridifolium Vill. Bl, gelb. 


\section{HIERACIUM L. Habichtskraut.}

I. 'Rotte. Piloselloidea. St. schaftf. Strahlen des Pappus sehr fein, einreihig u. gleichlang, nur cin u. der andere kurze eingemischt.

a. St. blattlos, einfach, 1köpfig; od. in eine Gabel gespalten u. 2 köpfig, Bthsticle verlängert, in einem spitzen Winkel aufrecht; od. wiederholt-gabelig u. 3-5-, seltener mehrköpfig. Bl. gelb.

1. H. Pilosella L. St. kahl, einköpfig; Ausläufer hingestreckt, unfruchtbar od. bthtragend, letztere an der Spitze aufstrebend, in einen 1köpfigen od. gabelig $2-3$ köpfigen Bthstiei verlängert; $H K$. kurz-walzl.; B. etwas ins Meergriine spielend, vkteyf.-lanzettl. od. lanzettl., borstig-behaart, unterseits gran-filzig. 2. Trockne Triften, Haiden, unkultiv. O. Mai-Herbst. Var. a. vulgare: Köpfehen kleiner; HK. drïsig-behaart; Ausläufer verlängert u. dünn; B. unterseits filzig. - $\beta$. robustius: an allen Theilen grösser, behaarter; HK. . einfachen Haaren rauhh.; Ausläufer zwar verlängert, jedoch merklich dicker; B. unterseits weiss-filzig. - $\gamma$ farinaceum: B. beiderseits, doch unterseits dichter, v. einem fein-sternf. Flaume filzig. H. Pilosella $\beta$. farinaceum Hornung, $H$. velutinum Heg. u. Heer. - $\delta$. pilosissimum: v. d. Grösse der vorhergehend. Varietät, aber dch verlängerte Haare sehr rauhh.; Köpfchen $v$. langen Haaren sehr, zottig, wie an H. alpinum; Blättchen des HK. an der Spitze verschmälert-spitz; Ausläufer dick, kurz. H. Peleterianum Merat. - $\varepsilon$. grandiflorum: Köpfchen fast noch einmal so gross; HK. mit kurzen Drüsenhaaren besetzt; Ausläufer kurz, ziemlich dick. H. Pilosella $\gamma$. grandiflorum DC. - $\zeta$. Hoppeanum: ebenso wie die vorhergehende, aber die äusseren Blättchen des HK. oval-lanzettl., fast eyf., ziemlich stumpf. H. Hoppeanum Schultes. H. pilosellaeforme Hoppe. Die Var. $\varepsilon$. u. $\zeta$. auf den A.

2. H. stolon iflorum WK. St. meist 1hlätterig, gabelig-2köpfig od. wiederholt-gabelig-3-u. mehrköpfig; Bthstiele verlängert, aufrecht; Auslänfer liegend, unfruchtbar n. bthtragend, letztere anfstrebend, $1 \mathrm{köpfig}$ od. gabelig-mehrköpfig; HK. an der Basis niedergedrücktbauchig; B. grasgriin, vktey-lanzettf., borstig-behaart, unterseits dch den fein-sternf., zerstreuten Flaum etwas grau. \%. Bergtriften, Grasplätze; Böhm., Hamburg. Mai-Jul. Bl. schwefelgelb, die äusseren unterseits meist purpurn gestreift.

3. H. b ifurcum M. Biebst. St. meist 1blätterig, gabelig, 2köpfig od. wiederholt-gabelig $u$. 3- u. mehrköpfig; Bthstiele verlängert, aufrecht; Ausläufer liegend, verlângert, unfruchtbar u. bthtragend, letztere aufstrebend, $1 \mathrm{köpfig} \mathrm{od.} \mathrm{gabelig-mehrköpfig;} H K$. an der $B a$. sis bauchig; B. in das Meergrine spielend, vktey-lanzettf., unterseits dch den zerstreuten fein-sternf. Flaum etwas grau. 4. Sonnige un- 
kultiv. O.; zerstr. deh das Geb. Mai-Jul. Bl. schwefelgelb, meist gleichfarbig, auch die randst.: $H$. brachiatum Bertol.

4. H. furcatum Hoppe. St. nackt od. 1blätterig, gabelig, 2köpfig od. wiederholt-gabelig u. 3-4köpfig; Bthstiele verlängert, aufrecht; Ausläufer fehlend od. kurz; HK. nach dem Verblühen kugelig; B. kahl od. zerstreut-borstig, unterseits mit fein-sternf. Flaume bestrent u. auf der Mittelrippe borstig, die inneren lanzettl., spitz, die äusseren halb so lang, vkteyf., stumpf. 24. Triften der A. Jul. Aug. H. sphaerocephalum Fröl., DC. - $\beta$. alpicola: Schaft sehr rauhh.; HK. dicht-zottig v. schwarzen Haaren; Ausläufer kurz. - H. alpicola Schleich.

b. St. an der Spitze 2-5köpfig, mit ebensträussig-zsgestellten Köpfchen; od. an verkümmerten Expl. mit einem einzelnen Köpfchen od. an wuchernden in mehr als 5 endigend. Bl. gelb.

5. H. brevis ca pum DC. St. nackt od. 1blätterig, an der Spitze 3-5köpfig; Bthstiele fast ebensträussig; Ausläufer sehr kurz od. fehlend; B. beiderseits v. cinem fein-sternf. Flaum graulich $u$. borstig-steifh., die inneren lanzettl., die äusseren vkteyf. u. oberseits kahl. 24. Höhere A. der Schwz. Jul. Aug. Wohl Abart v. H. angustifolium.

6. H. a ngustifolium Hoppe. St. nackt od. 1blätterig, an der Spitze 2-5köpfig; Bthstiele ebensträussig, nach dem Verblühen aufstrebend; Ausläufer sehr kurz od. fellend; Bth. gleichfarbig; B. freudig-grün, lanzettl. od. fast lineal., kahl od. am Rande und auf der Rippe feinsternf.-flaumig, zerstreut-borstig-behaart. 24. Höhere A. Jun.-Aug.

7. H. A u ricula L. St. nackt od. 1blätterig, an der Spitze 2-5köpfig; Bthstiele ebensträussig, nach dem Verblühen aufstrebend; Ausläufer liegend, verlängert, unfruchtbar od. (sehr selten) aufstrebend und bthtragend und gabelig-2-mehrköpfig; Bth. gleichfarbig; B. bläulichgrün, lanzettl., kahl, zerstreut-borstig-behaart, die äusseren stumpf, die inneren spitz. 24. Wiesen, Triften. Jun.-Oct. H. dubium Willd. u. der Autor.

c. St. an der Spitze ebensträussig - vielköpfig, 20-100köpfig. B. mehr od. weniger bläulichgrün, am Rande od. überall borstigsteifh., u. unterseits od. auf beiden Flächen mit sternf. Flaum bestreut, selten ganz kahl. Bl. gelb.

8. H. piloselloides Vill. St. schlank, nackt od. unterwärts armblätterig, kahl; Ebenstrauss vielköpfig, fast rispig, locker, kahl od. zerstreut-behaart; HK. schwach fein-sternf.-flaumig; Bthstiele nach dem Verblühen abstehend u. aufstrebend; B. bläulich-grün, schmallanzettl., kahl od. am Rande od. auf der ganzen Oberfläche zerstreutborstig-behaart; Borsten stark, starr. 24. Felsige O.; Flusskies; südl. Geb., besonders über den A. Jun. Jul. - $\beta$. glareosum: niedrig, der St. v. der Mitte an ïstig; Aeste schlank, eine lockere, verbrei- 
terte, spreitzende R. darstellend. H. Michelii Tausch. Flusskies der Save in Krrain u. des Isonzo in Litt.

9. H. praealtum Koch. (Villars mit Zusätzen.) St. kahl od. zerstrent-borstig-behaart u. mit fein-sternf. Flaume bestreut, unterwärts 1-wenigblätterig; Ebenstrauss vielköpfig, gleichhoch, locker; Bthstiele u. HK. lockerer od. dichter-fein-sternh.-grau u. behaart, Bthstiele nach dem Verbliihen gerade; B. bläulich-grün, lanzettl., am Rande od. auf der ganzen Fläche borstig-haarig, Borsten stark, steif, länger als der Durchmesser des St. 24. Trockene Wiesen, unkultiv. O. Jun. Jul. Var. $\alpha$. florentinum: Ausläufer fehlend od. die aufstrebenden bthtragenden seitenständige St. darstellend; St. kahl; am Rande u. unterseits auf der Mittelrippe mit Borsten bewimpert. $\mathbf{H}$. praealtum Vill., DC. H. florentinum Willd.; die Form mit mehr behaartem St., u. schwarzdriisigen, behaarten Bthstielen u. HK.: H. obscurum Rehb. - $\beta$. Bauhini: St., B. u. alles ïbrige wie bei der Variet. $\alpha$., aber fädliche, verlängerte Ausläufer treibend. H. Bauhini Bess. H. Auricula Willd. - $\gamma$. fallax: Ausläufer fehlend od. aufstrebend u. bthtragend; B. oberseits iiberall mit steifen Borsten bestreut; Schaft ziemlich kahl. H. fallax DC. - $\delta$. decipiers: St., B. $u$. alles übrige wie bei der Variet. $\gamma$, aber verlängerte Ausläufer treibend. H. fallax Koch bei DC. - $\varepsilon$. hirsutum: St. durchaus u. die B. unterseits mit fein-sternf. Flaume bedeckt; Ausläufer aufstrebend, stengelf., bthtragend. $H$. fallax Willd, weniger rauhh.: $H$. cymigerum Rchb.; sehr rauhh.: H. Zizianum Tausch. - Die Var. $\varepsilon$. unterscheidet sich v. H. echioides deh die wenigen $u$. nicht allmählig an Grösse abnehmenden StB., u. die kleineren, nicht so dicht-filzigen Köpfchen.

10. H. e chioides W. K. St. reichblätterig, 10-20blätterig, v. fein-sternf. Flaume dicht-filzig u. borstig-haarig, Borsten steif, länger als der Dchmesser des St.; B. allmählig nach oben an Grösse abnehmend, bläulich-grïn, lanzettl., unterseits fein-sternf--flaumig, beiderseits von starken, verlängerten Borsten steifh.; Ebenstrauss vielköpfig, gleich-hoch, locker, weiss-filzig und behaart; Ausläufer fehlend od. aufstrebend, stengelf. u. bthtragend. 2. Hügel u. unkultiv. O.; nördl. u. östl. Geb. Jun.-Aug. - $\alpha$. setigerum: Borsten des St. u. der B. abstehend. H. setigerum Tausch. $-\beta$. verum: Borsten des St. u. der B. aufrecht od. angedriickt. $H$. echioides Lumn., WK. - $\gamma$. grandiflorum: Ebenstrauss aus wenigeren aber grösseren Köpfchen zsgesetzt, Köpfchen fast so gross wie an $\mathrm{H}$. Pilosella. H. cinereum Tausch.

11. H. Nestleri Vill. St. an der Basis 3-6blätterig, mit feinsternf. Flaum bestreut $u$. borstig-kurzhaarig, Borsten so lang als der Dchmesser des St. od. kiirzer; B. längl.-lanzettl. u. längl. beiderseits fein-sternf.-flaumig $u$. v. kurzen Borsten kurzh., die äusseren stumpf, die inneren spitz; Ebenstrauss gedrungen vielköpfig, graulich, 
v. driissigen Haaren od. Borsten rauhh.; Bthstielchen büschelig. 4. Unkultiv. O.; südl. u. mittl. Geb. Jun. Jul. Var. $\alpha$. hirsutum: Haare des St. so lang als dessen Dchmesser; Ebenstrauss v. einfachen, verlängerten Haaren rauhh. H. cymosum Fröl. - $\beta$. brevisetum: Borsten des St. u. der B. sehr kurz; Ebenstrauss v. einfachen, verlängerten Haaren rauhh. $-\gamma$. Vaillantii: Borsten des St. u. der B. sehr kurz; Haare des Ebenstrausses kuxz, drüsig, mit wenigen darunter gemischten längeren, einfachen. H. Vaillantii Tausch.

12. H. pratens e Tausch. St. unterwärts armblätterig, von verlängerten, schlanken Haaren rauhh., oberwärts nebst dem Ebenstrauss v. drïsentrag. Haaren u. Borsten schwarz-behaart; Ehenstrauss vielköpfig, gedrungen; Bthstielchen während der Bthzeit geknäuelt; $B$. grasgrün, od. nur etwas bläulichgriin, längl. - lanzettl., v. schlanken Haaren rauhh., aber ohne den fein-sternf. Flaum od. unterseits spärlich damit bestreut. 24. Hügel, torfhalt. Wicsen; mittl. u. häufiger nördl. Geb. Jun.-Aug. H. cymosum Willd. H. collinum Gochn. H. dubium $\mathrm{L}$.

d. St. 2-mehrköpfig, wie in der Abth. c., aber die B. grün ohne Mischung von Bläulichem, übrigens rauhh.

13. H. a urantia cum L. St. unterwärts armblätterig, von verlängerten, schlanken Haaren rauhh., oberwärts nebst dem Ebenstrauss schwarz-drüsig-behaart u. v. einfachen Haaren rauhh.; Ebenstrauss 2-10köpfig (bei kultivirten 15-20köpfig), geknäuelt, zuletzt locker; B. grasgrün, längl. od. vktey-lanzettf. od. vkteyf., v. schlanken Haaren rauhh., ohne fein-sternf. Flaum. 4 od. $\odot$. Triften der A. u. VorA. u. Voges.; Mähr., Böhm. u. Schles. Gbg. Jun. Jul. Bl. pomeranzenfarb. Var. $\beta$. luteum: Bth. gelb. H. aurantiacum $\delta$. flavum Gaud.; Schleich. Kommt dem H. sabinum am nächsten, untersch. sich aber hinlänglich dch die 3 mal grösseren Köpfchen u. den lockeren Ebenstrauss. - $\gamma$. bicolor: B1. am Rande pomeranzenfarb., im MittelfeIde citrongelb.

14. H. s a binum Sebast. u. Maur. St. unterwärts mehrblätterig, nebst den Bthsticlchen u. B. mit fein-sternf. Flaum bestreut u.v. verlängerten Borsten rauhh.; Ehenstrauss vielköpfig, 20-30köpfig, dicht-gedrängt; HK. sehr rauhh.; $B$. grasgrün, lanzettl., od. vkteylanzettf., d. ̈̈usseren stumpf, die inncren spitz. 24: Triften, lichte WaldO.; Wald v. Lippiza bei Triest. Jun.-Aug. H. cymosum Vill. Var. $\beta$. rubellum: BI. röthlich. H. multiflorum Schleich. Dieses in den A. der südl. Schwz.

II. Rotte. Aurella Tausch z. Theil. Die B. satt-bläulichgrün, lanzettl. od. längl., meist v. verlängerten Haaren zottig od. am Blattstiele bärtig. Die der nichtblühenden WKöpfe überwinternd u. noch zur Bthzeit vorhanden. Zühne der Bl. auswendig kahl. Haare der B. gezühnelt, nicht mit drüsigen gemischt. 
Strahlen des Pappus stärker als bei voriger Rotte, $\mathrm{u}$. wie bei allen folgenden undeutlich-zweireihig, die langen mit mehreren kurzen gemischt.

15. H. st aticefoli um Vill. St. fast nackt, 1-3köpfig; Bthstiele verlängert, oberwärts vielschuppig und nebst dem HK. graulich; Blättchen des HK. zugespitzt; WB. lineal. od. lanzettl.-lineal., zieml. stumpf, entfernt-gezähnt od. ganzrandig, nach der Basis verschmälert, kahl; W. kriechend. 24. A. u. VorA., u. Ebenen längs der A. Jun. Jul.

16. H. porrifolium L. St. beblättert, meist $r$. der Basis an ästig, locker-rispig, kahl; Aeste schlank, abstehend, meist 2köpfig; Bthstiele oberwärts schuppig u. nehst dem HK. v. fein-sternf. Flaume etwas graulich; Blättchen des HK. an der Spitze stumpf, angedrïickt; B. bläulichgrün, lineal.-lanzettl. $u$. lineal., zugespitzt, an der Spitze verschmälert, fust ganzrandig, kahl od. an der Basis gewimpert, die stengelst. sitzend. 2. VorA. u. A.; Oestr., Stmk., Krain, siidl. Schwz. Jul. Aug. Var. $\alpha$. armeriaefolium: B. $1 / 2-1 \frac{1}{2} "$ breit, ganzrandig od. mit einigen schwachen Zähnchen. H. porrifolium $a$. armeriaefolium Fröl. bei DC. - $\beta$. denticulatum: B. $3-6^{\prime \prime \prime}$ breit, schmäler u. breiter lanzettl., entfernt-gezähnelt, an der Basis od. aucl auf der Unterseite rauhh. H. porrifolium $\delta$. dentatum Fröl. bei DC. $-\gamma$. Froelichii: B. wie bei $\beta$, aber unterseits mit feinen Sternhärchen. H. saxatile Jacq. obs., Frölich bei DC. - Der Name H. saxatile Jacq. ist u. bleibt zweidentig.

17. H. g la u c u m Allioni. St. beblättert, 2-mehrköpfig, kahl; Bthstiele oberwärts schuppig u. nebst dem HK. v. fein-sternf. Flaume graulich, übrigens kahl od. mit einfachen od. driisigen Haaren spärlich bestreut; Blättchen des HK. angedrückt; B. bläulichgrün, lanzettl., zugespitzt, nach der Basis verschmälert, ganzrandig, entferntgezähnelt od. gezähnt, kahl od. an der Basis bärtig-gewimpert, die stengelst. entfernt, die unteren gestielt, die oberen sitzend. 2. A. u. VorA. u. Kies der Bäche in den A. Jun.-Aug. H. saxatile Jacq. ic. rar. t. 163., K. syn. ed. 1.

18. H. b u ple u roide's Gmel. St. blattreich, 2-melırköpfig, kahl ; Bthstiele oberwärts schuppig u. nebst dem HK. v. fein-sternf. Flaum etwas graulich $u$. behaart mit einfachen Haaren; Blättchen des HK. ziemlich spitz, die äusseren abstehend; B. bläulichgrün, larzettl.-zugespitzt, nach der Basis verschmälert, gestielt, ausgeschweift-gezähnelt od. gezähnt, kahl od. an der Basis gewimpert, die stengelst. zahlreich, genähert, die oberen sitzend. 24. A. u. VorA.; Schwäbische Alp. Jul. Aug. H. polyphyllum Willd. H. graminifolium DC. prodr.

19. H. dentatum Hoppe. St. beblättert, 1-mehrköpfig u. etwas ebensträussig, mit sternf. Flaume bestreut $u$. zottig; B. bläulich- 
grün, rauhh. od. oberseits kahl 'werdend, lanzettl., zugespitzt, ausgeschweift od. kleingezähnt, in den Bstiel verschmälert, die stengelst. zahlreich, genähert, die oberen kleiner, eyf., sitzend; Bthstiele nebst dem HK. graulich u. rauhh.; Blättchen des HK. zugespitzt-verschmälert, angedrückt. 4. A. u. VorA. Jul. Aug. H. speciosum Hornem.

20. H. gl abratum Hoppe. St. beblättert, 1-mehrköpfig u. etwas ebensträussig, kahl; B. bläulichgrün, lanzettl., zugespitzt, flach, ganzrandig od. entfernt-gezähneIt, in den schmalen Bstiel verschmälert, ganz kahl od. an der Basis etwas gewimpert, die oberen stengelst. sitzend; Bthstiele oberwärts v. fein-sternf. Flaume graulich u. nebst dem HK. v. weissen Haaren sohr zottig; Blättchen des HK. nach vorne verschmälert u. sehr spitz, die äusseren etwas abstehend. 4. A. u. VorA. H. flexuosum Fröl., DC. Jun. Jul.

21. H. villos um L. St. beblättert, 1-mehrköpfig u. etwas ebensträussig u. nebst den B. wollig-rauhh.; B. bläulichgrün, längl.lanzettl. $u$. lanzettl., gezähnelt, fast wellig, nach der Basis verschmälert, die stengelst. sitzend, die oberen eyf. u. halbstengelumfassend; St. oherwärts nebst den Bthstielen v. sternf. Flaume graulich, v. der Wurzel an nebst den Bthstielen $u$. dem HK. v. weissen Haaren sehr rauhh.; Blättchen des HK. aus einer eyf. Basis verschmälert u. sehr spitz, locker, die äusseren weit abstehend. 2. A. u. VorA. Jun. Jul. Var.: obere Bfläche kahl: H. flexuosum WK., nach der Abbildung.

22. H. Schraderi Schleicher. St. 1-werigköpfig, fast nackt, mit fein-sterrif., graulichem Flaume bedeckt u. nebst dem HK. v. verlängerten, drüserlosen, grauen, an der Basis schwarzen Haaren sehr zottig; Bthstiele in einem spitzen Winkel aufrecht; BIättchen des HK. locker, die äusseren abstehend; $B$. bläulichgrün, lanzettl., spitz, in den Bstiel verschmälert, ganzrandig od. gezähnelt, die wurzelst. rasig, die stengelst. wenige od. fehlend. 4. Triften der höheren A. Jun.-Aug.

23. H. gl anduliferum Hoppe. St. 1 köpfig, mit fein-sternf., graulichem Flaume u. kurzen, drüsentrag. Haaren dicht-bedeckt; HK. v. verlängerten, russfarbig-grauen, an der Basis schwarzen Haaren sehr zottig, Blättchen locker (nach Hoppe); B. grasgrün, lanzettl., spitz, in den Bstiel verschmälert, ganzrandig od. klein-gezähnelt, die wurzelst. rasig, die stengelst. wenige od. fehlend. 24. Höchste Joche der A.; Schwz., Kärnth. Jul. Aug.

III. Rotte. Cerinthoidea. B. satt-bläulich-grün, längl. od. elliptisch, meist v. verlängerten Haaren zottig u. am Bstiel bärtig, die der nichtblühenden WKöpfe iiberwinternd $u$. noch zur Bthezeit vorhanden. Zähne der Bth. auswendig mit kurz-gegliederten Här- 
chen besetzt. Haare der B. gezähnélt, nicht mit drüsigen gemischt, aber letztere an den Bthstielchen. Bl. gelb.

24. H. saxatile Vill. St. schlank, v. der Basis an ästig, unter den Aesten blattlos, Aeste mit einem Blatte gestïtzt, verlängert, fädl., meist 1köpfig, oberwärts schwach-grau, drüsig-behaart; B. bläulichgrün, elliptisch od. breit-lanzettl., zugespitzt od. stumpf mit einem Spitzchen, ganzrandig od. entfernt-gezähnelt, in den Bstiel verschmälert, beiderseits rauhh., u. ain Bstiel dicht-gebärtet, die aststiitzenden elliptisch, sitzend, die oberen klein; HK. drüsigh., Blättchen angedruickt, die innersten spitz. 24. Steinige $O$. bei Martigny im Wallis. Mai. Jun. Dem folgenden ähnlich, aber viel niedriger, der St. schlank, die Aeste diunn, die Bth. aber doch ansehnlich. Auf hohen Bergen ist die Pfl. einköpfig $u$. dieses ist nach Mougeot das eigentl. H. saxatile Vill. An niedrigeren $O$. ist sie $3-4$ köpfig u. bildet $H$. Lawsonii Vill., (nicht Smith.)

25. H. l ongi folium Schleich. St. beblättert, 1-mehrköpfig u. etwas ebensträussig, unterwärts rauhh.; B. bläulichgrün, breit-lanzettl., zugespitzt, ganzrandig od. entfernt-gezähnelt, in den langen Bstiel verschmälert, am Rande $u$. auf der Rippe rauhh.-bärtig, die stengelst. entfernt, die oberen sitzend, ey-lanzettf., halbstengelumfassend; Bthstiele graulich $u$. drüsig behaart; HK. zottig od. dichtdrüsig-behaart; Blättchen spitz, angedriickt, die äussersten ein wenig abstehend, die innersten verschmälert-pfrieml. u. spitz. 2. Triften der A. u. Gbge; stidl. u. westl. Schwz. Jul. Aug. H. Lawsonii Smith. H. cerinthoides der bot. Gärten. Die Köpfchen vor dem Aufblïhen länger $u$. auch die Bth. länger als bei $H$. decipiens.

26. H. decipiens Froel. bei DC. St. wenigblätterig, ziemlich ebensträussig, an der Basis rauhh.; B. bläulichgrün, breit-lanzettl., entfernt-gezähnt, in den Bstiel verschmälert, am Rande u. auf der Mittelrippe unterseits rauhh.-bärtig, d. stengelst. lanzettl., sitzend; Bthstiele graulich, nebst d. HK. drüsig-behaart; die Blättchen des HK. spitz, angedrückt, die äussersten ein wenig abstehend, die innersten verschmälert-pfrieml. u. sehr spitz. 24. Auf dem Hohneck der Voges. Jul. Aug. H. cerinthoides $\zeta$. decipiens Monnier, H. longifolium $\beta$. Mougeoti K. syn. ed. 1. Köpfelıen noch einmal so dick als bei $\mathbf{H}$. pallescens.

IV. Rotte. Pulmonarioidea. B. grasgrün od. bei einigen, dem Hieracium murorum verwandten Arten od. Abarten bläılichgrün, die der nichtblühenden Wköpfe überwinternd u. noch zur Bthezeit vorhanden. Zähne der Bl. auswendig kahl. Haare der BZähne gezähnelt, nur bei H. Jacquini mit drüsigen gemischt. Bl. gelb.

27. H. vulgatum K. syn. ed. 1., Fries. Novit. fl. suec. ed. 2. p. 258. St. einen Ebenstrauss tragend, v. der Basis an beblättert, 
an der Spitze nebst den Bthstielen $u$. dem HK. v. sternf. Flaume graulich u. v. kohlschwarzen, drüsentrag. Haaren kurzh.; B. grasgrün, unterseits u. am Rande rauhh., ey-lanzettf. od. eyf., nach der Basis verschmälert, gezähnt, die Zähne der Basis tiefer u. vorwärts gewandt, die StB. 3 od. mehrere, die W.- u. unteren StB. gestielt, die oberen fást sitzend. 2. Wälder, unkultiv. O. Jun. Jul. H. vulgatum Fries. 1. c., nach mitgetheilten Expl. u. nach der Diagnose "foliis radicalibus persistentibus." (nicht H. vulgatum Fries Novit. mant. 2. p. 48.). H. sylvaticum Sm., DC.

28. H. ram osum W.K. St. rispig, einen Ebenstrauss tragend, meist v. der Basis an ästig u. beblättert, an der Spitze nebst der Bthstielen u. dem HK. graulich u. v. schuarzen, an der Spitze grauen, einfachen Haaren kurzh.; B. grasgrün, am Rande u. unterseits rauhh., ey-lanzettf., nach der Basis verschmälert, gezähnt, die Zähne der Basis tiefer u. abstehend, die W.- u. unteren StB. gestielt, die oberen fast sitzend. 4. Wälder der sïdl. Schwz. Jun.-Aug.

29. H. pallescens W. K. St. einen Ebenstrauss tragend, 24blätterig, an der Spitze nebst den Bthsticlchen $u$. dem HK. graulich $u$. mit einfachen, grauen, an der Basis schwarzen Haaren behaart; B. bläulichgrün, am Rande u. unterseits rauhh., längl., nach der Basis allmählig 'verschmälert, gezähnt, die Zahhne der Basis tiefer $u$. vorwärts-gekehrt, die W.- u. unteren StB. gestielt, das oberste fast sitzend. 24. Schwz., Schleich., der den StandO. nicht angab. Jun.-Aug. Stimmt sehr mit H. Schmidtii überein u. untersch. sich vorziigl. deh den nicht drüsig-behaarten Ebenstrauss, v. H. incisum dch die an der Basis allmählig in den Bstiel verschmälerten B. u. die bläulichgrïne Farbe derselben, an $H$. incisum sind die $B$. an der Basis mehr od. weniger abgerundet $u$. die Zähne oft riickwärts gerichtet.

30. H. S chmidtii Tausch. St. einen Ebenstrauss tragend, meist 1 blätterig, an der Spitze nebst den Bthstielen $u$. dem HK. graulich u. mit an der Basis schwarzen, meist drüsentrag. Haaren behaart; B. bläulich-grün, am Rande u. unterseits rauhh., ey-lanzettf., nach der Basis versclimälert, gezähnt, die Zühne der Basis tiefer u. vorwärts-gekehrt, die WB. gesticlt, das StB. fast sitzend. 2. Felsenspalten; Böhm., Schles., Harz, Walpurgisberg bei Erlangen, Hohneck der Voges. Jun.-Aug.

31. H. lasiophyllum Koch. St. 2-mehrköpfig, etwas ebensträussig, einblätlerig, an der Spitze nebst den Aesten u. dem $H K$. graul. u. v. kohlschwarzen, drüsentragenden Haaren kurzh.; $B$. in das Meergrüne ziehend, beiderseits rauhh., ganzrandig, hinten weniggezähnt, die äusseren oval, vorne fast breiter, am Ende abgerundet, sehr stumpf, das innerste längl., spitzl.; die äusseren Blättchen des HK. stumpfl., die inneren spitz. 24. In der Grube Draga bei Orlich 
auf dem Karst. Jun. Jul. H. murorum rotundatum K. syn. ed. 1., nicht $H$. rotundatum Kit.

32. H. murorum L. zum Theil, Fries. St. ebensträussig, meist 1 blätterig, an der Spitze nebst den Aesten $u$. dem HK. graulich, u. v. kohlschwarzen, drüsentrag. Haaren kurzh.; B. grasgrün, unterseits u. am Rande rauhh., die wurzelst. ey-, fast herzf., gezähnt, die tieferen Zähne der Basis rückwärts gerichtet; das StB. kurz-gestielt od. sitzend; Blättchen des HK. verschmälert, die äusseren stumpflich, die inneren spitz. 2. Wälder, unkultiv. O. u. Mauern. Juu.-Aug. Blïhet früher, als $H$. vulgatum. Var.: $\beta$. sylvaticum: B. an der Basis eingeschnitten-gezähnt; Zähne rückwärts-gerichtet. H. murorum $\beta$. sylvaticum L., Pollich. - $\gamma$. villosum: Bstiele u. B. unterseits, od. diese auch auf beiden Seiten v. sehr langen Haaren wollig-rauhl. H. muror. $\gamma$. villosum Fröl. bei DC. H. murorum $\alpha$. pilosissimum L.? Bisher blos im südl. Frankreich.

33. H. incisum Hoppe. St. 1-mehrköpfig u. ebensträussig, meist 1blätferig, an der Spitze nebst den Bthstielen $u$. dem HK. graulich u. v. einfachen, grauen, an der Basis schwarzen Haaren kurzh.; B. bläulich-griin, unterseits u. am Rande rauhl., die wurzelst. gestielt, eyf. od. eyf.-längl., an der Basis stumpf, fast herzf., gezähnt, Zähne der Basis tiefer, abstehend, das StB. kurz-gestielt od. sitzend. 4. A. u. Grbge längs der A.; Harz. Jnn.-Aug.

34. H. bifidum Kritaib. St. schlank, zweisp. od. gabelsp.ästig, nackt od. 1blätterig, Aeste abstehend, einköpfig, fast ebeusträussig, nebst dem $H K$. graulich $u$. mit einfachen, grauen, an der Basis schwarzen Haaren bestreut; $B$. bläulich-grüin, unterseits $u$. am Rande rauhh., die wurzelst. elliptisch od. lanzettl., nach der Basis verschmälert, gezähnt, Zälıne der Basis länger, vorwärts-gekehrt od. abstehend, das StB. lineal. od. lanzettl.-lineal., fast sitzend. 2. Felsen der VorA.; Oestr., Stmk., Walpurgisberg bei Erlangen. Jul. Aug.

35. H. ru pestre Allioni. St. schlank, fast fädl., fast gabelig, geth., mit wenigen, verlängerten, 1 köpfigen, an der Spitze nebst dem $H K$. graulichen $u$. v. eirffachen $u$. drïsentrag. Haaren kurzh. Aesten; $B$. bläulich-grün, die wurzelst. breit-lanzettl., zugespitzt, ungleichwenigzähnig, in den Bstiel verschmälert, fast ungleichscitig, am Rande u. unterseits bchaart od. überall dicht-rauhh., die StB. wenige, lanzettl.-lineal. 2. Felsenspalten; Wallis, Waadt. Jun. Jul.

36. H. J a c qu ini i Vill. St. niedrig, aufstrebend, beblättert, v.

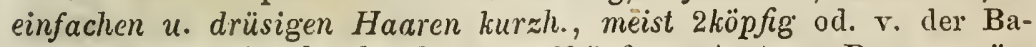
sis an ästig, mit abstehendeu, 1-2köpfigen Aesten; B. grasgrün, längl.-eyf., unterseits $u$. am Rande behaart, die $W .-u$. unteren stengelst. B. gestielt, an d. Basis tief-gezähnt od. fast fiedersp., die oberen sitzend, die obersten lanzettl., ganzrandig; HK. kurzh. 24. Felsige O. der A. u. VorA,; Schwäb. Alp. Jun. Jul. H, humile Host. H. pumilum Jacq. 
V. Rotte. Andryaloidea DC., Monn. Die B. bläulich-grün od. grau v. filzig-zottigen Haaren, die der nichtblühenden Wköpfe iiberwinternd $u$. noch zur Bthezeit vorhanden, d. Haare derselben deutlich federig, nämlich die Zähne der Haare 3- od. 4mal so lang als der Dchmesser des Haares. Bl. gelb.

37. H. andryaloides Villars. St. aufstrebend, einfach, 2köpfig od. ästig u. mehrköpfig, oberwärts fast nackt; Bthstiele verlängert, fast ebensträussig, nebst dem HK. u. den $B$. v. federigen Haaren grau-filzig; B. vkteyf.-längl., die W.- u. unterer StB. an der Basis gezähnt, gestielt, die oberen fast lanzettl., zugespitzt. 24. Felsen; Genf am Salcve, mittleres Wallis. Jun. Jul. Var. die B. oberseits kahl i. braun gefleckt: $H$. pictum Pers.

38. H. 1 a n a tum Vill. St. einfach, 2köpfig od. ästig, 5-6köpfig; Aeste verlängert nebst dem HK. $u$. B. v. federigen Haaren dichtwollig-filzig; B. dick, eyf., ganzrandig od. hinten entfernt-wenigzähnig, die W.- u. unteren StB. gestielt, die oberen sitzend, die unteren stumpf, die oberen zugespitzt. 24. Sonnige Felsen im Wallis. Mai. Jun. Andryala lanata L.

VI. Rotte. Pseudocerinthoidea Koch. Die B. grün od. kaum in das Bläuliche ziehend, die der nichtblühenden Wköpfe iiberwinternd u. noch zur Bthezeit vorhanden. Zälıne der Bl. auswendig mit kurzgegliederten Haaren besetzt. Haare der B. sämmtl. od. zum Theil drüsentragend.

39. H. Ps e udo-Cerinthe Gaud. Ueberall drüsig-behaart, die Haare gelbl.-wasserhell od. bis zu den Köpfchen an der Basis schwärzl.; St. 1-5köpfig, unter den Aesten 1-2blätterig, die Aeste mit einem Blatte gestützt, abstehend, verlängert, etwas ebensträussig, meist 1köpfig; $B$. weich, die wurzelst. längl.-lanzettl., in den Bstiel verschmälert, ganzrandig od. entfernt-gezähnelt, die stengelst. tief-herzf., stengelumfassend, die oberen breit-herzf.-zugespitzt; die inneren Blättchen des lockeren HK. borstl.-verschmälert u. sehr spitz. 24. Auf dem Salvan im Wallis. Jun. Jul. H. cerinthoides Schleich. Thomas. Das H. cerinthoides Gouan. hat an den WB. auf der Mittelrippe $u$. am Bstiele sehr lange Haare, aber keine Drüsenhaare, der St. ist kahl, mehrblätterig, oberwärts nebst den Aesten u. HK. drüsig-haarig v. gelbl., an der Basis nicht schwarzen Haaren, die inneren Blättchen des HK. wohl verschmälert, aber nicht sehr spitz.

40. H. amplexicaule L. Die B., der St. $u$. der HK. drüsigbehaart, die Haare gelbl.-wasserhell, die oberen an der Basis schwärzl.; der St. bis zu den Aesten 1-mehrblätterig, 3-vielköpfig, Aeste mit einem Blatte gestiitzt, abstehend, etwas ebensträussig; B. dickl., etwas starr, die wurzelst. elliptisch-längl., in den Bstiel verschmälert, am hinteren Theile grob-gezähnt, die stengelst. sitzend od. halbstengelumfassend, die oberen nebst den DeckB. eyf. oder herzf.; die inneren 
Blättchen des lockeren HK. borstlich verschmälert u. sehr spitz. 4 . A. u. VorA. Jun. Jul.

41. H. pulmonarioides Villars. Ueberall drüsig-behaart, die Haare gelbl.-wasserhell, die oberen an der Basis schwärzl., die WB. zugleich v. langen Haaren rauhh.; der St. bis zu den Aesten 1mehrblätterig, 3-vielköpfig, Aeste mit einem Blatte gestützt, abstehend, etwas ebensträussig; die wurzelst. B. elliptisch-längl., in den Bstiel verschmälert, am hinteren Theile grob-gezähnt, die stengelst. sitzend, die oberen aı der Basis verschmälert, lanzettl.; die inneren Blättchen des lockeren HK. borstl.-verschmälert u. sehr spitz. 4. A. u. VorA. Jun. Jul. H. petraeum Hoppe; loch wahrscheinlich Abart v. H. amplexicaule.

42. H. alp in um L. St. 1-wenigköpfig, mit feinsternf., graulichem Flaum bestreut u. nebst den $H K$. v. verlängerten, grauen, an der Basis schwarzen u. v. kurzen, drüsentrag. kohlschwarzen Haaren selır zottig; Bthstiele in einem spitzen Wirkel aufrecht; B. grasgrün, lanzettl. od. elliptisch, in den Bstiel verschmälert, ganzrandig od. gezähnt, die stengelst. 1 od. mehrere, fast sitzend. 2. Triften der A., VorA. u. höheren Gbge. Jun. Jul. Bthstiele bei den ästigen Formen aufrecht, nicht abstehend, wie bei H. murorum. Var. $\alpha$. alpinum genuinum: St. einköpfig, an der Basis 1-3blätterig; B. lanzettl., die äusseren oft vkteyf.; HK. v. verlängerten Haaren grau u. sehr zottig. H. alpinum L. u. der meisten Aut. - $\beta$. pumilum: Haare des HK. kürzer, zuweilen alle drüsentrag., sonst alles, wie bei dem vorherg. H. pumilum Hoppe. $-\gamma$. Halleri: WB. elliptischlängl., abgerundet-stumpf, an der Basis gezähnt $u$. oft fast spiessf., gestielt, StB. 1-2, lanzettl. H. Halleri Vill. - $\delta$. sudeticum: St. 1' hoch, blattreich; B. lanzettl. od. gezähnelt, die stengelst. kaum od. nur wenig-kleiner; St. 1-3köpfig: H. alp. sudeticum Wimm. - 8 . nigrescens: WB. eyf., gestielt, gezähnt; St. in der Mitte mit einem einzigen, kleineren B.; HK. mit schwarzen, driisentrag., u. spärlicher mit längeren, an der Spitze grauen Borsten. H. alp. nigrescens Wimm. H. nigrescens Willd.

43. H. cy donia efolium Fröl., DC., Tausch. pl. sel. St. an der Spitze einen Ebenstrauss tragend, v. der Basis an beblättert, rauhh., an der Spitze nebst den Bthstielen $u$. den $H K$. von feinsternf. Flaum etwas graulich $u$. drüsenhaarig v. kahlschwarzen, mit darunter gemischten längeren, an der Spitze grauen Haaren; $\boldsymbol{B}$. grasgrün, unterseits u. am Rande rauhh., gezähnt, elliptisch, an der Basis verschmälert, die unteren wurzelst. gestielt, die oberen sitzend. 4. Kesselberg im Riesengebirge Tausch., Quellen der Elbe Sternbg. Jun. Jul. H. sudeticum Sternbg., K. syn. ed. 1. Trägt im Garten bis 20 Bthköpfchen. Vielleicht doch Variet. v. H. alpinum.

VII. Rotte. Intybacea. Die Pfl, hat im Herbste keine WB., 
sondern Knospen auf den W., die sich im näehsten Jahre zu Stengeln erheben. Zähne der Bl. auswendig kahl; B., St. u. HK. dicht driisenhaarig.

44. H. a lb i du $\mathrm{m}$ Vill. St. blattreich nebst den Bthstielen, dem $H K$. u. den B. drïsig-behaart, klebrig, 1 köpfig, od. v. der Basis an ästig mit 1köpfigen Aesten; $B$. verlängert-lanzettl., gesclıweift- od. buchtig-gezähnt, die wurzelst. an der Basis verschmälert, die stengelst. sitzend od. stengelumfassend. 2. Felsige O. der A.; Hoheneck der Vogesen, Schwz., Tyr., Salzbg., Kärnth. Jul. Aug. H. intybaceum Jacq.

VIII. Rotte. Prenanthoidea. Die W. treibt im Herbste kleine Blätterbüschel, die sieh im folgenden Friihling vergrössern, aber nebst den unteren StB., auch an freien O., absterben, ehe die Bth. entwickelt sind, so dass zu dieser Zeit der St. keine WB. hat. Die Bthstiele u. HK. drüsig-haarig. Die Zühne der Bl. auswendig mit kurz-gegliederten Haaren besetzt. Die B. an H. Iycopifolium u. prenanthoides olne Driisenhaare, an $\mathrm{H}$. picroides dicht mit Drüsenhaaren besetzt.

45. H. ly e o p if oli u m Frölich. St. blattreich, rauhh., oberwärts rispig; Aeste (an grösseren Exemplaren) mehrköpfig, etwas traubig, u. nebst den Bthstielen u. HK. zerstreut-drüsig-behaart; B. halbstengelumfassend, grob-gezähnt, an der Basis eingeschnitten-gezähnt, die oberen eyf., etwas herzf., die unteren längl., gegen die Basis schmäler, die untersten in einen Bstiel verschmälert. 24. In der Waldanlage des Carlsruher Schlossgartens u. am Freiburger Schlossberg im Badischen, sodann um Stettin. Jul. Aug.

46. H. prenanthoides Vill. St. blattreich, unterwärts v. einfachen Haaren rauhh., oberwärts rispig; Aeste an grösseren Exempl. mehrköpfig, fast traubig, nebst den Bthstielen u. den HK. etwas filzig u. dicht-drïsig-behaart; B. mit herzf. Basis stengelumfassend, längl.-lanzettl. od. eyf., zugespitzt, gezähnelt, unterseits netzaderig, die unteren oberhalb der Basis etwas geigenf.-verschmälert, fast spatelig, die wurzelst. zur Bthezeit vertrocknet. 2. Wälder; VorA. u. höhere Gbge, Hoheneck der Voges., Gbge. v. Mähr., Böhm., Schles., Feldberg im Schwarzw. Jul. Aug. B. unterseits mehr od. weniger bläulichgrün, u. 1. B. gezähnelt: II. prenanthoides Fröl. 2. B. fast ganzrandig: H. perfoliatum Fröl. 3. B. gegen die Basis mit vorspringenden spitzen Zähnen: H. strictissimum Fröl. 24. 4. Köpfchen bemerklich grösser als gewöhnl.: H. cotoneifolium Fröl., nicht Lamarck.

47. If. ochr ol e u cum Schleicher. St. blattreich, oberwärts ästig, ebenstrüussig, v. der Basis an nebst den Aesten, Bthstielen, HK. u. den B. drüsig-behaart; $B$. mit herzf. Basis stengelumfassend, zugespitzt, gezälnelt, die unteren lüngl.-elliptisch, oberhall der Basis et- 
was geigenf-verschmälert, die oberen längl.-eyf. 4. Höchste A. der Schwz. Jul. Aug. H. picroides Vill.?

IX. Rotte. Accipitrina. Die Pf. hat im Herbste keine WB., sondern Kinospen auf der W., die sich im nächsten Jahre zu St. erheben, aber niemals WB. treiben. Zähne der B1. auswendig kahl. Haare der B. nicht drüsentragend.

48. H. racemosum WK. St. starr, reichblätterig, rauhb. od. fast kahl, von der Mitte od. v. unten an traubig-ästig, die Aeste blattwinkelständig, steif-abstehend, traubig-3-4bth. u. nebst den Bthstielen grau, die seitenst. Bthstiele der Aeste kürzer od. so lang als das stützende DeckB.; HK. fast kahl, nach dem Verbliihen längl.kegelf.; B. gezähnt, die unteren in den Bstiel verschmälert, die oberen eyf., zugespitzt, sitzend, etwas stengelumfassend; nichtbliihende Bbuischel fehlend. 24. Unkult. O. in Stmk. Jul. Aug:

49. H. s a ba udum L. St. starr, blattreich, rauhh. od. auch fast kahl, oberwärts rispig, an der Spitze fast ebensträussig; Bthstiele nebst dem $H K$. graulich u. oft etwas kurzh. u. bemerklich länger als das sie stïtzende DeckB.; B. eyf., gezähnt, die unteren in den kurzen verbreiterten Bstiel verschmälert, die oberen mit her:f. Basis genau sitzend, stengelumfassend, die wurzelst. fehlend; Blättchen des HK. angedriickt. 24. Unkultiv. O., unter Gesträuch; sehr zerstr. dch das Geb. Aug. Sept.

50. H. boreale Fries! St. starr, blattreich, rauhh., od. kahl, oberwärts ästig; Aeste fast ebensträussig; Bthstiele nebst dem HK. graulich $u$. oft etwas kurzh.; $B$. ey-lanzettf., od. lanzettf., gezähnt, die unteren in den kurzen Bsticl verschmälert, die oberen fast sitzend, die wurzelst. fehlend; Blättchen des HK. angedriickt, gleichfarbig, (getrocknet schwärzlich). 2. Unkultiv. O., Wälder. Aug.-Oct. 4. H. sylvestre Tausch.

51. H. rigidum Hartman. St. stari, blattreich, rauhh. od.kahl, oberuärts ästig, mit fast €bensträussigen Aesten; B thstiele nebst dem HK. graulich u. oft etwas kurzh.; $B$. ey-lanzettf., lanzettf. od. lineal.lanzettf., gezühnt, die unteren in den kurzen Bstiel verschmälert, die oberen fast sitzend, die wurzelst. fehlerıd; Blättchen des $H K$. angedrückt, am Rande bleich, getrocknet unverändert, die äusseren an den jiingeren Bthknöpfen aufrecht, den Bthknopf überragend. 24. Unkultiv. O., Wälder. Jun. Jul. Fängt $1 / 2$ Monat früher zu blühen an als die 2 vorhergehenden. H. affine Tausch. H. rigidum Fries. hb. norm. f. 3. H. laevigatum K. syn. ed. 1.

52. H. umbellatum L. St. steif, vielköpfig; rauhl. od. kahl, oberwärts ästig, d. obersten Aeste fast doldig; Bthstiele graulich; B. lanzettl. od. lineal., gezähnt od. ganzrandig, die unteren in den kurzen Bstiel verschmälert, die oberen fast sitzend, die wurzelst. 
fehlend; Blättchen des $H K$. an der Spitze zurückgekrümmt. 4. Wiesen u. trockene Triften, Haiden, w̧aldige O. Jul. Aug.

\section{Ordng. AMBROSIACEEN. Link.}

\section{XANTHIUM L. Spitzklette.}

1. X. strumarium L. Wehrlos; die Frïchte flaumh., die Schnäbel derselben gerade, etwas zsneigend, die Dornen gerade, an der Spitze hakig. $\odot$. Aecker, Schutt, Wege; zerstr. deh das Geb. Jul.Oct. Bth. grün.

2. X. macrocarpum DC. Wehrlos; die Früchte steifh., die Schnäbel derselben hakig, die Dornen fast v. der Mitte an gebogen, an der Spitze zirkelf.-hakig. $\odot$. Schutt, Wege; Istr. u. um Wien. Jul._Oct. X. orientale L. Bth. grün.

3. X. spinosum L. Dornen an der Basis der B. 3gabelig; B. ungeth. od. 3lappig, der mittlere Lappen verlängert, zugespitzt. $\odot$. Wege, Schutt; Triest, Fiume. Jul. Aug. Bth. grün.

\section{Ordng. LOBELIACEEN. .Juss.}

\section{LOBELIA L. Lobelie.}

1. L. Dortmanna L. B. lineal., 2fächerig, ganzrandig; Schaft fast nackt. 24. Unter dem Wasser in Seen u. Sümpfen, zur Bthzeit die Aehren emportauchend; nördl. Geb. Jul. Aug. Bl. blau.

\section{Ordng. CAMPANULACEEN. Juss.}

\section{JASIONE L. Jasione.}

1. J. montan a L. B. lineal.; $W$. einfach, vielstengelig. $\odot$. Sandige, trockene O., Haiden. Jun. Jul. Bl. blau. - Var. $\beta$. maior: W. dick, vielstengelig, die St. 2 Fuss hoch, Köpfchen noch einmal so gross. Felsenspalten der Porphyrgebirge, an der Nahe, im Rheingebiet. $-\gamma$. littoralis: W. vielstengelig, die St. fingerslang nach allen Seiten niederliegend, an der Spitze aufstrebend; sandiger Strand des Mecres.

2. J. perennis I,am. B. lineal.; W. ausläufertreibend, die Stämmchen 1stengelig. 24. Felsige, grasige, waldige O.; Rlıinpfalz, Elsass, Fl. v. Halle u. Spaa. Jun.-Aug. Bl. blau.

\section{PHY'TEÚMLA L. Rapunzel.}

I. Rotte. Bth. ährig; Aehre kugelig od. walzlich.

1. Pl. pauciflorum L. Das Köpfchen fast kugelig, 5bth.; $B$. vkteyf. od. vktey-lanzettf., stumpf, an der Spitze meist 3 kerbig, in den Bstiel verschınalert; die DeckB. rundl-eyf., stumpf, zottig-gewimpert, 
kürzer als das Köpfchen. 24. Höchste A. Jul. Aug. Bl. blau. - Var. $\beta$. P. globulariaefolium Hopp., B. breiter, fast vkteyf.

2. Ph. hemisphaericum L. Das Köpfchen kugelig, meist 12bth.; B. lineal. od. lanzettl.-lineal., ganzrandig od. an der Spitze etwas gekerbt; die DeckB. eyf., zugespitzt, ganzrandig, zottig-gewimpert, halb so lang als das Köpfchen. 24. Höhere A. Jul. Aug. Ph. graminifolium Sieb.: B. sämintl. schmal. Bl. blau.

3. Ph. humile Schleich. Das Köpfchen kugelig, meist 12bth.; B. lanzettl.-lineal., die oberen entfernt-gezähnelt, u. nebst den DeckB. am Rande v. sehr kurzen, etwas zurtickgebogenen Haaren gewimpertrauh; die äusseren DeckB. aus eyf., zugespitzt-gezähnter Basis lanzettl.-verschmälert, ungefähr so lang als das Köpfchen. 24. Hohe A.; iiber Zermatten u. Macugnaga in Wallis, Val de Fain u. Bernina, Graubïnd. Jul. Aug. Bl. blau.

4. Ph. Sieberi Spreng. Das Köpfchen kugelig, meist 15bth.; B. der unfruchtb. Büschel lang-gestielt, herzf., eyf. od. ey-lanzettf., gekerht, die stengelst. lanzettl., die oberen sitzend, aus rauten-eyf. Basis verschmälert; die äusseren DeckB. eyf., zugespitzt, geschärftgesägt. 2. Höchste A. v. Tyrol u. Krain. Jul. Aug. Bl. blau.

5. Ph. orbiculare L. Das Köpfchen vielblüthig, kugelig, od. nach dem Verblïhen oval; B. gekerbt-gesägt, die der unfruchtb. Büschel u. oft auch die untersten stengelst. lang - gestielt, herzf., eyf. od. ey-lanzettf., die oberen stengelst. lineal.; die äusseren DeckB. aus eyf. Basis lanzettl.-verschmälert, etwas gesägt. 4. Wiesen, unkultiv. O., bis in die A. Jul. Aug. Var. Ph. fistulosum Reichb., St. röhrig. Bl. blau.

6. Ph. Scheuchzeri All. Das Köpfchen vielblüthig, kugelig; B. gekerbt-gesägt, die unteren lang-gestielt, lanzettf., verschmälertzugespitzt, die der unfruchtbaren Büschel herzf., die oberen lineal.; die äusseren DeckB. lincal., ganzrandig, meist länger als das Köppfchen. 4. Felsige O. der A. u. VorA., südl. Schwz., Tyr. Jul. Aug. Bl. blau.

7. Ph. Mich eli i Bertolini. Aelve reichblüthig, rundl. od. oval, zuletzt walzlich; B. entfernt-gekerbt-kleingesägt, die wurzelst. u. unteren stengelst. herzf., eyf. od. lanzettf., od. fast lineal., gestielt, die oberen lanzettl.-lineal. od. lineal., sitzend, etwas gesägt; die DeckB. lineal., so lang od. kürzer als die Bth. 24. A. u. VorA. Jul. Aug. Var. $\alpha$. betnnicaefolium: IVB. u. unterste 'StB. herzeyf. od. herzf.-längl. $\mathrm{Ph}$. betonicaefolium Vill. $\mathrm{Ph}$. persicifolium Hoppe. $-\beta$. scorznnerifolium: WB. lanzettf., gestielt. $\mathrm{Ph}$. scorzonerifolium Vill. - $\gamma$. angustissimum: WB. lineal.-lanzettl., kurz-gestielt. Ph. Michelii Allion. Bl. blau.

8. Ph. nigrum Schmidt. 'Aehre längl.; B. einfach-gekerbt-gesägt, die unteren gestielt, eyf., an der Basis herzf., die obersten lineal,; 
die DeckB. lineal. 4. Laubwälder; zerstr. dch das Geb. Mai. Jun. Bl. dunkelviolett.

9. Ph. spicatum L. Aelıre längl.; B. doppelt-gekerbt-gesägt, die unteren gestielt, eyf., an der Basis herzf., die obersten lineal.; die DeekB. lineal. 24. Wälder, zerstr. deh uas Geb. Mai. Jun. BI. weiss mit grün-gelbl. Spitze.

10. Ph. Halleri All. Aehre vkteyf.-längl.; B. grob-doppelt-gesägt, die unteren gestielt, eyf., die obersten lanzettl.; die DeckB. lineal. 4. A., VorA. n. Sudet. Jun. Jul. Bl. dunkelviolett.

II. Rotte. Bth. gestielt, doldig.

11. Ph. co mos um L. Dolde endst.; Btlı. auf kurzen Bthstielchen; B. gezähnt, die wurzelst. nierenf. 24. Felsenspalten der Gebirge $u$. A.; Krain, Tyrol. Jun. Jul. Bl. himmelblau, vorue schwarzblau.

III. Rotte. Bth. kurz-gestielt, einzeln, zerstrent, eine Tr. od. R. bildend.

12. Ph. canescens WK. B. sitzend, die unteren eyf, gekerbtgesägt, an der Basis versehmälert, die oberen lanzettl., fast ganzrandig; Bth. kurz-gestielt, traubig-rispig. 24. Unkultiv. O.; Unterstmk. Jul.-Sept. Bl. blau.

\section{CAMPÁNULA L. Glocke.}

I. Rotte. Buchten des K. ohne Anhängsel. Btlı. gesticlt, an den reichblüthigen St. traubig od. rispig. - Bth. aller blau od. violett, selten als Variet. weiss.

a. Kapsel nickend, unter den Kzipfeln aufspringend.

1. C. Z o ys i i Wulfen. B. ganzrandig, die untersten eyf., gestielt, Bstiel so lang als das $B$., die mittleren stengelst. B. spatelig, die obersten lineal.-längl.; der St. 1-mehrbth.; Z $/$ fll. des K. pfrieml.; Bl. längl.-glockig, mit dicht-bärtigen $\mathrm{Zpfln}$. 24. Felsige O. der Krainer A. Jul. Aug.

b. Kapsel ïberhängend, an der Basis aufspringend. Bl. blau.

2. C. pulla L. B. elliptisch, gekerbt, gestielt, 3 mal so lang als der Bstiel, die unteren stumpf, die oberen spitz; St. 1bth.; Bth. nickend; Zpfl. des K. pfriemlich. 24. Triften der VorA. u. A.; Oestr., Stmk., Krain, Salzb. Jul. Aug. Bl. dunkelviolett.

3. C. ex eis a Schleich. B. lineal., ganzrandig, sitzend, die unteren lineal.-keilig, in den kurzen Bstiel verschmälert, etwas gezähnelt; St. 1-3bth.; Bl. bauchig-glockig, bis auf ein Drittel 5sp., Zpfl. eyf., an der Basis schmäler $u$. dch eine rundl. Bucht geschieden; Zpfl. des K. pfrieml. 24. Felsenspalten der höchsten A. v. Oberwallis. Jul. Aug. Bl. blau.

4. C. caespitosa Scop. Die W.- u. untersten StB. vkleyf., in einen zieml. breiten Bstie', kaum von der Länge des B., herablau- 
fend, wenig-kerbig, die stengelst. sitzend, lineal.-lanzettl., etwas gesägt, die oberen lineal., ganzrandig; St. mehrbth., traubig od. rispig;

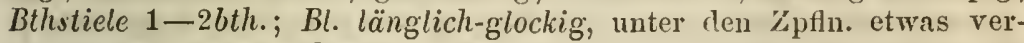
engert mit einem Adernetze dehzogen; Zpfl. des K. pfrieml. 24. In Felseuspalten der A. u. VorA.; Oberöstr., Stmk., Krrain. Jul. Aug. Bl. blau.

5. C. pusilla Haenk. B. der nichtblühenden WKöpfe eyf., herzu. nierenf., gesägt, gestielt, Bstiel mehrmals länger als das Blatt, die unteren StB. elliptisch, kiirzer-gestielt, die oberen lineal., sitzend; St. traubig, 3-6blüth.; Bl. halbkugelig-glockig, olne Adernetz; Zpfl. des K. pfrieml. 24. Felsige und kiesige O. der A., VorA. und Sudet., mit den Flüssen in die Ebenen. Jun. Jul. Var. $\beta$. C. pubescens Schmidt, gänzlich kurzh. B3. blau.

6. C. rotundifolia L. B. der nichtblühenden WKöpfe eyf., herz- $u$. nierenf., gestielt, Bstiel melırmals länger als das B., die untersten StB. lanzettl., die übrigen lineal., ganzrandig; St. rispigvielblüth.; Bi. ey- od. fast kreisel-glockenf.; Zpfl. des K. pfrieml. 2 Unkultiv. O. Jun.-Oet. Bl. blau. Var. $\beta$. hirta: unterwärts kurzh. - $\gamma$. velutina: $v$. dichten Haaren grau. - $\delta$. lancifolia: höher, die unteren StB. lanzettf., 2-3" lang. C. Hostii Baumg.

7. C. Schenehzeri Vill. B. der nichtblühenden WKöpfe eyod. herzf., gestielt, Bstiel mehrmals länger als das B., die StB. lineal.-lanzettl., ganzrandig od. die unteren gekerbt-gesägt; St. 1blüth. od. traubig-2-6blüth.; Zpfl. des K. pfrieml. 2. A. u. VorA., Sudet., Schwarzw. Jul. Aug. C. linifolia Lam. Var. $\beta$. kahl u. $\gamma$. kurzh. C. valdensis All. Bl. blau.

8. C. carnic a Schied. B. der nicht blühenden WKöpfe ey- od. herzf., gestielt, Bstiel mehrmals länger als das B., die StB. lineal., die oberen sehr schmal; St. 1blüth.; $K z p f$. lineal.-borstl., so lang als die Bl., zuriiekgebogen. 24. Felsensp. der Krrainer A. Jun. Jul. Bl. blau.

9. C. rhomboidalis L. B. ey-od. lanzettf., gesägt, die oberen sitzend, die unteren kurz-gestielt; Bth. rispig, einseitsuendig; Kzpfl. pfrieml. 24. VorA. u. Berge. In der Schwz. nicht selten, im Jura iiberall. Jun.-Aug. Bl. blau.

10. C. bononiensis L. B. gekerbt-gesägt, unterseits filziggrau, die unteren herzf., lang-gestielt, die oberen eyf., zugespitzt, sitzend; die endst. Tr. einfach od. rispig-zsgesetzt, sitzend; Kzpf. lanzettl.; der St. aufrecht, stielrund. 2. Trockene Wiesen, sonnige Hügel; sehr zerstr. deh das Gel. Jul. Aug. Bl. blau.

11. C. rapunculoides L. B. ungleich-gesägt, etwas rauhh., die unteren fast herzf., lang-gestielt, d. oberen lanzettl.; $\mathbf{T r}$. endst., einseitswendig; Kzpfl. lanzettl.; der St. aufrecht, stumpfkantig; $W$. kriechend. 21. Wälder, Hügel, kultiv. O. Jul. Aug. Bl, blau.

12. C. Trachelium L. B. grob-doppelt-gesägt, isteifh., die un- 
teren lang-gestielt, herzf., die oberen längl., sitzend; Bthstiele blattwinkelst., 1-3bliith., in eine Tr. zsgestellt; Kzpfl. ey-lanzettf.; der St. aufrecht, scharf-kantig. 2. Wälder, Gebiiscli. Jul. Aug. Var. $\beta$. dasycarpa: K. steifh. C. urticifolia Schmidt. Bl. blan.

13. C. latifolia I. B. ey-lanzettf., zugespitzt, grob-doppeltgesägt, kurzh., kurz-gestielt; Bthstiele blattwinkelst., einbth., in eine Tr. zsgestellt; Kzpfl. ey-lanzettf.; der St. aufrecht, stumpf-kantig. 4. Wälder; sehr zerstr. dch das Geb. Jul. Ang. Bl. blau.

14. C. Erinus L. Kurzh.; der St. ästig, oberwärts gabelsp.; die unteren B. vkteyf.-längl., in den kurzen Bstiel verschmälert, die blüthenst. gegenst., beiderseits $1-2$ zähnig; Bth. fast sitzend. $\odot$. Trockene, felsige O.; Mömpelgard im Oberelsass. Jun. Wahlenbergia Erinus Link. K. syn. ed. 1. Bl. blau.

c. Kapsel aufrecht, an der Basis aufspringend. Bl. aller Arten blau.

15. C. Elatines L. B. gesägt, die der nicht blühenden WKöpfe u. die unteren stengelst. herzf., lang-gestielt, die oberen stengelst. eyherzf., zugespitzt, kürzer-gestielt; die St. rasig, einfach, liegend; Bth. traubig-rispig; Bthstiele blattwinkelst., meist 3 blüthig; Kzpfl. lineal.lanzettl.; Bl. bis auf ein Drittel 5sp. 2. Felsenspalten; auf der Insel Cherso. Mai. Jun.

16. C. Morettia na Reichenb. B. einfach-gesägt, die der nicht blühenden WKöpfe herzf., lang-gestielt, die stengelst. eyf., in den kurzen Bstiel vorgezogen, die unteren u. oberen kleiner; der $\boldsymbol{S t}$. aufrecht, 1-2blüthig; Bth. aufrecht; BI. 4mal so lang als die lanzettl. Kzpfl, 5lappig. 24. Felsenspalten; Fassa im südl. Tyrol. Jul. Aug.

17. C. garganica Tenore. B. ungleich-od. doppelt-gesägt, die der nicht blühenden WKöpfe u. die unteren stengelst. herzf., langgestielt, die mittleren stengelst. eyf., in den Bstiel vorgezogen; die St. rasig, einfach, liegend; Bth. traubig-rispig; Bthstiele blattwinkelst., meist 3blüthig; Kzpfl. lanzettl.; $B l$. 5th. 2. Felsenspalten, auf der Insel Cherso. Mai. Jun.

18. C. Raineri Perpent. B. längl.-vkteyf., stumpf, entfernt-gekerbt, in den kurzen Bstiel herablaufend, flaumig, die unteren kleiner, spatelig; der St. aufstrebend, 1blüthig; Bth. nickend; Kzpfl. breit-lanzettl., zugespitzt, entfernt-gezähnelt; Bl. 5lappig, Lappen breit-eyf. 2. An felsigen O.; C. Tessin. Jul. Aug.

19. C. py ramidalis L. B. gesägt, ganz-kahl, eyf., die oberen lanzettl., die der nicht blühenden Whöpfe herzf., lang-gestielt; der St. steif, aufrecht, sehr ästig, Aeste aufrecht, dem St. genähert; Kzpfl. lanzettl. $\odot$. Steinige Hügel, Mauern; Krain, Litt. Jul. Aug.

d. Kapsel aufrecht, in der Mitte od. oben aufspringend. Bl. aller blau.

20.. C. patula L. B. gekerbt, die wurzelst. längl.-vkteyf., in den 
Bstiel herablaufend, die stengelst. lineal.-lanzettl., sitzend; $R$. etwas abstehend, fast ebensträussig; Bth. aufrecht; Aeste oberwärts getheilt; Kzpfl. pfrieml. $\odot$. Wiesen, Waldränder; zerstr. dch das Geb. Mai-Jul.

21. C. R a punculus L. B. gekerbt, die wurzelst. längl.vkteyf., in den Bstiel herablaufend, die stengelst. lineal.-lanzettl.; $R$. fast traubig, Aestchen an der Basis getheilt; Kzpfl. pfrieml. $\odot$. Trockene Wiesen, unkultiv. u. waldige $\mathrm{O}$. Mai-Aug.

22. C. persicifolia L. B. entfernt-kleingesägt, die wurzelst. längl.-vkteyf., in den Bstiel herablaufend, die stengelst. lineal.-lanzettl., sitzend; Tr. armblüth.; Kzpfl. lanzettl. 2. Wälder. Jun. Jul.

23. C. cenisia L. B. vkteyf., stumpf, in den kurzen Bstiel zsgezogen, ganzrandig, kahl, an der Basis gewimpert; die St. aufstrebend, 1blüthig, oberwärts nebst dem K. steifh.; Kzpfl. aus breiter Basis lanzettl.; Bl. fast 5th., Zpfl. ey-lanzettf. 4. Höchste A. im Wallis. Jul. Aug.

II. Rotte. Buchten des K. ohne Anhängsel. Bth. sitzend, in Achren od. Köpfchen zsgestellt.

24. C. th y r s o idea L. Steifh.; B. lineal.-längl., schwach-gekerbt; Bth. sitzend, in einer eyf.-längl., dichten Aehre; Kzpfl. ey-lanzettf. $\odot$. Wiesen der A. Jul. Aug. Bl. gelbl.-weiss.

25. C. spicata L. Steifh.; B. längl.-lanzettl., schwach-gekerbt, die unteren nach der Basis verschmälert, die oberen aus verbreiterter stengelumfassender Basis lanzettl.-zugespitzt; Bth. sitzend, in einer verlängerten, unterbrochenen Aehre, die unteren zu dreien, die oberen einzeln. $\odot$. Steinige O. $\operatorname{der}$ A. u. VorA., Krain, siidl. Tyr., Wallis, Tessin. Jun. Jul. Bl. blau.

26. C. Cervicaria L. Steifh.; B. klein-gekerbt, die wurzelst. lanzettl. in d. Bstiel verschmälert, die stengelst. lanzettl.-lineal., die oberen mit stengelumfassender Basis sitzend; Bth. sitzend in end- $u$. seitenst. Köpfchen. 2. Wälder; zerstr. dch das Geb. Jul. Aug. Bl. blau.

27. C. glomerata L. Kurzh. od. grau-flaumig od. kahl; $B$. klein-gekerbt, die wurzelst. ey-od. cy-lanzettf., an der Basis abgerundet od. herzf., die oberen stengelst. mit herzf., stengelumfassender Basis sitzend; Bth. sitzend in end- $u$. seitenst. Köpfchen. 4. Wiesen, unkultiv. O. Mai. Jun. Bl. blau. Var. Bth. gross od. um die Hälfte kleiner, u. $\beta$. C. farinosa Andrz: B. unterseits gran-filzig. - $\gamma$. C. aggregata Willd.: grasgrïn, Stiele der StB. breiter, geflügelt, Bth. grösser. - $\delta$. C. speciosa Hornem.: grasgriin, B. alie ey-herzf., Bth. gross. $-\varepsilon$. C. elliptica Kit.: DeckB. bleich, netzaderig:

III. Rotte. Buchten des K. mit Anhängseln. Bl. blau oder violett.

28. C. alpina Jacq. St. oberwärts nebst den B. am Rande $u$. den Bthstielen u. K. wollig-zottig; B. lineal. od. lineal.-längl., fast 
gauzrandig; Bth. lang-gestielt, fast traubig, hängend; Kzpfl. lanzettl.pfrieml., Anhängsel der Buchten sehr kurz; Bl. ein wenig länger als der K., an der Spitze spärlich mit Haaren bestreut. 2. Felsige O. der A. Jun. Jul.

29. C. barbata L. Rauhh.; B. längl.-lanzettl., fast ganzrandig; Bth. gestielt, traubig, hängend, etwas einseitswendig; $K z p f$. ey-lanzettf., Anhängsel der Buchten ungefähr so lang als die KRöhre; Bl. fast 3 mal so lang als der K., an der Spitze dicht-bärtig. 2. A. u. VorA. Jul. Aug.

30. C. sibirica L. Kurzh.; B. lanzettl. wellig, die untersten stumpf, in den Bstiel verschmälert, die oberen spitz, halbstengelumfassend; Bth. gestielt, rispig, nickend; $K z p f$. lanzettl.-pfrieml., Anhängsel der Buchten so lang als die KRöhre; Blkr. an der Spitze kahl. @. Grasplätze; östl. Geb. Mai. Jun.

4. EDRAJÁNTHUS A. DC. Büschelglocke.

1. E. tenuifolius A. DC. B. lineal., mit steifen Borsten bewimpert; DeckB. eyf., lang-lineal. zugespitzt, borstig-bevimpert; St. behaart. 2. Steinige O.; Triest, Fiume. Jul. Aug. Campanula tenuifolia W. K. C. graminifolia Host., K. syn. ed. 1. Bl. blau.

2. E. Kitaibelii A. DC. B. lineal, schmal-lanzettl, nach der Basis verschmälert, mit weichen Haaren bewimpert, oberwärts oft kahl; DeckB. eyf., beiderseits 1-2zähnig, weich-zottig-bewimpert; St. flaumig. 24. Steinige O.; Gipfel des Schneeberges in Karstgbg. Jul. Bl. blau.

5. ADENÓPHORA Fischer. Drüsenglocke.

1. A. suave olens Fisch. St. aufrecht; B. längl., die untereu kurz-gestielt; R. ausgebreitet; Kzpfl. mit einigen Drïsenzähnchen; Gf. länger als dic B1. 24. Gebiisch u. Wälder; Preussen, Böhm., Schles., südl. Tyr. Jul. Aug. Bl. blau.

6. SPECULARIA Heister. Spiegelglocke.

1. S. Speculum A. DC. St. aufrecht, ästig, spreitzend, die unteren Aeste verlängert, aufstrebend; B. längl., d. unteren vkteyf.; Bth. einzeln; Kpzfl. lineal., v. der Länge des Fruchtkn. $u$. der Bl. ○. Unt. der Saat, zerstr. deh das südl. u. mittl. Geb. Jun. Jul. Campanula Speculum L. Prismatocarpus Speculum L'Herit., K. syn. ed. 1. Bl. purp.-violett.

2. S. hybrida A. DC. St. aufrecht, ästig, die unteren Aeste verlängert, aufstrcbend; B. längl., die unteren vkteyf.; Bth. einzeln; Kzpfl. lanzettl., länger als die Bl., halb so lang als der Fruchtkn. $\odot$. Unter der Saat; selir zerstr. dch das Geb. Jun. Jul. Camp. hybrida L. Prismat. hybridus L'Herit., K. syn. ed. 1. Bl. purpurn. 


\section{WAHLENBERGIA Schrad. Wahlenbergie.}

1. W. hederace a Reichenb. B. her $\approx$ f-rundl., echig-5lappig, gestielt, kahl; der St. fädlich ästig; Bthstiele einzeln, verlängert. 7 . Torfh. Wiesen u. feuchte WaldO.; Kaiserslautern, Rheinpf., Neuendorf, Oldenb., Spaa, Malmedy. Jun. Aug. Campanula hederacea L.

\section{Ordng. VACCINEEN. DC.}

1. VACCINIUM I. Haidelbeere.

1. V. Myrtill us L. B. abfällig, eyf., klein-gesägt, kahl; Bthstiele 1 bth., einzeln, blattwinkclst., iiberlängend; Bl. kugelig; Atste scharfkantig. b. Wälder. Mai. Jun. Bl. hellgriin, röthl.-iiberlaufen; Beeren schwarz.

2. V. uliginos un L. B. abfällig, vkteyf., stumpf, ganzrandig, unterseits bläulich-grün, netzig; Aeste stielrund; Bthstiele gchäuft, iiberhängend; Bl. eyf. Ђ. Torfboden. Mai. Jun. Bl. weiss od. röthl.; Beeren schwarz.

3. V. Vitis ida ea L. B. immergriin, vkteyf., stumpf, ummerklich-gekerbt, am Rande zurïckgerollt, unterseits punktirt; Tr. endst., iiberhängend; Bl. glockig; Stbk. wehrlos; Gf. länger als die Bl. ち. Wälder, Haiden. Mai-Jul. Bl. weiss od. röthl.; Beeren roth.

4. V. intermedium Ruthe. B. immergriin, oval, stumpf, stumpfgezähnelt, am Rande etwas umgerollt, unterseits spärlich punktirt; Bth. einzeln od. endst. in armbth. Tr.; Bl. glockig; Gf. Eingeschlossen; Aeste kantig. $\hbar$. Auf fenchten 0 . in der Jungfernhaide, einem Nadelwalde bei Berlin. Mai. Jun. Beeren roth.

5. V. oxy coceos L. St. kriechend, Aeste fädl., liegend; $B$. immergrün, eyf., ziemlich spitz, unterseits aschgrau; Bth. lang-gestielt, nickend; Bl. radf., Zpfl. längl. ந. Nasse, torfhaltige O. Jun.Aug. BI. u. Beeren roth.

\section{Ordng. ERICINEEN. Desv.}

I. Gruppe. ARBUTEEN. Frucht beerenartig.

1. ÁRBUTUS L. Erdbeerbanm.

1. A. Únedo L. Stamm aufrecht; B. vkteyf. od. längl.-lanzettl., gesägt, lederig, kahl; R. endst., hängend; Bthstielchen kahl. ち. Gebirgige, felsige $\mathrm{O}$.; Krain, Istrien. Apr. Mai. Bl. weiss, an der Spitze grün.

2. ARCTOSTÁPHYLOS Adans. Bärentraube.

1. A. alpina Spreng. Stamm hingestreckt; B. vkteyf., ungleichklein-gesägt, kahl, an der Basis ganzrandig u. gewimpert, verwelkend, netzig-aderig, Adern unterseits etwas hervortretend; Tr. kurz, 
endst. †. Felsige, trockene 0 . der A. Mai-Jul. Arbutus alpina L. Bl. weiss, oberwärts grün.

2. A. officinalis Wimm. u. Grab. Stamm hingestreckt; $B$. längl.-vkteyf., ganzrandig, immergrün, kahl, netzig-aderig, Adern beiderseits eingedrïckt, unterseits unmerklich, die jüngeren am Rande flaumig; Tr. kurz, endst. Ђ. Haiden, Nadelwälder; zerstr. dch das Geb. Mai. Jun. Arbutus Uva ursi L. Bl. u. Beeren roth.

II. Gruppe. ANDROMEDEEN. Frucht kapselig; Scheidewände einfach; Bl. abfällig.

3. ANDRÓMEDA L. Andromede.

1. A. polifolia L. Bthstiele endst., fast doldig, 3mal so lang als die Bth.; B. lineal.-lanzettl., am Rande zurückgerollt, oberseits glänzend, unterseits bläulich-grün. Ђ. Torfige Sümpfe, nasse Haiden; zerstr. deh das Geb. Jun. Jul. Bthstiele u. K. rosenroth, Bl. weiss od. röthlich.

2. A. c a lyculata L. Tr. endst., beblättert, einseitswendig; $B$. oval-längl., stumpf mit einem kleinen Spitzchen, kaum merklich-gesägt, beiderseits schuppig. $\hbar$. Sumpfige Orte; Ostpreussen. Apr. Mai: Cassandra calyculata Don., DC. Bl. weiss.

III. Gruppe. ERICEEN. Frucht kapselig. Bl. verwelkend.

4. CALLÚNA Salisbury. Haidekraut.

1. C. vulgaris Salisb. ち. Wälder, Haiden, trockene Wiesen. Aug.-Oct. Erica vulgaris L. Bth. lila, selten weiss. Var. $\beta$. pubescens : B. flaumig.

5. ERICA L. Haide.

1. E. Tetralix L. Stbk. begrannt, eingeschlossen; Narbe kopfig; Bl. krug-eyf., 4zähnig; B. 3- od. 4ständig, lineal., am Rande abgerundet, steifh.-gewimpert; Bth. endst., kopfig-doldig. Ђ. Torfige Haiden; nördl. Geb. u. sehr zerstr. deh das mittlere. Jul.-Sept. Bl. fleischfarben.

2. E. cin e rea L. Stbk. begrannt, eingeschlossen; Narbe kopfig; Bl. krug-eyf., 4zähnig ; B. 3ständig, lineal., mit scharfem Rande, unterseits convex, mit einer Ritze dchzogen, kahl; Bth. quirlig-traubig. 5. Haiden; über Dottendorf bei Bonn. Jun. Jul. Bl. bläulich-roth.

3. E. carnea L. Stbk. wehrlos, hervorgestreckt, am Ende zweispaltig, an der Basis mit der Spitze des Trägers zsfiessend; Narbe klein; Bl. krugf.-röhrig, 4zähnig; Blättchen des K. länger als die halbe Bl.; B. 4ständig, lineal., mit einem scharfen Rande, spitz, kahl; Bth. traubig, meist einseitswendig. Ђ. Haiden u. Nadelwälder, VorA. u. Gbge; bei Regensburg, in Oestr., Mähr., Böhm., Schles. Apr. Mai. B1. fleischroth. 
4. E. vagans L. Stbk. wehrlos, hervorgestreckt, 2bth., an der Spitze des T'rägers seitl. angeheftet; Narbe klein; Bl. glockenf., 4zähnig; Blättchen des K. eyf., dreimal kürzer als die Bl.; B. 4ständig, lineal., mit einem scharfen Rande, stumpfl., kahl; Bth. traubig. Ђ. Zwischen Gebüsch auf der Ins. Osero u. Cherso. Apr. Bl. fleischroth. Die naheverwandte E. multiflora hat längere, eyf.-glockige Bl. u. 2sp., nicht bis auf die Basis getheilte Stbk.

5. E. arborea L. Stbk. mit einem Anhängsel, eingeschlossen; Gf. hervorgestreckt, etwas abwärtsgeneigt; Narbe schildf.; Bl. glockig, $4 s p$., mit eyf., stumpfen $\mathrm{Zpfln.;} \mathrm{B.} \mathrm{3ständig,} \mathrm{lineal.,} \mathrm{mit} \mathrm{einem} \mathrm{schar-}$ fen Rande, stumpf, unterseits convex, mit einer Ritze dchzogen, kahl; Aeste kurzh.; Bth. traubig-rispig. 2. Steinige O.; Istr. u. die Inseln, Veltlin, Giudicarie in Südtyrol. Mai. Jun. Bl. weiss.

IV. Gruppe. RHODOREEN. DC. Frucht kapselig; Scheide. wände gedoppelt, aus den eingeschlagenen Ränderu der Klappen gebildet. BI. abfällig.

6. AZÁLEA L. Azalie.

1. A. procumbens L. Ђ. Felsen der höheren A. Jul. Aug. Chamaeledon procumbens Link. Loiseleuria procumbens Desvaux, Bl. rosenroth.

7. RHODODENDRON L. Alpenrose.

1. Rh. ferrugineum L. B. längl.-lanzettl. od. elliptisch, ganzrandig od. schwach-gekerbt, am Rande kahl, unterseits drüsig-schuppig, die Schuppen die ganze Fläche dicht bedeckend, zuletzt rostfarben; Tr. fast doldig; Zähne des $K$. kurz-eyf., quer-breiter; Bl. trichterf. Ђ. A. u. VorA. Jul. Aug. BI. purp.

2. Rh. in termedium Tausch. B. längl.-lanzettl., od. elliptisch, schwach-gekerbt od. ganzrandig, mit entfernten Haaren bewimpert, unterseits dicht-drüsig-getüpfelt, die T'üpfel jedoch von einander getrennt, zuletzt rostfarben; Trauben fast doldig; Zähne des $K$. längl:lanzettl.; Bl. trichterf. $\hbar$. Zwischen dem vorhergeh. u. folg. u. vielleicht Bastard.

3. Rh. hirsutum L. B. elliptisch od. längl.-lanzettl., stumpfgekerbt, entfernt-gewimpert, kahl, unterseits drüsig-getüpfelt, Tüpfel locker-zerstreut; Tr. fast doldig; Zähne des $K$. längl.-lanzettl.; Bl. trichterf. Ђ. A., vorzügl. KalkA. Mai-Jul. Bl. purp. Var. latifolium Hoppe: B. breit-elliptisch od. vkteyf., d. Bth. grösser, heller gefärbt; - sodann mit dichter- od. entfernter-gewimperten od. auch fast kahlen $u$. auch auf der Oberseite getïpfelten B.

4. Rh. Ch am a ecistus L. B. elliptisch-lanzettl., gesägt-gewimpert, kahl, drüsenlos; Bth. meist gezweiet; Bthstiele u. K. drüsigbehaart; Bl. flach, radf. ђ. A. u. VorA. v. Oestr. bis Tyrol. Jun. Jul. Bl, purp. 
8. LEDUMI L. Porst.

1. L. pal ustre L. B. lineal., am Rande zurïekgerollt, unterseits nebst den Aestehen rostfarben-filzig; Bth. 10männig. Ђ. Sumpfige, torfige $\mathrm{O}$; nördl. Geb. u. sehr zerstr. dch das mittlere. Jul. Aug. Bl. weiss od. rosenroth.

LXIX. Ordng. PYROLACEEN. Lindl.

\section{PÝROLA L. Wintergrün.}

1. P. rotund ifoli a L. Stbg. aufwärts-gekrümmt; $G f$. abwärtsgeneigt, an der Spitze bogig; Blb. vkteyf.; Kzpf. lanzettl., zugespitzt, an der Spitze zurückgekrümmt, halb so lang als die Bl.; Tr. gleich. 24. Sehattige Wälder. Jun. Jul. Bl. weiss. Var. $\beta$. arenaria: kleiner, B. halb so gross, spitzlich; Bthstiele kaum so lang als der K.; Kzpfl. breiter, längl., ziemlich stumpf. Norderney.

2. P. ehlor antha Swartz. Stbg. aufwärts-gekrümmt; Gf. abwärts-geneigt, an der Spitze bogig; Blb. vkteyf., Kzpfl. eyf., kurzzngespitzt, so breit als lang, an die Bl. u. Krapsel angedrückt, 4 mal kiixzer als die Bl.; Tr. gleich. 24. Schattige Wälder; zerstr. deh das Geb. Jun. Jul. Bl. grünl.--weiss.

3. P. media Swartz. Stbg. gleichf.-zsschliessend; Gf. gerade, etwas schief, der Ring an der Spitze des Gf. breiter als die Narbe. 4. Schatt. Wälder; sehr zerstr. deh das Geb. Jun. Jul. Bl. weiss.

4. P. minor L. Stbg. gleichf.-zsschliessend; Gf. gerade, senkrecht; Narbe 5kerbig, noch einmal so breit als der $G f$. 24. Wälder, Jun. Jul. Bl. rosenroth.

5. P. secunda L. T'r. einseitswendig. 24. Wälder. Jun. Jul. Bl. oval-längl., grïinl.-weiss.

6. P. un iflora L. Schaft 1blumig. 2. Sehattige Wälder. Jun. $J$ ul. Monesis grandiflora Salisb., DC. Bth. ansehnlich, weiss.

7. P. u m bellata L. Bth. doldig; B. lanzettl.-keilig. 2. Wälder; zerstr. deh das Geb. Jun. Jul. Climophila umbellata Nutt., DC. Bl. rosenroth.

\section{Ordng. MONOTROPEEN. - Nutt.}

\section{MONÓTROPA L. Ohnblatt.}

1. M. Hyр opitys L. Tr. reichlth.; Blb. gezälnelt. 24. Sehattige Wälder. Jul. Aug. Die Pflanze farblos u. bleich, nur die Narbe honiggelb. Var. $\alpha$. glalira: ganz kahl; Fruchtkn. mit kleinen, erhabenen Punkten besetzt. M. Hypophegea. Wallr. Hypopitys glabra Bernh., DC. pr. - $\beta$. hirsuta: DeekB. gewimpert; KB. inwendig, am Rande, Blb. auf beiten Seiten, Stbg. 11. Stempel ranhb. M. Hypopitys Wallr. IIypopitys multiflora Seop., DC. pr. 
III. Unterclasse. COROLLIFLORAE. (Kronblüthige.)

K. frei, einblätterig. Blkx. einblätterig, unterweibig. Stbg. der Blkr. eingefügt. Fruchtkn. frei.

LXXI. Ordng. EBENACEEN. Vent.

1. Dióspyros L. Dattelpfaume.

1. D. L otu S L. B. eyf.-längl., unterseits verschiedenfarbig. $\hbar$. Hügel u. Züune; C. Tessin, doch wahrscheinlich nur verwildert. Jul. Ang. B. purpurn.

\section{Ordng. AQUIFOLIACEEN. DC.}

1. ILEX L. Stechpalme.

1. I. Áqui fo li um L. B. wechselst., eyf., spitz, kahl, spiegelnd, dornig-gezähnt, od. ganzrandig u. mit einem Dorne endigend; Bthstiele blattwinkelst., kurz, reichbth.; Bth. fast doldig. ฤ. Wälder u. Bergtriften; nördl. Gel. u. längs der A.; u. zerstr. im mittleren Geb. Mai. Jun. Bl. weiss.

\section{Ordng. OLEACEEN. Lindl.}

I. Gruppe. OLEINEEN. Frucht fleischig.

1. ÓLEA L. Oelbaum.

1. O. e u ropa a L. B. gegenst., lanzettl., ganzrandig, verschiedenfarbig; die Tr. blattwinkelst., zsgesetzt. $\hbar$. In warmen Gegenden jenseits der A. kultiv. u. daselbst heimisch geworden. Mai. Jun. Bl. weiss.

2. PHILLYRÉA L. Steinlinde.

1. Ph. media L. B. ey-lanzettf. od. längl., kleingesägt u. ganzrandig; Steinfrucht mit einem vorspringenden Spitzchen. ђ. Wälder, Zäune; Fiume, Istrien, See v. Toblin im südl. Tyrol. März. Apr. Bl. weiss.

3. LIGUSTRUM L. Hartriegel.

1. L. vulgare L. B. längl.-lanzettl., kahl; R. endst., gedrungen. Ђ. Wälder, buschige Hügel. Jun. Jul. Bth. weiss.

II. Gruppe. LILACEEN. Vent. Frucht trocken.

4. SYRINGA L. Flieder.

1. S. vulgaris L. B. herzf., zugespitzt. t). In Zäunen verwildert. Apr. Mai. Bl. blau. Var. roth u. weiss. 
5. FRAXINUS L. Esche.

1. F. excelsior L. B. 3-6paarig; Blättchen sitzend, lanzettl.längl., zngespitzt, gesägt; Bth. nackt; Nüsse an der Spitze schiefausgerandet. $\hbar$. Wälder. Apr. Mai. Bth. brann.

2. F. Ornus L. B. meist 3paarig; Blättchen gestielt, lanzettl. od. elliptisch, zugespitzt, gesägt; Bth. vollständig. ち. Gebirge; südl. Tyr., Kärnth., KKrain. Apr. Mai. Bl. weiss.

\section{Ordng. JASMINEEN. R. Brown.}

1. JASMínUM L. Jasmin.

1. J. officinal e L. B. gegenst., gefiedert; Blättchen zugespitzt; KZähne fädl., länger als die halbe Röhre der Bl. ち. Weinberge u. Mauern im Littor. u. südl. Tyr.; verwildert. Jul. Aug. Bl. weiss.

\section{Ordng. ASCLEPIADEEN. R. Brown.}

1. CYNANCHUM R. Brown. Hundswürger.

1. C. Vincetoxicum R. Br. St. aufrecht; Bl. blattlos; Bthstielchen der einfachen Dolde 3 mal so lang als der gemeinschaftliche Bthstiel; Krone 5lappig. 2. Gebirgige, felsige O. Jul. Aug. Asclepias Vincetoxicum L. Bl. weiss.

2. C. 1 axum Bartling in briefl. Mittheilungen. Der St. oberwärts sich uirdend; Bl. bartlos; Bilstielchen der nicht selten getheilten Dolde kaum länger als der gemeinschaftliche Bthstiel; Krone 5lappig. 24. Felsige O.; Littor. Jul. Aug. Bl. gelbl.-weiss. C. medium K. syn. ed. 1.; ob R. Brown's gleichnamige Pfl.?

\section{Ordng. APOCYNEEN. R. Brown.}

\section{APÓCYNUM L. Hundstod.}

1. A. ven et u m L. B. längl.-lanzettl., kahl, stachelspitzig; am Rande gezähnelt-rauh; Dolden rispig; Bthstielchen u. Bth. staubigflaumig. 24. Sumpfige O. am Meerc; bei Triest, zw. Monfalcone u. Aquileja. Jul. Aug. Bl. rosenroth.

2. VINCA L. Sinngrün.

1. V. in aj or I. B. eyf., vorne verschmälert, hinten abgerundet $u$. fast herzf.; Kzpfl. gewimpert; der St. gestreckt, kriechend, die bthtrag. Aeste aufrecht. 24. Zäune; Krain, Görtz, Istrien. Wallis. Apr. Mai. Bl. blau.

2. V. minor L. B. lanzettl.-elliptisch, die oberen an beiden Enden spitz; Kzpfl. kahl; der St. gestreckt, kriechend, dic bthtrag. Aeste aufrecht. 24. Haine, schattige Zäune. Apr. Mai. Bl. blau.

3. V. herbacea W. K. Die unteren B. eyf., die oberen lanzettf.; K\%pfl. gewimpert; W. reichstengelig; die St. liegend, nicht uurzelnd. 
7. Berge an dem Biesamberg in der Gegend v. Wien. Apr. Mai. Bl. blau.

\section{NÉRIUII L. Oleancier.}

1. N. Oleauder L. B. lanzettl., zu 3 quirlig, unterseits gleichlatufend-aderig; Kzzpl. abstehend; Zähne des Kranzes 3sp. †. Felsen an der westl. Seite des Gardasees anf tyrol. Geb. Jul. Aug. Bl. rosenroth.

\section{Ording. GENTIANEEN. Juss.}

I. Gruppe. MENYANTHEEN. Fruchtln. auf eine unterweibige Scheibe gestellt ud. mit Drüsen umgeben. B. wechselst.

1. MENYÁNTHES L. Zottenblume.

1. M. trifoliat a L. B. 3zählig. 2f. Sumpfige O., torfige Wiesen. Apr. Mai. B. hellrosenroth, mit weissen Barte.

2. LIMNÁNTHEMUM Gmel. act. petrop. 1769, Grieseb. gen. et sp. Gent. Pfitzenblume.

1. L. Ny m plo ides Link. B. schwimmend, herzf.-kreisrund; Dolden blattwinkelst., sitzend; Bl. gewimpert. 2. In stehend. und langsam fliess. Wassern schwimmend; zerstr. deh das Geb. Jul. Aug. Nenyanthes Nymphoides L. Villarsia Nymphoides Vent., K. syn. ed. 1. Bl. gelb.

II. Gruppe. AECHTE GENTIANEEN. Die unterweibige Scheibe fehlend. B. gegenst.

3. CHLORA L. Bitterling.

1. Ch. perfoliata L. Die StB. 3-eckig-eyf., mit ihrer ganzer Breite verwachsen; $K$. bis an die Basis 8sp., $Z$ pfl. pfrieml., 1nervig, kürzer als die Bl.; Zpfl. der Bl. längl., stumpf. $\odot$. Torfige, feuchte O.; zerstr. deh das siidl. u. mittl. Geb. Jul. Aug. Gentiana perfoliata L. Bl. gelb.

2. C. serotina Koch. Dic StB. ey-od. ey-lanzettf., an der abgerundeten Basis verwarhsen; K. tief-8sp., Zptl. lanzettl.-pfrieml., getrocknet schwach-3̂nervig, ungefähr so lang als die Bl.; Zpfl. der Bl. zieml. spitz od. zugespitzt. $\odot$. Torfige, feuchte 0. ; Rheinfläche v. d. Schwz. bis Worms. Aug.-Oet. Var. Blzpfi. zugespitzt: C: acuminata K. u. Z. Bl. gelb.

4. SWERTIA L. Swertie.

1. $\int$ perennis L. Bl. 5th.; Bthstiele fast geflügelt-4kantig; der St. einfach; die WB. elliptisch. 24. Torfige Wiesen der A., VorA. u. höheren Gloge; Niederungen im nördl. Geb. Jul. Aug. Bl. trüb. violett. 


\section{LOMATOGÓNIUM A. Braun. Fransenkante.}

1. L. carinthiaeum A. Br. Bl. im Schlunde bärtig; Kzpfl. lanzettl. : B. eyf., spitz, die wurzelst. vkteyf., stumpf; der St. an der Basis ästig u. beblättert; Bthstiele verlängert, nackt. $\odot$. Sonnige, steinige O. der A. u. Kies der Bäche der A.; Salzb., Kärnth., Wallis. Aug. Sept. Swertia carinthiaca Wulf. Bl. hellblan. Pleurogyne carinthiaca Grieseb. gent.

\section{GENTIÁNA L. Enzian.}

I. Rotte. Coelanthe Fröl. Schlund der Bl. naekt. Bl radf., mit kurzer Röhre; od. fast gloekig, mit keulenf. Röhre; Röhre zwischen den $Z$ pfln. mit einer am Ende abgestutzten od. in ein ungeth. od. 2sp. Anhängsel vorgezogenen Falte versehen. - Der St. aller ganz einfach.

a. Bth. quirlig od. kopfig. K. halbirt, seheidenf., od. glockig u. nur mit 2-3 Zähnen unregelmässig gezälnnt.

1. G. I u t e a L. Bth. quirlig, die unteren gestielt; Bl. im Schlunde nackt, radf., 5th., Zpfl. lanzettl., verschmälert-spitz, 3 mal so lang als die Röhre; Stbk. frei; $K$. halbirt, scheidenf.; B. elliptisch, nervig. 4. Triften der A., VorA. u. höherer Gbge. Jul. Aug. Bl. gelb, Zpfl. oft mit 3 Reihen brauner Punkte vezeichnet. Die drei folgenden Nummern werden als Bastarde betrachtet.

2. G. Thom a sii Hall. fil., (G. purpureo-lutea Grieseb.) Bth. quirlig, die unteren gestielt; Bl. im Selılunde nackt, radf., tief-5sp., Zpfl. längl.-lanzettl., kurz-gespitzt, halb od. 3mal so lang als die Röhre; Stbk. frei; $K$. halbirt, scheidenf.; B. elliptisch, nerrig. 2t. Triften der A. iiber Bex und am Rhonegletseher in der Sehweiz. Jul. Ang. G. rubra Clairv. G. Lybrida Sellleich., DC. fl. fr. Bth. purpurn; an einer Variet. mit violetten Punkten.

3. G. Charpentieri Thomas. (G. punctato-lutea Grieseb.) Bth. quirlig, die unteren gestielt; Bl. im Schlunde nackt, tief-5sp., Zpt. längl.-lanzettl., halb so lang als die Röhre; Stbk. frei; $K$. glockig, abgeschnitten, kurz-2zähnig, Zähne lanzettl.-pfrieml., zugespitzt. 4 . Thal v. Bevers in clem Engadin der Schwz., Charpentier. Der K. hat zuweilen noch ein paar sehr kleine Zähnchen. Bl. gelb.

4. G. Gau diniana Thomas. (G. punetato-purpurea Grieseb.) Bth. am Ende des St. köpfig od. quirlig; Bl. 6sp., im Schlunde nackt, Röhre glockig, Zpfl. eyf., 4 mal kürzer als die Röhre; $K$. glockig; häutig, abgeschnitten, auf einer Seite 2-3zähnig, auf der anderen zahnlos u. daselbst auch bis zur Mitte gespalten; Stbl. zsgewachsen; B. nervig, die unteren elliptisch. 2. A. iiber Bex in der Schwz. Bl. purp.-violett.

5. G. purpurea L. Bth. köpfig u. quirlig, sitzend; Bl. im Schlunde nackt, glockig; Saum meist 6sp. Zpfl. oyf., 3mal kürzer 
als die Röhre; Stbk. zsgewachsen; K. halbirt, scheidenf.; B. nervig, die unteren elliptisch. 24. Siidlichere A. der Schwz. Jul. Aug. Bl. auswend. purp., inwend. gelblich.

b. Bth. quirlig od. küpfig. K. glockig, fast gleichf.-gezähnt; seltener sind halbirte unter regelmässige IK. gemischt.

6. G. pannonica Scop. Bth. quirlig; Bl. 6-7sp., im Schlunde nackt, Röhre glockig, $Z$ pll. des Saumes 3mal kürzer als die Röhre, ziemlich stumpf; K. glockig, Zähne lanzettl., zurückgekrümmt; B. sitzend, nervig, die unteren gestielt, elliptisch. 2. A., VorA. u. Böhmerwald. Aug.- Sept. Bl. dunkelpurp. mit schwarz-purp. Punkten.

7. G. punctata L. Bth. quirlig; B. 6sp., im Schlunde nackt, Röhre glockig, Zpfl. des Saumes tmal kiurzer als die Röhre; $K$. glockig, Zähne lanzettl., aufrecht; B. sitzend, nervig, die unteren gestielt, elliptisch. 2. A. u. VorA., Gesenk der Sudet. Jul. Aug. Bl. hellgelb, mit schwarz-purp. Punkten. Var. concolor: Bl. unpunlitirt. Gr. campanulata Jacq.

8. G. cruciata L. Bth. quirlig; Bl. 4sp., im Schlunde nackt, Röhre fast keulig; $B$. lanzettl., 3nervig, an der Basis scheidig, die unteren Scheiden verlängert, oberwärts erweitert. 24. Unkultiv. O., Trift.; zerstr. deh das Geb. Jul.-Sept. Bl. violett, inwendig azurblau.

c. Bth. einzeln, blattwinkelst. od. an der Spitze des St. einzeln od. gezweiet.

9. G. as cle piadea L. Bth. entgegengesetzt, blattwinkel - u. endst.; Bl. 5sp., im Schlunde nackt, Rühre keulig-glockig; B. sitzend, als eyf., abgerundeter Basis lanzettl.-zugespitzt, J́nervig, am Rande rauh. 2. A. u. VorA., Sudet., Voges. Aug. -Sept. B. inwendig azurblau mit dunkleren Punkten.

10. G. Pne umonantye I. St. 1-vielbth.; Bth. einzeln, wechsel- od. gegenst.; Bl. 5sp., im Schlunde nackt, Röhre keulig-glockig; $B$. sehr kurz-scheidig, lanzettl.-lineal., stumpf, die untersten klein, schuppenf.; Stbk. zsgewachsen; die Narben lineal., verlängert. 4 . Feuchte torfige Wiesen; zerstr. deh das Geb. Jul.-Oct. Bl. inwendig dunkel-azurblau, mit grünpunkt. Streifen.

11. G. Frölichii Hladn. St. 1bth.; Bl. im Schlunde nackt, Röhre keulig-glockig; B. lanzettl.-lincal., die wurzel- u. unteren stengelst. gehäuft, scheidig, Scheiden häutig, oberwärts erweitert; Stbk. zsgewachsen; der Gf. verlängert, ungefähr lialb so lang als der Fruchtkn.; die Narben längl. 24. Möchste A., Krain. Aug. Sept. Bl. hellblau, unpunktirt.

12. G. frigida Haenk. St. 1-2bth.; Bl. im Schlunde nackt, Röhre keulig-glockig; B. lanzettl.-lineal., die wurzelst. u. unteren stengelst. gehäuft, scheidig, Scheiden hïutig, oberwärts erweitert; Stbk. frei; Gf. kurz, viclmal kürzer als der Fruchthn,; die Narben 
längl. 2. Höchste A.; Stmk. Jul. Aug. Bl. weisslich mit zerstr. Punkten, inwend. 5 bläuliche streifen.

13. G. aca ulis L. St. 1bth.; Bl. im Schlunde nackt, Rölre keu. lig-gluckig; Zähne des $K$. aus breiterer Basis verschmälert-lanzettl., an die Blkr.-Röhre ang€drïckt; die WB. rosettig, lanzettl. od. elliptisch; Stbk. zsgewachsen; die Narben halbkreisrund, gezähnelt. 4. Wiesen der A. u. VorA. u. Ebenen des suidl. Geb. bis an die Donau. Jul. Aug. G. angustifolia Vill. Bl. azurblau.

14. G. excis a Presl. St. 1bth.; Bl. im Schlunde nackt, Röhre keulig-glockig; KZähne aus einer ein wenig schmäleren Basis eylanzettf., absteherd; die WB. rosettig; oval od. elliptisch; Stbk. zsgewachsen; die Narben halbkreisrund, gezähnelt. 24. Wiesen der höchsten GranitA., nicht in die Thäler herab. Jul. Aug. G. acaulis $\alpha$. L., G. acaulis Vill. Bl. azurblau. Var. $\beta$. minor: B. u. Bth. halb so gross. G. alpina Vill.

II. Rottte. Calathi a Fröl. Röhre walzlich od. etwas bauchig; sonst alles, wie bei der vorhergehenden Rotte. - Die Stbk. aller frei.

a. Die W. reichstengelig, rasig, bthtragende einfache, $1 \mathrm{bth}$. St. n. nichtbliihende Wköpfe treibend. Bth. satt azurblau, seltener als Var. weiss.

15. G. bavarica L. St. rasig, 1bth.; BI. im Schlunde nackt, Röhre walzl.; B. vkteyf., abgerundet-stumpf, in den kurzen Bstiel zsgezogen, die unteren od. alle gedrungen; der $G f$. tief-2sp.; die Narben halbkreisrund. 2. Etwas fenchte O. der A. Jul. Aug. Var. B. rotundifolia: B. sämmtl. an dem kurzen St. dachig. G. rotundifolia Hoppe.

16. G. brachyphylla Vill. St. rasig, 1bth.; Bl. im Schlunde nackt, Röhre walzl.; B. rundl.-eyf., kurz-gespitzt, in den kurzen Bsticl zsgezogen, die wurzelst. rosettig f. ungeth.; Narben halbkreisrund. 24. Höchste A. Jul. Aug.

17. G. verna I. St. rasig, 1bth.; B. im Schlunde nackt, Röhre walzl.; Kanten des K. schmal-geflügelt, Flügel gleich; $B$. elliptisch od. lanzettl., spitz, nach der Basis schmäler, die wurzelst. rosettig; Gf. ungeth.; Narben kreisrund. 2. Wiesen der A., VorA. u. Niederungen des südI. Geb., selt. im mittl. Mai-Jul.

18. G. aestiva Rocm. et Schult. St. rasig, 1bth.; Bl. im Schlunde nackt, Röhre walzl.; Kanten des $K$. geflügelt, Flügel in der Mitte breiter; B. elliptisch od. lanzettl., spitz, nach der Basis schmäler, die wurzelst. rosettig; Gf. ungetlı.; Narben halbkreisrund. 4. A. in Kärnth. u. Krain u. bis in die Gbge des Karstes hinab, Vord, in Siidtyı. Mai. Jun. G. angulosa MB. Wolıl Variet. v. G. verna.

19. G. imbricata Fröl. St. rasig, 1bth.; Bl. im Sehlunde arckt, Röhre walzl.; B. lanzettl.-elliptisch, spitz, an der Basis ver- 
schmallert, am Rande ranh, sämmtl. dachig; Gf. ungeth.; Narben. halbkreisrund. 24. Höchste A., Krrain, Tyrol. Jul. Aug.

20. G. pumila Jacq. St. rasig. 1bth.; Blkr. in Schlunde nackt, Röhre walzl.; B. lineal., an der Basis kaum schmäler, die unteren gedrungen; Gf. ungeth.; Narben halbkreisrunrl. 24. Höehste A.; Krain, Stmk., Oestr. Jul. Aug.

b. W. einfach, St. ästig; nicht bliihente WKäpfe fehlend.

21. G. prostrata Haenke. St. an der Basis ästig; W. einfach; Schlund der Bl. nackt, Rölne walzl.; Auhängsel halb so lang als die Zpfl. des Saumes; B. vkteyf. stumpf; Narben stumpf; Gf. 2th., zurïckgerollt. ○. Höchste A., Salzb., Kärnth. Jul. Aug. Bl. hellblau.

22. G. utriculosà L. St. \%. der Basis an ästig; WV. einfach; Schlund der Bl. nackt; B. eyf. od. längl., stumpf, die wurzelst. rosettig; $K$. aufgeblasen, geflügelt-kantig, längl.-oval; Gf. verlängert, 2sp.; Narben halbkreisrund. $\odot$. Triften der A. und VorA.; in den Ebenen bis an die Donau, in Rheinthale bis Mannheim. Jun.-Aug. Bl. brennend-blau.

23. G. nivalis I. St. v. der Basis an ästig; W. einfach; Schlund, der Bl. nackt; B. eyf. od. längl., die wurzelst. rosettig; $K$. walzl., kielig.kantig; Gf. ziemlich kurz, 2sp:; Narben halbkrcisrund. $\odot$. Höchste A. Jul. Aug. Bl. sehr schön blau.

III. Rotte. Endotrich a Fröl. Schlund der Bl. inwendig bärtig; an der Basis der einzelnen $\mathrm{Zpfl}$. ist nämlich eine 2sp. u. zugleich haarfein-vielsp. Schuppe gelegen. Bl. violett, wie der folgenden.

24. G. campestris L. Bl. 4sp., im Schlunde bärtig; KZähne ungleich, die 2 äusseren breit-elliptisch; B. ey-lanzettf., spitz, die wurzelst. vkteyf., gesticlt. $\odot$. Triften der A. u. VorA. u. zerstr. auf Niederungen dch das Geb. Jul. Ang.

25. G. germanica Willd. Bl. 5sp., im Schlurde bärtig; K. 5zähnig, Zühne lineal.-lanzettl., fast gleich; $B$. sitzend, eyf., aus breiter Basis verschmälert, spitz, die wurzelst. vkteyf., gestielt. $\odot$. Wiesen, waldige $O$. his in die A. Aug. Sept.

26. G. Am a rella L. Bil. 5sp., im Schlunde bärtig; K. 5zähnig, Zühne lineal.-lanzettl., fast gleich; B. sitzend, aus breiterer Basis lanzettl. od. lineal.-lanzettl., spitz, die wurzelst. vkteyf., gestielt. $\odot$. Wiesen u. feuchte Triften; nördl. Geb. n. Sachs., Böhm., Schles. Aug. Sept. G. uliginosa Willd.

27. G. obtusifolia Willd. Bl. 5sp., im Schlunde bärtig; K. 5 zähnig, Zähne lanzettl. od. eyf. u. in eine lanzettl. Spitze auslaufend, fast gleich; $B$. sitzend, längl., stumpf, die wurzelst. vkteyf., die obersten ey-lanzettf., spitz. - . Triften der A., VorA. u. höheren Gbge. $J$ ul. Aug. Var. $\beta$. calycina: Zpfl. des K. sehr breit-eyf., in eine lanzettl. Spitze zugespitzt. Im suidl. Tyrol. 
28. G. ten ella Rottböll. Bl. 4sp., röhrig-glockig, im Schlunde härtig; K. 4th., Zptl. ey-lanzettf., fast gleich; B. elliptisch-längl., zienlich spitz; St. an der Basis ästig u. beblättert; Bthstiele verlängert, nackt. $\odot$. Höchste A. Aug. Scpt. G. glacialis Thom., K. syn. ed. 1.

29. G. n an a Wulf. $B l$. 4-5sp., röhrig-glockig, im Schlunde bärtig; K. 4-5th., Zpfl. eyf., fast gleich; B. vkteyf., abgerundet-stumpf; St. ästig, Aeste aufstrebend. $\odot$. Höchste A. v. Kärnth., Salzbg. Aug. Sept.

IV. Rotte. Grossopetalum Fröl. Zppl. der Bl. gefranst; Schlund nackt.

30. G. ciliata L. Bth. endst.; Bl. 4sp., im Schlunde nackt, Zpfi. gesägt, in der Mitte eingeschnitten-gefrarıst; B. lineal.-lanzettl.; St. schlängelich, kantig. $\odot$. Unkultiv., etwas feuclite $\mathrm{O}$., steinige Gbge Aug. Sept. Bl. blau.

7. CICENDIA Adans. Bitterblatt.

1. C. filiform is L. St. v. der Basis an ästig; Bthstiele verlängert, nackt; W. einfach; Sclllund der Bl. nackt; B. lanzettl.; $K$. kurz-glockig, 4zährig; Narbe köpfig, 2lappig. ( ). Feuchte Sandtriften; nördl. Geb. u. bei Hanau. Jul. Aug. Gentiana filiformis L., K. syn. ed. 1. Bl. gelb.

8. ERYTHRAÉA Richard. Tausendgüldenkraut.

1. E. Centaurium Pers. St. einfach, 4kantig; B. oval-längl., meist 5nervig; Ebenstrauss endst., gebüschelt, nach dem Verblühen ziemlich locker, immer gleichhoch; Zpfl. der 131. oval. ๑. Triften, lichte, etwas feuchte WaldO. Jul. Aug. Gentiana Centaurium L. Bl. schön fleischroth. Var. $\beta$. capitata: Ebcnstrauss auch nach der Bthzeit sehr gedrungen $u$. nicht verlängert. E. capitata $R$. et $\mathbf{S}$.

2. E. linaria efoli a Pers. St. 4 kantig; $B$. lineal. od. lineal.längl., meist 3nervig; Ebenstrauss zuerst gleichboch, später in aufrechte, rispig-verlängerte Aeste, mit entfernt-gestellten Bth. sich entwickelnd; Zpfl. der 13l. oval. - - Sandige Triften, an der Küste der Nord- u. Ostsec, u. salzhaltige $\mathrm{O}$. in Brantenburg u. Thiiring. Jul. Aug. E. littoralis Fies. Bl. fleischroth.

3. E. pulchella Frics. St. scharf-4kantig, sehr ästig u. in $a b$ stehende Aeste sich auflösend; B. eyf., 5nervig; Bth. blattwinkelst., gestielt; $Z \mathrm{p}$ A. der Bl. lanzettl. $\odot$. Triften u. unkultiv. etwas feuchte O. Jul. Aug. E. ramosissima Pers. Gentiana Centaurium $\beta$. L. Bl. fleischroth.

4. E. spicata Pers. St. 4 kantig, Aeste einfach, verlängert-ährig; B. längl., meist 5nervig; Zpfl. der Bl. lanzettl.; KZähne ungleich, der grössere länger als die Kapsel. $\odot$. Morastige $O$. am Meere; Triest, Aquileja. Jul. Aug. Gentiana spicata L. Bl. rosenroth. 


\section{Ordng. POLEMONIACEEN. Lindl.}

1. POLEMONIUN L. Sperrkiaut.

1. P. ca eru I e um L. St. kahl, blattreich; B. gefidert, Fieder eylanzettf., zugespitzt, kahl; R. driisig-behaart; Zpfl. des 5sp. K. eylanzettf., zugespitzt; Bth. aufrecht. 2. Feuchte Wiesen u. Wälder, sehr zerstr. deh das Geb. Jun. Jul. Bl. blau, selt. weiss.

\section{Ordng. CONVOLVULACEEN. Juss.}

\section{CONVOLVULUS L. Winde.}

1. C. sepium L. B. pfeilf., Oehrehen abgeschnitten, oft gezähnt; Kelch v. herzf. DeckB. cingeschlossen; Bthstiele 4 kantig, 1 bth., länger als der Bstiel. 24. Hecken, Zäune. Jul.-Oct. Bl. weiss. Der C. sylvestris Willd., um Triest nicht selten, ist kaum als Art verschieden, alle angegebenen Kennzeichen fand ich, wenigstens an den getrockneten Expl., schwankend; B. u. Bth. in der Regel grösser als an C. sepium.

2. C. Soldanella L. B. nierenf.; $K$. mit cyf., stumpfen DeckB. gestützt; Bthstiele gefligelt-kantig, 1btl. 24. Meeresstrand, bei Aquileja u. Ins. St. Audrea bis Istr. Jul. Aug. Bl. weiss.

3. C. a rvensis L. B. pfeilf., mit spitzen Oehrchen; Bthstiele meist 1btl.; DeckB. v. der Bth. entfernt. 24. Kultiv. O., Raine, Flusskies. Jun. Jul. Bl. rosenroth oder woiss, auswendig mit 5 rothen Streifen. Var. B. hirtus: kurzh. C. villosus Lej.

4. C. al tha eoides L. B. herzf. u. nebst dem St. silberfarbenseidig, die unteren ungeth., die oberen fussf.-geth., Zpfl. lineal., ganzrandig; Bthstiele 1-2btl. 2. Unkultiv. O.; Istrien, Cherso. Jun. Jul. B1. rosenroth.

5. C. Cantabrica L. B. lineal.-lanzettl., spitz; die St. ästig, gestreckt; K. behaart; Bthstiele meist 1 bth. 2. Unkultiv. O.; südl. Tyr., Triest, Unteröstr. Jun. Jul. Bl. rosenrotl.

2. CÚSCUTA I. Hachsseide.

1. C. e urop a a L. St. ästig; Röhre der Bl. walzl., so lang als der Saun, die Schuppen in der Röhre aufrecht-angedrückt; Narben äidlich. $\odot$. Auf der Urtica dioica, Hopfen, Hanf u. Weiden schmarotzend. Jul. Aug. C. major DC. Bl. röthl.

2. C. Epith y m u L. St. ästig; Röhre der Bl. walzl., so lang als der Saum, dch die gegen einander neigenden Schuppen geschlossen; Narben fädlich. $\odot$. Auf Haide, Ginster, Quendel schmarotzend. Jul. Aug. C. europaea $\gamma$. Epithymum L. C. minor DC. Bl. halb so gross als bei der vorhergehend., röthl.

3. C. planiflora Tenore. St. ästig; Röhre der Bl. kurz-glockig, Saum 2 mal so lang als ihre Röhre, Schuppen....; Narben fädlich. 
○. Südl. Tyr., bei Botzen, auf Colutea arborescens. Jul. Aug. Bl. weiss.

4. C. Epilinum Weihe. St. sehr einfach; Rölre der Bl. fast kugelig, 2 mal so lang als der Saum, die Schuppen in der Röhre aufrecht, angedriickt. $\odot$. Auf Flachs schmarotzend. Jul. Aug. Bl. weiss.

5. C. monogyna Vahl. St. ästig; Bth. einweibig, ährig, dch ein DeckB. gestützt, zuletzt gestielt; Röhre der Bl. walzl., 2 mal so lang als der Saum, die Schuppen in der Röhre aufrecht, angedrückt. ○. Schles., Böhm., auf Weiden u. Pappeln schmarotzend. Jul. Aug. Bl. roth.

\section{Ordng. BORAGINEEN. Desv. Juss.}

I. Gruppe. HELIO'ROPEEN. Fruchtkn. 1, mit 4 Näthen, an der Spitze den gemeinsamen Gf. tragend, bei der Reife sich in 4 , an der Basis flache, Niisse spaltend.

1. HELIOTROPIUM L. Somnenwende.

1. H. e uropa e um L. St. ausgebreitet, krautig; B. eyf., ganzrandig, flach, gerade-aderig, filzig-raul ; Achren seitenst., meist einzeln, u. endständig-gezweiet; Fruchtkelche sternf-abstehend. $\odot$. Kultiv. 0.; zerstr. deh das mittl. u. sïdl. Geb. Jul. Aug. Bl. weiss.

II. Gruppe. CYNOGLOSSEEN. Niisse 4, an den bleibenden Gf. angeheftet.

\section{ASPERUGO L. Scharfkraut.}

1. A. procumbens L. $\odot$. Kultiv. O., Schutt; zerstr. dch das Geb. Mai. Jun. Bl. röthl.-blau.

\section{ECHINOSPÉRMUM Schwartz. Igelsame.}

1. E. Lappula Lehm. St. oberwärts ästig; B. lanzettl., angedrückt-haarig, gewimpert; Bl. länger als der K.; Bthstiele auch nach dem Verblühen aufrecht; Nüsse am Rande mit 2 Reihen widerhakiger Stacheln, auf dem Mittelfelde।u. den Seiten mit Knötchen besetzt. $\odot$. Trockene, unkult. O. Jul. Aug. Myosotis Lappula L. Bl. blau.

2. E. d efl exum Lehm. St. rispig-ästig; B. lanzettl., abstehendbehaart; Bthstiele nach dem Verblühen zurüclgehogen; Nüsse am Rande mit 1 Reihe widerhakiger Stacheln. $\odot$. Steinige schattige 0. der Gbge; sehr zerstr. im mittl. u. suidl. Geb. Mai. Jun. Bl. blau.

4. CYNOGLOSSUM $\mathrm{J}_{\lambda}$. Hundszunge.

1. C. officinale L. St. aufrecht; B. v. feinem, weichern Filze graulich, spitz, die unteren elliptisch, in den Bstiel vorgezogen, die oberen aus fast herzf., halbstengelumfassender I3asis lanzettl.; Tr. deckblattlos; Stbg. eingeschlossen; Nïsse vorne flach, mit einem ziemlich dicken, hervortretenden Rande umgeben. $\odot$. Unkultiv., stei- 
nige O. Mai-Jul. Bl. roth-violett. Var.: Bl. weiss, Deckklappen purpurn: C. bicolor W.

2. C. pi ctum Aiton. St. aufrecht; B. v. feinem, weichem Filze graulich, spitz, die unteren längl,, in ren Bstiel verschmälert, die oberen aus fast herzf, halbstengellimfassender Basis lanzettl.; Tr. deckblattlos; Sthg. eingeschlossen; Nüsse vorne ziemlich convex, ohne vortretenden Rand. (.). Unkultiv. steinige O.; Triest, Istrien, siidl. Tyr. Mai. Jun. Bl. hellbIau, mit pu'purnen Adern, Deckklappen blutroth.

3. C. mon tan u $\mathrm{m}$ Lam. St. aufrecht; B. zerstrent-behaart, spitz; oberseits fast kahl, glünzend, unterseits etwas rauh, die unteren elliptisch, in den Bstiel vorgezogen, die mittleren an der Basis verschmälert, beinahe spatelig, die oberen aus fast herzf., halbstengelumfassender Basis längl.; Tr. deckblattlos; Stbg. eingeschlossen. $\odot$. Gebirgswälder des mittl. u. südl. Geb. bis gegen die A. Jun. Jul. C. sylvaticum Haenke. C. Dioscoridis Vill. Bl. roth-violett.

\section{OMPHALÓDES Touruef., Lehm. Omphalode.}

1. O. verna Moench. B. gestielt, fast kahl, die wurzelst. herzeyf., die oberen stengelst. ey-lanzettf.; 'Tr. gezweiet, armbliithig. 2 . Schattige Wälder, Krain, Salzb. Apr. Mai. Cynoglossum Omphalodes L. Bl. azurblau.

2. O. scorpioides Lehın. St. niederliegend, oberwärts gabelsp.; B. rauh, die wurzelst. spatelig, die stengelst. lanzettl., sitzend, die unteren gegenst., die oberen wechselst.; Bthstiele blattwinkelst. ○. Haine, schattige O.; Schles., Mähr., Böhmen bis Dresden, Schweinfurt. Apr, Mai. Cynoglossum scorpioides Haenke. BI. blau.

III. Gruppe. ANCHUSEEN. Niisse 4, der "unterweibigen Scheibe eingefügt, an der Basis nit einem gedunsenen, gerieften Ringe versehen, $u$. innerhalb des Ringes ausgehöhlt. Gf. frei.

\section{BORÁGO L. Borretseh.}

1. B. officinalis L. Die unteren B. elliptisch, stumpf, nach der Basis verschmälert; Zpfl. des Saumes eyf., zugespitzt, flach. (- Kultiv. u. zufällig auf Gartenauswurf. Jun. Jul. Bl. blau.

\section{ANCHÚSA L. Ochsenzunge.}

1. A. offi cinalis L. B. Ianzettl., steifh.; DeckB. ey-lanzettf.; K. 5sp., Zpfl. ziemlich spitz; Haare der Rispenäste $u$. des $K$. etwas abstehend; Deckklappen eyf., sammetig. $\odot$, manchmal 2. Unkultiv. O. Mai-Oct. Bl. violett, od. die Zptl. mit cinem azurblauen Streifen od. ganz azurblau, selten fleischroth od. weiss.

2. A. lept ophylla R. et S. B. lanzettl., steifh.; DeckB. eylanzettf.; K. 5sp., Zpt. sehr stumpf; Haare der Rispenäste u. des 
K. anliegend; Deckklappen eyf., sammetig. ๑. Unkultiv. O.; Tyr., sïdl. Schwz. Jul. Aug. A. angustifolia Lehmann. Bl. blau.

3. A. italica Retzius. B. lanzettl., wellig, steifh., glänzerı; Tr. gezwciet, deckblätterig; DeckB. lineal.-lanzettl.; Zpfl. des K. pfriemlich, länger als die Röhre der etwas ungleichen Bl.; Deckklappen länglich, pinselig-behaart.,. . Weinberge, Wege; südl. Geb. jenseits der A. A. panienlata Ait. Bl. azurblau.

\section{LYCóPSIS L. Krummhals.}

1. L. arvensis L. Der St. aufrecht, ästig; B. lanzettl., ausgeschweift-gezähnt, steifh., die unteren in den Bstiel verschmälert, die oberen halbstengelumfassend; Tr. beblättert; Rölure der Bl. in der Mitte gekrümmt. $\odot$. Brachäker u. kult. O. Jun.-Oct. Bl. blau.

2. L. variegata L. Die St. anfstrebend; B. längl.-lanzettl., ausgeschweift-gezähnt, steifh., die unteren in den Bstiel verschmälert, die oberen halbstengelunfassend; Tr. oberwärts nackt, meist einzeln; Röhre der Bl. ziemlich gerade, Saum unregelmässig, schief. $\odot$. Kiultiv. O., Wege; Istrien. Mai. Jun. Bl. azurblau mit 5 weissen Linien.

3. L. orientalis L. Der St. aufrecht, gabelsp. -ästig; B. eyf.längl., ganzrardig od. entfernt-undeutlich-ausgeschweift-gezähnelt, steifh., die unteren in den Bstiel verschmälert, die oberen an der Basis ungleich, halbstengclumfassend; Tr. beblättert; Röhre der Bl. unterhalb der Mitte gekrünmt. $\odot$. Unter der Saat, bei Verviers, ohne Zweifel mit Baumwolle eingefiilnt. Bl. azarblau.

9. NONNÉA Med. Nomnee.

1. N. pulla DC. St. aufrecht, fast einfach; B. lanzettl., ganzrandig, angedrückt-haarig, d. blïthenst. ey-lanzettf.; Saum der gleichen Bl. v. der Länge der Röhre. (-). Aecker u. an Wegen; östl. Geb. v. Oestr. bis Brandenhg., Sachs. u. Thiiring. Mai. Jun. Lycopsis pulla L. Bl. satt-purpurbram.

\section{SÝMPHYTUM L. Beinwurz.}

1. S. officinal e L. W. spindelf., ästig; der St. ästig; B. herablaufend, die unteren und die wurzelst. ey-lanzettf., in den Bstiel zs: gezogen, die oberen u. die bliithenst. lanzettl.; Saum der 13l. 5zähnig, Zähne zuriickgekrüinmt; Stbk. noch einmal so lang als der Stbf. $y$. Nasse Wiesen, Flussufer, Gräben. Mai.Jun. Bl. weiss, od. rosenrotll orl. violett.

2. S. bulbosum Schimp. Rhizom nebst den unterirdischen Ausläufern stielrund, schlank, verlängert u. runzelige, zerstreute Knollen tragend; der St. beblättert, etwas ïstig, an der Spitze 2sp.; B. eyf.längl., halbherablaufend, die unteren in den Bstiel zsgezogen, die oberen sitzend, an der Basis,abgerundet; Bl. fast walzl., Saum halb 
5sp., Zpfl. aufrecht; Stbk. v. der Länge der Stbf.: Deckklappen hervertretend. 24. Weinberge; bei Heidelberg, Cant. Tessin. S. punctatum Gaud. Bl. hellgelb.

3. S. tuberosum I. Rhizom schief, stielrund, fleischig, knotig, linten abgebissen u. kurz-ästig, vorne mit hinabsteigenden, starken Fasern versehen; der St. ganz einfach od. an der Spitze 2 sp.; $\boldsymbol{B}$. herablaufend, die unteren eyf., in den Bstiel zsgezogen, die oberen elliptisch, die urtersten kleiner, während der Bthezeit schon verwelkt; Bl. trichterf.-röhrig, 5zähnig, Zähne zuriickgekrümmt; Stbk. noch einmal so lang als die Stbf. 24. Schattige, besonders gebirgige Wälder; Oberbayern, Salzb., Krain, Litt., Oestr., Mähr., Böhm., Schles., Erzgeb. Apr. Mai. B1. gelblich-weiss.

IV. Gruppe. LITHOSPERMEEN. Niisse 4, der unterweibigen Scheibe eingefügt, an der Basis nicht ausgehöhlt, sondern init einem flachen od. etwas convexen Hofe angeheftet. Gf. frei.

\section{ONÓSMA I. Lotwurz.}

1. O. echioides L. Der St. sehr ästig; b. lincal.-lanzettl., steifh., die Borsten auf einem kahlen Knötchen sitzerd; die blüthenst. B. ey-lanzettf.; Stluf. halb so lang als die kahlen Stbk. $\odot$, selt. 24. Unkultiv. O.; siidöstl. u. sïdl. Geb., v. Mähr. bis Fiume, Wallis. Jun. Jul. Bl. gelbl.-weiss, wie der folgend.

2. O. a renarium W. K. Der St. ästig; B. lineal.-lanzettl., steifh., die Borsten auf einem kahlen Knötchen sitzend, die blïthenst. B. cylanzettf.; Stbf. küirzer als die am Rande gezälınelt-rauhen Stbk. $\odot$. Trockene, sandige Wälder, Sandplätze im Föhrenwalde bei Mainz hinter der Hartmiihle. Jun. Jul.

3. O. stellulatum W. K. Die St. ganz einfach; 13. lineal.lanzettl., steifh., die Borsten auf sternf.-behaarten Knötchen sitzend, die blïthenst. I3. aus eyf. Basis lanzettl.; Stbf. länger als die Stbk. 7. Steinige, sonnige O.; suidl. Geb. jenseits der A. Jun. Jul. O. montanum Bertol. - $\beta$. angustifolium: B. schmäler, dichter-behart; Haare manchmal dïimer. O. montanum Sm.

\section{CERÍNTHE L. Wachsblume.}

1. C. major L. Bl. jzährig, Zälne liurz-eyt., zuriickgebogen; Stbf. so lang als die Stbk. $\odot$. Wälder, Berner A. u. YorA. Jul. Aug. Bl. gelblich-weiss, od. gelb-violett.

2. C. $\mathrm{min}$ or L. Bl. ïber $1 / 3$ 5sp., Zähne pfrieml., aufrecht, zsschliessend; Stbf. 4 mal kürzer als die Stbk. $\odot$. Felder, Wege; Oberbayern bis Regensb., Oestr., Mähr., Schles., Böhm., Sachs. Mai-Jul. Bl. gelb. Var. $\beta$. C. maculata MIB.: Bl. mit 5 braunen Flecken.

3. C. a lpina Kit. Bl. 5zähnig, Zähne eyf., an der Spitze zurückgekrümmt; Stbf. 4mal kürzer als die Stbk. 2. A., mit den Flüs- 
sen in die Ebencn; Schwz., Allgäu, Tyrol, an der Iller u. dem Lech bis gegen die Donau. Jun.-Aug. Bl. gelb.

\section{3. ÉCHIUM I. Natterkopf.}

1. F. vulgare L. Borstig-steifh.; der St. krautig; B. lanzettl.; Aehren ungeth.; Röhre der Bl. kürzer als der $K$.; Gf. an der Spitze 2sp.; Stbg. abwärtsgeneigt, spreitzend, an dem Saum der Bl. anliegend. $\odot$. Unkultir. O., Brachfelder. Jun.-Sept. Bl. blau, selten roth oci. Weiss. Var. mit halb so grossen Bl. u. langen u. kurzen Sthg.

2. E. pustulatum Sibth. u. Sm. Borstig-steith.; der St. krautig; B. lanzettl.; Aelıren ungeth.; Röhre der Blb. länger als der K.; Gf. an der Spitze 2sp.; Stbg. abwärtsgeneigt, gleichlaufend, $v$. dem Saum der Blkr. entfernt. (.). Unkultiv. O.; Istrien, Veglia. Mai-Jul. Bl. blau.

3. E. rubrum Jacq. Borstig-steifh.; der St. krautig, steif; B. lineal.-lanzettl.; Aehren ungeth.; Röhre der Bl. noch einmal so lang als der K.; Gf. an der Spitze ungeth.; Stbg. länger als die Blkr. ... u. 2. Wiesen, waldige O.; Unteröstr., Mähr. Jun. Jul. Bl. roth.

4. E. italicum L. Borstig- sehr steifh.; der St. krautig, steif; B. lanzettl.; Aeliren 2sp., gedrungen; Gf. an der Spitze 2sp.; Stbg. noch einmal so lang als die Blkr. -.. Unkult. Hügel; Istr., Litt., südl. Tyr., Wallis. Jun. Jul. Bl. weiss.

5. E. violaceum L. Der St. krautig, üstig; B. steifh., die unteren längl.-lanzettl., in den Bstiel versehmälert, die oberen aus her $z$., stengelumfassender Basis verschmälert; Aehren. ungeth., verlängert; Stbg. v. der Länge der Blkr. ○. Felder, Wege; Istr., Insel Osero. Mai. Jun. Bl. blau.

\section{PULMONARIA L. Lungenkraut.}

1. P. offiein al is L. Die äusseren B. der nichtblühenden Wköpfe herzf., gestielt; Bthstiel schmal-geflügelt; Haare des St. borstig, mit wenigen gegliederten 11 . drïsentrag. gemischt. 24. Sehattige Laubwälder; zerstr. deh das ganze Geb. März. Apr. Bl. zuerst rotl, dann violett.

2. P. saceharata Mill. Die äusseren B. der nichtblühenden Whöpfe eyf., in den schmal-gefiïgelten Bstiel plötzlich zsgezogen, die inneren längl., in den Bstiel hinablaufend; Haare des St. horstig, mit wenigen gegliederten $u$. drüsentrag. gemischt. 24. Schattige Wälder; Geb. der Fl. v. Spaa, bei Stettin in Pommern, Piperalpen in Stmk. Mär\%. April. Bl. lila od. weiss. B. weissl.-gefleckt.

3. P. mollis Wolff. B. der nichtblühenden Wküpfe elliptischlanzettl. u. lanzettl., in den breitgeflügelten Bstiel hinablaufend; Haare des St. weich, gegliedert, klebrig-drüsig. 21. Felsige, sehattige 0 .; zerstr. deh das südl. "1. mittlere Geb. Apr. Mai. P. media Host. B1. erst roth, dann violett.

4. P. angustifolia L. B. der nichtblühenden Wköpfe elliptisch- 
lanzettl. u. lanzettl., in den gefliigelten Bstiel hinablaufend; Haare des St. borstig, mit wenigen drüsigen gemischt; Schlund inwendig unterhalb des bärtigen Kreises behaart. 2. Haine. Apr. Mai. P. tuberosa Schrank. Bl. erst roth, dann violctt. Bl. lanzettl., od. $\beta$. P. oblongata Schrad.: B. ey-lanzettf.

5. P. a zurea Besser. B. der unfruchtb. Wköpfe lanzettl., an der Basis in den geflïgelten Bstiel verschmälert; Haare des St. borstig; Schlund inuendig unterhalb des bärtigen Kreises kahl. 2 . Haine; Oberbayern, Oestr., Böhın., Schles., Sachs., Harz. Apr. Mai. P. angustifolia Schrank. Bl. azurblau. Der kahle Schlund esweist sich sehr beständig.

\section{LITHOSPERMUM L. Steinsame.}

1. L. officinale L. St. krautig, aufrecht, sehr ästig; B. lanzettl., spitz, aderig, sehr rauh; Haare an der Basis lnotig, angedriickt; Nüsse glatt. 24. Gebirgige, steinige O. Mai-Jul. Bl. grïnlich-weiss.

2. L. purpureo-caeruleum L. St. krautig, die blüthentrag. aufrecht, an der Spitze 2-3sp., die nichtblühenden kriechend; B. lanzettl., spitz, nach der Basis verschmälert, v. angedrückten Haaren kurzh.-ranh; Nüsse glatt. 2. Gebirgswälder; siidl. u. mittl. Geb. Mai. Jun. Bl. erst roth, danu azurblau.

3. L. arvense L. St. krautig, aufiecht, an der Spitze ästig, einfach od. an der Basis mit NebenSt. versehen; B. lanzettl., ziemlich spitz, v. angedrückten Haaren kurzl., die unteren längl.-lanzettl., stumpf, in den Bstiel verschmälert; Fruchthelche entfernt; Nüsse runzel.-rauh. - A Aecker. Apr. Jun. Bth. weiss, selt. blau.

4. L. ap ulunı Vahl. Steifh. v. etwas abstehenden Borsten; St. krautig, aufiecht, an der Spitze ästig, einfach, od. an der Basis mit NebenSt. versehen; B. lineal., die untersten in den Bstiel verschmälert, fast spatelig-lanzettl.; Fruchtkelche dicht nebeneinander; Nüsse höckerig-rauh. $\odot$. Brachäcker; Istrien. Apr. Mai. Myosotis apula L. Bl. gelb.

\section{MYOSÓTIS L. Mauseohr. (Vergissmeinnicht.)}

1. M. palustris Withering. $K$. 5zähnig, angedrücht-behaart, nach dem Verbliihen offen; $G f$. ungefältr so lang als der $K$.; die StB. längl.-lanzettl., ziemlich spitz; der St. kantig; Rhizom schief, kriechend. 24. Wiesen u. feuchte $O$. u. Gräben. Mai-Jul. MI. scorpioides $\beta$. palustris L. B. himmelblau.

2. M. caespitos a Schultz. Nüsse kahl; K. 5sp., angedrückt. behaart, nach dem Verblühen offen; Gf. sehr kurz; StB. lineal.-längl., stumpf; der St. (an der lebenden Pfl.) stielrund; W. hinabsteigend, überall faserig. (-). Gräben, Sümpfe. Jun. Jul. Bl. himmelblau, ZpH. schmäler als bei voriger. 
3. M. sylvatiea Hoffm. $K$. tief-5sp., abstehend-behaart, Haare der Basis spreitzend, hakig, Zpfl. des FruchtK. aufrecht-zsschliessend; Bthstielehen nach dem Verblühen so lang als der K. u. länger; Saum der Bl. flach. $\odot$. Gebirgswälder. Mai-Jul. Bl. azurblau. Var. $\beta$. alpestris: niedriger, Haare am K. dichter anliegend, K. grösser. M. alpestris Sehmidt., M. suaveolens Kit. - $\gamma$. lactea: wie Var. $\beta ., \mathrm{Bl}$. milehweiss. M. lactea Bönuingh.

4. M. variabilis MIoritz Angelis. $K$. tief-5sp., nach dem Verblühen geschlossen, Haare der Basis spreitzend, hakig; Tr. gestielt; Bthstielchen nach dem Verbliihen so lang als der K.; Röhre der Bl. zuletzt noch einmal so lang als der $K$.; Stbk. hervortretend, die Deckklappen ïberragend; StB. breit-lanzettl. $\odot$. In der Waldregion am Rottenmanner Tauern in Stmk. Jun.-Aug. B1. erst gelb, dann roth, zuletzt blau.

5. M. interme dia Link. $K$. tief-5sp., nach dem Verblüluen geschlossen, abstehend-behaart, die Haare spreitzend, hakig; Bthsticlchen nach dem Verblïhen abstehend, noch einmal so lang als der $K$.; Saum der Bl. concav. -.. Aecker. Jun.-Aug.

6. M. hispida Schlechtend. K. 5sp., nach dem Verblühen offen, absteheud-behaart, Haare der Basis spreitzend, hakig; Tr. gestielt; Bthstielchen nach dem Verblühen wagerecht-abstehend, so lang als der K.; Röhre der Bl. eingeschlossen. - . Raine, kultiv. O. Mai. Jın. Bl. klein, sattblau.

7. M. versicolor Persoon., M. arvensis $\gamma$. versicolor. K. tief5 sp., nach dem Verblühen geschlossen, behaart, Haare der Basis spreitzend, hakig; Tr. gestielt; Bthstielehen kïrzer als der K.; Röhre der Bl. zuletzt noch einmal so lang als der K.; Stbk. bis an die Deckklappen reichend; StB. lineal.-lanzettl. $\odot$. Etwas fenchte, kultiv. u. unkultiv. O. Mai. Jun. Bl. erst schwefelgelb, dam bläulieh, endlieh riolett.

8. M. striet a Link. K. tief-5̌sp., nach dem Verblühen geschlossen, behaart, Haare der Basis spreitzend, hakig; I'. an der Basis beblättert; Fruehtstielehen kürzer als der K.; Röhre der Bl. eingesehlossen. $\odot$. Sandige, unkultiv. n. kultiv. O. Ajr. Mai. Bl. klein, blau.

9. M. sparsiflor a Mikan. K. tief-5sp., behaart, Haare der Basis spreitzend, hakig; 'Tr. armbth., an der Basis beblättert; die unteren Fruchtstielchen vielmal länger als dev $K$., zurückgeschlagen. ○. Wälder, feuchtes Gebüisch; östl. Geb. bis zum Harz. Mai. Jun. Bl. blau.

\section{ERITRICHIUM Sehrad. Eritrichium.}

1. E. nanum Schrad. 2. Joehe der höchsten A. Jul. Aug. BI. blau. Var. $\alpha$. odontospermum: Rand der Nüsse stachelig-gefranst. Myosotis nana Vill. - $\beta$. lejospermum: Rand der Nüsse glatt od. 1-2zithnig. E. Macruetii Koch syn. ed. 1. Myosotis tergloviensis Inequet. 


\section{Ordng. SOLANEEN. JusS.}

1. LYCIUM Linn. Bocksdorn.

1. L. e u rop a e u L. B. lanzettl., nach cler Basis verschmälert od. vkteyf.-lanzettl.; der Saum der Bl. halb so lang als die Röhre. ђ. Unter Gebüsch bei Bresca Nuova auf Veglia. Mai. Jun. Bl. weiss od. röthlich.

2. L. barbar um L. B. fast rauten-eyf., od. lanzettl., nach der Basis verschmälert; der Saum der Bl. so lang als die Röhre. b). In Zäunen, früher angepflanzt, jetzt hin u. wieder verwildert. Jun. Jul. Bl. purpurn.

\section{SOLÁNUM L. Nachtscliatten.}

1. S. villosum Lam. Jährig; Kanten der Aeste sehr schwach, mit wenigen Knötchen besetzt: $B$. eyf., buchtig-gezähnt u. nebst den St. fast filzig-zottig; Tr. einfach; Bthstielchen bei der Frucht an der Spitze verdickt, herabgebogen. ○. Schutt, Wege. Jul.-Oct. Beeren gelb. Bl. weiss od. bleichviolett, wie bei den 3 folgenden.

2. S. miniatum Bernh. Jährig; Kanten der Aeste hervortretend, lnotig; $B$. eyf., fast deltaf., buehtig-gezähnt n. nebst dem St. abstehend-zottig; Tr. einfach; Bthstielchen bei der Frucht an der Spitze verdickt, herabgebogen. $\odot$. Schutt, Wege. Jul.-Oct. Beeren roth.

3. S. humile Bernh. Jährig; Kanten der Aeste sehr schwach, mit wenigen Knötchen besetzt; $\boldsymbol{B}$. ey-, fast rautenf., ausgeschueiftgezähnt u. nebst dem St. fast kahl; Tr. einfach, Bthstielchen bei der Fucht an der Spitze verdickt, herabgebogen. $\odot$. Kultiv. O. Wege. Jul.-Oct. Beeren wachsgelb od. griinlich.

4. S. n igr um L. Jährig; Kanten der Aeste hervortretend, knotig; B. eyf., fast deltaf., buchtig-gezähnt u. nebst dem St. mit eirwärts-gekrümmt-aufrechten Haaren besetzt; Bthstielchen bei der Frucht an der Spitze verdickt, herabgebogen. ○. Kult. O., Wege, Schutt. Jul.-Oct. Beeren schwarz. Var. $\beta$. stenopetalum: B. schmäler, Bl. tief-getheilt, mit sehr schmalen Zpfln.; Beeren auch schwarz. Sol. nigrum stenopetalum Alex. Braun. - $\gamma$. chlorocarpum: mit grasgrünen Beeren bei vollkommener Reife. S. nigrum chlorocarpum Fl. frib. suppl.

5. S. D u le a mara L. Der St. strauchig, schlängelich; B. eyherzf., die oberen spiessf.; Ebensträusse meist blattgegenst. f). Gebïsch, feuchte $\mathrm{O}$., Ufer. Jun.-Aug. Bl. violett, mit 2 grasgriinen, weiss-berandeten Flecken an der Basis der Zpfl., selten weiss. Beeren roth. Var. $\beta$. tomentosum: St. u. B. filzig. S. littorale Raab. Verfallene Feldmanern; sïdl. Schwz., siidl. Tyrol, Swinemünde in Pomm.

6. S. tubexosum L. St. krautig; B. gefiedert, Blättehen ungleich, abwechselnd sehr klein; Bthstielchen gegliedert; Blkr. 5win- 
lelig; die Aeste unter der Erde knollentragend. 4. Die Knollen aber nur jährig. Jul. Aug. Kultiv.

\section{PHÝSALIS I. Schlutte.}

1. Ph. Alkekengi L. B. gezweiet, ungeth., spitz; der St. krautig, v. der Basis an ästig. 2. Trockene Hïgel, Weinberge, Wege; zerstr. deh das Geb. Jun. Jul. Bl. weiss. Beere scharlachroth. K. aufgeblasen, mennigroth.

4. ÁTROPA L. Tollkraut.

1. A. Bella do nna L. Der St. krautig; B. eyf., ungeth. 4. Wälder. Jun. Jul. Bl. violett-braun.

5. SCOPOLINA Schult. Scopoline.

1. S. a tropoides Schult. Bl. röhrig-glockig. 24. Schattige Wälder in Krain. Apr. Mai. Hyoseyamus Scopolia L. Bl. auswendig glänzend, braun, inwendig glanzlos, olivengrün.

2. S. viridiflora Freyer. Bl. vktkegelf.-glockig. 4. Berg Schelmlje in Krain. Apr. Mai. Bl. einfarbig-grün.

\section{HYOSCÝAMUS L. Bilsenkraut.}

1. H. niger L. $B$. eyf.-längl., fiedersp.-buchtig, die untersteu gestielt, die stengelst. halbstengelumfassend, die blüthenst. beiderseits 1-2zähnig; Bth. fast sitzend. - u. $\odot$. Kultiv. u. unkultiv. O., Schutt. Jun. Jul. Bl. schwefelgelb, schwarz-aderig, Schlund schwarzpurp. Auf kultiv. O. jälrig, B. weniger buchtig: H. agrestis Kit. Dieser mit einfarbig-bleiclıgelben Bl.: H. pallidus Kit.

2. H. albus L. B. sämmtl. gestielt, rundl-eyf., buclitig, stumpflappig, d. oberen ausgeschweift-gezähnt; Bth. fast sitzend. $\odot$. Kultiv. O., Wege; Fiume, Istrien. Mai. Jun. Bl. bleichgelb, Schlund violett.

7. NiCOTí́NA L. Tabak.

1. N. Tab acum L. B. lüngl.-lanzettl., zugespitzt, die unteren verschmälert-herablaufend; Schlund der Bl. aufgeblasen-bauchig, Saum 5th., mit zumespitzten Lappen. $\odot$. Gebauet. Jul. Aug. Bl. rosenroth.

2. N. lat is sim a Mill. B. ey-lanzettf., aus geölerelter Basis herablaufend; Sclnlund der Bl. aufgeblasen=bauchig, Saum 5sp., mit kurzzugespitzten Lappen. - Gebauct. Jul. Aug. N. macrophylla Spreng. Bl. rosenroth.

3. N. rustica L. St. sticlrund; B. gesticlt, eyf., ganzrandig; Röhre der 13l. walzlich, länger als der K., $\mathrm{Z} p$ l. des Saumes rundl., stumpf. $\odot$. Gebauct. Jul. Aug. B1. gelblichgrün.

8. DATÚrA L. Stechapfel.

1. D. Stramonium L. B. eyf., kahl, ungleich-buchtig-gezähnt; Kapseln aufrecht, dornig. - Kultiv. O. Jul. Aug. Bl. weiss. Var. 
H/s. Nicandra, thanr. Giftbrom.

$496 / 49 \%$

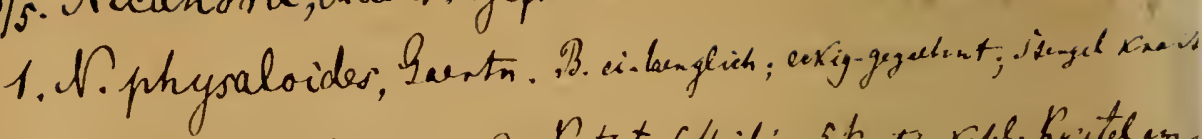

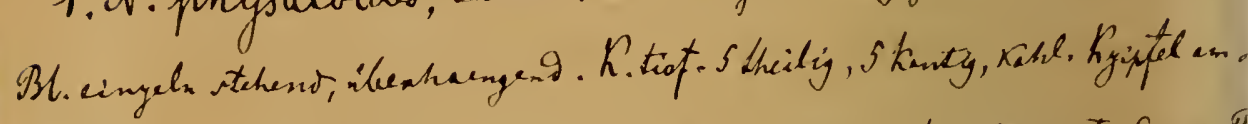

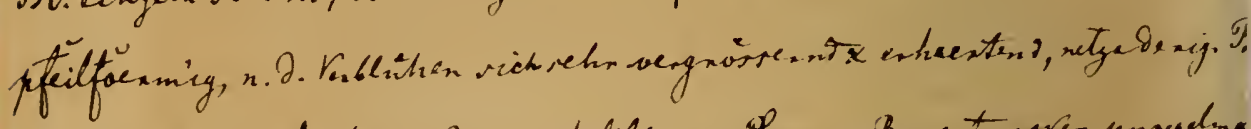

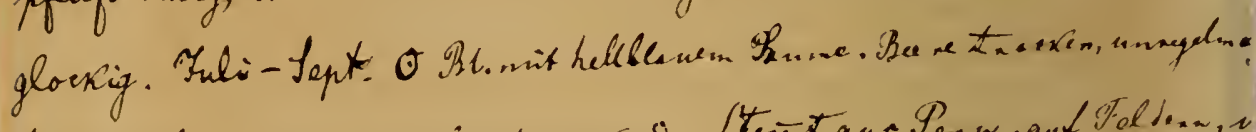

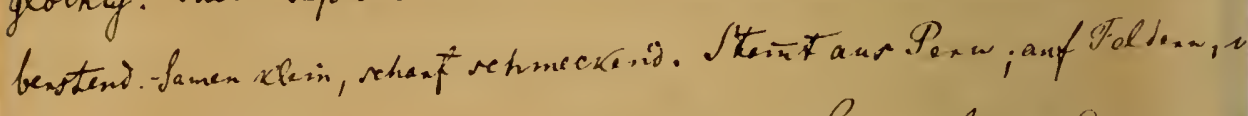

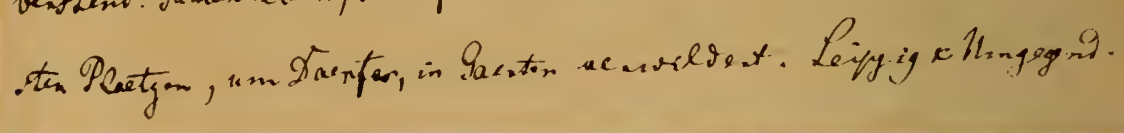

in 
B. chalybea: St., Bstiele, Blattnerven satt-violett; Bl. violett. D. Tatula L. Unterrhein.

\section{LXXXU. Ordng. VERBASCEEN. Bartling.}

\section{VERBASCUM L. Wollkraut.}

I. Rotte. Blätter völlig v. Blatt zu Blatt herablaufend. Bl. gelb, Wolle der Stbf. weiss.

1. V. Schraderi Meyer. V. Thapsus L., nach Fries u. Sm. B. kleingekerbt, filzig, der Filz gelblich, alle v. B. zu B. hinablaufend; Tr. meist einzeln; die blüthentrag. Bthstielchen kürzer als der K.; Bl. trichterf.; Stbg. weiss-wollig, die 2 längeren kahl od. oberwärts spärlich-behaart, $4 \mathrm{mal}$ so lang als ihr auf der einen Seite. kurz-hinablaufendes Stbk. $\odot$. Unkult., steinige O., Sandfelder. Jul. Aug. V. Thapsus Schrad. Var. Bl. bleichgelb: V. pallidum N. v. E.; Bl. weiss: V. elongatum Willd.

2. V. thapsiforme Schrad. $B$. gekerbt, filzig, der Filz gelblich, alle von $B$. zu B. hinablaufend; Tr. meist einzeln; die bliithentrag. Bthstielchen kürzer als der K.; Bl. radf.; Stbf. weiss-wollig, die 2 längeren kahl od. oberwärts spärlich-behaart, $11 / 2$ od. noch einmal so lang als illr auf der einen Seite langhinablaufendes Stbk. $\odot$. Mit dem vorigen. Jul. Aug. V. Thapsus Meyer chl. han., Koch. syn. ed. 1. Var. in Fichtenwäldern: Filz dïnner, Aehre unterbrochen: V. cuspidatum Schrad.

II. Rotte. Blätter kurz- od. halb-hinablaufend.

a. Bl. gelb; Wolle der Stbf. weiss.

3. V. phlomoides L. B. gekerbt, filzig, der Filz gelblich, die oberen kurz- od. halbhinablaufend; Tr. meist einzeln; die blüthentrag. Bthstielchen kürzer als der K.; Bl. radf.; Stbf. weiss-wollig, die 2 längeren kahl od. oberwärts spärlich-behaart, $1 \frac{1}{2}$ od. noch einmal so lang als ihr auf der einen Seite lang-hinablaufendes Stbk. $\odot$. Unkult., steinige O., Sandfelder; zerstr. dch das Geb. Jul. Aug.

4. V. montanum Schrad. B. gekerbt, filzig, der Filz gelbl., die oberen halbhinablaufend; Tr. meist einzeln; Bth. einzeln und büschelig, Büschel $3-4 b$ th.; die blüthentrag. Bthstielchen kürzer als der K.; Bl. radf.; Sthf. sämmtl. weiss-wollig, die 2 längeren an der Spitze kahl, 3mal kürzer als ihr auf der einen Seite kurzhinablaufendes Stbk. $\odot$. Waldige Hügel; Unterwallis. Jul. Aug. - Die folgenden Nummern 5 bis 9 einschliessl. sind wirkliche oder muthmassl. Bastarde.

5. V. s purium Koch. (Thapso-Lychnitis). B. gekerbt, halbhinablaufend, filzig, der Filz angedrückt, grau; der St. oberwärts scharfkantig; Bthstielchen so ling als der K.; Stbf. sämmtl. veiss-wollig; Stbk. gleich, die der längeren Stbf. nicht hinablaufend. (-). Unkult. Hïgel; Rheimpfalz. Jul. Aug. V. Thapso-Lychnitis M. u. K. 
6. V. ramiger u m Schrad. (Thapsiformi-Lychnitis). B. gekerbt, kurz- od. halbherablaufend, filzig, der Filz angedrückt, graulich; der Stengel oberwärts scharf-kantig; Büschel der Tr. reichblüthig; die blüthentrag. Bthstielchen länger als der K.; Stbf. sämmtl. weisswollig; Sthk. der läıgeren Stbf. auf der einen Seite kurz-hinablaufend. ๑. Unkult. O.; zerstr. im nördl. Geb. Jul. Aug. V. ThapsiformiLychnitis Schied. Bl. 3mal grösser als an dem vorigen.

b. Bl. gelb; Wolle der Stbf. heller-od. dunkler-violett.

7. V. nothum Koch. (Thapsiformi-floccosum). B. gekerbt, kurzod. halbhinablaufend, filzig, der Filz gelbl.-grau, die oberen langhaarspitzig; St. stielrund, Büschel der Aeste reichblüthig; die blüthentrag. Bthstielchen so lang als der K.; Stbf. sämmtl. hell-purpurnwollig; Stbk. der längeren Stlf. etwas hinablaufend. $\odot$. Unkultit. Hügel, Wege; Mittelrhein. Jul. Aug. Dem V. floccosum ähnl. Bl. $3 \mathrm{mal}$ grösser, die Wolle hellviolett, die $B$. hinablaufend.

8. V. collinum Schrad. (Thapso-nigrum). B. gekerbt, halbhinablaufend, filzig, der Filz gelblich, die oberen längl., spitz; der St. oberwärts scharf-kantig; Büschel der Tr. meist 5bth.; die blüthentrag. Bthstielchen so lang als der K.; Sthf. sämmtl. purpurn. wollig; Stbk. gleich, keine hinablaufend. ๑. Unkultiv. steinige 0.; nördl. Geb., sodanu Unterharz, Hessen, Oberbayern. Jul. Aug. V. Thapso-nigrum Schiede.

9. V. adulterinum Koch. (Thapsiformi-nigrum). B. gekerbt, kurz- od. halbhinablaufend, filzig, der Filz graulich, die oberen haarspitzig; der St. oberwärts scharf-kantig; Bïschel der Tr. 5-7bth.; die bliithentrag. Bthstielchen so lang als der K.; Sthf. sämmtl. purpurri-wollig; Stbk. der längerere Stbf. längl., hinablaufend. $\odot$. Flusskies, Triften, hie u. da. Jul. Aug. V. Thapsiformi-nigrum Schied. Bth. ansehnlich, wie bei V. phlomoides.

10. V. sinu at um L. B. filzig, die wurzel- u. unteren stengelst. buchtig, die oberen gekerbt, kurz-hinablaufend; Tr. rispig; Stbf. sämmtl. purpurn -wollig; Stbk. gleich. $\odot$. Trockene, steinige O.; Istrien, Osero. Jul. Aug.

c. Bl. rothbraun; Wolle der Stbf. violett.

11. V. versiflorum Schrad. B. gekerbt, kurz-hinablaufend, filzig, der Filz graulich; der St. stielrund; Tr. rispig, die Hauptbüschel 3-5bth.; die blüthentrag. Bthstielchen $1 \frac{1}{2}$ mal, die fruchttrag. fast 3 mal so lang als der $K$.; Sthf. violett-wollig; Stbk. der längeren Stbf. etwas herablaufend. ๑. Unikultiv. O.; bei Prag. Jul. Aug. Bth. rothhraun.

III. Rotte. Blätter nicht herablaufend. Bth. büschelig.

a. Bl. gelb, (an Varietäten weiss); Wolle der Stbf. weiss.

12. V. speciosum Schrad. B. ganzrandig, wellig, filzig, der 
Filz bleibend, die unteren längl., spitz in den Bstiel verschmälert, die stengelst. geöhrelt-herzf., sitzend; Aeste kantig; Tr. rispig; Stbf. weiss-wollig; Stbk. gleich. $\odot$. Grasige Hügel, Waldränder; Unteröstr. Jul. Aug. V. longifolium DC.

13. V. floceosum W. K. B. dicht-filzig, der Filz weiss, flockig, abfällig, die wurzelst. längl.-elliptisch, in den Bstiel verschmälert, die übrigen sitzend, unmerklich-gekerbt, die oberen lang-zugespitzt, halbstengelumfassend; der St. nebst den Aesten stielrund; Tr. rispig, abstehend; Stbf. weiss-wollig. $\odot$. Sonnige Hügel, Wege; Rheinfläche v. Basel bis Coblenz, Littor. Jul. Aug. V. pulverulentum Smith.

14. V. pulverulentum Vill. (Lychniti-floccosum). B. gekerbt, oberseits dünre, unterseits dichter-filzig, der Filz graulich, die unteren längl.-elliptisch, in den Bstiel hinablaufend, die übrigen sitzerı, die oberen zugespitzt; St. oberwärts u. Aeste stumpf-kantig; I'r. rispig, abstehend; Stbf. weiss-wollig. (-). Hiigel, Wege; Elsass, Gegend von Mainz. Jul. Aug. Muthmasslich Bastard v. V. floccosum u. Lychnitis.

15. V. Lychnitis L. B. gekerbt, oberseits ziemlich kahl, unterseits staubig-filzig, graulich, die unteren elliptisch.-längl., in den Bstiel verschmälert, die übrigen unteren kürzer-gestielt, die oberen sitzend, eyf., zugespitzt; Aeste aufrecht- ttwas abstehend, pyramidenf.rispig, scharf-kartig; Stbf. weiss-wollig. $\odot$. Unkultiv. O. Jul. Aug. Var. $\beta$. album: mit weissen BI.: V. album Mill. Eine Form mit dïnnerem Filze: V. incanum Gaud.

\section{b. Bl. gelb; Wolle der Stbf. purpurn.}

16. V. Sch ot tian um Schrad. B. gekerbt, beiderseits filzig, oberseits dünner, unterseits dichter, die wurzelst. oval-längl., ziemlich spitz, gestielt, die mittleren stengelst. länglich, spitz, sitzend, d. oberen eyf., zugespitzt, fast herzf., halbstengelumfassend; der St. oberwärts kantig; Aeste rispig; Bthstielchen noch einmal so lang als der K.; Stbf. purpurn-wollig. $\odot$. Unkult. O.; Oestr., Elsass, Unterrhein. Jul. Aug.

17. V. nigrum L. B. gekerbt, oberseits ziemlich kahl, unterseits fein-filzig, die urteren stengelst. längl.-eyf., an der Basis herzf. lang-gestielt, die oberen eyf.-längl., fast sitzend; der St. oberuärts scharf-kantig; $T r$. verlängert; Bthstielchen noch einmal so lang als der K.; Stbf. purpurn-wollig. $\odot$. Unkult. O., Wege. Jul. Aug.

18. V. lanatum Schrad. B. unterseits wollig-fllzig, die unteren u. mittleren längl., gestielt, fast buchtig-doppelt-gekerbt, die oberen längl.-eyf., sitzend, spitz-gekerbt; der St. oberwärts kaintig; T'r. einfach; Bthstielchen noch einmal so lang als der K.; Stbf. purpurnwollig. (.). Gebirgige O.; Krain, Kärnthen. Jul. Aug. V. thyrsoideum Host. Nach Facchin. Variet. v. V. nigrum.

19. V. Schiedé an um Koch. (Nigro-Lychnitis). B. gekerbt, 
oberseits ziemlich kahl, unterseits fein-filzig, die unteren stengelst. längl.-eyf., an der Basis stumpf $u$. in den Bstiel zsgezogen, langgestielt, die oberen eyf.-längl., fast sitzend; der St. oberwärts scharfkantig; Tr. verlängert; Bthstielchen noch einmal so lang als der K.; Stbf. purpurn-wollig. $\odot$. Unkult. O.; sehr zerstr. deh das Geb. Jul. Aug. V. nigro-Lychnitis Schiede. V. nigrum $\gamma$. ovatum K. syn. ed. 1.

20. V. oriental e MBieb. B. gekerbt, oberseits fast kahl, unterseits dünnfilzig, die unteren eyf.-längl., in den Bstiel zsgezogen od. seichtherzf., die mittleren eyf., kurz-gestielt, die oberen sitzend, fast herzf.; Aeste rispig u. nebst dem St. fast stielrund; Bthstiele $11 / 2 \mathrm{mal}$ so lang als der K.; Stbf. purpurn-wollig. $\odot$. Unkult., steinige O.; Böhm., Mähr., Oestr., südl. Tyrol. Jul. Aug. B. an der Basis tiefer-gekerbt. Var. mit unterseits weniger-filzigen B.: V.austriacum Schrad., V. virens Host.; und $\beta$. Chaixi: B. an der Basis fast leyerf.-eingeschnitten: V. Chaixi Vill.

c. Bl. rostbraun.

21. V. rubiginos um W. K. (Nigro-phoeniceum.) B. gekerbt, unterseits flaumig, die unteren längl., stumpf, gestielt, die stengelst. längl.-eyf., ziemlich spitz, sitzend, die oberen eyf., spitz, fast herzf., halbstengelumfassend; Tr. rispig; Bthstielchen vielmal länger als der $K$. ; Stbf. purpurn-wollig. $\odot$. Felder; bei München, bei Montreux am Genfersee. Jun. Jul. V. nigro-phoeniceum C. H. Schultz.

IV. Rotte. Blätter nicht himablaufend. Bth. einzeln oder gezweiet.

22. V. pho eniceum L. B. unterseits flaumig, die wurzelst. gestielt, eyf. od. längl., gekerbt, die mittleren und oberen stengelst. viel kleiner, klein-gekerbt, sitzend; Tr. drüsig-behaart; Btlıstielchen einzeln, viel länger als die DeckB.; Stbk. sämmtl. gleich, nicht hinablaufend. (-) Unkult. O.; sehr zerstr. deh das Geb. Jun. Jul. Bl. dunkelviolett.

23. V. Blattaria L. B. kahl, die unteren vkteyf.-längl., an der Basis verschmälert, buchtig, die stengelst. längl., spitz, gekerbt, sitzend, die oberen fast herzf., zugespitzt, halbstengelumfassend; $\mathbf{T r}$. drüsig-behaart; Bthstielchen einzeln, $1 \frac{1}{2}$ od. noch einmal so lang als die DcckB. $\odot$. Kiesige, feuchte O., Wege. Jun. Jul. Bl. gelb, Stbf. violett-wollig. Var.: Bl. weiss. Diese Variet. an manchen Orten häufiger.

24. V. Pseudo-Blattaria Schleich. B. oberseits schwach-, unterseits stärker-flaumig, die wurzelst. längl.-lanzettl., spitz, nach der Basis allmählig in einen breiten Bstiel verschmälert, doppeltgekerbt od. etwas buchtig, die mittleren längl., die oberen eyherzf., zugespitzt-gekerbt mit kurz-stachelspitzigen Kerben; St. oberwärts ruthenf.-ästig, Aeste nebst den Bthstielchen u. K. v. kurzen borstl. Haaren kurzh.; Bth. einzeln oder zu zweien, Bthstielchen so lang 
als der K., nach dem Verblihhen etwas länger. $\odot$. Unkultiv. O, Wege; Wallis. Jun. Jul. Bl. gelb, Wolle der Stbf. violett. Nach Gaudin's Vermuthung Bastard v. V. Blattaria u. Lychnitis.

\section{SCROPHULARIA L. Braunwurz.}

I. Rotte. Rispige. Bth. in endst., länglichen, aus gabelsp. Aesten zsgesetzten Tr.

a. Unter der oberen Lippe ein rundliches od. nierenf. od. querlängliches Anhängsel, aus dem Ansatze zu einem fünften, unfiuchtb. Stbf. entstanden.

1. S. nodosa L. B. eyf.-längl. od. ey-herzf., kahl, doppelt-gesägt, die unteren Sägezähne länger $u$. spitzer; der St. geschärft4eckig; Bstiele fligellos; R. endst.; Zpfl. des IK. eyf., stumpf, selı schmal-häutig-berandet; Ansatz des fünften Stbf. quer-längl., seichtausgerandet. 2. Feuchte O. Jun.-Aug. Bl. olivenfarb., auf dem Riicken braun.

2. S. a qua tica L. B. eyf.-längl. od. ey-herzf., kahl, gesägt, die unteren Sägezähne kleiner; St. u. Bstiele breit-geflügelt; R. endst.; Zpfl. des K. rundl., sehr stumpf, breit-häutig-berandet; Ansatz des füinften Stbf. 2sp., dessen Zpfl. spreitzend. 2. Ufer, Gräben. Jun.Aug. Bl. wie bei S. nodosa.

3. S. B alb is i Hornem. B. herzf. - längl., abgerundet-stumpf, kahl, stumpf-gekerbt, an der Basis oft mit einem kleinen Blättchen beiderseits geöhrelt; St. u. Bstiele breit-geflügelt; R. endst.; Zptl. des K. rundl., sehr stumpf, breit-häutig-berandet; Ansatz des fünften Stbf. rundl.-nierenf., kaum ausgerandet. 24. Sumpfige O.; Aachen, Baden, Elsass. Jun. Jul. Bl. grösser als bei der vorhergehenden, purpur-braun, nur an der Basis grün.

4. S. S co p olii Hoppe, Pers. B. eyf.-längl. od. eyf., fast herzf., beiderseits flaumig, doppelt-gekerbt; St. u. Bstiele zottig; $R$. endst.; Zpfl. des K. rundl., sehr stumpf, breit-häutig-berandet. $\odot$. Gebirgswälder; Schles., Mähr., Kärnth., Krain. Jun. Jul. S. glandulosa W.K. Bl. wie an S. nodosa.

5. S. 1 a ciniata W. u. Kit. B. kahl, lappig-eingeschnitten u. an der Basis fiedersp. od. gefiedert, Lappen u. Fieder ungleich-gezähnt; R. endst., drïsig, Driisen kurz-gestielt; Zpfl. des K. rundl., sehr stumpf, breit-häutig-berandet; Ansatz des fünften Stbf. rundl.nierenf. 24. Felsen, Mauern; bei Fiume. Apr. Mai. Bl. grünlich, Rücken u. Oberlippe purpur-braun.

b. Anhängsel unter der oberen Lippe schmal, lineal. od. lanzettl., spitz, auch ganz fehlend.

6. S. canina L. B. kahl, gefiedert, Fieder ungleich- od. eingeschnitten-gezähnt; R. endst., driisig, Driisen fast sitzend; Zpfl. des K. rundl., sehr stumpf, breit-häutig-berandet; Ansatz. des fünften 
Stbf. lanzettl., spitz od. auch fehlend; die Oberlippe der Bl. 3 mal so lang als die Röhre. 24. Unkultiv. O., Flusskieș; Schwz., Rheinufer bis Rastatt hinab, südl. Tyrol., Krain, Litt. Jun. Jul. S. chrysanthemifolia MB. Bl. klein, violett, $\mathrm{Z}$ pf. weissberandet.

7. S. Hoppii Koch. B. kahl, gefiedert u. doppelt-gefiedert, Zpfl. eingeschnitten u. gezähnt; $R$. endst., drüsig-behaart, Haare fast so lang als der Querdchmesser der Bthstielchen; Zpfl. des K. rundl., sehr stumpf, breit-häutig-berandet; Ansatz des fünften Stbf. lanzettl., spitz od. auch fehlend; Oberlippe der Bl. länger als die halbe Röhre. ๑. A. u. VorA., südlich niedriger; Schwz., südl. Tyr., Kärnth., Krain, Stmk. Jul. Aug. S. canina var. $\beta$. et $\gamma$. DC. K. noch einmal so gross als an der vorhergeh. Bl. ebenfalls violett.

II. Rotte. Bth. blattwinkelst.; Bthstiele mehrblüthig u. ebensträussig od. nur 1-2bth.

8. S. vernalis L. B. herzf., doppelt-gekerbt, flaumig; St. $u$. Bstiele zottig; Bthstiele blattwinkelst., 3-7bth.; Bth. ebensträussiggehäuft; Zpfl. des $K$. längl., ziemlich spitz, unberandet, an der Spitze zurückgekrümmt. ๑. Feuchte, schattige O., Zäune; sehr zerstr. dch das Geb. Mai. Jun. Bl. grünlich-gelb.

9. S. peregrina L. B. herzf., grob-, fast doppelt-gekerbt-gesägt, kahl, glänzend, die oberen wechselst.; Bthstiele blattwinkelst., armbth.; Zpfl. des $K$. ey-lanzettf., zugespitzt, unberandet. 2. Kult. O., Schutt; Istrien. Apr. Mai. Bl. dunkel-blutroth.

\section{Ordng. ANTIRRHINEEN. Juss.}

\section{GRATÍOLA L. Gnadenkraut.}

1. G. officinalis L. B. sitzend, lanzettl., 3nervig, kleingesägt, an der Basis ganzrandig; Bthstiele blattwinkelst., 1bth. 24. Feuchte Wiesen, Ufer; zerstr. deh das Geb. Jul. Aug. Bl. weiss od. röthl., mit gelbl. Röhre.

\section{DIGTTÁLIS L. Fingerhut.}

1. D. purpurea L. B. ey-lanzettf., gekerbt, unterseits nebst dem St. $u$. den Bthstielen filzig, d. unteren in den Bstiel verschmälert; Zpfl. des K. ey-lanzettf., kurz-zugespitzt, 3nervig, flaumig; Bl. erweitert-glockig, auswendig ganz kahl, Oberlippe sehr stumpf, abgestutzt od. seicht-ausgerandet, $\mathrm{Zpfl}$. der Unterlippe kurz-eyf., abgerundet. $\odot$. Gebirgige, waldige $O$.; westl. Geb. bis Thüring. Jul. Aug. Bl. purpurn, mit satteren, weissberandeten Punkten.

2. D. purpurascens Roth. B. längl.-lanzettl., gesägt, kahl, unterseits auf den Nerven flaumig, die unteren in den Bstiel verschmälert, die oberen mit eyf. Basis sitzend; Zpfl. des $K$. längl.-lanzettl., zugespitzt, 3nervig, am Rande nebst den Bthstielen u. dem K. 
oberwärts driisig-flaumig; $B l$. röhrig-glockig, auswendig ganz kahl, Oberlippe stumpf, ausgerandet, $\mathrm{Zpfl}$. der Unterlippe eyf., die seitenst. ziemlich spitz, der mittlere sehr stumpf, viel kürzer als die $B l$. $\odot$. Auf Porphyrgebirgen der Rheinpfalz; von Kusel deh das Glahn- u. Nahegbg. Jun.-Aug. Bl. gelb, mit einem hellpurp. Anstrich, selten purpurn; inwendig bleich $u$. auf dem Bauche mehr od. weniger mit purp. Punkten bestreut.

3. D. gran diflor a Lam. B. längl.-lanzettl., gesägt, gewimpert, flaumig, die unteren in den Bstiel verschmälert, die oberen mit eyf. Basis halbstengelumfassend; Zpfl. des K. lanzettl., spitz; Bthstiele nebst dem St. oberwärts drüsig-behaart; Bl. erweitert-glockig, drüsigflaumig, Oberlippe sehr stumpf, ausgerandet od. etwas gezähnelt, Zpfl. der Unterlippe 3eckig, der mittlere noch eirmal so breit, spitz od. stumpf, viel kürzer als die Bl. 4. Felsige, steinige O. Jun. Jul. D. ambigua Murr. D. ochroleuca Jacq. Bl. trüb-schwefelgelb, inwendig mit einem verwischten braunen Adernetze. Var. $\alpha$. acutifora: Zpfl. der Unterlippe spitz: D. grandiflora Reichenb. - $\beta$. Zpfl. stumpf: D. ochroleuca Reichenb.

4. D. media Roth. B. längl.-lanzettl., gesägt, kahl, gewimpert, die unteren in den Bstiel verschmälert, die oberen mit eyf. Basis sitzend; Zpfl. des K. lanzettl., 1nervig, spitz, am Rande nebst den Bthstielen u. dem St. oberwärts drïsig-flaumig; Bl. röhrig-glockig, auswendig drüsig-flaumig, Oberlippe stumpf, ausgerandet, Läppchen spitz, die seitenst. Zpfl. der Unterlippe 3eckig, spitz, der mittlere eyf., stumpf, viel kürzer als die $B l$. $\odot$. Gebirgige, waldige O.; Rheinpfalz, Glahn - u. Nahegbg. selten. Jul. Aug. Untersch. sich v. D. lutea dch die grösseren, breiteren, inwendig am Bauche schwach braun-netzigen $u$. an der Einfïgung der Stbg. beiderseits mit einer breiten, rostfarbenen Binde bezeichneten $\mathrm{Bl}$.

5. D. lu tea L. B. längl.-lanzettl., gesägt, kahl od. an der Basis etwas gewimpert, die unteren in den Bstiel verschmälert, die oberen mit eyf. Basis sitzend; der St. nebst den Bthstielchen kahl; Zpfl. des $K$. lanzettl., 1nervig, spitz, am Rande driisig-flaumig; Bl. röhrig, auswendig kahl, Oberlippe spitz-ausgerandet, mit spitzen Läppchen, $Z p f l$. der Unterlippe eyf., die seitenst. spitz, der mittlere ziemlich spitz od. stumpf, viel kürzer als die $B l$. ๑. Hügel, steinige $\mathrm{O}$; westl. Geb. u. suidl. Schwz., siidl. Tyr. Jul. Aug. Bl. gelb, ungefleckt.

6. D. fuscescens W. K. B. längl.-lanzettl., entfernt-gezähnelt, kahl, gewimpert, die unteren in den Bstiel verschmälert, die oberen mit eyf. Basis stengelumfassend; Zpfl. des K. längl.-lanzettl., spitz, nebst den Bthstielchen u. dem St. oberwärts wollig-zoltig; Bl. glockig, drüsig-flaumig, Oberlippe stumpf, ausgerandet, die seitenst. Z $p f$. der Unterlippe 3eckig, der mittlere eyf., kurz-zugespitzt, so lang als der dritte Theil der Bl. $\odot$. Gebirgige O.; bei Fiume. Jul. Bl. ochergelb, inwendig mit einem rothbraunen, auswendig durchschimmernden Netze. 
7. D. la evigata W.K. B. lanzettl, entfernt-gezähnelt od ganzrandig u. nebst dem St. kahl; Zpfl. des $K$. lanzettl., zugespitzt, am Rande so wie die Bl. drüsig-flaumig; Bl. kurz-glockig, hinter der Unterlippe buckelig, der mittlere Zpfl. der Unterlippe fast so lang als die Bl., eyf., zugespitzt. $\odot$. Steinige Hügel; Krain, Fiume. Jul. Bl. ochergelb, mit braunen Adern, Unterlippe weiss, mit bleichgrünen Adern.

8. D. ferruginea L. B. lanzettl., entfernt-gezähnelt, etwas gewimpert, $Z p f$. des $K$. längl.-eyf., abgerundet-stumpf, mit einem breithäutigem Rande umgeben; Bl. kurz-glockig, hinter der Unterlippe buckelig, der mittlere Zpf . der Unterlippe fast $v$. der Länge der $B l$., eyf., abgerundet-stumpf. $\odot$. Felsige O.; Krain u. Littor. Jul. Aug. Bl. ochergelb, inwendig rostroth, Unterlippe mit einem braunpurp. Netze.

\section{ANTÍRRHINUM L. Löwenmaul.}

1. A. majus L. B. gegenst. od. wechselst., lanzettl., kahl; Bth. traubig; $Z$ pfl. des $K$. eyf., stumpf, viel kürzer als die $B l$.; Oberlippe der B1. 2th. 24. Alte Mauern, Flusskies; Istr., Oestr., Böhm., Schles., Schwz., Rheinthal, im südl. Tyrol bei La Sega unweit Rovoredo an sehr warmen Abhängen u. Felsen. Jun.-Aug. Bl. purpurn od. weiss, 2 gelbe Flecken auf dem Gaumen.

2. A. Orontium L. B. gegenst. od. wechselst., lanzettl.;-Bth. entfernt; Zpfl. des $K$. lanzettl., länger als die Bl. $\odot$. Kult. O. Jul. -Herbst. Bl. purpurn, od. weiss.

\section{LINARIA Tournef. Leinkraut.}

I. Rotte. Cymbalaria. Die St. v. der Basis an in rankenartige, fädliche, niedergestreckte Aeste geth. B. breit, rundlich, eyod. spiessf., sämmtl., auch die obersten, deutlich-gestielt.

1. L. Cymbalaria Mill. B. herzf- rundl., 5lappig, kahl. 24. Alte Mauern, vorzügl. in Weinbergen, selten in Felsenspalten; südl. Geb., weniger im nördl. Jun.-Aug. Antirrhinum Cymbalaria L. Bl. hellviolett, Gaumen mit 2 gelben Flecken.

2. L. Elatine Mill. B. zerstreut, ey-spiessf., die unteren eyf.; St. niedergestreckt; Sporn gerade; Bthistiele kahl. $\odot$. Aecker, Kalkund Lehmboden. Jul.-Oct. Antirrhinum Elatine L. Bl. weisslich, Oberlippe inwendig violett, Unterlippe schwefelgelb.

3. L. commutat a Bernhardi. B. zerstreut, spiessf., die untersten vkteyf.; St. niedergestreckt; Sporn fast hakig; Bthstiele kahl. $\odot$. Aecker in Istr. Aug. Sept. Bl. noch einmal so gross als bei der vorhergehenden.

4. L. spuria Mill. B. zerstreut, rundl.-eyf., ganzrandig; St. niedergestreckt; Sporn bogig; Bthstiele zottig. $\odot$. Aecker, Kalkund. Lehmboden. Jul. Aug. Antirrhinum spurium L. Bl. weisslich. 
II. Rotte. Chaenorrhinum DC. Bth. einzeln in den Blattwinkeln, beblätterte, schr lockere Tr. bildend; B. lanzettl. od. elliptisch, sitzend, die unteren kurz-gestielt.

5. L. minor Desf. Ueberall drüsig-behaart; B. lanzettl., stumpf, in den Bstiel verschmälert, die unteren gegenst., d. oberen wechselst., lineal.; Bth. einzeln, blattwinkelst., fast traubig; Bthstiele 3 mal so lang als der $K . ; Z_{p f l}$. der Oberlippe spreitzend; Samen längl., gefurcht. $\odot$. Aecker, kultiv. O. Jul.-Herbst. Antirrhinum minus L. Bl. hellviolett, Lippen gelblich-weiss.

6. L. litt or a l is Bernhardi. Ueberall drüsig-behaart; B. lanzettl., stumpf, in den Bstiel verschmälert, die unteren gegenst., die oberen wechselst., schmäler; Bth. einzeln, blattwinkelst., fast traubig; Bthsticle so lang als der $K$.; Zpfl. der Oberlippe gleichlaufend mit geschlossener Bucht; Samen länglich, gefurcht. 24. Meeresufer in Istr. Jun. Jul. Bl. ein wenig grösser als bei der vorhergeh., freudigerviolett.

III. Rotte. Linariastrum DC. Der St. nebst den Aesten mit einer Tr. od. Aehre endigend. B. sitzend od. nur die untersten in den kurzen Bstiel verschmälert.

7. L. triphylla Mill. Kahl; B. gedreiet, sitzend, oval-länglich, 3nervig; Bth. gedrungen-ährig; Zpfl. des K. längl., ziemlich spitz, schwach-5nervig, ungleich, länger als die rundliche, ausgerandete Kapsel; S. schief-eyf., 3kantig, grübig-runzelig. ๑. Kultiv. O.; Istr. Jun. Jul. Antirrhinum triphyllum L. Bl. gelbl.-weiss, Gaumen dottergelb, Sporn violett.

8. L. a lpi n a Mill. Völlig kahl; $B$. zu vieren, lineal.-längl., an der Basis verschmälert; Tr. eyf., kurz; $Z_{p f l}$. des $K$. lanzettl., spitz, kürzer als die vkteyf., an der Spitze nicht ausgerandete Kapsel; S. flach, mit einem kreisrunden Flügel umgeben, kahl. $\odot$. Steinige und kiesige $\mathrm{O}$. der A., mit den Flüssen in die begleitenden Ebenen hinab. Jul. Aug. Antirrhinum alpinum L. Bl. blau, Höcker des Gaumens safranfarben.

9. L. pelisseriana Mill. Völlig kahl; B. lineal., nach der Basis u. Spitze verschmälert, die unteren zu vieren, die der unfruchtbaren St. elliptisch; $T r$. gestielt, köpfig; später verlängert; $\mathrm{Z} p f$. des $K$. aus breiterer Basis verschmälert, sehr spitz, noch einmal so lang als die Kapsel; S. flach, zsgedrückt, kammartig-bewimpert. $\odot$. Steinige, unkultiv. O.; Istrien. Mai. Jun. Antirrhinum pelisserianum L. Bl. hellblau mit dunkleren Adern, Gaumen weiss, mit bläulichen Streifen.

10. L. arvensis Desf. Kahl; $K$. nebst den Bthstielchen drüsigbehaart; B. lineal., nach der Basis u. Spitze verschmälert, die unteren zu vieren; $\boldsymbol{T r}$. gestielt, köpfig, später verlängert; $\mathrm{Zpfl}$. des $\mathbf{K}$. lineal:, stumpfl., die unteren kürzer als die vkteyf., nicht ausgeran- 
dete Kapsel; $\mathbf{S}$. flach, mit einem breiten, kreisrunden Flügel umzogen, glatt. $\odot$. Aecker, Sandfelder; mittl. u. nördl. Gebiet. Jul. Aug. Bl. klein-hellblau, dunkler gestreift, am Gaumen netzig.

11. L. simplex DC. Kahl; K. nebst den Bthstielchen drüsigbehaart; $B$. lineal., an der Basis u. Spitze verschmälert, die untersten zu vieren; Tr. gestielt, köpfig, später verlängert; Zpfl. des K. stumpfl., die unteren kürzer als die vkteyf., nicht ausgerandete Kapsel; S. flach, mit einem breiten Flügel umzogen, in der Mitte knotig-rauh. $\odot$. Aecker bei Lüttich. Antirrhinum simplex Willd. A. parviflorum Jacq. A. arvense $\beta$. L. BI. hellgelb, mit feinen violetten Streifen, Unterlippe u. Gaumen dottergelb, einfarbig.

12. L. striata DC. Völlig kahl; B. schmal-lanzettl. und lineal., Inervig od. schwach-3nervig, spitz, die unteren quirlig, die oberen zerstreut; Tr. locker; $Z_{p} f$. des $K$. lanzettl., spitz, kürzer als die Kapsel; S. eyf., 3kantig, flügellos, dch zsmündende Runzeln eingedrückt-punktirt, die Kanten scharf $u$. nicht punktirt. 24. Unkultiv. O.; Waadt, Elsass, Luittich, Westerplatte bei Danzig. Jul. Aug. Antirrh. repens u. A. monspessulanum L. Bl. bläulich mit violetten Streifen.

13. L. chape lensis Mill. Völlig kahl; B. lineal.-lanzettl., spitz, schwach-3nervig, die untersten quirlig; $\operatorname{Tr}$. verlängert, locker, schlängelich; Zpfl. des $K$. lineal., spitz, abstehend, noch einmal so lang als die rundliche, zsgedrückte, ausgerandete Kapsel; $\mathbf{S}$. eyf., 3lkantig, quer-grübig - runzelig. $\odot$. Steinige O.; Fiume, Veglia u. Cherso. Mai. Jun. Antirrhinum chalepense L. Bl. weiss, Lippen gelbl.-weiss.

14. L. Loeseli i Schweigger. Völlig kahl; B. lineal.-lanzettl., lang-verschmälert, schwach-3nervig, wechselst., entfernt; Tr. locker; Zpfl. des K. längl.-lanzettl., kurz-zugespitzt, schwach-3nervig, kürzer als die Kapsel; S. flach, mit einem nierenf. Flügel umzogen, kahl. 4. Sandige O. am Meere; Pommern, Preussen. Jul. Aug. A. linifolium L. (wahrscheinl.) Bl. schwefelgelb, Sporn röthlich.

15. L. g enistifolia Mill. Ueberall kahl; $B$. lanzettl. oder lineal.-lanzettl., 3nervig, zugespitzt, wechselst. od. zerstreut; Tr. locker ; Zpfl. des K. aus breiterer Basis verschmälert-spitz, länger als die Kapsel; S. eyf., 3kantig, flügellos, mit feinen zsmündenden Runzelchen eingedrückt-punktirt, Kanten scharf, unpunktirt. 2. Sonnige Hügel ; Oestr., Mähr., Böhm., Erzgeb. Jul. Aug. Antirrh. genistifolium L. Var.: B. breiter: L. chloraefolia Rchb. Bl. gelb.

16. L. vulgaris Mill. Kahl; Spindel nebst den Bthstielchen drüsig-flaumig; B. lanzettl.-lineal., spitz, 3nervig, ohne Ordnung gedrängt-gestellt; Tr. gedrungen od. auch dachig; $\mathrm{Zpfl}$. des K. längl.lanzettl., 3nervig, spitz, kürzer als die Kapsel; S. flach, mit einem kreisrunden Flügel umgeben, in der Mitte knotig-rauh. 24. Unkultiv. O. Jul.-Sept. Antirrhinum Linaria L. BI. gelb, Gaumen satter. Var. B. breiter, Tr. gedrungen und locker, Bthstielchen stark- u. 
schwach-driisenhaarig u. ganz kahl. Eine Variet. mit lockeren Tr. u. kleineren Bth.: L. italica Trev., L. Bauhini Gaud.

5. ANÁRRHINUM Desf. Lochschlund.

1. A. bellidifoli u m Desf. WB. längl.-vkteyf., stumpf, ungleichgesägt; StB. 5-7tlı., Zpfl. lineal., ganzrandig. 24. Sonnige Gebirgsabhänge längs der Mosel zw. Trier u. Bernkassel; im C. Genf. Jul. Aug. Bl. klein, violett, Sporn schlank aufstrebend.

6. ÉRINUS I. Leberbalsam.

1. E. alpinus L. Ebenstrauss einfach, später traubig; B. spatelig, vorne gekerbt. 2. Felsige O. der A.; Schwz. Mai. Jun. Bl. violett.

\section{VERÓNICA L. Ehrenpreis.}

I. Rotte. Ch a m a edrys. Tr. blattwinkelst. W. ausdauernd.

1. V. scutell ata L. B. sitzend, lanzettl.-lineal., spitz, entferntrückwärts-gezälınelt; Tr. blattwinkelst.; Bthstielchen nach dem Verblühen weitabstehend; Kapsel zsgedrückt, ausgerandet-2lappig, querbreiter. 2. Feuchte O., Gräben. Jun.-Sept. Bl. weissl., röthl.- oder blaugestreift. Var.: $\beta$. pubescens: St., Bthstiele od. auch K. u. Kapselrand zottig. V. parmularia Poit. I. Turpin.

2. V. Anagalli s L. B. sitzend, lanzettl. u. eyf., spitz, gesägt; Tr. blattwinkelst.; fruchttrag. Bthstielchen weitabstehend; Kapsel kreisrund, seicht-ausgerandet. 2. In stehenden Wassern u. Bächen. Mai-Aug. Bl. hellblau mit dunkleren Adern.

3. V. Beccabunga L. B. gestielt, elliptisch oder länglich, stumpf, gekerbt-gesägt; Tr. blattwinkelst.; fruchttrag. Bthstielchen abstehend; Kapsel rundl., gedunsen, seicht-ausgerandet. 2. Stehende Wasser, Quellen, Bäche. Mai-Aug. Bl. blau mit dunkleren Adern.

4. V. urticifolia L. fil. B. sitzend, eyf., geschärft-gesägt, die oberen lang-zugespitzt; Tr. blattwinkelst.; fruchttrag. Bthstielchen weit-abstehend; Kapsel fast kreisrund, quer-breiter, ausgerandet; St. zerstreut-behaart. 2. Haine der VorA. und Gbge längs der A. MaiJul. Bl. hellblau oder röthl. mit dunkleren Streifen.

5. V. Cham a drys L. B. fast sitzend, eyf., eingeschnitten-gekerbt-gesägt; Tr. blattwinkelst.; fruchttrag. Bthstielchen aufstrebend, länger als die 3eckig-vktherzf., gewimperte Kapsel; St. aufstrebend, zweireihig-behaart. 24. Trockene Wiesen, Waldränder, Zäune. Apr. Mai. Bl. schön hellblau, dunkler-gestreift.

6. V. montan a L. B. lang-gestielt, eyf., eingeschnitten-gekerbtgesägt; Tr. blattwinkelst.; fruchttrag. Bthstielchen etwas abstehend; Kapsel quer-breiter, an der Basis u. Spitze ausgerandet, flach, kahl, am Rande fein-gekerbt, gewimpert; St. an der Basis kriechend, zer- 
streut-behaart. 24. Schattige Laubwälder; zerstr. deh das Geb. Mai. Jun. Bl. weissl., bläul.-gestreift.

7. V. of ficinal is L. B. kurz-gestielt, vkteyf.-elliptisch od. länglich, gesägt; $T r$. blattwinkelst., reichbth., gedrungen; fruchttrag. Bthstielchen aufrecht, kürzer als die 3eckig-vktherzf., stumpf-ausgerandete Kapsel; St. rauhh., an der Basis kriechend, an der Spitze aufstrebend. 2. Triften, waldige Haiden. Jun. Jul. Bl. hellblau, dunkler-gestreift.

8. V. aphylla L. B. kurz-gestielt, vkteyf. - elliptisch, gekerbtgesägt u. ganzrandig; Tr. blattwinkelst., meist einzeln u. meist 4bth. ; fruchttrag. Bthstielchen aufrecht, länger als die vktherzf. Kapsel. 4. Steinige O. der A. u. in Schles. auf dem Gipfel der Babia Gora. Jun.-Aug. Bl. sattblau, dunkler-gestreift.

9. V. prostrata L. B. kurz-gestielt, lineal.-lanzettl., gekerbtgesägt $u$. an der Basis etwas eingeschnitten, od. fast ganzrandig; Tr. blattwinkelst.; Bthstielchen ungefähr so lang als die vkteyf., seicht ausgerandete Kapsel; $K$. 5sp.; die unfruchtb. St. gestreckt, die blïthentrag. aufstrebend. 24. Trockene Haiden, sonnige Hügel; zerstreut deh das Gebiet. Mai. Jun. Bl. bleichlblau od. röthl.

10. V. a ustriac a I. B. etwas gestielt, gekerbt, od. fiedersp.gesägt u. lanzettl. od. vielsp. u. im Umriss eyf.; Tr. blattwinkelst.; die oberen Bthstielchen so lang als die vkteyf., spitz-ausgerandete Kapsel; K. 5sp.; die St. sämmtl. aufrecht od. aus bogiger Basis aufstrebend. 24. Trockene, sonnige Hügel; östl. u. südl. Geb. Jun. Jul. Bl. schön blau. Var. $\alpha$. dentata: B. lanzettl. od. lanzettl.-lineal., meist entfernt-gekerbt-gesägt, manchmal ganzrandig. V. dentata Schmidt. - $\beta$. pinnatifida: B. lanzettl. od. lanzettl.-lineal., fiedersp.gezähnt. V. austriaca L. - $\gamma$. bipinnatifida: B. doppeltfiedersp., im Umrisse eyf. V. multifida $L$.

11. V. latifolia L. B. sitzend, aus fast herzf. Basis eyf. u. längl., eingeschnitten-gesägt od. fiedersp.; Tr. blattwinkelst.; Bthstielchen aufrecht, ungefähr so lang als die vkteyf., spitz-ausgerandete Kapsel; K. 5sp.; die St. sämmtl. aufrecht od. aus bogiger Basis aufstrebend. 24. Trockene Wiesen, steinige 0 ; zerstr. dch das Gebiet. Jun. Jul. V. Pseudochamaedrys Jacq. Bl. schön blall.

II. Rotte. Pseudo-Lys imachium. Tr. endst. u. oft mehrere seitenständige Nebentrauben. Röhre der Bl. walzlich, länger als ihr Querdchmesser; Saum fast 2lippig. W. mehrjährig.

12. V. spuria L. B. gegenst., zu 3 u. 4, längl.- lanzettl. od. lanzettl., spitz, einfach-od. fast doppelt-gesägt; die Trauben endist., fast rispig, verlängert, ziemlich locker; DeckB. lineal.-lanzettl., so lang od. kürzer als die Bthstielchen; Kapsel rundl., ausgerandet, gedunsen. 24. Grasige, buschige 0 ; ; bei Halle u. zw. Limburg $u$. Verviers. Jul, Aug. Bl, blau. Var. $\alpha$, Schraderi: B, lanzettl., kürzer 
zugespitzt; Sägezähne entfernt, gleich (doch nicht immer), Bthstielchen meist lang. V. spuria Schrad. V. amethystina Willd. - $\beta$. laxiflora: B. lanzettl., ${ }^{x}$ lang-zugespitzt; Sägezähne genähert. V. laxiflora Isej. $-\gamma$. foliosa: B. elliptisch-lanzettl., meist ungleich-gesägt. V. foliosa WK. - $\delta$. subcordata: B. aus ey- u. fast herzf. Basis verschmälert. V. glabra Ehrh.

13. V. $\mathrm{lon}$ g ifolia L. B. gegenst., zu 3 od. 4, aus ey-od. herzf. Basis lanzettl., zugespitzt, bis zur Spitze geschäıft-doppelt-gesägt; die Trauben endst., verlängert, ährenf., sehr gєdrungen; DeckB. lineal.-pfrieml., ungefähr so lang als der K.; Kapsel rundl., gedunsen, ausgerandet. 2. Feuchte Wiesen, Gräben, Ufer. Jul. Aug. Bl. blau. Var., wiewohl selten, mit breit-herzf. B. u. häufig dch alle Breiten bis zum Lanzett-linealen; u. a. vulgaris: B. an der Basis tief-herzf. - $\beta$. maritima: B. an der Basis abgerundet, (V. maritima L., wenn die B. ungleich schmal sind.) - $\gamma$. media: B. an der Basis keilf. in den Bstiel verlaufend. V. media Schrad. - $\delta$. glabra: B. ganz kahl.

14. V. spicat a L. B. gegenst., ey- od. lanzettf., gekerbt-gesägt, an der Spitze ganzrandig, die unteren stumpf; Tr. endst., meist einzeln, verlängert, ährig, sehr gedrungen; DeckB. lanzettl.-pfrieml., länger als die Bthstielchen; Kapsel rundl., ausgerandet, gedunsen. 24. Sonnige, trockene O.; zer'str. deh das Geb. Jul. Aug. Bl. blan, selten roth od. weiss. Var. $\alpha$. vulgaris: gekräuselt- od. driisig-flaumig, die unteren B. längl., an der Basis keilig. V. spicata der Aut. V. Clusii Schott., wenn die Haare drüsig sind; dieselbe mit kahlem, gewimpertem K.: V. squamosa Presl. - $\beta$. latifolia: gekräuselt- od. drïsig-flaumig, die unteren B. eyf. od. auch fast herzf., geschärftergesägt. V. hybrida L. V. australis Schrad. Am Harze, Hampe. $\gamma$. lancifolia: gekräuselt-flaumig, B. lanzettl., geschärfter-gesägt. V. alternifolia Lej. $t$. spa. V. media Lej. r'ev. - $\delta$. nitens: völlig kahl, B. nebst dem K. gewimpert. V. nitens Host. V. Sterubergiana Bernl. im Herb. Willdenow's. Krain, südl. Tyr. - $\varepsilon$. setulosa: feinbor'stigflaumig, v. geraden, drüsenlosen Haaren; K. kahr, gewimpert. V.

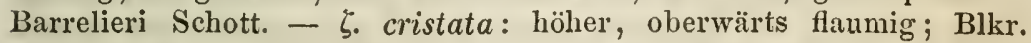
mit schmäleren, gewundenen Zpfln. V. cristata Bernh. V. orchidea Crantz.

III. Rotte. Veronicastrum. Die Tr. an dem St. u. den Aesten endst. Röhre der Bl. seln kurz. Die StB. gehen bei den meisten allmählig in DeckB. über.

* Samen flach, schildf.

15. V. bellidioides L. B. vkteyf., stumpf, etwas gekerbt, die unteren grösser, dicht-zsgestellt, fast rosettig, die stengelst. entfernt; Tr. endst., kurz, armbth., v. gegliederten Haaren zottig; Kapsel vkteyf., 
seicht-ausgerandet. 4. Grasige O. der A., VorA. u. Sudet. Jul. Aug. Bl. trübblau.

16. V. fruticulosa L. B. längl., stumpf, etwas gekerbt, die unteren kleiner; $\boldsymbol{T r}$. endst., armbth., drüsig-flaumig; Kapsel oval, seicht-ausgerandet. 24. Felsige, grasige O. der VorA. Jul. Aug. Bl. hellroth mit rothen Adern; Fruchtkn. zur Bthezeit drüsig-behaart.

17. V. s axatilis Jacq. B. längl. od. elliptisch, etwas gekerbt, die untersten kleiner; T'r. endst., armbth., v. gekräuselten, drüsenlosen Haaren flaumig; Kapsel eyf., oberwärts verschmälert, kaum ausgerandet. 24. Grasige, felsige $O$. der A., VorA. u. Voges. Jul. Ang. Bl. blau. Fruchtkn. driisenlos behaart.

18. V. al pin a L. B. elliptisch, gekerbt od. ganzrandig, die untersten kleiner, rundl.; Tr. endst., armbth., v. ahstehenden, gegliederten, drüsenlosen Haaren rauhh.; Kapsel längl.-vkteyf., ausgerandet. 4. Grasige O. der A., VorA. u. Sudet. Jul. Aug. Bl. klein, blau.

19. V. serpyllifolia L. B. eyf. od. längl., etwas gekerbt, die untersten kleiner, rundl., die oberen bliithenst. lanzettl., ganzrandig; St. $u$. Aeste reichbth., locker-traubig; Bthstielchen aufrecht, ungefähr so lang als der K.; Kapsel zsgedriickt, rundl.-vktherzf., quer-breiter, stumpf-ausgerandet, Gf. hervorgestreckt. 2. Triften, feuchte O. Apr.Oct. Bl. weiss, mit blauen Adern.

20. V. a cinifolia L. B. cyf., ctwas gekerbt, die blüthenst. lanzettl., ganzrandig; St. u. Aeste reichbth., locker-traubig; Bthstielchen abstehend, noch einmal so lang als der K.; Kapsel zsgedrückt, ziemlich flach, quer-breiter, halbzueisp., Lappen kreisrund; Gf. v. der Länge der Spalte. $\odot$. Aecker; Oberbad., Oberelsass, Thal der Rhone, Istr. Apr. Mai. Bl. blan.

21. V. arvensis L. B. herz-eyf, gekerbt, die oberen blithenst. lanzettl., ganzrandig; St. $u$. Aeste reichbth., locker-traubig-ährig; Bthstielchen aufrecht, kürzer als der K.; Kapsel zsgedrückt, vktherzf.2lappig, Gf, ein wenig länger als die Spalte. ○. Kultiv. O., Sandfelder. März-Oct. Bl. blau. Kapsel gewimpert.

22. V. peregrina L. Die unteren $B$. vkteyf-längl., schwach- u. wenig-gekerbt, die blüthenst. lineal.-längl., ganzrandig, alle in den Bstiel keilig verlaufend; St. u. Aeste reichbth., traubig-ährig; Bthstielchen aufrecht, kürzer als der K.; Kapsel zsgedrückt, vktherzf., Gf. sehr kurz, so lang als die Spalte. $\odot$. Kultiv. O.; um Hambg. Apr. Mai. Kapsel ganz kahl.

23. V. verna L. B.' fiederth., die untersten eyf., ungeth., die blüthenst. lanzettl.; St.u. Aeste reichbth., traubig-ährig; Bthstielchen aufrecht, kürzer als der K.; Kapsel zsgedrückt, vktherzf., Gf. v. der Länge der Spalte. $\odot$. Sonnige Raine, Sandfelder. Apr. Mai. Bl. blau. * Samen concav, beckenf.

24. V. triphyllos L. B. fingerig-geth., die untersten eyf., un- 
geth., die blüthenst. lanzettl.; St. u. Aeste reichbth., locker-traubig; Bthstielchen länger als der $K$., abstehend, aufstrebend; Kapsel rundl.vktherzf., gedunsen. $\odot$. Aecker, kultiv. O. März-Mai. Bl. sattblau.

25. V. praecox All. Die unteren B. herz-eyf., gekerbt, stumpf, die blüthenst. lanzettl.; St. u. Aeste reichbth., locker-traubig; Bthstielchen ungefähr so lang als der $\mathbf{K}$. od. länger, aufstrebend; Kapsel oval-vktherzf., gedunser. $\odot$. Aecker; zerstr. dch das Geb. MärzMai. Bl. blau.

IV. Rotte. Alsinoides. Die DeckB. fehlend. Die blüthenst. B. den unteren gleichgestaltet. Bthstiele blattwinkelst., einzeln, nach dem Verblühen zurückgekrümmt.

26. V. agrestis L. Bthstiele blattwinkelst, einzeln, ungefähr v. der Länge des B., nach dem Verblïhen zurückgekrümmt; B. ey•, fast herzf., gesägt-gekerb̂t; Kapsel zerstreut-drüsig-behaart, rundl., spitz-ausgerandet, Lappen gedunsen, an der Naht etwas zsgedrückt. ○. Aecker, kultiv. O. März-Mai. Bl. milchweiss, der obere Lappen blau od. röthl.

27. V. polita Fries. Bthstiele blattwinkelst., einzeln, ungefähr so lang als die B., nach dem Verblïhen zurückgekrïmmt; B. rundl.eyf., fast herzf., tief-gesägt-gekerbt; Kapsel v. abstehenden Haaren dicht-flaumig, spitz-ausgerandet, Lappen kugelig-convex. (. Aecker u. kultiv. O. März-Mai. V. didyma K. syn. ed. 1. Bl. blau.

28. V. o paca Fries. Bthstiele blattwinkelst., einzeln, ungefähr so lang als die B., nach dem Verbliihen zurückgelkrümmt; B. rundl.eyf., fast herzf., gesägt-gekerbt; Kapsel gekräuselt-flaumig, querbreiter, spitz-ausgerandet, Lappen gedunsen, am Rande zsgedrückt. gekielt. $\odot$. Aecker. März-Mai. Bl. blau.

29. V. Bux b a m i i Tenore. Bthsticle blattwinkelst., einzeln, nach dem Verblühen zurückgekrümmt, d. oberen länger als die B.; B. ey-, fast herzf., tief-gekerbt-gesägt; Kapsel quer-breiter, v. erhabenen Adern netzig, stumpf-ausgerandet, Lappen an der Naht zsgedrückt, spreitzend. $\odot$. Kult. O., Aecker; zerstr. deh das Geb. Apr. Mai. Bl. blau.

30. V. hederifolia L. Bthstiele blattwinkelst, einzeln, ungefähr so lang als die B., nach dem Verblühen zurückgekrümmt; B. herzf.-rundl., kerbig, fast 5lappig; Kapsel kugelig-4lappig; Zpfl. des $K$. her $z f$, nach dem Verblühen aufrecht. $\odot$. Aecker, kult. O. MärzMai. Bl. hellblau.

31. V. Cymbalaria Bodard. Bthstiele blattwinkelst., einzeln, nach dem Verblühen zurückgekrümmt, die oberen länger als die B.; B. fast halbkreisrund, etwas herzf., lappig-gekerbt; Kapsel kugelig4lappig, Zpfl. des $K$. elliptisch, nach dem Verblühen weit abstehend. $\odot$. Alte Feldmauern u. kult. O.; Triest. März. Apr. Bl. hellblau. 


\section{PAEDERÓtA L. Päderote.}

1. P. B o n arota L. B. gesägt, die oberen eyf., spitz; Oberlippe der Bl. ungeth.; Stbg. länger als die Bl. 2. Felsen der A.; südl. Kärnth., südl. Tyrol u. Kirschbaumeralpe. Jun. Jul. Bl. blau, selten roth.

2. P. Ageria L. B. gesägt, die oberen ey-lanzettf, lang-zugespitzt; Oberlippe der Bl. 2sp.; Stbg. kürzer als die Bl. 2. Felsen der A. u. VorA.; Krain. Jun. Jul. Bl. gelb.

9. WULFÉNIA Jacq. Wulfenie.

1. W. carinthiaca Jacq. 2. Fette Erde der Kühweger A. in Kärnth. Jul. Bl. blau.

\section{LINDÉRNIA L. Lindernie.}

1. L. pyxi dari a All. B. längl.-eyf., ganzrandig, 3nervig, sitzend; Bthstiele 1bth.; St. liegend. $\odot$. Feuchte O., Ufer; sehr zerstr. deh das Geb. Jul. Ang. Bl. weissl., Saum röthl.

\section{LIMOSÉLLA L. Sumpfkraut.}

1. L. aquatica L. $\odot$. Feuchte O., Ufer. Jul. Aug. Röhre der Bl. griin, Saum fleischroth.

\section{- LXXXIV. Ordng. OROBANCHEEN. Juss.}

\section{OROBÁNCHE L. Sommerwurz.}

1. Rotte. Osproleon. Wallr. K. 2blätterig, mit einem einzigen DeckB. gestiitzt. Blättchen des K. zuweilen vorne zsgewachsen. - Um die Nerven des K. beobachten zu können, muss man ein Blättchen desselben gegen $d$. Licht halten; zeigt dasselbe nun ausser einem od. 2 stärkeren Nerven noch einige hindurchziehende zartere, so nenne ich dasselbe mehrnervig.

1. O. c rue nta Bertolini. Blättchen des K. mehrnervig, ziemlich gleichförmig-2sp., länger als die Röhre der Bl.; Bl. glockig, vorne an der Basis kropfig-bauchig, auf dem Rücken gekrümmt, Lippen ungleich-gezähnelt, drüsig-fransig, die obere helmartig, ungeth. od. etwas ausgerandet, mit abstehenden Seiten, Zpfl. der Unterlippe fast gleich; Stbg. in die Basis der Bl. eingefügt, dicht-behaart, oberwärts nebst dem Gf. drüsenhaarig; Narbenscheibe sammetartig, erhabenberandet. 24. Grasige O. u. Wiesen, auf Lotus corniculatus u. Hippocrepis comosa schmarotzend; v. Regensbg. an im südl. Geb. Jun. Jul. Bl. inwendig blutroth. Narbe gelb, mit braun-purpurnem Rande.

2. O. Ra pum Thuill. Blättchen des $K$. mehrnervig, meist ziemlich gleichf.-2sp. od. ungeth., ungefähr so lang als die Röhre der Bl.; Bl. glockig, vorne an der Basis kropfig-bauchig, auf dem Rücken 
gekrïmmt, Lippen $\pi$ cllig, schwach-gezähnelt (nicht gefranst), Oberlippe helmartig, ausgerandet, mit abstehenden Lappen, der mittlere Zpfl. der Unterlippe noch einmal so gross als die seitenst.; Stbg. in der Basis der Bl. eingefügt, unterıärts ganz kahl, an der Spitze nebst dem Gf. drüsenhaarig; Narbenscheibe sammetig, ohne hervortretenden Rand. 2. Unkultiv. O., auf Sarothamnus schmarotz.; Westph., Unterrhein, Schwarzw. Mai. Jun. Stbk. nach dem Verblülıen weiss. Bl. hellröthl.-braun od. fleischfarben.

3. O. procera Koch. Blättchen des K. mehrnervig, breit-eyf., zieml. gleichf.-2sp. od. ungeth., küirzer als die Röhre der Bl.; Bl. glockig, vorne an der Basis kropfig-bauchig, auf dem Rücken gekrümmt, Lippen ungleich-gezähnelt, am Rande ein wenig drüsig, Oberlippe ausgerandet mit gerade vorstehenden Lappen, der mittlere Zpfl. der Unterlippe ein wenig grösser; Stbg. in der Basis der Bl. eingefügt, kahl, an ihrem Ursprunge spärlich-behaart, an der Spitze nebst dem Gf. etwas driisig. 21. Aecker bei Mannheim, auf Cirsiun arvense schmarotzend. Jun.

4. O. pruinos a Lapeyr. Blättchen des K. 5nervig, 2sp., Zpfl. ziemlich gleich, schmal, pfriemlich, v. der Länge der Röhre der BI.; Bl. glockig, auf dem Rëlcken etwas gekrümmt, Lippen ausgebreitet, wellig-faltig $u$. kraus, stumpf-gezähnelt, nicht gewimpert, farbigaderig, Oberlippe 2lappig, $Z \mathbf{H}$ H. der Unterlippe abgerundet, der unittlere noch einmal so gross; sthg. gleich über der Basis der Bl. eingefügt, unterwärts zottig, oberwärts nebst dem Gf. etwas driisig. (). Auf Vicia Faba schnarotzend, bei Fiume, aucl nach Wimmer in schles. Jun.? Lippen der Bl. gross, faltig-kraus, zierlich mit blaten Adern bemalt. Narbe violett.

5. O. S c a biosa e Koch. Biättchen des K. mehrnervig, eyf., in eine pfrieml. Spitze verschmälert, kürzer als die Röhre der Bl. od. 2sp. mit gleichlanfenden $\mathrm{Z}_{\mathrm{p}} \mathrm{fln}$.; Bl. glockig, auf dem Rücken sanft gekrümmt, auswendig, so wie die Oberlippe invendig haarig-rauh vor zerstreuten kurzen Drüsenhaaren, die auf einem violetten od. schwarzen Knötchen sitzen, Lippen ungleich, spitz-gezälnt, an Rande gekräuselt, Oberlippe an der Spitze ein wenig aufwärts-gebogen, 2lappig, Lappen ausgebreitet, Zpfl. der Unterlippe gleich; Stbg. nahe an der Basis der Bl. eingefïgt, unterwärts zerstreut-behaart, an der Spitze nebst dem Gf. fast kahl. 24. ATriften, auf Scabiosa columbaria und Carduus defloratus schmarotzend. Jun. Bl. hell ochergelb, am Rande rostfarb., der Rïcken violett; Narbe dunkel-purp. od. schwarz.

6. O. pallidiflora Wimm. u. Grab. Blättchen des K. mehrnervig, breit-eyf., plötzlich in eine pfrieml. Spitze zsgezogen, so lang als die Röhre der Bl.; Bl. glockig, auf der Mitte des Rückens ziemlich gerade, oben vorwärts-gekrïmmt, auswendig so wie die Oberlippe inwendig v. Haaren, die auf einem ochergelben Knötchen sitzen, drüsig-behaart, Lippen ungleich-spitz-gezähnelt, am Rande gekräuselt, 
Oberlippe an der Spitze ein wenig aufwärts gekrümmt, 2lappig, mit ausgebreiteten Lappen, $Z_{p} f$. der Unterlippe fast gleich; Sthg. nale über der Basis der Bl. eingefïgt, unterwärts zerstreut-behaart, oberwärts kahl; Gf. oben drïsig-behaart. 24. Auf Cirsium arvense schmarotzend; Schles. u. bei Frankf. an der O. Jun. Bl. gelblich-weiss mit röthl. Nerven. Narbe kastanienroth.

7. O. Epithy mu m DC. Blättchen des $K$. melrnervig, lanzettl., pfrieml.-zugespitzt, länger als die Röhre der Bl., ungeth. od. dch einen spreitzenden Zahn 2sp.; Bl. glockig, auf dem Rücken sanft-gebogen, auswendig, so wie die Oberlippe inwendig v. Haaren, die auf einem sehr feinen Knötchen sitzen, drüsig-behaart, Lippen ungleich, spitz-gezähnt, am Rande gekräuselt, Oberlippe an der Spitze ein wenig aufwärts gebogen, 2lappig, die Lappen ausgebreitet, der mittlere $\mathrm{Z} p f$. der Unterlippe noch einmal so lang als die seitenst.; Stbg. gleich über der Basis der Bl. eingefügt, unterwärts zerstreut-behaart, an der Spitze nebst dem Gf. drüsig-behaart; Narbenscheibe fein-sammetig, ohne hervortretenden Rand. 2. Haiden, unkultiv. Felder, auf Thym. Serpyll.; zerstr. deh das siidl. u. mittl. Geb. Jun. Jul. Bl. gelbl., purpurn iiberlaufen, Haare rostbraun. Narbe dunkelroth.

8. O. Galii Duby. Blättchen des $K$. mehmervig, ziemlich gleichf.2 sp., halb so lang als die Röhre der B., vorne zsstossend od. zsgewachsen; Bl. aus allmählig erweiterter Basis glockig, auf dem Rücken gekrümmt, Lippen ungleich-gezähnelt, Oberlippe helmartig, mit vorwärts gerichteten, (nicht abstehenden) Seiten, Zpfl. der Unterlippe eyf., fast gleich, vorwärtsgerichtet, nicht halb so lang als die Röhre; Stbg. oberhalb der Basis der Bl. eingefügt, dicht-hehaart, oberwärts nebst dem Gf. drüsig-behaart; Narbenscheibe fein-sammetig, olne hervortretenden Rand. 24. Unkultiv. Hiigel, Felder; auf Galium. Jun. Jul. O. caryophyllacea Sm. Narbe dunkel-purpurn. Bl. weissl. mit röthl. oder bläul. Anfluge.

9. O. rubens Wallroth. Blättchen des K. mehrnervig, breit-eyf., pfriemlich-zugespitzt, hinten u. vorne mit einem Zahne versehen od. ungleich-2sp., ungefähr so lang als die halbe Röhre der Bl., vorne zsstossend od. zsgewachsen; Bl. aus gekrümmter Basis röhrig-glockig, auf dem Rücken gerade, an der Spitze helmartig-abschüssig, Lippen ungleich-gezähnt, die obere 2lappig, mit abstehenden Lappen, Zpfl. der Unterlippe eyf., ziemlich gleich, die seitenst. abstehend; Stbg. in der Biegung der Bl. eingefïgt, v. der Basis bis zur Mitte dichtbehaart; Narbenscheibe fein-sammetig, ohne hervortretenden Rand. 4. Aecker, Triften, auf Medicago schmarotzend. Mai. Jun. Narbe wachsgelb. Bl. gelbl. od. bräunl.

10. O. Teucrii F. W. Schultz. Blättchen des $K$. mehrrervig, breit-eyf., fast gleichf.-2sp., Zpfl. lanzettl., ungefälır halb so lang als die Röhre der Bl., vorne zsstossend od. zsgewachsen; Bl. glockigröhrig, auf dem Rücken gerade, an $d$. Spitze helmartig-abschüssig, 
Lippen ungleich-gezähnelt, die obere ganz, am Rande abstehend, die untere 3lappig, hinabgerichtet, Zpfl. abgerundet-stumpf; Stbg. über der Basis der Bl. eingefügt, von der Basis bis zur Mitte behaart; Gf. an der Spitze driisig-l haarig; Narbe (nach Schultz) sammetig-warzig, ohne hervortretenden Rand. 24. Unkult. O., auf Teucrium Chamaedrys, T. montanum u. Thymus serpyllum schmarotzend; Salzbg., Zweibrücken, Dorlisheim im Elsass, Bl. nach Sch., an der Basis gelbl., iibrigens braunroth, mehr od. weniger in das Violette od. Pomeranzenfarb. ziehend. Gf. weiss, zuletzt violett; Narbe bräunl.liirschroth.

11. O. stigmatodes Wimmer. Blättchen des $K$. mehrnervig, eyf., fast gleichf.-2sp., Zpfl. lanzethl., etwas kiirzer als die Röhre der Bl.; Bl. glockig-röhrig, auf dem Rücken bogenf., Lippen ausgefressengezähnelt, die obere undeutlich-2lappig, mit geradehervorgcstreckten Lappen, die untere etwas abstehend, dreilappig, Lappen längl.-rund, fast gleich; Stbg. unter der Mitte der Rölure eingefïgt, von der Basis bis zur Mitte zottig-bchaart, oben schwach-drüsig; Gf. an der Spitze drüsig-behaart. 24. Auf Centaurea Seabiosa in Schles. u. Stmk. Jul. Aug. Bl. gelbl., vorne gelb-braun, mit schwachröthl. Schimmer. Narbe erst wachsgelb, dann goldgelb. Die abgeblüheten Stbk. weiss. Ob diese O. elatior Sutton?

12. O. loricata Reichenb. Blättchen des K. 3-5nervig, 2 th., so lang als die Röhre der Bl.; Bl. röhrig-glockig, auf dem Rücken gerade, an der Spitze vorwärts-gekrümmt, Lippen stumpf-gezähnelt, die obere 2lappig, mit abstehenden Lappen; Stbg. unter der Mitte der Rölre eingefïgt, kahll, an der Basis spärlich-behaart; Narbenscheibe.... 2. Gebirgige, unkult. O., auf Artemisia campestris schmarotzend; Westerberge bei Aschersleben u. bei Frankenhausen in Thüring., Wallis.

13. O. Picridis F. W. Schultz. Blättchen des K. 1-2nervig, ungetlı. od. vorne mit einem Zahne versehen, länger als die Röhre der Bl.; $\boldsymbol{B}$ l. röhrig-glockig, auf dem Riicken gerade, an der Spitze vorwärts-gekrümmt, Lippen stumpf-gezähnelt, die obere ungeth., am Seitenrande abstehend; Stbg. fast in der Mitte der Röhre eingefügt, von der Basis bis über die Mitte dicht-bchaart, oberwärts v. klcinen Wärzchen etwas rauh; Narbenscheibe fast glatt, mit sehr kleinen $u$. selır stumpfen Körnchen dicht-bedeckt. ○. Gebirgige O., auf Picris hieracioides schmarotzend. Jun. Rarbe schmutzig-violett.

14. O. flava Martius. Blättchen des K. 1nervig od. schwach3nervig, ungeth. od. vorne mit einem Zahn versehen, halb so lang als die Röhre der Bl.; Bl. röhrig-glockig, auf dem Rücken gekrümmt, Lippen gezähnelt, die obere 2lappig, mit zurückgeschlagenen, rückwärts anliegenden Lappen; Stbg. fast in der Mitte der Röhre eingefügt, vou der Basis bis iiber die Mitte dicht-behaart; Gf. kahl; Narbenscheibe warzig-narbig. 24. Fenchte Triften, auf Tussilago ni- 
vea; Isar-Auen bei Münch. Jul. Lappen der Oberlippe wie bei Antirrhinum, zuriickgeschlagen und hinten einander stossend. Die ganze Pf. wachs- oder hellgelb; Narbe wachsgelb.

15. O. I ucorum A. Braun. Blättchen des $K$. 2nervig, ungleich2sp., so lang als die Röhre der Bl.; Bl. röhrig-glockig, auf dem Rücken gekrümmt, Lippen fein-drüsig-gewimpert, schwach-gezähnelt, die obere 2lappig, mit abstehenden Lappen; Stbg. nahe an der Basis der Bl. eingefügt, von der Basis bis über die Mitte dicht-behaart; Gf. kahl; Narbenscheibe glatt, sammetig. 24. Auf Berberis u. Rubus schmarotzend; Oberbayern, Siidtyrol. Jun. Jul. Narbe hellgelb u. satter bis zum Braunrothen.

16. O. Salviae F. W. Schultz. Blättchen des K. 1nervig, ungleich-2sp., länger als die Röhre der Bl.; Bl.röhrig-glockig, auf dem Rücken gekrümmt, Lippen gezähnelt, etwas gewimpert, die obere 2lappig, mit geradevorgestreckten Lappen; Stbg. iiber der Basis der Bl. eingefügt, $\mathrm{v}$. der Basis bis über die Mitte dicht-behaart, oberwärts mit drüsentrag. Haaren spärlich-bestreut; Narbenscheibe sammetig. 24. VorA., auf Salvia glutinosa; Oberbayern, Salzb. Jun. Jul. Narbe dunkel-wachsgelb.

17. O. minor Sutton. Blättchen des $K$. melrnervig, aus eyf. Basis plötzlich schmal-pfrieml. od. in 2 pfrieml. Zpfl. gespalten, so lang od. länger als die Röhre der $\mathrm{Bl}$.; Bl. röhrig, sanft gekrümmt, Lippen stumpf-gezähnelt, aderig, wellig, die obere 2lappig, vorwärts gerichtet, Lappen der Unterlippe rundlich, fast gleich; Stbg. unter der Mitte der Röhre eingefügt, kahl, unterwärts mit zerstreuten Haaren besetzt. $\odot$. Auf Trifolium pratense schmarotzend; Bonn, Waadt, Wallis, Fiume. Jun. Jul.? Narbe purpurn od. lila.

18. O. am ethystea Thuill. Blätchen des K. 3-6nervig, aus eyf. Basis plötzlich schmal-pfrieml.-verschmälert, od. 2sp., $\mathrm{Zpfl}$. schmal, pfrieml., so lang als die Bl.; Bl. röhrig, an der Basis plötzlich in ein Knie gebogen u. vorwärts-gekrümmt, sodann ziemlich gerade, Lippen ungleich-spitz-gezähnelt, wellig-kraus, ästig-aderig, die obere helmurtig, gerade-vorgestreckt, ausgerandet od. beinahe 2lappig, die seitenst. Lappen der Unterlippe fast 2 sp., der mittlere noch einmal so gross, 2-3lappig; Stbg. in der Biegung der Bl. eingefügt, kahl, unterwärts zerstreut-behaart. $\odot$. Auf Eryngium campestrc schmarotzend; Bonn und Coblenz. Jun.Jul. O. Eryngii Dub. Narbe braun od. rothbraun. Bl. weissl. od. lila mit purp. Adern.

19. O. Buekiana Koch. Blättchen des $K$. mehrnervig; eyf., 2sp., Zpfl. lanzettl., so lang als die halbe Röhre der Bl.; Bl. glockig-röhrig, über der Basis plötzlich vorwärts-gekrümmt, über dem Rücken gebogen, Lippen ungleich-gezähnelt, die obere abgerundet, ganz-od. schwach-ausgerandet, hervorgestreckt, etwas helmartig, an den Seiten ein wenig zurückgebogen, die untere herabgebogen, die Lappen rundl., ganz, der mittlere ein wenig grösser; Stbf. unter der Mitte der 
Röhre eingefügt, an der Basis mit. Härchen spärlich bestreut; Gf. kahl, mit sehr wenig Drüsenhärchen. 2. Unkult. O., auf Medicago sativa schmarotzend; in der Neumark bei Frankf. a. d. O., auf dem Berge Lessow vom Apoth. Buek entdeckt. Jun. O. elatior Dietrich Preuss. Flor. t. 148, das Synon. O. rubens Wallr. und M. u. K. ausgeschlossen, u. auch niclit $O$. elatior Sutton, welche spätblïhend ist, u. im Jul. u. Aug. ihre Bth. entfaltet. Dic Bl. bleichgelb, mit einem röthl. Anfluge. Gf. nach oben purpurn, Narbe gelb.

20. O. frag rans Koch. Blättchen des K. ungeth. oder ungleich2sp.; Bl. an der Basis röhrig, nach oben allmählig erweitert, auf dem Rücken gekrümmt; Stbg. in der Mitte der Röhre cingefügt, aus bogig-abstehender Basis aufstrebend, unterwärts behaart, oberwärts kahl; Säckchen der Stbk. kurz- u. sehr fein-stachelspitzig. 24.? Jun.? Unteröstr. v. Dr. Schiede gesammelt. Die Pflanze, auch getrocknet, duftend.

21. O. caerulescens Stephan. Blättchen des K. ungeth. od. 2sp., länger als die Röhre der Bl.; Bl. röhrig, Röhre gekrümmt, unterwärts eyf., über dem Fruchtkn. cingeschnürt, Zpfl. der Unterlippe concav; Stbg. über der Mitte der Röhre eingefiigt, an der Basis spärlich behaart. - Mai. Jun. Auf Artemisia campestris schmarotzend; bei Regensburg, Frankf. a. d. O. u. Danzig. Bl. blau, gehören zu den kleineren.

II. Rotte. Trionych on Wallr. K. 1 blätterig, ringsum geschlossen, mit $3 \mathrm{DeckB}$. gestützt.

22. O. ca erulea Vill. K. 1blätterig, 5zähnig, Zähne lanzettl., spitz; Bl. röhrig, vorwärts-gekruimmt, Röhre in der Nitte verengert, Zpfl. der Lippen spitz, flach; Stbk. kahl od. an der Basis ein wenig flaumig; St. einfach. 2. Auf Achillea Millefolium schmarotzend; zerstr. dch das Geb. Jun. Jul. O. purpurea Jacq. Bl. amethystfarben.

23. O. a ren aria Borkhansen. K. 1blätterig, 5zähnig, Zähne prieml.; Bl. röhrig, fast gerade, Röhre in der Mitte verengert, Schlund etwas aufgeblasen, Zpfl. der Lippen stumpf, am Rande zu. rïckgebogen, Nath der Stbk. wollig-behaart; St. einfach. 2. Auf Artemisia campestris schmarotzend; zerstr. dch das Geb. Jul. Aug. Bl. amethystfurben.

24. O. ramosa L. K.1blätterig, 4zähnig, Zähne eyf.-3eckig, pfrieml.-zugespitzt; Stbk. kahl; St. ästig. - - Auf Hanf, Tabak u. Nachtschatten; zerstr. deh das Geb. Jun.-Aug. Bth. halb oder ein Drittel so gross als an den beiden vorhergeh., weiss od. bläul.

2. LATHRAÉA L. Schuppenwurz.

1. L. S qu a maria L. St. einfach; Bth. hängend, einseitswendig; Unterlippe der Bl. 3sp. 2. Laubwälder, schattige O. März. Apr. Das ganze Gewächs weiss od. röthl. überlaufen. 


\section{Ordng. RHINANTHACEEN. DC.}

1. TOZZLA L. Tozzie.

1. T. alpina L. 24. Schattige, nasse Felsen der A. u. VorA., u. Sudet. Jul. Aug. Bl. gelb, Unterlippe blutroth-punktirt.

2. MELÁMPYRUM L. Wachtelweizen.

1. M. cristatum L. Aehren 4kantig, dicht-dachig; DeckB. herzf., aufwärts zsgeschlagen, zurückgekrümmt, kämmig-gezähnt. $\odot$. Wälder $u$. trockene Wiesen. Jun. Jul. Bl. weisslich, vorne blassgelb mit dottergelber, oder purpurn mit inwendig gelber Unterlippe.

2. M. arvense L. Aehren locker, gleich; DeckB. eyf., lanzettl.zugespitzt, pfrieml.-gezähnt, unterseits zweireihig-punltirt; $K$. flaumig-rauh, fast so lang als die Röhre der Bl., Zähne aus eyf. Basis verlängert, borstlich-zugespitzt. $\odot$. Aecker. Jun. Jul. Bl. purpurn, in der Mitte mit weissem Ringe, ein gelber Flecken an der Basis der Unterlippe; DeckB. purpurn.

3. M. barbatum W. K. Aehren locker, gleich; DeckB. eyf., lanzettl.-zugespitzt, pfrieml.-gezähnt, unterseits nicht punktirt; $K$. rauhh., 3mal kürzer als die Röhre der Bl., Zähne eyf., zugespitzt. ○. Unter der Saat; Littor., Oestr., Mähr. Mai. Jun. DeckB. gelbgrün, selten purpurn. Bl. gelb.

4. M. nemorosum L. Aehren Iocker, einseitswendig; die oberen DeckB. tief-herzf., gezähnt; K. rauhh., ungefähr halb so lang als die Bl., Zähne lanzettl.-pfrieml., abstehend. (. Wälder, Haine; nicht überall. Jul. Aug. DeckB. azurblat. Bl. goldgelb, Röhre rostbraun.

5. M. pratense L. Aehren locker, einseitswendig; DeckB. lanzettl, die, oberen an der Basis beiderseits 1-2zähnig; $K$. kahl, $3 \mathrm{mal}$ kürzer als die $\mathrm{Bl.;}$; Bth. wagerecht-abstehend. $\odot$. Wälder, Haiden. Jun. Jul. Bl. gelb, od. weiss u. oberwärts gelb.

6. M. sylvaticum L. Aehren locker, einseitswendig; DeckB. lanzettl.-ganzrandig; $K$. kahl, so lang als die Bl.; Bth. aufrecht. $\odot$. Wälder u. Wiesen der VorA. ul. höheren Gbge. Jul. Aug. Bl. goldgelb.

3. PEDICULARIS L. Läusekraut.

I. Rotte. Oberlippe der Bl. in einen, an der Spitze abgeschnittenen, u. daselbst oft kleingekerbten Schnabel zsgezogen; die unteren Ecken der Schnabelspitze nicht in einen deutlichen Zahn vorgezogen.

1. P. Jacquini Koch. Oberlippe der Bl. plötzlich in einen verlängerten, lineal., an der Spitze abgeschnittenen u. ausgerandeten Schnabel verschmälert; die längeren Stbf. an der Spitze zerstreutbehaart; $K$. längl.-glockig, kahl od. auf den Nerven u. am Rande flaumig, $\mathrm{Zpf}$. oberwärts blattig, ungleich-gekerbt, an der Spitze zu- 
rückgekrümmt, 3 mal kürzer als die Röhre des K.; B. tief-doppeltfiedersp., Fiederchen gezähnt; St. aufstrebend. 24. Feuchte O. der A.; Bayern, Tyrol, Oestr. Jul. Aug. P. rostrata Jacq. Bl. rosenroth. Haarlinie des St. aus sehr kurzem Flaume.

2. P. rostrata L. Oberlippe der Bl. plötzlich in einen verlängerten, lineal., an der Spitze abgeschnittenen nud ausgerandeten Schnabel verschmälert; die längeren Stbf. über der Nitte bärtig; $K$. rölurig, nach der Basis verschmälert, überall kurz-zottig, Zpfl. oberwärts blattig, ungleich-gekerbt, an der Basis hakig, 3mal kïrzer als die Röhre des Kr.; B. tief-fiedersp., Fiederchen doppelt-gezähnt; St. gestreckt, aufstrebend. 24. Feuchte O. der A.; Schweiz, Tyrol. Jul. Aug. Bl. rosenroth. Haarlinie des St. zottig.

3. P. asplenifolia Floerke. Oberlippe der Bl. plötzlich in einen verlängerten, lineal., an der Spitze abgeschnittenen und ausgerandeten Schnabel verschmälert, Stbf. kahl; K. längl.-glockig, wollig-zottig, Zpfl. oberwärts blattig, gekerbt, an d. Spitze hakig, $3 \mathrm{mal}$ kiirzer als die Röhre des K.; B. tief-fiedersp., Blättchen doppelt-gezähnt; St. aufrecht. 2. Feuchte O. der A., v. Tyr. bis Stmk. Jul. Aug. Bl. rosenroth.

4. P. Portenschlagi i Sauter. Oberlippe der Bl. in einen kurzen, kegelf., an der Spitze abgeschnittenen Schnabel allmählig verlaufend; die längeren Stbf. über der Nitte bärtig; K. röhrig-glockig, kahl, auf den Nerven 1 . am Rande flaumig, Zpfl. oberwärts 'ungleich-gekerbt, an der Spitze zurückgekrümmt, kürzer als die KRöhre; B. fiedersp.; Fieder doppeltgezähnt; St. aufrecht, dicht-beblättert. 2. Feuchte O.d. höchsten GranitA.; Oberstmk. Jun. Jul. Bl. rosenroth.

5. P. fasciculata Bellardi. Oberlippe der Bl. in einen kurzen, kegelf., an der Spilze abgeschnittenen Schnabel allmählig verlaufend; die längeren Stbf. iber d. Mitte bärtig-zottig; K. glockig, bis iiber d. Mitte $5 \mathrm{sp}$., dicht-flaumig, $\mathrm{Z} p f$. blattig, fiedersp. u. gezälınt, gerade; die oberen DeckB. $3 \mathrm{sp} ., \mathrm{Zpfl}$. fiedersp.; B. gefiedert, Fieder fiedersp., Läppchen gezälint. 24. A. u. VorA.; Berg Fedai in Primiero 'u. ïber dem Wirthshause Braccon in Tessino, südl. Tyrol, Monte Generoso im C. Tessin. Jul. Aug. P. gyroflexa Gaud., nicht Vill. u. nicht DC. Bl. purp. Var. Bl. weiss, rosenroth ïberlaufen.

6. P. $\mathrm{t} u$ berosa L. Oberlippe der Bl. plötzlich in einen verlängerten, lincal., all der Spitze abgeschnittenen $u$. ausgerandeten Schnabel verschmälert; die längeren Stbf. oberwärts bärtig-zottig; $K$. glockig, bis zur Mitte 5sp., $\mathrm{Z}_{p}$ fl. blattig, eingeschnitten-gezähnt, gerade; die oberen DeckB. 3sp., Zpfl. eingeschnitten-gezähnt; B. tiefdoppelt-fiedersp., Fiederchen gezähnt. 2. Feuchte 0 . d. höheren A.; Schwz., Tyr., Salzb., Kärnth. Jul. Aug. P. ascendens Hopp. u. Sternbg. Bl. gelb. Var. selten mit zottiger Röhre des K.

7. P. Barrelierii Reichenb. Oberlippe der Bl. plötzlich in einen verlängerten, lineal., an der Spitze abgeschnittenen u. ausge- 
randeten Schnabel verschmälert; die längeren Stbf. oberwärts bärtigzottig; K. schmal-glockig, bis zul Mitte 5sp., kahl, Zpfl. lanzettl., zugespitzt, ganzrandig, gerade, am Ranje flaumig; die oberen DeckB. fiederig-3-5sp., die seitenst. $Z \mathrm{p}$ fl. ganz ${ }^{2}$ ndig; B. tief-doppelt-fiedersp., Fiederchen gezähnt. 24. Berner A. Jul. Aug. P. adscendens Gaud., nicht Schleich. Aehre viel länger u. unterwärts lockerer als bei der vorherg. Bl. gelb.

8. P. incarnat a Jacq. Oberlippe der Bl. in einen verlängerten, lineal., an der Spitze abgeschnittenen u. ausgerandeten Schnabel verschmälert; Stbf. kahl; K. röhrig-glockig, wollig, 5sp., $Z_{p} f$. lanzettl.-pfrieml., spitz, ganzrandig, gerade, die längeren ungefähr so lang als die KRöhre; die oberen DeckB. 3sp., ganzrandig; B. doppelt-fiedersp. u. kleingesägt. 24. Feuchte O. d. A. Jul. Aug. Bl. rosenroth, Oberlippe dunkler, Aehre sehr locker.

9. P. atrorubens Schleicher. Oberlippe der Bl. kurz-geschnäbelt, Schnabel abgeschnitten, meist 3zähnig; die längeren Stbf. oberwärts behaart; K. glockig, wollig, Zpfl. breitlanzettl., zugespitzt, kleingesägt; $d$. oberen Deck $B$. lanzettl.-lineal., ungeth., an der Spitze kleingesägt; B. tief-fiedersp., Fieder eingeschnitten-gesägt, Sägezähne kleingesägt. 2. Höchst. A.; auf dem grossen Bernhard, nicht weit v. d. Kloster. Jul. Aug. Aehre gedrungen, Bl. satt-purpurn.

II. Rotte. Oberlippe der BI. kurz-geschnäbelt; Schnabel vorne abgeschnitten $u$. beiderseits an den Ecken in einen spitzen oder pfriemlichen $Z$ ahn vorgezogen.

10. P. sylvatica L. Oberlippe der Bl. fast sichelf., sehr kurzgeschnäbelt, abgeschnitten, die Ecken in einen 4eckig-pfrieml. Zahn vorgezogen; K. 5zälnnig, Zähne oberwärts blattig u. gezähnt; B. gefiedert, Fieder oval, fast fiedersp.-kleinlappig, Läppchen 2-3zähnig; der Ifauptst. aufrecht, v. der Basis an blüthentrag., die Nebenst. gestreckt. 2 od. $\odot$. Feuchte Wiesen, Haiden. MIai-Jul. Bl. rosenroth.

11. P. palustris L. Oberlippe der Bl. fast sichelf., sehr kurzgeschnäbelt, abgeschnitten, die Ecken in ein pfrieml. Zähnchen vorgezogen; K. 2lappig, Lappen eingeschnitten-gezähnt, kraus; B. gefiedert, Fieder länglich, fast fiedersp., kleinlappig, Läppchen gekerbt; der St. aufrecht, v. der Basis an ästig. 7 od. $\odot$. Sümpfe. MaiJul. Bl. rosenroth.

12. P. sudetica Willd. Oberlippe der Bl. sichelf., sehr kurzgeschnäbelt, abgeschnitten, die Ecken in einen 3cckig-pfrieml. Zahn vorgezogen; $K$. $5 s p$., auf den Kanten zottig, Zälıne lanzettl., ungeth., kleingesägt; B. fiedersp., mit verbreiterter Mittelrippe, Fieder lanzettl., kleingelappt-gezähnt, Zähne kleingesägt; der St. einfach. Y. Nasse O. d. Sudet. Juu. Jul. Bl. fleischroth.

13. P. Friederici $A$ ugusti Tommasini. Oberlippe der Bl. 
sichelf., kurz-geschnäbelt, abgeschnitten; $d$. Ecken in einen 3eckigpfrieml. Zahn vorgezogen; $K$. cyf., 5zähnig, v. langen Haaren wollig, Zälnne lanzettl., spitz, 2-3mal länger als breit; B. gefiedert, Fieder längl., fiedersp., Zpfl. ichelspitzig-gesägt. 2. Auf Bergwiesen des Slavnik im Littorale auf d. Grenze zw. Krain u. Istrien. Mai. Bl. gelbl.-weiss. - Die als im südl. Tyrol vorkommend angegebene $P$. comosa wächst nach Facchini auf d. Grenze im Veronesischen, könnte aher im siidl. Tyrol noch gefunden werden, deswegen hier die Diagnose: P. comos a L. Oberlippe der Bl. sichelf., kurzgeschnäbelt, abgeschnitten, die Ecken in einen 3eckig-pfrieml. Zahn vorgezogen; K. 5zähnig, auf den Kanten flaumig, Zähne sehr kurz, euf., stumpf, breiter als lang; B. gefiedert, Fieder länglich, fiedersp., $Z$ pfl. stachelspitzig-gesägt. 24. Jun.-Aug. Bl. gelblich-weiss od. citrongelb.

III. Rotte. Oberlippe der Bl. gerade od. sichelf., an der meist nicht breiteren Spitze helmartig-stumpf, aber nicht geschnäbelt $u$. nicht mit Zähnen versehen.

14. P. foliosa L. Oberlippe der Bl. fast gerade, stumpf, zahnlos, rauhh.; K. glockig, ungeth., auf d. Kanten zottig, 5zähnig, Zähre viel kürzer als die Röhre, aus 3eckiger Basis zugespitzt, der hintere Zahn länger; Stbf. sämmtl. an der Spitze dieht-bärtig; B. nebst den unteren DeckB. gefiedert, Fieder tief-fiedersp., Fiederchen lineal.lanzettl., eingeschnitten-stachelspitzig-gesägt; die oberen DeckB. lanzettl., fiedersp.-gesägt. 2. Kiesige O. der VorA. u. Voges. Jul. Aug. Bl. schwefelgelb.

15. P. Ha equetii Graf. Oberlippe d. Bl. fast gerade, stumpf, zahnlos, ziemlich kahl; $K$. glockig, halb-2sp., fast blumenscheidig, auf der vorderen Seite zottig, 3-5zähnig, Zähne sehr kurz, 3eckig, der hintere ein wenig grösser; die längeren Stbf. an der Spitze dicht-bärtig; B. nebst den unteren DeckB. gefiedert, Fieder tieffiedersp., Fiederchen lineal.-lanzettl., ungleich-stachelspitzig-gesägt; die oberen DeckB. lanzettl., fiedersp.-gesägt. 2. Wocheiner A., Krain, Slavnik u. Monte Maggiore im Küstenlande. Mai. Bl. schwefelgelb.

16. P. re cutita L. Oberlippe der Bl. fast gerade, stumpf, zahnlos, kahl; K. glockig, kahl, fast halb-5sp., Zäline ungleich, lanzettl., spitz; DeckB. lanzettl., ungeth. u. 3sp., kürzer als die Bth., die unteren fiedersp., verlängert; B. tief-fiedersp., Fieder lanzettl., fiedersp.gezähnt u. gezähnelt, die oberen an der Basis breit-zsfiessend. 2. Feuchte O. d. A. Jul. Aug. Bl. rostbraun-purp.

17. P. ros ea Wulf. Oberlippe der Bl. gerade, fast sichelf., zahnlos, stumpf, kahl; K. röhrig, glockig, wollig, fast halb-5sp. Zähne gleich, lanzettl.-pfrieml., spitz; DeckB. fiedersp., gezähnt, ein wenig länger als der K.; B. gefiedert, Fieder schmal-lanzettl., spitz-gesägt. 2. KalkA.; Tyr., Stmk., Kärnth. Jul. Aug. Bl. rosemroth. 
18. P. versieolor Wahlenb. Oberlippe der Bl. gerade, fast sichelf., an der Spitze zahnlos, stumpf, kahl; K. röhrig-glockig, nebst den DeckB. zottig, 5zähnig, Zähne ungleich, lanzettl., an der Spitze zuriickgekrümmt, etwas gekerbt; DeckB. länglich, fiedersp.-gekerbt, die oberen fast ganzrandig, ein wenig länger als der K.; B. gefiedert, Fieder oval, doppelt-gekerbt, die oberen sich abwärts deckend. 4. Feuchte O. $\operatorname{der}$ A. Jun. P. flammea Wulf. Bl. citrongelb, mit einem scharlachrothen od. schwarzpurp. Flecken unter der Spitze der Oberlippe.

19. P. ac a ulis Scop. Oberlippe der Bl. sichelf., abgerundetstumpf, zahnlos, am Rande zottig; K. halb-5sp., Zähne oberwärts blattig, eingeschnitten-gezähnt; Bthstiele wurzelst., einzeln, viel kürzer als die B.; B. gefiedert, Fieder eyf., fiedersp.-eingeschnitten, stachelspitzig-gezähnt. 24. Feuchte, sonnige Abhänge unter Gesträuch; Krain, südl. Tyrol. Apr. Mrai. Bl. weiss, ins Röthl. spielend.

20. P. verticillata L. Oberlippe der Bl. fast gerade, zahnlos, kahl; K. aufgeblasen, rauhh., an der Spitze gespalten, Zähne sehr kurz; B. tief-fiedersp., Fieder eyf.-länglich, stumpf, ungleich-gezähnt; StB., DeckB. u. Bth. quirlig. 24. Feuchte O. der A. JuI. Aug. Bl. purpurn.

IV. Rotte. Bl.-Röhre in einen glockigen, deh die zsneigenden Lippen geschlossenen Schlund erweitert.

21. P. Sceptrum Carolinum L. Röhre der Bl. oberwärts glockig, Schlund dch die zsneigenden Lippen geschlossen, Oberlippe sichelf., stumpf, zahnlos; K. kahl, 5zähnig, Zähne längl., stumpf, spitz-ungleich-gekerbt; die DeekB. eyf., ungeth.; B. fiedersp., Fieder eyf.-längl., stumpf, doppelt-gekerbt. 24. Torfwiesen; nördI. Geb. u. Mähr., Stmk., Salzbg., Oberbayern. Jun.-Aug. Bl. schwefelgelb, Rand der Unterlippe blutroth.

\section{RHINANTHUS L. Klappertopf.}

1. Rh. min or Ehrh. DeckB. gleichfarbig, die oberen eingeschnitten-gesägt, Zähne zugespitzt; Lippen der Bl. gerade-vorgestreckt, Röhre gerade, Zahn auf beiden Seiten der Oberlippe kurz-eyf., so lang als breit; B. längl.-lanzettl. $\odot$. Wiesen. Mai. Jun. Rh. Crista galli $\alpha$. L. Bl. gelb, wie an folgend., Zahn der Oberlippe weissl. od. violett. DeckB. griin od. braun. Var. $\beta$. fallax: höher, St. mit schwarzen Strichen. - $\gamma$. angustifolius: B. halb so breit, lanzettl.-lineal.; letzterer auf d. A.

2. Rh. major Ehrh. DeckB. verschiedenfarbig, bleich, die oberen eingeschnitten-gesägt, Zähne pfrienlich, haarspitzig; Lippen der Bl. gerade-vorgestreckt, Röhre etwas gekrümmt, Zahn auf beiden Seiten der Oberlippe eyf.; $K$. kahl od. etwas flaumig; Flügel der Samen breiter als der halbe Same; B. längl.-lanzettl. $\odot$. Wiesen. Mai. Jun. 
Rh. Crista galli $\beta$. L. Der Zahn d. Oberlippe violett. Var. $\beta$. angustifolius: B. nur halb so breit, lanzettl.-lineal. Rh. major var. angustif. Fries herb. norm.

3. Rh. Alect or ol oph u s Pollich. DeckB. verschiedenfarbig, bleich, dic oberen eingeschnitten-gesägt, Zähne pfriemlich, haarspitzig; Lippen der Bl. gerarle-hervorgestreckt, Röhre etwas gekrimmt, Zahn auf beiden Seiten der Oberlippe eyf.; $K$. zottig; Samenflügel schmäler als der halhe Same; B. längl.-lanzettl. $\odot$. Aecker; mittleres $u$. südl. Geb., selten im nördl. Mai. Jun. Rl. Crista galli $\gamma$. L.

4. Rh. alpinus Baumgart. DeckB. verschiedenfarbig, bleich, oft schwarz-gefleckt $u$. punktirt, d. oberen eingeschnitten-gesägt, Zähne pfriemlich, lang-begrannt; die obere Lippe der BI. aufstrebend, Zalın auf beiden Seiten der Oberlippe längl.; B. längl.-lanzettl. od. aus einer lanzettl. Basis lang-verschmälert. ○. A. u. VorA. Jul. Aug. Zahn der Oberlippe blau u. oft an der Unterlippe ein od. mehrere blaue Flecken. Var. mit abstehender u. angedriickter Unterlippe; u. $\beta$. angustifolius: B. halb so breit: Rh. angustifolius Gmelin, K. syn. ed. 1. Dieser auch auf Kalkbergen in Oberbaden u. am Harze.

5. BARTSIA L. Bartsie.

1. B. alpin a L. B. gegenst., eyf., fast stengelumfassend, stumpfgesägt. 24. Wiesen u. Kies der A., mit den Flïssen in d. Ebenen; Sudet., Schwarzw. Jul. Aug. Bl. violettroth.

6. TRIXÁGO Link. Trixago.

1. T. latif olia Rchb. B. handf-gezähnt; Rth. fast kopfig-zsgehäuft. ○. Unkult. O.; Istrien. Apr. Mai. Euphrasia latifolia L. Bl. purpurn.

\section{EUPHRASIA L. Augentrost.}

I. Rotte. Euphrasium. Das untere Stbk.-Säckchen der kür* zeren Stbg. mit einem längeren Dörnchen bewehrt, dic iibrigen Säckchen sehr fein- u. kurz-stachelspitzig.

1. E. officinalis L. B. eyf., meist beiderseits 5zähnig, die unteren Zähne genäherter, die d. oberen B. zugespitzt, kürzer- u. länger-stachelspitzig; obere Lippe der Bl. 2lappig, Lappen abstehend, 2-3zähnig, dic untere $3 \mathrm{sp} ., \mathrm{Zp} f$. tief-ausgerandet. $\odot$. Wiesen, lichte WaldO., Haiden. Jul. Aug. Var. $\alpha$. pratensis: drüsig-behaart v. abstehenden Haaren; Zähne der oberen B. stachelspitzig; Bl. grösser, weiss, mit einem citrongelben Flecken an der Basis der Unterlippe, auf der oberen Lippe mit 6, auf der unteren mit 9 violetten Linien. E. pratensis Rchb. E. Rostkoviana Hayn. Wiesen. $\beta$. reglecta: v. abstehenden, drüsenlosen Haaren behaart, die oberen B., so wie bei der folg. Variet., tiefer-gesägt, mit haarspitzigen Zähnen. E. off. $\beta$. neglecta W. u. G. Sehr behaarte Exemplare: E. nẹ- 
morosa $\beta$. pectinata Rchb. VorA. - $\gamma$. nemorosa: v. gekräuselten, angedrückten Haaren flaumig, d. oberen B. tief-gesägt, mit haarspitzigen Zähnen; Oberlippe meistens u. manchmal die ganze Bl. blau. E. off. $\beta$. nemorosa Pers. E. officinalis Hayn. Trockenere O. $-\delta$. alpestris: For'm der B., wie bei der Variet. $\alpha$.; Flaum wie bei $d$. Var. $\%$ Kommt vor 1) BI. wie bei $\alpha_{.}$: E. off. alpestris W. u. G. 2) Bl. grösser, blau: E. caerulea Tsch. 3) Bl. klein, B. stumpf: E. micrantha Rehb. - Die mannichfaltigen Varietäten der E. officinalis sind besonders auf höheren Gebirgen noch weiter zu untersuchen.

2. E. min im a Schleich. B. eyf., meist beiderseits 5zähnig, Zähne der oberen kurz-stachelspitzig; die obere Lippe d. Bl. 2lappig, Läpp-

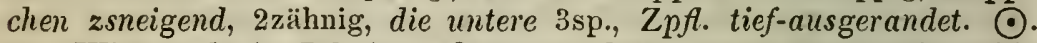
Auf Wiesen d. A. Jul. Aug. Oberlippe blau, untere ganz gelb, beide mit vier Linien. Wohl nur Abart der E. officinalis, ist noch weiter $z u$ beobachten.

3. E. sa lisburgensis Funk. B. lanzettl. od. längl., an der Basis keilig, beiderseits 2-3zälnnig, Zähne gleichweit-entfernt, die der oberen B. u. des K. haarspitzig-begrannt; die obere Lippe der Bl. 2lappig, Lappen 2-3zähnig, die untere $3 \mathrm{sp}$., Zpfl. tief-ausgerandet. $\odot$. A. u. VorA. Jul. Aug. E. alpina DC. Bl. wie bei E. off.

4. E. tricuspidata L. B. lireal., an der Spitze beiderseits 1zähnig, Zähne, auch die der oberen B. u. des K., spitz, wehrlos; die obere Lippe der Bl. 2lappig, Lappen 2-3zähnig, die untere $3 \mathrm{sp}$, $Z_{p f l}$. tief-ausgerandet. $\odot$. Gebirg. O. des stidlichsten Tyr., u. nördl. bis zu dem Eingange in das Geb. v. Val di Non. Jul. Aug. Bl. wie bei $\mathrm{E}$. off.

II. Rotte. Odontites Dub. Stbk.-Säckchen gleichf.-stachelspitzig.

5. E. Odoutites I. B. aus breiterer Basis verschmälert, lanzettl.-lineal., entfernt-gesägt; DeckB. längl.-lanzettl., länger als die Bth.; Bl. auf der Oberfläche u. am Rande dicht-flaumig, Oberlippe zsgedrückt, abgeschnitten-stumpf; Stbk. an der Spitze dch Zotten verbunden. $\odot$. Feuchte kuItiv. u. unkult. O. Jun.-Oct. E. verna Bellard. BI. hellpurpurn.

6. E. serotina Lam. B. lanzettl., zugespitzt, nach der Basis etwas verschmälert, ziemlich entfernt-gesägt; DeckB. längl.-lanzettl., kürzer als die Bth.; $B$. anf der Oberfläche u. am Rande dichtfaumig, obere Lippe zsgedrückt, abgeschnitten-stumpf, Zpfl. der unteren länglich, stumpf; Stbk. an der Spitze dch Zotten verbunden. ○. Gebirg., trock. O.; südl. Schwz., Litt. Jul.-Aug. E. Odontites ק. L. Bl. hellpurp.

7. E. lutea L. B. lanzettl.-lineal., schwach-entfernt-gesägt, die olıeren lineal., ganzrandig, alle nebst den St. oberwärts u. dem K. v. angedrückten, gekräuselten, drüsenlosen Haaren flaumig; $B l$. bär- 
tig-gewimpert, Oberlippe zsgedrückt, abgeschnitten-stumpf; Stbg. länger als die Bl.; Stbk. kahl, frei. $\odot$. Unkult. O., Kalkboden; südl. u. mittler. Geb., selt. im nördl. Jul. Aug. Bl. dottergelb.

8. E. vi s c os a L. B. lanzettl. -lineal., scliwach-entfernt-gesägt, die oberen lineal., ganzrandig, letztere nebst $d$. St. oberwärts u. dem K. v. drüsentrag., abstehenden Haaren flaumig; Bl. am Rande kahl, Oberlippe zsgedrückt, abgeschnitten-stumpf; Stbg. kiirzer als die Bl.; Stbk. an der Spitze dch Zotten vereinigt. $\odot$. Im mittleren Wallis. Jul. Aug. E. linifolia $\beta$. L. Bl. blass-gelb.

\section{Ordng. LABIATEN. Juss.}

I. Gruppe. OCYMOIDEEN. Benth. Stbg. abwïrtsgeneigt; Stbk. nierenf., 1fächerig, mit einer halbkreisrunden Ritze aufspringend, nach Ausstreutung des Bthstaubes ein krcisrundes, flaches Plättchen darstellend.

\section{1. ÓCYMUM L. Basilienkraut.}

1. O. Basilic u m L. 'B. gestielt, eyf. od. längl., entfernt-schwachgesägt, kahl; K. gewimpert; St. flaumig. $\odot$. Aus Ost-Indien, als Topfpfl. u. Küichengewiichs kultiv. Jul. Aug. Bl. weiss.

\section{LAVÁNDULA L. Lavendel.}

1. L. vera DC. B. längl.- lineal. od. lanzettl., ganzrandig, die jüngeren grau, am Rande zurïckgerollt; Aehren unterbrochen; DeckB. rauten-eyf., zugespitzt, sämmtl. Blithen stïtzend, die obersten kiirzer als der K. 24. Trockene, unkult. O.; Litt., siidl. Tyr., häufig über Vully zw. Murten u. den Nenenburger See, u. häufig auf dem Lavendelberg bei Kreuznach in der Rheinpfalz, in Schwaben an einigen O. Jul. Aug. L. Spica $\alpha$. L. Bl. blau.

II. Gruppe. MENTHOIDEEN. Benth. Bl. fast glockig od. trichterf., Saum $4-5 \mathrm{sp}$., Lappen fast gleich. Stbg. von einander entfernt, gerade.

\section{ELSHOLTIA Willd. Elsholtie.}

1. E. c ristat a Willd. Krautig, ziemlich kahl; B. gesticlt, eyf. od. längl., nach beiden Enden verschmälert; DeckB. breit-eyf., spitz, gewimpert, einseitswendig; Quirle genähert, einseitswendig; Aehren rispig. $\odot$. Ǩnlt. O.; Hamburg. Jul. Aug. Bl. rosenroth.

\section{MENTHA L. Münze.}

1. M. rotundifolia L. Aehren lineal.-walzlich; DeckB. lanzettl.; K. schwach-gerieft, $d$. fruchttrag. fast kugelig-bauchig, Zälune lanzettl.-pfrieml., zuletzt zsneigend; B. sitzend, fist eyf., gekerbt-gesägt. 24. Feuchte O.; zerstr. dclı d. südl. u. mittl. Geb. Jul. Aug. Bl. hellviolett od. lila, wio an den folgenden. 
2. M. sylvestris L. Aehren lineal.-walzl.; DeckB.lineal.-pfrieml.; $K$. schwach-gerieft, der fruchttrag. bauchig, oberwärts eingeschnürt, Zähne lineal.-pfrieml., zuletzt ein wenig zsneigend; $B$. fast sitzend, ey- od. lanzetff., gezähnt-gesägt. 24. Ufer, feuchte 0. Jul. Aug. Var.: a. vulgaris: B. filzig, flach, od. nur wenig wellig; u. diese kommt weiter vor: $A$. Filz an dem St. u. den B. locker, dicker: M. sylvestris Willd. - B. Filz des St. u. der unteren Blattfläche angedriickt, weissl.: M. nemorosa Willd. - C. Filz des St. u. der B. dickl., B. beiderseits filzig, oben dïnner filzig: MI. mollissima Borkh. - $\beta$. undulata: B. meist kïrzer, am Rande wellig $u$. eingeschnitten-gezähnt, Zähne lanzettl., ungleich, zugespitzt. M. undulata Willd. - $\gamma$. pubescens: B. auf d. ersten Anblick oberseits kahl u. unterseits Haumig. M. balsamea Willd. - $\delta$. glabra: B. kahl od. unterseits auf den Adern zerstr.-behaart, St. kahl od. etwas flaumig. M. viridis I. - $-\varepsilon$. crispata: B. kahl, blasig-runzelig, eingeschnittengezähnt. M. crispata Schrad., Willd. M. hercynica Röhl.

3. M. n e petoides Lej. Aehren längl.-ualzl.; die oberen DeckB. lineal.-pfrieml.; Zähne des K. lineal.-borstl., des fruchttrag. gerade vorgestreckt, Röhre gerieft; $B$. gesticlt, eyf., gesägt. 24. Gräben, Ufer. Jul. Aug. B. der M. aquatica u. Aehren der M. sylvestris, aber dicker.

4. M. piperita L. Aehren längl.-valzl.; die oberen DeckB. lanzettl.; Zähne des K. lanzettl.-pfrieml., die des fruchttrag. geradevorgestreckt, Röhre gefurcht; $B$. gestielt, längl. od. eyf.-längl., gesägt. 2. Ufer; Oberbaden am Klemmbach bei Mïhlheim; im Laberthal bei Aichhofen unweit Regensbg. in grosser Menge, Tyrol. Jul. Aug. Var. $\alpha$. Langii: St., Bstiele, B. unterseits, Bthstielchen u. K. rauhb., oberseits zerstreut-behaart. M. Langii Stendel. M. pyramidalis Tenor. M. suavis Guss. - $\beta$. officinalis: kahl, der St. nebst den B. unterseits mit kurzen, angedrickten Haaren weitläuftig bestreut. $-\gamma$. crispa: St., Aeste, Aehren, Bthstielchen, K. u. Bth. genau so, wie bei der vorhergeh., aber die B. eyf., blasig-runzelig, am Rande kraus u. cingeschniten-gezähnt, mit lanzettl., zugespitzten Zähnen. M. crispa $\mathrm{L}$.

5. M. aquatica L. Bth. quirlig-kopfig, Zähne des K. aus 3eckiger Basis pfrieml., die des fiuchttrag. K. gerade-vorgestr., Röhre gefurcht; B. gestielt, eyf., gesägt. 24. Ufer, Gräben. Jul. Aug. Var. $\beta$. hirsuta: behaarter, B. oft kïrzer-gestielt. M. hirsuta L. $-\gamma \cdot$ glabrata: kahl, nur die K. gewimpert. M. citrata Ehrh.

6. M. sativa Smith. Bth. quirlig; Quirle sämmtl. entfernt, kugelig; K. röhrig-trichterf., Zähne 3eckig-larıettl., zugespitzt, die des fruchttrag. gerade-vorgestreckt; $B$. gestielt, eyf. od. elliptisch, gesägt mit auswärts gerichteten Zähnen. 2. Gräben, Ufer. Jul. Aug. M. sativa Sm. nach Benth. Var. $\alpha$. vulgaris: Haare des St. herabgebogen od. abwïrts angedrückt; diese geht über in die Var. $\beta$. glabra: 
wenn die meisten Haare verschwinden: M. rubra Sm. nach Benth. Var., wie die Art überhanpt, mit um die Hälfte kleineren K., dazu ziehe ich M. sativa (agardhiana) Fries. - $\gamma$. hirsuta: Haare, auch die des K. u. der Bthstielchen wagerecht-abstehend. - $\delta$. crispa et pilosa: B. breit-eyf., blasig-runzelig, unregelmässig-eingeschnitten-gezälınt. M. dentata Roth. M. sativa Tausch. u. Linn. nach den Synonymen. - $-\varepsilon$. crispa el glabra: dieselbe mit kahlen B. M. dentata Moench. Die Variet. $\delta$. u. $\varepsilon$. sehr selten. - $\zeta$. parviflora: Bl. nur ein wenig länger als der K. M. parviflora Schultz.

7. M. g cntilis L. Bth. quirlig; Quirle sämmtl. entfernt, kugelig; K. rührig-trichterf., Zähne 3eckig-lanzettl., zugespitzt, dic des fruchttrag. gerade-vorgestreckt; B. gestielt, elliptisch, an beiden Enden spitz, gesägt, Sägezähne zugespitzt, vorwärts gerichtet. 24. Ufer u. feuchte O.; sehr zerstr. dch das Geb. Jul. Aug. Die K. oberwärts borstig-rauhh., die Bth. so gross wie bei der kleinbth. Form der M. sativa Sm. - Die M. gentilis Maly Fl. styr. stimmt in Allen mit M. gentilis ïberein, die Bth. aber sind so gross, wie an der grossbth. Form der M. sativa Sm., sie bildet nach meiner Ansicht eine grossbth. Form der M. gentilis. - Genau die letztere, aber selır rauhh. ist: $\beta$. acutifolia, M. acutifolia Rabenhorst. Flor. Lusat., u. wohl auch Sm. Fl. brit., dazu auch M. hortensis Tausch., die M. gentilis ist mehr od. weniger kahl. - Var. ferner: $\gamma_{0}$ gracilis: B. lanzettl., die Pfl. fast kahl. M. gracilis Sm. Dieselbe Form, nur die B. etwas breiter: M. pratensis Sole, K. syn. ed. 1.

S. M. arvensis L. Bth. quirlig; Quirle sämmtl. entfernt, kugelig; K. glockig, Zähne 3eckig-eyf., so lang als breit, die des fruchttrag. K. gerade-vorgestreckt; $\mathbf{H}$. gestielt, eyf., od. elliptisch, gesägt. 4. Ufer, kultiv., feuchte O. Jul. Aug. Der fruchttrag. $K$. von voriger sehr verschied. Var. $\alpha$. vulgaris: St. u. B. zottig; Bthstielchen zottig od. kahl. M. arvensis $\zeta$. vulgaris Benth. - $\beta$. glabriuscula: Bthstielchen kahl, B. 1l. St. ziemlich kahl. M. arvensis $\eta$. Benth. M. gentilis Sm. nach Benth.

\section{PULEGIUM Mill. Polei.}

1. P. v ulgar e Mill. Bth. quirlig; Quirle kugelig, sämmtl. entfernt; $K$. röhrig, der fruchttrag. mit einem Ringe $v$. Haaren geschlossen, dic oberen Zähne zurïckgckrümmt; B. gestielt, ellipt., stumpf, schwach-gezähnt. 2. Ufer u. sumpfige O.; zerstr. dch d. Geb. Jul. Aug. Mentha Pulegium L. Bl. hell-purp. od. lila.

\section{LYCOPUS L. Wolfsfuss.}

1. L. e ur o p a e us L. B. gestielt, eyf.-längl., grob-eingeschnittengezähnt, an der Basis fiedersp.; Zähne des K. zugespitzt; der mittlere Zpfl. der Unterlippe gerade-vorgestreckt, fast 4eckig, gestutzt, noch einmal so breit als die seitenst. 24. Feuchte O., Ufer. Jul. Aug. B1. weiss, inwendig mit purpurnen Punkten, wie an folg. 
2. L. exaltatus L. fil. B. gestielt, die unteren im Umrisse breiteyf., die oberen lanzettl., alle bis auf den Mittehnerven fiedersp., die unteren Zpfl. etwas gezähnt, die oberen zsfliessend; Zähne des K. zugespitzt; die Zpfl. der Unterlippe eyf., fast gleich, an der Spitze zurückgebogen. 24. Gräben, Ufer; in der Ecke des Rheines u. Maines bei Mainbischoffsheim; Insel Veglia. Jul. Aug.

III. Gruppe. MONARDEEN. Benth. Bl. 2lippig, Zwei fruchtbare, unter der Oberlippe der Bl. gleichlaufende Stbg:

\section{ROSMARÍNUS L. Rosmarin.}

1. R. officinalis L. B. sitzend. Ђ. Auf unkult., rauhen Hügeln; Littor. u. südl. Schwz. Apr. Mai. Bl. blass-blau.

8. SALVIA L. Salbey.

1. S. officinalis L. St. strauchig; Aeste nehst den jüngeren B. grau-filzig; B. ey-lanzettf. u. lanzettf., dicht-kleingekerbt, runzelig; Quirle 6-12bth., nackt; Deck $B$. hinfällig; Zähne des $K$. geradevorgestreckt, dornig-begrannt; Röhre der Bl. inwendig mit einer Haarleiste. 5. Steinige O.; Litt., Tessin. Jun. Jul. Bl. violett.

2. S. glutinosa L. St. krautig, oberwärts nebst den DeckB. u. K. drüisig-zottig, klebrig; B. herz-spiessf., grob-gesägt, flaumig, die oberen lang-zugespitzt; Quirle getrennt, 6bth.; obere Lippe des K. cyf., 3zähnig, mit sehr kleinen Zähuen, untere 2zähnig, Zähne eyf., spitz, wehrlos. 24. Wälder, schattige O., VorA.; siidl. Geb., sodann in Schles. u. Böhm. Jun. Jul. Bl. schwefelgelb, braun-punktirt.

3. S. A thiopis L. St. krautig; B. eyf., fast herzf., grob-gekerbt, buchtig od. lappig, sehr runzelig, nebst d. Kelche weiss-wollig; DeckB. rundl.-eyf., haarspitzig, concav; Quirle getrennt, 6-10bth.; Zähne des $K$. eyf., spitz, dornig-begrannt. $\odot$. Unkult. O.; Oestr. Jun. Jul. Bl. weiss.

4. S. Scla rea L. St. krautig, zottig, oberwärts drüsig-behaart; B. eyf., doppelt-gekerbt, fast filzig, die unteren herzf., runzelig; Deck$B$. breit-eyf., haarspitzig, häutig, farbig, länger als die K.; Quirle 6bth., getrennt; Zähne des $K$. $\epsilon y f$., spitz, lang-dornig-begrannt. $\odot$. Grasige Hügel, Wege; Wallis, Istr. Jun. Jul. Bl. bläulich; DeckB. rosenroth.

5. S. a ustriaca Jacq. St. krautig, oberwärts nebst den DeckB. u. K. driisig-bchaart u. zottig; B. eyf., doppelt-gekerbt, lappig u. fast fiedersp., flaumig, die wurzelst. gesticlt, die stengelst. wenige $(2-4)$, sitzend, vielmal kleiner; DeckB. eyf., spitz, so lang als der K., krautig; obere Lippe des K. kurz-3zähnig, untere 2sp., Zähne eyf., feinstachelspitzig; Stbg. noch einmal so lang als die Bl. 2. Unkultiv. Hügel; Oestr. Mai.Jun. Bl. weisslich.

6. S. pratensis L. St. krautig, obenwïrts nebst den $D \epsilon c k B$., $K$. 
u. Bl. klebrig-behaart; B. eyf. od. längl., doppelt-gekerbt, ungeth. od. 3lappig, runzelig, unterseits flaumig, die wurzelst. an der Basis herzf., gestielt, die stengelst. wenige, die oberen viel kleiner, stengelumfassend; DeckB. eyf., zugespitzt, kürzer als der K., krautig; Quirle meist 6bth.; obere Lippe des K. kurz-3zähnig, untere 2sp., Zähne eyf., staehelspitzig; obere Lippe der Bl. länger als die untere; Stbg. kürzer als die Bl. 24. Trockene Wiesen, Raine. Mai-Jul. Bl. blau, roth od. weiss. Var.: Mittl. Zpfl. der Unterlippe weiss. S. variegata Kit.

7. S. sylvestris L. St. krautig, reichblätterig $u$. nebst den $\mathbf{B}$. unterseits u. dem $K$. grau-flaumig; die unteren B. gestielt, doppeltgekerbt, an der Basis herzf., die oberen allmählig an Grösse abnehmend, kürzer-gestielt u. sitzend, meist einfaeh-gekerbt, an der Basis eyf. od. herzf.; DeckB. eyf., zugespitzt, farbig, kürzer als die Bth.; Quirle meist 6bth. getrennt; obere Lippe des K. kurz-3zähnig, untere 2sp., Zälnne eyf., zugespitzt-staehelspitzig; Stbg. kürzer als die Bl. 2. Unkultiv. O., Wege; östl. Geb. bis Thüring., zw. Cöln u. Limburg. Jul. Aug. Bl. violett od. rosenroth. Var. S. nemorosa L., Haare am St. länger, mehr abstehend.

8. S. elandestina L. spec. plant, nicht des Herbarium. St. krautig, flaumig od. zottig, armblätterig; B. längl., lappig-gezähnt od. fiedersp., ungleich-gekerbt, runzelig, kahl od. unterseits flaumig, die unteren gestielt, an der Basis fast herzf., die obersten sitzend; DeckB. rundlieh-eyf., zugespitzt, krautig, am Rande nebst d. K. rauhh., zuletzt herabgebogen; Quirle meist 6bth., die unteren entfernt; obere Lippe des $K$. abgerundet, klein-3zähnig, untere 2sp., Zähne eyf., stachelspitzig. 24. Grasige Hügel; Istrien. Mai-Aug. S. verbenaea Vahl. S. praecox Savi. Bl. violett.

9. S. verticill ata I. B. fast 3eckig-herzf., ungleieh-gezähnt-gekerbt, Bstiele der unteren geöhrelt; Quirle fast kugelig, reichbth., getrennt; Bthstielehen ungefähr so lang als der K.; Gf. auf der Unterlippe liegend. 2. Unkult. O., Wege; südl. u. südöstl. Geb. Jul. Aug. Bl. violett.

IV. Gruppe. SATUREINEEN. Benth. Bl. 2lippig. Stbg. 4, v. einander entfernt $u$. entwed. oberwärts auseinanderfahrend od. unter der oberen Lippe der Bl. zsneigend; Säckchen der Stbk. von einander getrennt, an das quer-verbreiterte Connectiv beiderseits schief-angewachsen.

9. ORÍGANUM L. Dosten.

1. O. vulgare L. K. 5zähnig, Zähne gleieh; DeckB. auf der inneren Seite drüsenlos; B. eyf., spitz. 2. Unkult.. sonnige O. Jul. Aug. Bl. purp. od. weiss. Var. $\beta$. megastachyum: Aehren fast 1 Zoll lang, prismatiseh. $O$. vulgare $\beta$. prismaticum Gaud. O eretieum DC, O. eretieum L. Herbar. u. O. eretieum $\beta$. L. spee. 
2. O. hirtum Link. K. 5zähnig, Zähne gleich; DeckB. auf der äusseren'u. inneren Seite drüsig-punktirt; B. breit-eyf., kurz-zugespitzt. 24. Trockene, unkult. O.; Istrien. Jun. Jul. Var.: Aehren lang und $-\beta$. kurz. Letzteres: $O$. heracleoticum Benth. Bl. purp. oder weiss.

3. O. Ma iorana L. K. halbirt, zahnlos; DeckB. gefurcht, sehr dicht-dachig; Aeluren oval, 3zählig, sitzend; B. gestielt, elliptisch, stumpf, ganzrandig, beiderseits grau-filzig. - u. 24. Aus d. nördl. Africa, jetzt überall z. Küchengebrauch kultiv. Jul. Aug. Bl. weiss.

\section{THYMUS L. Thymian.}

1. Th. vulgaris'L. Quirle kopfig od. traubig; B. lineal. od. längl.-eyf., spitz, drüsig-punktirt, am Rande umgerollt, in den Blattwirkeln büschelig, die blüthenst. lanzettl., stumpf. Ђ. Felsige O., Istrien. Mai. Jun. Bl. purp.

2. Th. Serpyllum L. Quirle kopfig od. traubig; $B$. lineal. od. elliptisch, stumpf, an der Basis in einen kurzen Bstiel zsgezogen, ganzrandig, flach, drüsig-punktirt, kahl od. rauhh., am hinteren Rande gewimpert, die bliithenst. fast gleichgestaltet; obere Lippe $d$. Bl. ausgerandet, eyf.-fast 4erkig. Ђ. Felder u. unkult. O. Jul.-Sept. Bl. purp. Hauptsächl. Varietäten sind: $\alpha$. Chamaedrys: der St. 2reihig-behaart. Th. Chamaedrys Fries. Th. Serpyllum Pers. Th. Serpyllum $\beta$. L. Kommt rauhh. vor, B. beiderseits u. St. rauhh., aber 2 Seiten des St. kahl od. weniger rauhh. Th. lanuginosus Schk. Th. Serpyllum $\gamma$. L.; mit dem Geruche der Citrone: Th. Serpyllum $\delta$. L. Th. citriodorus Link. - $\beta$. pulegioides: Bth. fast noch einmal so gross als an der grossbth. Form v. Th. Chamaedrys, die B. meist rundl.-eyf., das übrige wie bei letzterem. Th. pulegioides Lang. Dieser im Kessel des Gesenkes der Sudet. - $\gamma$. angustifolius: der St. überall gleichf.-behaart. Th. angustifolius Pers. Th. Serpyllum Fries. B. lineal.-länglich, aber auch ellipt. od. vkteyf. $\delta$. parnonicus: grösser als Th. angustifolius, die B. meist länglich od. lanzettl., nach der Basis verschmälert, zuweilen auch lineal., übrigens behaart, wie Th. angustifolius. Th. pannonicus All., K. syn. ed. 1. Das Merkmal v. der Oberlippe der Bl. hat sich nicht constant erwiesen.

\section{SATURÉJA L. Pfefferkraut.}

1. S. hortensis L. St. aufrecht, sehr ästig, krautig; Ebensträusschen blattwinkelst., meist 5bth.; B. lineal.-lanzettl., spitz, wehrlos. $\odot$. Flusskiese d. Isonzo in Krain; wird häufig gebauet. Jul.Oct. Bl. lila od. weiss u. im Schlunde punktirt.

2. S. montan a L. St. halbstrauchig, ziemlich stielrund, flaumig; Tr. quirlig; fast einseitswendig, Ebensträusschen blattwinkelst., gesticlt, meist 3bth.; B. lanzettl., zugespitzt, nach der Basis ver- 
schmälert, beiderseits drüsig-punktirt, die oberen stachelspitzig; Zpfl. der unteren Lippe d. Bl. längl., stumpf, fast gleich, die obere Lippe tief-ausgerandet. Ђ. Gebirg. O.; siidl. Tyr., Krain, Littor. Jul. Aug. BI. weiss od. röthl., Schlund purp.-punktirt; Röhre der Bl. noch einmal so lang als die Unterlippe.

3. S. vari egat a Host. St. halbstrauchig, fast stielrund, flaumig; Tr. quirlig, fast einscitswendig, Ebensträ̈usschen blattwinkelst., gestielt, meist 3bth.; B. lanzettl., zugespitzt, nach der Basis verschmälert, beiderseits drïsig-punktirt, die oberen stachelspitzig; die seitenst. Zpfl. der Bl. gestutzt, der mittlere noch einmal so breit, rundlich, ungeth., am Rande wellig, die obere Lippe seicht ausgerandet. Ђ. Gebirg., rauhe O.; Krain, Littor., Fiume. Jul. Aug. Bl. weiss od. röthl., Schlund purp.-punktirt; Röhre d. Bl. so lang als die Unterlippe.

4. S. pygmata Sieber. St. halbstrauchig, 4eckig, kahl; Tr. quirlig, fast einseitswendig, Ebensträusschen gestielt, meist 3bth.; B. lanzettl., zugespitzt, nach der Basis verschmälert, unterseits spärlich-drüsig-punktirt, die oberen stachelspitzig; die seitenst. Zpfl. der unteren Lippe d. Bl. gestutzt, der mittlere breiter, verkehrt-herzf. $\hbar$. Gebirg., felsige O.; Krain. Jul. Aug. S. subspicata Vis. S. illyrica Host. Bl. violett, im Schlunde dunkler punktirt.

\section{MICROMÉRIA Benth. Micromeric.}

1. M. Juliana Benth. St. halbstrauchig, stumpf-4kantig; Bth. quirlig, Ehensträusschen der Quirle 3-5bth., fast stiellos, aufrecht, sehr gedrungen, gleich-hoch; Nïsse längl., zugespitzt, stachelspitzig; B. beinahe sitzend, flaumig-kurzh., eyf., ziemlich stumpf, an der Basis abgerundet, am Rande zuriiclgerollt, die oberen lineal.-zsgerollt, d. bliithenst. an den Quirl angedriielst. 2. Steinige O.; Cherso u. Osero. Jul. Aug. Satureja Juliana L. Bl. purp.

2. MI. graeca Benth. St. halbstrauchig, stumpf-4kantig; Bth. quirlig, Ebensträusschen der Quirle 3-5bth., gestielt, etwas cinseitswendig; Nüsse längl., stumpf; B. Jeinahe sitzend, flaumig-kurzh., am Rande zurückgerollt, die unteren eyf., die oberen lanzettl. od. lineal. 2. Trockene O. u. Felsen; Gandria im C. Tessin. Satureja graeca L. Bl. purp.

13. CALAMÍNTHA Mönch. Calaminthe.

I. Rotte. A cinos Mönch. Quirle aus 6 ungeth. Bthstielen zsgesetzt.

1. C. A cinos Clairville. Quirle 6bth.; Bthstiele ungeth.; B. eyf., gesägt; $W$. einfach; der St. aufrecht, an der Basis ästig, Aeste aufstrebend; FruchtK. an der Spitze zsgezogen, dch die anliegenden Zähne geschlossen. $\odot$. Felder, unkultiv. O. Jun.-Aug. Thymus Acinos L. Bl. hell-violett. 
2. C. alpina Lam. Quirle 6bth.; Bthstiele ungeth.; B. eyf., gesägt; W. vielköpfig; die St. liegend, aufstrebend; Zähne des FruchtK. aufrecht-abstehend, Schlund v. Haaren geschlossen. 4. A. u. VorA. Jul. Aug. Thymus alpinus L. BI. hell-violett.

II. Rotte. Aechte Calaminthen. Quirle aus gabelsp. Ebensträussen zsgesetzt.

3. C. grandiflora Mönch. Quirle ebensträussig; Bthstiele gabelsp., 3-5bth.; B. eyf., spitz, tief-u. spitz-gesägt u. nebst dem St. behaart; Nüsse rundl.-oval. 24. Fels., waldige O.; südl. Schwz., südl. Tyr., Krain, Littor., Istr. Jul. Aug. Melissa grandiflora L. Bl. rosenroth; Nüisse schwarz.

4. C. officin a lis Mönch. Quirle ebensträussig; Bthstiele gabelsp., 3-5bth.; B. eyf., stumpf, angedrückt-gesägt u. nebst d. St. kurzh.; Schlund des K. spärlicher behaart, Haare kaum hervorragend; Nüsse rundlich. 2. Wälder; zerstr. deh das südl. u. mittl. Geb. Jul. Aug. Melissa Calamintha L. Bl. purpurn; Nüsse fast kugelig, braun.

5. C. Népeta Clairv. Quirle ebensträussig; Bthstiele gabelsp., 12-15bth.; B. rundlich-eyf., stumpf, angedrückt-gesägt u. nebst d. St. kurzh.; Schlund des $K$. von hervorragenden Haaren dicht-behaart; Nüsse länglich. 24. Felsen, unkult. O.; zerstr. deh das südl. Geb. Jul. Aug. Melissa Nepeta L. Bl. bläulich-purp.; Nüsse länglich, braun.

6. C. thym ifolia Rehb., nicht Host. Quirle ebensträussig; Bthstiele gabelsp., meist 5bth.; B. elliptisch, stumpf, schwach gesägt, kahl; Schlund des K. kahl; Nüsse länglich, in eirce Stachelspitze verschmälert. 2. Felsige O.; Krain, Görz, Kärnth., südl. Schwz. Jul. Aug. Satureja thymifolia Scop. Bl. weiss, ob. Lippe violett, untere violett-punktirt.

\section{CLINOPODIUM L. Wirbelborste.}

1. C. vulgare L. St. aufrecht, zottig; Quirle gleich, reichbth.; Hülle so lang als der K. 24. Liclite, waldige, buschige, unkult. O. Jul. Aug. Bl. purpur.

V. Gruppe. MELISSINEEN. Benth. Bl. 2lippig. Stbg. 4, von einander entfernt, $u$. entw. oberwärts auseinandertretend, od. unter der oberen Bl.-Lippe zsneigend. Säckchen der Stbk. an der Spitze zsgewachsen, an der Basis aber später auseinanderfahrend od. v. Anfang an beide in einer Linie fast wagereclit aufliegend u. beide mit einer gemeinschaftlichen Ritze aufspringend.

\section{MELÍSSA L. Melisse.}

1. M. officinalis L. Krautig, aufrecht, ästig; B. eyf., gekerbtgesägt, die unteren an der Basis fast herzf.; Quirle blattwinkelst., halbirt, einseitswendig; DeckB. eyf. 2. Waldige O., Zäune; Oestr., 
Littor., südl. Tyr., süll. Schwz., Weinberge in Untcrelsass. Jul. Ang. M. graveolens Host., nach Benth. Bl. weiss. Var. ß. villosa: zottig. M. hirsuta Hornem. M. cordifolia Pers.

\section{HORMÍNUNI L. Drachenmaul.}

1. H. pyrenaicum L. 2. Grasige, trockene O. d. A.; Tyr., Graubiind. Jul. Aug. Bl. violett.

\section{HYSSÓPUS L. Ysop.}

1. H. offi in al is L. Bth. quirlig-traubig, einseitswendig: Zähne des K. aufrecht, fast gleich; B. lanzettl., ganzrandig. 24. Sonnige, fels. O.; Oestr., Krain, Littor., südl. Tyr., Unterwallis. Jul. Aug. Bth. violett.

VI. Gruppe. NEPETEEN. Benth. Bl. 2lippig. Stbg. unter der oberen Lippe d. Bl. gleichlaufend, genähert, nach dem Verblühen manchmal zur Seite hinabgebogen, die oberen länger. (Benth. lab. p. 462.) Zähne des FruchtK. etwas abstehend od. zsneigend.

18. NÉPETA L. Katzenminze.

1. N. Cataria L. B. gestielt, eyf., spitz, tief-gesägt-gekerbt, an der Basis herzf., unterseits grau-filzig; Ebensträusschen gestielt, gedrungen, reichbth.; DeckB. ungefähr so lang als die Röhre des K.; Mïndung des eyf., flaumigen, etwas gekrïmmten K. schicf, Zähne aus lanzettl. Basis pfrieml.-stachelspitzig; Nüsse glatt u. kahl. 2. Schutt, Wege. Jun.-Aug. Bl. röthl.-weiss, Unterlippe purp.-punktirt.

2. N. Nepetella L. B. kurz-gestielt, lanzettl., gekerbt, an der Basis abgerundet od. herzf., beiderseits grau-flaumig od. filzig; Ebensträusschen gestielt, reichbth.; DeckB. kaum länger als die Bthstielchen; Mündung des röhrigen, filzigen, gekriimmten $K$. schief, Zähne aus lanzettl. Basis pfriemlich; Nüsse knotig-rauh, an der Spitze kahl. 2. Sonnige Thäler; Wallis, Unteröstr. Jul. Aug. Bl. weiss od. fleischroth, purp.-punktirt. N. austriaca Host. - N. lanceolata Lam. die Form mit an der Basis abgerundeten B.

3. N. nu d a L. Aufrecht, fast kahl; B. herzf.-längl., gekerbt-gesägt, beiderseits grasgrïn, sitzend, die unteren kurz-gestielt; Ebensträusschen gestielt, reichbth.; DeckB. kürzer als der K.; Mündung des fruchttrag., eyf., flaumigen $K$. fast gleich, Zähne lineal., spitzlich, wehrlos; Nüsse knotig-rauh, an d. Spitze flaumig. 24. Unkult. Hügel; südl. u. südöstl. Geb. Jul. Aug. Bl. weiss. Var. $\beta$. violacea: Bl. hellviolett, dunkler punktirt. N. panonica Jacq. N. violacea Vill.

19. GLECHOMA I. Gundelrebe.

1. G. hederacea L. B. gekerbt, nierenf., die oberen fast herzf.; Quirle 6bth.; Zähne des $K$. eyf., in eine Granne zugespitzt, 3mal kürzer als die Röhre. 2. Haine, feuchtes Gebüsch, Wiesenränder. 
Apr. Mai. Nepeta Glechoma Benth. Bl. hellviolett, dunkel-violette Flecken an Schlunde $u$. auf der Unterlippe. Var. $\beta$. major : in allen Theilen noch einmal so gross. G. hederacea $\beta$. major Gaud. $-\gamma$. villosa: zottig. G. heterophylla Opitz.

2. G. hirsuta W. K. B. gekerbt, herzf., die unteren nierenf.; Quirle 6bth.; Zälne des $K$. lanzettl., in eine Granne zugespitzt, länger als die halbe Röhre. 24. Wälder, Zäune; Unteröstr. Mai. Jun. Nepeta Glechoma $\beta$. hirsuta Benth.

20. DRACOCÉPHALUM L. Drachenkopf.

1. D. Moldavica L. Quirle blattwinkelst.; B. lanzettl., stumpftief-gesägt, an der Spitze stumpf u. ganzrandig, die oberen nebst den DeckB. lanzettl., spitz-gesägt, Sägezälnne lang-stachelspitzig. $\odot$. Kult. O., in der Neumark nach Rebentisch; auch als Küchengewächs kultiv. Jul. Aug. Bl. violett od. weiss.

2. D. Ruyschiana L. Quirle ährig; B. lineal.-lanzettl., ungeth., ganzrandig, wehrlos. 2. A. u. VorA.; Wallis, Berner A., südl. Tyr., Berge bei Schweinfurt u. Kissingen in Franken, bei Königsberg. Jul. Aug. Bl. violett.

3. D. a ustriacum L. Quirle unterbrochen-ährig; B. gefiedert5th., mit lineal., stumpfen Zpfln., die ast- u. blithenst. 3th.; Zpfl. u. die obersten ungeth. B. stachelspitzig. 24. Felsige O.; Böhm., Unteröstr., Wallis. Mai-Jun. Bl. violett.

VII. Gruppe. STACHYDEEN. Benth. Bl. 2lippig. Stbg. unter der Oberlippe gleichlaufend, genähert, nach dem Verbliihen manchmal zur Seite hinabgebogen, die unteren länger. Zähne des FruchtK. abstehend.

21. MELÍTTIS L. Immenblatt.

1. M. Melissophyllum L. 2. Waldige, buschige 0 .; zerstreut dch d. südl. u. mittl. Geb. Jul. Aug. Bl. purpurn od. weiss od. gescheckt.

22. LAMIUM L. Bienensaug.

a. Röhre der Bl. gerade.

1. L. Orvala L. B. breit-eyf., zugespitzt, an der Basis abgeschnitten od. herzf., etwas zottig, doppelt-tief-gesägt; Röhre der Bl. gerade, an der Basis inwendig haarig-beringelt; Rand des Schlundes vorne beiderseits mit einem 2-3sp. Zahne; Stbk. kahl. 24. Unkult., buschige O.; Litt., Kärnth., Krain, südl. Tyr.-Apr. Mai. Orvala lamioides DC. Bl. purp. Eine Monstrosität: Orvala garganica L.

2. L. amplexicaule L. B. ungleich-stumpf-gekerbt, die unteren herz-eyf. od. rundl., gestielt, die oberen sitzend, stengelumfasrend, etwas lappig; Röhre der $\mathrm{Bl}$. gerade, inwendig nackt; KZähne 
vor u. nach dem Blühen zsschliessend; Stbk. bärtig. $\odot$. Kultiv. 0. März-Oct., im Frühling heimlich. B1. purpurn.

3. L. intermedium Fries. 3l. ungleich-stumpf-gekerbt, die unteren herz-eyf. od. rundl., gestielt, die oberen nieren-herzf., die obersten sehr kurz gestielt, mit verbreitertem Bstiele; Röhre der Bl. gerade, gleichf.-walzl.; Kzähne nach d. Verblühen abstehend; Stbk. bärtig. $\odot$. Kultiv. O.; Oldenb., Hamburg. März-Oct. Bl. purpurn.

4. L. incis u m Willd. B. ungleich-eingeschnittert-gekerbt, die unteren herz-eyf. od. rundl., gestielt, die oberen eyf., fast rautenf., kurz gestielt mit verbreiterten Bstielen; Röhre der Bl. gerade, gleichf.walzl.; Kzähne nach d. Verbliihen abstehend; Stbk. bärtig. ○. Kultiv. O.; Westphalen bis Mecklenbg., Schwz. März-Oct. L. dissectum With. L. hybridum DC. Bl. purpurn.

b. Röhre der Bl. über der Basis gekriimmt, unter der Krümmung schmäler u. enger.

5. L. pu rpureum L. B. ey-herzf., ungleich-gckerbt-gesägt, gestielt, die Stiele alle gleichbreit; Röhre der Bl. über der Basis gekrïmmt, unter der Krümmung enger, an der Einschnïrung inwendig mit einer Haarleiste; Schlund der Bl. beiderseits mit 2 Zähnchen, wovon das obere pfrieml.; Kzähne nach dem Verblïhen abstehend; Stbk. bärtig. $\odot$. Kultiv. O. März-Oct. Bl. purp.

6. L. m aculatum L. B. ey-herzf., zugespitzt, ungleich-gesägt; Röhre der Bl. gekrümmt, über der Basis bauchig-erweitert, unter der Erweiterung eingeschnürt u. inwendig mit einer Haarleiste, Einschnürung $u$. Leiste quer; Rand des Schlundes abgerundet, mit einem pfriemlichen Zahne bezeichnet; Stbk. bärtig. 2. Feuchte Waldränd., Wege. Apr.-Oct. Bl. purpurn., Unterlippe lila, purp.-gefleckt.

7. L. al b um L. B. ey-herzf., zugespitzt, ungleich-gesägt; Rölıre der Bl. gekrï̈mmt, über der Basis mit einer Kerbe erweitert, unter der Kerbe zsgeschnürt, $u$. inwendig mit einer Haarleiste, Zschnürung. $u$. Leiste schief-aufsteigend, Schlundränder mit 3 kleinen u. einem längeren, pfrieml. Zähnchen; Stbk. bärtig. 24. Zäune, Mauern. Apr. Mai. Bl. weiss, untere Lippe blass-olivengrün-gefleckt.

23. GALEÓBDOLON Huds. Waldnessel.

1. G. I ut e um Huds. 2. Wälder, feuchtes Gebüisch. Mai. Jun. G. vulgare Pers. Galeopsis Galeobdolon L. Bl. gelb, der mittlere Lappen der Unterlippe überall $u$. die seitenst. an der Basis dottergelb, mit bräunlichen Flecken. Exèmplare mit grösseren lanzettl. B.: G. vulgare $\beta$. montanum Pers.

\section{GALEÓPSiS L. Hohlzahn.}

1. G. Lád an u m L. St. v. abwärts angedriickten, weichen Haaren flaumig, unter den Gelenken nicht verdickt; B. lanzettl. od. längl.- 
lanzeltl., gesägt od. fast ganzrandig; obere Lippe der Bl. schwachgezähnelt. $\odot$. Unter d. Saat. Jul. Aug. Bl. purpurn, mit einem gelblichweissen, purpurn-gefleckten Hofe auf der Basis der Unterlippe. Var. $\alpha$. latifolia: B. längl.- od. ey-lanzettf., entfernt-stumpfl.-gesägt. G. latifolia Hoffm. Röhre der Bl. noch einmal so lang als d. K., od. nur so lang. - $\beta$. latifolia parviflora: wie die vorhergehende, aber die Bl. nicht halb so gross. G. intermedia Vill. G. parviflora Lam. $-\gamma$. canescens: B. ein wenig schmäler, mit wenigeren Sägezähnen; DeckB. an der Spitze oft zuriickgebogen; St. oberwärts u. $K$. kurzh., Haare abstehend ohne Drüsen, od. nur wenige Drüsenhaare eingemischt. G. canescens SchuIt., MIB. $-\delta$. angu.stifolia: B. schmäler lanzettl. od. lineal.-lanzettl., am Rande mit wenigen entfernten Zühnen, oft ganzrandig; Kzähne u. DeckB. schmäler, zurückgebogen, Haare alle angedriickt. G. angustifolia Ehrh., Hoffm. Var. Bl. 2mal kleiner.

2. G. ochrole uca Lam. St. v. abwärts angedrückten, weichen Haaren flaumig, unter den Gelenken nicht verdickt; $B$. gesägt, die stengelst. eyf., die astst. ey-lanzettf.; obere Lippe der Bl. eingeschnitten-gezähnelt. $\odot$. Aecker, Sandfelder. Jul. Aug. G. cannabina Pollich. G. villosa Huds. Bl. gross, gelblichweiss, mit einem schwefelgelben Hofe an der Basis der Unterlippe.

3. G. Tetrahit L. St. steifh., unter den Gelenken verdickt; B. längl.-eyf., zugespitzt; Röhre der Bl. so lang als der $K$. od. kürzer; Mittel-Zpfl. d. Unterlippe fast 4eckig, flach, kleingekerbt, stumpf od. seicht-ausgerandet. $\odot$. Aecker, WäId., Schutt, Wege. Jul. Aug. Bl. hell-purpurn od. weiss, mit einem schwefelgelben, purpurn-gefleckten Hofe an der Basis der Unterlippe. Var. mit halb so grossen Bth.

4. G. bifida v. Bönningh. St. steifh., unter den Gelekken verdickt; B. längl.-eyf., zugespitzt; Röhre der Bl. nicht so lang als der $K$.; Mittel-Zpfl. der Unterlippe längl., ganzrandig, an der Spitze ausgerandet, später am Rande zurückgerollt. $\odot$. Aecker, Wäld., Wege. Jul. Aug. Bl. klein, rosenroth, der Mittel-Zpfl. der Unterlippe dunkler-purpurn od. violett, mit einem weisslichen Rande umgeben $u$. an der Basis mit 2 gelben Flecken bemalt. Unterste DeckB. der Quirle meistens blattig.

5. G. versicolor Curt. St. steifh., unter den Gelenken verdickt; Bl. längl.-eyf., zugespitzt; Röhre der Bl. roch einmal so lang als $\operatorname{der} K$.; Mittel-Zpfl. der Unterlippe rundl.-4eckig, flach, kleingekerbt, stumpf od. ausgerandet. $\odot$. Hainc, Flusskies; nördl. Geb., Böhm., Schles. u. VorA. des südl. Geb. Jul. Aug. G. canuabina Roth, nicht Pollich. G. Tetrahit $\beta$. L. Bl. gross, schwefelgelb, Unterlippe an der Basis citrongelb, die seitenst. Zpfl. v. der Mitte an weiss, der mittlere violctt, weisslich berandet.

6. G. pubescens Bess. St. mit abwärts angedrücktem, weichem 
Flaume bedeckt, unter den Gelenken steifh. $u$. etwas verdickt; B. breit-eyf., zugespitzt, die unteren fast herzf.; Röhre der BI. länger als der K.; Mittel- $Z$ pfl. der Unterlippe fast 4 eckig; flach, kleingekerbt, seicht-ausgerandet. $\odot$. Aecker, Wege; zerstr. deh das Geb. Jul. Aug. BI. meist satt-purpurn, auf der Basis der Unterlippe heller u. daselbst purpurn-gefleckt, Röhre weissl., oberwärts bräunlich gelb.

\section{STACHYS L. Ziest.}

a. Quirle reichbth.; BI. purpurn.

1. S. germanica L. Quirle reichbth.; St. aufrecht, v. einfachen Haaren dicht-wollig-zottig; $B$. gestielt, ey-herzf., gekerbt, wollig-filzig, die oberen sitzend, sclimäler, lanzettl.; Kzähne eyf., zugespitzt, stachelspitzig, stechend. $\odot$. Steinige, unkult. O., Wege. Jul. Aug. Bl. purpurn.

2. S. italica Miller. Quirle reichbth.; St. aufrecht, wollig-filzig; B. gestielt, klcingekerbt, filzig, die stengelst. längl., an d. Basis abgerundet od. fast herzf., die untersten in den Bsticl verschmälert, die oberen sitzend, fast 3eckig-єyf.; Kzähne lanzettl., zugespitzt, dornigstachelspitzig. 24. Steinige O.; Istr., Fiume. Jul. Aug. S. salviaefolia Tenore, K. syn. ed. 1. BI. purpurn.

3. S. al pin a L. Quirle reichbth.; St. aufrecht, rauhh., oberwärts drüsig-behaart; B. gestielt, ey-herzf., spitz, gesägt; Kzähne eyf., stumpflich, stachelspitzig. 24. Wälder höherer Gebirge, VorA.; zerstr. dch d. Geb. Jul. Aug. Bl. bräunlich-purpurn.

b. Quirle 2-6bth.; BI. purpurn.

4. S. sylvatica L. Quirle 6bth.; St. aufrecht, rauhh., oberwärts ästig $u$. drüsig-behaart; $B$. gestielt, ey-herzf., zugespitzt, gesägt, rauhh.; Kzähne aus 3eckiger Basis pfrieml., stachelspitzig; Bl. noch einmal so lang als der K.; die unterirdischen Ausläufer an der Spitze gleich-dick. 2. Waldige, etwas feuchte O. Jul. Aug. Bth. braun-purpurn, Unterlippe mit schlängelichen, weisslichen Streifchen. Die Röhre der Bl. von der Einschnürung an bis zum Schlunde gleich-breit.

5. S. a mbigua Smith. Quirle 6bth.; St. aufrecht, von abwärts gebogenen Haaren steifh.; B. gestielt, aus herzf. Basis lanzettl. od. ey-lanzettf., zugespitzt, gesägt; Kzähne aus 3eckiger Basis pfrieml., zugespitzt; Bl. noch einmal so lang als der K.; die unterirdischen Ausläufer an d. Spitze keulig-verdickt. 2. Feuchte $\mathrm{O}$; ; sehr zerstr. dch das Gebiet. Jul. Aug. BI. der folgend., aber trïber; Röhre der Bl. v. der Einschniirung an nach oben allmählig etwas weiter.

6. S. palustris L. Quirle 6-12bth.; St. aufrecht, einfach, steifh. od. v. herabgebogenen Haaren kurzh.; B. aus herzf. Basis lanzettl., spitz, gekerbt-gesägt, flaumig, die unteren kurz-gestielt, die oberen sitzend, halbstengelumfassend; Kzälnne aus 3eckiger Basis 
pfriemlich, stachelspitzig; Bl. noch einmal so lang als d. K.; die unterirdischen Ausläufer an der Spitze keulig-verdickt. 24. Ufer, sumpfige Wiesen, feuchte Aecker. Jul. Aug. Bl. purpurn, mit schlängelichen weissen Streifchen auf der Unterlippe.

7. S. arvensis L. Quirle 6bth.; St. steifl., an der Basis ästig, Aeste aufstrebend; $B$. gestielt, ey-herzf., stumpf, gekerbt, zerstr.-behaart, die bliithenst. sitzend, eyf.-längl., begrannt; $K$. fast so lang als die $B l$., Zähne lanzettl., stachelspitzig. $\odot$. Kult. O., sehr zerstr. deh d. Geb. Jul.-Oct. Bl. bleichröthl.

c. Quirle 2-6bth.; Bl. gelbl.-weiss.

8. S. annua L. Quirle 4-6bth.; St. v. der Basis an bis zur Spitze ästig, oberwärts flaumig; $B$. kahl, gestielt, gekerbt-gesägt, die unteren oval-längl., die blütheltst.-lanzettl., zugespitzt, ganzrandig, kurz-stachelspitzig; K. zottig, Zähne kürzer als die Röhre der Bl., lanzettl., stachelspitzig-pfrieml., Stachelspitze fast bis an das Ende flaumig. $\odot$. Unter d. Saat; zerstr. dch d. Geb. Jul.-Oct.

9. S. maritima L. Quirle meist 6 bth.; St. aufstrebend, oberwärts nebst $d$. oberen B. filzig-zottig; $B$. gestielt, oval-längl., gekerbt, stumpf, in den Bstiel verschmälert, die blüthenst. eyf.-lärigl., stumpf, etwas bespitzt, ganzrandig, wehrlos; K. filzig-zottig, Zähne länger als die Röhre der Bl., ey-lanzettf., zugespitzt, bis in die Spitze flaumig. 2. Meeresufer; bei Monfalcone, Triest $u$. in Istr. Jun. Jul.

10. S. recta L. Quirle 6-10bth.; St. aufrecht od. aufstrebend und nebst den B. kurzh.; B. längl. od. lanzettl., gekerbt-gesägt, nach d. Basis verschmälert, die unteren gestielt, die oberen blüthenst. eyf., zugespitzt, ganzrandig, begrannt; K. rauhh., Zähne 3eckig, zugespitzt, mit einer kahlen Stachelspitze endigend, ungefähr so lang als die Röhre d. Bl. 2. Gebirg., steinige O.; zerstr. deh d. Geb. Jun.-Aug.

11. S. subcrenata Visiani. Quirle 6-10bth.; St. aufrecht od. aufstrebend $u$. nebst den $B$. mit zerstreuten kurzen Haaren besetzt; B. längl. od. lanzettl., entfernt-gekerbt od. ganzrandig, nach d. Basis verschmälert, die unteren gestielt, die oberen bthenst. eyf--zugespitzt, ganzrandig, begrannt; K. kurzh., Zähne 3eckig, zugespitzt, mit einer kahlen Stachelspitze endigend, ungefähr so lang als die Röhre der Bl. 2. Unbebaute O. u. Brachfelder, bei Fiume auf Veglia. Jul. Aug.

\section{BETONICA L. Betonie.}

1. B. officinalis L. B. aus herzf. Basis eyf.-längl. oder eyf., rauhh. od. kahl; $K$. aderlos; Bl. auswendig dicht-flaumig, Lippen auseinanderstehend, die obere längl.-eyf., ganzrandig, gekerbt oder ausgerandet, später zurückgebogen; Stbg. kürzer als die halbe Oberlippe. 4. Wiesen, Haiden, lichte Wälder. Jun.-Aug. Bl. pur- 
purn. Var. $\alpha$. hirta: St. kurzh., K. rauhh. B. hirta Leyss. - $\beta$. glabrata: St. nebst den K. kalıl. B. officinalis Spreng. $-\gamma$. stricta: grösser, rauhhaariger, B. breiter. B. stricta Ait. Auf d. A. u. VorA. - . latifolia: stärker, B. breiter, Aehre gedrungen. B. incana Rchb. Diese ist dch Cultur entstanden. - Eine kurzh. Form mit unterbrochenen Quirlen: B. serotina Host. Zwischen allen diesen Variet. keine Grenzen.

2. B. hirsuta L. B. aus herzf. Basis länglich, stumpf-gekerbt, rauhh.; $K$. netzig-aderig; Bl. mit zerstrcutem Flaume bewachsen; Oberlippe kahl, geradevorgestreckt, vorne breiter, sehr stumpf od.

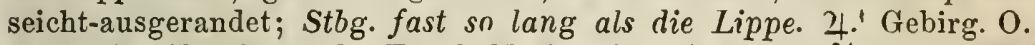
u. VorA.; Wallis, sidd. Tyrol, Krain. Jul. Aug. K. 1/2" lang, Bl. purpurn.

3. B. Alopecuros L. B. aus herzf. Basis breit-eyf., tief-gekerbt, rauhh.; K. oberwärts netzig-aderig; Bl. kahl, Lippen auswendig zottig-bärtig, die obere in eine 2lappige Spitze verschmälert; Stbg. nicht so lang als die halbe Lippe. 2. Triften der A.; Tessin, Tyrol bis Oestr. Jul. Aug. Bl. hell-grünl.-gelb.

\section{SIDERÍTIS L. Gliedkraut.}

1. S. scordioides L. Halbstrauchig, rauhh. od. fast kahl; St. aufstrebend; $B$. eyf., längl. od. längl.-lineal., an der Basis verschmälert, eingeschnitten-gekerbt od. fast ganzrandig, die unteren grannenlos, die oberen stachelspitzig, die blüthenst. breit-eyf., dorniggezähnt. 24. Sonnige O.; am Thoiry u. Dole im Jura. Jul. Aug. Bl. gelb.

2. S. montana I. Krantig; W. einfach; B. lanzettl., in d. Bstiel verschmälert, vorne gesägt; $K$. länger als die Bl., Oberlippe desselben 3sp. $\odot$. Brachäcker, Weinberge; Oestr., bei Hornburg u. Ebersrode in der Fl. von Halle. Jul. Aug. Blkr. zuerst gleichfarbiggelb, bald aber die Lippen am Rande braun, zuletzt überall braun.

3. S. romana L. Krautig; W. einfach; B. ellipt.-lanzettl., in den Bstiel verschmälert, vorne gesägt; $\mathbf{K}$. so lang als die Bl., obere Lippe desselben eyf., ungeth., untere 4zähnig. $\odot$. Aecker, Meeresufer; Istr., Veglia u. Cherso. Jul. Aug. Bl. weiss, Oberlippe manchmal rosenroth.

\section{MARRUBIUMI L. Andorn,}

1. M. peregrinum L. St. sehr ästig, Aeste spreitzend; B. grau-filzig, unten netzaderig, die untersten eyf., stumpf, gekerbt, die ob’eren länglich-lanzettl., gekerbt-gesägt, hinten ganzrandig; Quirle 6-mehrbth., fast gleich-hoch; K. 5-10zälnig, Zähne nebst d. DeckB. pfrieml., filzig. 24. Unkult. O., Schutt; Oestr., Erdeborn Flora v. Halle. Jul. Aug. Bl. weiss, wie die folgenden. Var. u. latifolium: B. breiter, Filz ein wenig lockerer, Stachelspitze der Kzähne weiter 
kahl, an den meisten K. zw. den grösseren Zähnen kleinere. M. peregrinum $a$. I. M. paniculatum Desr. - $\beta$. angustifolium: B. an dem oberen Theile des St. u. der Aeste schmäler, spitzer, entferntergesägt; Filz dichter, an den Zähnen weiter hinauf. M. peregrinum $\beta$. L. M. creticum Mill.

2. M. candidissimum L. St. weiss-filzig, an der Basis ästig, Aeste aufstrebend, einfach; B. filzig, unterseits netzaderig, die unteren breit-eyf., ungleich-gekerbt, die oberen oval, gekerbt-gesägt; Quirle reichbth., fast kugelig; $K$. 5zähnig, Zähne nebst den DeckB. pfriemlich, filzig. 2. Unkult. O.; Littor. Jul. Aug.

3. M. ulgare L. St. weiss-filzig, an der Basis ästig, Aeste aufstrebend, einfach; B. eyf., in den Bstiel hinablaufend, ungleichgekerbt, filzig, runzelig, unterseits netzig-grubig, die unteren herzfrundl.; Quirle reichbth., fast kugelig; K. 10zähnig, Zähne nebst den DeckB. pfriemlich, zottig, v. der Mitte an kahl, an der Spitze hakigzurückgerollt. 2. Sandfelder, Wege; sehr zerstr. dch das Geb. Jul.Sept.

29. BALLÓTA L. Ballote.

1. B. nigra L. B. eyf.; K. 5zähnig, Zähne eyf., begrannt. 4 . Sandfelder, Schutt, Wege. Jun.-Aug. Bl. violett. Var. $\alpha$. foetida: Kzähne breit-eyf., in eine Granne endigend, so lang oder kürzer als der Zahn: B. foetida Lam.; mit weissen Bl.: B. alba L. - $\beta$. ruderalis: Kzähne eyf., in eine Granne, die länger als d. Zahn ist, endigend: B. ruderalis Fries.

30. LEONÚRUS L. Löwenschwanz.

1. L. Cardiaca L. Die unteren B. handf.-5sp., eingeschnittengezühnt, die oberen ganzrandig, 3lappig, an der Basis keilig; K. kahl; untere Lippe der Bl. in einen längl. Zpfl. zsgerollt. 24. Schutt, Wege. Jul. Aug. Bl. purpurn, Unterlippe in der Mitte gelbl. u. punkt., schnell zsgerollt.

\section{CHAITÚRUS Host. Katzenschwanz.}

1. Ch. M arrubiastrum Rchb. $\odot$. Schutt, Wege; östl. u. nördl. Geb. u. Ostheim in Ober-Elsass. Jul. Aug. Bl. röthl. Leonurus Marrubiastrum L.

32. PHLOMIS L. Filzkraut.

1. Ph. tuberosa L. Die wurzelst. B. eyf., an der Basis tiefherzf., gekerbt, die blüthenst. längl.-lanzettl.; DeckB. pfriemlich, steifh.; Röhre d. K. nebst dem St. kahll. 24. Waldige O., Wege; Oestr., Mähr. Jun. Jul. Bl. purpurn.

VHI. Gruppe. SCUTELLARINEEN. Benth. Bl. 2lippig. Stbg. unter der oberen Lippe der Bl. gleichlaufend, genähert. K. 2lip- 
pig, die obere Lippe ungeth. od. kurz-3zähnig; FruchtK. dch die aufeinanderliegenden Lippen platt-geschlossen.

33. SCUTELLARIA L. Helmkraut.

1. S. alpin a L. St. liegend; B. fast sitzend od. kurz-gestielt, eyf., gesïgt-gekerbt, einfarbig; DeckB. häutig, dachig; Aehren 4seitig. 24. A. d. südwestl. Schwz. Jul. Aug. Obere Lippe violett, untere weiss.

2. S. galericulata L. B. aus herzf. Basis längl.-lanzettl., entfernt-stumpf-gekerbt-gesägt; Bth. blattwinkelst., gegenst., eirseitswendig; K. kahl; Röhre der Bl. an der Basis fast reehtwinkelig-gekrümmt, vielmal länger als der K. 2. Feuclite Haine, Ufer. Jul. Aug. Bl. hell-violett.

3. S. hastifolia L. B. längl.-lanzettl., an der Basis beiderseits 1-2zähnig, fast spiessf., die untersten eyf., die obersten 'lanzettl., an der Basis fast herzf.; Bth. blattwinkelst., gegenst., einseitswendig, fast traubig; K. drïsig-flaumig; Röhre d. Bl. an d. Basis fast rechtwinkelig-gekrümmt, vielmal länger als der K. 24. Feuchte Wiesen, Gräben; zerstr. dch d. Geb. Jul. Aug. Bl. violett.

4. S. minor L. B. längl.-lanzettl., an der Basis beiderseits 12zähnig, fast spiessf., die untersten eyf., die obersten lanzettl., an der Basis fast herzf.; Bth. blattwinkelst., gegenst., einseitswendig; K. v. drüsenlosen Haaren kurzh.; Röhre $d$. Bl. gerade, an der Basis ein wenig bauchig. $\hbar$. Sumpfige Wiesen; westl. u. nördl. Geb. Jul. Aug. Bl. violett.

\section{PRUNELLA I. Brunelle.}

1. P. vulgaris L. Die längeren Stbg. an der Spitze mit einem dornf., geraden Zahne versehen; Zähne der oberen KLippe sehr kurz, abgeschnitten, stachelspitzig, die der unteren ey-lanzettf., stachelspitzig, schwach-wimperig; B. gestielt, längl.-eyf., ganzrandig, gezähnt od. fiedersp. 2. Wiesen, Triften, lichte WaldO. Jul. Aug. Bl. violett, seltener weiss. Var. $\beta$. parviflora: Bth. kaum länger als der K. P. parviflora Poir. - $\gamma$. pinnatifida: B. fiedersp.: P. laciniata $\gamma$. L., u. mit weissen Bl. $\beta$. L.

2. P. grandiflor a Jaeq. Stbg. alle wehrlos, die längeren an d. Spitze mit einem kleinen Höcker versehen; Zähne d. oberen KLippe breit-eyf., zugespitzt-begrannt, die der unteren lanzettl., in eine Granne zugespitzt, gewimpert; B. gestielt, längl.-eyf., ganzrandig, gezähnt od. fiedersp. 24. Steinige, trockene O., Kalkboden; zerstr. dch d. Geb. Jul. Aug. P. vulg. $\beta$. grandifl. L. Bl. violett. - Var. $\beta$. pinnatifida: B. fiedersp. P. grandiflora $\beta$. pinnatifida K. u. Z.

3. P. a lb a Pallas. Die längeren Stbg. an d. Spitze mit einem vorwärts gebogenen Dorn versehen; Zähne der oberen KLippe breiteyf., zugespitzt-begrannt, die der unteren lanzettl.-pfrieml., kammf.- 
gewimpert; B. gestielt, längl.-eyf., ganzrandig, gezälınt od. fiedersp. 2. Gebirg., trockene O.; Unteröstr., siidl. Tyr., Schwz., Rheingeg., Blankenburg in Thüring. Jul. Aug. Bl. gelbl.-weiss. Zähne der Unterlippe d. K. zw. d. Nerven nicht aderig. - Var. $\beta$. pinnatifida: mit fiedersp. B. : P. laciniata L., mit Ausschl. d. Var. $\beta$. u. $\gamma$.

IX. Gruppe. PRASIEEN. Benth. B1. 2lippig. Frucht steinfruchtartig.

35. PRASIUMI L. Niccoline.

1. P. maju s L. ち. Steinige, unkult. Hügel; auf der Insel Osero. März-Mai. Bl. weiss.

X. Gruppe. AJUGOIDEEN. Benth. Bl. 1lippig, obere Lippe fehlend od. sehr kurz. Niisse netzig-runzelig.

36. ÁJUGA L. Günsel.

1. A. reptans L. Bth. quirlig; Ausläufer kriechend; B. ausgeschweift- od. schwach-gekerbt. 24. Wiesen, Triften; in die A. hinauf. Mai. Jun. BI. blau, seltener fleischroth od. weiss. Var. $\beta$. alpina: Ausläufer kurz od. fehlend. A. alpina Vill.

2. A. genevensis L. Bth. quirlig; Ausläufer fehlend; die unteren DeckB. 3lappig, gezähnt od. ganzrandig, die oberen kürzer als d. Quirl. 24. Sandfelder, Haiden. Mai. Jun. Bl. blan oder rosenroth.

3. A. pyramidalis L. Bth. quirlig; Ausläufer fehlend; die Deck $B$. ausgeschweift-gekerbt, die oberen noch einmal so lang als d. Quirl. 24. Lichte WaldO. d. VorA.; übrigens sehr zerstr. dch d. Geb., Halle, Berlin u. andere O. Mai. Jun. Bl. blau.

4. A. Chamaepitys Schreb. Bth. einzeln, blattwinkelst., kürzer als das stiitzende B.; die Röirre d. Bl. noch einmal so lang als der K.; B. 3sp., Zpfl. lineal. $\odot$. Aecker, Brachfelder; zerstr. dch d. Geb. Jul.-Oct. Teucrium Chamaepitys L. Bl. weissl., Unterlippe citrongelb, braun-punktirt.

5. A. chia Schreber. Bth. einzeln, blattwinkelst., fast so lang als das stützende B.; die Röhre $d$. Bl. dreimal so lang als der $K$.; B. 3sp., $\mathrm{Zpf}$. lineal. $\odot$. Trockene Haiden u. unfruchtb. Aecker zw. Rovigno u. Dignano in Istr. Jun. Jul.

37. TEUCRIUM L. Gamander.

I. Rotte. Scorodonia Adans. K. 2lippig, obere Lippe eyf., ungeth., untere 4zähnig.

1. T. Scorodonia L. B. herz-eyf. od. herzf.-längl., gekerbtgesägt, runzelig, flaumig; Tr. blattwinkel- u. endst.; obere KLippe eyf., ungeth. 24. Steinige, unkult. O.; zerstr. deh d. Geb. Jul. Aug. Bl. grünl.-weiss. Stbg. braunroth.

II. Rotte. Scordium. K. 5zähnig. Quirle 2-6bth., blatt- 
winkelst., von einander entfernt; die blüthenst. B. den stengelst. gleichgestaltet.

2. T. B o trys L. B. doppelt-fiedersp.-geschlitzt, d. blüthenst. gleichgestaltet; Quirle 2-6bth. $\odot$. Aecker. Jul.-Herbst. Bl. purp.

3. T. Scordium L. $B$. sitzend, lanzettl.-längl., grob-stumpf-gesägt, flaumig, die unteren an der Basis abgerundet, die oberen hinten verschmälert, $\mathbf{u}$. v. der Mitte an abwärts ganzrandig, die blüthenst. gleichgestaltet; Quirle 4bth.; St. zottig. 24. Sumpfige Wiesen, Gräben. Jul. Aug. Bl. purpurn.

4. T. s c or di o i d e s Schreb. B. herzf.-längl., gekerbt-gesägt, weisswollig, die der Aeste herzf.-eyf., an d. Basis breiter, ringsum-gekerbt, die blüthenst. gleichgestaltet; Quirle 4bth.; St. wollig-zottig. 4. Meeresufer; bei Monfalcone. Jun. Jul. Bl. purp.

III. Rotte. Chamaedrys Dillen. K. 5zähnig. Quirle 2-6bth., in eine endst. Tr. zsgestellt, die oberen od. alle blïthenst. B. deckblattförmig.

5. T. Chamaedrys L. B. gestielt, keilig-eyf., eingeschnittengekerbt; Quirle 6bth., traubig; St. liegend, Aeste aufstrebend, flaumig. 24. Unkult., steinige O. Jul.-Sept. Bl. purp.

6. T. flavum L. B. gestielt, fast 3eckig-eyf., stumpf-gekerbt, u. an der Basis fast abgeschnitten; Quirle 6bth., traubig; St. aufstrebend, strauchig. Ђ. Gebirg., steinige O.; Littor. Jul. Aug. Bl. gelb.

IV. Rotte. Polium Benth. K. 5zähnig. Quirle in endst. Köpfchen zsgedrängt.

7. T. Polium L. Graulich-filzig, wollig od. haarig u. steifh.; B. sitzend, keilig, längl. od. lineal., stumpf, gekerbt, am Rande umgerollt, filzig; Köpfchen mundlich u. oval, gestielt; St. halbstrauchig, aufstrebend. 2. Fels., sonnige O.; häufig im südl. Istr., nach Sieber auch bei Aquileja. Jul. Aug. Bl. gelbl.-weiss. Var. $\beta$. vulgare: B. länglich, Köpfchen filzig-wollig. T. Polium L. $-\gamma$. angustifolium: B. lineal. od. lineal.-längl. u. nebst den kleinen Köpfehen grau-filzig, seltener gelbl. T. capitatum L.

8. T. montanum L. B. lineal-lanzettl., ganzrandig, unterseits od. beiderseits grau; Ebensträusse endst.; St. halbstrauchig, gestreckt. 4. Sonnige, steinige O. Jun.-Aug. Var. schmalblätterig: T. supinum L. Bl. weiss.

\section{Ordng. VERBENACEEN. Juss.}

\section{VITEX L. Müllen.}

1. V. Agnus castus J. B. gefingert-5- u. 7zählig, Blättchen lanzettl., zugespitzt, ganzrandig, unterseits grau-filzig; Aehren endst., unterbrochen. Ђ. Sandige O. u. Felsen am Meere; Littor. Jul. Aug. Bl. violett. 


\section{VERBÉNA L. Eisenkraut.}

1. V. officinalis L. Aehren füdlieh, rispig; B. eyf.-längl., 3sp., geschlitzt u. gekerbt, in den breiten Bstiel zsgezogen. $\odot$. Schutt, Wege, Manerk. Jun.-Oct. Bl. hell-purpurn.

\section{Ordng. ACANTHACEEN. Juss.}

\section{ACÁNTHUS L. Bärenklaue.}

1. A. mollis L. B. fiedersp., mit buchtig-gezähnten, wehrlosen Zpfln. 2. Grasige O., unter Gesträuch; Littor., Istrien, Fiume. Mai Jun. Bl. fast $2^{\prime \prime}$ lang, weisslich.

\section{Ordng. LENTIBULARIEEN. Richard.}

\section{PINGUÍCULA L. Fettkrant.}

1. P. alpina L. Sporn kegelf., zurückgekrümmt; Kapsel zugespitzt-gesehnäbelt. $\odot$. Moosige Wiesen d. A. u. VorA., in die Ebenen hinab. Apr. Mai. Bl. weiss, anf der Unterlippe 2 citronengelbe, oft zsfliessende Fleeken.

2. P. vulgaris L. Sporn pfrieml., ziemlich gerade; Kapsel eyf. 4. Torfige Wiesen; zerstr. deh d. Geb. Mai. Jun. Bl. violetteinfarbig od. inwendig mit 2 weissl. Linien od. Flecken. Var. $\alpha . p r a-$ tensis: die Bthe mittelmässig gross. $\mathrm{P}$. vulgaris $\mathrm{d}$. Autoren. $-\beta$. minor: die Bthe fast nur halb so gross. P. gypsophila Wallr. $\gamma$. grandiflora: die Bthe fast noch einmal so gross als an der Var. a. P. grandiflora Lam., K. syn. ed. 1. p. 579. P. leptoceras Rchb. P. vulgaris macrantha Tauseh. $-\delta$. longifolia: die B. länger, schmäler. P. longifolia Ramond., K. syn. ed. 1. p. 579.

2. UTRICUI,ARIA L. Wasserschlauch.

1. U. vulgaris L. B. mach allen Seiten hin abstehend, gefiedert-vielth., im Umrisse eyf., Zpfl. haarfein, entfernt-fein-dornig; Sporn kegelf., Oberlippe von der Länge des Gaumens; Antheren zsgewachsen. 24. Stehendes Wasser. Jun.-Aug. Bl. dottergelb.

2. U. neglecta Lehmann. B. nach allen Seiten hin abstehend, gefiedert-vielth., im Umrisse eyf., Zpfl. haarfein, entfernt-fein-dornig; Sporn kegelf.; Oberlippe 2-3mal so lang als der Gaumen; Antheren frei. 24. In stehenden Wassern; IIambg., Oldenbg., Unterharz. Jul. Aug. Bl. dottergelb.

3. U. in termedi a Hayn. B. 2zeilig, gabelsp.-vielth., im Umrisse nierenf., $Z p f l$. borstlich, dornig-gezälnelt; Sporn kegelf.; Oberlippe ungeth., noch einmal so lang als der Gaumen; d. fruchttrag. Bthstiele aufrecht. 2. Stehendes Wasser; zerstr. deh d. Geb. Jul. Aug. B1. schwefelgelb.

4. U. minor L. B. nach allen Seiten hin abstehend, gabelsp.- 
vielth., im Umrisse kurz-eyf., Zpfl. borstlich, kahl; Sporn sehr kurz, kegelf.; Oberlippe ausgerandet, von der Länge des Gaumens; die fruchttrag. Bthstiele zurückgebogen. 2. Sumpfige O. u. Gräben. Jun. -Aug. Bl. hellgelb.

\section{Ordng. PRIMULACEEN. Vent.}

\section{TRIENTÁLIS L. Trientale.}

1. T. europaea L. 24. Feuchte Gebirgswälder, schwammige Haiden; nördl. Geb., Mähr., Böhm., Schles., Fichtelgbg. , Harz, Schwarzw., Vintschgau in Tyr., Urserenthal d. Schwz. Mai-Jul. Bl. schneeweiss, Ring der Basis gelblichweiss.

\section{LYSIMÁCHIA L. Lysimachie.}

I. Rotte. Naumburgia Mönch. Bth. in gedrungenen, blattwinkelst. Tr. Ein kleiner Zahn zw. den Bl.- Zpfln. Stbg. unten kurz zsgewachsen. S. glatt.

1. L. thyrsiflora L. Tr. blattwinkelst., gestielt, gedrungen, walzl., kürzer als das stützende B.; B. gégen- u. 3- u. 4st., verlängert-lanzettl. 24. Fischteiche, tiefe Sümpfe, Gräben; zerstr. dch d. Geb. Jun. Jul. Bl. gelb.

II. Rotte. Lysimastrum Dub. Bth. rispig, od. blattwinkelst.; Buchten $\mathrm{zw}$. den Bl.-Zpfln zahnlos. S. glatt.

a. Stbg. 10, frei, abwechselnd kleiner u. ohne Stbk.

2. L. ciliata L. St. aufrecht; B. gegenst., 3- od. 4st., gestielt, eyf.-längl., fast herzf., kahl, am Rande rauh, Bstiele gewimpert; Bthsticle blattwinkelst., gegenst. u. quirlig, an d. Spitze nickend; Zpfl. der Bl. rundl., spitz-gekerbt, sehr stumpf, mit einer aufsitzenden Haarspitze; Stbg. 10, abwechselnd ohne Stbk. 4. Gräben u. Ufer; im Geb. d. Fl. v. Spaa, nach Lejeune wirkl. eingebürgert. Jun. Jul. Bl. gelb.

b. Stbg. 5, unterwärts od. z. Hälfte zsgewachsen, den Fruchtkn. bedeckend.

3. L. vulgaris L. St. aufrecht; B. gegenst. oder quirlig, kurzgestielt, längl.-lanzettl. od. eyf., unterseits etwas zottig; Bthstiele aufrecht, wechselst. od. quirlig, traubig; Tr. rispig; $Z_{p f l}$. der $B l$. eyf., ziemlich spitz, ganzrandig, am Rande kahl; Stbg. 5, von der Basis bis zur Mitte zsgewachsen. 2. Sumpfige O., Ufer, Wiesengebüsch. Jun. Jul. Bl. goldgelb. Zipfel des K. breiter od. schmäler, kürzer od. länger als d. Frucht. Var. im Sumpfschlamme mit 4-8 Fuss langen Ausläufern: L. paludosa Baumg.; mit grossen unteren Bthblättern der Endtraube: L. westphalica Weih.

4. L. punctata L. St. aufrecht; B. gegenst. od. quirlig, kurz- 
gestielt, längl.-lanzettl. od. eyf., flaumig; Bthstiele blattwinkelst., gegenst. od. quirlig, 1 bth. od. die untersten 2-3bth.; Zpfl. der Bl. spitz, drüsig-gewimpert; Stbg. 5, von der Basis bis zur Mitte zsgewachsen. 24. Ufer; Oestr., Böhm., Mähr., Schwz. Jun. Jul. Bl. gelb od. an d. Basis rostfarb. Var. Bthstiele d. unteren Quirle 23bth.: L. verticillata MB.

c. Stbg. 5, frei, od. unterwärts kurz-zsgewachsen, den Fruchtkn. nicht bedeckend.

5. L. Nummularia L. St. gestreckt, kriechend; B. gegenst., herzf.-rundl.; Bthstiele blattwinkelst., einzeln, kürzer als die B.; $K$ Zpfl. herzf. 24. Gräben, feuchte Wälder. Jun. JuI. Bl. gelb.

6. L. n e morum L. St. gestreckt; B. gegenst., eyf., od. etwas berzf., spitz, kahl; Bthstiele blattwinkelst., einzeln, länger als das B.; KZpfl. lineal.-pfrieml. 24. Haine, feuchte Laubwälder. Jun. Jul. Bl. gelb.

III. Rotte. Aste rolinum Link. Bth. blattwinkelst.; Buchten zw. den $Z$ pfln. der Bl. zahnlos. Stbg. frei. S. quer-runzelig.

7. L. Linum steliatum L. St. aufrecht; B. gegenst., sitzend, lanzettl., zugespitzt, kalll, am Rande etwas rauh; Bth. blattwinkelst., einzeln; Kzpfl. lanzettl., haarspitzig, 3 mal so lang als die Bl. $\odot$. Sonnige O., Istrien. Jun. Asterolinum stellatum Fl. port. Bl. weisslich.

\section{ANAGÁLLIS L. Gauchheil.}

1. A. arvensis L. St. ansgebreitet; B. gegenst. od. 3st., sitzend, eyf.; Zpfl. der Bl. klein-gekerbt, fein-drüsig-gewimpert, ein werig länger als der $K$; Bthstiele länger als die B. $\odot$. Aecker, kult. 0 . Jun.-Oct. A. phoenicea Lam. BI. mennigfarben, an der Basis blutroth; selt. rosenroth: A. carnea Schrank; od. weiss.

2. A. c a e rulea Schreb. St. ausgebreitet; B. gegenst. oder 3st., sitzend, eyf.; $Z_{p f l}$. der Bl. klein-gekerbt, fast völlig drüsenlos, ein werig länger als der $K$.; Bthstiele ungefähr so lang als die B. $\odot$. Aecker, kult. O. Jun.-Oct. Bl. blau, selten weiss. - Die A. Monelli L. ist auch im bot. Garten zu Erlangen eine planta perennis.

3. A. tenella L. St. fädlich, gestreckt, an der Basis kriechend; B. gegenst., gestielt, rundl.-eyf., kurz-bespitzt; Bthstiele länger als die B.; K. 3mal kürzer als die Bl. 2. Torfige O.; Westph., Ostfriesl., C. Waadt. Jul. Aug. Bl. rosenroth.

\section{CENTÚNCULUS L. Kleinling.}

1. C. minimus L. B. wechselst., eyf.; Bth. sitzend. $\odot$. Aecker, Triften, Haiden. Jun. Jul. Bth. weiss od. blass-rosenroth.

5. ANDRÓSACE I. (Aretia d. Sp. pl. eingeschlossen.) Mannsschild. 
I. Rotte. Aretia L. Stämmchen schr ästig, dichte Rasen bildencl. St. eimbth. Bth. ohne DecklB.

1. A. helvetica Gaud. B. dicht-dachig, lanzettl., von abwärts gekchrten, einfachen Haaren kurzh.; Bth. eimzelu, fast sitzend; KZpH. spitzlich, so lang als die Röhre der Bl. 24. Felsenspalt. der höheren A.; Tyr., Bayern, Schwz. Jul. Aug. A. bryoides DC. Aretia helvetica Schk. Bl. weiss, in der Mitte gelbl., Deckklappen gelb.

2. A. imbric ata Lam. B. dicht-dachig, lanzettl., stumpf, nebst den 'Bthstielen u. K. von sehr kurzen, sternf. Haaren filzig-grau; Bth. einzeln, fast sitzend $u$. aucl gestielt; $K Z$ pfl. stumpf, länger als die Röhre der Bl. 24. Felsen der höchst. A., Wallis, Graubiind., südöstl. Tyrol. Jun. Jul. A. argentea Gärtn. Var. Btlıstiele länger: A. tomentosa Schleich. Saum d. Bl. weiss, selt. rosenroth, Deckklappen roth.

3. A. He eri i (Aretia Hegetschw.). B. dicht-dachig, lanzettl., kurzh. von abstehenden, einfachen u. gabeligen Haaren; Bth. einzeln, fast sitzend od. gestielt; Zpfl. des K. spitz, länger als die Röhre der Bl. 4. Alpen des Kleinthals C. Glarus gegen das Martinslocl in der Höhe von $7-8000^{\prime}$. Heer. Jul. Aug. Bl. rosenroth.

4. A. glacialis Hoppe. B. dicht-genähert, an d. Spitze der. Aeste rosettig, lanzettl., spitzl., an der Basis verschmälert, nebst den Bthstielen u. K. flaumig, die Haarc zerstreut, sternf., sehr kurz, kürzer als der Querdchmesser der Bthstiele; Bth. einzeln, fast sitzend u. auch gestielt; KZpfl. spitz, länger als die Röhre d. Bl. 2. Felsen der höheren A. Jul. Aug. A. pennina Gaud. A. alpina Lam., K. syn. ed. 1. Aretia glacialis Schleich. Bl. rosenroth od. weiss, Deckklappen gelb.

5. A. pubescens DC. B. dicht-genähert, an der Spitze der Aeste rosettig, lanzettl., stumptl., an der Basis verschmälert, nebst den Bthstielen n. K. kurzh-flaumig, die Haare abstehend, von der Länge des Querdchmessers der Bthstiele, einfach, mit gabligen untermischt od. sämmtl. einfach; Bth. einzeln, last sitzend $u$. auch gestielt; KZpfl. spitz, länger als die Röhre der Bl. 2. Höhere A.; d. Schwz. Jun. Jul. A. alpina Gaud. Bl. weiss.

II. Rotte. Chamaeiasme. Stämmchen an der Spitze rosettig, Rasen bildend; Bthstiele doldig, mit einer Hiille umgeben.

6. A. villos a L. W. vielköpfig; Rosetten entfernt, fast kugelig; Schaft, Dolde u. B. von verlängerten, undeutlich-gegliederten Haaren zottig; B. lanzettl., an der Basis verschmälert, ganzrandig; Bthstiele während der Bthezeit so lang od. Kürzer als die Hülle; Bl. länger als der K. 24. Felsen der A. 'Jun.-Aug. Bl. weiss od. rosenroth.

7. A. Chamaeiasme Host., nicht Wulf. W. vielköpfig, rasig; Rosetten flach; Schaft, Dolde u. BRand von verlängerten, deutlichgegliedcrten Haaren zottig; B: lanzettl., an der Basis verschmälert, 
ganzrandig; Bthstiele zur Bthezeit so lang od. kürzer als die Hülle; Bl. länger als der K. 2. Felsen der A. u. VorA. Jun.-Aug. Bl.weiss.

8. A. obtusifolia All. W. vielköpfig, rasig; Schaft nebst den Bthstielen, K. $u$. dem Blattrande flaumig, Haare sehr kurz, an dem Schafte u. den Bthstielchen sternf.; B. lanzettl., nach d. Basis verschmälert, ganzrandig; Bthstiele länger als die Hülle; Bl. länger als der K. 24. Felsen der A. u. Schneegrube d. Sudet. Jun. Jul. A. Chamaeiasme Wulf. Bl. weiss od, röthl. Var. exscapa: die Bth. einzeln auf wurzelst. Stielen.

9. A. I a ctea L. W. vielköpfig, rasig; Schaft nebst d. Bthstielen u. K. ganz kahl; B. lanzettl.-lineal. u. lineal., ganzrandig, kahl od. an der Spitze od. dem Rande spärlich-gewimpert; Bthstiele verlängert; Bl. länger als der K. 2. KalkA. Jul. Aug. Bl. weiss, Schlund goldgelb.

10. A. carnea L. W. vielköpfig, rasig; Schaft nebst den Bthstielchen flaumig, v. sehr kurzen, fein-sternf. Haaren; B. lineal., von der Basis nach der Spitze verschmälert, kahl, kurz-gewimpert, unterseits gekielt, an der Spitze zurückgekrümmt; Bthstiele ungefähr so lang als die Hülle; Bl. länger als d.K. 2. Granitfelsen; Ballon d. Voges., A. d. Schwz. (Tyrol?) Jul. Aug. Bl. rosenroth, Schlund gelb.

III. Rotte. TwW. einfach, eine Rosette trag., ohne bleibende Stämmchen. Bth. dôldig:

11. A. elongata L. W. einfach, mit einer Rosette v. B. bekrönt; B. lanzettl., gezähnt, am Rande nebst dem Schafte u. der Dolde von sehr kurzen fein-sternf. Haaren flaumig; $K$. länger als die Bl. $\odot$. Sonnige, unkult. O.; sehr zerstr. dch d. Geb. Jul. Aug. Bl. weiss, Schlund gelbl.

12. A. septentrionalis L. W. einfach, mit einer Rosette v. B. bekrönt; $\boldsymbol{B}$. lanzettl., gezähnt, nebst dem Schafte $\boldsymbol{u}$. den Bthstielen von sehr kurzen, fein-sternf. Haaren flaumig; $K$. kahl, kürzer als die Bl.; Zpfl. der Bl. ungeth. $\odot$. Sandfelder, kult. O.; sehr zerstr. dch d. Geb. Mai. Jun. Bl. weiss, Schlund gelb.

13. A. maxima L. W. einfach, mit einer Rosette v. B. gekrönt; B. elliptisch od. lanzettl., gezähnt; Schaft u. Dolde behaart, die Haare gegliedert; $K$. länger als die $B l$., der fruchttrag. sehr gross. ○. Aecker; Rhein- u. Moselthal, Wallis, Unteröstr. Apr. Mai. Bl. weiss od. röthl., Schlund gelbl.

6. ARÉTIA Gaud.” Aretie.

1. A. Vitaliana L. Primelartige A. 2. Felsen d. höchsten GranitA.; südl. Wallis, südl. Tyr. Jul. Aug. Primula Vitaliana L. Bl. gelb.

7. Prímula L. Primel.

I. Rotte, Aleuritia Dub. Die jüngeren B, rückwärts zsge- 
rollt, nach der Entwickelung flach, wenig runzelig u. unterseits mehr od. weniger mit Mehl bestreut. Hüllblättchen an der Basiø sackf.-verdickt. Deckklappen am Schlunde.

1. P.' farinosa L. B. verkehrteyf.-längl., stumpf-gekerbt, kahl, unterseits dicht-bepudert; Dolde reichbth.; KZähne eyf.; Röhre der Bl. am Schlunde mit kurzen Deckklappen, meist anderthalbmal so lang als der K. u. Saum; Hüllblättchen lineal., an d. Basis sackartig-verdickt. 24. Torfige, sumpf. Wiesen d. Ebenen. Gebirg. u. A.; südl. u. nördl. Geb., zerstr. dch d. mittl. Jun.-Aug. Bl. fleischroth. Var. $\beta$. denudata: B. unterseits ohne Puder.

2. P. longifl o r a All. $B$. verkehrteyf.-längl., schwach-gekerbt, kahl, unterseits dicht-bepudert; Dolde 3-5bth.; KZähne lanzettl., Röhre der Bl. am Schlunde mit kurzen Deckklappen, fast 3mal so lang als der K. u. Saum; Hüllblättchen lineal., an der Basis sackartig-verdickt. 24. Triften der höchsten A. Jun. Jul. Bl. fleischroth.

II. Rotte. Primulastrum Dub. Die jüngeren B. riickwärts zsgerollt, runzelig, flaumig od. filzig, unbestäubt. K. geschärftkantig. Deckklappen am Schlunde.

3. P. a ca ulis Jacq. B. längl.-verkehrteyf., nach dem Bstiel verschmälert, gezähnt, runzelig, unterseits auf den Adern kurzh.; Bthstiele wurzelst., 1 bth. u. nebst dem K. zottig, od. auf einem Schafte doldig; die Haare der Bthstielchen länger als der Querdchmesser des Bthstielchens; Zähne des geschärft-kantigen, fast 5sp. K. lanzettl., zugespitzt. 24. Wälder d. VorA. u. auf den Ebenen im südl. Geb. März. Apr. P. veris $\gamma$. acaulis L. P. grandiflora Lam. Bl. schwefelgelb, mit einem sattgelben Schlunde, selten fleischroth. Die mit einem Schafte versehene bildet die Variet. $\beta$. caulescens.

4. P. elatior Jacq. B. eyf.-länglich od. eyf., in den geflügelten-gezähnten Bstiel hinabziehend, runzelig, wellig-gekerbt, unterseits nebst dem Schafte u. der Dolde kurzh.; Haare d. Bthstielchen so lang als der Querdchmesser des Bthstielchens; Dolde mehrbth.; Zähne des geschärft-kantigen $K$. eyf., zugespitzt; Bl. trichterf., $\mathrm{Zp} f$. des Saumes flach; Hüllblättchen aus eyf. Basis pfrieml. 24. Wälder, Waldwiesen. März. Apr. P. veris $\beta$. elatior I. Bth. schwefelgelb; var. ein dottergelber Kreis am Schlunde, $u$. mit roth. Bl.

5. P. officinalis Jacq. B. eyf,, od. etwas herzf., in den geflügelten, gezähnten Bstiel hinabziehend, runzelig, wellig-gekerbt, unterseits nebst dem Schafte $u$. der Dolde sammetig; Dolde reichbth.; Zähne des geschärft-kantigen, aufgeblasenen K. eyf., kurz-zugespitzt; Saum der Bl. glockig-concav; Hüllblättchen aus eyf. Basis pfrieml. 4. Wiesen, lichte WaldO. Apr. u. Mai. P. veris $\alpha$. officinalis $L$. Bl. gelb, am Schlunde 5 safranfarb. Flecken. Var. $\beta$. ampliata K. syn. ed. 1.: Kelch glockig-erweitert.

6. P. suaveolens Bertolon. B. eyf. od. etwas herzf., in den 
geflügelten, etwas gezähnten Bstiel hinabziehend, wellig-gekerbt, unten schneeweiss-filzig; Schaft u. Dolde sammetig; Dolde reichbth.; Zähne des geschärft-kantigen, aufgeblasenen K. eyf., kurz-zugespitzt; Saum der Bl. glockig-concav; Hiillblättchen aus eyf. Basis pfrieml. 4. Bergwiesen; am Monte maggiore u. Plavnik im Litt. Apr. Mai. P. Columnae Tenore.

III. Rotte. Auricula. Die jüngeren B. einwärts-zsgerollt, nach der Entwickelung flach, u. etwas fleischig, aber nicht runzelig. K. nicht kantig. Schlund ohne Deckklappen.

a. Dolden der grösseren Exemplare reichbth.; Bthstiele ungleich, die längeren $2-3 \mathrm{mal}$ so lang als der $\mathrm{K}$.

7. P.Auricula L. B. vkteyf,, gezähnt-gesägt od. fast ganzrandig, am Rande bepudert, od. dicht bewimpert mit kurzen Drüsenhaaren; Schaft kahl od. oberwärts so wie die Bthstielchen u. K. bepudert; Hülle viel kürzer als die Bthstielchen, Blättchen eyf., stumpf; Schlund der Bl. dicht bepudert; Stbg. des kurzgriffeligen Geschlechtes in dem Schlunde eingefügt; Kapsel ein wenig länger als der K. 4. A. u. VorA. u. Torfgebrüche v. Oberschwaben u. Oberbayern. Apr. Mai, in den A. nach geschmolzenem Schnee. Bl. gelb, selten roth. Var. die B. kahl od. mit kurzgestielten Drischen bestreut, der Rand derselben sehr kurz bewimpert $u$. nicht od. schwach bepudert, od. dicht bepudert, so dass die Wimpern bedeckt sind, od. $\beta$. die Wimpern längər, $u$. wenn die B. zugleich mit kurzen Drüsenhärchen bestreut sind: P. ciliata Moretti. Diese hat zuweilen unbepuderte K.

8. P. pubescens Jacq., (nach einem Exempl. v. Wulf in Frölich's Sammlung). B. vkteyf.-längl., au der Spitze gezähnt-gesägt, am Rande dicht-bewimpert mit kurzen Drüsenhaaren; Schaft kahl, od. oberwärts so wie die Bthstielchen $\mathrm{u}$. K. bepudert; Hülle viel kürzer als die Bthstielchen, Blättchen eyf., stumpf; Schlund der Bl. dichtbepudert; Stbg. d. kurzgriffeligen Geschlechtes etwas über der Mitte der Röhre eingefügt; Kiapsel.... 2. Um Pregraten bei Windisch Matray in Tyr., u. auf d. gleichnamigen A., Wulfen. April, in d. A. später. P. helvetica Schleich., kultiv. v. Schleicher. Bl. purp.

9. P. rha etica Gaud. B. längl.-vkteyf. od. eyf., an der Spitze gezähnt-gesägt, am Rande dicht bewimpert von kurzen Drüsenhaaren; Schaft u. Bthstielchen kahl od. nit sehr feinen sitzenden Drüsen bestreut; Hülle viel kürzer als die Bthstielchen, Blättchen eyf., stumpf; Schlund nicht bepudert; Stbg. des kurzgriffeligen Geschlechtes unter dem oberen Ende der Röhre eingefügt. 7. A. v. Graubünd. Gaud. Jun. Jul. Bl. purp. P. alpina Rclıb. Ic. Der P. villosa sehr ähnlich, aber die B. länglicher, weniger gezähnt, der K. bemerklich kleiner. Stbg. höher eingefügt $u$. der Ueberzug ganz verschieden.

10. P. pedemont a na Thomas. B. längl. od. vkteyf., geschweiftschwach-gezähnt, am Rande wimperig von kurzen Drüseuhaaren; 
Schaft $u$. Bthstielchen mit sehr kurzgestielten, klebrigen Drüsen bestreut; Hülle vielmal kürzer als die Bthstielchen; Blättchen eyf., stumpf; Schlund nicht bepudert; Stbg. des kurzgriffeligen Geschlechtes etwas über der Mitte der Röhre eingefïgt; Kapsel v. der Länge des K. 24. Schwz., Walliser u. Bïndner Gbge, Hegetschweiler, Vallee de Lanzo in Frölich's Samml. Jun. Jul. Die Drïsen am Rande der B. meistens fleischroth.

11. P. villos a Jacq. 'B. vkteyf. od. rundl., in den Bstiel zsgezogen, von der Mitte an nach der Spitze gezälnt-gesägt, beiderseits klebrig-flaumig und mit drüsentrag. Haaren bewimpert; Schaft $u$. Bthstielchen kurz-zottig, von gegliederten, mit blebrigen Drüsen besetzten Haaren; Hülle vielmal kürzer als d. Bthstielchen, Blättchen eyf., stumpf; Schlund nicht bepudert; Stbg. des kurz-griffeligen Goschlechtes etwas über die Mitte der Röhre eingefügt; Kapsel um die Hälfte kürzer als der $K$. 2. Felsen der höheren A. Mai-Jul. P. ciliata Schrank. P. hirsuta DC. Bl. hellpurp., selten weiss. K. kreiself.

12. P. latifolia Lapeyrouse. B. vkteyf. od. längl.-vkteyf., in den Bstiel verlaufend, von der Mitte nach der Spilze gezähnt-gesägt, beiderseits mit kurzen Haaren bestreut u. mit driisentrag. Haaren bewimpert; Schaft u. Bthstielehen mit kurzen Drüsenhärehen bestreut; Hülle vielmal kürzer als die Bthsticlehen, Blättchen eyf.stumpf; Schlund schwach-bepudert; Stbg. des liurzgriffeligen Geschlechtes in dem Schlunde eingefügt; Kapsel ein uienig länger als $\operatorname{der}$ K. 2. A. d. Schwz. Jun. Jul. P. graveolens Hegetselıw. P. viscosa DC. Geruch wie Geran. robertianum nach Heg. Bl. purp. Kelch halb-kugelig. Die B. weich, getrocknet fast dehscheinend.

13. P. venusta Host. $B$. vkteyf., gezähnt-gesägt od. fast ganzrandig, beiderseits kahl; Schaft kahl, oberwärts nebst d. Dolde spärlich-, die K. am Rande u. inwendig dicht-bepudert; Hülle vielmal kürzer als die Bthstielchen, Blättchen eyf., stumpf; K. 3mal kürzer als die Röhre der Bl., Zähne desselben eyf., inwendig u. am Rande bepudert; Kapsel ungefähr so lang als der K. 2. Gebirg. u. VorA.; bei Idria. Apr. Mai. Bl. purpurn.

14. P. carnioli c a Jaeq. B. vkteyf. od. längl., ausgeschweiftgekerbt od. ganzrandig nebst dem Seliafte, den Bthstielen u. K. kahl; Hülle vielmal kürzer als die Bthstielchen; Blältchen cyf., stumpf; K. 3mal kürzer als die Röhre der Bl., Zälıne desselben eyf., kahl; Kapsel ungefähr so lang als der K. 24. Gebirge u. A.; Krain. Mai. Jun. B1. purpurn.

b. Dolde meist armbth., die Bth. sehr kurzgestielt od. sitzend.

15. P. s pectabilis Tratt. B. ellipt.-lanzettl. od. lanzettl., ganzrandig, kahl, knorpelig-berandet, der Rand sehr kurz-gewimpert od. gezähnelt; Schaft von Driischen etwas rauh, 1-3bth.; Hüllblättchen 
lineal., so lang als die Bthstielchen $u$. länger; $K$. röhrig-glockig, kürzer als die Röhre der Bl. 24. Kiese d. A. u. VorA., v. Salzbg., Tyrol, Krain, Stmk., Oestr. Jul. - Aug. P. Clusiana Tausch. Bl. purpurn.

16. P. integrifolia L., nach dem Citate aus Haller u. nach dem StandO. B. elliptisch od. längl., kahl od. oberseits zerstr.-behaart, am (nicht knorpeligen) Rande so wie der Schaft zottig; Schaft $1-3$ bth. ; Hüllblättchen lineal., länger als d. Bthstielchen; K. röhrigglockig, kürzer als die Röhre der Bl. 24. Höchste A. d. Schwz. Jul. Aug. P. Candolleana Rchb. Bl. purp.

17. P. D in y a n a Lagger. B. längl. - od. lanzettl.-keilig, am oberen Ende geschweift od. gezähnelt, mit grannenlosen Zähnen, von sehr kurzen, locker aufgestreuten Haaren flaumig, am Rande dichtu. kurz-wimperig; Schaft 2-4bth.; Bth. kurzgestielt; Blättchen der Hülle ey-lanzettf., länger als die Bthstielchen; K. glockig. 24. Hohe A.; auf dem Albula in Graubünd. Jun. Jul. P. Muretiana Moritzi. P. Mureti De Charpentier. Bl. purp.

18. P. glutinosa Wulf. B. keilig-lanzettl., stumpf, klebrig $u$. nebst dem Schafte völlig kahl, von der Mitte zur Spitze gesägt mit grannenlosen Zähnen; Schaft 3-5bth.; Bth. fast sitzend; Hüllblättchen bis zur Spitze der Zähne des K. od. noch weiter hinaufreichend; Röhre des K. glockig-röhrig. 4. Feuchte O. der höheren A.; Tyr., Kärnth., Stmk. Jul. Aug. Bl. violett.

19. P. Alli oni Loiseleur. B. vkteyf., stachelspitzig - gezähnelt, od. fast ganzrandig, auf beiden Seiten nebst dem Schafte u. den K. drüsig-haarig $u$. klebrig; Schaft 1-2bth.; Bth. sehr kurz gestielt; Hüllblättchen keilf., länger als die Bthstielchen. 24. Kalkfelsen auf d. Berge Castellazo di Paneveggio in Fiemme $u$. von da östlich, an d. obersten Baumgrenze. Facch. Jun. P. glutinosa All.

20. P. Floerkean a Schrad. B. vkteyf., an der Basis keilig u. nebst $d$. Schafte kahl, etwas klebrig, vorne abgerundet $u$. fast von d. Mitte an gekerbt-gezähnt, Zähne zugespitzt-stachelspitzig; Schaft 1-5bth.; Bth. sehr kurz-gestielt; Hüllblättchen oval-längl., ungefähr so lang als der K.; K. röhrig-glockig. 24. Höchste A.; Oberkärnth., südl. Tyr. Jul. Aug. Bl. purpurn.

21. P. minima L. B. vkteyf.-keilig u. nebst dem Schafte kahl, vorne abgeschnitten-stumpf $u$. gekerbt, Kerben zugespitzt-stachelspitzig; Schaft 1-2bth.; Bth. fast sitzend; Hüllblättchen lineal., ungefähr so lang als der K.; K. röhrig-glockig. 24. Felsige $O$. der A.; Gotth. u. v. Graubünd. dch Tyr. u. Salzbg. bis Oestr.; Schneekoppe der Sudet. Jul. Aug. Bl. rosenroth, selt. weiss. Var. $\beta$. pubescens: B. 11/2" lang, etwas flaumig. P. truncata Lehm. Die Form mit breiteren Zpfln. der Bl. ist P. Sauteri Schultz. 
8. HOTTÓNLA L. Hottonie.

1. H. palustri s L. Tr. endständig, quirlig; Bth. gestielt; Glieder des St. gleichdick; Bl. länger als der K.; B. kammf.-fiedersp. 4. Gräben, stehende u. langsam fliessende Wasser. Mai. Jun. Bl. weiss od. hellrosenroth.

9. CORTÚSA L. Cortuse.

1. C. Matthi oli L. 24. Nasse O. der AThäler u. VorA.; Schwab., Bayern, Tyr., Stmk. Mai. Jun. Bl. purp.

\section{SOLDANÉLLA L. Drottelblume.}

1. S. montan a Willd. B. rundlich, seicht-entfernt-gekerbt; Schaft 2-4bth.; Bthstielchen flaumig, Flaum sehr kurz u. drüsentrag.; Bl. bis zur Mitte gespalten, Schlundschuppen ungefähr so lang als die Stbf.; Gf. so lang als die Bl. od. länger. 24. Torfige, moorige O., Gbge u. VorA.; Salzbg., Oestr., Böhm. Mai-Jul. Bl. getrocknet violett.

2. S. al pina L. B. rundl--nierenf., ganzrandig od. etwas ausgeschweift; Schaft 2-4bth.; Bthstielchen von kleinen, sitzenden Drüsen etwas rauh; Bl. bis zur Mitte gespalten, Schlundschuppen so lang als die Stbf.; Gf. so lang als die Blkr. od. länger. 2. A. u. VorA.; Feldberg im Schwarzw., Mähr. Geb. Mai-Jul. Bl. violett, ein dunkler Mittelnerv auf d. Zpfln.

3. S. pusilla Baumg. B. herz-nierenf., etwas ausgeschweift; Schaft 1bth.; Bthstielchen von kleinen, sitzenden Drüsen etwas rauh; Bl. kaum auf den dritten Theil gespalten, $\mathrm{Zpfl}$. gerade, Schlundschuppen fehlend; Gf. kürzer als die Bl. 2. Höchste A. Mai-Jul. Bl. fast kupferroth, in das Bläuliche spielend.

4. S. minima Hopp. B. kreisrund; Schaft 1bth.; Bthstielchen flaumig, Flaum sehr kurz, drüsentrag.; Bl. bis auf den dritten Theil gespalten, Zpfl. an der Spitze abstehend, Schlundschuppen sehr kurz od. fehlend; Gf. kürzer als die Bl. 2. A. u. VorA.; Tyr., Kärnth., Krain, Stmk. Jun. Jul. Bl. hell-lila, inwendig bis an die Zpfl. purpurn-gestreift.

\section{CYCLÁMEN L. Erdscheibe.}

1. C. europaeum L. Bl. am Schlunde nicht gezähnt, Zpfl. spitz; B. ausgeschweift od. kleingekerbt, rundl. od. eyf., mit einem Spitzchen, an der Basis tief-herzf., mit spitzer Bucht, Kerben grannenlos. 4. Bergwälder, VorA.; südl. Geb. u. Böhm., Mähr. Aug.Oct. Bl. purp.

2. C. hederifolium Ait. Bl. am Schlunde 10zähnig, Zpfl. spitz; B. eyf., gekerbt u. eckig, an der Basis tiefherzf., mit geschlossener Bucht, Kerben u. Ecken grannenlos. 24. Felsige 0.; im Wallis. Blühet im Spätherbste, vor der Entwickelung der B. C. neapolitanum Tenore. Bl. purpurn. 
3. C. repandum Sibth. u. Sm. Bl. am Schlunde ungezähnt, Zpfl. spitz; B. herzf., ausgeschweift u. eckig, Ecken u. Kerben kurzstachelspitzig. 2. Haine; Istrien. Apr. C. hederaefolium Ten. BI. purp.

12. SÁMOLUS L. Pungen.

1. S. Valer andi L. Aufrecht; B. vkteyf. od. längl., stumpf; Tr. zuletzt verlängert; DeckB. in der Mitte der Bthstielchen; Kapsel fast kugelig. 2. Feuchte Wiesen u. Gräb. an salzhalt. O. Jun.Aug. Bl. weiss.

13. GLAUX L. Milehkraut.

1. G. maritima L. 24. Feuchte, salzhalt. O., am Meere u. an Salinen. Mai. Jun. Bl. rosenroth.

\section{Ordng. GLOBULARIEEN. DC.}

\section{GLOBULARLA L. Kugelblume.}

1. G. vulgaris L. Krautig; W. vielköpfig; WB. spatelig, ausgerandet od. kurz-3zähnig; St B. zahlreich, lanzettl. 4. Trockene Wiesen u. felsige Hügel, Kalkboden. Mai. Jun. Bl. blau.

2. G. nu di caulis L. Krautig; W. vielköpfig; WB. längl.-keilig, an der Spitze abgerundet-stumpf; St. nackt oder mit 1-2 entfernten Schuppen besetzt. 24. Felsige O. der A. u. VorA. Mai-Jul. Bl. blau.

3. G. eordifolia L. Halbstrauchig, liegend, fast kriechend; B. vkteyf., hinten keilig-verschmälert, an der.Spitze sehr stumpf, ungeth., ausgerandet u. 3zähnig. 24. Trockene O. d. A., VorA. u. südl. gelegener Gbge, bis Triest. Mai. Jun. Bl. blau.

\section{Ordng. PLUMBAGINEEN. Juss.}

\section{STÁTICE I. Seestrandnelke.}

I. Rotte. Armeria DC. Bth. in Köpfchen zsgestellt, v. einer gemeinschaftl., dachigen Hülle bedeckt. Die äusseren Hiillblättchen an der Basis aljwärts in eine walzliehe Scheide vorgezogen.

1. S. plantagine a All. Schaft $1 \mathrm{köpfig;B}$. lineal.-lanzettl. od. lanzettl., zugespitzt, an der Basis in den Btiel verschmälert, 3-7nervig; die äussersten Hïllblättchen haarspitzig, die inneren sehr stumpf, dch den auslaufenden Nerven kurz-stachelspitzig; Bthstielchen v. der Länge der Röhre des zottig-gerieften $\mathbf{K}$.; Blb. abgerundet od. abgeschnitten. 2. Sandige O.; im Kieferwalde zw. Mainz u. Niederingelheim, südl. Seite der Walliser A. Jun. Jul. Bl. rosenroth.

2. S. elongata Hoffin. Schaft $1 \mathrm{köpfig} ;$ B. lineal., spitzl., 1nervig, gewimpert; die äussersten Hüllblättchen haarspitzig, die inneren sehr stumpf, dch den auslaufenden Nerven stachelspitzig; Bthstiel- 
chen $\mathrm{v}$. der Länge der Röhre des zottig-gerieften K.; Blb. ungeth., klein-gekerbt od. ein wenig ausgerandet. 21. Sandige, unkult. O.; zerstr. deh d. Geb. Mai-Oct. Bl. rosenroth. S. Armeria L. Arm. vulgaris Willd. Var. $\beta$. pubescens: Schaft flaumig.

3. S. purpurea Koch. Schaft $1 \mathrm{köpfig;} \mathrm{B.} \mathrm{lineal.,} \mathrm{stumpf,} \mathrm{1ner-}$ vig, an der Basis gewimpert; die äussersten Hüllblättchen stumpf, stachehspitzig, die inneren sehr stumpf, wegen des vor d. Spitze verschwindenden Nerven welurlos; Bthstielchen v. d. Länge d. Röhre des zottig-gerieften $\mathbf{K}$; ; blb. abgeschnitten. 2. Triften, schlammige Wiesen; auf d. Riede bei Memmingen. Jul. Aug. Armeria purpurea Koch. b. Ztg. Untersch. sich sogleich deh die sattpurpurnen Bl.

4. S. maritima Miller. Schaft $1 \mathrm{köpfog} ; B$. lineal., stumpf, 1nervig, am Rande gegen d. Basis bewimpert; die äusseren Hüllblättchen grannenlos, od. mit einer kurzen, dicken, krautigen Granne endigend, die irneren sehr stumpf, wegen des vor $d$. Spitze verschwindenden Nerven wehrlos; Bthstielchen v. d. Länge der iiberall zottigen Röhre des K.; Blb. ausgerandet. 24. Am Seestrande bei Cuxhaven, Sonder. Bl. lila.

5. S. alpin a Hopp. Schaft 1 köpfig; B. lineal.-lanzettl. od. lineal., kahl, meist 3nervig; diє äusseren Hüllblättchen stumpf, sehr kurzstachelspitzig, die inneren sehr stumpf, regen des vor der Spitzc verschwindenden Nerven wehrlos; Bthstielchen halb so lang als die Röhre des zottig-gerieften K.; Blb. ausgerandet. 24. Triften d. A. Jul. Aug. B1. rosenroth.

II. Rotte. Limonium Dub. Bth. älrig; Aehren einseitswendig. Die WB. rosettig.

6. S. Gmelin i Willdenow. B. längl.-vkteyf. od. vkteyf., stachelspitzig, in d. Bstiel verschmälert, kahl, 1nervig; St. aufrecht, stielrund, kahl od. flaumig, v. der Mitte an ästig, rispig; di€ Aeste weitabstehend, die Aestchen zurückgebogen, die untersten Aeste unfruchtbar; Aehren einseitswendig; Bth. dicht aneinander-gestellt; das innere Deckblatt breit-häutig-berandet; Zähne des K. eyf., spitz. 24. Am Seestrande, Littor. Jul. Aug.

7. S. Limonium L. Bl. längl. od. vkteyf., staclelspitzig, in den Bstiel verschmälert, kahl, 1nervig; St. aufrecht, stielrund, kahl, oberwärts ästig; die Aeste aufrecht-abstehend, etwas ebensträussig, die Aestchen zuletzt zurückgebogen; Aehren einseitswendig; Bth. dicht aneinander-gestellt; das innere Deckblatt breit-häutig-berandet; Zähne des K. eyf., spitz. 24. Am Seestrande im nördl. Geb. Aug. Sept. S. Pseudo-Limonium Rchb. Bl. violett-blan. - Die in Schweden u. Dänemark vorkommende S. rariflora Drejer untersch. sich dch aufrechte, kaum gekrimmte Aehren u. auseinander-gestellte Bth.

8. S. globulariaefolia Desf. Kahl; die B. längl.-spatelf., stachelspitzig, in den Bstiel verschmälert, 3-5nervig; St. stielrund, 
glatt, rispig, die unteren Aeste unfruchtbar; die Aehren einseitswendig, die Bth. locker-gestellt; Saum des K. 5th., Zpfl. längl., abgerundet-stumpf, bei der Frucht weit abstehend. 4. Auf den Dünen von Primiero zw. Grado u. dem Ausflusse des Isonzo. Mai-Jul. Bl. blau-violett.

9. S. caspia Willdenow. B. vkteyf. od. lanzettl.-keilig, in den Bstiel verschmälert, kurz-stachelspitzig, dreinervig, kahl; St. sehr ästig, rispig, körnig-rauh, die unteren Aeste unfruchtbar; Aehren kurz, sehr gedrungen; die äusseren Deckblätter völlig, die inneren v. der Hälfte bis zur Spitze weiss-häutig; die Zähne des K. eyf., kurz-zugespitzt, fein-gezähnelt. 24. Im Sande am Meere bei Grado, im Littor. Jul. Aug. S. bellidifolia DC. fl. franc. Bl. blau.

10. S. cancell at a Bernhardi bei Bertolini Fl.ital. Filzig-kurzh.; B. vkteyf.-spatelig od. keilig, ausgerandet; St. fast rechtwinkelig hinu. her-gebogen, sehr ästig, Aeste zurückgebrochen-ausgesperrt, die nnteren unfruchtbar; Aehren ziemlich locker; $\mathrm{Zpfl}$. des fruchttrag. K. längl.-lanzettl., abstehend. 24. Felsen am Meere bei Triest u. Fiume. Mai. Jun. S. pubescens. K. syn. ed. 1. S. furfuracea Rchb.

\section{PLUMBÁGO L. Bleywurz.}

1. P. europaea L. B. stengelumfassend, lanzettl., am Rande rauh; St. steif. 2. Unkult. O., Zäune; Pola in Istrien und bei Fiume. Aug. Sept. Bl. lila.

\section{Ordng. PLANTAGINEEN. Juss.}

1. LITTORÉLLA L. Strändling.

1. L. lacustris L. 24. An $u$. in. Fischteichen u. Seen; sehr zerstr. dch d. Geb. Jun. Jul. Bl. weisslich.

\section{PLANTÁgo L. Wegetritt.}

I. Rotte. Aechter Wegetritt. Der St., die WKöpfe der ausdauernden Arten abgerechnet, fehlend od. sehr kurz; die wurzelst. Bthstiele (Schäfte) nackt. - Die Bl. aller Arten d. Gattg. sind weissl. od. bräunlich.

a. Samenträger 2flügelig, beiderseits 2-4samig. Röhre der Bl. kahl.

1. P. major L. B. gestielt, eyf. od. elliptisch, etwas gezähnt, kahl od. zerstr.-flaumig, 5-9nervig; Schaft aufstrebend, stielrund, schwach-gerieft, ungefälir so lang als die B.; Aehre lineal.-walzl., verlängert; DeckB. eyf., stumpflich, gekielt, am Rande häutig, ungefähr so lang als der K.; Kapsel 8samig. 24. Kultiv. u. unkultiv. O., Wege. Jul.-Oct. Var. an sandigen, feuchten O.: Schaft $1 / 2$ " lang, Achre 3-10bth.: P. minima DC. 
2. P. Cornuti Gouan. B. gestielt, eyf. od. elliptisch, ganzrandig od. etwas gezähnt, kahl, 5-7nervig; Schaft aufrecht, tief-gerieft, 2od. $3 \mathrm{mal}$ so lang als die B.; Aehre lineal.-walzlich, verlängert; DeckB. eyf., stumpf, gekielt, am Rande häutig, um die Hälfte kürzer als der K.; Kapsel 4samig. 4. Salzhalt. Wiesen am Meere bei Triest. Jul. Aug.

\section{b. Samenträger beiderseits 1samig. Röhre der Bl. kahl.}

3. P. media L. B. elliptisch, etwas gezähnt, 7-9nervig, beiderseits kurzh., in den kurzen, breiten Bstiel zsgezogen; Schaft stielrund, seicht-gerieft; 'Aehre längl.-walzl., gedrungen; DeckB. eyf., spitzl., kahl, am Rande häutig; Röhre d. Bl. kahl. 4. Wiesen u. Triften. Mai. Jun.

4. P. altissima L. B. lanzettl, nach beiden Enden verschmälert, etwas gezähnelt, 5-7nervig, kahl od. behaart; Schaft viclfurchig; Aehre längl.-walzenf., gedrungen; DeckB. eyf.-verschmälertzugespitzt, trockenläutig, kahl; seitenst. Kzpfl. gekielt, an der Spitze abgerundet-stumpf, am Rande bewimpert. 4. Wiesen; Krain, Litt. Apr. Mai.

5. P. lance olata L. B. lanzettl., nach beiden Enden verschmälert, etwas gezähnelt, 3-6nervig, kahl od. raulih.; Schaft 5furchig; Aehre eyf., od. längl.-walzl., gedrungen; DeckB. eyf., verschmälertzugespitzt, trockenhäutig, kahl; seitenst. Kzpfl. kahnf., in eine stumpfe Spite zugespitzt, am Rande kahl, auf d. Rücken gekielt, am Kiel bewimpert od. kahl. 24. Wiesen u. Triften. Apr.-Oct. Var. $\beta$. pumila: B. an d. Basis sehr rauhh., Aehre fast kugelig; trockene, steinige $0 .-\gamma$. lanuginosa: B. sehr rauhh. P. lanata Portenschl.; die B. auf der oberen Seite weniger rauhh. P. hungarica W.K.

6. P. Victorial is Poiret. B: lanzettl., nach beiden Enden verschmälert, etwas gezähnelt, 3-5nervig, angedrückt-behaart, fast seidig; Schaft stielrund, seicht gerieft; Aehre eyf., gedrungen; DeckB. eyf., zugespitzt, trockenhäutig, in der Mitte zerstr.-behaart; die seitenst. Kzpfl. fast flügelig-gekielt, am Kiele kahl. 24. Sonnige, stein. O.; Littor. Mai. Jun. P. capitata Hoppe. P. sericea W. K., K. syn. ed. 1.

7. P. Lagópus L. B. lanzettl., nach beiden Enden verschmälert, etwas gezähnelt, 3-5nervig, rauhh. od. auch ziemlich kahl; Schaft gefurcht; "Aehre eyf. od. längl.-walzl., gedrungen; Deck-B. ey-lanzettf., zugespitzt, trockenhäutig, nebst d. K. an d. Spitze bärtig-zottig; die seitenst. Kzpfl. gekielt; Röhre der Bl. kahl. ○. Unkultiv. steinige O.; Istrien. Apr. Mai.

8. P. montana Lam. B. lanzettl., nach beiden Enden verschmälert, etwas gezähnelt, 3-5nervig, zottig od. kahl; Schaft stielrund; Aehre eyf., gedrungen; DeckB. breit-vkteyf., sehr stumpf, kurz-u. stumpf-stachelspitzig, trockenhäutig, an der Spitze bärtig; Kzpfl. 
häutig, ungekielt, kahl, an der Spitze bärtig. 24. Triften d. A. u. VorA., Kessel d. Sudet. Jul. Aug. P. atrata Hopp. P. alpina Vill., Bertol. Var.: $\beta$. holosericea: B. beiderseits dicht-zottig. P. montana $\beta$. holosericea Gaud.

9. P. pilos a Pourrett. B. lanzettl. od. lanzettl.-linealisch, 3nervig, rauhh.; Schaft stielrund, von weit abstehenden Haaren zottig, Aehren eyf. od. walzlich, gedrungen; DeckB. u. äussere Kzpf. krautig, am Rande etwas häutig, eyf., verschmälert-zugespitzt, flaumig, die inneren häutig, mit einem krautigen Rückenstreifen; Röhre der Bl. kahl. (- Unkultiv. trockene O.; Istr. Jun.

c. Samenträger 2 flügelig, beiderseits 1 samig. Röhre d. Bl. zottig-behaart od. flaumig.

10. P. alpina L. B. lanzettl.-lineal. od. lineal., nach beiden Enden verschmälert, ganzrandig od. etwas gezähnt,-fleischig, meist 3nervig, Nerven nicht gleichweit entfernt, der Raum zwischen dem Mittelnerven $u$. den Seitennerven doppelt-breiter als der von d. Seiterinerven zum Rande; Schaft stieIrund; Aehre längl.-walzl., gedrungen; DeckB. eyf., spitz, am Rande häutig, so lang als d. K.; vordere Kzpfl. am Rande häutig, der häutige Theil so breit wie der krautartige, die hinteren krautig-gekielt, mit spitzem Kiele; Röhre d. Bl. etwas zottig. 2. Triften der A.; Schwz., Vorarlberg, Tyr. Mai im Garten, in d. A. später.

11. P. maritima L. B. lineal. od. lanzettl.-lineal., nach beiden Enden verschmälert, ganzrandig od. gezähnt, am Raude kahl od. fein-borstig-gewimpert, fleischig, 3nervig, Nerven gleichweit-entfernt; Schaft stielrund; Aelre lineal., verlängert, walzl., gedrungen; DeckB. eyf., spitzlich, am Rande liäutig, ungeführ so lang als der $K$.; die vorderen Kzpfl. am Rande häutig, der häutige Theil so breit wie der krautige, die hinteren krautig-gekielt, mit spitzem Kiele; Röhre $\operatorname{der} \mathrm{Bl}$. etwas zottig. 24. Feuchte O. am Nieere u. an Salinen; auch auf d. A. u. dort wohl eiuen salzhalt. Boden andeut. Jun.-Octb. P. graminea DC. Var. $\alpha$. genuina: B. kahl, ganzrandig. P. maritima Roth. - $\beta$. dentata: B. kahl, mit einigen lineal., verlängerten Zähnen versehen: P. dentata Roth. - B. schmal, ganz od. über d. Mitte mit zwei Zähnen: P. bidentata Murith. $-\gamma$. ciliata: B. fein-borstiggewimpert, ganzrandig oder mit einem od. dem and. Zahn bezeichnet. P. Wulfeni MK. P. aspera Gaud.

12. P. serpentina Lam. B. lineal, halbstielrund-3kantig, getrocknet-gekielt, am Rande fein-borstig-gewimpert; Schaft stielrund; Aehre lineal.-verlängert, walzl., gedrungen; DeckB. aus eyf. Basis pfrieml.-verschmälert, spitz, am Rande häutig, länger als der'K.; die vorderen Kzpfl. am Rande luäutig, der häutige Theil so breit wịe der krautige, die hinteren krautig-gekielt, mit spitzem Kiele; Rōhre 
der Bl. ziemlich zottig. 24. Felsen u. steinige O.; Litt. Jul.-Sept. P. carinata Schrad.

13. P. recurvata L. B. lineal. od. lanzettl.-lineal, nach beiden Enden verschmälert, ganzrandig od. gezähnt, am Rande kahl, fleischig, rinnig, 3nervig, die Nerven gleichweit-entfernt; Schaft stielrund; Aehre lineal.-verlängert, walzl., gedrungen; DeckB. eyf., spitzl., am Rande häutig, kürzer als der K.; die vorderen Kzpfl. am Rande häutig, der häutige Theil $4 \mathrm{mal}$ schmäler als der krautige, die hinteren krautig-bekielt, der Kiel geflügelt mit einem häutigen Flügel. 4. Auf den Sanddünen von Primiero zw. Grado u. dem Ansflusse des Isonzo. Jul. Aug. P. incurvata Murray. P. maritima DC.

d. Samenträger 3-4flügelig, in jedem Fache 1 Same.

14. P. Corónopus L. B. fiedersp. od. fiedersp.- gezähnt, $\mathrm{Zpfl}$. od. Zähne entfernt; Schaft stielrund; Aehre lineal.-verlängert, walzl.; DeckB. aus eyf. Basis pfrieml.; seitenst. Kzpfl. auf dem Rücken geflügelt, Flügel häutig, gewimpert; Rölre der Bl. etwas zottig. $\odot$. Triften u. Wiesen der Küstenländer; auch bei Genf. Jul. Aug. P. integralis Gaud. Var. B. kahl od. rauhh., einfach-gezähnt od. doppeltfiedersp.-gezähnt, selten ganzrandig.

II. Rotte. Psyllium Tournef. Der St. beblättert, an vollständigen Expl. ästig, Bthstiele blattwinkelst. Samenträger 2flügelig.

15. P. Psyllium I. St. krautig, aufrecht, ästig, B. lineal., ganzrandig od. etwas gezähnt; Aehren eyf., zieml. locker; DeckB. aus eyf. Basis pfrieml.; Kzpfl. lanzettl., allmählig zugesp., gleichgestaltet. $\odot$. Sandige 0 . am Neere; Istr. u. d. Inseln. Jul. Aug.

16. P. a renaria W.K. St. krautig, aufrecht, ästig; B. lineal., ganzrandig od. etwas gezähnt; Aehren eyf.-längl., gedrungen-dachig; die untersten DeckB. rundl.-eyf., krautig-begrannt, die oberen spatelig, sehr stumpf; die vorderen Kzpfl. schief-spatelig, sehr stumpf, die hinteren lanzettl., spitz. $\odot$. Sandige 0 .; sehr zerstr. deh d. Geb. Jul. Aug.

17. P. Cynops L. St. strauchig, ästig, an der Basis liegend; B. schmal-lineal., ganzrandig; Aehren eyf.; DeckB. breit-eyf., stumpf, die unteren mit einer fädl., krautigen Granne, die oberen stachelspitzig; die vorderen Kzpfl. breit-eyf., stumpf, stachelspitzig, die hinteren schmäler, gekielt, am Kiele gewimpert. Ђ. Unkult. O.; C. Waadt, Baden bei Wien, Monfalcone, hier nicht wiedergefundeu. Jul. Aug.

\section{Unterclasse. MONOCHLAMYDEEN. Blumen- lose.}

Perigon einfach, nämlich die Blb. entweder fehlend od. mit dem K. verschmolzen. 


\section{Ordng. AMARANTHACEEN. Juss.}

\section{AMARANTHUS L. Amaranth.}

1. A. s ylvestris Desf. Knäuelchen 3männig, sämmtlich blattwinkelst., eine endst. Aehre nicht vorhanden; der HauptSt. aufrecht, die Nebenst. aufstrebend; B. rauten-eyf., am Rande wellig, an der Spitze ganz, die untersten seicht-ausgerandet; die DeckB. ungefähr so lang als die Bth. $\odot$. Kult. O., Wege; Rheinfläche am Mittelrheine, Böhm., Fiume. Jul. Aug. Bth. grünl., wie der folgenden Arten.

2. A. Blitum L. Knäuelchen $3 \mathrm{männig,} \mathrm{die} \mathrm{blattwinkelst.} \mathrm{rund-}$ lich, die endst. in eine nackte Achre zsgereihet; St. ausgebreitet, aufstrebend, kahl; B. eyf., fast rautenf., sehr stumpf od. ausgerandet; DeckB. kürzer als die Bth.; Kapsel rundl.-eyf. $\odot$. Kult. O., Wege; zerstr. dch d. Geb. Jul. Aug. A. adscendens Lois. B. gefleckt u. ungefleckt.

3. A. prostratus Balb. Knäuelchen 3männig, die blattwinkelst. rundlich, diє endst. in eine nackte Aehre zsgereihet; St. gestreckt, oberwärts behaart; B. rauten-eyf., vorne zugespitzt-verschmälert, an der Spitze selbst stumpf od. ausgerandet, am Rande wellig; die DeckB. ungefähr so lang als die Bth.; Kapsel längl.-eyf. $\odot$. Kult. O., Wege; Littor. Jul. Aug.

4. A. retroflexus L. Knäuelchen ährig, 5männig, die endst. Aehre zsgesetzt; St. aufrecht, behaart; B. eyf., zugespitzt, an der Spitze selbst stumpf; DeckB. noch einmal so lang als das Perigon, fast dorrig-slachelspitzig; Zptl. des Perigons lineal. - längl., stumpf od. gestutzt mit einem Stachelspitzchen. $\odot$. Kultiv. O.; zerstr. dch d. Geb. Jul. Aug. A. spicatus Lam.

\section{Ordng. PHYTOLACCEEN. R. Brown.}

\section{PHYTOLÁCCA L. Kermesbeere.}

1. Ph. decandra L. Bth. 10männig, 10weibig. 24. Im südl. Tyr. u. im Littor. kultiv.; an Wegen u. auf Felsen am Meere verwildert. Jul. Aug. Bth. röthlich.

\section{Ordng. CHENOPODEEN. Vent.}

1. SCHOBERIA C. A. Meyer. Schoberie.

1. S. maritima Mey. Krautig, kahl; St. ausgebreitet, ästig; B. halbwalzl., spitz; Bth. meist zu 3, blattwinkelst., Zpfl. gekielt; S. fein-punktirt. $\odot$. Meeresstrand; nördl. u. südl. Küste. Aug. Sept. Chenopodium maritimum L.

2. SALSOLA L. Salzkraut.

1. S. Kali L. Krautig, mit kurzen, dieklichen Haaren bestreut 
oder kahl, ausgebreitet-ästig; B. pfriemlich, an der Spitze dornig, abstehend; Bth. blattwinkelst., einzeln; FruchtP. knorpelig, nervenlos, Zpfl. zugespitzt, an der Spitze häutig, in der Mitte quer-bekielt und daselbst mit einem kurzen innorpeligen Rande od. mit einem rundl. abstehenden Anlängsel von d. Länge des P. ○. Sandige O. am Meere u. zerstr. deh d. Geb. Jul. Aug. Var.: kurz-steifhaarig od. kahl, B. dicker u. dünner, u. a. vulgaris: das P. rosettig-berandet, das Anhängsel auf dem Rücken so lang als die Spitze des P. - $\beta$. brevimarginata: das Anlängsel sehr kurz, nur ein kurzer knorpeliger Rand. S. Tragus L. $-\gamma$. mixta: die meisten P. wie an $\beta$. mit wenigern eingemischten der Var. $\alpha$, auf derselben Pflanze.

2. S. So d a L. Krautig, kahl, ästig; Aeste aufstrebend; B. lineal., halbstielrund, spitzlich, kurz-stachelspitzig; Frucht $P$. häutig, ZpH. in der Mitte quer-bekielt. $\odot$. Meeresufer, bei Triest. Jul.-Sept.

3. SALICORNIA L. Glasschmalz.

1. S. herbacea L. St. krautig, ästig, gegliedert; Glieder der Aehren beiderseits 3 bth.; die $P$. in ein Dreieck geordnet. $\odot$. Meeresufer u. an Salinen. Aug. Sept. Var.: Aehren dicker: S. radicans Sm.

2. S. fruticosa L. St. strauchig, ästig, gegliedert; Glieder der Aebren beiderseits 3bth.; die P. ncbeneinandergestellt. $\hbar$. Insel Osero u. Cassion bei Veglia. Jul. Aug. Var.: Aehre dicker: S. macrostachya Moricand.

4. CORISPERMUM L. Wanzensame.

1. C. Marschallii Steven. Perigon fehlend; Nüsse kahl, fast kreisrund, geflügelt, Flügel gezähnelt, an der Spitze ausgeschnitten, auf der Mitte des Ausschnittes mit 2 Stachelspitzchen; die obersten DeckB. ey-lanzettf., verschmälert-spitz u. nebst den 1nervigen B. stachelspitzig. $\odot$. Sandige $O$. der Rheinfläche; bei Schwetzingen. Jul. Aug.

2. C. intermedium Schweigg. Perigon fehlend; Nüsse kabl, fast kreisrund, geflügelt, Flügcl breit; dchscheinend, an der Spitze ganz u. mit 2 Stachelspitzchen; die oberen DeckB. eyf., zugespitzt, mit einem häutigen Rande von der halben Breite des krautigen Theiles umzogen $u$. nebst den 1nervigen B. stachelspitzig. $\odot$. Sandige 0. ; am Meere in Preussen. Jul. Aug.

3. C. hyssopifolium L. Perigon 2blätterig; Nïsse kahl, rundl.oval, geflügelt; - Flügel undurchsichtig, am Rande sehr schmal-dchscheinend, an $d$. Spitze ganz u. mit 2 Stachelspitzchen versehen; die oberen DeckB. eyf., zugespitzt, mit einem häutigen Rande v. der halben Breite des krautigen Theiles umzogen, und nebst den 1nervigen B. stachelspitzig. $\odot$. Kiesige $0 . ;$ am Donauufer in der Ge- 
gend von Wien, besonders bei Lobau. Aug. Sept. Nüsse halb so gross als an C. intermedium.

4. C. nitidum Kitaib. Perigon 2blätterig; Nüsse kahl, rundl.oval, geflügelt, Flügel an d. Spitze ganz u. mit 2Stachelspitzchen; die oberen DeckB. eyf., zugespitzt, mit einem häutigen Rande vnn der Breite des krautigen Theiles umzogen $\mathfrak{u}$. nebst d. Inervigen B. stachelspitzig. $\odot$. Kiesige $\mathrm{O}$.; auf den Donauinseln, bei Wien. Jul. Aug. B. sehr schmal-linealisch. Nüsse nur halb so gross als an C. hyssopifolium.

5. POLYCNÉMUM L, Knorpelkraut.

1. P. arvense L. B. 'ziemlich steif, 3kantig-pfrieml., stachelspitzig; Bth. blattwinkelst., sitzend; die Deckblättchen kaum so lang als das Perigon. (- Aecker, Wege; zerstr. dch das Geb. Jul. Aug.

2. P. majus Alex. Braun. B. ziemlich steif, 3kantig-pfrieml., stachelspitzig; Bth. blattwinkelst., sitzend; die Deckblättchen länger als das Perigon. $\odot$. Aecker, hin $\mathfrak{u}$. wieder auf Kalk- u. Thonboden. Jul. Aug. Die Früchte noch einmal so gross als an voriger, die Pflanze oft stärker $u$. vom Ansehen der Salsola Kali.

I. KOCHIA Roth. Kochie.

1. K. S c oparia Schrad. Krautig, faumig; B. lineal.-lanzettl., gewimpert; Bth. gezweiet; Anliängsel des FruchtP. sehr kurz, 3eckig, spitz. $\odot$. Aecker, kult. O.; Littor., Unteröstr., Böhm., Mähr. Jul.Sept. Chenopodium Scoparia L.

2. K. arenaria Roth. Krautig, rauhh.; B. pfrieml.-fädl., etwas fleischig, unterseits mit einer Furche dchzogen; Bth. meist zu 3, blattwinkelst., sitzend; Anhängsel des FruchtP. fast rautenf., ungleich. ○. Sandige O.; Mähr., Rheinfläche v. Schwetzingen bis Ingelh. MaiJul. Salsola arenaria WK. Var. $\alpha$. longifolia: blüthenst. B. vielmal länger als die Bth. Camphorosma monspeliaca Poll., nicht L. - $\beta$. brevifolia: die blüthenst. B. von der Länge $d$. Bth. od. kaum länger. Camphorosma acuta Pollich, nicht $\mathrm{L}$.

3. K. prostrat a Schrad. Halbstrauchig; B. lineal., flach, flaumig od. zottig-grau; Bth. meist zu 3, blattwinkelst., sitzend; Anhängsel des FruchtP. rundlich, etwas länger als der Durchmesser der Bth. 2. Sandfelder; Unteröstr. u. Mähr. Jul.-Sept. S. prostrata L.

4. K. hirsut a Nolte. Krautig, rauhh.; B. lineal., stumpf; Bth. gezweiet, blattwinkelst.; Anhängsel des FruchtP. kegelf. $\odot$. Unkultiv. O. am Meeresstrande; Holst., in Mecklenb. nur einmal gefund. Aug. Sept. Salsola hirsuta L.

7. CHENOPODIUM L. Gänsefuss.

1. Ch. hybridum L. B. herzf., eckig-gezähnt, Ecken zugespitzt, 
die mittlere grösser, verlängert; Bthschweife rispig; S. grubig-punktirt. ○. Iiult. O., Zäune. Jul. Aug.

2. Ch. urbicum L. B. glänzend, 3eckig, an d. Basis in den Bstiel vorgezogen, buchtig- od. ausgeschweift-gezähnt; Aeltren zsgesetzt, aufrecht, fast blattlos; S. glatt. $\odot$. Kultiv. O., Wege; zerstr. del das Gebiet. Aug. Sept. Var. $\alpha$. : B. kürzer-gezähnt. - $\beta .:$ B. buchtig-gezähnt. Ch. intermedium M. et K. Ch. rhombifolium Miihlenb.

3. Ch. murale L. B. rauten-eyf., glänzend, spitz-gezähnt; Bthschweife spreitzend; $S$. glanzlos, gekielt-berandet. $\odot$. Schutt an Dörfern, Wege. Jul.-Sept.

4. Ch. alb u m L. B. rauten-eyf., ausgebissen-gezähnt, die oberen längl., ganzrandig; Bthschweife fast blattlos; S. glatt, glänzend. $\odot$. Jul.-Sept. Ch. album Sm. Ch. leiospermum DC. Var. B. gezähnt od. auch ganzrandig, u. $\alpha$. spicatum: Bthknäuel ährig: Ch. album L. - $\beta$. cymigerum: Bthknäuel trugdoldig: Ch. viride L.

5. Ch. o p u lif o li um Schrad. B. rundl.-rautenf., fast 3lappig, seltr stumpf, ansgebissen-gezälnt, die oberen ellipt.-lanzettl.; Bth.-Schweife fast blattlos; S. glatt, glänzend. $\odot$. Wege, Schutt; zerstr. dch d. Geb. Jul.-Sept.

6. Ch. ficifolium Sm. Die unteren B. 3lappig, spiessf., gezähnt, nach der Basis verschmälert, der mittlere Lappen verlängert, längl.lanzettl., stumpf, die oberen B. lineal.-lanzettl., ganzrandig; Bth.Schweife fast blattlos; S. glänzend, fein-eingedrüclt-punktirt. $\odot$. Wege, Schutt; zerstr. dch das südl. u. mittl. Geb. Jul. Aúg.

7. Ch. a mbrosioides L. B. lanzettl., an beiden Enden verschmälert, entfernt-gezähnt, unterseits drüsig, mit sitzenden, zerstreuten Drïsen; Tr. beblättert. ○. Kult. O., Flusskies; Oestr., Bad. am Ufer d. Murg. Jun. Jul.

8. Ch. polyspermum L. B. eyf., ganzrandig, stachelspitzig, ganz kahl; Tr. blattlos; S. glänzend, sehr fein-punktirt; FruchtP. $a b$ stehend. ○. Kult. O., Wege, Flusskies. Aug. Sept. Var. $\alpha$. cymosoracemosum: Tr. aus Trugdolden zsgesetzt. Ch. polyspermum d. Autoren. - $\beta$. spicato-racemosum: Tr. aus kleinen Aehren zsgesetzt. Ch. acutifolium Kit.

9. Ch. Vulvaria L. B. rauten-eyf., ganzrandig, grau-mehlig; Tr. blattlos; S. glänzend, sehr fein-punktirt. $\odot$. Wege, Zäune, Schutt. Jul. Aug. Ch. olidum Curt. Ch. foetidum Lam.

10. Ch. B otry s L. Drüsig-flaumig; B. längl., fast fiedersp.buchtig, stumpf-gezähnt, die obersten deckblattf., lanzettl., ganzrandig; Bth.-Schweife in verlängerte Tr. geordnet. $\odot$. Unkult. O., Flusskies; südl. Schwz., südl. Tyrol, Oestr., Schles. Jul. Aug.

8. BLITUM L., verbessert v. C. A. Meyer.

a. Fruchtperigon beerenartig.

1. B. capitatum L. B. 3eckig, fast spiessf., wenigzähnig; Aeh. 
ren nackt; FruchtP. beerenartig; S. am Rande spitz-gekielt. (-) Kult. u. kiesige O.; südl. Geb. Jun.-Aug.

2. B. virgatu m L. B. längl.-3eckig, fast spiessf., tief-gezähnt; Knäuclchen sämmtl. blattwinkelst.; die FruchtP. beerenartig; S. mit stumpfem, auf der einen Seite rinnigem Rande. $\odot$. Kult. O., Wege; siidl. Geb!. Jun.-Aug.

b. Fruchtperigon saftlos od. wenig saftig.

3. B. Bonus Henricus C. A. Meyer. B. 3eckig-spiessf., ganzrandig; die end- u. blattwinkelst. Aehren zsgesetzt, die endst. in eine kegelf., blattlose Aehre zsgestellt; FruchtP. saftlos; alle S. aufrecht. 24. Wege, Dörfer. Mai-Aug. Chenopodium Bonus Henricus L.

4. B. rubrum Rchb. B. glänzend, rautenf.-3eckig, fast spiessf.3lappig, buchtig-gezähnt, Zähne lanzettl.; Aehren zsgesetzt, beblättert; FruchtP. saftlos; S. glatt, aufrecht, die der endst. Bth. an den Knäuelchen' wagerecht. $\odot$. An Dörfern, Wegen; zerstr. dch d. Geb. Jul.Sept. Chenopodium rubrum L. Var. B. eingeschnitten-gezähnt; und B. acuminatum: St. höher, B. lang-spitz vorgezogen, Knäuel zuletzt blutroth: Chenopodium blitoides Lejeune. - $\gamma$. paucidentatum: unterste B. 3eckig-spiessf., obere rautenf. od. lanzettl., fast zahnlos u. stumpf:' Chenop. botryoides Sm.

5. B. gl a u cum Koch. B. längl. oder eyf.-längl., stumpf, entfernt-gezähnt, unterseits graugrün; Aehren blattlos; S. glatt, aufrecht u. wagerecht. $\odot$. Feuchte 0 . um Dörfer. Jul.-Sept. Chenopodium glaucum L.

\section{BETA L. Mangold.}

1. B. vulgaris L. W. einstengelig; St. aufrecht; WB. eyf., stumpf, etwas herzf.; StB. rauten- eyf.; Narben eyf. $\odot$. u. $\odot$. Kultivirt, die Variet. $\alpha$. am Meere, ob im Geb.? - Var. $\alpha$. maritima: Wurzel kaum dicker als d. St., St. diinn. B. maritima MBieberst. B. foliosa Ehrenb. B. vulg. maritima K. syn. ed. 1. - $\beta$. Cicla: der Variet. $\alpha$. ganz ähnlich, aber dch Kultur sehr vergrössert und fetter. B. vulgaris Cicla L. $-\gamma$. rapacea: W. dick, fleischig: B.

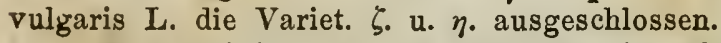

2. B. maritima L. W. vielstengelig; St. niedergestreckt; B. rauten-eyf., kurz-zugespitzt; N. lanzettl. 4. Ufer der Nordsee. Jul. Aug.

10. CAMPHORÓSMA L. Kampferkraut.

1. C. monspeliaca L. Rauhh.; B. u. DeckB. pfriemlich; Bth. blattwinkelst., geknäuelt-ährig, fast sitzend. 2. Sandige O.; im Littor. u. auf Veglia. Jul. Aug.

11. SPINACIA L. Spinat.

1. S. in er mis Mönch. B. längl.-eyf.; Früchte vehrlos. ○. od. ๑. Zum Küchengebrauche kultiv. Mai. Jun. S. oleracea $\beta$. L. 
2. S. spinosa Mönch. B. an der Basis beiderseits 'spiessf.-2zähnig; Früchte behörnt. (- od. ๑. Kultiv. Mai. Jun. S. oleracea $\alpha$. L.

12. EUROTIA Adans. Eurotie.

1. E. ceratoides C. A. Meyer. B. lanzettl., grau-filzig; weibl. Bth. wollig. Ђ. Unkult. O.; Unteröstr. bei Ehrensbrunn u. um d. Stadt Retz. Aug. Sept. Axyris ceratoides L. Diotis ceratoides Schreb. K. syn. ed. 1 .

\section{HÁLIMUS Wallr. Halimus.}

1. H. portulacoides Wallr. St. halbstrauchig, aufstrebend; B. gegenst., ganzrandig, vkteyf.-längl., stumpf, an d. Basis verschmälert; FruchtP. sitzend, 3lappig, auf d. Riicken weichstachelig. Ђ. Feuchte O. am Meeresufer. Jul. Aug. Atriplex portulacoides L.

2. H. peduncul atus Wallr. St. krautig, schlängelich, ästig; B. ganzrandig, stumpf, an der Basis verschmälert; FruchtP. lang-gestielt, umgekehrt-3eckig, ausgerandet-2lappig, mit einem dazwischen gelegenen Zähnchen. $\odot$. Am Meeresufer u. d. Salinen bei Artern in Thüring. Sept. Oct. Atriplex pedunculata L.

\section{4. ÁTRIPLEX L. Melde.}

a. Weibl. P. bei der Reife krautig od. häutig, nur an der Basis zsgewachsen.

1. A. hortensis L. St. krautig, aufrecht; B. herzf.-3eckig, gezahnt, gleichfarbig, glanzlos, die oberen länglich, 3eckig, fast spiessf.; Frucht $P$. rundl. - eyf., kurz-zugespitzt, netzaderig, ganzrandig, bis auf die Basis getheilt. $\odot$. Kult., u. auf Schutt. Jul. Aug. Var. ganz blutroth.

2. A. nitens Rebentisch. St. krantig, aufrecht; $B$. herzf.-3eckig, buchtig-gezähnt, oberseits glänzend, unterseits silbern-bläulichgrün, die oberen aus 3eckiger, buchtig-gezähnter Basis lang-gespitzt, ganz* ranđig; Frucht $P$. eyf., zugespitzt, netzaderig, ganzrandig, bis auf die Basis getheilt. $\odot$. Schutt, Wege; zerstr. dch d. östl., nördl. u. mittlere Geb. Jul. Aug. A. acuminata WK.

3. A. oblongifolia W. K. St. krautig u. nebst den Aesten aufrecht; die unteren $B$. ey-lanzettf., gezähnt, fast spiessf., die oberen lanzettl., ganzrandig; Frucht $P$. ey- fast rautenf., ganzrandig, bis auf die Basis getheilt; die fruchttrag. Achren locker, an d. Spitze überhängend. $\odot$. Wege, Felder, trockene 0. ; Rheinfläche v. Basel bis Coblenz, Mähr. Jul. Aug. Eine schmalblätterige Form: A. campestris Koch.

4. A. patula L. St. krautig; die unteren Aeste spreitzend; $B$. lanzettl., die unteren gezähnt, fast spiessf., die übrigen lanzettl., die obersten lineal.; FruchtP. spiess-rautenf., bis auf die Basis getheilt; 
Fruchtähren steif. $\odot$. Wege, kult. O. Jul. Aug. A. angustifolia Sm. Var. $\beta$. microcarpa: Eruchtperigone kaum grösser als der S., deswegen convex. A. erecta Sm.

5. A. latifo lia Wahlenb. St. krautig, die unteren Aeste spreitzend; die unteren B. 3eckig, spiessf., gezähnt, die oberen spiess-lanzettf., die obersten lanzettl., ganzrandig; FruchtP. 3eckig, ganzrandig $\delta d$. gezälnelt, bis auf die Basis getheilt. $\odot$. Wege u. kult. O. Jun.Aug. A. patula Sm. A. hastata Pollich u. vieler Aut. Var. F. microcarpa: FruchtP. kaum grösser als der S. und convex. A. microsperma WK. A. ruderalis Wallr. - $\gamma$. salina: schilferig-grau. A. patula var. salina Wallr. A. oppositifolia DC. A. Sackii Rostk.

6. A. hastata L. St. krautig, die unteren Aeste spreitzend; die unteren B. 3eckig-spiessf., tief-buchtig-gezähnt, die oberen spiess-lanzettf., die obersten ganzrandig; FruchtP. herzf.-3eckig, buchtig-gezährit, bis auf die Basis getheilt, Zähne zugespitzt u. pfriemlich. $\odot$. Schutt, Wege; in Pommern, bei Berlin u. Königsberg. Jul. Aug.

7. A. littoralis L. St. krautig, die Aeste nicht spreitzend; $B$. lineal.-lanzettl. od. lineal., geschärft-gezähnt od. ganzrandig; FruchtP. rauten-eyf., gezähnt; Aehren steif. (-). Meeresufer der Ost- u. Nordsee. Jul. Aug. Var. B. buchtig-gezähnt: A. marina der Aut.

b. Weibl. P. bei der Reife v. der Basis bis zur Mitte knorpelig-hart $u$. weisslich $u$. bis zur Hälfte ungef. zsgewachsen.

8. A. laciniata L. St. krautig; B. tief-buchtig-gezähnt, fast spiessf., die unteren 3eckig-rautenf., d. oberen spiessf.-längl.; Aeltren nackt, nur an der Basis beblättert; Frucht $P$. rauterf. od. fast 3lappig-gezähnt od. fast ganzrandig, von der Basis bis zur Mitte weisslich-knorpelig $u$. bis dahin zsgewachsen. $\odot$. Schutt, Wege; Oestr., Nähren, Böhmen, bei Würzburg, 'Warnemüinde. Jul. Aug.

9. A. ros e a L. St. krautig, spreitzend; B. buchtig-gezähnt, die unteren rautenf., die oberen eyf.; Aehren unterbrochen, beblättert; FruchtP. 3eckig-rautenf., spitz, gezähnelt, an der Basis bis zur Mitte weisslich-knorpelig $u$. bis dahin zsgewachsen. $\odot$. Wege, Schutt; zerstr. deh d. Geb. Jul. Aug.

\section{THELIGONUM L. Hundskohi.}

1. Th. Cynocrambe L. $\odot$. Felsenspalten, schattige 0 ; auf der Insel Cherso. Jun. Bth. gelblichweiss.

\section{Ordng. POLYGONEEN. Juss.}

\section{RUMEX L. Ampfer.}

I. Rotte. La patl u m Tournef. Bth. zwitterig od. vielehig. Gf. frei. B. an der Basis verschmälert, abgerundet od. herzf., aber weder spiessf. noch pfeilf. 
1. R. maritimus L. Die inneren $\mathrm{Zpfl}$. des Frucht $P$. fast rautenf., beiderseits borstlich-2zähnig, an der lanzettl.-vorgezogenen Spitze ganzrandig, alle schwieletragend, die Zähne v. der Länge des Längedchmessers des Zpfls.; Quirle mit einem B. gestützt, die oberen zsfliessend; B. lanzettl.-lineal., in den Bstiel verschmälert. ๑. Teich- u. Sumpfränder, Meeresufer. Jul. Aug.

2. R. palustris Smitl. Die inneren Zpfl. des FruchtP. eyf.länglich, beiderseits borstlich-2zähnig, an der lanzettl.-vorgezogenen Spitze ganzrandig, sämmtl. schwieletragend, Zähne kürzer als die Zpfl. des P.; Quirle mit einem B. gestützt, ziemlich entfernt; $B$. lanzettl.-lineal. od. verlängert-lanzettl., in den Bstiel verschmälert. ๑. Sumpfige O., Teiche u. Seeränder; zerstr. deh d. Geb. Jul.'Aug.

3. R. Ste inii Becker. Die inneren Zpfl. des FruchtP. eyf., beiderseits horstlich-2zälnig, an der vorgezogenen Spitze ganzrandig, alle schwieletragend, Zähne kiirzer als die Zpfl. des P.; Quirle entfernt, die unteren mit einem B. gestützt, die oberen nackt; die vourzelst. B. breit-lingl., an der Basis her $z f$., die stengelst. aus abgerundeter Basis lanzettl., die oberen lanzettl. 2. Am Mainufer zw. Frankf. थ. Offenbach; selır selten. Jul. Aug.

4. R. conglomeratus Murr. Die inneren Zpfl. des FruchtP. lineal.-längl., stumpf, ganzrandig; sämmtl. schwieletragend; die untersten $B$. herzf.- od. eyf.-längl., stumpf od. spitz, die mittleren herzlanzettf., zugespitzt; Aeste weit-abstehend, aufstrebend; Quirle entfernt, mit cinem $B$. gestützt, nur die obersten nackt. 24. Ufer, Gräben. Jul. Aug. R. Nemolapathum Ehrh.

5. R. sanguineas L. Die inneren Zpfl. des FruchtP. lineal.längl., stumpf, ganzrandig, ein einziger schwieletragend; die untersten B. herzf.-längl. od. etwas geigenf., stumpf od. spitz, die mittleren herz-lanzettf., zugespitzt; Aeste gerade, aufrecht-abstehend; Quirle sämmtl. nackt, od. nur die untersten mit einem B. gestiitzt. 4. In feuchten Hainen. Jun. Aug. $\alpha$. viridis: St. u. B.-Adern nicht farbig. R. sanguineus $\beta$. viridis Sm. R. nemorosus Schrad. $-\beta$. genuinus: St. u. die Adern d. B. blutroth.

6. R. pulcher L. . Die inneren Zpfl. des FruclutP. eyf.-längl., grübig-netzig, fast dornig-vielzähnig, schwieletragend; die untersten B. herzf.-längl. od. herz-geigenf, stumpf, die mittleren spitz, die obersten lauzettl.; Aeste sehr abstehend; Quirle entfernt $u$. die meisten mit einem B. gestiutzt. (.). Kult. O.; Littor., Oberbad., Oberelsass. Mai. Jun. Var. B. über d. Basis nicht zsgezog.: R. divaricatus L. nach Bertoloni.

7. R. obtusifolius L. Die inneren Zpfl. des FruchtP. eyf.3eckig, linten gezälint, in cine längl., stumpfe, ganzrandige Spitze vorgezogen, sämmtl. schwieletragend, Zälıne 3eckig, zugespitzt od. pfrieml.; Tr. blattlos; Quirle ziemlich entfernt; die unteren B. herzeyf., stumpf od. spitzl., die mittleren herzf.-längl., spitz, die obersten 
lanzettl. 4. Wiesen, um Dörfer. Jul. Aug. R. divaricatus L. nach Fries. Var. $\beta$. discolor: St., Bstiele, BAdern und Tr. blutroth. R. purpureus Poir. In Oberbayern häufig. - $\gamma_{\text {. sylvestris: Perigon }}$ halb so gross, spärlicher-gezähnt. R. sylvestris Wallr. R. obtusifolius L. nach Fries. R. acutus Tausch.

8. R. pratensis Mert. u. Koch. Die inneren $Z$ pfl. des Frucht$P$. eyf., fast herzf., stumpf, gezähnt, an d. Spitze ganzrandig, sämmtl. od. nur d. vordere schwieletragend, Zähne 3eckig, zugespitzt od. pfriemlich; Tr. blattlos; Quirle genähert; die wurzel- u. unteren stengelst. 'B. herzf.-längl., spitz, die obersten lanzettl. 24. Fruchtb. Wiesen; Rheinfläche bis Westphal., um Halle. Jul. Aug. R. cristatus Wallr. R. acutus Linn. nach Anderer Ansicht.

9. R. crispus L. Die inneren Zpfl. des FruchtP. rundl., fast herzf., ganzrandig od. an der Basis gezähnelt, sämmtl. schwieletragend; Tr. blattlos; Quirle genähert; $B$. lanzettl., spitz, wellig, kraus. 24. Wiesen, kultiv. O. Jul. Aug.

10. R. Patientia L. Dic inneren $\mathrm{Z} p f$. des R̈ruchtP. rundl.herxf., stumpf, ganzrandig od. kaum gezähnelt, ein cinziger schwieletragend; Tr. rispig, blattlos; Quirle genähert; die wurzel- u. unteren stengelst. $B$. ey-lanzettf., flach, zugespitzt, die obersten lanzettl.; Bstiele rinnig. 24. An Gräben, um Dörfer; in Unteröstr. Auch zum Küchengebrauch kult. Jul.-Aug.

11. R. Hy drolapa thum Huds. Die inneren $Z_{p} f$. d. FruchtP. eyf.-3eckig, ganzrandig od. hinten gezähnelt, alle schwieletragend; Tr. rispig, blattlos; B. lanzettl., zugespitzt, nach der Basis verschmälert, flach, am Rande wellig-kleingekerbt; Bstiele oberseits flach. 4. Sümpfe, langsam fliessende Wasser. Jul. Aug.

12. R. maximus Schreb. Die inneren Zpfl. des FruchtP. 3eckigherzf., hinten gezähnelt, alle schwieletragend; Tr. rispig, blattlos; die wurzel- u. unteren stengelst. B. längl., spitz, an der Basis schiefeyf. od. herzf.; Bstiele oberseits flach, u. zu beiden Seiten mit einer hervortretenden Rippe berandet. 24. Gräb., Teiche: Jul. Aug.

13. R. a quaticus L. Die inneren $Z p f$. des FruchtP. eyf. oder seicht-herzf., häutig, ganzrandig oder etwas gezähnelt, ohne Schwiele; Tr. rispig, blattlos; WB. herz-eyf., spitz, an d. Basis verbreitert; Bstiele zsgezogen-rinnig. 24. An Gräben, Teichen; zerstr. dch d. Geb. Jul. Aug.

14. R. alpinus L. Die inneren Zpfl. des FruchtP. herz-eyf., häutig, ganzrandig od. etwas gezähnelt, ohne Schwiele; Tr. gedrungen-rispig, blattlos; WB. rundl--herzf., abgerundet-stumpf od. an der stumpfen Spitze kurz-zugespitzt; Bstiele oberseits rinnig. 2. A. u. höhere O.; Mähr. Gbge, Riesengbg., u. Schwarzw. Jul. Aug.

II. Rotte. Acetos a Tournef. Bth. 2häusig od. vielehig. Die 
Gf. oberwärts an die Kanten des Fruchtk. angewachsen. B. spiessod. pfeilförmig.

15. R. scutatus L. Die inneren Zpfl. des FruchtP. rundl.-herzf., ganzrandig, häutig, ohne Schwiele, d. äusseren an dem unteren Rande der inneren anliegend; Halbquirle armbth., entfernt, blattlos; B. spiessf., eyf., od. fast geigenf. 2. Steinige O.; A. u. VorA., u. niedrigere Gbge im westl. Geb. Mai-Jun. Var. $\alpha$. hastifolius: B. beiderseits mit einer tiefen u. schmalen Bucht, der Endlappen eyf., fast breiter als lang: R. hastifolius MB.; die gewöhnlichste Form. - $\beta$. hastilis: B. 3eckig, spitz, dch den beiderseits vcrlängerten $\mathrm{Z}$ ahn der Basis spiessf. Die untersten B. oft wie bei der vorlhergeh. Variet. - $\gamma$. triangularis: B. 3eckig-eyf., der Zahn der Basis fehlend od. sehr kurz. R. glaucus Jacq.

16. R. nivalis Hegetschw. u. Heer. Die inneren Zpfl. des FruchtP. rundl.-herzf., häutig, ganzrandig, an der Basis mit einer herabgebogenen-Schuppe, die äusseren zurückgeschlagen; B. dickl., fast aderlos, die wurzelst. äusseren rundl.-eyf., sehr stumpf, etwas herzf., die inneren eyf. od. längl., spiessf., die stengelst. zu 1-2, od. fehlend; der St. einfach, quirlig-traubig, od. unter der Tr. mit wenigen einfachen Aesten; NebenB. ganzrandig. 24. Im Gerölle der hohen A.; Schwz., Baiern, Krain. Jul. Aug.

17. R. arifolius All. Die inneren $Z_{p} f$. des FruchtP. rundI.herzf., häutig, ganzrandig, an der Basis mit einer herabgebogenen Schuppe, die äusseren zurückgeschlagen; B. spiess-pfeilf., an der Basis 5-7nervig, die stengelst. zugespitzt; der St. oberwärts ästig, d. Aeste quirlig-traubig; NebenB. ganzrandig. 24. Wiesen d. A., VorA., u. höheren Gbge. Jul. Aug. R. montanus Poir.

18. R. Acetosa L. Die inneren $Z_{p} f$. des FruchtP. rundl.-herzf., häutig, ganzrandig, an d. Basis mit einer herabgebogenen Schuppe versehen, die äusseren zurückgeschlagen; $B$. pfeil- od. spiessf., aderig; NebenB. geschlitzt-gezähnt. 2. Wiesen, lichte WaldO. Mai. Jun. u. wieder Jul. Aug. Var. $\alpha$. vulgaris: B. pfeilf., die unteren eyf., stumpf, die oberen spitz. - $\beta$. auriculatus: B. spiess-pfeilf., unterste längl., obere verlängert-lanzettl., wellig, oberste sebr schmal. $-\gamma$. multifidus: genau wie die Variet. $\beta$., aber die Oehrchen 2-3sp. R. intermedius DC. R. Acetosa $\gamma$. L.

19. R. Acetosella L. Die inneren $\mathrm{Zpfl}$. des FruchtP. rundl.herzf., häutig, netzaderig, ganzrandig, ohne Schuppe, v. d. Länge der Nuss, die äusseren aufrecht, angedrückt; B. spiessf., lanzettl. od. lineal. 24. Felder, lichte WaldO. Mai-Jul. Var.: $\alpha$. vulgaris: B. lanzettl., pfeilf. - $\beta$. angustifolius: B. lineal. od. schmal-lanzettl., oft nur mit einem, selt. ohne Oehrchen. - $\gamma \cdot$ multifidus: grösser, Oehrchen der B. 2-3sp.: R. Acetosella $\delta$. L. u. R. multifidus L. 


\section{OXYRIA Hill. Säuerling.}

1. O. digyna Campdera. 2. Felsen d. A.; Tyr., Salzb., Stmk., Kärnth. Jul. Aug. O. reniformis Hooker. Rumex digynus L. B. nierenf., ausgerandet.

\section{POLYGONUM L. Knöterig.}

I. Rotte. Bistórta Tournef. Eine einzige Aehre an d. Spitze des ganz einfachen St. Gf. dreith.; N. sehr klein.

1. P. Bistórta L. St. ganz eirfach, 1ährig; Aehre gedrungen; B. längl.-eyf., fast herzf., wellig; Bsticle geflügelt. 2. Feuchte Wiesen der Ebenen u. niedrig. Berge. Jun. Jul. Bth. purp.

2. P. viviparum L. St. ganz einfach, 1ährig; Aehre gedrungen; B. oval od. lanzettl., am Rande umgerollt, gerieft-kleingekerbt, dch die verdickten Aederchen des Randes; Bstiele flügellos. 2. Triften der A. Jul. Aug. Bth. weisslich.

U. Rotte. Persicaria Tournef. St. ästig, jeder Ast mit einer Aehre endigend. Gf. dreispaltig; N. gross, kopfig.

3. P. a m phibium L. Aehren einzeln, gedrungen, walzl.; Bth. 5männig; B. längl.-lanzettl.; $W$. kriechend. 2 . Feuchte 0. u. stehende Wasser. Jun. Jul. Bth. purp. Var.: $\alpha$. natans: B. schwimmend, langgestielt, kahl. In Wasser. - $\beta$. coenosum : der St. nach ausgetrocknetem Sumpfe mit den B. niedergestreckt, wurzelnd, an d. Spitze aufstrebend $u$. daselbst die B. der folg. Variet. treibend. - $\gamma$. torrestre: aufrecht, B. kurz-gestielt, schmäler, flaumig-rauh. An feuchten 0 . - $\delta$. maritimum: der St. gestreckt; B. wie bei der vorhergeh. Variet., aber wellig. Am Seestrande.

4. P. I a $\mathrm{p}$ a th ifolium L. Aehren längl.-walzl., gedrungen, aufrecht od. etwas nickend; Bth. 6männig; B. eyf., elliptisch od. lanzettl.; Tuten kahl od. ctwas wollig, kurz- u.. sehr fein-gewimpert; Bthstiele nebst dem $K$. drüsig-rauh. $\odot$. Feuchte O., Ufer. Jul.Herbst. St. it. Bth. grïn od. roth od. der St. roth-gefleckt, bald gestreckt, bald aufrecht, die Gelenke manchmal sehr verdickt: P. nodosum Pers. - $\beta$. incanum: B. unterseits wollig-filzig. P. incanum Schmidt.

5. P. Persicaria L. var. $\alpha$. Aehren längl.-walzl., gedrungen, aufrecht od. etwas nickend; Bth. 6männig; B. eyf., elliptisch od. lanzettl.; Tuten rauhh., lang-gewimpert; Bthstiele ncbst den $K$. drüsenlos. $\odot$. Mit den vorhergeh. überall. Jul.-Herbst. Var. wie d. vorhergeh. Bth. purp. od. weissl.

6. P. mite Schrank. Aehren fädl., locker, überhangend, fast gestielt; Bth. 6männig; B. lanzettl. od. längl.-lanzettl.; T'uten rauhl., lang-gewimpert; Bth. drüsenlos. $\odot$. Feuchte O., Gräben; sehr zerstr. dch d. Geb. Jul.-Oct. P. laxiflorum Weihe. Bth. purp., selten weiss.

7. P. Hydrópiper L. Aelıren fädl., locker, überhangend, un- 
terwärts unterbrochen; Bth. 6männig; B. lanzettl. od. ellipt.; Tuten fast kahl, kurz-gewimpert, die blïthenst. fast wimperlos; Bth. drüsigpunktirt. $\odot$. Feuchte O., Gräben. Jul.-Herbst. Bth. grün, am Rande purp. od. weissl., selten rosenfarben.

8. P. minus Huds. Aehren fädl., locker, meist aufrecht; Bth. 5männig; B. aus abgerundeter Basis fast gleich-breit, vorne allmählig verschmälert, lanzettl.-lineal.; Tuten angedriickt-behaart, lang-gewimpert; Bth. drüsenlos. ○. Gräben, feuchte O. Jul.-Herbst. P. Persicaria $\beta$. angustifolim $L$. Bth. purp., selt. weiss.

III. Rotte. Avicularia Meissn. Bth. in den Bwinkeln büschelig, od. deh Verkleinerung der B. an der Spitze der Aeste in unterbrochenen Aehren. Gf. 3, kurz, frei; N. sehr klein.

9. P. aviculare L. Bth. blattwinkelst.; B. lanzettl. oder elliptisch, aderig, flach; Tuten meist 6nervig, 2sp., die Zpfl. lanzettl., zugespitzt, zuletzt vielsp.; St. ästig; Aeste bis an d. Spitze beblättert; Nüsse fein-runzelig-gestrichelt, fast glanzlos. $\odot$. Wege, kult. $O$. Jul.-Herbst. Bth. grün, mit purp. od. weissem Rande, wie an den 2 folgend. Var. St. gestreckt, an d. Erde angedrückt, u.: P. erectum, St. aufrecht. $-\gamma$. littorale: B. ziemlich dick: P. littorale Link. Dieses am Meeresufer.

10. P. maritimum L. Bth. blattwinkelst.; B. elliptisch, aderig, am Rande umgerollt; Tuten meist 12nervig, 2sp., Zpfl. lanzettl., zugespitzt, zuletzt vielsp.; der St. ästig; Nüsse sehr glalt, glänzend. 4. Ufer d. Adriat. Meeres; bei Monfalcone, Insel Sansego. Jul. Aug.

11. P. Bellardi All. Bth. blattwinkelst.; B. aderig, flach, elliptisch, die oberen lanzettl., zugespitzt; Tuten meist 6nervig, zuletzt vielsp.; St. aufrecht; Aeste ruthenf., unterbrochen-ährig; Aelhren oberwärts blattlos; Nüsse sehr fein-runzelig-gestrichelt. $\odot$. Kult. O.; Litt. Jun. Jul. P. patulum NIBieb.

IV. Rotte. Helxine. Bth. in d. Bwinkeln gebüschelt. Gf. 1, kurz, mit einer einzigen, 3lappigen $\mathrm{N}$.

12. P. Convolvulus L. St. krautig, windend, kantig-gerieft; B. herz-pfeilf.; die 3 inneren Zpfl. des P. stumpf-gekielt; Niisse 3kantig, glanzlos. $\odot$. Kult. O. Jul.-Herbst. Bth. grün, am Rande u. inwendig weiss, wie an d. folgend.

13. P. dumetor u m L. St. krantig, windend, kantig-gerieft; B. herz-pfeilf.; die äusseren $Z p f$. des $P$. häutig-geflügelt; Nüsse $3 \mathrm{kan}$ tig, glänzend. ○. Zäune, Hecken. Jul. Aug.

V. Rotte. Aconógonum Meissn. Bth. traubig; Tr. rispig. Frucht länger als das $P$.

14. P. alpin um All. Tr. endst., rispig; Bth. 8männig; St. aufrecht, ästig; $B$. längl.-lanzettl., zugespitzt, wellig, gewimpert, unterseits flaumig, in d. kurzen Bstiel verschmälert; Tuten rauhh. 24. 
Fruchtbare Wiesen d. AThäler; Uri, Wallis, Tessin. Jul. Aug. Bth. gelbl.-weiss od. rosenroth.

15. P. Fagopy rum L. T'r. blattwinkelst., einfach, die endst. ebensträussig ; Nüsse zugespitzt, 3kantig, Kanten ganzrandig; St. aufrecht, wehrlos; B. pfeil-herzf., zugespitzt. ○. Kult. Jul. Aug. Bth. rosenroth od. weiss, an der Basis grün.

16. P. tataricum L. Bth. büschelig; Büschel in den Blattwinkeln einzeln, $u$. endst. in unterbrochenen, hangenden, blattlosen Aehren; Nïsse spitz, 3kantig, Kanten ausgeschweift-gezähnt; St. aufrecht, wehrlos; B. pfeil-herzf., zugespitzt. - . Aecker; Westphal. u. Hannov. Jul. Aug. Bth. grün.

\section{Ordng. THYMELAEEN. Juss.}

1. PASSERÍNA L.; n. Wickström's Verbess. Vogelkopf.

1. P. annua Wickstr. St. kahl, ästig; B. zerstr., lanzettl.-lineal., spitz, aufrecht-abstehend; Bth. blattwinkelst., zu 5, 3 od. einzeln, flaumig; $Z$ pfl. des P. nach dem Verblïhen zsneigend. $\odot$. Aecker, sonnige O.; zerstr. dch das mittl. u. siidl. Geb. Jul. Aug. Stellera Passerina L. Bth. grün.

\section{DAPHNE L. Kellerhals.}

1. D. Mezeréum L. Bth. seitenst., sitzend, meist zu 3, flaumig; Zpfl. des P. eyf., spitz; B. lanzettl., an der Basis keilig-verschmälert, kahl. ち. Haine. Febr. März. Bth. rosenroth, selten weiss.

2. D. L a u reola L. Tr. kurz, meist 5bth., überhangend, blattwinkelst.; Bth. u. DeckB. kahl; B. lanzettl., an der Basis keiligverschmälert, kahl. Ђ. Gebirgswälder; westl. Schwz., südl. Tyrol, u. Oestr. März. Apr. Bth. gelbl.-grün.

3. D. alpin a L. Bth. endst., gehäuft, sitzend, zottig; Zpfl. des P. lanzettl., zugespitzt, ein Drittel kürzer als die Röhre des P.; $B$. lanzettl. od. vkteyf., flaumig, später kahl, abfällig. ち. Felsen d. A. Mai-Jul. Bth. weiss.

4. D. B l a g a y a n Freyer. Bth. endst., büschelig, kurz-gestielt, die Röhre mit aufrechten Härchen bestreut; Zpfl. des P. eyf., 3mal kürzer als die Röhre; das Büschel an der Basis deckblätterig, die untersten DeckB. vkteyf., unten u. am Rande seidenh. u. ohne Bth., die oberen, die unteren Bth. stützenden, lineal.-keilig, fast so lang als die Röhre; B. längl.-vkteyf., stumpf, kurz-stachelspitzig, kahl. ち. Wälder auf d. St. Lorenziberge bei Billichgrätz in Krain, Göstinger Berg bei Grätz in Stmk. Mai. Bl. gelbl.-weiss.

5. D. collin a Sm. Bth. endst., büschelig, auswendig filzig-zot†ig; Zpfl. des P. eyf., stumpf; $B$. längl.-vkteyf., stumpf oder gestutzt, glänzend, oberseits kahl, unterseits rauhh., immergrünend. $\hbar$. Felsige O.; im Isonzothale, Brignoli. März. Apr. Bth. rosenroth. 
6. D. striata Trattinnick. Bth. endst., biischelig, sitzend, kahl; Zpfl. des P. elliptisch, ein Drittel kürzer als die Röhre des P.; DeckB. eyf., kurz-stachelspitzig, ein Drittel so lang als die Röhre des P.; B. lineal.-keilig, stumpf od. ausgerandet, kurz-stachelspitzig, kahl. 5. Felsen d. A. Jul. Aug. Bl. rosenroth.

7. D. Cneor um L. Bth. endst., büschelig, kurz-gestielt, nebst den DeckB. u. dem St. oberwärts flaumig; Zpfl. des P. ellipt.; DeckBsehr kurz, abgeschnitten; B. lineal.-keilig, stumpf oder ausgerandet, kurz-stachelspitzig, kahl. $\hbar$. Trockene Trift., Haiden; zerstr. dch d. mittl. u. siidl. Geb. Jun. Jul. Bth. rosenroth.

\section{XCIX, Ordng. LAURINEEN. DC.}

1. LAURUS L. Lorbeer.

1. L. nobilis L. B. längl.-lanzettl., an beiden Enden zugespitzt, etwas wellig, aderig; Bth. blattwinkelst., büschelig. $\hbar$. In Südeuropa, jetzt jenseits der A. heimisch geworden. Apr. Mai. Bth. weiss.

\section{Ordng. SANTALACEEN. R. Brown.}

\section{THESÍUM L. Thesium.}

I. Rotte. Dreideckblätterige. Der St. oberwärts rispig od. traubig. R. od. Tr. bis an den Gipfel mit Bth. besetzt. DeckB. 3 unter jeder Bth.

a. P. nach dem Verblühen bis auf die Basis eingerollt, einen kurzen Knoten auf der Frucht bildend, welcher kaum den dritten Theil der Länge der Frucht erreicht.

1. Th. montanum Ehrh. W. hinabsteigend, ästig, zuletzt vielstengelig; St. aufrecht, oberwärts rispig; R. pyramidenf., Aestchen abstehend; B. lanzettl. od. lineal.-lanzettl., lang-zugespitzt, 3-5nervig; DeckB. zu 3; Frucht rundl.-eyf., gestielt; das eingerollte FruchtP. 3 mal kürzer als die Frucht. 24. Gebirgige, waldige 0 ; zerstr. deh d. Geb. Jul. Aug. Bth. grün, inwendig weiss, wie folgende.

2. Th. interme dium Schrader. W. ausläufertreibend, die St. aufrecht od. aufstrebend, oberwärts rispig; R. pyramidenf., Aestchen abstehend; B. lineal.-lanzettl. od. lineal., spitz, 3nervig; DeckB. zu 3; Frucht oval od. längl., gestielt; das eingerollte FruchtP. 3mal kürzer als die Frucht. 2. Bergwiesen u. zw. Gesträuch; zerstr. dch d. Geb. Jul. Aug.

3. Th. divaricatum Jan. W. hinabsteigend, ästig, zuletzt vielstengelig; St. aufrecht od. aufstrebend, oberwärts rispig; R. pyramidenf., Aestchen abstehend; B. lineal., spitz, 1nervig oder schrvach3nervig; DeckB. 3, am Rande ein wenig rauh, kïrzer als die Frucht; Frucht walzl.-längl., gestielt; Stielchen länger als die halbe Frucht; das eingerollte FruchtP. 3mal kürzer als die Frucht. 4. Bergige, 
unbebaute O.; Triest u. Fiume. Jul. Aug. Nicht so sperrig, wie das folgende.

4. Th. humifusum DeC. W. hinabsteigend, ästig, zuletzt vielstengelig; St. gestreckt od. aufstrebend, traubig, od. ästig mit traubigen Aesten, die bthetrag. Aestchen so lang als die Bth. od. länger, zuletzt fast wagerecht-abstehend; die Kanten d. Acstchen u. der Rand der oberen B. gezähnelt-rauh; B. lineal., schwach-1nervig; DeckB. zu 3, von d. Länge der Frucht od. das mittlere der unteren Aestchen länger; Frucht eyf., fast sitzend; das eingerollte FruchtP. 3mal kürzer als die Frucht. 24. Hügel u. Ackerränder bei Wagram unweit Wien, Dolliner. Jun. Jul.

5. Th. ramosum Hayne. W. spindelig, zuletzt vielstengelig; St. aufrecht od. aufstrebend-ästig, Aeste traubig und so wie die Aestchen aufrecht, etwas abstehend, und nebst dem Rande der oberen $B$. und der DeckB. gezähnelt-rauh; die, bthetrag. Aestchen 3-4mal länger als die Frucht; B. lanzettl.-lineal. oder lineal., schwach-3nervig; DeckB. zu 3, das mittlere aller Bth. länger als die Frucht; Früchte eyf., fast sitzend; das eingerollte FruchtP. 3mal kürzer als die Frucht. 24. Trockene Wiesen u. Bergtriften; bisher blos bei Wien. Jun. Jul.

6. Th. húmile Vahl. W. spindelig, ein-mehrstengelig; St. aufrecht od. aufstrebend, ästig, die Aeste traubig u. so wie die Aestchen u. der Rand der oberen B. u. DeckB. gezähnelt-rauh; die bthetrag. Aestchen sehr kurz, kürzer als die Bth., aufrecht; die Früchte eyf., fast sitzend, an den St. angelehnt; B. lineal., 1nervig; DeckB. zu 3, das mittlere länger als d. Frucht; das eingerollte FruchtP. 3mal kürzér als die Frucht. 24. od. $\odot$ ? Brachäcker $\mathrm{zw}$. Wiener-Neustadt u. Katzelsdorf in Unteröstr., Welwitsch. Jun. Jul.

b. P. nach dem Verblühen röhrig, nur an der Spitze eingerollt, von der Länge der Nuss od. länger.

7. Th. pratense Ehrh. W. spindelf.; St. traubig od. rispig; die fruchttrag. Aestchen wagerecht-abstehend, B. lanzettl.-lineal., schwacl-3nervig; DeckB. zu 3; Steinfrïchte fast kugelig; FruchP. röhrig, an der Spitze eingerollt, so lang als die Frucht. 24. Bergwiesen; zerstr. dch d. Gcb. u. hoch in die A. Jun. Jul.

8. Th. alpinum L. W. spindelf.; St. u. Aeste traubig; die fruchttrag. Aestchen aufrecht-abstehend, einseitswendig; B. lineal., 1nervig; DeckB. zu 3; Steinfrüchte fast kugelig; FruchtP. röhrig, an der Spitze eingerollt, so lang als die Frucht od. länger. 4. Haiden u. Triften d. Ebenen, Berge u. A. Jun. Jul.'

II. Rottc. Eindeckblättcrige. Der fruchttrag. St. an der Spitze dch unfruchtb. DeckB. schopfig. Ein einziges DeckB. unter jeder Bth.

9. Th. ebracteatum Hayn.

W. kriechend; Tr. einfach, die 
fruchttrag, dch unfruchtbare DeckB. an der Spitze schopfig; Bth. 1. deckblätterig; Steinfrüchte oval, gestielt, lederig, 3mal küirzer als das röhrige, an der Spitze eingerollte FruchtP. 2. Trockene, grasige 0 .; nördl. Geb. Jun. Jul.

10. Th. rostratum M. u. Koch. W. abgebissen, vielköpfig; Tr. einfach, die fruchttrag. deh unfruchtb. DeckB. an der Spitze schopfig; Bth. 1deckblätterig; Steinfrüchte fast kugelig, sitzend, beerenartig, saftig, um die Hälfte kürzer als das röhrige, an der Spitze eingerollte FruchtP. 24. Steinige O. der A. u. Bette der ABäche. Jun. Jul. Frucht weich, citrongelb.

2. ÓSYRIS L. Harnkraut.

1. O. alba L. Ђ. Felsige, unkult. O.; Littor. Apr. Mai. ,Bth. trübgelb.

\section{Ordng. ELAEAGNEEN. R. Brown.}

\section{ElAEÁGNUS L. Oleaster.}

1. E. angustifolia L. B. lanzettf., spitz, ganzrandig, beiderseits silberweiss-schülferig; Bth. blattwinkelst., gestielt, aufrecht, einzeln od. zu 3. ђ. Unkult. O.; häufig auf d. Insel Osero. Mai. Jun. Bth. auswendig silberweiss-schülferig, wie die B., inwendig hell-pomeranzengelb.

\section{HIPPÓPHA $\ddot{E}$ L. Sanddorn.}

1. H. rhamnoides L. Ђ. Fluss- u. Meerufer; Giesbäche der A. u. Flüsse im südl. Geb., im nördl. v. Holstein bis Preussen. Apr. Mai. Bth. rostfarben.

\section{Ordng. CYTINEEN. A. Brongn.}

\section{CÝTINUS L. Hypocist.}

1. C. Hypocistis L. 2. Auf der W. der Cisten schmarotzend; auf d. Inseln Osero u. Veglia. Mai. Die ganze Pfl. vor d. Aufblühen blutroth, nachher röthl.-gelb.

\section{Ordng. ARISTOLOCHIEEN. Juss.}

\section{ARISTOLÓCHIA L. Osterluzei.}

1. A. rotunda L. W. fast kugelig; St. einfach, aufrecht; B. kahl, eyf., tief-herzf., sehr kurz-gestielt; Bstiele viel kürzer als der Bthstiel; Bth. einzeln; Lippe des P. oval, an der Spitze abgerundet, ausgerandet, von der Länge der Röhre. 24. Trockene Wiesen, unkult. O.; Litt., Tessin. Apr. Mai. P. gelb, inwendig mit schwarz-purp. Streifen, Lippe gelb-braun. 
2. A. pallida Willd. W. fast kugelig; St. einfach, aufrecht; B. kahl, fast 3eckig-eyf., tief-herzf., gestielt; Bstiele so lang als der Bthstiel od. länger; Bth. einzeln; Lippe des P. halb so lang als die Röhre, ey-lanzettf., zugespitzt, an der Spitze selbst stumpf. 24. Gebirg. O. unter Gesträuch; Innerkrain, Triest, Fiume, Valle Bergami, Tessin. März. Apr. P. grün-gelblich, inwendig schwarz-purp.-gestreift, ein solcher Flecken an d. Basis d. Lippe. A. lutea Desf. aus d. Valle Bergami hat kleinere Bth. u. längeres Zünglein, ist aber sonst nicht verschieden.

3. A. Clematifis L. W. kriechend; St. einfach, aufrecht; B. eyf., tief-herzf., gestielt, kahl; Bth. blattwinkelst., büschelig. 24. Weinberge, Zäune; zerstr. deh d. Geb. Mai. Jun. Bth. gelb.

\section{4. ÁSARUM L. Haselwurz.}

1. A. e uropa e um L. B. nierenf., stumpf. 24. Bergwälder, schattige Zäune. März. Apr. Bth. auswendig grünbräunl., inwendig dunkelblutroth.

\section{Ordng. EMPETREEN. Nutt.}

\section{1.- ÉMPETRUM L. Rauschbeere.}

1. E. nigrum L. Liegend; B. längl. od. lineal., am Rande zurückgerollt, die Ränder in einer weissen Linie verbunden; N. 9strahlig. Ђ. Felsige, feuchte $O$. der A. u. höheren Gbge und Brücher des nördl. Geb. Apr. Mai. Bth. rosenroth.

\section{Ordng. EUPHORBIACEEN. Juss.}

\section{BUXUS L. Buxbaum.}

1. B. sempervirens L. B. eyf., gestielt, am Rande etwas behaart; Stbk. ey-pfeilf. ђ. Gebirg., unkult. O.; zerstr. im südl. Geb. u. bei Bertrich a. d. Mosel. März. Apr. Bth. gelbl.-griin.

2. EUPHÓRBIA L. Wolfsmilch.

I. Rotte. Anisophyllum Roep. B. mit NebenB.

1. E. C h a ma e s y c e L. Bth. blattwinkelst., einzeln; Drüsen ganz; Kapselklappen gekielt, glatt; $S$. quer-munzelig; $B$. nebenblätterig, gegenst., gestielt, rundlich, an der Basis schief, vorne seicht-gekerbt, Kerben grannenlos; St. gestreckt, ästig u. nebst den B. kahl od. rauhh. $\odot$. Dürre Raine u. kultiv. O. im Littor. Jun.-Aug. Drïs. roth. Var. kahl u. zottig, letztere: E. canescens $L$.

2. E. P e plis L. Bth. blattwinkelst., einzeln; Drüsen ganz; Kapselklappen gekielt u. nebst den $S$. glatt; $B$. nebenblätterig, gegenst., gestielt, länglich, stumpf, ausgerandet, ganzrandig oder hinten kleingekerbt, an del Basis halblierzf.; St. gestreckt, ästig u. nebst d..B. kabl. ○. Ufer d. Meeres bei Triest. Jul. Aug. Drüsen roth. 
II. Rotte. Tithymalus. B. nebenblattlos. Drüsen rundl. od. quer-oval, u. ganz, nicht mondf. ausgeschnitten, noch 2 hörnig.

a. Samen mit vertieften Punkten od. Grübchen.

3. E. helios copia L. Dolde 5sp., Aeste 3 gabelig, mit gabelsp. Aestchen; Drïsen ganz; Kapsel glatt; S. wabig-netzig; B. vkteyf., vorne gesägt. $\odot$. Kult. $\mathrm{O}$. Jul.-Sept.

b. Samen glatt. Kapsel mit Warzen besetzt, welche halbkugelig, od. kurz-walzl. od. fadenf. verlängert sind.

4. E. platyphyllos L. Dolden 3-5sp., Aeste 3gabelig, mit gabelsp. Aestchen; Drüsen ganz; Kapsel warzig, Warzen zerstreut, stumpf, fast halbkugelig; S. glatt; B. spitz, v. d. Mitte an ungleichkleingesägt, vktlanzettl., mit herzf. Basis sitzend, die untersten vkteyf., sehr stumpf, in den Bstiel verschmälert; Hüllchen fast 3eckigeyf., stachelspitzig, kleingesägt; S. rundl. $\odot$.Kult. O., Wege. Jul.Sept. Var. $\beta$. literata: B. unterseits u. am Rande dicht.-zottig, die ersten oft mit einem purp. od. braunen Flecken bezeichnet. E. literata Jacq.; am Meere bei Monfalcone, Triest, Steyer in Oestr.

5. E. stricta L. Aeste der $3-5$ sp. Dolde 3 gabelig, mit gabelsp. Aestchen; Drüsen ganz; Kapsel warzig, Warzen zerstr., kurzwalzl.; B. spitz, v. der Mitte an ungleich-kleingesägt, vktlanzettl., mit herzf. Basis sitzend, die unteren vkteyf., sehr stumpf, in den Bstiel versclımälert; Hüllchen fast 3eckig-eyf., stachelspitzig, kleingesägt; S. oval, glatt. $\odot$. Waldige 0 .; sehr zerstr. deh d. G. Jun. -Sept. E. foetida Hoppe.

6. E. duleis L. Aeste der 5sp. Dolde einmal 2sp.; Drüsen ganz; Kapsel warzig, Warzen zerstreut, ungleich, stumṕf; B. lanzettl. - längl., stumpf, nach der Basis verschmälert, ganzrandig od. vorne kleingesägt, sehr kurz-gestielt; Hüllen lanzettl.; Hüllchen an der Basis abgeschnitten, 3eckig-eyf., kleingesägt; Rhizom wagerecht; der St. stielrund, (getrocknet) feingerieft. 2. Haine u. Waldwiesen; zerstr. dch d. südl. u. mittl. Geb. Apr. Mai. Drüsen schwarzpurp. Var.: Kaps. behaart, od. $\beta$. E. purpurata Thuill.: Kaps. ohne Haare.

7. E. angulata Jacq. Aeste der 5sp. Dolde aufrecht, einmal 2sp.; Drüsen ganz; Kapsel warzig, Warzen zerstreut, stumpf, fast halbkugelig; S. glatt; B. längl.-oval od. längl., fast sitzend, vorne kleingesägt; Hüllen eyf., sitzend; Hüllchen an d. Basis abgeschnitten, fast 3eckig-eyf., so breit als lang, kleingesägt; Rhizom wagerecht; der St. geschärft-kantig-gerieft. 24. Gebirgige WaldO.; Oestr. u. Mähr. Mai. Jun.

8. E. c arniolic a Jacq. Aeste der 5sp. Dolde überhangend, einmal 2sp.; Drüsen ganz; Kapsel warzig, Warzer zerstreut, stumpf, fast halbkugंelig; S. glatt; B. lanzettl.-längl., stumpf, ganzrandig, nach der Basis verschmälert, kurz-gestielt; Hüllchen elliptisch, an der 
Basis abgerundet, ganzrandig u. nebst d. Hüllen kurz-gestielt; Rhizom wagerecht. 24. Sonnige Hügel; wärm. Krain, südl. Tyr. Apr. Mai.

9. E. verrucosa Lam. Aeste der 5sp. Dolde aufrecht, 3sp. $u$. noch einmal 2sp.; Drüsen ganz; Kapsel warzig, Warzen kurz, walzlich; S. glatt; B. längl.-eyf., fast sitzend, kleingesägt; Hüllen eyf.; Hüllchen elliptisch, stumpf, an der Basis verschmälert od. abgerundet, kurz-gestielt u. nebst der Hülle kleingesägt; W. vielköpfig. 24. Unkult. O., Wege; südl. Geb., zerstr. im mittl. Mai. Jun.

10. E. epithymoides L. Aeste der 5sp. Dolde aufrecht, 3sp. u. noch einmal 2sp.; $\mathrm{Zpfl}$. der eigenthümlichen Hülle so lang als die Hülle selbst; Drüsen ganz; Kapsel warzig, Warzen verlängert, fadenf.; S. glatt; B. längl., sitzend; Hüllchen elliptisch, stumpf, ausgerandet, an der Basis verschmälert od. abgerundet, kurz-gestielt u. nebst der Hülle ganzrandig; W. vielköpfig. 24. Rauhe, waldige O.; Krain, Stmk., Unteröstr., Mähr. Mai. Jun. Drüsen gelb.

11. E. fragifera Jan. Aeste der 5sp. Dolde 2sp.; Zpfl. der eigenthümlichen Hülle 4 mal kürzer als die Hülle selbst; Drüsen ganz; Kapsel warzig, Warzen verlängert, fadenf.; S. glatt; B. längl. od. lanzettl., sitzend; Hüllchen rundl.-eyf., an der Basis abgerundet, ganzrandig od. kleingesägt; W. vielköpfig. 2. Gebirg. O.; Krain, Litt. Apr. Mai. Driis. braun-roth. Der St. bald zottig, bald kahl.

12. E. palustris L. Aeste der vielsp. Dolde 3sp. u. weiter 2sp.; Drüsen ganz; Kapsel warzig, Warzen längl., kurz-walzl.; S. glatt; B. sitzend, lanzettl., ganzrandig od. etwas gezähnelt, kahl; Hüllchen ellipt., stumpf, an d. Basis verschmälert, sitzend. 2. Feuchte Wiesen, Ufer; zerstr. deh d. Geb. Mai. Jun.

c. Samen glatt. Kapsel glatt od. mit feinen Wärzchen oder erhabenen Pünktchen bestreut, aber eigentlich nicht warzig.

13. E. procera MBieb. Strahlen der 5sp. Dolde 3sp. u. noch einmal 2sp.; Drüsen ganz; Kapsel glatt od. mit kleinen Knötchen bestreut, lang-behaart od. kahl; S. glatt ; B. sitzend, längl.-lanzettl., kleingesägt, hinten ganzrandig, ober-u. unterseits zottig, manchmal auch kahl werdend; Hïllchen oval, stumpf, linten abgerundet od. etwas verschmälert. 24. Waldige, etwas feuchte $O$; suidöstl. u. östl. Geb. bis Schles.; Oberbad. Jun. Jul. Var. $\alpha$. : Kaps. glatt, kahl. E. villosa WK. - $\beta$. trichocarpa: Kaps. glatt, lang-behaart. E. mollis Gmel. E. coralloides L. nach Roep. - $\gamma$. tuberculata: Kaps. mit zerstr. Knötchen u. kahl. E. villosa Willd. - $\delta$. lasiocarpa: die vorhergeh., Kaps. langbehaart. E. pilosa Rochel.

14. E. Gerardiana Jacq. Strahlen der vielsp. Dolde wiederholt-2sp.; Drüsen ganz, Kapsel glatt od. sehr fein-punktirt-rauh; S. glatt; B. bläulich-grün, lanzettl.-lineal. od. lineal., zugespitzt-stachelspitzig, ganzrandig, ganz kahl; Hüllchen 3eckig, eyf., quer-breiter, 
begrannt-stachelspitzig, an der Basis abgeschnitten od. herzf,; W. vielköpfig, hinubsteigend. 24. Sandfelder, Wege; Rheinfläche, Mainthal, Thüring. u. zerstr. dch d. siidl. Geb. Jun. Jul.

15. E. pannonica Host. Strahlen der vielsp. Dolde einmal 2sp.; Drüsen abgesclenitten; Kapsel vor der Reife dicht-behaart v. ziemlich dicken, fein-gegliederten Haaren; S. glatt; B. bläul.-grün, lanzettl., spitz, kurz-stachelspitzig, vorne schwach-klein-gekerbt, dio oberen breiter:; Hüllchen breit-eyf., stumpf, stachelspitzig; W. vielköpfig. 4. Wiesen, Felder bei Lanzendorf u. Himberg unweit Wien. Jun.

III. Rotte. Esula Roeper. Drüsen halbmondf. od. 2hörnig.

a. Samen glatt. Hüllchen zsgewachsen.

16. E. amygdaloides L. Aeste der vielsp. Dolde wiederholt2sp.; Drüsen halbmondf., 2hörnig; Kapseln kahl, fein-punktirt-rauh; S. glatt; B. flaumig, die vorjährigen vkteyf.-längl. od. lanzettl., in den Bstiel verschmälert, die heurigen der jungen St. längl.; Hüllen eyf.; Hïllchen in ein flaches Scheibchen zsgewachsen. 24. Schattige Laubwälder; sehr zerstr. deh d. Geb. Apr. Mai.

17. E. W u If enii Hopp. Aeste der vielsp. Dolde wiederholt-2sp.; Drüsen halbmondf., 2 hörnig, Kapseln dicht-zottig; S. glatt; B. sitzend, lanzettl.-lineal., ganzrandig, ober- u. unterseits sammetig-filzig; Hüllen vkteyf. od. länglich; Hüllchen kräuself.-zsgewachsen. 24. Felsige, rauhe O. im östr. Littor. Apr. Mai. E. Characias Wulf, Drüs. gelb, niemals schwarz.

b. Samen glatt. Hüllchen frei.

18. E. Cyparissias L. Strahlen der vielsp. Dolde wiederholt2sp.; Drüsen 2hörnig; Knöpfe der Kapsel auf dem Rücken feinpunktirt-rauh; S. glatt; B. genau-lineal. od. nach d. Basis ein wenig verschmälert, ganzrandig, kahl, die astst. sehr schmal; Hüllchen rautenf. od. 3eckig-eyf., breiter als lang, kurz-zugespitzt, ganzrandig; W. kriechend. 4. Sandfelder, Wege. Apr. Mai.

19. E. Esula L. Strahlen der vielsp. Dolde wiederholt-2sp.; Drüsen 2hörnig; Knöpfe der Kapsel auf d. Rücken fein-punktirt-rauh; S. glatt; B. lanzettl. od. lineal.-lanzettl., nach der Basis verschmälert, kahl, am Rande nach der Spitze zu etwas rauh, die unteren kurzgestielt, die astst. schmäler; Hüllchen rautenf. od. 3eckig-eyf.; breiter als lang, stumpf, stachelspitzig od. kurz-zugespitzt; W. kriechend. 4. Wiesen, Weidengebüsch, Grüben; zerstr. dch d. Geb. Jul. Aug.

20. E. salicifolia Host. Strahlen der vielsp. Dolde wैiederholt-2sp.; Drüsen 2hörnig; Knöpfe der Kapsel auf dem Rücken punktirt-rauh; S. glatt; B. lanzettl. nach der Basis u. Spitze verschmälert, ganzrandig, dicht-flaumig; Huillchen rautenf. od. 3eckig-eyf., breiter als lang, stumpf, stachelspitzig od. kurz-zugespitzt; W. kriechend. 24. Wiesen, Wege; Unteröstr. Mai. Jun. 
21. E. virgat a W. K. Strahlen der vielsp. Dolde wiederholt2sp.; Drüsen 2hörnig; Knöpfe der Kapsel auf d. Riicken punktirtrauh; S. glatt; B. lineal.-lanzetll, von der Mitte nach d. Spitze allmählig verschmälert, ganzrandig; kahl, glanzlos; Hüllchen rautenf. od. fast 3eckig-eyf., breiter als lang, stumpf, stachelspitzig od. kurzzugespitzt; $\boldsymbol{W}$. hinabsteigend, vielköpfig. 24. Wiesen, Wege; Oestr., Mähr. u. Böhm. Mai. Jun.

22. E. lucida W. K. Strahlen der vielsp. Dolde wiederholt-2sp.; Drüsen 2hörnig; Knöpfe der Kapsel auf d. Rücken punktirt-rauh; S. glatt; B. lanzettl. od. lineal.-lanzettl., von der Mitte an nach der Spitze allmählig verschmälert, ganzrandig, kahl, glänzend; Hüllchen rautenf. oder fast 3eckig-eyf., breiter als lang, stumpf, stachelspitzig od. kurz-zugespitzt; $W$. wagerecht-kriechend. 24. Feuchte Wiesen, Gräben; Mähr., Schles. Jul. Aug. Var. B. längl.-lanzettl., lineal.lanzettl. u. lineal., immer mit einem schwachen Glanze.

23. E. saxatilis Jacq. Strahlen der 5sp. Dolde einmal 2sp.; Drüsen vorne abgeschnitten, 2hörnig, Hörnchen kurz, stumpf; Knöpfe der Kapsel feinpunktirt u.-dadurch etwas rauh, auf dem Rücken mit einem dünnen Kiele; S. glatt; $B$. bläulich-grün, kahl, ganzrandig, die unteren lineal.-längl., stumpf od. ausgerandet, mit einer Stachelspitze, nach der Basis verschmälert, die obersten elliptisch; Hüllchen quer-breiter, stumpf, stachelspitzig, an der Basis abgeschnitten od. fast herzf.; W. hinabsteigend, vielköpfig. 2. Felsige, gebirgige 0. ; Unteröstr., Stmk., Krain, südl. Tyrol. Mai. Jun.

24. E. nicaeensis All. Strahlen der vielsp. Dolde einmal 2sp.; Drïsen halhmondf. od. 2hörnig; Knöpfe der Kapsel (getrocknet) runzelig, auf dem Rücken mit einem dünnen Kiele; S. glatt; B. kahl, bläulich-grün, längl.-lineal., stumpf, kurz-zugespitzt u. kurz-stachelspitzig, ganzrandig, nach der Basis ein wenig verschmälert; Hüllchen herz-eyf., stumpf, kurz-stachelspitzig. 2. Unkult. O.; südl. Tyrol, Krain, Litt. Jul. Aug. Var. $\beta$. E. glareosa MB. : Drüsen halbmondf., aber nicht 2hörnig.

25. E. Paralias L. Aeste der 5-, seltener $3-4$ sp. Dolde 2sp.; Drüsen halbmondf.; nicht 2hörnig; Knöpfe d. Kapsel (getrocknet) runzelig, auf dem Rüclien mit einer Furche dchzogen; S. glatt; B. kahl, bläulich-grün, längl.-lineal. u. lineal., spitz od. ziemlich stumpf, grannenlos, ganzrandig; Hüllchen quer-oval, concav, grannenlos od. sehr kurz-bespitzt. 24. Sandige O. am Adriat. Meere, Jun.

c. . Samen runzelig, knotig, od. mannigfach-grubig u. ausgestochen.

26. E. Myrsinites L. Aeste der 5-8sp. Dolde 2sp.; Drüsen 2hörnig, Hörner verbreitert; Kapsel (getrocknet) runzelig; Knöpfe auf d. Rücken etwas zsgedrückt, stumpf-gekielt; $S$. grubig-runzelig; B. bläulich-grün, vkteyf.-längl. od. vkteyf., stumpf od. kurz-zugespitzt, 
stachelspitzig, kahl, am Rande etwas raulı; Hüllchen nierenf., stachelspitzig. 24. Felsige $O$. am Meere; anf Cherso. Jun. Jul.

27. E. pin e a L. Aeste der 5-9sp. Dolde wicderholt-2sp.; Drüsen 2hörnig; Knöpfe der Kapsel auf dem Rücken mit einem feinpunktirt-rauhen Strcifen; S. grubig-netzig; B. bläulich-grin, stumpf, stachelspitzig, kahl, die unteren lineal., die oberen breiter, die obersten nebst den Hüllblättchen fast 3lappig; Hiillchen herz-nierenf. 24. Felsige O. am Meere; auf Cherso, Scoglio bei Pola. Mai. Jun. E. caespitosa Ten. E. pinea Guss.

28. E. segetalis L. Aeste der 5sp. Dolde wiederlıolt-2sp.; Drïsen 2hörnig; Knöpfe der Kapsel auf dem Rücken mit einem feinpunktirt-rauhen Streifen; S. grubig-netzig; B. bläulich-griin, lineal., zugespitzt, stachelspitzig, $\mathrm{kahl}$, die oberen breiter; Hüllchen nierenf. od. fast rantenf., stachelspitzig. $\odot$. Unter d. Saat; sehr zerstr. dch d. Geb. Jun. Jul.

29. E. Peplus L. Aeste der 3sp. Dolde wiederholt-2sp.; Drüsen 2 hörnig; Knöpfe der Kapsel auf d. Rücken $2 \mathrm{kielig,} \mathrm{Kiele} \mathrm{etwas} \mathrm{ge-}$ flïgelt; S. auf der inneren Seite der Länge nach 2 furchig, auf den anderen grubig-punktirt, die 2 Rückenlinien aus 4 Grübchen geßildet; B. gestielt, vkteyf., sehr stumpf, in d. Bstiel vorgezogen, ganzrandig, die untersten fast kreisrund; Hüllchen cyf. $\odot$. Kult. O. Jul.-Oct.

30. E. peploi des Gouan. Aeste der 3sp. Dolde 2sp.; Driisen 2 hörnig; Knöpfe der Kapsel auf d. Rücken 2 kielig, Kiele etwas geflügelt; $S$. auf der inneren Seite der Länge nach 2furchig, auf den anderen grubig-punktirt, die 2 Rückenlinien aus 3 Grïbchen gebildet; B. gestielt, vkteyf., sehr stumpf od. ausgerandet, in den Bstiel vorgezogen-ganzrandig, die untersten fast kreisrund. $\odot$. Unkultiv. O. unter Gebüsch; zw. Pola u. Veruda an d. Süidspitze v. Istrien. Mai. E. rotundifolia Lois. Viel kleiner als E. Peplus. Die Samen nur mit 12 runden Grübchen, 11. dch Standort u. Bthezeit verschieden.

31. E. falcata L. Aeste der 3sp. Dolde wiederholt-2sp.; Driisen kurz-2hörnig; Kapseln glatt; S. mit 4 Reilten von ausgestochenen Querlinien bezeichnet; B. lanzettf., an der Basis rerschmälert, spitz od. zugespitzt, kahl, die untersten spatelig, stumpf oder ausgerandet mit einem Stachelspitzchen; Hiillchen eyf. oder elliptisch, stachelspitzig. $\odot$. Unter der Saat; zerstr. deh d. siidl. und mittl. Geb. Jul.-Oct.

32. E. exigua L. Aeste der 3sp. Dolde wiederholt-2sp. ; Drüsen 2 hörnig; Kapseln glatt; S. knotig-runzelig; B. lineal. od. lineal.keilig, spitz od. stumpf mit einem Stachelspitzchen od. gestutzt, kahl; Hüllchen aus fast herzf. Basis lineal., spitz. $\odot$. Aecker, kult. O. Jun.-Oct. B. alle spitz, var. aber $\beta$. truncata: B. abgeschnitten mit einem Spitzchen. - $\gamma$. tricuspidata: B. an d. Spitze fast geöh- 
relt-ausgeschnitten, mit einem Spitzchen. E. rubra DC., ob anch die จ. Cavan.

33. E. Lathyris L. Aeste der 4sp. Dolde wiederholt-2sp.; Drüsen 2hörnig; Kapseln (getrocknet) runzelig; S. runzelig, fast netzig; $B$. gegenst., ins Kreuz gestellt, längl.-lineal., sitzend, die oberen an der Basis herzf.; Hüllchen längl.-eyf., spitz. $\odot$. Kult. O.; südl. Schwz., südl. Tyr., Litt.; im nördl. Geb. verwildert. Jun. Jul.

\section{MERCURIÁLIS L. Bingelkraut.}

1. M. perennis L. St. ganz einfach; B. gestielt, eyf.-längl. od. lanzettl.; d. weibl. Bth. lang-gestielt. 2. Bergwälder. Apr. Mai.

2. M. ovata Sternb. u. Hoppe. St. ganz einfach; $B$. fast sitzend od. kurz-gestielt, eyf.; die weibl. Bth. lang-gestielt. 24. Bergwälder; zerstr. dch d. südl. Geb. Apr. Mai.

3. M. annu a L. St. ästig; B. gestielt, ey-lanzettf. oder eyf.; die weihliche Bth. fast sitzend. $\odot$. Kultiv. Orte, Schutt. Jun.-Oct.!

\section{Ordng. URTICEEN. Juss.}

\section{URTíCA L. Nessel.}

1. U. pilulifera L. B. gegenst., eyf., zugespitzt, eingeschnittengesägt; die weibl. Aehren kugelig, gestielt. $\odot$. Kultiv. O., Schutt; Thüringen. Jun.-Oct.

2. U. urens L. B. gegenst., oval, spitz, eingeschnitten-gezähnt; $\boldsymbol{R}$. blattwinkelst., gezweiet, kürzer als d. Bstiel. ○. Kult. O., Schutt, Wege. Jul.-Sept.

3. U. di o i c a L. B. gegenst., längl.-herzf., zugespitzt, grob-gesägt; $R$. blattwinkelst., länger als der Bstiel, hängend; Bth. 2häusig. 4. Zäune, Wälder. Jul.-Sept.

\section{PARIETÁRIA L. Glaskraut.}

1. P. er e cta M. u. Koch. B. wechselst., gestielt, längl.eyf., an der Basis u. Spitze zugespitzt, ganzrandig, dreifältig-benervt, durchscheinend-punktirt, kurzh.; Bthstiele gabelsp.; DeckB. sitzend, kürzer als die Bth.; die P. glockenf., die mit Stbgf. versehercen so lang als die Stbg.; St. aufrecht, einfach. 2. Mauern, Schutt; zerstr. dch das Geb. Jul._Oct. P. officinalis Willd. DC.

2. P. diffusa M. u. K. B. wechselst., cyf., an der Basis und Spitze zugespitzt, ganzrandig, 3fältig-benervt, durchscheinend-punktirt, kurzh.; Bthstiele gabelsp.; DeckB. herablaufend, kïrzer als die Bth.; die mit Sthgf. versehenen $P$. zuletzt verlängert, noch einmal so lang als die Stbf.; St. gestreckt, ausgebreitet, ästig. 24. Mauern, Wege; zerstr. im Rhein-, Nahe- u. Moselthal; Götting., südl. Tyr., südl. Schwz. Jul.-Oct. P. officinalis Sm. P. judaica Aut, nicht L. 
3. CÁNNABIS L. Hanf.

1. C. sativa L. $\odot$. Aus Indien eingebracht, fast überall kult. Jul. Aug.

4. HUMULUS L. Hopfen.

1. H. Lupulus L. 2. Hecken u. Zäune; in Grossen kultiv. Jul. Aug.

5. FICUS L. Feigenbaum.

1. F. Carica L. B. herzf, ganz od. handf., oberseits rauh, unterseits flaumig. $\hbar$. In den wärmeren Provinzen kult.; im südl. Tyrol u. im südl. Tessin häufig verwildert. Jul. Aug.

6. MORUS L. Maulbeerbaum.

1. M. al ba L. B. herzf., an der Basis ungleich, eyf,, ungeth. od. lappig, gesägt; weibl. Kätzchen ungefähr so lang als der Bthstiel; $P$. am Rande kahl; Narben kahl, mit kurzen Papillen. $\hbar$. Kultiv. Mai. Frucht weiss.

2. M. nigra L. B. herzf., eyf., ungeth. od. lappig, gesägt; weibl. Kätzchen fast sitzend, vielmal länger als der Bthstiel; $P$. am $R$ ande nebst d. Narben rauhh. ち. Kult. Mai. Frucht schwarz.

7. CELTIS L. Ziirgelbaum.

1. C. a ustralis L. B. längl.-lanzettl., zugespitzt, geschärft-gesägt, oberseits rauh-, unterseits weich- u. kurz-zottig, an der Basis ungleich. Ђ. Gebirg., steinige O.; südl. Schwz., siidl. Tyr., Litt. Mai.

8. ULMUS L. Rüster.

1. U. campestris L. B. doppelt-gesägt, an der Basis ungleich; Bth. fast sitzend; Früchte kahl. ち. Bergwälder. März. Apr. Kommt vor: $\alpha$. nuda: Rinde d. Aeste glatt. - $\beta$. suberosa: Rinde der Aeste mehr od. weniger korkig-geflügelt. U. suberosa Ehrh. U. tetrandra Schk.

2. U. effusa Willd. B. doppelt-gesägt, an der Basis ungleich; Bth. gestielt, hängend; Früchte am Rande zottig-gewimpert. 市. Bergwälder. März. Apr. U. ciliata Ehrh. U. octandra Schk.

CVII. Ordng. JUGLANDEEN.

1. JUGLANS L. Wallnussbaum.

1. J. r e gi a L. Blättchen meist zu 9, oval, kahl, etwas gesägt, fast gleich; Friichte kugelig. $\hbar$. Häufig kultiv. Mai.

CVIII. Ordng. CUPULIFEREN. Rich.

1. FAGUS L. Buche. 
1. F. sylvatica L. B. eyf., kahl, schrach-gezähnt, am Rande gewimpert. Ђ. Wälder der Ebenen, Gbge u. VorA. Mai. Var. die B. lederbraun, iiber Castellano in Rovored. Facch.

2. CASTÁNEA Tournef. Kastanienbaum.

1. C. vulgaris Lam. B. längl.-lanzettl., zugespitzt, stachelspitzig-gesägt, beiderseits kahl. $\hbar$. Wird kult. u. bildet in wärmeren Gegenden Wälder, die jedoch dch Kult. entstanden sind. Jun. Fagus Castanea L.

3. QUERCUS L. Eiche.

a. Blätter abfällig.

1. Q. ses siliflora Sm. B. gestielt, vkteyf., an der Basis ausgerandet od. in den Bstiel vorgezogen, buchtig, kahl, mit abgerundet-stumpfen, wehrlosen Lappen; Bthstiele so lang als der Bstiel od. kürzer; Schuppen des Bechers angedrückt. ந. Gebirg., etwas höhere O. Mai. Q. Robur $\beta$. L. fl. suec.

2. Q. pedunculata Ehrh. B. kurzgestielt oder fast sitzend, längl.-vkteyf., an der Basis tief-ausgerandet, kahl, buchtig od. fiedersp., mit abgerundet-stumpfen, welvrlosen Lappen; Bthstiele vielmal länger als der Bstiel; Schuppen des Bechers angedrückt. $\hbar$. Ebene u. niedrige Gegenden. Mai. Q. Robur Sm. Q. Robur $\alpha$. L. fl. suec.

3. Q. pubescens Willd. B. gestielt, vkteyf., an der Basis ausgerandet od. in den Bstiel vorgezogen, buchtig, im Frühlinge filzig, die herangewachsenen unterseits flaumig od. zuletzt kahl, Lappen stumpf, ganz oder stumpf-1-2eckig, wehrlos; Schuppen des Bechers angedrückt. Ђ. Hügel, waldige Gbge; zerstr. im südl. u. südöstl. Geb. Mai. Var. mit 1/2" langen Bthstielen. Q. apennina Lam.?

4. Q. C erris L. B. vkteyf. od. längl., buchtig od. fiedersp., flaumig od. unterseits grau-filzig, mit stachelspitzigen Lappen; Schuppen des Bechers verlängert, lineal.-pfrieml., abstehend, gewunden. $\hbar$. Waldige Gbge; Litt., Irrain, südl. Tyr., Unterstmk., Unteröstr. Mai. Q. Cerris $u$. austriaca Willd.

b. Blätter ausdauernd.

5. Q. Suber L. B. immergrün, eyf. od. lanzettl., stachelspitzig, ganzrandig od. stachelspitzig-gesägt, unterseits grau od. flzig; Rinde ritzig-schwammig. ). Hügel am Meere in Istr. Mai.

6. Q. Ilex L. B. ey- od. lanzettf., immergrün, stachelspitzig, ganzrandig od. stachelspitzig-gesägt, unterseits grau od. fizig; Rinde eben. $\hbar$. Hügel; Tessin, Litt., Val di Sarea, südl. Tyr. Mai.

7. Q. c oc cifera L. B. immergrün, eyf., dornig-gezähnt, kahl. ち. Hügel in Istrien. Mai.

4. CóRYLUS L. Haselnussstaude. 
1. C. Avell a n a L. NebenB. längl., stumpf; Fruchthüllen glockig; an der Spitze etwas abstehend, zerrissen-gezähnt; B. rundl., herzf., zugespitzt. $\hbar$. Wälder, Hecken. Febr. März.

2. C. tubulosa Willd. NebenB. längl., stumpf; Fruchthüllen röhrig-walzl., an d. Spitze verengert, eingeschnitten-gezähnt; B. rundl., herzf., zugespitzt. $\hbar$. Hecken; Istrien. Febr. März.

\section{CARPÍNUS L. Hainbuche.}

1. C. B etulus L. Schuppen der Zapfen 3th., Zpfl. lanzettl., der mittlere verlängert, gesägt od. ganzrandig. †). Wälder. Apr. Mai. Var. Schuppen d. Kätzchen ganzrandig: C. Carpinizza Host.?

2. C. duinensis Scop. Schuppen d. Zapfen eyf., ungleich-gesägt, etwas eckig, ungeth. ち. Wälder; im Litt. Apr. Mai. C. orientalis Lam.

\section{6. ÓSTRYA Micheli. Hopfenbuche.}

1. O. carpinifolia Scop. Zapfen eyf., hängend; B. eyf.-zugespitzt, an d. Basis fast herzf.; Knospen stumpf. $\hbar$. Flussufer, Gebüsch; südl. Geb., südl. d. A. Apr. Mai. Carpinus Ostrya L.

\section{Ordng. SALICINEEN. Richard.}

\section{SALIX L. Weide.}

I. Rotte. Fragiles. Kn a ckwe i den. Kätzchenschuppen gleichfarbig, gelblichgrün, vor d. Fruchtreife abfallend. - Kätzchen seitenst., die fruchttragenden auf einem seitenst., neugetriebenen, mit $3-5$ entwickelten B. versehenen Aestchen, meist nach entwickelten B. blühend. Honigdriise eine vordere $u$. eine hintere.

1. S. pentandra L. Fünf-zehnmännig; Kätzchen gestielt, der Stiel beblättert; Schuppen gleichfarbig, hinfällig; Kapseln aus eyf. Basis verschmälert, kahl, kurz-gestielt, Stielchen noch einmal so lang als die Honigdrüse; Gf. mittelmässig; N. ziemlich dick, 2sp.; B. eyf.elliptisch od. ey-lanzettf., zugespitzt, dicht-klein-gesägt, ganz kahl; NebenB. eyf.-längl., gleichseitig, gerade; Bstiel oberwärts vieldriisig. ち. Thäler der VorA. u. höhere Gbge des südl. u. mittl. Geb. u. Ebenen des nördl. Mai. Jun. Var. $\alpha$. B. ey-lanzettf.; Stbg. ungef. 5: S. pentandra $\alpha$. L. - $\beta$. latifolia: B. eyf.-ellipt.; Stbg. 5-10: S. pentandra $\beta$. L. S. polyandra Bray.

2. S. cuspid ata Schultz. Vier-fünfmännig; Kätzchen gestielt, der Stiel beblättert; Schuppen gleichfarbig, abfällig; Kapseln aus eyf. Basis verschmälert, kahl, gestielt, Stielchen 3-oder 4 mal so lang als die Honigdrïse; Gf. mittelmässig; N. ziemlich dick, ausgerandet; B. längl.-lanzettl., lang-zugespitzt, dicht-klein-gesägt, ganz kahl; NebenB. halbherzf., schief; Bstiel oberwärts-vieldrüsig. $\hbar$. 
Sumpige, wald. Wiesen; Pommern u. Mecklenb., Mittersill im Salzb. Mai. Jun. Die B. an den kurzen Kätzchen trag. Zweigen fein-gesägt, nur die untersten sind ganzrandig; an $\mathrm{S}$. fragilis sind diese B. alle ganzrandig. Var. wie andere mit rückwärts-gekehrten Schuppen d. männl. Kätzch.: S. Meyeriana Willd.

3. S. fragilis L. Zweimännig; Kätzchen gestielt, d. Stiel beblättert; Schuppen gleichfarbig, abfällig; Kapseln aus eyf. Basis lanzettl., kahl, gestielt, Stielchen 3-od. 4mal so larg als die Honigdrïse; Gf. mittelmässig; N. ziemlich dick, 2sp.; B. lanzettl., zugespitzt, ganz kahl od. die jüngeren etwas seidig, gesägt, Sägezähne einwärtsgebogen; NebenB. halbherzf. Ђ. Ufer, feuchte O. Apr. Mai. Var. $\alpha$. decipiens: die Rinde der Aestchen ledergelb, die Knospen schwarzbraun, die untersten B. der Aestchen breit-vkteyf., sehr stumpf, S. decipiens Hoffm. - $\beta$. vulgaris: Aestchen rothbraun, die untersten B. der Aestchen längl.-vkteyf. S. fragilis Sm. $-\gamma$. Russeliana: die jüngeren B., daher auch die oberen der heurigen Aestchen gegen den Herbst hin, seidig-behaart, Sägezähne meist kleiner; NebenB. mehr zugespitzt. S. Russeliana Sm.

4. S. a I b a L. Zweimärınig; Kätzchen gestielt, Stiel beblättert; Schuppen gleichfarbig, abfällig; Kapseln aus eyf. Basis verschmälert, stumpf, kahl, zuletzt etwas gestielt, Stielchen kaum so lang als die sehr kurze Honigdrüse; Gf. kurz; N. ziemlich dick, ausgerandet; B. lanzettl., zugespitzt, kleingesägt, beiderseits seidig; NebenB. lanzettl. ந. Ufer, feuchte O. Apr. Mai. Var.: $\beta$. caerulea: ältere B. kahl. S. cacrulea Sm. - $\gamma$. vitellina: Aestchen dottergelb od. freudig-mennigroth. S. vitellina $L$. nach d. Synon.

II. Rotte. Am ygdalinae. Mandelweiden. Kätzchenschuppen gleichfarbig, gelbl.-grün, bleibend. Kätzchen wie bei d. vorhergeh. Rotte am Ende von kurzen Nebenästchen. Eine vordere u. hintere Driise.

5. S. amygda lin a L. Dreimännig; Kätzchen gestielt, der Stiel beblättert; Schuppen hleibend, gleichfarbig, an der Spitze kahl; Kapseln ey-kegelf., ziemlich stumpf, kahl, gestielt, Stielchen 2- od. 3mal so lang als die Honigdrüse; Gf. sehr kurz; N. wagerecht-auseinanderfahrend, ausgerandet; B. lanzettl. od. längl., zugespitzt, gesägt, ganz kahl; NebenB. halbherzf. ち. Ufer, feuclite O. Apr. Mai. Var. $\alpha$. discolor; B. unterseits bläulichgrün: S. amygdalina L., u. dieselbe mit androgyn. Kätzchen: S. Hoppeana Willd. - $\beta$. concclor: B. unterseits grasgrün od. nur wenig ins Bläulichgrüne spielend. S. triandra L., nach Sm.

6. S. und ulata Ehrh. Dreimännig; Kätzchen gestielt, der Stiel beblättert; Schuppen bleibend, gleichfarbig, an der Spitze bärtig; Kapseln ey-kegelf., flaumig od. kahl, gestielt, Stielchen noch einmal so lang als die Honigdrüse; Gf. verlängert; N. 2sp.; B. lanzettl., 
lang-zugespitzt, kleingesägt, flaumig, zuletzt kahl; NebenB. halbherzf. 5. Ufer im nördl. Geb. Apr. Mai. Var. $\alpha$. Fruchtkn. flaumig: S. undulata Ehrh. nach Originalexempl. $-\beta$. Fruchtkn. kahl: S. lanceolata $\mathrm{Sm}$.

7. S. hippophaëfolia Thuill. Zweimännig; Kätzchen gestielt, d. Stiel beblättert; Schuppen bleibend, gleichfarbig, rauhh.; Kapseln ey-kegelf., filzig od. kahl, gestielt, Stielchen so lang als die Honigdrüse; Gf. verlängert; N. 2sp.; B. lanzettl. lang-zugespitzt, kleindrüsig-gezähnelt, flaumig, zuletzt kahl; NebenB. halbherzf. $\hbar$. Ufer, feuchte O.; Rhein-, Main- u. Nahegeb.; ausserdem sehr zerstr. dch d. mittl. u. nördl. Geb. Apr. Mai. Kätzchen halb so gros wie an d. vorhergeh. Var. $\alpha$. planifolia: Fruchtkn. grau-filzig, B. flach. $-\beta$. undulaefolia: Fruchtku. grau-filzig od. flaumig, B. zierlich-wellenf. S. undulata Ehrh. nach Trev. - $\gamma$. lejocarpa: Fruchtkn. kahl.

III. Rotte. Pruinosae. Schimmelweiden. Kätzchenschuppen an der Spitze verschiedenfarbig. Kätzchen seitenst. u., auch d. fruchttragenden, sitzend, vor den B. blüheud. Stbk. nach dem Verblühen gelb. Innere Rinde im Sommer citrongelb. Aeste oft hechtgrau-bereift.

8. S. a cutifolia Willd. Kätzchen sitzend, mit kleinen DeckB. am Grunde; Kapseln ey-kegelf., kahl, sitzend; Honigdrïse über die Basis des Fruchtkn. hinaufreichend; Gf. verlängert; N. lineal.-längl.; B. lineal.-lanzettl., lang-zugespitzt, gesägt und nebst den jüngeren Aestchen kahl; NebenB. lanzeltl., zugespitzt. $\hbar$. Ufer; Schles., Pomm., Preussen. März.

9. S. da phnoides Vill. Kätzchen sitzend, mit kleinen DeckB. am Grunde; Kapseln ey-kegelf., kahl, sitzend; Honigdrüse über die Basis des Fruchtkn. hinaufreichend; Gf. verlängert; N. längl.; B. längl.-lanzettl., zugespitzt, drüsig-gesägt, kahl, die jüngeren nebst den jungen Aestchen zottig; NebenB. halbherzf. b. Thäler der VorA., mit den Flüssen; am Rheine bis Pforzheim, an den übrigen bis zur Donau; Flächen des nördl. Geb. März. Apr.

IV. Rotte. Purpureae. Purpurweiden. Kätzchenschuppen a. d. Spitze verschiedenfarbig. Die Kätzchen seitenst., sitzend, vor den B. bliihend. Stbk. purpurn, nach d. Verbliihen schwarz. Die innere Rinde im Sommer citrongelb.

10. S. P ontederana Schleicl. Einbrüderig; Kätzchen sitzend, an der Basis mit DeckB. gestiitzt; Kapseln ey-lanzettf., gestielt, filzig, Stielchen so lang als die Honigdrüse; Gf. mittelmässig; N. eyf., ausgerandet; B. vktey-lanzettf., kleingesägt, kahl, die jüngeren flaumig; NebenB. halbherzf. ち. Gebirgswälder, Ufer; Böhm., Unteröstr., Krain, Tyr., Schwz, März. Apr. S. Pontederana Willd. nach Schleich. S. discolor u. S. austriaca Host.

11. S. purpurea L. Einmännig dch zsgewachsene Stbf.; Kütz- 
chen sitzend, an d. Basis mit DeckB.; Kapseln eyf., sitzend, filzig; Honigdrüse über die Basis des Fruchtkn. hinaufreichend; Gf. kurz; N. eyf.; B. lanzettl., nach vorne breiter, zugespitzt, geschärft-kleingesägt, kahl, flach. Ђ. Ufer, feuchte O. März. Apr. S. monandra Hoffm. Staubf. bis z. Spitze zsgewachsen, bei Var. $\delta$. nur ungef. bis zur Mitte. Var. $\alpha$. Stamm niedriger, Aeste mehr spreitzend, Kätzchen sehr schlank: S. purpurea Sm. - $\beta$. Lambertiana: Kätzchen noch einmal so dick; B. grösser, breiter; sonst wie die vorhergeh. S. Lambertiana Sm. - $\gamma$. Helix: Aeste aufrecht, wenig abstehend; B. länger. S. Helix L., Sm. - $\delta$. monadelpha. Stbg. nach oben frei. - $\varepsilon$. sericea: die jüngeren $B$. mit dichtem, seidigem Flaume bedeckt, der später verschwindet. - $\zeta$. androgyna: Kätzchen aus männl. u. weibl. Bth. zsgesetzt. S. mirabilis Host.

12. S. rubra Huds. Einbrüderig; Kätzchen sitzend, an der Basis mit DeckB. gestützt; Kapseln eyf., sitzend, filzig; Honigdrüse über d. Basis des Fruchtkn. hinaufreichend; Gf. verlängert; N. längl.lineal. od. fädl.; $B$. verlängert-lanzettl., zugespitzt, ausgeschweift-gezähnelt, am Rande etwas zurückgerollt, flaumig, die erwachsenen kahl; NebenB. lineal. $\hbar$. Ufer, feuchte O. März. Apr. S. fissa Ehrh. Staubf. bis gegen d. Mitte zsgewachsen, selt. bis zur Spitze, letztere: S. Forbyana Sm. Var. $\beta$. sericea: die B., auch die erwachsenen, auf der unteren Seite mit einem dichten seidigen Flaume bedeckt.

V. Rotte. Viminales. Korbweiden. Kätzchenschuppen an der Spitze verschiedenfarbig. Die Kätzchen seitenst., sitzend, vor der Entwickelung der B. blülend od. fast gleichzeitig. Stbk. nach d. Verblühen gelb. Innere Rinde grünlich. Kapseln sitzend od. selır kurz-gestielt, d. Stielchen nicht länger als d. Honigdrüse.

a. Weibl. Kätzchen gerade.

13. S. molli s sim a Ehrl. Kätzchen sitzend od. kurz-gestielt, an d. Basis mit DeckB. gestützt; Kaps. ey-kegelf., filzig, sitzend; Honigdrüse üher d. Basis des Fruchtkn. hinaufreichend; Gf. verlängert; N. lineal., 2sp., so lang als die Haare der Schuppen; B. verlängertlanzettl., zugespitzt, entfernt-ausgeschweift-gezähnelt, $d$. jüngeren un. terseits fein-filzig; NebenB. eyf., spitz. ந. Ufer, feuchte O.; nördI. Geb. Apr. Schuppen der Kätzchen gelbl.-rostbraun, Haare derselben schmutzig-weiss.

14. S. viminalis I. Kätzchen sitzend, an der Basis mit DeckB. gestützt; Kapscln aus eyf. Basis lanzettl., filzig, sitzend; Honigdrüse über die Basis des Fruchtkn. hinaufreichend; Gf. verlängert; N. fädl., ungeth.; Haare d. Schuppen kürzer als der Gf.; B. verlängert-lanzettl., zugespitzt, ganzrandig, etwas ausgeschweift, unterseits seidig $u$. glänzend; NebenB. lanzettl.-lineal., kürzer als der $B$ stiel. Ђ. Ufer, feuchte O. März. Apr. Schuppen d. Kätzchen schwarzbraun, Haare derselben silberweiss. 
15. S. stipularis Sm. Kätzchen sitzend, an der Basis mit DeckB. gestiitzt; Kapseln aus eyf. Basis lanzettl.-filzig, sehr kurzgestielt; Honigdrüse über die Basis des Fruchtkn. hinaufreichend; Gf. verlängert; N. fädl., ungeth.; Haare der Schuppen ungefähr so lang als die N.; $B$. verlängert-lanzettl., zugespitzt, ganzrandig, etwas ausgeschweift, unterseits filzig, ein venig glänzend; Neben B. aus halbherzf. Basis lanzettl.-verschmälert, so lang als der Bstiel. $\hbar$. Ufer, feuchte O.; Unteröstr., Ins. Norderney. März. Apr.

16. S. Smithiana Willd. Kätzchen sitzend, an der Basis mit DeckB. gestützt; Kapseln aus eyf. Basis lanzettl., filzig, gestielt, Stielchen so lang als die Honigdrïse; Gf. kürzer als die N.; N. fädl., oft 2th.; B. längl.-lanzettl. od. lanzettl., zugespitzt, wellig, schwachgekerbt, sehr klein-gezähnelt, unterseits filzig; Filz seidig; NebenB. nieren-halbherzf., zugespitzt. $\hbar$. Ufer, feuchte 0 .; sehr zerstr. deh d. Geb. März. Apr. S. mollissima Sm., nicht Ehrh. S. Ianceolata Fries.

17. S. a cuminata Sm. Kätzchen sitzend, an der Basis mit DeckB. gestiitzt; Kapseln aus eyf. Basis lanzettl., filzig, gestielt, Stielchen so lang als die Honigdrïse; $G f$. von der Länge der $N$.; $N$. fädl., ungeth.; B. längl.-Ianzettl., zugespitzt, am Rande etwas wellig, klein-drüsig-gezähnelt, unterseits bläulich-grün, filzig, Filz glanzlos; NebenB. nieren-halbherzf., spitz. 24. Ufer, feuchte O.; sehr zerstr. dch d. Geb. Apr.

VI. Rotte. Capreae. Sahlweiden. Kätzchenschuppen an der Spitze verschiedenfarbig. Kätzchen seitenst., die blühenden sitzend, die fruchttragenden melrr od. weniger gestielt, der Stiel mit DeckB. oder mit grösseren und wirklichen B. bekleidet. Stbk. nach d. Verblühen gelb. Kapseln gestielt, d. Stielchen wenigstens noch einmal so lang als d. Honigdrise.

18. S. S eringean a Gaud. Kätzcher sitzend, gekrümmt, an der Basis mit DeckB. gestützt; Kapseln aus eyf. Basis lanzettl., filzig, gestielt, Stielchen noch einmal so lang als die Honigdrüse; Gf. verlängert; N. 2sp.; B. lanzettl.-längl., zugespitzt, klein-gekerbt, unterseits weiss-filzig, runzelig-aderig; NebenB. eyf., spitz. t). Bäche in den Thälern der VorA., Schwz., Tyr., Krain. Apr. S. lanceolata Sering, nicht Sm.

19. S. salvia efolia Link. Kätzchen sitzend, gekrümmt, an der Basis mit DeckB. gestützt; Kapseln aus eyf. Basis lanzettl., filzig, gestielt; Stielchen 2 mal so lang als die Honigdrüse; Gf. kurz; N. längl., fast ungeth.; B. längl.-lanzettl., spitz, nach der Basis verschmälert, schwach-gezähnelt, unterseits grau-filzig, runzelig-aderig, die unteren stumpf; NebenB. lialbherzf., spitz. $\hbar$. Sumpfige O., Ufer; Schwz., südl. Tyr. Apr. Mai. S. patula Sering.

20. S. in can a Schrank. Kätzchen fast sitzend, gekrümmt, an der Basis mit DeckB, gestuitzt; Kapseln ey-lanzettf., kahl, gestielt, 
Stielchen noch einmal so lang als die Honigdrüse; $G f$. verlängert; N. 2sp.; B. lanzettl.-lineal., zugespitzt, gezähnelt, unterseits filziggrau. Ђ. Thäler der A., mit d. Flüssen in d. Ebenen, am Rheine in das Badische, mit d. übrigen bis in das Donauthal; Weichsel im Teschn. Apr. Mai. S. riparia Willd.

21. S. holosericea Willd. Kätzchen sitzend, an d. Basis mit DeckB. gestïtzt; Kapseln aus eyf. Basis lanzettl., filzig, gestielt, Stielchen 2- od. 3 mal so lang als die Honigdrüse; Gf. sehr kurz; N. eyf., ausgerandet; B. lanzettl., zugespitzt, nach d. Spitze verschmälert und geschärft-gezähnelt, unterseits filzig; NebenB. halbeyf., stumpf. $\hbar$. Ufer, feuchte Wiesen; Gegend von Göttingen, u. bei Berlin. März. Apr. S. velutina Schrad.

22. S. cinerea L. Kätzchen sitzend, an d. Basis mit DeckB. gestützt; Kapseln aus eyf. Basis verlängert-lanzettl., filzig, gestielt, Stielchen 4 mal so lang als die Honigdrüse; Gf. sehr kurz; N. eyf., 2sp.; B. elliptisch- od. lanzettl.-vhteyf., kurz-zugespitzt, flach, welliggesägt, grau-grün, oberseits flaumig, unterseits filzig-kurzh.; NebenB. nierenf.; Knospen grau. Ђ. Triften, feuchte Hecken u. Wälder. März. Apr. S. acuminata Hoffm., nicht Sm.

23. S. ni gri can s Fries. Kätzchen sitzend, die fruchttrag. kurzgestielt, an der Basis klein-beblättert; Kapseln aus eyf. Basis pfrieml., gestielt, Stielchen 2-3mal so lang als d. Honigdrüse; Gf. verlängert; N. 2sp.; B. eyf., elliptisch od. lanzettl., wellig-gesägt, unterseits grau, meist mit grüner Spitze, die jüngeren nebst den Zweigen kurzh.-flaumig, zuletzt kahl; NebenB. halb-herzf. mit gerader Spitze. ђ. Feuchte Haine u. Ufer, Thâler d. A. u. Ebenen d. suidl. Geb., zehr zerstr. dch d. mittlere u. nördl. Apr. Mai. S. phylicifolia Wahlenb. S. stylaris Sering. - $\beta$. eriocarpa: die Frucktkn. überall filzig od. kurzh., od. nur an d. Basis mit einem kahlen Flecken bezeichnet. S. nigricans Wahlenb. $-\gamma$. concolor: die B. unterseits grün u. glänzend. S. nigricans $\gamma$. punctata Hartm. scand. Fl. ed. 3. p. 235.

24. S. silesiaca Willd. Kätzchen sitzend; Kapseln aus eyf. Basis lanzettl., kahl od. seidig, gestielt, Stielchen 3-od. 4 mal so lang als die Honigdrüse; Gf. mittelmässig; N. eyf., 2sp.; B. vkteyf., zugespitzt, wellig-gesägt, unterseits fast gleichfarbig, die älteren ganz kahl, die untersten sehr stumpf; NebenB. nierenf.-halbherzf. Ђ. Gebirgswälder; Sudeten, Mälr. Karpaten. Mai. Jun. Früchte kahl. Var. $\beta$. Früchte filzig: S. fagifolia Willd.

25. S. grandifolia Sering. Kätzchen sitzend, die fruchttrag. gestielt, an $d$. Basis meist beblättert; Kapseln aus eyf. Basis verlängert-lanzettl., filzig, gestielt, Stielchen $6 \mathrm{mal}$ so lang als die Honigdrüse; Gf. sehr kurz; N. eyf., 2sp.; B. längl.-vkteyf., zugespitzt, flach, schwach-wellig-gesägt, kahl, unterseits grau-grün, flaumig; NebenB, nierenf.; Knospen kahl. b. Wälder der VorA., Schwarzw. 
März. Apr. S. stipularis Sering., nicht Sm. Wahrscheinl. Variet. d. folgenden.

26. S. Caprea L. Kätzchen sitzend, an der Basis mit kleinen DeckB. gestützt; Kapseln aus eyf. Basis verlängert-lanzettl., filzig, gestielt, Stielchen 3-6mal so lang als die Honigdrüse; Gf. sehr kurz; N. eyf., 2sp.; B. eyf. od. elliptisch, flach, zugespitzt, mit zurückgekrümmter Spitze, schwach-wellig-gekerbt, oberseits kahl, unterseits bläulichgrïn, filzig; NebenB. nierenf.; Knospen kahl. ち. Wälder, Haine. März. Apr.

27. S. a urita L. Kätzchen sitzend, die fruchttrag. gestielt, an der Basis etwas beblättert; Kapseln aus eyf. Basis verlängert-lanzettl., filzig, gestielt, Stielchen 3-od. 4mal so lang als die Honigdrüse; Gf. sehr kurz; N. eyf., ausgerandet; B. vkteyf. oder längl.vkteyf., zurückgekrümmt-bespitzt, wellig-gesägt, runzelig, oberwärts flaumig, unterseils bläulichgrün, filzig-kurzh.; NebenB. niercnf.; Knospen kahl. $\hbar$. Triften, Wiesen, feuchte Wälder. Apr. Mai.

28. S. depressa L., nach Fries. Die fruchttrag. Kätzchen gestielt, der Stiel beblättert; Kapseln aus eyf. Basis verlängert-lanzettl., filzig, gestielt, Stielchen $5 \mathrm{mal}$ so lang als d. Honigdrüse; Gf. sehr kurz; N. eyf., 2sp.; B. vkteyf. od. elliptisch, ganzrandig od. entfernt-stumpf-gesägt, unterseits bläulichgrün, sammetig od. flaumig od. die älteren gänzlich kahl; NeberıB. nierenf. b. Moorige Sümpfe um Tschirnau in Schles. Apr. S. livida Wahlenb. S. Starkeana Willd.

29. S. phylicifolia L. nach Fries. Die Kätzchen sitzend, an der Basis mit DeckB. gestützt, die fruchttrag. etwas gestielt $u$. an der Basis etwas beblättert; Kapseln aus eyf. Basis verlängert-lanzettl., filzig od. kahl, Stielchen 2-3mal so lang als die Honigdrüse; $G f$. verlängert; N. 2sp.; B. eyf., elliptisch od. lanzettl., entfernt-ausgeschweift-kleingesägt od. ganzrandig, unterseits bläulichgrün, die älteren völlig kahl; NebenB. halbherzf., mit schiefer Spitze. $\hbar$. Feuchte O. auf d. Brocken u. im Riesengrunde d. Sudet. Mai. Jun. S. bicolor Ehrh. K. syn. ed. 1. S. arbuscula Wahlb. S. Weigeliana Willd.

30. S. glabra Scop. Die Kätzchen gestielt, Stiel beblältert; Kapseln aus eyf. Basis pfrieml., gestielt, kall, Stielchen ungefähr noch einmal so lang als die Honigdrüse; Gf. verlängert; N. 2th.: $B$. elliptisch od. vkteyf., gesägt, kahl, spiegelnd, unterseits bläulichgrün; Neben B. fehlend od. drüscnf., die an den kräftigen Trieben vielmal kürzer als der Bstiel; Schuppen behaart, zuletzt nach abgefallenem Flaume kahl; Stbg. von der Basis bis über d. Mitte zottig. Ђ. Bäche u. feuchte Abhänge d. VorA.; Bayern, Salzbg., Kärnth., Krain. Jun. Jul. S. coruscans Willd. u. S. Wulfeniana Willd. u. Host.

31. S. H egets chweileri Heer. Kätzchen zuletzt gestielt, Stiel beblättert; Kapseln aus eyf. Basis pfrieml., gestielt, kahl, mit filzigem Stielchen od. überall dünn-filzig; Stielchen ungefähr noch einmal so lang als die Honigdrüse; Gf. verlängert; Narben 2th.; B. 
oval od. längl.-vkteyf., fein-gesägt, unterseits bläulichgrün; Neben B. an den jüngeren $Z$ weigen halblierzf. mit gerader Spitze, so lang als der Bstiel; Schuṕpen zottig, die Zotten bei d. Frucht nicht gekräuselt, bleibend; Stbf. kahl. $\hbar$. An der Reus im Urserenthal u. am Inn im Engadin. Jun. Jul.

32. S. hastat a L. Kätzchen gestielt, Stiel beblättert; Kapseln aus eyf. Basis pfrieml., gestielt, kahl, Stielchen ungefähr $1 \frac{1}{2}$ mal so lang als die Honigdrüse; Gf. verlängert; N. 2sp.; B. eyf., elliptisch od. lanzettl., kahl, klein-gesägt; NebenB. halbherzf., mit gerader Spitze; Schuppen sehr zottig, Zotten lang, aber bald zsgezogen u. gekräuselt; Stbf. kahl. ђ. Triften der A. u. im Gesenke d. Sudet., Harz im Stolberg. Jun.

33. S. my rtilloides L. Die fruchtrag. Kätzchen langgestielt, Stiel beblättert; Kapseln aus eyf. Basis lanzettl., kahl, langgestielt, Stielchen 4- od. mehrmal länger als die Honigdrüse; Gf. kurz; N. eyf., ausgerandet; $B$. eyf., an der Basis fast herzf., längl. od. lanzettl., ganzrandig, glanzlos, völlig kahl, unterseits netzaderig; Kätzchenschuppen kahl od. gewimpert; Neben B. halbeyf. $\downarrow$. Sumpfige Haiden u. moorige Triften; Schles., bayer. A., Brücher bei München. Mai. Jun.

34. S. a m bigua Ehrh. Kätzchen sitzend, die fruchttrag. kurzgestielt, Stiel klein-beblättert, Kapseln aus eyf. Basis lanzettl., filzig, lang-gestielt, Stielchen 3-od. 4mal so lang als die Honigdrüse; Gf. kurz; N. eyf., ausgerandet; $B$. elliptisch, vktey-od. lanzettf., zurückgekrümmt-bespitzt, ganzrandig od. entfernt-gezähnelt, unterseits runzelig-aderig, angedrickt-zottig, fast seidig, zuletzt kahl; Neben B. halbeyf., gerade. $\hbar$. Sumpfige Wiesen, feuchte Triften. Apr. Mai. S. plicata Fries. S. incubacea L. nach Fries. S. aurito-repens Wimmer. Die Variet. mit lanzettl. B.: S. cinereo-repens Wimmer.

35. S. repens L. Kätzehen sitzend, die fruchttrag. oval-walzlich, kurz-gestielt, der Stiel beblättert; Kapseln aus eyf. Basis lanzettl., filzig od. kahl, lang-gestielt, Stielchen 2-od. 3mal so lang als d. Honigdrüse; Gf. mittelmässig; N. eyf., 2sp.; B. oval, elliptisch od. lanzettl., mit rückwärtsgekrümmter Spitze, am Rande etwas herabgebogen, ganzrandig od. entfernt-drüsig-gezähnelt, glänzend, unterseits seidig; Neben B. lanzettl., spitz. ந. Feuchte, sandige, auch trocknere Wiesen $u$. Triften und moorige $O$. Apr. Var. $\alpha$. vulgaris: B. lanzettl., Kapseln belaart. S. repens Sm. - $\beta$. fusca: B. längl.oval, Kapseln behaart. S. fusca Sm. $-\gamma$. argentea: B. breit-oval od. oval-rundlich, unterseits od. auf beiden Seiten seidenhaarig, Kapseln behaart. S. argentea Sm. S. arenaria L. - $\delta$. leiocarpa: B. lanzettl., Fruchtkn. u. Kapseln kahl. - - . finmarchica: B. kahl, od. die oberen in der Jugend seidenhaarig, Kapseln kahl. S. finmarchica Willd. S. ambigua $\beta$. glabrata K. syn. ed. 1.

36. S. angustifolia Wulf. Kätzchen sitzend, d. fruchttrag. 


$$
11 / 35 \cdot 5 \cdot 116 \cdot 5 \cdot 356
$$

- purpuncar-repens,...

Bastand won 11 \& 35.

Taniont:

Syx: 

oval, kurz-gestielt, der Stiel beblättert; Kapseln aus eyf. Basis lan. zettl., filzig od. kahl, langgestielt, Sticlchen 2-od. 3 mal so lang als die Horigdrüse; Gf. mittelmässig; N. eyf., 2 sp.; B. verlängert-lanzettl., steif, mit gerader Spitze zugespitzt, am Rande etwas zurückgerollt, ganzrandig oder entfcrnt-drüsig-gezähnelt, unterseits seidig; Neben B. lanzettl. †. Feuchte Wiesen, östl. u. nördl. Geb. Apr. S. incubacea Willd. u. L. nach Sm.

37. S. rosmarinifolia $L$. Kätzchen sitzend, die fruchttragenden rundlich, kurz-gestielt, der Stiel beblättert; Kapseln aus eyf. Basis lanzettl., filzig, langgestielt, Stielchen 2-od. 3 mal so lang als die Honigdrüse; Gf. kurz; N. eyf., 2sp.; B. lineal. od. lineal.-lanzettl., verschmälert-zugespitzt, am Rande flach, an der Spitze gerade, ganzrandig od. entfernt-driisig-gezähnelt, unterseits seidig; Neben B. lanzettl. $\hbar$. Sumpfige, moorige O.; nördl. Geb. Mai.

38. S. Doniana Smith. Einbrüderig; Kätzchen sitzend, die fruchttragenden etwas gestielt, an d. Basis klein-beblättert; Kapseln ey-kegelf., filzig, grestielt, Stielchen 2 mal so lang als die Honigdrüse; Gf. sehr kurz; N. kurz, ausgerandet; B. oft gegenst., lanzettl. od. vktey-lanzettf., spitz, steif, an der Spitze gerade, entfernt-kleingesägt, oberseits spiegelnd, unterseits seidig; die Haare an den ausgewachsenen B. zerstreut. ந. An Rändern feuchter Wiesen; Steinfurth in Westphalen, Unterharz. Apr. Mai. 3-4' hoch, der S. purpurea ähnlich, aber d. Kapseln gestielt u. d. Stbk. nach d. Verblühen
gelbbraun.

VII. Rotte. Frigidae. Alpenweiden. Kätzchenschuppen an der Spitze ungleichfarbig. Kätzchen seitenst., u. wenigstens d. fruchttragenden mehr od. weniger gestielt, mit einem beblätterten Stiele. Stbk. nach d. Verblühen gelb od. braun. Kapseln sitzend od. kurzgest., aber d. Stielch. nicht länger als d. Honigdriise.

39. S. arbuscula L., nach der Ansicht v. Laestadius, Fries u. Hartm. Kätzchen gestielt, der Stiel beblättert; Kapseln ey-kegelf., filzig, sitzend, zuletzt kurzgestielt; Honigdrüse über die Basis der Kapsel hinaufreichend; Gf. verlängert, oft bis zur Mitte gespalten; N. 2sp.; B. kahl, lanzettl., spitz od. eyf., an d. Basis u. Spitze stumpf od. kurz-zugespitzt, entfernter- od. dichter-gesägt, oberseits glänzend, unterseits bläulichgrün, glanzlos. Ђ. Feuchte Triften d. A. Jun. Jul. $\alpha$. Waldsteiniana: Sägezähne der B. entfernter, mehr angedruickt; Gf. sehr oft tief-geth. S. Waldsteiniana W. - $\beta$. foetida : Sägezähne der B. häufig, mit einer dickeren Drüse endigend, darum mehr genähert; Gf. meist nicht gespalten. S. foetida Schleich. $-\gamma$. prunifolia: Sägezähne der B. etwas wellig; Gf. kurz, nach der Bthezeit nur wenig verlängert; Schuppen grau-blau. S. prunifolia Sm.

40. S. La p p o n u L L, nach Laestad. u. Fries. Kätzchen sitzend, die fruchttrag. etwas gestielt; Kapseln ey-lanzettf., filzig od. kahl, 
sitzend, zuletzt sehr kurz-gestielt; Honigdrüse länger od. so lang als die Bthstielchen; Gf. verlängert; N. lineal., 2sp.; B. lanzettl. od. clliplisch, zugespitzt, ganzrandig od. kleingesägt, die jüngeren seidig-zottig, die erwachsenen oberseits runzelig, unterseits filzig, glanzlos; NebenB. halbherzf., mit zurückgekrümmter Spitze. ち. Feuchte, morastige O. der A., Sudet. u. Mähr. Karpaten. Mai. Jun. S. limosa Wahlenb. S. helvetica Vill. S. nivea Ser.

41. S. glauca L. Kätzchen langgestielt, d. Stiel beblättert; Kapseln ey-lanzettf., filzig, kurz-gestielt, Stielchen so lang als die Honigdrïse; Gf. 2sp.; N. verlängert, 2sp.; B. lanzettl. oder elliptisch, ganzrandig, unterseits grau, beiderseits seidig-zottig, zuletzt ziemlich kahl, spitz, die untersten aber sehr stumpf; NebenB. eyf., spitz, gerade. ). Höchste A. der südl. Schwz. Jun. Jul. S. sericea Vill. Die B. unterseits grau-gefärbt u. mit langen, geraden, angedriickten Zotten, nicht mit verwebtem Filze bedeckt, wie bei d. vorhergeh.

42. S. caesia Villars. Kätzchen kurzgestielt, der Stiel beblättert; Kapseln ey-kegelf., filzig, sitzend, zuletzt sehr kurzgestielt, Honigdrïse über die Basis der Kapsel hinaufreichend; Gf. verlängert od. auch ziemlich kurz; N. eyf.-längl., ungeth. u. 2sp.; B. elliptisch od. lanzettl., zugespitzt, ganz kahl, beiderseits bläulichgrün, glanzlos, am Rande zurückgerollt, ganzrandig. Ђ. Auf der A. Enzeindaz im C. Waadt. Jun. Jul.

43. S. myrsinites L. Kätzchen langgestielt, der Stiel ungefähr von der Länge des Kätzchens, beblättert, oberwärts blattlos; Kapseln aus eyf. Basis lanzettl.-zugespitzt, sitzend, wollig-zottig, zuletzt sehr kurz-gestielt, kahl geworden; Honigdrüse über die Basis der Kapsel hinaufreicher, ; Gf. verlängert; N. lineal., ungeth. u. 2sp.; $B$. elliptisch od. lanzettl., beiderseits netzaderig, spiegelnd, gleichfarbig, zuletzt ganz $\mathrm{kahl}$, am Rande dicht drüsig-kleingesägt. $\hbar$. Feuchte O. der A. Jun. Jul. Fruchtkn. und Gf. schwarz-purpurn, Stbf. blau, Stbk. violett. - Var.: $\beta$. lanata: B. durchaus mit einer fast seidigen, dichten Wolle bedeckt. - $\gamma$. leiscarpa: Kapseln zuletzt kahl. - $\delta$. Jacquiniana: B. ganzrandig. S. Jacquiniana Willd., K. syn. ed. 1. S. fusca Jacq.

VII Rotte. Glaciales. Glets cherweiden. Kätzchen endst. Es sprosst nämlich aus d. Endknospe der vorjährigen Aeste ein neues Aestchen hervor, das mit B. u. in deren Winkeln mit Knospen, welche sich im folg. Jahre entwickeln, bekleidet $\mathfrak{u}$. auf dessen Spitze das Kätzchen befindlich ist.

44. S. reticulata L. Kätzchen gestielt, endst.; Kapseln eyf., filzig, fast sitzend; Honigdrüse über die Basis der Kapsel hinaufreichend; Gf. kurz; N. 2sp.; B. langgestielt, elliptisch-kreisrund, stumpf, kurz-bespitzt od, gestutzt, am Rande zurückgerollt, ganz- 
randig, oberseits runzelig, unterseits bläulichgrün, n€tzig, zuletzt kahl. Ђ. Feuchte Felsen der A. Jul. Aug.

75. S. retusa L. Kätzchen gestielt, der Stiel beblättert, knospentrag.; Kapseln ey-kegelf., kahl, kurzgestielt; Honigdriise ungefähr von der Länge des Bthstielchens; Gf. mittelmässig; N. 2sp., lineal.; B. sehr kurz-gestielt, vkteyf. oder längl.-keilig, stumpf od. gestutzt, ganzrandig od. an der Basis drïsig-gezähnelt, gleichlaufendaderig, ganz kahl. Ђ. Felsige O. der A. u. VorA. Jul. Aug. Var. a.: B. $1 / 2$ Zoll lang; Kätzchen mehrbth. - - . major: B. 1 Zoll lang; Kätzchen reichbth. S. Kitaibeliana Willd. $-\gamma$. viel kleiner; 'Stamm nebst den Aesten an die Erde angedrückt, ineinander verflochten; B. halb so gross, die meisten nicht ausgerandet; Kätzchen kurzgestielt, armbth., 3-5, ja sogar nur $1 \mathrm{bth}$. S. serpyllifolia Scop., Willd. Diese auf den höheren $A$.

46. S. herbacea L. Kätzchen endst., gestielt; Stiel 2blätterig, knospentrag.; Kapseln ey-kegelf., kahl, fast sitzend; Honigdrïse länger als das kurze Bthstielchen; Gf. kurz; N. 2sp.; B. kreismend u. oval, stumpf od. gestutzt, gesägt, kahl, netzaderig, beiderseits glänzend. $\hbar$. Felsige O. der A. u. höchsten Sudeten. Jul. Aug.

\section{PÓPULUS L. Pappel.}

1. P. alb a L. B. rundl.-eyf., winkelig-gezähnt, unterseits nebst den Zweigen schneєweiss-filzig, die an den endst. Zweigen herzf., hardf.-5lappig; Schuppen des weibl. Kätzchens lanzettl., an der Spitze gekerbt, gewimpert. 方. Feuchte Wälder; zerstr. dch d. Geb. u. so wie die folgende in d. Rheinwaldungen urspriinglich wild. März. Apr. P. nivea Willd.

2. P. can escens Smith. B. rundl.-eyf., winkelig-gezähnt, unterseits nebst d. Zweigen grau-filzig, die an den endst. Zweigen herzeyf., ungelappt; Schuppen d. weibl. Kätzchens an d. Spitze gespalten, am Rande getwimpert. 占. Feuchte Wälder; sehr zerstr. dch d. Geb. März. Apr. P. alba Willd.

3. P. tremula L. B. fast kreisrund, gezähnt, beiderseits nebst den $Z$ weigen kahl, die der wurzelst. Triebe $u$. der jïngeren Pflanzen kurzh. u. eyf. u. spitz; Kätzchenschuppen fingerig-eingeschnitten, dicht-zottig-gewimpert. ち. Wälder. März. Apr. Kommt vor: die B. auf beiden Seiten angedrückt-wollig: P. villosa Lang.

4. P. pyramidalis Rozier. B. rautenf., zugespitzt, gesägt, am Rande kahl, Acste aufrecht. $\hbar$. Aus dem Oriente, nun überall neben den Strassen kultiv. Apr. P. fastigiata Poir. P. dilatata Ait., ein zweideutiger Name.

5. P. nigra L. B. 3eckig-eyf., zugespitzt, gesägt, am Rande $k a h l$, an der Basis abgeschnitten u. gesägt; Aeste abstehend. $\hbar$. Feuchte O., Ufer hie u. da. Apr.

6. P. monilifera Ait. B. 3eckig-eyf., zugespitzt, gesägt, an 
der Basis abgeschnitten u. fast ganzrandig, am Rande flaumig. $\hbar$. Aus Nordamerika, nun an Strassen gepflanzt. Apr.

\section{Ordng. BETULINEEN. Rich.}

\section{BÉTULA L. Birke.}

I. Rotte. Die Blätter aderig, die Adern ästig.

1. B. al b a L. B. rautenf.-3eckig, lang-zugespitzt, doppelt-gesägt, kahl; die fruchttrag. Kätzchen lang-gestielt, hängend, die Seitenlappen der Schuppen zurückgebogen; der S. elliptisch, der Flügel noch einmal so breit als der Same sellst und bis zu der Spitze der Narben hinaufreichered. ち. Wälder. Apr. Mai. Var. B. tieffiedersp. und fast handf.-getheilt: B. alba var. dalecarlica L. suppl.

2. B. pubescens Ehrh. B. eyf. od. rautenf., spitz od. zugespitzt, doppelt-gesägt, anfängl. oft flaumh., später ganz kahl od. in den Winkeln der Adern unterseits bärtig; die fruchttrag. Kätzchen lang-gestielt, hängend, die Seitenlappen der Schuppen zurückgebogen od. weitabstehend und gestutzt; der S. vkteyf., der Flügel so breit als der S. u. bis an die Spitze desselben hinaufreichend. Ђ. Wälder, Moore. Apr. Mai. B. odorata Bechst. In d. VorA. u. höheren Gebgn oft strauchartig u. dann auch mit unterseits kahlen B.: B. carpatica Willd. B. glutinosa Wallr.

II. Rotte. Die Blätter unterseits mit einem engen Adernetze.

3. B. intermedia Thomas. B. unterseits netzaderig, rundl.eyf., fast doppelt-gesägt-gekerbt, die Kerben spitz; die fruchttrag. Kätzchen gestielt (aufrecht?), der Stiel halb so lang als d. Kätzclıen und länger; die Lappen der Schuppen sich berührend, die seitenst. abgerundet-stumpf, breiter $u$. kürzer als der mittlere; die $\mathrm{S}$. längl.vkteyf., der Flügel ungefähr so breit wie der S. ち. Auf Torfgebrüch in dem Jura. Mai. Jun.

4. B. fruticosa Pallas. B. unterseits netzaderig, rundl.-eyf. oder oval, ungleich-gesägt-gekerbt, die Kerben spitz; die fruchttrag. Kätzchen aufrecht, sehr kurz-gestielt, der Bthstiel vielmal kürzer als das Kätzchen; die Schuppen fingerig-3spaltig, die $\mathrm{Zpfl}$. längl., auseinandertretend; die S. vkteyf., der Flügel halb so breit als der S. ち. Torfgebrüch an d. nördl. Seite der A., u. im nördl. Deutschland. Apr. Mai. B. humilis Schrank.

5. B. nana L. B. unterseits netzaderig, fast kreisrund und stumpf, od. breiter als lang u. fast abgeschnitten-stumpf, gekerbt, $d$. Kerben abgerundet-stumpf; $d$. fruchttrag. Kätzchen aufrecht, sitzend od. sehr kurz-gestielt, die Schuppen fingerig-3spaltig, die $\mathrm{Zpfl}$. längl., auseinandertretend; die S. rundl.-vkteyf., der Flügel halb so breit als der S. ந. Torfgebrüch der A. u. VorA. u. der die A. begleitenden Flächen, sodann in Mähr., Böhm., Sudeten, Brocken. Mai. 
2. ALNUS Tournef. Erle.

1. A. viridis DC. B. eyf., spitz od. kurz-zugespitzt, geschärftdoppelt-gesägt, kahl, gleichfarbig; Adern unterseits kurzh., die S. mit einem breiten häutigen Flügel umgeben. ち. A. u. VorA., Schwarzw. Mai. Jun.

2. A. in can a DC. B. eyf., spitz, od. kurz-zugespitzt, geschärftdoppelt-gesägt, unterseits bläulichgrün, flaumig od. fast filzig; die S. ohne häutigen Flügel. Ђ. Thäler der A. u. höherer Berge mit den Flüssen in die Ebenen, u. nördl. Geb. Febr.-Apr. $\beta$. B. fiedersp.eingeschnitten, $Z$ pfl. gesägt, stumpf. $A$. incana $\beta$. pinnatifida Wahlb. Bisher nur in Schweden. - $\gamma$. B. fiedersp.-eingeschnitten, Zpfl. spitz. Im südl. Tyr. v. Sartorelli gefunden.

3. A. pubescens Tausch. B. rundl. od. vikteyf., stumpf od. die oberen spitzl., doppelt-gekerbt-gesägt, auf beiden Seiten grasgriin, unterseits flaumig od. fast flzig; die S. ohne häutig. Flügel. $\hbar$. Feuchte O.; Baden, Böhm. Febr. März. Später als A. glnt. u. incana. A. badensis Lang. A. barbata C. A. Meyer.

4. A. glutin os a Gärtn. B. rundl., sehr stumpf, gestutzt, an der Basis keilig, kahl, Winkel der Adern unterseits bärtig; die S. ohne häutigen Flügel. Ђ. Sïmpfe, Ufer. Febr. März. Betula Alnus $\alpha$. glutinosa L. Var. $\beta$. incisa: B. eingeschnitten. $-\gamma$. laciniata: B. fiedersp., Zpfl. spitz. Beide kultiv.

\section{Ordng. MYRICEEN. Rich.}

1. MYRÍCA L. Gagel.

1. M. Gale L. B. lanzettl., etwas gesägt; St. strauchig. ち. Fenchte, torfige Haiden; nördl. Geb. Apr. Mai.

\section{Ordng. CONIFEREN. Juss.}

I. Gruppe. EPHEDRINEEN. Nees v. Esenb. Bth. in Kätzchen; Stbg. zsgewachsen, an der Spitze frei; Stbk. 2fächerig.

1. ÉPHEDRA L. Meerträubchen.

1. E. distachya L. Bthstiele gegenst.; Kätzchen gezweiet. ち. Sonnige, felsige O.; Wallis, Ruine Siegmundskron bei Botzen $u$. Hügel Dos Tronto in Südtyrol. Apr. Mai.

II. Gruppe. TAXINEEN. Rich. Männl. Bth. in Kätzchen; Schuppen schildf, rund, unterseits mit 1fächerigen in einen Kreis gestellten Stbk. besetzt. Weibl. Bth. endst., einzeln. Same aufrecht.

2. TAXUS L. Taxbaum.

1. T. baccata L. B. genähert, lineal., spitz; Bth. blattwinkelst., sitzend. ち. Gebirge, VorA.; südl. u. mittl. Gebiet. März. Apr. 
III. Gruppe. CUPRESSINEEN. Rich. Männl. Bth. in Kätzchen. Stbk. 4-7, 1 fächerig, an dem unteren Rande der schildf. Schuppen unterseits angewachsen. Weibl. Kätzchen; Eychen in dem Winkel der Schuppen aufrecht.

\section{JUNÍPERUS L. Wachholder.}

1. J. nana Willd. Strauchig, liegend; B. zu 3 , einwärts-gekrümmt, lanzettl.-lineal., in eine stechende Stachelspitze zugespitzt, oberseits seicht-rinnig, unterseits stumpf-gekielt, mit einer eingedrückten, den Kiel dchziehenden Linie; Beeren eyf., bereift, ungefähr so laug als die B. 5. An felsig. O. d. A., VorA., Karp. u. Sudet. Jul. Aug. Beeren schwarz, blau-bereift.

2. J. communis L. Strauchig, aufrecht, zuletzt baumartig; $B$. $z u$ dreien, weit-abstehend, lineal.-pfrieml., in eine stechende Stachelspitze zugespitzt, oberseits seicht-rinnig, unterseits stumpf-gekielt, mit einer eingedrückten, den Kiel durchziehenden Linie; Beeren eyf., bereift, 2- od. 3mal kürzer als die B. ち. Unkult. O., Haiden, Wälder. Apr. Mai. Beeren schwarz, blau-bereift.

3. J. macrocarpa Sibthorp. Strauchig; B. $\approx u$ 3, weit-abstehend, lanzettl.-lineal., in eine stechende Stachelspitze zugesp., oberseits 2furchig, unterseits spitz-gekielt; Beeren eyf. od. kugelig, bereift, so lang als die B. und länger. Ђ. Felsige Küste zw. Triest u. Duino. Mai. Beeren selır gross, rothbraun, blau-bereift.

4. J. Oxycedrus L. Strauchig; B. zu 3, weit-abstehend, lineal., in eine stechende Stachelspitze zugespitzt, oberseits 2 furchig, unterseits spitz-gekielt; Beeren kugelig, bei der Reife glänzend, nicht so lang als $d . \mathbf{B}$. $\hbar$. Istr. $u$. d. benachb. Inseln. Mai. Beeren roth, glänzend.

5. J. phoenicea L. B. kurz-eyf., ziemlich stumpf, 6reihig-dichtdachig, auf dem Rücken mit einer Furche dchzogen; Beeren abstehend. Ђ. Steinige O.; Cherso u. Osero. Mai. Beeren roth.

6. J. Sabin a L. B. rautenf., spitz, 4reihig-dicht-dachig u. auf dem Rücken mit einer Drüse eingedrückt, od. lanzettl., zugespitzt, etwas abstehend, herablaufend $u$. mehr od. weniger entfernt; Beeren

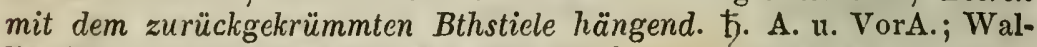
lis, Südtyrol, Krain. Apr. Mai. Beeren blau.

\section{CUPRESSUS L. Cypresse.}

1. C. sempervirens L. Aeste aufrecht od. etwas abstehend; Zweige 4kantig; B. 4reihig-dachig, stumpf, angedrïckt, convex; Zapfen fast kugelig, Schuppen in der Mitte mit einem wehrlosen Buckel. $\hbar$. Südl. Krain, Istr., Siidtyr., Tessin, nur angepflanzt. Febr. März.

IV. Gruppe. ABIETINEEN. Rich. Bth. in Kätzchen. Männch.: Stbk. 2, 1fächerig, an die Schuppen des Kätzchens unterseits angewachsen. Weibl. Kätzchen aus schuppenf. DeckB., in deren 
Winkel die Eychen tragenden Schuppen befindl. sind, die zuletzt die grösseren holzigen Schuppen eines Zapfens bilden. Eychen umgekehrt. Samen nussartig mit einem Flügel umzogen.

\section{PINUS L. Fichte.}

I. Rotte. Pinus Link. Flügel der Samen abfällig.

1. P. sylvestris L. B. gezweiet, lauchgrün; die stützenden Schuppen lanzettl.-pfrieml., weiss-berandet, und an der Spitze weiss, gefranst, die Fransen sninnwebig-zshängend, den jungen Zweig locker umgebend; Zapfen olıne Glanz, die heurigen auf tinem hakenf. Stiel, von der Länge des Zapfens selbst, nach der Erde hinatgebogen, die reifen kegelf.; der Schild der Schuppen convex od. an den unteren stumpf-geschnäbelt mit kurzem, zuriicligebogenem Schnabel; der Flïgel 3mal länger als d. Same; männl. Kätzchen eyf. od. längl.; Kamm der Stbk. nierenf. od. kurzeyf., wenig- u. stumpf.-gezähnelt. $\hbar$. Wälder der Flächen niedriger Gbge u. VorA. Mai. Nimmt auf den A. v. Krain die Gestalt der P. Mughus an.

2. P. Mughus Scop. (erweitert). B. gezweiet, grasgrün; die stützenden Schuppen lanzcttl.-pfrieml., oberioärts weiss-berandet $u$. an der spitze weiss, gefranst, die Fransen spinnwebig-zshängend, den jungen $\mathrm{Z}$ weig locker umgebend, Zapfen glänzend, die heurigen auf einem Stiele $v$. der halben Länge des Zapfens, aufrecht, die reifen oval od. kegelf., abstehend od. hinabgebogen; der Schild der Schuppen convex od. stumpf-geschnäbelt, mit kurzem, zurückgebogenem Schnabel; d. Flügel 2-3mal länger als d. Same; märrul. Kätzchen eyf.; Kamm der Stbk. nierenf. od. fast viereckig, unregelmässig-gezähnelt. Ђ. A., VorA. u. niedrigere Gbge. Mai, auf den A. später. Var. $\alpha$. uliginosa: der Stamm aufrecht, bis 40 Fuss hoch. P. obliqua Sauter. P. rotundata Link. P. uliginosa Neumann. Diese in den Thälern der A., in Schlesien und in der Oberpfalz. - $\beta$. Pumilio: der Stamm aufstrebend $u$. von der Basis an ästig mit niederliegen. den Aesten. P. Pumilio Haenke. Diese auf den A., auf Felsenkämmen tiefer hinabsteigend, sodann Voges., Schwarzw. u. Sudeten.

3. P. uncinat a Ramond. B. gezweiet, grasgriin; d. stuitzenden Schuppen eyf., lanzettl.-zugespitzt, sehr schmal weiss-berandet, spärlich-gefranst; Zapfen glänzend, die heurigen auf einem Stiele v. der halben Länge des Zapfens, aufrecht, die reifen oval od. kegelf., abstehend od. hinabgebogen; d. Schild aller Schuppen od. der der vorderen Seite des Zapfens verlängert-geschnäbelt, der Schnabel zurückgebogen; der Flügel 3mal länger als der Same; männl. Kätzchen eyf.; Kamm der Stbk. rundl., dicht-u. geschärft-gezähnelt. ந. A. der südwestl. Schwz. Jun. Jul. P. Mugho Poiret.

4. P. nigricans Host. B. gezweiet, grasgrün; die stützenden Schuppen lanzettl.-pfrieml., breit-weissberandet und an der Spitze weiss, fransig, die Fransen frei; Zapfen zieml. glänzend, die heuri- 
gen aufrecht, sehr kurz-gestielt, der Stiel viel kürzer als der Zapfen, die reifen sitzend, abstehend, kegelf., der Schild der Schuppen convex; der Flügel 3mal länger als der Same; männl. Kätzchen walzl., zuletzt seltr verlängert; Kamm der Stbk. rundl., convex, dicht- $u$. geschärft-gezähnelt, fast durchscheinend, in der Mitte dunkler. Ђ. Wälder in Unteröstr. u. im Litt. Mai. P. maritima B. minor Duham. arb. ed. 2. t. 92 . bis. P. maritima K. synops. ed. 1. P. nigra Link Abh. d. Berl. Ak. P. nigricans Link Linnaea 1841. P. Laricio $\beta$. austriaca Antoine. - Die Corsische P. Laricio hat nach Link nach der Basis u. nach d. Spitze verschmälerte Zapfen. - Die Flügel der S. der P. nigricans sind hellbräunl. überlaufen; an der verwandten P. maritima maior Duham. DC., P. Pinaster Lam. sind sie russfarben; die Samen noch einmal so gross, die jungen Triebe von den spinnwebig verbundenen Fransen dicht umwickelt $u$. die heurigen Zapfen sitzen auf einem Stiel v. der halben Länge des Zapfens.

5. P. Pin ea L. B. gezweiet-lauchgrün; die stützenden Schuppen eyf.-lanzettl., verschmälert-zugespitzt, dicht-fransig u. nebst der Basis der Fransen braun, nur gegen den Rand heller, d. Fransen frei; Zapfen stark-glänzend, fast stiellos, rundl.-eyf., stumpf; der Schild der Schuppen convex, in der Mitte eingedrückt; Flügel 3mal kürzer als der Same; männl. Kätzchen längl.; Kamm der Stbk. nierenf., am Rande kleinlappig u. geschärft-gezähnelt. $\hbar$. In Südtyrol angebauet. Mai.

6. P. Cembra L. B. $z u 3-5$, grasgrün, die älteren nach $a b-$ gefallener Scheide an der Basis nackt; die stützenden Schuppen eylanzettf., pfrieml.-zugespitzt, weiss-berandet, spärl.-befranst, die Fransen frei; die Zapfen sitzend, eyf., stumpf; Schuppen flach, aufrecht, flaumig, an der Spitze etwas abstehend, ohne Schild, Flügel des Samens fehlend. b. Hohe Alpen. Jun.

II. Rotte. Abies Link. Flügel der Samen nicht abfällig. Schuppen der Zapfen abfällig.

7. P. Pice a L. B. kammf., ausgerandet, unterseits mit 2 weissen Linien; Zapfen walzl.-aufrecht, Zapfenschuppen sehr stumpf, angedrückt. ち. Wälder der Ebenen, VorA. u. A. Mai. Abies pectinata DC. Link.

III. Rotte. Pice a Link. Flügel d. Samen nicht abfällig. Schuppen d. Zapfen bleibend. DeckB. bald verschwindend.

8. P. A bies L. B. zsgedrückt, fast 4 kantig, stachelspitzig, einzeln; Zapfen walzl., hängend, Schuppen ausgebissen-gezähnelt. †. Gebirge, VorA. u. A. Mai. Picea vulgaris Link. Abies excelsa DC.

IV. Rotte. Larix Tourn. Fliigel der Samen nicht abfällig. Schuppen der Zapfen bleibend. DeckB. bleibend.

8. P. Larix L. B. büschelig, flach, etwas rinnig, abfällig; 
Zapfen eyf., aufrecht, Schuppen sehr stumpf, an d. Spitze locker. ち. VorA. u. A." Apr. Mai. Larix europaea DC. Abies Larix Lam. K. syn. ed. 1 .

\section{Classe. Phanerogamische ENDoGENEN. MONO- COTYLEDONEN.}

Gefässbündel im Stengel zerstreut; Keim mit wechselst. Keimblättern.

\section{Ordng. HYDROCHARIDEEN. DC.}

1. VALLISNERIA L. Vallisnerie.

1. V. spiralis L. In Seen; südl. Tyrol, im Gardasee bei Sopra il confine u. Cant. Tessin, im Luganersee in der Bucht von Agno u. Capo di Lego. 24. Jul. Aug. Die B. linealisch, grasartig, ähnlich den untergetauchten der Sagittaria, aber spitzl. u. gegen das obere Ende hin stachelspitzig-gezähnelt.

2. STRATIÓTES L. Wasserscheer.

1. S. al oides L. B. schwertf.-3eckig, stachelig-gewimpert. 4 . In stehenden Wassern schwimmend; östl. u. nördl. Geb. Jul. Aug. Bl. weiss.

3. HYDRÓCHARIS L. Froschbiss.

1. H. Morsus ranae L. 2. Stehende Wasser; zerstr. dch das Geb. Jul. Aug. Bl. weiss.

4. UDÓRA Nutall. Udore.

1. U. occidentalis Pursh. B. lanzettl.-lineal., gerade, sehr fein-stachelspitzig-kleingesägt, Sägezähne vorwärtsgekehrt. 4. Stehende Wasser; im Damm'schen See in der Nähe des Bodenberges bei Stettin in Pommern. Serpicula verticillata Rost. u. Schm. Bth. noch nicht gefunden.

CXIV. Ordng. ALISMACEEN. Juss.

1. ALISMA L. Froschlöffel.

1. A. Plantago L. Schaft quirlig-rispig; Fruchtkn. inwendig über der Basis den Gf. tragend; Früchtchen an der Spitze abgerundet-stumpf, wehrlos, auf dem Rücken 1-2furchig, in eine stumpf3eckige Frucht zsgestellt; B. herzf., eyf. od. lanzettl. 2. Gräben, stehende Wasser. Jul. Aug. Bl. weiss od. röthl. Var. $\beta$. lanceolatum: B. lanzettl., nach der Basis verschmälert, 6 Zoll lang u. 1 
Zoll breit. A. lanceolatum Wither. A. Plantago $\beta$. Willd. $-\gamma \cdot$ graminifolium: alle $B$. grasartig od. schwimmend, nur ein od. das andere mit d. schmal-lanzettl. Blattfläche über das Wasser hervortretend. A. Plantago $\gamma$. graminifolia Wahlenb. A. graminifolium Ehrh. A. natans Pollich.

2. A. parnassifolium L. Schaft quirlig-traubig oder an der Basis etwas rispig; Früchtchen vkteyf., an der Spitze auswärts abgerundet $u$. einwärts begrannt, vielrillig; $B$. tief-herzf., ziemlich stumpf. 24. In einem kleinen See bei Tempelhof in der Gegend v. Berlin; am See bei dem Basedower Theerofen und am.Longritzer See in Mecklenb., bei Frankf. an der O. Jul. Aug. Bl. weiss.

3. A. natans L. St. beblättert; Bth. an den Gelenken des St. einzeln od. zu 3 od. 5; Früchtchen längl., stumpf, zugespitzt-gesclınähelt, 12-15rillig, etwas abstehend; stengelst. $B$. gestielt, oval od. längl., d. wurzelst. lineal., sitzend. 2. Stehende Wasser; Trier, Andernach, am Unterrheine u. v. da dch Westph., u. das nördl. Geb. Jun.-Aug. Bl. weiss. Die untergetauchten B. oft linealisch, häutig, zuweilen alle so gestaltet $u$. schwimmend: A. natans sparganifolium Fries.

4. A. ranunculoides L. Schaft an der Spitze doldig oder quirlig-doppelt-doldig; Früchtchen schief-elliptisch, fürfkartig, spitz, in ein kugeliges Köpfchen zsgerollt; B. lanzettl., 3nervig. 24. Sümpfe, feuchte O.; Unterrhein, nördl. Geb., Böhm., Neuenburg. See in d. Schwz., Monfalcone. Jun.-Aug. Bl. weiss. Die B. zuweilen sämmtl. lineal., häutig u. schwimmend: A. ran. zosterifolium Fries.

2. SAGITTARIA L. Pfeilkraut.

1. S. sagittaefolia L. B. tief-pfeilf.; Schaft einfach. 24. Stehende Wasser. Jun. Jul. Bl. weiss, Nägel purp.

CXV. Ordng. BUTOMEEN. Rich.

1. BÚTOMUS L. Wasserviole.

1. B. umbellatus L. 2. Gräben, Fischteiche, langsam tliessendo Wasser. Jun.-Aug. Bth. rosenroth.

CXVI. Ordng. JUNCAGINEEN. Rich.

1. SCHEUCHZÉRIA I. Scheuchzerie.

1. S. palustris L. 2. Torfige Sümpfe der Ebenen u. VorA.; zerstr. deh das Geb. Mai. Jun. Bth. grünl.

2. TRIGLÓCHIN L. Dreizack.

1. T. maritimu m L. Früchte eyf., kantig, unter d. zurückgekrümmten Narbe eingeschnürt, in 6 Kapseln zerfallend; Tr. ver- 
längert. 24. Seestrand u. salzige Wiesen im Binnenlande. Jun. Jul. Bth. grünl.

2. T. palustre L. Früchte lineal., kantig, nach der Basis verschmälert, an die Spindel angedrïckt, in 3 Kapseln zerfallend; Narben sitzend. 2. Wiesen u. feuchte Triften. Jun. Jul.. Bth. grünl.

\section{Ordng. POTAMEEN. Juss.}

\section{POTAMOGÉTON L. Laichkraut.}

I. Rotte. Heterophylli, Verschiedenblätterige B. wechselst., nur die die Bthstiele stützenden gegenst., die obersten bei der vollkommen erwachsenen Pflanze schwimmend, nach der Gestalt $\mathfrak{u}$. oft auch nach ihrem Gewebe von den untergetauchten verschieden.

a. Die bthst. B. alle lederig u. schwimmend.

1. P. natans L. B. alle lang-gestielt, die jüngeren untergetauchten schmäler, lanzettl. od. längl., die schwimmenden lederig, an der Basis seicht-herzf., oval od. längl.; Bstiele auf der oberen Seite seicht-rinnig, die untergetauchten zur Bthezeit, wegen der dch Fäulniss zerstörten Bfäche blattlos; Bthstiele gleich; die frischen Früchte zsgedrückt, am Rande stumpf; St. einfach. 2. Teiche, Gräben, Flüsse. Jul. Aug. P. natans $\alpha$. vulgaris D. Fl. 1. 837. Die schwimmenden B. erheben sich an ihrer Basis beiderseits in eine Falte, wenn sie auf eine Fläche angedrückt werden. Die Steinfrucht wird irrig mit bekieltem Rande beschrieben, dieser entsteht bei dem Trocknen durch Einschrumpfen, wobei die normale Gestalt verloren geht. Die Normalform in stehenden Wassern, Teichen $u$. Gräben hat breit-ovale B. u. mässig lange Bstiele; in schnell fliessenden Bächen, $\beta$. prolixus: sind St. u. Bstiele sehr verlängert, und die B. zuweilen nur halb so breit, letzteres: P. serotinus Schrad. in Brief.

2. P. oblongus Viviani. B. alle lang-gestielt, die untergetauchten, während der Bthezeit vorhandenen lanzettl., die schwimmenden lederig, längl., die ohersten eyf. $u$. an dєr Basis seicht-herzf., Bstiele auf der oberen Seite seicht-rinnig; Bthstiele gleich; die frischen Früchte zsgedrückt, am Rande stumpf; St. einfach. 24. Gräben in Torfbrüchen. Jul. Ang. P. natans intermedius u. minor D. FI. 1. p. 839. Von P. natans untersch. deh die während der Bthezeit vorhandenen untergetauchten B. u. dch kleinere Frïchte, übrigens in allen Theilen, was die Grösse betrifft, sehr wechselnd.

3. P. flutans Roth. B. alle lang-gestielt, die untergetauchten, während der Bthezeit vorhandenen verlängert-lanzettl., häutig, durchscheinend, die schwimmenden längl.-lanzettl. od. oval, an der Basis spitz od. abgenundet; Bstiele auf der oberen Stite convex; Bthstiele gleich; Früchte im frischen Zustande zsgedrückt, mit ziemlich spitzem 
Rande. 2. Flüsse; Schwz., Rheinpfalz u. nördl. Geb. Jul. Aug. Von P. natans u. P. oblongus dch die an der Basis nicht seicht-herzf. ausgeschweiften B. versch., was auch an den obersten Statt hat. Das Merkmal der oberseits convexen Bstiele habe ich v. Nolte genommen, in der Erlanger Flora wurde die Pfl. noch nicht gefunden. Var. $\boldsymbol{\beta}$. stagnatilis: in Gräben $u$. Pfützen, die untergetauchten B. weniger dchscheinend. P. natans explanatus D. Fl. 1. 837.

4. P. spathulatus Schrader. B. alle gestielt, die untergetauchten häutig, dchscheinend, die untersten schmal-lanzettl., in den Bstiel lang-keilig-verschmälert, die folgenden allmählig mehr längl., in den langen Bstiel hinablaufend, die schwimmenden lederig, oval-längl., stumpf, an der Basis vorgezogen, 2- bis 3mal kürzer als der Bstiel; Bthstiele gleich; die frischen Früchte linsenf.-zsgedrückt, mit einem spitzen Rande versehen. 2. Bäche; westl. Geb., Rheinpfalz, Unterelsass. Jul. Aug.

b. Die blüthenst. B. den stengelst. ähnlich, nur die späteren schwimmend $u$. entweder lederig od. häutig u., wiewohl nicht bei allen, auch in der Gestalt verschieden. Diese schwimmenden B. sind oft nicht vorhanden.

5. P. rufescens Schrad. Die untergetauclten B. sitzend, häutig, durchscheinend, lanzettl., nach der Basis u. Spitze verschmälert, ziemlich stumpf, am Rande glatt, die schwimmenden lederig, vkteyf., stumpf, in den Bstiel, der kürzer als das B. ist, verschmälert; Bthstiele gleich; die frischen Früchte linsenf.-zsgedrückt, mit einem spitzen Rande versehen; St. einfach. 2. Stehende Wasser, Bäche. Jul. Aug.

6. P. Hornemanni Meyer. B. alle gestielt, häutig, durchscheinend, am Raride glatt, die unteren untergetauchten lanzettl., die schwimmenden fast herz-eyf., Bstiele halb so lang als die B.; Bthstiele gleich; die frischen Früchte zsgedrückt, am Rande stumpf; St. ästig. 4. Stehende Wasser; sehr zerstr. deh das Geb. Jul. Aug. P. coloratus Hornem. P. plantagineus Ducros.

7. P. gr a mineus L. Die untergetauchten B. häutig, dchscheinend, lanzettl.-lineal. od. schmal- od. breit-lanzettl., zugespitzt, nach der Basis verschmälert, sitzend, am Rande ein wenig rauh, die obersten kürzer, breiter, gestielt, die schwimmenden lanzettl. od. eyf., lang-gestielt, lederig, Ietztere oft fehlend; Bthstiele nach der Spitze verdickt; die frischen Frïchte zsgedrückt, am Rande stumpf; St. sehr ästig. 2. Fliessende u. stehende Wasser. Jul. Aug. P. heterophyllus Schreb. Var. $\alpha$. graminifolius: die untergetauchten B. lanzettl.-lineal., nach beiden Enden verschmälert, schlapp; St. verlängert. Ich besitze ein Exemplar mit 5 Zoll langen, 3 Linien breiten B. - $\beta$. heternphyllus: die untergetauchten B. kürzer, zurückgekrümmt, meist starrer, nicht selten beträchtlich starr. P. gramineus $\beta$. heterophyllus Fries. 
Die schwimmenden B. sind lederig u. oft sehr lang-gestielt. - $\boldsymbol{\gamma}$. Zizii: 2- od. $3 \mathrm{mal}$ so gross als die vorhergehenden Formen, besonders die oberen B. stumpf, aber immer mit einer Stachelspitze u. oft auffallend wellig. P. heterophyllus $\delta$. latifolius D. Fl. P. Proteus B. Zizii Cham. u. Schl. Erscheint auch in einer gehörnten Form, indem den meisten B. der Saum fehlt u. diese fast auf den Mittelnerven zurückgeführt sind. Bei zurückgetretenem Wasser elscheinen gestielte, lederige B., wie an den vorhergeh., u. auch, wiewohl selten, im Wasser selbst: P. lucens $\delta$. coriaceus D. Fl.

8. P. nitens Weber. Die untergetauchten B. häutig, dchscheinend, lanzettl. od. lineal.-lanzettl., spitz, grannenlos, an d. Basis abgerundet, halbstengelumfassend, am Rande ein wenig rauh, die schwimmenden längl. od. lanzettl., in den Bstiel verschmälert, lederig, letztere oft fehlend; Bthstiele nach der Spitze meist dicker; die getrockneten Früchte zsgedrückt, am Rande gekielt; St. sehr ästig. 2 . Fliessende u. stehende Wasser; nördl. Geb. Jul. Aug. Var. wie das vorhergehende: $\alpha$. salicifolius : die untergetauchten B. lineal.-lanzettl., gerade; der St. verlängert. P. nitens $\alpha$. salicifolius Fries. - $\beta$. heterophyllus: die untergetauchten B. kürzer, lanzettl., manchmal eylanzettf., zurückgekrümmt; St. kürzer, sehr ästig. P. nitens $\beta$. heterophyllus Fries. P. curvifolius Hartm.

II. Rotte. Homophylli, Gleichblätterige. Die ganze Pflanze untergetaucht, nur die Aehren während der Bthezeit über das Wasser hervortretend. Die B. wechselst., die blüthest. gegeniiber, alle häutig, lanzettl. u. breiter, bis zu einer rundl. Gestalt.

9. P. lucens L. B. alle untergetaucht, häutig, durchscheinend, gestielt, oval od. lanzettl., stachelspitzig, am Rande fein-gesägt-rauh; Bthstiele oberwärts verdickt; die frischen Frïchte zsgedriickt, am Rande stumpf, schwach gekielt; St. ästig. 2. Stehende u. fliessende Wasser. Jul. Aug. Erscheint in einer gehörnten Form: d. Blattfläche kürzer u. schmäler mit einer dornf. Spitze: P. acuminatum Schumacher; od. die ganze Blattläche bis auf d. Mittelnerv verschwunden.

P. decipiens Nolte, in Schleswig, vielleicht aber auch in Holstein einheimisch, steht dem P. lucens am nächsten, untersch. sich jedoch deutlich: P. decipiens. B. alle untergetaucht, häutig, dchscheinend, mit abgerundeter Basis sitzend, oval od. länglich, stumpf, stachelspitzig, am Rande glatt; Bthstiele gleich; Früchte...

10. P. praelongus Wulf. B. alle untergetaucht, häutig, dchscheinend, aus eyf., stengelumfassend. Basis verlängert-längl., od. lanzettl., stumpf, wehrlos, an der Spitze kappenf.-zsgezogen, am Rande glatt; Bthstiele gleich; die getrockneten Früchte zsgedrïckt, auf dem Rücken flügelig-gekielt; St. ästig. 24. Flüsse u. Seen; nördl. Geb., Schwz, in d. Seen der A., Krain im Laibacht. Jul. Aug. 
11. P. perfoliatus L. B. alle untergetaucht, durchscheinend, aus herzf., stengelumfassender Basis eyf. od. ey-lanzettf., am Rande etwas rauh; Bthstiele gleich; die frischen Früchte zsgedrückt, am Rande stumpf; St. etwas ästig. 24. Pfützen u. Flüsse; zerstr. dch d. Geb. Jul. Ang.

12. P. crispus L. B. alle untergetaucht, häutig, durchscheinend, sitzend, lineal.-längl., ziemlicl stumpf, kurz-zugespitzt, kleingesägt, wellig kraus; Bthstiele gleich; Früchte zsgedrückt, geschnäbelt; St. ästig, zsgedrückt. 4 . Stchende u. fliessende Wasser. Jun. -Aug.

III. Rotte. Chl o ëphylli, Grasblättrige. Die ganze Pflanze untergetaucht, nur die Aehren während der Bthezeit iiber das Wasser hervortretend. B. grasartig, genau-lineal., alle gleichgestaltet, sitzend u. wechselst., bloss die blïthenst. gegenüber.

13. P. compressus L. B. alle untergetaucht, häutig, dchscheinend, sitzend, genau-lineal., stumpf, kurz-stachelspitzig, vielnervig, mit 3-5 stärkeren Nerven; Aelven walzl., 10-15bth.; St. geflügeltplattgedrückt, ästig. 2. Stehende u. langsamfliessende Wasser. Jul. Aug. P. zosteraefolius Schumacher.

14. P. acutifolius Link. B. alle untergetaucht, häutig, dchscheinend, sitzend, genau-lineal., am Ende haarspitzig, vielnervig, mit 3-5 stärkerer Nerven; Aehren 4-6bth., die fruchttrag. rundl.; St. geflügelt-plattgedrückt, sehr ästig. 24. Stehende Wasser, Bäche; zerstr. deh d. Geb. Jul. Aug.

15. P. obtusifolius M. u. Koch. B. alle untergetaucht, häntig, dchscheinend, sitzend, genau-lineal., stumpf, kurz-stachelspitzig, 3-5nervig; Bthstiele so lang als die 6-8blüthige, ununterbrochene Aehre; St. zsgedrückt, an den Rändern abgerundet, sehr ästig. 24. Stehende Wasser, Bäche; zerstr. dch d. Geb. Jul. Aug. P. gramineum Sm.

16. P. pusill us L. B. alle untergetaucht, häutig, durchscheinend, sitzend, genau-lineal., ziemlich spitz, kurz-stachelspitzig, 3-5nervig; Bthstiele 2-od. 3 mal so lang als dic 4-8blïthige, oft unterbrochene Aelure; Früchte schief-elliptisch; der St. aus dem stielrunden zsgedrückt, sehr ästig. 24. Stehende Wasser, Bäche. Jul. Aug. Var.: $\alpha$. major: B. breiter, fast 1 Linie breit. P. compressus D. Fl. - $\beta$. vulgaris: $B$. ungefähr $1 / 2$ Linie breit. $-\gamma$. tenuissimus: B. sehr schmal, manchmal kaum eine $1 / 4$ od. $1 / 3$ Linie breit.

17. P. trichoides Chamisso u. Schlechtend. B. alle untergetaucht, häutig, durchscheinend, sitzend, borstl.-lineal., zugespitzt, 1nervig, aderlos; Bthstiele 2- od. $3 \mathrm{mal}$ so lang als die $4-8$ blüthige, oft unterbrochene Aehre; Früchte halbkreisrund; St. ziemlich sticlrund, sehr ästig. 24. Seen, Fischteiche; Schlesien, und nördl. Geb.; bei Nürnberg, Dresden. Jul. Aug. 
IV. Rotte. Coleophylli, Scheidenblättrige. Die ganze Pflanze untergetaucht, nur die Aehren während der Bthezeit über das Wasser hervortretend. Die B. grasartig, genau-lineal., alle gleichgestaltet, wechselst., an der Basis scheidig, die Scheide an die NebenB. angewachsen.

18. P. pectinatus L. B. alle untergetaucht, häutig, dehscheinend, an der Basis scheidig, lineal., od. lineal.-borstl., spitz, 1nervig, quer-aderig, Adern ziemlich dick; Aehren langgestielt; Früchte schiefvkteyf., halbkreisrund, zsgedriickt, im getrockneten Zustande auf dem Rücken gekielt, mit kurzern, aufsteigendem Griffel. 2. Stehende Wasser, Flüsse, Jul. Aug.

19. P. marin u s L. B. alle untergetaucht, häutig, durchscheinend, an der Basis scheidig, lineal. od. lineal.-borstl., spitz, 1nervig, queraderig, Adern ziemlich dick; Aehren lang-gestielt; Früchte vkteyf., fast kugelig, im trockenen Zustande runzelig; auf dem Riccken breitabgerundet $u$. kiellos, mit breiter, sitzender N. 24. In salzigem Wasser am Meeresstrande $u$. in einem kleinen Teiche auf der Alpe zw. Badia u. Gardona im südl. Tyrol. Jul. Aug.

V. Rotte. Enantiophylli, Gegenblättrige. Die ganze Pflanze untergetaucht, nur die Aehren während der Bthezeit über das Wasser hervortretend. B. dchscheineud, alle gegenst.

20. P. densus L. B. alle gegenst. u. untergetaucht, häutig, dchscheinend, sitzend, stengelumfassend, elliptisch, lanzettl. od. lineal.lanzettl.; Aehren gabelständig, kurzgestielt, nach d. Verblühen zurückgebogen; d. getrockneten Früchte zsgedrückt, breit-gekielt, geschnäbelt. 24. Stehende u. fliessende Wasser; zerstr. deh d. Geb. Jul. Aug. Var. $\alpha$ : B. eyf., zugespitzt: P. densus L. $-\beta$. lancifolius: B. aus eyf. Basis allmählig verschmälert-spitz; ungefähr 1 Zoll lang, 3-4 Linien breit. P. oppositifolium DC. P. serratum L. $-\gamma$. angustifolius: wie die vorhergeh., aber die B. nur 1 od. $1 \frac{1}{2}$ Linien breit. P. setaceum $\mathbf{L}$.

2. RUPPIA L. Ruppie.

1. R. maritima L. Säckchen der Stbk. längl.; Früchte eyf., schief-aufrecht. $\%$. Gräben u. Siimpfe am Meere und an Salinen im Hannöv. Aug.-Oct.

2. R. rostellata Koch. Säckchen der Stbk. fast kugelig; Frïchte fast halbmond-eyf., aus stumpfer Basis aufstrebend. 24. Gräben; an d. Ostsee u. an d. Salinen bei Artern. Aug,-Oct.

3. ZANICHELLIA L. Zanichellie.

1. Z. palustris L. Früchtchen kurzgestielt, Gf. halb so lang als die Früchte. 24. Stehende u. fliessende Wasser. Jul.-Sept. Kommt vor: der St. im tiefen Wasser verlängert, fluthend, aber an der Basis 
nicht kriechend: Z. major v. Bönningh.; der St. in nicht hohem Wasser an den Gelenken wurzelnd: Z. repens v. Bönningh.; ferner mit Früchten, die auf dem Rücken kaum geflügelt, daselbst geflügelt u. gekerbt od. auf beiden Seiten geflügelt sind. Wenn die Flügel auswittern, so bleiben die Zähne als 'Dörnchen.

2. Z. pedicell at a Wahlenb. Fries. Früchtchen zieml. lang-gestielt, Gf. schlank, so lang als die Frucht. 24. Im Meere u. in Gräben an den Salinen. Jul.-Sept. Kommt in den Formen der Vorhergeh. vor. Die Form mit breitem Riickenkiel: Z. pedunculata Rchb.; die mit beiderseits geflitgeltem Kiele: $Z$. gibberosa Rchb.

Die Zanichellia polycarpa Nolte hat fast sitzende Friichtchen u. einen Gf. von dem vierten Theil der Länge der Frucht, wurde bisher in Schleswig $u$. Schweden gefunden.

\section{Ordng. NAJADEEN. Link.}

1. NAJAS L. Najade.

1. N. maj or Roth. B. lineal., ausgeschweift-gezähnt, Zähne stachelspitzig, BScheiden ganzrandig. $\odot$. Seen, Flïsse, Teiche; zerstr. dch d. Geb. Aug. Sept. N. marina $\alpha$. L.

2. N. minor Allion. B. schmal-lineal, ausgeschweift-gezähnt, zurückgekrümmt, Zähne stachelspitzig, BSchciden feinwimperig-gezähnelt. $\odot$. Seen, Teiche; zerstr. dch d. Geb. Aug. Sept.

3. N. flexilis Rostk. u. Schm. B. schmal-lineal., sehr feinstachelspitzig-gezähnelt, BScheiden feinuimperig-gezähnelt. $\odot$. Im Linowschen See bei Stettin. Aug. Sept. Caulinia flexilis Willd.

2. ZOSTÉRA L. Wasserriemen.

1. Z. marina L. B. 3nervig; Stiel d. Blumenscheide oberwärts breiter; Nüsse gerillt. 2. Sandiger Meeresgrund. Aug.

2. Z. n an a Roth. B. 1nervig; Stiel der Blumenscheide von gleicher Breite; Nïsse bei der Reife ganz glatt. 24. Sandiger Meeresgrund der Insel Norderney. Z. Noltei Hornem. Aug.

CXIX. Ordng. LEMNACEEN. Link.

1. LEMNA L. Wasserlinse.

1. L. trisulca L. Laub lanzettl., zuletzt gestielt, Glieder kreuzweise zshängend; Wurzeln einzcln. $\odot$. In stehenden Wassern, untergetaucht. Mai.

2. L. polyrrhiza L. Laub rundl.-vkteyf.; W.büschelig. $\odot$. In stehenden Wassern schwimmend. Mai.

3. L. min or L. Laub vkteyf., unten u. oben flach, Glieder sitzend; W. einzeln. $\odot$. In stehenden Wassern schwimmend. Mai.

4. L. gibba L. Laub vkteyf., ziemlich convex, unterseits schwam- 
mig-convex, Glieder sitzend; W. einzeln. $\odot$. In stehenden Wassern schwimmend. Jun. Jul.

\section{Ordng. TYPHACEEN. Juss.}

1. TYPHA L. Rohrkolbe.

1. T. latifolia L. B. lineal., flach, länger als der blüthentrag. St.; männliche $u$. weibl. Aehre sich berührend. 24. Stehende Wasser u. Flüsse. Jul. Aug.

2. T. angustifolia L. B. lineal., unterwärts fast rinnig, länger als der blüthentrag. St.; männl. Aehre von der weibl. entfernt. 4. Stehende Wasser u. Fliisse. Jul. Aug.

3. T. min ima Hoppe. B. der blüthentrag. St. lanzettl., vielmal länger als der St., die der unfruchtb. Büischel schmal-lineal.; Aehren walzlich, die weiblichen zuletzt elliptisch. 24. Sümpfe; Salzbg., Oberbad., Elsass, Bodensee, südl. Schw. Apr. Mai. T. minor Sm. T. angustifolia $\beta$. L.

Die Arten der Gattung Typha sind noch weiter zu beobachten.

2. SPARGANIUMI L. Igelknospe.

1. S. ramosum Huds. B. an der Basis 3 kantig, an den Seiten concav; St. ästig; Narben lineal. 4. Gräben, Ufer. Jul. Aug. S. erectum $\alpha$. L.

2. S. simplex Huds. mit Ausschl. der Var. $\beta$. B. an der Basis $3 \mathrm{kantig}$, an den Seiten flach; St. einfach; Narben lineal. 4. Lachen, Gräben. Jul. Aug. S. erectum $\beta$. L.

3. S. natans L. B. liegend, flach; St. einfach; Narben längl.; männliche Aehre meist nur eine. 24. Fischteiche, Sümpfe. Jul. Aug.

\section{Ordng. AROIDEEN. Juss.}

I. Gruppe. AECHTE AROIDEEN, Bth, ohne Perigon.

1. ARUM L. Aron.

1. A. ma culatum L. B. spiess-pfeilf., gleichfarbig oder braungefleckt; Kolben gerade, kürzer als die Blumenscheide, keulig, Keule 3 mal kürzer als ihr Stiel. 24. Schattige Haine. Mai. B. meist gleichfarbig, seltencr mit braunen Flecken bestreut. Kolbe schwarzpurp.

2. A. italicum Mill. B. spiess-pfeilf., weissaderig; Kolben gerade, kürzer als die Blumenscheide, keulig, Keule so lang als ihr Stiel. 24. Weinberge u. Waldungen der wärmeren Gegenden; Fiume. Apr. Kolben gelb.

3. A. A risarum L. B. herz-pfeilf., stachelspitzig, Lappen der Basis stumpf; Kolben walzl., an der Spitze etwas keulig; einwärtsgekrümmt, kürzer als die kapuzenf. Blumenscheide. 2. Weinberge, schattige 0 . der wärmeren Gegenden; Fiume n. die benachbarten Inseln. März. 
2. CALLA L. Drachenwurz.

1. C. palustris L. B. herzf.; Blscheide flach. 24. Sumpfige 0.; zerstr. dch d. Geb. Jul. Aug. Blscheide oberseits schneeweiss.

II. Gruppe. ORONTIACEEN. Brown. Bth. mit einem Perig.

3. ÁCORUS L. Kalmus.

1. A. Calamus L. Spitze des Schaftes blattig, sehr lang. 4. Stehende Wasser, Flüsse. Jun. Jul.

\section{Ordng. ORCHIDEEN. Juss.}

I. Gruppe. OPHRYDINEEN. Stbk. ganz angewachsen; Staubmassen kleinlappig, elastisch-zshängend.

\section{ORCHIS L. Knabenkraut.}

\&. 1. DeckB. 1nervig. Knollen ungeth.

a. Lippe 3 th., der mittlere $\mathrm{Zpfl}$. vorne verbreitert, 2sp., meist mit einem Zähnchen in der Ausbuchtung der auseinandertretenden Zipfel.

1. O. fusca Jacq. lippe pinselig-punktirt, 3th., die seitenst. $Z_{p} f$. lineal., der mittlere von der Basis an allmählig verbreitert, vktherzf., meist mit einem dazwischen liegenden borstlichen Zahne, Lappen eyf., fast abgeschnitten, ausgebissen-gekerbt, Sporn mehr als um d. Doppelte kürzer als d. Fruchtkn., Zpfl. d. P. in eineu eyf. Helm zsschliessend, unterwärts zsgewachsen; DeckB. häutig, 1nervig, vielmal kürzer als d. Fruchtkn.; B. längl.; Knollen ungeth. 2. Waldige, gebirg. O. Mai. Jun. O. militaris $\beta$. u. $\gamma$. L. Helm schwarzpurpurn od. grünlich mit schwarzpurp. Punkten; Lippe weiss od. hell-rosenroth purp.-rauhh.-punktirt.

2. O. militaris L. Lippe pinselig-punktirt, 3 th., die seitenst. Zpfl. lineal., der mittlere lineal., an der Spitze verbreitert, 2sp., mit einem dazwischen liegenden borstlichen Zahne, Lappen längl., spreitzend, an der Spitze fein-gekerbt, Sporn mehr als um das Doppelte kürzer als der Fruchtkn., Zpfl. des P. in einen ey-lanzettf. Helm zsschliessend, unterwärts zsgewachsen; DeckB. häutig, 1nervig, vielmal kürzer als der Fruchtkn.; B. länglich; Knollen ungeth. 2. Unkult., waldige 0. Mai. Jun. Helm aschgrau od. hell-purp.; Lippe blass-purp., in der Mitte weissl., mit purp. Punkten bemalt.

3. O. Simia Lam. Lippe sammetig-punktirt, 3th., die seitenst. Zpfl. schmal-lineal., ganzrandig, einwärtsgekrümmt, der mittlere 2sp., mit einem dazwischer liegenden lineal. Zahne, die Schenkel verlängert,

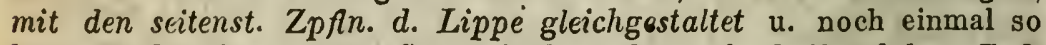
lang als der Zpfl. selbst, Sporn halb so lang als d. Fruchtkn., Zpfl. des $\mathbf{P}$. in einen ey-lanzettf. Helm zsschliessend, unterwärts zsge- 
wachsen; DeckB. häutig, 1nervig, vielmal kürzer als d. Fruchtkn.; B. längl.; Knollen ungeth. 24. Kalkhügel; Schwz., Südtyr., Elsass, Oberbad., Litt. Mai. O. tephrosanthos Vill. O. militaris $\varepsilon$. L. Helm röthl.-grau; Lippe blass-purp. od. weissl., dunkler purp.-punktirt.

4. O. variegat a All. Lippe punktirt, kahl, 3th., die seitenst. Zpfl. längl., der mittlere breit-vktherzf., meist mit einer dazwischen liegenden Stachelspitze, alle spitz-gezähnt, Sporn halb so lang als der Fruchtkn. od. länger, Zpfl. des P. in einen Helm zsschliessend, sämmtl. verschmälert-spitz, die 2 innersten nur ein wenig kürzer als der rückenst., DeckB. häutig, 1nervig, halb so lang als der Fruchtkn. od. länger; B. längl.; Knollen ungeth. 24. Wiesen, Bergtriften; Stettin, südl. Hannov., Halle, Mähr., Oberschlesien, Südtyr., Littorale, Oberbaden. Mai. O. Simia Vill., nach Haller's Syn., nicht Lam. Bth. hellpurpurn; Lippe purpurn-punktirt. O. tridentata Scop., zwar älterer Name als $O$. variegata, aber wegen Mühlenbergs $O$. tridentata wohl nicht einzuführen.

5. O. ustulata L. Lippe sammetig-punktirt, 3th., die seitenst. Zpfl. längl.-lineal., an der Spitze etwas gekerbt, der mittlere 2sp., meist mit einem dazwischen liegenden Zähnchen, Lappen längl.-lineal., etwas gekerbt, Sporn 3mal kuirzer als der Fruchtkn., Zpfl. des P. kugelig-helmartig-zsschliessend, eyf., frei, die inneren fast spatelig, stumpf; DeckB. häutig, 1nervig, halb so lang als der Fruchtkn.; B. längl.-lanzettl.; Knollen ungeth. 2. Wiesen; südl. u. nördl. Geb. Mai. Jun. Helm dunkel-schwarz-purp.; Lippe weiss, mit satt-purpurnen Tropfen.

b. Lippe tief-3sp., der Mittelzpfl. längl., ungeth. od. abgeschnittenausgerandet.

6. O. coriophora L. Lippe halb-3sp., herabhängend, Zpfl. fast gleich, der mittlere längl., ungeth., die seitenst. fast rautenf., kürzer, Sporn kegelf., gekrimmt, hinabsteigend, 2- od. 3mal kürzer als der Fruchtkn., ZpH. des P. helmartig-zsschliessend, zugespitzt; DeckB. häutig, 1nervig, so lang als der Fruchtkn. oder länger; B. lineal.lanzettl.; Knollen ungeth. 2. Wiesen; siddl. u. mittl. Geb. Mai. Jun. Helm schmutzig-rothbraun; Lippe in der Mitte hell-röthl. mit dunkelpurp. Punkten; Zpfl. grïn mit röthl. Rande.

7. O. globosa L. Lippe halb-3sp., gerade-hervorgestreckt, Zpfl. längl., der mittlere breiter, abgeschnitten-ausgerandet, oft mit einer dazwischen liegenden Stachelspitze, Sporn fast walzl., gekrümmt, hinabsteigend, 2- od. 3mal kürzer als der Fruchtkn., $Z_{p} f$. des $P$. glockighelmartig-zsschliessend, eyf., mit einer spateligen Haarspitze endigend; DeckB. 1nervig, so lang als der Fruchtkn. od. länger, die untersten manchmal 3nervig; B. lanzettl.; Knollen ungeth. 4. A. u. VorA. u. hohe Gbge., auch bei Frankf. a. d. O. Mai. Jun. Bth. purp., Lippe punktirt. 
c. Lippe 3lappig, Lappen breit, kurz.

8. O. M orio L. Lippe 3lappig, Lappen breit, der mittlere abgeschnitten-ausgerandet, Sporn walzl. od. fast keulig, wagerecht od. aufstrebend, ungefähr so lang als der Fruchtkn., Zpfl. des $P$. stumpf, alle helmartig zsschliessend; DeckB. 1nervig, die untersten meist 3 nervig, so lang als der Fruchtkn.; B. längl.-lanzettl.; Knollen ungeth. 4. Wiesen. Apr. Mai. Bth. purp., mit grünen starken Adern auf den Zpfin. des P. Var. Bth. satt-violett, purp., rosenroth u. weiss.

9. O. Spitzelii Sauter. Lippe 3lappig, etwas sammetig, herabbängend, Lappen breit, gekerbt, der mittlere ausgerandet, Sporn kegel-walzenf., senkrecht hinabsteigend, viel kürzer als der Fruchtkn., $\mathrm{Z}_{p} f$. des $P$. stumpf, die seitenst. abstehend, die 2 innersten an der Spitze abgeschnitten od. ausgerandet; DeckB 1nervig, so lang als der Fruchtkn.; B. längl.-vkteyf., stumpf; Knollen ungeth. 24. Grasige O. der A.; auf der Weissbachelalpe im Buchweissbach bei Saalfelden in Tyrol, auch auf VorA. im Val die Ledro in Südtyr. Jun. Bth. purpurn.

10. O. pallens L. Lippe seicht 3lappig, ganzrandig, od. kaum fein-gekerbt, an der Basis sammetig; Sporn walzl., wagerecht oder aufstrebend, ungefähr so lang als der Fruchtkn., Zpfl. des $P$. eyf., stumpf, die 3 inneren fast gleich, die 2 seitenst. zuletzt zurückgebogen; DeckB. 1nervig, so lang als der Fruchtkn.; die entwickelte Aelre eyf.; B. vkteyf.-längl., stumpf; Knollen ungeth. 24. Waldige, buschige O.; sehr zerstreut dch das südl. u. mittl. Geb. Apr. Mai. Bth. gelbl.weiss, sehr selten purp.

11. O. mascula L. Lippe tief-3lappig, an der Basis kurzh., Lappen breit, gezälht, der mittlere ausgerandet mit einem dazwischen liegenden Zahne, Sporn walzl., wagerecht od. aufstrebend, ungefähr so lang als der Fruchtkn., Zpfl. des $P$. eyf.-längl., stumpf od. spitz, od. zugespitzt, die 2 innersten kürzer als der rückenst., die 2 seitenst. zuletzt zurückgeschlagen; DeckB. 1nervig, so lang als der Fruchtkn.; die entwickelte Aehre verlängert, locker; B. längl. od. lanzettl. 4. Mai. Jun. Bth. purp. Sporn an der entwickelten Aehre immer wagerecht od. aufstrebend. Var. $\alpha$. obtusiflora: Zpfl. des P. stumpf. - $\beta$. acutiflora: Zpfl. spitz od. kurz-zugespitzt; diese Form ist gemeiner. - $\gamma$. speciosa: Z Zpfl. lang-zugespitzt. O. speciosa Host.

8. 2. DeckB. 3-mehrnervig u. entweder die untersten od. alle zugleich netzaderig. Knollen ungeth. od. (bei O. sambucina) an der Spitze kurz-2lappig.

12. O. laxiflora Lam. Lippe 3lappig, die seitenst. Lappen vorne abgerundet, der mittlere tief-ausgerandet, breiter, kürzer od. ein wenig länger als die seitenst., Sporn walzl., wagerecht od. aufstrebend, kürzer als der Fruchtkn., Zpfl. des P. längl., stumpf, die seitenst. zurückgeschlagen; DeckB. 3-5nervig, die unteren zugleich aderig; 
Aehre verlängert, locker; B. lanzettl.-lineal.; Knollen ungeth. 4. Torfige, sumpfige Wiesen; suidl. n. mittleres Geb., sehr selten im nördl. Mai. Jun. Bth. purp. Var. $\boldsymbol{\alpha}$. der Mittellappen der Lippen bemerklich kürzer: O. laxiflora Lam., O. Tabernaemontani Gmel. B. palustris: der Mittellappen der Lippe so lang als die seitenst. od. auch ein wenig länger: $O$. palustris Jacq.

13. O. s a mbucina L. Lippe kurz-3lappig, Sporn kegel-walzenf., hinabsteigend, so lang als der Fruchtkn., die seitenst. Zpfl. des P. abstehend; DeckB. sämmtl. nervig $u$. aderig, länger als die Bth.; St. 4-6blätterig; Knollen längl., ungeth. od. an der Spitze kurz-2-3. lappig. 2. Gebirgswälder u. VorA.; südl. u. mittl. Geb. Mai. Jun. Bth. geruchlos, gelblichweiss; Lippe hellgelb, an der Basis mit purp. Piinktchen. Var. $\beta$. purpurea: Bth. purpurn. O. incarnata Willd $u$. der deutschen Autoren.

14. O. papili on a cea L. Lippe rundl.-eyf., gezähnt, ungeth., Sporn pfrieml., hinabsteigend, kürzer als der Fruchtkn., Zpfl. des P. in einen ey-lanzettf. Helm zsschliessend; DeckB. 3-5nermig; B. lanzettl.; Knollen ungeth. 24. Wiesen; wärmeres Krain, Istrien. März. O. rubra Jacq. Bth. purpurn.

\$. 3. DeckB. 3-mehpnervig u. entweder die untersten od. alle zugleich netzaderig. Knollen handf.

15. O. maculata L. Lippe 3lappig, Sporn kegel-walzenf., hinabsteigend, kürzer als der Fruchtkn., die seitenst. Zpfl. des P. abstehend; Deck $B$. 3nervig $u$. aderig, die mittleren so lang als der Fruchtkn., die untersten länger als derselbe; St. nicht hohl, meist 10 lätterig; die oberen B. verkleinert, deckblattf., das oberste v. der Aehre weit entfernt, die mittleren lanzettl., nach beiden Enden verschmälert, die untersten längl.; Knollen handf. 24. Wälder, feuchte Wiesen. Jun. Bth. hell-lila, mit purp. Flecken u. Strichen. B. oft braun-gefleckt.

16. O. Iatifolia L. Lippe 3lappig, Sporn kegel-walzenf., hinabsteigend, kürzer als der Fruchtkn., die seitenst. Zpfl. des P. aufwärts zurückgeschlagen; untere $u$. mittlere DeckB. länger als die Bth., alle 3 nervig $u$. aderig; St. röhrig, 4-6blätterig; B. abstehend, die untercn oval od. längl., stumpf, die oberen kleiner, lanzettl., zugespitzt; Knollen handf. 2. Feuchte Wiesen. Mai. Jun. O. latifolia Fries. Novit. mant. 2. O. majalis Rchb. Bth. purpurn; B. oft braun-gefleckt.

17. O. incarnata L. (nach Fries.) Lippe 3lappig; Sporn kegelwalzenf., hinabsteigend, kürzer als der Fruchtkn., die seitenst. Zpf. des P. abstehend, nachher aufwärts-zurïckgeschlagen; DeckB. alle länger als die Bth., 3nervig $u$. aderig; St. röhrig, 4-6blätterig; $B$. aufrecht, mit dem St. gleichlauferd, verlängert-lanzettl., nach oben verschmälert, an der Spitze kapuzenf.-zsgezogen, das oberste über die Basis der Aehre hinaufreichend, das unterste kürzer, abstehend; Knollen handf. 24. Torfige, sumpfige Wiesen. Jun., später als die 
vorhergeh. O. angustifolia Wimm. u. Grab. Bth. gewöhnl. hellpurp., selten dunkler.

18. O. Traunsteineri Sauter. Lippe 3lappig, Sporn kegelwalzenf., kürzer als der Fruchtkn., die seitenst. Zpfl. des P. aufwärts zurückgeschlagen; Deck $B$. 3nervig $u$. aderig, die unteren so lang, die oberen ktirzer als die Bth.; St. röhrig, 4-5blätterig; die unteren $B$. lanzettl.-lineal., aufrecht- etwas abstehend, die oberen lineal., aufrecht, an der Spitze flach, ein wenig rinnig; Knollen handf. 4. Auf torfigen, moorigen Wiesen; Tyrol, Schwz. Mai. Jun. O. angustifolia Reichenb. I. Fries. Bth. purp.

\section{ANACÁMPTIS Richard. Anacamptis.}

1. A. pyramidal is Richard. Lippe halb-3sp., an der Basis mit 2 Plättchen, die Lappen längl., stumpf, gleich, ganzrandig, Sporn fädlich, so lang als der Fruchtkn. od. länger, Zpfl. des P. ey-lanzettf., ziemlich spitz, die seitenst. abstehend; DeckB. an der Basis 3nervig; Aehre gedrungen; B. lanzettl.-lineal.; Knollen ungeth. 24. Wiesen, buschige Hiigel; zerstr. deh das Geb. Mai-Jul. Orchis pyramidalis L. K. syn. ed. 1. Bth. purp.

3. GYMNADENIA R. Brown. Nachtdrüse.

1. G. c o n o p s e a R. Brown. Lippe 3sp., Lappen eyf., stumpf, sporn fädlich, fast noch einmal so lang als der Fruchtkn., die äusseren $Z_{p f l}$. des $P$. meist-abstehend; DeckB. 3nervig, so lang als der Fruchtkn. od. länger; Aehre walzl., verlängert; B. verlängert-lanzettl.; Knollen handf. 4. Wiesen. Jun. Jul. Bth. purp., selten weiss; letztere ist $O$. ornithis Jacq.

2. G. odoratissima Richard. Lippe 3sp., Lappen eyf., stumpf, Sporn fädl., ungefähr so lang als der Fruchtkn., die äusseren $\mathrm{Zpf}$. des $P$. weit-abstehend; DeckB. 3nervig, so lang als der Fruchtkn. $u$. länger; Aehre walzl., verlängert; B. lineal.-lanzettl. u. lineal.; Knollen handf. 24. Wiesen der A. u. VorA., seltener niedriger; zerstr. dch das Geb. Jun. Jul. Bth. purp., rosenroth od. weiss.

\section{HIMANTOGLÓSSUM Spreng. Riemenzunge.}

1. H. hircin um Rich. Lippe 3th., Zpfl. lineal., der mittlere sehr lang, etwas gedreht, die seitenst. viel kürzer, wellig kraus. 24. Buschige Hügel, waldige $\mathrm{O}$; ; zerstr. dch das südl. u. mittl. Geb. Mai. Jun. Satyrium hircinum L. Spenn. Loroglossum hircinum Rich. Helm weiss, inwendig purp. u. grün gestreift, Lippe weisslich-grün, röthl. punktirt.

5. PERISTÝLUS Blum. Peristylus.

1. P. viridis Lindley. Lippe lineal., an d. Spitze 3zähnig, der mittlere Zahn sehr kurz, die seitenst. geradehervorgestreckt, 
Sporn sehr kurz, beutelf., P. helmartig zsneigend. 2. Feuchte Wiesen, in die A. hinauf; zerstr. deh d. Geb. Jun. Jul. Satyrium viride $L$. Habenaria viridis $R$. Brown. K. syn. ed. 1. Bth. grün, od. bräunl.-grüin.

2. P. albidus Lindley. Lippe tief.-3sp., Zpfl. ganzrandig, die seitenst. spitz, der mittlere noch einmal so breit, längl., stumpf, Sporn 3 mal kürzer als d. Fruchtkn.; $\mathrm{Z} p f$. des $P$. in einen rundl. Helm zsschliessend; DeckB. 3nervig, so lang als der Fruchtkn.; Aehre verlängert, fast einseitswendig; die untersten $B$. längl.-vkteyf., die oberen lanzettl.; Knollen büschelig. 24. Grasige O., A., VorA. u. Gbge; zerstr. deh das Geb. Jun.-Aug. Satyrium albinum L. Habenaria albida R. Br. Gymuadenia albida K. syu. ed. 1. Bth. grünl.-weiss.

6. PLATANTÉRA Rich. Breitkölbchen.

1. P. bifolia Richard. Lippe ungeth., lineal., Sporn $1 \frac{1}{2}-2 \mathrm{mal}$ so lang als der Fruchtkn., fädl.; Fächer der Stbk. gleichlaufend. 4. Wälder. Jun. Jul. Orchis bifolia L. Bth. weiss.

2. P. chlorantha Custor. Lippe ungeth., lineal., Sporn noch einmal so lang als der Fruchtkn., fädl., nach hinten fast keulig; Fächer der Stbk. mit der Spitze an einander stossend, unterwärts spreitzend. 24. Schattige Wälder. Jun. Jul. Orchis virescens Zollikof. Bth. weiss.

7. NIGRITELLA Rich. Schwärzling.

1. N. angustifolia Rich. Lippe eyf., zugespitzt, Zpfl. des P. lanzettl., zugespitzt, Sporn vkteyf., 3 mal kürzer als der Fruchtkn. 4. Grasige O. der A. u. VorA. Mai-Aug. Satyrium nigrum L. Bth. schwarzpurp., selten hellpurp.

2. N. suaveolens Koch. Lippe eyf., beiderseits in d. Mitto mit einem stumpfen Zahne u. deswegen fast 3lappig, der mittlere Lappen vorgezogen, an der Spitze selbst stumpf, $Z$ ptl. des P. eylanzettf., spitzl., Sporn walzl.-pfrieml., so lang als der Fruchtkn. 4. Sehr selten auf dem Dolaz in der Schweiz, u. dem Sollstein bei Zierl in Tyrol, angebl. auch in Krain. Jul. Aug. N. fragrans Sauter. Orchis suaveolens Vill. Aehre fast walzlich, Bth. grösser als bei der vorhergeh. u. freudig-purp.

\section{OPHRYS L. Ragwurz.}

1. O. muscifer a Huds. Lippe längl., sammetig, in der Mitte mit einem fast 4eckigen kahlen Flecken, noch einmal so lang als das P., 3sp., die seitenst. Lappen lanzettl., der mittlere noch einmal so lang, an der Spitze tief-2lappig, ohne Anhängsel, die 2 inneren Zpfl. des P. zottig, lineal., zsgerollt u. fädl. 24. Gebirgswälder; zerstr. dch das südl. u. mittl. Geb., selt. im nördl. Jun. O. myodes Swartz. O. insectifera $\alpha$. myodes $L$. Lippe satt-purpurbraun, in der Mitte mit einem grau-bläulichen Flecken. 
2. O. aran if er a Huds. Lippe längl.-vkteyf., ungeth., convex, gedunsen, am Rande zurückgebogen, an der Spitze stumpf od. seichtausgerandet, ohne Anhängsel, behaart, in der Mitte mit 2-4 an der Basis querverbundenen kahlen Längenlinien, die äusseren $\mathrm{Zpfl}$. des $\mathrm{P}$. ungefähr so lang als die Lippe, die inreren kürzer, kahl. 4. Kalkige Hügel u. Berge; zerstr. deh das südl. u. mittl. Geb. Mai. Jun. Lippe ungeth. mit einem stumpfen, kleinen Zahne beiderseits in der Mitte des Randes, aber nicht 4lappig, purpurbraun od. gegen den Rand hin gelbl., die kahlen Iinien trübgelb. P. grïn.

3. O. Bertolonii Morett. Lippe breit-vkteyf., zieml. flach, behaart, vor der ein wenig aufstrebenden Spitze mit einem fast 4eckigen, kahlen Flecken, sehr stumpf, ganz an der Spitze kurz-3lappig, der mittlere Lappen schmal, zahnf., an der Spitze kahl, die inneren Zpfl. des P. lineal.-lanzettl., spitz, kahl, am Rande flaumig; Befruchtungssäule geschuäbelt, zugespitzt. 24. Grasige Hügel; Istrien. Apr. Mai. O. Speculum Bert. Lippe schwarzpurp., der kahle Flecken bleicher.

4. O. arachnites Reichard. Lippe breit-vkteyf., ungeth., convex, gedunsen, am Rande flach, vorne abgeschnitten u. sehr stumpf, sammetig, an der Basis gescheckt, an der Spitze seicht-ausgerandet, mit einem kahlen, aufwärts-gebogenen Anhängsel, die 2 inneren $\mathrm{Zpfl}$. des P. eyf., sammetig; Befruchtungssäule kurz-geschnäbelt. 24. Buschige Kalkhügel; zerstr. deh das siidl. u. mittl. Geb. Jun. P. rosenroth. Lippe satt-purpurbraun, an der Basis mit gelblichen Zeichnungen und Punkten, das Anhängsel grïn-gelb.

5. O. a pifer a Huds. Lippe rundl.-vkteyf., convex, gedunsen, sammetig, gescherkt, 5sp., die 2 hinteren Lappen eyf., etwas abstehend, an der Basis mit einem rauhh. Höcker versehen, die 3 vorderen zurückgekrümmt, unterscits zsneigend, der mittlere in ein kahles Anhängsel endigerd, die inneren $\mathrm{Zpfl}$. des P. kurz, kurzh. 2. Buschige Kalkhügel; zerstr. dch das südl. und mittl. Gebiet. Jun. Jul. Lippe braun, mit gelblichen Zeichnungen.

9. CHAMAEORCHIS Rich. Zwergknabenkraut.

1. Ch. alpin a Rich. Lippe eyf.-längl., stumpf, an d. Basis beiderseits mit einem schwachen Zahne bezeichnet; B. schmal-lineal., so lang als der St. u. länger. 24. Triften der höheren A. Jul. Aug. Ophrys alpina L. Bth. klein, gelb-grün.

10. ÁdERAS R. Brown. Spornlose.

1. A. a nthrop oph or a R. Brown. Lippe 3th., der mittlere Zpfl. lineal., 2sp., oft mit einem dazwischen geschobenen Zähnchen, die Abschnitte desselben so wie die seitenst. Zpfl. lineal.-fädl. 2. Hügel, Wiesen; südl. Geb., sehr selt. im mittl. Mai. Jun. Ophrys anthropophora L. P. grünl., am Rande purp.; Lippe rothbraun, znletzt ins Goldgelbe spielend. 
11. HERMINIUM R. Brown. Herminie.

1. H. Monorchis R. Brown. Die inneren Zpfl. des P. 3lappig, der Mittellappen verlängert, Lippe tief-3sp., Zpfl. lineal., die seitenst. fast spiessf.-abstehend, der mittlere noch einmal so lang. 2. Wiesen, Triften; A. u. VorA. u. Gbge, zerstr. deh d. Geb. Mai. Jun. Ophrys Monorchis L. Bth. klein, grïnl.-gelb.

12. SERAPIAS I. Stendelwurz.

1. S. pseudo-cordigera Moricand. Das hintere Glied der Lippe 2lappig, an der Basis mit 2 längl. Plättchen, das vordere ey-lanzettf., zugespitzt, an der Basis bärtig. 24. Hügel und Bergwiesen; C. Tessin, suidl. Tyrol, Krain, Litt. Apr. Mai. S. Lingua Scop., Gaud., Bertolon. S. cordigera Heer. S. longipetala Pollin. Die wirkl. S. cordigera untersch. sich nur dch ein breiteres vorderes Glied der Lippe.

2. S. Lingua L. Das hintere Glied der Lippe 2lappig, an der Basis mit einer einfachen Schwiele, das vordere längl.-lanzettl., spitz, an der Basis schwach-bärtig. 24. Hügel auf d. Insel Osero. Apr. Mai. S. Lingua DC. S. oxyglottis Bertolon.

3. S. triloba Vivian. Das hintere Glied d. Lippe sehr kurz u. schmal, die Lappen kaum bemerkl., das vordere $3 s p$. , gezähnelt, die Seitenzipfel schief-eyf., der mittlere eyf.-zugespitzt, an der Basis schwach-bärtig. 24. Auf Wiesen bei Triest, v. Tommasini nur einmal gefunden. Mai.

II. Gruppe. LIMODOREEN. Stbk. frei; Bthstaubmassen aus zahlreichen, kantigen, elastisch-zshängenden Läppchen zsgesetzt od. mehlig, oft mit ihrer Basis an einer nackten Driise anhängend.

13. EPIPOGIUM (Gmelin. fl. sib. Epipogium.) Oberkinn.

1. E. Gmelini Rich. Blattlos; der St. bescheidet, armbth.; Bth. hängend. 2. Schattige Wälder, auf faulem Holze; VorA., hölere Gbge im südl. u. mittl. und Niederungen im nördl. Geb. Jul. Aug. Satyrium Epipogium L. Die Pfl. farbelos; P. gelbl., Sporn fleischroth.

\section{LIMODóRUM Tournef. Dingel.}

1. L. abortivum Swartz. Blattlos; Schaft bescheidet; Lippe eyf., wellig; Sporn pfrieml., von d. Länge des Fruchtkn. 24. Buschige Hügel, Wälder; Schwz., Oberbad. am Kaiserstuhle, Trier, Herborn, Oestreich, südl. Tyrol, Littor. Mai. Jun. Orchis abortiva L. Die Pflanze hell-violett, Schaft und Striche auf dem P. gesättigter.

15. CEPHALANTHÉRA Rich. Cephalanthere.

1. C. pallens Richard. Fruchtkn. kahl; Platte der Lippe herzeyf., breiter als lang, alle $Z \mathrm{p} f$. des $P$. stumpf; DeckB. länger als 
der Fruchtkn.; B. eyf. oder ey-lanzettf., zugespitzt. 24. Wälder; zerstr. dch d. Geb. Mai. Jun. Epipactis pallens Sw. Bth. gelbl.-weiss.

2. C. ensifolia Richard. Fruchtkn. kahl; Platte der Lippe sehr stumpf, quer-breiter, die äusseren $\mathrm{Zpfl}$. des $\mathrm{P}$. spitz; DeckB. vielmal kürzer als der Fruchtkn., die untersten manchmal so lang als derselbe; B. lanzettl., die oberen lineal.-lanzettl., verschmälert-spitz. 2 . Waldige 0 .; zerstr. deh d. Geb. Mai. Jun. Epipactis ensifolia Swartz. Bth. schneeweiss, mit einem gelben Flecken an der Spitze der Lippe.

3. C. rubra Richard. Fruchtkn. Alaumig; Zpfl. des P. alle zugespitzt, Platte der Lippe eyf., zugespitzt, so lang als die inneren Zpfi. 2. Wälder u. buschige Hügel; zerstr. dch d. Geb. Jun. Jul. Serapias rubra L. Bth. schön-purpurn.

16. EPIPACTIS Richard. Sumpfwurz.

1. E. latifolia Allioni. B. eyf., am Rande u. auf den Nerven flaumig-rauh, länger als die $Z$ wischenglieder; $P$. zuletzt weitabstehend, die $\mathrm{Zpfl}$. desselben alle kahl, Platte d. Lippe zugespitzt, an der Spitze zurückgebogen, die Höcker an der Basis derselben glatt. 2. Wälder. Jul. Aug. Bth. grünlich od. grünl. u. röthl. angeflogen. Lippe lila.

2. E. $r$ ubiginosa Gaudin. B. eyf., am Rande und auf den Nerven flaumig-rauh, länger als die Zwischenglieder; P. glockigoffen, die drei äusseren $\mathrm{Z}$ pll. etwas flaumig, Platte der Lippe zugespitzt, an der Spitze zurïckgekrümmt, die Höcker an der Basis derselben faltig-kraus. 24. UnkuIt. Hügel. Jun. E. latifolia $\beta$. rubiginosa Gaud., K. syn. ed. 1. Serapias latifolia atrorubens Hoffm. Bth. schmutzig-violett, od. grünl. u. rostroth überlaufen.

3. E. microply yll a Ehrh. B. ey-lanzettf. od. lanzettf., am Rande flaumig-rauh, auf den Nerven kahl, die mittleren u. oberen kürzer od. so lang als die $Z$ wischenglieder; $P$. glockenf., die $Z$ pfl. an $d$. Spitze gerade-vorgestreckt, die drei äusseren flaumig, Platte der Lippe zugespitzt, an der Spitze zuu ückgekrïmmt, die Höcker an d. Basis faltig-kraus. 24. Schattige Wälder; Westphal., Harz, siidl. Hannov., Thüringen. Jun. Jul. Bth. grün, am Rande röthl., Lippe am Rande weisslich.

4. E. palustris Crantz. B. lanzettl.; Platte d. Lippe rundl., stumpf, so lang als die Zpfl. d. P. 24. Sumpfige Wiesen; zerstr. deh d. Geb. Jun. Jul. Serapias palustris Scop. S. longifolia L. Bth. graugrünl., inwend. an d. Basis röthl. Lippe weiss, roth-gestr.

17. LISTÉRA R. Brown. Listere.

1. L. ovata R. Brown. St. 2blätterig; B. eyf., gegenst.; Lippe lineal., 2sp. 4. Bergwiesen, WaldO. Mai. Jun. Ophrys ovata L. Bth. grün.

2. L. c ordata R. Brown. St. 2blätterig; B. herzf., gegenst.; 
Lippe $3 s p$, die seitenst. Zpfl. lineal., kurz, der mittlere $2 s p$. , Schenkel desselben verlängert, lineal., zugespitzt. 24. Schattige Wälder; VorA. u. höhere Grbge des südl. u. mittl. Geb. Mai-Jul. Ophrys cordata L. Bth. grïn.

18. NEOTTIA L. Nestwurzel.

1. N. Nidus avis Richard. 24. Auf den W. der Bäume in schattigen Wäldern schmarotzend. Mai. Jun. Ophrys Nidus avis L. Pflanze blattlos, überall bräunl.-weiss.

19. GOODYERA R. Brown. Goodyere.

1. G. repens R. Brown. WB. eyf., gestielt, netzig; St. oberwärts nebst den Bth. behaart. 24. Schattige Wälder; Gebirge u. VorA., zerstr. durch das Geb. Jul. Aug. Satyrium repens L. Bth. weisslich.

20. SPIRANTHES Richard. Bliithenschraube.

1. S. a estivalis Richard. St. beblättert; B. lanzettl.-lineal.; Aehre schraubenf.; Lippe längl.-eyf., an d. Spitze abgerundet. 24. Triften, feuchte Wiesen; zerstr. dch d. südwestl. u. westl. Geb. Jul. Bth. weisslich.

2. S. a utumnalis Richard. St. blattlos, bescheidet; WB. eyf. oder eyf.-längl., in den Bstiel zsgezogen, dem St. seitlich; Aehre schraubenf.; Lippe vkteyf, ausgerandet. 24. Feuchte Bergtriften; zerstr. deh d. Geb. Aug.-Oct. Ophrys spiralis I. Bth. weissl.

III. Gruppe. MALAXIDINEEN. Stbk. frei; Bthstaub wachsartig od. aus Körnchen bestehend, welche zuletzt in eine wachsartige Masse zsfliessen.

\section{CORALLORRHIZA Hall. Korallenwurz.}

1. C. in n ata R. Brown. Aehre armbth.; Zpfl. des P. spitz, die unteren herabgebogen, Lippe längl., stumpf, beiderseits stumpf-1zähnig, das Mittelfeld der Länge nach 2schwielig. 2. Schattige Wälder; VorA. u. Gbge längs d. A., ausserdem sehr zerstr. dch d. Geb. Jun.-Aug. Ophrys corallorrhiza L. Bth. griinl.-weiss.

22. STURMIA Rchb. Sturmie.

1. S. Loeselii Rchb. St. 3kantig, an der Basis 2 blätterig; B. elliptisch-lanzettl.; Aehre 3-8bth.; Lippe eyf., stumpf, fein-gekerbt, v. d. Länge der Zpfl. des P. 2. Moorige Sümpfe; sehr. zerstr. dch d. Geb. Jun.-Aug. Ophrys Loeselii L. Liparis Loeselii Rich. Bth. grün-gelblich.

23. MALAX'̌́I Swartz. Weichkraut.

1. M. paludosa Swartz. St. 5seitig, unterwärts 3-4blätterig; Lippe concav, zugespitzt. 4. Auf torfigen Wiesen zwischen Sumpf- 
moosen; nördl. u. westl. Geb. Jul. Aug. Ophrys paludosa L. Bth. grünlich.

\section{MICROSTÝLIS Nuttal. Kleingriffel.}

1. M. monophylla Lindl. St. meist 1blätterig, 3kantig; Lippe concav, zugespitzt. 2. Moorige feuchte O. der VorA. hin u. wieder; im Gesenke der Sudet. u. in den kalten Brüchern v. Preussen. Jul. Ophrys monophyllos L. Bth. grünlich.

IV. Gruppe. CYPRIPEDIEEN. Bth. 2männig.

25. CYPRIPEDIUM L. Frauenschuh.

1. C. Calceolus L. St. beblättert; Lappen der einwärtsgekrümmten Befruchtungssäule herabgebogen, eyf., stumpf; Lippe etwas zsgedrückt, kürzer als die $Z$ pfl. des P. 21. Waldige O.; zerstr. deh das südl. u. mittlere Geb., selten im nördl. Mai. Jun. Perigonblätter purpurbraun. Lippe gelb.

\section{Ordng. IRIDEEN. Juss.}

\section{CROCUS I. Safran.}

1. C. vernus All. Bthscheide 1blätterig; Schaft eng-bescheidet; Schlund des P. bärtig; Narben 3sp., ungefähr um die Hälfte kürzer als der Saum des $P$., die $\mathrm{Zpfl}$. aufrecht, aufwärts kammf.-verbreitert, gezähnelt; Fasern der Wurzelschalen haarfein, ineinandermündond, die Maschen längl., schmal. 2. A. u. VorA.; südlicher in die niederen Gebirge u. Ebenen hinab, auch im Würtemb. bei Zavelstein. März. Apr. Bth. einfarbig satt- od. hellviolett, od. violett-streifig, od. ganz weiss. Var. ausserdem mit $1^{1} / 2$ Zoll langem Saume der Bthe: C. vernus grandiflorus Gay.; mit nur 1 Zoll langem Saume: C. vernus parviflorus Gay., u. mit weisser Bthe: C. albiflorus Hoppe $u$. Hornsch.

2. C. variegatus Hopp. u. Hornsch. Bthscheide 2blätterig; Schlund des P. kahl; Narben 3sp., ungefähr um die Hälfte kürzer als der Saum des $\boldsymbol{P}$., die Zpfl. aufrecht, aufwärts breiter, gezähnelt u. eingeschnitten; Fasern der Wurzelschalen stark, netzig, ineinandermündend, die Maschen eyf. od. rundl. 24. Grasige, steinige O. um Triest. Febr. März. Bth. hellblau, die 3 äusseren $Z$ pfl. auswendig mit 3 violetten, fransig-gestrichelten Binden bemalt. C. reticulatus $\beta$. MB.

3. C. sativus All. Bthscheide 2blätterig; Schlund des P. bärtig; Narben 3 th., so lang als der Saum des $P$., die $Z$ pfl. verlängert, oberwärts ein wenig verdickt, an der Spitze gezähnt, abstehend, seitlich hervortretend; Faser der Wurzelschalen haarfein, dicht aneinandergestellt, die Maschen schmal. 24. Wird in Oestreich, Südtyrol und im wärmeren Wallis kultiv. Sept. Oct. Bth. blau. 


\section{TRICHONÉMA Ker. Fadennarbe.}

1. T. Bulboc odium Ker. B. pfrieml., zsgedrückt, gefurcht, gerade, später gewunden u. zurückgekrümmt; die inneren Bthscheiden breit-häutig-berandet; Stbg. kürzer als der Stempel. 24. Grasige 0.; Fiume, Istr. Febr. März. Ixia Bulbocodium L. Bth. inwendig von der Basis bis zur Mitte satt-gelb, an dem übrigen Theile violett od. weissl.

\section{GLADíoluS L. Siegwurz.}

1. G. palustris Gaud. Die Fasern der Wurzelschalen stark, netzig, mit rurden $u$. eyf. MIaschen; die oberen seitl. Zppl. des P. rauten-eyf.; die Antheren küizer als der Träger, die Oehrchen an der Basis der Antheren stumpf u. parallel; die Z $\mathbf{p f l}$. der Narbe aufwärts allmählig verbreitert u. fast v. ihrer Basis an mit Papillen bewimpert; die Kapsel längl.-vkteyf., gleichf.-sẹchsfurchig, an der Spitze abgerundet, nicht eingedrückt. 2. Nasse Wiesen; zerstrent deh das Geb. Jun., etwas später als G. communis. G. Boucheanus v. Schlechtend. K. syn. ed. 1. Bth. purp. mit einem weissen, sattpurp.-eingefassten Streifen auf den 3 unteren $\mathrm{Zpfln}$. des $\mathrm{P}$., wie die folgenden.

2. G. communis L. Die Fasern der Wurzelschalen stark, parallel, oberwärts ineinandermündend, mit linealischen schmalen MIaschen; die oberen seitl. Zpfl. des P. rautenf.-eyf.; Antheren kürzer als der Träger, die Oehrchen an der Basis der Autheren stumpf u. parallel; die $\mathbf{Z}_{p} f$. der Narbe aufwärts allmählig verbreitert, $u$. fast von ilurer Basis an mit Papillen bewimpert; die Kapsel vkteyf., dreikantig, an der Spitze eingedrückt; die Karten nach oben in einen Kiel hervortretend. 24. Wiesen bei Frankfurt an d. O. u. bei Stettin, in Gärten überall kultivirt. Jun.

3. G. illyricus Koch. Die Fasern der Wurzelschalen fein, parallel, gedrungen, ineinandermündend, mit häufigen sehr schmalen Maschen; die oberen seitl. Zpfl. des P. rauten-eyf. od. rautenf.-längl.; die Antheren kürzer als der Träger, die Oehrehen an der Basis der Antheren zugespitzt, zuletzt spreitzend; die Zpfl. der Narhe von der Basis bis zur Mitte linealisch, am Rande kahl, üher d. Mitte plötzlich rundl.-eyf. erweitert u. am Rande mit Papillen bewimpert; die Kapsel vkteyf., 3kantig, an der Spitze eingedrückt, die Kanten nach oben in einem Kiel hervortretend. 24. Wiesen u. grasige O.; Krain, Litt., Fiume. Jun.

4. G. imbricatus Linn. Die Fasern der Wurzelschalen fein, parallel, sehr gedrungen, oberwärts ineinandermündend, mit sehr schmalen Maschen; die oberen seitl. Zpfl. d. P. rauten-eyf.; die Antheren kürzer als der Träger, die Ochrchen an der Basis der Antheren parallel; die Zpfl. der Narbe aufwärts allmählig verbreitert, fast von ihrer Basis an mit Papillen bewimpert; die Kapsel vkteyf., dreikantig, an der Spitze eingedrückt, die Kanten überall abgerundet. 
4. Wald - u. Torfwiesen; Wobschna in Böhmen, Grafsch. Glatz, Frankf. an d. O., Steiger in Thüringer Wald. Juli.

5. G. s egetu m Gawler. Die Fasern der Wurzelschalen parallel, ziemlich stark, oberwärts netzig-ineinandermündend, mit längl. u. ovalen Maschen; die oberen seitl. Zpfl. des P. lineal.-keilig, von dem obersten entfernt; die Träger kürzer als die Anthere; die Kapsel kugelig, 3furchig, an der Spitze eingedrückt, die 3 Höcker abgerundet, nicht in einen Kiel zsgedrückt. 24. Auf Aeckern auf Stramare zw. Zaule u. Muchia bei Triest, in Istrien u. bei Fiume. Mai, Jun. G. communis Sibth., Bertolon.

4. IRIS L. Schwertlilie.

I. Rotte. Gebärtete. Die äusseren Zpfl. des P. an der Basis inwendig mit einem Streifen dicht-gestellter Haare besetzt.

1. I. pallid a Lamarck. Bärtig; die B. schwertf.; der St. mehrbtlı., länger als die B.; Bthscheiden schon vor dem Aufblühen durchaus trockenhäutig; innere $\mathrm{Zpfl}$. des $\mathrm{P}$. so lang als die äusseren, rundl.-vkteyf., plötzlich in den Nagel zsgezogen; die Stbg. bis zur Hälfte des Zpfls. der Narbe hinaufreichend; Stbk. kürzer als der Träger, nach dem Verblühen von der Mitte an hakenf.-zurïckgebogen; Zpfl. der Narbe längl., in der Mitte ein wenig breiter, die Lappen eyf., gerade vorgestreckt. 24. Steinige $O$. in Istrien. Mai. Jun. Bth. wohlriechend, bleichviolett, $Z$ pfl. an der Basis mit braunen Adern.

2. I. germanica L. Bärtig; die B. schrertf.; der St. mehr'bth., länger als die B.; Bthscheiden während des Aufblïhens v. der Basis bis zur Mitte krautig; innere Zpfl. des P. so lang als die äusseren, breit-vkteyf., plötzl. in den Nagel zsgezogen; Stbk. so lang als der Träger; Zpfl. der Narbe längl., an der Spitze breiter, die Lappen eyf., ausgesperrt. 24. Felsen, steinige 0 . im südl. Tyrol u. überhaupt im siidl. Geb., ausserdem hin u. wieder verwildert. Mai, früher als n. 1. 3. 4. Bth. geruchlos, sattviolett, Nägel gelblich-weiss mit braunen Adern.

Die Iris florentina, hin u. wieder in Gärten gebauet, unterscheidet sich v. I. germanica: d. B. breiter, d. inneren zwar spitz, aber nicht lang- $u$. fein-zugespitzt, die 13th. weiss, oft mit einem bläulichen Schimmer, die Zpfl. des P. übrigens an der Basis ebenfalls mit grïnen und braunen Adern bemalt, die inneren $Z p$ fl. längl.vkteyf., dic Narbe in der Mitte etwas breiter, die Lappen geradevorgestreckt. Die Bth. angenehm duftend, aber nicht so stark wie die der I. pallida.

3. I. squalens L. Bärtig; die B. schwertf.; der St. melurbth., länger als die B.; Bthscheiden während des Aufblithens von der Basis bis zur Mitte krautig; äussere Zpfl. des P. vkteyf., innere so lang als die äusseren, oval, an der Spitze ganz od. seicht-ausgerandet, plötzlich in den Nagel zsgezogen; Träger anderthalbmal so lang 
als das Stbk.; Zpfl. der Narbe längl., in der Mitte ein wenig breiter, die Lappen eyf., vorgestreckt, auseinandertretend. 24. Steinige u. Gebirgsabhänge um Heidelberg, Schlossberg bei Oppenheim. Jun. Aeussere Zpfl. des P. violett, hinten weissl. mit dunkleren Adern bemalt, die inneren bleich-schmutzig-gelb.

4. I. sambucina L. Bärtig; die B. schwertf.; der St. mehrbth., länger als die B.; Bthscheiden während des Aufblühens v. der Basis bis zur Mitte krautig, äussere $\mathrm{Zpfl}$. des P. vkteyf., innere so lang als die äusseren, oval, mit einer spitzen u. deutl. Kerbe ausgerandet, plötzlich in den Nagel zsgezogen; T'räger anderthalbmal so lang als das Stbk.; ZpH. der Narbe längl., in der Mitte ein wenig breiter, die Lappen eyf. mit ihrem inneren Rande zsschliessend. 24. Felsige 0. ; in Würtemberg an vielen $O$., bei Monheim an der Donau, Ehrenbreitstein am Rhein. Jun., später als I. squalens. Bth. stark nach Hollunder riechend; äussere $Z$ pfl. des P. wie bei I. squalen§, aber die Adern stärker ausgedrückt; die inmeren $\mathrm{Zpfl}$. grau-bläulich.

5. I. bohemica Schmidt. Bärtig; die B. schwertf.; der St. mehrbth., zur Zeit der Bth. ungefähr so lang als die B.; der unterste Bthstiel unter der Mitte des St. od. fast auf der W. entspringend; die Bthscheiden zur Zeit der Bth. überall frisch, nicht oberwärts trockenhäutig, die inneren $Z p f$. des $P$. so lang wie die äusseren, oval, plötzlich in einen Nagel zsgezogen; die Zpfl. der Narbe längl.keilf, in ihre Oberlippe allmählig verbreitert, mit geraden Rändern; Fruchtkn. ziemlich stielrund, beinahe gleichförmig-sechsfurchig. 4 . Felsige $\mathfrak{u}$. waldige $O$. in Böhmen, um Halle an vielen Orten. Mai. Perig. violett.

6. I. nudicaulis Lamarck. Bärtig; die B. schwertf.; der St. mehrbth., zur Zeit der Bth. ungefähr so lang als die $B_{\text {; }}$; die untersten Bthstiele, 1 od. 2, fast auf der W. entspringend, fast so lang als der St.; die Bthscheiden zur Zeit der Bthe überall frisch, nicht oberwärts trockenhäutig; die inneren $\mathrm{Zpfl}$. des P. so lang wie die äusseren, oval, plötzlich in einen Nagel zsgezogen; die $Z p f l$. der Narbe vkteyf.-längl. mit nach aussen geschwungenen Rändern, unter ihrer Oberlippe etwas schmäler; der Fruchtkn. stumpf-3kantig, die Kanten mit einer schwachen Rille dchzogen. 24. In lichten Gehölzen in Schles. Mai. P. violett.

7. I. variegata L. Bärtig; B. schwertf., fast so lang als der mehrbth. St.; Bthscheiden krautig; $\mathrm{Zpfl}$. des $P$. längl.-vkteyf., die inneren nach der Basis allmählig-verschmälert. 24. Unkult. O.; Oestr. Mai. Jun. Bth. gelb, äussere Zpfl. braun-aderig.

8. I. p u mila L. Bärtig; B. schwertf, länger als der sehr kurze, 1bth. St.; Röhre des P. über die Bthscheide hervortretend, Zpfl. längl.vkteyf. 24. Sonnige Hügel; Ostr., ausserdem wohl ursprüngl. angepflanzt. Apr. Mai. Bth. violett, selten hellblau od. weiss.

9. I. Iutescens Lam. Bärtig; B. schwertf., kürzer als der meist 
1bth. St.; Röhre dcs P. von den Bthscheiden eingeschlossen', Zpt. längl.-vkteyf. 24. Kalkfelsen; am Schlosse Tourbillon bei Sitten in der Schwz. Mai. „Bth. gelbl.- weiss, die äusseren Zpfl. schwachviolett-aderig" Gaud.

II. Rotte. Bartlose. Die äusseren Zpfl. des P. bartlos.

10. I. Pseud-Á cor us L. Bartlos; B. schwertf., lanzettl.-lineal., ungefähr so lang als der stielrunde, melhrbth. St.; die äusseren $Z p f$. des $P$. eyf., breit-benagelt, die irneren lineal., schmäler $u$. kürzer als die Zpfl. der Narbe. 4. Gräben, stehende Wasser. Jun. Jul. Bth. gelb.

11. I. sibirica L. Bartlos; B. schtwertf., lineal., kürzer als der stielrunde, röhrige, meist 2 bth. St.; die äusseren $Z$ pfl. des $P$. vkteyf., in einen kurzen Nagel verschmälert; Frucktku. 3seitig; Kapsel kurzbespitzt. 24. Wiesen; zerstr. deh das Geb. .Jun. Aeussere Zpfl. des P. hellblau, von violetten Adern netzig, innere violett.

12. I. s puria L. Bartlos; B. schwertf., lanzettl.-lineal., kürzer als der armbth., stielrunde, dichte St.; die äusseren Zpfl. des $\boldsymbol{P}$. rundl., kürzer als der lanzettl. Nagel; Fruchtkn. 6seitig; Kapsel lang-geschnäbelt. 24. Nasse Wiesen; Oestreich, Rheinfläche in d. Gegend v. Mainz. Jun. Platte der äusseren $Z$ pfl. weiss-gelblich, mit blauen Adern; Nägel schief-gestreift; innere Zpfl. violett.

13. I. graminea L. Bartlos; B. schwertf., lineal., viel länger als der 2schneidige, meist 2bth. St.; Platte der äusseren Zpfl. des $P$. anhängself., eyf., viel kürzer als der verbreiterte Nagel; Fruchtkn. 6seitig. 24. Wiesen u. grasige 0 .; sehr zerstr. deh das südl. u. mittlere Geb. Mai. Jun. Nagel der äusseren Zpfl. des P. purp. mit einer gelben Linie, Platte weisslich, mit violetten Adern; innere $\mathbf{Z p f l}$ satt-violett.

Die I. foetidissima wächst nicht im Gebiete.

\section{Ording. AMARYLLIDEEN. R. Brown.}

\section{STERNBERGLA W. u. Kit. Sternbergie.}

1. S. I ute a Ker. B. lineal.; Bth. aufrecht; Schaft 2schneidig; Zpfl. des P. oval.-längl., stumpf. 24. Grasige $O$. bei Rovigno in Istrien, Ins. Lossino. Herbst. Amaryllis lutea L. Bth. gelb.

2. AGAVE L. Agave.

1. A. americana L. B. gezähnt-dornig; St. ästig; Röhre des P. in der Mitte schmäler; Stbg. länger als das P., kürzer als der Gf. 24, aber einfrüchtig. Felsige O. auf der Südspitze der Ins. Cherso. Jun. Bth. grün-gelb.

3. NARCISSUS L. Narzisse.

1. N. poëticus L. B. líneal., stumpf, ziemlich flach, stumpf- 
gekielt; Schaft zsgedriickt, 2schneidig, gerillt, 1bth.; Nebenkrone sehr kurz, schüsself., mit einem feingekerbten, scharlachrothen Rande; Zpfl. des P. eyf. 2. Wiesen, grasige O.; südl. Geb., ausserdem hin u. wieder verwildert. Apr. Mai. Saum weiss, Nebenkrone gelb, am Rande scharlachroth.

2. N. biflorus Curt. B. lineal., stumpf, ziemlich flach, stumpfgekielt; Schaft zsgedrückt, 2schneidig, gerillt, 2bth.; Nebenkrone sehr kurz, schüsself., mit einem feingekerbten, farblosen Rande; $\mathbf{Z p f l . ~ d e s ~}$ P. eyf. 2. Wiesen; Wallis, u. Gegend des Genfersees. Apr. Mai. Saum schmutzig-weiss; Nebenkrone gelb, mit weissl. Rande.

3. N. Tazetta L. B. lineal., stumpf, ziemlich flach; Schaft zsgedrückt, 2schneidig, glatt, 3-10bth.; Nebenkrone becherf., ganzrandig, 3 mal kürzer als die lanzettl.-eyf., spitzen $Z$ pfl. des $P$. 24. Steinige O.; Insel St. Andrea bei Rovigno in Istr., Insel Osero. März. Saum weiss, Nebenkrone gelb.

4. N. P se udo-Narcis u s L. B. lineal., etwas rinnig, kiellos, in der Mitte 2rillig; Schaft zsgedrückt, 2schneidig, 1lbth.; Nebenkrone glockig, am Rande wellig u. ungleich-gekerbt, so lang als die $\mathrm{Z}_{p f l}$. des $\boldsymbol{P}$. 24. Bergwiesen; zerstr. deh das Geb. März. Apr. Saum gelb, Nebenkrone goldgelb od. fast gleichfarbig.

\section{LEUCOJUM L. Knotenblume.}

1. L. veru u m L. Bthscheide 1bth.; Gf. kenlig. 24. Haine, feuchte Wiesen; zerstr. dch das Geb. Febr. März. Bth. weiss; Zpfl. des P. mit grüner Spitze.

2. L. aestivum L. Bthscheide vielbth.; Gf. fädlich-keulig. 4. Feuchte Wiesen; Krain, Oestr., Bölım., Erzgeb., Westphal., Hamburg, Lübeck. Mai. Bth. wie der vorlhergeh.

5. GALANTHUS L. Schneeglöckchen.

1. G. nivalis L. 2. Haine, feuchte Wiesen; zerstr. deh d. Geb. Febr. März. Bth. rein-weiss, innere Zpfl. des P. an der Spitze einen grünen Flecken $u$. inwendig 8 grïne Linien tragend.

\section{Ordng. ASPARAGEEN. Juss.}

\section{ASPÁraguS I. Spargel.}

1. A. officinalis L., var. $\gamma$. St. krautig, stielrund, aufrecht; $B$. buischelig, borstl., stielrund u. nelst den Zueigen ganz kahl u. glatt; Röhrchen des P. ha!b so lang als der Saum; Stbf. der männl. Bth. v. der Länge des längl. Stbk. 21. Fruchtb. Wiesen; zerstr. dch d. Geb. Jun. Jul. Bth. grünl.-weiss, wie an folgend.

2. A. s c a b e r Brign. St. krantig, stielrund, aufrecht; Riefen der fein-kantig-gerieften Zweige $u$. die Kanten der büscheligen, borstl. $B$. gezähnelt-rauh; Röhrchen des $P$. halb so lang als der Saum; 
Stbf. der männl. Bth. von der Länge des längl. Stbk. 2. Grasige O. ; Litt., Fiume. Mai. Jun. A. amarus DC. A. officinalis $\alpha$. L.

3. A. tenuifolius Lam. St. krautig, stielrund, aufrecht; $B$. büschelig, haardünn $u$. nebst den Zweigen ganz kahl; Röhrchen des $P$. sehr kurz, vielmal kürzer als der Saum; Stbf. der männl. Bth. viel länger als das rundl. Stbk. 24. Wälder, Bergwiesen; Istrien, Litt., Krain. Mai. Jun. A. sylvaticus WK. A. officinalis $\beta$. L.

4. A. acutifolius L. St. strauchig, wehrlos, kantig; Zweige flaumig; B. lineal., ziemlich stielrund, steif, stachelspitzig, immergrün; Röhrchen des $P$. so lang als der Saum. b. Hecken, gebirgig. O.; Litt., Fiume. Aug. Sept.

2. STRÉPTOPUS Michaux. Knotenfuss.

1. S. amplexifolius DC. B. stengelumfassend $u$. nebst dem St. kahl. 24. Wälder der A., VorA. u. höheren Gbge. Jul. Aug. Uvularia amplexifolia L. Bth. weisslich. Beeren roth.

3. PÁRIS L. Einbeere.

1. P. quadrifolia L. B. zu 4 ; die äusseren $\mathrm{ZpH}$. des P. lanzettl., die inneren an Breite u. Länge übertreffend. 24. Schattige Haine. Mai. Bth. grün; Fruchtkn. u. Narben schwarz-purp.

4. CONVALLARIA L. Maiblümchen.

I. Rotte. Polygonatum Tournef. P. walzlich-röhrig. Bth. weiss, an der Spitze grün.

1. C. verticillata L. St. aufrecht, kantig; B. quirlig. 4 . Bergwälder; zerstr. dch das Geb. Mai. Jun. Beeren roth.

2. C. Polygonatum L. St. kantig; B. stengelumfassend, wechselst., eyf.-längl. od. elliptisch, ziemlich stumpf, $k a h l ;$ Bthstiele blattwinkelst., 1-2bth. u. nebst den Stbg. kahl. 24. Steinige Bergwïlder. Mai. Jun. Beeren violett, wie bei den 2 folgenden.

3. C. latifolia Jacq. St. kantig; B. kurz-gestielt, wechselst., eyf., zugespitzt, unterseits auf den Nerven flaumig; Bthstiele blattwinkelst., 1-4bth., flaumig; Stbg. kahl. 24. Bergwälder; Oestr., Steyerm. Mai. Jun. Bth. so gross, wie die der C. Polygonatum.

4. C. multiflora L. Kahl; St. stielrund; B. stengelumfassend, wechsclst., eyf.-längl. od. elliptisch, ziemlich stumpf, kahl; Bthstiele blattwinkelst., 3-5bth., kahl; Stbf. behaart. 24. Feuchte Wälder. Mai. Jun. Bth. um die Hälfte schmäler als bei 3 u. 4. Var. $\beta$. bracteata: dic unteren Bthstiele in cin Aestchen verlängert $u$. an der Basis der Bth. mit einem od. 2 B. besetzt. C. bracteata Thomas., Gand.

II. Rotte. Coelocrinon. Lilium convallium Tournef. Bth. glockig, ganz weiss.

5. C. majalis L. St. nackt, halbsticlrund; Bth. traubig, überhangend. 2. Schattige Wälder. Mai. Jun. 
5. MAJÁNTHEMUM Wiggers. Schattenblume.

1. M. bif oli um DC. St. 2 blätterig; $\bullet B$. wechselst., gestielt, herzf. 4. Schattige Wälder. Mai. Jun. Convallaria bifolia L. Bth. weiss.

6. SMILAX L. Stechwinde.

1. S. as pera L. St. stachelig, kantig; B. fast spiess-herzf., eyf. od. lanzettl., 7-9nervig, stachelig-gezähnt, lederig. \$. Gebüsch aun Ufer des Adriat. Meeres. Aug. Sept. Bth. grünl.

7. RUSCUS L. Mäusedorn.

1. R. aculeatus L. B. eyf., in eine sehr spitze Stachelspitze zugespitzt, oberseits blüthentragend; Büschel d. Bth. mcist 2bth., an der Basis mit einem kleinen, trockenhäutigen, haarspitzigen, 1nervigen $B$. gestützt. $\hbar$. Unkult. O. unter Gesträuch, Wälder; Istrien, Littor., siidl. Tyr., südl. Schwz. März. Apr. Bth. griinlich, wie bei dem folgenden.

2. R. Hy poglossum L. B. längl.-lanzettl., zugespitzt, ohne Stachelspitze, oberseits blithentragend; Büschel der Bth. vielhth., an der Basis mit einem kleinen, lerautigen, lanzettl., spitzen, $3 \rightarrow 5 n \in r v i$ gen B. gestuttzt. ち. Gebirgige, waldige 0 .; wärmeres Krain, Littor. März. Apr.

CXXVI: Ordng. DIOSCOREEN. Rob. Brown.

\section{TAMUS L. Schmeerwurz.}

1. T. c o mmunis L. B. herzf., zugespitzt, ungeth. 4. Zäune, schattiges Gebüsch; Littorale, Krain, Südtyrol, Schwz., Oberbad. März. Apr. Bth. griinlich.

\section{Ordng. LILIACEEN. DC.}

I. Gruppe. T'ULIPEEN. P. 6blätterig. Kapselfächer vielsamig. S. flach, reihenweise dicht übereinander liegend. Samenhaut immer bleich od. braun, nicht krustig u. schwarz.

1. TÚLIPA L. Tulpe.

1. T. sylvestris L. St. 1bth., kahl; Bth. vor dem Aufblühen überhangend; die inneren Blätter des P. u. die Stbg. an der Basis bärtig. 24. Aecker, Weinberge, Waldwiesen; zerstr. dch d. südl. u. mittlere Geb., seltener im nördl. Mai. Jun. Bth. gelb.

2. T. Oculus s olis St. Amans. St. 1bth., kahl; B. längl.-lanzettl.; die äusseren Blätter des P. zugespitzt, die inneren stumpf, bespitzt, alle ey-lanzettf. u. nebst d. Stbg. ganz kahl. 24. Kult. 0.; bei Sitten im Wallis. Mai. B. des P. sattpurp., an der Basis mit einem schwarzblauen, gelb-eingefassten Flecken. 
2. FRITILLARIA L. Schachblume.

1. F. montana Hoppe. St. 1bth., beblättert, oberwärts nackt; die 2 blüthenst. $B$. gegenüber-gestellt, von den stengelst. weit-entfernt; B. lanzettl.-lineal., verschmälert-spitz, wechselst., die 2 untersten gegenst.; P. würfelig-bemalt. 24. Gebirgige, grasige $O$. im Littorale. Mai. Bth. gelbl. mit röthl.-braunen Flecken.

2. F. Meleágris L. St. 1 -2bth., beblättert; $B$. lineal., rinnig, zurïckgekrümmt, fast gleichweit v. einander entfernt, alle wechselst.; P. würfelig-bemalt, mit an der Spitze zsgezogenen B. 2. Feuchte Wiesen; zerstr. deh das Geb. Apr. Mai. Bth. mit purp. u. weissl. Flecken gescheckt, selten weiss.

\section{LILIUM L. Lilie.}

1. L. bulbi ferum L. B. zerstr.; Bth. aufrecht; P. glockig, inwendig von fleischigen Warzen rauh. 24. Wälder; A., VorA. u. Gbge im sïdl. u. mittl. Gebiet. Bth. safranfarben mit braunrothen Flecken.

2. L. carniolic um Bernh. B. alle aufrecht u. etwas abstehend, gleichmässig zerstreut, lanzettl., spitz, am Rande u. auf den 5-7 Nerven der unteren Seite flaumig-rauh, die oberen allmählig kleiner; St. kahl; Bth. überhangend; $P$. zurückgerollt. 24. Gbge u. VorA.; Krain, Littor. Mai-Jul. L. chalcedonicum Jacq. Bth. mennigroth od. gelb, von d. Mitte gegen d. Basis mit braun-purp. Wärzchen u. Linien.

3. L. M artagon L. B. quirlig, ellipt.-lanzettl., zugespitzt, am Rande rauh; St. flaumig-rauh; Bth. überhangend; P. zurückgerollt. 4. Bergwälder; zerstr. dch das Geb. Jul. Aug. Bth. violett-fleischroth, mit purpur-braunen Flecken.

4. LLOYDIA Salisbur. Lloydie.

1. L. serotina Salisb. 24. Sonnige, grasige O. d. höchsten A. Jun.-Aug. Anthericum serotinum L. Bl. weiss, mit 3 röthlichen Streifen, Nägel gelblich. Ist keine spätblühende Pfl.

II. Gruppe. ASPHODELEEN. P. 6blätterig. Kapselfächer wenigsamig. S. v. mannichfacher Gestalt, oft mit ciner schwarzen Samenhaut versehen.

5. ERYTHRONIUM L. Hundszahn.

1. E. Dens canis L. B. längl.-elliptisch, so wie die Blätter des P. spitz. 2. Gebirgige, waldige O.; westl. Schwz., Litt., Krain. Apr. Mai. Bth. rosenroth.

6. ASPHÓDELUS L. Affodill.

a. StB. fehlend, Bth, weiss.

1. A. ramosus L. B. breit-lineal., flach; St. blattlos, ästig, 
Aeste traubig; Bth. gedrungen; Basis d. Stbf. rundl.-vkteyf., schr stumpf, plötzlich in den Stbf. zsgezogen; Kapsel kugelig. 24. Steinige Hügel; Fiume. März. Apr.

2. A. a lbu s Miller. B. breit-lineal., flach; St. blattlos, sehr einfach; .Tr. gedrungen; Basis der Stbf. längl.-lanzettl., in den Stbf. verschmälert; Kapsel eyf., 3seitig, mit 3 dazwischen gelegenen schwachen Kanten. 24. Gebirgige O.; Krain, Littor., Sïdtyrol im Rovoredisclien. Mai. Jun.

b. St. ganz oder zum Theil mit BScheiden der B. bedeckt. Bth. gelb.

3. A. I u teu s L. B. pfrieml., 3kantig-gerillt, glatt, an der Basis in eine häutige Scheide verbreitert; St. ganz einfach, mit BScheiden bis an die Tr. bedeckt; Bth. gedrungen; DeckB. ungefähr so lang als die Bth. 24. Steinige Hügel; Fiume, Veglia. Mai. Jun.

4. A. liburnicus Seop. B. pfriemlich, 3kantig, gerillt, auf den Rillen gezähnelt-rauh, an der Basis in eine häutige Scheide verbreitert; St. ganz einfach, oberseits nackt; Bth. locker-traubig; DeckB. viel kürzer als die Bthstielchen. 2. Wiesen; bei Fiume. Jun. Jul.

7. ANTHÉRICUM L. Zaunblume.

1. A. Liliago L. B. lineal., etwas rinnig, aufrecht, kürzer als der ganz einfache St.; Gf. abwärts geneigt. 2. Buschige Hügel, felsige, gebirg. O.; zerstr. dch d. Geb. Mai. Jun. Bth. weiss.

2. A. ramosum L. B. lineal., rinnig, aufrecht, kuirzer als der ästige St.; Gf. gerade. 2. Gebirg., steinige O. ; zerstr. dch das Geb. Jun. Jul. Bth. weiss.

8. PARADISIA Mazzucati (nach Bertolini). Paradisie.

1. P. Liliastrum Bertolon. 24. Berg- u. ATriften; Schwz., Tyr., Kärnth. Jul. Aug. Anthericum Liliastrum L. Czackia Liliastrum Andrz. Bth. weiss.

\section{ORNITHÓGALUM L. Milchstern.}

1. O. pyrenaicum I. Tr. verlängert, reichbth.; Bthstiele abstehend, die fruchttrag. an den Schaft angedrückt; DeckB. ey-lanzettf.; allmählig in eine Spitze verschmälert; Blätter des P. lineal.längl.; Gf. so lang als die Staubf.; Fruchtkn. oval, an beiden Enden gleichf.-abgerundet; B. lauchgrün, lineal., tief-rinnig. 24. Bergwiesen im südl. Geb. Jun. Jul., 14 Tage später als 0 . sulfureum. Bth. weissl. mit einem sehwachen, meergrünen Schimmer, die Blätter des P. unterseits mit einem lauchgrünen Streifen. O. pyrenaicum Jacq. gehört hierher.

2. O. s u lf u re u m R. et S. Tr. verlängert, reiehbth.; Bthstiele abstehend, $d$. fruchttrag. an den Schaft angedrückt; DeckB. ey-lanzettf., allmählig in eine Spitze verschmäbert; B. des P. lineal.-längl. ; 
Gf. so lang als die Stbf.; Fruchtkn. eyf., nach oben spitzer; B. grasgriin, lanzettl.-lineal., zieml. flach od. mässig-rinnig. 24. Zerstr. im siidl. Geb. Mai. Jun. Bth. schwefelgelb od. grünl.-gelb, unterseits mit einem grasgrünen Streifen auf den B. des Perig. Anthericum sulfureum W. K.

3. O. stach yoides Schult. Tr. verlängert, reichbth.; Bthstiele abstehend, die fruchttrag. ari den Schaft angedrückt; DeckB. eyf., plötzlich in eine lange Spitze zsgezogen; Blätter des P. lanzettl.-längl.; Gf. etwas länger als die Stbf.; B. lineal., rinnig. 24. Aecker der wärmeren O.; um Triest, in Istrien. Mai. Jun. Bth. reinweiss, ein breiter, grüner Streifen auf der unteren Seite der B. des Perig. O. stachyoides Ait? Die Stbgf. sind nicht abwechselnd um die Hälfte kürzer, sondern nur ein wenig kürzer.

4. O. a rcuatum Steven. Tr. verlängert, reichbth.; Bthstiele in einem rechter Winkel abstehend, die fruchttrag. in einen Bogen gekrümmt $u$. aufstrebend; DeckB. ey-lanzettf., allmählig in eine Spitze verschmälert; B. des P. elliptisch; Gf. um die Hälfte kürzer als der Fruchtkn.; B. lineal., rinnig. 24. In grasigen Obstgärten bei Steyer in Oberöstr. Jun. Von Dr. Sauter entdeckt.

5. O. c o m o s u m Linn. Tr. zuletzt längl.; die blüthen-u. fruchttrag. Bthsticle in einem halbrechten Winkel abstehend, und zuletzt alle v. gleicher Länge; B. des P. längl., stumpf; Stbf. ungezähnt; B. lineal., gewimpert. 2. Zwischen Gebüsch um Fiume. Mai. Jun. Bth. reinweiss mit grünem Rückenstreifen, wie bei den 3 Folgenden.

6. O. collinum Gussone. Bth. ebensträussig; die blüthen- u. fruchttrag. Bthstiele in einem halbrechten Winkel abstehend, die unteren länger; B. des P. breit-längl., stumpf; Stbf. ungezähnt; B. lineal. mit einer weissen Linie dchzogen, oft gewimpert. 24. Auf Wiesen des Karstgbges in der Gegend v. Triest. Mai. Jun. O. saxatile Visiani. - Das ähnl. O. montan u Cirillo hat breitere B. u. keine weisse Linie auf denselben $u$. O. tenuifolium Guss. sehr schmale B. u. spitze $\mathrm{Zpfl}$. des Perig.

7. O. umbell atum L. Bth. ebensträussig; die unteren fruchttray. Bthstiele wagerecht abstehend mit aufstrebender Frucht; $\mathbf{B}$. des P. längl., stumpf; Stbf. ungezähnt; B. lineal., kahl, mit einer weissen Linie dchzogen. 24. Wiesen, Aecker, zerstr. deh d. Geb. Apr. Mai.

8. O. refractum Kitaibel. Bth. ebensträussig; die unteren fruchttrag. Bthstiele vom St. spreitzend-hinabgeschlagen mit aufstrebender Frucht; DeckB. kürzer als die Bthstiele; Blätter des P. längl., stumpf; Stbf. ungezïhnt; B. lineal., kahl, mit einer weissen Linie dchzogen. 24. Aecker, Weinberge um Triest. Apr. Mai. - Das ähnl. O. exscapum liat DeckB. v. der Länge der Bthstiele u. länger.

9. O. nutans L. Bth. locker-traubig, schon zur Bthezeit einscitswendig u. hängend; Blätter des $P$. glockig-offen, ellipt.-lanzettl., 
stumpf; Stbf. alle 3zähnig, abwechselnd um die Hälfte kürzer, die Seitenzähne der längeren über d. Anthere hinausragend; B. zur Bthezeit völlig frisch. 24. Wiesen, Aecker; zerstr. deh das Geb. Apr. Mai. Blätter des P. inwendig weiss mit grïnl. Schimmer, auswendig hellbl.-grün, mit weissem Rande.

10. O. chloranthum Sauter. Bth. genähert-traubig, zur Bthezeit wagerecht, später einseitswendig u. hängend; Blätter des $P$. fast wagerecht-abstehend, lanzettl., spitz; Stbf. alle 3zühnig, abwechselnd um die Hälfte kürzer, die Seitenzähne der längeren so lang als die Anthere oder kürzer; B. zur Bthezeit oberwärts vertrocknet. 2. Grasplätze bei Steyer. Apr. Mai. Bthe inwendig weiss, auswendig mit breitem sattgrünem Streifen auf den B. des Perig.

10. GAGEA Salisb. Gagee.

I. Rotte. W. aus 3 wagerechten, nackten $\mathfrak{u}$. v. keiner gemeinschaftl. Haut eingeschlossenen Zwiebeln zsgesetzt, v. diesen die zwei diesjährigen blattlos, die einjährige dritte aber ein einzelnes B. und einen blüthentragenden Schaft treibend. - Bth. aller Arten der Gattung gelb.

1. G. stenopetala Rehb. Das WB. einzeln, lineal., nach der Basis und Spitze verschmälert, flach, geschärft-gekielt, die 2 blüthenst. B. gegenst.; Bthstiele kahl, einfach, nach $d$. Verblühen nach allen Seiten abstehend; Zwiebeln 3, wagerecht, die heurigen keulig od. eyf. 2 . Aecker. Apr. Mai. Var. $\beta$. pratensis: das untere bthständige B. wie eine Bthscheide umfassend, die Bthstiele nach dem Verblühen einseitswendig. Dieses auf Wiesen. G. pratensis K. syn. ed. 1.

II. Rotte. W. aus 2 aufrechten, von einer gemeinschaftlichen Haut eingeschlossenen Zwiebeln gebildet, zwischen denen d. Schaft hervorsprosst. Die eine Zwiebel mit WFasern versehen, bei der anderen, der Nebenzwiebel, welche im folg. Jahre Blüthen trägt, die Wfasern fehlend.

2. G. a r ven sis Schult. WB. zu 2, lineal, rinnig, stumpf-gekielt, zurückgekrïmmt; StB. fehlend, die 2 blüthenst. B. gegenst.; Bthstiele ästig, ebensträussig, zottig; Blätter des $P$. lanzettl., spitz; Zwiebel rundlich. 24. Aeker, knltiv. O. März. Apr. Ornithogalum arvense Pers. O. minimum Roth. O. villosum MBieb.

3. G. b o hemica Schult. WB. zu 2, fädlich, rinnig, die stengelst. wechselst., lanzettl., zugespitzt od. mit verlängert-fädlicher Spitze endigend; Bth. endst., meist einzeln; Blätter des $P$. längl., vorne breiter, abgerundet-stumpf, an der Basis nebst dem St. oberwärts u. den B. am Rande flaumig; Fruchtkn. vktherzf., mit concaven Seiten; Zwiebel rundl. 24. Felsige, feuchte O.;Böhm., Mähr., Schles. März. Apr. Ornithogalum bohemicum Zauschner. Var. fast kahl.

4. G. saxatilis Koch. WB. zu 2, fädl., rinnig, die stengelst. 
wechselst., lanzettl., zugespitzt, od. mit verlängert-fädlicher Spitze endigend; Bth. endst., meist einzeln; Blätter des $P$. längl.-lanzettl., stumpf, an der Basis nebst dem St. und dem Rande der B. zottig; Fruchtkn. längl., vktcyf., gestutzt mit ziemlich convexen Seiten; Zwiebel rundl. 24. Felsige, etwas feuchte O.; Rheinpfalz, Thüring. Mitte März.

5. G. L i ottar di Schult. WB. einzeln od. zu 2, röhrig, kahl, halbstielrund, an der Basis rinnig, die blüthenst. gegenüber, das grössere scheidig, zsgerollt, an der Basis eyf.; Bthstiele 1-5, einfach, doldig, zottig; Blätter des $P$. ellipt.-lanzettl., stumpf; Zwiebel rundl. 4. Triften der A.; Schwz., Tyr., Salzb., Kärnth. Mai. Jun. Ornithog. Liottardi Sternb. O. fistulosum Ramond. Var.: Bthstiele kahl.

6. G. spathace a Schult. WB. zu 2, aufrecht, fädl., halbstielrund, oberseits flach od. seichtrinnig, das blüthenst. einzeln, lanzettl., scheidig-zsgerollt, $v$. der gestielten, 2-ibth. Dolde entfernt; d. besonderen Bthstiele einfach, kahl ; Blätter des P. längl.-lanzettl., stumpf; Zwiebel eyf. 2. Feuchte Haine; nördl. Geb., selten im mittleren. Apr. Mai. Ornith. spathaceum Hayne.

7. G. minima Schult. Das WB. einzeln, aufrecht, lineal., oberu. unterseits flach od. etwas rinnig, das blüthenst. einzeln, scheidig, lanzettl., an der Basis den gemeinschaftlichen Bthstiel der 2-5bth., gestielten Dolde einschliessend; die besonderen Bthstiele einfach od. ästig, kahl; Blätter des P. lineal.-lanzettl., zugespitzt; Zwiebeln eyf. 4. Haine, Gebüsch; zerstr. deh d. Geb.; in den A. häufiger. Apr. Mai. Ornith. minimum L. O. Sternbergii Hoppe.

III. Rotte. W. aus einer festen, aufrechten Zwiebel gebildet, welche an der Basis den Schaft umgiebt $u$. ein einzelnes B. trägt. Die Nebenzwiebel fehlend.

8. G. I u te a Schult. Das wurzelst. B. einzeln, aufrecht, lineal.lanzettl., plötzlich-zngespitzt, flach, geschärft-gekielt, die 2 blüthenst. fast gegenüber; die besonderen Bthstiele einfach, doldig; kahl; Blätter des P. längl.-stumpf; Zwiebel eyf., einzeln. 2. Haine, Waldwiesen; zerstr. dch d. Geb. Apr. Mai. Ornithogalum luteum $\beta$. L. O. sylvaticum Pers. O. Personii Hopp.

9. G. pu silla Schult. Das uurzelst. B. einzeln, aufrecht, schmallineal., rinnig, die 2 blüthenst. gegenüber, das untere grösser, zsgerollt-scheidig; Dolde 2-3bth.; Bthstiele kahl; Blätter des P. lanzettl., stumpf; Zwiebel eyf., einzeln. 24. Waldige, steinige 0.; Böhmen, Oestreich. März. Apr. Ornithog. pusillum Schmidt. O. tunicatum Presl. u. O. Clusianum Tausch. sind nicht verschieden.

\section{SCILLA L. Meerzwiebel.}

1. S. a moen a $\mathbf{L}$. Zwiebel vielblättrig; B. aufrecht, breit-lineal., ziemlich flach, an d. Spitze fast kappenf.-stumpf; Schaft kantig; Bthstiele aufrecht; DeckB. kurz, abgeschnitten od. gezähnt. 2. Anf Wiesen an der Donau bei Wien, Jacquin, u. im Gehölze bei Wall- 
beck am Harze, Hampe; ausserdem auf Grasgärten um Häuser hin u. wieder, vielleicht hier aus Gärten eingewandert. Apr. Mai. Bth. blau.

2. S. bifolia L. Zwiebel 2blättrig; B. abstehend od. zurickgekrümmt, lanzettl.-lineal., rinnig, in eine stielrunde Spitze zsgerollt; Schaft stielrund; Bthstiele aufrecht; DeckB. fehlend. 2. Felsige, steinige Wälder; zerstr. dch das Geb. März. Apr. Bth. blau.

3. S. italic a L. Zwiebel vielblättrig; B. lineal.; Tr. kegelf.; Deck $B$ zu zweien, das eine v. der Länge des Bthstielchens; P. abstehend. 24. Felder u. unkult. O., in der Gegend v. Bern, TrachseI, bei Kleinlaufenberg in Oberbad., Alex. Braun, nach dessen brief. Bemerkung wächst diese u. nicht Scilla verma daselbst. Apr. Mai. S. verna K. syn. ed. 1.

4. S. a utumnalis L. Zwiebel mehrblättrig; B. schmal-lineal., sich nach den Bth. entwickelnd; Tr. fast ebensträussig, nach dem Verblühen verlängert; Bthstiele aufstrebend; DeckB. fehlend. 24. Kalkhügel u. Weinberge; Elsass bei Orschwylır, Kästelwald bei Colmar, östr. Littor u. Fiume. Aug. Sept. Bth. blau.

\section{2. ÁLLIUM L. Lauch.}

I. Rotte. Anguinum Don. Die W. ein Rhizom, auf welchem die $Z$ wiebeln sitzen. Der St. wegen verlängerter Bscheiden mit wechselst. B. bekleidet. Stbg. einfach.

1. A. Victorialis L. St. bis zur Mitte beblättert, stielrund, oberwärts kantig; B. kurzgestielt, lanzettl. od. elliptisch, flach; Bthscheide 1klappig, bleibend; Dolde kapseltragend, kugelig; Stbg. zahnlos, länger als das P. 24. Felsige O. der A. u. höheren Gbge. Jul. Aug. Bth. grünl.-weiss.

II. Rotte. Molium Don. W. zwiebelig. B. verbreitert od. breit-lineal., flach, alle wurzelst. St. nackt. Stbg. ganz unten in dem $P$. eingefügt, einfach.

2. A. u r sin u m L. St. blattlos, stumpf-3kantig; B. langgestielt, elliptisch-lanzeltl.; Bthscheide 1klappig, 2-3sp., bleibend; Dolde kapseltragend, gleichhoch, locker; Stbg. zahnlos, küuzer als das P. 4. Schattige, feuchte Wälder, Rand der Gebirgsbäche; zerstr. dch das Geb. Apr. Mai. Bth. schneeweiss.

3. A. nigrum L. St. blattlos, stielrund; WB. sitzend, breit-lanzettl., zugespitzt, flach, am Rande kahl; Bthscheide 1klappig, 2-3lappig, bleibend; Dolde kapseltrag., convex; Stbg. zahnlos, an der Basis breit-verwachsen, länger als das halbe P.; Zwiebel plattgedrückt-kugelig. 2. Gebirgsäcker; bei Wien, bei Beuel in der Gegend v. Bonn. Mai. Blb, weissl. mit grünem Rückenstreifen. Fruchtkn. schwarzgrïn.

4. A. roseum L. St. blattlos, stielrund; WB. breit-lineal., zugespitzt, flach, gekielt, an der Spitze eingerollt, am Rande gezähnelt- 
rauh; Bthscheide 1klappig, 2-4lappig, bleibend; Dolde convex; Stbg. zahnlos, kürzer als das P.; Zwiebel rundlich. 24. Weinberge, Aecker, grasige Hügel; Istrien auf der Ins. St. Andrea, Fiume. Apr. Mai. Bth. rosenroth, gross. Var.: Dolde ohne $\mathrm{Zwiebeln} \mathrm{u.} \beta$. mit solchen: A. Tenorii Spreng., A. carneum Tenor.

5. A. subhirsutum L. St. blattlos, stielrund; WB. breit-lineal., zugespitzt, flach, gekielt, am Rande zottig-gewimpert; Bthscheide 1klappig, eyf., ungeth., halb so lang als die Dolde; Dolde gleichhoch; Stbg. zahnlos, halb so lang als das P.; Zwiebel rundlich. 24. Grasige Hügel ; Insel Osero, Lossino. Apr. Bth. weiss.

III. Rotte. Rhizirideum Don. W. ein wagerechtes Rhizom, welches die $Z$ wiebeln trägt. Der St. an der Seite des Blätterbüschels u. mit diesem Büschel an der Basis v. gemeinschaftl. Scheiden eingeschlossen. Stbg. einfach.

6. A. fallax Don. St. nackt, oberwärts scharf-kantig; B. lineal., ungefähr $v$. der Breite des St., flach, unterseits schwach nervig, kiellos; Bthscheide 2-3sp.; Dolde rundlich, kapseltrag.; Sthf. zahnlos, länger als das P.; Zwiebel an den querliegenden Wurzelstock angewachsen, mit ganzen Häuten bedeckt. 24. Felsen d. Gbge u. VorA.; zerstr. dch das Geb. Jul. Aug. A. montanum Schmidt. Bth. rosenroth. B. 1-2 Linien breit, getrocknet dchscheinend, mit stärkeren u. schwächeren Nerven dchzogen, d. mittlere aber nicht dicker; bei der folg. ist der Mittelnerv dicker.

7. A. acutangulum Schrad. St. oberwärts scharf-kantig; B. flach, lineal., ungefähr v. der Breite des St. unterseits 5nervig und dch den hervortretenden Mittelnerven scharf-gekielt; Bthscheide 23sp., halb so lang als die Dolde ; Dolde fast gleichhoch, kapseltrag.; Stbg. so lang als das $P$., zahnlos; Zwiebel an den querliegenden Wurzelstock angewachsen, mit ganzen Häuten bedecǩt. 24. Nasse Wiesen; zerstr. deh das Geb. Jun.-Aug. A. angulosum Pollich u. der meisten Aut. Bth. rosenroth.

IV. Rotte. Scorodon. Der St. unterwärts od. bis zur Mitte beblättert, B. nicht röhrig. Die Stbg. einfach od. abwechselnd an der Basis mit einem kurzen, stumpfen Zahne versehen, in dem $\mathbf{P}$. ganz unten eingefügt.

a. Die Stbg. abwechselnd breiter, aber an der Basis nicht gezähnt.

8. A. moschatum L. St. stielrund, unterwärts beblättert; $B$. borstlich-pfrieml., stielrund, gefurcht, schmal-u. tief-rinnig, am Rande fein-wimperig-rauh; Bthscheide 1klappig, stachelspitzig; Dolde locker, kapseltrag.; Stbg. um den dritten Theil kürzer als das $\boldsymbol{P}$., alle einfach; Zwiebclhäute an der Spitze zuletzt netzig-faserig. 24. Trockene, felsige Hügel; Fiume. Jul. Aug. A. setaceum W. u. Kit. Bl. weiss od. röthlich, mit einem purp. Rückenstreifen. 
9. A. saxatile MBieb. St. stielrund, an der Basis beblättert; B. lineal.-pfrieml., sti lrund, geturcht, schmal- u. tief-rinnig, am Rande kahl; Bthscheide 2klappig, lang-stachelspitzig; Dolde convex, kapseltrag.; Stbg. fast noch cinmal so lang als das $P$., alle einfach; Zwiebelhäute ungeth. 2. Felsenspalten am ganzen siidl. Abhang des Karstgebirges. Aug. Sept. Bth. weiss od. schwach-bleichröthl.

10. A. ochroleucum W. K. St. stielrund, an der Basis beblättert; B. lineal., flach, unterseits durch 2-3 mehr hervortretende Nerven scharf-gekielt, getrocknet vielnervig, mit 2-3 stärkeren Nerven; Blattscheiden an d. Spitze quer-abgeschnitten; Bthscheiden 2klappig, kürzer als die Bthstiele; Dolde fast kugelig, kapseltrag.; Stbg. zuletzt noch einmal so lang als das $P$., alle einfach; $Z$ wiebelhäuto an der Spitze unregelmässig-gespalten. 4. Felsige O.; Krain, Litt. Jul. Aug. Bth. weissl. od. gelbl.

11. A. su a ve olens Jacq. St. stielrund, an der Basis beblättert; B. lineal., flach, etwas rinnig, unterseits scharf-gekiclt, getrocknet vielnervig, mit 2-3 stärkeren Nerven; Blattscheiden an der Spitze schiєf-abgeschnitten; Bthscheide 2klappig, kürzer als die Bthstiele; Dolde fast kugelig, kapseltrag.; Stbg. $1 \frac{1}{2} \mathrm{mal}$ so lang als das P., alle einfach; $Z$ wiebelhäute an der Spitze unregelmässig-gespalten. 4 . Moorige, sumpfige Wiesen; Unteröstreich, im Riede bei Memningen in Schwaben, bei Dachau in Oberbayern, Valle di Vestino in Tyr., Zermatten im Wallis. Jul. Aug. Bth. hell-purpurn.

b. Die Stbg. an der Basis beiderseits mit einem kurzen, stumpfen Zahne versehen; die Dolde kapseltragend.

12. A. strictum Schrad. St. stielrund, an der Basis beblättert; B. lineal., oberseits rinnig, gegen die Spitze hin flach, unterseits fast halbstielrund, glatt, schwach-nervig; Bthscheide 2klappig; Dolde fast kugelig, kapseltrag.; Stbg. abwechselnd an d. Basis beiderseits 1 zähnig, Zähne viel kürzer als der Stbf.; Zwiebelhäute zuletzt durchaus netzig-faserig. 24. Felsige O.; Bielstein am Meissner im Hessisch., Kugelbad in Böhm., Krain, Nicolaithal in d. Schwz. Jul. Bth. hellpurp.

c. Die Stby. an der Basis beiderseits mit einem kurzen, stumpfen Zahne versehen; die Dolde zwiebeltragend.

13. A. sativum L. St. stielrund, bis zur Mitte beblättert; B. breit-lineal., flach, etwas rinnig; Bthscheide 1klappig, sehr lang-geschnäbelt, hinfällig; Dolde zwiebeltrag.; Stbg. abwechselnd an der Basis beiderseits 1zähnig, Zähne viel kürzer als der Stbf.; Zwiebel gehäuft; Zwiebelchen eyf.-längl., in eine Haut eingeschlossen. 24. Zum Küchengebrauche kultiv. Jul. Aug. Bth. schmutzig - weiss. St. vor der Bthezeit in einen Ring zsgedrehet, wie bei der folgenden.

14. A. Ophioscórodon Don. St. stielrund, bis zur Mitte beblättert; B. breit-lineal., flach; Bthscheide 1klappig, sehr langge- 
schnäbelt, hiniällig; Dolde zwiebeltrag.; Stbg. abwechselnd an der Basis beiderseits 1zähnig, Zähne viel kürzer als der Stbf.; Zuiebel gehäuft; Zwiebelchen rundl.-eyf., in eine Haut eingeschlossen. 2. Zum Küchengebrauche unter dem Namen Rockenbolle, Rocambole der Franzosen, kultiv. Jul. Aug. Scheint Variet. der vorhergeh. A. Ophiosc. Link ist A. controversum Schrad. u. dch einfache Z wiebel verschieden.

V. Rotte. Porrum Tournef. W. zwiebelig. St. unterwärts od. bis zur Mitte beblättert. Stbg. abwechselnd 3fach-haarspitzig, die mittlere Haarspitzc des Stbk. tragend, die seitenst. fädlich, meist zsgedrehet.

15. A. Porrum L. St. stielrund, bis zur Mitte beblättert, aus dem Mittelpunkte einer einfachen Zwiebel hervorgehend; B. flach; Dolde kapseltrag., kugelig; Blätter des P. am Kiele raub; Stbf. ein wenig länger als das P., die 3 inneren 3 fach-haarspitzig, die mittlere Haarspitze des Stbk. trag., halb so lang als der Stbf. selbst. (-) u.' 2. Zum Küchengebrauche kultiv., in wärmeren Gegenden'auch verwildert. Jun. Jul. Bth. hellpurp.

16. A. Ampelóprasum L. St. stielrund, bis zur Mitte beblättert; Zwiebel seitenst., fest, Brutzwiebeln trag.; B. fach; Dolde kapselstrag., kugelig; P. auswendig rauh; Stbf. ein wenig länger als das P., die 3 inneren 3 fach-haarspitzig, die mittlere Haarspitze das Stbk. trag., so lang als der Stbf. seibst. \%. Aecker; Gegend v. Basel bei Wiesa, Crenzach u. Neudorf; im Littorale. Jun. Jul. Bth. hellpurpurn.

17. A. rotundum L. St. stielrund, bis zur Mitte beblättert; Zwiebeln aus zahlreichen, v. einer Haut eingeschlossenen, Zwiebelchen gebildet; B. flach; Dolde kapseltrag., fast kugelig; die seitenst. Bthstiele viel kürzer; Blätter des P. auf dem Ruicken rauh; Stbg. eingeschlossen, nicht so lang als das P.; die 3 inneren Stbf. 3 fachhaarspitzig, die mittlere Haarspitze das Stbk. trag., 3mal kürzer als der Stbf. selbst. 2. Aecker; zerstr. deh das Geb. Jul. Aug. Bth. purp.

18. A. sphaerocéphalum L. St. bis zur Mitte beblättert; $B$. halbstielrund, oberseits tief-rinnig; Dolde kapseltrag., kugelig, zuletzt fast kegelf.; Blätter des P. mit einem glatten Kiele; Stbk. hervortretend; die 3 inneren Stbf. 3fach-haarspitzig, die mittlere Haarspitze das Stbk. trag., halb so lang als der Stbf. selbst. 24. Aecker; zerstr. deh das Geb. Jun. Jul. Bth. purp. Eine gewöhnl. Form, an der die inneren Bthstiele verlängert sind, ist nach Bertoloni A. descendens L.

19. A. vineale L. St. bis :ur Mitte beblättert; B. stielrund, oberseits schmal-rinnig, inwendig hohl; Dolde zwiebeltrag.; Stbg. länger als das $P$., die 3 inneren 3 fach-haarspitzig, die mittlere Haarspitze das Stbk. tragend, länger als der Stbf. selbst. 4. Aecker. 
Jun. Jul. A. arenarium L. Al. suec. nach Fries. Bth. purp. Var. $\beta$.: Dolde blos kapseltrag.: A. descendens K. syn. ed. 1., nicht I.

20. A. Scorodóprasum L., mit Ausschl. der Var. $\beta$. St. bis zur Mitte beblättert, gerade; $\mathrm{B}$. flach, am Rande rauh; Dolde zwiebeltrag.; Stbg. kürzer als das $P$., abwechselnd 3fach-haarspitzig, die mittlere Haarspitze das Stbk. trag., halb so lang als der Stbf. selbst. 4. Wiesen; zerstr. deh das Geb. Jun. Jul. A: arenarium Sm. u. der meisten Autor. Bth. dunkel-purpurn.

VI. Rotte. Codonóprasum. Die W. zwiebelig. Der St. bis zur Mitte beblättert. Stbg. sämmtl. einfach, über der Basis der PBlätter eingefiigt. Bthscheidc $2 \mathrm{klappig}$, die eine Klappe lang-gehörnt.

21. A. oler aceum L. St. stielrund, bis zur Mitte beblättert; B. lineal., rimnig, gegen die Spitze hin flach, unterseits vielriefig, 2klappig, bleibend, die eine Klappe lang-geschuähelt; Dolde zwiebeltragend; Stbg. zahnlos, ungefähr so lang als das $P$.; Blätter des P. stumpf. 24. Aecker, kult. O. Jun. Jul. Bth. weissl. od. röthl., der Rückenstreif grün, od. purp. Kommt. vor: $\alpha$. angustifolium: B. $1-1 \frac{1}{1} \mathbf{2}^{\prime \prime \prime}$ breit, deswegen mehr rinnig: A. oleraceum K. syn. ed. 1. - $\beta$. latifolium: B. $3^{\prime \prime}$ breit, deswegen flacher: P. carinatum Pollich. K. syn. ed. 1.; eigentlich bloss magere u. itppige Expl. Die B. inwendig öfters hohl. Das Allium Haller's de All. t. 1. f. 2. ist mir jetzt $\mathrm{zweifelhaft.}$

22. A. carinatum L. St. stielrund, bis zur Mitte beblättert; B. lineal., rinnig, gegen die Spitze hin flach, unterseits mit $3-5$ hervortretenden Riefen; Bthscheide 2klappig, bleibend, die eine Klappe sehr lang-geschnäbelt; Dolde zwiebel- od. kapseltrag.; Stbg. zahrilos, zuletzt noch einmal so lang als das $P$.; Blätter des P. längl.-vkteyf., an der Spitze sehr concav, abgeschnitten-stumpf, etwas ausgerandet. 4. Buschige Hügel; sehr zerstr. deh das Geb. Jun. Jul. A. carinatum Fries. Bth. rosenroth, getrockn. violett. Var. $\beta$. capsuliferum: Dolde bloss kapseltrag. A. montanum Sibth. et. Sm. A. paniculatum Redouté, nicht L.

23. A. flavum L. St. stielrund, bis zur Mitte beblättert; B. lineal., markig, (an der lebenden Pf.) ganz glatt, unterseits convex, oberseits oft seicht-rinnig, am Rande stumpf; Bthscheide 2klappig, bleibend, die eine Klappe lang-geschnäbelt; Dolde kapseltragend; Sibg. zahnlos, zuletzt noch einmal so lang als das $P$.; Blätter des P. abgeschnitten od. gestutzt. 2. Steinige, grasige O.; Siidtyr., Unteröstr., Måhr. Jul. Aug. Bth. schön gelb.

24. A. pallens L. St. stielrund, bis zur Mitte beblättert; $B$. lineal., grasartig, doch inwendig hohl, an d. Basis seicht-rinnig, oberwärts flach, unterseits kantig-gefurcht; Bthsch. 2klappig, bleibend, die eine Klappe sehr lang-geschnäbelt; Dolde kapseltrag.; Stbg. zahnlos, kürzer als das P.; Blätter des P. abgerundet-stumpf od. 
fast gestutzt. 4. Sonnige Hügel; Insel Losino, Tommasini. Jul. Aug. Bth. hellpurp. A. paniculatum K. syn. ed. 1.

25. A. paniculatum L. St. stielrund, bis zur Mitte beblättert; B. schmal-lineal., halbstielrund, rinnig, inwendig ausgefüllt, (Bertoloni); Bthscheide 2klappig, bleibend, die eine Klappe sehr langgeschnäbelt; Dolde kapseltrag.; Stbgf. zahnlos, kürzer als das' $\boldsymbol{P}$.; Blätter des P. spitzlich. 24. Sonnige Hiigel; Istrien u. Insel Brioni, nach Bertolon. Bth. hellpurp. - Bertoloni nennt die B. unterseits striata, Treviranus nennt sie laevia. Die Pfl. ist mir im Garten zu Grunde gegangen.

VII. Rotte. S cho enópras u m. W. zwiebelig. B. vollkommenröhrig, stielrund od. halbstielrund. Bthscheide kurz, 2klappig.

26. A. Schoenóprasum L. Schaft nackt od. an der Basis armblätterig; B. lineal., pfrieml., gleichf.-stielrund od. aus dem Stielrunden zsgedrückt, vollkommen -röhrig; Bthscheide 2klappig, ungefähr so lang als die Dolde; Dolde kapseltrag., fast kugelig; Blätter des P. lanzettl., spitz; Sthg. kürzer als das P., zahrlos. 2. Flussufer; Mosel, Unterrhein, Elbe, Bodensee. Jun. Jul. Bth. hellpurp. Var. $\beta$. alpinum: grösser; die Blätter des P. breiter u. stärker, schmäler zulaufend. A. foliosum Clarion. bei DC. A. sibiricum Willd.

27. A. ascalonicum L. St. gleich, an der Basis beblättert; B. pfrieml., gleichf.-stielrund, vollkommen-röhrig; Bthscheide 2klappig, kürzer als d. kapsel- od. zwiebeltragende Dolde; Stbg. ein weniger länger als das $\mathrm{P}$., abwechselnd an der Basis beiderseits kurz. 1zähnig. 4. Zum Küchengebrauche gebauet. Blühet selten.

28. A. C e p a L. St. an der Basis beblättert, unterhalh der Mitte bauchig-aufgeblasen; B. vollkommen-röhrig, stielrund, bauchig; Dolde kapseltrag., kugelig; Stbg. länger als das P., wechselweise an der Basis beiderseits kurz-1zähnig. 2. Ueberall gebauet. Jun. Jul. Bth. weisslich.

29. A. fistulosum L. St. an der Basis beblättert, in der Mitte aufgeblasen; B. vollkommen-röhrig, stielrund, bauchig; Dolde kapseltrag., kugelig; Stbg. zahnlos, länger als das P. 2. Zum Küchengebrauche gebauet. Jun. Jul. Bth. weisslich.

III. Gruppe. HEMEROCALLIDEEN. R. Brown. P. 1blätterig, getheilt. Kapselfächer wenigsamig. Gestalt des S. mannigfach, (bei den unsrigen) mit einer schwarzen Samenhaut.

\section{HEMEROCÁLLIS L. Tagblume.}

1. II. flava L. Zpfl. des P. flach, nervig, aderlos. 2. Sumpfige, schattige O.; Wallis, Krain, Gegend v. München u. Salzbg. Jun. Bth. schön gelb.

2. H. fulva L. $Z_{p f l}$. des $P$. nervig u. aderig, die inneren am 
Rande wellig. 24. Wiesen; Wallis $u$ : in d. Gegend v. Aelen; auch in D. hin u. wieder, aber wohl nur verwildert. Jul. Aug. Bth. rothgelb.

\section{ENDYMION Dumortier. Endymion.}

1. E. $n u t a n s$ Dumort. B. breit-lineal.; Tr. ïberhangend; Bth. glockig-walzl., Zpfl. an d. Spitze zurückgekrümmt; DeckB. gezweiet. 4. Schattige Haine; bei Coesfeld $u$. Kürenzig in Westphal. Mai. Hyacinthus non scriptus L. Bth. blau.

\section{MÚSCARI Tournef. Bisamhyacinthe.}

1. M. comosum Mill. Bth. kantig-walzl., die unteren entfernt, wagerecht-ahstchend, die oberen länger-gestielt, aufrecht, genähert, schopfig, geschlechtlos; B. lineal., rinnig. 24. Aecker, Weinberge; zerstr. deh d. Geb. Mai. Jun. Hyacinthus comosus L. Bth. bräunlich, an d. Basis u. Spitze olivengriin, die oberen nebst den Bthstielen u. der Spitze des St. amethystblau.

2. M. $\mathrm{racemosum}$ Mill. Bth. eyf., überhangend, gedrungen, die obersten aufrecht, geschlechtlos; $B$. lineal., rinnig, bogig-zurückgekrümmt, schlapp. 2. Aecker, Weinberge; zerstr. dch das Geb. Apr. Mai. Hyacinthus racemosus L. Bth. sattblau.

3. M. botryoides Mill. Bth. fast kugel-eyf., überhangend, zuletzt mässig-entfernt, die obersten aufrecht, geschlechtlos; B. lanzettl.lineal., rinnig, nach der Basis verschmälert, aufrecht. 2. Aecker, Weinberge; zerstr. dch d. Geb. Apr. Mai. Hyacinthus botryoides L. Bth. sattblau.

IV. Gruppe. $A B A M E E N$. P. 6blätterig. Samenhaut locker, an der Basis u. Spitze mit einem Anhängsel.

\section{NARTHÉCIUM Moehring. Narthecie.}

1. N. os s ifr a g u muds. Die WB. lineal.-schwertf.; Kaps. spitz, ein wenig länger als das bleibende P. 2. Torfige, moorige 0 .; nördl. Geb. v. Niederrheine an. Jul. Aug. Anthericum ossifragum L.

\section{Ordng. COLCHICACEEN. DC.}

\section{BULBOCÓDIƯM L. Lichtblume.}

1. B. vernum L. 2. Wiesen, im unteren Wallis. März. Apr. Bth. hell-violettroth.

\section{CÓLCHICUM L. Zeitlose.}

1. C. a utumnale L. Röhre des P. 5- od. $6 \mathrm{mal}$ so lang als d. Saum; Zpt. wellig-nervig, lanzettl., die äusseren vkteyf.-lanzettf.; Stbg. wechselsweise länger und höher eingefügt; Zwiebel mehrblüthig; B. sich nach d. Bth. entwickelnd, breit-lanzettl., spitz, steif. 4. Wiesen; südl. Geb. u. bis zum südl. Theil des nördl. Aug.-Oct. Bth. fleischfarben. 
2. C. alpinum DC. Röhre des P. 5- od. $6 \mathrm{mal}$ so lang als d. Saum; Zpfl. wellig-nervig, lanzettl.; Stbg. gleichf.-eingefügt (Gay.); Zwiebel 1bth.; $B$. sich nach den Bth. entwickelnd, lineal.-lanzettl., stumpf, nach d. Basis verschmälert. 2. Wiesen d. Walliser A. Jul. Aug. Bth. fleischfarben.

\section{VERÁTRUM L. Germer.}

1. V. nigrum L. Tr. rispig, filzig; Zpfl. des $P$. elliptisch, ganzrandig, weit abstehend, so lang als die Bthstielchen; DeckB. kürzer als die Bthstielchen; die unteren B. breit-ellipt., kahl. 24. Gebirg., waldige O.; südl. Schwz., Siidtyr., Krain, Stmk., Oestr. Aug. Bth. schwarzpurp.

2. V. album L. Tr. rispig, flaumig; $Z p f$. des $P$. längl-lanzettl., gezähnelt, abstehend, viel länger als $d$. Bthstielchen; DeckB. länger als die Bthstielchen; $B$. ellipt. od. ellipt.-lanzettl., unterseits Haumig. 2. Wiesen d. A., VorA. u. höheren Gloge. Jul. Aug. Bth. grün, inwendig weissl. Var. $\beta .:$ Bth. inwendig hellgrün. V. Lobelianum Bernh. K. syu. ed. 1.

\section{TOFJELDIA Huds. Tofjeldie.}

1. T. c a lyculata Wahleub. Bthstielchen doppelt-deckblätterig; das eine DeckB. längl., die Basis des Bthstielchens stützend, das andere kelchf., 3lappig, der Bth. genähert; B. vielnervig, verschmälertselır spitz. 24. Sumpfige Wiesen; A. u. VorA., auch zerstr. im übrigen Geb. Jul. Aug. Anthericum calyculatum L. Bth. gelbl. Var. auf magerem Torfboden u. auf hohen Gbgn. mit einem kleinen, runden Bthenköpfchen: T. palustris $\gamma$. capitata Hoppe, T. glacialis Gaud.

2. T. borealis Wahlenb. Bthstielchen an der Spitze nackt, an der Basis mit einem einfachen, 3lappigen DeckB.; B. meist 3nervig, Nerven entfernt. 2. Moorige O. der höchst. A. Jul. Aug. T. alpina Hopp. u. Sternb. Anthericum calyculatum $\beta$. L. Bth. gelbl.

\section{Ordng. JUNCACEEN. Bartling.}

\section{JUNCUS I. Simse.}

I. Rotte. Die nicht blühenden Halme pfrieml. u. wie die blühenden knotenlos, an der Basis v. blattlosen od. blättertrag. Scheiden eingeschlossen. S. mit Anhängseln, die Samenhaut an beiden Enden in ein Säckchen erweitert. Spirre eigentlich endst., aber wegen des unteren, aufrechten, eine Fortsetzung des Halmes darstellenden Hüllblattes oft scitenständig erscheinend.

1. J. maritim us Lam. Halm nackt; WB. stielrund, stechend, knotenlos; Spirrc doppelt-zsgesetzt, aufrecht; Blätter des P. lanzettl., die äusseren spitz, die inneren stumpf, ganz; Kapsel elliptisch, sta- 
chelspitzig, so lang als das P. 24. Feuchte u. sumpfige O. am Meere. Jul. Aug.

2. J. a cutus I., var. $\alpha$. Halm nackt; WB. stielrund, stechend, knotenlos; Spirre mehrfach-zsgesetzt, geballt; die äusseren Blätter des P. lanzettl., ziemlich stumpf, gekielt, die inneren eyf., sehr stumpf, tief-ausgerandet; Kapsel rundl.-eyf., zugespitzt, noch einmal so lang als das P. 2. Feuchte, schlammige O. am Adriat. Meere. Mai. Jun.

3. J. J a cquin i L. Halm nackt, oberwärts 1 blätterig; wurzelst. Scheiden stachelspitzig; Köpfchen endst., 4-8bth., gestielt, v. dem HüllB. entfernt; Blätter des P. lanzettl., spitz, halb so lang als die ausgerandete Kapsel; Stbf. kaum halb so lang als das Stbk.; W. kriechend. 24. Feuchte O. der höheren A. Jun. Jul.

II. Rotte. Samen ohne Anhängsel. Das Uebrige wie bei der I. Rotte.

4. J. c onglomeratus L. Halm nackt, feingerillt, mit ununterbrochenem Marke angefüllt; wurzelst. Scheiden blattlos; Spirre seitenst., doppelt-zsgesetzt, gedrungen; Blätter des P. lanzettl., sehr spitz; Gf. fast fehlend; Kapsel vkteyf., gestutzt, mit der auf einer erhabenen Zitze sitzenden Basis des Gf. endigend. 2. Sumpfige u. feuchte O. Mai. Jun. 4 Wochen früher als J. effusus. Scheiden gelbbraun. Var.: L. Spirre ausgebreitet.

5. J. effu sus L. Halm nackt, ganz glatt, getrocknet feinrillig, mit ununterbrochenem Marke angefüllt, wurzelst. Scheiden blattlos; Spirre seitenst., doppelt-zsgesetzt, gedrungen; Blätter des P. lanzettl., sehr spitz; Gf. fast fehlend; Kapsel vkteyf., eingedrückt-gestutxt, mit der kurzen, in einem Grübchen sitzenden Basis des Gf. endigend. 4. Feuchte O. Jun. Jul. Scheiden gelb, braun. Var.: Spirre geknäuelt.

6. J. diffusus Hoppe. Halm nackt, feingerillt, mit. ununterbrochenem Marke angefüllt; wurzelst. Scheiden blattlos; Spirre seitenst., doppelt-zsgesetzt, gedrungen; Blätter des P. lanzettl., schr spitz; Gf. bemerklich; Kapsel vkteyf., stumpf, stachelspitzig. 4. Gräben; sehr zerstr. dch d. Geb. Jun. Jul. Scheiden schwarzpurp. Halm grasgrün.

7. J. gla ucus Exhrh. Halm nackt, tiefgerillt, mit fächerig-unterbrochenem Mark angefüllt; wurzelst. Scheiden blattlos; Spirre seitenst., doppelt-zsgesetzt, gedrungen; Blätter des P. lanzettl., sehr spitz; Gf. bemerklich; Kapsel längl.-elliptisch, stumpf, stachelspitzig. 4. Feuchte O. Jun.-Aug. Scheiden schwarzpurp.

8. J. paniculatus Hopp. Halm nackt, tief-gerillt, mit fächerig-unterbrochenem Marke angefüllt; wurzelst. Scheiden blattlos; Spirre seitenst., doppeltzsgesetzt, locker; die äusseren Aeste sprossend-verlängert; Bth. entfernt; Blätter des P. lanzettl., sehr spitz; Gf. be- 
merklich; Kapsel längl.-elliptisch, stumpf, stachelspitzig. 2. Ufer des Adriat. Meeres. Jul. Aug. Spirre strohgelb.

9. J. balticu s Willd. Halm nackt, ganz glatt, getrocknet schwach-rillig, mit ununterbrochenem Marke angefüllt; wurzelst. Scheiden blattlos; Spirre seitenst., doppelt-zsgesetzt; Blätter des P. eylanzettf., stachelspitzig, die inneren ziemlich stumpf; Gf. bemerklich; Kapsel elliptisch, stumpf, stachelspitzig. 4. Sandige, etwas feuchte 0. am Strande der Nord- u. Ostsee. Jul. Aug.

10. J. arcticus Willd. Halm nackt, ganz glatt, getrocknet schwach-rillig, steif-aufrecht; wurzelst. Scheiden blattlos; Spirre seitenst., kopfig, meist $7 \mathrm{bth}$.; Blätter des P. wehrlos, die äusseren lanzettl., spitz, die inneren eyf., ziemlich stumpf; Gf. bemerklich; Kapsel oval, stumpf, stachelspitzig. 4. Höchste AThäler, sehr selten, Breuil, Matterhorn, iiber Saas, See Mat-Mor der Wallis. A., Schlehern u. Doronthal im südl. Tyrol. Jun. Jul.

11. J. filif or mis L. Halm nackt, fädl., ïberhangend, glatt, getrocknet feingerillt; wurzelst. Scheiden blattlos; Spirre seitenst., meist 7bth.; Blätter des P. lanzettl., spitz; Gf. fast fehlend; Kapsel rundl., sehr stumpf, kurz-stachelspitzig. 24. Feuchte Wiesen der A. u. VorA. u. Niederungen des nördl. Gebietes, seltener im mittler. Jun. Jul.

III. Rotte. Nichtblühende Halme fehlend u. statt dieser nicht blühende Blätterbuischel. Bth. kopfig od. auf der Spitze des Halmes einzeln. S. mit einem Anhängsel.

12. J. stygius L. Halm 1-2blätterig; B. borstl., etwas zsgedrückt, oberseits rinnig; Köpfchen endst., meist einzeln, 3bth. od.zu 2 übereinanderstehend; Blätter des P. spitz, fast um die Hälfte kürzer als die längliche, spitze Kapsel; Stbf. viel länger als das Slbk.; W. faserig. $\odot$.? Sumpfige, moorige O., A. bei Einsiedeln im Cant. Schwyz, Algau, Kärnth., Niederungen bei Rothenbach in Oberbaiern. Jul. Aug.

13. J. castan eus Sm. Halm 2blättr.; WB. pfrieml, oberseits zieml. flach; Köpfchen endst., einzeln, zu 2 od. 3; Blätter des P. lanzettl., spitz, kürzer als die längl., stumpfe Kapsel; Stbf. noch einmal so lang als das Stbk.; $W$. ausläufertreibend. 4 .Feuchte AWiesen, u. Kiesplätze der höchsten A., Graubünd., Tyr., Salzburg, Steyermark, Kärnthen. Jul. Aug.

14. J. triglumis L. Halm nackt; WB. pfrieml., zieml. stielrund, an der Basis rinnig; Köpfchen endst., aufrecht, meist $3 b$ th.; Blätter des P. ziemlich stumpf, kürzer als die längliche, stumpfe, stachelspitzige Kapsel; Stbf. vielmal länger als das Stbk.; W. faserig. 24. Moorige O. der A. Jul. Aug.

15. J. trifidus L. Halm nackt, fädl., 1-3bth., an der Basis bescheidet; die oberste Scheide blatttragend; das B. sehr kurz, viel kürzer als der Halm, pfrieml., rinnig; am Ende des Halmes 2-3 
wechselständige, verlängerte, borstliche Hüllb.; Blatthäutchen 2öhrig, gewimpert-geschlitzt; P. so lang als die Kapsel; Kapselklappen eyf.; W. kriechend. 24. Feuchte O. der A.; Sudet. u. Mähr. Gbge. Jun. Aug. Die Stolonen haben lange B.

16. J. Hos ti i Tauscl. Halm nackt, fädl., 1-3btlı., an der Basis bescheidet; die oberste Scheide od. die 2 obersten blatttragend; $B$. verlängert, länger als die Hälfte des Halmes, borstlich, rinnig; am Ende des Halmes 2-3 wechselständige, verlängerte, borstliche HüllB.; Blatthäutchen 2öhrig, wimperig-geschlitzt; P. ungefähr so lang als die Kapsel; Kapselklappen eyf.-längl.; W. kriechend. 4. Feuchte O. der A. Jul. Ang. Auf Kalk. J. monanthos Jacq.

IV. Rotte. Nichtblühende Halme fehlend, statt dieser nichtblühende Blätterbüschel. Bth. in Köpfchen, die Köpfchen einzeln am Ende des Halmes, od. zu 2, eines über dem anderen, od. mehrere od. viele in einer Rispe. S. ohne Anhängsel.

17. J. capitatus Weigel. Halm nackt; WB. borstl, an der Basis rinnig; Köpfchen endst., einzeln od. ein zweites od. drittes gestieltes; Blätter des $P$. ey-lanzettf., zugespitzt-haarspitzig, länger als die eyf., stumpfe Kapsel. 2. Sandige, feuchte Aecker und Triften; zerstr. deh das Geb. Jun.-Aug.

18. J. obtu sifl o rus Ehrh. Halm 2-3blätterig, u. nebst den Scheiden u. B. stielrund, letztere fächerig-röhrig; Spirre endst., doppelt-zsgesetzt, spreitzend; die seitenständigen Aestchen zurückgebrochen; Blätter des $P$.gleich, abgerundet-stumpf, ungefähr so lang als die eyf., spitze Kapsel. 24. Gräben, Teiche; zerstr. dch das Geb. Jul. Aug. J. bifolius Hopp.

19. J. sylvaticus Reichard. Halm 2-3blätterig, nebst den Scheiden u. B. rundl.-zsgedrückt; $\mathrm{B}$. fächerig-röhrig, mit aussen deutlichen Querwänden, die Glieder glatt od. getrocknet sehr fein-gerillt; Spirre endst., doppelt-zsgesetzt, ausgesperrt; Blätter des P. zugespitzt-begrannt, die inneren länger, an der Spitze zurückgebogen, alle kürzer als die eyf., zugespitzt-geschnäbelte Kapsel. 24. Gräben, sumpfige O. Jul. Aug. J. acutiflorus Ehrh. Var. mit braunen od. schwärzlichen Köpfchen, u. $\beta$. macrocephalus: die Köpfchen noch einmal so gross, weniger zahlreich, auch die Bth. grösser; Kapsel v. der Länge des P. J. brevirostris N. ab E.

20. J. 1amprocarpus Ehrh. Halm 2-3blätterig, nebst den Scheiden u. B. rundl.-zsgedrückt; B. fächerig-röhrig, mit aussen knötigen Querwänden, die Glieder ausgetrocknet glatt od. sehr schwachgerillt; Spirre endst., doppelt-zsgesetzt, abstehend od. ausgesperrt; Blätter des $P$. gleich-lang, gerade, an der Spitze kurz-stachelspitzig, die äusseren spitz, die inneren stumpf, alle kürzer als die ey-lanzettf., stachelspitzige Kapsel. 24. Gräben, feuchte O. Jul. Aug. J. aquaticus Roth. J. articulatus $\alpha$. $\beta$. L. Var. mit strohgelben u. schwärz- 
lichen Köpfchen, u. $\beta$. fluitans: Halm in dem Wasser verlängert, fluthend; legt sich nieder und wurzelt, wenn das Wasser sich verliert.

21. J. a tratus Krocker. Halm 2-3blätterig, nebst Scheiden u. B. rundl-zsgedrückt; B. fächerig-röhrig, mit aussen undeutlichen Querwänden, die Glieder getrocknet tiefgerillt; Spirre endst., doppeltzsgesetzt, abstehend; Blätter des $P$. zugespitzt-begrannt, die inneren länger, an der Spitze etwas zurückgebogen, ungefähr von der Länge der eyf., zugespitzt-geschnäbelten Kapsel. 24. Gräben, Lachen in Schles. Jul. Aug. Die B. bei der lebend. Pfl. fein-gerillt, bei J. sylvaticus u. lamprocarpus ganz glatt.

22. J. alpinus Vill. Halm 2blätterig; Scheiden auf dem Rücken mit einer spitzen Kante bezeichnet; B. fächerig-röhrig; Spirre endst., zsgesetzt, aufrecht; Blätter des $\boldsymbol{P}$. gleichlang, abgerundetstumpf, kürzer als die eyf.-längl., stachelspitzige Kapsel, die äusseren unter der Spitze kurz-stachelspitzig. 24. Feuchte O. $\operatorname{der}$ A., VorA., auch d. Niederungen; zerstr. deh das Geb. Jul. Aug. J. fusco-ater Schreb. J. ustulatus Hopp. J. nodulosus Wahlenb.

23. J. su pinus Moench. Halm fädl.; B. fast borstl., oberseits schmal-rinnig, unterseits convex; Aeste der endst. Spirre verlängert, fast einfach; Köpfchen entfernt; Blätter des P. lanzettl., kürzer als die längl.; stumpfe, stachelspitzige Kapsel, die äusseren spitz, die inneren stumpf; Stbf. so lang als das Stbk. 24. Feuchte O. Jul. Aug. J. subverticillatus Wulf. Köpfchen oft schopfig. Var.: $\beta$. fluitans: Halme verlängert, fluthend. J. fluitans Lam. Im Wasser. $-\gamma \cdot r e$ pens: Halme liegend, wurzelnd. J. uliginosus Roth. Auf Schlamm, wenn das Wasser sich verliert. - $\delta$. nigritellus: Kapseln kürzer, an der Spitze etwas eingedrückt. J. nigritellus Koch syn. ed. 1.

V. Rotte. Die unfruchtbaren Halme fehlend, statt dieser Blätterbüschel. Bth. einzeln, entfernt od. ebensträussig u. eine endst. Rispe bildend. S. ohne Anhängsel.

24. J. squarrosus L. Halm etwas kantig, nackt, an d. Basis mit BScheiden umgeben; B. lineal., rinnig, abstehend, starr; Spirre endst., zsgesetzt, mit ebensträussigen Aesten; Blätter des P. ey-lanzettf., spitz od. etwas stumpf, so lang als die vkteyf., stumpfe, stachelspitzige Kapsel; Stbf. 4mal kürzer als das Stbk. 4. Haiden, torfige Wiesen; mittl. u. nördl. Geb. Jul. Aug.

25. J. compressus Jacq. Halm zsgedrückt, in der Mitte 1blätterig; die WurzelB. u. das stengelst. B. lineal., rinnig; Spirre endst., zsgesetzt; Aeste aufrecht; Aestchen ebensträussig; Blätter des $P$. eyf.-längl., sehr stumpf, fast um die Hälfte kürzer als die fast kugelige Kapsel; Gf. halb so lang als der Fruchtkn. 24. Feuchte Triften, Wege der Wiesen. Jul. Aug. J. bulbosus der Aut.

26. J. Gerardi Lois. Halm fast stielrund, in der Mitte 1blätterig; die WurzelB. u. das stengelst. B. lineal., rinnig; Spirre endst., 
zsgesetzt; Aeste aufrecht; Aestchen ebenstrüussig; Blätter des $P$. eyf.-längl., sehr stumpf, fast so lang als die längl.-ovale, etwas 3seitige Kapsel; Gf. so lang als der Fruchtkn. 24. Mecresufer u. feuchte, besonders salzhaltige $\mathrm{O}$. Jul. Aug. J. bottnicus Wahlenb. J. bulbosus I. nach Fries u. Meyer.

27. J. te $\mathrm{n}$ u is Willd. Halm ziemlich stielrund, nackt, an der Basis mit BScheiden eingeschlossen; $B$. lineal., rinnig, aufrecht; Spirre endst., zsgesetzt, gedrungen; Aeste trugdoldig, abstehend; Blätter des $\boldsymbol{P}$. lanzettl., verschmälert-spitz, 3nervig, ein wenig länger als die eyf.-längl. Kapsel; Stbf. länger als das Stbk. 24. Wege, Triften; Dickenreishausen in Oberşchwab., Oldesloe in Holst. Jun. Jul.

28. J. Tenageia Ehrh. Halm 1-2blätterig; B. borstl., an der Basis rinnig; Aeste der Spirre verlängert, 2sp., abstehend; Bth. einzeln, entfernt; Blätter des P. ey-lanzettf., spitz, stachelspitzig, so lang oder ein wenig länger als die rundliche, sehr stumpfe Kapsel. ○. Sandige feuchte O.; mittleres u. nördl. Geb., selten im südl. Jun. Jul.

29. J. sphaerocarpus Nees ab E. Halm 1-2blätterig; B. borstl., an der Basis rinnig; Aeste der Spirre verlängert, 2sp., aufrecht; Bth. einzeln, entfernt; Blätter des P. längl.-lanzettl., zugespitzt, stachelspitzig, bemerklich länger als die rundl., stumpfe Kapsel. $\odot$. Feuchte O.; Röhn, Heller, Umgegend v. Wien; Welwitsch. Jun. Jul.

30. J. bufonius L. Halm beblättert; B. borstl., an der Basis rinnig; Aeste der Spirre verlängert, 2sp., aufrecht; Bth. einzeln, entfernt; Blätter des P. lanzettl., zugespitzt, bemerklich länger als die längliche, stumpfe Kapsel. $\odot$. Feuchte O. Jul. Aug. Var. $\beta$. fasciculatus: St. niedriger, stärker; Bth. zu 2 od. 3, büschelig. J. mutabilis Sav. Rheinfläche zw. Mainz u. Worms.

2. LÚZULA DC. Hainsimse.

1. L. flavescens Gaud. Spirre doldig, einfach; Aeste abstehend, meist 1bth., die blïthen- u. fruchttragenden aufrecht; Anhängsel des S. sichelf.; die WB. lineal.; W. ausläufertreiberd. 2. VorA., Gbge. Jun. Jul. Juncus flavescens Host.

2. L. Forsteri DC. Spirre ebensträussig, einfach od. zsgesetzt, die blüthen- $u$. fruchttragenden Aeste aufrecht; Bth. einzeln; Anhängsel des S. gerade, stumpf; die WB. lineal.; W. rasig. 4. VorA. u. höhere Berge; zerstr. dch das Geb. Jun. Jul. Juncus Forsteri Sm.

3. L. pilosa Willd. Spirre ebensträussig, einfach; Aeste meist 3 bth., aufrecht, die oberen nach dem Verblühen zurückgebrochen; Bth. einzeln; Anhängsel des S. sichelf.; die WB. lanzettl. 2. Wälder. Apr. Mai. Juncus vernalis Ehrh. J. pilosus $\alpha$. L. Die Expl. mit 1 bth. Aesten v. I. Forsteri deh das sichelf. Anlängsel der S. verschieden. 
4. L. maxim a DC. Spirre melurfach-zsgesetzt, ausgesperrt, länger als die Hülle; Bthstiele an der Spitze 3 bth.; Blätter des P. stachelspitzig, ungefähr so lang als die Kapsel; Stbf. sehr kurz; B. lanzettl.-lineal., am Rande behaart. 2. Bergwälder, in die A. hinauf; südl. u. mittl. Geb. Mai. Jun. Junc. maximus Ehrh. J. pilosus $\delta$. L.

5. L. glabrata Hoppe. Spirre mehrfach-zsgesetzt, länger als die Hülle; die unteren Aeste iiberhangend; Bthstiele 1bth.; Blätter des P. ungefähr so lang als die Kapsel, stachelspitzig; Stbf. $6 \mathrm{mal}$ kürzer als das Stbk.; Gf. von der Länge des Fruchtkn.; B. lanzettl., kahl. 2. Triften der A., Kalkboden; Salzb., Tyrol, Steyermark, Oestr. Jun. Jul.

6. L. spadicea DC. Spirre mehrfach-zsgesetzt, länger als d. Hülle, abstehend; Bthstiele oberwärts schlärgelich, meist 4bth.; Blätter des P. ungefähr v. der Länge der Kapsel, stachelspitzig; Stbf. 4mal kürzer als das Stbk.; Gf. v. der Länge des Fruchtkn.; B. lineal. od. lanzettl.-lineal., an der Basis bärtig. 2. Triften der A. u. VorA.; Vogesen, Schwarzw., Sudet. Jun. Jul. Juncus spadiceus All.

7. L. albid a DC. Spirre mehrfach-zsgesetzt, abstehend, die Hülle nicht erreichend; Bthstiele meist 4bth.; Blätter des $P$. spitz, länger als die Kapsel; Stbk. fast sitzend; B. lineal., am Rarde behaart. 4. Wälder; v. den Ebenen bis in die A. hinauf. Jun. Jul. Juncus albidus Hoffm. Var. $\beta$. rubella: Bth. in das Kupferrothe spielend. L. albida b. cuprina Rochel.

8. L. nivea DC. Spirre doppelt-zsgesetzt, abstehend, die Hülls nicht erreichend; Bth. büschelig; Blätter des P. spitz, grannenlos, länger als die Kapsel; Stbf. v. der Lärge des Stbk.; B. lineal., am Rande behaart. 21. Thäler der A.; Schwz, Tyrol, bayer. A., Salzbg. Krain. Jun. Jul. Juncus niveus L. Bth. weiss.

9. L. lute a DC. Spirre doppelt-zsgesetzt, länger als die Hülle; Ebensträusschen gedrungen, zuletzt fast ährig-geballt; Blätter des P. stachelspitzig, so lang als die Kapsel; Stbf. halb so lang als das Stbk.; B. lanzettl.-lineal., ganz kahl. 24. Triften der A.; Schwz, Südtyrol. Jul. Aug. Juncus luteus All. J. campestris $\varepsilon$. L. Bth. gelb.

10. L. cam pestris DC. Aehren doldig, sitzend u. gestielt, letztere zuletzt etwas nickend; Blätter des P. zugespitzt, länger als die rundl., stumpfe, stachelspitzige Kapsel; die verblüheten Stbk. $3 \mathrm{mal}$ länger als ihr Träger; B. am Rande behaart, zuletzt kahl. 24. Haiden, unkult. O. März-Mai. Junc. campestris $\alpha$. L.

11. L. multiflor a Lejeun. Aehrer eyf., doldig, sitzend u. gestielt; Bthstiele steif; Blätter des $\mathrm{P}$. zugespitzt, stachelspitzig, länger als die rundl., stumpfe, stachelspitzige Kapsel; Sthf. ungefähr so lang als das Stbk.; B. am Rande behaart, zuletzt kahl. 4. Wälder, Haiden. Mai. Jun. L. erecta Desv. Juncus multiflorus'Ehrh. Aehren braun, gestielt. Var.: $\beta$. congesta : Aehren in ein lappiges Köpfchen zsgeballt. L. congesta Lej. Junc, cong. Thuill. $-\gamma$. nigricans: Aehren 
braun-schwarz. L. nigricans Desv. Junc. sudeticus Willd. Diese auf A. u. VorA., Sudet. - $\delta$. nivalis: Köpfchen lappig, schwarzbraun. L. campestris nivalis Wahlenbg. Die Variet. der L. multiflora sind noch weiter zu beobachten.

I2. L. s p i c a ta DC. Aehre längl., lappig, üherhangend; Blätter des $\mathbf{P}$. zugespitzt, länger als die rundlich-eyf., stachelspitzige Kapsel; B. rinnig, an der Basis behaart; Stbf. halb so lang als das Stbk. 4. Triften der A., Sudeten. Jun.-Aug. Junc. spicatus L.

CXXX. Ordng. CYPERACEEN. Juss.

I. Gruppe. CYPEREEN. Bth. zwitterig; Bälge 2reihig.

1. CYPÉRUS L. Cypergras.

1. C. flavescens L. Spirre zsgesetzt; Köpfchen rundl., gestielt u. sitzend; Aehrchen lanzettl., zsgedrückt-flach; Bälge längl.eyf., dicht-dachig; Narben 2 ; Nüsschen rundl.-eyf., zsgedrückt; Hülle meist 3 blätterig, länger als die Dolde; $W$. faserig. $\odot$. Feuchte Triften, nasse O. Jul. Aug. Bälge gelbl., Rüickenstreif grïn, vor der Spitze verschwindend.

2. C. fuscus L. Spirre fast doppelt-zsgesetzt; Köpfchen rundl., gestielt u. sitzend, auf der Spitze der längeren Aeste zu 2 od. 3; Aehren lineal., zsgedrückt-flach; Bälge längl.-eyf., zuletzt etwas abstehend $u$. etwas entfernt; Narben 3 ; Nüsschen elliptisch, nach beiden Enden verschmälert, scharf-3kantig; Hülle meist 3 blätterig, länger als die Dolde; W. faserig. $\odot$. Nasse, morastige O. Jul. Aug. Bälge schwarzbraun, Rüickenstreif grün in d. Spitze auslaufend. Var. $\beta$. virescens: Bälge blassgelb, mit braunem Rückenstreifen, od. bräunlich, der Kiel immer grün. C. virescens Hoffm.

3. C. esculentus L. Spirre doppelt-zsgesetzt; Aehren gestielt u. sitzend, an der Spitze der längeren Aeste zu 3 od. 5, die seitenst. gestielt, abstehend, die mittlere sitzend; Aehrchen lineal., zsgedriicktetwas gedunsen, ziemlich entfernt; Bälge eyf., stumpf, auf dem Rïcken gerillt; Narben 3; Hülle sehr lang; $W$. ausläufertreibend, mit an fädlichen Fasern hängenden quer-gestreiften Knollen. 24. In wärmeren Gegenden kultiv. Jul. Aug. Aehrchen strohgelb.

4. C. badius Desf. Spirre doppelt-zsgesetzt; Aehren gestielt $u$. sitzend, an der Spitze dev längeren Aeste zu $3 u$ u. 4, die seitenst. Aestchen in einem fast geraden Winkel ausgehend; Aehrchen lanzettl.-lineal., zsgedriickt; Bälge eyf., stumpf, auf dem Rücken gerillt; Narben 3 ; Nüsschen längl.-vkteyf., scharf-3kantig; Hülle sehr lang; W. kriechend. 24. Sumpfige 0 ; ; an den Bädern v. Burtscheid bei Aachen, im Schleidener Thale der Eifel. Jul. Aug. C. thermalis Dumort.

5. C. Iongus L. Spirre doppelt-zsgesetzt, die längeren Aeste an der Spitze doldig; Bthstiele der Döldchen aufrecht, ungleich, 
theils verlängert, theils kurz; Aehrchen lineal., flach-zsgedrückt; Bälge eyf., stumpf, auf dem Rücken rillig; Narben 3 ; Nüsschen längl.vkteyf., scharf-3kantig; Hülle sehr lang; $W$. kriechend. 24. Gräben, feuchte Wiesen; südl. Schweiz, Südtyrol, Littorale, Baden bei Wien, Lindau am Bodensee. Jul. Aug. Bälge röthlichbraun, Kiel grün.

6. C. Monti I. Spirre doppelt-zsgesetzt; Aehren gestielt u. fast sitzend, an der Spitze der längeren Aeste zu 3 u. 4; Achrchen fast rechtwinkelig-abstehend, verlängert-lanzettl., zsgedruickt, aber etwas gedunsen; Bälge eyf., stumpf, auf dem Rücken gerillt; Narben 2; Nüsschen vkteyf., zsgedrückt, mit abgerundeten Rändern; Hülle sehr lang; W. kriechend. 4. Sumpfige O., Gräben; sïdl. Schwz., Südtyr. Littor. Jul. Aug.

7. C. glomeratus L. Spirre doppelt-zsgesetzt; Aehren sehr gedrungen-zsgeballt, kugelig $u$. oval, sitzend u. gestielt, an der Spitze der längeren Aeste zu 3; Aehrchen lineal., sṕitz, zsgedrückt; Bälge lineal.; Narben 3 ; Nüsschen längl., 3kantig; Hülle sehr lang; $W$. kriechend. 24. Ufer des Meeres; bei Monfalcone, Sümpfe bei Grätz. Jul. Aug. C. australis Schrad.

2. SCHOENUS L. Knopfgras.

1. S. mucronatus L. Halm stielrund, nackt; Köpfchen endst., halbkugelig; Hülle 3-6blätterig, weit-abstehend; B. lineal., flach, etwas rinnig. 24. Meeresufer bei Aquileja. Jun. Jul.

2. S. nigricans L. Halm stielrund, nackt; Köpfchen aus 5-10 Aehrchen zsgesetzt, endst.; das äussere Hüllblättchen schiefaufstrebend; die unterweibigen Borsten meist fehlend; B. pfrieml., halb so lang als der Halm. 4. Torfige Wiesen; zerstr. deh das Geb. Mai. Jun. Aehrchen schwarz-braun.

3. S. ferrugineus L. Halm stielrund, nackt; Köpfchen aus 2-3 Aehrchen zsgesetzt, auf der Spitze des Halmes seitenst.; das äussere Hüllblättchen steif-aufrecht; unterweibige Borsten 3-5; B. pfrieml., viel kürzer als der Halm. 4. Torfige Wiesen; zerstr. deh das Geb. Mai. Jun. Aehrchen schwarz-braun.

II. Gruppe. SCIRPFEN. Bth. zwitterig; Bälge v. allen Seiten her dachig-aufeinandergelegt.

3. CLÁDIUM Patrick Brown. Sumpfgras.

1. C. Mariscus R. Brown. Spirren doppelt-zsgesetzt, eine am Ende, die übrigen seitenst.; Aehrchen kopfig-geknäuelt; Halm stielrund, glatt, beblättert; Ränder u. Kiel der B. rauh. 2. Gräben, Sümpfe, stehende Wasser; zerstr. dch das Geb. Jul. Aug. Schoenus Mariscus L. Cladium germanicum Schrad.

4. RHYNCHOSPORA Vahl. Schnabelsame.

1. Rh. alb a Vahl. Aehrchen fast ebensträussig-geknäuelt, Büschel 
ungefähr so lang als die Hülle; unterweibige Borsten 10, v. der Länge der Nuss; W. faserig. 2. Sumpfige, torfige O. Jul. Aug. Schoenus albus L. Aehrchen während der Bthezeit weiss.

2. Rh. fusca R. u. Schult. Aehrchen kopfig-geknäuelt, Büschel vielmal kürzer als die Hülle; unterweibige Borsten 3 , noch einmál so lang als die Nuss; W. kriechend. 2. Torfige Wiesen; zerstr. deh das Geb. Jun. Jul. Schoenus fuscus L. Aehrchen während der Bthezeit braun.

\section{HELEÓCHARIS R. Brown. Teichbinse.}

1. H. palustris R. Brown. Aehrchen enảst., einzeln, längl.; Bälge ziemlich spitz, der unterste nicht über die folgenden hinausragend, das halbe Achrchen umfassend; Narben 2; Nuss vkt-eyf., zsgedrückt, glatt, an den Rändern abgerundet-stumpf; Halm stiel.. rund, etwas zsgedrückt; W. kriechend. 24. Sümpfe, Gräben, nasse O. Juu.-Aug.

2. H. unig lumis Link. Aehrchen endst., einzeln, längl.; Bälge ziemlich spitz, der unterste nicht iiber die folgenden hinausragend, rundl., das Aehrchen ganz umfassend; Narben 2; Nuss vkteyf., zsgedrückt, glatt, an den Rändern abgerundet-stumpf; Halm stielrund; W. kriechend. 4. Sumpfige u. feuchte O. Jun.-Aug. Nüsse bräunl.

3. H. multicaulis Lindl. Aehrchen endst., einzeln, längl.; Bälge abgerundet-stumpf, der unterste nicht iiber die folgenden hinausragend, rundl., das Aehrchen ganz umfassend; Narben 3; Nuss längl.-vkteyf., scharf-3kantig, glatt; Halm stielrund; W. faserig. 4 . Torfige, sumpfige O.; Westph., Holst. Jul. Aug. Nïsse schwarzbraun. Scirpus multicaulis Sm.

4. H. o va ta R.Brown. Aehrchen endst., einzeln, rundI. od. breit-eyf.; Bälge breit-eyf., abgerundet-stumpf, der unterste nicht ïber die folgenden hinausragend; Narben 2; Nuss vkteyf., zsgedrïckt, glatt, scharf-berandet; Borsten anderthalbmal so larig als die Nuss; Halm stielrund, getrocknet fein-gerillt; W. faserig. $\odot$. Am Rande stehender Wasser u. an überschwemmt gewesenen O. Jun. Jul. Scirpus capitatus Schreb. Nüsse strohgelb.

5. H. atropurpurea Kunth. Aehrchen endst., einzeln, eyf., Bälge längl.-eyf., abgerundet-stumpf, der unterste nicht iiber die folgenden hinausragend; Narben 2; Nuss vkteyf., zsgedrückt, glatt; Borsten etwas kürzer als die Nuss; Halm stielrund, getrocknet tief-gerillt. $\odot$. Sandplätze am Genfersee zw. Lausanne u. Morges an einem Orte, Pierettes genannt. Jul. Aug. Scirpus atropurpureus Retzius nach Gay. S. Lereschii Thomas. Nüsse bei der Reife schwarz.

6. H. a cicularis R. Brown. Aehrchen endst., einzeln, eyf.; Bälge eyf., stumpf, der unterste nicht tiber die folgenden hinaufragend; Narben 3; Nuss längl., fein-vielrippig; Halm gefurcht-4seitig; W. 
kriechend. $\odot$. Sumpfige O. u. am Rande stehender Wasser. Jun.Aug. Scirpus acicularis L.

\section{SCIRPUS L. Binse.}

I. Rotte. Aehrchen endst., einzeln an Ende des Halmes od. der Halmäste, aber die Aeste nicht rispig.

1. S. ca espitosus L. Halm stielrund, an der Basis bescheidet; die oberste Scheide in ein kurzes B. endigend; Aehrchen endst., einzeln, eyf.; Bälge stumpf, der unterste grösser, ungefähr so lang als das Aehrchen u. dieses umfassend, stachelspitzig; Stachelspitze ziemlich dick, fast blattig; Narben 3; Nuss 3seitig, glatt; Borsten länger als die Nuss. 24. Torfige O. der A., VorA. u. höheren Gbge u. Niederungen längs der A., u. im nördl. Geb. Mai. Jun.

2. S. alpinus Schleicher. Halm stielrund, an der Basis bescheidet, die oberste Scheide in ein kurzes B. endigend; Aehrchen endst., einzeln, eyf.; Bälge stumpf, der unterste nicht grösser, das Aehrchen mit seiner Basis halbumfassend, stachelspitzig, die Stachelspitze sehr kurz, dicklich; Narben 3; Nuss 3seitig, glatt, ohne Borsten. 2. Nasse $O$. der höchsten A. bei Zermatten in der Schwz. Jul. Aug.

3. S. pauciflorus Lightfoot. Halm stielrund, an der Basis bescheidet; Scheiden blattlos; Aehrchen endst., einzeln, eyf.; Bälge stumpf, grannenlos, der unterste grösser, das Aehrchen umfassend, mit einem vor der Spitze sich verlierenden Nerven dchzogen; Narben 3 ; Nuss 3seitig, glatt; Borsten ein wenig kürzer als die Nuss. 4. Torfige u. feuchte O. Jun. Jul. S. Baeothryon Ehrh.

4. S. parvulus R. u. S. Halm stielrund, inwendig querwandig; Scheiden sehr dünn-häutig, hlattlos; Achrchen endst., einzeln, eyf.-längl.; Bälge stumpf, wehrlos; Narben 3; Nuss 3seitig, glatt; Borsten länger als die Nuss. $\odot$. Feuchte O., Elbufer bei Hamburg, am siissen u. salzigen See im Mansfeld., Monfalcone im Litt. JuI. Aug. S. nanus Wallr.

5. S. fluitans L. Halm gestreckt od. fluthend, ästig, beblättert, an der Basis wurzelnd; Aeltrchen auf der Spitze der blattwinkelst. Bthstiele einzeln; Narben 2; Nuss zsgedrückt, mit spitzem Rande, ohne Bursten. 24. Sümpfe, stehende Wasser; v. Niederrhein dch das nördl. Geb. bis Mecklenb. Jul.-Sept.

II. Rotte. Spirre trugseitenst., indem das grössere Hüllblatt sich aufrichtet $u$. eine Fortsetzung des Halmes darstellt. Aehrchen 2 , mehrerc in ein einzelnes Büschel gehäuft, od. viele einzeln am Ende der Rispenäste od. daselbst büschelig-gehäuft; B. der Hülle u., wenn sie vorhanden sind, des Halmes, halbstielrund od. 3kantig-rinnig.

* Bälge an der Spitze ganz, stachelspitzig. 
6. S. setace us L. Halm stielrund; Achrchen cinzeln, gezweiet od. gedreiet, trug-seitenst.; das HüllB. vielmal kürzer als der Halm, aufrecht, zuletzt etwas zurückgebogen; Bälge stumpf, stachelspitzig; Narben 3 ; Nuss zsgedriickt, längsrippig; Borsten fehlend. $\odot$, nach Wahlenb. 24. Feuchte O., Ufer. Jul. Aug.

7. S. supinus L. Halm stielnund; Aehrchen in ein Büschel gehäuft, sitzend, trug-seitenst.; das HïllB. aufrecht, ungefähr so lang als d. Halm; Bälge stumpf, fein stachelspitrig; Narben 3; Nuss 3seitig, quer-runzelig; Borsten fehlend. $\odot$. Nasse 0 ., Ufer; selten u. sehr zerstr. dch d. Geb. Jul. Aug.

8. S. mucronatus L. Halm 3kantig; Aehrchen in ein Büschel gehäuft, sitzend, trug-seitenst.; das grössere HïllB. aufrecht, zuletzt wagerecht-zurückgeschlagen; Bälge stumpf, stachelspitz.; Narben 3; Nuss 3seitig, quer-runzelig; unterweibige Borsten rïckwärts feinstachelig. 24. Stehende Wasser; Littor., Krain, Kärnth., Stmk. und ausserdem sehr zerstr. deh das südl. u. mittl. Geb. Jul. Ang.

* Bälge an der Spitze mit einer Stachelspitze ausgerandet.

9. S. lacustris L. Halm stielrund; Spirre zsgesetzt, trug-seitenst.; das grössere HiillB. aufrecht; Aehrchen büschelig-gehäuft; Büschel gestielt u. sitzend; Bälge glatt, fransig, mit einer Stachelspitze ausgerandet; Narben 3 ; Nuss 3 seitig, glatt; unterweibige Borsten rückwärts fein-stachelig. 4. Stehende u. langsam fliesende Wasser. Jun. Jul.

10. S. Taberna emontani Gmel. Halm stielrund; Spirre zsgesetzt, trug-seitenst.; das grössere HüllB. aufrecht; Aehrchen büschelig-gehäuft; Büschel gestielt u. sitzend; Bälge punktirt-rruh, fransig, mit einer Stachelspitze ausgerandet; Narben 2; Nuss fast 3seitigconvex, glatt; unterweibige Borsten rückwärts fein-stachelig. 24. Stehende Wasser. Jun. Jul.

11. S. D uvali i Hoppe. Halm unterwärts stielrund, in dev Mitte 3seitig, Kanten stumpf, zwei von d. Seiten ziemlich convex, die dritte flach; Spirre zsgesetzt, trug-seitenst.; das grössere HüllB. aufrecht; Aehrchen büschelig-gehäuft; Büschel gestielt u. sitzend; Bälge glatt, fransig, mit einer Stachelspitze ausgerandet; Narben 2; Nuss glatt, auf dem Rïcken convex; unterweibige Borsten rückwärts fein-stachelig. 24. Ufer d. Seen u. Flüsse; sehr zerstr. dch d. Geb. Jun. Jul. S. trigonus Nolte, K. syn. ed. 1. S. carinatus Sm.

12. S. Iittoralis Schrad. Halm 3 kantig; Spirre zsgesetzt, trugseitenst.; das grössere HüllB. aufrecht; Aehrchen einzeln, gestielt u. sitzend; Bälge ganzrandig, etwas gezähnelt, an der Spitze mit einer Stachelspitze ausgerandet; Narben 2; Nuss glatt, auf dem Ruicken convex; unterweibige Borsten pinselig-federig, Haare aufrecht, gegliedert. 2. Am Ufer des Meeres; bei Duino u. Monfalcone. Jun. Jul.

13. S. triqueter L. Halm 3kantig; Spirre zsgesetzt, trugsei- 
tenst.; das grössere HüllB. aufrecht; Achrchen eyf., büschelig-gehäuft; Büschel gestielt $u$. sitzend; Bälge am Rande fransig, mit einer Stachelspitze ausgerandet, Läppchen stumpf; Narben 2; Nuss glatt, auf dem Rücken convex; unterweibige Borsten rückwärts fein-stachelig. 24. Ufer, Gräben; zerstr. deh d. Geb. Jul. Aug. S. trigonus Roth. n. Beitr.

14. S. Rothii Hoppe 1814. Halm 3kantig; Spirre geknäuelt, trug-seitenst.; das grössere HüllB. aufrecht; Aehrchen alle sitzend, eyf.-längl.; Bälge am Rande fransig, mit einer Stachelspitze ausgerandet, Läppchen spitz; Narben 2; Nuss glatt, auf dem Rücken convex; unterweibige Borsten 2- od. 3mal kürzer als die Nuss. 2. Ufer; am Ausflusse d. Weser, an d. Elbe, im Holst. u. bei Hambg., Rheininseln im Breisgau, Schwz. sehr selten. Jul. Aug. S. triqueter Roth. n. Beitr. S. pungens Vahl. 1827. K. syn. ed. 1.

III. Rotte. Spirre trug-seitenst., aus kugeligen, dicht zsgeballten Köpfchen zsgesetzt. Holoschoenus Link.

15. S. Holos cho enus L. Haln stielrund; Spirre trug-seitenst.; das grössere HüllB. aufrecht, verlängert; Köpfchen dicht-zsgeballt, kugelig, sitzend u. gestielt; Bthstiele einfach od. zsgesetzt; Bälge abgeschnitten, stachelspitzig; Narben 3; Nuss kahl; Borsten fehlend; B. halbstielrund, rinnig. 2. Feuchte O., Ufer; südl. Schwz., Südtyr., Littor., Elbe in Böhm. u. bei Barby, Oder in Schles. u. bei Frankf., bei Werder hinter Potsdam. Jul. Aug. $\alpha$. vulgaris: Halm höher, 2-3 Fuss lang; Spirre zsgesetzt. S. Holoschoenus L. - $\beta$. australis: Halm niedriger, dümner; Köpfchen klein, ungefähr erbsengross, ein einzelnes sitzend $u$. wenige gestielt. S. australis L. $-\gamma$ romanus: Halm niedriger; Köpfchen grösser, v. d. Grösse einer Haselnuss, einzeln od. mit 1 od. 2 gestielten kleineren gestützt. S. romanus L.

IV. Rotte. Spirre endst., zsgesetzt. B. des Halmes und der Hülle grasartig.

16. S. maritimus L. Halm 3 kantig, beblättert; Spirre zsgesetzt; Aehren büschelig, gestielt u. sitzend; Hülle flachblätterig; Bälge an der Spitze stachelspitzig u. 2sp., Läppchen spitz, gezähnelt; Narben 3 ; unterweibige Borsten rückwärts steifhaarig. 24. Meeresstrand, Ufer, Gräben. Jul. Aug. $\beta$. compactus: Aehrchen alle sitzend, geknäuelt. Scirpus compactus Krock. $-\gamma$. macrostachys: Aehrchen 1" lang. S. macrostachys Willd.

17. S. sylvaticus L. Halm 3kantig, beblättert; Spirre ebensträussig, mehrfach-zsgesetzt; Aehrchen büschelig; Büschel gestielt u. sitzend; Hülle flachblätterig; Bälge stumpf, fein-stachelspitzig; Narben 3; unterweibige Borsten gerade, rückwärts steifhaarig. 4 . Feuchte Wiesen, Ufer. Jun. Jul.

18. S. radicans Schkuhr. Halm 3 kantig, beblättert; Spirre eben- 
sträussig, mehrfach-zsgesetzt; Aehrchen alle gestielt; Hülle flachblätterig; Bälge stumpf, wehrlos; Narben 3; unterweibige Borsten zsgedreht, glatt. 2. Sumpfige Wiesen $u$. O., welche im Winter unter Wasser stehen, schlammige Ränder v. Pfützen u. Teichen; nördl. u. östl. Geb., selt. in d. Rheinpfalz, Trier. Jul. Aug.

19. S. M i ch elianus L. Halm $3 \mathrm{kantig}$, beblättert; das Köpfchen endst., rundlich, lappig; Hülle flachblätterig; Bälge lanzettl., in eine etwas abstehende Stachelspitze verschmälert; Narben 2 ; unterweibige Borsten fehlend. $\odot$. Feuchte O., Flussufer; Littor., Mähr., Schles., Wittenberg. Jul. Aug.

V. Rotte. Aehrchen in eine endst. Aehre geordnet, 2reihig, genähert, einzeln. Blysmus Panzer.

20. S. compressus Pers. Halm undeutl.-3seitig; Aehre 2zeilig; Aehrchen 6-8bth.; B. unterseits gekielt; Borsten rückwärts stachelig. 4. Wiesen u. feuchte Triften. Jul. Aug. Schoenus compressus L.

21. S. rufus Schrad. Halm stielrund; Aehre 2zeilig; Aehrchen 2-5bth.; B. kiellos; Borsten aufrecht-flaumhaarig od. fehlend. 4. Meeresstrand, salzhalt. Wiesen; Berlin, Halle. Jun. Jul.

7. FIMBRÍSTYLIS Vahl. Fransenbinse.

1. F. dichotoma Vahl. Halm fast 3 seitig, beblättert; B. Alach, ungefähr so lang als der Halm; Dolde aus zahlreichen Aehrchen zsgesetzt; Aehrchen eyf. -längl., gestielt, einzeln, d. mittelpunktst. sitzend; Bälge stachelspitzig; Narben 2; Nuss längsrippig, mit querrunzeligen Furchen. $\odot$. Nasse $\mathrm{O}$.; Südtyrol u. wohl auch im C. Tessin. Jun.-Aug. Scirpus dichotomus L. Der Standort dieser Art ist noch näher zu ermitteln.

2. F. annu a Röm. u. S. Halm fast 3seitig, beblättert; B. flach, kürzer als d. Halm; Dolde fast einfach; Aehrchen meist 5 , eyf., das mittelpunktst. sitzend; Bälge stachelspitzig; Narben 2; Nuss längsrippig; Furchen quer-runzelig. $\odot$. Feuchte O.; Südtyr. zw. Botzen u. Meran, Link rgb. bot. Ztg. 1827. p. 29., u. südl. Schwz. Jul. Aug. Scirpus annuus All.

\section{ERIÓPHORUM L. Wollgras.}

I. Rotte. Trichophorum Pers. Unterweibige Borsten 4-6, nach vollendeter Bthezeit in eine kräuslich-schlängeliche Wolle verlängert.

1. E. a lp in u m L. Halm 3kantig, rauh; Aehrchen einzeln, längl. 4. Torfige O.; A., VorA., höhere Gbge, Flächen längs d. A. u. des nördl. Geb. Apr. Mai.

II. Rotte. Eriophor u m Pers. Unterweibige Borsten zahlreich, nach vollendeter Bthezeit in eine gerade Wolle verlängert. 
2. E. vagin a tu m L. Halm kahl, oberwärts 3seitig; B. am Rande rauh; Aehrchen einzeln, längl.-eyf.; W. faserig. 24. Torfsümpfe. Apr. Mai.

3. E. Scheuchzeri Hoppe. Halm stielrund, kahl; B. kahl; Aehrchen einzeln, längl.-eyf.; W. ausläufertreibend. 2. Tarfige 0 . der höheren A. Jun. Jul. E. capitatum Host.

4. E. latifolium Hoppe. Halm fast 3seitig; B. flach, an der Spitze 3kantig; Aehrchen sehr viele; Bthstiele rauh. 24. Sumpfige Wiesen. Apr. Mai. E. polystachyum $\beta$. L. E. pubescens Smith.

5. E. angustifoli um Roth. Halm ziemlich stielrund; B. lineal.rinnig, an der Spitze 3kantig; Aehrchen mehrere; Wolle 3 mal so lang als das Aehrchen; Bthstiele glatt. 24. Sumpfige Wiesen. Apr. Mai. E. polystach. $\beta$. L. Aehre mit der Wolle $1^{1} / 2^{\prime \prime}$ lang. E. polystachyum Smith. Var. $\beta$. elatius: B. an $3^{\prime \prime \prime}$ breit. E. angustif. Iongifol. Hopp. $-\gamma$. minus: spannelang, die B. fast nur aus der 3eckigen Spitze bestehend.

6. E. Vaillantii Poiteau u. Turpin. Halm stumpf-3kantig; Bl. schmal-lineal., unterwärts rinnig, oberwärts 3kantig; Aehrchen mehrere; Wolle 4 mal so lang als das Aehrchen; Bthstiele glatt. 24. Sumpfige

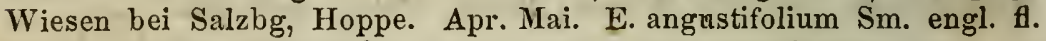
Aehre mit der Wolle $1^{3} / \mathbb{4}^{\prime}$ lang. E. angustifolium Smith.

7. E. gracile Koch. Halm undeutlich-3seitig; B. 3kantig; Aehrchen mehrere; Bthsticle filzig-rauh. 2. Moorige, torfige Sümpfe. Mai. Jun. E. triquetrum Hopp.

III. Gruppe. CARICEEN. Bth. eingeschlechtig.

9. ELÍNA Schrad. Elyne.

1. E. spicata Schrad. 4. Höchste A. Jun. Jul.

10. KOBRÉSLA Willd. Kobresie.

1. K. caricina Willd. 2. Höchste A., nahe an den Gletschern; Schwz., Tyr., Kärnth. Aug. Carex mirabilis Host.

11. CAREX L. Segge.

I. Rotte. Ps yllophorae Lois. Flohseggen. Aehrchen einzeln auf d. Spitze des Halmes. Granne an d. Fruchtbasis fehlend.

a. Narben 2 ; Aehrchen 2 häusig.

1. C. dioica L. Das Aehrchen endst., einzeln, 2häusig; Narben 2 ; Frïchte ziemlich aufrecht, eyf., vielnervig, oberwärts am Rande rauh; B. u. Halme kahl; W. Ausläufer treibend. 2. Sumpfige Wiesen in die VorA. hinauf; zerstr. dch das Geb. Apr. Mai. C. Linnacana Host. Kommt vor mit mannweibigen Aehrchen: C. Metteniana C. B. Lehmanu.

2. C. Davallian a Sm. Das Aehrchen endst., einzeln, 2häusig; 
Narben 2; Früchte zurückgekrümmt-abstehend, längl.-lanzettl., feinvielnervig, oberwärts am Rande etwas rauh; B. am Rande nebst den Halmen rauh; W. faserig. 24. Torfige Wiesen. Apr. Mai. Die männl. Pfl. kommt mit oberwärts weibl. Aehre vor: C. Sieberiana Opitz.

b. Narben 2; Aehrchen mannweibig.

3. C. pulicaris L. Das Aehrchen endst., einzeln, mannweibig, oberwärts männl.; Narben 2; Früchte entfernt, längl., nach beiden Enden verschmälert, nervenlos, zurïickgebogen; Bälge abfälig; $\mathbf{B}$. borstlich. 2. Feuchte Wiesen; zerstr. dch das Geb. Mai. Jun.

4. C. capitata L. Das Aehrchen endst., einzeln, mannweibig, oberwärts männl., rundl.-eyf.; Narben 2; Frïchte dicht-gedrungen, eyf., zugespitzt, flach-zsgedrückt, ganz glatt, nervenlos, auf dem Rücken ein wenig convex, länger als der bleibende Balg. 24. Moorige Wiesen; Oberbaiern, Oberschwab., Tyr. Mai.

c. Narben 3.

5. C. o btus at a Liljeblad. Das Aehrchen endst., einzeln, lineal., mannweibig, oberwärts männl.; Narben 3; Früchte länger als der Balg, eyf. od. elliptisch, gedunsen, glänzend, in einen stielrunden, glatten, an d.Spitze weissen u. durchscheinenden zweispaltigen Schnabel zugespitzt; B. lineal., flach. 24. „Auf einem sandigen Waldhügel, den Bienitz, 2 Stunden von Leipzig, von mir zuerst wiedergefunden" Kunze; auf dem Zettelchen der mitgetheilten Pfanze. Apr. Mai. C. spicata Schk.

6. C. rupestris All. Das Aehrchen endst., einzeln, lineal., mannweibig, oberwärts märınl.; Narben 3 ; Früchte vkteyf., sehr kurz-geschnäbelt, mit gestutztem Schnabel, zsgedriickt-3kantig, kürzer als der bleibende Balg, dachig; B. lineal., flach. 2. Felsen d. A.; Wallis, Siidtyrol, Glockner, rothe Berg im Gesenke in Schles. Jul, Aug.

7. C. pau ciflor a Lightf. Das Aehrchen endst., einzeln, mannweibig, meist 4bth.; männl. Bth. endst., meist einzeln; Narben 3; Früchte lanzettl.-pfrieml., stielrund, zurückgebogen; weibliche Schuppen hinfällig. 24. Torfige Wiesen; zerstr. deh das Geb. Jun. Jul. C. leucoglochin L. fil.

II. Rotte. Orth o c erate's. Geradhörnige. Aehrchen endst., einzeln. Eine fädlich-pfrieml. Granne an der vorderen Basis der Nuss, welche aus einem fehlgeschlagenen Aehrchen entstanden.

8. C. microglochin Wahlenb. Das Aehrchen endst., einzeln, mannweibig, meist 10bth.; männl. Bth. meist 6, endst.; Narben 3; Früchte lanzettl.-pfrieml., zsgedrückt-stielrund, zurückgebogen; die grundst. Granne gerade, länger als die Hautfrucht. 4. Moorige Sümpfe; Wallis, Oberbaiern, Südtyrol. Mai-Jul., in den A. später.

III. Rotte. Cyperoideae. Cypergrasartige. Aehrchen in ein 
rundliches od. lappiges Köpfchen geballt, welches an d. Basis mit einer 2-3blätterigen, verlängerten Hülle umgeben ist. Pflanzen von dem Ansehen eines Cyperus.

a. Narben 2. Aehrchen an der Basis männlich.

9. C. cyperoides L. Das Aehrchen mannweibig, unterwärts männl., in ein kugeliges, mit einer meist 3blätterigen, verlängerten Hülle umgebenes Köpfchen zsgeballt; Narben 2; Früchte lanzettl., sehr lang-geschnäbelt, doppelt-haarspitzig; W. faserig. 2. See- u. Sumpfränder; zerstr. dch das südl. u. mittl. Geb. Aug. Sept.

b. Narben 3. Aehrchen an der Spitze männl.

10. C. baldensis L. Aehrchen mannweibig, oberwärts männl., meist 3 , in ein lappiges, an der Basis mit einer 2blätterigen, wagerecht-abstehenden Hülle umgebenes Köpfchen gehäuft; Narben 3; Früchte walzl.-längl., stumpf, sehr kurz-geschnäbelt. 24. VorA. bei Partenkirchen in Oberbaiern, Schongau; südl. Tyrol weit verbreitet, Facchini; Schwz in d. Egina, Zehnden-Gombs, Lagger. Jun.Aug. Köpfchen weiss.

IV. Rotte. Vignea e. Vigneen. Aehrchen mannweibig, in eine ununterbrochene oder unterbrochene Aehre geordnet, mit einem DeckB. gestuitzt, von denen das unterste oft in ein BlüthenB. übergeht.

a. Narben 3. Aehrchen oberwärts männl.

11. C. gynomane Bertol. Aehrchen mannweibig, 2-4, oberwärts männl., entfernt, lockerbth., das untere oft gestielt; DeckB. blattig, das unterste länger als der Halm; Narben 3; Früchte entfernt, ellipt., geschnäbelt, 2nervig, Schnabel an d. Spitze häutig, ungeth. od. kurz-2lappig. 2. Gebirg O..; Istrien u. auf. d. Inseln. Apr. Mai. C. Linkii Schk.

12. C. curvula All. Aehrchen mannweibig, oberwärts männl., angedrückt $u$. in ein längliches Köpfchen sehr gedrungen-gehäuft; Narben 3; Früchte längl., 3kantig, in einen an der Spitze häutigen, 2lappigen, unter d. Spitze am Rande rauhen Schnabel verschmälert; W. faserig, dichtrasig. 4. Grasige O. der A. Jul. Aug.

b. Narben 2. Aehrchen oberwärts männlich.

*Wurzel lange Ausläufer treibend.

13. C. inc urva Lightf. Aehrchen mannweibig, oberwärts männl., in ein rundl.-cyf. Köpfchen gehüuft; Narben 2; Früchte aufgeblasen, höckerig-convex, zugespitzt-geschnäbelt; Schnabel glatt, an der Spitze schief-abgeschnitten; Halm glatt, einwärtsgebogen, so lang als die B.; W. lange Ausläufer treibend. 24. Glimmerboden d. höchsten GranitA.; Schwz, Tyr. Jul. Aug. C. juncifolia All.

14. C. chord or rhiz a Ehrh. Aehrchen mannweibig, oberwärts 
männl., in ein eyf. Köpfchen gehäuft; Narben 2; Früchte eyf., nervig-rillig, in einen am Rande glatten, an $d$. Spitze trockenhäutigen, kurz-2lappigen Schnabel zugespitzt; Halm glatt, an der Basis ästig, viel länger als die B.; W. lange Ausläufer treibend. 24. Tiefe Sümpfe u. morastige O.; nördl. Geb., Oberbaiern, Oberschwaben, Rheinpfala, Schles., Waadt, Zürich. Mai. Jun.

15. C. sten ophylla Wahlenb. Aehrchen mannweibig, oberwärts männl., in ein eyf. od. längl. Köpfchen gehäuft; Narben 2; Früchte eyf., auf dem Rücken convex, 9-11nervig, in einen an der Spitze weissl.häutigen, auf der Rückenseite ausgerandeten, am Rande feingesägt-rauhen Schnabel zugespitzt; Bälge spitz; Halm glatt, an der Spitze etwas rauh; W. Ausläufer treibend. 24. Grasige Hügel, Wiesen ; Holst., Böhm., Mähr., Unteröstr. Apr. C. juncifolia Host.

16. C. divisa Hudson. Aehre zsgesetzt, eyf. od. längl.; Aehrchen längl., gedrungen, oberwärts männl.; Narben 2; Früchte breit-eyf., auf dem Rücken convex, 3-11nervig, in einen tief u. spitz-2sp., am Rande feingesägt-rauhen Schnabel zugespitzt; Bälge so lang als d. Frucht; Halm an der Spitze etwas rauh; W. Ausläufer treibend. 4. Wiesen, feuchte O.; Unteröstr., Littor. Mai. Jun. C. schoenoides u. divisa Host. C. lobata, Bertolonii u. austriaca Schk. Kommt vor mit einer längl., etwas unterbrochenen Aehre u. eyf.-gedrungener; letztere C. schoenoides K. syn. ed. 1 .

17. C. dis tich a Huds. Aehre doppelt-zsgesetzt., längl., gedrungen, od. unterwärts unterbrochen; die obersten $u$. untersten Aehrchen weibl., die mittleren männl.; Narben 2; Früchte eyf., flach-convex, 9-11nervig, mit einem schmalen, feingesägt-rauhen Rande umgeben, in einen 2zähnigen Schnabel zugespitzt, länger als der Balg; Bälge spitz, mit einem vor der Spitze verschwindenden Nerven; Halm an den Kanten rauh; W. Ausläufer treibend. 4. Feuchte Wiesen. Mai. Jun. C. intermedia Good.

18. C. a renaria L. Aehre doppelt-zsgesetzt, längl. od. fast eyf., gedrungen od. unterwärts unterbrochen; die oberen Aehrchen männl., die unteren weibl., die mittleren an d. Spitze männl.; Narben 2; Früchte eyf., flach-convex, 7-9nervig, von der Mitte an mit einem verbreiterten, feingesägt-rauhen, an dem 2 sp. Schnabel hinaufziehenden Flügel eingefasst; Bälge zugespitzt, so lang als die Frucht; Halm oberwärts auf den Kanten rauh; W. Ausläufer treibend. 24. Sandige 0. am Meere; von Norden landeinwärts bis Magdeburg u. Osnabrïck. Mai. Jun.

** W. einen dichten Rasen von Blättern u. Halmen, aber keine od. sehr kurze Ausläufer treibend.

19. C. foetida All. Aehrchen mannweibig, oberwärts männl., in ein rundl.-eyf. Köpfchen gehäuft; Narben 2; Früchte aufrecht, eyf., schwach-nervig, in einen langen, an der Spitze zweispaltigen, 
am Rande fein-gesägt-raulen Schnabel zugespitzt; Halm von $d$. Basis an auf den Kanten rauh; W. kurze Ausläufer treibend. 24. Grasige, feuchte O. d. höchsten A.; Schwz nicht sehr selten, in D. nur am Salendferner im Südtyrol. Jul. Aug.

20. C. mi crostyla Gay. Aebre zsgesetzt, eyf. od. längl.; Aehrchen zahlreich, längl., spitz, meist dicht-zsgedrängt, oberwärts männl., od. mit ganz männl. u. ganz weibl. gemischt; Narben 2; Früchte aufrecht, eyf., zsgedruickt, nervenlos, so lang als der Balg, v. der Mitte an allmählig in den Schnabel verschmälert, d. Schnabel an dem Rande etwas rauh, an der Spitze einwärts ganz, auf dem Rücken gespalten; Halm oberwärts rauh; W. Rasen u. kurze Wurzelläufer treibend. 24. Auf den hohen Berner u. Walliser A.; auch auf d. Salzburger v. Mielichhofer entdeckt. Jun.-Aug.

21. C. vulpina L. Aehre doppelt-zsgesetzt, eyf.-längl. und gedrungen oder verlängert n. unterbrochen; Aehrchen oberwärts männl.; Narben 2; Früchte sparrig-abstehend, eyf., flach-convex, in einen 2sp., am Rande dicht-feingesägt-rauhen Schnabel zugespitzt, 6-7nervig; Bälge stachelspitzig, kürzer als die Frucht; Halm an den Kanten sehr rauh; W. faserig. 24. Sumpfige O., Gräben. Mai. Jun. Var. $\beta$. nemorosa: Bälge ausser einem grünen Rückenstreifen weissl., am Rande bräunlich. C. nemorosa Willd. u. Rebentisch, nicht Lumnitzer.

22. C. muricata L., nach Sm. u. Wahlenb. Aehre zsgesetzt, längl., gedrungen od. an d. Basis unterbrochen; Aehrchen oberwärts männl.; Narben 2; Früchte sparrig, die unteren fast wagerecht-abstehend, lanzettl.-eyf., flach-convex, in einen am Rande dicht-feingesägtrauhen Schnabel zugespitzt, nervenlos, od. undeutlich-nervig; Bälge stachelspitzig, kürzer als die Frucht; Halm an den Kanten oberwärts rauh; Rhizom dicht-rasig ohne Ausläufer. 24. Wiesen, Wälder. Mai. Jun. C. contigua Hopp. - $\beta$. virens: Bälge bleicher; Aehre gewöhnlich mehr verlängert $u$. unterbrochen; Frïchte grün $u$. oft ein wenig grösser; in Hainen u. Gebüsch. C. nemorosa Lumnitzer. C. muricata Hopp. - Dieselbe Pfl. mit einem blattigen, langen DeckB. an dem untersten Aehrchen: C. virens Lamarck.

23. C. divuls a Goodenough. Aellre zsgesetzt, verlängert, die Aehrchen an der Spitze männl., die oberen genähert, die übrigen entfernt, die unteren oft zsgesetzt, das unterste weiter abstehend und meist gesticlt; Narben 2; Früchte aufrecht-abstehend, eyf., flach convex, in einen am Rande ziemlich rauhen Schnabel zugespitzt, nervenlos od. undeutlich-nervig; Bälge stachelspitzig, kürzer als die Frucht; Halm schlank, etwas überhängend, oberwärts rauh; Rhizom dicht-rasig ohne Ausläufer. 24. Haine; sehr zerstr. dch. d. Geb. Mai. Juni.

24. C. gusstphalica Boenningh. Aehre zsgesetzt, verlängert, dic Aehrchen an der Spitze männl, die oberen genähert, die unteren entfernt, zuweilen zigesetzt, das unterste weiter abstehend und meist 
gestielt; Narben 2; Früchte aufrecht-abstehend, rundl.-eyf., vorne convex, in einen am Rande ziemlich ranhen Schnabel zugespitzt, nervenlos od. undeutlich-nervig; Bälge stachelspitzig, kürzer als die Frucht; Halm sehr schlank u. dünn, zuletzt in einem Bogen zur Erde gekrümmt; Rhizom dicht-rasig ohne Ausläufer. 24. Westphalen, v. Bönningh. in briefl. Mittheilungen. Mai. Jun. Ob diese Pfl, eine gute Art od. eine sehr schlanke Variet. von C. divulsa ist, wird die Zucht aus Samen lehren.

25. C. teretiuscula Good. Aehre zsgesetzt od. doppelt-zsgesetzt, gedrungen-gehäuft; Aehrchen oberwärts männl.; Narben 2; Früchte eyf., höckerig-convex, glänzend, nevvenlos, glatt, auf d. Rücken an der Basis etwas rillig, in einen 2zähnigen, am Rande feingesägtrauhen Schnabel verschmälert; Bälge ungefähr so lang als die Frucht; Halm oberwärts rauh, 3kantig, die Seiten ziemlich convex; Rhizom schief, ein wenig kriechend. 2. Sumpfige Wiesen. Mai.Jun. Var. $\beta$. major, C. Ehrhartiana Hoppe: oft noch einmal so hoch, Rasen grösser, Aehre dicker; weiter zu untersuchen.

26. C. p an ic u lat a L. Aehren rispig; Aehrchen oberwärts männl.; Narben 2; Früchte eyf., höckerig-convex, nervenlos, glatt, auf dem Rücken an der Basis etwas rillig, in einen 2zähnigen, am Rande feingesägt-rauhen Schnabel zugespitzt; Bälge ungefähr so lang als die Frucht; Halm oberwärts sehr rauh, 3kantig, die Seiten flach; W. fastrig, dicht-rasig. 24. Sumpfige, moorige O. Mai. Jun.

27. C. paradoxa Willd. Aehren rispig; Aehrchen oberwärts männl.; Narben 2; Früchte eyf., höckerig-convex, auf d. Rücken u. auf der vorderen Seite nervig-gerillt, in einen 2zähnigen, am Rande feingesägt-rauhen Schnabel zungespitzt; Bälge so lang als die Frucht; Halm oberwärts sehr rauh, 3kantig, die Seiten etwas convex; W. faserig, dicht-rasig. 24. Torfige Wiesen; zerstrent deh d. Geb. MIai. Jun.

c. Narben 2. Aehrchen an der Basis männl., in einer einfachen Aehre wechselst., seltener (bei C. axillaris u. C. Bönninghausiana) die $2-3$ unteren aus $2-5$ zsgesetzt.

* W. weit kriechend.

28. C. Schreberi Schrank. Aehre zsgesetzt; Aehrchen meist 5, wechselst., gedrungen, gerade, eyf.-längl., unterwärts männl.; Narben 2 ; Früchte aufrecht, so lang als der Balg, längl.-eyf., flach-convex, fast v. d. Basis an am Rande feingesägt-wimperig, in einen $2 s p$. Schnabel zugespitzt; W. weit kriechend. 24. Sandige O., Wege; zerstr. dch d. Geb. Mai. Jun. C. praecox Schreb. Aehrchen dunkelbraun.

29. C. brizoides L. Aehre zsgesetzt, fast 2zeilig; Aehrchen meist 5, wechselst., genähert, gekrümmt, längl.-lanzettl., alle mannweibig, unterwärts männl.; Narben 2; Früchte aufrecht, so lang als der Balg, lanzettl., flach-convex, glatt, geschnäbelt-verschmälert, am Rande von der Basis an feingesägt-wimperig; Schnabel 2sp.; W. 
weit kriechend. 2. Wälder; zerstr. dch das Geb. - Aehrchen weisslich, alle androgynisch.

30. C. Ohmülleriana O.F. Lang. Aehre zsgesetzt, oberwärts etwas 2zeilig; Aehrchen 8-12, die oberen 4-6 männl., genähert, lanzettl., zuletzt oft gekrümmt, die unteren 2-3entfernt, längl.-vkteyf., an der Basis männl., das unterste mit einem blattigen DeckB. gestützt; Narben 2; Früchte aufrecht, anderthalbmal so lang als der Balg, lanzettl., in einen 2sp. Schnabel zugespitzt, flach-convex, berandet, am Rande fast $v$. d. Basis an feingesägt-wimperig; $W$. weit kriechend. 2. Feuchte Wiesen bei Rothenbuch in Oberbaiern, v. Pfr. Ohmüller entdeckt. Mai. Jun. Der C. Boenninghausiana sehr ähnl., aber die unteren Aehrchen nicht zsgesetzt, die Früchte deutlicher berandet, und das Rhizom ausläuferartig, an den Gelenken B. u. Halme treibend.

** W. einen dichten Rasen v. Blätter $\boldsymbol{u}$. Halmen, aber keine oder nur kurze Ausläufer treibend.

31. C. B oenningha usian a Weihe. Aehre zsgesetzt, an d. Spitze etwas 2zeilig; Aehrchen 8-12, wechselst., an der Basis männl., die oberen lanzettl., genähert, an der Basis u. Spitze od.durchaus männl., zuletzt gekrümmt, die unteren entfernt, längl.-lanzettl., zsgesetzt, das unterste mit einem blattigen DeckB. gestützt; Narben 2; Früchte aufrecht, so lang als der Balg, ey-lanzettf., in einen 2sp. Schnabel verschmälert, flach-convex, am Rande fast von d. Basis an klein-gesägt-rauh; W. dicht-rasig, Wurzelläufer fehlend. 2. Sumpfige Wiesen z. Halle u. Diessen, in Westph., neben d. Ammer bei Rothenbuch in Oberbaiern. Jun. Jul. C. axillaris Fries novit, nicht Good.

32. C. remota L. Aehre zsgesetzt; Aehrchen wechselst., unterwärts männl., die 3-4 unteren entfernt, mit einem über den Halm hinausragenden Deck $B$. gestützt, alle einfach od. selten das unterste żsgesetzt; Narben 2; Früchte aufrecht, flach-zsgedrückt, eyf., in einen 2zähnigen, feingesägt-rauhen Schnabel zugespitzt, länger als der Balg; Halm schlank $u$. schuach in einem Bogen überhängend; W. dichtrasentreibend, ohne Auslëufer. 24. Feuchte schattige O. Mai. Jun.

33. C. axillaris Goodenough. Ahre zsgesetzt; Aehrchen wechselst., unterwärts männl., die unteren entfernt, zsgesetzt, das unterste mit einem steifen, über den Halm hixausragenden DeckB. gestützt; Narben 2; Früchte aufrecht, flach zsgedrückt, eyf., in einen 2zähnigen, fein-gesägt-rauhen Schnabel zugespitzt, länger als der Balg; Halm steif; W. dicht-rasentreibend, ohne Ausläufer. 2. Sumpfwiesen bei Möllen im Lauenburg., v. Rostkovius mitgetheilt.

34. C. stellulata Good. Aehre zsgesetzt; Aelirchen meist 4, ziemlich entfernt, unterwärts männl.; Narben 2; Früchte sparrig-abstehend, flach-convex, eyf., in einen 2zälınigen, fein-gesägt-rauhen Schnabel zugespitzt, zart-nervig-gerillt; DeckB. kürzer als d. Aehr- 
chen; W. rasentreibend. 24. Feuchte O. Mai. Jun. C. echinata Murray, u. dieser ist eigentl. der ältere Name. Var. auf den hohen Alpen mit 3 mehr genäherten, dunkler gefärbten Aehrchen, und oft einwärts gekrümmtem Schnabel der Frucht: C. grypus Schk. K. syn. ed. 1.

35. C. leporina L. Aehre zsgesetzt; Aehrchen meist 6, wechselst., genähert, rundl.-elliptisch, unterwärts männl.; Narben 2 ; Früchte aufrecht, flach-convex, eyf,, in einen 2zähnigen Sclnnabel zugespitzt, nervig-gerillt $u$. mit einem geflügelten, fein-gesägt-rauhen, in die Spitze des Schnabels auslaufenden Rande umzogen; W. rasentreibend. 4. Triften, Wiesen, Wege. Jun. Jul. C. ovalis Good. Die Bälge graubraun. Var., wiewohl selten, im Schatten der Wälder: $\beta$. argyroglochin: Bälge weissl. od. strohgelb, jedoch mit dem grünen Rückenstreifen der Art: C. argyroglochin Hornemann.

36. C. elongata L. Aehre zsgesetzt; Achrchen wecliselst., genähert, walzl., unterwärts männl.; Narben 2; Früchte abstehend, lanzettl., zsgedrückt, auf d. Rücken ziemlich convex, auf der vorderen und hinteren Seite nervig-vielrillig, in einen fast ganzen, am Rande etwas rauhen Schnabel verschmälert, länger als der eyf. Balg, etwas zurückgekrümmt; W. dichte Rasen treibend. 2. Sumpfige Wiesen. Mai. Jun. Var. auf höheren Gebirgen mit kürzeren Aehrchen: C. Gebhardi Willd.

37. C. lagopina Wahlenb. Aehre zsgesetzt; Aehrchen 3, rundl.elliptisch, wechselst., gedrungen, unterwärts männl. ; Narben 2 ; Früchte aufrecht, eyf., flach-convex, glatt, in einen ungeth., am Rande kahlen Schnabel zugespitzt, ein wenig länger als d. Balg; W. kurze Ausläufer treibend. 24. Höchste GranitA. an feuchten O. Jul. Aug. C. approximata Hoppe. C. leporina Good.

38. C. Heleonastes Ehrh. Aehre zsgesetzt; Aehrchen 3-4, rundl., genähert, unterwärts männl.; Narben 2; Früchte eyf., zsgedrückt-3kantig, glatt, in einen kurzen, ungeth., am Rande etwas rauhen Schnabel zugespitzt, ein wenig länger als d. Balg; Halm rauh. 4 . Sumpfige, torfige O.; Salzbg., Oberbayern, Oberschwab., C. Bern. Mai.

39. C. canescens L. Aehre zsgesetzt; Aehrchen 5-6, eyf., längl., etwas entfernt, unterwärts männl., das endst. an d. Basis lang verschmälert; Narben 2; Früchte eyf., fein-gerieft, zsgedrïckt, auf dem Rücken ziemlich convex, in einen kurzen, ausgerandeten, übrigens ungetheilten, am Rande etwas rauhen Schnabel zugespitzt, länger als der Balg; W. rasig u. kurze Ausläufer treibend. 2. Sumpfige Wiesen, feuchte O. Mai. Jun. C. curta Good. Bälge weissl. od. gelbl.

40. C. Personii Sieber. Aehre zsgesetzt; Aelurchen 5-8, die oberen meist dicht-genähert, die unteren entfernt, alle eyf. u. unterwärts männl., das oberste an der Basis sehr kurz verschinälert; Narben 2; Früchte eyf., fein gerieft, auf dem Riicken ziemlich convex, in einen kurzen, hinten seiner ganzen Länge nach gespaltenen, 
am Rande fein gesägt-rauhen Schnabel zugespitzt, länger als der Balg; IV. rasig, kurze Ausläufer treibend. 4. Feuchte O. der A. C. canescens $\beta$. brunescens K. Syn. ed. 1. C. curta $\beta$. brunescens Pers. C. Gebhardi Hopp., nicht Willd. Bälge bräunlich.

41. C. 1 oliace a L. Aehre zsgesetzt; Aehrchen meist 4, ziemlich entfernt, unterwärts männl., die fruchttrag. 'rundl.; Narben 2; Früchte elliptisch, stumpf, schnabellos, am Munde ganzrandig, nervig; Halm glatt, an d. Spitze rauh; W. kurze Ausläufer treibend. 4. Torfige Wiesen; im Bourtanger Moore Kreis Meppen in Westph. Mai. Aehrchen strohgelb.

V. Votte. Legitim a e. Aechte Seggen. Die endst. Aehre männl., die seitenst. weibl.; seltener die endst. an d. Spitze weibl. od. die männlichen mehr als eine.

§. 1. Narben 2.

A. Früchte in einen berandeten, auf der vorderen Seite flachen Schnabel endigend.

42. C. mucronata All. Die männliche Aehre einzeln, lanzettl., die 1-2 weibl. genähert, halb so lang, elliptisch-rundl., sitzend, die Scheiden umfassend, die unterste in eine borstliche, blattige Spitze endigend; Narben 2; Früchte längl., in einen berandeten, 2sp., auf der vorderen Seite flachen Schnabel verschmälert, flaumig, am Rande wimperig-rauh, länger als der spitze Balg; B. borstl., rinnig. 2. Felsige Triften der A. u. VorA. Jul. Aug.

43. C. Gaudinian a Guthnick. Die endst. Aehre lineal., an der Spitze od. an d. Basis u. d. Spitze weibl., selten ganz männl., d. 2-3 seitenst. bemerkl. kürzer, weibl., genähert, sitzend; DeckB. häutig, ohne Scheide; Narben 2; Früchte kahl, aus einer eyf. Basis allmählig verschmälert, in einen auf der vorderen Seite flachen, am Rande fein-gesägt-rauhen, an der Spitze 2zähnigen Schnabel; St. oberwärts stumpfkantig; B. schmal-lineal., tiefrinnig, an der Spitze flachzsgedrückt, an den beiden Rändern etwas rauh. 24. Auf moorigen Wiesen; C. Bern, Vorarlberg bei Bregenz, nördl. Tyrol bei Kitzbichel. Jun. Jul. Von der folgend. Art sehr deutlich verschieden. Die Früchte noch einmal so gross.

44. C. microstachy a Ehrhart. Die endst. Aehre männl., od. an der Spitze weibl., die $2-3$ seitenst. bemerkl. kürzer, weibl., genähert, sitzend; DeckB. häutig, ohne Scheide; Narben 2; Früchte kahl, eyf., in einen auf der vorderen Seite flachen, am Rande glatten od. schwach-gezähnelten, an der Spitze kurz-2zälınigen Schnabel zugespitzt; St. oberwärts spitz-3kantig; B. schmal-lineal., tiefriunig, an der Spitze geschärft-3kartig mit rauhen Rändern. 24. Moorige Wiesen in Ostfriesland, Pommern, in Schles. zw. der Schindel- $u$. Giesemühle, selten. Jun. 
- B. Früchte schnabellos, od. mit einem sehr kurzen, stielrunden, gestutzten od. schief-abgeschnittenen od. 2zähnigen SchnabeI endigend.

a. Die DeckB. nicht scheidig od. sehr kurz-scheidig.

45. C. stricta Goodenough. Männl. Aehre 1 od. 2, weibl. 2-3, aufrecht, verlängert-walzl., sitzend od. die untere gestielt; DeckB. an der Basis beiderseits geöhrelt ohne Scheide, das untere blattig; Narben zwei; Früchte elliptisch, flach, nervig, kahl, sehr kurz geschnäbelt, Schnäbelchen stielrund, ungeth.; Bscheiden sämmtlich netzig-gespalten; Halm steifaufrecht, scharflkantig, rauh; W. dichte Rasen bildend ohne Ausläufer. 24. Moosige Sümpfe, wo sie sehr grosse u. dichte Rasen bildet, zerstr. deh das Geb. Apr. Mai. Fruclıt sogleich mit der Reife abfallend. C. caespitosa L. nach Gay.

46. C. caespitosa L. nach Fries. Männl. Aehre 1-2, selten 3, aufrecht, länglich-walzl., kurz-gestielt, die obere meist sitzend; DeckB. an der Basis fast scheidig-umfassend, beiderseits geöhrelt, das untere blattig; Narben 2; Frïchte elliptisch, zsgedrïckt, auf beiden Flächen etwas convex, v. sehr kleinen Pünktchen fein-rauh, nervenlos, sehr kurz geschnäbelt, Schnäbelchen stielrund, ungeth.; die unteren Bscheiden netzig-gespalten; Halm zieml. schlaff, scharfkantig, rauh; W. dicht rasig ohne Ausläufer. 2. Nasse Wiesen bei Hambg., Hannover, Leipzig. April, früher als C. vulgaris. C. pacifica Drejer., C. Drejeri O. F. Lang.

47. C. v ulgaris Fries. (C. caespitosa Autor.) Männl. Aehre 1, selten 2, weibl. $2-3$, selten 4 , aufiecht, längl.-walzl., sitzend, seltener die untere gestielt; DeckB. an der Basis beiderseits sehr kurz geöhrelt, ohne Scheide, das untere blattig, kürzer als der Halm, selten so lang als dieser; Narben 2; Früchte kahl, elliptiscl, vorne flach, auf dem Rücken ein werig convex u. viehnervig, sehr kurz geschnäbelt, Schnäbelchen stielrund, ungeth.; die Bscheiden nicht netzig gespalten; Halm steifaufrecht, scharfkantig, rauh; W. locker-rasig, 11. Ausläufer treibend. 24. Feuchte Wiesen, Triften u. Waldstellen. Apr. Mai. C. Goodenowii Gay. C. caespitosa Good., K. syn. ed. 1. u. fast aller Autoren. Eine niedrigere Form ist: C. stolonifera Hoppe.

48. C. a cuta L. Männl. Aehren 2-3, weibl. 3-4, verlängertwalzl., die blühenden nickend, die unterste länger oder kürzer gestielt; DeckB. blattig, an der Basis beiderseits sehr kurzgeöhrelt, ohne Scheide, das untere länger als der Halm; Narben 2; Früchte kahl, elliptisch, zsgedriickt, etwas aufgeblasen, auf beiden Seiten ziemlich convex, undeutlich-nervig, kurz- u. dïnngeschnäbelt, Schnäbelchen stielrund, ungeth.; Bscheiden nicht netzig-gespalten; Halm steifaufrecht, scharfkantig, rauh; W. Ausläufer treibend. 24. Sumpfige O., Gräben, Bachufer. Mai. Die reifen Frïchte fallen friiher ab als an C. vulgaris. 
49. C. rigida Good. Die männl. Aehre einzeln, weibliche 3, aufrecht, walzl., sitzend, die unterste gestielt; DeckB. an d. Basis beiderseits geöhrelt, ohne Scheide, das unterste blattig; Narben 2; Früchte kahl, elliptisch, linsenf.-zsgedrückt, fast 3seitig, glatt, sehr kurz-geschnäbelt, Schnäbelchen stielrund, ungeth.; B. zurückgekrümmt; Bscheiden ungeth.; Halm scharfkantig, rauh; W. weitkriechend. 4 . Steinige, sumpfige O. der Gbgskämme der Sudeten, des Brocken. Jun. Aug. C. saxatilis Willd. Ob. diese Art die C. saxatilis Linn. oder ob letztere in d. C. pulla Good. zu suchen sei, dariber sind selbst die Schweden nicht einig.

b. DeckB. scheidig.

50. C. bicolor All. Aehren gestielt, 3 an der Spitze des Halmes, gedrungen, zuweilen eine vierte entfernte, länger-gestielt $u$. mit einem blattigen, scheidigen DeckB. gestützt, die endständige an d. Basis männl., die folgenden weibl.; Narben 2; Früchte kahl, vkteyf., stumpf, schnabellos, an der ringf. Mündung ganzrandig; Bälge eyf., stumpf. 24. Höchste GranitA. Jul. Aug.

§. 2. Narben 3. Die endst. Aehre männl. od. mannweibig, näml. die unteren Bth. männlich.

A. Früchte schnabellos od. mit einem stielrunden, am Ende gestutzten oder schief-abgeschnittenen oder 2zähnigen Schnabel en. digend.

a. DeckB. nicht scheidig oder sehr kurz scheidig. Früchte kahl. 51. C. Buxbaumii Wahlenb. Die endst. Achre mannweibig, verkehrteyf., unterwärts männl., weibliche meist 3 , d. unterste kurzgestielt, entfernter, mit einem an der Basis beiderseits geöhrelten od. sehr kurz-scheidigen DeckB.; Narben 3; Früchte kahl, elliptisch, 3kantig, stumpf, sehr kurz-geschnäbelt, Schnäbelchen stielrund, klein2zähnig; Bälge haarspitzig; BScheiden netzig-gespalten. 24. Torfige Wiesen; zerstr. durch d. Geb. Apr. Mai.

52. C. Vahlii Schkuhr. Aehren 3, dicht-gehäuft, kurz-gestielt, rundl., die endständige mannweibig, an der Basis männl., die übrigen weibl.; Narben 3; Früchte kahl, elliptisch, auf dem Rücken convex, stumpf-gekielt u. dadurch 3 kantig, mit einem kurzen, stielrunden, klein-2zähnigen Schnäbelchen endigend; Bscheiden ganz; Halm glatt. 24. Höchste A. der Schwz., Albula, Val Bevers. Jul. Aug. C. alpina Wahlenb. Die Früchte gelbl., selten bräunl.; sie sind auf dem Rücken gegen die Spitze hin von sehr feinen Knötchen $u$. Runzelchen ein wenig rauh, was sich unter einem scharfen Glase sehr zierlich ausnimmt, aber auch bei den verwandten Arten mehr oder weniger vorkommt.

53. C. nigra All. Aehren 3 od. 4, dicht-gehäuft, sitzend od. kurzgestielt, eyf., die endständige mannweibig, an der Basis männl., die 
übrigen weibl.; Narben 3 ; Früchte kahl, vkteyf., zsgedrückt, auf $d$. Rücken stumpf-gekielt, mit einem sehr kurzen stielrunden, klein2zähnigen Schnäbelchen endigend; Bscheiden ganz; Halm glatt. 4. Grasige, trockene O. der A. Jul. Aug. Früchte violett-schwarz, am Rande griin.

54. C. a terrima Hoppe. Aehren 3-5, gedrungen, alle längl.walzl., aufrecht, die endständige mannweibig, an d. Basis männl., die weiblichen gestielt, die unterste länger-gestielt u. mit einem blattigen DeckB.; Narben 3; Früchte kahl, rundl.-eyf., zsgedrückt, auf dem Rücken stumpf-gekielt, mit einem kurzen, stielrunden, klein2zähnigen Schnäbelchen endigend; Bscheiden ganz; Halm rauh. 2 . Grasige, nasse O. der höchst. A. Aug. Frïchte violett-schwarz, am Rande $u$. an der Basis grün, breiter, als die schwarzen Bälge.

55. C. atrata L. Aehren 3-5, gedrungen, die endständige eyf., mannweibig, an $d$. Basis männl., die weiblichen längl., gestielt, $z u$ letzt hängend, d. unterste länger-gestielt 1 . mit einem blattigen DeckB.; Narben 3; Früchte kahl, rnndl.-eyf., zsgedrückt, auf dem Rücken stumpf-gekielt, mit einem kurzen, stielrunden, klein-zweizähnigen Schnäbelchen endigend; Bscheiden ganz; Halm glatt. 24. Kiesige, trockene O. d. A. u. Sudet. Jun.-Aug. Frïchte grün, breiter als der schwarz-violette Balg, getrocknet gelblich.

56. C. irrigua Sm. Männl. Aehre einzeln, weibl. 2-3, ziemlich genähert, nickend od. hängend, lang- $u$. dünn-gestielt, eyf., gedrungenbth.; DeckB. schmal-blattig, an d. Basis beiderseits geöhrelt od. kurz-scheidig; Narben 3; Früchte rundl.-oval, stumpf, linsenf.-zsgedrückt, kahl, nervenlos od. schwach-nervig, mit einem kleinen, stielrunden, abgeschnittenen Sclnäbelchen bespitzt, kahl; $B$. lineal., flach, glatt, am Rande nach der Spitze hin rauh; W. Ausläufer treibend. 2 . Sumpfige, moorige O. der A., VorA. u. Riesengbg. Die männl. Aehre um die Hälfte kürzer als bei der Folgenden.

57. C. limosa L. Männl. Aehre einzeln, weibl. 1-2, ziemlich genähert, nickend od. hängend, lang- $u$. dünn-gestielt, längl., gedrungenblüthig; DeckB. schmal-blattig, an d. Basis beiderseits geöhrelt od. kurz-scheidig; Narben 3 ; Früchte rundl.oval, stumpf, linsenf.zsgedrückt, kahl, vielnervig, mit einem kleinen, stielrunden, abgeschnittenen Schnäbelchen bespitzt, kahl; $B$. schmal-lineal., faltig-rinnig, am Rande v. der Basis an etwas rauh; W. Ausläufer treibend. 4. Schlammige, moosige Sïmpfe. Mai. Jun.

58. C. supin a Wahlenb. Männl. Aehre einzeln, lineal.-lanzettl., weibl. 1-2, genähert, halb so lang, rundlich, sitzend; DeckB. häutig, stengelumfassend, das untere haarspitzig; Narben 3; Früchte kugelig-elliptisch, 3kantig, glänzend, ganz kahl, in einen an d. Spitze trockenhäutigen u. 2lappigen Schnabel zugespitzt; W. Ausläufer treibend. 4. Sonnige Hiigel; zerstr. dch d. Geb. Apr. Mai. 
b. Die DeekB. nicht scheidig od: sehr kurz-scheidig; Früchte flaumig od. filzig.

5ั9. C. pilulifera L. Männl. Aehre einzeln, weibl. meist 3, genähert, rundl., sitzend; das untere DeckB. lineal.-pfrieml., nicht scheidig, gänzl. blattig, aufrecht abstehend; Narben 3 ; Früchte kugeligvkteyf., 3seitig, kurz-geschnäbelt, am Munde etwas ausgerandet, flaumig; Bälge dch ten auslaufenden Nerven kurz-stachelspitzig; die fruchttragenden Halme auswärts nach d. Erde gekrümmt; W. faserig. 4. Waldungen. Apr. Mai.

60. C. to mentosa L. Männl. Aehre einzeln, weibl. 1-2, fast sitzend, walzl., stumpf; das untere DeckB. blattig, sehr kurz-scheidig, wagerecht-abstehend; Narben 3 ; Früchte kugelig-vkteyf., 3seitig, kurzgeschnäbelt, am Munde etwas ausgerandet, kurzh.-filzig; Bälge spitz, mit einem in die Spitze auslaufenden Nerven; Halme steif-aufreeht; W. Ausläufer treibend. 24. Feuchte Triften, Wiesen; zerstr. deh d. Geb. Mai. Jun. - Was ich bisher als C. Grassmanniana Rabenh. erhielt, war eine Form der C. tomentosa.

61. C. montana L. Männl. Aehre einzeln, weibl. 1-2, dichtgenähert, eyf.; DeckB. gänzl. häutig, stengelumfassend, begrannt od. mit einer blattigen Spitze versehen; Narben 3 ; Früchte längl.-vkteyf., 3seitig, kurz-gesehnäbelt, am Munde ausgerandet, kurzh.-flaumig; Bälge stumpf od. gestutzt, stachelspitzig; W. faserig, gedrungen-rasig. 2. Wälder, schattiges Gebiiseh. Apr. Mai. C. collina Willd. Bälge sehwarz-braun; Bseheiden purpurn. Var. mit flaumhaarigen B.

62. C. erie e to r u m Pollich. Männl. Aehren einzeln, weibl. 1-2, genähert, eyf.; DeckB. häutig, stengelumfassend, spitz od. begrannt; Narben 3; Frïchte vkteyf., 3seitig, sehr kurz-geschnäbeit, am Munde abgesehnitten, flaumig; Bälge vkteyf., kurzgewimpert, sehr stumpf, mit einem vor d. Spitze verscliwindenden Nerven; W. Ausläufer treibend. 2. Sandige, troekene O.; zerstr. deh d. Geb. Apr. Mai. Var.: Bälge länglicher. C. membranaeea Hoppe. Diese auf d. Alpen.

63. C. pra e e ox Jacq. Männl. Aehre einzeln, weibl. 1-3, genähert, längl.-eyf., die unterste oft gestielt; DeckB. an Rande häutig, stengelumfassend od. das unterste seheidig; Narben 3; Früchte vkteyf., 3seitig, kurz-geschnäbelt, am Munde etwas ausgerandet, flaumig, Bälge deh den auslaufenden Nerven stachelspitzig; Halme aufrecht; W. Ausläufer treibend. 24. Unkult. Hügel, Wege. AIärz. Apr. Im Schatten höher: C. umbrosa Host. - Abänderung mit ausgerandeten, lang-stachelspitzigen Bälgen: C. mollis Host., wenigstens was ieh unter diesem Namen erhielt. Der Halm über der ersten Aehre in einen Winkel zur Seite gebrochen: C. reflexa Hoppe.

64. C. pol y rrhiza Wallroth. Männl. Aehre einzeln, weibl. 1-3, genähert, längl.-eyf., die unterste etwas gestielt; Deck $B$. am Rande häutig, stengelumfassend, das unterste scheidig; Narben 3; Früchte 
vkteyf., 3seitig, kurz-geschnäbelt, am Munde etwas ausgerandet, Aaumig; Bälge deh den auslaufenden Nerven stachelspitzig; Halme aufrecht; W. faserig, gedrungen-rasig. 4 IVälder; zerstr. deh d. südl. u. mittlere Geb. Mai. C. longifolia Host. K. syn. ed. 1., nicht R. Brown. C. umbrosa Hoppe, Host's gleichnamige PA. hat „rad. repens."

c. Die DeckB. scheidig; Friichte flaumig.

65. C. In milis Leysser. Männl. Achre einzeln, gestielt, weibl. 2-3, ertfernt, meist 3bth., alle gestielt; Bthsticle v. einem häutigen, scheidigen, blattlosen DeckB. eingeschlossen; Narben 3 ; Früchte vkteyf., 3seitig, sehr kurz-geschnäbelt, am Munde abgeschnitten, an d. Spitze flaumig; B. rinnig, lïnger als d. Halm; W. faserig, rasig. 4. Hügel, sonnige Berge; zerstr. deh d. Geb. auf Kalk. März. Apr. C. clandestina Good.

66. C. g y n o b a s is Vill. Männl. Aehre einzeln, weibl. 2-3, meist 5bth., die oberen genähert, die unterste fast wurzelst., sehr lang-gं $\epsilon$ stielt; die untersten DeckB. scheidig; Narben 3; Früchte vkteyf., 3kantig, sehr kurz-geschnäbelt, am Munde etwas ausgerandet, nervig, fein-flaumig; W. faserig, rasig. 2. Grasige Hügel; sïdl. Schwz., Litt., siidl. Tyrol, Unteröstr. März. Apr. C. alpestris All. Aehren blass.

67. C. digit a ta L. Männl. Aehre einzeln, sitzend, weibl. meist 3 , lineal., etwas entfernt, gestielt, die fruchttragenden lockerbth.; Bthstiele v. einem hëutigen, scheidigen, schief-abgeschnittenen DeckB. eingeschlossen; Narben 3; Früchte vkteyf., 3seitig, sehr kurz-geschnäbelt, an d. Mündung etwas ausgerandet, flaumig, so lang als der Balg; W. faserig, rasig. 24. Schattige Wälder. Apr. Mai.

68. C. ornith o p o d a Willd. Männl. Aetre einzeln, sitzend, weibl. meist 3, lineal., dicht-zsgestellt, gestielt, die fruchttragenden lockerbthig; Bthstiele v. einem häutigen, scheidigen, schiefabgeschnittenen DeckB. eingeschlossen; Narben 3; Früchte vkteyf., 3seitig, sehr kurzgesclinäbelt, an d. Mündung etwas ausgerandet, flaumig, länger als d. Balg; W. faserig, rasig. 24. Lichte Waldplätze; zerstr. dch d. Geb. Apr. Mai.

d. Die DeckB. scheidig; Frïichte kahl.

69. C. alba Scopol. Männl. Aehre einzeln, gestielt, weibl. 2, gestielt, meist 5bth.; DeckB. scheidig, häutig, blattlos, auf d. Rüicken mit einem krautigen Streifen bezeichnet; Narben 3; Früchte kugeligeyf., gerillt, kurz-geschnäbelt, kahl, Schnabel stielrund, an d. Spitze häutig, schief-abgesclınitten; B. schmal-lineal.; W. Ausläufer treibend. 2. Wälder d. VorA. u. Niederungen längs d. A.; v. Oberschwaben bis Oestr. u. nördl. bis an die Donau hinab. Apr. Mai.

70. C. nitid a Host. Männliche Achre einzeln, weibl. 2, längl., die unterste heraustretend-gestielt, gedrungenblüthig, meist $12 \mathrm{bth}$, die obere fast sitzend; DeckB. scheidig, das untere blattig-stachelspitzig; Narben 3; Früchte kugelig-eyf., gerillt, kurz-geschnäbelt, 
kahl, Schnabel stielrund, an d. Spitze weisslich-häutig, 2lappig; B. lineal., W. Ausläufer treibend. 24. Sonnige, unkultiv. O.; südl. Schwz., Südtyr., Litt., Unteröstr. Apr. Mai.

71. C. pilos a Scop. Männl. Aehre einzeln, gestielt, weibl. 2-3, entfernt, aufrecht, heraustretend-gestielt, lockerbth.; DeckB. scheidig, blattig; Narben 3 ; Früchte fast kugelig-vkteyf., 3seitig, ganz kahl, gerillt, geschnäbelt, Schnabel stielrund, an d. Spitze häutig, schiefabgeschnitten; Halme ganz glatt, gerillt, meist blattlos; $B$. der nichtblühenden Büschel länger als die Halme, breit-lineal., behaart-wimperig. 24. Bergwälder; südl. u. südwestl. Geb., Hannover bei Förste. Apr. Mai.

72. C. panicea L. Männl. Achre einzelu, gestielt, immer aufrecht, weibl. meist 2 , entfernt, aufrecht, lockerbth., die unterste heraustretend-gestielt; DeckB. blattig, scheidig; Narben 3; Früchte fast kugelig-eyf., kurz-geschnäbelt, kahl, Schrabel stielrund, abgeschnitten; Halme glatt, an der Basis beblättert; B. lineal., kahl, am Rande rauh; W. Ausläufer treibend. 24. Wiesen, feuchte O. Mai. Jun.

73. C. vaginata Tausch. Männl. Aehre einzeln, gestielt, während der Bthzeit rechtwinkelig-zurückgebogen, weibliche $2-3$, entfernt, aufrecht, heraustretend-gestielt, lockerbth.; DeckB. blattig, scheidig; Narben 3; Früchte fast kugelig-eyf., 3seitig, ganz kahl, geschnäbelt, Schnabel stielrund, schief-abgeschnitten, ausgerandet; Halme ganz glatt, gerillt, an d. Basis beblättert; B. breit-lineal., kahl, am Rande gegen die Spitze hin rauh; W. Ausläufer treibend. 24. Nasse O. der Sudet. u. des Brocken. Jun. Jul. C. phaeostachya Smith.

74. C. gla u a Scop. Männl. Aehren meist 2, weibl. 2-3, entfernt, walzl., gedrungenblüthig; lang-gestielt, zuletzt hängend; DeckB. blattig, die untersten kurz-scheidig; Narben 3; Früchte elliptisch, stumpf u. mit einem selw kurzen, etwas ausgerandeten Schnäbelchen bespitzt, zsgedrückt-convex, ein wenig rauh, nervenlos; Halm glatt; B. am Rande rauh; W. Ausläufer treibend. 24. Triften, lichte, feuchte WaldO. Apr. Mai. C. recurva Huds. Fine Abänderung mit aufrechten, kürzer gestielten Aehren u. längeren Bälgen als die Kapsel: C. erythrostachys Hoppe; eine andere, an welcher der Mittelnerv in eine krautige Spitze von der halben od. ganzen Länge des Balges vorgezogen ist: C. acuminata Willd., C. cuspidata Host.

75. C. clava eformis Hoppe. Männl. Aehren meist 2, weibl. 2-3, entfernt, keulig, an d. Spitze breiter, verlängert-gestielt, hängend; DeckB. blattig, die untersten kurz-scheidig; Narben 3 ; Früchte elliptisch-längl., stumpf, mit einem sohr kurzen, etwas ausgerandeten Schnäbelchen bespitzt, zsgedrückt-convex, ein wenig rauh, nervenlos; Halm glatt; B. am Rande rauh; W. Ausläufer treibend. 2. A. von Kärnthen u. d. Schwz. Mai.

76. C. maxima Scop. Männl. Aehre einzeln u. nebst den weibl. gekrümmt, zuletzt hängend, weibl. meist 4, auseinanderstehend, walzl., 
verlängert, gedrungenblüthig, die oberen eingeschlossen-, die unteren heraustretend-gestielt; DeckB. blattig, scheidig; Narben 3; Früchte elliptisch, 3kantig, kurz-geschnäbelt, kahl, Schnabel 3seitig, ausgerandet; Halm 3kantig, oberwärts etwas ranh; B. lanzettl.-lineal.; W. rasig, faserig. 2. Feuchte WaldO.; zerstr. dch d. Geb. Jun.

77. C. strigos a Huds. Männl. Aehre einzeln, weibl. meist 4, auseinander-stehend, nickend, schlank, lockerblüthig, die unteren heraustretend-gestielt; DeckB. blattig, scheidig; Narben 3 ; Früchte längl.lanzettl., nervig, 3stitig, nach vorne verschmälert, am Munde schiefabgeschnitten; W. Ausläufer treibend. 2. Feuchte WaldO.; sehr zerstr. dch d. nördl. u. westl. Geb. Mai.

78. C. pallescens L. Männl. Aehre einzeln, weibl. 2-3, genähert, nickend, längl.-eyf., gedrungenblüthig, heraustretend-gestielt; DeckB. blattig, scheidig; Narben 3; Früchte elliptisch-längl., stumpf, schnabellos, beiderseits convex, etwas zsgedriickt, schwach-nervig, kahl, die kleine Mündung abgeschnitten; $B$. . die unteren Scheiden bchaart; W. faserig, rasig. 24. Wiesen, lichte WaldO. Mai.

79. C. capillaris L. Männl. Aehre einzeln, weibl. 2-3, langgestielt, nickend, locker- $u$. meist 6bth., die 2 oberen gegenst. länger als d. männliche, die dritte oft entfernt; DeckB. scheidig, blattig; Narben 2; Früchte elliptisch, gedunsen, 3seitig, an d. Basis u. Spitze verschmälert, kahl; Schnabel stielrund, schief-abgeschnitten; B. flach ; W. faserig. 24. Felsige, feuchte O. der A., VorA. u. höheren Sudeten. Jun. Jul.

80. C. ustulata Wahlenb. Männl. Aehre einzeln, weibl. 2-3, etwas genähert, gestielt, hängend, eyf., gedrungenblüthig; DeckB scheidig, die unterste Scheide in eine blattige Stachelspitze, nicht $v$. d. Länge der Aehre, endigend; Narben 3; Früchte flach-zsgedrückt, oval, kahl, in einen stielrunden, an der Spitze 2lappigen Schnabel plötzlichzugespitzt; B. flach, am Rande nach d. Spitze hin rauh; W. faserig. 4. Moorige O. der höchsten A.; Krain, Kärnth., Stmk., Oester., Schwz. Aug. Diese Art habe ich auf Autorität von Host., Hoppe u. a. aufgenommen, ein deutsches Ex. sah ich noch nicht, eben so wenig eines aus der Schwz.

B. Die Früchte geschnäbelt; der Schnabel berandet, auf dem Rücken ziemlich convex, auf der vorderen Seite flach, an der Spitze 2sp., mit gerade vorgestreckten Zähnen, seltener fast ungeth. Männliche Aehre einzeln, manchmal an der Spitze weiblich; seltener zwei männliche Aehren.

81. C. fuliginos a Schk. Aehren alle gestielt, ziemlich genähert, die endstärdige mannweibig, an d. Basis männl., keulig, weibliche $2-3$, längl., gedrungenblüthig, die unteren zuletzt hängend; DeckB. scheidig-blattig; Narben 3; Früchte lanzettl., kahl, in einem berandeten, feingesägt-wimperigen, 2zähnigen, auf d. vorderen Seite flachen 
Schnabel verschmälert; W. faserig, rasig. 24. Kiesige, feuchte 0 . d. A.; Tyr., Salzbg., Kärnth., Krain, Oberöstr. Jul. Aug. C. frígida Wahlenb. Schnabel dex Frucht vorne weiss-berandet.

82. C. frigida All. Männl. Achre endst., lanzettl., seltener an d. Spitze weibl., weibl. meist 4, längl., gedrungenblüthig, die oberste sitzend, die unterste entfernt, sehr lang-gestielt, hängend; DeckB. scheidig-blattig; Narben 3; Früchte lanzettl., kahl, in einen berandeten, feingesägt-wimperigen, auf d. vorderen Seite flachen, 2zähnigen Schnabel verschmälert; W. Ausläufer treibend. 24. Felsige, feuchte O. d. A., Voges., Schwarzw., Sudet. Jul. Aug. C. fuliginosa Wahlenb. Früchte grün-berandet, Schnabel ohne weissen Rand.

83. C. s empervire ns Vill. Aehren längl.-länzettl., die männl. endst., einzeln, die weibl. meist 3 , etwas lockerbth., die unteren hervortretend-gestielt, aufrecht; DeckB. blattig, scheidig; Narben 3; Früchte ey-lanzettf., in einen berandeten, feingesägt-uimperigen, auf d. vorderen Seite flachen, an d. Spitze trockenhäutig-2lappigen Schnabel zugespitzt, auf dem Rücken nach d. Spitze hin fein-kurzh.; $B$. schmal-lineal., aufrecht, der nicht blühenden Büschel verlängert, am blühenden Stengel kurz u. viel kleiner; Halm stumpfl.-kantig, glatt; W. faserig, gedrungen-rasig. 2. Grasige O. d. A., VorA. u. Niederungen längs d. A. Jun.-Aug. C. ferruginea Schk. C. varia Host. Var. Früchte überall kurzh.: C. erecta DC.

84. C. hispidula Gaudin. Aehren längl.-lanzettl., die männl. einzeln, weibliche meist 2 , aufrecht, die unterste eingeschlossen-, selten hervortretend-gestielt; DeckB. blattig, scheidig; Narben 3 ; Früchte eyf., berandet, feingesägt-wimperig, in einen ziemlich kurzen, auf der vorderen Seite flachen, mit 2 Spitzen endigenden Schnabel zugespitzt, auf dem Rïcken flaumig; B. lineal., die des Halmes u. der nicht blühenden Büschel gleichgross, halb so lang als der Halm; Halm geschärft-3kantig, rauh; W. Ausläufer treibend. 24. In Felsenritzen der höchsten Alpen; ïber Zermatten an dem Matterhorn u. Räfel, über dem Bagnesthal in Wallis. Jul. Aug. C. fimbriata Schk.

85. C. firma Host. Männl. Aehre einzeln, weibl. meist 2, aufrecht, gedrungenbth., elliptisch, die obere genähert, fast sitzend, die unteren entfernt, hervortretend-gestielt; DeckB. scheidig, mit einer blattigen Spitze, ungefähr v. der Länge der Aehre; Narben 3; Früchte lïngl.-lanzettl., kahl, in einen berandeten, feingesägt-wimperigen, auf d. vorderen Seite flachen, an d. Spitze abgeschritten-2lappigen Schnabel zugespitzt; B. lanzettl.-lineal., 3reihig-abstehend, steif. 24. Felsige, feuchte O. der A., VorA. u. Mähr. Karpat. Jun.-Aug.

86. C. ferruginea Scop. Männl. Achre einzcln, weibl. 2 od. 3 , entfernt-stehend, lineal., etwas lockerbth., alle hervortretend-gestielt, die fruchttragenden überhangend; DeckB. scheidig; Narben 3; Friichte elliptisch-länglich, 3seitig, in einen berandeten, feingesägt-rauhen, auf der vorderen Seite flachen, an der Spitze kurz-2zähnigen Schnabel 
zugespitzt; B. lineal., aufrecht; W. Ausläufer treibend. 2. Fenchte O. der A. u. VorA. Jun. Jul. C. Mielichhoferi Schk.

87. C. tenu is Host. Männl. Achre einzeln, weibl. 2-3, entfernt-stehend, lineal., etwas lockerbth., alle hervortretend-gestielt, die fruchttragenden überhangend; DeckB. scheidig; Narben 3; Früchte lanzettl.-länglich in einen berandeten, auf der vorderen Seite flachen, an d. Spitze 2zähnigen Schnabel verschmälert, 3seitig, auf der Oberfläche u. am Rande kahl; B. borstlich-lineal.; W. gedrungen-rasig u. zugleich Ausläufer treibend (nach Hopp.). 24. Felsige, feuchte O. d. A. u. Mähr. Gbge. Jun. Jul. C. brachystachys Schkuhr.

88. C. depa uperata Goodenough. Männl. Aehre einzeln, weibl. neist 3, entfernt, hervortretend-gestielt, aufrecht, 3-6bth.; DeckB. scheidig, blattig, viel länger als die Aehre, fast so lang als der Halm; Narben 3; Friichte elliptisch-vkteyf., 3seitig, gedunsen, kahl, vichnervig, mit ungefähr 30 hervortretenden Nerven, in einen lineal., verlängerten, am Rande feingesägt-rauhen, auf der vorderen Seite flachen, am Ende trockenhäutigen u. 2lappigen Schnabel plötzl. zugespitzt; W. (uach Smith) faserig. 24. In Wäldern u. zw. Gebüsch; südl. Istr. zw. Pola u. Stignano, Tommas., Kästelwald bei Colmar, Kampmann. Mai. Jun.

89. C. Michelii Host. Männl. Aehre einzeln, weibl. 1-2, entfernt-gestellt, elliptisch, eingeschlossen- od. die untere hervortretendgestielt, aufrecht, 6-12bth.; DeckB. scheidig, ungefähr so lang als die Aehre, vicl kürzer als der Halm; Narben 3; Frïchte vkteyf., bauchig-3seitig, kahl, in einen lineal., verlängerten, am Rande feingesägt-rauhen, auf der vorderen Seite flachen, am Ende spitz-2sp. Schnabel plötzlich verschmälert, schwach-nervig; W. Ausläufer treibend. 2. Waldige Gebirge; Mähren, Böhmen, Oestr., Unterkärnth., Siidtyr., Littorale. Mai.

90. C. hordeiformis Wahlenb. Männl. Aehren 2, weibl. 3, aufrecht, eyf., gedrungenbth., d. unterste hervortretend-gestielt; Deck $B$. scheidig, aufrecht, blattig u. nebst den WB. viel länger als der Halm; Narben 3; Früchte elliptisch, 3seitig, glatt, kahl, in einen spitz-2sp., berandeten, am Rande feingesägt-rauhen, auf d. vorderen Seite flachen Schnabel zugespitzt; Halm glatt. 24. Gräben, Sümpfe; Mähr., Unteröstr., Istr., Rheinpfalz zw. Alzei u. Wörstadt. Apr.

91. C. flava L. Männl. Aehre einzeln, weibl. 2-3, zieml. genähert, lundl.-eyf., die oberen fast sitzend, die unterste meist eingeschlossen-gestielt; DeckB. blattig, kurz-scheidig, zuletzt weit abstehend od. zurückgebrochen; Narben 3; Früchtє eyf., aufgeblasen, nervig, kahl, in einen zurückgekrümmten, auf d. vorderen Seite flachen, am Rande feingesägt-rauhen, 2zährigen Schnabel zugespitzt; Halme kahl; W. gedrungen-rasig, faserig. 24. Sumpfige O., feuchte Wiesen. Mai. Jun. - C. lepidocarpa Tausch hat bemerkl. kleinere Früchte 
als C. flava, sonst dieser ganz ähnlich; die wesentl. Unterschiede sind mir nicht klar geworden.

92. C. O e d e ri Ehrh. Alännl. Aehre einzeln, weibl. 2-3, genähert, rundl.-eyf., d. oberen fast sitzend, d. unterste eingeschlossengestielt, oft entfernt; DeckB. blattig, zuletzt weit abstehend od. zurückgebrochen, kurz-scheidig od. das unterste entfernt und verlängertscheidig; Narben 3; Früchte rundl., aufgeblasen, nervig, kahl, in einen geraden, auf der vorderen Seite flachen, am Rande feingesägtrauhen, 2zähnigen Schnabel zugespitzt; Halm kahl; W. faserig, rasig. 4. Sumpfige O. Mai-Jul.

93. C. fulva Good. Männl. Aehre einzeln, weibl. 2, die untere entfernt, hervortretend-gestielt, od. 3 , die 2 oberen genähert, alle aufrecht, eyf.-längl., gedrungenbth.; DeckB. lang-scheidig, das unterste blattig, die männl. Achre erreichend od. überragend; Narben 3; Früchte eyf., etwas aufgeblasen, beiderseits convex, nervig, kahl, in einen 2sp., geraden, auf der vorderen Seite flachen, am Rande feingesägt-rauhen Schnabel zugespitzt, weit-, die unteren oft wagerechtabstehend; Bälge spitz; Blatthäutchen blattgegenst., eyf., kurz, abgeschnitten; Halm rauh; W. Rasen u. kurze Ausläufer treibend. 4. Feuchte Wiesen. Mai. Jun. C. biformis $\alpha$. sterilis F. W. Schultz.

94. C. Hornschuchian a Hoppe. Männl. Aehre einzeln, weibl. meist 3, aufrecht, eyf.-längl., gedrungenbth., die unterste weit entfernt, hervortretend-gestielt; DeckB. lang-scheidig, das unterste schmalblattig, länger als die Aøhre; Narben 3; Früchte eyf., etwas aufgeblasen, beiderseits convex, nervig, kahl, in einen $2 \mathrm{sp}$., auf der vorderen Seite flachen, am Rande feingesägt-rauhen Schnabel zugespitzt, aufstrebend; Bälge spitz; Halm kahl od. an der Spitze ein wenig rauh; Blatthäutchen blattgegenst., eyf., kurz, abgeschnitten; W. Rasen u. kurze Ausläufer treibend. 24. Feuchte Wiesen. Mai. Jun. C. speirostachya Sm. C.-Hosteana DC.? Die Beschreibung passt nicht ganz u. DCandolle citirt nicht C. fulva Host. 4. t. 65., sondern C. distans Host. 1. t. 77. unter seiner C. Hosteana. C. biformis $\beta$. fertilis F. W. Schultz. Noch weiter zu beobachten.

95. C. distans L. Männl. Aehre einzeln, weibl. meist 3, aufrecht, cyf.-längl., gedrungenbth., die unterste weit-entfernt, hervortretend-gestielt; DeckB. lang-scheidig, die untersten blattig, länger als die Aehre; Narben 3; Frïchte eyf., 3seitig, etwas aufgeblasen, auf der vorderen Seite ziemlich flach, in einen 2sp., geraden, am Rande feingesägt-rauhen Schnabel zugespitzt, kahl, nervig, die seitenst. Nerven ein wenig mehr hervorspringend; Bälge eyf., stumpf, mit einer rauhen Stachelspitze endigend; Halm kahl; Blatthäutchen blattgegenst., längl.; W. rasig. 24. Wiesen, feuchte Triften; zerstr. dch das Geb. Mai. Jun. Der innere Rand d. Zähne der Frucht ist mit kleinen Dörnchen besetzt, wodurch sich C. distans leicht von C. fulva u. Hornschuchiana unterscheidet. 
96. C. bi nervis Sm. Männl. Aehre einzeln, weibl. meist 3, aufrecht, entfernt, gedrungenbth., die unterste weiter entfernt, hervortretend-gestielt; DeckB. scheidig, die untersten blattig, länger als die Aelure; Narben 3; Früchte 3seitig, mit 2 starken, hervortretenden Nerven dchzogen, übrigens schwachnervig, in einen 2sp., geraden, feingesägt-rauhen, auf der vorderen Seite flachen Schnabel zugespitzt, kalıl; Bälge eyf., stumpf, mit eirer rauhen Stachelspitze endigend; Halm kahl; Blätthäutchen blattgegenst., längl.; W. rasig. 24. Trockenere Haiden; Westphal. zw. Bentheim u. Nordhorn; Holst. Mai. Jun. Frïchte purpurn-gefleckt, mit 2 grasgrümen Nerven.

97. C. exte n s a Good. Männl. Aehre einzeln, weibl. 2-4, längl.oval od. rundl., gedrungenbth., die oberen sitzend, ziemlich zsgestellt, die unterste etwas entfernt, eingeschlossen-gestielt; DeckB. sehr lang, länger als der Halm, zuletzt zurückgekrümmt u. weit-abstehend, das unterste kurz-scheidig; Narben 3; Frichte eyf., beiderseits convex, nervig, kahl, in einen kurzen, 2zähnigen, an Rande kahlen Sclinabel zugespitzt; Bälge stumpf, fein-stachelspitzig; Halm ganz glatt; B. schmal-lineal., rinnig; W. rasig. 2. Feuchte O. am Meere v. Ostfriesland bis Holst., Litt. Jun. Jul.

98. C. punctata Gaud. Männl. Aehre einzeln, weibl. meist 3, entfernt, aufrecht, gedrungenbth., die unterste hervortretend-gestielt; DeckB. scheidig, blattig, verlängert, das "unterste ungefähr so lang als der Halm od. länger; Narben 3; Früchte $\epsilon y f$. , beiderseits convex, schwach-nervig, in einen kurz-2zälnigen, am Rande kaßler Schnabel zugespitzt; Bälge zugespitzt, mit einer rauhen Stachelspitzo endigend; Halm ganz glatt; B. schmal-lineal., flach; Blatthäutchen blattgegenst., längl. 24. Grasige Hiigel bei Salzb. u. im Tessin. Apr. Mai.

99. C. laevigat a Sm. Männl. Aehre einzeln, weibl. 3-4, entfernt, aufrecht, walzl., gedrungenbth., hervortretend-gestielt, die unterste weit-entfernt, etwas hängend; DeckB. blattig, verlängert-bescheidet; Narben 3; Früchte eyf., beiderseits convex, nervig, in einen am Rande ein wenig rauhen, haarspitzig-2sp., auf der vorderen Seite flachen Schnabel zugespitzt; Bälge lanzettl., verschmälert-zugespitzt, stachelspitzig; Halm glatt; $B$. breit-lineal.; Blatthäutchen blattgegenst., längl. 24. Feuchte, schattige Wiesen; bei Eupen, Malmedy u. Spaa, bei Clausdorf in d. Gegend v. Kiel. Mai. Jun. C. biligularis DC.

100. C. sylvatica Huds. Männl. Aehre einzeln, selten 2, weibl. 4, entfernt, lang-gestielt, hängend, lineal., lockerbth.; DeckB. blattig, verlängert-scheidig; Narben 3; Früchte elliptisch, 3scitig, kahl, ganz glatt, in einen lineal., berandeten, 2sp., am Rande kahlen Schnabel zugespitzt; Halm glatt; B. breit-lineal.; das blattgegenst. Blatthäutchen fast fehlend. 2. Wälder. Jun.

C. Die Friichte geschnäbelt, der Schnabel stielrund od. zsge- 
drückt u. berandet, doppelthaarspitzig, die Haarspitzen auseinanderstehend. Männl. Aehren meist melurere.

a. DeckB. nicht od. kurz-scheidig. Früchte kahl.

101. C. Pseudo-Cypérus L. Männl. Aehre einzeln, weibl. 4-6, lang-gestielt, hängend, walzl., gedrungenbth.; DeckB. blattig, die unteren kurz-, seltener länger-scheidig; Narben 3; Früchte eylanzettf., in einen doppelthaarspitzigen Schnabel verschmälert, nervig, kahl; Bälge lineal.-pfrieml., rauh; Halm scharfkartig, Kanten rauh. 4. Sumpfige, waldige O. Jun.

102. C. a mpullacea Good. Mänǹl. Aehren 1-3, weibl. 2-3, entfernt, walzl., kurz-gestielt, aufrecht, gedrungenbth.; DeckB. blattig, scheidenlos; Narben 3; Früchte sehr weit-abstehend, fast kugelig, aufgeblasen, kahl, auf d. Rücken meist 7nervig, Schnabel lineal., zsgedriickt, doppelthaarspitzig; Halm stumpf-kartig, glatt. 2. Sumpfige O., Ufer. Mai. Jun.

103. C. vesicaria L. Männl. Aehren 1-3, weibl. 2-3, entfernt, längl.-walzl., sitzend od. kurz-gestielt, aufrecht, gedrungenbth.; DeckB. blattig, scheidenlos; Narben 3 ; Frïchte schief-abstehend, eykegelf., allfgeblasen, in einen zsgedrückten, doppelthaarspitzigen Schnabel verschmälert, kahl, auf $d$. Rücken meist 7nervig; Halm scharfkantig, Kanten rauh. 24. Sumpfige O., Ufer. Mai. Jun.

104. C. paludosa Good. Männl. Aehren 2-3, die unteren Bälge stumpf; weibl. Aehren 2-3, walzl., aufrecht, gedrungenbth., sitzend od. gestielt, Bälge zugespitzt od. haarspitzig; DeckB. blattig, scheidenlos; Narben 3; Friichte eyf., od. längl.-eyf., zsgedrïckt, etwas 3seitig, nervig, in einen kurzen 2zähnigen Schnabel zugespitzt, kahl; Halm scharfkantig, Kanten rauh. 2. Feuchte O., Ufer. Mai. Var. Früchte längl., Bälge begrannt-zugespitzt: C. Kochiana DC.

105. C. riparia Curt. Männl. Aehren 3-5, mit haarspitzigen BäIgen, weibl. 3-4, walzl., aufrecht, gedrungenbth., sitzend od. gestielt, mit haarspitzigen Bälgen; DeckB. blattig, scheidenlos; Narben 3 ; Früchte kegelf., am Rande abgerundet, beiderseits convex, vielnervig, in einen kurzen, spitz-2zähnigen Schnabel übergehend, kahl; Halm scharfkantig, Kanten rauh. 4. Gräben, Fluss- u. Teichufer. Mai. Jun.

106. C. nutans Host. Männl. Aehren 1-2, weibl. 3-4, walzl. od. eyf., aufrecht, sitzend, od. die unteren gestielt, gedrungenbth.; Bälge haarspitzig; DeckB. blattig, scheidenlos; Narben 3; Früchte ey-kege'f., am Rande abgerundet, beiderseits convex, fein-eingedrücktrillig, in einen kurzen, doppelthaarspitzigen Schnabel verschmälert, kalıl; Halm glatt od. an der Spitze cin wenig rauh. 24. Schattige, feuchte O.; im Laaer Wäldchen bei Wien. Apr. Mai.

b. Deckb. nicht scheidig, od. das unterste kurz-scheidig. Früchte kurzh. 
107. C. evoluta Hartm. Männl. Aehren 2-3, weibl. 3, entfernt, walzl., aufrecht, gedrungenbth., sitzend oder die unterste gestielt; Bälge haarspitzig; DeckB. blattig, scheidenlos; Narben 3; Früchte eyf., gedunsen, kurzh.-flaumig, in einen kurzen, doppelthaarspitzigen Schnabel übergehend; Halm scharfkantig, an den Kanten rauh; B. flach, breiter als d. Halm. 2. Ufer; bisher blos am Donauufer im Steinhäule bei Ulm. Mai?

108. C. filiform is L. Männl. Aehren 1-2, weibl. 2-3, entfernt, längl. od. eyf., aufrecht, gedrungenbth., sitzend od. die unterste gestielt; Bälge stachel- od. haarspitzig; DeckB. blattig, das unterste oft kurz-scheidig; Narben 3 ; Früchte längl.-eyf., gedunsen, kurzh.flaumig, in einen kurzen, doppelthaarspitzigen Schnabel übergehend; Halm stumpfkantig, glatt od. an der Spitze ein wenig rauh; $B$. rinnig, kaum breiter als d. Halm. 24. Stehende Wasser, tiefe Sümpfe. Mai. Jun.

c. DeckB. lang-scheidig. Früchte kurzh.

109. C. hirta L. Männl. Aehren 2, weibl. 2-3, aufrecht, längl.walzl., die unteren gestielt, die oberste fast sitzend; Bälge begrannt; DeckB. blattig, das unterste lang-scheidig; Narben 3; Früchte eyf., in einen doppelthaarspitzigen Schnabel zugespitzt, kurzh.; Halm glatt; B. u. Scheiden behaart. 24. Sandige O., feuchte sowohl als trockene. Mai. Jun.

\section{Ordng. GRAMINEEN. Juss.}

I. Gruppe. OLYREEN. Nees. v. Esenb. Bth. 1häusig; die männlichen den weiblichen nicht ähnlich.

\section{ZEA L. Mais.}

1. Z. Mays L. $\odot$. Aus Siidamerika, wird zum ökonomischen Gebrauche kultiv. Jun. Jul.

II. Gruppe. ANDROPOGONEEN. Kunth. Aehrchen vom Rücken her zsgedrückt, 1bth., mit einem spelzigen Ansatz einer unteren $B t h$. oder mit einer unteren männl. Bth. Untere Klappe grösser. Aelirchen an den Gelenken einer Aehre od. Rispe gezweiet, das eine sitzend, das andere gestielt, die endständigen zu 3 , wovon die 2 seitenständigen gestielt, das mittlere sitzend erscheint.

2. ERIÁNTHUS Richard. Wollzucker.

1. E. Ravenna e Palisot de Beauv. R. sehr ästig; B. gekielt; Klappen des sitzenden Aehrchens kahl, des gestielten Aehrchens an der Basis behaart, Haare das Aehrchen umgebend u. v. der Länge desselben. 24. Sandige, feuchte O.; Insel Cherso, Sansego. Jul. Andropogon Ravennae L. spec. Saccharum Ravennae L. syst. 


\section{ANDROPÓGON L. Bartgras.}

1. A. Is cha emum L. Aehren 5-10, fingerig-zsgestellt; Bälge gerillt; die untere Klappe des zwitterigen Aehrchens v. der Basis bis fast zur Mitte behaart, die des männl. Aehrchens kahl; Spindel u. Bthstielchen behaart. 24. Trockene, sonnige O.; zerstr. deh das südl. u. mittlere Geb. Jul. Aug. A. angustifolius Smith.

2. A. pubescens Visiani. Aehren am Ende der Bthstiele zu zweien; Bthstiele verlängert, mit einem kahlen Blatte bescheidet, rispig; die uretere Klappe der Aelurchen behaart, die obere kahl od. an der Spitze spärlich-behaart; die Granne des zwitterigen Aehrchens $6 \mathrm{mal}$ länger als das Aehrchen selbst; Spindel u. Bthstielchen behrart. 7 . Trockene O. auf der Insel Sansego. Tommasini. Aug. Sept.

3. A. distachyus L. Aehren endst., gezweiet; Aehrchen kahl; Halm einfach, aufrecht. 24. Rauhe, sonnige Hügel; Istr. Jul.

4. A. Gryllus L. Rispenäste einfach; die Aelirchen endst. zu 3, seitenständige felılend; Bthstielchen an der Basis bärtig. 24. Hügel u. trockene Wiesen; Litt., südl. Tyrol, Tessin. Jun. Jul.

4. HETEROPÓgON Persoon. Schopfgras.

1. H. Alli o n i i Roem. u. S. Männl. Aehrchen kahl. 2. Felsige O.; suidl. Tyr., Tessin. Jul. Aug. Andropogon contortum Allion.

5. SORGHUM Persoon. Moorhirse.

1. S. ha l e p ens e Pers. Aehren rispig; Rispenäste ästig; Klappen der Zwitterährchen flaumig. 2. Weinberge, unkultiv. O. Litt., siidl. Tyr. Jun. Jul. Holcus avenaceus L.

III. Gruppe. PANICEEN. Kunth. Aehrchen vom Rücken her zsgcdrückt, 1hth. od. 1hth. mit tinem Ansatz einer unteren Bth., welche eine dritte Klappe darstellt. Untere Klappe kleiner, oft sehr klein, an die fluche od. ziemlich flache Seite des Aehrchens arigedrückt.

\section{TRAGUS Desf. Stachelgras.}

1. T. racemosus Desf. $\odot$. Sandige O.; Littor., Südtyrol, Wullis; Wagram bei Wien. Jun. Jul. Cenchrus racemosus L. Lappago racemosa Schreb.

7. PÁNICUM L. Fennich. $($ iv $/$ )

I. Rotte. Digitaria Scopoli. Syntherisma Schrad. Aehrchen in einfache, fast fingerige Aehren geordnet, $z \mathbf{u} 2$, das eine längergestielt.

1. P. sanguinale L. Aehren meist zu 5, fingerig, aufrechtetwas abstehend; B. u. Scheiden zieml. behaart; Aehrchen längl.lanzettl.; die Spelze der geschlechtlosen Bthe kahl, am Rande flaumig, 
auf dem äussersten Seitennerven olne Wimpern. ○. Kultiv. O., Sandwege. Jul.-Herbst.

2. P. ciliare Retzius. Aelhren meist zu 5, fingerig, aufrechtetwas abstehend; B. u. Scheiden zieml. behaart; Aehrchen längl.-lanzettl.; Spelze der geschlechtlosen Bthe kahl, am Rande fluımig, auf dem äusserston Seiterinerven steifh.-geuimpert. $\odot$. Sandfelder; sehr zerstr. deh d. Geb. Jul.-Herbst.

3. P. glabrum Gaudin. Aeliren meist zu 3, fingerig; B. u. Scheiden kahl; Aehrchen elliptisch, flaumig, auf den Nerren kahl. $\odot$. Felder u. Aecker mit Sandboden. P. Ischaemum Schreb.

II. Rotte. Echinochloa Beauv. Aehrchen rispig, die Rispe aus einseitigen, zsgesetzten Aehren gebildet. Klappen in eine Stachelspitze od. rauhe Granne verschmälert.

4. P. Crus-galli L. Aelren wechsel- u. gegenst., zsgesetzt, lineal.; Aehrchen genähert, begrannt; Spindel an d. Basis 5kantig. ○. Aecker, etwas feuchte O. Jul. Aug. Var.: kurz- u. langbegrannt.

III. Rotte. Milium. Aehrchen rispig. Die Rispe ausgebrei• tet od. geknäuelt. Die Klappen in eine kurze Granne zugespitzt od. grannenlos.

5. P. miliace um L. R. weitschweifg, ausgebreitet, üherhangend; B. lanzettl. u. nebst den Scheiden behaart; Klappen zugespitzt-stachelspitzig. (-). Aus dem Oriente eingebracht, zum Küchengebraucho kultiv. Jul. Aug.

6. P. capillare L. R. ueitschweifig, abstehend, Aeste sehr dürn, steif; Klappen zugespitzt-stachelspitzig; B. u. Scheiden sehr rauhh. $\odot$. An kultiv. O. um Wien verwildert. Jul. Aug.

IV. Rotte. Oplis m en us Palis. Orthopogon R. Brown. Aehrchen in armbth. Buischel od. kurze Aeliren, welche wechselweise u. in Zwischenräumen an der gemeinschaftlichen Spindel stehen, geordnet. Die untere Klappe sehr lang-begrannt.

7. P. undulatifolium Arduin. Büschel meist 10, ir cine un. terbrochene Aelure geordnet, armbth.; Klappen kahl, gewimpert, begrannt, Grannen kahl, stumpf; Spindel, Halm u. Scheiden von abstehenden Haaren rauhl.; B. ey-lanzettf., wellig. $\odot$. Schattige Wälder; Litt. bei Aquileja, südl. Tyr., Tessin. Aug. Sept. P. hirtellum All. Wulf.

8. SETÁRIA Palis. de Beauv. Borstengras.

1. S. verticillata Beauv. R. ährenf., gedrungen, an der $\mathrm{Ba}$ sis oft unterbrochen; Hüllen durch rïckwärtsgekehrte Zähnchen rauh; Spelzen d. Zwitterbth. ziemlich glatt. $\odot$. Kultir. O., Flusskies; zerstr. dch. d. Geb. Jul. Aug. Panicum verticillatum L.

2. S. viridis Beauv. R. ährenf., walzl.; Hüllen dch vorwärts. 
gerichtete Zähnchen rauh; Spelzen d. Zwitlerbth. zieml. glatt, so lang als die Spelze der geschlechtlosen Bth. ○. Kultiv. O., Sandfelder. Jul. Aug. Panicum viride L.

3. S. gl a u c a Beauv. R. ährenf., walzl.; Hüllen dch vorwärtsgerichte Zähnchen rauh; Spelzen der Zwitterbth. quer-runzelig, noch einmal so lang als die Spelze der geschlechtlosen Bth. $\odot$. Kultiv. O., Sandfelder. Jul. Aug. Panicum glaucum L.

4. S. it ali ca Beauv. $R$. ährenf., doppelt-zsgesetzl, lappig; Hüllen dch vorwärtsgerichtete Zähnchen rauh; Spelzen der Zwitterbth. ziemlich glatt. $\odot$. Kultiv. O., Wege; Tessin, ausserdem kultiv. Jul. Aug. Die Hüllen viel länger als die Aehrchen. Var. Hüllen nur ein wenig länger: $\mathrm{P}$. germanicum Roth.

IV. Gruppe. PHALARIDEEN. Kunth. Aehrchen v. d. Seite her zsgedrückt, 1bth., mit einem spelzigen Ansatze zu ciner zweiten od. dritten unteren Bth., od. mit einer od. zwei unteren männl. Bth. Gf. lang; Narben fädl. od. fast sprengwedelf., aus d. Spitze des Aehrchens hervortretend.

9. PHALARIS L. Glanzgras.

1. Ph. canariensis L. R. ährenf., oval; Klappen zugespitzt, am Rande 1nervig, auf dem Rücken geflügelt, mit einem ganzrandigen Flügel; die 2 unfruchtbaren Bth. halb so lang als die fruchtbare; Spelzen der letzteren angedrückt-behaart. $\odot$. Kultiv. O., Wege; Istrien, ausserdem hin $u$. wieder verwildert. Jul. Aug.

2. Ph. min or Retz. R. ährenf., längl.; Klappen zugespitzt-stachelspitzig, am Rande 1nervig, auf dem Rücken geflügelt, mit einem ausgehissen-gezähnelten Flügel; die eine unfruchtb. Bthe sehr klein, die andere halb so lang als die fruchtbare; Spelzen der letzteren angedrückt-behaart; Halm an der Basis gleich. $\odot$. Am Meere; Littor. zw. Fiume u. Laurana. Mai. Jun. Ph. aquatica Ait.

3. Ph. a qu a ti c a L. R. ährenf., längl.; Klappen zugespitzt-stachelspitzig, am Rande 1nervig, auf dem Riicken geflügelt, mit einem ausgebissen-gezähnelten Flügel; die eine unfruchtbare Bth. sehr klein, die andere fehlend; Spelzen der fruchtbaren Bth. kahl; Basis des Halmes knollig-verdickt. 24. Feuchte O. bei Stramare in der Gegend v. Triest. Mai. P. caerulescens Desf.

4. Ph. paradoxa L. R. ährenf., walzl.; Aestchen 6 Aehrchen tragend, das mittlere zwitterig, die seitenst. geschlechtlos 2-od. 4 mal kleiner, die 4 vorderen der unteren Aestchen keulig, sehr stumpf, kleingekerbt; Klappen d. fruchtbaren Bth. lang-zugespitzt, am Rande 3 nervig, auf d. Mitte des Rückens geflügelt, mit einem lanzettl., zahnf. Flügel. $\odot$. Kultiv. O., Wege; Istrien. Neue Aufschüttung bei Triest. Mai. Jun.

5. Ph. ar undinacea L. $R$. abstehend; Aehrchen büschelig-zsge- 
stellt; Klappen fligellos; dic Zwitterbthe kahl, die unfruchtbaren behaart. 4. Ufer, stehende Wasser. Jun. Jul.

\section{HIERÓCHLOA Gmelin. Darrgras.}

1. H. od or a ta Wahlb. R. ansgesperrt; Bthstielchen kahl; dio Zwitterbthe wehrlos, die männl. Bth. unter d. Spitze sehr kurz-begrannt, W. kriechend. 2. Fenchte Wiesen; nördl. Geb. u. Schles., Böhm., Mähr., bei München selten. Mai. Jun. Hierochloa borealis Roem. et Schult. Holcus borealis Schrad.

2. H. a ustralis R. u. Schult. R. ausgesperrt; Bthstielchen an der Basis der Aehrchen behaart; die Zwitterbthe wehrlos, die unter'e männl. Bth: unter d. Spitze sehr kurz-begrannt, mit einer geraden Granne, die obere männl. Bthe auf der Mitte des Rückens mit einer geknieten Gianne; W. kriechend. 24. Schattige Wälder; zerstr. dch das südl. u. nittl. Geb. März. Apr.

\section{ANTHOXÁNTHUM L. Ruchgras.}

1. A. o dorıtum L. R. ährenf., längl., ziemlich locker; die untere Klappe halb so lang als das Aehrchen, spitz; Spelze der unfruchtbaren Bthen angedriickt-behaart, abgerundet-stumpf, halb so lang als die innere Klappe. 2. Wiesen, Wälder. Mai. Jun.

12. IMPERÁTA Cyrill. Imperate.

1. I. cylindrica Pallis de Beauv. 2. Olivenwälder, Weinberge; Istrien u. die Inseln. Jul. Aug. Imperata arundinacea Cyrill. Lagurus cylindricus $\mathrm{L}$.

V. Gruppe. ALOPECUTRIDEEN. Aehrchen v. d. Seite her zsgedrückt, 1bth., od. 1blh. mit einem Ansatze zu einer oberen Bthe, rispig od. in einer einfachen $\mathrm{Tr}$. wechselständig. Klappen so lang als die Bthe od. länger. Gf. lang; Narben verlängert, fädl., behaart, aus der Spitze des Aehrcheris hervortretend.

\section{ALOPECÚRUS L. Fuchsschwanz. Mfy"}

1. A. pratensis L. Halm aufrecht, kahl; R. ährenf., walzl., stumpf; Aeste der R. 4-6 Aehrchen tragend; Klappen spilz, unterhalb d. Mitte zsgewachsen, zottig-gewimpert; die Rhizome schief, kurz od. kurz-ausläuferartig. 2. Wiesen. Mai. Jun. Die Wurzel auf Sandboden etwas kriechend. Granne bald cingeschlossen, bald hervortretend.

2. A. nigricans Hornem. Halm aufrecht, kahl; R. ährenf., walzl., stumpf; Aeste der R. 4-6 Aehrchen tragend; Klappen spitz, unterhalb der Mitte zsgevachsen, zottig-gercimpert; die Ausläufer weitumherkriechend. 2. Wiesen um Hamburg. Maj. Jun. Aehrchen 
bei der Reife schwarz, bei der vorhergehenden verbleicht od. selten an der Basis schwärzl.

3. A. agrestis L. Halm aufrecht, oberwärts ein wenig rsuh; R. ährenf., walzl., beiderseits verschmälert; Aeste der R. 1-2 Aehrchen tragend; Klappen bis zur Mitte zsgewachsen, zugespitzt, am Kiele schmal-geflügelt, sehr kurz gewimpert. $\odot$. Aecker. Jun.Jul.

4. A. geniculatus L. Halm aus liegender Basis aufstebend, kahl; R. ährent., walzI.; Aehrchen eyf.-längl.; Klappen stumpf, gewimpert, nur an der Basis zsgewachsen; Spelze unter der Mitte begrannt. $\odot$. Gräben, Siimpfe, feuchte O. Mai-Aug. Stbk. gelbl.weiss, nach d. Verbliihen braun; Granne fast noch einmal so lang als ihre Spelze.

5. A. fulvus Sm. Halme aus liegender Basis aufstrebend, kahl; R. ährig, walzl.; Aehrchen elliptisch; Klappen stumpf, gewimpert, nur an der Basis zsgewachsen; Spelze aus d. Mitte begrannt. $\odot$. Gräben, Sümpfe. Mai. Aug. A. paludosus Palis. Bscheiden hechtblau. Stbk. rothgelb. Granne kaum länger als der Balg.

6. A. utriculatus Pers. Halme aufrecht u. aufstrebend; Aehre eyf. od. eyf.-längl., Aeste 1-2 Aehrchen tragend; Klappen bis zur Mitte verwachsen u. allmählig verbreitert, über der Mitte plötzlich in eine plattgedrückte Vorspitze zsgezogen; die oberste Bscheide. schlauchig - aufgeblasen. $\odot$. Wiesen; Triest, Schlettstadt im Elsass, Blies- u. Saarthal u. von da im Moselthal bei Trier. Mai. Jun.

14. CRYPSIS Aiton. Dornengras.

1.C. acule a t a Ait. Halme ästig, etwas zsgedrückt; $\boldsymbol{R}$. ährenf., halbkugelig, in die blattige Hülle tingesenkt; Bth. 2männig. $\odot$. Sümpfe, feuchte O.; Litt., Unteröstr., Mähr. Jul. Aug. Schoenus aculeatus $\mathrm{L}$.

2. C. schoenoides Lam. Halme ästig, etwas zsgedrückt; $\boldsymbol{R}$. ährenf., oval-längl., an der Basis $v$. der obersten Scheide eingeschlossen; Bth. 3männig. $\odot$. Feuchte O.; Littor. Jul. Aug. Phleum schoonoides $\mathrm{L}$.

3. C. alpecuroides Schrad. Halme einfach, zieml. stielrund; $\boldsymbol{R}$. ährig, längl.-walzenf., nackt; Bth. 3männig. $\odot$. Nasse $0 . ;$ Unteröstr., Mähr. Aug. Sept.

\section{PHLEUM L. Lieschgras.}

1. Ph. tenue Schrad. R. ährig, walzenf.; Aehrchen flach-zsgedrückt, elliptisch; Klappen am Rücken halbmondf-gekrümmt, kurzstachelspitzig, kahl, sehr fein-knotig-rauh. $\odot$. Grasige $0 . ;$ Istr., Insel St. Andrea bei Rovigno. Phalaris bulbosa L.

2. Ph. arenarium L. R. ährenf., längl., an d. Basis meist verschmälert; Klappen lanzettl., in eine kurze Granne zugespitzt, am Kiele steifh.-gewimpert; W, mehṛhalmig; unfruchtbare Blätterbüschel 
fehlend. $\odot$. Sandige 0 . am Meere, auch auf d. Sande bei Mainz, Aachen. Jun. Jul.

3. Ph. Michelii All. R. ährenf., walzl.; Klappen lanzettl., in eine kurze Granne zugespitzt, auf d. Rücken steifh.-gewimpert; $W$. einen Rasen von fruchtbaren Halmen u. unfruchtbaren Blätterbïscheln treibend. 2. Triften d. A. Jul. Aug.

4. Ph. B o ehmeri Wibel. R. ährenf., walzl.; Klappen linenl.längl., schief-abgeschnitten, zugespitzt-stachelspitzig, zsgedrückt, auf dem Rücken steifh.-gewimpert od. rauh; W. einen Rasen von fruchtbaren Halmen u. unfruchtb. Blätterbiischeln treibend. 24. Unkult. O., trockene Wiesen; zerstr. deh d. Geb. Jun. Jul. Phalaris phleoides L.

5. Ph. a speru m Vill. R. ährenf., walzl.; Klappen keilf., abgeschnitten, an d. Spitze aufgeblasen-kantig, stachelspitzig, rauh. Aecker, Weinberge; zerstr. dch d. südl. u. mittl. Geb. Mai. Jun.

6. Ph. pratense L. R. ährenf., walzl.; Klappen längl., querabgeschnitten, in eine Granne plötzlich zugespitzt, am Kiele steifh.gewimpert, Granne dreimal kürzer als d. Balg; Bscheiden walzl. 4. Wiesen. Jun. Jul. An trockenen O. ist der Halm über d. W. zmiebelig-verdickt: $\mathrm{Ph}$. nodosum $\mathrm{L}$.

7. Ph. a l pinum L. R. ährenf., walzl. oder oval; Klappen längl., quer-algeschritten, in eine Granne plötzlich zugespitzt, am Kiele steifh.-gewimpert, Granne so lang, oder kaum um die Hälfte kürzer als der Balg; oberste Bscheide aufgeblasen. 4. Triften der A., VorA., Sudet., Mähr. Gbge. Jun.-Aug. Var.: mit walzlichen, verlängerten u. kurzen, ovalen Aehren, und beide Variet. mit lang-gewimperten Grannen und ohne Wimpern an denselben: letzteres Ph. commutatum Gaud.

8. Ph. echinatum Host. R. ährig, oval; Aehrchen abstehend, die untersten herabgebogen; Klappen eyf.-längl., quer-abgeschnitten, in eine Granne plötzl. zugespitzt, am Kiele steifh.-gewimpert, Granne ein wenig länger als d. Balg. $\odot$. Bergwiesen; Istr. Mai. Ph. felinum Sm.

16. CHAMAGROSTIS Borkhaus. Zwerggras.

1. Ch. minima Borkh. $\odot$. Sandfclder; Rheinfläche v. Philippsburg bis Mainz, Maingebiet bis Würzbg., Holstein. März. Apr. Sturmia minima Hopp. Agrostis minima L. Mibora verna Beauv.

VI. Gruppe. CHLORIDEEN. Kunth. Achrchen v. der Seite her zsgedrückt, 1bth. (bei ausländischen 2-vielbth.), in einseitige Aehren geordnet $\mathfrak{u}$. zwar auf der unteren Seite der Aehrenspindel eingefügt.

17. CÝNODON Richard. Hundszahn.

1. C. Dactylon Pers. Aehren zu 3-5fingerig; Spelzen kahl, 
ctwas gewimpert; B. unterseits behaart; Ausläufer gestreckt. 4 . Sandfelder, Wege; sïdl. u. westl. Geb., sehr zerstr. d. dch übrige. Jul. Aug. Panicum Dactylon L.

18. SPARTINA Schreb. Besengras.

1. S. stricta Roth. Aehren 2, 4, angedrückt; Aehrchen flaumig, locker-dachig, aufrecht; B. eingerollt. 24. Schlammige, vom Meereswasser getränkte Wiesen auf dem rechten Ufer des Isonzo, gegen Aquileja u. Gardo, sumpfige O. am Ufer des Meeres bei Monfalcone. Ang. Sept.

VII. Gruppe. ORYZEEN. Kunth. Aehrchen v. der Seite her zsgedrückt. Klappen fehlend od. sehr klein.

19. LEERSIA Solander. Leersie.

1. L. oryzoides Schwartz. R. abstehend, Aeste schlängelich; Aehrchen 3männig, halboval, gewimpert. 2. Gräben, Ufer. Aug. Sept. Phalaris oryzoides $\mathbf{L}$.

\section{COLEÁNTHUS Seidel. Scheidenblüthgras.}

1. C. subtilis Seid. $\odot$. Ansgetrocknete Fischteiche, sumpfige O. in Böhm. Jul.-Sept. Schmidtia utriculosa Sternb.

VIII. Gruppe. AGROSTIDEEN. Kunth. Aehrchen v. d. Seite her mehr od. weniger zsgedrückt, 1 bth. oder 1 bth. mit einem Ansatze zu einer oberen Bthe. Deckspelzen 2. Gf. fehlend od. kurz; $\mathbf{N}$. federig, an der Basis des Aehrchens heraustretend. Karyopse mit den häutigen Spelzen bedeckt.

21. POLYPÓGON Desf. Bürstengras.

1. P. monspeliensis Desf. R. gedrungen, lappig; Klappen längl., kurzh.-rauh, aus der kurz-ausgerandeten, stumpf-2lappigen Spitze begrant, Granne $3 \mathrm{mal}$ so lang als ihre Klappe; Bthe ganz oben unter der Spitze begrannt; W. faserig. $\odot$. Feuchte $O$. am Mecre; Littor., Istrien, auf dem Ramis, einem Sandsteinfelsen in der Stadt Freiburg in der Schwz. Mai. Jun. Alopecurus monspeliensis L.

2. P. littoralis Smith. R. gedrungen, lappig; Klappen lineal.: lanzettl., ein wenig rauh, aus d. Spitze begrannt, Granne der unteren Klappe so lang als die Klappe selbst, die der oberen kürzer; Bth. unter der Spitze begrannt; W. kriechend. 24. Am Meere im Nordwest. d. Insel Norderney. Jul. Aug. Agrostis littoralis Sm.

22. AGRÓsTIS L. Windhalm.

a. Vilfa Beauv. Die B. alle flach. Die obere Spelze nicht fehlend.

1. A. stol onifera L. var. $\beta$. Die blüthetrag. R. längl.-kegelf., 
Aeste wagerecht-abstehend, Aestchen gegen d. Seiten der Aeste u. abwärts-gerichtet, die fruchttragende R. zsgezogen; Aeste u. Bthstielchen rauh; Blatthäutchen längl.; B. alle lineal., flach. 2. Wiesen, unkult. O., Wälder, Ufer. Jun. Jul. R. gefürbt oder grün, letztere : A. alba L. Aehrchen grannenlos, selten begrannt. Var. $\beta$. gigantea: grösser, reichblüthiger. A. gigantea Roth. $-\gamma$. prorepens: meist niedriger, weit u. breit herumkriechend; R. dicht-gedrungen, lappig u. meist satt-gefärbt; im Flusskiese u. an sandigen $O$. hie u. da: A. alba $\beta$. stolonifera Meyer.; auf höheren Gbgen u. A. kleiner, R. sattviolett: A. pauciflora Schrad., A. patula Gaud. - $\delta$. maritima: weit $u$. breit umherkriechend; $R$. gedrungen, B. bläulichgrün: A. maritima Lam., A. stolonifera $\beta$. L. spec. - Lebendiggebärende Expl.: A. sylvatica Huds.; Bth. deh Brand verdorben: A. alba pumila Kunth.

2. A. vulgaris Withering. R. im Umriss längl.-eyf., während u. nach der Bthezeit weit-abstehend, Aestchen gesprcitzt, nach allen Seiten hin gerichtet, etwas rauh; Blatthäutchen kurz, abgeschnitten; B. alle lineal., flach. 2. Mit d. Vorhergeh. Jun. Jul. Var. $\beta$. stolonifera: Ausläufer an sandigen $O$. verlängert kriechend: A. stolonifera $\alpha$. L. Var. selten mit begrannten Aehrchen: A. vulgaris $\varepsilon$. M. et. K. D. Fl. mit Ausschluss der A. rubra L., die in dem Gebiete noch nicht gefunden wurde. - Lebendiggebärende Expl.: A. sylvatica Pollich; Bth. deh Brand verdorben: A. pumila L.

b. Trichodium Michaux. Die Wurzelblätter zsgefaltet-borstlich. Die obere Spelze meist fehlend.

3. A. c anina L. R. ausgebreitet, eyf.; Aeste rauh, während der Bthezeit auseinanderfahrend, nach dem Verblühen zsgezogen; untere Spelze unter der Mitte des Rückens begranrt, an d. Spitze fein-gekerbt, obere fehlend od. sehr klein; WB. zsgefaltet-borstl.; Blatthäutchen längl. 2. Feuchte Wiesen u. Haiden. Jun.-Aug. Auf trockenen Orten kleiner: A. alpina Leyss. Roth.

4. A. alpina Scopol. R. abstehend; Aeste u. Bthstielchen rauh; untere Spelze an der Basis begrannt, an der Spitze kurz-2borstig, obere sehr klein; WB. gefaltet-borstl.; Blatthäutchen längl. 24. A., VorA., Schwarzw., Mähr. Gbg. Jul. Aug. Trichodium rupestre Schrad.

5. A. rupestris All. R. abstehend; Aeste u. Bthstielchen kahl; untere Spelze an $d$. Spitze feingekerbt, mit einer unterhalb der Mitte des Rückens hervortretenden Granne; WB. zsgefaltet-borstl.; Blatthäutchen längl. 2. A., VorA., Schwarzw., Sudet. Jul. Aug. Trichodium alpinum Schrad.

\section{APÉRA Adans., Beauv. Windfahne.}

1. A. Spicarenti Beaur. $R$. weitschweifig; Bth. unter der Spitze begrannt, Granne gerade od. etwas schlängelich, 3- od. 4 mal so lang als ihre Spelze; Stbk. lineal.-längl. $\odot$. Aecker, auch an unkultiv. O. 
Jun. Jul. Agrostis spica venti L. - Die Agrostis purpurea Gaud. ist noch weiter $\mathrm{zu}$ beobachten.

2. A. interrupta Beauv. $R$. schmal, zsgezogen; Bth. unter der Spitze begrannt, Granne gerade od. etwas schlängelich, 3- od. $4 \mathrm{mal}$ so lang als ihre Spelze; Stbk. rundl.-oval. $\odot$. Aecker u. unkultiv. O.; südl. Geb.; Salzderhelden in Hannov. Jun. Jul. Agrostis interrupta $\mathbf{L}$.

24. LAGÚRUS L. Sammetgras.

1. L. ovatus L. $\odot$. Hügel, Weinberge in Istr. Jun. Jul.

\section{CALAMIAGRÓSTIS Roth. Reithgras.}

I. Rotte. Epigeios. Spelzen häutig, dchscheinend-weiss. Ansatz $z u$ einer zweiten Bthe fellend.

1. C. lance ol a ta Roth. R. abstehend; Klappen schmal-lanzettl., zugespitzt; Haare länger als d. Spelzen; Grarıne endst, gerade, aus einer sehr kurzen Ausrandung hervortretend u. kaum länger als diese. 2. Feuchte Wiesen; zerstr. dch d. Geb. Jul. Aug. Arundo Calamagrostis $\mathrm{L}$.

2. C. littorea DC. R. abstehend; Klappen schmal-lanzettl., in eine pfriemliche, zsgedrückte Spitze verschmälert; Haare länger als die Spelzen; Granne endst, gerade, so lang od. länger als die Hälfte ihrer Spelze. 2. Flusskies, Ufer; südl. Geb., Harz an d. Bude. Jul. Aug. Arundo littorea Schrad. A. Pseudophragmites Hall. fil.

3. C. e pigeios Roth. $R$. steif, abstehend, gєkräuelt-lappig; Klappen lanzettl., in eine pfriemliche, zsgedrückte Spitze endigend; Haare länger als die Spelzen; Granne aus der Mitte des Rückens herisortretend, gerade. 4. Waldige O., Sandfelder. Jul. Aug. Arundo epigeios L.

4. C. Halleriana DC. R. abstehend; Aehrchen fast gleichf.zerstreut; Klappen lanzettl., zugespitzt; Haare länger als die Spelzen; Granne untcrhalh des Rückens eingefügt, gerade. 2. Waldige, feuchte O. d. VorA., Sudet., Erzgeb., Harz u. nördl. Geb. Jul. Aug. Arundo Halleriana Gaud. A. Pseudophragmites Schrad., nicht Hall. Var.: Aehrchen grannenlos.

5. C. tenell a Host. R. abstehend; Klappen lanzettl., spitz, Haare halb so lang als die Spelzen, die obere grannenlos od. auf dein Rücken begrannt; Granne gerade. 2. Triften d. A., Wälder d. VorA. Jul. Aug. Var. $\alpha$. Aehrchen grannenlos: Arundo tenella Schrad.

- $\beta$. Aehrchen begrannt: A. tenella Host.

II. Rotte. Deyeuxia Beauv. Ansatz" zu einer zweiten Bth. in einem behaarten, aus der Basis der oberen Spitze hervortretenden Stielchen bestehend.

6. C. stricta Spreng. $R$. schmal, abstehend, steif; Klappen spitz; 
Haare kürzer als die Spelzen; Granne unterhalb der Mitte des Rückens entspringend, gerade. 2i: Feuchte Wiesen; nördl. Geb. Jul. Aug. Arundo stricta Timm.

7. C. montan a Host. R. abstehend; Kilappen zugespitzt; Haare so lang als $d$. Spelzen od. fast um d. Hälfte kürzer; Granne rïckenst., gekniet, kaum über die Klappen hinausragend. 24. Wälder, Gbge u. VorA.; zerstr. deh d. Geb. Jul. Aug. Arundo varia Schrad. Var. $\beta$. acutiflora: höher, Klappen schmäler, pfriemlicher: Arundo acutiflora Schrad.

8. C. sylvatica DC. R. abstehend; Klappen zugespitzt; Haare 4 mal kürzer als die Spelzen; Granne rückenständig, gekniet, über die Klappen hinausragend. 24. Waldige O.; zerstr. dch d. Geb. Jul. Aug. Arundo sylvatica Schrad.

26. PSAMnIA Beauv. Sandried.

1. Ps. arenaria R. et. S. R. älrenf., gedrungen, walzl., oberwärts verschmälert; Klappen lineal.-lanzettl., spitz; Haare 3mal kürzer als die Spelzen; B. eingerollt. 24. Sandige O. am Meere des nördl. Geb. u. sandige O. im Binnenlande bis Wittenberg; auch bei Dresden u. Darmstadt. Jul. Aug. Arundo arenaria L. Ammophila arenaria Lk.

2. Ps. baltica R. et. S. $R$. ährenf., gedrungen, lanzettl., spitz; Klappen lanzzettl., in eine pfriemliche Spitze verschmälert; Haare halb so lang als die Spelzen; B. eingerollt. 2. Sandige O. am Meere; nördl. Geb. Jul. Aug. Arundo baltica Flügge. Ammophila baltica Lk.

27. GASTRIDIUM Beauv. Nissengras.

1. G. I endigerum Gaud. $\odot$. Aecker, kultiv. O.; Genf, Istr. Jul. Milium lendigerum L. Var. grannenlos.

IX. Gruppe. STIPACEEN. Kunth. Aelvchen convex, vom Rücken her ein wenig zsgedrückt oder stielrund, 1bth. Untere Klappe grösser. Gf. fehlend od. kurz; N. federig, an den Seiten des Aehrchens heraustretend. Karyopse von den erhärteten, knorpeligen od. papierartigen Spelzen dicht-eingewickelt.

\section{MÍLIUM L. Milisgras.}

1. M. effusum L. R. abstehend; Spelzen spitz; Halm kahl ; B. lanzettl.-lineal. 24. Schattige Wälder. Mai-Jul. Rispe griin, var. selten: Aehrehen auf der einen Seite purp., v. Shuttleworth am unteren Aargletscher gefunden.

\section{PIPTÁTHERUM Beauv. Grannenhirse.}

1. P. paradoxum Beauv. R. abstehend; Aehrchen ey-lanzettf; Spelzen flaumig; B. flach. 4. Wälder; Krain, Istr. Mai. Jun. Milium paradoxum $L$. 
2. P. multiflorum Beauv. R. abstehend; Aehrchen ey-lanzettf.; Spelzen kahl; B. flach. 24. Waldige 0.; siidl. Tyrol, Istr. Jun. Jul. Milium multiflorum Cav. Agrostis miliacea L.

30. STIPA L. Pfriemengras.

1. S. pennata L. R. an der Basis eingeschlossen; Granner sehr lang, gekniet, federig, an d. Basis bis zu dem vierten Theile ihrer Länge kahl; untere Spelze unterwärts mit 5 seidigen Linien bezeichnet. 24. Trockene, somnige Hïgel, Sandfelder; zerstr. dch $d$. Geb. Mai. Jun.

2. S. capillata L. R. an der Basis eingeschlossen; Grannen sehr lang, gekniet, kahl; untere Spelze unterwärts mit 5 seidigen Linien bezeichnet. 2. Dürre, sonnige Hügel; zerstr. deh d. Geb. Jul. Aug.

3. S. Ar istella L. R. schmal, zsgezogen; Grannen gerade, kahl, noch einmal so larg als die Bthe; Spelzen ïberall angedrückt-flaumig. 2. Rauhe 0.; Istr. Jul. Aug.

31. LASIAGRÓSTIS Link. Rauhgras.

1. L. Calamagrostis Link. R. abstehend; Granne 3mal so lang als die Bthe. 24. Felsige O.; VorA., Schwz., Tyr., Krain. Jul. Aug. Agrostis Calamagrostis L. Arundo speciosa Schrad.

X. Gruppe. ARUNDINACEEN. Kunth. Aehrchen 2-reichbth. Gf. verlängert. N. sprengwedelf., aus der Mitte od. über d. Mitte der Bthe hervortretend.

32. PHRAGMÍTES 'Trinius. Rohrschilf.

1. Ph. com $\mathrm{mun}$ is Trin. R. ausgebreitet; Aehrchen $4-5 \mathrm{bth}$. 4. Stehende Wasser, Ufer. Aug. Sept. Arundo Phragmites L: Var. $\beta$. pallescens: mit bleichbraunen Aehrchen, im Uebrigen in keinem Merkmal verschieden: Arundo Phragmites $\beta$. flavescens Custor. Phragmites isiaca Rchb. fl. exc., ob auch Arundo isiaca Delile?

33. ARÚNDO L. Rohr.

1. A. donax L. R. sehr ästig, etwas abstehend; Aehrchen meist 3bth.; untere Spelze an der Spitze doppelt haarspitzig u. begrannt, auf d. Rücken mit verlängerten Haaren besetzt. 2. Sumpfige O.; Istr., Littor., südl. Tyrol; daselbst auch kultiv. Oct.

XI. Gruppe. SESLERIACEEN. Aehrchen 2-reichbth. Balg gross, fast die Bthen bedeckend. Gf. fehlend od. sehr kurz; Narben fädlich, aus der Spitze der Bthe hervortretend, gezähnelt od. kurz-behaart.

\section{ECHINÁRIA Desf. Klettengras.}

1. E. capitata Desf. ○. Grasige O.; Istrien. Mai. Jun. Cenchrus capitatus L. 
35. SESLERIA Arduin. Seslerie.

1. S. ten uifolia Schrad. Aehre länglich; Aehrchen meist 3bth.; untere Spelze in 2-4 Borsten $u$. in eine Granne aus d. Mitte endigend, Borsten $u$. Granne nicht halb so lang als die Spelze; B. schmallineal., stumpf od. kurz-zugespitzt, rinnig od. zsgerollt; Scheiden zuletzt in schiängelich-vєrwebte Fäden aufgelöst; W. rasig u. zugleich ausläufertreibend. 24. Steinige 0 . am Ufer des Meeres; Triest, Fiume. Mai. Expl. mit dickeren, starreren Blättern: S. juncifolia Host.

2. S. c a e rule a Arduin. Aehre oval-längl., meist einseitswendig; Aehrchen 2-3bth.; untere Spelze in 2-4 Borsten u. eine Granne aus der Mitte endigend; Borsten $u$. Granne nicht halb so lang als d. Spelze; B. lineal., flach, an d. Spitze plötzl. in eine rauke Stachelspitze zsgezogen; Scheiden ungeth., zuletzt am Rande gespalten; W. rasig; Ausläufer fehlend. 24. Felsige O., besonders Kalkfels.; zerstr. deh d. südl. u. mittl. Geb. Apr. Mai. Cynosurus caeruleus L.

3. S. el ong a ta Host. Aehre verlängert-walzl.; Aehrchen meist 3bth.; untere Spelze in 2-4 Borsten u. eine Granne aus d. Mitte endigend; Borsten $u$. Granne nicht halb so lang als d. Spelze; $B$. lineal., rinnig, in eine sehr rauhe Spitze verschmälert; Scheiden ungeth., zuletzt am Rande gespalten; W. rasig u. ausläufertreibend. 2 . Felsige O., trockene Wiesen; Krain, Littor., Fiume. Aug.-Herbst; blühet seltener im Frühling; letztere ist $\mathrm{S}$. elongata Visian.

4. S. microcephala DC. Aehre eyf.; Aehrchen 2bth., untere Spelze 5grannig, mittlere Granne länger als die Spelze; B. schmallineal., stumpflich. 24. Felseuspalten u. steinige O. der höchsten A ; Oestr., Stmk., Kärnth., Salzb., Watzmann in den bayer. A., Tyrol. Jun. Jul. S. tenella Host.

5. S. sphaerocephala Arduin. Aehre kugelig; Aehrchen meist $3 b$ th.; untere Spelze an der Spitze ausgerandet, aus d. Ausrandung kurz-begrannt; B. schmal-lineal., stumpflich. 2. Felsen der A.; südl. Schwz., Tyrol, Stmk., Kärnth., Salzbg. Jul. Aug. Aehren weissl., selten blau.

6. S. distich a Pers. Aehre eyf., 2zeilig; Aehrchen 3-6bth., untere Spelze grannenlos od. kurz-begrannt; B. fadenf. 24. Felsen der höheren A., Schwz. u. bis Stmk. Jun. Jul. Poa disticha Wulf.

XII. Gruppe. AVENACEEN. Kunth. Aehrchen 2-vielbth., d. endst. Bthe oft verkümmernd. Balg gross, fast das ganze Aehrchen ungebend. Gf. sehr kurz od. fehlend; Narben federig, aus der Basis der Bthe beiderseits hervortretend.

36. KOELERIA Pers. Kölerie.

1. K. cristata Pers. R. ährig, an der Basis unterbrochen; Aehren 2-4bth.; untere Spelze zugespitzt, wehrlos od. stachelspitzig; B. flach, die unteren gewimpert; d. vertrockneten Bscheiden ungeth. 
4. Grasige Hügel, trockene Wiesen. Jun. Jul. Aira cristata L. sp. Var. $\beta$. gracilis: B. sehr schmal; Aehre verlängert, schmal, schlank. K. cristata $\gamma$. DC. fl. fr. $-\gamma$. major: Halm 2 Fuss lang u. länger; R. fast $1 / 2$ Fuss lang, lappig; Aehrchen 4 Linien lang. K. cristata $\gamma$. DC. Poa pyramidata Lam.

2. K. gl a u c a DC. R. ährig, an der Basis unterbrochen; Aehrchen 2-3bth.; untere Spclze stumpfl., wehrlos od. mit einem auf der stumffer Spitze aufgesetzten Stachelspitzchen; $B$. flach, kahl; die vertrockncten Bscheiden ungeth. 24. Sandfelder; zerstr. deh d. Geb. Jun. Jul. Poa glauca Schk.

3. K. valesiaca Gaud. R. ährig, dicht-gedrungen; Aehrchen 2-3bth.; untcre Spelze zugesp., wchrlos od. stachelspitzig; WB. zsgerollt, kahl; die vertrockneten Bscheiden zuletzt in schlängelich-verwebte Fäden aufgelöset. 24. Sonnige Hügel im unteren Wallis. Apr. Mai. Aira valesiaca All. Var. $\beta$. setacea: untere Spelze auf dem Rücken zottig-bewimpert. K. setacea DC.

4. Ir. hirsuta Gaud. R. ährig, eyf., od. eyf.-längl.; Aehrchen 2-3bth., zottig; Bth. aus ungeth. od. 2 sp. Spitze begrannt; R. schmallineal., kahl; Halm oberwärts filzig; W. rasig, blühende u. nichtblühende Wurzelköpfe tragend. 24. Felsige Triften d. höchsten A., Schwz., Tyrol. Jul. Aug. Aira hirsuta Schleich.

כ. I. phle oides Persoon. R. ährig, walzl.; Aehrchen 4-5bth., zottig; die unteren Bth. unter d. Spitze begrannt; Grannen über d. Bthe hinausragend, borstl., weich; B. breit-lineal., behaart; Halm kahl; W. mehrhalmig, nichtblühende Büschel fehlend. ○. Kultiv. O. u. Wege; Istrien, um Fiume u. auf d. Inseln. Mai. Jun. Festuca phleoides Vill. F. cristata $\mathbf{L}$.

37. LAMARCKIA Mocnch. Lamarckie.

1. 'L. a urea Moench. $\odot$. Steinige, grasige O.; Istr. Mai. Jun. Cynosurus aureus $\mathrm{L}$.

38. AIRA L. Schmiele.

I. Rotte. Deschampsia Beauv. Granne nur ein wenig einwärts gebogen $\mathrm{u}$. an der Basis kaum gedrehet.

1. A. caespitosa L. B. flach, oberseits sehr rauh; R. weitschweifig, breit-pyramidenf., Bthstielch. rauh; Granne borstl., meist so lang als die Spelze; $W$. dicht-rasig. 4 . Wiesen u. waldige, etwas feuchte O. Jun. Jul. Var. $\beta$. pallida: Klappen gelbl.-weiss, auf d. Rücken grün; Spelzen grün-gelbl., an der Spitze weiss. Aira altissima Lam. Schattige Wälder.

2. A. Wibeliana Sonder. B. Aach, oberseits etwas rauh; R. weitschweifig, längl.-pyramidenf.; Bthstielchen rauh; Granne borstl., meist so lang als d. Spelze; W. Ausläufer treibend. 24. In feuchtem Sande od. im Schlamme am Ufer der Elbe bei Hambg. u. Altona, 
nicht in Sïmpfen. Jun. Jul. A. paludosa Wib., der sie bei Altona sammelte, nicht A. paludosa Roth, die er citirt. A. caespitosa $\gamma$. M. et. K. D. Fl. ist wirklich Varietät u. gehört nicht hieher.

II. Rotte. Avenella. Granne deutlicher in ein Knie gebogen u. an d. Basis gedrehet. Von Avena untersch. sich diese Rotte dch die abgeschnittene, gezähnelte, aber nicht 2zähnige od. doppelt-haarspitzige untere Spelze.

3. A. flexuosa L. R. abstehend, ïberhangend; Bthen kaunt länger als der sehr ungleiche Balg, iiber der Basis begrannt; Stielclien der zweiten Bthe 4 mal kürzer als die Bthe selbst; B. sehr schmal, fast borstlich, stielrund-fädl., nicht ausgehöhlt; Blatthäutchen ziemlich kurz, abgeschnitter. 24. Wälder, Haiden. Jun.-Aug. Avena flexuosa D. Fl. - Die Form mit einer mehr zsgezogenen R. u. dunkler gefärbten Aehrchen: A. montana L. Diese auf trockenen sonnigen $O$., besonders aber auf hohen Gbgen.

4. A. uliginosa Weihe. R. abstehend, aufrecht; Bthen kaum länger als der gleiche Balg, oberhalb der Basis begrannt; Stielchen der zweiten Bthe halb so lang als die Bthe selbst; $B$. sehr schmal, flach od. zsgefaltet; Blatthäutcher längl., verschmälert-spitz. 4. Ueberschwemmte u. morastige, torfige O.; Westphal., Ostfriesland. Aug. Sept., viel später als die vorhergeh.

39. CORYNÉPHORUS Beauv. Keulengranne.

1. C. canescens Beauv. R. abstehend; Bth. kürzer als d. Balg; B. borstlich. 24. Trockene Sandfelder. Jul. Aug. Aira canescens L.

40. HOLCUS L. Honiggras.

1. H. lanatus L. R. abstehend; Granne der männl. Bthe zurückgekrümmt, im Balg eingeschlossen; W. fasserig. 4. Wiesen, Wälder. Jun.-Aug.

2. H. mollis L. R. abstehend; Granne der männl. Bthe geknietèingebogen, über den Balg hinausragend; W. kriechend. 24. Wälder. Jul. Aug.

\section{ARRHENÁTHERUM Beauv. Glatthafer.}

1. A. elatius M. u. Koch. B. flach. 2. Wiesen, Triften, Waldränder. Jun. Jul. A. avenaceum Beauv. Avena elatior L. Var. mit kurz-begrannten u. grannenlosen Aehrchen u. kahlen u. zottigen Halmknoten, u. $\alpha$. vulgare: der Halm an der Basis nicht knollig aufgetrieben, u. $\beta$. bulbosum: der Halm an der Basis in 2-3 übereinanderliegende Knollen verdickt; unterscheidet sich zwar bloss durch dieses Merkmal, scheint aber doch eigene Art. A. elatius $\beta$. D. Fl. 547. A. bulbosum Schlechtd. Avena bulbosa Willd. 


\section{AVÉNA L. Hafer.}

I. Rotte. Avenae genuinae. Aechte Haferarten. Aehrchen wenigstens nach dem Verblühen, hängend. Klappen 5-9nervig. Fruchtkn. an der Spitze behaart. W. jährig; nichtblühende Blätterbüschel fehlend.

1. A. brevis Roth. R. einseitswendig; Bälge meist 2bth., so lang als die Bthen; obere Klappe 7 nervig; Bthen kahl od. oberwärts borstig-behaart, längl., stumpf,-an d. Spitze 2sp. u. gezähnelt; Achse kahl, unter d. Bthen büschelig-behaart. $\odot$. Unter der Saat; Herzogth. Bremen, seltener, häufig aber im Herzogth. Verden; Unteröstr. Jul. Aug.

2. A. sativa L. $R$. abstehend, gleich; Bälge meist $2 \mathrm{bth}$, länger als die Bthen; obere Klappe 9nervig; Bthen kahl, lanzettl., nach d. Spitze verschmälert, an d. Spitze 2sp. u. gezähnelt, die obere Bthe wehrlos; Achse kahl, an d. Basis der untersten Bthe kurzbüschelig-behaart. $\odot$. Kultiv. O. Jul. Aug.

3. A. orientalis Schreb. R. einseitswendig, zsgezogen; Bälge meist 2 bth., länger als d. Bthen; obere Klappe 9uervig; Bthen kahl, lanzettl., nach d. Spitze verschmälert, an d. Spitze 2sp. u. gezähnelt, die obere welirlos; Achse kahl, an d. Basis der untersten Bthe kurz-büschelig-behaart. $\odot$. Kultiv. Jul. Aug.

4. A. strigo sa Schreb. R. fast einseitswendig; Bälge meist 2 bth., so lang als d. Bthen; obere Klappe 7-9rervig; Bthen kahl, lanzettl., nach $d$. Spitze verschmälert, auf d. Rücken begrannt, mit geknieter Granne, an d. Spitze 2sp., mit begrannten $\mathrm{Z}_{p} f i n$. u. geraden Grannen; Achse kahl, an der Basis der oberen Bthe mit einem kurzen Haarbüschel. $\odot$. Kultiv., hie u. da unter d. Saat verwildert. Jul. Aug.

5. A. nuda L. R. etwas einseitswendig; Bälge meist 3bth.; obere Klappe 7-9nervig; Bthen üb. d. Balg hervorragend, lanzettl., kahl, v. d. Basis bis zur Spitze stark-nervig, an d. Spitze haarspitzig2sp., die obere wehrlos; Achse kahl. $\odot$. Hie u. da kultiv. Jul. Ang.

6. A. sterilis L. R. einseitswendig; Bälge meist 4bth.; obere Klappe 9nervig; Bth. lanzettl., an der Spitze gezähnt-2sp., die 2 unteren auf d. Rücken begrannt, v. der Basis bis fast zur Mitte borstig-behaart, die oberen wehrlos $u$. so wie die Achse kahl. $\odot$. Unter der Saat; Istrien, Fiume. Jul. Aug.

7. A. fatua L. R. gleich, abstehend; Bälge meist 3bth.; obere Klappe 9nervig; Bthen lanzettl., an d. Spitze gezähnt-2sp., auf d. Rücken begrannt, v. der Basis bis zur Mitte borstig-behaart od. kahl; Achse rauhh. $\odot$. Unter der Saat. Jul. Aug.

8. A. hirsuta Roth. R. einseitswendig etwas abstehend; Bälge meist 2bth.; obere Klappe 9nervig; Bth. lanzettl., auf d. Rücken begrannt, von d. Basis an fast bis zur Mitte borstig-behaart, an $d$. 
Spitze 2sp., Zpfl. borstl., in eine gerade Grarne auslaufend; Achse rauhh. ○. Aecker, Wiesen, Wege; Fimne u. die Inseln. Jul. Aug.

II. Rotte. Avenastrum. Aehrelien nicht liängend. Klappen 1-3nervig. Fruchtkn. an der Spitze behaart. W. ausdauernd, nicht blühende Blätterbüschel $u$. blühende Halme treibend.

9. A. planiculmis Schrad. R. verlängert, zsgezogen; Aeste zu 2, 3 od. 4, die längeren 2-3 Aehrchen tragend; Aehrchen meist 6bth.; Klappen 3nervig; Fruchtkn. an d. Spitze so wie die Achse behaart; B. kahl, am Rande rauh, die halmst. lanzettl.-lineal.; Scheiden 2schneidig, flach-zsgedrückt. 2. Schles. im Gesenke u. auf d. Schneeberge in d. Grafsch. Glaz. Jul. Aug.

10. A. pubescens I. R. gleich, traubig; Aeste ein einzelnes Aehrchen, die längeren deren 2 tragend, die unteren meist zu 5; Aehrchen 2-3bth.; die urtere Bth. in der Mitte des Rückens begrannt, nach der Spitze zu silberig-trockenhäutig; Klappen einnervig, an der Spitze weiss-trockenhäutig, die obere so lang als das Aehrchen od. etwas kiirzer; Fruchtkn. an der Spitze so wie die Achse behaart; Haare an d. Basis der zweiten Bthe fast halb so lang, als $d$. Bthe selbst; B. lineal., flach, auf beiden Seiten nebst den unteren Scheiden zottig. 24. Wiesen. Mai. Juni.

11. A. a methystina Clarion bei DC. in d. Fl. franc. R. gleich, traubig, Aeste ein einzelnes Aehrchen, die längeren deren 2 tragend, die untersten meist zu 5; Aehrchen meist 2 bth., die unterste Bth. ein Drittel über der Basis begrannt, v. der Mitte bis zur Spitze silberigtrockenhäutig; die Klappen dreinervig, von der Basis bis zu einem Drittel ilhrer Länge gefärbt, die obere länger als das Aehrchen; Fruchtkn. an d. Spitze so wie die Achse behaart, Haare an der Basis der zweiten Bth. fast halb so lang als die Bth. selbst; B. linealisch, flach, auf beiden Seiten nebst den unteren Scheiden zottig. 4. Am Monte Baldo bei St. Giacomo, suidl. Tyrol. Kelchklappen fast noch einmal so gross als an A. pubescens, von der Basis bis zu einem Drittel ihrer Länge violett.

12. A. a lpin a Smith. R. zsgezogen, traubig; Aeste zu 2, ein einzelnes Aehrchen, die längeren seltener deren 2 tragend; Aehrchen meist 8bth., auf dem Rücken oberhalb d. Mitte begrannt; obere Klappe 3nervig; d. Achse behaart, die obersten Haare der Glieder dreimal so lang als die Schwiele; der Fruchtkn. an der Spitze behaart; $B$. lineal., oberseits sehr rauh; Scheiden stiellund. 2. Krainer A., in der Wochein. Jul. Aug.

13. A. pratensis L. R. zsgezogen, traubig, die unteren Acste gezweiet, die oberen einzeln, alle ein einzelnes Aehrchen, od. die längeren $\nabla$. den untersten deren 2 tragend; Aehrchen 4-5bth., auf $d$. Rücken in der Mitte begrannt; obere Klappe 3nervig; Achse behaart, die obersten Haare d. Glieder 3 mal so lang als die Schriele: 
d. Fruchtkn. an d. Spitze behaart; B. lineal., oberseits sehr rauh; Scheiden stielrund. 24. Trockene Wiesen, unkult. O., zerstr. dch d. Geb. Jun. Jul. Die Avena bromoides L., nicht M. et. K. Deutschl. Fl., v. H. Sonder im südl. Frankreich gesammelt, ist der A. pratensis sehr ähnlich, hat aber 6-8 Bth. im Aehrchen, einen sehr kurzen Flaum an der Achse u. Haare an der Spitze der Glieder derselben, die kaum die Schwiele überragen. Diese wäre im Littorale zu suchen.

14. A. versicolor Vill. R. fast eyf., traubig; Aeste gezweiet, ein einzelnes Aehrchen od. deren 2 tragend; Aehrehen 5bth., in der Mitte des Rückens begrannt; obere Klappe 3nervig; $d$. Achse behaart, die obersten Haare der Glieder dreimal so lang als d. Schwiele; der Fruchtkn. an der Spitze behaart; B. lineal., oberseits ziemlich glatt. 2. Triften der höheren A. Jul. Aug. A. Scheuchzeri All.

15. A. s em pervirens Vill. R. ausgebreitet; die mittleren Aeste meist zu 3, die längeren 2-5 Aehrchen tragend; Aehrchen 2-4bth.; Klappe 3nervig; Fruchtkn. an d. Spitze so wie d. Achse behaart; B. steif, oberseits sehr rauh. 2. Felsige Abhänge der A., Oestr., Stmk., Südtyrol. Jul. Aug.

III. Rotte. V entenata Koel. Untere Bthe an d. Spitze, nicht auf d. Rücken, begrannt. Klappen 7-9nervig. Fruchtkn. kahl.

16. A. tenuis Mönch. R. gleich; Aehrchen meist 3bth.; Klappen 7-9nervig; untere Bthe an d. Spitze in eine Granne zugespitzt, auf $d$. Rücken nicht begrannt, die folgenden an der Spitze haarspitzig-2grannig u. auf d. Rücken mit einer gekniet-einwärtsgebogenen Granne versehen; W. faserig. $\odot$. Unkultiv. O. der Gbge; Rheinpfalz bis Niederland., vom Maine bis z. Harz; Unteröstr. Mähr. Jun.

IV. Rotte. Trisetum Persoon. Granne aus der Mitte der Bthe od. oberhalb der Mitte hervortretend. Klappen 1-3nervig. B. lineal., flach. Fruchtkn. kahl, mit Ausnahme, v. A. alpestris.

17. A. flavescens L. $R$. ausgebreitet, gleich; die längeren Aeste 5-8 Aehrchen tragend; Aehrchen 3bth.; obere Klappe 3nervig, längl.-lanzettl., oberhalb d. Mitte zugespitzt; Fruchtkn. kahl; Achse behaart, Haare viel kürzer als d. Bthe; untere Spelze doppelt-haarspitzig dch 2 kurze Borstchen; Halme einfach; B. flach. 4. Wiesen. Jun. Jul.

18. A. alpestris Host. $R$. ausgebreitet, gleich, die längeren Aeste 3-6 Aehrchen tragend; Aehrchen 3bth.; obere Klappe 3nervig, lanzettl., von der Mitte an allmählig verschmälert; Fruchtkn. an $d$. Spitze flaumig; Achse behaart; Haare viel kürzer als d. Bthe; untere Spelze an d. Spitze deh kurze Borstchen doppelt-haarspitzig; Halm einfach; B. flach $u$. nebst den Scheiden behaart. 4. Triften d. A.; Oestr. u. Steyerm. Jul. Aug.

19. A. distichophylla Vill. R. ausgebreitet, gleich, die längeren Aeste 3-4 Aehrchen tragend; Aehrchen meist $3 \mathrm{bth}$; beide Klap- 
pen 3nervig; Fruchtkn. kahl; Achse behaart; Haare an der Basis der unteren Bthe halb so lang als die Bthe; untere Spelze doppelthaarspitzig; Halme an d. Basis liegend u. wurzelnd, sehr ästig; B. flach. 2. Höhere A. auf abschiissigen, nackten Stellen 11. im Kiese der Giessbäche; suidl. Schwz., Tyr., Salzb., Kärnth. Jul. Aug. A. brevifolia Host.

20. A. argentea Willdenow. R. ausgebreitet, gleich, die längeren Aeste 4-8 Aehrehen tragend; Aehrchen meist 3bth.; obere Klappe an der Basis 3nervig; Fruchtkn. kahl; Achse behaart; Haare an der Basis der unteren Bthe ein Drittel so lang als die Bthe; untere Spelze doppelt-haarspitzig; Halme an der Basis liegend u. wurzelnd, sehr ästig; B. flach. 2. Felsen u. Gerölle hoher u. niederer A., Tyrol, Salzb., Kärnth., Stmk. Jul. Aug.

21. A. s ubspicat a Clairv. R. älrig, eyf. od. walzl. u. fast lappig, gedrungen; Aehrehen meist 3bth.; obere Klappe 3nervig; Fruchtkn. kahl; Achse behaart; Haare viel kiirzer als die Bthe; untere Spelze an d. Spitze 2sp., Zpfl. lanzettl., stachelspitzig; Halme meist einfach; B. flach. 24. Höchste A. Jul. Aug. Aira subspicata L. syst.

22. A. Cavanillesii Koch. R. ährig, gedrungen; Aehrchen 2bth.; obere Klappe schwach-3nervig; Fruchtkn. kahl; Achse behaart; Haare ungefähr so lang als die Bthe; Bthe oberhalb d. Mitte des Rückens begrannt, an $d$. Spitze 2borstig, Borsten um die Hälfte länger als die Bthe; Halm an der Spitze so wie die B. u. Scheiden flaumig. $\odot$. Unkult. O., Wege um Montorge bei Sitten u. um St. Leonhard im Wallis. Apr. A. Loefflingiana Cav. Trisetum Cavanillesii Trin.

V. Rotte. Caryophyllea. Granne unterhalb d. Mitte der Bthe hervortretend. Klappen 1-3nervig. Fruchtkn. kahl. B. zsgerollt-borstlich. - Diese Rotte untersch. sich v. Aira dch die an der Spitze doppelt-haarspitzige, nicht abgeschnittene u. gezähnelte untere Spelze.

23. A. caryophyllea Wigg. $R$. abstehend, 3 gabelig; Aehrchen 2bth., an d. Spitze der Aestchen etwas gedrängt; Bthstielchen oft kürzer als die Aehrchen; Balg länger als die Bthen; untere Spelze an d. Spitze doppelt-harspitzig, an beiden Bthen unter d. Mitte des Rückens begrannt; $B$. borstl. $\odot$. Sandfelder, Haiden, Waldränder. Jun. Jul. Aira caryophyllea L. Var. Aehrchen nur an einer Bthe begrannt.

24. A. capillaris M. u. Koch. R. ausgespert, 3 gabelig; Aehrchen $2 b t h$., gleichf.-zerstreut; Bthsticlchen verlängert u. die meisten viel länger als das Aehrchen; Balg länger als die Bthen; untere Spelze an d. Spitze doppelt-haarspitzig, die der unteren wehrlos, die der oberen unterhalb d. Mitte des Rückens begrannt; $B$. borstl. $\odot$. Unkult. O.; südl. Tyrol, Litt. Mai. Aira capillaris Host.

25. A. praecox Beauv. R. längl., ährig-gedrungen; Aehrchen 
2bth.; Balg läuger als die Bthen; untere Spelze an d. Spitze doppelt-haarspitzig, an bciden Bthen unter der Mitte des Rückens begrannt; B. borstl. $\odot$. Unkultiv O. Apr. Mai. Aira praecox I.

43. DANTHONIA DC. Dantlionie.

1. D. provincialis DC. Tr. fast cinfach; Bälge 4-6bth., länger als d. Bthen; untere Spelze an d. Spitze doppelt-haarspitzig; Scheiden an der Spitze bärtig. 24. Bergwiesen, Krain, Littor., südl. Tyrol. Jun. D. alpina Vest.

\section{TRIÓDIA Brown. Dreizahn.}

1. T. decumbens Beauv. R. traubig; Aeste einfach, ein einzelnes Aehrchen od. die unteren 2-3 derselben tragend; Aehrchen längl.-eyf., 3-5bth.; B. flach u. nebst d. Scheiden belıart; Halme niederliegend od. wälırend d. Bthzeit aufstrebend. 2. Wiesen, Haiden, lichte Waldo. Jun. Jul. Festuca decumbens L.

\section{MÉLICA L. Perlgras.}

1. MI. ciliata L. R. ährig, gleich; untere Spelze am Rande $v$. d. Basis bis zur Spitze dicht-gewimpert-zottig; geschlechtlose Bthe längl. 24. Steinige, felsige 0.; zerstr. dch d. südl. u. mittl. Geb. Mai. Jun.

2. M. B a u hin i All. R. locker, fast einseitswendig; untere Spelze vor d. Rande $v$. d. Basis an bis üher d. Mitte gewimpert-behaart; geschlechtlose Bthe kreiself., nach d. Basis verschmälert. 24. Felsige O. Istrien. Jun.

3. M. uniflora Retz. R. locker, einseitswendig; Aeste etwas abstehend; die unteren meist 2 Aehrchen tragend; Aehrchen aufrecht, eyf.; Bthen bartlos, eine einzige vollkommen; B. flach; Blatthäutchen blattgegenst., zugespitzt, fast krautig. 24. Schattige Wälder. Jun. Jul.

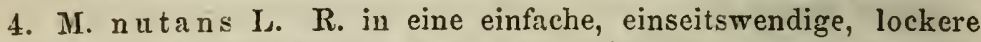
Tr. zsgezogen; Aehrchen hängend, eyf.; Bthen hartlos, zwei vollkommen; B. flach; Blatthäutchen schr kurz, abgeschnitten. 2. Schattige Wälder. Mai. Jun.

XIII. Gruppe. FESTUCACEEN Kunth. Aehrchen 2-vielbth., mit einer oft verkümmerten 'endst. Bthe, gestielt, Balgklappen kürzer als d. nächste Bthe. Gf. sehr kurz od. fehlend; Narben aus d. Basis der Bth. beiderseits heraustretend.

\section{BRIZA L. 'Zittergras.}

1. B. maxima L. R. an der Spitze überhangend; Aehrchen eyf., 9-17bth.; Blatthäutchen verlängert, lanzettl., spitz. ○. Grasige 0.; Istrien, Fiume. Mai. Jun.

2. B. media I. R. aufrecht, abstehend; Aehrchen fast herz- 
eyf., 5-9bth.; Blatthäutchen sehr kurz, abgeschnitten. 24. Wiesen. Jun. Jul.

3. B. minor L. R. aufrecht, ausgebreitet; Aehrchen 3eckig, 5Tbth.; Blatthäutchen verlängert, lanzettl., spitz. 2. Brachäcker; Istrien, C. Waadt bei Vevay. Mai. Jun.

47. ERAGROSTIS Beauv. Liebesgras.

1. E. megastachya Link. Rispenäste einzeln od. gezweiet; Aehren lineal.-längl., 15-20bth.; Bth. auf d. stumpfen, etwas ausgerandeten Spitze kurz-stachelspitzig, mit einem starken, seitenst. Nerven dchzogen; Scheiden kahl, an der Mündung bärtig; W. faserig. ๑. Sandige Brachfelder; zcrstr. deh d. siidl. u. mittl. Geb. Jul. Aug. Briza Eragrostis L. Poa mechastachya Koel.

2. E. poa e oides Beauv. Rispenäste cinzeln od. gezweiet; Aehrchen lanzettl.-lineal., 8-20bth.; Bth. stumpf, mit eiuem seitenst. starken Nerven dchzogen; Scheiden an d. Mündung bärtig; W. faserig. ○. Kultiv. O., Sandfelder; zerstr. dch d. südl. u. mittl. Geb. Jul. Aug. Poa Eragrostis L.

3. E. pilosa Beauv. Die untersten Rispenäste halb-quirlig, zu 4 od. 5; Aehrchen lineal., 5-12bth.; Bth. ziemlich spitz, mit einem schwachen seitenst. Nerven dchzogen; Scheiden an d. Mündung bärtig; W. faserig. (- Kultiv. (). Sandfelder; Istr., Stmk., südl. Tyrol, südl. Schwz., sodann bei Basel, Colmar, Bruchsal, Halle. Jul. Aug. Poa pilosa L.

\section{POA L. Rispengras.}

I. Rotte. Catapodium Link. Aehrchen auf sehr kurzen, dicken Bthstielchen, in eine einfache, 1seitige Aehre od. in eine, aus einfachen, einseitigen Aehren gebildete R. geordnet. Aehrenspindel zsgedruickt, schlïngelich, starr. Bälge u. Spelzen lederig.

1. P. 10 liace a Huds. Aehre starr, 1seitig, 2zeilig, schmal, einfach od. an der Basis ästig; Aehrchen sehr kurz-gestielt, genähert, eyf., spitzl., 5-7bth.; Bth. stumpf; W. faserig. $\odot$. Am Meere; Ins. Brioni, Istr., Fiume, Veglia. Mai. Jun.

2. P. du ra Scop. R. eyf., einseitig, gedrungen, starr, aus kurzen, 3-6 Aehrchen tragenden Achren zsgesetzt; Aehrchen sehr kurzgestielt, längl., 5bth.; untere Spelze lineal.-längl., nervig, stumpf od. ausgerandet, meist kurz-stachelspitzig; W. faserig. $\odot$. Triften, Wege; sehr zerstr. dch d. südl. u. mittl. Geb. Mai. Jun. Cynosurus durus L.

II. Rotte. Poae gen uinae. Aehrchen gestielt, zerstreut in, einer R. Bth. frei od. mit wolligen Haaren zshängend, stumpll., spitz od. zugespitzt.

a. W. faserig, weit-austreibende Ausläufer fehlend.

3. P. a п и a L. R. meist eiuseitswendig, spreitzend; Aeste kahl, 
einzeln oder gezweiet, zuletzt herabgeschlagen; Aehrchen längl.-eyf., 3-7bth.; Bth. kahl; die oberen Blatthäutchen längl.; Halm zsgedrïckt, an der Basis bisweilen wurzelnd $u$. ausläuferf.; W. faserig. ○. Kultiv. u. unkult. O. iiberall. Blïhet deh d. ganze Jahr. Var. P. varia: Aehrchen auffallend bunt. P. annua varia Gaud. P. supina Schrad. Diese auf A.

4. P. l ax a Haenke. $R$. längl., zsgezogen, an der Spitze nickend; Aeste fädl., gezweiet od. einzeln, kahl; Aehrchen eyf., meist 3bth.; Bth. ey-lanzettf., am Rande u. auf d. Rücken dicht-flaumig, meist frei; B. schmal-lineal., verschmälert-spitz; Blatthäutchen alle längl., spitz; W. faserig, rasig. 2. Triften der A., VorA., Sudet. u. Belchen im Schwarzw. Jun.-Aug. Bthstiele u. Bthstielchen zwar dünn, aber doch augenfällig dicker als bei der folgenden Art.

5. P. min or Gaud. $R$. längl., od. fast eyf., zsgezogen, überhangend; Aeste haardünn, gezweiet $u$. einzeln, ziemlich kahl; Aehrchen längl.-eyf., 4-6bth.; Bth. lanzettl., am Rande u. auf dem Rücken dicht-flaumig, an d. Basis dch Wolle zshängend; B. schmal-lineal.; Blatthäutchen alle längl., spitz; W. faserlg, rasig. 2. Triften u. Flussbette der A. Jul. Aug.

6. P. pumila Host. R. aufrecht, spreitzend; Aeste gezweiet $u$. einzeln $u$. nebst den Aestchen fast rechtwinkelig auseinanderfahrend, rauh; Aehrchen während des Aufblühens fast gleichf.-zerstreut, eyf., 4-6bth.; Bth. längl. - lanzettl., am Rande u. auf d. Rücken dichtflaumig, frei; B. schmal-lineal.; Blatthäutchen alle längl., spitz; W. faserig, rasig. 24. Berge u. Bergwiesen; Krain. Mai. Jun.

7. P. concinn a Gaud. $R$. aufrecht, abstehend; Aeste gezweiet u. einzeln, rauh; Aehrchen an der Spitze der Aeste gedrungen, eyf.spitz, 6-10bth.; Bth. längl. -lanzettl., am Rande u. auf d. Riicken dicht-flaumig, frei; B. schmal-lineal.; Blatthäutchen alle längl., spitz; W. faserig, rasig. 24. Sandige, trockene O.; Wallis, Triest. Jun.

8. P. bulbosa L. R. aufrecht, abstehend; Aeste gezweiet $u$. einzeln, rauh; Aehrchen an d. Spitze der Aestchen gedrungen, eyf., 4-6bth.; Bth. längl.-lanzettl., am Rande u. auf d. Rücken dichtflaumig, mit einer häufigen, sich lang hervorziehenden Wolle zshängend; B. schmal-lineal.; Blatthäutchen alle längl., spitz; W. faserig, rasig; Halm an der Basis oft $z$ wiebelf. - verdickt. 24. Sonnige, unkult. 0.; zerstr. deh d. Geb. Mai. Jun. Var. $\beta$. vivipara: Bth. in blattige Knospen verwandelt, u. diese kommt sogar häufiger vor, als die normale Form. P. bulbosa $\beta$. L.

9. P. alpina L. $R$. aufrecht, während $d$. Bthezeit weitabstehend; Aeste gezweiet, glatt od. rauh; Aehrchen eyf., 4-10bth.; Bth. ey-lanzettf., am Rande u. auf d. Riicken dicht-flaumig, frei od. dch spärliche Haare zshängend; B. zieml. breit-lineal., plötzl. in ein spitzes Ende zsgezogen; die unteren Blatthäutchen kurz, abgeschnitten, die oberen längl., spitz; Blätterbüschel an der Basis nebst dem 
blühenden Halme von gemeinschaftl. Scheiden eingeschlossen. 4. Triften d. A. u. VorA. Mai._Jul. Halme bis $1^{\prime}$ lang. Var.: Pi. vivipara: Bth. in blattige Knospen verwandelt. $-\gamma$.minor: niedrig, $3^{\prime \prime}$ hoch; höchste A. $-\delta$. brevifolia: B. kurz, mit einem knorpe-

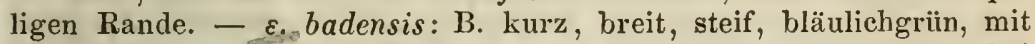
einem weissen, knorpeligeu Rande umzogen. P. badensis Haenk. bei Willd. P. collina Host. P. trivialis Pollich. Sandplätze; Oestr., Thüringen, Wetter., Pfalz.

10. P. caesia Sm. R. abstehend; Aeste rauh, die unteren zú 2-5; Aehrehen ey-lanzettf., 2-5bth.; Bth. schwach-nervig, am Rande u. auf d. Riicken flaumig; Scheiden länger als d. Halmglieder, die Halmknoten deckend, die oberste länger als ihr B.; Blatthäutchen kurz, abgeschnitten od. das oberste eyf.; W. faserig, rasig. 24. Sonnige Felsen der A. u. VorA.; Schwz., südl. Tyr., Gesenke der Sudet, Jun. Jul. Die lebende Pfl. schön blaubereift. Var. $\beta$. aspera: Halm oberwärts bemerklich rauh. P. aspera Gaud.

11. P. nemoralis L. $R$. abstehend; Aeste rauh, die unteren $z u 2$ bis 5; Aehrchen ey-lanzettf., 2-5bth.; Bth. schwach-nervig, am Rande u. auf d. Rücken flaumig; Scheiden kürzer als die Halmghicder, Halmknoten entblösst, die oberste Scheide kürzer als ihr B.; Blatthäutchen selır kurz, fast fehlend; W. rasig u. kurz-ausläufertreibend. 24. Wälder, Felsen. Jun. Jul. Var.: $\alpha$. milgaris: grasgrïn; Halme dünn, schwach, mit der lockeren R. überhangend; Aelirchen 2bth., zuweilen 1bth. - $\beta$. firmula: grasgrün; Halme steif; Blattscheiden glatt; R. aufrecht od. an d. Spitze iiberhangend; Aehrchen 3-5bth. Weidengebiisch $d$. Wiesen; die $R$. abstehend: P. nemoralis firmula Gaud.; auf Mauern; die R. zsgezogen: P. nemoralis

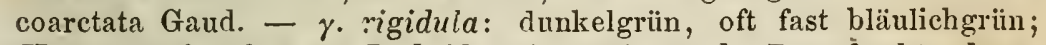
Halme steif, nebst den Bscheiden ein wenig rauh; R. aufrecht od. an d. Spitze iiberhangend; Aehrchen 3-5bth. P. serotina Schrad. -

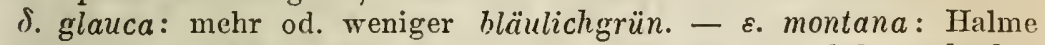
schlank; $R$. mit auseinandergestellten grossen, $3-5 \mathrm{bth}$. Aeltrchen spärlich-besetzt; Rispenäste 1-3 Aehrchen tragend; Aehrehen auf dünnen $u$. langen Stielen.

12. P. fertilis Host. $R$. ausgebreitet, abstehend; Aeste rauh, die unteren meist $z u 5$; Aenrrchen ey-lanzettf., 2-5bth.; Bthen schwach-nervig, am Rande nach d. Basis u. auf d. Rïcken mit einer schmalen, flaumigen Linie bezeichnet; Halme nebst den Bscheiden glatt; Blatthäutchen längl., spitz; W. faserig, rasig. 2. Feuchte Wiesen, Ufer. Jun. - Jul. P. palustris Roth. P. serotina Ehrhart, ein unpassender Name; sie bliiht nicht später, als d. verwandte $P$. nemoralis.

13. P. sudetica Haenke. R. ausgebreitet; Aeste rauh, die unteren zu 5; Aehrchen eyf.-längl., 3-4bth.; Bth. erhaben-5nervig, ganz kahl, od. an der Basis mit wolligen Haaren spärlich besetzt; 
B. lanzettl.-lineal., an der Spitze plötzlich zsgespitzt u. kaputzenf.zsgezogen; Bscheiden 2schneidig; Blatthäutchen kurz; unfruchtbare Blätterbüschel 2zeilig, flach-zsgedrücht, zur Bthzeit frisch. 24. Wälder der VorA., höhere Gbge u. dann zerstr. deh d. Geb. Jun. Jul. P. sylvatica Vill. Var. remota: Rispenäste sehr verlängert, hängend. P. sudetica $\beta$. remota Fries nov. p. 11. Diese habe ich in meiner Synops. mit Unrecht zu P. hybrida gebracht. In den Sudeten im Gesenke, in der Brucker Lache bei Erlangen, Wälder bei Darmstadt.

14. P. hybrida Gaud. R. ausgebreitet; Aeste rauh, die unteren zu 5 ; Aehrchen eyf.-längl., 3-5bth.; Bth. erhaben 5rervig, kahl, an d. Basis mit wolligen Haaren spärlich bestreut; $B$. aus eirier lanzettl.-lireal. Basis allmählig verschmälert u. sehr spitz; Bscheiden 2schneidig; Blatthäutchen kurz; unfruchtb. Blätlerbüschel 2zeilig, flach zsgedriickt, zur Bthezeit meist vertrocknet. \%. Feuchte Wälder; Jura, Grimsel in der Schwz., Kitzbichel in Tyrol., Untersberg in Salzbg. Jun. Jul. Festuca montana Strnbg. u. Hoppe.

15. P. trivialis L. $R$. abstehend; Atste rauh, die unteren zu 5 ; Aehrchen cyf., meist 3bth.; Bth. erhaben-5nervig, kahl, an der Basis schwach-behaart; Schciden etwas zsgedrückt, rauh; Blatthäutchen der oberen Scheiden vorg€zogen, längl., spitz; W. faserig. 4. Nasse Wiesen; feuchte $O$. Jun. Jul.

b. Wr. mit verlängerten Ausläufern weit $u$. breit umherkriechend.

16. P. pratensis L. R. abstehend; Aeste rauh, die unteren meist zu 5; Aehrchen eyf., 3-5bth.; Bthen auf d. Rücken u. am Rande dicht-flaumig, u. rach ihrer 'T'renkung mit einer langen Wolle zshängend, 5nervig, Nerven hervortretend; Halm nebst d. Scheiden kahl; die oberste Scheide viel länger als ihr B.; Blatthäutchen kurz, abgeschnitten; W. mil verlängerten Ausläufern kriechend. 24. Wiesen, Triften, kult. u. unkult. O. Mai. Jun. $\beta$. latifolia: die WB. kürzer u. breiter u., wie die ganze Pflanze, v. bläulichgriiner od. hechtblauer Farbe. P. humilis Ehrh. P. subcaerulea Engl. bot. Trockene Berge, Sandfelder. $-\gamma$ - argustifolia: WB. zsgefaltet- od. zsgerolltborstlich. P. angustifolia L. nach Sm. Trockene O., Mauern. - $\delta$. anceps Gaud.: grösser, Halm zsgedrückt, fast 2schneidig. Auswurf d. Gräben, fette feuchte $O$.

17. P. cenisia All. R. abstehend; Bthenstiele glatt od. etwas rauh, die unteren gezweiet, selten zu 5 ; Aelırchen eyf., $3-5$ bth.; Bth. auf d. Riicken u. am Rande dicht-flaumig u. nach ilerer Trennung mit einer langen Wolle zshängend, 5nervig, die stitlichen Nerven schwach; Halm nebst den Scheiden kahl; die oberste Scheide viel länger als ihr B.; Blatthäutchen kurz, das obere eyf., $W$. mit verlängerten Ausläufern kriechend. 24. Kies der Giessbäche der A. Jul. Aug. P. distichophylla Gaud. P. flexuosa Wahlnbg. Var. $\beta$. pal- 
lescens: bleich $u$. flatterig; an schattigen O. P. pallescens Gaud. P. Halleridis R. et $\mathrm{S}$.

18. P. compressa L. R. abstehend, mcist einseitswendig; Bthstiele rauh, die unteren meist zu 2, seltener zu 5; Aehrchen eyf.längl., 5-9bth.; Bth. auf d. Rücken $u$. am Rande nach d. Basis zu flaumig, frei od. mit spärlicher Wolle zshängend, schwach-nervig; Halme 2schneidig-zsgedrïckt, an der Basis liegend; $W$. mit verlängerten Ausläufern kriechend. 2. Trockene, kultiv. u. unkultiv. O. Jun. Jul. Var. Halm 2' hoch, R. locker, reichlich mit Aehrchen versehen: P. Langeana Reichenb., $P$. compressa $\beta$. effusa Tausch.

49. GLYC'ÉRIA R. Brown. Sïssgras.

1. G. spectabilis M. u. Koch. R. gleich, weitschweifig, sehr ästig; Aehrchen 5-9bth.; Bth. stumpf, 7nervig, Nerven stark, hervortretend; W. kriechend. 24. Stehende Wasser, Ufer. Jul. Aug. G. aquatica Wahlberg. Poa aquatica L.

2. G. plicata Fries. R. quirlig, fast gleich, die unteren Aeste meist zu 5; Aehrchen 7-11bth., bth. oval-längl., sehr stumpf, schwach-3kerbig, 7 nervig, Nerven stark, hervortreterid; die jungen B. mehrfach gefaltet. 4. Stehende Wasser, Bäche; zerstr. dch das Geb. Jun. Jul.

3. G. fluitans R. Brown. R. einseitswendig; Aeste während der Bthezeit rechtwinkelig-abstehend, die unteren meist zu 2; Aehrchen 7-11bth., an d. Ast argedrückt; Bth. lanzettlich-längl., ziemlich spitz, oft schwach-3kerbig, 7nervig, Nerven stark, hervortretend; die jungen B. zsgefaltet; W. kriechend. 2. Stehende Wasser, Bäche, Gräben. Jun. Jul. Festuca fluitans L.

4. G. distans Wahlenb. R. gleich, ausgesperrt; die unteren Aeste meist zu 5, die fruchttragenden herahgeschlagen; Aehrchen 4-6bth.; Bth. eyf.-längl., abgeschnitten-stumpf, erloschen 5nervig; W. faserig. 24. Feuchte O., Gräben, besond. Salzboden; zerstr. dch d. Geb. Mai. Jun. Poa distans L. P. salina Pollich.

5. G. festuca eform is Heynhold. R. gleich, abstehend, die unteren Aeste mcist zu 5, die fruchttragenden aufrecht, etwas abstehend; Aehrchen 5-9bth., Bth. lineal.-längl., stumpf od. schwach3 kerbig, erloschen 5nervig; die nichtblühonden, ausläuferartigen, niederliegenden Halme fellend; $W$. faserig. 2. Am adriat. Meere. Jun. Jul. Poa festucaeformis Host.

6. G. maritima M. u. Koch. R. gleich, abstehend; die unteren Aeste meist zu 2, die fruchttragenden zsgezogen; Aehrchen 4-6bth.; Bth. lineal.-längl., stumpf od. schwach-3kerbig, erloschen 5nervig; die nichtblühenden Stengel ausläuferartig $u$. niederliegend; die W. kriechend. 24. Am Meere, v. Ostfriesland bis Mecklenbg. Jun. Jul. Poa maritima Huds.

7. G. a qua tic a Presl, R. gleich, ausgebreitet; Aehrchen lineal., 
meist 2 bth.; Bth. längl., stumpf, 3nervig, Nerven hervortretend. W. mit Ausläufern kriechend. 7 . Stehende Wasser, sandige, nasseO.; zerstr. dch d. Geb. Jun. Jul. Aira aquatica L. Catabrosa aquatica Beauv.

\section{MOLINIA Schrank. Molinie.}

I. Rotte. Aechte Molinien. Aehrchen wehrlos.

1. M. c a e rule a Mönch. R. etwas zsgezogen; Aehrchen aufrecht, wehrlos, meist 3bth.; Bth. 3nervig; Halm fast nackt. 24. Wälder, feuchte Waldwiesen, morastige O. Aug. Sept. In fettem Waldboden grösser : M. altissima Link., M. arundinacea Schrank.

II. Rotte. Diplachne Beauv. Untere Spelze aus ungeth. od. kurz-2sp. Spitze begrannt; Granne gerade, kurz.

2. M. serotina M. u. Koch. R. abstehend; Aehrchen $2-5$ bth., kurz-begrannt; Bth. 5nervig; Halm bis an d. Spitze mit Bscheiden bcdeckt. 2. Steinige Hügel; Istrien, Littor., siidl. Tyr. Aug. Sept. Festuca serotina L. sp. Agrostis serotina L. mant.

\section{DÁCTYLIS L. Knäuelgras.}

1. D. glomerata L. Untere Spelze 5nervig; W. rasig; Ausläufer fehlend. 7. Wiesen, Wälder. Jun. Jul. $\beta$. hispanica: R. in eine lappige Aehre zsgezogen; Aeste v. der Basis an mit Aehrchen besetzt. D. hispanica Roth.

2. D. littoralis Willd. Untere Spelze 9-11rervig; Ausläufer verlängert, gestreckt. 2. Am Meere; Triest, Fiume. Jun. Jul. D. maritima Schrad.

\section{CYNOSÚRUS L. Kammgras.}

1. C. cristatus L. R. ährig, gedrungen, lineal., gerade; Bälge der DeckB. in eine Stachelspitze verschmälert. 24. Wiesen. Jun. Jul.

2. C. e chinatus L. R. ährig-zsgezogen, eyf.; Bälge der DeckB. sehr lang begrannt. $\odot$. Kultiv. O., Wege; Istrien, Steyer in Oestr., am Gardasee, Südtyr., Wallis. Mai. Jun.

\section{FESTÚCA L. Schwingel.}

I. Rotte. Nard urus. Achrchen in einer einfachen Tr. sehr kurz-gesticlt; Bthstielchen dick, aber v. gleicher Breite. W. klein, jährig. Nichtllühende Blätterbüschel fehlend.

1. F. ten u ifl or a Schrad. Tr. einfach; Aehrchen sehr kurz-gestielt, 2 zeilig-1 seitig; Klappen lanzettl., verschmälert-spitz, untere um d. Hälfte schmäler, 1nervig; Bth. lanzettl.-lineal., sehr spitz, in eine kürzere Stachelspitze od. verlängerte Granne verschmälert. $\odot$. Unkult., sonnige O.; Istrien, Wallis. Jun. Jul. Var. Bth. kahl od. flaumig, u. a. mutica: Bth. alle nur kurz-stachelspitzig. Triticum unilaterale L. DC. - $\beta$. biuncialis: Bth, der unteren Aehrchen der 
Traube stachelspitzig, die d. oberen lang-begrannt. T. biunciale All., nacl Bertol. $-\gamma$. aristata: Bth. mit Grannen $v$. der Länge der Bthe. T. Nardus DC.

2. F. L achenalii Spenn. Tr. einfach; Aehrchen sehr kurz-gestielt, wechselst.; Klappen längl.-lanzettl., stumpfl., die untere ein wenig kürzer, beide 3nervig; Bth. längl.-lanzettl., stumpfl., wehrlos od. begrannt. $\odot$. Sandige 0 ., häufig auf Sandplätzen d. granit. Voges.; Oberbad., siidl. Schwz. Jun.Jul. Triticum Lachenalii Gmel. T. tenellum L. T. Poa DC. Var. ramosum: Aehre unterwärts ästig. T. Festuca DC. $-\beta$. aristatum: Bth. begrannt. T. tenuiculum Lois.

II. Rotte. Sclerochloa. R. steif. Bthstielchen kurz, dick, aber v. gleicher Breite. W. klein, jährig. Nichtblühende Blätterbüschel fehlend.

3. F. rigi a Kunth. R. 2zeilig-1seitig, gedrängt, starr; Aeste nebst $d$. Aestchen 3kantig; Ae7urchen längl., 6-12bth., aufrecht, ein wenig abstehend, genähert, die seitenst. der Aeste sehr kurz-gestielt; Bth. lineal., stumpf, seicht-ausgerandet u. sehr kurz-stachelspitzig; W. faserig. $\odot$. Trockene O., Weinberge, Wege; Litt., Südtyr., Genf, Tessin. Jun. Jul. Poa rigida L.

4. F. divaricata Desf. $R$. steif, Aeste 3 kantig; Aehrchen lineal., 6-12bth., während d. Bthezeit ausgesperrt-abstehend, die seitenst. der Aeste sehr kurz-gestielt; Bth. lineal.-lanzettl., stumpf, kurzausgerandet $u$. sehr kurz-stachelspitzig; W. faserig. $\odot$. Dürre, steinige O., Fiume. Apr. Mai.

III. Rotte. Vulpia Gmel. Mygalurus Link. Rispenästchen ziemlich dick od. auch nach der Spitze bemerklich verdickt $u$. fast keulig. Bth. lanzettl.-pfrieml., lang-begrannt, bei mehreren $1 \mathrm{männig.}$ W. klein, faserig. Nichtblühende Blätterbüschel fehlend.

5. F. uniglumis Soland. R. einseitswendig, zsgezogen, fast ährig; obere Klappe begrannt, untere sehr klein od. fehlend; Bth. lanzettl., pfrieml.-verschmälert, lang-begrannt, kürzer als d. Granne, kahl, an d. Spitze ein wenig rauh; W. faserig. $\odot$. Trockene O., Litt. Mai.

6. F. myurus L. R. einseitswendig, zsgezogen, fast ährig; obere Klappe spitz, untere sehr kurz od. fehlend; Bth. lanzettl., pfrieml.verschmälert, lang-begrannt, kürzer als $d$. Granne, zottig $u$. dichtbewimpert; Blatthäutchen 2röhrig; W. faserig. $\odot$. Unkult. O.; Istr., Fiume. Mai. Jun. F. ciliata Danth.

7. F. pseudo-myuros Soyer-Willemet. $R$. einseitswendig, zsgezogen, fast ährig, überhangend; obtre Klappe spitz, untere 2-od. mehrmal kürzer; Bth. lanzettl., pfrieml.-verschmälert, lang-begrannt, kürzer als die Granne, rauh; Halm bis zur $R$. mit Bscheiden bedeckt; Blatthäutchen 2öhrig; W. faserig. $\odot$. Unkult. O., Hügel, Sandfelder. Mai. Jun. F. Myurus der Aut. 
8. F. s ciuroides Roth. $R$. einseitswendig, zsgezogen, fast ährig, aufrecht; obere Klappe spitz, untere 2- od. mehrmal kürzer; Bth. lanzettl., pfrieml.-verschmälert, lang-begrannt, kürzer als die Granne, rauh; Halm oberwärts lang-nackt; Blatthäutchen 2öhrig; W. faserig. $\odot$. Unkult. O., trockene Triften. Mai. Jun. F. bromoides d. Aut.

IV. Rotte. Fe stuca gen uinae. Aechte Schwingel. Bthstielchen der R. fädl., unter d. Bthen nur mässig dicker. Rth. lanzettl., spitz od. zugespitzt, wehrlos od. begrannt. B. alle zsgefaltet-fädlich od. die halmst. flach. Blatthäutchen 2 öhrig, nämlich sehr kurz u. beiderseits in ein rundlíches Oehrchen vorgezogen. W. ausdauernd, faserig od. ausläufertreibend. Nichtblühende Blätterbüschel stets vorhanden.

9. F. H a lleri All. - R. zsgezogen, während der Bthzeit aufrecht, etwas abstehend; Achrchen 4-5bth., die oberen einzeln, fast sitzend, die unteren länger-gestielt, einzeln, od. 2 od. 3 auf einem Aste wechselst.; Bth. lanzettl., begrannt; Granne halb so lang als die Bth.; untere Spelze 5nervig, lanzettl.-verschmälert, an der Spitze 2sp.;B. alle zsgefaltet-borstl.; Blatthäutchen 2öhrig; $W$. faserig. 24. Höchste A.; sïdl. Schwz, südl. Tyrol. Jul. Aug. Untersch. sich v. F. ovina deh die deutlich-nervigen Bth. u. die fast v. der Basis an verschmälerte obere Spelze. F. Halleri Gaud. vom Autor selbst, ist die ächte Pfl. u. nicht F. Gaudini Kunth.

10. F. ovin a L. R. während der Bthezeit abstehend; Aehrchen 4-8bth.; Bthen lanzettl., wehrlos od. begrannt; Granne kurz oder auch länger $u$. halb so lang als $d$. Bthe; untere Spelze schwach-5nervig, obere längl.-lanzettl., an der Spitze 2zähnig; $B$. alle zsgefaltet-borstl.; Blatthäutchen 2öhrig; W. faserig. 2. Wiesen, Triften, unkult. O. bis in d. liöchsten A. hinauf. Mai. Jun. Var. $\alpha$. vulgaris: B. grasgrün od. nur etwas lauchgrün, sehr fein, etwas od. bemerkl. rauh; Aehrchen klciner, grannenlos: F. tenuifolia Sibth., Schrad.; dieselbe mit 6 bth. Aehrchen: F. paludosa Gaud.; B. lang, sehr dünn, im Schatten d. Wälder: F. capillata Lam. - $\beta$. alpina: ebenso, aber niedriger, B. glatt, R. armbthiger, Aehrchen grösser, Grannen länger, manchmal so lang als d. Bthe. F. alpina Gaud., auf den A. u. VorA. - Diese Form mit violettgefärbten Bthen ist nach Shuttlewortlı: F. Gaudini Kunth. enum. mit Ausschluss aller Synonyme. - $\gamma$. violacea: ebenso, aber die Bthn glänzend, violett, gelb u. grün zierlich-gescheckt. F. violacea Gaud., auf d. A. u. VorA. - $\delta$. valesiacx: höher; Aehrchen grösser; B. verlängert, sehr dünn, hechtblau, sehr rauh. F. valesiaca Schleich., unter d. gewöhnlichen Formen bie u. da. $-\varepsilon$. duriuscula: höher; Aehrchen grösser; B. grasgrün od. bläulichgrün, dünner od. auch ziemlich dick, steif od. zurückgekrümmt: F. duriuscula L. sp., nicht syst. nat., Pollich., F. ovina Schrad.; B. kurz, zurückgekrümmt, auf Felsen: F. curvula 
Gaud.; B. dick: F. dura Host. - $\zeta$. glauca: ebenso ; B. bläulichgrün: F. glauca Schrad., F. pallens Host.; am Meere hechtblau: F. glauca Lam.; B. auf d. A. dick, starr: F. laevigata Clairv., F. pungens R. et S. - $\eta$. anıethystina: B. gras- od. bläulichgrün, steif, stechend; Aehrchen wehrlos od. kurz-stachelspitzig. F. amethystina Host. Aehrchen kleiner als bei den vorhergeh.; in Oestr. - $\vartheta . v a g i-$ nata: B. dünn, weicl, verlängert, gras- od. bläulichgrün; Aehrchen länger, 8bth., wehrlos. F. vaginata Willd.; Oberschwab., Oberbayern. `. pannonica: B. ein wenig dicker, bläulichgrün; Aehrchen lang, 810 bth., begrannt. F. pannonica Host.

11. F. heterophylla Lam. R. während der Bthezeit abstehend; Aehrchen 4-5bth.; Bthe begrannt, lanzettl.; Granne kurz od. auch fast so lang als die Bth.; WB. zsgefaltet-borstl., halmst. B. flach, Blatthäutchen 2öhrig; W. faserig. 24. Wälder, A. u. VorA., auf niedrigen Bergen selten. Mai. Jun. F. heterophylla Haenke, F. duriuscula L. syst. In Schatten die B. lang u. dünn, die R. iiberhangend; in der Sonne B. u. R. steif; auf d. A. Aehrchen violett u. gelb-bunt: F. nigrescens Lam.

12. F. rubra L. R. während der Bthezeit abstehend; Aehrchen meist 5bth.; Bth. lanzettl., begrannt; Granne kürzer od. länger; die wurzelst. B. zsgefaltet-borstl., d. halmst. flach; Blatthäutchen 2öhrig; W. ausläufertreibend u. lockere Rasen bildend. 2. Wiesen, Sandfelder, Waldränder. Mai. Jun. An sandigen O. weit-kriechend. Var. $\beta$. villosa: Aehrchen mit kurzen Zotten. F. dumetorum L. - $\gamma$. lanuginosa : Aehrchen grösser, wollig-zottig. F. cinerea DC. F. arenaria Osb.

V. Rotte. Schedonori. Bthstielchen der R., Aehrchen u. Bthen wie bei der vorhergeh. Rotte; aber d. Blatthäutchen nicht 2öhrig. Die B. öfters flach, bei anderen auch fädlich.

13. F. varia Haenk. R. zsgezogen, während d. Bthezeit abstehend; Aeste einzeln od. gezweiet; Aehrchen 5-8bth., kurzbegrannt od. wehrlos; untere Spelze schwach-5nervig, lanzettl., v. d. Mitte an allmählig schmäler; Fruchtkn. an d. Spitze behaart; B. alle zsgefaltet, fädl., fast stielrund; Blatthäutchen länglich; W. faserig, ohne Ausläufer. 24. Felsige Triften d. A., VorA. u. Sudet. Jul. Aug. B. grasgrün od. bläulichgrïn. Aehrchen grün, weiss u. purpurn zierlich gescheckt; Blatthäutchen bald stumpf, bald spitz. Var. $\beta$. flavescens: Aehrchen blass $u$. weit-weniger bunt. F. flavescens Bellard. $-\gamma$. crassifolia: B. dick u. steif. F. Eskia Ramond.

14. F. p u mila Vill. R. aufrecht, zsgezogen, während der Bthezeit etwas abstehend; Aeste einzeln od. gezweiet; Aehrchen 3-4bth., begrannt; untere Spelze schwach-5nervig, längl.-lanzettl., über der Mitte plötzlich zugespitzt; Fruchtkn. an d. Spitze behaart; B. alle zsgefaltet-fädl., fast stielrund; Blatthäutchen längl.; W. faserig. 4. Felsige Triften d. A. Jul. Aug. 
15. F. pilos a Haller fil. R. abstehend; Aeste halbquirlig, die unteren meist zu 5; Aehrchen meist 3bth., begrannt od. wehrlos; Achse unter den Bthen mit einem Büschel v. Haaren gebartet; Fruchtkn. kahl; die wurzelst. B. fast stielrund, die halmst. zsgefaltet od. flach; Blatthäutchen längl.-lanzettl.; W. faserig. 24. Höchste A.; Schwz, Tyr., IKärnth. Jul. Aug. F. rhaetica Sut.

16. F. laxa Host. $R$. abstehend, schlapp-überhangend; Aeste haarfein, ein wenig rauh, n. d. Basis an lang-entblösst, einzeln od. gezweiet; Aehrchen meist 5bth., wehrlos od. begrannt; Achse flaumig; untere Spelze schwach-5nervig, nicht punktirt; Fruchtkn. an der Spitze behaart; B. schmal-lineal., oberseits sammetig, die untersten zsgefaltet; Blatthäutchen kurz, abgeschnitten, fast 2lappig. 4. Krain, auf dem Loibl. Jun. Jul.

17. F. spectabilis Jan. R. weitschweifig, überhangend, die unteren Aeste gezweiet od. gedreiet, unterwärts nackt; Aestchen rauh; Aehrchen meist 5bth., wehrlos; Achse mit sehr kurzem Flaume besetzt; untere Spelze sehr fein-purktirt, deutli_h-5nervig; Fruchtkn. an der Spitze behaart; Blätterbüschel unterwärts mit blattlosen, allmählig in B. übergehenden Schuppen bedeckt; $B$. verlängert-lirieal., flach, gleichfarbig, oberseits rauh, Blatthäutchen vorgezogen, längl.; W. faserig. 24. Auf den VorA. der siidl. Alpenseite in Krain u. Tyrol. Jun. Jul.

18. F. spadicea L. R, zsgezogen, während der Bthezeit etwas abstehend; Aeste einzeln od. gezweiet u. nebst d. Aestchen kahl; Aehrchen meist 5bth., wehrlos od. kurz-stachelspitzig; Achse ein wenig rauh; untere Spelze sehr fein-punktirt, 5nervig, 3 Nerven hervortretend; Fruchtkn. an der Spitze hehaart; B. schmal-lineal., ganz kahl, flach, die wurzelst. zuletzt zsgerollt; Blatthäutchen längl., ausgerandet-2lappig. 4. Triften der höchsten A. Jul. Aug. Anthoxanthum paniculatum L.

19. F. sylvatica Vill. R. aufrecht, ausgebreitet, sehr ästig; Aeste rauh, die unteren zu 2,3 od. 4; Aehrchen meist 5bth.; Achse ein wenig rauh; obere Spelze verschmälert, sehr spitz, wohrlos, feinpunktirt-rauh, fast 3nervig, 3 Nerven stärker hervortretend; Fruchtkn. an der Spitze behaart; Blätterbüschel unterwärts mit blattlosen, allmählig in B. übergehenden Schuppen bedeckt; $B$. lanzettl.-lineal., oberseits bläulichgrün, unterseits freudig-grün, am Rande rauh; Blatthäutchen längl., stumpf; W. faserig. 24. Schattige Wälder; zerstr. dch d. Geb. Jun. Jul. F. calamaria Smith.

20. F. drymeia M. u. Koch. R. ausgebreitet, sehr ästig; an der Spitze überhangend; Aeste rauh, die unteren zu 2 od. 3; Aehrchen meist 5bth.; Achse etwas rauh; untere Spelze zugespitzt, stachelspitzig, sehr fein-punktirt, 5nervig, 3 Nerven stärker hervortretend; Fruchtkn. an d. Spitze behaart; Blätterbüschel v. der. Basis an beblättert; B. lanzettl.-lineal., oberseits bläulich-grün, unterseits freudig. 
grün, am Rande rauh; Blatthäutchen längl., stumpf; W.mit verlängerten, beschuppten Ausläufern kriechend. 24. Feuchte Gebirgswälder; Oestr., Mähr., Böhm. Jun. Jul. F. sylvatica Host., nicht Vill.

21. F. Sche uchzeri Gaud. R. abstehend, an der Spitze überhangend; Aeste kahl, d. unteren gezweiet; Aehrchen 4-5bth.; Achse ein wenig rauh; untere Spelze spitz, wehrlos od. unter d. Spitze fein-stachelspitzig, rauh, 5nervig; Nerven hervortretend; Fruchtkn. kahl; B. lineal., flach, kahl; Blatthäutchen länglich, stumpf; W. kriechend, schwach-rasig. 2. Triften d. A. Jul. Aug. F. pulchella Schrad. F. nutans Host.

22. F. gigantea Vill. R. weit-abstehend; Aeste an d. Spitze schlapp-iiberhangend; Aehrchen 5-8bth.; Bth. unter der Spitze begrannt; Grannen schlängelich, noch einmal so lang als d. Spelze, Fruchtkn. kahl; B. lineal., flach, kahl; Blatthäutchen sehr kurz. 4. Schattige Wälder. Jun. Jul. Bromus giganteus L. Var. $\beta$. triflora: Aehrchen 3bth.; Halm niedriger, B. schmäler. F. triflora Engl. bot. Bromus triflorus L.

23. F. borealis M. u. Koch. R. ausgebreitet, an d. Spitze überhangend, sehr ästig; Aeste rauh, meist zu 5; Aehrchen 4-5bth., Achse ein wenig rauh, untere Spelze 5nervig, feinpunktirt-rauh, au der Spitze stumpf, mit 3 stachelspitzigen Zähnchen, an der Basis mit einem Haarbüschel umgeben; Fruchtkn. an der Spitze behaart; B. lanzettl.-lineal., am Rande rauh, Blatthäutchen längl., abgeschnitten, zerrissen; W. kriechend. 2. Im Wasser, in der Spree, Havel u. d. Seen bei Berlin, Stettin; bei Friedrichsort im Holst. Jun. Jul. F. arundinacea Liljebl. 1792., nicht Schreb. Arundo festucacea Willd.

24. F. ar undin a ce a Schreb. 1771. R. ausgebreitet, überhangend; Aeste rauh, gezweiet, verzweigt, 5-15 Aelwchen tragend; Aehrchen ey-lanzettf., 4-5bth.; untere Spelze unter der Spitze stachelspitzig od. auch wehrlos; Fruchtkn. kahl; B. Each, lanzettl.-lineal; Blatthäutchen seler kurz. 4. Wiesengebiisch, Ufer; zerstr. deh d. Geb. Jun. Jul. F. elatior Sm. - Die F. decolorans M. et $\mathrm{K}$. ist eine F. arundinacea mit einem feinen Ueberzug von kohlensaurem Kalk, ein Niederschlag aus dem staubartigen Regen des Staubbaches im Thale Lauterbrunn, Cantons Bern, in dessen Nähe alle Pflanzen damit überzogen sind. Guthnick u. v. Charpent.

25. F. elatior L. R. einseitswendig, zsgezogen, während der Bthezeit abstehend; Aeste rauh, gezueiet, der cine davon sehr kurz u. 1 Aehrchen, der zueite traubig $u$. 3-4 Aehrchen tragend; Aehrchen lineal., 5-10bth.; Klappen stumpf; untere Spelze 5nervig, an der Spitze gezähnelt, wehrlos od. unter d. Spitze stachelspitzig; Fruchtkn. kahl; B. flach, lanzettl.-lineal.; Blatthäutchen sehr kurz. 4. Wiesen. Jun. Jul. F. pratensis Huds.

26. F. loliacea Huds. Tr. 2zeilig, etwas überhangend; Aehr. chen lineal.-längl., wechselst., entfernt, die unteren kurz-gestielt, bis- 
weilen gezweiet, die oberen sitzend; B. flach, lanzettl.-lineal. 4. Wiesen; zerstr. dch d. Geb. Mai. Jun. F. elongata Ehrh. Obere Klappe nicht länger als die nächste Bthe.

54. BRACHYPODIUM Palisot. de Beauv. Zwenke.

1. B. s y lvatic um Röm. u. S. Aehre 2zeilig, überhangend; Aelurchen zalureich, begrannt; Grannen der oberen Bthen länger als die Spelze; B. flach, lanzettl.-lineal., schlapp; W. faserig. 24. Wälder. Jul. Aug. Festuca sylvatica Huds. Bromus pinnatus $\beta$. L. B. sylvaticus Pollich.

2. B. pinnatum Beauv. Aehre 2zeilig, aufrecht oder ein wenig überhangend; Aehrchen zahlreich begrannt; Grannen kürzer als die Spelze; B. flach, lineal. od. lanzettl.-lineal., zieml. steif; W. kriechend. 4. Unkult. O., zwischen Gebüsch. Jun. Jul. Bromus pinnatus L. Var. $\alpha$. vulgare: Aehrchen rauh od. zottig, gerade od. gekrimmt. $\beta$. rupestre, Aehrchen kahl, nicht selten verlängert $u$. sichelf. Brumus rupestris Host. - $\gamma$. caespitosum: Aehrchen kleiner, B. schmäler. Bromus caespitosus Host. Triticum gracile DC. fl. fr.

3. B. ramos um Röm. u. S. Aehre aufrecht, aus 2-5 Aehrchen zsgesetzt; Bth. begrannt; Grannen kürzer als die Spelze; B. abstehend, zsgerollt, sehr schmal, bläulichgriin, steif; Halme an d. Basis sehr ästig. 24. An trockenen, felsigen 0 . in Istrien. Jun. Bromus ramosus L. B. Plukenetii All. Triticum caespitosum DC. Var. $\beta$. phoenicoides: Halm weniger ästig, B. aufrechter, Aehre reicher. T. phoenicoides DC.

4. B. dista ch y on Röm. u. S. Aeltrchen 1-3, eng- $u$. wechselst., 6-12bth., hegrannt; Grannen länger als die Spelze; Halm kahl; B. flach; W. faserig. $\odot$. Kultiv. O., Wege; Istr., Fiume. Mai. Bromus distachyos $\mathrm{L}$.

\section{BROMUS L. Trespe.}

I. Rotte. Libertia Weihe. Untere Spelze beiderseits unterhalb d. Mitte mit einem eyf., häutigen Zahne.

1. B. arduennensis Kunth. R. abstehend, zuletzt überhangend; Bth. aus eyf. Basis verschmälert; untere Spelze 9nervig, am Rande unterhalb d. Mitte beiderseits mit cinem Anhängsel aus einem eyf., häutigen Zahne bestehend, versehen. $\odot$. Aecker in d. Ardennen bei Aiwaille, Provinz Lüttich. Jun. Jul. Libertia arduennensis Lejeun.

II. Rotte. Bromi secalini. Aehrchen, auch nach d. Verblühen, nach der Spitze zu schmäler. Untere Klappe 4-5nervig, obere 5-vielnervig. Obere Spelze mit ziemlich steifen Borsten entfernt-kammf.-gewimpert.

2. B. secalinus L. R. abstehend, nach d. Verblühen überhangend; Aehrehen längl.; Bthen breit-elliptisch, die fruchttrag. am 
Rande zsgezogen, stielrund, sich nicht deckend; untere Spelze 7nervig, am Rande abgerundet, so lang als die obere, Granne hervorgestreckt, schlängelig, or. ziemlich gerade; Scheiden kahl. $\odot$. Aecker Jun. Jul. Var. $\alpha$. grossus: Aehrchen grösser, kahl od. rauh. B. grossus $\beta$. Gaud. $-\beta$. velutinus: Aehrehen grösser, kurzh.-sammetig. B. grossus $\alpha$. Gand. B. velutinus Schrad. $-\gamma$. vulgaris: Aehrchen kleiner, kahl od. raul. B. secalinus Schrad. - $\delta$. hordaceus: Aehrchen ebenso, aber flaumig od. kurzh. B. hordaceus Gmel. bad., nicht B. hordaceus Fries., welcher mir noch nicht deutlich ist.

3. B. commutatus Schrad. R. abstehend, zuletzt überhangend; Aehrchen längl.-lanzettl., kahl; Bthen elliptisch-längl., die fruchttra. genden am Rande sich dachig-deckend, untere Spelze 7nervig, am Rande oberhalb $d$. Mitte in einem stumpfen Winkel hervortretend, bemerklich länger als die obere, Granne geradehervorgestreckt, fast r. d. Länge ihrer Spelze; die unteren Scheiden behaart. $\odot$. Unter der Saat u. auf Triften; zerstr. dch das Geb. Mai. Jun. B. simplex Gaud.

4. B. racemosus L. $R$. abstehend, aufrecht od. etwas überhangend, nach dem Verblühen zsgezogen; Aehrchen eyf.-längl., kahl; Bthen breit-elliptisch, die fruchttragenden am Rande sich dachigdeckend; untere Spelze 7nervig, am Rande abgerundet, bemerklich länger als die obere, Granne gerade-hervorgestreckt, fast v. der Länge ihrer Spelze; die unteren Scheiden behaart. $\odot$. Wiesen, Triften. Mai. Jun. B. pratensis Ehrh.

5. B. mollis L. $R$. aufrecht, nach d. Verblühen zsgezogen; Aehrchen eyf.-längl., weich-behaart, seltener fast kahl; Bthen breitellipt., die fruchttragenden am Rande dachig sich deckend; untere Spelze 7 nervig, am Rande oberhalb der Mitte in einem stumpfen Winkel hervortretend, bemerklich länger als die obere, Granne gerade-hervorgestreckt, fast v. der Lünge ihrer Spelze; Scheiden u. B. behaart. $\odot$. Wiesen, Wege. Mai. Jun.

6. B. confertus MBieb. R. gedrungen, aufrecht, nach d. Verblühen zsgezogen; Aehrchen eyf.-längl., weich-behaart; Bth. elliptisch, bei der Fruchtreife am Rande sich dachig-deckend; untere Spelze 7nervig, bemerklich länger als die obere, Granne im getrockneten Zustande gencunden $u$. gebogen fast v. der Länge ihrer Spelze; Scheiden u. B. behaart. $\odot$. Unter d. Saat; Istrien. Mai. Jun. B. intermedius Guss. Kommt in Gürten anch mit kahlen u. nur etwas rauhen Aehrehen vor.

7. B. brachystachys Hornung. $\boldsymbol{R}$. aufrecht-abstehend, nach dem Verblühen unverändert; Aehrchen ey-lanzettf. od. eyf.; Bth. fast rautenf., bei d. Fruchtreife am Rande dachig sich deckend; untere Spelze 7nervig, am Rande oberhalb d. Mitte in einem stumpfen Winkel hervortretend, die obere fast so lang als die untere, Granne gegerade-hervorgestreckt, halb so lang als die Bth.; die unteren Blatt- 
scheiden behaart. $\odot$. Ackerraine bei Aschersleben, Provinz Magdeburg. Jun.

8. B. arvensis L. R. abstehend, aufrecht, bei d. Fruchtreife etwas überhangend; Aehrchen lineal.-lanzettl.; Bth. ellipt.-lanzettl., die fruchttrag. am Rande dachig sich deckend; untere Spelze 7nervig, am Rande oberhalb der Mitte in einem stumpfen Winkel hervortretend, die obere ungefähr so lang als die urtere; Granne gerade-hervorgestreckt, fast v. der Länge der Spelze, im trockenen Zustande manchmal auswärts-gebogen; Scheiden u. B. behaart. $\odot$. Aecker. Jun. Jul.

9. B. patulus M. et K. $R$. abstehend, nach dem Verblühen 1seitig-überhangend; Aehrchen lanzettl.; Bth. ellipt.-lanzettl., bei der Fruchtreife etwas entfernt; untere Spelze 7nervig, am Rande oberhalb der Mitte in einem stumpfen Winkel hervortretend, bemerklich länger als die obere, Granne bei der Reife spreitzend-zuruckgebogen; Scheiden u. B. behaart. $\odot$. Aecker, Weinberge; zerstr. dch das Geb. Mai. Var. $\beta$. velutinus: Aehrchen weich-behaart.

10. B. squarrosus L. R. abstehend u. schlapp überhangend; Aehrchen längl.-lanzettl.; Bth. breit-ellipt., die fruchttragenden am Rande dachig sich deckend; untere Spelze 7nervig, am Rande oberhalb d. Mitte in einem stumpfen Winkel hervortretend, bemerklich länger als die untere; Granne im getrocknten Zustande zsgedrehtspreitzend. ๑. Aecker, Weinberge; südl. Schwz, Südtyrol, Littor., Oberbad. Mai. Jun. Var. $\beta$. villosus: Aehrchen weich-behaart.

III. Rotte. Bromi festucacei Bertol. Aehrehen, auch die verblüheten, nach der Spitze hin schmäler. Untere Klappe 1-, obere 3nervig. Obere Spelze am Rande sehr kurz-flaumig.

11. B. a sper Murr. $R$. ästig, schlapp-überhangend; Aehrchen lineal.-lanzettl., 7-9bth.; Bth. lineal.-lanzettl., spitz; untere Spelze aus schr kurz-2zähniger Spitze begrannt u. länger als die Granne, 5nervig, die 2 mittleren Nerven schwach-ausgedrückt, die obere Speize am Rande fein-flaumig-gewimpert; die unteren Scheiden nebst d. B. rauhh. 2. Wälder. Jun. Jul.

12. B. erectus Huds. $R$. gleich, aufrecht; die unteren Aeste zu 3 u. 6; Aehrchen lineal.-lanzettl.; Bth. lanzettl.; untere Spelze an der Spitze sehr kurz-2zähnig, aus der Ausrandung begrannt u. länger als die Granne, 5-7nervig, die ohere am Rande fein-flaumig-gewimpert; WB. schmäler, am Rande gewimpert. 24. Unkult., sonnige 0 ., trockene Wiesen. Mai. Jun. B. agrestis All.

13. B. incrmis Leysser. R. gleich, aufrecht; die unteren Aeste zu 3 u. 6; Aehrchen lineal.-lanzettl.; Bth. lanzettl.; untere Spelze an der Spitze sehr kurz-2zähnig, aus d. Ausrandg. stachelspitzig od. kurz-begrannt, 5-7nervig, die obere am Rande fein-flaumig-gewimpert; B. kahl. 24. Unkultiv., sonnige O., trockene Wiesen. Jun. Jul. 
IV. Rotte. Brom i genuini. Aehrchen oberwärts breiter. Untere Klappe 1-, obere 3nervig. Obere Spelze mit starren Borsten kammf.-gewimpert.

14. B. sterilis L. R. locker, zuletzt uiberhangend; Aeste verlängert, an der spitze hängend; Achrchen längl., oberwärts breiter; Bthen lineal.-pfrieml.; untere Spelze aus 2th. Spitze begrannt, Granne gerade, länger als d. Spelze; obere Spelze kammf.-gewimpert; Halm kahl. $\odot$. Kultiv. O., Wege, Schutt. Mai-Oct.

15. B. tect or u m L. $R$. hängend, fast einseitswendig; Aehrchen lineal., zuletzt oberwärts breiter; Bthen lanzettl.-pfrieml.; untere Spelze aus 2 th. Spitze begrannt. Granne gerade, so lang als die Spelze; obere Spelze kammf.-gewimpert; Halm an der spitze flaumig. $\odot$. Aecker, Felder, Mauern. Mai. Jun.

16. B. rigidus Roth. R. u. Bthstiele aufrecht; Aehrchen längl., oberwärts breiter; Bthen lanzettl., verschmälert-spitz; untere Spelze unterhalb der bis zur Mitte 2sp. Spitze begrannt, Granne gerade, länger als die Spelze; obere Spelze kammf.-gewimpert; Halm oberwärts flaumig. $\odot$. Kult. O., Wege, Weinberge; Littor., Istrien. Mai. Jun. B. rubens Host.

17. B. madritens is L. R. u. Bthstiele aufrecht; Aehrchen lineal.längl., oberwärts breiter; Bth. lanzettl.-pfrieml.; untere Spelze unterh. der fast bis zur Mitte 2 sp. Spitze begrannt, Granne gerade, so lang als die Spelze; Halm kahl. $\odot$. Kult. O., Wege; Oestr., Littor., südl. Tyrol. Mai. Jun. B. diandrus Curt.

XIV. Gruppe. HORDEACEEN. Kunth. Aehrchen 2-vielbth., an den Ausschnitten der Spindel sitzend; Bthstielchen fehlerı. Die endst. Bthe oft verkümmernd. Gf. sehr kurz oder fehlend. Narben federig, aus $d$. Basis der Bth. beiderseits hervortretend.

56. GAUDINIA Palisot. de Beauv. Gaudinie.

1. G. fragilis Beauv. Aehre gegliedert, an den Gelenken zerbrechlich. $\odot$. Unkult. O.; Istrien, C. Waadt, auf einer Wiese bei Eppendorf unweit Hamburg, Ins. Sansego bei Istr. Jun. Avena fragilis $L$.

\section{TRÍTICUM L. Waizen.}

I. Rotte. Cerealien, Getraide. Aehrchen mehr od. weniger bauchig-gedunsen. Klappen eyf. od. länglich.

1. T. vulgare Vill. Aehre 4seitig, dachig; Spindel zähe; Aehrchen meist 4bth.; Klappen bauchig, eyf., abgeschnitten, stachelspitzig, unter d. Spitze zsgedrückt, auf dem Rüicken abgerundet-convex, Nerve stumpf-hervortretend; Früchte frei. ๑. u. ๑. Kultiv. Jun. Jul. Var.: Aehre begrannt: T. aestivum L.; od. fast wehrlos: T. hybernum L., sodann weiss, bräunl., schwarz. 
2. T. turgidum L. Aehre 4seitig, dachig; Spindel zähe; Achrchen meist 4 bth.; Klappen bauchig, eyf., abgeschnitten, stachelspitzig, gekielt, Kiel der ganzen Länge nach hervortrctend, fast flügelf.; Früchte frei. $\odot$. u $\odot$. Kultiv. Jun. Jul. Var., wie d. vorhergeh., u. ausserdem mit zsgesetzter Achre: T. compositum L.

3. T. d urum Desf. Aehre 4seitig, dachig; Spindel zähe; Aehrchen meist 4bth.; Klappen bauchig, längl., 3 mal so lang als breit, breit-stachelspitzig, gekielt, Kiel der ganzen Länge nach hervortretend, fast flügelf.; Früchte frei. $\odot$. u. $\odot$. Jun. Jul. Hie u. da in $d$. Schwz kultiv. Klappen $3 \mathrm{mal}$ so lang als breit, sonst alles wie bei T. turgidum.

4. T. polonicum L. Aehre unregelmässig-4seitig, od. zsgedrückt; Spindel zähe; Aelırchen meist 3bth.; Klappen etwas bauchig, längl.-lanzettl., papierartig-krautig, deutlich-vielnervig, auf dem Rücken gekielt, an der Spitze kurz-2zähnig, der vordere Zahn schwach; Früchte frei. $\odot$. u. $\odot$. Hie und da in der südl. Schwz kultiv. Jun. Jul.

5. T. Spelta L. Aehre fast gleichseitig viereckig, vom Rücken her ein wenig zsgedrückt, locker-dachig; Spindel zerbrechl.; Aehrchen meist 4bth.; Klappen breit-eyf., abgeschnitten, 2zälınig, der Zahn am Kielrande gerade, der vordere schwach; Früchte beschalt. $\odot$. Auf Lehm- u. Kalkboden iiberall kultiv. Jun. Jul. Var. in Farbe u. Ueberzug, wie T. vulgare.

6. T. dicoccum Schrank. Aehre v. d. Seite her zsgedrückt, dicht-dachig; Spindel zerbrechl.; Aehrchen meist 4bth.; Klappen schief-abgeschnitten, gezähnt-stachelspitzig; Kiel zsgedrückt, sehr hervortretend, oberwärts mit dem Zahne $d$. Spitze einwärtsgebogen; Früchte beschalt. $\odot$. u. $\odot$. Wird kultiv. Jun. Jul. T. amyleum Sering. T. tricoccum Schübl.

7. T. monococcum L. Aehre von der Seite her zsgedrückt, dicht-dachig; Spindel zerbrechl.; Aehrchen meist 3bth.; Klappen an d. Spitze 2zähnig, Zähne spitz u. nebst der Spitze des Kieles gerade; Früchte beschalt. $\odot$. u. $\odot$. In Gebirgsgegenden auf magerem Boden, wo T. Spelta nicht fortkommt, kultiv. Jun. Jul.

8. T. villosum MBieb. Aehre 2zeilig; Aehrchen meist 3bth.; Klappen keilig, abgeschnitten, begrannt u. nebst d. Spindel büschelig-behaart; B. knotig-haarig. (-) Aecker in Istrien. Mai. Jun. Secale villosum $\mathbf{L}$.

II. Rotte. Agropyrum. Aehrchen nicht bauchig-gedunsen. Klappen lanzettl. od. lineal.-längl., an der Spitze gerade u. nicht auswärtsgebogen.

a. Die Nerven der Blätter oberseits mit zahlreichen Réihen sehr kurzer Haare dicht-besetzt.

9. T. junceum L. Aehre 2zeilig; Aehrehen 5-8bth., entfernt; 
Klappen lineal.-lanzettl., 9-11nervig, stumpf, um d. dritten Theil kürzer als d. Aehrchen; Bthen ziemlich stumpf, wehrlos; B. oberseits weich und sehr dicht- und sehr kurz-sammetig; Spindel kahl; W. weitkriechend. 24. Sandige O. am Meere. Jun.-Aug.

10. T. strictum Dethard. Aehre 2zeilig; Aehrchen 5bth., genähert; Klappen lineal.-lanzettl., kahl, 5nervig, spitz, länger als das halbe Aehrchen; Bth. stumpf, wehrlos, \%. der Basis an bis oberhalb d. Mitte nebst d. Achse behaart; Spindel am Rande rauh; $B$. oberseits sehr dicht-u. sehr kurz-sammetig $u$. dabei ein wenig rauh; W. weitkriechend. 2. Sandige O. am Meere bei Warnemünde. Jun. Jul. Halm dick, steif aufrecht.

11. T. acutum DC. Aehre 2zeilig; Aehrchen 5-8bth., genähert; Klappen lineal.-lanzettl., 7 nervig, spitz od. stumpflich, um den dritten Theil kürzer als die Aehrchen; Bthen spitz oder stumpflich, wehrlos od. kurz-begrannt, kahl; Spindel meist kahl; B. oberseits mit spitzcn Pünktchen sehr dicht besetzt, rauh; W. weitkriechend. 24. Sandige O. am Meere; Triest, Insel Norderney. Jun. JuI. Var. Spindel am Rande rauh u. auch mit einer auf dem Rücken zottigen Spindel. Das T., welches unter dem Namen T. affine Dethard. vorkommt, ist von $\mathrm{T}$. acutum nicht verschieden, $u$. T. laxum Fries scheint mir eine Variet. mit schlapperen B.

b. Blattnerven oberseits mit einer einfachen Reihe sehr kleiner Stacheln od. Borstchen besetzt u. dadurch rauh.

12. T. rigidum Schrad. Aehre 2zeilig; Aehrchen 5-10bth., die unteren entfernt, die oberen genähert; Klappen längl., 9nervig; breitabgeschritten od. sehr stumpf, halb so lang als d. Aehrchen; Bthen sehr stumpf, wehrlos; Spindel kurzborstig-rauh; B. oberseits v. einzelnen kurzen Borstchen sehr rauh; W. faserig, rasig, ohne Ausläufer. 4. Sandige O. am Adriat. Meere, Sandfelder in Oestr. und Böhm. Jul. Aug. T. elongatum Host. W. stets ohne Ausläufer.

13. T. pungens Pers. Aehre zweizeilig; Aelırchen 5-10bth., genähert; Klappen lanzettl., 7nervig, spitzl. od. kurz-stachelspitzig, halb so lang als d. Aehrchen; Bthen stumpf, wehrlos; Spindel kahl od. rauh; B. oberseits v. einzelnen, kurzen Borstchen sehr rauh; W. kriechend. 2. Sandige 0 . am adriat. Meere. Jun. Jul. Vielleicht Variet. $v$. T. repens.

14. T. gla u cum Desf. Aehre 2zeilig; Aehrchen meist 5bth., genähert, die unteren ein wenig entfernt; Klappen längl., 5-7nervig, sehr stumpf od. abgeschnitten, halb so lang als die Aehrchen; Bth. sehr stumpf, wehrlos od. begrannt; Spindel fein-borstig-rauh; B. oberseits v. spitzen, einzelnen Pünktchen etwas rauh; W. kriechend. 4. Ufer, Wege, zerstr. dch d. Geb. Jun. Jul. Wohl eine grössere Variet. v. $T$. repens.

15. T. repens L. Aehre 2zeilig; Aehrchen meist 5bth.; Klappen 
lanzettl., 5nervig, zugespitzt; Bth. zugespitzt od. stumpflich, wehrlos od. begrannt; Spindel meist rauh; $B$. oberseits $v$. spitzen, einzelnen Pünltchen mehr oder weniger rauh; $W$. kriechend. 4. Kultiv. O., - Felder, Zäune, auf Sandboden uiberall. Jun. Jul.

16. T. bifl o r u m (Brignol. jot. Ztg. 23, 638. Fasc. 1810.) Aehre 2zeilig; Aehrchen 2-4bth.; Klappen lanzettl., 3nervig, zugespitzt; Bth. begrannt, Granne fast 3 mal kürzer als die Bth.; Spindel ein wenig rauh; B. glatt, am Rande ein wenig rauh; W. faserig. 4. Auf d. Matajur in Krain. Jul. Aug. T. violaceum Hornemann Flor. dan.

17. T. caninum Schreb. Aehre 2zeilig; Aehrchen meist 5bth.; Klappen lanzettl., 4-7nervig, zugespitzt; Bth. zugespitzt, begrannt, Granne länger als $d$. Bth.; Spindel fein-borstig-rauh; $B$. beiderseits rauh; W. faserig. 2. Wälder, Waldbäche, Zäune. Jun. Jul. Elymus caninus $\mathrm{L}$.

58. SECÁLE L. Roggen (Korn).

1. S. cereale L. Klappen kürzer als d. Aehrchen; Spindel zähe. ○. u. $\odot$. Ueberall kultiv. Mai.

59. ÉLYMUS L. Haargras.

1. E. arenarius L. Aehre aufrecht, gedrungen; Aelurchen meist 3bth., flaumig, an d. Mitte der Aehre zu 3, so lang als die auf dem Kiele gewimperten Klappen od. länger; B. zuletzt zsgerollt, starr. 24. Sandige $O$. an d. Nord- u. Ostsee $u$. sehr zerstr. auf Sandfeldern im Binnenlande. Jul. Aug.

2. E. europaeus L. Aehre aufrecht; Aehrchen 2bth. od. 1bth. mit dem Ansatze zu einer zweiten Bthe., in der Mitte der Aehre zu 3 ; Klappen gerade, lineal.-pfrieml., begrannt; untere Spelze rauh, begrannt, die Granne 2 mal länger als die Spelze; B. flach, kahl; Scheiden behaart. 24. Wälder der Gebirge u. VorA., zerstr. deh d. Geb. Jun. Jul.

3. E. crinitus Schreber. Aehre aufrecht; Aehrchen 1 bth., mit dem Ansatze zu einer zweiten Bth., gezweiet; Klappen gerade, lineal.-pfrieml., begrannt; untere Spelze rauh, begrannt, die Granne vielmal länger als die Spelze; B. flach, oberseits zottig; Scheiden kahl. ○. Felder u. Schutt, auf der neuen Aufschüttung bei Triest in Menge, Tommasini. Mai. Jun.

60. HÓRDEUM L. Gerste.

I. Rotte. Hordea sariva. Meistens angepfanzie Gerstenarten. Bth. alle $\mathrm{zwitterig}$ od. die seitenst. männlich $u$. diese immer wehrlos.

1. H. vulgare L. Aehrchen alle zwitterig, die fruchttragenden 6reihig-geordnet, 2 Reihen auf beiden Seiten mehr hervorspringend. $\odot$. u. ๑. Wird kultiv. Jun. Jul. Var. mit schwarzer Aehre u. freien, 
nicht an die Spelzen angewachsenen Samen; zur letzten gehört: H. vulgare $\beta$. coeleste $L$.

2. H. hexastich o n L. Achrchen alle zwitterig, gleichf.-6reihig-

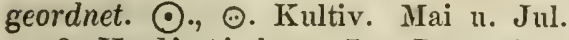

3. H. distichum L. Das mittlere Aehrehen zwitterig, eyf., begrannt, die Granne aufrecht, die seitenst., nnännl., lineal., wehrlos; Grannen der Klappen v. der Länge der Aehrchen; W. faserig. $\odot$. Kultiv. Jun. Jul.

4. H. z e o crito n L. Die seitenst. Aehrchen männl., wehrlos, das mittlere zwitterig, eyf., begrannt, die Grannen fächerf.-abstehend. $\odot$. Kultiv. Jul.

5. H. strictum Desfontaines. Die Aehrchen lanzettl., das mittlere zwitterig, begrannt, die Granne aufrecht, die seitenst. männl., grannenlos, Grannen der Klappen länger als die Aehrchen; Halm iiber der W. zwiebelig aufgetrieben. 2. Auf Grasplätzen in Istrien, Biasol., bei Preuss. Oldendorf in Westph. Mai. Jun. H. bulbosum L.? "flosculi omnes fertiles" passt nicht.

II. Rotte. Horde a murina. Mäusegerste. Die seitenst. Bth. männl. od. geschlechtslos; alle begrannt.

6. H. murinum L. Aelurchen alle begrannt; Klappen, des mittleren Aehrchens lineal.-lanzettl., bewimpert, die der seitenst. Aehrchen borstl., rauh, die nach innen befindl. auf der einen Seite bewimpert. $\odot$. Wege, Mauern, Schutt. Jul. Aug.

7. H. se calin um Schreber 1771. Aehrchen alle begrannt; Klappen aller Aehrchen borstl. u. rauh. 24. Wiesen; zerstr. deh d. Geb. Jun. Jul. H. pratense Huds. 1778. H. nodosum K. syu. ed. 1. Das H. nodosum L. ist der Beschreibung nach eine andere Pf. Bth. kahl, oberwärts rauh r. mit einigen kurzen Härchen besetzt. Var. $\beta$. marinum: die seitenst. Bth. mehr mit Härchen besetzt: $\mathbf{H}$. maritimum Roth. tent. fl. g.

8. H. maritimum Withering. Aehrchen alle begrannt; Klappen aller Aehrchen rauh, die inneren der seitenst. Aehrchen halblanzettl. u. etwas geflügelt, die iibrigen borstl. $\odot$. Sandige 0 . am Meere, Nordsee in Holst.; Adriat. Meer. Mai. Jun.

\section{LÓLIUM L. Lolch.}

I. Rotte. Die W. blühende Halme u. nicht-blühende Blätterbiischel treibend, perennirend. Die Bth. lanzettl. Die Spelzen häutig, die obere lanzettl., v. der unteren bedeckt.

1. L. perenne L. Aehrchen länger als die Klappe; Bthen lanzettl.; $W$. blühende Halme $u$. nichtblühende Blätterbüschel treibend, die jungen B. einfach-zsgefaltet. 24. Wiesen, Triften, Wege. Jun.Herbst. Bth. unbegrannt od. kurz-stachelspitzig. Eine Form mit 34bth. Aehrchen ist L. tenue L. nach Smith. 
2. I. it alicu in Alex. Braun. Aehrchen länger als die Klappe; Bth. lanzettl.; $\boldsymbol{W}$. blühende Halme $u$. nichtblühende Blätterbüschel treibend; die jü̈tgeren B. zsgerollt. 24. Wiesen, Grasplätze; zerstr. dch $d$. Geb., an manchen $O$. angesäet, an andern aber auch ganz sicher einheimisch. Jun.-Herbst; multiflorum Poiret. L. Boucheanum Kunth. Bth. begrannt od. auch unbegrannt.

II. Rotte. Die W. bloss blühende Halme hervorbringend, zweijährig od. bei $L$. rigidum vielleicht jährig. Die Bth. lanzettl. Die Spelzen häutig, die obere lanzettl.

3. L. m ultiflor um Gaudin u. der Gärten. Klappen 3 mal kürzer als das Aelurchen; die Aehrchen nach vorne verschmälert, spitz, 12-20bth.; Bth. lanzettl., dicht dachig, die oberen begrannt; nichtblühende Blätterbïschel fehlend. $\odot$. Aecker der südl. Schwz. Jun. Jul. Habe ich bisher bloss kultivirt gesehen u. selbst kultivirt. Die obere Spelze lanzettl.

4. L. rigidum Gaudin. Klappen länger als die Hälfte des Achrchens od. ungefähr so lang als dieses; Aehrchen 5-10bth., stumpf; Bth. lanzettl., unbegrannt; nichtblühende Blätterbüschel fehlend. ๑. u. ๑.? Trockne Wiesen, Wege; Triest, Fiume; eigentlich nicht in der Schwz, sondern in Piemont v. Gaudin gesammelt. Die obere Spelze lanzettl.

III. Rotte. Die W. bloss blühende Halme hervorbringend, einjährig. Bth. bei der Fruchtreife elliptisch. Die untere Spelze an ihrer unteren Hälfte fast knorpelig, bemerklich schmäler als die obere, welche bei der Frucht zu beiden Seiten breit hervortritt.

5. L. ar vens e Withering. Klappe länger als das halbe Aellrchen od. beinahe so lang; Aelrchen längl. od. eyf.; Bth. kurz-begrannt od. unbegrannt, bei der Fruchtreife elliptisch; nicht blühende Blätterbiischel fehlend. $\odot$. Aecker unter dem Flachs. Jun. Jul. Eine Form mit breiteren Aehrchen, deren Bth. mehr abstehen: L. complanatum Schrad.

6. L. te mulentum L. Klappen länger als das Aehrchen; Aehrchen längl.; Bth. kürzer- od. länger-begrannt, bei d. Fruchtreife elliptisch; nicht blühende Blätterbüschel fellend. $\odot$. Aecker unter Sommergetraide. Jun. Jul. Die Hauptart hat rauhe Bscheiden u. Halme u. starke Grannen. Var. $\beta$. submuticum: dieselbe Pfl, aber die Grannen sehr kurz u. schlängelich. L. speciosum K. syn. ed. 1. zum Theil. L. robustum Reichenb. - $\gamma$. laeve: Bscheiden und Halm glatt. L. speciosum M. B., K. syn. ed. 1. var. glabra.

62. AÉGILOPS L. Walch.

1. A. ovata L. Aehre eyf., aus 3-4 Aehrchen zsgesetzt; Klappen kurzh., alle meist 4 grannig, Grannen aller Aehrchen fast gleich, v. der Basis an am Rande rauh; untere Spelze 2-3grannig, Gran- 
nen etwas abstehend, viel länger als die Spelze. $\odot$. Kultiv. O. Litt., Istr., Fiume. Mai. A. geniculata Roth.

2. A. triaristata Willd. Aehre eyf., nach oben. verschmälert, aus 4-5 Aehrehen zsgesetzt; Klappen steifh., alle 2-3grannig, Grannen aller fast gleich, am Rande ihrer Basis kahl; untere Spelze 2-3grannig, Grannen aufrecht, viel länger als d. Spelze. ๑) Mit der vorhergeh. Art. Mai. A. ovata Roth.

3. A. tri uncialis L. Aehre lineal.-verlängert, aus 5-6 Aehrchen zsgesetzt; Klappen alle 3 grannig od. die der untersten Aehrchen 2 grannig, Grannen der oberen Aehrchen noch einmal so lang; untere Spelze 3zähnig, Zähne spitz od. begrannt, Zähne $u$. Grannen kürzer als die Spelze. $\odot$. Kultiv. O., Wege; Litt., Fiume. Mai. Jun.

63. LEPTÚRUS R. Brown. Fadenschwanz.

1. L. ineurvatus Trinius. Aehre stielrund, im trockenen Zustande einwärts gekrimmt; Balg 2klappig, ein Drittel länger als die Bthe. $\odot$. Sandige O. am Meere; Triest, Veglia. Mai. Rottboellia incurvata L., fil. Aegilops ineurvata I. sp.

2. L. fil iformis Trinius. Aehre stielrund, ein wenig zsgedrüekt, aufrecht od. etwas gebogen; Balg 2klappig; so lang od. kaum cin wenig länger als die Bthe. $\odot$. Sandige $\mathrm{O}$. am Meere, Istrien, Oldenburg bei Varel. Mai. Jun. Rottboellia filiformis Roth. R. erecta Savi.

3. L. cylindricus Trin. Aehre stielrund, aufrecht; Balg 1klappig. $\odot$. Sandige O. am Meere, bei d. Triester Salzwerken. Mai. Rottboellia cylindrica Willd. R. subulata Savi.

64. PSILÚRUS Trin. Borstensehwanz.

1. Ps. nardoides Trin. $\odot$. Trockene, unkult. O.; Triest, Istr. Mai. Jun. Nardus aristata L. Rottboellia monandra Cav.

XV. Gruppe. NARDOIDEEN. Aehrchen in den Aushöhlungen einer Aehrenspindel sitzend. N. fädlich, flaumig, aus der Spitze der Bth. hervortretend.

65. NARDUS L. Borstengras.

1. N. stricta L. 24. Mooriger, torfiger Boden bis in die A. hinauf. Mai. Jun. 



\section{Register}

über die Namen der Ordnungen und Gattungen. Die zweite Zahl mit römischen Ziffern zeigt die Seite der Uebersicht der Ordnung'en und Gattungen des natürlichen Systemes an.

Abutilon 94. XIVII.

Acanthaceen 400. LxxII.

Acanthus 400. xurr.

Acer 97. XxxII.

Aceras 472. LVII.

Acerineen 97. LxVIII.

Achillea 259. LV.

Aconitum 16. Xxxvirr.

Acorus 466. XXXII.

Actaea 17. xxxvirr.

Adenophora 330. xxாI.

Adenostyles 242. Lr.

Adonis 7. xxxrx.

Adoxa 226. xxxIII.

Aegilops 570. XV.

Aegopodium 202. XxVI.

Aesculus 97. XXXII.

Aethionema 52. XLIV.

Aethusa 208. XxVII.

Agave 480. $\mathbf{x x x}$.

Agrimonia 163. xxxvi.

Agrostemma 76. XXXVI.

Agrostis 538. xvir.

Aira 544. XVIII.

Ajuga 398. $\mathbf{I L}$.

Alchemilla 170. $\mathrm{xx}$.

Alisma 457. XXXI.

Alismaceen 457. LXXVIII.

Allium 489, хxxr.
Alnus 453. LIX.

Alopecurus 535. XVI.

Alsine 79. $\mathrm{xxxy}$.

Alsineen 76. $\mathrm{LXV}$.

Althaea 93. xLVu.

Alyssum 40. xurv.

Amaranthaceen 416. LXXVI.

Amaranthus 416. IIX.

Amaryllideen 480. I.XXIx.

Ambrosiaceen 324. LXXI.

Ammi 202. xxVI.

Ampelideen 98. Lxvir.

Ampelopsis 98. XxIr.

Amygdaleen 151. IxVI.

Amygdalus 151. xxxvII.

Anacamptis 470. LVI.

Anacyclus 264. LV.

Anagallis 402 . XxIr.

Anarrhinum 363. XIIII.

Anchusa 345 . XxI.

Andromeda 332. xxxIV.

Andropogou 532. XV.

Androsace 402. XxIr.

Androsaemum 95. xLIX.

Anemone 5. xxxIx.

Anethum 215. xxviII.

Angelica 212. XxVI.

Anthemis 262. LV.

Anthericum 485. $\mathbf{x} \times \mathbf{I}$. 
Anthoxanthum 535. XVI. Anthriscus 221. XXIX. Anthyllis 114. xLVII. Antirrhineen 358. LXXII. Antirrhinum 360. XLIII. Apera 539. xvir. Apium 200. $\times x v$. Apocyneen 336. Lxxiv. Apocynum 336. xxv. Aposeris 294. LII. Aquifoliaceen 335. LxxmI. Aquilegia 15. $\mathrm{xxxIx.}$ Arabis 25. XLVI. Araliaceen 225 . Lxx. Arbutus 331. xxxiv. Archangelica 213. xxvi. Arctostaphylos 331. xxxIv. Aremonia 163. xxxvi. Arenaria 83. xxxy. Aretia 404. XxII. Aristolochia 431. LVII. Aristolochieen 431. LXXIV. Arnica 268. LIV. Arnoseris 294. LI. Aroideen 465. LXXIX. Aronia 172. xxxyIr. Aronicum 267. LIV. Arrhenatherum 545. xVII. Artemisia 255. LIV. Arum 465. LVIII. Arundo 542. xvir. Asarum 432. XXXVI. Asclepiadeen 336. LXxIV. Asparageen 481. LXXIX. Asparagus 481. XxxI. Asperugo 344. XXI. Asperula 228. XIX. Asphodelus 484. XxxI. Aster 244. LIII. Asteriscus 248. LV. Astragalus 134. XLVIrI. Astrantia 199. $\mathrm{xxV}$. Athamanta 211. XxvII. Atragene 2. $\mathrm{xxxIx}$. Atriplex 421. LIX.
Atropa 352. xxirr. Avena 546. xvirI. Azalea 333. xxir. Ballota 396. $\mathrm{xL}$. Balsamineen 102. I.XVII. Barbarea 25. XLVI. Bartsia 379.' XLII. Bellidiastrum 245. LIV. Bellis 245. LIV. Berberideen 18. LXIII. Berberis 18. $\mathrm{xxx}$. Berula 204. xxvi. Beta 420. XxIV. Betonica 394. xLI. Betula 452. LX. Betulineen 452. LxxVIr. Biasolettia 223. xxIx. Bidens 251. LV. Bifora 225. XxIx. Biscutella 50. xLIV. Blitum 419. $\mathrm{xxv}$. Bonjeania 130. xLVIIr. Boragineen 344. LxxII. Borago 345. XXI. Brachypodium 562. XIX. Brassica 38. xuvr. Braya 34. XLVI. Briza 550. XviII. Bromus 562. xIx. Bryonia 180. LX. Buffonia 76. xx. Bulbocodium 495. XxxI. Bulliarda 183. $\mathrm{xx}$. Bunias 53. XLIII. Bunium 203. xxvr. Buphthalmum 248. Lv. Bupleurum 205. Xxv. Butomeen 458. Lxxvir. Butomus 458. xxxrIr. Buxus 432. LIX. Cactecn 188. LXIX. Caesalpinicen 151. LXIV. Cakile 54. XLIV. Calamagrostis 540. XVIr. Calamintha 387. XLIr. 
Calendula 274. LVI.

Calepina 53. xLIII.

Calla 466. LVIII.

Callitriche 178. Lvirr.

Callitrichineen 178. Lxxv.

Calluna 332. xxxirr.

Caltha 14. xxxIx.

Camelina 47. xLv.

Campanula 326 . xxirr.

Campanulaceen 324. LXxI.

Camphorosma 420. xx.

Cannabis 439. LXI.

Capparideen 55. LXIV.

Capparis 55. xxxvmI.

Caprifoliaceen 226. LXXI.

Capsella 51. xuIV.

Cardamine 29. xLV.

Carduus 282. LII.

Carex 510. LviIr.

Carlina 285. LII.

Carpesium 252. LIV.

Carpinus 441. LX.

Carthamus 288. LIII.

Carum 202. xxvI.

Castanea 440. LIX.

Caucalis 219. xxvIII.

Celastrineen 104. LXVIII.

Celtis 439 . xxIv.

Centaurea 288. LV.

Centranthus 236. XII.

Centunculus 402. xIx.

Cephalanthera 473. IVII.

Cephalaria 238. xIx.

Cerastium 86. $\mathrm{xxxv}$.

Ceratocephalus 7. xxxIx.

Ceratonia 151. XxIv.

Ceratophylleen 178. LxxvI.

Ceratophyllum 178. LIX.

Cercis 151. xxxrv.

Cerinthe 3 7. xxI.

Chaerophyllum 222. XxIx.

Chaiturus 396 . XLI.

Chamaeorchis 472. LVII.

Chamagrostis 537. XVI.

Cheiranthus 23. XIVI.
Chelidonium 20. xxxviII.

Chenopodeen 416. LXXVI.

Chenopodium 418. xxIV.

Cherleria 82. $\mathrm{xxxv}$.

Chlora 337. xxxiI.

Chondrilla 302. LI.

Chrysanthemum 264. LIV.

Chrysosplenium 198. xxxIII.

Cicendia 342. xIx.

Cicer 140. XuvirI.

Cichorium 294. L.

Cicuta 200. xxrI.

Cimicifuga 17. xxxvirr.

Cineraria 268. LIV.

Circaea 177. XIII.

Cirsium 275. LII.

Cistineen 55. Lxv.

Cistus 55. xxxvirI.

Cladium 504. XIV.

Clematis 1. xxxix.

Clinopodium 388 . XLII.

Clypeola 43. xLIV.

Cnidium 210. XxvII.

Cochlearia 46. XIV.

Colchicaceen 495. LxxviII.

Colchicum 495. XxxII.

Coleanthus 538. xvI.

Colutea 132. XLIX.

Comarum 156. xxxviIr.

Compositen 242. LXXI.

Coniferen 453. LXXVII.

Conioselinum 212. xxvIr.

Conium 224. XxIx.

Convallaria 482 . xxx.

Couvolvulaceen 343 . LxxIIr.

Convolvulus 343. XxIr.

Corallorrhiza 475 . LVII.

Coriandrum 225. XxIx.

Corispermum 417. xxIV.

Corneen 225. LXx.

Cornus 225. $\mathrm{xx}$.

Coronilla 138. XLIX.

Corrigiola 181. xxIx.

Cortusa 409. XxII.

Corydalis 20. xuvir. 
Corylus 440. LX.

Corynephorus 545. XVIII.

C'otoneaster 171. XXXVII.

Cotula 259. LIV.

Crambe 54. XIIV.

Crassula 183. xxx.

Crassulaceen 183 . LxIII.

Crataegus 171. xxxvir.

Crepis 306 . LI.

Crithmum 212. xxyr.

Crocus 476. XIV.

Crucianella $229 . \quad$ xIx.

Cruciferen 22. LXIV.

Crupina 293. LV.

Crypsis 536. xvi.

Cucubalus 70. xxxy.

Cucumis 180. Lx.

Cucurbita 180. Lx.

Cucurbitaceen 180. LxxI.

Cupressus 454. LIX.

Cupuliferen 439. LXXVII.

Cuscuta 343. Xxv.

Cyclamen 409. xxrr.

Cydonia 171. xxxvir.

Cynanchum 336 . Xxv.

Cynara 282. LII.

Cynodon 537. xvi.

Cynoglossum 344. IXI.

Cynosurus 556. xvIII.

Cyperaceen 503. LXXIX.

Cyperus 503. xIv.

Cypripedium 476 . LVIr.

Cytineen 431. Ixxiv.

Cytinus 431. Lx.

Cytisus 109. XIVII.

Dactylis 556. xviIr.

Danthonia 550. xvIIr.

Daphne 428. xxxIII.

Datura 352. xxrr.

Daucus $219 . \quad$ XXVIII.

Delphinium 16. xxxvrIr.

Dentaria 31. xLv.

Dianthus 66. xxxIv.

Dictamkus 104. xxxIv.

Digitalis 358 . xLIII.
Dioscoreen 483. LXXvirI.

Diospyros 335. xxxIII.

Diplotaxis 39. XIVI.

Dipsaceen 237. LXXI.

Dipsacus 237. xIx.

Doronicum 266. LIV.

Doryenium 130. xLVIII.

Draba $43 . \quad$ XLV.

Dracocephalum 390. XI.I.

Drosera 63 . xxx.

Droseraceen 63. LXV.

Dryas 154. xxxvir.

Drypis $76 . \quad \mathrm{xxIx}$.

Ebenaceen 335. LxxIII.

Ecballion 181. LX.

Echinaria 542. xvIr.

Echinophora 224. xxvIII.

Echinops 274. LVI.

Echinospermum 344. XXI.

Echium 348. XXI.

Edrajanthus 330. XxIII.

Elaeagneen 431. LxxVI.

Elaeagnus 431. $\mathrm{xx}$.

Elatine 89. xxxrm.

Elatineen 89. LXVIr.

Elsholtia 381. XLI.

Elymus 568. XV.

Elyna 510. LVIII.

Empetreen 432. LXVIII.

Empetrum 432. LX.

Endymion 495 . xxx.

Ephedra 453. LXII.

Epilobium 173. xxxIr.

Epimedium 18. $\mathrm{xx}$.

Epipactis 474 . LVII.

Epipogium 473. LVII.

Lragrostis 551. xvIII.

Eranthis 14. XxxIX.

Erianthus 531. Xv.

Erica 332. xxxrII. !

Ericineen 331. LxxIv.

Erigeron 246. LIII.

Erinus 363 . XLIII.

Eriophorum 509. xv.

Eritrichium 350. XXI. 
Erodium 102. xLVII.

Eruca 40. XLVI.

Erucastrum 39. XLVI.

Ervum 145. XLVHI.

Eryngium 199. XxV.

Erysimum 35. XLVI.

Erythraea 342. XXII.

Erythronium 484. $\quad$ XXXI.

Euclidium 52. XLIII.

Eupatorium 242. LII.

Euphorbia 432.' LVIII.

Euphorbiaceen 432. LXXY.

Euphrasia 379. XLII.

Eurotia 421. LIX.

Evas 247. LVI.

Evonymus 104. XxIII.

Facchinia 79. $\quad \mathbf{x x y}$.

Fagus 439. LIX.

Falcaria 202. XxvI.

Farsetia 43 . xLIV.

Ferulago 213. XXVIr.

Festuca 556. xVIrI.

Ficus 439. LvIm.

Filago 252. LIII.

Fimbristylis 509. XIV.

Foeniculum 208. XxVII.

Fragaria 156. xxxvIr.

Fraxinus 336. xIII.

Fritillaria 484. XXXI.

Fumaria 22. XLVII.

Fumariaceen 20. LXIV.

Gagea 487. xxxI.

Galanthus 481. $\mathrm{xxx}$.

Galasia 301. L.

Galatella 245.

Galega 132. xuvir.

Galeobdolon 391. XL.

Galeopsis 391. $\quad$ xxxIx.

Galinsoga 251. LV.

Galium 230. Xx.

Gastridium 541. xVII.

Gaudinia 565. xV.

Gaya 212. XxviI.

Genista 107. XIVII.

Gentiana 338. $\mathrm{xXY.}$
3 Gentianeen 337. LxxIv.

Geraniaceen 98. LXVII.

Geranium 98. XLVI.

Geum 154. XxxVIII.

Gladiolus 477. XIV.

Glaucium 20. XXXVIII.

Glaux 410. XxIV.

Glechoma 389. XLI.

Globularia 410. XIX.

Globularieen 410. LXXII.

Glyceria 555. xvIII.

Glycyrrhiza $131 . \quad$ xLVIII.' Gnaphalium 253. LIII. Goodyera 475. LVII.

Gramineen 531. Lxxx.

Granateen 173. LXX.

Gratiola 358. XIII.

Grossularieen 188. LXIX.

Gymnadenia 470. LVI.

Gypsophila 65. xxxIv.

Hacquetia 199. Xxv.

Halianthus 79. $\mathrm{xxxv}$.

Halimus 421. LIX.

Halorageen 177. Lxx.

Hedera 225. XxIv.

Hedypnois 295. L.

Hedysarum 140. XIIX.

Heleocharis 505 . XIV.

Helianthemum 55. xxxvirr.

Helianthus 252. LV.

Helichrysum 254. LIII.

Heliotropium 344. XXI.

Helleborus 14. XxxIX.

Helminthia 298. L.

Helosciadium 201. xxv.

Hemerocallis 494. $\mathrm{xxx}$.

Heracleum 216. Xxviu.

Herminium 473. LVII.

Herniaria 182. xxIv.

Hesperis 32. XLV.

Heteropogon 532. xv.

Hibiscus 94. XLVIr.

Hieracium 311. LI.

Hierochloa 535. xvIr.

Himantoglossum 470. LVY. 
Hippoeastaneen 97. LxVIII. Hippocrepis 139 . XLIX. Hippophaё 431. LXI. Hippurideen 178. Lxxv. Hippuris 178. XII.

Holcus 545. xvir.

Holosteum 84. xxxv.

Homogyne 242. LIII.

Horminum 389. XL.

Hordeum 568. xv.

Hottonia 409. xxIr.

Hugueninia 34. xIVI.

Humulus 439. LxI.

Hutchinsia 51. xurv.

Hydrocharideen 457. LxxvIII.

Hydrocharis 457. . LXIr.

Hydrocotyle 198. Xxv.

Hyoscyamus 352. XXII.

Hyoseris 295. L.

Hypecoum 20. $\mathrm{xx}$.

Hypericineen 95. LXVII.

Hypericum 95. XIIX.

Hypochoeris 301. XLIX.

Hyssopus 389. xLI.

Jasione 324. xxIII.

Jasmineen 336. LXXIII.

Jasminum 336 . XIII.

Iberis 49 . XLIV.

Ilex $335 . \mathrm{xx}$.

Illecebrum 182. xxrv.

Impatiens 102. xxIII.

Imperata 535. xVI.

Imperatoria 215. xxvIrI.

Inula 248. LIII.

Irideen 476. LxxVII.

Iris $478 . \quad \mathrm{XIV}$.

Isatis 53. XLIV.

Isnardia 176. $\mathrm{xx}$.

Isopyrum 15. XxxIx.

Juglandeen 439. LXXvi.

Juglans 439. LIX.

Juncaceen 496 . LXXIX.

Juncagineen 458. LxxvIII.

Juncus 496. XXxIr.

Juniperus 454. LXI.
Jurinea 288. LII.

Kentrophyllum 288. LII.

Knautia 238 . XIX.

Kobresia 510. LVIII.

Kochia 418. xxrv.

Koeleria 543. xvIII.

Labiaten 381. LXXIr.

Lactuca $303 . \quad$ Lr.

Lagurus 540. xvI.

Lamarckia 544. x xIr.

Lamium 390. $\mathrm{xL}$.

Lappa 285. LIII.

Lapsana 294. LII.

Laserpitium 217. XxVIIr.

Lasiagrostis 542. xvIr.

Lathraea 373. xLIr.

Lathyrus 147. XLVuI.

Laurineen 429. LXXV.

Laurus 429 . XXXIII.

Lavandula 381. XL.

Lavatera $94 . \quad$ XLVII.

Ledum 334. xxxrv.

Leersia 538. XVI.

Lemna 464. XIII.

Lemnaceen 464 . LXXIX.

Lentibularieen 400. LXXIr.

Leontodon 295. L.

I seonurus 396 . XII.

Lepidium 50. xuIV.

Lepigonum $78 . \quad \mathrm{xxxv}$.

Lepturus 571. xv.

Leucojum 481. xxx.

Levisticum 212. XXvII.

Libanotis 210. xxVII.

Ligularia 269. LIV.

Ligusticum 211. xxvח.

Ligustrum 335. xIrI.

Liliaceen 483. LXXIX.

Lilium 484. XxxI.

Limnanthemum 337. XXIr.

Iimodorum 473 . LVII.

Limosella 368. XIIII.

Linaria 360. xLIII.

Lindernia 368 . XLIII.

Lineen 90. LXVII. 
Linnaea 228. xLIII.

Linosyris 243. LII.

Linum 90. $\mathrm{xxx}$.

Listera 474. LVII.

Lithospermum 349. XXI.

Littorella 412. LVIII.

Lloydia 484. Xxxr.

Lobelia 324. xxII.

Lobeliaceen 324. LXXI.

Lobularia 43. XLV.

Lolium 569. xv.

Lomatogonium 338. xxv.

Lonicera 227. xxIIr.

Loranthaceen 225. LXIX.

Loranthus 226. $\mathrm{xxx}$.

Lotus 130. XLVIII.

Lunaria 43. XLV.

Lupinus 112. XLVII.

Luzula 501. XxxII.

Lychnis 75. xxxvi.

Lycium 351. xxIrI.

Lycopsis 346. XxI.

Lycopus 383. XIII.

Lysimachia 401. XxIr.

Lythrarieen 179. LXVI.

Lythrum 179. xxxvi.

Majanthemum 483. xx.

Malabaila 224. XxIx.

Malachium 86. xxxv.

Malaxis 475 . LVII.

Malcolmia 33. xLVI.

MIalva $92 . \quad$ XLVII.

MIalvaceen 92. LXVI.

NIarrubium 395. XL.

Matricaria 264. LIV.

Matthiola 23. xLV.

Medicago 114. XLVIII.

Melampyrum 374. xLII.

Melica 550. xvirI.

Melilotus 120. XLVIII.

Melissa 388. XLI.

Melittis 390. XLI.

Mentha 381. XLI.

Menyanthes 337. XxI.

Mercurialis 438, LXI,
Mespilus 171. xxxvir.

Meum 211. xxvI.

Micromeria 387. XLII.

Micropus 247. LVI.

Microstylis 476 . LVII.

Milium 541. XvI.

Moehringia 82. xxxy.

Moenchia 85. xxxy.

Molinia 556. xvilr.

Molopospermum 224. XxIx.

Monotropa 334. xxxIv.

Monotropeen 334. LXVIII.

Montia 181. XIV.

MLorus 439. LIX.

Mulgedium 304. LI.

Muscari 495. $\mathrm{xxx}$.

Myagrum 53. xLIII.

Myosotis 349 . $\mathrm{xxr}$.

Myosurus 7. xxxIx.

Myrica 453. Lxr.

Myriceen 453. LXxVII.

Myricaria 180. XIVI.

Myriophyllum 177. LIX.

Myrrhis 224. xxIx.

Myrtaceen 180 . LXx.

Myrtus 180. xxxvIr.

Naiadeen 464. LXXIX.

Naias 464. LVIII.

Narcissus 480 . XXX.

Nardus 571. $x v$.

Narthecium 495. XXXI.

Nasturtium 23. XLV.

Neottia 475. LVII.

Nepeta 389. XLI.

Nerium 337. XXII.

Neslia 53. xLIII.

Nicotiana 352. $\mathrm{xxIr}$.

Nigella $15 . \quad \mathrm{xxxIX}$.

Nigritella 471. LVI.

Nonnea 346. XXI.

Nuphar 19. xxxviII.

Nymphaea 18. xxxvirI.

Nymphaeaceen 18. LXIV.

Ocymum 381. xI.

Oenanthe 207. XXVIr. 
Oenothera 176. XxxII.

Olea 335. XIII.

Oleaceen 335. LXXIII.

Omphalodes 345. $\mathrm{xxI}$.

Onagrarieen 173, LXIX.

Onobrychis 140 . XLVIII.

Ononis 113. XLVIr.

Onorpodum 285. LII.

Onosma 347. XxI.

Ophrys 471. LVIr.

Opuntia 188. xxxvr.

Orchideen 466. LXXVIII.

Orchis 466. LVI.

Origanum 385 . XLII.

Orlaya $219 . \quad$ xxvirI.

Ornithogalum 485. . xxxI.

Ornithopus 139 . XLIX.

Orobanche 368. xLII.

Orobancheen 368. LXXII.

Orobus 149. xLIX.

Ostericum 212. XXvI.

Ostrya 441. LX.

Osyris 431. LX.

Oxalideen 102. LxVII.

Oxalis 102. xxxvI.

Oxyria 426. XXXII.

Oxytropis 133. XLVIII.

Paederota 368. xாr.

Paeonia 17. XxxIx.

Paliurus 105. xxIv.

Pallenis 248. LV.

Panicum 532. xv.

Papaver 19. xxxvilr.

Papaveraceen 19. LxIV.

Papilionaceen 107. LxIv.

Paradisia 485. XXXI.

Parietaria 438. $\mathrm{xx}$.

Paris 482. $\mathrm{xxxIII.}$

Parnassia 63. $\mathrm{xxx}$.

Paronychia $182 . \quad$ xxIv.

Paronychieeu 181. LXV.

Passerina 428. XXXIII.

Pastinaca 216. xxviII.

Pedicularis 374. XLII.

Peltaria 43. XIIV.
Peplis 179. $\mathrm{xxx}$.

Persica 151. XxxvII.

Peristylus 470. LVI.

Petasites 243. LIII.

Petrocallis 43. xLv.

Petroselinum 201. xxv.

Peucedanum 213. XxvIII.

Phaca 132. xLVIII.

Phalaris 534. XVI.

Phaseolus 150. XLIX.

Philadelpheen 180. LXX.

Philadelphus 180. xxxvI.

Phillyrea 335. xIII.

Phleum 536. XVI.

Phlomis 396. XLI.

Phragmites 542. xvir.

Physalis 352. xxIII.

Physocaulus 222. XxIx.

Phyteuma 324. xxIII.

Phytolacea 416 . XxxvI.

Phytolacceen 416. LXXVI.

Picridium 305. Lr.

Picris 297. L.

Pimpinella 203. xxvI.

Pinardia 266. LIV.

Pinguicula 400. XIII.

Pinus 455. LvIII.

Piptatherum 541. xvI.

Pistacia 106. LxI.

Pisum 146. XLIX.

Plantagineen 412. LxxII.

Plantago 412. XIX.

Platanthera 471. LVI.

Pleurospermum 224. XxIx.

Plumbagineen 410. LXXII.

Plumbago 412. XXII.

Poa 551. xvirI.

Podospermum 300. L.

Polemoniaceen 343. LxxIII.

Polemonium 343. XxIr.

Polycarpum 182. XIX.

Polycnemum 418. XIV.

Polygala 63. xLvII.

Polygaleen 63. LxxIIr.

Polygoneen 422. LXxv. 
Polygonum 426. $\mathrm{xxxII.}$

Polypogon 538. xvi.

Pomaceen 171. Lxx.

Populus 451. LxI.

Portulaca 181. xxxvi.

Portulaceen 181. LXVI.

Potameen 459. LxxVIII.

Potamogeton 459. $\mathrm{xx}$.

Potentilla 156. XxxviII.

Poterium 170. XxxvII.

Prasium 398. XL.

Prenanthes 303. LI.

Primula 404. XxIr.

Primulaceen 401. LXXII.

Prunella $397 . \quad \mathrm{xL}$.

Prunus 151. xxxvil.

Psamma 541. XvII.

Psilurus 571. $\mathrm{xv}$.

Pterotheca 306. I.

Ptychotis 201. XxvI.

Pulegium 383. XII.

Pulicaria 251. LIII.

Pulmonaria 348. $\mathrm{xxI}$.

Punica 173. xxxvil.

Pyrola 334. xxxiv.

Pyrolaceen 334. LXVIII.

Pyrus 171. xxxvir.

Quercus 440. Lx.

Radiola 92. xx.

Ranunculaceen 1. LXIII.

Ranunculus 8. xxxIx.

Raphanus 54. XLV.

Rapistrum 54. XIIV.

Reseda 62. Xxxvi.

Resedaceen 62. LxIV.

Rhagadiolus 294. LI.

Rhamneen 105. LXVI.

Rhamnus 105. XXIII.

Rhinanthaceen 374. LXXII.

Rhinanthus 378 . XLII.

Rhodiola 183. LXI.

Rhododendron 333. xxxIv.

Rhus 107. XxIx.

Rhynchospora 504. XIV.

Ribes 188. Xxrv.
Rosa 163. xxxvII.

Rosaceen 153 . LXIII.

Rosmarinus 384. xIV.

Rubia 230. xx.

Rubus 155. xxxvII.

Rumex 422. Xxxu.

Ruppia 463. XIII.

Ruscus 483. IXII.

Ruta 103. XxXIII.

Rutaceen 103. LXVIII.

Sagina $76 . \quad \mathrm{xxx \nabla}$.

Sagittaria 458. LIX.

Salicineen 441. LXXVII.

Salicornia 417. xIII.

Salix 441. LX.

Salsola 416. XxIV.

Salvia 384. XIv.

Sambucus 226. $\mathrm{xxx}$.

Samolus 410 . XxIII.

Sanguisorba 170 . $\mathrm{xx}$.

Sanguisorbeen 170. LXXV.

Sanicula 199. xxvI.

Santalaceen 429. LXXV.

Santolina 259. LV.

Saponaria 70. xxxIv.

Sarothamnus 107. XLVII.

Satureja 386. XLII.

Sanssurea 286. LII.

Saxifraga 189. xxxIv.

Saxifrageen 189. LXIX.

Scabiosa 239. xIx.

Scandix 221. XxIX.

Scheuchzeria 458. XXXII.

Schoberia 416. XxIV.

Schoenus 504. XIV.

Scilla 488. xxxI.

Scirpus 506. xv.

Sclerantheen 182. LXXVI.

Scleranthus 182 . xxxIv.

Scolymus 294. LI.

Scopolina 352. XXII.

Scorpiurus 138 . XIIX.

Scorzonera 299. L.

Scrophularia 357. xum.

Scutellaria 397. XLI. 
Secale 568. Xr.

Securigera 140 . XLVII.

Sedum 183. Xxxvi.

Selinum 212. xxvIr.

Sempervivum 186. XxXVI.

Senebiera 52. xuIV.

Senecio 270. LIV.

Serapias 473 . IVII.

Serratula 287. LII.

Seseli 209. xxVII.

Sesleria 543. xVII.

Setaria 533. XVI.

Sherardia 228. $\mathrm{xx}$.

Sibbaldia 162. xxx.

Sideritis 395. xu.

Silaus 211. XxvIr.

Silene 70. $\mathrm{xxxv}$.

Sileneen 65. LXV.

Siler 217. $\mathrm{xxvmI.}$

Silybum 282. LII.

Sinapis $38 . \quad \mathrm{xLVI}$.

Sison 202. XxvI.

Sisymbrium $33 . \quad x L V I$.

Sium 204. Xxvi.

Smilax 483. LXI.

Smyrnium 224. XxIx.

Solaneen 351. LXXIV.

Solanum 351. xxIrI.

Soldanella 409 . xxII.

Solidago 247. LIII.

Sonchus 305. LI.

Sorbus 172. XxxvII.

Sorghum 532. xv.

Soyeria 310. LI.

Sparganium 465. LYIII.

Spartina 538. xvI.

Spartium 107. xLVII.

Specularia 330. xxIII.

Spergula 78. $\mathrm{xxxy}$.

Spinacia 420. LXI.

Spiraea 153. XxxVII.

Spiranthes 475. LVII.

Stachys 393. XL.

Stachelina 286. III.

Staphylea 104. xxIx.
Statice 410. $\mathrm{xxx}$.

Stellaria 84. XXXV.

Stellaten 228. LXXI.

Stenactis 245. LIII.

Sternbergia 480 . $\mathrm{xxx}$.

Stipa 542. xvIr.

Stratiotes 457. LXII.

Streptopus 482. XXXI.

Sturmia 475. LVII.

Subularia 48. XIV.

Succisa 239. XIX.

Swertia 337. xxv.

Symphytum 346 . XxI.

Syrenia $37 . \quad x L V I$.

Syringa 335. xIII.

Tamariscineen 179 . LXV.

Tamarix 179. XxIx.

Tamus 483 . LXI.

Tanacetum 258. LIV.

Taraxacum 301. II.

Taxus 453. LX:

Teesdalia 49 . ẊLIV.

Telekia 247. LV.

Telephium 181. xxIx.

Terebinthaceen 106. LxvI.

Tetragonolobugs 131. XLVIII.

Teucrium 398. xLI.

Thalictrum 2. xxxIx.

Theligonum 422. LIX.

Thesium 429. xxrv.

Thlaspi 48 . xLIV.

Thrincia 295. L.

Thymelaeen 428 . Lxxv.

Thymus 386 . xLII.

Thysselinum 215 . xxvIIr.

Tilia 94. xxxvIII.

Tiliaceen 94. LXVI.

Tillaea 183. XX.

Tofieldia 496. XxxIr.

Tommasinia 215. xxvIII.

Tordylium 217. xxvIIr.

Torilis 220. XXvIII.

Tozzia 374. XIIr.

Tragopogon 298. L.

Tragus 532. XVI. 
Trapa 177. $\mathrm{xx}$.

Tribulus 103 . xxxiv.

Trichonema 477. xIv.

Trientalis 401. xxxIr.

Trifolium 121. xLVIII.

Triglochin 458. xxxII.

Trigonella 119. xuvir.

Trinia 201. xxv.

Triodia 550. xvIr.

Triticum 565. xv.

Trixago 379. XLII.

Trochiscanthes $211 . \quad$ XxvII.

Trollius 14. xxsIx.

Tulipa 483. $\mathrm{xxxI}$.

Tunica 66. xxxIv.

Turgenia 220. xxvirr.

Turritis 25 . XLVI.

Tussilago 243. LIV.

Typha 465. LVIII.

Typhaceen 465. LxxIX.

Tyrimnus 282. LII.

Udora 457. LXI.

Ulex 107. xLVII.

Ulmus 439 . xxIv.

Umbelliferen 198. LXIX.

Umbilicus 188. XxxVI.

Urospermum 298. L.

Urtica 438. LIX.

Urticeen 438. LXXVI.

Utricularia 400. xIII.

Vaccinieen 331. LXXI.

Vaccinium 331. XXXIII.
Vaillantia 234. $\mathrm{xx}$.

Valeriana 234. xrv.

Valerianeen 234. LXXI.

Valerianella 236. xIV.

Vallisneria 457. Lx.

Veratrum 496. XXXII.

Verbasceen 353. Lxxiv.

Verbascum 353. XXII.

Verbena 400. XIIIII.

Verbenaceen 399 . LxxIII.

Veronica 363. xIII.

Vesicaria 40. XLV.

Viburnum 226. Xxx.

Vicia 141. XIIX.

Vinca 336. xxir.

Viola 57. xxirI.

Violarieen 57. Lxv.

Viscum 225. LXI.

Vitex 399. XLIII.

Vitis $98 . \quad$ xxIII.

Wahlenbergia 331. xxIII.

Willemetia 301 . LI.

Wulfenia 368 . xIII.

Xanthium 324. LIX. -

Xeranthemum 293. LV.

Zacyntha 305 . L.

Zahlbrucknera 198. xxxIv.

Zanichellia 463 . LVIII.

Zea 531. LVIII.

Zizyphus 105. xxIV.

Zostera 464. IVIII.

Zygophylleen 103 . LXVIII. 


\section{Berichtigungen.}

Seite 176 Zeile 19 v. o. lies: OENOTHERA anstat OEONTHERA.

"475 " 3 v. u. lies: MALAXIS anstatt MALAXSI. 


